
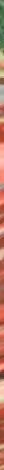



HEINRICH KLOSE.

TOGO. 
. 



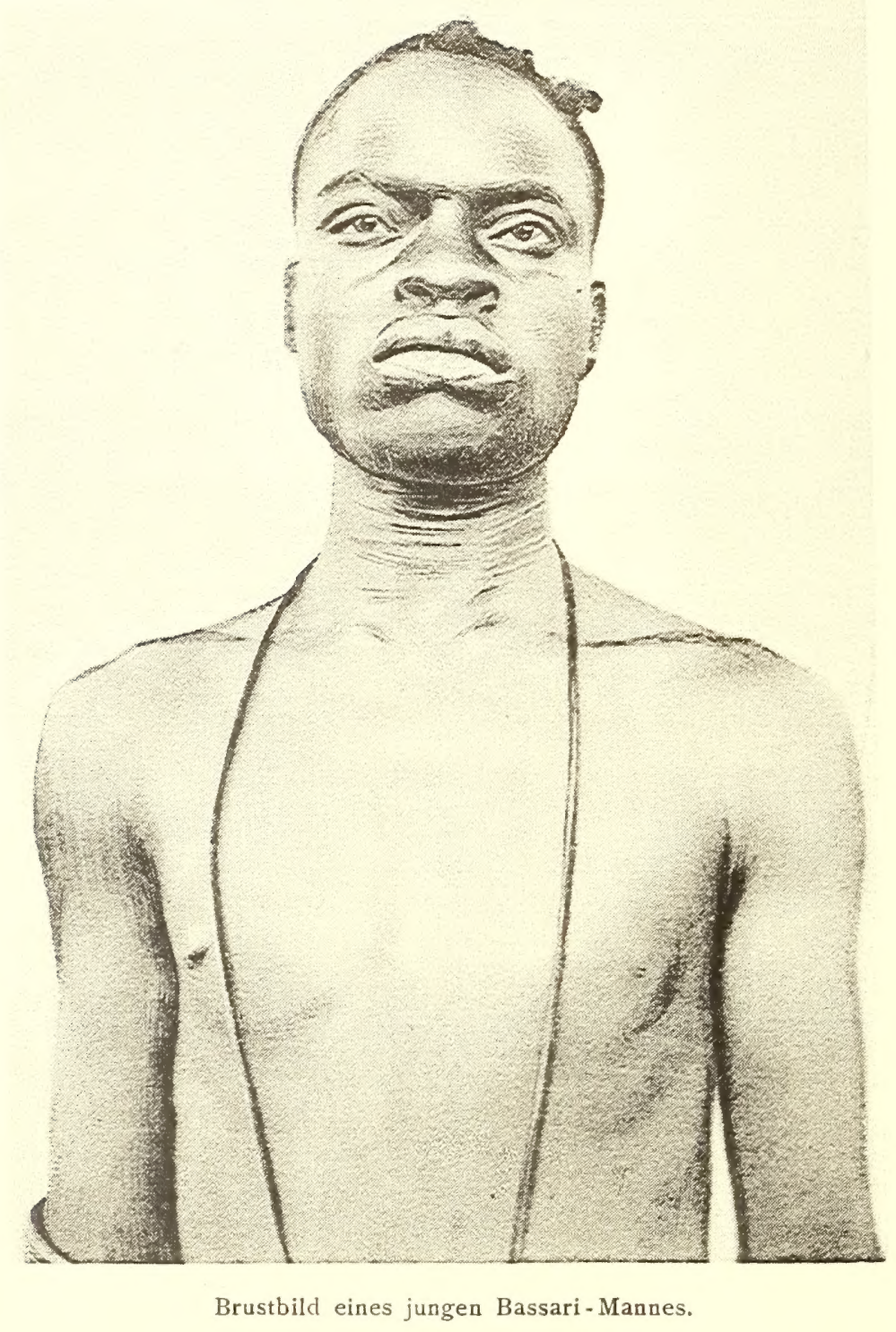




\title{
TOGO
}

\section{UNTER DEUTSCHER FLAGGE}

\author{
REISEBILDER UND BETRACHTUNGEN \\ VON \\ HEINRICH KLOSE
}

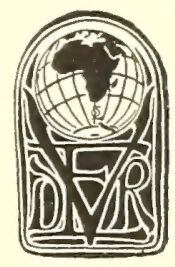

BERLIN 1899

DIETRICH REIMER (ERNST VOHSEN) 
Das Recht der Uebersetzung und Vervielfåltigung ist vorbehalten.

Geduckt bei Julius Sittenfeld in Berlin W 


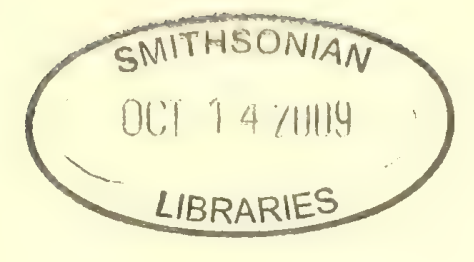

\author{
DEM ERLAUCHTEN PRÄSIDENTEN \\ DER DEUTSCHEN KOLONIALGESELLSCHAFT
}

SEINER HOHEIT

\title{
DEM HERZOG JOHANN ALBRECHT
}

REGENT DES GROSSHERZOGTUMS MECKLENBURG-SCHWERIN

\author{
IN TIEFSTER EHRFURCHT GEWIDMET
}

VON DEM VERFASSER 


\section{.}




\section{VORWORT.}

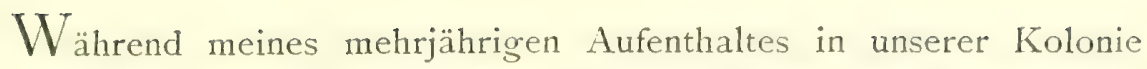
Togo habe ich an der Küste und im Innern Land und Leute sowie deren Sitten und Gebräuche im vielseitigen persönlichen Verkehr mit den Eingeborenen kennen gelernt und lege das Resultat meiner Beobachtungen in schlichter Erzählung an der Hand meiner Reisen in dem vorliegenden Buche nieder. Besonderer Wert wurde auf die unter deutscher Flagge·geförderte Kulturentwicklung, sowie auf die Erschliessung wirtschaftlicher Quellen gelegt. Um die Lücken meiner Beobachtungen auszufüllen und dadurch dem Werke den Charakter eines abgeschlossenen Bildes zu verleihen, habe ich die Schriften der im Register aufgeführten, bekannten Togoreisenden und Missionare berücksichtigt.

Die Photographieen, namentlich aus dem Hinterlande, sind eigene Aufnahmen, während wertvolle Aufnahmen von der Küste mir von den Inhabern in dankenswerter und liebenswürdiger Weise zur Verfügung gestellt worden sind.

Vor allem bin ich ganz besonderen Dank der Deutschen Kolonialgesellschaft schuldig für die thatkräftige Unterstützung, die mir dieselbe gewährt hat.

Möge das Buch freundliche Aufnahme und wohlwollende Beurteilung finden und dazu dienen, das Interesse für unsere afrikanischen Kolonieen im allgemeinen, insbesondere aber für Togo in weiteren Kreisen des deutschen Volkes zu wecken und zu erhöhen.

Berlin, im November 1899 .

Heingich Klose. 



\title{
INHALTS - VERZEICHNIS.
}

\author{
ERSTER TEIL.
}

AUSREISE. KÜSTE UND VORLAND IM EVHEGEBIET.

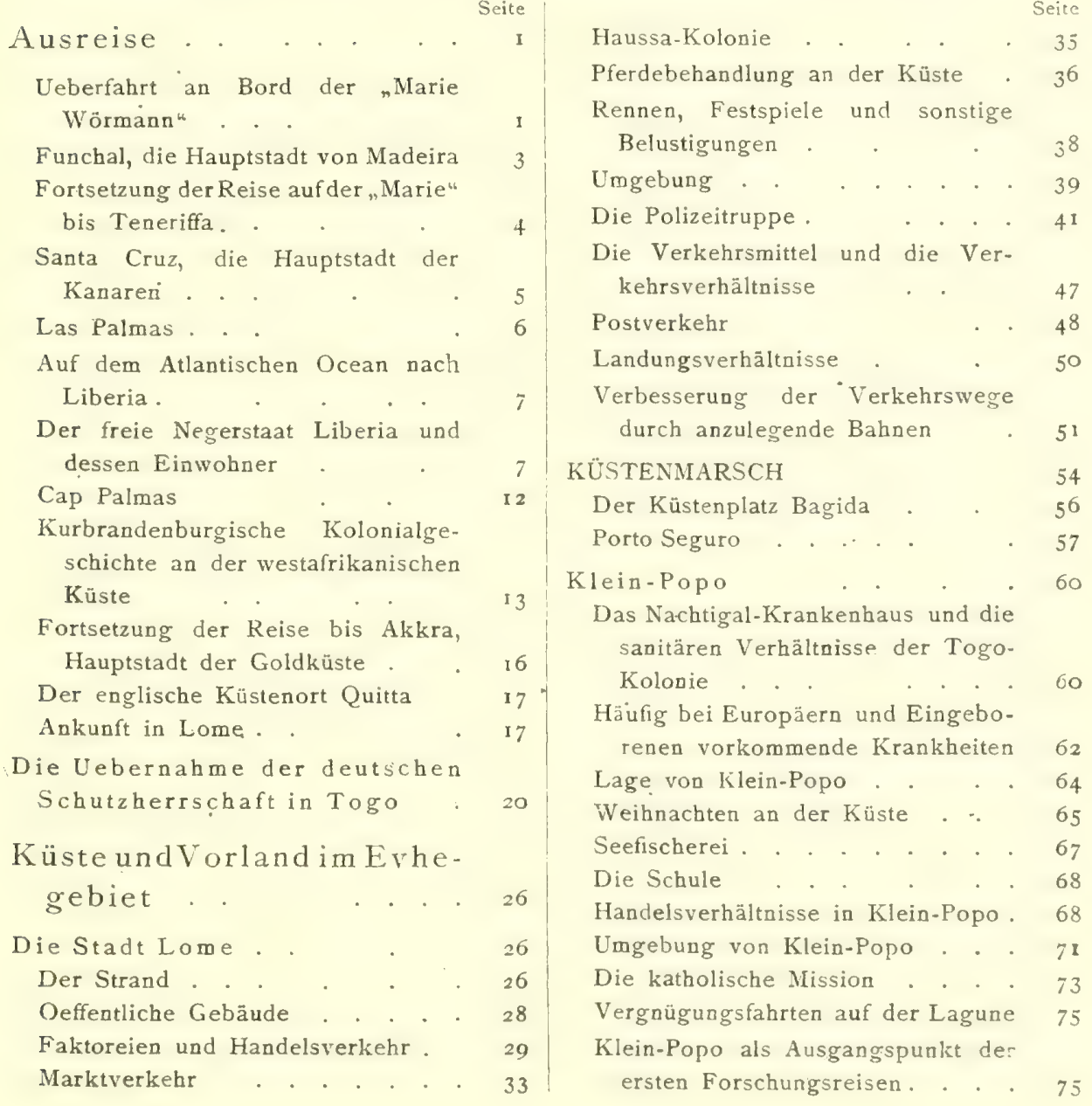


Kaffeeplantagen und deren Schädlinge . . . . . . . .

Kokos- und Gummiplantagen

DIE LAGUNE.

Salzbereitung

Die Lagune als Wasserstrasse .

Die Bewohner der angrenzenden Dörfer

Fischfang auf der Lagune . $\quad 83$

Fauna der Lagune . . . . 84

Topographenleben auf dem Togosee. . . . 85

Das Dorf Togo . . . . 86

Das Leben auf der Mission . 87

Besuch des Häuptlings Blaku . . 87

Umfahrt des Togosees . . . . 89

Dorf Degbo. . . . . 91

Degbo-Sogbe : . . . . . . 92

Nachtlager im Fischerdorf Abobo . 93

Der Sio-Fluss . . . . . . . . 95

Rückfahrt an dem Südufer des Sees 96

Porto-Seguro . . . . . . . . 97

Triangulierung des Sees . . . 98

REISE AUF DEM HAHO UND

DEN ANGRENZENDEN GEBIE-

TEN DES WEST- UND SÜDUFERS

AM TOGOSEE . . . . . . 105

Fortsetzung der Reise an der Küste II 3

Im Bett der Lagune. . II5

REISE NACH MISAHÖHE . II I

Akeppe . . . . 124

Geldkurs . . . . 127

Noëppe . . . . . 128

Palmweinbereitung . . . . . 129

Nach dem Marktflecken Badja . I 30

Grasbrände . . . . . . . . ${ }_{132}$

Ackerbau . . . . . . . 133

In der Landschaft Keve . . . 135

Totenfeste . . . . . . . 138

Ueber den Marktplatz von Assahun nach der südlichen Tove-Landschaft . . . . . . . . 139

Jagd . . . . . . . . . 143

Häusliches Lẹben in den Jäger- und

Farmđörfern . . . . . I 47

In der Gbin-Ebene . . . . . I50

Das Dorf Assahun in der Landschaft

Agotime als Kulturscheide. . . ${ }_{54}$
Ueber die südlichen Vorberge des Agome-Gebirges nach dem zerstörten Dorfe Tove-Djibe . . 157

Töpferei . . . . . . . . $\mathrm{x} 60$

Ursachen des Tove-Aufstandes . . 162

Tove-Aufstand . . . . . . . 164

Durch die Landschaft Agome . 167

Termiten . . . . . . . . . 173

Nach dem Dorfe Yo. . . . . 174

Schmiedehandwerk . . . 174

Anstieg nach Misahöhe . $\quad{ }_{176}$

DIE STATION MISAHÖHE . . I77

Bedeutung der Stationen und Hauptverkehrsstrassen . . . . 178

Die Aufgabe der Station Misahöhe 179

Umgebung von Misaböhe . . 184

REISE NACH DEM AGU . . $\mathbf{1 8 6}$

Fetisch Bagba . . . . 189

Günstige Bodenverhăltnisse für Plantagen . . . . . 189

Im Osten und Süden des AguGebirges . . . . . . Igo

IM NORDWESTLICHEN EVHE-

GEBIET * . . . . 192

Reisenach Kpando . . . 192

Ueberschreiten des Gebirges . $\quad 192$

Marsch in der Danyi-Ebene . 196

Der Yewe-Orden . . . 197

Eintritt in den Orden . . . . 199

Das Verwildern von Yewe-Mitgliedern . . . . 202

Auffindung des grossen Yewe-Gottes 205

Totenerweckung durch den YeweGott . . . . 207

Schutz der Yewe-Mitglieder durch den richterlichen Spruch der Priester 209 Festlicbkeiten im Orden . . 2 2 io Ausstossung aus dem Orden . . 210 Weitermarsch nach Kpando . . 2 II Ankunft in Kpando . . . . 213 Kpando als Handelsplatz . . 215 Stadt und Umgebung von Kpando . 216 König Dakadu und seine Herrschaft 218 MILITÄREXPEDITION ÜBER

KPANDO NACH KRATYI . . 219

Empfang der Expedition . . . 220

Grosser Aufzug Dakadus . . . . 221

Austausch von Geschenken . 223 
Festliche Tanzaufführungen in Kpando

Maassnahmen gegen Dogbadja und Anfoë . . . . . Marsch nach Anfoë.

Verbandlung mit dem Häuptling von Anfoë

Flaggenhissung in Anfoë.

Marsch von Kpando nach der Landschaft Kunya.

Zug gegen Biakpa undVhane zurUnterstützung des Hăuptlings von Tafi

Feldlager in Tafi.

Gefechtsbereiter Narsch in den feindlichen Gebieten der Landschaft Avatime . . . . 238

Einrücken in Biakipa . . . . $2 q^{2}$

Besetzung von Vhane . 242

Ruhetag auf der Missionsstation Amedjovhe . . . . . 243

Entwickelung und Thătigkeit der Norddeutschen oder BremerMission 244

Ackerbau in den Gebirgsgegenden von Avatime . . . . . 246

Wiedereintreffen in Kpando und Weitermarsch nach Kratyi . 248

CHARAKTERISTIK DES EVHE-

STAMMES . . . . . 248

Anthropologische Eigenschaften 248

Geburt . . . 250

Kindererziehung . $25 \mathrm{I}$

Brautwerbung . . . 252
Seitc

Hochzeitsgebräuche . . . . . 254

Die Ehe . . . . . . . 254

Ehebruch. . . . . . . 254

Rechtsbegriffe in der Ehe. . 255

Reinlichkeit . . . . 256

Kleidung . . . . . . 257

Ackerbau und Handel . . 258

Viehzucht. . . . . . 259

Jagd und Fischerei . . . . 261

Gewerbe . . . . . 262

Weberei und Spinnerei . . 262

Töpferei und Schnitzerei . . . 263

Gerberei . . . 264

Flechterei . . . . 2044

Hüttenbau . . . . . 264

Religion . . . $\quad 266$

Die Untergötter als dienstbare

Geister des Mavu . . . . . . 268

Gottesurteile des Fetisch . . 269

Der Teufel der Evheneger . . $27 \mathrm{I}$

Die Priester und Priesterinnen des

Fetisch . . . . 272

Begräbnisfeierlicbkeiten . . . 272

Gesetze und Rechtsgewohnheiten . 275

Familienverbältnisse . . . 275

Erbfolge . . . . 276

Strafbestimmungen. Mord . . 277

Diebstahl. . . . . . 278

Schuldentilgung . . . . 278

Grundbesitz . . . . 279

Regierungsform. Häuptlingswahl . 279

Die Rechtsprechung durch den Häupt-

ling und den Fetischpriestér . 280

\section{ZWEITER T.EIL.}

\section{DAS HINTERLAND UND DER DEUTSCHE SUDAN.}

\begin{tabular}{|c|c|c|c|}
\hline & Seite & & Seite \\
\hline Im Westendes Hinterlandes & 285 & Soldatenspiele der Negerjugend. & 288 \\
\hline REISE ÜBER KETE-KRATYI NACH & & Die Ebene des Danyiflusses. . & 289 \\
\hline SALAGA : . . . . . & 285 & $\begin{array}{c}\text { Marsch im Ueberschwemmungs- } \\
\text { gebiet . }\end{array}$ & 289 \\
\hline $\begin{array}{l}\text { Politische Umtriebe in der neutralen } \\
\text { Zone }\end{array}$ & 285 & $\begin{array}{c}\text { Abschied in Kpemme rom Evhe- } \\
\text { stamme }\end{array}$ & 290 \\
\hline Abmarsch von Misahöhe & 286 & Im Gebiet der Guanivölker in der & \\
\hline Das Gebirgsdorf Liati & 287 & Landschaft Kunya. . . . . & 291 \\
\hline Elternliebe . . & 287 & Kunya und seine Bewohner. & 292 \\
\hline Kollem unter deutscher Flagge. & 288 & Die Baseler Mission & 294 \\
\hline
\end{tabular}


Sprachtalent der Togoneger. Mein kleiner Diener Meppo . . . . 296

Dolmetscherfrage . . . . 297

Weitermarsch nach Wurupong . 298

Besuch beim Fetischpriester und Häuptling von Wurupong .

Der Fetisch Sia . .

Untergötter des Sia. Der Fetisch Kombi . : 30

Kanibalismus und Aberglaube.

Weitermarsch von Wurupong durch Boëm

Durch das Gebiet von Boẽm. .

Das : Emporblühen Kwamikrums durch den Haussa Abu Karimo . 306

In der Landschaft Tappa . . 308

Die Tshisprache als Verkehrsvermittlerin

Handel in Tappa und die Kolanuss

Expedition gegen den Häuptling von Tappa . . . . . 31

Flaggenhissung in Tappa . . 312

Heiligabend in Konfokrum . . $3^{13}$

Marsch nach der.Landschaft Apai 3 I 4

Akroso im Gebiet der Tshi-

sprache . . . . . .

Kanoefahrt auf dem Asioko und dem Volta . . . . .

Nachtquartier in Akroso, Moskito. plage . . . . . 3r

Marsch auf der Karawanenstrasse nach Apaso. Schwierigkeiten der afrikanischen Jagd . . .

Apaso und die Bewohner der Landschaft Apai . . . .

Beschleunigte Reise nach Kratyi

Das Dorf Otisu am Otilluss . .

Uebersetzen über den Oti und Weitermarsch über Abinkru .

Im engeren Kratyi-Gebiet

Marschbeschwerden.

Nächtliches Eintreffen in Kete .

Begrüssung durch Sofo und die Haussa . . . . . . 324

Vereitelung des Planes durch die Abwesenheit des p. Krause.

Die Handelsstadt Kete.

Bauliche Einrichlung der HaussaGehöfte .
Die mohamedanische Fremdenstadt

Kete

Seite

Marktverkehr in Kete. Wertvolle Handelsartikel von einbeimischen und europäischen Stoffen . . . 328

Erzeugnisse der äfrikanișchen L,ederindustrie . . . . . . 329

Artikel des einheimischen Schmiede. handwerkes . . . . . 329

Einheimische Flechtwaren, Gebrauchs-undSchmuckgegenstände 330

Wertvolle Landesprodukte. Gold und Elfenbein . . 330

Gummi . 331

Felle und Straussenfedern 331

Europäische Messingwaren . 33 I

Waffen und Pulver . . . 332

Alkohol . . . . 332

Gemüse- und Fruchthandel . 332

Narkotische Genüsse und Gewürze 332

Seife und Farbstoffe . . . . . 333

Genuss- und Nahrungsmittel . $\quad 333$

Fleischmarkt . . . 333

Marktbilder und Scenen . . 334

Viehmarkt . . . . . 334

Das Handwerk und Gewerbe auf den Strassen. . . 335

Geschäfts- und Geldverkehr . . 335

Verdeckter Sklavenhandel . $\quad 336$

Schwarze Handelsvertreter aus dem

Hinterlande . . . . . 336

Der Islam in Kete . . . . 337

317 Bauart und sanitäre Verhältnisse . 337

Sanitătspolizei . . . . . 337

Geographische Lage von Kete und die Erweiterung der Verkehrsmittel . : . . . $33^{8}$

Der Bade- und Wasserplatz in Kete . . . . . . . $33^{8}$

Die Königs - und Fetischstadt Kratyi . . . . . 339

Der Fetischgott Odente. . . 340

Die Willkürḥerrschaft der Fetischpriester . . . . . . 34 I

Verbreitung des Odentefetisch und seine Opferstätten . . . . . 342

Verhăngnisvolle Folgen der Wegnahme eines Opferhuhnes . . 343

Fetisch-Auguren . . . . 344 
Strafen des Fetisch . . . . . 344

Geschichte und Herkunft des Fetisch

Odeate

Die Wahrsagerin Koko.

Menschenopfer .

Charakteristik der Kratyileute und der Haussa . . 346

Anthropologische Eigenschaften $\quad 346$

Kleidung und Hüttenbau • . 347

Beschäftigung . . . . 349

Haussklaverei . . . . 349

Sitten und Gebrāuche . 350

Die eingewanderten Haussa. Anthropologische Eigenschaften . . 350

Tracht und Schmuck. . . . $35 \mathrm{I}$

Beschäftigung und Belustigung . 351

Mohamedanische Schulen . . 352

Verzögerter Aufenthalt in Kete 352

Pferderennen . . . 353

Pferdekauf . . . . . 354

Der Haussa als Reiter und Pferdepfleger. . . . 354

Sattelung und Zãumung $\quad 356$

Deputation alter Haussa-Soldaten 356

Besuch der Haussa-Honorationen und der Jendi-Prinzessin . . 357

Aufzug des Fetischpriesters Bosumfo 358 Furcht vor dem Fetischpriester $\quad 359$

Begegnung mit dem Fetischpriester. 359

Ein Tornado . . . 360

Besuch des Königs Odukru . . ${ }_{3}^{6} 62$

Die vertriebenen Salaga Prinzen $\quad 362$

Der Thronfolgestreit in Salaga . $\quad 364$

Gegenbesuch beim König Odukru . 365

Vorbereitungen zur Weiterreise . 366

Von Kete nach Salaga . . 366

Marsch durch die Savanne . 367

Das Sklavendorf Bombatá . . 368

Bayamso als Grenz- und Verkehrsort 368

Weitere Salagaflüchtlinge . . . . 369

Marsch durch das verwüstete Königreich Gonya . . . . 360

Gestörte Nachtruhe durch Löwengebrüll . . . . . . 370

Besichtigung eines Fetischhauses . $37 \mathrm{I}$

Verzögerung des Marsches durch Fieber . . . . 372
Begrŭssung durch die Eskorte des Sultans von Salaga . . . . 372

Nachtlager in Kurupi . . . . 373

In der Residenzstadt Pembi und der Hauptstadt Salaga des Königreichs Gonya. . . 374

Einzug in die Königsstadt Pembi . 374

Empfang beim Sultan von Isafa. 375

Musikkapelle bei den Haussa und an denmohamedanischenFürstenhöfen 376

Protest vor dem Sultan gegen die englischen Intriguen in Salaga . 377

Austausch von Geschenken . . 378

Ausnutzung meiner bedrängten Lage 379

Salaga . . . . 380

Kurze Charakteristik der Gonyaleute 380

Die Sklaverei. Sklavenraub und Sklavenhandel . $\quad 382$

Die Sklaverei als wirtschaftlicher Faktor . . . . . . 383

Plötzliche Abschaffung der Sklaverei $3^{8} 3$

Verhandlungen mit dem Sultan Isafa . . . . . 384

Der unrechtmässige Vertrag von Ferguson . . . . . 385

Schwierigkeiten beim Abmarsch von Salaga . . . . . 386

Rückmarsch ūber Kratyi . . 387

Nächtlicher Aufbruch . . . 387

Wiedereintreffen in Kete und peinliches Strafgericht . . . . 388

Rückmarsch zur Küste, Verhandlung und Abschied von Kōnig Odukru 389

DIE STATION KETE-KRATYI . $390^{\circ}$

Krönung des Sultans Sulemana . · 39r

Handelsverbältnisse in Kratyi und Uebermut der englischen Hăndler $39 \mathbf{I}$

Expedition nach Yegi . . 392

Einrücken in Yegi . . . . 393

Yegi als Handelsplatz . . . . 394

Die Bewohner von Yegi und der Landschaft Bron . . . . 394

Englische Untriebe und Anmaassungen . . . . . . . 395

PolitischeVerhältnissein Kratyi 396

Schutzmaassregeln gegen englische Uebergriffe . . . . . 396 


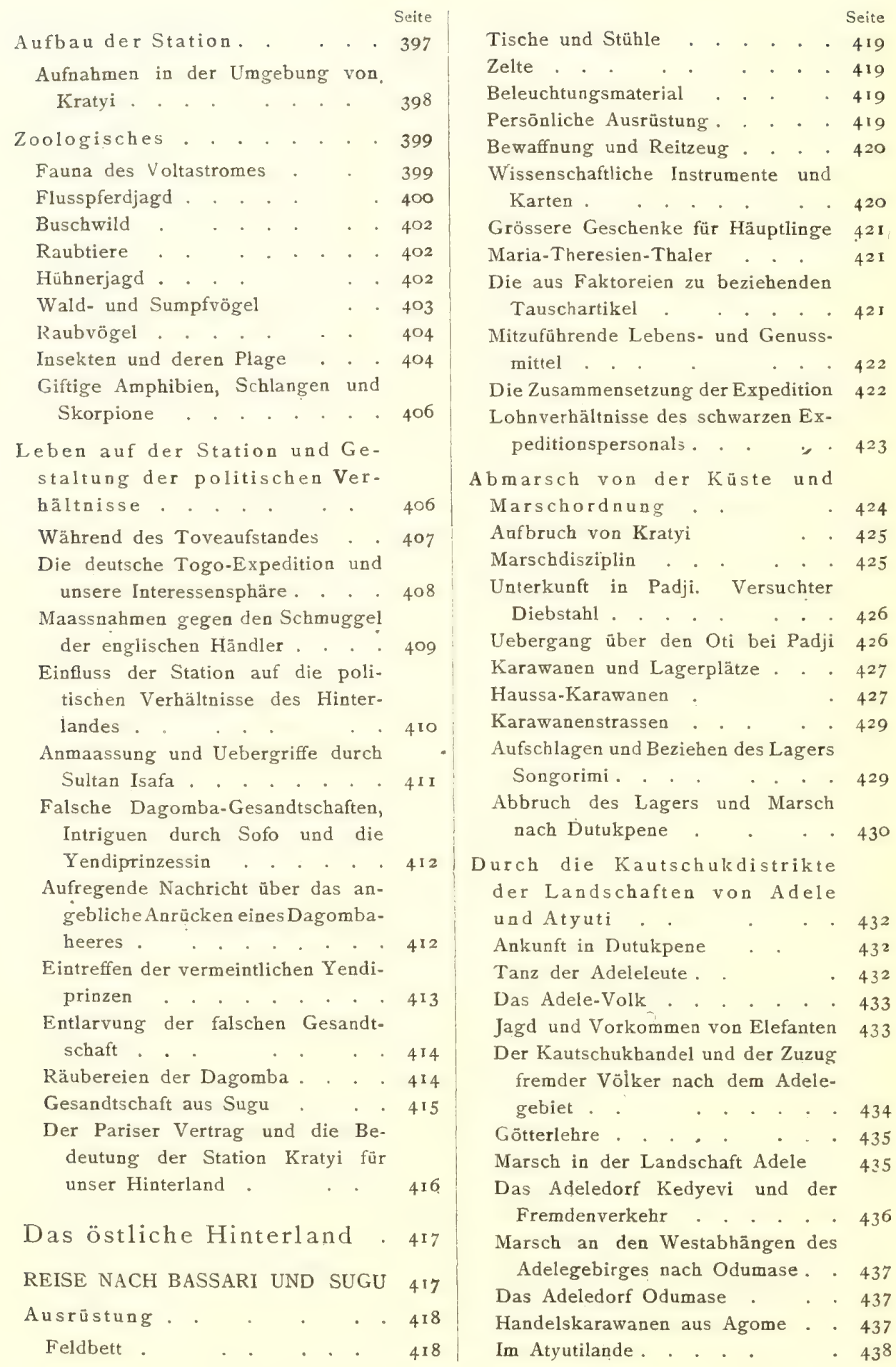


Nyambo und seine Bewohner . $\begin{array}{r}\text { Seite } \\ 43^{8}\end{array}$

Der Einfluss des Landesfetisch

Buruku . . . . . . . . . 439

Musikinstrumente und der Serpentin$\tan z$ der Atyutileute . . . . 439

Kautschuk und dessen Gewinnung . 440

Gummihandel und Schutzmaassregeln gegen die Raubwirtschaft . . . 44 I

Paua und dessen Wildreichtum . $44^{2}$

Im Gebiet der Landschaft Bo . $44^{2}$

Mobamedanischer Einfluss . . . 443

Verkauf von Nahrungsmitteln . . 443

Aufenthalt in Kuëda . . . . 444

Geologische Untersuchungen im

Kuëthale . . . . . . . 445

Marsch nach Tashi, westlich des

Bogebirges . . . . . . . 445

Tashi als Kreuzungspunkt der

Handelsstrassen . . . . . . 446

Suruku, die Vorstadt von Akpande 446

Behandlung eines Geisteskranken $\quad 447$

Der Wasserfall des Sako . . . . 447

Empfang durch den Oberhăuptling

Urabaya . . . . 447

Urabaya als Herrscher . - 448

Austausch der Geschenke . . 448

Tanzfestlichkeiten am Hofe Urabayas 449

Charakteristik der Boleute . 449

Haartracht . . . . . . 450

Die Temusprache . . . . . . 450

Kleidung . . . . . . . 450

Bewaffnung und Hüttenbau . . . 45 I

Der ăussere Einfluss des Mohamedanismus und die heidnische Re-

ligion der Eingeborenen . . . 452

Ackerbau . . . . 452

Viebzucht . . . . . . . . . 453

Pflege und Verwertung des Viehes 453

Der Markt und die Landesprodukte 454

Gebrauchsgegenstande und Handelsartikel . . . . . . . . 4 454

Ausflugg nach Yerepangá . . . . 454

Tod des Oberbăuptlings Urabaya • 455

Bestattung des Häuptlingss . . . 455

Marsch lăngs des Bogebirges nach

Kadiumbara . . . . . . 456

Im Gebiet der Buschvölker. Das

Dorf Kadiumbara . . . . . 456

Das Grenzdorf Bolo am Mo . . $45^{8}$
Nach Bassari- Seite

Flussülergang über den Mo ... 458

IM BASSARILANDE . . . . . 459

Das Farmdorf Dyodjega . . . . 459

Einmarsch in den Bereich des eigent-

lichen Bassari . . . . . . . ${ }_{4} 60$

Begrũssung mit der Dr. Grunerschen

Expedition . . . . . . 46 I

Besuch des Königs Tagba im Lager 461

Gegenbesuch bei Tagba in der

Königsstadt Kore . . . . $46_{3}$

LEBEN UND THÄTIGKEIT AUF

DER STATION BASSARI . . $4_{4}$

Einrichtung einer provisorischen Station in Bassari . . 464

Die Beschäftigung der Träger und weitere Ausbildung unserer Soldaten . . . . . . . $44^{6}$

Die Verpflegung und die Einführung von Geld . . . . . . 466

Der Markt von Kore und Naparba 466

Landesprodukte und Nahrungsmittel 467

Handel mit Gebrauchs- und Bedarfsartikeln . . . . . . 467

Gewerbsmässige Wahrsager . . 468

Auflehnung der Konkomba . . . 468

Geographische und geologische Aufnahmen in der Umgebung von Bassari . . . . . 470

Bassari-Trunkenbolde . $47 \mathrm{I}$

Zechgelage und Hazardspiele der Bassarileute. . . . 47 I

Wein- und Bierbereitung bei den Bassari . . . . . . 473

Charakterzüge der Bassarileute . . 473

Anthropologische Messungen . . 474

Photographische Aufnahmen . . . 474

Erfahrungen über die photographische Technik in den Tropen. . 475

Astronomische Bestimmungen . . 477

CHARAKTERISTIK DES BASSARI-

VOLKES . . . . . . . . . . 478

Die Gyambasprache . . . . . . 478

Anthropologische Ëigenschaften der Bassari . . . . 478

Die Tătowierung der Bassari . . 480

Krankheiten . . . . . . 48 I 
Haartracht und Reinlichkeit . . . 483

Kleidung und Schmuck der Bassarimānner. . . . . . . . . . 483

Kleidung und Schmuck der BassariFrauen und Mädchen. . . . 48

Die Bewaffnung der Bassarileute $\quad 486$

Gehöfte und Hütten in Bassari . . 487

Verzierungen an den Hüttẹ, sogenannte Graffiti . . . . . . 488

Stălle und Kornspeicher . . . 489

Die heidnische Religion der Bassari 490

Beschäftigung der Bassarileute. Ackerbau . . . . . . . 49 I

Die Viehzucht und die Fulbe in Bassari .

Negroide Eigenschaften und Tracht der Fulbehirten . . . . . .

Die Fulbe als Pfleger und Viehzüchter

Molkereiprodukte . . . . . .

Die Jagd und der Fischfang in Bassari

Die Eisenindustrie in Bassari. Schmelzöfen . . . . . .

Bassari-Schmiedemeister und Einrichtung ihrer Werkstătten. . .

Steinerne Schmiedehandwerkzeuge .

Erzeugnisse des Schmiedehandwerkes. . . . . . 498

Die Töpferei in Bassari . . . 500

Flechterei und Schnitzerei der Bassarileute . . . . . . 500

Regierung und Verwaltung des Landes 500

Thronfolge in Bassari . . . . 50I

Gebräuche beim Tode des Königs und bei der Einsetzung seines Nachfolgers . . . . . . 508

Kriegführung . . . . . . 502

Der Dagombakrieg mit Bassari. . 502

Die Sabermareiter als Kriegssöldner 503

Das Richteramt des Bassarikönigs . 504

DieRechte und Einnahmen des Königs 504

Strafbestimmungen. Mord . . 505

Körperverletzung und Diebstahl . 505

Ehebruch . . . . . . 505

Gottesurteile . . . . . 505

Kindererziehung . . . . . 506

Brautwerbung. . . . . . . 507

Hocbzeitsgebräuche und Familienleben . . . . . 508
Geburt . . . . . . . 509

Zwillinge . . . . . . . . 509

Tot- und Missgeburten . . . 510

Sympathiemittel des Fetischpriesters

gegen Unfruchtbarkeit . . . 5 ro

Uneheliche Kinder . . . . . 510

Sklaverei. Kabrésklaven . . . 5 II

Behandlung der Sklaven und ihre

Rechte . . . . . . . . . 512

Tod und Beerdigungsgebräuche. . 513

Die Trauerzeit . . . . . . 514

Erbrecht . . . . . . . . 515

Politische Verhăltnisse. . . 515

Die deutsche und französische Besetzung der streitigen Gebiete . 515

VON BASSARI NACH SUGU • , 516

Bedrängnis der deutschen Besatzung in Sugu . . . . . . . ${ }_{516}$

Im Gebiet der Temuvölker. Dako und seine Bewohner... . . 517

Ueber das Gebirge von Dako nach Aledjo-Kadara . . . . . 518

Der obere Lauf des Flusses Mo . 519

Steiler Aufstieg und Eintreffen in Aledjo-Kadara . . . . . 519

Das Bergdorf Aledjo-Kadara . . 520

Marsch in den Felsengebirgen nach Kumondé . . . . . . $52 \mathrm{I}$

Flaggenhissung in Péva und Busiré 521

Die Felsenstadt Kumondé und ihre Bewohner . . . . . . . 522

Auf dem Hochplateau nach Sudu 524

In der befreundeten Königsstadt Sudu . . . . . . . 524

Im Gebiet von Semere • . 525

Die befestigte Stadt Semere . . 525

Thronstreitigkeiten und Parteispaltungen in Semere. . . . . 526

Mohamedanischer Fürstenhof in Semere. . . . . , 527

Handel und Gewerbe unter mohamedanischem Einfluss . . . 527

Bevölkerung von Semere : . . $527^{\circ}$

Vegetation in den nồrdlichen Gebieten $\quad 528$

Im Gebiet der Kyilina-Völker . 528

Begrüsșung und Einzug in die deutsche Station Sugu . . . . 529 


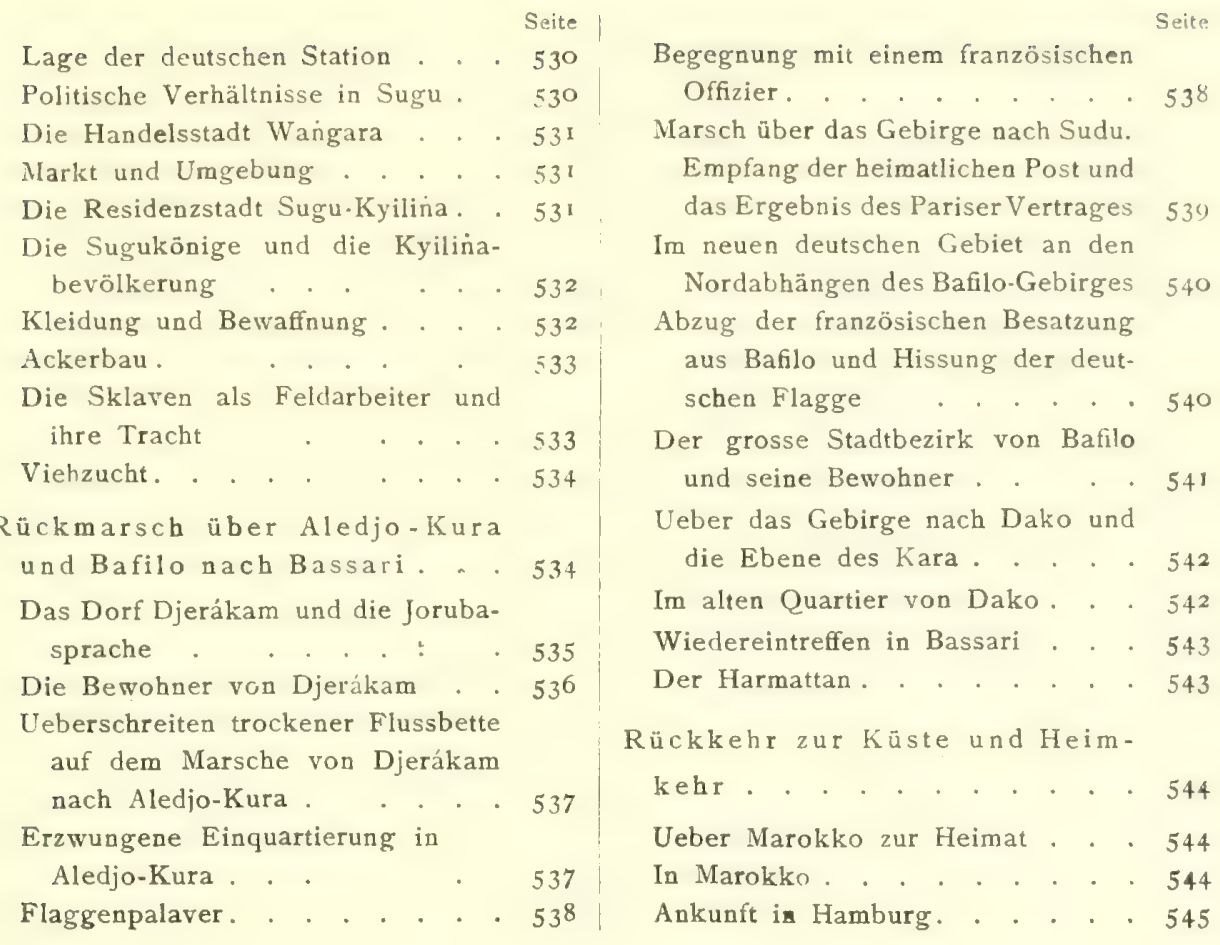

\section{ENTWICKELUNG DER KULTUR-VERHÄLTNISSE.}

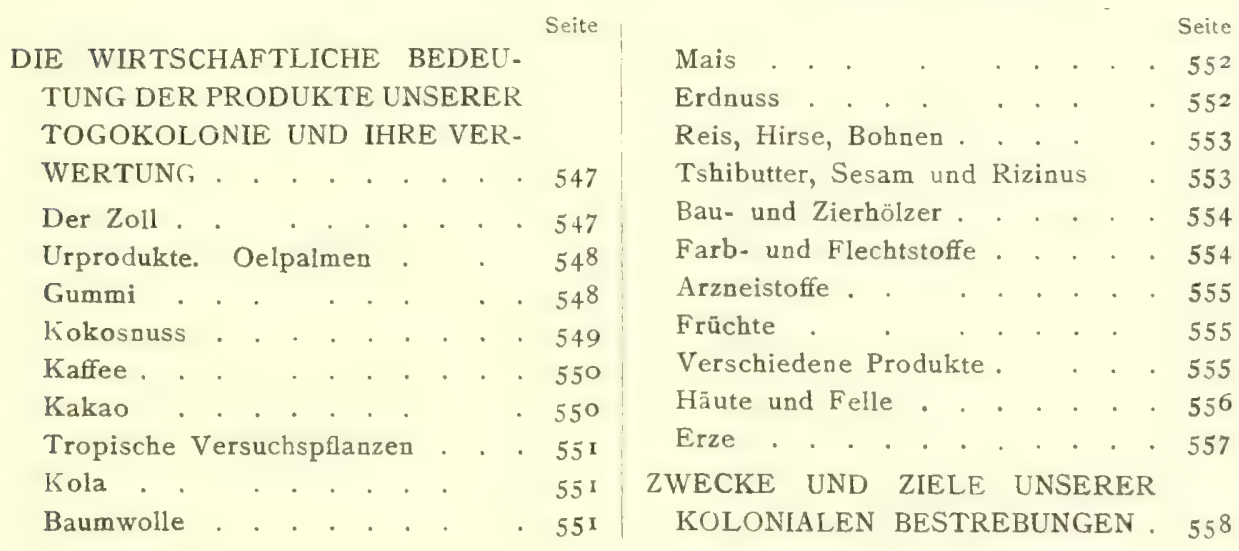




\section{BILDER-VERZEICHNIS.}

Die mit einem Stern bezeichneten Bilder sind mir gütigst von dem Kolonialverein dem früheren Amtsvorsteher Gerlach, dem Oberstabsarzt Wicke, dem Kaufmann Witt und' der Firma Wölber \& Zimmermann in Togo überlassen worden. Die Originale der von dem Maler Wilhelm von den Steinen in dankenswerter Weise gezeichneten Abbildungen wurden mir durch gütige Vermittlung des Professors $\mathrm{Dr} v$ Luschan von dem Berliner Völkermuseum zur Verfügung gestellt. Die Karte mit meinen, zum grössten Teil selbst aufgenommenen Routen wurde in liebenswürdiger Weise von dem bekannten Kartographen P. Sprigade konstruiert.

Brustbild eines jungen Bassari-Mannes . . . . . Titelbild

Funchal, die Hauptstadt von Madeira . . . . . . . . . . . 2

Hafen von St. Cruz auf Teneriffa. . . . . . . . 5

*Die Rhede von Lome . . . . . . . . . $\quad$ I 8

Flurskizze von Lome . . . . . . . . . . . . . 25

*Das Gouvernement . . . . . . . . . . . 28

*Die Bremer Faktorei in Lome, Abmarsch einer Trägerkolonne ins Innere . 32

* Der Markt in Lome . . . . . . . . 32

*Die grosse und kleine Pferderasse des Hinterlandes . . . 37

*Auf dem Schiessstande . . . . . . 44

*Das Nachtigal-Krankenhaus in Klein.Popo . . . . 6 I

*Hof der Faktorei von Wölber \& Zimmermann in Klein-Popo . . . . . . 62

*Die Faktorei von Wölber \& Zimmermann an der Lagune in Klein-Popo 72

*Badyi, die Residenz des Königs Lawson III. von Klein-Popo . . . 72

*Das Hauptgebäude der kathol Mission mit Kirche und Wohngebăude in Adjido . . 74

Lagunenbildung bei Klein-Popo, von Sebbe aus gesehen . . . . 80

*Die Lagune mit Kanoes . . . . . . $\quad$. . . 84

* Der Fetischort Gross-Be bei Lome . . . . . I17

Schutzmarke des Fetisch von Be. . . . . . . . . . . 118

Landschaft der ersten Wellenterrassen hinter Lome, die Affenbrotbăume Baobabs . 120

*Das Dorf Kevega mit den grossen Wasserbehăltern . . . . . . $\quad$ I 36

Ein Gehöft der Evhe-Neger . . . . . . . 149

Ein Weber in Assahun . . . . . . . . . . . . . 152

*Das zerstörte Dorf Tove-Djibe . . . . . . . 160

Schmiedewerkstatt in dem Dorfe Yo . . $\quad 175$

Der François-Pass und die Station Misahöbe von der Kaffeeplantage aus gesehen . 176

Hauptgebäude der Station Misahöhe. . . . . . . . 1.80

Die Wirtschaftsgebäude der Station Misahőhe . . . 18 I

Hâuptling und Leute vom Agu bei einem Palawer auf der Station Misahöhe. . 188

*Das Dorf Leglebi. . . . . . . . . . . . . . 196 
Evhe-Frau aus dem Hinterlande, mit einheimischem Tuch bekleidet 252

Evhe-Frau mit Kind . . . . . . . . . . . . . 252

Evhe-Mädchen im Putz . . . . . . . . . . 253

Ein Evhe-Vater mit seinen Kindern . . . . . . . 256

Junge Evhe-Frau einen grossen Wassertopf tragend . 256

* Reiche Evhe-Frauen von der Küste. . . . . . . . $25^{8}$

Eine im Bau begriffene Hütte der Evhe-Neger. . . . . . . 265

Dorfstrasse mit Kornspeichern in Kunya-Ntshumuru. . . 293

Brief von Wilhelm (Meppo) . . . . . . . . 296

Meppo in Europa . . . . . . $\quad 297$

Kriegstrommel der Evhe und Fetischobjekte . . . . 304

Aschanti-Tätowierung . . . . . . . . . . . . . . 315

Der Voltastrom . . . . . . . . . . . . . . . . . . 316

Ein Haussafleischer . . . . . . . . . . . $\quad . \quad 333$

Haussaleute auf dem Marsch . . . . . . . . 350

Ein Haussareiter . . . . . . . . . . . . . . 352

Gesatteltes Haussapferd . . . . . . . . . . . . . . 355

Fahrender Sänger mit Trommel bei mohamedanischen Fürstenhöfen . . . . . 368

Tierzeichnungen am Fetischtempel in Kurupi . . . . . . . . . 371

Im deutschen Sudan gebrāuchliche Musikinstrumente. . . . . . . 376

Tätowierung der Gonyaleute . . . . . . . . . . . . . 381

Hüttenform mit platten Dächern . . . . . 395

Träger von dem Evhestamm . . . . . . . . . . . . . . 423

Haussakarawane. $\quad$. . . . . . . . . 428

Gummihändler von der Küste . . . . . . . . . . . . 434

Expeditions-Soldaten . . . . . . . . . 444

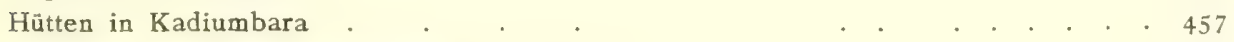

Ein Vornehmer aus Kadiumbara. . . . . . . . . . . $45^{6}$

Das Dorf Bassari mit den Duadior-Bergen . . . . . 460

Ein Dorfbāuptling von Bassari mit seinen Getreuen . . . . 462

Die Station Bassari im Dorfe Yatre . . . . . . 464

Kaurispiel der Bassari-Leute . . . . . . . . 472

Bassari-Mädchen mit Tätowierung . . . . 478

Bassari-Mănner . . . . . . . . . . . . . . . . . 479

Bassari-Marken . . . . . . . . . . . . . . . . . . . . . 480

Bassari-Frau . . . . . . . . . . . . . . . . . . . . 480

Bassari-Frau, Vorder- und Seitenansicht . . . . . . . . . . . . 4 48

Drei Altersstufen von Bassari-Frauen . . . . . . . 482

Das Schröpfen bei den Bassari-Leuten . . . . . . 482

Haartracht, kleines Bassari-Mädchen . . . . . . 484

Ein Bassari-Krieger mit Steinschlossflinte . . . . . . . . . . . 486

Eingangshütte in einem Häuptlingsgehöft in Bassari . . . . . . . 487

Das Innere eines Bassarigehöftes. . $\quad . \quad$. . . . . . . . 488

$\begin{array}{lllll}\text { Rückseite eines Bassari-Dorfes } & \text {. } & & 489\end{array}$

Die Graffito-Verzierungen an den Bassari-Hütten . . . . . . . 490

Ställe für Kleinvieh und Kornspeicher in Bassari . . . 491

Eine zerfallene Hủtte und ein Fetischkegel in Bassari . . . . . . . . 492

Ackergerăte der Bassari . . . . . . . . . . . . . . . . . . . . . . 493

Bassari-Mann mit Feldhacke und Axt, Vorderansicht. . . . . . . . 494 
Seite

Kehrseite eines Bassari-Mannes . . . . . . . . . 494

Gehöft mit Viehkral in Bassari . . . . . . . . . . . . . . 495

Waffen sowie Werkzeuge und Erzeugnisse des Schmiedehandwerks in Bassari . . 499

Eine Musikkapelle in Bassari . . . . . . . . . . 500

Ein Trommler mit der Kriegstrommel . . . . . . . . 502

Ein Saberma-Reiter . . . . . . . . . $\quad . \quad 504$

Ein Familien-Idyll in Bassari . . . . . . . 506

Bassari-Mädchen in drei Altersstufen . . . . . . . 508

Ein Kabré-Sklave . . . . . . . . . . . . . . 512

Häufig vorkommende Hüttenform in den Temu-Landschaften . . 52

Tätowierung junger Männer in Kumondé. . . . . . . . . . . 523

Eingangsthor zur Stadt Mogador . . . . . . . . 544

Der Hafen von Tanger . . . . . . . 546 


\section{LITTERATUR.}

Baumwolle aus Togo. D. K. BL. 1893

Brücken- und Kanoebau Globus ${ }^{\top}$ i 894

Christaller, J. G. Die Sprachen des Togo-Gebietes Zeitschrift für afrikanische und oceanische Sprachen 1895

Clerk, N. Meine Reisen in den Hinterländern von Togo nach Nkonya, Boem, Obooso, Salaga, Krakye vom 2 Dezember 1889 bis 5 Februar 1890 , mitgeth. v Christaller Mitth d Geog. Ges., Jena. IX

Deutsch-englisches Abkommen vom I. Juli i 890 .

Dier, P M Begräbnisfeierlichkeiten und Totenklage im Togoland "Gott will es" I805. Ellis The Ew'e-speaking of the Slave Coast of West Africa London 1898

Fauna des Togolandes. Beiträge zur M. a d. Sch. 1893.

Flora des Togolandes. Beitı̈ge zur M a d. Sch. 1893 .

François, C v Expedition M a d Sch I888, $1889,1890$.

Bericht über die zweite Reise nach Salaga. M. a d Sch. 1880.

Frobenius, H. Der Fetischismus im Togo-Gebiet Afrika 1894 (Evgl. Afr Ver)

Gracle, P. Volkstümliche Gebräuche und Gesetze im Togoland Aus all Weltth 1889.

Hall, P, Negerprediger in Ntshumuru. Das Jahresfest des Sia in Nkonya. Uebersetzt von J G. Christaller Evgl Miss. Mag. 1893.

Herold, Lt Bericht betr. religiöse Anschauungen und Gebräuche der deutschen Evhe. Neger. M. a. d. Sch. I 892

- Trinkschalen aus menschlichen Schädeln im Hinterlande von Togo. M a d Sch. 1893 .

Jahresbericht über die Entwickelung der deutschen Schutzgebiete 1897/98

Kling, Hptm. Bericht über eine Reise nach Dutukpenne im August r889. M. a. d. Sch. I889.

- Die Tierwelt von Togo. M. a. d Sch. 1890.

- Bericht über seine letzte von Lome über Salaga und Naparri nach Bismarckburg ausgeführte Reise M a. d Sch I890.

- und Büttner, R., Dr Ergebnisse der Forschungsreisen im Hinterlande von Togo 1890 bis 1892 . M. a. d Sch. 1893 .

Luschan, v. Beiträge zur Völkerkunde der deutschen Kolonieen.

Mischlich, A. Aus einem Reisebericht des Missionars A Mischlich in Bismarckburg. 
Nkonya, Das Jahresfest des Sia in -, Evgl. Miss. Mag., Basel 1893 D. K. Z. 1894.

Oettinger, Johann, Peter. Unter kurbrandenburgischer Flagge, Deutsche Kolonialerfahrungen vor 200 Jahren. Berlin 1886.

Rackow, H Der Ackerbau in Togo. D. K Bl. I89I

- Die Anbauverhältnisse der Nutzpflanzungen im Togo-Gebiet K J. I89 I

Ratzel, Friedrich, Dr. Völkerkunde Leipzig 1885.

Rottmann, W Der Götze Odente, Ein Bild aus dem westafrikanischen Heidentum Miss-Buchhdlg. Basel 1895 . Vergl. evangel. Miss.-Mag. 1894

Salaga, Reise nach. D. K. Bl $\$ 890$

Schmidt, Rochus. Deutschlands Kolonieen.

Schück. Brandenburg-Preussens Kolonialpolitik unter dem Grossen Kurfürsten und seinen Nachfolgern, 1647 bis 1721 . Leipzig 1889.

Seeger Die Sklaverei in dem Togolande und der englischen Goldküsten-Kolonie D. K. Z 1892 .

Seidel, A. Beiträge zur Kenntniss der Sprachen in Togo. Zeitschrift für afrikanische und oceanische Sprachen, Jahrg. IV, Heft 3

Seidel, H Der Yewe-Dienst im Togolande. Zeitschrift für afrikanische und oceanische Sprachen.

Sklavenwesen in Togo D. K. B1. 1895.

Spieth, H. J, Miss. Jagdgebräuche in Avatime. Monatsblatt und Nordd. Miss.-Ges. $1889 / 90$.

Der Yewedienst der Evheneger. Mitth. d Gg Ges. Jena 1894 Vergl. Monatsblatt der Nordd. Miss.-Ges. Bremen 1893.

Tierwelt des Hinterlandes von Togo D. K. Bl. 1895.

Tsetsefliege. D. K. B1. I 895 .

Volz, B., Dr. Unsere Kolonieen, Land und Leute. Leipzig I89ı.

Wangara. Hinterland von Togo. A. all. Weltt. I894/95.

Warburg, O., Dr. Die aus den Kolonieen exportierten Produkte und deren Verwertung in der Industrie. Berlin 1896.

Weissbuch, Teil I und VII.

Wolf, L., Dr. Expedition. Mitteilungen aus den deutschen Schutzgebieten I888,89.

Zech, Graf, Oberlt. Vermischte Notizen über Togo und das Togohinterland. M. a. d. Sch. 1898 . 


\section{ERSTER TEIL.}

\section{AUSREISE.}

Nach zweijähriger Vorbereitung für meine künftige Laufbahn in Ueberfahrt den Museen von Berlin, auf dem orientalischen Seminar, auf der See- an Bord der warte zu Hamburg und auf dem geodätischen Institut zu Potsdam bekam ich am 20. März r894 von der Kolonial-Abteilung des Auswärtigen Amtes "Marie Wörmann". den Auftrag, mich nach Westafrika auf die Station "Misahöhe" im Togogebiet zu begeben.

Nachdem ich meine Ausrüstung besorgt und Abschied von meinen Eltern und Freunden genommen hatte, ging ich von Hamburg aus am II. April I 894 mit der "Marie Wörmann" zum ersten Mal in See. Mit dem Scheiden von der geliebten Heimat trat der Ernst des Lebens in den Vordergrund und manche Pläne und Sorgen, mit denen ich der nächsten Zukunft entgegensah, wurden wachgerufen. Bald wurde ich mit den Passagieren bekannt, welche mit mir drei Wochen Freud und Leid auf der "Marie" teilen sollten. Die Unterhaltung kam leicht in Gang und jeder war glücklich, aus seinen Träumen herausgerissen zu werden. Nach Verlauf einiger Stunden gelangten wir mit dem kleinen Dampfer, den wir in Hamburg bestiegen hatten, vor Brunshausen zur "Marie", die uns nach Togo bringen sollte. Nachdem die Ladung an Bord genommen war, ging es in See. Währenddessen war unten im Speisesaal des Schiffes Lunch serviert, welches mit grossem Appetit eingenommen wurde. Bald hatten wir Helgoland passiert, welches im grauen Nebel vor uns lag, und damit entschwand unseren Blicken für lange Zeit das deutsche Heimatland.

Das Wetter war herrlich, rasch durcheilte unsere "Marie" die Fluten der Nordsee. Am I 2. April gelangten wir in den Kanal, in welchem viele Segelschiffe und Dampfer unseren Weg kreuzten. Auf französischer wie auf englischer Seite bemerkte man viele Schifferboote, 
welche mit ihren kleinen, weissen Segeln malerisch auf dem Meere hinund herschaukelten. Meisen sowie andere Vögel ruhten auf den Raen unseres Schiffes, ein Zeichen, dass Land an beiden Seiten nicht weit entfernt liegen konnte. Weithin blitzten uns am Abend die Leuchttürme von Calais und Dover entgegen und in der Nacht passierten wir das stattlich erleuchtete Dover, welches in der Dunkelheit wie ein Lichtmeer erschien.

Obwohl unsere Fahrt durch das Wetter begünstigt war, so machte sich doch hinter Dover der stürmische Kanal bemèrkbar, so dass die meisten Passagiere Neptun ihren ersten Tribut zahlen mussten. Die Meisen hatten nun unser Schiff verlassen, statt ihrer umkreisten Möven dasselbe und spähten emsig nach Brosamen und Küchenabfällen. Am I +. April passierten wir die Insel Aldernay und erreichten in der Nacht zum I5. die nördliche Spitze der Bretagne. In der Ferne sah man in der Dunkelheit den Leuchtturm aufblitzen. Nun ging es mit Volldampf und einer günstigen Brise, welche unsere Segel schwellte, in den blauen Fluten des Golfes vorwärts. Bereits in der Nacht wurde uns mit einem Schlage unsere veränderte Situation klar, denn wir wurden durch die fortwährenden Schwankungen des Schiffes in unserer Koje von einer Seite des Bettes nach der anderen geworfen, bald auch durch das Knarren der Schraube und das Dröhnen der Maschine im Schlafe gestört. Beim Ankleiden des Morgens ging aber das Leiden erst recht los. Wie ein Gummiball wurde man von einer Ecke der Koje in die andere geschleudert, so dass man nach mangelhafter Toilette sofort dem engen Raum des Schmerzenlagers zu entfliehen suchte; um sich auf Deck bei der kräftigen Brise zu erholen. Alle suchten möglichst in horizontale Lage zu kommen, um sich dadurch Linderung zu verschaffen. Der Golf war sehr bewegt. Unsere "Marie", die gewöhnlich ro Seemeilen in der Stunde zurücklegte, konnte trotz aller Anstrengung nur 6 Knoten in derselben Zeit laufen. Bald ging das Vorderteil des Schiffes hoch in die Luft, um nach Ueberwindung eines Kammes wieder tief in den dunkelblauen Grund des Wellenthales hinabzugleiten; bald wurde das Schiff zur Seite geworfen, so dass sich das. Wasser in den unteren Teil desselben ergoss. Auch auf dem Oberdeck wurde man von einem fortwährenden Sprühregen belästigt. Da ich, wie einige andere beherzte Passagiere, das einzige Heil in der frischen Brise suchte, blieben wir trotz der-Unbilden der Witterung und des Sturmes auf Deck, wo wir uns krampfhaft an den Bänken festhielten.

Nachdem wir Cap Finisterre passiert hatten, bekamen wir nach achttägiger Fahrt Madeira in Sicht. Es war das erste lang ersehnte Ziel, wo man als geborene Landratte wieder festen Boden unter seinen Füsseı fühlen sollte. Da wir erst um 3 Uhr des Morgens landen konnten, 


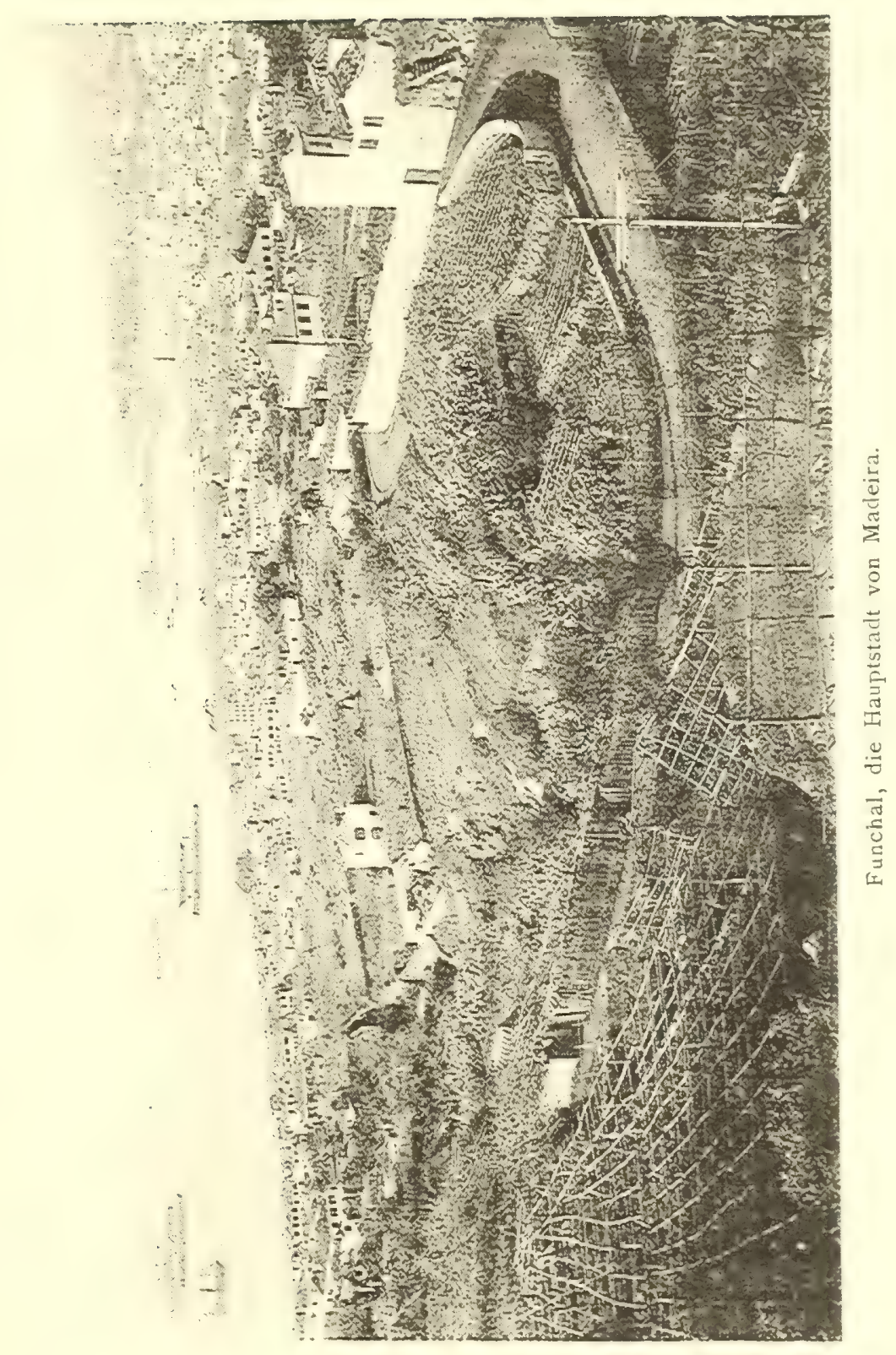



beschlossen wir früh zu Bett zu gehen, um schon bei Sonnenaufgang Madeira in Augenschein zu nehmen. Der erste, der erwachte, weckte die anderen Passagiere. Herrlich wie ein Zauberbild lag das prächtige Eiland, von den blauen Fluten umspült, mit den hohen Bergzügen im Hintergrunde vor uns. Inmitten der Gärten mit Lorbeerbäumen und Palmen lagen die schönen weissen Villen und Häuschen, von Weinbergen umgeben. Um unser Schiff schaukelten kleine Kähnẻ und Boote, bemannt mit braungebrannten halbwüchsigen Leuten, die uns auf deutsch verständlich machten, dass sie nach einer Mark tauchen wollten, sich aber auch mit 5 oder ro Pfennigen begnügen würden. Kleinere und grössere Jungen zeigten vorzügliche Taucherleistungen, indem sie unter dem Schiffe durchschwammen und fröhlich ihre Beute emporhaltend, wieder auftauchten.

Sobald wir in Funchal, der auf den Vorbergen liegenden Haupt-Funchal, die stadt von Madeira, festen Fuss an Land gefasst hatten, wurden wir auch Hauptstadt von den unvermeidlichen Ciceronen belästigt.

Anfangs wurde ein Ritt durch den Ort und durch die Berge geplant, jedoch diese Absicht bald wieder aufgegeben, da die meisten Passagiere nicht ein unsicheres Ross mit unserer "Marie" vertauschen wollten. Die zum Reiten gestellten Pferde gehörten fast durchweg der feurigen spanischen Race an und könnten einem Berliner Tattersall alle Ehre machen.

Ein anderes, in seiner Art einzig dastehendes Beförderungsmittel ist auf diesem Insellande der Ochsenschlitten, welcher meistens von zwei kräftigen Stieren gezogen wird. Auf mehreren zusammengefügten Brettern ist gleich einer römischen Sänfte ein Aufbau für die Insassen angebracht. In diesem Schlitten fährt man nun die steile Höhe hinauf, um sich dort der herrlichen Aussicht zu erfreuen und alsdann auf einem sogenannten Hörnerschlitten mit Windeseile auf dem glatten "Strassenpflaster bis in die innere Stadt heruntergleiten zu lassen. Pferdegespanne scheinen auf der Insel, wenigstens in Funchal, gar nicht vorhanden zu sein. Lebensmittel werden teils auf Schlitten transportiert, teils von den Eingeborenen auf den Köpfen getragen.

Die Häuser sind fast durchgängig weiss und zumeist mit schrägem roten Dach versehen. Die wenigen nach der Strasse zu liegenden Fenster sind meistens durch grüne Jalousieen verschlossen. Ab und $z u$ sieht ein schöner Kopf durch die geöffnete Jalousie auf die seltsame von den vor Anker liegenden Schiffen herkommende Karawane.

Von der oberen Stadt hat man einen reizenden Blick in die Gärten, welche viele Bananen, Lorbeerbäume, Oel- und Fächerpalmen zieren und auch vielfach in herrlicher Pracht unsere deutsche Eiche tragen. Terassenförmig breitet sich zu unseren Füssen die Stadt bis an die 
dunkelblauen Fluten des Meeres aus, auf welchen die Boote schaukeln und majestätisch ruhig unsere "Marie" liegt.

In dem in der Mitte der Stadt liegenden öffentlichen Garten kann man im wahren Sinne des Wortes unter dichten Palmen wandeln. Ferner zieren den Ort ein schön angelegtes Hospiz, sowie einige grössere Hòtels.

Das Volk ist zumeist ärmlich, ja zum Teil unsauber gekleidet. Vor den Thüren paradierten kleine braungebrannte Knaben, zum Teil nur mit einem Hemde bekleidet; bei einigen fehlte auch dieses. Das Tolk stach in seinen Formen wie in seinem Wesen unvorteilhaft von den später zu erwähnenden Kanaren ab.

Unser Weg führte uns, nachdem wir unsere Korrespondenz in die Heimat erledigt hatten, in ein Hôtel, wo wir unseren Durst mit portugiesischem Wein bei dem Gesange fröhlicher deutscher Lieder löschten. 'Auf dem Marktplatze zog zu derselben Zeit die portugiesische Wache auf. Die Mannschaften waren sämtlich in kurze blaue Jacken gekleidet und trugen auf der Mütze eine grosse „I2"; die Bewaffnung bildeten Gewehr und Seitengewehr. Die Mannschaften marschierten mit angefasstem Gewehr, bei dem Kommando "Gewehr über" hätte sich einem preussischen Unteroffizier das Herz im Leibe umgedreht.

Nachdem wir noch den Fleisch- und Fischmarkt, ferner den Gemüsemarkt, auf welchem eine Menge von Südfrüchten, wie Bananen, Apfelsinen, sowie Mispeln und viele Blumen zum Kauf angeboten wurden, besichtigt hatten, kehrten wir befriedigt an Bord zurück. Hier war noch ein lebhafter Handel mit Früchten, Strohhüten und den sogenannten Madeiramöbeln in flottem Gange; erst das Signal zum Aufbruch machte demselben ein Ende. Die Flaggen wurden gehisst und vorwärts ging es; allmählich verschwand vor unseren Augen im blauen Nebel das herrliche Eiland.

Fortsetzung Bei ruhiger See und einem günstigen, die Segel schwellenden der Reise auf Nordwinde steuerten wir den Kanaren zu. Viele schwarze Möwen und der "Marie“ braune Meerschwalben begleiteten unser Schiff, während im Wasser eine bis Teneriffa. Schaar von Delphinen, von den Seeleuten Schweinsfische genannt, von nun an unsere Eskorte bildeten.

Schon am 2x. April erblickte man in dunkler Ferne die Umrisse der Insel Teneriffa und bald leuchtete uns der Pic de Teneriffa mit seinem schneebedeckten Gipfel entgegen. Je näher wir herankamen, desto romantischer gestaltete sich das Bild und grell hob sich der weisse Bergesgipfel von den von der untergehenden Sonne rot beleuchteten Bergzügen ab. Bald verschwand der Pic und ein neues Panorama eröffnete sich vor unseren Blicken. In malerischem Grunde, dicht am Meere und von hohen Bergen umrahmt, lag Santa-Cruz, die Hauptstadt der Kanaren. Ein reger Verkehr entfaltete sich am Strande; neben 
unserer schwarz-weiss-roten Flagge sah man englische, spanische, portugiesische, amerikanische Flaggen auf hohen Masten wehen. Da unser Dampfer hier Ladung nahm, benutzten wir die Zẹit und fuhren an Land.

Wir durchwanderten die engen Strassen. Kasernenartig reihten Santa-Cruz, sich die kleinen weissen Häuser ohne besondere Abwechslung einander dieHaurtstadt an. Auch fand "man ausser dem öffentlichen Carten "Almeda" und der Fanaren. einem vor der Kaserne mit Bäumen bepflanzten Platze wenig von der tropischen Fülle, im Gegensatz zu der üppigen Vegetation von Madeira. Das Volk jedoch sah reinlicher aus als die Portugiesen und machte

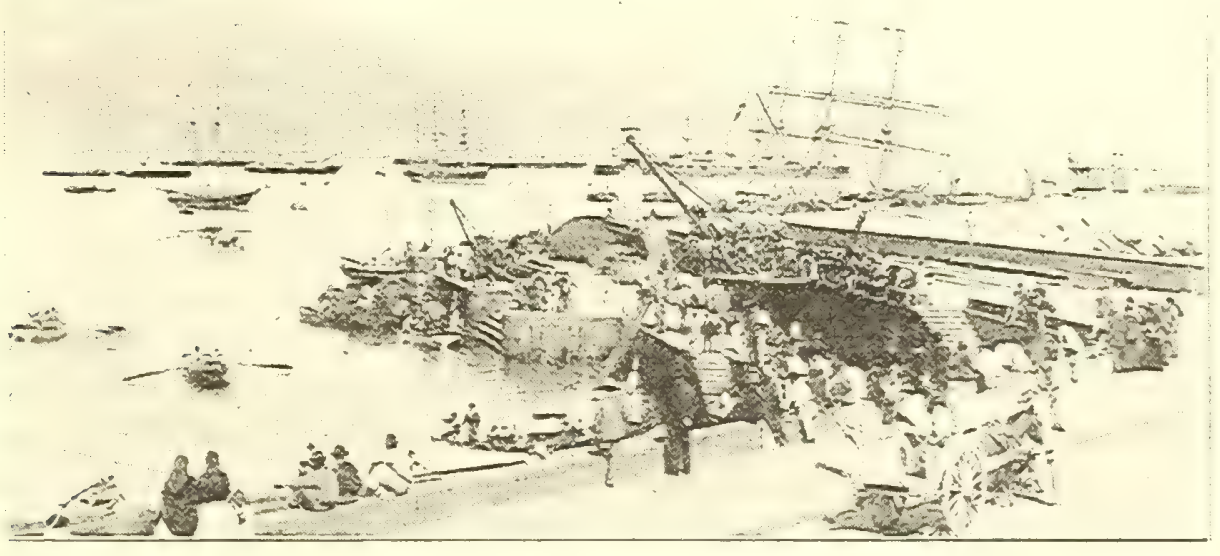

Hafen von Santa-Cruz, auf Teneriffa.

einen freundlicheren Eindruck als diese. Aus den verbrannten Gesichtern blitzten schöne schwarze Augen hervor und die halbwüchsigen Jungen mit ihren Spitzbubenaugen erinnerten uns sehr an unsere Berliner Schusterjungen. Die Grandezza geht meistens ganz schwarz gekleidet, während das gewöhnliche Volk die helleren Farben vorzieht.

Abends entwickelte sich auf dem plaça de la constitutione das Leber der haute-volée, welche im Scheine der Gaslaternen und dem magischen Mondlichte promeniefte. Von hier aus übersieht man einen Teil des Hafens. Nach der Hafenseite zu ist die Stadt durch Pallisaden, vierkantige grosse Blöcke, gegen die Brandung, sowie durch einen grossen 
Panzerturm an der einen Flanke, vor Feinden geschützt. In den unteren Räumen des Turmes waren spanische Truppen kaserniert, den Turm selbst krönten schwere, gut erhaltene Geschütze.

Bevor wir Teneriffa verlassen, wollen wir auch noch unseres verdienstvollen deutschen Landsmannes Dr. Zintgraf gedenken, der hier Ende des Jahres 1897 zur ewigen Ruhe gebettet wurde. Er ist einer unserer Afrika-Pioniere, der sich in den letzten Jahren ein grosses Verdienst um die Erforschung und Entwickelung von Kamerun erworben hat. Nach Ueberwindung schwerer Kämpfe ist Dr. Zintgraf auf der Rückfahrt nach der Heimat dem Tropenfieber an der Küste der kanarischen Insel zum Opfer gefallen. -

Nachdem wir die Stadt besichtigt und uns an dem schönen kanarischen Weine erquickt hatten, gingen wir des abends an Bord der "Marie" zurück. Noch in der Nacht wurden die Anker gelichtet und wir dampften weiter unserem Ziele zu. Am anderen Morgen schon fuhren wir in clen interessanten Hafen Las Palmas von Grand Canaria ein.

Las Palmas. Hier lagen Dampfer von fast sämtlichen Nationen und ein reger Schiffsverkehr vermittelte die Verbindung mit dem Lande. Da unsere "Marie" Kohlen einzunehmen hatte, war uns wieder Gelegenheit geboten, den Hafen und die lebhafte Handelsstadt der Kanaren zu besichtigen. Hafen und Stadt sind von Bergzügen umgeben und ruhig lagen die Dampfer in dem sicheren Hafen, der in einer natürlichen Bucht $8 / 4$ Stunden von der eigentlichen Stadt entfernt liegt. Auf dem Lande wird die Verbindung durch Dampfbahn, sowie durch zahllose Maultierkarren und Pferdegespanne vermittelt. Auch wir bestiegen einen zweirädrigen Maultierkarren und in rasendem Galopp gelangten wir auf der staubigen, rechts und links von kleinen weissen Häusern begrenzten Chaussee nach halbstündiger Fahrt in die Stadt; denn was den Pferden und Maultieren an Mut fehlte, wurde durch die gewohnheitsmässigen Schläge des auf dem Bock kauernden Rosselenkers ersetzt. Ueberall luden die weissen glatten Dächer zur Abendpromenade ein. Die sich aneinander reihenden Häuser mit ihren grünen Fensterläden bildeten die Strassen; alle grösseren Grundstücke hatten einen geräưmigen, durch herrliche Palmen und andere tropische Gewächse gezierten Hof. Da es gerade Sonntag war, waren die Strassen verhältnismässig leer. Alles ging in Weiss oder - die Vornehmen - in Schwarz zur Kathedrale. Auch wir lenkten unsere Schritte dorthin und fanden eine reich ausgestattete Kirche im romanischen Stile erbaut, vor. Von hier wanderten wir auf den Markt, ım die Produkte des Landes kennen zu lernen und Einkäufe an Früchten zu besorgen.

Nachdem wir von dort wieder glücklich an Bord angelangt waren, dampfte auch bald unsere "Marie" zum Hafen hinaus. Als wir gerade 
die Anker lichteten, wurde uns noch eine merkwürdige Ovation gebracht. Eine kleine Schaluppe mit ungefähr zwölf Insassen, darunter drei Damen, näherte sich rasch unserem Schiffe und als sie die deutsche Flagge bemerkten, riefen sie uns in deutscher Sprache einen Gruss nach Kamerun $z u$, indem sie „Deutschland, Deutschland über Alles" intonierten. Sogleich wurden alle Mann auf Deck aufgeboten und mit einem kräftigen Hurrah erwiderten wir den, jedem, zumal fern von der Heimat weilenden Deutschen zu Herzen gehenden Gruss. Noch einmal grüssten uns die Zinnen und Türme von Las Palmas und bald entschwand auch dieser Hafen unseren Blicken.

Wieder fanden wir uns auf hoher See und mit jedem Grad, den wir südlicher kamen, um so brennender sandte die Sonne ihre Strahlen hernieder, so dass wir die Tropenkleider anzulegen genötigt waren. Der Ocean wurde auch lebendiger und rudelweise begleiteten uns wieder Delphine, die pfeilschnell ảus den Wogen emportauchten und im nächsten Augenblick wieder in denselben verschwanden. Des Abends schnellten reizende fliegende Fische aus den Fluten des Meeres empor, um nach kurzem Fluge wieder in dieselben hineinzutauchen. Häufig jedoch werden diese Fische von dem beleuchteten Schiffe angezogen und verirren sich auf Deck, wo sie den Matrosen einen wohlschmeckenden Bissen abgeben. Auch ein $\mathrm{I}_{5}$ bis $20 \mathrm{~m}$ langer Walfisch kreuzte, wie eine Fontaine die Wasserstrahlen emporsendend, unser Fahrwasser und abends leuchteten in den Fluten die Infusoriae phosphorescentes. Die Möwen traten nun nach meiner Beobachtung seltener auf, die braune Seeschwalbe schien sie abgelöst zu haben. Am 26. April bemerkte ich ungefähr vom I $3^{\circ}$ nördlicher Breite an das südliche Kreuz an dem dunkelblauen Firmamente, unter dem wir nun Freud und Leid teilen sollten. Mit ihm erschienen auch bald der Skorpion, der Centaur, der Cirkel und der Kanopus, während uns noch weit unten am nördlichen Horizont der Polarstern sein mattes Licht zum Abschied sendete.

Am 29. April früh sah ich in dunkler Form zuerst das afrikanische Festland an der Liberia-Küste. Mit gespannter Erwartung folgte ich mit dem Fernglase dem Küstensaume, welcher in der Gegend nördlich von Monrowia meistens flach und mit einigen Oelpalmen bestanden ist. Die Küste nahm vor und hinter der Stadt einen vollkommen bewaldeten Charakter an. Die einzelnen Höhenzüge erreichten an dem Leuchtturme von Monrowia ihren Höhepunkt. Mit Volldampf ging es nun auf Monrowia los, schnell näherten wir uns der Küste und bald kam die Hauptstadt der Negerrepublik ganz in Sicht; sofort kündigten wir unsere Ankunft durch einen Kanonenschuss an.

Von Nordosten nach Südwesten sich erstreckend, liegt südlich ron dem Ausfluss des St. Pauls-River, welcher mit einem winzigen Küsten-

Der freie Negerstaat Liberia und dessen Einwohner. 
flüsschen ein kleines Delta bildet, die Krutown. An der Küste ansteigend breitet sich die eigentliche liberianische Hauptstadt aus. Ich ging mit einigen Passagieren an Land und ehe die Brandung wiederkehrte, sprangen wir zum ersten Mal auf afrikanischen Boden, wo uns die kleinen schwarzen Bengels mit "good morning, Sir" freundlich begrüssten; auch zwei Krudamen kamen auf uns zu und reichten uns zum Gruss ihre schwarze Rechte. Nun durchwanderten wir die Krutown, wohin uns ein zwischen den Hütten der Kruleute hindurchgehender Fusspfad führte. Die Hütten sind viereckig gebaut mit schrägem Dach. Die Seiten sind, soweit ich wahrnehmen konnte, aus der Mittelrippe des Oelpalmenblattes geflochten, während das Dach aus derselben Palme besteht. Im Innern der Hütten befanden sich Ruhestätten aus Stangen gezimmert, auf denen man Frauen, ihre Kinder säugend oder sich gegenseitig frisierend, sah. Viele der Hütten hatten nach hinten heraus einen kleinen, von Matten abgegrenzten Hofraum. 'Die kleinen Kinder gingen durchweg nackt; viele trugen eine kleine Perlenschnur um den Leib, und um den Hals hingen bei einigen an einem Bindfaden Amulets, d. h. geweihte Schutzgehänge aus Messing, anscheinend europäisches Fabrikat. Die kleinen Mädchen trugen einen kleinen, die Backfische und Frauen dagegen einen aus blauem Kattun oder anderem Stoff gefertigten, um die Hüften geschlagenen und bis an die Kniee reichenden Schurz. Das Haar der Krujungens ist kurz geschnitten; die jungen Mädchen und Frauen aber haben eine ziemlich komplizierte Frisur, die längs des Kopfes liegt und in der Form drei nebeneinander liegender Rollen einem bairischen Raupenhelm nicht unähnlich sieht. Mit einem Holzstabe werden die einzelnen Locken sorgfältig in ihre Lage gebracht. Viele Ringe und Ketten bilden den Halsschmuck. Die Mehrzahl der Kruweiber malt sich zu ihrer besonderen Verschönerung drei weisse Striche auf den Oberarm und drei auf jede Brusthälfte. Auch habe ich einzelne alte Frauen bemerkt, die ihre Gesichter ganz weiss angemalt hatten, andere wieder hatten einen kleinen Stein auf einem grösseren zerrieben und den mit Wasser benetzten schwarz-roten Abfall auf die Brust geschmiert. Bei den Frauen hängen die Brüste schlaff herunter.

Frauen und Männer haben den eigentlichen Negertypus. Kurzes Nasenbein mit platter Nase und breitem Mund mit aufgeworfenen Lippen. Die Augen sind rabenschwarz, wogegen die weissen Zähne zu der braunschwarzen Farbe einen auffallenden Kontrast bilden. Viele Männer haben die mittleren Schneidezähne auseinander oder spitz gefeilt. Das Haar tragen die Männer kurz geschoren; auf der Stirn haben sie als Stammesabzeichen einen schwarzblauen Strich, welchen einzelne Stämme noch bis zur Nasenspitze verlängert tragen; andere haben noch an beiden Seiten des Gesichts unterhalb der Backenknochen ein Dreieck von 
derselben Farbe. Diese Tätowierung soll durch Einreiben mit Har\% hergestellt werden. Die letzteren Zeichen werden auch von Frauen getragen. Später erfuhr ich, dass die Kruleute, welche die Dreiecke und den kurzen Strich haben, Kruleute von Wapi sind, diejenigen aber, welche die Marke bis an die Nasenspitze und die Dreiecke unterhalb der Schläfen haben, aus Nifu stammen sollen. Bei einzelnen Kruboys bemerkte ich kleine, in einer Fellscheide steckende Dolchmesser, welche sie an einer Schnur auf der linken Seite der Hüfte tragen. Die Klinge schien mir europäisches Fabrikat zu sein. Im allgemeinen kann man die Krus als mittelgross bezeichnen. Die Bewohner der Krutown scheinen sämtlich gute Schiffer zu sein, denn auf ihren kleinen, aus einem Baumstamm hergestellten, 3-5 $\mathrm{m}$ langen Kanoes fuhren sie sicher durch die Brandung unserem Schiff weit in die See entgegen. Die meisten Kanoes wurden durch zwei Knaben, von denen der eine vorn, der andere hinten sass, während inmitten sich die Ladung befand, mit spatenförmigen Rudern fortbewegt. Die Kleidung der Männer besteht aus allerhand europäischen Hosen, halb abgeschnittenen oder ganz langen, oder auch aus einem hosenartig genähten Schurz. Die Wohlhabenderen besitzen noch Panzeroder Flanellhemden oder verschiedenartige europäische Jacken; als Kopfbedeckung dienen Mützen oder Hüte, wovon einige nur noch die Krempe zeigten.

Nach Durchwanderung der Krutown gelangten wir bergansteigend zur eigentlichen liberianischen Stadt, wo man überall einstöckige Häuser in europäischer Bauart, meistens mit Balkon erblickte. Die Unfassungsmauern waren teils aus Ziegeln, teils aus Holz aufgeführt. Die Dächer bestanden zum grösseren Teil aus Wellblech und Holzschindeln, zum geringeren Teil aus Ziegeln. Monrowia hat sechs Kirchen, von welchen allerdings nur die der Methodisten einen Turm besitzt, während die übrigen fünf, welche von den der amerikanischen unierten Sekte Angehörigen besucht werden, mehr das Ansehen von Bethäusern haben. Die Strassen sind ziemlich breit, jedoch uneben und mit Gras bewachsen; auf denselben sieht man Schafe, Rinder und Schweine gemütlich bei einander weiden. Zu beiden Seiten der Strasse führen die eigentlichen Pfade. An dem Ort bestehen mehrere kaufmännische Niederlassungen, darunter drei deutsche und zwei norwegische Faktoreien, den Wohnsitzen des deutschen und englischen Konsuls.

Nachdem wir eine Stunde vergnügt im Kreise der Landsleute zugebracht hatten, kehrten. wir zu dem Anlegeplatze unseres Bootes zurück, der sich bei den sogenannten Stores befand.

Jede der Faktoreien hat am Flusse ihr Warenhaus und Lager. Da es gerade Sonntag war, konnte man wenig von dem Treiben und sonstigen Leben bemerken. Es war uns jedoch Gelegenheit geboten. 
die Toiletten der liberianischen Damen zu bewundern, von denen viele in rosa, weiss und anderen hellen Farben gekleidet gingẻn. Die Herren waren schwarz gekleidet und trugen Cylinder - schwarze Gigerln. Sämtliche Garderoben waren nach europäischem Schnitt und manche junge Liberianerin trug ihre Schleppe mit einer Grandezza, die einer Marquise Ehre gemacht hätte. Alles eilte würdevoll und selbstbewusst in die Kirche.

Als wir glücklich wieder am Bord waren, fanden wir eine grosse Anzahl schwarzer Passagiere vor. Es waren Kru- sowie Weiboys, die eigentlichen Bewohner von Liberia. Die Kruboys haben im allgemeinen den nördlichen Teil der Republik inne, während die Weiboys den Süden bewohnen. Die Letzteren gehen meistens nach den deutschen Kolonien, wo sie ein vortreffliches Material an Trägern sowie Arbeitern unserer Stationen im Innern stellen. Sie sind vorzüglich als Träger zu gebrauchen, da sie wegen ihrer Ausdauer beim Marsch und wegen ihrer Genügsamkeit den eingeborenen Schwarzen unserer Kolonien bei weitem vorzuziehen sind.

Die Kruboys dagegen finden ihr Element auf dem Wasser und bilden an der afrikanischen Westküste eine nicht zu unterschätzende Besatzung der Handelsschiffe, ja zum Teil auch der Kriegsflotte. Sie sind gewandt im Seedienst und unterziehen sich mit Mut und Ausdauer allen seemännischen Obliegenheiten. Durch die hohe Brandung an der Küste von Westafrika steuern sie mit Unerschrockenheit und Entschlossenheit die kleinen Landungsboote und sind daher in den Faktoreien zur Einund Ausschiffung der Waren und Produkte fast unentbehrlich. Auf den Schiffen verdingen sie sich meist nur auf eine Reise und kehren dann wieder auf ihre heimatlichen Plätze an der liberianischen Küste zurück, um das verdiente Geld schnell mit ihren Frauen zu verjubeln und dann wieder von Neuem ihre Arbeit auf dem nächsten Schiffe zu beginnen. Was die Weiboys anbelangt, so sind diese meist schmächtiger als die Kruboys gebaut, aber an Muskulatur und Ausdauer im allgemeinen den Letzteren überlegen. Ihre Stammesabzeichen bilden eine Reihe von sogenannten Knöpfen, die sich an dem Halse und Rückgrat entlang ziehen. Die Weiboys haben. ebenso wie fast alle westafrikanischen Negerstämme eine schwarze Hautfarbe. Ihre Kleidung ist im allgemeinen ziemlich dürftig. Sie besteht vorzugsweise aus einer meist eigenhändig hergestellten Kattunhose von europäischem Fabrikat oder auch häufig nur aus einem Schurz. Alle möglichen und unmöglichen Kopfbedeckungen, wie alte Militärmützen und abgelegte Tropenhelme, findet man bei ihnen vor. Die Wei-Jungens sind sehr leichter Natur und verlieren oft ihr ganzes Geld im Kaurispiel. Die Haare haben sie meist kurz geschoren. Häufig sieht man bei den aus dem 
Innern kommenden Männern kleine Zöpfchen vorn an der Stirn, an den Schläfen und im Nacken. Die Zähne sind, wie ich bemerken konnte, im Gegensatze zu den Kruboys nicht gefeilt. Die Weiboys sind der einzige afrikanische Stamm, der eine eigene Schriftsprache besitzt. Die Kruboys und Weiboys sind Todfeinde und nicht selten kommt es zu einem Zusammenstoss zwischen der Krubesatzung des Schiffes und den öfters zu Hunderten auf dem Deck sich aufhaltenden Wey-Jungens, so dass der nie rastende erste Offizier des Schiffes diese Streitigkeiten noch neben seinen sonst so mühevollen Arbeiten zu schlichten hat.

Was die Vegetation von Liberia anbetrifft, so ist hauptsächlich der in dem ganzen Gebiet allbekannte liberianische Kaffeebau zu erwähnen. Fast in allen Gärten und in vielen Plantagen der Eingeborenen findet man diese Pflanze sowohl als Baum wie auch Strauch gepflegt und veredelt, sowie auch verwildert vor. Der Kaffee ist in Liberia das eigentliche Ausfuhrprodukt und in geringeren Massen die Piassawa. Ferner trifft man dort auch viele Mangopflaumenbäume, sowie an den Flüssen in grossen Mengen Mangroven an.

Eine der grössten Einnahmen der liberianischen Republik aber wird aus ihren Briefmarken erzielt, welche von den Markensammlern sehr gesucht sind. Damit diese Einnahmequelle erhalten bleibt, werden die Marken häufig einer Aenderung unterworfen. Nilpferde, Krokodile oder das Bild eines General-Postmeisters zieren diese Marken. Jeder hier sich aufhaltende Reisende ist natürlich bemüht, die verschiedenen Wertzeichen dieser Neger-Republik zu kaufen und seinen Freunden und Bekannten in der Heimat zu übersenden.

Erwähnenswert ist noch die liberianische Miliz, welche der Präsident alljährlich zu den Waffen oder zu Paraden einberuft. Grosse Uniformen giebt es natürlich nicht, nur ein blaues oder rotes Schamtuch unterscheidet die verschiedenen Regimenter. Jeder legt bei den Paraden seine eigene Bewaffnung an: Gewehr, Steinschlossflinte, Haumesser oder alte Säbel; Generale, Exzellenzen, Kolonels, Kapitäns und Leutnants soll diese Armee in Massen zählen. Drollig wurde mir von den dort ansässigen Europäern eine solche Parade geschildert. In einer nichts weniger als guten Richtung wird die Front aufgestellt und Meldungen von Offizieren kommen und gehen an His Excellency Mr. General, der diese würdig entgegennimmt. Ab und zu ereignet sich ein kleiner Zwischenfall und ein Vaterlandsverteidiger tritt mit der Meldung aus dem Gliede: „Massa, I must go at home, I have no more time, my wife wait for me." Ein Exerzieren giebt es natürlich nicht und so bildet die ganze Einziehung dieser bewaffneten Macht eigentlich nur ein Trolksfest, bei welchem die schwarzen Dandys ihre Phantasieuniform bei Gelage und Tanz ihren schwarzen Ladies vorführen. 
Nachdem das Schiff seine Besatzung an Krujungens sowie eine Menge Passagiere aufgenommen hatte, dampften wir nach Salutierung des einzigen der liberianischen Kriegsschiffe von der Rhede ab. Das Kriegsschiff liegt fast immer vor Anker, da der liberianischen Regierung die Mittel zur Anschaffung von Kohlen fehlen und daher hängt es von der Gnade der Wörmann'schen Dampfer-Kapitäne ab, ob das Schiff seine Anker lichten kann. Die Besatzung - sowohl Offiziere als auch Mannschaften - besteht nur aus Schwarzen.

Wir dampften nun die liberianische Küste entlang. Ueberall zeigten sich im Hintergrunde derselben kleinere Bergzüge, die ihre grösste Höhe in dem Grand Bassaberg erreichen. Vorbei ging es an Grand Bassan, einem grossen Küstenplatze, auf welchem wir in weiter Ferne die weissen Häuser der Faktoreien bemerken konnten, zu dem letzten grösseren Küstenplatze der Republik, dem Orte Cap Palmas.

Palmas. Das Cap ragt ziemlich weit ins Meer hinein und erreicht in einer Höhe von ungefähr $50 \mathrm{~m}$ seinen Abschluss in einer Nehrung, auf welcher die fast ausschliesslich deutschen Faktoreien liegen. Die vielen Felsen und Klippen, welche die Küste aufweist, gebieten dem Führer des Schiffes Vorsicht und verbieten ein zu weites Herangehen an die Küste. Einén schönen Eindruck gewährt Cap Palmas mit seinen Faktoreien, welche zum Teil an der Küste, zum Teil auf den unmittelbar an dieselbe anstossenden Höhen liegen. Nicht weniger als sieben deutsche Flaggen wehen uns hier entgegen und laden die deutschen Landsleute zu einem Besuch ein. Auch erweckt dieser Ort immer wieder von neuem die Erinnerung an unsere tapferen Vorkämpfer und Pioniere im Westen des schwarzen Erdteils. Hier ist auch die ursprüngliche Grabstätte unseres allverehrten urdeutschen Forschers Nachtigal, dessen patriotischem Wirken wir unsere Besitzung im tropischen Westafrika von Togo und Kamerun zu verdanken haben. Aus Dankbarkeit hat man den verdienstvollen Mann der deutschen Sache später in deutsche Erde gebettet. Er ruht nun an der Stätte seiner früheren Thätigkeit, in dem Gouvernementsgarten von Kamerun und seinen Grabhügel ziert zum ewigen Andenken ein schönes Denkmal.

Der ganze Handel in Cap Palmas ist hauptsächlich in deutschen Händen und in Folge dessen sind auch die Eingeborenen meist in deutschen Diensten. Das Volk ist daher der deutschen Nation besonders zugeneigt, während der Händler mehr den Engländer bevorzugt.

Wir fuhren nun, bei schönem Tropenhimmel, aber unter brennender Sonne, unter der Liberia besonders zu leiden hat, weiter in See und steuerten direkt unserem nächsten Ziel, der englischen Goldküste und seinem Hauptplatze - Akkra - zu.

Ein unaufhörlicher Harmattan weht von Osten, von der Sahara herüber, und hüllt alles in dunkle Staubwolken. Nur undeutlich zeichnet 
sich von weitem in schmalem Streifen clie Küste ab. Das ganze Deck des Schiffes ist wie nach dem Einnehmen von Kohlen mit Staub überzogen. Zu grossem Verdruss der Offiziere und der Mannschaften muss es nun wieder von oben bis unten gewaschen werden, ein auch für die Passagiere zweifelhaftes Vergnügen, denn schon des Morgens wird man durch das Waschen und Scheuern des Decks aus dem Schlafe gestört. Das ganze Deck schwimmt unter Wasser und man ist auf geraume Zeit auf den Aufenthalt in der Kajüte angewiesen. Von weitem sieht man nun die Küste in Form eines ganz flachen Streifens, ab und zu mit einigen Palmen besetzt liegen; so geht es eine Weile fort, bis man in der Ferne wieder Höhenzüge bemerkt, die an der englischen Goldküste bei Axim bis an die Küste herantreten.

Ueberall knüpfen sich hier Sagen an den früheren Sklavenhandel der Portugiesen wie der Holländer und hin und wieder sieht man noch die Ueberreste ihrer alten Burgen auf bewaldeten Höhen. An der Küste liegt zerfallen, öde und verlassen, jetzt im Besitz der englischen Herrschaft, die alte brandenburgische erste deutsche Ansiedelung in Afrika und vom Sturme der Zeiten vermorscht das alte brandenburgische Fort Gross-Friedrichsburg, welches vor mehr als zweihundert Jahren durch die Flotte des grossen Kurfürsten in Besitz genommen und nach hartnäckigem Kampfe erobert wurde.

Es dürfte hier nicht uninteressant sein, einen Rückblick auf die Kurbrandenbrandenburgische Kolonialgeschichte zu werfen. Der Aufschwung des holländischen Handels und seiner Kolonieen liess in dem grossen Kurfürsten den Wunsch aufsteigen, sich neue Absatzgebiete für sein geschichte Fürstentum Brandenburg zu schaffen. Natürlich musste Brandenburg afrikanischen dazu eine Flotte haben, die der grosse Kurfürst von holländischen Küste Rhedern charterte. Durch die Erfolge dieser Mietsflotte zur See wie infolge des Aufblühens des Handels und der Erwerbung der Kolonie an der Goldküste, die als erste brandenburgische Besitzung seinen Namen trug, ermutigt, entschloss sich Friedrich Wilhelm I684 eine eigene Flotte zu errichten. Er löste das Mietsverhältnis auf und kaufte von dem bewährten Marinedirektor Raule neun Schiffe zu dem einen bereits vorhandenen dazu, so dass am I. Oktober 1684 die aus zehn Schiffen bestehende kurbrandenburgische Flotte ihre eigentliche Entstehung feierte. Der Kurfürst sah ferner ein, dass sein Land nur durch Handel $z u$ heben war und dass dazu nében einer Flotte auch Kolonieen gehörten, um für den Handel neue Absatzgebiete zu schaffen. Ausserdem reizten ihn zu neuen Unternehmungen die Erfolge dieser jungen Flotte, welche die kurbrandenburgische Flagge auch auf fernem Ocean zum Ansehen brachten. Auf die Bitte von holländischen Kaufleuten um Schutz an der westafrikanischen Küste, sandte der Kurfüst im Herbst I68o zwei Schiffe: 
"Wappen von Brandenburg" und „Morian" unter dem Befehl des Kapitän Blonk dorthin. Blonk erreichte trotz der Uebermacht der spanischen Flotte, welcher er geschickt auszuweichen wusste, glücklich die afrikanische Küste und ging zwischen dem Cap der drei Spitzen und Axim an der Küste von Guinea vor Anker. Er trat hier mit einigen Häuptlingen der Goldküste in Unterhandlung und es gelang ihm auch einen Vertrag zu schliessen, nach welchem die Häuptlinge die Oberhoheit des Kurfürsten anerkannten und versprachen mit den brandenburgischen Schiffen Handel zu treiben. Die Holländer jedoch griffen die Schiffe des Kurfürsten an und zwangen Blonk nach Verlust eines Schiffes zur Aufgabe des Platzes und zur Heimreise.

Durch die Schilderungen Blonks bewogen, gründete Friedrich Wilhelm im März 1682 die erste afrikanische Handels-Kompagnie. Im Juli desselben Jahres sandte er seinen Kammerjunker Major von Gröben mit zwei Schiffen zu den schwarzen Unterthanen an der Goldküste, um ihnen die von Blonk versprochenen Geschenke überbringen zu lassen. Da Gröben den Platz nicht fand, ging er vor Accada vor Anker, musste jedoch von hier auf die Vorstellungen des holländischen Gouverneurs von Elmina weichen und wieder in See gehen, um bei dem Dorfe Poqueson zu landen. Hier gelang es ihm auch einige Häuptlinge zu gewinnen, welche sich unter brandenburgischen Schutz stellten. Am I. Januar 1683 wurde unter dem Salut der Schiffe feierlich von dem Lande Besitz genommen und auf dem Berge Manfro die brandenburgische Flagge gehisst. Hier entstand auch, nicht weit von dem Cap der drei Spitzen, das erste brandenburgische Fort, welches nach seinem Schirmherrn "Gross-Friedrichsburg" benannt wurde, weil, wie Oettinger schreibt: „Seiner Kurfürstlichen Durchlaucht Name in aller Welt gross ist." Trotz der Ränke, welche die Holländer mit den Eingeborenen schmiedeten, wurde die Feste von den tapferen Brandenburgern mit den an Land gebrachten Geschützen gehalten und bald gewannen sie mehr Ansehen und Macht, so dass sich viele der angrenzenden Ortschaften unter brandenburgische Flagge stellten. Der fruchtbare Boden dieser brandenburgischen Kolonie an der Goldküste begünstigte sehr das Gedeihen derselben. Der Handel mit Gold, Elfenbein und Sklaven berechtigte zu den weitgehendsten Plänen und Hoffnungen der jungen Kolonie. Im November I682 hatte der Kurfürst der afrikanischen Handels-Kompagnie das Privilegium, sich dor niederzulassen und Handel zu treiben auf 30 Jahre gewährt; auch verpflichtete sich der Kurfürst eine Festung zu bauen und dieselbe achtzehn Monate hindurch zu unterhalten. Nach Ablauf von vier Jahren sollte jedoch die Kompagnie ihre eigene Miliz stellen. Der Kurfürst verpflichtete sich indesśen, weitere neue Schiffe zum Schutze des Handels zu stellen. I684 unterwarfen sich die Häuptlinge in der Gegend 
ron Accada. Es wurde in ihrem Gebiet ein neues Fort gebaut, welches den Namen "Dorotheenschanze" erhielt. Ferner wurden noch das Fort "Taccaray", sowie auf dem Cap der drei Spitzen das Fort "Sophie Louise" erbaut. Auf diesen Hügeln auf der Goldküste, die von den Engländern den Namen „three points" erhalten haben, sieht man noch heute die alten Erdwälle als Ueberreste der alten brandenburgischen Forts, den Seefahrer an die weitgehenden Pläne unseres grossen Kur-fürsten erinnernd.

Der Handel jedoch liess zu wünschen übrig und so bewog der Kurfürst I 688 Dänemark ihm einen Strich Land auf der virginischen Insel St. Thomas abzutreten, um von dort aus einen besseren Markt für die schwarze Menschenware nach Amerika zu gewinnen. Da die Kompagnie in den ersten Jahren wenig erreichte, so übernahm der Kurfürst I 686 auf eigene Rechnung und Gefahr hin das begonnene Werk. Doch seine Anstrengungen hatten wenig Erfolg, da sowohl Franzosen wie Holländer Hindernisse in den Weg legten und die Eingeborenen aufwiegelten, so dass die brandenburgische Besatzung sich in stetem Kampfe mit denselben befand. I 687 gingen sogar die Holländer selbst aggressiv vor. Sie blockierten den Hafen Gross-Friedrichsburg und vertrieben die Brandenburger aus der Dorotheenschanze und aus dem auf dem Cap der drei Spitzen belegenem Fort Sophie Louise, welches die Verbindungzwischen Gross-Friedrichsburg und der Dorotheenschanze aufrecht zu erhalten hatte. Auch wurde ein brandenburgisches Schiff genommen. Trotzdem ermüdete der Kurfürst nicht und eröffnete durch die neue Erwerbung der Insel Arguin bei Cap Blanko dem Handel neue Thore. Er war selbst entschlossen, aus Anlass der hinterlistigen Ueberfälle seiner afrikanischen Kolonie den Generalstaaten den Krieg zu erklären. Bevor jedoch der Kurfürst seine Pläne verwirklichen konnte, starb er inmitten seiner Unternehmungen.

Sein Nachfolger Friedrich III. unterstützte aus Pietät das begonnene Werk, aber er selbst konnte nur wenig die Interessen dieser entfernten Kolonieen wahren und so plünderten Franzosen wie Holländer Friedrichsburg sowie die Niederlassungen auf St. Thomas. Die Kriegsflotte, wegen Mangel an Mitteln fast gänzlich ausser Dienst gestellt, war bald unbrauchbar und für grosse Fahrten nicht mehr zu verwenden. Friedrich Wilhelm I., der nur noch Mühe hatte, die durch diese Besitzungen entstandenen Streitigkeiten zu schlichten und in den Kolonieen lediglich eine Last für das kleine Königreich sah, verkaufte am I3. August I 720 sämtliche brandenburgische Kolonieen für 6000 Dukaten und 6000 Dollars an die holländische Handelsgesellschaft. Wie schwer es dem König fiel, diesen Schritt zu thun, geht daraus hervor, dass er in den Kaufvertrag eine Bestimmung aufnehmen liess, wonach Preussen das Vorkaufsrecht 
bei einem etwaigen Wiederverkauf vorbehalten wurde. So hatte die brandenburgische Flagge an der westafrikanischen Küste zu wehen aufgehört. Mit den Kolonieen ging auch die kleine Flotte ihrem Untergange entgegen, bis sie nach der Entstehung des neuen deutschen Reiches ihre Wiedergeburt feierte und nun unter dem schwarz-weiss-roten Zeichen von neuem die Gestade unserer westafrikanischen Schutzgebiete befährt.

Als unter unserem grossen Kaiser Wilhelm der koloniale Gedanke ron neuem auflebte und wir an der Westküste von Afrika festen Fuss gefasst hatten, soll unseres grossen Kaisers Majestät zu seiner Umgebung geäussert haben: „Erst jetzt kann ich beruhigt dem Standbild des Grossen Kurfürsten wieder ins Angesicht schen."

Unter der Herrschaft Kaiser Wilhelms II. hat dann der Ausbau der Kolonieen sowie die Vermehrung unserer Flotte wie bekannt erhebliche Fortschritte gemachit und dadurch zur Förderung des deutschen Handels beigetragen. Denn wo die Flotte nicht mit starker Hand unserer Flagge in den Kolonieen Achtung verschafft, dort giebt es keine friedlichen Kolonieen und ohne diese keinen Handel.

Fortsetzung Wieder ging es die Goldküste entlang und abends sahen wir in Jer Reise bis weiter Ferne die Lichter der ältesten Stadt dieser englischen Kolonie, Akkra, Haupt-

Cap Coast, sowie der vor Anker liegenden Schiffe und der auf der Höhe liegenden Kastelle uns entgegenleuchten. Nach zweitägiger Fahrt erreichten wir unser nächstes Ziel, Akkra, die Hauptstadt der GoldküstenKolonie. Die hügeligen Bergkoppen treten mehr an das Meer heran. Die etwa 60 bis $80 \mathrm{~m}$ hohen bizarren Sandsteinfelsen fallen steil zum Meere ab. Die sich hoch türmenden und brandenden Wogen umsäumen die Küste mit einem weissen Gischt. Oben auf dem Sandsteinfelsen liegt die Stadt Akkra, im Westen derselben das Kastell, aus welchem uns schwere, wohl erhaltene Geschütze entgegenstarren. Die Küste fällt im Osten ab und senkt sich schnell nach der Residenz, Christiansburg. Die Stadt wird von schönen breiten Strassen durchzogen, die zum grossen Teil gepflastert sind. Ueberall sieht man geschäftig schwarze Dandies einherschreiten; auf kleinen von Schwarzen gezogenen Wagen fährt der schwarze Gentleman, der sich protzenhaft in lässiger Haltung auf seinem Vehikel breit macht. Eine schöne grosse Markthalle befindet sich im Centrum der Stadt, welche neben vielen kleinen Läden den geschäftlichen Verkehr vermittelt. Eine breite Chaussee führt vom Marktplatz durch die Stadt nach Christiansburg, dem Sitze des Gouverneurs. Täglich zieht hier unter klingendem Spiel die Wache auf, welche ausschliesslich aus Haussasoldaten besteht. Die Mannschaften tragen eine kleidsame dunkelblaue Uniform mit weissen Gamaschen. An der Strasse nach Christiansburg liegt auch die an Grösse und Schönheit alle anderen übertreffende Faktorei der Baseler Mission. Ihre Schaufenster zieren die Strasse 
während im Hofe die Wohnungen der Missionare sowie die Schule und Kapelle liegen. Der ganze Ort macht durch die vielen nach europäischer Art gebauten massiven Häuser den Eindruck einer kleinen europäischen Stadt, nur auffallend ist, dass hier die Häuser fast durchgängig weiss angestrichen sind. Soviel in Akkra und in den Küstenplätzen im allgemeinen gethan worden ist, so wenig ist verhältnismässig im Hinterlande dieser 60 Jahre alten Kolonie der englischen Goldküste geschehen; ein gebahnter Weg führt erst seit kurzer Zeit in das Innere hinein. Allerdings sind die vielen Kämpfe, welche die Engländer mit den kriegerischen Aschantis zu bestehen hatten, wohl ein grosses Hindernis in der kulturellen Arbeit im Hinterlande gewesen.

Wir verliessen nun Akkra; die Küste wurde immer flacher und bald gelangten wir an den Ausfluss des Voltas, der sich hier, ein weites Thal bildend, in einem Delta in den atlantischen Ocean ergiesst.

Noch eine Fahrt von wenigen Stunden und die letzte Station vor Der englische unserem Ziele, Quitta, ist erreicht. Schon von weitem sieht man die Küstenort Faktoreien mit ihren weissen Dächern, vielfach die deutsche Flagge gehisst; fast ausschliesslich hat hier, obwohl auf englischem Gebiete, der deutsche Handel festen Fuss gefasst. Der weite flache Strand und die in einer Strasse am Strande angebauten Faktoreien geben dem Orte fast das Aussehen unserer deutschen Kolonial-Küstenstädte. Tor den letzteren hat Quitta insofern einen erheblichen Vorteil voraus, als hier eine schwächere Brandung vorhanden ist, denn Quitta wird noch durch das Cap „Three points“ vor der mächtigen Strömung des Guineastromes und durch die in südöstlicher Richtung fortlaufenden Dünen geschützt. Hier ist ein vorzüglicher Handelsplatz für die meisten Schiffe der westafrikanischen Küste. Geflügel, Puten, Hühner, Enten und Tauben werden in Menge zum Kauf angeboten. Massenhaft kommen die kleinen Kanoes an die Schiffe heran, um ihre Waren in Körben auf der Strickleiter an Bord zu bringen. Was die sanitären Verhältnisse anbetrifft, so ist Quitta bedeutend ungesunder als die Küstenplätze der Togokolonie. Dicht hinter der Stadt liegt die grosse Quitta-Lagune, die in der Regenzeit Quitta vollkommen von dem Verkehr mit dem Hinterlande abschneidet, dagegen in der regenlosen Zeit häufig ausgetrocknet ist. Während des Ueberganges von der Trocken- zur Regenzeit werden in den Sümpfen gesundheitsschädliche Ausdünstungen erzeugt.

Mit Volldampf die Fahrt fortsetzend, erreichten wir nach einigen Stunden endlich die Rhede von Lome. Schon von weitem leuchteten uns die weissen Häuser der Faktoreien und der helle Strand entgegen; fast auf sämtlichen Faktoreien weht die deutsche Flagge und brausend türmen sich die Fluten des Meeres zu hoher Brandung auf. Ein Kanonenschlag Quitta.

Ankunft in Lome. 
kündete den Dampfer und die damit oft lang ersehnte Post von der fernen Heimat an. Sofort begann das Leben am Strande. Auf vielen Masten gingen die kleinen Signalflaggen hoch und begrüssten die ankommenden Fremden mit einem Willkommen. Boote wurden aus dem Schuppen hervorgeholt und klar gemacht. Stossweise gelang es dann auch den Krujungens auf das Zeichen ihres Hetmanns die Boote in die hohen Wellen zu schieben. Alles sprang auf ein gegebenes Zeichen in die Boote und mit einem vorzüglichen Tempo leitete diesc Krubesatzung die Boote sicher und mit vielem Geschick durch die hohe Brandung. Der hinten am Steuer stehende Hetmann feuert die Mannschaft an

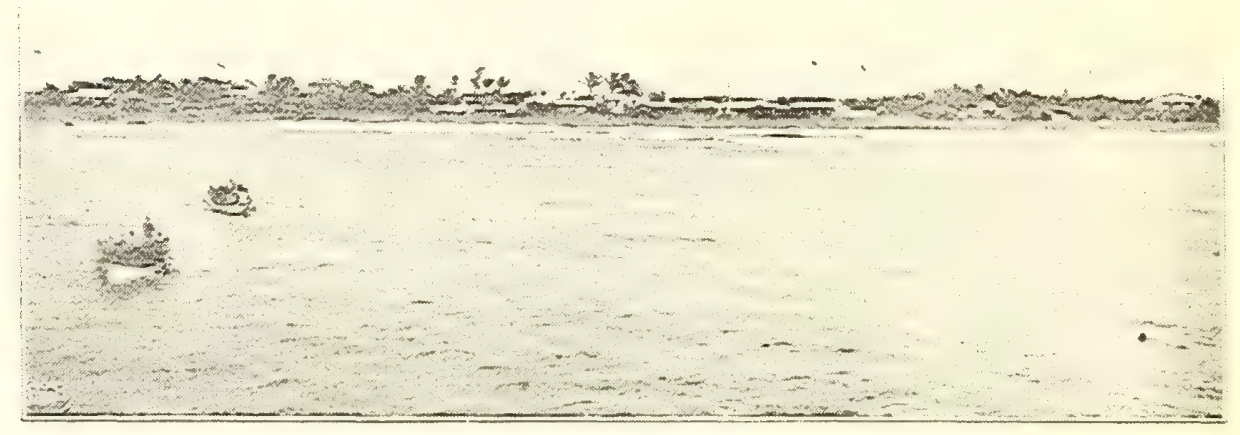

Die Rhede von Lome.

und giebt das Zeichen zum Halten oder zum Rudern. Oft auch steht noch einer der Krujungens an der Küste und giebt von dort aus durch Pfeifen und Schreien ein Zeichen, sobald es günstig ist, über die hohen Kämme der Brecher zu fahren. Hoch türmt sich dann das Vorderteil des Bootes auf und nur der grössten Kraftanstrengung der Krujungens gelingt es, einen Kamm nach dem andern zu nehmen; natürlich ist, besonders bei hoher See, die Arbeit mit grosser Gefahr verbunden. Häunig kommt es vor, dass die Boote umschlagen und die wertvollen Waren auf Nimmerwiedersehen in der Tiefe des Meeres verschwinden, denn durch die rastlos arbeitende Brandung wird innerhalb kurzer Zeit alles versandet. Auf das Kommando des Hetmanns muss beim Umschlagen des Bootes die Bemannung so schnell als möglich über Bord springen. Da die Wellen von Westen nach Osten streichen und das Boot sich daher immer nach Osten überschlägt, muss das Herausspringen nach den Erfahrungen der Küstenbewohner meist nach Westen geschehen. 
Leider ist auch mit dem Verlust der Waren für die Kaufleute ein solcher für die Kruboys verbunden, denn aus triftigen Gründen wird diesen häufig ein geringer Prozentsatz des verloren gegangenen Gutes abgezogen. Nicht selten kommt es auch vor, dass einer oder der andere der Insassen von dem umschlagenden Boote nicht unbedeutend verletzt wird, oder den Tod in den Weilen findet.

Das erste Boot, welches an unser Schiff gelangte, war durch seine Flagge mit Reichsadler und Anker als das Zollboot erkennbar. Ton einer uniformierten Mannschaft, die eine kleidsame Matrosenuniform trägt, wird dasselbe nach Ueberwindung der Brecher, schnell an das Schiff geführt. Ein schwarzer Zollbeamter mit grüner Mütze und deutscher Kokarde regelt mit dem Kapitän die Geschäfte an Bord. So an unserem Ziele angelangt, wurde noch zum Abschied ein gemeinsamer Trunk gethan und nach einem Händedruck und Dank das Schiff verlassen, auf dem wir 3 bis 4 fröhliche Wochen verlebt hatten. An einer Strickleiter lässt man sich in die tanzenden Boote hinunter und vertraut sich der Gnade oder Ungnade der schwarzen Besatzung an. Mit einem taktmässigen Zeichen der Schwarzen: "Hehep, Hehep" steuert das Boot sicher der Küste zu. Ungefähr $400 \mathrm{~m}$ vor derselben kommt man in das Bereich der Brecher; das Boot hält und mit dem Ablaufen der Brecher streichen die Schwarzen mit fürchterlichem Lärm, welcher zur gégenseitigen Ermunterung dient, ihre Riemen. Nun ist man inmitten der Brecher, hoch vor sich sieht man eine grosse Schaumwelle treiben und im Rücken fasst ein anderer Brecher das Boot mit brausender Gewalt, um es mit Windeseile vorwärts zu treiben. Alsbald erfasst eine neue Welle das kleine Fahrzeug und setzt es mit einem kräftigen Ruck auf den Strand. Sofort wird man von den schwarzen Evhenegern empfangen und auf kräftigen Armen wie ein Packet aus dem Boot gehoben; bevor der nächste Brecher wiederkehrt, befindet man sich auf festem Boden. Schnell wird das Boot von den angestellten Schwarzen der Faktorei so hoch wie möglich an Land gezogen und von dort aus werden die kostbaren Waren in die sogenannten Stores der Faktoreien gebracht. Inzwischen findet eine freudige Begrüssung mit den Weissen der Stadt, die sich bei allen solchen feierlichen Ereignissen fast ohne Ausnahme am Strande einfinden, statt und eine Vorstellung folgt der anderen. Bald sitzt man in dem gastlichen Hause eines Beamten oder in einer Faktorei bei einem Glase Sekt oder Bier und den Verhältnissen entsprechend wird das Band der ersten Bekanntschaft geknüpft. Der dumpfe Ton der Dampfpfeife des Schiffes ertönt, die Anker werden gelichtet und eine Reihe vom Wimpeln erscheinen am Topp. Nit einem Abschiedsgruss, welcher mit einem "Adieu", "glückliche Fahrt" auf den Flaggenmasten der Faktoreien erwidert wird, geht es wiederum vorwärts. 
Ueberall neigen sich die Flaggen und grüssen zum Abschied den abgehenden Dampfer. Noch einmal blickt man ihm von der hohen Veranda eines Hauses nach, bis er in der dunklen Ferne verschwindet. Nun erst, nachdem jede Verbindung mit dem Heimatlande abgeschnitten ist, wird man aus den Träumen des Seelebens herausgerissen und die afrikanische Thätigkeit mit ihren Freuden und Leiden nimmt ihren Anfang.

Bevor wir jedoch auf Land und Leute unserer Togo-Kolonie näher eingehen, wollen wir erst schildern, wie dieselbe unter deutsche Flagge gekommen ist.

\section{DIE ÜBERNAHME DER DEUTSCHEN SCHUTZHERRSCHAFT IN TOGO.}

Im Jahre I88o hatten sich die ersten kaufmännischen Niederlassungen an der nunmehrigen deutschen Togoküste etabliert. Sie wollten sich damit den drückenden Steuern der englischen Zollverwaltung an der Goldküste entziehen und hier auf unabhängigem Terrain ihr Glück versuchen. Aber nicht lange sollten sie sich ihrer Unabhängigkeit freuen, denn die Engländer suchten auch ihrerseits ihr Gebiet nach Osten auszudehnen. Anfangs wollten die Eingeborenen von einem englischen Schutzvertrage nichts wissen, da sie in dem Handel mit den deutschen Kaufleuten für sich einen grösseren Vorteil erblickten. Die englische Regierung suchte indessen durch Unterhändler die Eingeborenen mit den deutschen Kaufleuten zu entzweien, was ihr leider bald gelang. Durch diese unhaltbare Lage gezwungen, wandten sich hierauf die Kaufleute an die deutsche Regierung mit der Bitte um Schutz.

Inzwischen waren in Klein-Popo Thronstreitigkeiten ausgebrochen, welche die Lage der Europäer noch verschlimmerten. Klein-Popo stand nämlich unter dem Oberhäuptling von Gridji, welcher wiederum Unterhäuptlinge in den umliegenden Ortschaften eingesetzt hatte. Diese hatten in Klein-Popo die Abgaben und Steuern einzutreiben und bis auf einen geringen Teil an den Häuptling von Gridji abzuführen. Klein-Popo hatte allein als grösste Stadt drei Unterhäuptlinge und zwar zu damaliger Zeit: Georg Lawson, Quadjowi und Pedro Quadjo. Von diesen hatte Quadjowi I882 mit den Faktoreien in Klein-Popo Verträge abgeschlossn, wonach es denselben freistand, überall ungehindert in dem Gebiete Handel zu treiben, wofür die Faktoreien alljährlich gewisse Abgaben, zum Teil in klingender Münze bestehend, an den vorerwähnten Häuptling zu zahlen hatten. Trotz der englischen Hetzereien verstanden es die wackeren Kaufleute, denselben Stand zu halten, bis durch den Tod des Oberhäuptlings von Gridji 1883 Thronstreitigkeiten entstanden. 
Ein Jahr nach dessen Tode, welcher anfangs im Volke verheimlicht wurde, war auf Wunsch des Verstorbenen unter dem Zeichen der königlichen Würde, des Königsstockes, für seinen minderjährigen Nachfolger die Regierung ohne irgend welche Hindernisse von den Verwandten weitergefühṛt worden. Nach dem Tode von Georg Lawson jedoch trat William Lawson, ein Sierra-Leonemann, an dessen Stelle. Dieser suchte sich mit Hilfe der Engländer zum Oberhäuptling zu machen, was aber an dem einmütigen Widerstande der übrigen Häuptlinge scheiterte. Die Regentschaft wurde nunmehr einem nahen Verwandten des William Lawson, dem G. A. Lawson, übertragen. Der neu ernannte Regent proklamierte sich bald, durch die englisch-freundliche Partei unterstützt, zum König von Klein-Popo und machte an Stelle des Häuptlings Quadjowi seinen Verwandten, William Lawson, zu seinem ersten Ratgeber. Lawson beanspruchte nun sämtliche Abgaben für sich, während die übrigen Häuptlinge dagegen Einspruch erhoben, indem sie sich hierbei auf ihr Recht stützten. Es kam zu Streitigkeiten, durch welche sowohl das Eigentum, als auch das Leben der Europäer bedroht wurde. In diesem kritischen Augenblick dampfte S. M. S. "Sophie“ auf die Rhede von Klein-Popo. Der Kapitän Stubenrauch wurde angegangen, mit den Schwarzen zu unterhandeln und es gelang ihm auch, die Anerkennung der mit dem Häuptling Quadjowi geschlossenen Handelsverträge durchzusetzen. Kaum jedoch hatte das Kriegsschiff die Anker gelichtet, so begannen die Unruhen von neuem. Sie wurden hauptsächlich von der Lawson-Partei geschürt und richteten sich nun direkt gregen die Kaufleute, welche die ersten Pläne der Gegenpartei vereitelt hatten. Sofort stieg einer der deutschen Kaufleute zu Pferde und ritt längs des Strandes bis nach Gross-Popo, wo die Sophie noch vor Anker lag. Sobald der Kapitän über die neu ausgebrochenen Unruhen und die kritische Lage in Klein-Popo unterrichtet war, dampfte er dorthin zurück. Alle inzwischen seitens der Kaufleute gemachten Vorstellungen waren fruchtlos verlaufen und ihre Drohungen mit dem Eingreifen des deutschen Kriegsschiffes verlacht worden. Sofort nach Ankunft der Sophie liess der Kapitän ein Landungskorps von roo Mann an Land setzen und die Haupträdelsführer festnehmen. King Lawson, der Ministerpräsident William Lawson, der eigentliche Anstifter, ein gewisser Gomez und Willson, sowie der Sohn des letzteren, wurden als Geiseln an Bord genommen. Der Vertrag von Quadjowi wurde von sämtlichen Häuptlingen anerkannt und somit war den Zwistigkeiten ein Ende bereitet. Lawson wurde als englischer Unterthan dem Gouverneur von Lagos ausgeantwortet, während die Sophie mit den übrigen Geiseln nach Deutschland dampfte. Nach Iotägigem Aufenthalt, während dessen ihnen die Riesenstadt Berlin ror Augen geführt wurde, 
verliessen sie Deutschland wieder und fuhren auf S. M. S. "Möve" nach ihrer Heimat zurück. Das schnelle Eingreifen des deutschen Kriegsschiffes und die sofortige Schlichtung des Streites hatten bei den Schwarzen ihren Eindruck nicht verfehlt.

Inzwischen hatten die Häuptlinge an Se. Majestät den deutschen Kaiser sich mit folgender Denkschrift gewandt:

I. Wir die Unterzeichneten, König und Häuptlinge von Little Popo und Grigi, bringen Euer Majestät unseren besten Dank dar für den zur Aufrechterhaltung des Friedens geleisteten Beistand.

2. Es würde hier keinerlei Gefahr oder Beunruhigung entstehen, wenn die englische Regierung sich der Einmišchung enthalten und sich nicht um unsere Angelegenheiten bekümmern wollte, indem sie Verlangen nach unserem Lande trägt, welches wir kein Verlangen haben, ihr zu lassen.

3. Wit bitten Euer Majestät uns zu schützen und die Annexion zu verhindern.

4. Wir erflehen Hilfe von Eurer Majestät, da wir uns ganz und gar unter Ihren Schutz gestellt haben.

5. Wir bitten demütig um schnelle Maassnahmen.

gez.: König Aiauschi Aghanor von Little Popo und Grigi, Geboceer Quadjowi, Pedro Quadjo etc.

Als die Engländer den Erfolg der deutschen Regierung erkannten, liessen sie kein Mittel unversucht, um eine deutsche Schutzherrschaft zu verhindern. Ein englischer Beamter, Mr. Firminger, suchte abermals die Häuptlinge zu gewinnen. Er forderte sie auf, die deutschen Kaufleute innerhalb vier Wochen zu vertreiben. Einzelne der Häuptlinge sträubten sich dagegen, da sie bis jetzt aus den Handelsbeziehungen zu den deutschen Firmen nur Vorteil gezogen hatten. Firminger aber drohte ihnen, mit Gewalt und Hilfe von englischen Kriegsschiffen ihr Land in Besitz zu nehmen. Durch diese Drohungen eingeschüchtert, liessen sich wirklich die zaghaften Häuptlinge bewegen, die deutschen Kaufleute aus Lome und Bagida aufzufordern, binnen einigen Wochen das Land zu verlassen. Sie gaben jedoch ihre Beweggründe an und enthüllten dadurch die Machinationen des englischen Abgesandten. Hierauf beschwichtigte man sie und erklärte ihnen, dass England nur Interesse habe, die Deutschen zu vertreiben, um alsdann mit englischen Soldaten in ihr Land einzurücken und so mit Gewalt ihr Land zu annektieren.

Wie Mr. Firminger die Eingeborenen gegen die deutschen Kaufleute aufgestachelt hatte, suchte er andrerseits diese vor einem Ueberfall zu warnen und bot ihnen zu ihrem Schutz und zur Verteidigung ihrer 
guten Rechte die englische Haussatruppe an. Auf diese Weise glaubten die Engländer, den Vorwand eines Aufstandes vorschützend, sich einnisten und des Landes bemächtigen zu können.

Diese Enthüllungen der deutschen Kaufleute öffneten den Schwarzen die Augen und gaben ihnen neuen Mut, den Drohungen der Engländer zu widerstehen.

Der Zwistigkeiten müde, begehrten sie endlich nichts anderes als unter die deutsche Schutzherrschaft zu kommen. Bald auch sollten die Kaufleute sowohl wie die Schwarzen von dem ewigen Drucke erlöst werden, denn am 2. Juli I 884 erreichte das Kanonenboot "Möve" die Rhẻde von Klein-Popo. Ausser den Geiseln brachte dasselbe zur grossen Freude der deutschen Kaufleute den bewährten Dr. Nachtigal mit. Dieser hatte die Aufgabe als kaiserlicher Kommissar Verträge mit den unabhängigen Häuptlingen abzuschliessen.

Am 5. Juli wurde in Bagida unter dem Salut S. M. S. "Möve" zum Jubel der Kaufleute sowie der bedrängten Schwarzen feierlich die deutsche Flagge gehisst. Am 6. Juli begab sich Dr. Nachtigal nach Lome und hisste auch hier die schwarz-weiss-rote Flagge. Da der König von Togo in dem Dorfe Togo selber residierte und als Fetischpriester den Ort nicht verlassen durfte, so schloss Dr. Nachtigal mit Plakku, dem Minister und königlichen Stabträger des Königs Mlapa von Togo, von demselben dazu bevullmächtigt, einen Vertrag, wonach der König sein Land von der englischen Grenze westlich von Lome bis zur Grenze des Gebietes von Klein-Popo unter das Protektorat Sr. Majestät des Kaisers von Deutschland stellte und setzte den Hauptagenten Heinrich Randad von Wölber und Brohm für das neu erworbene Gebiet als ersten deutschen Konsul ein.

Obwohl Lawson wiederum durch die glänzenden Versprechungen der Engländer wankelmütig geworden war, so hatte er doch, zum Teił durch die Erfolge und durch das Hissen der deutschen Flagge in Lome und Bagida, zum Teil auch durch den Wunsch der meisten Häuptlinge bewogen, seine Ansicht geändert und versprach Dr. Nachtigal, von nun an nur die deutschen Interessen wahrzunehmen und so viel in seinen Kräften stände, den deutschen Kaufleuten jeglichen Schutz angedeihen zu lassen. Die Geiseln, welche nun freigegeben wurden, konnten nicht genug von der Grösse der deutschen Städte und ihren vielen Soldaten erzählen. Sie lobten auch die gute Behandlung, welche ihnen allen auf dem Kriegsschiffe sowie auf dem deutschen Festlande zu Teil geworden war. Diese Schilderungen trugen nicht wenig dazu bei, bei den Schwarzen die falschen Vorstellungen, die sie von dem deutschen Reiche und seiner Macht hatten, zu vertreiben. Die Engländer hatten ihnen nämlich einzureden versucht, dass Deutschland nur ein kleines Ländchen sei und weder 
Flotte noch Kolonieen besitze. Nun von dem Gegenteil überzeugt, fühlte sich Lawson um so mehr bewogen, Dr. Nachtigal inständig um die deutsche Flagge und somit um den Schutz des deutschen Reiches zu bitten. Da inzwischen aber auch die Franzosen Anspruch auf KleinPopo erhoben, so konnte Nachtigal nicht gleich ihrem Wunsche Folge leisten, versprach jedoch die Angelegenheit sofort seiner Regierung zu unterbreiten. Er versprach Lawson, dass ihm spätestens bis zum Juli I 885 ein Bescheid zugehen würde. Die Franzosen behaupteten ebenfalls ein Recht auf Porto-Seguro zu haben, da der alte Häuptling Mensa ihnen die Uebernahme der Schutzherrschaft angetragen hätte. Eine Antwort hierauf ist jedoch seitens der französischen Regierung nie ergangen. Als daher die Korvette „Leipzig“ im September 1884 Bagida und die Hafenplätze der dortigen Küste anlief, schloss Kapitän Herbig am 5. September I884 auf Ansuchen des alten King Mensa mit demselben einen besonderen Vertrag, wonach auch in Port Seguro die deutsche Flagge gehisst werden durfte und gehisst wurde.

Die Franzosen, welche nun auch ein Auge auf Klein-Popo geworfen hatten, begannen dort ebenfalls Unfrieden zu stiften und suchten die schwankende Lawson-Partei für sich zu gewinnen. Obwohl ein französischer Agent den Häuptlingen in Grand-Popo wie in Klein-Popo verkündete, dass jeder, der die französische Herrschaft nicht anerkenne, als Verräter bestraft werden solle, so erklärten die Häuptlinge, der ewigen Wirren endlich satt, dass sie vor dem Juli I 885 mit keiner anderen Macht Verträge abschliessen würden, da sie sich Deutschland gegenüber verpflichtet hätten. Durch diese einmütige Haltung wurde auch Lawson gezwungen, die gestellte Frist einzuhalten. Nichtsdestoweniger hissten die Franzosen am 12. April in Grand-Popo und am 17. April 1885 in Klein-Popo ihre Flagge. Noch lagen die zu diesem $Z$ wecke entsandten zwei französischen Schiffe vor Klein-Popo vor Anker, als die deutsche Korvette „Bismarck“, mit Admiral Knorr am Bord, auf der Rhede von Klein-Popo eintraf. Als dieser von der französischen Besitzergreifung Kenntnis bekommen hatte, dampfte er sofort nach Porto Seguro ab, um hier den Franzosen zuvorzukommen. Aber auch hier schon war eins der französischen Kriegsschiffe im Begriff, die französische Flagge zu hissen. Der Kapitän des französischen Schiffes machte dem Admiral Knorr seinen Besuch und teilte ihm mit, dass er die Absicht habe die französische Flagge zu hissen. Hiergegen legte der Admiral Knorr sofort Protest ein, indem er darauf hinwies, dass Porto Seguro schon deutsches Gebiet sei. Der französische Kapitän forderte nun den Admiral Knorr auf, den Einspruch gegen die Flaggenhissung in französischer Sprache zu wiederholen, da diese die Diplomatensprache wäre, worauf der bewährte Admiral erwiderte, dass fur einen guten Deutschen die deutsche Sprache die Diplomatensprache sei. 
Admiral Knorr hisste dann zur Bekräftigung der deutschen Ansprüche, ungeachtet des vor Anker liegenden französischen Kriegsschiffes zum zweiten Male die deutsche Flagge in Porto Seguro. Während dieser Vorgänge hatte die deutsche Regierung Unterhandlungen mit den beteiligten Ländern - England und Frankreich - gepflogen, um mit denselben ein Uebereinkommen hinsichtlich der fraglichen Ländereien in dem neuen Schutzgebiet zu vereinbaren.

In dem von Frankreich unterzeichneten Vertrage frel uns Porto Seguro mit Klein-Popo zu. Die französische Regierung gab ihre Rechte auf die Ländereien auf und erkannte die Grenzen unserer nunmehrigen Togo-Kolonie an. Obwohl später durch unermüdliche Forscher neue Verträge geschlossen wurden, wodurch das Gebiet vergrössert wurde, so bildet doch die Anerkennung der ersten Verträge im September 1885 die Grundlage für die Entstehung der deutschen Togo-Kolonie. Durch die Ernennung des ersten deutschen Kommissars Falkenthal wurde nun auch noch in demselben Jahre mit der Verwaltung des Gebietes thatsächlich begonnen. Falkenthal schlug seinen Wohnort in Bagida auf und damit war eine neue deutsche Kolonie an der westafrikanischen Sklavenküste entstanden. So wehte nach etwa 200 Jahren an der Stelle der brandenburgischen Flagge an der Goldküste, an der benachbarten Sklavenküste die schwarz-weiss-rote Flagge des vereinigten deutschen Reiches. 


\section{KÜSTE \\ UND \\ VORLAND IM EVHEGEBIET.}

DIE STADT LOME.

Die Stadt Lome, welche erst in den letzten Jahren eine grössere Bedeutung erlangt hat und ihre Existenz der deutschen Kolonie verdankt, gehört eigentlich in den Bereich des zwei Kilometer im Nordosten der Stadt gelegenen Fischerdorfes Be. Noch zu Nachtigals Zeiten, im Jahre 1884, war Lome nur ein elendes kleines Fischerdorf, welches aus wenigen Negerhütten bestand; heute ist es eine Stadt von ungefähr 3000 Einwohnern, darunter 60 Weisse mit ungefähr I3 europäischen und einigen von Eingeborenen geleiteten Faktoreien. Hier findet man die Missionen mit ihren Kirchen, ferner den Sitz der kaiserlichen Regierung und einer grossen Haussakolonie. Die Stadt ist etwa viereckig angelegt und zieht sich im Süden von Westen nach Osten dicht an dem Strande entlang; sie wird im Osten von der an der katholischen Mission vorbeiführenden Missionsstrasse und im Westen von der Bismarckstrasse begrenzt. Den Norden der Stadt bildet das Haussaviertel, weiter nördlich liegt die Plantage von Lome. An der Strandstrasse, die längs des Meeres sich hinzieht, befinden sich fast sämtliche europäische Faktoreien, ferner die kaiserliche Landeshauptmannschaft und die katholische Mission. An dem Westende der Strasse ist die grosse und geräumige Faktorei von Friedrich M. Victor Söhne gelegen. Ein kleines, aber gemütliches Bretterhaus, welches auf Pfählen gebaut ist, steht in dem grossen Hofe der Faktorei, welche von vielen schönen Kokospalmen beschattet wird. Dort auch liegen die Schuppen, oder wie sich die Kaufleute ausdrücken, die Stores. Man betritt sie, wie fast bei allen Faktoreien, die an der Strandstrasse gelegen sind, von der Hamburger Strasse aus. Beinahe sämtliche Wohngebäude der Agenten haben ihre Front nach der Strandstrasse dem Meere zugekehrt, während sich die ganze Anlage zwischen der letzteren und der Hamburgerstrasse befindet.

Ein kahler, weisser Sandstreifen bildet die Strandstrasse. An dem Strande, an welchem die immer wiederkehrende Brandung tobt, stehen vor den einzelnen Faktoreien kleine Grasschuppen, welche für die 
Bergung der Brandungsboote der Faktorei bestimmt sind und die boote ror den glühenden Strahlen der Tropensonne schützen. Dieselben bedürfen dieses Schutzes um so mehr, als sie fur die einzelnen Faktoreien einen hohen Wert besitzen; sie sind fest und dauerhaft, meist auf deutschen Werften in Hamburg erbaut und haben einen Geldeswert von rooo bis I 200 Mark.

Von Westen nach Osten gehend, folgt eine Faktorei der anderen. Sie bestehen häufig aus zwei Stockwerken; in dem unteren Teile befinden sich die Verkaufsläden, im oberen Stock die Wohnungen der Angestellten. Die Häuser sind zumeist aus Holz gebaut; das Material zu denselben kommt schon vollständig zubereitet mit dem Wörmann-Dampfer aus Europa. Die Veranden ziehen sich fast ohne Ausnahme um das Haus herum und werden häufig von Holzjalousiéen geschützt, hinter denen die Weissen nach des Tages Last und Arbeit Schutz vor den unerbittlichen Sonnenstrahlen suchen und sich an der kühlen Brise, die den grössten Teil des Jahres hindurch von der See herüberweht, erfrischen. Interessant ist es, dem Ausschiffen eines solchen Hauses beizuwohnen. Die Balken, welche die Wände des Hauses bilden, sind in einzelnen Stössen auf den Schiffen verladen. Mittelst des Dampfkrahns werden die Stösse in das Wasser gelassen, wo sie die schwarzen Evheneger oder die Kruboys in Empfang nehmen. Ein paar beherzte Kerle setzen sich nun auf einen solchen Stoss und geben ihm mit einem Langpadel die Richtung. Auf diese Weise wird das sonderbare Gefährt durch die Wellen an Land getrieben. Eigentümlich sieht es aus, wenn die Balken durch die Brandung gehen und die sonderbaren Passagiere bei jeder Drehung sich bald auf den Balken, bald wieder im Wasser befinden, was den Küstennegern sowie den Kruboys, die man als geborene Wasserratten bezeichnen kann, nicht wenig Vergnügen macht. Die Häuser werden dann aus den einzelnen Teilen, die alle numeriert sind, zusammengesetzt und in wenigen Wochen ist der einfache Bau fertiggestellt. Das ganze Gebäude wird gewöhnlich mit weisser Oelfarbe angestrichen, die gegen die brennenden Sonnenstrahlen und gleichzeitig auch gegen die Fäulnis schützt, welche durch die ewige von der Seebrise herrührende Feuchtigkeit leicht gefördert wird.

Man kommt dann zu der Amutivestrasse, die ihren Anfang an dem Strande nimmt und über den Marktplatz weiterführt. Weiter nach Osten liegt der grosse Hof der Faktorei von Wölber und Zimmermann, der besonders durch seine vielen und schönen Kokospalmen einen reizenden Anblick gewährt. In diesem Hofe sieht man häufig grosse Fässer lagern, die bestimmt sind, eins der wichtigsten Ausfuhrprodukte der Kolonie, das Palmenöl, aufzunehmen. Dieselben werden durch schwarze Böttcher in Stand gehalten, und jeder Schlag des Hammers 
erinnert den Fremden an die wohlbekannten Töne unserer heimatlichen Böttchereien.

Es folgt dann das grosse Bereich des Kaiserlichen Gouvernements mit seinen Wohn- und Amtsgebäuden. Vor denselben steht ein Posten vor Gewehr, welcher die Honneurs erweist. Einen Teil nimmt auch das aus Eisen konstruierte Dienstgebäude der Kaiserlichen Post wie des Zollamtes ein. Leider bewährt sich diese Art von Häusern weniger, als die von Holz erbauten. Denn wenn auch das Holz durch den ewigen salzhaltigen Niederschlag leidet, so leidet das Eisen durch den Rost noch mehr, so dass bei diesen Häusern jedes Jahr der Anstrich erneuert werden

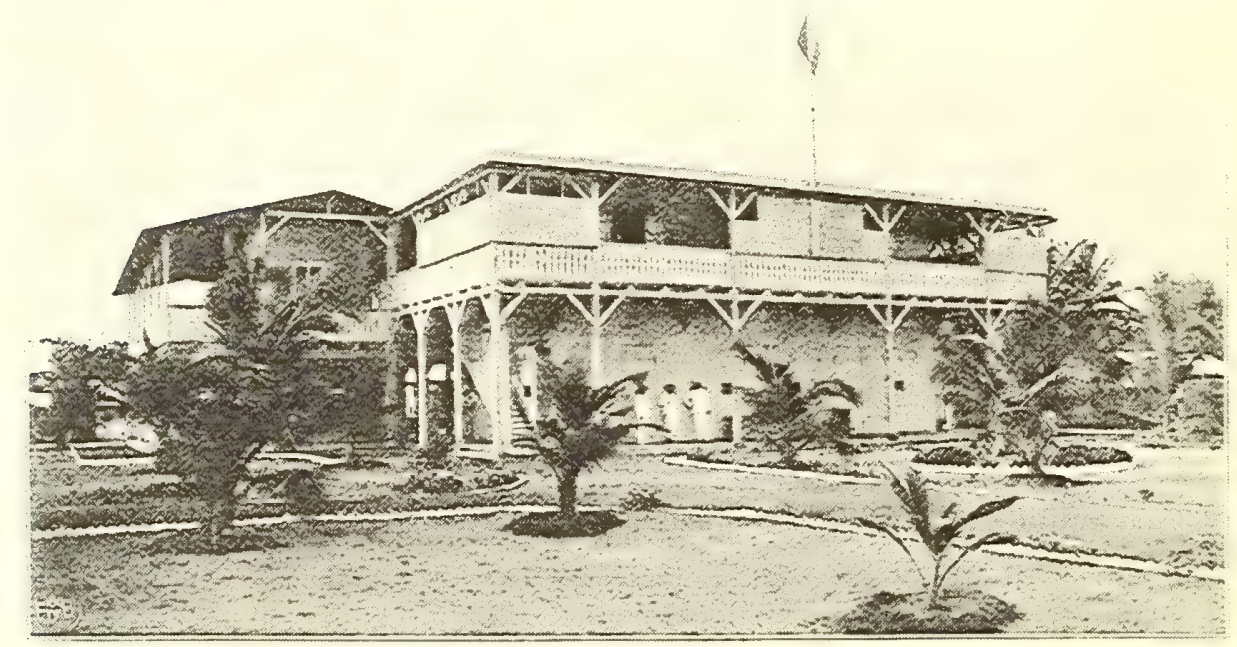

Das Gouvernement.

muss. In wohlbedachter Berücksichtigung der jetzigen Bedürfnisse ist auf Veranlassung des Gouverneurs Köhler an den bedeutendsten Platz unserer Kolonie der Regierungssitz von Sebbe nach Lome verlegt worden. Mit der grösseren Ausdehnung der Kolonie wächst sowohl die Anzahl der Beamten als auch die Repräsentationspflicht des obersten Beamten der Kolonie. Aus diesem Grunde ist noch ein weiteres Gebäude zur Benutzung des nunmehrigen Kaiserlichen Gouverneurs aufgeführt worden.

Den Osten der Strasse bildet die katholische Mission aus Steyl. Das Hauptgebäude derselben ist in Kreuzform gebaut und wird in der Mitte von einem kleinen Turm geziert, dessen Glocke die Gläubigen der Stadt täglich zur Messe ruft. Mit den vielen kleinen Fenstern und der Veranda giebt das Gebäude, namentlich vom Schiff aus gesehen, der 
Stadt einen schönen Abschluss im Osten. Im unteren Stockwerk befindet sich die Kirche, welche der schmerzhaften Vutter Gottes geweiht und demnach ausgestattet ist. Einen eigentümlichen, sonderbaren, aber feierlichen Eindruck macht der Gottesdienst. Auf dem hohen Altar zelebriert einer der Ordenspriester feierlich die Messe, in den weissen langen Gewändern beten andächtig die Brüder und intonieren im Verein mit ihren schwarzen Schülern den Chorgesang. Ergreifend ist es, wenn in den Bänken der Kirche die kleinen schwarzen Bengels mit den schwarzen Augen und zusammengefalteten Händen den feierlichen Gesang der Messe anstimmen. Der Oberstock des Hauptgebäudes enthält die einzelnen Wohnzellen, die jetzt von den Schwestern der Mission bewohnt werden. Im Norden des geräumigen Hofes befinden sich die Schul- und Wirtschaftsräume der schwesterlichen Niederlassung. Daran schliesst sich der Acker, sowie eine stattlich angelegte Kokosplantage der Mission. Seit neuerer Zeit sind die Brüder mit ihrer Niederlassung in die Hamburgerstrasse verzogen.

Parallel zu dieser Strandstrasse läuft die vorerwähnte Hamburgerstrasse, welche mit Laterit befestigt ist und somit einen guten festen Weg für Fussgänger bildet. In der letzten Zeit ist die Regierung emsig daran, sämtliche grössere Strassen auf diese Weise zu verbessern. Eine kleine Feldeisenbahn ist zu diesem Zwecke längs der Strasse nach Misahöhe bis zur ersten Wellenterrasse, ungefähr $2 \mathrm{~km}$ von der Stadt entfernt angelegt. Auf der südlichen Hamburgerstrasse liegen die meisten Stores der grossen Faktoreien, während auf der Nordseite sich mehr die Besitzungen der Schwarzen befinden, welche meistens von einer sogenannten Fence, einem dürftigen Zaune von Palmenblättern oder Knüppelholz umgeben sind. Ebenfalls auf der Nordseite liegt die Ansiedlung der Väter der schon erwähnten Steyler Mission. Die Zellen der Patres und Brüder haben sämtlich einen besonderen Eingang, der auf die Veranda führt. Der Hof wird von einer kleinen Kapelle sowie von einer Schule begrenzt. Diese Niederlassung ist erst kürzlich entstanden; sie diente ursprünglich als Unterkunft für die Schwesterniederlassung und die damit verbundene Mädchenschule. Jetzt haben sich hier aus praktischen Gründen die Patres niedergelassen, denn einmal wollten sie näher dem Herzen der Stadt sein, um dadurch einen grösseren Einfluss auf die Bevölkerung ausüben zu können, ausserdem aber auch wollten sie den Schulkindern einen längeren Weg ersparen.

Haussaleute und echte Buschleute, nur dürftig bekleidet und alle Faktoreien mit Lasten beladen, die sie in der üblichen Weise auf dem Kopfe und Handelstragen, eilen in kleineren und grösseren Trupps zu den Faktoreien, verkehr. erstere um Stoffe aufzukaufen und sie mit Vorteil in dem Hinterlande gegen die Produkte des Landes wieder abzusetzen, letztere um ihr Oel 
und Palmenkerne sowie meistens bei diesen Gelegenheiten auch ihren weit aus Adele hergebrachten Gummi zu verkaufen. In den Höfen der Faktoreien ist ein geschäftiges Treiben zu bemerken, überall werden Palmenkerne gewogen, Gummi mit Seewasser besprengt und präpariert, Palmenkerne werden in Schuppen geschaufelt oder fertig in Säcken zur Verladung auf dem nächsten Dampfer verwogen. Natürlich geht dieses Treiben, wie jede Arbeit bei den Schwarzen, nicht ohne Lärm ab. Wir betraten ebenfalls den Store einer Faktorei und fanden dort die Agenten derselben bei ihrer Arbeit an den Büchern vor. In den geräumigen Schuppen lagen in Regalen die verschiedensten Baumwollstoffe, sowie allerhand sogenannte Prints-(Kattun)stoffe, welche zu unserer grossen Freude meistens das "Made in Germany" trugen. Auch bessere Stoffe, die zur Herstellung der sogenannten Coverclothes, dem hauptsächlichsten Kleidungsstück der Evhe verwendet werden, liegen hier in geschmackvollen gestreiften und karrierten Mustern aus, wobei die blaue Farbe vorherrschend ist. Die Zeuge und Stoffe sind zumeist in Ballen, das Stück zu I 2 Yards, aufgespeichert. Zu dem erwähnten Kleidungsstück reichen gewöhnlich vollkommen für eine erwachsene Person 6 Yards aus. Die billigen Prints, die ebenfalls in Stücken zu I 2 Yards gerollt sind, werden mit 3 Mark verkauft, während die besseren Baumwollstoffe, die gleichfalls zu je i 2 Yards verpackt sind, einen Preis von 7,50 Mark erzielen. Auch finden sich in den hohen Regalen die grossen zu 30 Yard gewickelten Greybaftsballen, die beliebtesten Stoffe der Haussa und werden hier mit je 7 Mark veräussert. Auch Seide wird zum Verkauf gehalten, da die reichen Frauen, besonders die der schwarzen Händler, sich den Luxus gestatten, bei feierlichen Gelegenheiten in Seide zu erscheinen. Neben der beliebten blauen Farbe wird auch häufig die grüne und schwarze gewählt; aber allen diesen wird die gelbe vorgezogen. Und nicht mit Unrecht hat sich der Geschmack dieser Schönen hauptsächlich für diese Farbe entschieden, da sie im allgemeinen einen schönen Kontrast zu ihrer schwarzen Hautfarbe bildet. Auch kleine weisse, rote und buntfarbige seidene Tücher gelangen hier zum Verkauf und werden als Kopftücher getragen. * Glasperlen jeglicher Art blitzen hier den Beschauer entgegen, bedruckte Taschentücher in den grellsten und buntesten Farben, die das Herz der Schwarzen erfreuen, werden feil geboten. Grosse Packete mit Rot- und Blaugarn liegen in den Fächern aufgespeichert; dieses ist ebenfalls einer der wichtigsten Tauschartikel sowohl für den Europäer, als auch für die schwarzen Händler, welche damit Handel im Hinterlande treiben. Auch Tabak ist hier zu haben, der häufig, besonders in der trockenen Zeit, mit Wasser benetzt wird, um ihm die nötige Feuchtigkeit zu erhalten. Auf der einen Seite des Schuppens lagert in einer besonderen Abteilung in Tonnen der 
Gummi; den Einkauf dieses wichtigen Handelsartikels besorgt in der Regel der Agent der Faktorei in eigener Person. Der Gummi wird hier auf seine Güte und Feuchtigkeit geprüft, auch werden probeweise Bälle zerschnitten, weil die raffinierten Schwarzen häufig Steine und Sand hineinlegen, um das Gewicht zu erhöhen und dadurch einen besseren Preis zu erzielen. Nach dieser Prüfung wird der Gummi gewogen und nun beginnt das umständliche Hin- und Herreden über den Preis. StundenInang sucht der schwarze Verkäufer oder clerk, wie ihn mit Vorliebe unsere Kaufleute nennen, eine Einigung zu erzielen. Häufig gehen die Leute aus einer Faktorei in die andere und kehren schliesslich wieder zur ersteren zurück, um dann, nachdem sie sich über die Preislage orientiert haben, dieser ihre Ware zu verkaufen. Der Erlös wird nur selten in barem Gelde genommen; meistens werden dafür Waren eingetauscht, welche nach Belieben des Käufers in Tabak, Spiritus, Wollzeugen, Perlen oder sonst dergleichen bestehen.

Ferner sieht man hier sogenannte Daneguns, lange grosse Steinschlossflinten von meist minderwertigem Fabrikat; auch findet sich der beliebteste Tauschartikel, das grobe sogenannte Negerpulver in kleinen Fässern zum Transport ins Innere verpackt, vor. Ebenso fehlen wohl in keiner Faktorei die für den Europäer nicht gerade allzu wohlriechenden Pomaden, die, wie das Lawendelwasser für die schwarzen Damen des Landes einen besonders schätzenswerten Toilette-Artikel bilden. Um sich an denselben erfreuen zu können, dürfen selbstverständlich die Spiegel nicht fehlen. Kleine weisse Thonpfeifen sind ebenfalls ein sehr begehrenswerter Frauenartikel, denn in Afrika ist es mit dem Rauchen umgekehrt wie bei uns. Dort rauchen die Damen des Landes und oft sieht man die Frauen auf dem Markte mit Wohlbehagen ihren Knaster aus den oben erwähnten Pfeifen rauchen.

In allen solchen Stores sind auch Bedarfsartikel und Lebensmittel für die Weissen zu haben. Konserven aller Art sind in Büchsen aufgestapelt, daneben Weine, unter denen im allgemeinen die französischen Bordeaux den Vorzug haben; ferner Batterieen von Bier in Flaschen, Mützen, Tropenhelme, Drellstoffe sowohl für die Europäer als auch für die dortige Truppe, die in braunen Karkey-Drell gekleidet ist; rote Feze, die auch zur Uniformierung dieser Truppe gehören und die Kopfbedeckung der mohamedanischen Bevölkerung ausmachen; kleinere Bedarfsartikel, wie Zigarren, Zigarrenspitzen u. s.w. gehören gleichfalls zu dem mannigfaltigen Waren der Faktoreien.

Parallel zu der Hamburger-Strasse liegt die Bremer-Strasse. An dem Westende dieser Strasse befindet sich die norddeutsche Mission, die sogenannte Bremer Mission. Sie ist äusserlich erkennbar an einem schönen grossen Gebäude, das erst in den letzten Jahren erbaut worden 
ist. Im Unterstock ist die einfache, aber schöne und geräumige Kirche, während in dem oberen Stock sich die Wohnung des Missionars befindet. Eine grosse Treppe, deren Aufgang zu beiden Seiten Palmen zieren, führt auf die Veranda des ersten Stockes und von da in die behaglich eingerichteten Zimmer; hier waltet mit Fleiss die Hausfrau, die durch Ordnungsliebe und Umsicht die Wohnung zu einem trauten Heim macht. Ein neuer, aber schön angelegter Garten umgiebt das Haus; in dem nach hinten belegenen Flügel befinden sich die Wirtschaftsräume, die

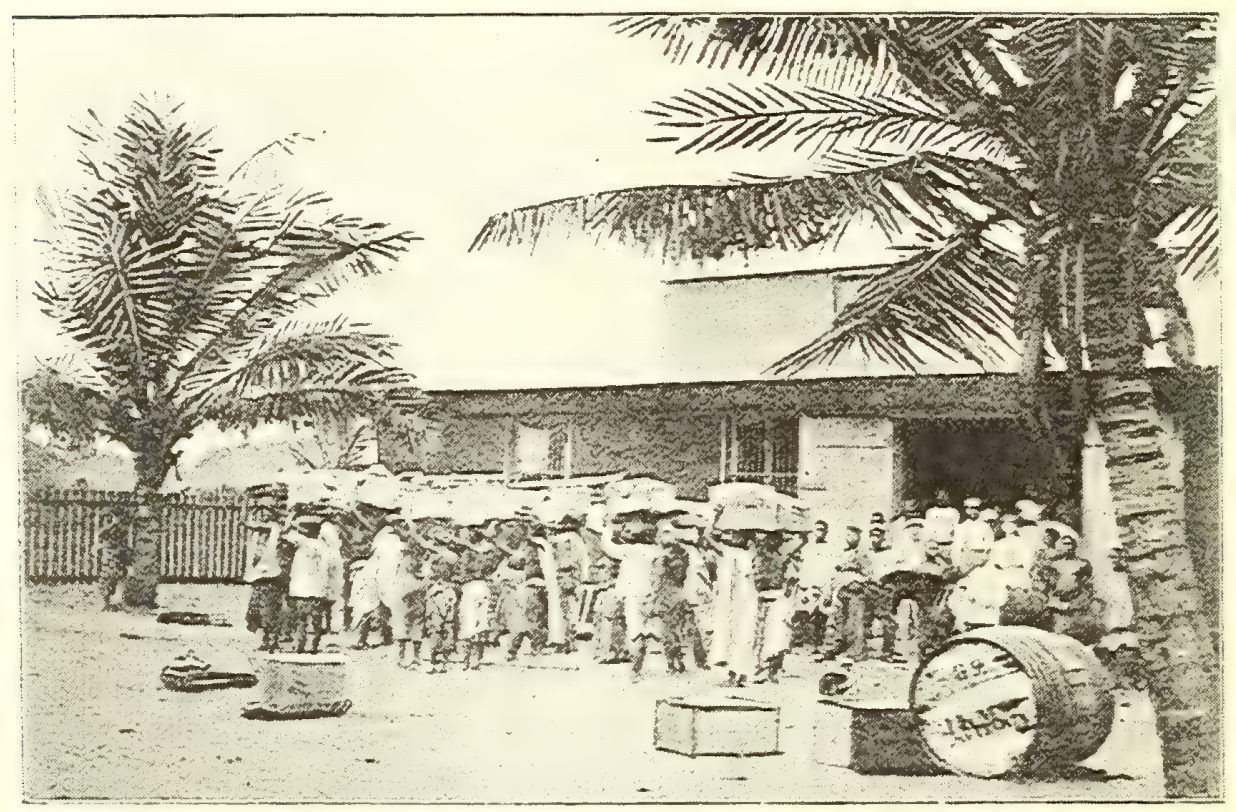

Die Bremer Faktorei in Lome; Abmarsch einer Trägerkolonne in's Innere.

Sěhule und die Wohnung für einen schwarzen Lehrer. Von der Veranda dieses Gebäudes hat man einen schönen Ueberblick über die zum Teil vorgelagerte Stadt und auf das Meer. Die Aussicht macht namentlich dann einen schönen Eindruck, wenn Dampfer auf der Rhede von Lome liegen.

Einen Gegensatz zu diesem schönen, grossen Gebäude bilden die auf der anderen Seite der Strasse stehenden, aus Lehm erbauten, viereckigen Nègerhäuser, welche mit einem von der Witterung geschwärzten Grasdach bedeckt und von einem grossen Zaune von vertrockneten Palmblättern umgeben sind. Auf der von beiden Seiten mit Kokospalmen gezierten Strasse versinkt man bis an die Knöchèl im Sande.

Dié Verlängerung dieser Strasse führt nun in das neu entstandene Sebbe, wie es die Schwarzen nach dem früheren Regierungssitz nennen, 


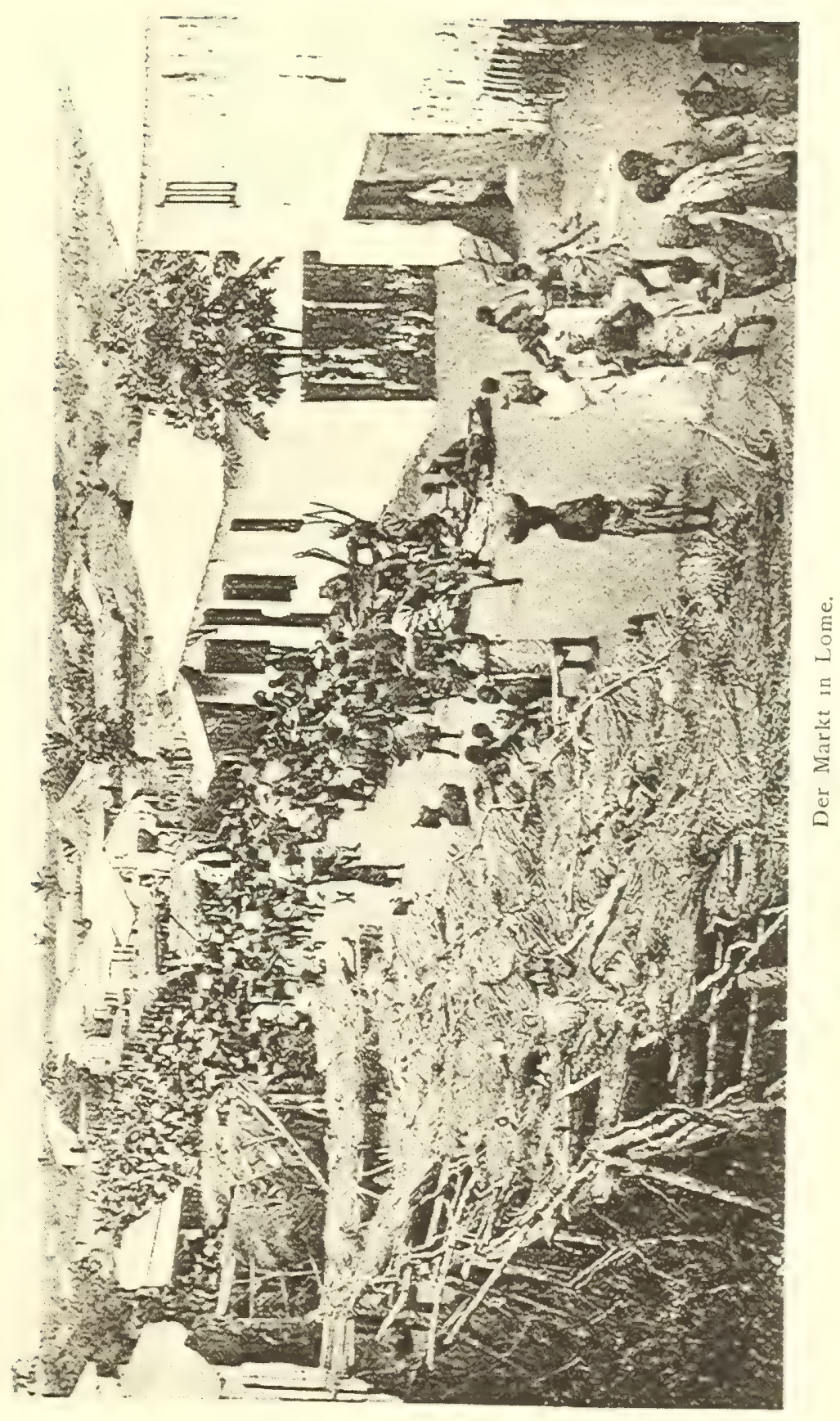



da sich dort die neuen Wohnhäuser und Bureaux der Beamten und das Gefängnis befinden. Eine breite Strasse, die mit Laterit befestigt ist, fuhrt zu der neuen Anlage.

Im Osten der Bremer-Strasse schliesst sich der Markt an, ein grosser, freier, mit Schattenbäumen bepflanzter Platz, auf welchem die sogenannten Kernermärkte stattfinden. Auf der Ost- und Nordseite des Marktes befinden sich die Filialen der grossen Faktoreien, eine Menge von Läden, etwa 50 an der Zahl. Die Gewohnheit der Schwarzen hat die Anlage dieser Läden erforderlich gemacht. Der Schwarze will nicht nur Waren erstehen, sondern er will dabei auch sein V'ergnügen haben. Er geht häufig von einem Laden zum andern, lässt sich die verschiedenen Waren zeigen und erwägt deren Preise und Güte, und nicht selten kommt es vor, dass er, nachdem er mehrere Läden abgesucht hat, schliesslich doch in einem der von ihm bereits besuchten Läden seine Einkäufe besorgt. Hier in Lome bildet im Gegensatz zu Klein-Popo das Kassageschäft, wie es die Kaufleute nennen, die Haupteinnahme, während in Klein-Popo, unserer zweitgrössten Handelsstadt in dem Gebiete, der Engroshandel vorherrscht.

Die Läden werden zum grössten Teil von schwarzen sogenannten clerks verwaltet, welche täglich des Abends ihre Einnahme an die Agenten der Faktorei abführen. Natürlich machen diese kleinen Filialen dem Kaufmann nicht wenig Schmerzen, da er häufiger Stock zu nehmen hat, wie der technische Ausdruck lautet, d. h. durch die Aufnahme der Ladenbestände seine schwarzen Angestellten in steter Kontrolle halten muss.

Auf dem Marktplatz befinden sich an bestimmten Markttagen die sogenannten catcher, die schwarzen Angestellten der Faktoreien. Fast jede Faktorei ist dort durch ihren clerk vertreten, der bei seinen grossen Tonnen oder einem Berg von Säcken mit der Ware bereit steht, um die zum Kauf angebotenen Waren an Oel und Kernen in Empfang zu nehmen. Grosse Karawanen mit Kalabassen und Schalen kommen familienweise aus den umliegenden Dörfern angezogen und bieten ihre Produkte an. Früher wurden sie noch bevor sie auf den Marktplatz gelangten, auf den Strassen von den sogenannten catchern abgefangen, welche kein Mittel unversucht liessen, um den unbeholfenen Landbewohnern ihre Ware abzuschwatzen. Schliesslich griff diese Unsitte so weit um sich, dass der eigentliche Handel sich gar nicht mehr innerhalb der Stadt, sondern weit vor derselben auf der Landstrasse bewegte. Natürlicherweise kam es dabei nicht selten zu Schlägereien unter den konkurrenzneidischen Angestellten sowie Gewalthätigkeiten gegen die Eingeborenen, die ihre Ware nicht fur einen billigen Preis losschlagen wollten. Mit Recht wurde diesem Treiben seitens der Regierung energisch entgegengetreten, 
so dass nun der Markt an den bestimmten Plätzen unter Aufsicht der schwarzen Polizisten stattfindet.

An den Marktplatz lehnt sich im Norden die Marktstrasse an, die ebenfalls parallel zur Bremerstrasse liegt und nach Westen führt, während sich nach Osten in derselben Linie die Bestrasse hinzieht, die ausserhalb der Stadt in einen, das Fetischdorf Be mit der Stadt verbindenden Fusspfad übergeht. Von dem Markte führt in nordöstlicher Richtung eine breite und schöne Strasse nach Amutive.

Auf der Marktstrasse spielt sich der eigentliche Handel mit Lebensmitteln ab. In langen Reihen̉ sitzen dort zu beiden Seiten der Strasse die schwarzen Marktweiber mit ihren Produkten und nur mühsam kann man sich durch die Menschenmasse drängen. Zum Schutze vor der glühenden Hitze sind seitens der Regierung zu beiden Seiten der Strasse lange Schattendächer aus Wellblech errichtet. Hier ziehen sich die Läden der schwarzen Grosshändler entlang, welche die eigentlichen Zwischenhändler zwischen den Faktoreien und dem Volke bilden. Häufig haben die schwarzen Landleute mehr Vertrauen zur schwarzen als zur weissen Farbe, selbst wenn sie für die Waren einen entsprechend höheren Preis zahlen müssen.

Im Osten der Strasse trifft man sehr viele Leute aus $B e$ an, in einer nichts weniger als vollständigen Toilette, nur dürftig mit einem kleinen weissen Schurz bekleidet. Sie bieten kleine Bündel Feuerholz zum Verkauf an. Weiter nach Westen gelangt man zu den Fischweibern, was man schon von ferne gewahr wird, denn wenig wohlriechend sind die kleinen zum Kauf angebotenen getrockneten Fische, die für den Küstenneger eine Delikatesse bilden, von den Europäern aber mit Abscheu betrachtet und Stinkfische genannt werden. Lebensmittel aller Art, wie Maisbrote, kleine Fleischklösse, die an Ort und Stelle mit einer Palmölsauce oder einer grünen Fischsauce von den Käufern verzehrt werden, werden hier feilgeboten. Jams, Kassawa, Maiskolben geröstet und ungeröstet, sowie kleine Zwiebeln und Mehl bilden den Gemüse- und Vorkosthandel auf dem Markte; ausserdem wird mit Ananas, Orangen, kleinen Citronen, Papayas, sowie gerösteten und ungerösteten Erdnüssen gehandelt.

Auch Glasperlen und Tücher, die erst aus den Faktoreien gekauft sind, werden hier, namentlich von den Haussaleuten, angeboten; Thontöpfe, europäische Flaschen aller Art, kleine Messer, ja auch Pomaden, sowie zur Herstellung von Armringen dienende Messingstäbe bilden ein begehrenswertes Kaufobjekt. Daneben sieht man Zucker packweise und in einzelnen kleinen Stücken verhandeln. Schalen, Kürbisflaschen und Kalabassen, die wichtigsten Hausgeräte unserer schwarzen Landsleute, sind dort ebenfalls zu haben. Tabak in einzelnen Strähnchen, Schnaps, der flaschenweise verhandelt wird und der in grossen Kalabassen feil- 
gebotene beliebte Palmenwein bilden die narkotischen Genussmittel. Pulver, sowie seltener Gewehre machen den Schluss dieses bunten Allerlei.

Im Westen der Strasse ist der Fleischmarkt. Auch hier haben wiederum die Haussa als schlaue Kaufleute das einträgliche Geschäft inne. Schaf- und Ziegenfleisch, auch das bei den Eingeborenen beliebte Schweinefleisch, wird in grossen und kleinen Portionen feilgeboten, während Rindfleísch nur selten zu haben ist, da die Rinder erst weither aus dem Innern transportiert werden müssen. Reihenweise sind Holzspiesse aufgestellt, um über dem Feuer kleine Fleischstücke zu rösten, eine besondere Delikatesse für die Eingeborenen. Schwarze Polizisten halten in dem bunten Gewirre die Ordnung aufrecht, denn häufig ist der Markt in den Vormittagsstunden sehr stark besucht. Ueberall stehen Gruppen feilschend und schreiend umher.

Es bleibt nun noch die fast parallel zur Marktstrasse laufende Küas. strasse zu erwähnen, die nach dem ersten Amtsvorstand in Lome ihren Namen erhalten hat. Auf dieser Strasse findet man europäische Niederlassungen nicht mehr vor. Auch die Leute an der Küste haben teilweise ihre Bauten in europäischem Styl aufgeführt. Viele hier wohnende schwarze Händler besitzen ebenfalls aus Ziegeln gemauerte Häuser mit regulären Thüren und Fenstern; letztere jedoch zumeist ohne Glas und mit Holzläden verschlossen. Ein schlecht geflochtener Mattenzaun umgiebt die Hausgrundstücke, zu denen oft noch Ländereien gehören. Auf dem dürftigen Acker wächst mit wenigen Ausnahmen nur Kassawa.

Die nächste Parallelstrasse, die im Norden die vorerwähnten Grundstücke begrenzt, ist die sogenannte Haussastrasse; sie ist nach der anliegenden Haussakolonie benannt. Die Kette der langen Zäune wird $\mathrm{ab}$ und zu durch freie Plätze unterbrochen, die häufig einen schönen Bestand an Kokosnussbäumen aufweisen. Zwischen dieser und der nächsten Parallelstrasse, der nach dem verdienstvollen Landeshauptmann der Kolonie benannten Putkamerstrasse, liegt das eigentliche Haussaviertel. Grosse Mattenzäune schliessen hier das von den mohamedanischen Fremdlingen bewohnte Land ein, welches eigentlich als Gemeingut dieser Haussaleute zu betrachten ist. Nur einige grössere Händler, die sogenannten Haussa-Chiefs und die mohamedanischen Priester besitzen eigene Grundstücke. In diesem Haussaviertel gehen die einzelnen Hütten oft von einem Fremden auf den anderen über, entweder für ein kleines Entgelt oder einfach durch die Besitznahme irgend eines neuen Ankömmlings. Der Haussa, der fast ausschliesslich Händler und fast immer auf der Wanderschaft ist, schlägt dann hier für einige Zeit sein Quartier auf, um teilweise die aus dem Innern mitgebrachten Rohprodukte, wie Gummi, ja auch Vieh und Pferde gegen gangbare Waren einzutauschen und dieselben alsdann im Hinterlande wieder meistens mit grossem Gewinn loszuschlagen. 
Betritt man ein solches Viertel, so sieht man sich unwillkürlich nach Kete in Kratyi versetzt. Die engen schmutzigen Gassen und Pfade, die zwischen den kleinen runden, meist nur aus Matten geflochtenen Hütten hindurch führen, tragen denselben Charakter wie die der Haussaniederlassung im Hinterlande. Grosse hübsche Gestalten mit Kinnbärten in langen blauen Toben und fast unglaublich weiten Hosen treten einem hier mit ihrem Grusse entgegen; sie machen den Eindruck gewiegter Handelsleute und Weltmänner und verhalten sich den Weissen gegenüber ungezwungen und zuvorkommend. Die Häuptlinge und Grossen sind an ihrem hohen Turban erkennbar, während die ärmeren meist nur einen roten Fez tragen. Die Frauen erkennt man an den typisch hohen Frisuren und dem Korallenpflock, welcher ihren rechten Nasenflügel ziert. Die Jungens tragen zumeist kleine Toben und häufig eine kleine weisse Kappe. Der Priester dieser Kolonie ruft schon beim Morgengrauen von dem Dache seines Hauses die Gläubigen zum Gebet. Ein langes "Allah - Allachu" lässt er früh, mittags und abends beim Sonnenuntergange ertönen. Alles fällt dann auf die Kniee zum Gebet, mit dem Gesicht nach Osten gewendet und unterzieht sich überall, auf Plätzen oder Wegen, gläubig der Zeremonie.

Da die vielen mit Gras bedeckten Hütten in so grosser Nähe der Stadt eine Feuersgefahr bilden, so ist in den letzten Jahren durch die Regierung den neu ankommenden Karawanen nördlich von der Putkamerstrasse unentgeltlich ein freier grosser Platz zum Anbau zur Verfügung gestellt worden. Schon jetzt bauen einzelne Haussas dort ihre Hütten und Gehöfte auf, so dass es nicht lange dauern wird, bis auch dieser Platz eine grosse Haussakolonie bildet. Nördlich von dieser Kolonie ziehen sich die Kassawafelder der Lomeleute hin; ab und zu versperrt eine undurchdringbare Dornenhecke die Aussicht.

Die Aflaüstrasse begrenzt im Norden die eigentliche Stadt. Im Osten bildet, wie schon erwähnt, die Bismarckstrasse die Grenze. Diese ist eine der wichtigsten Verkehrsstrassen, die weiter in die sogenannte, jetzt etwa $\mathrm{x} 20 \mathrm{~km}$ in das Innere hineinführende Misahöhestrasse übergeht. Rechts und links dieser Strasse sieht man viele Filialen der Faktoreien sowie die Läden der schwarzen Händler. Westlich von dieser Strasse liegt der schon erwähnte neu entstehende Sebbeteil mit den Regierungsgebäuden; weiter nördlich davon gelangt man auf den Rennplatz von

Pferde- Lome. Die meisten Pferde kommen aus dem Hinterlande über Kete-Kratyi, behandlung insbesondere aus Mossi, sowie aus Sugu und Tchautscho. Hier an der an der Küste. Küste fehlt den Pferden das Guineakorn, an welches sie gewöhnt sind und das so reichlich in der nördlichen Gegend angebaut wird, eben so weiches Gras. Das Guineakorn wird durch den für Pferde wenig geeigneten Mais ersetzt und das hier als Futter verwendete Gras ist eigentlich 
Schilf von der Lagune. Das Wasser, welches aus den auf den Höfen der Faktorei angelegten Brunnen entnommen wird, ist mit wenigen Ausnahmen brackig und ungesund. Es kommt daher sehr häufig vor, dass die aus dem Innern kommenden Pferde schon nach kurzer Zeit eingehen; sie bekommen eine Art Wassersucht. Die äusseren Symptome sind in der Regel geringe Fresslust und grosse Mattigkeit, die Hinterbeine und der Bauch schwellen an und zuletzt tritt unfehlbar der Tod ein.

Man nimmt auch an, dass die Pferde auf dem Transport von der Tsetse gestochen werden; die Tsetse ist eine Fliegenart, welche sich

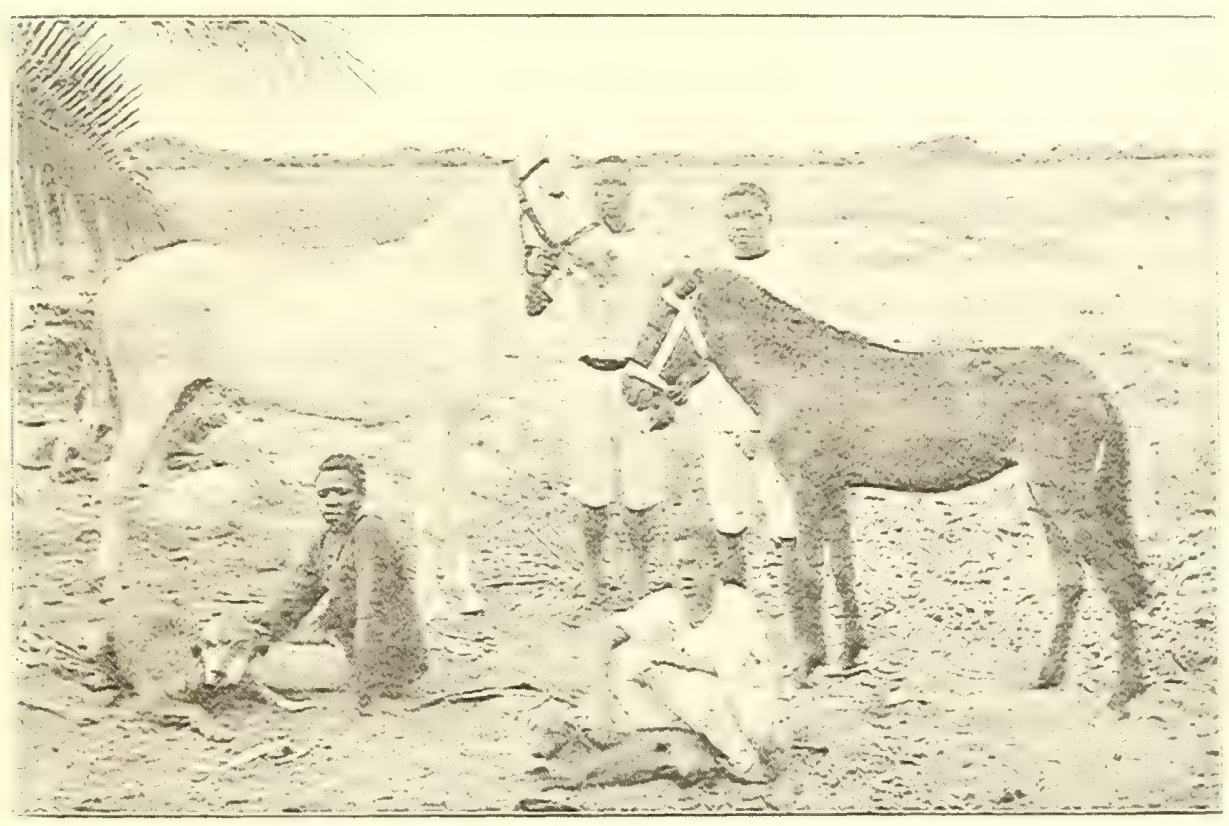

Die grosse und kleine Pferderasse des Hinterlandes.

besonders in dem Küstenstrich südlich von Misahöhe vorfindet. Auch findet man öfter beim Sezieren der Pferde im Magen fast erbsengrosse Würmer in Menge vor, welche dem Tiere die von demselben in grossen Quanitäten zu sich genommene Nahrung entziehen. Ein deutlich wahrnehmbarer Kräfteverfall tritt ein, das Pferd wird magerer und geht allmählich ein. Noch eine andere Todesursache habe ich öfter im Hinterlande, beim Sezieren von Pferden gefunden. Sämtliche Teile wurden als gut und gesund befunden, nur die Leber war von einem kleinen Eiterherde besetzt. Auch in diesem Falle stellt sich ein langsamer Kräfteverfall ein und das Pferd fällt plötzlich ohne weitere Symptome. 
Rennen, Fest spiele und sonstige Be lustigungen

Trotz aller dieser Missstände sind die in der letzten Zeit veranstalteten Rennen in Lome als gelungen zu bezeichnen. Dieselben finden meistens an bestimmten Festtagen, wie Sedantag oder Kaisers Geburtstag, statt. Tiele Gäste aus Quitta, auch die schwarzen berittenen Händler von dort, kommen auf ihren kleinen oder mittelgrossen Pferden an diesen Tagen nach Lome. Es finden nur Flachrennen statt, die allerdings durch komische Scenen und Hindernisse, wie Absitzen, Anbrennen einer Zigarre oder Trinken eines Schoppens Bier zu Pferde erheitert werden. Es spielt dabei nicht nur die Gewandtheit der Reiter als solche mit, sondern auch die Geschicklichkeit bei Ausführung der kleinen Kunststücke.

Aus Mangel an Pferden und Reitern hat man andere, sowohl für die Schwarzen als auch für die Weissen nicht wenig interessante und drollige Belustigungen eingerichtet. So folgt dem eigentlichen Rennen ein Rennen mit Hängematten und Kernerwagen. Letztere sind kleine Karren, die ihren Namen nach den zu ihrer Beförderung bestimmten Produkten erhalten haben. Sie werden von Schwarzen gezogen und meistens von einem fidelen weissen Herrn geleitet, der seine schwarzen Transporteure vom Wagen oder der Hängematte aus nicht wrenig anfeuert. Im Verhältnis zu den niedrigen ausgesetzten Preisen werden in kritischen Augenblicken vor dem Ziele hohe Versprechungen gemacht und so die Freude der schwarzen Mannschaft an dem Gewinn erheblich erhöht. Tauziehen zwischen Weyboys und Kruboys, den beiderseitigen Todfeinden, bildet den Schluss dieser allgemeinen Volksbelustigung. Lome, das nur als Sitz der Landeshauptmannschaft mit Beamten und Kaufleuten die stattliche Anzahl von 6o Weissen aufweist, kann sich auch noch andere Vergnügungen leisten. Es besteht ein Kegelklub, dem fast sämtliche Europäer angehören. Die schöne Kegelbahn ist Eigentum der Klubmitglieder und ein Aktienunternehmen derselben. Jeden Sonnabend rollen dort die Kugeln und so wird in fröhlichem Beisammensein die arbeitsreiche Woche beschlossen. Auch die Schwarzen gehen in der Regel am Sonnabend ihrem Vergnügen nach. Die Honoratioren unter ihnen, welche sich zum grössten Teil aus den angestellten Verkäufern der Faktorei zusammensetzen, unterhalten eine Musikkapelle, bei welcher allerdings der Bass und die grosse Pauke die Hauptrolle spielen.

Die von Akra herübergekommenen Händler haben auch schon die europäischen Tänze in der Metropole Lome eingeführt, so dass man dort bei dem Takte der Paukenschläge die galanten schwarzen Dandies mit den schönen schwarzen Damen der Stadt im Tanze bewundern kann. Die noch nicht auf dieser Höhe der Kultur stehende übrige schwarze Bevölkerung ergötzt sich an den Tönen ihrer eigenartigen Kapelle. Die 
Instrumente bestehen aus einer Trommel oder Kürbisflasche, die von Kaurinetzen umgeben sind. Die Musik wird durch Händeklatschen der umstehenden Menge begleitet, wodurch nicht wenig zu dem Einhalten des Taktes der Tanzenden beigetragen wird. Der Tanz besteht wie bei den meisten Negern aus nicht gerade ästhetischen Gliederverrenkungen.

Ich wende mich nun noch zu den anliegenden Dörfern und der Umgebung Umgebung ausserhalb der Stadt Lome. Von dem Markte aus führt, wie bereits erwähnt, nordöstlich die sogenannte Amutivestrasse. Es ist eine schöne, breite Strasse, die mit Laterit befestigt ist und zu beiden Seiten des Weges von grossen, hohen Schattenbäumen eingefasst ist. Diese Strasse führt zu dem Strande und wird häufig an Sonntagen oder nach Sonnenuntergang als Promenade benutzt. Sie hat in neuerer Zeit eine günstige Veränderung dadurch erfahren, dass sie ungefähr $5 \mathrm{~km}$ hinter der Lagune ihren ursprünglichen Weg nach Ague verlässt und nach Nordwesten abbiegt, um dann nach einer Entfernung von $10 \mathrm{~km}$ ungefähr $4 \mathrm{~km}$ vor Akeppe in die eigentliche alte Strasse von Misahöhe einzubiegen. Es ist dies von besonderer Bedeutung, denn die frühere Strasse führte etwa $3 \mathrm{~km}$ hinter Lome über englisches Terrain, welches dort in einem Dreieck in unser deutsches Gebiet einschneidet; infolgedessen konnte dieser Weg zu jeder Zeit durch die Willkür der englischen Nachbarkolonie gesperrt werden. Obwohl die alte Strasse infolge ihrer geringeren Ausdehnung noch viel von den herumziehenden Karawanen benutzt wird, so sind doch aus den vorangeführten Gründen viele Läden der Faktoreien an der Amutivestrasse eröffnet worden.

Nach $\mathrm{I}^{\mathrm{r}} / 2 \mathrm{~km}$ Entfernung gelangt man auf dieser Strasse nach dem benachbarten Negerdorf Amutive. Es ist dieses der erste und letzte Aufenthaltspunkt der auf diesem Wege von und nach Lome ziehenden Landleute. Hier hat sich infolgedessen ein kleiner Hökermarkt etabliert. Namentlich Weiber aus Be und Amutive sitzen hier vor ihren grossen Kalabassen mit Palmwein und gerösteten Erdnüssen; auch die beliebten Stinkfische sowie zubereitete Speisen mit kräftig gewürzten Saucen werden dem ankommenden oder abgehenden Wanderer feilgeboten.

Amutive macht mit seinem von vielen Kokospalmen bestandenen Marktplatze und seiner im Hintergrunde nach Osten hin neu erbauten Kapelle der katholischen Mission, die mit ihrem weissen Anstrich malerisch aus dem grünen Laubwerk hervorlugt, einen recht günstigen Eindruck. Auch hier findet man noch einige Häuser, deren Bauart europäischen Charakter zeigt, wenn sie auch aus Lehm aufgeführt sind; sie sehen einem ärmlichen deutschen, mit Stroh eingedeckten Bauernhause nicht unähnlich. Daneben sieht man natürlich häufig die typisch viereckig gebauten armseligen Hütten der Evheleute. 
Sobald man das Dorf auf der Nordseite verlässt, liegt vor dem Wanderer die hier ungefähr I $\mathrm{km}$ breite Lagune mit ihren baumlosen und sumpfigen Grassteppen ausgebreitet. Hinter ihr erhebt sich die circa 50 Meter hohe Felsenterasse, welche im Norden die Lagune abschliesst. Auf dieser Terrasse hat sich dicht am Wege ein schlauer Schwarzer eine Ziegelei eingerichtet, allerdings nur mit einem kleinen Feldofen, welcher heute nicht mehr ausreichend ist, da der Bedarf an Ziegeln infolge der von der Regierung auszuführenden Bauten bedeutend grösser geworden ist. Der dort gewonnene rote Lehm liefert ein vorzügliches Material für die Ziegeln. Ueber diese Terrasse zieht sich wie ein roter Faden auf dem eisenschüssigen Lateritboden der Weg nach Aguë respektive nach Misahöhe hin, dessen Höhen mächtige Affenbrotbäume zieren.

Zwischen dieser Strasse und der vorerwähnten alten Misahöhestrasse, der Verlängerung der Bismarckstrasse, liegt nördlich der Aflaüstrasse, wie ein Keil eingetrieben, das grosse Areal der Regierung, ein Geschenk des Häuptlings Adjiale von Amutive, welches mit zwei bis drei Meter hohem undurchdringlichem Buschwerk bestanden ist. Nördlich davon zieht sich dann fast bis zur Lagune das grosse Gebiet der Kokosplantage von Lome hin. Leider wird die Plantage nicht im geringsten gepflegt, so dass sie sich wenig entwickelt hat. Ueberall wuchert das hohe Gras empor und die Palmenreihen werden häufig von leeren Stellen unterbrochen. Ab und zu sieht man noch einzelne Baumwollfarmen der Eingeborenen; die gelben Blüten auf den Feldern stechen schön von den übrigen Farben ab. Vietor hat früher einige Versuche mit Baumwolle angestellt und dadurch die Eingeborenen bewogen, mehr von dieser Pflanze anzubauen. Da jedoch die gewonnene Baumwolle vorläufig nicht mit der feinen amerikanischen konkurrieren kann, ist sie sehr im Preise gesunken und sind dadurch viele Leute unter den Eingeborenen in Armut geraten. Die Häuptlinge und Grossen haben deshalb beschlossen, grössere Baumwollfarmen nicht mehr anzulegen. Infolge dieses Umstandes fällt es heute sehr schwer, die Leute zu einem abermaligen Versuch zu bewegen.

Die alte Misahöhestrasse ist ebenso wie die neu angelegten Strassen, die nach dem sogenannten Sebbe führen, durch den rührigen Regierungsgärtner mit Kokospalmen bepflanzt worden.

Nach $I^{1} / 2 \mathrm{~km}$ Marsch auf der alten Misahöhestrasse gelangt man ebenfalls zur Lagune. Hier wie auf der Amutivestrasse führt ein gut aufgeschütteter Fusssteig über die Lagune, auf welchem man bei hoher Regenzeit, wenn die Lagune überschwemmt wird, trockenen Fusses auf die Wellenterrasse gelangt. An den Abhängen dieser Terrasse liegt, hart an der Strasse, der sogenannte Versuchsgarten, der erst in letzter Zeit 
mit vielem Fleiss ron dem Regierungsgärtner angelegt ist. Er musste, wie mir der Gärtner richtig erklärte, so weit herausgelegt werden, weil hier erst die Pflanzen Süsswasser aufnehmen können, während an der Küste in dem brackigen Wrasser nur die Kokospalme gedeiht. In diesem Garten sind viele Kulturen von Palmen und anderen Schatten spendenden Bäumen, auch viele Fikusarten, in Pflanzbeeten angelegt. Der Samen einzelner ausländischer Bäume ist gut aufgegangen und die älteren Beete weisen schon kleine junge Pflanzen auf. Einige europäische Gemüsearten, wie Kohl, Radieschen, Karotten, Salat, Zwiebeln und dergleichen, haben sich anscheinend hier gut eingeführt, so dass die Europäer in Zukunft die Gemüse ihrer Heimat nicht zu entbehren brauchen.

Im Osten der Stadt, fast $\mathrm{I}^{\mathrm{I}} / 2 \mathrm{~km}$ von derselben entfernt, liegen hinter der katholischen Mission zwei grosse Friedhöfe, welche mit einem Drahtzaun umgeben sind und auf welchem Schwarze wie Weisse friedlich neben einander ruhen. In früheren Jahren begruben die Schwarzen nach ihrer Sitte, wie es jetzt auch noch fast an allen anderen Orten geschieht, ihre Toten im Hofe vor der Hütte oder in derselben. Aus sanitären Rücksichten sind diese Begräbnisplätze jetzt verboten und sämtliche Beerdigungen finden auf dem gemeinsamen Kirchhofe in Lome statt.

Nicht weit von den Friedhöfen liegt weiter östlich an dẹ See der Pulverschuppen. Wegen der Feuersgefahr ist dieser Schuppen so weit entfernt von der Stadt angelegt. Er beherbergt die rerhältnismässig grossen Pulvervorräte der Faktoreien und den Munitionsbedarf der Polizeitruppen. Grössere Vorräte müssen nach einer Regierungsverordnung in diesem Schuppen niedergelegt werden, so dass die einzelnen Faktoreien meist nur einen kleinen Vorrat zum Verkauf in ihren Läden in der Stadt halten.

In Lome, der Metropole unserer Togokolonie, ist auch unsere Die schwarze Polizeitruppe untergebracht. Dieselbe stand in früheren Jahren Polizeitruppe in Sebbe, dem früheren Regierungssitze von Togo und ist erst im verflossenen Jahre mit Verlegung der Landeshauptmannschaft nach Lome ebenfalls nach hier übergesiedelt. Die ersten Versuche mit dieser nun circa 200 Mann starken Truppe sind im Jahre 1885 durch den ersten Polizeimeister von Piotrowski gemacht worden. Zuerst bestand sie nur aus circa 20 bis $3^{0}$ Mann, die eine weisse, mit einer roten Baspel besetzte Matrosenuniform trugen. Unter dem tüchtigen Drill dieses gewissenhaften Exerziermeisters, der aus dem zweiten Garderegiment hervorgegangen ist und dasselbe als Feldwebel verlassen hatte, um auf afrikanischem Boden unsere neuen schwarzen Rekruten zu tüchtigen Soldaten zu machen, schritt die Ausbildung schnell vorwärts. Trotz der Strenge im Dienst, hat es der brave Polizeimeister verstanden, sich bald die Liebe seiner schwarzen Untergebenen zu erwerben. Noch bis jetzt haben sich bei 
den schwarzen Unteroffizieren, von denen der älteste, Mollu, jetzt sogar zum Feldwebel avanciert ist, die Eigentümlichkeiten und die Ausdrücke ihres ersten Lehrmeisters erhalten. Komisch und erheiternd ist es, wenn man die schwarzen Unteroffiziere kommandieren hört. Man glaubte sich auf dem Exerzierplatz einer unserer Garnisonen zu befinden. „Rechts um, links um, marsch, chargiert fertig, schlecht, schlecht, noch einmal Schafskopf", klingt es barsch aus einer alten schwarzen Unteroffizierkehle. „So, so", der beliebteste Ausdruck unseres Polizeimeisters Piotrowski, hat ihm auch den Namen "So so" eingebracht, so dass Master "So so" lange noch nach seinem Tode als Ehrenname in Erinnerung geblieben ist. Noch zu Soso's Lebzeiten erhielt die kleine Truppe auf seinen Vorschlag eine dunkelblaue Uniform, die rot eingefasst und mit roten Achselklappen versehen war. Dazu wurde eine preussische Infanteriemütze mit der deutschen Kokarde getragen, so dass die Uniform der unserer preussischen Infanterie ähnlich sah. An Stelle des Waffenrocks trat eine blaue Bluse mit gelben Knöpfen und die lange Biesenhose wurde durch eine kurze bis an das Knie reichende ersetzt.

Im Frühjahr I 894 übernahm ich auf Befehl des früheren Landeshauptmanns von Togo, jetzigen Gouverneurs von Kamerun, Herrn von Puttkamer, nach dem Tode des Polizeimeisters von Piotrowski als erster Offizier die für afrikanische Verhältnisse musterhaft ausgebildete Truppe. Sie war inzwischen auf 70 Mann angewachsen. Die Bewaffnung bestand und besteht auch noch heute aus der Jägerbüchse Modell $7 \mathrm{r}$ und dem dazu gehörigen Hirschfänger. Als Reserve-Offizier der Kavallerie machte es mir in der ersten Zeit nicht wenig Mühe, mich in die Verhältnisse zu finden und sonderbar kam es mir oft vor, wenn ich, anstatt mit Kompass und Theodolit das Land zu durchforschen, welches der eigentliche Zweck meiner Afrikareise war, auf meinem Zimmer Griffe kloppte oder hinter dem Exerzierreglement sass. Bald jedoch hatte ich mich in meine neue Stellung hineingefunden und begann nun die Truppe zu organisieren. Dieselbe wurde in Korporalschaften eingeteilt, was nicht wenig Mühe machte.

Die Truppe besteht nur aus Söldnern, die natürlich den verschiedensten Stämmen angehören. Die Mehrzahl waren Haussa, Anagoleute, Leute von der Küste, vom Evhestamme; ferner einige Weyboys und Kruboys und etliche von anderen Stämmen. Ja sogar ein Baluba, namens Kalala, vom Kassai, fehlte nicht. Letzterer war ein treuer Begleiter des verdienstvollen Reisenden Dr. Wolf, welcher ihn von seiner Reise mit Major von Wissmann mitgebracht hatte. Dieser Hanfraucher hatte ein bewegtes Leben hinter sich; zuerst war er als Junge mit Dr. Wolf gezogen, später hatte er als Soldat und Dolmetscher diesen auf seinem letzten Marsch ins Innere begleitet und als Einziger treu bei dem Schwer- 
kranken gewacht, ihm auch nach dem Tode die letzte Ehre erwiesen und ihn in eine deutsche Flagge gehüllt in die kühle Erde gebettet. Kalala spricht fertig deutsch und scheint, überhaupt ein grosses Sprachtalent zu besitzen, da er sich sowohl in der Evhe- wie Haussa-, als auch in der englischen Sprache verständlich machen kann. Infolge dieser Eigenschaften wurde Kalala, der mittlerweile zum Unteroffizier befördert ist, als Dolmetscher für die Truppe gebraucht.

Da ich ausser einem Hoboisten, der die aus etwa 15 bis 20 Mann bestehende Kapelle mühevoll einstudierte, der einzige Weisse bei der Truppe war, so musste ich mir Unterorgane schaffen. Die Truppe war mit der Zeit zu der stattlichen Anzahl von ıoo Köpfen angewachsen. Ich teilte sie daher je nach dem Stamme in Korporalschaften. An der Spitze waren zwei Haussa-Korporalschaften mit je 20 Mann, die wieder unter ihrem, demselben Stamme angehörigen Führer, einem Unteroffizier oder Grefreiten, standen. Es folgten die Anagos, die Evhe und die je nach Kenntnis der Sprachen zu Gruppen zusammengestellten übrigen Stämme, die ebenfalls von einem mit der Sprache seiner Mannschaften vertrauten Unteroffizier befehligt wurden. Mollu, der damals Sergeant war, vertrat gewissermaassen den Feldwebel. Um eine Instruktionsstunde abzuhalten und unsere schwarze Garde mit den Pflichten eines Soldaten bekannt machen zu können, wurde in Korporalschaften angetreten. Kalala verdolmetschte dann aus dem Deutschen oder Englischen in die Evhesprache, welche sämtliche Chargierten verstanden. Diese wiederum traten vor ihre Korporalschaften und verdolmetschten diesen das Gehörte in der ihnen bekannten Sprache. Natürlich kann in einer solchen Instruktionsstunde bei der Verschiedenheit der Sprachen nicht gerade allzuviel gelehrt werden, denn häufig kommt der Unterrichtsstoff erst durch vier Sprachen und Dolmetscher an die eigentliche Stelle; doch man musste sich eben helfen so gut wie es ging. Nicht unempfänglich war diese schwarze Gesellschaft für gute Behandlung und oft ging, nachdem sie durch eine Ansprache über die Strammheit des deutschen Soldaten angefeuert war, das Exerzieren bedeutend besser. Einen Soldaten zu schlagen, galt als schimpflich und so konnte ich von einer Prügelstrafe vollkommen absehen und durch Arrest L'ngehörigkeiten ahnden. Die Truppe wird hauptsächlich in der Feuerdisziplin und ihrem Zwecke entsprechend im Felddienst ausgebildet. Auch wird Kompagnie Exerzieren abgehalten.

Ich habe zu meiner Zeit die Truppe zu einer Kompagnie mit drei Zügen formiert. An der Spitze standen die Spielleute, dann folgte die Kapelle mit ihrem weissen Lehrmeister und dahinter die fast jo Mann starke Mannschaft. Da die Truppe, wie schon gesagt, aus Söldnern bestand, so war es bei den vielen Desertionen nicht leicht, sie immer 
in derselben Stärke zu erhalten. Häufig musste man minderwertiges Material einstellen und da der eine heute, der andere morgen kam, waren immer Rekruten vorhanden. Die alten Unteroffiziere bekamen dann zur Ausbildung die Rekruten, die nun im Marschieren und langsamen Schritt vier Wochen lang gedrillt wurden; nach weiteren vier Wochen fand Exerzieren mit dem Gewehr statt und danach wurden sie in die Kompagnie eingestellt. Zweimal in der Woche wurde auf dem naheliegrenden Schiessstande scharf geschossen, wobei

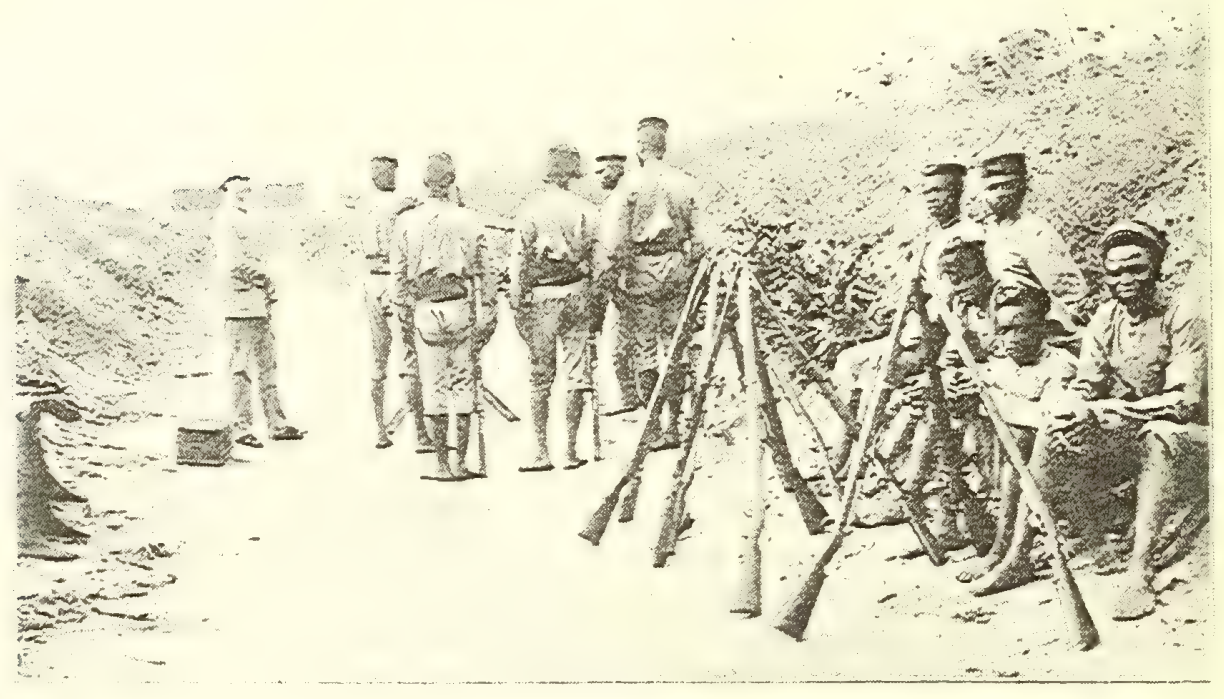

Auf dem Schiessstande

es viel Mucker giebt. Man kann sich daher denken, wie viele Scharfschützen sich dort unter den schwarzen Kameraden befinden. Alles Nachzielen und Nachexerzieren hilft nicht viel gegen die Scheu, mit welcher die Rekruten das Gewehr betrachten. Aber nach ihren Begriffen von einer Flinte, wie sie ihre schwarzen Brüder besitzen, kann man es ihnen nicht sehr verargen, wenn sie lieber an der Hüfte anlegen als an der Backe, denn bei diesen aus Gasrohr hergestellten Waffen ist der Schütze oft selbst in grosser Gefahr, verletzt zu werden. Doch mit der Zeit verlieren auch die schwarzen Soldaten die Angst und werden mit dem Gewehr vertraut. Die alten Mannschaften schiessen dann sicher auf Ioo und 1 5o Meter nach der Scheibe. 
Was das Exerzieren anbetrifft, so sind diese Barfüssler allerdings im grossen Nachteile unseren mit Fussbekleidung versehenen Truppen gegenüber, so dass das Marschieren und Kniedurchdrücken ihnen viele Mühe macht. Griffe und Gefechtsexerzieren machen ihnen alle Ehre. Auch die Feuerdisziplin im Manövrieren ist für schwarze Soldaten eine ausgezeichnete. Ferner wird viel das sogenannte Buschgefecht in einem oder zwei Gliedern geübt, wobei die Leute auf das Kommando: "zum Chargieren halt" abwechselnd rechts- und linksum machen und das Gewehr gleichzeitig zum Anschlage bereit halten. Bei dem Felddienst und auf dem Marsch im feindlichen Gebiete wird stets eine Spitze vorausgeschickt, die durch V'erbindungsleute mit dem Gros Fühlung hält.

In Sebbe wohnte die Truppe in dem sogenannten Haussalager dicht neben dem Exerzierplatz in Hütten, die sich ein jeder nach seinem Belieben aufbauen konnte. Das Lager war im übrigen regelmässig in Strassen angelegt, was noch ein Werk des Polizeimeisters von Piotrowski war. Hier hausen die Mannschaften mit ihren Frauen, von denen sie meist mehrere hatten und zwar je nach den Vermögensverhältnissen zwei, drei oder vier. Zumeist waren die Frauen Töchter des Landes und gehörten dem Evhestamme an. Viele, namentlich die Haussa, hatten ihre Frauen aus der Heimat.

Bei dem Löhnungsappell ging es, namentlich in den ersten Zeiten, so $z u$, dass die Frauen und Gläubiger der betreffenden Soldaten gleich dicht hinter der Front standen und, sobald sie ihre Löhnung empfangen hatten, über sie herfielen, um ihnen den Sold abzunehmen. Natürlich wurde dadurch die Disziplin nicht wenig gestört, so dass durch Absperrung des Platzes dem Treiben ein Ende gemacht werden musste. Der Soldat, der als Rekrut nur 25 Pfennige Verpflegungsgeld pro Tag empfängt, erhält, sobald er ausexerziert ist, bis eine Mark für den Tag, während die Gefreiten I,25 Mark und die Unteroffiziere I,50 Mark pro Tag erhalten. Der empfangene Sold würde häufig sehr bald verspielt. Viel verbreitet war unter den Soldaten das Kaurispiel; zuweilen, wenn ich unbemerkt hinzutrat, bemerkte ich einen Einsatz von I bis 3 Mark und mit einem Wurf war das Glück entschieden. Aus diesem Grunde gerieten die Leute oft in Not und das Kreditnehmen beginnt. Natürlich fanden sich bald gute Freunde und Bekannte, die das Geld - aus reiner Gefälligkeit - gegen roo auch 200 Prozent gern vorstreckten. Dadurch gerieten die Leute selbstverständlich immer mehr in Schulden und Bedrängnis und oft gab alsdann das Drängen der Gläubiger Anlass zur Desertion. Das Desertieren war sehr leicht und häufig, weil die französische Grenze von Dahome in einer halben Stunde zu erreichen war. Um diesem Uebelstande vorzubeugen, wurde öffentlich bekannt gemacht, 
dass einem Soldaten kein Kredit gewährt werden dürfe und dass die Gläubiger bei etwaigen Gewaltmaassregeln gegen ihre Schuldner streng bestraft werden würden.

$\mathrm{Zu}$ meiner Zeit war man als einziger Weisser alles in allem. Man war sein eigener Kompagniechef, Exerziermeister, Zahlmeister, Auditeur, sogar sein eigener Kammerunteroffizier, dem die Aufsicht über die Schneiderei oblag, was bei der notwendigen Sparsamkeit nicht wenig zu schaffen machte. Die eine Garnitur Sachen war natürlich einer steten Metamorphose durch den Schneider unterworfen, und die Uniformen waren mit den verschiedensten Flicken besetzt, welche deutlich in ihrer Farbe je nach der Zeit ihres Daraufflickens von einander abstachen.

Die eigentliche Feuertaufe hat diese Truppe bei einem Aufstande in Tove 1895 erhalten, wo sie sich gut bewährt hat. A.ber ihren grössten Ruhm hat sie sich in dem Dagomba-Feldzug unter Führung des Herrn von Massow im Jahre 1896 erworben. Hier hat sie nach den Berichten ihres mutigen Führers einer gewaltigen Uebermacht an Kriegern sowohl zu Fuss als auch zu Pferde gegenüber gestanden und die Feinde nach einem heftigen gegenseitigen Feuerkampfe mit aufgepflanztem Seitengewehr in die Flucht gejagt. Leider hatte die Truppe bei diesem ruhmreichen Kampfe den Verlust ihres kühnen und bis zum letzten Atemzuge pflichttreuen Polizeimeisters Heitmann zu beklagen. Heute ist die Truppe mit der Besatzung auf den Stationen etwa 200 Mann stark. Ihre Uniform besteht jetzt in einer Bluse aus gelbem, rot eingefassten Drell mit roten Achselklappen. Die Kniehose aus demselben Stoff ist mit roter Biese versehen. Als Kopfbedeckung dient ein roter Fez mit dem Reichsadler.

Die Bewaffnung besteht auch heute noch aus der Jägerbüchse Modell 7 I und dem Hirschfänger, welcher an einem gelben Lederkoppel getragen wird. Ferner besitzt jeder Soldat zwei Patronentaschen mit 40 scharfen Patronen, einen wasserdichten aus Leinwand bestehenden Brotbeutel und einer Feldflasche. Anstatt unseres gerollten Mantels trägt unser schwarzer Kamerad ein Tuch aus Leinwand, das auch nach dem geflügelten Wort: „was nützt der Mantel, wenn er nicht gerollt ist" in einer Rolle über die Schulter getragen wird. Nach dem DagombaFeldzug ist auch noch ein Maximgeschütz eingeführt und der Truppe überwiesen worden. Heute steht an der Spitze der Truppen ein Offizier, dem 2 bis 3 weisse Unteroffiziere zugeteilt sind.

Die Musik trägt sehr zu dem militärischen Treiben in Lome bei. Jeden Morgen übt sie ihr aus etwa 8 Stücken bestehendes Repertoir ein. Ausser dem "Heil Dir im Siegerkranz" wird auch der Präsentiermarsch gespielt, wobei das Trommlerkorps zur Geltung kommt. Die ebenfalls vorhandenen Hornisten thun namentlich auf Expeditionen ihre guten 
Dienște, indem sie im Lager die Träger wie die Soldaten zusammenblasen und viel zu dem schnellen Aufbruch einer Expedition und der ganzen Führung derselben beitragen. Allabendlich wird der Zapfenstreich geblasen, worauf sich alles nach Hause zu verfügen hat; des Morgens ruft wiederum die Trompete oder der Wirbel einer Trommel zum Beginn der Tagesarbeit, so dass wohl jeder weisse Soldat selbst im tiefsten Innern von Afrika sich in das Soldatenleben der fernen Heimat zurückversetzt glaubt. Des Morgens zieht die Truppe mit klingendem Spiel von dem Gouvernementsgebäude durch die Strassen der Stadt zum Exerzierplatz und ebenso wie bei uns freut sich jung und alt bei dem Anblick unserer schwarzen Burschen; die Knaben folgen dem Zuge und ahmen dessen Exerzitien nach, und auch die jungen Damen des Landes blicken neugierig aus ihrem Versteck hinter den Palmenzweigen hervor und freuen sich, wenn sie ihren Geliebten nach dem Takte der Musik stramm in den Reihen marschieren sehen.

Die Verkehrsverhältnisse zwischen den Küstenplätzen sind leider DieVerkehrs. wegen des hohen Dünensandes sehr beschwerlich, so dass die Weiter- mittel und beförderung der Reisenden nur mittelst der Hängematte erfolgt. Dagegen die Verkehrsist Lome nach Quitta hin mit der englischen Kolonie durch den Telegraphen verbunden und hat somit Anschluss an das grosse Kabel, das über die kanarischen Inseln nach Europa führt. Ferner steht es ebenfalls in Verbindung durch Telegraph und Telephon mit unserer zweitgrössten Handelsstadt Klein-Popo und, da diese wiederum an Gross-Popo Anschluss hat, auch mit der französischen Kolonie Dahome. Weiter besteht auch eine Briefpost mit der englischen Goldküstenkolonie und der französischen Kolonie von Dahome. Jeden Mittwoch und Sonnabend früh um 8 Uhr geht ein schwarzer Briefträger von Klein-Popo über Porto Seguro und Bagida und trifft nach achtstündigem Marsch an der Küste entlang meistens um 4 Uhr nachmittags in Lome ein. Donnerstag und Sonnabend befördert er dann wieder die mitgegebene Post von Lome nach Klein-Popo, von wo aus jeden Dienstag und Donnerstag die Post zum Anschluss an die französischen Dampfer nach dem nächsten französischen Küstenplatz Agué gesandt wird. Diese Beförderung ist unter Umständen der mit unseren Dampfern vorzuziehen, da die französischen Dampfer von Kotonou, welche die Postsachen mitnehmen, weit früher als unsere Wörmann-Dampfer Europa erreichen. Sie legen die Strecke von Kotonou bis Marseille in I 8 Tagen zurück und somit gelangt die Kotonoupost etwa 8 Tage früher in die Heimat, während die WörmannDampfer über die kanarischen Inseln und Madeira im günstigsten Falle 4 Wochen laufen.

Auch über die englische Goldküste besteht ein Postanschluss, der Lome mit Quitta verbindet. In dem Betriebsjahre $1897 / 98$ haben 
236 Schiffe mit zusammen 296760 Registertonnen die Rheden von Lome und Klein-Popo angelaufen. Von diesen berührten die Rhede von Lome 60 deutsche, $3^{\text {I }}$ englische und 23 französische Dampfer, während nur I deutscher und 4 englische Segler dort vor Anker gingen. Die Rhede von Klein-Popo besuchten in demselben Zeitraum 56 deutsche, 40 englische, sowie I8 französische Dampfer und 2 deutsche Segelschiffe. $\mathrm{Ab}$ und zu legt auch ein deutsches Kriegsschiff in unserer Togokolonie an.

Drei Dampfer der Wörmannlinie vermitteln monatlich den Verkehr mit Togo. Am zwanzigsten jeden Monats geht von Hamburg aus der sogenannte Togodampfer ab, der dann am einundzwanzigsten bezw. zweiundzwanzigsten des darauffolgenden Monats in Lome eintrifft. Er hat hauptsächlich die Häfen der Togoküste und diejenigen von Dahome und der Goldküste anzulaufen.

Meistens jedoch sind es nur kleinere Dampfer von circa i 200 bis I 300 Tonnen Ladung, während der sogenannte Süddampfer, I 800 bis 2500 Tonnen fassend, der speziell für Kamerun bestimmt ist und der auch für Passagiere grösseren Komfort aufweist, am zehnten jeden Monats von Hamburg in See geht und am ersten oder zweiten des folgenden Monats je nach der Gunst des Wetters in Lome eintrifft.

Ferner geht noch am letzten jeden Monats oder am darauffolgenden Tage der sogenannte Südwestdampfer von Hamburg ab. Er berührt jedoch nur $\mathrm{ab}$ und $\mathrm{zu}$ die Rhede von Lome und bringt häufig nur Briefpost mit, die er dann auf hoher See dem avisierten Postboot abgiebt, um sofort seinen Kurs weiter zu dampfen.

Bei den ungünstigen Landungsverhältnissen ist es oft schwierig, die einlaufende Postsendung von der Heimat trocken an Land zu bringen. Diesem Uebelstande ist man jedoch bemüht abzuhelfen. Die Postpackete werden nämlich, wie die Briefbeutel an der Küste, in grosse Fässer eingeküfert und auf diese Weise sowohl gegen die Feuchtigkeit als auch gegen die Gefahr des Untergehens bei der oft mächtig hoch gehenden Brandung geschützt. Anders dagegen ist es mit dem Frachtgut der Kaufleute, weil der Quantität wegen dasselbe Verfahren nicht angewendet werden kann.

Der Postverkehr wird durch zwei weisse Postbeamte geleitet. In Lome befindet sich seit Verlegung der Landeshauptmannschaft das Haupt-Postamt, während in Klein-Popo nur ein Postamt besteht. Den weissen Beamten stehen 6 farbige Hilfsbeamte und 8 farbige Unterbeamte zur Seite: Die Thätigkeit dieser Postanstalten erstreckt sich auf alle Zweige, der Posteinrichtung mit Ausnahme der Absendung von Wertpacketen und Wertbriefen. Es wurden nach den statistischen Erhebungen im letzten Berichtsjahr 62592 Briefsendungen befördert, während die 
Zahl der Postpackete I 55 betrug. Ferner sind in dem gleichen Zeitraum I 546 Postanweisungen befördert worden. Die Zahl der im letzten Jahre ein- und abgegangenen Telegramme belief sich zusammen auf 4375 .

Das Telephon wurde in dem letzten Jahre 4027 mal benutzt. Diese Art der Verkehrsvermittelung hat sich in kurzer Zeit auch bei der schwarzen Bevölkerung eingebürgert. Durch den eigentümlichèn Zauber, den diese Art des Verkehrs für die Schwarzen hat, erfreut es sich einer ganz besonderen Beliebtheit und wird von einer grossen Anzahl, namentlich von Händlern, aber auch nicht selten von der weiblichen Bevölkerung zwischen Lome und Klein-Popo benutzt. Einen̉ komischen Eindruck macht es, wenn die nur wenig bekleideten schwarzen Töchter Evas von den schwarzen Gehilfen in der Handhabung dieses sonderbaren Fetischinstrumentes unterrichtet werden, und verklärt leuchtet ihr Gesicht auf, wenn ihnen aus weiter Ferne die wohlbekannte Stimme eines Freundes oder Verwandten antwortet.

Die Telegraphenleitung ist aus einem starken Gussstahldraht hergestellt und Mannesmannröhren bilden die Telegraphenstangen. Häufig erleidet natürlich auch dieses feste Material durch die Unbilden der Seestürme und durch die Witterung Schaden. Auch sollen sowohl nach Aussage der Beamten als auch nach der Ansicht der schwarzen Bewohner diese Drähte durch die aus dem Busch heraustretenden Affen beschädigt werden. Eine eigentliche Vorstellung von dem Zweck dieser Drähte scheint bei den meișten Schwarzen absolut nicht vorhanden zu sein. Als einem Kruboy, der in Klein-Popo gestohlen hatte und auf telegraphische Requisition wieder in Lome angehalten und festgenommen war, seitens des betreffenden Beamten gesagt worden war, der Fetisch hätte per Draht zu ihm gesprochen, dass er der Dieb sei, erwiderte er naiv, er werde bei der nächsten Gelegenheit nicht mehr so dumm sein und werde, bevor er wieder ausreissen würde, erst den Draht durchschneiden.

Für den Verkehr höchst wichtig ist die grosse von Lome nach Misahöh führende Strasse. Wie schon vorerwähnt, ist sie nicht gepflastert, aber zum grössten Teil frei von Busch und Gestrüpp und an den Seiten zum Ablaufen des Wassers mit Gräben versehen. Die Strasse ist durchschnittlich vier Meter breit und gestattet mehreren Personen bequem nebeneinander zu gehen. Leider ist es jedoch Gewohnheit der Schwarzen im Gänsemarsch zu marschieren. Daher muss die Strasse häufig gereinigt werden, damit sie nicht in ihren früheren Zustand verfällt und sich zu einem kleinen Pfade verengt. Zu diesem Zwecke sind in Akeppe wie in Keve Wegeaufseher stationiert. Weiter im Innern aber ist von der Station Misahöhe aus ein anderes Verfahren eingeführt worden, indem man nämlich die Häuptlinge der einzelnen Ort- 
schaften verpflichtete, selbst den Weg in ihrem eigenen Gebiete in Ordnung zu erhalten, wofür sie von der Station entschädigt werden.

Diese Strasse ist von Lome bis Gbin etwa Ioo $\mathrm{km}$ fertig gestellt, während man von Gbin aus bis nach Agome-Palime auf einem sogenannten Negerpfad durch die grosse Gbin-Ebene marschieren muss. Von letztem Orte beginnt dann wieder die bis zur Station Misahöh und darüber hinaus führende Kunststrasse, welche von der Station aus angelegt ist. Dieselbe Strasse vermittelt auch den Postverkehr in das Innere; jeden Monat geht ein Postbote, öfters auch ein Geldtransport, dem zur Bewachung Soldaten beigegeben sind, von Lome aus über die Station. Natürlich haben die Postboten mit den Unbilden der Witterung und den Elementen zu kämpfen; häufig kommt es, besonders in der Regenzeit vor, dass die grossen Ströme und zahllosen Bäche und Flüsse ihren Marsch verzögern oder auch namentlich im tiefen Hinterlande wochenlang hemmen. Nicht selten ereignet es "sich, dass auf den entfernten Stationen, wie Mango und Shautsho die Post sich um einen ganzen Monat verspätet.

Ein grosses Verkehrshindernis bilden, wie schon erwähnt, die ungünstigen Küstenverhältnisse, welche durch den Guineastrom und die vorgelagerten Felsenriffe öfter das Löschen der Güter unmöglich machen. Bei hoher Brandung kann es vorkommen, dass beinahe jedes zweite Boot umschlägt und so alle Mühe und Arbeit vergeblich ist. Eine der heikelsten Waren ist das Salz, welches einer der wichtigsten Handelsartikel in den salzarmen Gegenden des Hinterlandes ist. Nur ein paar Brecher, das Boot schlägt um und die ganze Ladung ist verloren. Aehnlich ist es mit Zement, der schon durch die Feuchtigkeit fast ganz entwertet wird. Auch bei der Landung von Kalk besteht ein Risiko für den Kaufmann. Wird er gelöscht gelandet, so ist zwar das Risiko geringer, aber der erhöhte Preis drückt den Gewinn derart, dass der Kaufmann oft spekulieren muss. Sind die Fässer, in welchen der Kalk verfrachtet wird, nicht sehr solide gearbeitet, so gerät beim Kentern sowohl das Boot als die Bemannung in Gefahr, durch das nun entfesselte Element zu verbrennen. Die schwarze Mannschaft springt in einem solchen Falle aus dem Boot, welches rauchend und zischend an Land treibt und bietet alles auf, die noch nicht gefährdeten Fässer aufs Trockene zu bringen. Auch Pulver zu landen ist unter diesen Verhältnissen ein undankbares Geschäft.

Es ist daher sehr erfreulich, dass endlich durch den Bau einer Landungsbrücke diesen Uebelständen abgeholfen werden soll. Der Bau dieser Brücke soll wie der der Landungsbrücke von Kontonu ausgeführt werden. Die Brücke soll bis über die verderbenbringenden Brecher hinausgehen und in einer sogenannten Landungsbrücke endigen, 
auf welche dann die Boote unter normalen Verhätnissen ruhig und ohne Gefahr die ankommenden Güter verladen können. Natürlich würde eine solche Brückenanlage nur der Stadt Lome Vorteil bringen, dagegen die Gefahr für Klein-Popo nahe liegen, dass dieser so wichtige Ort noch mehr vereinsamen würde.

Es ist deshalb auch der Bau einer Bahn geplant worden, die den Verbesserun.r Verkehr zwischen den Küstenorten und unserer zweitgrössten Stadt der Verkebrs. Klein-Popo im Osten des Gebietes vermitteln soll. Dadurch würde wege durch zugleich ein Aufleben der jetzt fast ganz verlassenen Orte Bagida und Porto-Seguro stattfinden. Ein Erfolg versprechendes Projekt dieser Art anzulegende Bahnen ist von der Firma Vehring \& Wächter vorgelegt worden, nach welchem die Verbindung der Landungsbrücke durch kleine Kippkarren direkt mit den Gehöften der einzelnen Faktoreien vermittelt werden soll. Es ist wünschenswert und auch höchst erforderlich, dass der Bau einer Bahn nach dem Hinterlande recht bald ausgeführt wird. Die Torarbeiten für eine solche bis nach Kpanelo sind durch eine Expedition der Firma Vehring \& Wächter schon bewirkt worden.

Infolge der unglücklichen Lage unserer Grenze im Westen des Gebietes mit der englischen Goldküstenkolonie sind wir von jedem Verkehr an der Mündung des grössten Stromes in dieser Gegend, von dem wir in der Höhe von $6^{\circ} 4^{\prime}$ nördlicher Breite nur das linke Ufer besitzen, vollkommen abgeschnitten; es ist deshalb geboten, dass unsererseits alle Anstrengungen gemacht werden, dort eine bessere T'erkehrsstrasse, als es der. Volta mit seinen Katarakten ist, zu schaffen. Es ist dies um so notwendiger, als auch die Engländer bemüht sind, die Mündung des Volta für grössere Schiffe schiffbar zu machen und dadurch den Verkehr auf dem Volta besser zu gestalten.

Nach dem letzt erwähnten Projekt der Firma Vehring \& Wächter soll diese Bahn auf der grossen Strasse bis nach Kewe gehen. Von dort aus sind drei zum Volta führende Linien vorgeschlagen.

Die eine soll direkt weiter auf der Strasse bis Keve führen und dann durch das Thal, welches der Aehä in das Agomegebirge schneidet, über Kpando zum Volta gehen.

Die zweite Linie soll von Keve aus westlich bis zur Grenze von Akrofá, von hier aus nördlich der Grenze gehen, dann weiter nordwestlich in der Nähe von. Avatime die südwestlichen Ausläufer des Agomegebirges überschreiten und über Kpando an den Volta führen.

Ein dritter Plan besteht darin, die Bahn auf dem jetzt beschriebenen Wege bis zum $6^{\circ} 4^{\prime}$ nördlicher Breite und von hier aus in westlicher Richtung über Kpeve an den Volta zu führen. Auf diesen projektierten Strecken ist das lästige Agomegebirge umgangen und somit ein schwacher Punkt in dem Bau dieser Bahn beseitigt. 
Eine andere grosse Schwierigkeit bietet das Beschaffen des Feuerungsmaterials für die Maschinen. Kohle, welche bis jetzt leider an der ganzen Westküste von Afrika noch nicht aufgefunden worden ist, würde dem Betriebe erhebliche Kosten bereiten. Man bleibt daher nur auf das allerdings fast überall vorhandene Holz angewiesen. Auch ist bereits daran gedacht worden, sich die Kräfte von Wasserfällen nutzbar zu machen und darauf hin hat man auch den Krednerfall von dem Aka, einem kleinen rechten Nebenfluss des Sio, untersucht. Leider söllen sich aber bei dieser Untersuchung die Wasserkräfte zum Betriebe einer elektrischen Eisenbahn als zu schwach erwiesen haben. Aus diesen Gründen hat die Firma Vehring \& Wächter den Bau einer Bahn vorgeschlagen, die durch Menschenkräfte bewegt werden soll und zwar durch Treten. Obwohl eine solche primitive Bahn schon einen Fortschritt in der Verkehrsvermittelung bedeuten würde, weil je ro Trägerlasten durch die Kraft eines Mannes befördert werden könnten, so wäre doch zu wünschen, dass auch hier eine Bahn mit elementarem Kraftbetrieb gebaut werden könnte.

Um die Kosten einer Bahn möglichst herabzusetzen, hat die Firma den interessanten Vorschlag gemacht, dieselbe auf eisernen Böcken zu bauen, wodurch die Unebenheiten des Terrains ausgeglichen und die Kosten für Anschüttung und Ausgrabung erheblich vermindert werden sollen. Günstiger vielleicht würde sich der Bau einer Bahn bis Kpando und dann weiter, dem Voltathale entlang, bis Kratyi erweisen - was natürlich erhebliche Mehrkosten verursachen würde. Leider aber ist unser Reichstag nicht immer geneigt, den erst in Zukunft Früchte tragenden kolonialen Unternehmungen diẹ durchaus erforderlichen Mittel zu bewilligen. Kratyi, der Haupthandelsplatz in dem Hinterlande unserer Togo-Kolonie, ist ein Stapel- und Durchgangspunkt für sämtliche Produkte aus dem Hinterlande. Hier ist auch die Verladungsstelle der Erzeugnisse, die auf dem Volta mittelst Kanoes herunterkommen und weiter auf dem Wasserwege zur Küste befördert werden sollen. Sollte die Bahn nur bis Kpandu führen, so müsste der Schwarze, wenn er zum Transport die Bahn benutzen wollte, seine Produkte umladen; ehe er sich aber der Arbeit einer wiederholten Verladung unterzieht, wird er es vorziehen, sein Kanoe weiter auf dem Volta nach der Küste treiben zu lasseṇ.

Immerhin würde aber auch der Bau einer Bahn bis Kpandu einen bedeutenden Aufschwung des Handels zur Folge haben, insbesondere die fruchtbaren Gegenden, welche sie durchschneidet, für die Anlagen von Plantagen erschliessen. Ehe man jedoch mit dem Bau einer Bahn beginnt, dürfte es unbedingt erforderlich sein, dass zunächst eine Landungsbrücke errichtet wird; denn ohne eine solche würde es schwer 
sein, das nötige Material wie Maschinen u. s. w. an Land zu schaffen. Auch ein Leuchtturm würde in Verbindung mit dieser Landungsbrücke ron höchstem Nutzen sein. Nicht selten kommt es ror, dass des Nachts die Schiffe an unserer Togoküste ihr Ziel verfehlen. Sie fahren in der Dunkelheit weit über Bagida hinaus und gehen dort irrtümlicher Weise vor Anker, um bei Tagesanbruch dann wieder an den eigentlichen Bestimmungsort Lome zurückzudampfen. Oefters auch gehen sie schon weit rorher vor Anker und gelangen mitunter in das Bereich der gefürchteten Brecher. Aus diesen Gründen würde eine Landungsbrücke und ein Leuchtturm für Lome von unendlichem Vorteil sein und dasselbe als Ankerplatz an der westafrikanischen Küste eine der ersten Rheden werden.

Zweifellos würde auch eine Bahn im Osten unseres Schutzgebietes von hoher Bedeutung sein, deren baldiger Bau um so wünschenswerter wäre, als in neuester 'Zeit die französische Regierung von der Küste nach Abome, der Residenz der alten Könige von Dahome, eine Bahn baut. Obwohl uns schon im Osten durch den letzten Pariser Vertrag ein grosser Gewinn dadurch erwachsen ist, dass das französische Dreieck im Osten des grossen Monoflusses bis zur Lagune hin und die freie Schifffahrt auf dem Mono und dieser Lagune in unsere Hände übergegangen ist, so würde es selbstverständlich von grossem Vorteil sein, wenn die bisher so wenig zugänglich gemachten Gebiete im direkten Hinterlande von Klein-Popo, sowie die Ebene des Hao und vor allem das an Erzeugnissen reiche Atakpamegebiet durch eine Bahn erschlossen würden. Die neu angelegte Station in Atakpame würde dann auch ihre handelspolitische Aufgabe leichter erfüllen können. Durch den Bahntransport könnten die jetzt bei der weiten Entfernung wertloseren Kernerprodukte lohnend verwertet werden; die Viehzucht würde in dem viehreichen Atakpame sich noch steigern und das Vieh einen sich aufs höchste lohnenden und rentablen Absatz an der Küste finden. Dem lange fühlbaren Fleischmangel an der Küste würde ebenfalls abgeholfen und auch den Schiffen an der westafrikanischen Küste würde eine günstige Gelegenheit geboten werden, sich zu proviantieren. Mit dem Aufschwung der Viehzucht würde vielleicht auch ein Viehexport aus unserer Togokolonie, wenigstens nach den benachbarten Kolonieen lohnend werden. Auch ein neuer Handelsweg im Osten des Gebietes könnte dann nach dem reichen Tshautsho und dem Kotokoliland, wie es die Haussa nennen, leichter angebahnt werden. Dem Mangel an Trägern auf der grossen Karawanenstrasse über Kete würde ebenfalls abgeholfen und neue Gebiete wie Strassen dem Handel erschlossen werden. 


\section{KÜSTENMARSCH.}

Wir verlassen nun die Metropole Lome und gehen an dem Strande entlang nach -Klein-Popo. Die Hängematte, in deren Herstellung die Eingeborenen sehr geschickt sind, ist bei dem tiefen Sande das einzige und beste Beförderungsmittel, welches im allgemeinen von den Europäern, sei es von Kaufleuten, Beamten oder Missionaren am meisten benutzt wird. Eine solche Hängematte besteht gewöhnlich aus einer starken 'Stange, die einer Kokospalme oder Oelpalme entnommen und an der die eigentliche Hängematte befestigt ist. Zum Schutze vor den brennenden Sonnenstrahlen und dem blendenden Sande ist über derselben ein sogenanntes Sonnensegel angebracht. Die Hängematte wird von vier kräftigen Schwarzen auf dem Kopfe getragen. Als Unterlage für den Kopf dient ihnen meistens ein zusammengerolltes Tuch, welches sie bei Nacht als Schlafdecke benutzen. Diese Hängemattenträger sind vorzugsweise in Lome und Klein-Popo gut zu haben. Nachdem man sich acht Träger, von denen immer vier abwechselnd tragen, gemietet und pro Mann und Träger von Lome bis Klein-Popo den hohen Lohn von 8 Mark gezahlt hat, geht die Reise vorwärts.

Zumeist wählt man zu derselben die Zeit der Ebbe, um den festen Sand am Strande benutzen zu können. Nicht selten wird auch die Nacht zur Reise gewählt, weil es dann kühler ist und der grell leuchtende Sand und die spiegelnde Fläche des Meeres die Augen weniger angreifen. Im Geschwindmarsch der vier schwarzen Träger geht es zur Stadt hinaus, hart am Strande, so dass nicht selten die Füsse der Träger von dem Meerwasser bespült werden. Der Strand bildet bei der Ebbe den besten Verbindungsweg zwischen den Küstenplätzen, denn durch die fortdauernde Brandung ist der hohe Dünensand festgepeitscht und gewährt so, abgesehen von der Feuchtigkeit, die unseren schwarzen unbeschuhten Trägern aber nicht schadet, einen ganz vorzüglichen Pfad. Bei guter Beschaffenheit des Weges schlagen die geübten Träger eine Gangart an, die einem Hundetrab nicht unähnlich ist, und halten dieses Tempo oft lange Strecken aus, bis die wiederkehrende Brandung ein langsameres Tempo gebietet. Zur Linken hat man die hoch abfallenden Dünen mit 
ihren unterwaschenen Höhlen; eine Windenart von spärlichem Wuchs überzieht den Boden, weiterhin beginnt der niedrige Busch, der bald eine Höhe bis zu $2 \mathrm{~m}$ erreicht und vollständig undurchdringlich wird. Derselbe zieht sich in dieser Weise weiter an der Küste bis zur Lagune hin.

Nach einstündigem Marsche erreicht man die kleine Fischerniederlassung Ablogame. Hier wird eine kurze Rast gemacht, um den Trägern Gelegenheit $z u$ geben, an dem Brunnen, der aus einem gegrabenen Loch besteht, mit dem brackigen Wasser ihren Durst zu löschen.

Netze sieht man überall am Strande ausgebreitet. Ausserdem aber haben hier die Leute noch einen eigentümlichen Fischfang. Dicht am Strande ist ein Stock in den Sand gesteckt und an demselben eine Kalabasse befestigt, mit der Oeffnung nach oben. Tritt nun die Flut ein, so werden diese kleinen Fangapparate überflutet, kleine Fische und Krabben fangen sich in den Behältern und fallen dem Fischer zur Beute.

Viele Mören und zahllose Strandläufer bevölkern den Strand; auch trifft man des Nachts häufig die grossen Seeschildkröten an, vor denen man sich in der Dunkelheit in acht nehmen muss, um nicht über sie zu fallen. Diese Schildkröten haben eine Länge von I bis $\mathrm{I}^{\mathrm{I}} \mathrm{z}_{2} \mathrm{~m}$ und eine Breite von $1 / 2 \mathrm{~m}$. Håufig kommen siẹ bei mondhellen Nächten an Land und können hier erlegt werden. Ich bereitete meinen Schwarzen durch den Fang eines solchen Tieres grosse Freude. Wie die Raben stürzten sie sich darauf und lösten das Fleisch ab, um es bei der nächsten Station, dem Orte Bagida, zu rösten und in Ruhe zu verzehren.

Schon von weitem sieht man zwar die grossen Dächer der Faktoreien, aber unendlich lang und eintönig erscheint einem dieser Küstenmarsch. Nur die einzelnen Telegraphenstangen bilden einen Anhaltspunkt für den noch zurückzulegenden Weg. Eine interessante Abwechselung bieten die kleinen Strandvögel oder auch die kleinen Schaaren der sogenannten Taschenkrebse, die bei dem Annähern der Karawane emsig wieder in's Wasser krabbeln. Grosse Schweinsfische schnellen aus dem Meere empor und jagen in Windeseile vorbei. Ab und $\mathrm{zu}$ taucht auch die typische Rücken- oder Schwanzflosse eines Haies aus den schäumenden Fluten. Möven und Seeschwalben schweben über den Wogen und netzen sich in den Fluten, während am Strande schwarz- und weissgefiederte Raben krächzen und hoch in der Luft Habichte kreisen, um nach Beute zu spähen. Tintenfische sowie Muscheln lagern in allen Formen und Gestalten auf dem Strande und zur Rechten braust und schäumt die unermüdlich immer wiederkehrende Brandung. Des Nachts dagegen ist alles ruhig und still, nur die Infusoriae phosphorescentes beleuchten mit ihrem magischen Scheine die rauschenden Fluten. Noch eine Rast und in der Zeit von zwei Stunden ist der erste, langersehnte Küstenplatz von Bagida erreicht. 

platz Bagida. umfangreichen Gehöfte $a b$, in welchen die grossen, geräumigen, aber zerfallenen nnd verödeten Faktoreien liegen. Statt der grossen Brandungsböte sieht man hier die kleinen Kanoes der Fischer am Strande liegen und zwischen diesen die zum Trocknen ausgespannten Netze hängen.

Ueberall ragen aus den verlassenen Gehöften grosse, schöne Kokospalmen hervor, die an die frühere Thätigkeit und den Fleiss der hier vor Zeiten angesiedelten Europäer erinnern. Eine grosse Strasse führt vom Strande durch das Dorf zur Lagune. An derselben steht dicht am Strande das grosse Gebäude der Vietor'schen Faktorei, in der ehemals ein reger Betrieb geherrscht hat. Weiter vom Strande ab liegt noch ein Laden der Oloff'schen Faktorei, der für die geringen Bedürfnisse der hier ansässigen Eingeborenen ausreicht und dem die Küste entlang kommenden Reisenden und Händler eine kleine Erfrischung gewährt. Weiterhin ziehen sich die Wohnungen von schwarzen Händlern, die zum Teil noch mit dem Hinterlande der Lagune und mit den Orten am Togosee - wie Degbo und Abobo - in Handelsbeziehungen stehen. Palmenkerne und Oel sind die einzigen Produkte, welche hier gehandelt nnd teilweise zur Trockenzeit von den nicht allzuweiten Dörfern Abobo und Degbo auf dem ausgetrockneten, durch die Lagune führenden Pfade gebracht werden, während die meisten dieser Produkte mittels Kanoes über den Togosee und die Lagune nach KleinPopo gehen. Jetzt werden diese Plätze nur von schwarzen clerks besorgt, während früher, in den ersten Jahren der kaufmännischen Niederlassung, hauptsächlịch Weisse hier thätig waren. Bagida war der Sitz und die Residenz des nach der Besitzergreifung von Togo im Jahre I 885 ersten kaiserlichen Kommissars von Falkenthal.

Heute bietet das grosse Gebäude der Faktorei von Victor dem Weissen, der den mühsamen Strandweg zurückgelegt hat, gastfreie Aufnahme, denn hier wird häufig über Nacht geblieben. Betritt man das Gehöft, so gelangt man in einen prachtvollen Hain von Kokospalmen, in welchem nach der See zu das grosse, aber zerfallene Gebäude der ehemals so stolzen Faktorei liegt. Ein für die jetzigen Verhältnisse viel zu grosser Speicher ist für die Aufnahme der Handelsprodukte wie Oel und Palmenkerne, die hier gegen die bekannten europäischen Erzeugnisse oder Geld eingetauscht werden, bestimmt. Alte Reifen und Ueberreste zerfallener Tonnen erinnern an den früheren grossen Handelsverkehr.

Ein bedeutender Rückgang in demselben trat hier ein, als der Sitz der Regierung von Bagida in die Nähe der Handelscentrale von KleinPopo nach Sebbe verlegt wurde. 
$\mathrm{Ab}$ und zu läuft noch auf besonderen Wunsch der Hauptagenten der in Lome oder Klein-Popo ansässigen Firmen ein Dampfer in Bagida an, der dann den seit Monaten aufgespeicherten Vorrat von Palinenkernen zur Verladung nimmt. Natürlich können die geringen Einnahmen der Faktorei in Bagida nicht die Mittel für Unterhaltung und Instandsetzung der grossen Gebäude abwerfen. Aus diesem Grunde werden fast sämtliche Reparaturen, die nicht von den Eingeborenen selbst ausgeführt werden können, unterlassen. Die scharfe Seebrise trägt auch nicht wenig zu dem immer mehr fortschreitenden Verfall dieser Gebäude bei und über kurz oder lang werden nur noch Trümmer an die frühere europäische Niederlassung erinnern.

Nachdem wir hier Nachtquartier genommen hatten, marschierten wir am folgenden Tage weiter am Strande entlang. Einer der schwarzen Begleiter riss uns aus unseren Betrachtungen mit dem Ausrufe: „Massa, Massa, one steamer" und richtig sah man am fernen Horizont eine Rauchwolke dahinziehen; nach und nach wurden die Umrisse eines grossen Dampfers erkennbar, der bald in voller Majestät an uns vorbei dampfte. Man erkannte an dem Schornstein die grün-weiss-blauen Farben; der graue Rumpf und die deutsche Flagge am Heck zeigten einen Wörmann-Dampfer, aus der Heimat kommend, an.

Die Hoffnung, Briefe oder sonstige Nachrichten von den Eltern oder Angehörigen aus der geliebten deutschen Heimat zu erhalten, spornte die ermatteten Kräfte um so mehr an, das Ziel zu erreichen. Rüstig ging es nun vorwärts und in $1 \% \frac{2}{2}$ Stunde ist ein kleines Fischerdorf, das nur eine Fischerfamilie beherbergt, erreicht. Erschöpft lässt man sich am Strande in der Sonne nieder, trinkt das wenig gute Wasser und erfrischt geht es dann mit den Trägern immer weiter an der Küste entlang, den Dampfer verfolgend, der in Porto-Seguro, unserem nächsten Ziel, nicht anläuft, sondern stolz vorbei nach seinem Bestimmungsort Klein-Popo steuert.

Allmählich kommen auch die wenigen hohen Bäume von Porto- Porto-Segurc Seguro in Sicht; das weisse Gebäude der katholischen Mission leuchtet aus dem Dunkel hervor und ladet uns gastfrei zu einem Besuche ein.

Immer näher und näher rückt das Dorf heran und in etwa zwei Stunden wird es nach einem erschöpfenden Marsche erreicht. Man lenkt natürlich seine Schritte zu den einzigen Weissen des Ortes, den katholischen Missionaren. Dort wird man freudig ron dem Pater und den Brüdern begrüsst und gastfrei zu dem frugalen, aber guten Mahle eingeladen. Ausnahmsweise giebt es hier Bier, wobei die Brüder und Patres beweisen, dass auch sie vergnügt mit dem Gaste die Becher schwingen können. 
Dicht am Strande ist die Mission gelegen: ein Holzkreuz ziert das Dach. Im unteren Raume befindet sich die Kirche, während im Oberstock die Brüder wohnen. Eine um das Gebäude herumlaufende Veranda gewährt eỉnen angenehmen Aufenthalt. Gegenüber der Mission am Strande liegt noch die alte Faber'sche Faktorei, sowie diejenige der Gebrüder Regis. Beide Faktoreien sind jetzt ebenfalls von den Europäern verlassen und werden von schwarzen Angestellten verwaltét.

Weiter am Strande, nach dem Togosee zu, liegt die eigentliche Stadt der Eingeborenen, die Residenz des alten King Mensa beziehungsweise seiner Nachfolger. Durch viele Kaktushecken winden sich die engen Strassen an dem Palaste des Königs vorbei und führen im Norden an den Togosee.

Die Häuser sind aus Lehm aufgeführt, zum Teil in europäischem Stil; manche haben einen Oberstock mit Veranda.

Die Söhne des alten King, die sich den Titel „Prinz" beilegen, sind hier als Händler ansässig und haben sich vermittelst des ihnen von europäischen Faktoreien gewährten Kredits kleine Faktoreien erbaut. Sie sind allerdings eigentlich nur Unterhändler für die Firmen in KleinPopo, denen gegenüber sie zur Abführung der Produkte verpflichtet sind.

Einen komischen Eindruck machte früher das Gehöft des alten King Mensa, Man gelangt zu. diesem durch einen grossen Thoreingang, an dem rechts und links die sogenannten Soldaten stehen; diese sind kleine Thonfetische, die den Eingang bewachen sollen, damit kein böser Geist das Gehöft betritt. Hier befinden sich die Schuppen und die Wohnungen der schwarzen Unterthanen, welche die königliche Familie zu bedienen haben. Nach Norden zu steht ein grosses Gebäude, das ebenfalls in den unteren Räumen Schuppen und Wohnungen enthält. Nach dem Oberstock führt ein Treppenaufgang, von welchem man in die Gemächer des Königs gelangt. Hier begregnet einem freundlich der alte König; die mit ihm geführten Unterredungen betreffen meistens die Anwerbung von Trägern. Bei solcher Gelegenheit wurde dem Gaste eine Kalabasse mit Palmenwein vorgesetzt, der in alten, zum Teil zerschlagenen und schmutzigen Gläsern kredenzt wurde; so beschaffen ist der Glanz an dem fürstlichen Hofe eines Negerhäuptlings.

Eigentümlich waren die Gemächer ausgestattet. Die alten europäischen Möbel bestanden aus einem Tisch, einem Sopha und einem Lehnstuhl. An den Wänden hingen alte Fetiśchamulette, Perlen, Kaurimuscheln, Federn von weissen geopferten Hühnern, die bekannten roten Schwanzfedern des grauen Papageis, alte Kalabassen und zerbrochene europäische Gefässe. Die grossen, nach dem Hof führenden Fenster sind wie in den ähnlich gebauten, sogenannten schwarzen Faktoreien durch einfache Holzläden verschlossen. 
Weiterhin befindet sich ein sogenanntes Fetischhaus, in welchem die Yevepriester ihr Unheil stifteten. Ein dichter Mattenzaun und eine Kaktushecke verschliessen dem Vröübergehenden den Einblick.

Verlässt man im Norden die Stadt, so gelangt man auf einer schwachen Anhöhe an den schönen und breiten Togosee. Von hier aus sieht man das Dorf Togo auf den Höhen des nördlichen Seerandes. und auf einem erhöhten Punkte die Zweigniederlassung der schon vorerwähnten katholischen Mission. Abends kann man von der Veranda der Mission die Lichter von Togo betrachten.

Was die Faber'sche Faktorei anbetrifft, so wurde diese von einem Schwarzen, namens Wilson, verwaltet, der im Jahre 1885 als Geisel in Berlin weilte und auch die Ehre hatte, unseren alten Reichskanzler, den Fürsten Bismarck zu sehen. Jedesmal, wenn man Wilson traf, erzählte er von seinem alten Freunde, dem Fürsten Bismarck und erkundigte sich, wie es ihm ginge. Natürlich war die Freude sehr gross, wenn man ihm sagte, dass Fürst Bismarck seinen alten Freund Wilson grüssen lasse.

Porto Seguro ist einer der ältesten Orte dieser Sklavenküste, denn schon lange vor der deutschen Schutzherrschaft war er eine wohlbekannte portugiesische Rhede für, die schwarze Ware, wie der Name Porto Seguro besagt. Aus denselben Gründen wie Bagida hat auch Porto Seguro an Bedeutung gegenwärtig sehr verloren und erst die fortschreitende Kultur wird hier Wandel schaffen. Allerdings hat Porto Seguro durch seine günstige Lage an dem Togosee einen grossen Vorteil, weil es dadurch in Verbindung mit dem naheliegenden Hinterlande steht. Es kommen deshalb auch zeitweise Palmenkerne und -Oel auf die anliegenden Dampfer zur Verladung.

Wir lenken nun unsere Schritte weiter unserem Ziele zu und in einer halben Stunde erreichen wir die grosse Kokosnussplantage Kpemme. Ein Bestand von etwa 33000 Kokosnussbäumen bedeckt die mächtige Fläche dieser Plantage. Ihr Gebiet erstreckt sich von der Küste fast bis zur Lagune. Ausser den Kokosbäume sind noch versuchsweise andere Pflanzen, wie der bekannte Gummibaum Manihot glaziovii, sowie Kickxia angepflanzt worden. Ein schön angelegtes Europäerhaus ziert den Strand. Dieses, seit langer Zeit verlassen, wird jetzt wieder von einem europäischen Gärtner bewohnt, welcher die Plantage in Ordnung hält und verwaltet.

Wir ziehen an dem stattlichen Gebäude, welches ganz nach Art der europäischen Gebäude der Faktoreien von Lome erbaut ist, vorüber und erreichen in drei Viertelstunden das kleine, in einem Kokoshain reizend gelegene Fischerdorf Gumkovhe. Die Bewohner sind auch hier meistens Fischer, die bei unserem Eintreffen friedlich unter melancholischen 
Gesängen ihre Fischerboote und Netze in Ordnung brachten. Wir ruhten auf einen Kanoe aus und liessen uns einen Trunk frischen Wassers reichen.

Nach kurzer Zeit wurde wieder aufgebrochen und der Marsch mühsam bis über die Knöchel im Sande weiter fortgesetzt.

Schon von Ferne erblickten wir die Rhede von Klein-Popo, wo bereits unser alter Freund aus der Heimat, der Wörmanndampfer, welchen wir in Porto Seguro vorbeidampfen sahen, vor Anker lag. Bald zeigten sich auch die Umrisse des grossen Krankenhauses von Popo; die Flaggen der Faktoreien wurden sichtbar und nach eineinhalbstündigem Marsche hatten wir unser Ziel erreicht. Ich wurde von meinem alten Freund, dem späteren Leiter der Zollbehörde Joop, freudig begrüsst und gastfrei aufgenommen. Leider ist auch dieser bewährte und beliebte Mann des Schutzgebietes im Jahre 1897 dem Klima zum Opfèr gefallen.

\section{KLEIN-POPO.}

Klein-Popo zieht sich weit hin von Westen nach Osten am Strande entlang; es ist erbaut auf den Dünen, die hier das Meer angespült hat. Hinter diesem Landstreifen, der durchschnittlich etwa nur eine Breite von 100 bis $150 \mathrm{~m}$ hat, befindet sich die Lagune. Im Westen der

Das Stadt liegt das schöne und grosse Gebäude des Nachtigal-Krankenhauses, Nachtigal- das gleichsam ein Denkmal für unseren verdienstvollen Reisenden NachKrankenhaus tigal bildet. Die Anregung zu dem Bau dieses, für die sanitären Verund die hältnisse in unserer Kolonie ausserordentlich segensreichen Krankenhauses, gab die Nachtigal-Gesellschaft. Diese hat durch langjährige Sammlungen ein bedeutendes Kapital zusammengebracht, welches in hochherziger Weise durch die Regierung erhöht worden ist. Die Anlage besteht aus einem grossen viereckigen Gebäude, das von einer freundlichen Veranda geziert wird. Neben den Krankenzimmern für die Europäer enthält es auch Wohnräume für den Arzt. In dem unteren Geschoss befinden sich das Speisezimmer und die Apotheke mit Sprech- und Verbandzimmer. Ausserdem wohnen dort die stets hilfsbereiten schwarzen Diener und Dienerinnen. Im oberen Stockwerk liegen die Krankenzimmer, die einfach, jedoch gut eingerichtet sind und je zwei bis vier Betten zur Aufnahme von Kranken enthalten.

Ausserdem befindet sich noch in einem besonderen Gebäude das Lazarett für die Schwarzen. Die Pflege die hier den Kranken zu Teil wird, und die Tüchtigkeit des Stabsarztes Dr. Wicke hat den Ruf dieser Krankenanstalt weit über die Grenzen unseres Togogebietes verbreitet. 
Aus weit entlegenen Ortschaften, aus Grand-Popo, aus Weyda, ja noch weiter her werden europäische Kranke, auch reiche Schwarze und Mulatten hierher gebracht; selbst aus dem englischen Gebiet, aus Quitta, suchen Kranke Hilfe und finden hier häufig Genesung.

Ein schwarzer Lazarettgehilfe unterstützt den Arzt bei den Handreichungen, beim Verbinden u.s. w., während die Pflege der Kranken hauptsächlich den bewährten Schwestern vom roten Kreuz obliegt, die sich derselben opferfreudig und unermüdlich widmen und dem Kranken

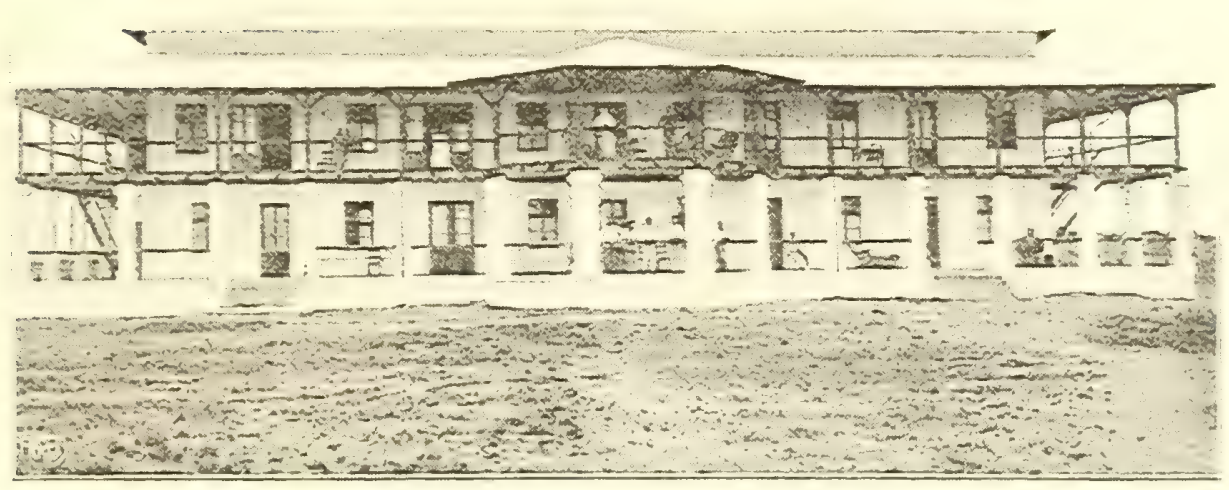

Das Nachtigal-Krankenhaus in Klein-Popo.

auf dem einsamen Lager durch ihre Unterhaltung, Zerstreuung und Linderung der Qualen schaffen.

Auch ich selbst habe diese Wohlthaten erfahren, denn ich fand hier nach meiner Salagareise, auf der ich von dem schleichenden Malariafieber befallen wurde, gute Pflege und Genesung. Die kräftige, hier beständig wehende Seebrise, sowie die gute Kost und Behandlung verfehlten ihre Wirkung nicht.

Die breite, schattige Veranda, von der man dem Brausen des Meeres lauschen und sich an dem Anblick der hohen Brandung erfreuen kann, grewährt reichlichen Schutz vor den Sonnenstrahlen. Nan freut sich hier wieder einmal mit weissen Damen bei einer Tasse Thee oder Kakao über die ferne Heimat Gedanken austauschen zu können. 
Noch nachträglich bei Bearbeitung dieses Buches trifft die traurige Nachricht ein, dass der verdienstvolle und allbeliebte Dr. Wicke aus seinem segensreichen Wirken durch den Tod abberufen und dem Klima zum Opfer gefallen ist. Der Heimgang dieses tüchtigen Tropenarztes ist ein grosser Verlust fur die Kolonie, welche sein Andenken stets dankbar bewahren wird.

Auch die schwarzen Rekonvaleszenten befinden sich in dem kleinen einfachen, aber schön und sauber eingerichteten Lazarett, wenn sie das schwere Krankenlager verlassen haben, gewiss wohler denn je: Häufig sieht man sie promenieren oder behaglich auf den Bänken vor dem Lazarett ihren Tabak schmauchen. Merkwürdig ist im allgemeinen die Konstitution dieser Schwarzen. Grosse Wunden, welche in diesem heissen Klima bei dem Europäer so schwer heilen, schliessen sich bald und sind nach kurzer Zeit volikommen verheilt.

Das Krankenhaus hat auch ein kleines Laboratorium, welches Dr. Wicke in. der letzten Zeit eingerichtet hat und ein Obduktionshaus, welches die wissenschaftlichen Arbeiten in hervorragendem Maasse unterstützt. Was die Gesundheitsverhältnisse in den letzten Jahren anbetrifft, so waren sie bedeutend besser als im Jahre 1896 , in welchem in den Monaten Mai oder Juni an den Küstenplätzen eine schwere Malariaepidemie auftrat, die sich weiter bis unach Akkra nd Lagos verbreitete.

Von den damals an der Küste ansässigæen Europäern, etwa 70 an der Zahl, sind binnen wenigen Wochen I3 dem schweren Fieber erlegen. Zumeist fallen die Europäer dem Schwarzwasserfieber oder auch häufig auftretenden Dysenterie zum Opfer. Auch starben viele an den Nachwehen der Malaria, an chronischer Nierenentzündung. Auffallend trat in dem Jahre 1897 eine Beriberi-Epidemie auf, zumeist bei den Kruboys einer Faktorei in Klein-Popo; sie war von schweren Erkrankungen des Herzens begleitet und hat bei 28 Erkrankten in drei Fällen nach kurzer Zeit, in einem Falle sogar nach 20 Stunden, den Tod herbeigeführt.

Häufig bei

Europäern und

Eingeborenen vor-

kommende Krankheiten
Von den angeführten Krankheiten wie Dysenterie, Lungenentzündung, Beriberi und Malaria werden nicht nur die Europäer, sondern auch die Schwarzen befallen. Das Malariafieber sucht letztere meistens nur dann heim, wenn sie in andere Gegenden kommen, wo andere klimatische Verhältnisse herrschen. Nicht selten konnten wir in Kratyi bemerken, dass unsere von der Küste mitgebrachten Leute in der Volta-Niederung von heftigem Fieber befallen wurden. Eine bei den Eingeborenen sehr häufig auftretende Krankheit ist der Guineawurm. Der Keim zu diesem scheusslichen Schmarotzer soll mit dem Wasser aufgenommen werden und sich in dem Körper des Menschen fortentwickeln, bis er an irgend einer Stelle, meistens an den unteren Gliedmaassen, am Fuss oder am Bein, unter furchtbaren Schmerzen heraustritt. Der Guineawurm sieht 
aus wie ein weisser Faden, den man an der betreffenden Stelle, wo er an die Oberfläche der Haut kommt, auf ein Stäbchen aufrollt und entfernt. Bleibt jedoch der Kopf des Tieres in dem Körper, so soll er sich, ähnlich wie der Bandwurm bei uns, weiter fortpflanzen und neue Schmerzen verursachen. Meistens eitern die abgestorbenen Teile des IVurmes aus. Häufig haben wir den Leuten, die bei uns Hilfe suchten, mit Quecksilbersalbe diese Stellen eingerieben, was anscheinend den Wurm zum Absterben und zur Auseiterung brachte. Eigentümlicherweise scheint der Weisse dieser Krankheit gegenüber widerstandsfähiger zu sein, da bis jetzt noch kein Fall bekannt geworden ist, wo ein Europäer in der Kolonie ron ihr heimgesucht wurde. Wie der Guineawurm durch die Aufnahme von Trinkwasser sich verbreiten soll, so sollen auch die Keime der bekannten Tropenkrankheit "sanguinis filarii“ durch Moskitostiche in das Blut des Menschen übertragen werden; sie verursacht häufig ein Anschwellen der unteren Gliedmaassen und wird dann "Elefantiasis" genannt. Im Hinterlande begegnet man vielfach einer Anschwellung des Hodensacks, die ron derselben Krankheit herrühren soll, und in dieser Form eine Folge mangelhafter Bekleidung sein mag. Ferner treten auch noch ungefährliche Infektionskrankheiten wie der Ringwurm auf, der Schwarze wie Weisse befällt und sich in einem ringförmigen Hautausschlag äussert. Man vertreibt ihn jedoch leicht mit der Ringwurmsalbe: An den Küsten sind die unbeschuhten Schwarzen den Sandflöhen ausgesetzt. Die Vernachlässigung der infizierten Stellen hat schlimme Folgen und kann schliesslich durch Eiterung den Verlust von Zehen herbeiführen. Bei einiger Aufmerksamkeit sind die Tiere jedoch leicht zu entfernen. Sehr häufig findet man bei Kindern einen Ausschlag vor, der „Krokro" genannt wird und zuweilen Gesicht und Körper derselben mit einem weissen Schorf überzieht. Jedoch verliert sich diese Krankheit mit dem Altèr und soll im allgemeinen ungefährlich sein. An der Küste sind die Geschlechtskrankheiten sehr verbreitet, gegen welche die Eingeborenen kein Mittel zu kennen scheinen; seltener begegnet man ihnen im Hinterlande. In den Thälern trifft man bei alten Leuten häufig die Abzehrung, an welcher sie nicht selten zu Grunde gehen. Auch kommt Atrophie, namentlich einseitig an den unteren Gliedmaassen vor. Ferner findet man, wie wir noch später sehen werden, in den feuchten Gebirgsthälern den Kropf. Ab und zu kommen Albinos vor, deren weisse Hautfarbe und rote Haare sich schlecht mit dem Negertypus vertragen; eigentümlich ist, dass man häufig Albinos mit blauen Augen beobachten kann.

Mit der Impfung ist im Schutzgebiet begonnen worden. $\mathrm{Zu}$ diesem 'Zwecke hat man geeignete Personen angelernt. Die Lymphe wird frisch aus Europa bezogen und von der Apotheke auch an die Stationen im 
Innern versandt. In diesem Jahre ist durch besondere Verordnung der Impfzwang an der Küste, vorläufig für Klein-Popo und Lome eingeführt worden.

Was die allgemeinen gesundheitlichen Verhältnisse des Schutzgebietes anbelangt, so ist es damit in der Uebergangsperiode von der Trockenzeit zur grossen Regenzeit, also etwa in den Monaten Mai und Juni, am schlechtesten bestellt. Diese Monate haben uns die Malariaepidemie und die meisten damit in Verbindung stehenden Krankheiten gebracht. Durch die Feuchtigkeit der überall stagnierenden Gewässer sollen die Malariaerreger wieder neu belebt werden und sich durch das Ausdünsten der Sümpfe schnell verbreiten.

Einige Orte, wie Lome, sind gesundheitlich unseren anderen Küstenplätzen bei weitem vorzuziehen, da hier die Lagune sehr selten unter Wasser steht und andererseits auch verhältnismässig weit von der Stadt entfernt ist.

Klein-Popo dagegen und auch Sebbe, der frühere Regierungssitz, welche beide hart an der Lagune liegen, haben für den Europäer ein weniger günstiges Klima als Lome. Letzteres wurde daher in früheren Zeiten von den Europäern als Seebad Lome bezeichnet.

Aus den vorerwähnten Gründen sind die Gebiete in den Niederungen und an den Flussläufen ungesünder und ebenso verhält es sich mit unseren Stationen im Hinterlande.

Während unsere Station Misahöh, welche an einer luftigen Berglehne etwa $45^{\circ} \mathrm{m}$ über dem Wasserspiegel liegt, durch schönes krystallhelles Wasser ausgezeichnet ist, kann man ein gleiches von der Station Kete-Kratyi nicht behaupten. Letztere liegt, wenn auch auf einer kleinen Anhöhe, vollständig in dem Flussgebiet des Volta und die Nähe dieses Flusses mit seinem Ueberschwemmungsgebiet wirkt natürlich nicht günstig auf die Gesundheit der dort stationierten Europäer. Aber es war trotzdem aus wirtschaftlichen und politischen Gründen nìcht möglich, unser grösstes Handelscentrum im Hinterlande Kete ohne eine Station zu lassen.

Den Europäern könnte eine Erleichterung dadurch geschaffen werden, dass ein ausreichendes Personal dort stationiert würde, welches in Krankheitsfällen sich gegenseitig Hilfe leisten und vertreten kann.

Auch Dr. Fisch sagt in seinem Werke: "man sollte nie einen

Lage von Klein-Popo. Europäer auf einer Station allein lassen, denn dies sei eine Grausamkeit.“

Wie aus den vorhergehenden Schilderungen zu entnehmen ist, schliesst Klein-Popo im Westen mit dem Krankenhause seinen Bereich ab. Wir wandern nun weiter nach Osten auf einem gut gebahnten Lehmwege, der schnurgerade am Strande hinführt und an dessen Nordseite sich Klein-Popo fast $2 \mathrm{~km}$ lang erstreckt. Weiter östlich kommen wir zuerst zu der Wesleyanischen Methodisten-Mission, welche von dem Super- 
intendenten Ulrich geleitet wird. Es ist ein grosses, viereckiges, aus Lehm aufgeführtes Gebäude mit einem Grasdach. Grosse Fenster, nach Art der Eingeborenen mit Läden rerschlossen, spenden einem geräumigen Zimmer das Licht. In demselben befindet sich die Schule, welche Sonntags auch zur Abhaltung des Gottesdienstes benutzt wird.

So einfach dieses Gebäude aussieht, so verfehlt es doch nicht seinen würdigen Zweck. Ich gedenke noch des feierlichen Taufaktes, welchen der durch sein bescheidenes Wesen überall beliebte Missionar Ulrich an drei schwarzen Soldaten vornahm.

Diese waren früher Sklaven des Königs Behanzin von Dahome und von letzterem unserem Kaiser während des Krieges mit den Franzosen zum Geschenk gemacht worden. Nach einer würdigen Ansprache an die Soldaten, in der er sie an die Gebote der christlichen Kirche ermahnte, taufte' er sie mit den Namen: Wilhelm, Karl und Johann. Dieser feierliche Akt wurde durch einen Gesang eingeleitet und geschlossen.

Der erhebenden kirchlichen Handlung wohnte die ganze Gemeinde, fast sämtliche Europäer mit dem Landeshauptmann, den Beamten und Kaufleuten bei.

Wir wandern weiter und gelangen zu der kleinen Kapelle und zur Schule der katholischen Mission. Ein kleiner Glockenstuhl ist hier auf dem Grasdach des Missionshauses angebracht; des Morgens beim Aufgang und des Abends beim Untergang der Sonne werden die Einwohner zur Arbeit und zum Gebet durch Glockengeläut gerufen.

Wir kommen nun zu der sogenannten Eingeborenen-"Town“, wie sich unsere deutschen Kaufleute auszudrücken belieben.

Hier finden wir neben den eigentümlichen kleinen Hütten der Evheneger auch die Häuser der reicheren Schwarzen, welche aus Lehm aufgeführt und sogar mit einer Veranda versehen sind.

Eine dieser Besitzungen gehört der Familie Garver, deren Ober-Weihnachten haupt der Ministerpräsident des Königs Lawson von Klein-Popo ist. an der Küste Hier hatte ich Gelegenheit, bei dem sogenannten Black-Christmas das Leben und Treiben im Hause eines schwarzen Notablen kennen zu lernen. Das Black-Christmas ist, wie auch die Bezeichnung andeutet, eigentlich nur eine heidnische Nachahmung unseres Weihnachtfestes. Es bildet eins der Hauptfeste der Schwarzen in Klein-Popo und fällt ungefähr in die Zeit des September. Es wird bei Spiel und Tanz in Saus und Braus gefeiert. Zu diesem Feste werden Ziegren und Schafe, ja von den Reichen der Stadt auch Kälber und namentlich Hühner in Masse geschlachtet. Die Honoratioren beschenken sich gegenseitig und bedenken sogar die Weissen mit einer Hammelkeule oder auch einem Stück Kalbfleisch, natürlich in der Hoffnung auf ein Gegengeschenk. 
Die Weissen werden besonders eingeladen, während es unter den Schwarzen Sitte ist, sich ohne irgend welche Aufforderung bei seinen Freunden zum gemeinsamen Gelage einzufinden.

Wir folgten gleichfalls einer Einladung der Garvers und wohnten mit fast sämtlichen Europäern von Klein-Popo dem Feste bei, bei dem es hoch herging. Während bei den gewöhnlichen Schwarzen der Gin das hauptsächliche Getränk ist, steht den vornehmen Schwarzen und den Weissen für afrikanische Verhältnisse eine sehr reichliche Auswahl von Getränken zur Verfügung. Neben Sekt giebt es auch Bier, Selterwasser, selbst die verschiedensten Liqueure, die besonders bei den schwarzen Damen Anklang finden; neben anderen Weinen spielt selbstverständlich der Palmenwein die Hauptrolle und der schwarze Gastgeber zeigt sich als liebenswürdiger Wirt.

Von den Bediensteten werde"n die verschiedenartigsten Tänze aufgeführt, welche zur allgemeinen Belustigung der gemischten Gesellschaft beitragen.

Die Männer führen Kriegstänze auf und sind $z u$ diesem $Z$ wecke meist mit kleinen Haumessern oder auch Streitäxten bewaffnet. Sie kommen einer nach dem andern in das dazu bestimmte Gehöft hereinmarschiert und nehmen hier in einer Reihe Aufstellung. Einzeln tritt jeder Krieger vor und führt beim Schwingen seiner Waffe und bei anderen Waffenübungen, sowie beim Gesang einer Kriegshymne, in welche der Chor einstimmt, in wilden Sprüngen seinen Tanz auf.

Auch die Mädchen und jungen Frauen beteiligen sich an den Aufführungen; sie bilden einen Kreis und während in demselben eine von ihnen vortanzt, singen die anderen und begleiten den Tanz mit Händeklatschen. Kleine Flaschenkürbisse, mit Kaurimuscheln gefüllt und mit Kaurinetzen überzogen, werden dabei als Rasseln verwendet.

Natürlich wird von den Christen das Weihnachtsfest in ganz anderer und ruhiger Weise am Tage der Geburt unseres Heilandes gefeiert, als durch lärmende Fetischtänze bei dem nachgeahmten sogenannten BlackChristmas. Der in Togo am 20. Dezember eintreffende und landende Togodampfer ist der sogenannte Weihnachtsdampfer. Er bringt die Briefe und Liebesgaben aus der férnen Heimat, ja auch die Bäume, die an diesem Abend keinem deutschen Herde fehlen dürfen. Es kommt aber auch vor, dass hier in Ermangelung eines Tannenbaumes eine Mimose oder eine Fikusart denselben Dienst verrichten muss. Bei dem Lichterglanz des Weihnachtsbaumes werden alsdann auch hier unter den befreundeten Weissen kleine Liebesgaben ausgetauscht.

Die grösseren Jungen und die Angestellten bekommen ebenfalls ihren Teil in Tüchern und dergleichen, während man den kleineren Knaben mit etlichen Packeten Zucker eine grosse Freude bereitet. 
Eine nicht geringe Ausgabe verursacht das Weihnachtsfest den grossen Faktoreien, da sie natürlich ihr sämtliches Personal, ob Heiden oder Christen, ziemlich ansehnlich beschenken müssen. Ein schwarzer Verkäufer wird z. B. mit 20 Mark oder zwei Flaschen Wein und Zigarren bedacht.

Unter der Arbeiterbevölkerung befinden sich verhältnismässig wenige Christen, während die besseren Familien, wie z. B. in Klein-Popo, die Lawson'sche Königsfamilie, die Familien der reichen Ameidas, sowie der Wilsons und Garvers sämtlich zum Christentum übergetreten sind, wenn sie auch, wie die vorhergehenden Schilderungen beweisen, aus praktischen und sozialen Gründen die Feste der heidnischen Bevölkerung nicht ignorieren können.

Ferner gehören noch viele Händler und Handwerker, die fast alle ihre Erziehung in einer der christlichen Missionen genossen haben, dem Christentum an:

Das neue Jahr wird auch im schwarzen Erdteil mit Läuten der Glocken in allen Kirchen und Kapellen eingeleitet; Böllerschüsse, die hier noch nicht so streng von der Polizei geahndet werden, erfüllen weithin die Luft.

Wir marschieren nun am Strande weiter und gelangen zu dem Seefischerei. Zollgebäude und der grossen Faktorei von I. K. Vietor.

Vor den einzelnen Faktoreien befinden sich wie in Lome grosse Schutzdächer, welche die Brandungsboote vor den Strahlen der Sonne schützen. Auch vor der Eingeborenen-Town sind kleine Schutzdächer aus Gras, welche die zahlreichen Kanoes der Fischer dieses Stadtviertels bergen. Die kleinen Kanoes sind überall aus einem Baumstamme gefertigt, dem sogenannten Kanoebaum - dem Seidenwollbaum - der in der Mitte ausgehöhlt wird und alsdann den Schwarzen als Fahrzeug dient. Diese Kanoes, welche die hohen Brecher und die Brandung passieren müssen, sind deshalb mit besonderen Schutzvorrichtungen versehen. Die Seitenwände sind durch Planken und Bretter erhöht und ein besonders hoher Aufsatz befindet sich an dem Vorderteil. Auch sind an diesen Kanoes Vorrichtungen zum Segeln angebracht. Geradezu bewundernswürdig ist es, wie die sonst nicht sehr mutigen Schwarzen ihre Kanoes durch die schäumende Brandung führen. Mit Spannung und Besorgnis sieht man den kleinen Fahrzeugen nach, die wie Nussschalen auf den Wellen herumgeworfen werden und nur mit der grössten Mühe und Anstrengung einen Kamm nach dem andern nehmen. Tereint werfen dann die Fischer zweier solcher Kanoes ihre Netze aus und beginnen ihre mühsame Arbeit, von welcher sie erst abends heimkehren; ihre Angehörigen, Frauen und Kinder, kommen dann an den Strand gelaufen, um sich mit Bangen zu überzeugen, ob auch das kleine Kanoe durch 
die Gewalt der Fluten glücklich an den Strand geworfen wird. Die Fische werden dann sofort in Körbe gelegt und die grossen von den kleinen geschieden; die grösseren werden meist bald am Strande verkauft und wandern nicht selten in die Häuser der Europäer, während die kleinen Fische in der Sonne getrocknet und dann auf dem nahen Markt an der Lagune feilgehalten werden.

Nicht selten wird auch ein Sägefisch gefangen, dessen für die Schiffe so gefährliche Säge von den Eingeborenen als Waffe benutzt wird. Ebenso werden häufig grosse Stachelrochen gefischt, deren Schwanz als Peitsche zum Verkauf angeboten wird. Nach beendigtem Fischfang werden die Netze am Strande ausgebreitet, zum Trocknen hingelegt und die zerrissenen Stellen durch neue Maschen ersetzt, damit mit Tagesanbruch die Fischer wieder ihre Arbeit beginnen können.

Die Schule. Wir wandern nun weiter am Strande entlang, und das nächste Gebäude, das unser Interesse in Anspruch nimmt, ist das Gebäude der Regierungsschule. Dasselbe ist ein ziemlich grosser, viereckiger Bau, nach der Seeseite mit einer Veranda versehen. Im oberen Stockwerk wohnt der Lehrer, während sich im Erdgeschoss das grosse Schulzimmer befindet. Der Unterricht wird in drei Abteilungen erteilt und besteht in biblischer Geschichte, Deutsch, Rechnen, Realien, welche sich auf die Heimatskunde und Himmelsrichtungen erstrecken. Auch haben die oberen Abteilungen Singen, Turnen, Zeichnen und Anschauungsunterricht über Tiere und Pflanzen.

Diese Regierungsschule hat vor allem den Vorteil, dass sie das Hauptgewicht auf das Erlernen der deutschen Sprache legt, so dass diese hoffentlich in nicht zu langer Zeit die englische Verkehrssprache verdrängen wird.

Aus dieser Schule gehen auch jetzt schon die unteren schwarzen Beamten hervor, welche als Zollaufseher oder Postagenten eine Verwendung finden. Leider kann den deutschen Kaufleuten der Vorwurf nicht erspart werden, dass sie bei dem Verkehr mit ihren schwarzen Jungens häufig die englische Sprache bevorzugen. Nach ihrer Angabe thun sie es nur aus dem Grunde, weil sie glauben, dass bei allgemeinem Verständnis der deutschen Sprache manches Geschäftgeheimnis ausgeplaudert werden würde. Wie soll das aber nun in unserem deutschen Vaterlande sein, wo in einem Geschäft alles bis auf den Lehrling und den Hausknecht sich nur der deutschen Sprache bedient?!

Handelsverhältnisse in Klein-Popo.

Den ganzen östlichen Teil von Klein-Popo nehmen mit Ausnahme des schon erwähnten Zollhauses die Faktoreien ein. Dieselben sind durchweg zwischen Strand und Lagune erbaut, und haben ausserordentlich grosse Hofräume, auf welchen in langen Reihen Tonnen zur Verschiffung der Kerne und des Oels lagern. Lange Schuppen 
bergen die Waaren und Produkte. In denselben werden auch die Kerne zum Trocknen mittelst Schaufeln ausgebreitet. Lange und hohe Zäune schliessen die Gehöfte nach der Seeseite ab. Die Wrohngebäude sind zumeist etwas zurückgebaut und liegen näher an der Lagune, an welcher das ganze geschäftliche Leben und Treiben sich abspielt. Einen herrlichen Ausblick hat man von den Veranden dieser Gebäude nach dem Süden auf das schäumende Meer und nach dem Norden auf das geschäftiche Treiben und auf die sich weithinziehende Lagune und ihre Arme, sowie auf die Insel Adjido, die so malerisch mit dem kleinen

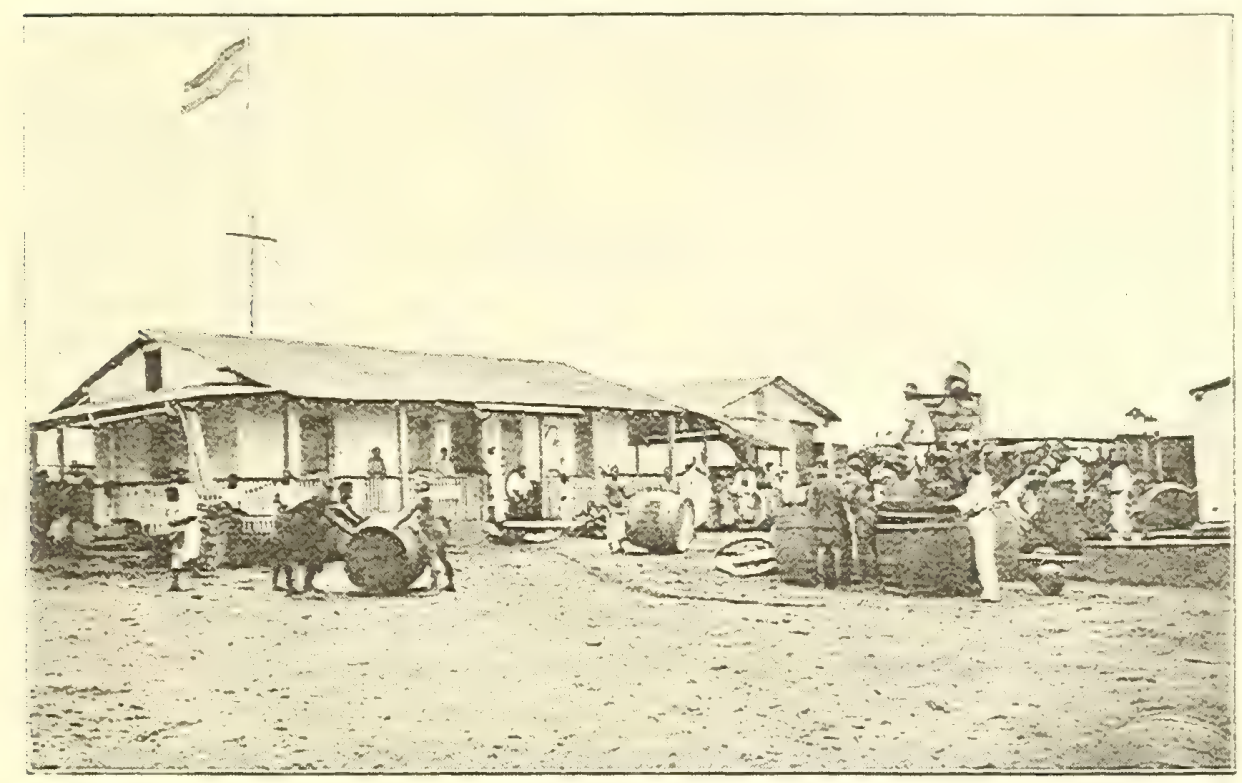

Hol der Fakrorei von Wölber \& Zimmermann in Klein Popo

Dorf und der daneben befindlichen katholischen Mission, welche einen hohen Kirchturm besitzt, daliegt.

Auf der Lagune schaukeln die beladenen Kanoes, die den Faktoreien Kernerprodukte zuführen, während Fischer ihre Netze werfen und die kleinen schwarzen Jungens sich fast den ganzen Tag im Wasser tummeln. Im Hintergrunde, wo der eine Arm der Lagune nach Sebbe abbiegt, um sich mit dem nach Grand-Popo führenden Hauptarm zu vereinigen, liegt Degbenu und Badyi, die Residenz mit dem Palast des Königs Lawson III. Auf einer kleinen Anhöhe, die fast steil zur Lagune abfällt, liegen die weissen, von Veranden umgebenen Häuser, die alle mit ihrem Oberstock den Europäer-Häusern gleichen. Die Kokospalmen, welche am Nordwestende der Stadt den Markt beschatten, sowie die vielen 
kleinen Gondeln und die weissen Gigs, die vor den Faktoreien liegen, geben der ganzen Landschaft ein malerisches Aussehen. Ueberall werden Waaren verladen, geschäftig wälzen die Schwarzen die Tonnen und tragen aus den Kanoes die gefüllten Säcke herbei, so dass das ganze Ufer an der Lagune einem Bollwerk gleicht. Abends, wenn die Sonne in die dunklen Meeresfluten taucht und zum Abschied noch alles mit goldigem Schimmer umrahmt, wenn am dunkelblauen Firmamente die Sterne leuchten, wenn schäumend, brausend und majestätisch sich die Meereswogen im hohen Bogen am Strande brechen, empfängt man Besuch auf der Veranda und vergisst in wechselseitigem Gespräch die vielen Unzuträglichkeiten, wie Hitze, Moskitos und Fieber, denen man sich in den Tropengegenden auszusetzen hat.

Während in L,ome hauptsächlich das Kassageschäft besteht, indem die Leute einzeln ihre Produkte zum Verkauf bringen und wieder einhandeln, wird in Klein-Popo mehr das Engros-Geschäft betrieben.

Der Handel wird hier hauptsächlich durch schwarze $Z_{\text {wischen- }}$ händler vermittelt, welche die Produkte auf den grossen Märkten in der Lagune in Gridji und in Vo an der Volagune, auch in den Orten am Togosee, wie in Degbo, sowie weiterhin in Hahoté am Haho aufkaufen.

Einige Faktoreien haben direkt schwarze Agenten, die in Degbo und Hahoté stationiert sind.

Aber auch die entfernter gelegenen Märkte abseits von der Lagune, wie der ganze Küstenstreifen, welcher die Zone der Oelpalmen bildet, das Hinterland von Klein-Popo, Sagada, Tshegbo und andere Centralpunkte liefern Produkte nach Klein-Popo. Die Wasserstrasse der Lagune erleichtert hier bedeutend den Verkehr.

Seit dem letzten Pariser Vertrage ist für den Osten unseres Gebietes und somit hauptsächlich für Klein-Popo erfreulicherweise eine neue Handelsstrasse in dem Mono eröffnet. Früher wurde die Grenze gebildet durch den Meridian, welcher die Insel Bajol in dem $0^{\circ} 40^{\prime}$ östlicher Länge von Greenwich durchschneidet. Somit gehörte ein Gebiet auf der rechten Seite des Mono zu der französischen Kolonie Dahome. Durch den erwähnten Vertrag ist uns dieses zwischen dem Mono und der Lagune liegende Dreieck zugefallen. Ferner gehört uns die Hälfte der Lagune vom Mono bis Bajol. Auch ist uns die Neutralität der Schifffahrt auf dem Mono zugesichert worden, so dass wir nun eine Wasserstrasse im Osten des Gebiets und somit eine Verbindung zu Wasser zwischen dem Hinterlande und Klein-Popo besitzen. Endlich gehört uns der grosse Markt von Topli, der früher ein streitiges Objekt bildete.

Während früher sämtliche Produkte, welche auf dem Mono verschifft wurden, durch französisches Gebiet gehen und, um den Zoll zu ver- 
meiden, in Grand-Popo abgesetzt bezw. verkauft werden mussten, haben sich innerhalb kurzer Zeit nach Abschluss des Vertrages die Handelsverhältnisse zu unseren Gunsten bedeutend verändert. Jetzt können die Kaufleute und ihre Unterhändler die Kanoes ungehindert den Mono aufwärts bis zu dem Hauptmarkt nach Topli schicken, welches früher ebenfalls unter französischem Einfluss stand. Hoffentlich werden die Kaufleute nicht verfehlen, diesen wichtigen Platz Topli durch Anlegung von Zweigfaktoreien, wie solches in Agome-Palime, im Hinterlande von Lome schon geschehen ist, weiter zu vergrössern.

Dieser erfreuliche Aufschwung ist Klein-Popo um so mehr zu gönnen, als es durch Verlegung der kaiserlichen Landeshauptmannschaft von Sebbe nach Lome nicht geringe Nachteile erlitten hat. Leider ist uns der schmale Küstenstreifen, welcher zwischen der Lagune und dem Meere und zwischen dem $0^{\circ} 40^{\prime}$ östlicher Länge und zwischen der Mündung des Mono gelegen ist, in diesem Vertrage nicht zugesprochen worden. Nichtsdestoweniger ist der Erwerb des Gebietes und die dadurch gewonnene Schiffahrt auf dem Mono von unschätzbarem Nutzen.

Eine direkte Verbindung zwischen Klein-Popo und dem Hinterlande existiert zu Lande nicht, man muss vielmehr mittels Kanoe den ersten, etwa I 50 bis $200 \mathrm{~m}$ breiten Arm der Lagune passieren, um auf die Insel oder besser gesagt Halbinsel Adjido zu gelangen. Bei niedrigem Wasserstande nämlich hängt Adjido im Osten mit dem Festlande zusammen. Bei hohem Wasserstande dagegen wird es im Osten vom Lande abgeschnitten.

Die Verbindung mit Adjido wird durch eine Regierungsfähre hergestellt, welche aus einem grossen Kanoe besteht. Oft war die Fähre so übermässig Kopf an Kopf mit Schwarzen beladen, dass sie nur eines geringen Anstosses bedurfte, um umzuschlagen. Die Gefahr erscheint jedoch grösser als sie in Wirklichkeit ist, denn die Schwarzen verstehen es, geschickt mit diesem Fahrzeug umzugehen und auch den geringen Raum desselben auszunutzen. Hintereinander hocken sie auf dem Boden des Kanoes, ohne irgendwie zu zucken und so gelangen sie meistens unbeschadet hinüber.

Wir haben nun Adjido erreicht und gelangen von dem Landungspatz auf einem ca. $4 \mathrm{~m}$ breiten und $\mathrm{I} \% 2 \mathrm{~km}$ langen angelegten Wege durch des sumpfige Terrain der Halbinsel auf einem Damm zu dem zweiten Arm der Lagune, welcher zwischen Sebbe und Adjido gelegen ist. Hier bildet eine auf Steinpfeilern erbaute Holzbrücke die Verbindung.

Schon vom jenseitigen Ufer übersieht man die schöne Lage von Sebbe, insbesondere den bis an die Lagune reichenden Park, der jetzt nach Lome verlegten Landeshauptmannschaft. Jetzt steht dort verlassen ein grosses zweistöckiges Beamtenwohnhaus, sowie das ehemalige Haussalager und die Arbeitsschuppen. 
Sebbe ist seit der Verlegung der Landeshauptmannschaft fast ganz ausgestorben. Nur im Osten des Parkes liegt noch unverändert das eigentliche kleine Dorf Sebbe, welches die Schwarzen noch heute bewohnen. Kleine viereckige, mit Gras bedeckte und von grossen Kokospalmen beschattete Hütten bilden das Dorf.

Weiter östlich an dem erhöhten Ufer der Lagune liegt die kleine Zollstation Hela Cofi, welche aus einigen aus Palmen und Gras hergestellten Hütten besteht. Ein grosser Flaggenstock mit der deutschen Zollflagge und ein Posten vor Gewehr kennzeichnet diesen Platz. Unweit östlich davon geht die französische Grenze. Von hier aus hat man eine vorzügliche Aussicht auf die Lagune und auf die kleine französische Insel Bajol, auf der ebenfalls eine in grossartigem Style angelegte französische Zollstation liegt, um die auf der Lagune ankommenden Kanoes zu kontrollieren.

Auf dieser kleinen Station Hela Cofi, welche den Zoll für die, die französische Grenze passierenden Waaren, insbesondere Ziegen oder Schafe zu erheben hat, kam es häufig zu Excessen. Die Schwarzen wollten natürlich nicht gutwillig den Zoll zahlen und mussten daher namentlich in der ersten Zeit durch Strafe dazu gezwungen werden.

Wir kehren nun zu der Halbinsel Adjido zurück, die uns als Sitz der katholischen Mission und als Hauptherd des Fetischtums des heidnischen Jevheordens interessiert.

Infolge der schönen Weiden auf Adjido wie bei der königlichen Residenz Badji werden von den Eingeborenen an beiden Orten Viehherden unterhalten, welche mir an der Küste und weiterhin nicht mehr begegnet sind. Erst wieder circa $350 \mathrm{~km}$ von der Küste entfernt, trifft man in unserem deutschen Togogebiet kleine Viehherden an, die jedoch dort nur kürzere Zeit bis zu ihrem Verkauf gehalten und aus Dagomba oder den Kotokolilanden eingeführt werden.

Des Morgens werden die sehr primitiv eingerichteten Gehöfte geöffnet und die Tiere zur Weide getrieben. Beim Anblick der behaglich grasenden Viehherde fühlt man sich unwillkürlich auf die grünen saîtigen Wiesen der Heimat versetzt.

Das Vieh wird von den Eingeborenen fast ausschliesslich nur zur Zucht und für Milchzwecke gehalten: die Milch wird als grosse Delikatesse für die Europäer nach Klein-Popo zum Verkauf gebracht.

Auch werden von den Eingeborenen, besonders hier in Adjido, sehr viel Schweine gehalten, welche von mittlerer Grösse sind und eine schwarze Farbe haben.

Beinahe sämtliche Leute von Adjido betreiben neben dem Handel in geringem Umfange auch den Ackerbau, meistens jedoch den Fischfang auf der Lagune. 


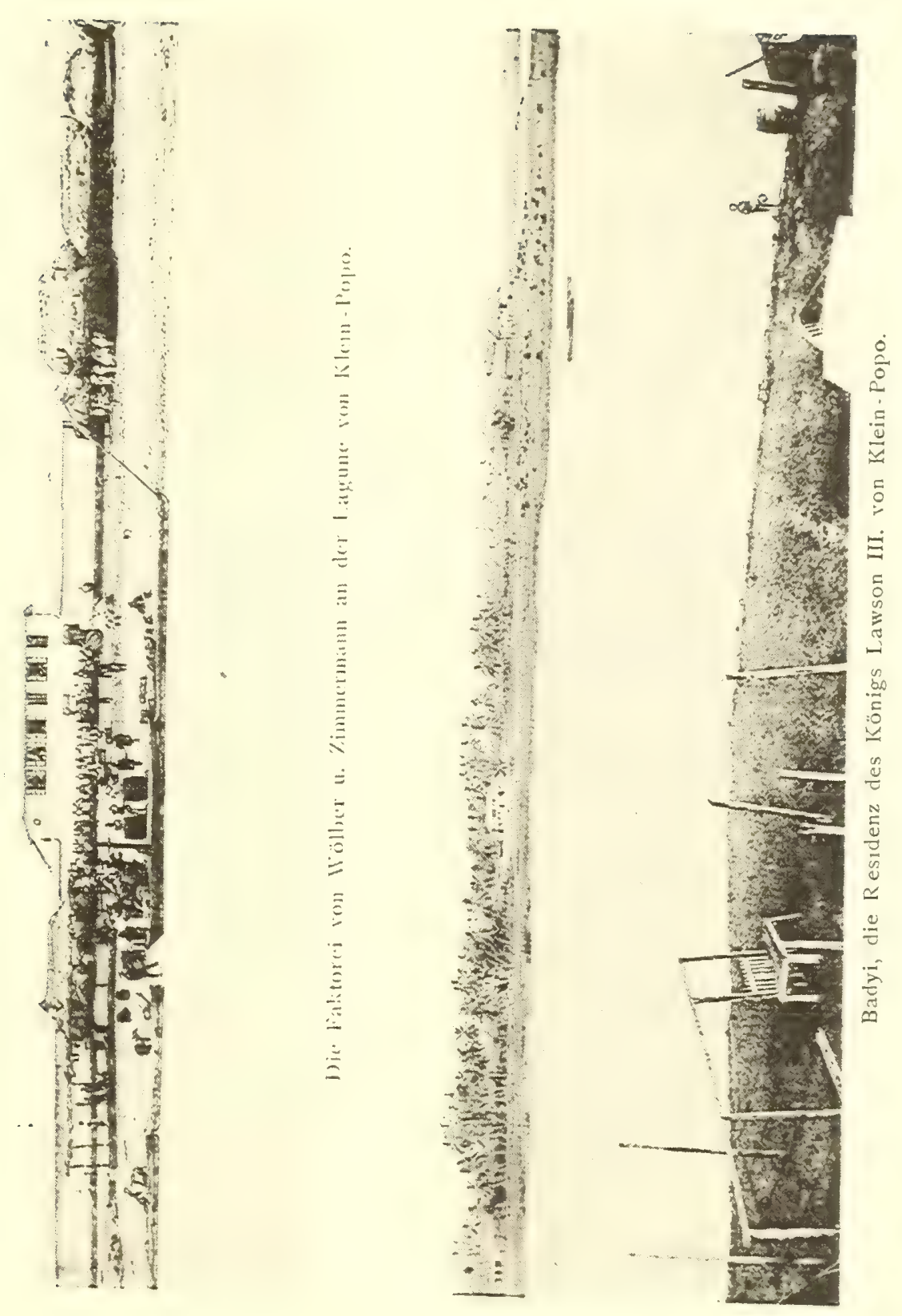



Trotzdem hier der ausgeprägteste Götzendienst der Jerhe-Gesellschaft herrscht, so liegt andrerseits doch an dieser Stelle der Ausgangspunkt der katholischen Mission.

Was die eigentümlichen Sitten dieser Fetischstämme anbelangt, so legen sie anscheinend cinzelne Gelübde ab, wie z. B., dass sie das Fleisch irgend eines bestimmten Tieres nicht essen wollen. Es kommt auch vor, dass die Fanatischen unter ihnen, namentlich Weiber, welche sich in irgend einer Weise gegen den Jevhegott versündigt haben, zur Sühne eine gewisse Zeit, anf das Gebot ihres Priesters, unbekleidet herumlaufen. Auch verbieten diese Priester den sämtlichen Angehörigen des Bundes jegliche europäische Kleidung zu tragen.

Der Yeweorden ist der grösste Feind des Christentums und der damit verbundenen Kultur. Die Priester desselben machen alle Anstrengungen, das Christentum fern zu halten und Abtrünnige werden auf das Strengste bestraft, oft auch hinterlistig ermordet. Später werden wir noch bei den Schilderungen der Religionsverhältnisse der Evhe auf diesen Yewebund zuruckkommen.

Neben dem eigentlichen Dorfe Adjido liegt hart an der Lagune auf dem erhöhten Ufer der grosse Komplex der katholischen Mission

Das Dorf besteht aus viereckigen, mit Gras eingedeckten Lehmhutten, welche von kleinen Gehöften eingeschlossen werden. Die Gehöfte umgeben Mattenzäune, häufig auch noch breite Kaktushecken, welche auf dem sandigen Teil dieșer Insel ganz besonders gedeihen.

Das katholische Missionshaus liegt mit der Front nach der Lagune. somit auch nach der See, und hat im unteren Teile eine geräumige Kirche. während im oberen Stockwerk sich die Wohnungen der Patres und Brüder befinden.

Eine schöne Aussicht hat man ron der V'randa auf die Lagune, auf die weite See und auf das sich lang dahinstreckende Klein-Popo.

Den hinteren Teil des Missionsgrundstückes schliessen die grossen Schul- und Wirtschaftsgebäude ab.

Die Präfektur der katholischen Mission, der Gesellschaft des göttlichen Wortes, wie sich dieser Orden nennt, hatte früher in Adjido ihren Sitz; nach Verlegung der kaiserlichen Landeshauptmannschaft, ist der Präfekt jetzt ebenfalls nach Lome übergesiedelt. Im Jahre i $897 / 98$ gehörten diesem Orden 9 Priester, 9 Brüder und 5 Schwestern an, welche in Togo stationiert waren.

Während sich die evangelischen Missionen, wie die Norddeutsche und Baseler mehr in das Hinterland von Togo gezogen haben und dort ihre Thätigkeit entfalten, verfolgt die katholische Mission ein anderes Prinzip, nämlich zuerst die Küstenplätze zu besetzen und sich von hier aus allmählich Schritt für Schritt an den grossen Karawanenstrassen 
im Innern auszubreiten. Sie zählt 5 Missionsstationen und zwar an der Spitze Lome, die neben der Präfektur eine Bruder- und Schwesterniederlassung enthält, ferner die schon erwähnte Station Porto Seguro, KleinPopo, Adjido, sowie die Station im Dorfe Togo am Togosee.

Die Missionare suchen die christliche Lehre hauptsächlich durch Schulunterricht zu verbreiten; so unterhalten sie nicht weniger als i 8 Schulen, welche von zusammen 7 oo Kindern, Knaben und Mädchen, besucht werden.

Auch ist in diesem Jahre erfreulicherweise in Adjido eine Handwerksschule von der Mission errichtet worden. In allen Schulen wird Religion, Englisch, Deutsch, Rechnen, Schreiben und auch Gresang gelehrt.

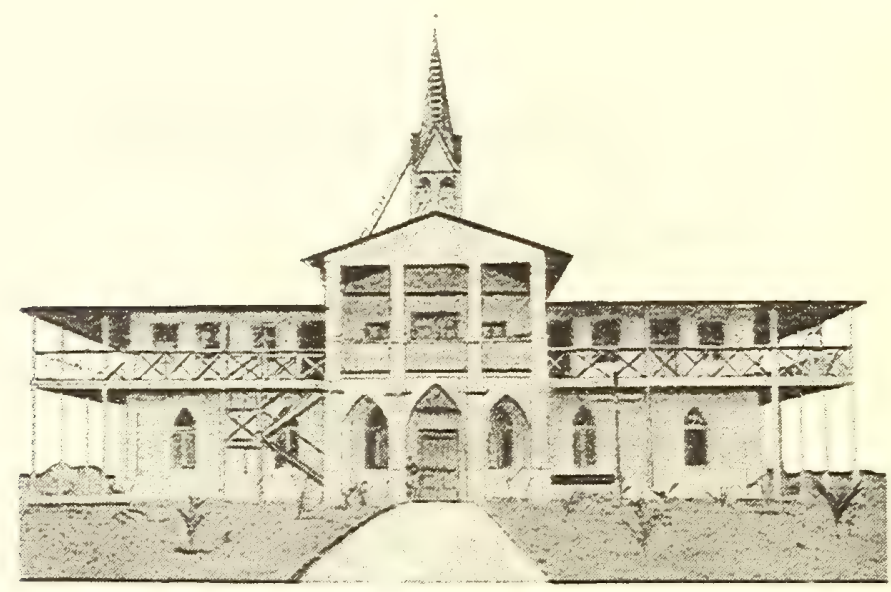

Das Hauptgebäude der kathol. Mission mit Kirche und Wohngebäude in Adjido.

Leider ist hier das Prinzip, erst englisch zu lehren, noch nicht aufgegeben worden. Die Mission glaubt nämlich, dass diese Sprache leichter den Uebergang zur deutschen vermittelt. Hoffentlich wird recht bald mit diesem Prinzip gebrochen.

Auch werden Belehrungsstunden für ältere Leute mit günstigem Erfolge ahgehalten. Um der Polygamie und dem Konkubinate, das in diesen Ländern allgemein herrscht, besser entgegentreten zu können, sind Mädchenschulen eingerichtet worden. Die Mission hofft dadurch christliche Ehen leichter herbeizuführen. Dieses ist von grosser Bedeutung, da in der Negerfamilie die Frau im Hause die Herrschaft hat und ihr allein die Erziehung der Kinder obliegt, während der Mann des Tages über seiner Arbeit nachgeht. Natürlich setzt das Fetischtum der Ausbreitung des Christentums grosse Hindernisse entgegen. Schlechte Ernten oder Fischarmut werden dem Christentum zur Last gelegt und als Strafe der Fetischgötter bezeichnet. 
Leider hatte auch im Jahre 1897 die Mission herbe Verluste durch den Tod mehrerer ihrer Mitglieder zu beklagen. Unter diesen befindet sich Pater Hoffmann, einer der würdigsten Priester der katholischen Mission. Binnen kurzer Zeit hatte er es durch Fleiss und Eifer so weit gebracht, dass er die Evhe-Sprache mit allen ihren Dialekten vollkommen beherrschte. Dadurch, sowie durch die Uebersetzung der biblischen Geschichte in die Evhe-Sprache hat er sich grosse Verdienste um die katholische Mission erworben.

$\mathrm{Zu}$ den Vergnügen der. Weissen gehört das Segeln oder das Vergnügungs. Rudern auf der Lagune. Häufig wird des Sonntags eine Gig ausgerüstet. fahrten auf Dieselbe ist mit Schattendach sowie mit Seitenwänden versehen, die der Lagune. genügend Schutz ror den heissen Sonnenstrahlen, so wie vor einem plötzlich auftretenden Tornado gewähren.

Die Gigs dienen jedoch nicht bloss zu Vergnügungsfahrten, sondern hauptsächlich den Kaufleuten von Klein-Popo zu ihren Geschäftsreisen auf der Lagune nach Aguë oder Grand-Popo, wo die meisten Firmen ebenfalls Faktoreien besitzen.

Neben diesen Gigs werden zu I'ergnügungsfahrten auch kleine Segelboote benutzt. Die Fahrten werden bis Porto Seguro, am Togosee, oder bis Vo unternommen. An einem Dorfe wird Halt gemacht, ein Picknick eingenommen und nach Untergang der Sonne die Rückfahrt angetreten. Der Mond breitet dann sein magisches Licht über die glänzende Fläche und in tiefes Schweigen hüllt sich die Natur. Von ferne tönt der Gesang der Schwarzen, die besonders in den hellen Nächten ihre Tänze aufführen, oder der dumpfe Knall einer Büchse dröhnt aus dem schweigenden Busch heraus. Bald sieht man die Lichter aufblinken, noch eine halbe Stunde Fahrt und man landet wieder am Ufer von Klein-Popo.

Klein-Popo war der Ausgangspunkt der vielen erfolgreichen Klein-Popo Forschungszüge, bei welchen unsere ersten Reisenden Dr. Wolf und als Ausgangs Hauptmann Kling weit in das Hinterland vorgedrungen sind. Dr. Wolf punkt gründete in den ersten Jahren nach der Besitzergreifung von Togo die der ersten Station Bismarckburg, von welcher er kühne Züge bis nach Borgu weit Forschungs im Norden unternommen hat. Hauptmann Kling setzte die begonnene Arbeit im Westen weiter fort und gelangte von dort aus bis Salaga und weit über den Volta bis Kintampo.

Leider ist auch Dr. Wolf, unser verdienstvollster Forscher, auf seiner Reise nach Borgu dem tropischen Fieber erlegen. Sein Nachfolger Hauptmann Kling ist gleichfalls, nachdem er im Hinterlande die Pfade geebnet und sich wie Dr. Wolf für die Wissenschaft und die deutsche Kolonialsache unsterbliche Verdienste erworben hatte, in der Heimat, in Berlin, den Nachwehen der Tropenkrankheit und Strapazen zum Opfer 
gefallen. In dankenswerter Anerkennung ihrer Leistungen hat sich ein Komité gebildet, welches es nnternommen hat, diesen gefallenen Pionieren der Kultur, zum bleibenden Andenken ein Denkmal in Togo zu setzen.

Um den Verkehr im Osten zu heben, hat die Regierung mit dem Bau einer Strasse bis nach Anfoi begonnen. Jedoch ist dieselbe, da der ganze Karawanenverkehr nach dem Innern sich nach dem Westen des Gebietes gezogen hat, nicht weiter ausgebaut worden.

Kaffee- An dieser Strasse liegen die grössten Kaffee-Plantagen im Togogebiet. plantagen und Die Plantage von I. K. Vietor zählt nạch dem letzten Jahresbericht deren 30000 Bäume; der im Vorjahr festgestellte Ertrag dieser Plantage belief Schädlinge sich auf tooo $\mathrm{kg}$ Kaffee. Ferner liegen hier die Plantagen von AiteAyavon mit 20000 Bäumchen und 6000 Pflänzlingen, die der Familie ron Almeide Br. \& Comp. mit 32500 Bäumen und nach vorjähriger Feststellung einer Ernte von $3000 \mathrm{~kg}$ Kaffee.

Ausserdem sind zu nennen die Plantagen der katholischen Mission mit 3000 Bäumen, die Plantagen von Chiko d'Almeida mit 6500 Bäumen, die Plantage von Creppy mit 4000 Bäumen und die Plantage Sebbe von Paul mit 2000 Bäumen. Die Anzahl der Bäume ist im Jahre I896/97 bedeutend zurückgegangen. Schuld daran war die lang andauernde Dürre der letzten Jahre. Die Bäume verloren die Blätter und verdorrten in ihren oberen Zweigen vollkommen, so dass noch im Mai i897 die Plantage von Vietor, welche ich damals besuchte, einen traurigen Anblick gewährte. Einige Plantagenbesitzer dachten deshalb schon daran, sämtliche Bäume herauszunehmen und andere an deren Stelle zu pflanzen. Durch den reichlichen Regen im Frühjahr 1897 wurden jedoch die Plantagen vor dem Untergange gerettet.

Ausser diesen Plantagen an der Küste befinden sich noch mehrere Kaffeeplantagen im Innern auf den Missionsstationen Ho und Amedjovhe, wo auch der arabischer Kaffee angebaut wird.

Leider zerstört nicht nur die Dürre, sondern auch ein Käfer eine grosse Anzahl von Bäumen. Dieser Käfer bohrt sich nach den Angaben des Missionars Kurz etwa 5 Zoll vom Boden unterhalb eines Astes in den Stamm des jungen Baumes hinein und vertilgt das Mark des Baumes. Der Käfer soll auch seine Eier in den Stamm hineinlegeri. Nach den Angaben des betreffenden Missionars will derselbe drei Stadien dieses Käfers beobachtet haben. Zuerst ist er eine Larve von gelblich brauner Farbe, deren Kopf flach und deren Leib mit 9 bis I 2 Einschnürungen versehen sein soll; im zweiten Stadium ist das Tier einem Käfer ähnlich, dessen Beine über der Brust gekreuzt und dessen Fühlhörner zurückgeschlagen spiralförmig zu beiden Seiten des Körpers aufgerollt sind. Das letzte Stadium bildet dann der Käfer selbst, welcher ungefähr einen Zoll lang und von brauner Farbe ist; die Beine sind in die Höhe geschoben 
und mit Zacken versehen, die das Tier beim Vorwärtsschreiten unterstützen. Der Käfer soll sich schwerfällig auf dem Boden bewegen. Interessant ist dabei die Wahrnehmung, dass der Käfer nur die arabischen Kaffecbäume angreift, während er den liberianischen Kaffee verschonen soll.

Ausser den Kaffeeplantagen kommen speziell für die Küste die Kokosnussanlagen in Betracht, die besonders in dem sandigen Küstenstreifen gut gedeihen. Auch haben die Versuche mit Gummibäumen, Manihot Glaziovii, in neuerer Zeit auf besserem Boden erfreuliche Erfolge erzielt, so dass der Anbau von diesen in Togo für die Hebung der Kolonie von hervorragender Bedeutung werden kann. Welche Ausdehnung dieser Anbau schon auf den einzelnen Plantagen erreicht hat, ersehen wir aus dem letzten Jahresbericht, nach welchem die Plantage Kpeme allein 59450 Kokosbäume und 2000 Gummibäume aufzuweisen hatte. Die Plantage von I. K. Vietor zählte 6000 Kokos- und I 500 Gummibäume, während sich der Anbau in der Plantage von Mensa bei PortoSeguro auf 3 ooo Kokosbäume und der in der Plantage von Olimpio bei Lome auf r 200 Kokosbäume belief. In der Plantage von Lome erreichte die Zahl der Kokosbäume 5000, während die Plantage Ayte-Ayavon 2600 Kokosbäume und 4800 Gummibäume besass. Auch die Plantage d'Almeida Br. \& Comp. hatte Iooo Kokos- und sogar 6000 Gummibäume aufzuweisen, während auf der Plantage Chiko d'Almeida ausser dem Kaffeebaume auch noch r600 Kokospflänzlinge und 3000 Gummibäume angepflanzt waren. Die Plantage Creppy besass 338 Kokos- und 3600 Gummibäume. - Bei der stetigen Ausdehnung dieser Plantagen ist es wohl zu erhoffen, dass ihre Erzeugnisse den erwarteten und gewinnbringenden Absatz finden werden.

\section{DIE LAGUNE.}

Wir kehren nun zu der Lagune von Klein-Popo zurück. Die Lagunen an der westafrikanischen Küste werden durch die starke Brandung hervorgerufen. Die südlichen Ausläufer des Guineastromes treiben hier mit Gewalt die Fluten an die Küste und bilden somit hohe Dünen. Die kleinen, meistens an der Sklavenküste befindlichen Küstenflüsse haben meist nicht die Gewalt diese Dünen zu durchbrechen. Da nun die Dünung von Südwesten nach Nordosten läuft, so wird der Lauf dieser kleinen Küstenflüsse zum grössten Teile nach Osten abgelenkt. Aus diesem Grunde setzen sie natürlich ihre Schwemmteile an den östlichen Ufern ab. Hierdurch haben sich die weit vorgelagerten Sand- 
bänke, auf denen unsere Küstenplätze, wie Lome, Bagida, Porto-Seguro und Klein-Popo liegen, gebildet. Dadurch entstehen auch die zu Seeen sich erweiternden Wasserbecken, wie der Togosee und die Volagune. Selbst die grösseren Flüsse, wie der Volta und der Mono in unserem Gebiet, werden nach Osten abgelenkt und gehen in einem Delta ins Meer. Die Lagunen ziehen sich längs der Küste von Quitta bis Grand-Popo hin; jedoch ist die Quittalagune ganz ausgetrocknet, da ihr bedeutendster Fluss, der Todjië, bei der Trockenzeit fast gar kein, oder doch nur wenig Wasser führt. Auch tritt die Verbindung mit dem Volta äusserst selten und nur bei sehr hohem Wasserstande ein. Die Quittalagune ist in den letzten Jahren fast ganz ausgetrocknet gewesen, während dies früher nach den Angaben der Eingeborenen nur alle 6 bis 8 Jahre vorkam. Häufig haben auch bei hohem Wasserstande die Fluten der Lagune oder vielmehr die in dieselbe führenden Küstenflüsse die vorgelagerte Nehrung durchbrochen und sind so direkt in das Meer gegangen.

Noch öfter wie die Quittalagune ist die Lagune, welche die Verbindung zwischen ersterer und dem Togosee bildet, ausgetrocknet. Namentlich war dies in den letzten Jahren der Fall, so dass die Verbindung zu Wasser zwischen Quitta und unseren Plätzen ganz aufgehört hat und heute in dieser ausgetrockneten Lagune hinter Lome sich viele Pfade befinden, die zu den anliegenden Ortschaften führen.

Infolge der engen Verbindungen, welche die Lagunen häufig mit der See haben, findet man in der ausgetrockneten Quittalagune weithin mit Erde vermischte Salzablagerungen; mit dem daraus gewonnenen Salz treiben die Eingeborenen einen ganz bedeutenden Handel nach dem Hinterlande, so dass das europäische Salz mit dem billigeren einheimischen Produkt fast gar nicht konkurrieren kann.

Salz- Schon Major v. d. Gröben schreibt in dem Bericht über seine bereitung Reise, die er im Auftrage des grossen Kurfürsten ausführte, über den Salzhandel und die Gewinnung dieses Produktes. Danach liess man das Seewasser künstlich verdunsten und gewann so ein reines, schönes, weisses Salz. Meistens jedoch sollen die Leute das Seewasser benutzt haben, welches bei hoher Brandung hinter den Dünen zurückgehalten und durch die Sonnenstrahlen einer natürlichen Verdunstung unterzogen wurde. Bereits zu jener Zeit hatte der Salzhandel eine grosse Bedeutung. Das Salz wurde von der Sklavenküste weit in das Innere gebracht. Die hauptsächlichsten Verkehrsstrassen für den Transport dieses Produktes sind heute wie auch schon in früheren Jahren die Ströme und Flüsse. Im Togogebiet sind die beiden Wasserstrassen im Westen der Volta und im Osten der Mono, auf welchen das Salz in unser Hinterland befördert wird. 
Die Bremer Missionare aus Quitta haben uns über die Salzgewinnung interessante Beobachtungen überliefert. In der Regenzeit sind die Seeen vollkommen unter Wasser, während sie in der grossen Trockenzeit häufig total austrocknen und sich dort Fusspfade hinziehen, wo bei Hochwasser nur grosse Kanoes den Verkehr vermitteln können. Jedoch ändern sich auch hier die Verhältnisse mit einem Schlage, wenn eine scharfe Seebrise einsetzt und die hohen Meeresfluten über die schmale Nehrung hinwegsetzen. Alsdann wird das grosse Becken der Quittalagune und der anstossenden Sümpfe mit Wasser überflutet. Aus der trockenen Niederung ist plötzlich ein Salzsee entstanden. Die dann des Abends häufig eintretende warme Landbrise fegt das Seewasser aus der Lagune wieder heraus, während natürlich schon des Tages über ein grosser Teil des grossen flachen Wasserspiegels verdunstet ist und das Salz sich kondensiert und niedergeschlagen hat. So soll häufig das ganze Becken der Lagune mit einer weissen Kruste überzogen sein. Die Anwohner der Lagune halten nun ihre Ernte, indem sie das Salz mit den Händen zusammenscharren und in Kalabassen gefüllt in ihren Hütten bergen. Das auf diese Weise gewonnene Salz sieht etwas grau aus, weil ihm stets Sand beigemischt ist.

Häufig wird auch die Lagune künstlich mit Meerwasser bewässert, indem die Eingeborenen kleine Durchstiche nach der See machen, um Salzablagerungen herbeizuführen.

Ausser diesen Salzablagerungen im Westen unseres Gebietes finden wir aber auch noch ähnliche Verhältnisse hinsichtlich der Salzgewinnung an der französischen Dahomeküste.

Leider ist unser deutsches Togogebiet in dieserBeziehung von der Natur nicht so begünstigt, weil die verhältnismässig hohe und breite Nehrung ein Ueberfluten des Meeres in die Seeen verhindert und ausserdem die Flüsse, welche die Seeen bewässern, denselben zu viel Süsswasser zuführen.

In der Regenzeit, wo die Lagunen fast alle hoch unter Wasser stehen, ist die Gewinnung des sogenannten Eingeborenensalzes eine verhältnismässig sehr geringe und deckt dann lange nicht den Bedarf. In dieser Zeit wird ein schwungvoller Handel mit europäischem Salz von den französischen und englischen Kolonieen den Mono und den Volta herauf in das Hinterland betrieben. So geht das einheimische, sogenannte Addasalz in unser weites Hinterland, namentlich von Adda den Volta hinauf, nach Kpandu und Kratji, wo überall grosse Salzlager ron eingeborenen Händlern errichtet sind. Unser östliches Hinterland dagegen wird speziell von Grand-Popo aus mit Salz versorgt. Jetzt kann sich im Osten durch den neuen Vertrag, in dem uns die Schifffahrt auf dem Mono zuerkannt ist, auch Klein-Popo beteiligen, um durch anzulegende Stapelplätze in Topli den Handel mehr auf unser Gebiet zu leiten. 
Im Westen unserer Kolonie, wo der Hauptflussarm, der Volta, uns nicht zugänglich ist, sind wir vorläufig bei den teuren Verkehrsmitteln ausser Stande, mit dem Eingeborenensalz, so wie auch mit dem eingeführten englischen Salz zu konkurrieren. Aus diesem Grunde geht uns ein grosser Teil der Erzeugnisse des Hinterlandes, wie speziell Gummi, verloren, weil der Transport aus dem englischen oder französischen Gebiete auf dem Wasserwege leichter und mit weniger Kosten möglich ist. Diesem Uebelstande könnte durch den Bau einer Eisenbahn abge-

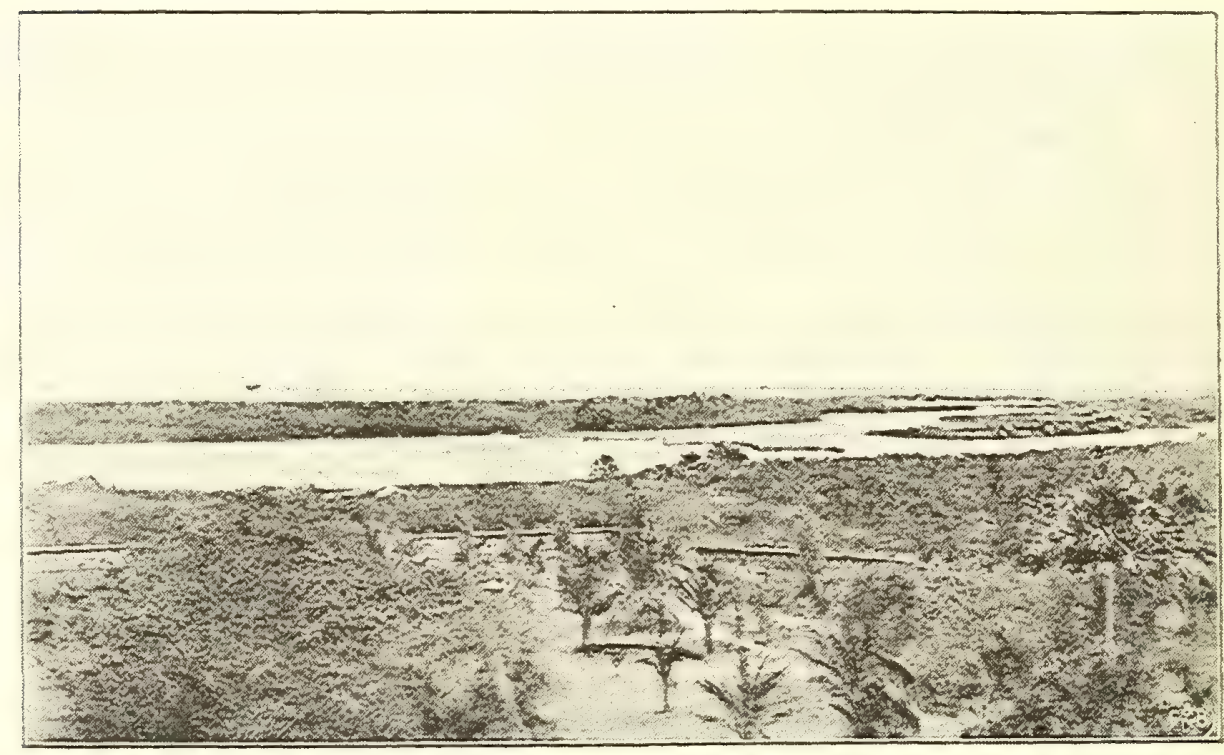

Lagunenbildung bei Klein.Popo und die eingebauten Fischreusen Von Sebbe aus gesehen.

holfen werden; jedenfalls wird unsere Regierung bei Feststellung der Westgrenze darauf Bedacht nehmen, dass uns die Schiffahrt auf dem Volta gesichert wird.

Die Lagune als Wasserstrasse.

Die Quittalagune hat in ihrer Länge eine ungefähre Ausdehnung von $40 \mathrm{~km}$, während ihre Breite etwa $\mathrm{I}_{4}$ bis I $8 \mathrm{~km}$ beträgt. Sie setzt sich hinter Lome in einer meist trocknen Thalmulde fort, die circa roo $\mathrm{m}$ breit ist und sich den Strand entlang bis zum Togosee und bis an die Mündung des Sio hinzieht. Hier beginnt mit dem Togosee unsere Wasserstrasse, die bis nach Klein-Popo führt und dasselbe mit Aguë und Gross-Popo, den Hauptstädten unserer französischen Nachbarkolonie, verbindet. Hinter der Lagune erhebt sich eine Wellenterrasse, welche Höhen bis zu $80 \mathrm{~m}$ aufweist und die uns, allmählich aufsteigend, etwa 120 bis $140 \mathrm{~km}$ in 
das Hinterland zu dem ersten Gebirgszuge, dem Agrome-Gebirge und dem Gebirge von Atakpame hinaufführt.

Bei Klein-Popo hat die Lagune mehrere Abzweigungen und Arme, von welchen die eine hart östlich von Klein-Popo bis auf cirka $100 \mathrm{~m}$ an das Meer heranreicht: Bei Hochwasser hat hier in früheren Jahren häufig ein Durchbruch stattgefunden. Diese Durchbrüche sind auch in der französischen Kolonie bei Cotonou vorgekommen, so dass zum grossen Erstaunen der schwarzen Bevölkerung im Jahre I897 ein französisches Kanonenboot bis nach Porto-novo dampfen konnte.

Bei Klein-Popo sind in der Lagune kleine Inseln, welche aber fast ganz versumpft sind und auf denen nur hohe Gräser oder die sogenannten Agobeams wachsen. Von Klein-Popo fuhrt der eine Arm der Lagune direkt nordöstlich um die Halbinsel Adjido nach Sebbe, während ein anderer Arm von Degbenu nordwestlich in einem Bogen bei Gridji in die Hauptlagune mündet.

Etwa $2 \mathrm{~km}$ nordwestlich von Gridji zweigt sich nach Norden zu ein kleiner Arm ab, welcher zu der kleinen Volagune führt. Diese bildet bei Soluga und Sokhé eine seeartige Erweiterung, die ungefähr $2 \mathrm{~km}$ breit und etwa $5 \mathrm{~km}$ lang ist. Von Soluga führt dann nordwestlich ein schmaler Arm bis nach Vo, einem äusserst wichtigen Handels- und Marktplatz für Palmenkerne. Von Sokhé und Saluga fährt man nordöstlich etwa noch $2 \mathrm{~km}$ bis ungefähr Afué auf dem See. Nordöstlich verzweigt sich die Lagune in drei weitere kleine Nebenarme, welche bei Hochwasser bis in die Nähe von Anfoi und Tro-Kutime führen.

Grosse, lange Kanoes befahren diese Lagunen und bringen die Produkte von den anliegenden Märkten herunter. Ein reges Treiben entfaltet sich an den Markttagen auf den Lagunen. Grosse, schwere Frachtkanoes, bis an den Rand mit Kernen beladen, werden von 2 bis 3 kräftigen Schwarzen schwerfällig vorwärts gestossen, während kleinere, leichtere Kanoes, die Kalabassen mit Palmöl oder auch Palmwein mit sich führen, von Weibern oder Mädchen geleitet werden. Auch Kanoes mit Schafen und Ziegen oder mit grossen Kürbisschalen, die Maismehl oder Kassava enthalten, gleiten von zwei kräftigen Burschen gestossen unter dem fröhlichen, aber eintönigen Gesange der Insassen, schnell dahin.

Neben den kleinsten Kanoes, die nicht mehr als $2 \mathrm{~m}$ in der Länge und $r / 4 \mathrm{~m}$ in der Breite betragen, sieht man auch grosse von 8 bis $10 \mathrm{~m}$ Länge, sowie $\mathrm{I}$ bis $\mathrm{I}^{\mathrm{z}} / 2 \mathrm{~m}$ Breite.

Dieses Leben und Treiben auf den Lagunen gründlich kennen zu DieBewohner lernen, hatte ich Gelegenheit, bei einer Aufnahme im Jahre i 895. Ich der mietete mir zu diesem Zwecke ein grosses Kanoe, welches 4 kräftige angrenzencen Leute stakten. $\mathrm{Zu}$ meiner Freude begleitete mich auf diesen Fahrten Dörfer 
noch ein Kaufmann, namens Lühnen, der zufällig in Klein-Popo anwesend war und Freud und Leid dieses Flissakenlebens mit mir teilte.

Bevor ich meine Reise antrat, musste ich natürlich behufs meiner Vermessung genau die Geschwindigkeit des Kanoes feststellen.

Das gerade Ufer bei Klein-Popo gab mir die beste Gelegenheit dazu; ich steckte mir hier eine Strecke von etwa $200 \mathrm{~m}$ ab, fuhr dieselbe in verschiedensten Tempos hin und her und gelangte so, nachdem ich ungefähr 3 Tage dieses fragliche Vergnügen fortgesetzt hatte, zu einem sicheren Urteil über die Geschwindigkeit meines Kanoes. Im Durchschnitt wurden in einer Minute und zwanzig Sekunden Ioo m zurückgelegt.

Unser Kanoe wurde nun mit Proviant versehen, der aus Schinken, Käse und Getränken bestand. Im Kanoe liess ich einen kleinen Stuhl und Feldtisch aufstellen; auf letzterem hatte ich meinen Kompass liegen, mit welchem ich jede Biegung der Lagune aufgenommen habe. Natürlich ist eine solche Fahrt nicht gerade eine Vergnügungsfahrt zu nennen, denn glühend heiss brennt die Tropensonne auf das kleine Kanoe und die Insassen; kein Lüftchen regt sich und keinerlei Schutz bietet die glatte trübe Fläche der Lagune. Morgens ging es vorwärts die Lagune entlang bis Gridji, wo gerade zu dieser Zeit Markt war. Gridji ist ein ansehnliches Negerdorf, welches an der flachen Anhöhe hart an dem Nordufer der Lagune liegt. Eine grosse Anzahl Kanoes liegt am Ufer, Kinder baden sich vergnügt in dem Wasser, und unter den grossen Kokospalmen, die den Markt beschatten, entfaltet sich ein buntes Treiben. Ueberall sitzen Weiber mit gefüllten Schalen und Kalabassen auf dem Markte und feilschen mit den umstehenden Käufern um den Preis. Säcke mit Palmenkernen und Kalabassen mit Palmenöl bilden hier den grössten Teil der feilgebotenen Waaren. Schwarze Händler sowie die schwarzen Angestellten der Faktoreien aus Klein-Popo kaufen diese Produkte zusammen und stapeln sie in grossen Säcken oder Fässern auf.

Auch hier wurde ein grosser Handel mit Fischen getrieben, der beliebtesten und hauptsächlichsten Nahrung der Küstenneger.

Das eigentliche Dorf besteht aus einzelnen, von Mattenzäunen umgebenen Gehöften, deren Eingang häufig von kleinen Thonfetischen bewacht wird. Diese sind meist in sitzender Stellung plump aus Lehm hergestellt; vor ihnen liegt eine Anzahl alter Knüppel, öfters auch ist ein kleines Schutzdach aus Gras über ihnen angebracht. Diese Fetische haben den $Z_{\text {weck, }}$ wie schon ihre Attribute, die Knüppel, zeigen, die bösen Geister vom Gehöfte fern zu halten.

Nicht weit von Gridji liegt eine Ziegelei, die von einem Schwarzen betrieben wird und in den letzten Jahren infolge der Bauthätigkeit in Klein-Popo einen grösseren Aufschwung genommen hat. 
Der Topfmarkt ist nicht unbedeutend, da die Töpferei an Ort und Stelle in grossem Maassstabe betrieben wird. Da Klein-Popo und Sebbe nahe liegen, stehen die Leute infolge des täglichen Umganges mit Europäern schon auf einer höheren Kulturstufe, als die Bewohner der weiter entfernt liegenden Orte. Sie bilden sich nicht selten unter Anleitung der Weissen zu Maurern oder Zimmerleuten oder sonstigen Handwerkern aus.

Die Gridjileute, wie die Leute aus Klein-Popo, vermitteln an der Küste den Verkehr, indem sie die besten Träger für die Hängematten stellen. Ferner bilden sie ein vorzügliches Trägermaterial für die Expeditionen und für die Proviantkolonnen, welche unsere weit im Innern liegenden Stationen mit Vorräten zu versehen haben. Sie eignen sich zu diesem Dienst besonders deshalb, weil sie nicht bei jeder Gelegenheit zurückschrecken, wie die ängstlichen Leute aus dem Hinterlande.

Es geht nun weiter auf der Lagune nach Westen; an dem südlichen Ufer ziehen sich grosse Grassavanner hin, während das Nordufer von cirka 40 bis $50 \mathrm{~m}$ hohen Laterithöhenzügen eingerahmt wird. Auf diesen Höhen liegen die meisten bedeutenden Orte, während das Südufer nur selten kleine Fischerdörfer oder Niederlassungen aufweist.

Diese häufig versumpften Grassavannen an dem Südufer bieten einen geeigneten Platz für die Delebpalme, die dort mit niedrigem Gesträuch vereinzelt und in Gruppen wuchert.

Wir fahren nun bei dem Einfluss der Volagune vorüber, wo ein reges Treiben stattfindet; viele Kanoes gleiten von Vo und den benachbarten Orten kommend, mit allerhand Waren beladen, an uns vorüber.

Wir passieren weiter die Orte Yankasse und Akoda, die auf den nördlichen Höhenzüge liegen, eingerahmt von Kokospalmen und mächtigen Affenbrotbäumen.

Ueberall befahren Fischer in kleinen Kanoes die Lagune, fischen Fischfang auf zu zweien mit dem Schleppnetz mit Erfolg, während andere, trotz der der Lagune. massenhaft die Lagune belebenden Krokodile in dem tiefen Schlamme bis an den Hals im Wasser stehen und ihre Wurfnetze ununterbrochen in die Fluten werfen, um die ersehnte Beute $z u$ erhaschen. An einer anderen Stelle fangen junge Leute gewandt mit der Hand kleinere Fische, welche sie in schwimmende Kürbisschalen legen, untersuchen die Uferlöcher nach den beliebten Krabben und reissen von den Felsen die wohlschmeckenden Austern ab.

Ferner sieht man alte Leute auf den Kanoes mit einer Angel sitzen und diesen Sport mit bewundernswürdiger Ausdauer und Geduld betreiben. 
Ein eigentümlicher Fischfang ist der mit den sogenannten Fischreusen. Grosse lange Zäune, die aus Ruten oder anderem Flechtwerk hergestellt sind, sperren zickzackförmig die Lagune ab und nur an einer Stelle ist für die Kanoes eine kleine Durchfahrt gelassen. In den Winkeln dieser Reusen sind kleine Fangnetze angebracht. Einen seltsamen Eindruck macht es nun, wenn man bei dunklen Nächten die Lagune befährt und in der Ferne auf derselben eine Kette von Lichtern und Feuern erblickt. In dunklen Umrissen erkennt man kleine Kanoes mit Gestalten, welche geisterhaft im Feuerschein umherhuschen. Kommt

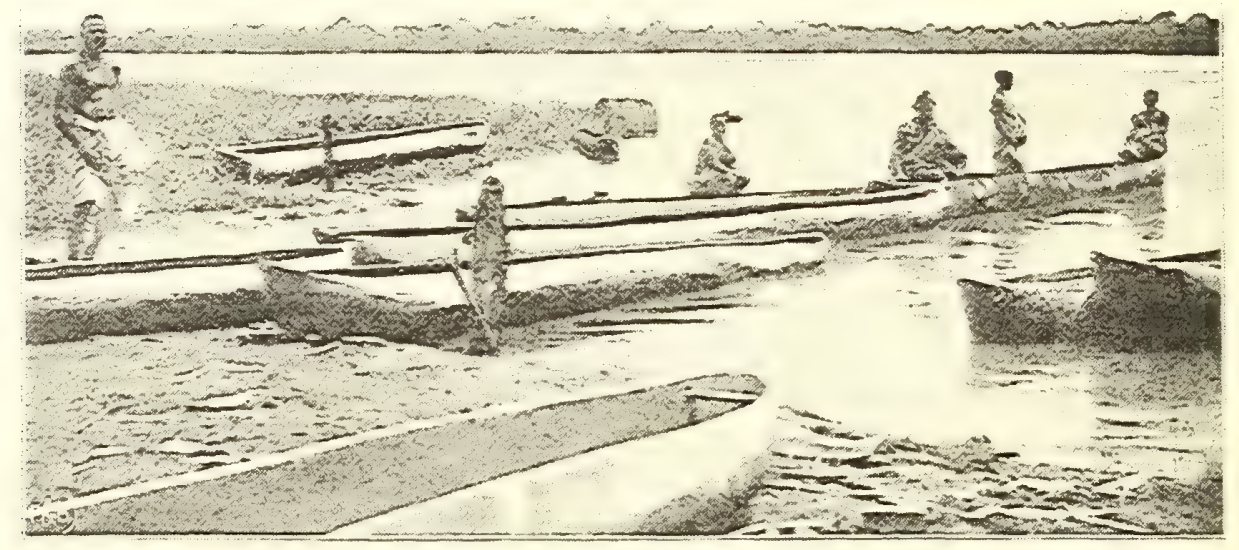

Die Lagune mit Kanoes

man näher, so sieht man, dass es Fischer sind, welche ihrer Arbeit obliegen und den günstigen Schein der Feuer für ihren Fang benutzen. Das Feuer beleuchtet die Wasserfläche vor den Netzen, die Fische folgen dem Feuerschein und steuern blindlings in die Netze.

Der Fischfang in der Lagune ist im allgemeinen ein ergiebiger. Neben den kleinen Röstfischen werden Austern und Krabben, Granellen und ein schmackhafter, mittelgrosser Fisch gefangen, der namentlich des Abends fast I bis $I^{2} / 2 \mathrm{~m}$ hoch aus dem Wasser schnellt.

Fauna der

Weiter fahren wir die Lagune entlang und passieren Banugbe mit Lagune. ca. 250 Hütten, sowie den kleinen Fischerort Apegame. Ab und zu sieht man die Schnauze eines Krokodils hervorlugen, welches gähnend 
seinen Rachen aufsperrt, um sich von der Strömung die kleinen Fische hineinspülen zu lassen. Schnell wird bei solchem Vorkommnis der Karabiner ergriffen, ein Schuss erdröhnt, das Aufspritzen des Wassers zeigt die Bahn der Kugel an; häufig aber geht der Schuss zu kurz oder zu hoch und im $\mathrm{Nu}$ ist in den schmutzigen Fluten der Lagune das Krokodil verschwunden. Nur ein wohlgezielter Kopfschuss giebt dieser scheusslichen Echse den Tod.

Kleine Strandläufer, sowie Schnepfen und andere Sumpfvögel beleben die Ufer der Lagune; auf den hohen Bäumen in den Dörfern sitzen viele Tauben, welche von den Eingeborenen als heilig geschont werden, ähnlich wie bei uns der Storch. Es sind meistens kleine Ringeltauben, mit schönem braunen Gefieder und schwarzen Ringeln am Halse; sie geben für den Europäer einen schmackhaften Braten ab.

Die kleinen gelben Webervögel haben bei Gumkovhe den schönen Hain von grossen Kokospalmen mit ihren niedlichen Nestern fast umwoben.

Ab und zu taucht ein Taucher aus den Wogen der Lagune auf, um bei dem Annähern des Kanoes sofort wieder zu verschwinden. Kleine Silberreiher, sowie schwarz und braun gefleckte Reiher, stolzieren an den Uferrändern umher; Eisvögel und Königsfischer lauern auf den Zweigen der an den Ufern stehenden Bäume auf ihre Beute. Viele Hühnerhabichte, Bussarde und Falken kreisen in den Höhen über den Dörfern und spähen nach jungen Kücheln, die hier überall massenhaft vorhanden sind; die Raubvögel sind infolgedessen den Schwarzen ein Dorn im Auge. Metallisch grün glänzende zeisigähnliche Vögel und bunte und rote Finken beleben die Uferränder. Scharen von Enten ziehen hoch in der Luft an uns vorüber nach dem Togosee.

Zwei Schwarze stossen das Kanoe abwechselnd mühsam vorwärts, den kleinen sumpfigen Inseln ausweichend, welche bei niedrigem Wasserstande häufig in der Lagune entstehen. Endlich kommt von weitem die grosse Fläche des Togosees in Sicht, dessen Fluten sich fast unbegrenzt nach Westen zu erstrecken scheinen. Nach fünfstündiger Lagunenfahrt kommen wir glücklich an die Mündung der Lagune und somit in den Bereich der Wellen des Togosees.

\section{TOPOGRAPHENLEBEN AUF DEM TOGOSEE.}

Stetig schwankt die Nadel des Kompasses und jede Abweichung wird genau mit der Uhr in der Hand notiert. Grössere Wellen kommen und das kleine Boot fängt bedenklich an zu tanzen. Die scharfe Brise, welche über die kleine Nehrung bei Porto Seguro von Süden herüber- 
weht, macht den Kanoeleuten nicht wenig zu schaffen. Alles sitzt im Kanoe ohne sich zu rühren, um ein Umschlagen des kleinen Fahrzeuges zu verhüten. Dabei versucht man den kleinen Tisch soviel wie möglich im Gleichgewicht zu erhalten.

Bei der Einfahrt in den Togosee erhebt sich auf dem Südufer desselben stattlicher Wald, der viele Fikusarten in sich birgt und von kleinen Meerkatzen bevölkert wird. Diese Kätzchen werden in der Gefangenschaft sehr zahm und folgen dann ihrem Herrn im Hause wie ein Hund auf Schritt und Tritt. In diesem Haine werden erkrankte Kinder ausgesetzt, welche, wie die Leute glauben, von dem Fetisch entweder geheilt werden, oder diesem zum Opfer fallen müssen. Den Kindern wird ein kleiner Fetisch aus Thon mitgegeben. So lange diese kleine Thonfigur bei dem Kinde verbleibt, ist es noch heilbar und wird ihm Nahrung zugeführt. Geht jedoch der Fetisch nach dem Glauben der Schwarzen von dem Kinde fort, so will er sich um dasselbe nicht mehr kümmern; alsdann wird dem Kinde die Nahrung entzogen und das arme Wesen verfällt dem sichern Hụngertode. Wahrscheinlich verhält es sich damit so, dass die berüchtigten Fetischpriester, falls sie die Familie oder die Mutter des Kindes strafen wollen, oder falls sie nicht genügend Tribut erhalten, den Fetisch selbst wegnehmen und dadurch bei den Leuten den Glauben erregen, dass das Kind vom Fetisch dem Tode geweiht sei. Diese Auslegung verdanke ich dem Leiter der katholischen Missionsstation von Porto Seguro, Pater Müller, der mir auch einen solchen Fetisch überlassen hat. Analog diesen Kinderfetischen wird allerdings auch im Evhegebiet häufig bei zu erwartenden Geburten eine solche kleine Thonfigur als Symbol vor der Hütte oder dem Gehöft aufgestellt.

Hinter diesem Haine breitet sich der Togosee in seiner ganzen Grösse vor uns aus. Etwa I I bis $12 \mathrm{~km}$ misst derselbe in der Länge und etwa $5 \mathrm{~km}$ breit dehnt er seine Fluten aus. Rastlos arbeiten die Kanoeleute der Strömung, welche von Südosten nach Nordwesten treibt, entgegen und immer näher führt uns das kleine Fahrzeug dem grössten Orte am Togosee, der Negerstadt Togo.

Das Dorf An den Lehnen des Höhenzuges, der das Nordufer des Togosees Togo. begrenzt, sieht man die fünf Teile dieser Negerstadt liegen. Der weisse Strand lehnt sich hier dicht an die steilansteigenden roten Laterithöhen. Den Kamm derselben zieren grosse Affenbrotbäume und den höchsten Punkt am Ufer des Sees krönt die Kirche der katholischen Missionsstation.

Inmitten von vielen Kokospalmen ziehen sich die kleinen Negerhütten an den Abhängen der Höhenzüge entlang. Der Kontrast der Farben, sowie die dürftigen Hütten zwischen den üppigen Kokospalmen mit dem davorliegenden weiten See, verleihen dem ganzen Ort ein 
romantisches Aussehen. Im See liegen zahllose Kanoes, den Strand bedecken die Netze der Fischer, denn der Fischfang bildet naturgemäss die Hauptbeschäftigung der Bewohner dieser Flecken. Eine Unmenge von Pfählen steht im Wasser, an denen Senkkörbe zum Fischen und Angeln befestigt sind.

Auf einem steilen Pfade gelangt man zu der Mission, welche aus drei Hauptgebäuden besteht. Die grosse Kirche, das daran stossende Schulgebäude und das grosse schöne Wohnhaus schliessen die Nordund Westseite des grossen Hofes ein. Von der Veranda des Wohnhauses überblickt man nach Süden zu den See und die Nehrung, auf welcher Porto Seguro liegt. Darüber hinaus sieht man das schäumende Meer.

In dieser Missionsstation fand ich später gastliche und liebevolle Das Lebenauf Aufnahme als ich fieberkrank und infolge der Strapazen völlig erschöpft der Mission. von meiner Reise aus Salaga zurückkehrte.

Für die liebenswürdige Unterstützung von Seiten der Missionare werde ich denselben stets dankbar sein; ich habe ihr mühevolles Wirken und ihre Thätigkeit unter Entbehrungen kennen und schätzen gelernt.

Früh des Morgens ertönt die Glocke und alles eilt zur Messe. Nach derselben geht dann jeder seiner Beschäftigung nach. Die Priester leiten mit den schwarzen Dolmetschern den Unterricht, während die Brüder sich an den praktischen Arbeiten beteiligen und den Ausbau, sowie die Instandhaltung der Gebäude sich angelegren sein lassen. Mittags wird ein einfaches Mahl eingenommen und nach einer kurzen Ruhepause geht jeder wieder zur Arbeit, bis beim Dunkelwerden die Glocke zur Vesperandacht läutet. Dann vereinigen sich wieder die Brüder zum Mahle und nach demselben wird von einem der Priester ein Kapitel aus der biblischen Geschichte vorgelesen.

Die Disziplin in einem solchen Orden ist eine vorzügliche und ein strikter Gehorsam gegen den Leiter der Station, der immer ein Priester ist, erhöht die Arbeitsleistungen. Der Priester einer solchen Station empfängt die Besuche, während die Brüder nur bei Tische erscheinen.

Der Häuptling dieses Ortes und zugleich der Fetischpriester war zu meiner Zeit der alte Blaku. Natürlich war dieser Mann für mich eine wichtige Persönlichkeit, da ich zur Auskundschaftung und Erforschung des

Besuch des Häuptlings Blaku. Sees, wie seines umliegenden Terrains, Führer brauchte, welche die Wege, Flüsse und Ortschaften kannten und mir auch Aufklärung über die Verhältnisse geben konnten. Ich begab mich daher zu Blaku, der mich schon Tags vorher besucht und mir als Geschenk eine fette türkische Ente verehrt hatte. Blaku empfing mich auf einem geschnitzten sogenannten Häuptlingsstuhl sitzend mit den Unterhäuptlingen der fünf Stadt- 
bezirke, von seinen Frauen und Sklaven umgeben. Die Häuptlinge an der Küste, wie auch weiterhin, tragen bei solchen Gelegenheiten ein grosses Tuch, das wie die römische Toga über die Schultern geschlagen wird. Bei Begrüssungen wird das Tuch von den Schultern heruntergenommen und als Zeichen der Ehrerbietung um die Hüften geschlagen. Diese einfache Tracht steht den Negern bedeutend besser, als aller europäischer Plunder. Die Tücher sind meistens von den Eingeborenen selbst gewebt und bestehen aus drei bis vier Zoll breiten, zu einem Tuch zusammengenähten Streifen. Blaku, ein grosser, kräftiger Neger mit weissem Haar und spärlichem weissen Bart, ist eine schöne Erscheinung und besitzt im Verhältnis zu den übrigen Häuptlingen des Evhe-Stammes eine grosse Macht über seine Untergebenen. Er lud mich freundlich ein, bei ihm Platz zu nehmen; ein kleiner Stuhl wurde mir gereicht und nachdem ich ihm meine Geschenke, bestehend aus Stoffen, Tabak und einer Flasche Gin überreicht hatte, wurden mir meinem Wunsche gemäss, zu meinen Fahrten einige landeskundige Leute zugewiesen. Eine grosse Kalabasse mit Palmwein wurde gebracht und nachdem mich Blaku seiner Freundschaft versichert und seiner Treue für die deutsche Regierung Ausdruck gegeben hatte, wurde die Schale mit Palmwein herumgereicht, welche Blaku nach Landessitte zuerst leerte, um mir zu zeigen, dass kein Gift darin sei.

Togo ist der Sitz des berüchtigten Yewe-Ordens, der hier grosse Verbreitung besitzt und wahrscheinlich auch meinem Freund Blaku, als Priester des Ordens, in dem Orte eine grosse Macht verleiht. Dieser Orden scheut weder vor Gift noch vor Mord zurück, um seine Macht zu verbreiten; die Priester desselben haben auch eine grosse Gewalt über ihre Jünger.

Im Hofe Blakus steht in der Mitte das Symbol eines Fetisches, nämlich ein kleiner Erdkegel, der mit Eisenstücken garniert ist. Vor den Hütten der Stadt sieht man auch hier kleine sitzende Thonfiguren, Symbole der Untergötter, die nach dem alten Glauben der Evheneger ihren obersten Gott Mawu unterstützen; auf diese Weise haben sich viele Nebengötter herausgebildet, die alle vermeintlich ihre bestimmten Funktionen haben; die eine Art der Fetische hat die bösen Geister von den Gehöften zu bannen, während ein anderer Gott die Blitze schleudert; andere wieder sind sogenannte Jägerfetische, und werden von den Jägern um gute Jagdbeute gebeten. Den Verkehr dieser Götter mit den Menschen vermitteln die Priester und Priesterinnen dieses heidnischen Ordens. Diese sind in Togo besonders zahlreich, erscheinen bei feierlichen Gelegenheiten in ihrem ganzen Staat und leiten bei mondhellen Nächten die Tänze und Orgien ihrer Glaubensgenossen. Die jungen Fetischmädchen, wie auch die übrigen Fetischleute bemalen sich bei 
diesen Gelegenheiten die Stirn sowie Arme mit Streifen won weisser Farbe, welche von der schwarzen Hautfarbe grell absticht. Ein besonderes Abzeichen der Fetischleute sind auch Armbänder und Ketten aus Kaurimuscheln. Eine ganze Reihe Halsketten aus Kaurimuscheln, Amulette aus kleinen Knochen, Federn oder Leopardenzähnen und dergleichen, werden bei Feierlichkeiten angelegt; auch Armbänder aus Messing und Kaurimuscheln zieren die Arme und nicht selten werden die Oberarme noch mit kleinen Ketten aus Kaurimuscheln geschmückt. Die Unterschenkel sind unterhalb der Kniee ebenfalls mit einer Schnur von Kaurimuscheln umbunden. Bei denjenigen Frauen und jungen Mädchen der Evhe aber, welche nicht Fetischpriesterinnen sind, bestehen die Schnüre an den Unterschenkeln meistens aus Perlen.

Als Kopfputz tragen die Priesterinnen Federn, während eine dichte Reihe von Schnüren aus Kaurimuscheln um die Hüfte den sogenannten Schlips halten. Neben den vielen Schmucksachen besteht der eigentliche Anzug bei allen anderen nicht verheirateten Evhe-Mädchen nur aus dem vorerwähnten Schlips, einem handbreiten Streifen Tuch, der hinten an der Perlenschnur um die Hüfte zu einer Rosette verknüpft ist und nach vorn durchgezogen über die Perlenschnur herunter hängt.

Nach Anwerbung der landeskundigen Leute begann die eigentliche Umfabrt des Aufnahme des Togosees.

Um seine Form festzustellen, musste ich den ganzen See dicht an den Ufern umfahren, weil ein Umschreiten desselben wegen des sumpfigen Ufers unmöglich war. Um die durchschnittliche Tiefe des Sees festzustellen, durchfuhr ich ihn seiner ganzen Länge nach und durchkreuzte ihn in seiner durchschnittlichen Breite; durch Lotungen, die ich alle ro Minuten vornahm, erhielt ich bei dem mittelhohen Wasserstande eine durchschnittliche Tiefe von 2 bis $2^{\mathrm{x}} / 2 \mathrm{~m}$.

Nach der Konstruktion dieser Routen bildet der See, was seine Form anbetrifft, im grossen und ganzen ein Dreieck, dessen gebrochene und gewundene Seiten bei dem Einfluss des Haho zusammentreffen, während die Südwestecke des Dreiecks an dem Einfluss des Sio und die südöstliche Spitze bei der Stadt Porto-Seguro liegt. Die Ost- und Westseite des Dreiecks verläuft in ziemlich gerader Richtung, während die Südseite sehr unregelmässig ist und durch weit hervortretende Landzungen unterbrochen wird. Bei Porto-Seguro tritt der See dicht an das Meer heran und ist von diesem nur durch eine schmale Nehrung von nicht mehr als $800 \mathrm{~m}$ getrennt.

An der Ostseite des Sees zieht sich, wie bei Togo, ein Höhenzug entlang, der durch den Haho unterbrochen wird. Das Nordufer ist bei der Mündung des Haho vollkommen versumpft und auch das ganze westliche Ufer ist weit über den Einfluss des Sio hinaus durchweg sumpfig. 
Am 4. September I 895 begann ich auf dem mit den notwendigsten Lebensmitteln ausgerüsteten Kanoe meine Umfahrt.

Ein Kochjunge, mein kleiner Diener Meppo und ein Führer mit vier kräftigen Leuten bildeten meine Begleitung. Vorwärts ging es an dem Ostufer des Sees entlang; die Höhen mit ihren Baobabs, die zerrissenen Ufer mit ihrem Buschwerk und ihren Schlupfwinkeln lauernder Krokodile zogen langsam an uns vorüber. Brennend heiss sandte die Sonne ihre glühenden Strahlen auf die glatte Fläche des Togosees; aber unermüdlich notierte ich meine Kompassablesungen, sowie die Uhrzeiten, denn jede kleine Krümmung verursachte eine Schwankung der Magnetnadel. Ein kleines Lot, welches ich mir in Ermangelung eines besseren Materials aus Bindfaden mit einem Pfundgewicht konstruiert hatte und das durch bunte Zigarrenbändchen die Meterzahl anzeigte, diente mir bei den Tiefmessungen dieses Gewässers. Alle ro Minuten hatte mein kleiner Meppo zu loten und nach einiger Uebung konnte ich den durchschnittlichen Wasserstand feststellen.

Nach einer guten Stunde Fahrt erreichte ich das grosse Negerdorf Ekui, das auf den steil abfallenden Lateritwänden erbaut ist. Mit den zerrissenen Wasserrinnen an den roten Lateritwänden gleicht dieses Negerdorf von weitem einer altertümlichen Felsenburg. Terrassenförmig ziehen sich die einzelnen Strassen und Hütten an dem steilen Abhange bis zur Höhe hinauf. Die einzelnen Gehöfte sind häufig mit zwei Meter hohen Lehmmauern umgeben, die vor dem Regen durch kleine Grasdächer geschützt sind. Die Bewohner dieses Dorfes sind meistens Fischer.

Wir fuhren nun weiter an der Küste entlang. Der Höhenzug tritt ron dem Ufer des Sees immer mehr zurück, das Terrain wird sumpfig und ist mit hohem Gras und Buschdschungel bestanden, in dem einzelne Fächerpalmen wachsen.

Der See hat im Norden grössere Buchten, an deren Endpunkten kleine Fischerdörfer liegen. In der Ferne sehen wir auf der Höhe Sevaga und nicht weit davon an einer dieser Buchten die kleine Fischerniederlassung Sevavi.

Eine kräftige Brise strich von dem Meere her in nordwestlicher Richtung und trieb die Fluten des Sees in die nördlichen Buchten. Da die Wellen unser kleines Kanoe von der Seite fassten, so hatten wir Mühe, es vor dem Umschlagen zu bewahren. Bald wurde es zur Seite geworfen, bald schlug eine Welle hinein, so dass wir fortwährend das Wasser ausschöpfen mussten. Ohne meine Arbeit zu unterbrechen, musste ich mit Tisch und Stuhl fortwährend die Balance des Fahrzeuges zu erhalten suchen. Man kann sich vorstellen, wie meine Bücher ausgesehen und wie bei einer solchen Reise die Instrumente gelitten haben. 
So wurde unter stetem Kampf mit den natürlichen Hindernissen jede Bucht befahren. Die brennende Sonne und die fortwährende Nässe in dem Kanoe verfehlten nicht ihre Wirkung. Hände und Gesicht wurden hochrot gefärbt, die Haut sprang auf und alle angegriffenen Teile schienen wie gelähmt zu sein.

Bei allen diesen Strapazen hatte ich grosse Freude über meinen kleinen Diener Meppo, der stets kaltblütig lächelnd meine Kanoeleute zu erneutem Eifer anspornte. Da ich bei dem geringen Proviant und der rastlosen Arbeit nicht zum Essen kam, bot er mir freiwillig ron seinen eignen Vorräten an mit den Worten: Massa, Du hast ja den ganzen Tag noch nichts gegessen. Aus solchen kleinen Fällen kann man ersehen, wie gross die Anhänglichkeit dieser Schwarzen an ihren Herrn ist, wenn sie gut behandelt werden.

Endlich senkte sich die Sonne zur Neige und beleuchtete im Norden das auf der Anhöhe belegene Dorf Degbo. Die Ebene erweitert sich jetzt nach Norden, das weite sumpfige Terrain durchschneiden im langsamen Lauf die Gewässer des Haho. Die Mündung desselben bildet ein kleines Delta, dessen Inseln die Brutstätte zahlloser wilder Enten sind. Sobald man sich nähert, gehen ungeheure Schwärme auf und umkreisen hoch in den Lüften den See.

Der Haho hat kurz vor der Mündung eine Breite von ca. 30 bis $40 \mathrm{~m}$. Ein kleiner Nebenarm, welcher anscheinend von den Bewohnern von Degbo in dem sumpfigen Terrain angelegt ist, führt uns nach dem grossen Marktplatz Degbo. Degbo sowie die übrigen Orte, die im Westen des Sees liegen, sind alle auf den ca. $50 \mathrm{~m}$ hohen Hügeln erbaut. Diese Höhenzüge rahmen gewissermaassen das Thal des Haho ein und ziehen sich dann, wie bereits erwähnt, nach Norden und Osten. Der Bergkamm, auf dem Degbo, Abobo und Lebbega liegen, begrenzt westlich von dem Flussgebiet des Haho das Westufer des Sees und fasst im Norden das Thal des Sio ein. Dieser Höhenzug bildet somit einen Damm gegen das Hochwasser.

Wir fahren den kleinen Kanal, der gewissermaassen den Hafen für Dorf Degtro. die zahllosen Fischerboote bildet, etwa eine halbe Stunde entlang und landen an dem Marktplatz von Degbo. Viele Kanoes liegen hier in den verschiedensten Grössen nebeneinander, denn ein grosser Markt hat die Anwohner des Haho und die Einwohner fast sämtlicher an der Lagune und dem See gelegenen Städte auf dem Wasserwege hierher geführt. Der grosse freie Marktplatz ist von ungeheuren Menschenmengen bedeckt, die alle geschäftig durcheinander wimmeln.

Degbo ist ein Hauptmarkt für die Kerne und das Palmöl aus den reichen Gegenden der Oelpalmzone. Von hier aus wird Klein-Popo, sowie in geringerem Maasse Porto Seguro und Bagida mit diesen Pro- 
dukten versehen. Der Markt von Degbo liegt ca. $300 \mathrm{~m}$ nördlich ron der eigentlichen Stadt und ist ein grosser freier Platz, den hohe, ron unzähligen Tauben bevölkerte Affenbrotbäume umrahmen. Sobald der Markt beendet ist, kommen die Tauben in Schwärmen herbeigeflogen, um die Ueberreste der verschütteten Maiskörner zu verzehren. Die Tauben werden von den Schwarzen nicht gejagt, sondern als unantastbar geschont. Für mich wie für meine Leute waren sie selbstverständlich ein gefundener Braten. Ein wohlgezielter Schuss bringt eine Beute von 2 bis 3 Stück ein, aber da die Scheu nur kurze Zeit dauert und sie bald wieder zusammenströmen, gewährt das Abschiessen derselben kein besonderes Jagdvergnügen. Bei solchen Reisen kommt es indessen weniger auf das Vergnügen an als darauf, für billiges Geld eine Abwechselung in den einförmigen Speisezettel zu bringen.

Degbo ist ein grosses Dorf, welches aus zwei Ortschaften besteht, von denen jede ${ }_{5}$ o Hütten zählt. Auch in Degbo befindet sich ein Clerk, der die Produkte ankauft und sie den Faktoreien in Klein-Popo übermittelt. Dieser Clerk gehört natürlich zu den Honoratioren des Ortes und macht bei der seltenen Ankunft eines Weissen die Honneurs. Auch ich nahm Gelegenheit bei ihm zu übernachten. Ein ziemlich grosser Holzschuppen, der von der Firma fur die Aufnahme der Palmkerne und der Tauschartikel erbaut ist, ist das beste und vornehmste Logis in diesem Negerdorfe.

Von dem Marktplatz erreicht man in wenigen Minuten das auf der Anhöhe gelegene Dorf Degbo-Kutime, wo eine Handels-Niederlassung liegt und cirka $400 \mathrm{~m}$ weiter westlich davon führt uns durch hohen Busch ein schmaler Pfad nach dem Orte Degbo-Sogbe.

Degbo- Ausser den kleinen Negerhütten, welche durchweg in viereckiger Sogbe Form aus Lehm gebaut und mit Gras eingedeckt sind, ist noch ein freier, viereckiger Platz, welcher von einer Art Wandelhalle umgeben ist, erwähnenswert, der sowohl bei den Ratsversammlungen als bei der Abhaltung der Tänze und Fetischspiele benutzt wird. Die Aussenwände dieser sogenannten Halle sind aus starken Lehmwänden erbaut und besitzen eine Höhe von ungefähr 3 bis $4 \mathrm{~m}$ und eine Stärke von ungefähr 30 bis $40 \mathrm{~cm}$. Die eigentliche Mauer ist etwa $\mathrm{I}^{\mathrm{x}}{ }_{4} \mathrm{~m}$ hoch und ist dann durch Lehmpfeiler weiter bis zu einer Höhe von etwa $3 \mathrm{~m}$ hochgeführt. Oefter sind die Pfeiler oben wieder durch eine Lehmmauer verbunden und mit einem Dach versehen, falls eine zweite Reihe von Innenpfeilern dasselbe halten. Von dieser Halle hat man überall einen schönen Ausblick auf den Togosee und das Hahothal.

Leider sind diese Hallen dem Verfall nahe und machen nur noch den Eindruck einer vergangenen Herrlichkeit. Wunderbar ist es, 
dass dieselben nur an diesen grossen am Togosee gelegenen Orten zu finden sind. Ihren näheren Ursprung hahe ich leider nicht ermitteln können. Von Degbo fahren wir nun nach der Mündung des Haho zurück, um hier unsere Umfahrt wieder aufzunehmen. Die Wellen kommen jetzt mehr von vorn und somit ist die grösste Gefahr für unser kleines Kanoe überwunden. Rüstig geht es auch an dem Westufer in südlicher Richtung rorwärts. Hinter dem sumpfigen Vorland liegen die Höhenzüge und von fern deuten uns die grossen Bäume und Palmen die auf der Höhe liegenden Dörfer an.

Wir passieren das grosse Negerdorf Abobugarri und landen abends bei dem Fischerdörfchen Abobo, welches den eigentlichen Vorhafen und Nachtlager in die Fischerkolonie des grossen Negerdorfes Abobo bildet. Hier wird Fischerdorf unser Kanoe an Land gezogen und in einer kleinen Negerhütte das Feldbett zur Nachtruhe aufgeschlagen. Ein Gehöft mit drei oder vier dieser kleinen Hütten gewährte uns Unterkommen. Eine kleine Hütte mit Schattendach habe ich mir zu meinem Lager ausgesucht. Das Schattendach besteht eigentlich nur aus dem verlängerten Grasdach, das weiter herunter geführt ist und von kleinen Holzpfeilern gestützt wird. In der anstossenden Hütte ist die Küche untergebracht, wo ein Küchenjunge auf einem kleinen ringförmigen Ofen, der häufig auch bloss aus drei Steinen besteht, das frugale Mahl bereitet. Die dritte Hütte, deren Lehmwände ihr Alter verraten und die einem ordentlichen Tornado nicht mehr Stand zu halten vermag, wurde von meinen Leuten eingenommen.

Der erste Wunșch ist nun, sich endlich wieder einmal ordentlich zu baden und den Schweiss abzuspülen; inzwischen sind die Jungen bemüht, ein Huhn oder etwas Yams für die Mahlzeit zu erstehen. Die Sonne ist längst hinter den Höhen verschwunden, die anbrechende Nacht bringt Kühlung, aber leider auch nicht zu unterschätzende Feinde, die Moskitos.

Die Jungen haben, da ihnen ein Huhn von den Eingeborenen nicht gutwillig verkauft wurde, ein solches erhascht und weggenommen. Alsbald erscheinen die Eingeborenen, die ihr Huhn zurückhaben wollen, doch beruhigen sie sich nach einem langen Palaver und sehen schliesslich ein, dass wir nicht ohne Nahrung bleiben können. Durch ein Geschenk von Stoff oder Perlenschnüren, das allerdings einen höheren Werth als das geraubte Huhn hat, wird der Streit vollends beigelegt.

Inzwischen wird der kleine Feldtisch aufgestellt und man macht Notizen über die Tagesereignisse.

Ueberall lodert Feuer auf den kleinen Herden, die sich zum grössten Teil vor den Hütten befinden und ihren Schein weit hinauswerfen. Vor uns liegt die dunkle Seefläche mit den fernen Feuern des Negerdorfes Ekui. Weithin tönt der Gesang und die Trommel der zum Tanz versammelten Jugend von Abbobo. 
Nachdem das Wasser zum Kochen gebracht ist und einer der Jungen das Huhn ausgenommen, flüchtig gerupft und dem brodelnden Wasser übergeben hat, wird der beste Teil der Mahlzeit, die Suppe, aufgetragen. Es folgt dann das zähe Huhn, das man noch vor einer Stunde munter herumspazieren sah. Die Mahlzeit ist hiermit beendet; aber noch darf man sich keine Ruhe gönnen, denn um Stützpunkte für die Routenaufnahme zu haben, muss man wenigstens die astronomische Breite des Ortes bestimmen. Es werden daher die Instrumente ausgepackt und an einem geeigneten Orte aufgestellt. Zunächst muss das Universal durch die Wasserwaage orientiert werden; alsdann sucht man sich die geeigneten Sterne aus; häufig ist aber das Identifizieren derselben nicht leicht, namentlich bei bewölktem Himmel oder wenn kein grösseres bekanntes Sternbild näher am Horizont steht. Es werden dann die Sternkarten aufgeschlagen und emsig nach den gewünschten Sternen gesucht. Die Jungens, welche die Laternen halten sollen, sind währenddessen eingeschlafen und liegen friedlich neben einander am Boden. Nachdem man sie endlich wieder wach bekommen hat, beginnt die Arbeit. Das Fadenkreuz wird sorgfältig eingestellt und nach einigem Visieren ist glücklich der Stern in das Fernrohr eingetreten. Aber leider hat der Junge gerade in dem Augenblick, in welchem der Stern den Faden treffen soll, das Licht ungeschickt gehalten und muss durch einen kleinen Katzenkopf zur Sache gerufen werden. Inzwischen hat der Stern in schneller Bahn das Fernrohr verlassen. Es beginnt nun die Einstellung wieder von neuem, die Zeit, die Libellen und die Nonien werden schnell abgelesen und nachdem so etwa ro Höhen auf beiden Seiten des Instruments und die Ortszeit festgestellt sind, wird im Süden oder im Norden ein Stern bei gegebener Höhe zur Breitenbestimmung eingestellt. Wie glücklich ist man, wenn man endlich nach den beschwerlichen Routenaufnahmen, den konventionellen Begrüssungen und Palavern mit den Eingeborenen und der aufreibenden Thätigkeit der astronomischen Bestimmungen das Tagewerk vollbracht hat. Leider fehlt es nun jedoch an einer anregenden Unterhaltung mit einem Weissen oder doch gebildeten Menschen der mit Verständnis auf unsere Pläne eingehen könnte. In Ermangelung dessen habe ich mir oft, wenn ich nicht zu müde war, die Zeit mit meinem kleinen Jungen vertrieben, indem ich ihm die Städte und Menschen der fernen Heimat schilderte. Eins der beliebtesten Gesprächsstoffe war immer das deutsche Militär im Vergleich zu unseren schwarzen Togosoldaten. So lange der Vorrat reichte, suchte man sich durch den Dampf einer Cigarre die unangenehmen Moskitos vom Leibe zu halten. Hier an dem sumpfigen Terrain und an den Gewässern ist der richtige Herd dieser ekelhaften Gesellschaft. Selbst wenn man über den Betten Moskitonetze hat, genügt doch ein kleines Schlupfloch, um 
ein Paar dieser lästigen Tiere hindurchzulassen, welche dann ihren Blutdurst an dem wehrlosen Opfer stillen. Man wälzt sich von einer Seite auf die andere und schlägt erfolglos um sich. Aber nicht bloss Moskitos, auch häufig der eintönige Gesang, welcher bisweilen noch zu Ehren der betreffenden Weissen veranstaltet wird, oder das fortwährende Blöken eines vereinzelten Schafes, rauben einem die Nachtruhe. Ein erlösendes Gefühl überschleicht einen, wenn man in diesem halb wachenden Zustande den ersten Hahnenruf hört und bevor noch die Sonne hervorlugt, verlässt man das Lager und begrüsst freudig den Tagesanbruch. Nachdem der Küchenjunge schnell eine Tasse Kakao bereitet, auch ein wenig Yams vom vorigen Tage aufgewärmt hat, und das Frühstück eingenommen ist, werden die Barometerstände abgelesen und brodelnd kochen zur Vergleichung mit ersterem die Siedethermometer. Hat man so auch dic Höhe des Ortes festgestellt, werden nach kurzer Begrüssung des Häuptlings, der gewissermaassen als Abgesandter den Morgengruss bringt, die Gerätschaften wieder zusammengepackt und unser kleines Gefährt flott gemacht. Der Häuptling und sämtliche Dorfbewohner strömen mit zur Lagune, um das Wundertier, den Weissen, zu sehen. Mit einem kräftigen Händedruck und einem Dank für das Unterkommen verabschiede ich mich vom Häuptling und nun steuern wir weiter nach Süden an dem Westufer entlang der Mündung des Sio zu.

Wieder geht es an sumpfigen Uferrändern vorüber und bald sendet die Sonne ihre glühenden Strahlen auf uns hernieder. Massenhaft fällt in diesen sumpfigen Gegenden der Thau nieder, weithin bezeichnen die weissen Fieberdämpfe den langsamen Lauf der Flüsse; bald jedoch werden die weissen Schleier von der am Horizont immer höher steigenden Sonne zerrissen.

Der Höhenzug, der bis jętzt das Westufer des Sees begleitet hat, verlässt dasselbe und zieht sich direkt nach Westen hin. Eine grosse sumpfige Thalmulde wird sichtbar. Viele weisse Wasserlilien und gleichsam schwimmende Grasinseln begrenzen das eigentliche Gewässer des Sees. Träge schleicht in einer Thalmulde zwischen Grasinseln der Sio dahin. Kaum erkennbar ist seine Mündung, nur eine kleine Wasserfläche, die weiter in die Mulde eindringt, bezeichnet sie. Auch wir arbeiten uns mühsam durch das Schilf, die Blattpflanzen und Grasbänke, die den Lauf des Sio versperren, hindurch, um weiter aufwärts in denselben einzudringen.

Ueberall wimmelt es von braunen Krokodilen und kleinen Reihern; auch der sogenannte Schattenreiher und die Rohrdommel haben hie: ihr Revier aufgeschlagen. Mühsam arbeitet sich das Kanoe weiter, bald erlahmt die Kraft meiner Leute, so dass ich gezwungen bin, auf demselben Wege, den ich gekommen, wieder weiter an dem Ufer des Sees 
entlang zu fahren. Der Sio hat hier gewissermaassen eine Bucht in den See gerissen, welche durch den Südrand in einer schmalen etwa $2 \mathrm{~km}$ langen Landzunge abgetrennt wird. Die Einfahrt in dieselbe ist etwa I $\mathrm{km}$ breit, während sie weiter eine Breite von $2 \mathrm{~km}$ und eine ungefähre Länge von $3 \mathrm{~km}$ besitzt. In der grossen Regenzeit dagegen soll der Sio grosse Wassermengen mit sich führen und eine für Kanoes schiffbare Wasserstrasse bilden.

Das sumpfartige Ueberschwemmungsgebiet, das derselbe beim Einfluss in den See bildet, hat eine Breite von etwa $2 \mathrm{~km}$. Obwohl das Wasser des Sio eine Tiefe von etwa $2 \mathrm{~m}$ aufweist, so ist er doch infolge seiner geringen Geschwindigkeit in seinem unteren Lauf, wie erwähnt, vollständig mit Schilf und Wasserpflanzen bewachsen. Sein mittlerer Lauf bei Adididogbo und Gablé kann als wirklich klarer Flusslauf bezeichnet werden; er ist ro bis $12 \mathrm{~m}$ breit und hat eine Tiefe von $\mathrm{I}^{\mathrm{T}} / 2$ bis $2 \mathrm{~m}$.

Hier wird der Sio von einem festen Ufer begrenzt, das von einem kleinen Galleriewald umgeben ist.

Schon oberhalb von Lebbega hat derselbe seinen eigentlichen Lauf verlassen und sich bei diesem Orte in einen grossen Sumpf verlaufen, durch den gewissermaassen seine Gewässer nach dem Togosee hin filtriert werden. Bei Lebbega ist von den Bewohnern eine Wasserstrasse, Jomme genannt, angelegt, welche etwa $2 \mathrm{~km}$ quer durch den unteren Lauf des Sio, einen Kilometer westlich von Donkovhe, auf das jenseitige Ufer führt. Von hier aus geht ein Flusspfad nach Bagida. Die bis $3 \%_{2} \mathrm{~m}$ breite Wasserstrasse verbindet direkt Lebbega und die grossen Dörfer, die im Osten vom Togosee liegen, sowie Degbo und Abobo mit Bagida. Dieser Wasserweg ist von Schilf und Wasserpflanzen vollkommen befreit und deshalb eine lebhafte Verkehrsstrasse, welche viele kleine mit Kernerprodukten beladene Kanoes befahren. Bei grosser Trockenzeit soll dieser Arm fast ganz eintrocknen und nur auf eine kurze Entfernung Wasser führen, so dass die anwohnenden Leute diese Wasserstrasse bis auf eine kleine Strecke zu Fuss zur.̈̈klegen können.

Rückfahrt an

Wir folgen nun weiter dem Ufer der Bucht in nördlicher Richtung dem Südufer und erreichen die nördlichste Spitze der vorher erwähnten Landzunge, des Sees wo die Nadel des Kompasses plötzlich nach Süden umschlägt. Von dem Einfluss des Sio aus haben wir somit die Bucht in einem Bogen von ungetähr 4 km Länge im Verlauf einer Stunde zurückgelegt. Die Ufer werden fest und der sandige Strand ist von vielen Oelpalmen bewachsen. Unser Kanoe gleitet nun rasch über die glatte, schwarze Spiegelfläche des Sees vorwärts. Das Südufer erhebt sich hier etwa I bis $\mathrm{I}^{\mathrm{x}} / 2 \mathrm{~m}$ über dem See und ist zum Teil mit dichtem Busch bestanden. So bevölkert das Westufer auf seinen Höhenzügen ist, so wenig Ansiedelungen findet 
man an dem Südrande des Sees. Nur ab und zu begegnet uns ein kleines Kanoe, welches den anwohnenden Fischern der Fischerdörfchen Agodikovhe oder Pessikonu gehört und auf dem weisseu sandigen Ufer sonnt sich zuweilen ein Krokodil. Endlich verraten menschliche Stimmen und das Krähen der Hähne die Nähe der oben erwähnten kleinen Ortschaft Agodikovhe und binnen kurzer Zeit gelangt man an den Einbuchtungen des Ufers entlang zu dem Fischerdörfchen Pessikonu.

Hier musste ich nach + Stunden Fahrt Rast machen, um meinen ermüdeten Leuten einige Ruhe zu gönnen. Ein schmaler Negerpfad führt durch den Busch hindurch in das Dörfchen. Dasselbe ist ron Oelpalmen umgeben, auch die Kokospalme und Papaya fehlen nicht: Kleine, armselige Hütten bilden den Ort; emsig stampfen die Frauen in grossen Holzgefässen ihren Fufu, die beliebteste Nahrung der Neger, welche aus gekochtem Yams besteht und einen unseren Stampfkartoffeln nicht unähnlichen Geschmack hat.

Nach weiterer dreistündiger Fahrt haben wir den Küstenplatz, der ebenfalls eine Landungsstelle hat, erreicht, um dort bis zum nächsten Tage Rast zu machen und dann die Umfahrt um den See zu beenden. Von Pessikonu steuern wir der Südostecke des Sees nach Porto Seguro zu. Das sandige Ufer ist mit kurzem Gras und Busch bewachsen und an den tiefer gelegenen Stellen erblickt man vereinzelt und in Gruppen die Delebpalme. Dies ist auch das Gebiet, wo häufig die Zwergantilope ihr Revier aufschlägt.

Das Ufer zieht sich in grossen Windungen entlang und bald kommt Togo mit den weissen Häusern der Mission in Sicht, während die hohen Bäume des Waldes dunkel die schmalen Ostufer des Sees umgeben. Der See wird von Kanoes befahren, welche von Togo nach Porto-Seguro hinübergleiten und plötzlich kommt die kleine Bucht des Landungsplatzes. von Porto Seguro mit den darauf befindlichen Kanoes in Sicht. Noch einige Minuten und wir gehen an dem Landungsplatz des Dorfes ror Anker. Die Schwarzen, die hier vermöge der Lage des Ortes, den Weissen besser kennen, kommen hilfreich herbeigesprungen und unterstützen meine Leute beim Ausladen unserer Lasten und im Bergen unserer Ladung. Zahlreiche Kinder plätschern vergnügt im Wasser umher und kleine Mädchen helfen ihren Müttern beim Waschen. Dort werden die gebrauchten Gefässe mit Sand ausgescheuert, andere waschen ihre Tücher oder baden sich, indem sie dazu reichlich die einheimische Seife gebrauchen.

Der See hat sich hier bis auf etwa $600 \mathrm{~m}$ Entfernung dem Meere Porta-Seguro genähert; nur eine kleine Nehrung, die sich 3 bis $4 \mathrm{~m}$ hoch über dem Wasserspiegel erhebt, trennt den See ron dem Atlantischen Ozean. 
Rüstig eilen meine Träger dem ihnen gut bekannten Gastplatz der Mission zu, welche hart am Meere liegt. Die Farmen durchwandernd, die auf lehmig sandigen Boden angelegt sind, passieren wir die Stadt und befinden uns in wenigen Minuten auf der Mission, wo wir von den anwesenden Brüdern freudig empfangen und gastlich aufgenommen werden.

Natürlich ist man nicht wenig erfreut, wieder einmal die erlebten Ereignisse und Gefahren, denen man ausgesetzt war, zu besprechen, auch hofft man einige Neuigkeiten von Europa zu hören.

Schon in der Frühe wird aufgebrochen und nun geht es an dem bewaldeten Ostufer des Sees entlang, bei der Einmündung der Lagune vorüber, um die Rundfahrt am Landungsplatz der Stadt Togo zu beschliessen.

Um sowohl eine Uebersicht über die Entfernung der nunmehr beendeten Route als auch die durchschnittlichen Tiefen des Sees festzustellen, befuhr ich am anderen Tage auf dem Kanoe von Porto-Seguro die Länge des Sees in nordwestlicher Richtung auf Degbo am Nordostufer zu. Die Fahrt dauerte 4 Stunden. Durchschnittlich wurden in der Minute $4^{8}$ bis $49 \mathrm{~m}$ zurückgelegt und damit hatte ich festgestellt, dass die Entfernung von der Stadt Togo bis an das Ostufer, I km südlich von dem Einfluss des Haho, ungefähr I $\mathrm{l}$ km, die Breite des Sees von Pessikonu bis Ekui aber $3 \frac{\mathrm{T}}{2} \mathrm{~km}$ beträgt.

Die Fahrgeschwindigkeit wird durch den hohen Wellengang sehr beeinträchtigt und ist fast nur halb so gross, als auf der Lagune. Es wurden Tiefen von $3,2 \mathrm{x} / 2$ und $2 \mathrm{~m}$ festgestellt, so dass man im Durchschnitt die Tiefe des Sees bei mittelhohem Wasserstande auf $2 \% / 2 \mathrm{~m}$ schätzen kann.

Triangulie- Wegen der Wichtigkeit des bis dahin in seinen Formen fast rung des Sees. gänzlich unbekannten Sees unterzog ich ihn nun noch einer Triangulation. Als Ausgangspunkt für meine Arbeiten wählte ich Porto-Seguro sowie die Stadt Togo. Auf diesen Fahrten begleitete mich zu meiner grossen Freude der schon erwähnte Kaufmann Lühnen. Auch nicht wenig unterstützte mich bei meinen Unternehmungen ein gewisser Herr Zippel, der in Porto-Seguro eine Nebenfaktorei der französischen Firma Régies frères ainés verwaltete. Da ich nur mit ganz gleichen Flaggen ausgerüstet war, so erhielt ich von ihm eine Kollektion alter Signalflaggen, die für meinen $Z$ weck immer noch gute Verwendung fanden.

Mit diesen Flaggen wurden nun die anzuschneidenden Punkte markiert. Ferner erhielt ich noch durch die Güte desselben, jetzt leider schon verstorbenen Elsässers, ein altes Marseiller Fischerboot, welches auf dem Togosee und der Lagune den Frachtverkehr zwischen der Hauptfirma in Klein-Popo und dieser Faktorei bewerkstelligte. Dieses 
Boot that mir vorzügliche Dienste, indem es die Arbeit ganz herrorragend beschleunigte, denn bei der ziemlich grossen Ausdehnung des Sees war es mir nicht immer möglich, am Abend zurückzukehren und benutzten wir dieses grosse Boot, welches etwa $+\mathrm{m}$ lang, $2 \mathrm{~m}$ breit und $I^{4} / 2 \mathrm{~m}$ tief war, während 3 Wochen als Wohnstätte. Zur Arbeit und zur Aufstellung der Flaggen diente mir dagegen ein kleines Kanoe. Das Boot wurde mit Proviant für einige Wochen ausgerüstet, unsere Betten, unser Tisch und ein Paar Stühle fanden darin Platz. Ein Teil des Bootes wurde mit einem alten Plane ron Segelleinwand bedeckt und bot so den Tag über genügenden Schutz gegen die heissen Sonnenstrahlen. Die Schwierigkeit bei unserer ganzen Arbeit war nun, die nötige Basis zur Vermessung zu finden. Zu diesem Zwecke fuhren wir nach Togo hinüber, um dort an dem Strande eine Basis von etwa $500 \mathrm{~m}$ abzumessen. Schon bei der kurzen Ueberfahrt von Porto-Seguro nach Togo stellte sich uns ein Hindernis entgegen, denn leider war das Boot für die seichten Stellen im Togosee von zu grossem Tiefgang. Da sassen wir nun mitten im See fest, ohne uns vorwärts oder rückwärts bewegen'zu können. Schnell wurde das kleine Kanoe, das immer hinten am Boote geführt wurde, gelöst und Hilfe von unserem schon bekannten Häuptling Blaku aus Togo geholt. Unsere Sachen wurden in das Kanoe umgeladen und so unser Boot erleichtert. Dann sprangen die schwarzen Gesellen ins Wasser und in der Erwartung, einen Verdienst oder ein Geschenk einheimsen zu können, hatter sich bald 50 bis 60 Leute eingefunden, die alle mit kräftigen Armen anfassten und das Boot wieder flott machten.

Wir gingen nun zuerst bei dem Dorfe Togo vor Anker und hier hatte ich endlich einmal Gelegenheit, mich für die vielen Mühen, welche die Missionare meinetwegen gehabt hatten, mit einem kleinen Frühstück zu revanchieren. Da Herr Lühnen zu meiner grossen Freude von Popo allerhand frische Konserven mitgebracht hatte, so konnte für afrikanische Verhältnisse ein opulentes Frühstück an Bord unseres kleinen Bootes eingenommen werden. Eier, Sardinen und gebratene Hühner, welche an der Küste fast $365 \mathrm{mal}$ im Jahre auf den Tisch kommen, gelten hier natürlich als Leckerbissen. Wir hatten gehofft im Boote von den lästigen Zuschauern befreit zu sein, die sich meistens an Land sammeln, um jeden Bissen mit Neid zu betrachten, den der Weisse in den Mund steckt. Aber unsere Hoffnung wurde getäuscht, denn auch hier liessen sich einige Neugierige nicht einmal durch die Furcht vor den Krokodilen abhalten und so umschaukelten uns des Abends, als wir vergnügt mit dem Becher anstiessen und unserer Heimat gedachten, kleine Kanoes, die aber wenig störten, vielmehr eine willkommene Abwechselung boten. 
Nach diesem Festtag begann am nächsten Morgen die Arbeit. Längs des breiten Strandes wurde in gerader Linie zwischen zwei Flaggen eine Strecke von genau $500 \mathrm{~m}$ mit dem Bandmass abgemessen, welche mir als Basis und Ausgangspunkt der Berechnung der Dreiecke dienen sollte. Die schwarzen Bewohner hielten dieses Verfahren für einen ganz unglaublichen Fetisch. Neugierig, aber ängstlich umstanden sie den Theodolithen und konnten meinen Jungen nicht genug über dieses sonderbare Instrument befragen. Ich steckte nun diese Basis mit den mir überlassenen Signalflaggen ab und legte die Spitze des Dreiecks gegenüber an den Landungsplatz von Porto Seguro. Dieses Dreieck, welches seine Basis an dem Strand von Togo und seine Spitze in Porto-Seguro hatte, bildete den Ausgangspunkt für die weiter anzulegenden Dreiecke, wobei immer wieder eine der Seiten des Dreiecks die künftige Basis bildet, so dass die ganze Triangulation auf diesem sehr sorgfältig gemessenen Dreieck beruht. Es war leider bei dem sumpfigen Terrain und dem mit Busch bewachsenen Ufer des Sees keine andere geeignete Strecke für eine Basis zu finden. Die Vermessung wurde noch durch astronomische Azimuthe verbessert, welche ich strahlenförmig von der Spitze des Hauptdreiecks am Landungsplatz von Porto-Seguro nach den gegenüberliegenden Schnittpunkten der Dreiecke feststellte. In Togo hatte ich zufällig den Buchstaben T von den Signalflaggen aufgestellt. Diese Signalflagge hatte eine frappante Aehnlichkeit mit der französischen Trikolore. Ich merkte schon, als ich mit der Arbeit fertig war, dass sich das ganze Volk mit dem Häuptling Blaku um die Flagge scharte, dachte aber in dem Augenblicke nichts anderes, als dass es die bekannte Neugier unserer schwarzen Evheleute sei. Als ich mich jedoch bei den Missionaren verabschieden wollte, erzählten sie mir, dass sie von Blaku, sowie von den Vätern der Stadt mit Fragen bestürmt worden wären, ob denn das Land nach so langer deutscher Herrschaft, an die sie sich nun gewöhnt hätten und unter der sie recht zufrieden wären, auf einmal wieder französisch werden sollte. Die Missionare waren selbstverständlich ganz erstaunt über diese plötzlich aufgetauchte Idee und fragten nach der Ursache derselben. Ja, meinte Blaku, dem Weissen ist nicht zu trauen, denn er hat schon ein Boot aus der französischen Faktorei und hat ausserdem alle möglichen Zaubermittel angewendet und dabei am Strande die französische Flagge gehisst. Die Missionare suchten ihm diese Ansicht so viel als möglich auszureden, aber erst nach langem Palaver waren die Leute davon abzubringen. In der Versammlung, die ich schnell einberufen liess, äusserte sich Blaku mir gegenüber, dass ich nicht einmal deutsche Soldaten, wie es sonst bei den deutschen Beamten und Offizieren üblich wäre, bei mir hätte. Ich machte ihm hierauf klar, dass ich nur zu friedlicher Arbeit 
grekommen sei und mein Aufenthalt lediglich den Zweck hätte, den Sec in seiner Grösse kennen zu lernen, und als ich ihm die Karten zeigte, welche aus meinen Aufnahmen hervorgegangen waren, ihn auch für seine, der deutschen Regierung bewiesene Treue lobte und diese mit einem Creschenk belohnte, gelang es mir, ihn zu beruhigen. Dieser Zwischenfall diente mir aber zur Warnung und ich hisste als Zeichen unserer deutschen Nationalität am Bord unseres kleinen Fahrzeuges die deutsche Flagge.

Lange noch umstanden die Eingeborenen die Flaggen am Strande und sahen unserem Gefährt nach. Ich teilte für meine Arbeit gewissermassen den ganzen See in vier Teile. Zuerst wurde der östliche Teil des Sees durch Dreiecke ausgemessen; dann begann die bei weitem schwierigere Arbeit: die Ausmessung des mittleren Teils des Sees, was nur mit Hilfe von Hilfsdreiecken bewirkt werden konnte, da. die Breite des Sees von Abobo bis Ekui etwa $4 \mathrm{~km}$ beträgt. Zur Erreichung dieses Zieles wurde mitten im Togosee ein grosser Flaggenstock aufgestellt, der den Schnittpunkt und die Spitze der vom Lande aus gemessenen Dreiecke bildete. Dann wurde der nordwestliche Teil des Sees durch Dreiecke verbunden und zuletzt der südwestliche Teil, der eigentlich nur eine Bucht des Sio ist, vermessen. Nachdem ich zuerst meine Dreiecke auf dem Papier konstruiert hatte, begann um 6 Uhr früh die Fahrt auf dem kleinen Kanoe. Man kreuzte den See hin und her, um an den bestimmten und geeigneten Punkten die Flaggen aufzustellen und so ein Dreieck an das andere anzufügen. Die Flaggen wurden dicht an das Ufer in den See gesteckt, da häufig das schlammige L'fer es nicht zuliess, die Instrumente dort aufzustellen.

Man musste sich zu diesem Zweck in das Wasser begeben, was bei der warmen Tropensonne nicht weiter unangenehm gewesen wäre, wenn man nicht stets auf Krokodile hätte gefasst sein müssen. Zur Abwehr dieser scheusslichen Echsen, von denen es namentlich am Sio wimmelt, stellte ich stets einen der Leute mit Karabiner auf, welcher auf die verdächtigen Stellen im Wasser zu schiessen hatte. Nachdem ein neues Dreieck durch die Flaggen markiert war, wurde dasselbe sofort durch die Messung der Winkel mit dem Theodoliten festgelegt. Denn häufig kam es vor, dass die Flaggen durch den Wind oder in Folge der Brandung umgeworfen wurden. Durch die von mir eingeschlagene Methode war jedoch, indem ich die Flaggen nur an markanten Punkten aufstellte und sofort jedes der Dreiecke an demselben Tage maass, ein Irrtum ausgeschlossen, man hatte nur die Mühe, die Flaggen an den bezeichneten Stellen wieder aufzustellen. Die roten Flaggen bewährten sich am besten, da sie am weitesten zu sehen waren. Das Instrument wurde im geeigneten Moment 
gleichfalls in das Wasser gestellt und die Ablesung wie das Einstellen desselbẻn wurde, bis an die Brust im Wasser stehend, bewirkt. Selbstverständlich ist eine mit so vielen Strapazen verbundene Arbeit der Gesundheit nicht gerade zuträglich. Sowohl Herr Lühnen wie ich büssten diese Fahrten mit einem tüchtigen Fieber.

Meistens verliess ich früh um 6 Uhr unser Boot, auf dem nun Herr Lühnen allein weiter waltete und kehrte dann, nachdem der See einige Male hin und her durchkreuzt und wiederum eine Fläche vermessen war, nachmittags, wenn die Sonne sich schon bedenklich zum Horizont geneigt hatte, zu unserem Boot zurück, wo ich mit Freuden von Herrn Lühnen empfangen wurde. Denn oft lag unser Gefährt, gerade wie es die Arbeit bedingte, an einem verlassenen und stillen Ufer des Sees. Und so gab es wenig Abwechselung für Herrn Lühnen, der meine Fahrten gerne mitgemacht hätte. Er hatte indessen die Verwaltung unserer spärlichen Küche übernommen; ausser Schinken, den wir zur Sicherheit mitgenommen hatten, stand fast täglich auf dem Küchenzettel Fisch und abermals Fisch. Ein Gemüse, wie Yams, war mitunter schwer aufzutreiben, da die Ortschaften häufig zu weit von unserem Boot entfernt lagen. Der Küchenjunge versuchte des Morgens alles, was irgend wie in der Nähe $z u$ haben war, für uns und unsere Leute zu erhaschen. Die unzähligen Fischer, welche auf dem See ihrer Arbeit oblagen, versorgten uns mit Fischen ziemlich reichlich, so dass wir wenigstens dieses, häufig fast einzige Gericht nicht zu entbehren brauchten. Die Fischerei wurde teils in kleinen mit Segeln versehenen Kanoes betrieben, teils waren mitten im See Pfähle aufgestellt, an denen, wie in der Lagune, Senkkörbe oder Angeln für den Fischfang ausgelegt waren. Bei Sonnenuntergang zogen die Fischer mit ihrer Beute bei uns vorüber und belebten öfters unseren einsamen Ankerplatz, den wir gewöhnlich am Südufer des Sees aufschlugen, um hier Schutz vor der Brise und den Wellen zu haben. Kein anderer Laut war häufig in unserer stillen Bucht zu hören, als das Plätschern des Wassers, welches an das Ufer schlug, das Krächzen eines Raubvogels oder das Geräusch einer aufgescheuchten Antilope. Herr Lühnen, welcher in meiner Abwesenheit oft auf Jagd ging, erlegte einmal zu unserer, wie unserer Leute grossen Freude, eine Schir-Antilope, die eine Abwechselung in unser tägliches Menu brachte.

Wenn es das Ufer einigermaassen gestattete, erfrischte man sich des Abends an einem Bade in der Lagune.

Unbequemlichkeiten bereitete uns auch die Wasserbeschaffung auf dem Togosee, denn das Seewasser ist brackig. Infolge der Nähe des Meeres wird es durch die schmale Nehrung gewissermaassen im Untergrunde filtriert. Häufig findet auch an den Durchbruchstellen, bei dem 
Fallen des Sees, ein Rückfluten des Seewassers statt, bis die rastlose Brandung den Durchbruch geschlossen hat. Auf diese Weise erklären sich wohl die grossen Salzablagerungen, die sich in der Kitta-Lagune vorfinden.

Des Abends schlugen wir auf unserem Boot den Plan zurück, um uns an der Kühle, welche die einbrechende Nacht mit sich brachte, $z u$ erfrischen.

Auf dem Vorderteil des Schiffes brannte helllodernd das Feuer, auf welchem unser frugales Mahl bereitet wurde. Nachdem mein kleiner Junge Meppo uns gravitätisch die Schüsseln mit dem Fisch serviert und wir unseren. Hunger gestillt hatten, wurden Tisch und Stühle entfernt und unsere Feldbetten aufgestellt. Mit knapper Not fanden gerade zwei schmale Bettstellen im Boote Platz. Stets war des Nachts eine Wache aufgestellt, um auf unsere Sachen und Boote zu achten. Nur hin und wieder kam noch ein einsames Kanoe angeschlichen, welches die ausgelegten Angeln untersucht hatte und nun nach Hause zurückkehrte. Ein tiefer dunkler Schleier senkte sich über den See und in herrlicher Pracht erglänzten die Sternbilder am dunklen Firmament. Häufig, namentlich bei mondhellen Nächten, störte der Ton der Trommel von den gegenüberliegenden Ortschaften unsern Schlaf und die Moskitos liessen uns trotz aller Netze auch hier keine Ruhe, doch nach einiger Zeit gewöhnt man sich sogar daran. Während es am Tage glühend heiss ist, wird es des Morgens und Abends beim Fallen des Thaues verhältnismässig kühl, ein erquickender Morgenschlummer bis zum Tagesgrauen gewährt dann die nötige Erfrischung.

Wir verlegten nun unseren Ankerplatz an die schmale Landzunge, welche die Bucht des Sio einschliesst. Von hier aus wurde nach Abobo hinüber gemessen und weiter im Süden genau der Einfluss des Sio festgestellt. An seiner Mündung wimmelte es von Krokodilen. Leider hatte mein guter Begleiter, trotz aller meiner Mahnungen schon vorher fast sämtliche Patronen verknallt, so dass nur noch einige zur Sicherheit für uns übrig geblieben waren. So kam es vor, dass, als wir mit dem Kanoe über ein Krokodil wegfuhren, welches sich vor unseren Augen unter unserem Boote in den Schlamm verkroch, wir nur noch mit unseren Staken darauf losschlagen konnten. Gott sei Dank sind diese scheusslichen Echsen sehr feige und greifen weder Kanoes noch, wie ich gehört habe, Leute auf dem Festlande an. Desto getährlicher sind sie im Wasser, wo sie im tiefen Schlamm versteckt, unterhalb der Oberfläche über ihre sichere Beute herfallen. Bei diesem sumpfigen Terrain konnten wir uns daher nicht in das Wasser wagen. Ich stellte also von dem Kanoe aus das Theodolith mit dem Stativ in den Sumpf und machte in dem Kanoe liegend meine Ablesung, während die 
Leute mit Staken bewaffnet auf die Krokodile aufzupassen hatten. Wir steuerten hierauf dem letzten Punkt, dem kleinen Fischerdorf Abobo zu. Auf diesem Wege geschah es, dass sich unser Boot bei dem geringen Wasserstande wieder festsetzte und wir mussten mit Hilfe unserer und der Leute von Abobo Hilfe das Boot eine ganze Strecke über eine Sandbank herüberziehen, ehe wir wieder flott waren.

Es wurde nun die letzte Hand an die Triangulation des Togosees gelegt, indem noch die Einmündung des Haho bestimmt wurde.

Auch auf dieser Fahrt begleitete mich Herr Lühnen in einem kleinen Kanoe. Auf der kleinen Insel, welche das Delta des Haho bildet, wimmelte es von Enten; es war für mich ein ganz besonderes Vergnügen, hier der Jagd mit unseren Schrotflinten obzuliegen; wir mussten indess abends lange hinter Buschwerk sitzen, bis die Enten vorsichtig aufgingen, hoch über uns kreisten und dann in das Wasser einfielen. Endlich kamen wir zum Schuss und erlegten ein paar Enten, welche einen schönen Braten für uns abgaben. Aber unsere Beute sollte nicht so leicht erkauft sein, wie es uns schien. Schon jagten alle die kleinen Fischerboote in Eile ihrem Ankerplatz zu, denn ehe wir uns noch besinnen konnten, hatte sich ein mächtiger Sturm erhoben. Mit Windeseile kamen die Gefahr drohenden Wolken herangezogen. Sie bilden die Vorboten eines in den Tropen häufig eintretenden Naturereignisses, des gefürchteten Tornado. Der Sturm peitschte die schwarze Flut und nur mühsam konnten wir vorwärts kommen. Mit einem Schlage war der See von sämtlichen Schifferbooten verlassen. Der riesige Sturm benahm einem fast den Atem, und die Wellen gingen immer höher. Alle Vögel und Tiere hatten sich geflüchtet; ein schwerer, lang gedehnter Donner durchdröhnte die Luft und in grossen Tropfen fiel der Tropenregen nieder. Binnen kurzer Zeit waren wir bis auf die Haut durchnässt und sassen mitten im Wasser, welches das Kanoe anfüllte. Mit Hilfe unserer grossen Tropenhelme konnten wir dasselbe ausschöpfen und unser Kanoe vor dem Sinken bewahren. Wir flüchteten aufs Land unter einen grossen Baum, der am Ufer stand, hockten beieinander und mussten uns nolens volens von dem Regen peitschen lassen. Nach einer Stunde hatte die Heftigkeit desselben nachgelassen und nun konnten wir wieder unser Boot betreten. Zähneklappernd sassen wir zusammen im Kanoe, denn der furchtbaren Glut der Sonne war nach dem Tornado empfindliche Ảbkühlung gefolgt, welche in den nassen Kleidern unsere Glieder fast erstarren liess. Unser Schrecken war nicht gering, als wir unser Boot wieder mit Wasser angefüllt vorfanden; die Leinewand und das Gestell, welches dieselbe trug, waren vom Sturme heruntergerissen und Kisten und Koffer schwammen im Wasser umher. Unsere Leute hatten sich in das naheliegende Fischerdörfchen Abobo geflüchtet, so 
dass uns weiter nichts übrig blieb, als uns ebenfalls dorthin zu begeben. Da unsere sämtlichen Sachen durchnässt waren, so mussten wir an das Mitgefühl der schwarzen Bewohner dieses Ortes appellieren. Alles drängte sich in eine kleine Hütte, wo unsere Leute Feuer angemacht hatten, um ihre Tücher zu trocknen und sich zu erwärmen. Auch wir versuchten dies zu thun und nach Ablegung unserer sämtlichen Kleider paradierten wir zum nicht geringen Erstaunen der Schwarzen in ihren sogenannten L awa-Lawa, einem Eingeborenen-Tuch, das uns ein alter Mann zur Verfügung gestellt hatte; inzwischen wurden unsere Sachen am Feuer getrocknet. Unter diesen Umständen mussten wir uns für die Nacht in dem kleinen Dorfe einquartieren und konnten erst am nächsten Tage mit der Reinigung unseres Bootes beginnen. Kisten und Kasten wurden nun ausgepackt und den Strahlen der Sonne zum Trocknen ausgesetzt. Das Wasser wurde fleissig ausgeschöpft und das Boot vom Schlamm gereinigt. Am Nachmittag waren wir wieder soweit, um nach unserem nächsten Ziel, Degbo, zu steuern.

Nachdem wir uns in Degbo von neuem verproviantiert hatten, setzte ich am nächsten Tage unsere Reise mittelst Kanoe auf dem Haho weiter aufwärts fort, um denselben auf seine Schiffbarkeit zu prufen und die anliegenden Ortschaften zu erforschen. Wir verliessen den Togosee, der uns mehrere Wochen beschäftigt hatte.

\section{REISE AUF DEM HAHO \\ UND IN DEN ANGRENZENDEN GEBIETEN DES WEST- UND SÜDUFERS AM TOGOSEE.}

Am 25. September 1895 trennte ich mich ron meinem Reisebegleiter Herrn Lühnen, der die Liebenswürdigkeit hatte, das geliehene Boot nach Porto-Seguro zurückzuführen. Jetzt war ich wieder auf mich und meine Schwarzen allein angewiesen. Am nächsten Morgen liess ich alle Sachen packen und fuhr auf dem Kanoe von Degbo ab. Das Wasser war infolge der langen Trockenzeit sehr gefallen und nur eine ganz kleine sumpfige Wasserrinne führte uns von Degbo zur Mündung des Haho. Dieser Fluss, der hier in einer ungefähren Breite von 20 bis 30 Meter langsam in ein aus zwei Armen bestehendes Delta übergeht, hat an dieser Stelle bei der Trockenzeit die beträchtliche Tiefe von ungetähr $3^{\mathrm{x}} / 2 \mathrm{~m}$. Langsam und in grossen Windungen fliesst er durch das versumpfte etwa $3 \mathrm{~km}$ breite Thal. Dasselbe wird im 
Osten und Westen von geringen Höhenzügen begrenzt, welche nach meiner Schätzung den Wasserspiegel des Haho etwa um $30 \mathrm{~m}$ übersteigen. Anfangs ist das Ufer ohne jeglichen Baumwuchs, weiterhin etwa $4 \mathrm{~km}$ nördlich von der Mündung des Haho, wird es von einem dichten Urwald begrenzt. Hier wimmelt es in den Gipfeln der hohen Bäume von Affen und Vögeln, während das Krokodil wieder die Ufer des Flusses unsicher macht. Man fährt nun wie unter einem Laubdach in dichtem Schatten auf dem Fluss, der eine durchschnittliche Breite von $20 \mathrm{~m}$ und eine Tiefe von etwa $3 \mathrm{~m}$ hat. Bei mittlerem Tempo legt man den Weg bis nach der kleinen Niederlassung Akodeseva, welche der Faktorei von Wölber \& Zimmermann in Klein-Popo gehört, in zwei Stunden zurück. Die Niederlassung besteht nur aus einigen armseligen Hütten, die gleich den übrigen typischen Hütten aus Lehm aufgeführt und mit einem Grasdach eingedeckt sind. Hier wohnt ein schwarzer Agent der erwähnten Firma, welcher die Kerne und das Oel von den umliegenden Ortschaften aufkauft und auf dem Wasserwege nach KleinPopo abführt. Trotz der erhaltenen Mahnung von dem Agenten setzte ich meine Reise weiter auf dem Haho fort. Aber schon gleich hinter dem eben verlassenen Orte begannen die Schwierigkeiten, denn die Bäume und das Gebüsch, welche dicht das Ufer bestanden, bildeten mit ihren Aesten und Zweigen ein grosses Hindernis beim Fortkommen. Mühsam musste man unter den herabhängenden Aesten durchfahren oder sie mit dem Haumesser abschlagen, um sich stossweise weiter zu arbeiten. Nach einer Stunde Fahrt - man kann wohl sagen Arbeit - hatten wir uns glücklich bis zum Einfluss eines kleinen Nebenflüsschens, des Lilli, durchgewunden, der in einem Winkel von $75^{\circ}$ in den Haho einmündet. Auch der Lilli soll bei Regenzeit beträchtliche Wassermengen führen, während er zu jener Zeit nur eine kleine Wasserrinne von etwa $3 \mathrm{~m}$ Breite bildete und seiner geringen Tiefe wegen nicht zu befahren war.

Um mich von der Schiffbarkeit des Haho zu überzeugen, zumal unrichtige Vorstellungen über seine Grösse herrschten, scheute ich nicht die mühsame Arbeit, die versperrenden Aeste aus dem Wege zu räumen, auch häufig das Kanoe über die grossen vermorschten Baumstämme hinüber zu ziehen und auf diese Weise vorwärts zu dringen. Umfangreiche Dornensträucher liessen ihre langen $Z$ weige herabhängen und ritzten nicht selten unsere Haut. Unzählbar waren die grossen Schwärme von Moskitos und anderen kleinen Fliegen- und Mückenarten, die sich über dem Wasser tummelten und uns stets umschwärmten. Alle Augenblicke schlug uns zur Abwechselung ein Zweig ins Gesicht oder man stiess mit dem Kopf heftig gegen einen überragenden Ast, so dass diese Fahrt nicht gerade zu den angenehmsten Wasserpartieen zu rechnen war. Trotzdem verfolgte ich peinlich meine Kompassrichtung. 
Zahlreiche Vögel hatten ihre Nester an den Uferrändern und belebten durch ihr Gezwitscher die Landschaft. Reizend sahen die Nester der kleinen traulichen Webervögel aus, welche kunstwoll in grossen Mengen an dünnen Zweigen über dem Wasser hingen.

Der Haho wurde jetzt schmäler und wies nur noch eine Breite von etwa ro $m$ auf. Auch die Tiefe nahm ganz beträchtlich ab; die letzten vorgenommenen Lotungen betrugen $\mathrm{I}^{\mathrm{r}}{ }_{2}$ und kurz darauf nur noch $\mathrm{I} \mathrm{m}$, so dass ich gezwungen war, die weitere Fahrt aufzugeben. Ausserdem hatten sich jetzt zu den Hindernissen, welche die Baumstämme verursachten, zu unserem grossen Aerger aus Flechtwerk hergestellte und quer über den Fluss gelegte Fischreusen gesellt. Es blieb uns nichts anderes übrig, als diese Reusen zu durchhauen, um mühsam unser Kanoe weiterzuschieben und irgend eine menschliche Niederlassung zu erreichen. Endlich wurde der dumpfe Schlag eines Haumessers, welches beim Fällen von Bäumen gebraucht wird, sowie das Knistern der herunterfallenden Zweige hörbar, was auf die Anwesenheit eines menschlichen Wesens schliessen liess. Gerade als wir uns wieder durch eine Fischreuse eine Durchfahrt verschaffen wollten, trat eilig aus dem Dickicht ein Schwarzer, der uns wütend drohte und sein Messer in der Luft schwang. Wir verliessen alsbald unser Kanoe und sprangen an Land, um uns nach einem Pfad nach dem nächsten Dorf zu erkundigen. Aber der Mann, der ja eigentlich in seinem Rechte war, schimpfte rasend darüber, dass wir ihm seine Reusen zerstört hätten und drohte uns niederzuschlagen. Schon hatte mir Meppo, mein kleiner Freund und Diener, meinen Karabiner aus dem Kanoe gereicht. In diesem kritischen Augenblicke stürzten sich auch schon meine Leute auf den Wüterich, bewältigten ihn, entwanden ihm das Messer und banden ihn. Sein Mut hatte sich nun gelegt und da er glaubte, dass ich ihn entweder zum Sklaven machen oder töten würde, sagte ich ihm auf sein flehentliches Bitten, dass er diesmal noch mit dem Leben davon kommen solle, wenn er uns den richtigen Weg nach Hahoté zeigen würde. Er versprach dies zu thun. Da ich die Reise zu Wasser nicht weiter fortsetzen konnte, gab ich zwei Trägern den Befehl, mit dem Kanoe nach Degbo zurückzufahren; ich selbst mit den übrigen vierTrägern ging unter Führung unseres Gefangenen auf einem schmalen, wenig betretenen Pfade, welcher sonst wohl nur von Fischern und Jägern benutzt wurde, durch den Wald. Von weitem sahen wir das auf einer Anhöhe liegende Dorf Hahoté. Wir passierten alsbald ein kleines Gehöft und befanden uns dann auf einem grossen ausgetretenen Pfade. Ein Höllenlärm schallte aus Hahoté zu uns herüber, denn die Eingeborenen hielten eine sogenannte Totenfeier ab. Wir stiegen die kleine Anhöhe hinauf und bald waren wir von der schwarzen Bevölkerung umringt, die nur selten einen 
Weissen gesehen hatte. Drohungen wurden laut und unser schwarzer Pfadweiser fühlte sich hier wieder sicher und begann seine Verwandten und Freunde gegen mich aufzuhetzen. Nur durch die Vermittelung des Häuptlings, wie durch das besonnene und einsichtsvolle Zwischentreten der älteren Leute gelang es, die aufgeregte Menge von Gewaltthätigkeiten zurückzuhalten. Nachdem sich das Volk von der Berechtigung meines Verfahrens überzeugt, und ich dem Gefangenen die Freiheit wiedergègeben hatte, würden mir ein paar Hütten im Gehöft des Königs zum Aufenthalt angewiesen. Bald darauf brachte mir der König seine Geschenke: Yams, Kassawa und Maiskörner; aber auch der Freigelassene spendete mir von der Beute seines Fischfanges eine grosse Menge, ferner ein Huhn und einen grossen Haufen Yams; indem er nach Landessitte sich auf die Knie warf und zur Erde beugte, sprach er die Dankesworte: „Donna donnalo", d. h. "Ich danke sehr". Jamit er einsah, dass ich nicht die Absicht gehabt hatte, seinen Fischfang zu stören und seine Reusen zu beschädigen, gab ich ihm das übliche Gegengeschenk und später noch eine besondere Entschädigung in Form von Zeug, worüber seine Freude übergross war.

Am nächsten Morgen wurden mir von dem Häuptling bereitwilligst Führer zur Verfügung gestellt und weiter ging die Reise nach unserem nächsten Ziel, dem grossen Negerdorf Bogame. Diesen Weg hatte ich speziell gewählt, um bei Hahoté den Haho, sowie die Nebenflüsse desselben genauer festzustellen. Ich zog zunächst mit meinen Leuten auf dem direkten Wege nach Bogame. Hier boten sich bei dem Ueberschreiten des Haho neue Schwierigkeiten, denn viele kleine Bäche, sowie der Lilli bildeten oberhalb ihres Zusammenflusses einen grossen Sumpf und Morast. Fast bis über die Kniee versank man in den Sumpf und alle Augenblicke musste ein kleiner Bach überschritten werden, so dass meine Träger mit ihren Lasten nur mühsam in dem hohen Schlamme den Hato und den Lilli passieren konnten. Um dies überhaupt bewerkstelligen zu können, stellten sich die Leute in diesen Flüssen in kurzen Abständen auf und einer reichte dem anderen die Last, da es für einen beladenen Träger fast unmöglich war, sich durch den tiefen Morast hindurch zu arbeiten. Wenn schon meine Schwarzen nach dieser Arbeit nicht gerade schön aussahen, so war ich ihnen gegenüber doch ganz bedeutend im Nachteil; denn mein gelber Anzug zeigte durch seine schwarze Färbung deutlich die Tiefe des Sumpfes an. Ein grosser hoher Busch bildete hier mit den Wasserpflanzen einen undurchdringlichen Wald, der an den sumpfigen Stellen mit hohem Schilf bestanden war.

Wir eilten nun dem Höhenzuge entgegen, auf dem Bogame liegt, und der den Ausläufer des Höhenzuges an dem Westufer des Togosees bildet. Nach dreistündigem Marsche erreichten wir das grosse Dort 
Bogame. Hier machten wir halt und hatten Gelegenheit unsere Kleider rom Moraste zu reinigen; aber wie gross war mein Schrecken, als ich bei dem Auspacken der Sachen bemerkte, dass die Butter in der Blechbüchse ausgelaufen war und in dem Koffer meine sämtlichen Sachen, ja selbst auch zum Teil meine Bücher und Karten durchdrang. Noch lange wurde ich durch den zurückgebliebenen üblen Geruch an diesen Marsch erinnert.

Am nächsten Tage marschierte ich, immer dem Höhenzuge folgend, über Degbo nach Abobo und Lebbega. Auf dem Wege von Bogame nach Lebbega traf ich viele Leute, welche teils rom Narkte kamen, teils wieder nach dem Markte von Degbo-Gbome gingen. In Degbus herrschte ein reges Treiben, so dass man sich nur schwer durch dic Menge hindurchwinden konnte. Hier kam es leider beim Einkaufen zu Unzuträglichkeiten zwischen einem meiner Träger und den Marktleuten

Wir marschierten durch Degbo hindurch und bekamen wieder einen schönen Ausblick auf den Togosee, der im Osten die Ufer der weiten Ebene bespült. Viele grosse und mächtige Baobabs krönten die Höhen, überall trat hier der Lateritboden zu Tage. Wie rote Fäden zogen sich die Wege durch den grünen Busch entlang und nach $\mathrm{I}^{\mathrm{T}} / 2$ stündigem kräftigen Marsch gelangten wir nach dem grossen Negerdorfe Abobo. Schon vorher liegen im Osten und Westen des Pfades kleine Farmdörfer, wie Bogeli, Abobugarri mit etwa roo Hutten und das kleine Farmdorf Bogodeyi. Breite Wege verbinden diese drei Dörfer. Die kleinen Gehöfte sind auch hier im Viereck angelegt und mit Mattenzäunen umgeben, während mächtige Kokospalmen, zuweilen auch Oelpalmen innerhalb der Gehöfte stehen. Die Wohnhäuser sind sämtlich aus Laterit erbaut und scheinen infolgedessen rot angestrichen. Sie gewähren mit ihren alten von der Witterung und vom Rauch geschwärzten Grasdächern von der Höhe aus gesehen ein farbenreiches Bild.

Wir liessen nun die vorher beschriebenen Dörfer liegen und kamen auf einem grossen ausgetretenen Pfade so zu sagen nach einer Grossstadt, dem- Dorfe Abobo, welches etwa 500 Hütten aufweist. Da man hier bei der dichten Bevölkerung im Durchschnitt 4 Personen auf jede Hütte rechnen kann, so zählt dieser grosse Negerort ungefähr 2000 Bewohner. Eine grosse Schar Kinder, die uns am Eingange des Dorfes bemerkt hatte, verbreitete schnell in dem Ort die Ankunft eines Weissen und bald folgte uns durch die engen und schmutzigen Strassen eine neugierige Menge, bis wir auf den grossen Marktplatz gelangten, wo wir uns auf einem geglätteten Baumstamm niederliessen. Hier wurde Rast gemacht und ich nahm einen kleiner Imbiss in Gestalt von Pagaya ein. Es ist dieses eine Baumfrucht mit einer grünlichen Schale, die bei der Reife gelblich wird und zuweilen die Grösse eines kleinen Kinderkopfes 
erreicht. Das innere zarte aromatische Fleisch, die Pulpa, wird mit dem Löffel gegessen und hat einen süsslichen Geschmack. Häufig geniesst man die Frucht auch mit dem Saft der Limone, einer kleinen Citronenart, die ebenfalls hier überall angepflanzt wird.

Rings um den Markt herum haben sich die jugendlichen Bewohner gesammelt, um jeder Bewegung des Weissen zu folgen; öfters werden von einem Witzbold über die komischen Manieren des Weissen Witze gemacht. Natürlich stimmt dann der Chor in das Gelächter ein und die jungen Damen des Landes stossen sich an und kichern ebenso vergnügt und verschämt im Hintergrunde, wie unsere Dirnen auf dem Lande. Die kleinen schwarzen Buben und Mädchen, die nur mit dem Fell, welches ihnen die Natur bei ihrer Geburt verliehen hat, bekleidet sind, flüchten vor dem Weissen zu ihren Müttern. Auch hier sind die einzelnen Stadtviertel von Mauern umgeben, welche häufig noch mit Kaktusarten umpflanzt werden; durch eine schmale Oeffnung gelangt man von einem Teil zum andern.

Wie Degbo hat Abobo ebenfalls einen Palaver-Platz, dessen Hallen allerdings nur noch Ueberreste der früheren Herrlichkeit sind.

Von Abobo führt ein ziemlich breiter Pfad nach dem kleinen Fischerort gleichen Namens, den wir schon vorher an dem Togosee kennen gelernt haben.

Nachdem noch die üblichen Begrüssungen des Häuptlings des Ortes stattgefunden und wir gegenseitig Geschenke ausgetauscht hatten, marschierte ich unserem nächsten Ziel und Nachtquartier, dem grossen Negerdorf Lebbega zu. Wir passieren die rechts und links des Weges liegrenden Farmen von Abobo; etwa I km südwestlich von Abobo teilt sich der Pfad in zwei Wege, von denen der eine direkt nach Lebbega, der andere nach Lebbevi, dem Landungsplatze des Yomme führt. An der Kreuzung des Weges bewacht ein grosser Lehmfetisch, welcher in üblicher sitzender Stellung unter einem kleinen Schattendache angebracht ist, die Strassen und schützt nach dem Glauben der Leute den Wanderer vor Unglück. Oefters ist bei einem solchen Fetisch eine kleine Thonschale aufgestellt, in welche die abergläubischen schwarzen Wanderer ein /Paar Kaurimuscheln, das landesübliche Geld, hineinlegen, in der Meinung, dass sie damit ein gutes Werk gestiftet haben und nun ohne Bangen bis zum nächsten Fetisch weiter wandern können. Selbstverständlich kommt dieser Tribut dem Fetischpriester zu gute.

Infolge eines Irrtums meines Führers verfehlten wir den eigentlichen Weg nach Lebbega und marschierten auf dem Pfade nach Lebbevi durch dichten fast $2 \mathrm{~m}$ hohen Busch und durch Dornenhecken weiter. Vor uns liegt das Thal des Sio mit seinem undurchdringlichen Morast und Schilf. Bald hatten wir den Landungsplatz Lebbevi erreicht. Auch 
hier bewacht ein grosser Thonfetisch, der unter einem mächtigen Baume thront, den Wasserweg des Yomme; diesem opfern die Schiffer, damit ihnen auf der Fahrt kein Unheil zustösst. Es ist der Fetisch, der von seinem grossen Gott Mawu beauftragt ist, die Gewässer zu beschützen. Nachdem wir den nur aus zehn Hütten bestehenden kleinen Fischerort Lebbevi, in dem die Fährleute wohnen, passiert hatten, gelangten wir auf den Laterithöhen nach dem grossen Orte Lebbega. Schon von weitem hört man die taktmässigen Töne der Fufustampfer, wobei man lebhaft an das Dreschen auf den Tennen unserer heimatlichen Bauerngehöfte erinnert wird.

Wir durchwandern den dichten Busch, welcher die Dörfer zum Schutze gegen einen Ueberfall umgiebt und gelangen an den Eingang des Dorfes. Die Strasse, welche nach Lebbega führt, ist infolge des vielen Verkehrs ausgetreten und, da sie bei Regenzeit gleichzeitig die Wasserund Abzugsrinne von der Höhe bildet, oftmals tief eingerissen und so beschaffen, dass man sich bei Nacht Hals und Beine brechen kann. Sie ist besonders deshalb belebt, weil die Lebbegaleute in Lebbevi aus der Yomme ihr Wasser für den Haushalt herholen. In langen Reihen ziehen die Weiber mit grossen Kalabassen, welche, wie alle Lasten, auf dem Kopfe getragen werden, zu der Lagune herunter. Diese Beschäftigung liegt hauptsächlich den jungen Mädchen ob und so bildet der Wasserplatz, welcher zugleich zum Baden und Waschen benutzt wird, immer einen Tummelplatz für die Backfische des Dorfes. Man kann sich die Güte des Trinkwassers vorstellen, welches durch den Morast filtriert und überdies noch durch die Wäsche und das Baden verunreinigt wird.

Wir durchwandern die engen Strassen, in denen sich munter Schweine und Ziegen tummeln und dazwischen die kleinen Kinder auf der Erde hockend ihr Spiel treiben. Wir gelangen auf den Marktplatz, welcher wie bei uns in kleinen Städten und Dörfern, der Versammlungsplatz der Bewohner ist und zumeist von grossen Bäumen beschattet wird. Der Reisende und die durchgehenden Karawanen machen gewöhnlich auf diesem Platze Halt, auf welchem auch in der Regel der Häuptling des Ortes wohnt, so dass man bald seiner ersten Sorge, ein Logis zu finden, überhoben ist. Auch mir wurde eine Hütte dicht am Markte angewiesen, in welcher alsbald die Jungen ihre erste Arbeit, die Reinigung, vornahmen und das Feldbett, sowie meine Blechkoffer aufstellten. Auch in Lebbega stösst an den Marktplatz eine grosse Palaverhalle, welche noch einigermaassen erhalten ist.

Am nächsten Tage brach ich auf, um das Südufer des Sees zu umwandern und meine Aufnahmen in den angrenzenden Gebieten des Togosees in Porto-Seguro zu beschliessen. Hier bestieg ich mit 
meinen Leuten eines von den Kanoes, die an dem Landungsplatze liegen und so ging die Reise eine kleine Strecke wieder auf dem Wasser vorwärts.

Die Yomme, der ausgehauene Arm in der grossen Ebene des Sio, fliesst in Schlangenwindungen in einer Breite von $3 \mathrm{~m}$ durch das hohe Schilf und Gras hindurch. Schnell gleitet in dem ruhigen Wasser unser Kanoe dahin. Es wird von einem kräftigen Neger mit einem sogenannten Bambusstock, der eigentlichen Mittelrippe des Oelpalmblattes, geschickt durch die Krümmungen des Armes geführt Eine solche Fahrt ist für den Europäer fast anstrengender wie ein Fussmarsch, denn in dem schmalen engen Kanoe kann man nur mit eingezogenen Knieen auf dem Boden hocken. In dieser unbequemen Stellung, die bei dem Neger Gewohnheit ist, darf man sich nicht rücken und rühren, um nicht das Boot zum Kentern zu bringen. Viele Kanoes fahren an uns vorbei und hier bemerkte ich auch ab und $z u$ noch eine sonderbare, bedeutend kleinere Art von Fahrzeug. Dieses, etwa $40 \mathrm{~cm}$ breite und $3 \mathrm{~m}$ lange Gefährt kann man eigentlich nur als einen Trog bezeichnen, der aus dem Stamme eines Agobims gefertigt ist. Der Stamm ist ungeschält, einfach zu einer Mulde ausgehöhlt und zu beiden Seiten quer abgeschnitten. Allerdings habe ich in diesem Gefährt niemals irgend welche Lasten bemerkt, auch halte ich es für unmöglich, dass in einem solchen Seelenverkäufer Lasten befördert werden können. Hauptsächlich scheinen die Schiffer bei ruhigem Wasser dieses Fahrzeug zu benutzen, um schnell ihre Netze und Angeln zu kontrollieren. Vermöge seiner Leichtigkeit ist es selbstverständlich jedem anderen Kanoe an Schnelligkeit bedeutend überlegen. Trotz des sonderbaren Eindrucks, den ein solches Gefährt macht, habe ich oftmals die Geschicklichkeit der Führer desselben bewundert. Am hinteren Ende steht ein schwarzer Kerl aufrecht und schiebt so balancierend das Kanoe rasch vorwärts. Der Führer ist zumeist nur mit einem 2 Zoll breiten Lappen bekleidet, welcher die Schamteile umhüllt und trägt auf seinem Kopfe einen riesengrossen Hut aus Grasgeflecht, der mit seinem breiten Schirm einen Durchmesser von fast I $m$ hat.

Diese Art Kopfbedeckung dient den Küstenbewohnern zugleich als Sonnen- und Regenschirm. Namentlich sieht man solche Hüte auf der Lagune, und es ist nicht zu leugnen, dass sie ihren Zweck vollkommen erfüllen. Allerdings ist bei einem ordentlichen Tornado selbst der beste Seidenregenschirm nicht dicht genug.

In $3 / 4$ Stunden waren wir aus unserer unangenehmen Lage befreit, wir hatten das Thal des Sio passiert und befanden uns wieder auf festem Boden. Dieser Kanal wird bei grosser Trockenheit von den Eingeborenen auch als Fusspfad benutzt und bietet mit dem $4 \mathrm{~km}$ südwestlich weiter- 
führenden Fusspfade die direkte Verbindung von Lebbega mit dem Küstenort Bagida. Ich marschierte nun in östlicher Richtung in tiefem Sandboden und zwischen Buschdschungeln in einer weiten Grassavanne weiter und gelangte nach einem Marsch von I km Länge nach Donkovhe, einer kleinen Niederlassung, die nur ein Gehöft umfasst und von Leuten aus $\mathrm{Be}$ angelegt worden ist, um sich durch armselige Kassawafarmen, sowie durch Kleinviehzucht von Schafen und Ziegen ihren Lebensunterhalt zu verdienen. Weiter geht es durch niederes Gestrüpp und Busch. Der Weg wird immer schmäler und enger, leider verlieren wir den Pfad und biegen zu weit nach Norden ab, bis wir wiederum in die Nähe des Sio gelangen und im sumpfigen Terrain fast stecken bleiben, so dass ich meinen Plan, das Ufer des Togosees zu erreichen, aufgeben und in südlicher Richtung meinen Weg fortsetzen musste. Es war eine recht verwilderte Gegend, in der viele Oelpalmen zwischen Dornbüschen standen; mächtige Agobims, vermorschte Stämme und hohes Schilfgras machten das Fortkommen trotz unserer Haumesser fast unmöglich und wir waren froh, bei einer kleinen Niederlassung Juvokoyi wieder auf einen betretenen Pfad zu gelangen. Dieser kleine Ort besteht aus einigen Gehöften. Zu meiner grossen Freude und zu meinem Erstaunen sah ich hier zum ersten Mal in Afrika die Reklame eines Gasthauses, indem auf einem an dem Stamme einer hohen Kokospalme befestigten Brett mit deutschen Lettern zu lesen war: "Zur Kokosnuss". Nicht mit Unrecht war diese Aufschrift angebracht. Sie stammte wahrscheinlich von einem Weissen, der zufällig in diese Gegend gekommen war und in der weit und breit sandigen Grassteppe ohne Wasser einen Kokoshain zu würdigen wusste. Natürlich wurde auch dieses unschuldige Schild van den Buschleuten, wie jegliche Schrift, als Fetisch aufgefasst, daher blieb es erhalten und wird vielleicht späterhin noch manchem Durchreisenden zur Freude gereichen.

Juvokoyi liegt einsam in dieser baumlosen dürftigen Grassteppe Fortsetzung und bildet für die Reisenden einen beliebten Rastplatz unter den mächtigen der Reise an Kokospalmen, welche den kleinen Flecken beschatten. Auch wir machen Halt und freudig begrüssen meine Leute die reifen gelblich schönen Früchte der Palme, welche in grosser Fülle und Schwere herabhängen. Sofort werden die Eingeborenen verständigt, dass wir mit ihnen ein Geschäft in Nüssen abschliessen wollen; schnell ist auch schon ein gewandter junger Bursche mit katzenartiger Geschwindigkeit den Stamm hinauf geklettert und bemüht, mit einem Haumesser die Kokosnüsse abzuschlagen. Gierig stürzen sich meine Leute auf dieselben, während mein kleiner Meppo die schönsten für mich und natürlich auch für sich heraussucht. Mittelst Haumesser wird die Spitze der Nuss von dem schützenden Bast befreit und eine kleine Oeffnung in die harte Schale 
geschlagen. Alsbald ist sie fertig zum Genusse hergerichtet und mit Wohlbehagen stillt man an der süssen Milch seinen Durst. Am besten ist die Kokosnuss für solche Zwecke zu benutzen, wenn der eigentliche Kern sich noch in flüssigem Zustande befindet, während die Ränder schon Fleisch angesetzt haben. Das Fleisch wird ebenfalls genossen und hat einen angenehmen mandelartigen Geschmack. Die Milch, welche vermöge ihrer dicken Schutzdecke fast immer kühl ist, bietet bei dem brennenden Durst in dieser wasserlosen Steppe einen erfrischenden Trunk.

Nach kurzer Rast brechen wir auf und wandern in dem tiefen Streusand weiter unserem Ziele zu. Der Boden wird allmählich fester und statt der weiten baumlosen Grassavanne treten mehr Fächer- und Oelpalmen auf; wir gelangen bald in eine kleine Niederlassung, wo wir unseren Durst mit Wasser aus dem dort angelegten Brunnen stillen. Derselbe besteht aus einem grossen tiefen Loch, aus welchem ein brackiges Grundwasser zu Tage tritt. Auch hier ist das Gehöft von Kokospalmen umgeben und kleine armselige Kassavafarmen liegen in der Nähe.

Um nun mein Routenetz an die Aufnahmen des Togo-Sees anzuschliessen, marschierte ich über das uns schon bekannte Fischerdörfchen Pessikonu und gelangte noch an demselben Tage nach Porto-Seguro. Hier wurde ich auf der Faktorei von Regis von Herrn Zippel freudig empfangen und konnte ihm bei einem Glase Absinth meinen Dank für das geliehene Boot wie für die Flaggen abstatten. Des Abends machten wir der katholischen Mission einen Besuch, wo ich von dem Leiter der Station, Pater Müller, den schon beschriebenen Kinderfetisch erhielt. Ich nahm diese Thonfigur dankend an und übergab sie später dem Berliner Völkermuseum. Ferner vertraute mir derselbe Pater, der sich sehr für ethnologische Sachen interressierte, an, dass er in der Nähe von PortoSeguro ein Grab gefunden hätte. Auf meine Bitte, mir dieses Grab zu zeigen, gingen wir noch vor Sonnenuntergang in den Busch hinaus, wo dasselbe versteckt lag. Vermutlich war es das Grab eines sogenannten Missethäters, der dem Fetisch unbequem geworden und, wie es häufig bei den Negern vorkommt, bei irgend einem Gottesurteil vergiftet oder durch die Mitglieder des Yewebundes heimlich in den Busch gelockt und dort erschlagen worden war. In solchen Fällen wird dann den Leuten gesagt, der grosse Gott des Yeweordens habe den Missethäter für seine frevelnden Handlungen bestraft, die aber meist nur darin bestehen, dass er die Fetischpriester nicht genug respektiert oder ihnen nicht genügenden Tribut gezahlt hat.

Die Begräbnisplätze der Evheneger befinden sich gewöhnlich im C Chöft oder im Hause der Familie, wo die Verwandten'ihre Toten ungetähr I $m$ tief in den Erdboden in sitzender Stellung begraben. 
Das vorerwähnte Grab, welches sich in dem Busch befand, war durch einen $\mathrm{I}^{\mathrm{x}} / 4 \mathrm{~m}$ langen, etwa $\% / 2 \mathrm{~m}$ breiten und $\mathrm{I} 5 \mathrm{~cm}$ hohen Hügel gekennzeichnet. Ringsherum waren alte zerschlagene Töpfe gelegt, welche der Verstorbene in seinem Haushalt gebraucht hatte, während sich auf dem Hügel ein alter Stuhl, der ebenfalls dem Verstorbenen gehörte, sowie eine kleine Thonschüssel befanden, die bestimmt war, das Essen für den Geist des Verstorbenen aufzunehmen. Es herrscht hier nämlich die Sitte, dass wenigstens einmal im Jahre, in der Regel am Todestage, Speise, häufig auch Palmenwein oder eine Flasche Gin auf dem Begräbnisplatze aufgestellt und dem Geiste des Verstorbenen geweiht wird. Die Leute glauben, dass der Geist auch im Jenseits weiter lebt und dort seine Bedürnnisse wie auf Erden befriedigt. Daher werden den Toten auch bisweilen Gebrauchsartikel, wie Stühle etc. mit in das Grab gelegt oder auf den Grabhügel gestellt. Aus demselben Grunde finden die Menschenschlächtereien bei dem Tode eines Königs in dem nahe gelegenen Dahomegebiet statt. Der König soll nämlich auch im Jenseits mit gewissem Pomp auftreten und somit müssen eine Schar von Sklaven und seine Frauen ihn in das Jenseits begleiten, um ihm dort in seinem Hofstaat zu dienen.

Nachdem ich in Porto-Seguro 9 Träger angeworben hatte, marschierte ich, um noch den sogenannten Buschweg, der in dem ausgetrockneten Bett der Lagune von Porto-Seguro über Bagida nach Lome führt, aufzunehmen, am anderen Morgen auf dem uns schon bekannten Wege über Juvokoy und Bagida nach Lome. Nach einem anstrengenden Marsche gelangten wir in das ausgetrocknete Bett der Lagune.

Dieses zeigte vollkommen den Charakter einer Grassavanne, ohne Im Bett der jeglichen Baum und Strauch. Der -eigentliche Moorboden tritt hier Lagune wenig zu Tage, da fast alles durch den Dünensand, den die kräftige Seebrise ziemlich das ganze Jahr hindurch herüberträgt, verweht ist. Im Norden der Lagune ziehen sich die etwa $60 \mathrm{~m}$ hohen Lateritberge, welche den Uebergang zum Hinterlande bilden nach Osten hin, während die Lagune im Süden von einem $\mathrm{I}^{\mathrm{\tau}} / 2 \mathrm{~m}$ hohen undurchdringlichen Busch begrenzt wird. Derselbe bedeckt gänzlich die bis zur Küste reichende $\mathrm{I}^{x} /_{2} \mathrm{~km}$ breite Nehrung, welche die Lagune von dem Meere trennt. Aus dem Busch ragen an den niedrigen Stellen vereinzelte grosse Agobims empor und Kokoshaine zeigen die Lage der kleinen Dörfer und Niederlassungen an. Ueberall bedeckt ein hartes, kurzes aber breites Schilfgras das Thal, während die Höhenzüge im Norden ron hohen Affenbrotbäumen bewachsen sind. Vorbei geht es an der kleinen Niederlassung Messakovhe und bald gelangen wir zu. dem Farmdörfchen Agbedráfo wo wir freudig den Platz unter den grossen schattenspendenden Kokospalmen zu einer kleinen Rast benutzen. Hier traf ich 
einen alten Haussa, welcher mit seinem einzigen Gefährten, einem kleinen Jungen, ebenfalls in dem Schatten der Ruhe pflegte und zur Erfrischung eine Kolanuss kaute. Er war von nun an mein Reisegefährte fast bis Lome; ich hatte so Gelegenheit, die Genügsamkeit und Ausdauer dieses alten Haussas kennen zu lernen. Das lange weisse Haussagewand, welches allerdings schon die Spuren einer weiten Reise erkennen liess, der Fez mit dem Turban und das scharf geschnittene schwarze Gesicht verrieten sofort den Aristokraten seines Geschlechts. Wie ich später erfuhr, war es der alte Häuptling Profojetu der Haussakolonie Kpando. Nur ein paar Bananen waren den ganzen Tag über seine Nahrung und eine Kokosnuss oder eine Kalabassa mit Wasser genügten, seinen Durst zu stillen. Das einzige Gepäck bestand aus einer kleinen Holzlade, worin er ausser seinem Koran, noch Perlen oder Stoffe zum Tausche mit sich führte. Ohne Handel zu treiben habe ich keine Haussa reisen sehen; selbst wenn er auch ganz andere grosse Geschäfte abzuschliessen hat, sucht er doch immer noch unterwegs durch den Verkauf von Perlen oder anderen kleinen Handelsartikeln Geschäfte zu machen, um so seinèn spärlichen Unterhalt zu verdienen und auch einen Ueberschuss zu gewinnen.

Bald haben wir Bagida erreicht und nun geht es durch die grosse Strasse, an welcher die meisten Geschäfte des Ortes, sowie die Läden der früher hier etabliert gewesenen Faktorei von Vietor und Oloff liegen. In dem grossen Hofe der Bremer Faktorei schlugen wir wieder unser Nachtquartier auf.

Früh am Morgen brach ich mit meinen Kisten und Kasten von Bagida auf und marschierte auf dem grossen Wege wieder der Lagune $\mathrm{zu}, \mathrm{um}$, dieser folgend, noch an demselben Tage die Metropole Lome zu erreichen. Unterwegs trafen wir, da in Lome gerader grosser Markttag gewesen war, viele Leute, die in umfangreichen Kalabassen ihre Produkte oder Einkäufe mit sich führten und meistens Bewohner von Bagida oder Porto-Seguro waren. Obwohl der Weg am Strande näher und auch nicht beschwerlicher als der Buschweg ist, so wird doch dieser von vielen Leuten vorgezogen, da er, namentlich von Porto-Seguro bis Bagida, einigen Schatten bietet. Auch ist besser für die Stillung des Durstes gesorgt, da sich an den Buschwegen kleine Niederlassungen befinden, in denen Wasser und Kokosnüsse die erwünschte Erquickung bieten, während am ganzen Strande nur in einigen Fischerniederlassungen schlechtes brackiges Wasser zu haben ist.

Der harte roteLaterit warvon der Sonnenhitze wie gebacken und zeigte grosse Risse. Rasch kamen wir auf diesem harten Wege vorwärts und bald zeigte uns ein grosser Fetisch, der mit seinem Schattendach einem Tempel ähnlich sah, die Nähe des grossen Fetischplatzes Bega an. 
Von der Höhe aus sah man im Süden der Lagune die kleinen Niederlassungen liegen, deren graue mit dem hellen Grün der Kokospalmen umgebene Hütten sich idyllisch von dem eintönigen dunkelgrünen Busche abhoben. Der beschwerliche Weg geht nun südwestlich von dem Nordrand der hier bei weitem schmaleren Lagune durch deren eigentliches Bett hindurch. Die Lagune war an den feuchten Stellen mit hohem Schilfgras bewachsen; unser Pfad führte über die schwankende Moordecke durch grosse Wasserlachen, worauf wir nach einem kurzen Marsch den berüchtigten Ort Be erreichten. Die Landschaft hat

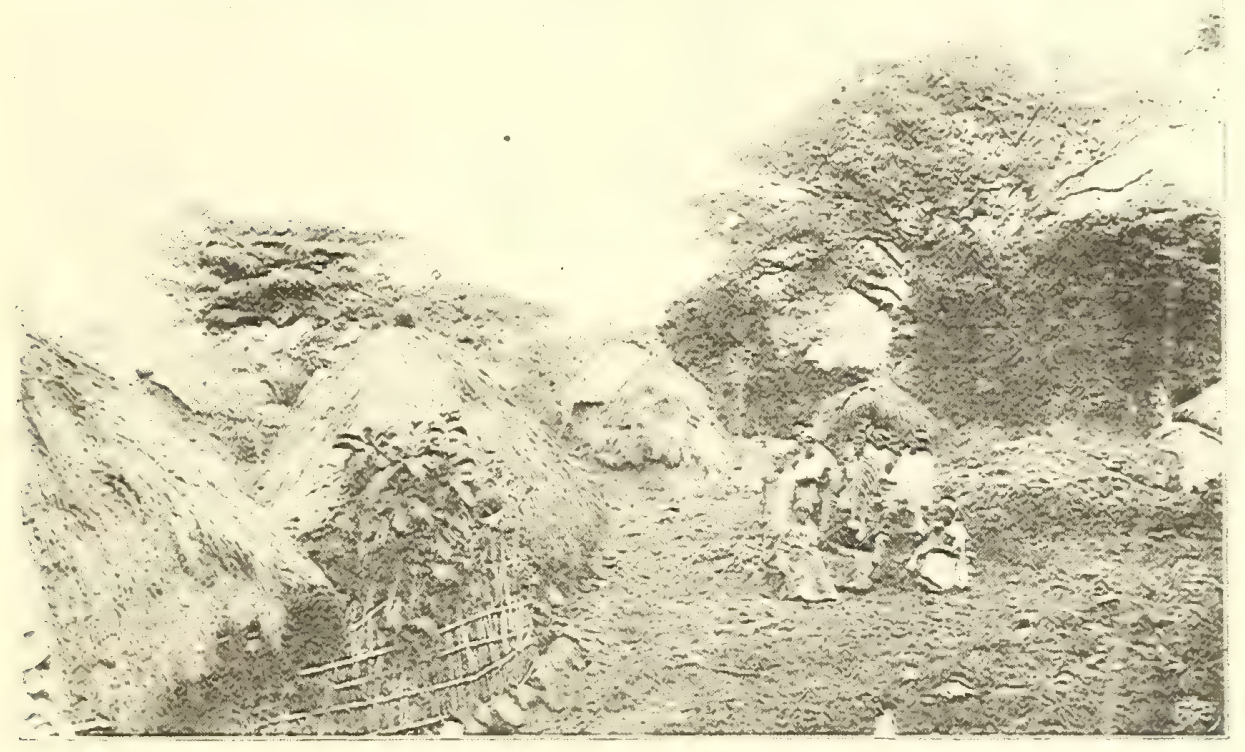

Der Fetischort Gross-Be bei Lome.

sich nun ganz geändert; aus der baumlosen Steppe kommen wir in einen Busch, welchen hohe Fikusarten und die nicht seltenen Affenbrotbäume beschatten. Weithin zieht sich dieses Eetischdorf unter dem Schatten der hohen Bäume. Trotz der Nähe von Lome hat es langer Zeit bedurft, ehe es Europäern gestattet war, dieses Dorf zu betreten. Lange, enge Strassen führen durch die Mattenzäune hindurch und in den Gehöften liegen verhältnismässig grosse viereckige Hütten. Ueberall sind in diesen Gehöften : Kokospalmen und auch Oelpalmen angepflanzt. In einem der Gehöfte, welches zu betreten ich leider nie Gelegenheit hatte, waltet der Fetischpriester des verbreiteten Fetischordens. Ab und zu sieht man die Fetischmädchen 
vorbeihuschen, die nur spärlich bekleidet sind und häufig die Haare zu einem kleinen Zopf geflochten tragen, an welchem Kaurimuscheln als Amulette an langen Schnüren herunterhängen.

Dieser Fetisch scheint besonders für das weibliche Geschlecht Bedeutung zu haben, da hauptsächlich nur Frauen und Mädchen die Marken dieses Ordens tragen. Derselbe giebt nämlich seinen Anhängern eine bestimmte Schutzmarke, die vor

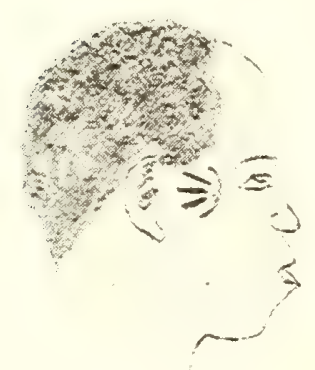
einem etwaigen Sklavenraub schützen soll; sie besteht aus einem kreisrunden Schnitt an beiden Schläfen, von welchem drei Querschnitte ausgehen. Zu gewissen Zeiten wird unter feierlichen Zeremonieen die Tätowierung mit dieser Fetischmarke gegen ein bestimmtes Opfer an Kaurimuscheln und sonstige Geschenke von dem Fetischpriester in Be vorgenommen. So abgeschlossen das Fetischleben und die Fetischgebräuche für den Europäer sind, so gewähren doch die Umzüge, welche die Fetischpriester mit den Dienerinnen des Fetisches in den Dörfern und der nahe gelegenen Stadt Lome unternehmen, einigen Einblick in dasselbe. Der Fetischpriester zieht mit einer Schar von 30 bis 40 jungen, erwachsenen Mädchen vor die einzelnen Faktoreien der Stadt Lome, um von den Europäern ein Geschenk für den Gesang zu erhalten. Eine Perlenschnur, Armringe von Kaurimuscheln am Oberarm, sowie Armbänder und auf einem Bande aufgereihte Kaurimuscheln, welche am Unterschenkel getragen werden, bilden die einzige Kleidung. Die Haare sind ebenfalls mit kleinen Kaurimuscheln durchflochten und endigen in Ermangelung eines grösseren Zopfes in einem Bande, an welchem Knochen und Kaurimuscheln als Amulette befestigt sind. Auf das Zeichen des Priesters wird ein Lied angestimmt, welches mit Händeklatschen begleitet wird. Auch finden Prozessionen der Leute statt, welche bei der Trockenzeit Regen und das Gedeihen der Felder von dem grossen Gott Mawu erbitten. Neuerdings sind jedoch diese Umzüge von der Regiérung verboten worden.

Wir verlassen nun den gefürchteten Fetischort, zu dessen Durchwanderung man in früheren Zeiten nur dann Erlaubnis erhielt, wenn man, wie die Eingeborenen, sich seiner Kleider entledigt hatte und im günstigsten Falle bloss ein Eingeborenentuch um die Hüften schlagen durfte. Heute ist natürlich, namentlich seit die Landeshauptmannschaft und die Truppe, welche beim Ausbruch von Zwistigkeiten sofort einschreiten kann, nach Lome verlegt worden sind, die äussere Macht des Fetischordens vollkommen gebrochen. 
Westlich ron Be gelangen wir nach dem bekannten, fast mit diesem Orte zusammenstossenden Amutive und ron hier aus in einer halben Stunde nach Lome, wo ich in dem damals noch unbewohnten Hause der Landeshauptmannschaft mein Quartier aufschlug.

\section{REISE NACH MISAHÖHE.}

Im August I 894 reiste ich zum ersten Male mit einer kleinen Karawane nach Misahöhe. Ich hatte von der kaiserlichen Landeshauptmannschaft, welche damals noch in Sebbe war, den Befehl erhalten, mich als wissenschaftlicher Assistent nach der Station Misahöhe zu begeben und dort Dr. Gruner zu unterstützen.

$\mathrm{Zu}$ diesem $Z$ weck begab ich mich von Popo, welches ich bei meinem systematischen Vordringen wegen der geographischen Lage von der Küste nach dem Innern vorweg genommen hatte, an der Küste entlang nach Lome. Von hier trat ich auf der alten grossen Strasse, welche, wie schon früher erwähnt, $3 \mathrm{~km}$ hinter Lome zum Teil durch englisches Gebiet führte, den Marsch nach Misahöhe an. Jetzt gehen die Expeditionen grösstenteils über die von mir neu angelegte Verbindungsstrasse, welche von Soluga aus westlich abgeht und von dort aus die alte Amutivestrasse ungefähr $7 \mathrm{~km}$ vor Akeppe mit der neuerlich angelegten Misahöhestrasse verbindet. Somit ist das Dreieck, welches die englische Grenze in das deutsche Gebiet hineinschneidet, umgangen.

Auf den Rat einiger Kaufleute schickte ich die Träger eine kurze Strecke voraus, um ihnen dann zu folgen. Aber die Erfahrungen, die ich mit diesem System machte, sollten mir eine Lehre für meine späteren Reisen sein; ich nahm mir vor, nie wieder die Karawane, und wenn sie auch noch so klein ist, zu verlassen. Ein Soldat oder ein freier Träger schreitet, die schwarz-weiss-rote Flagge tragend, der kleinen Karawane voran, während die Leute mit den Kästen und Koffern gewohnheitsmässig im Gänsemarsch, einer hinter dem andern, folgen. Am Queu der Karawane hatte ich meistens meinen Stab d. h. meine Dolmetscher und meine Jungens, von denen der stärkste mit meiner Verteidigungswaffe, einem Karabiner Modell 88, versehen war; öfters wurde auch von meinem anderen Jungen noch eine Schrotflinte geführt, die zur Erlegung eines Wildes oder eines Raubvogels von grossem Nutzen war. Einige Schritte hinter diesen Waffenträgern marschiert der Führer der Karawane selbst am besten, namentlich wenn er noch auf dem Marsche Routenaufnahmen vorzunehmen hat. Das durchschnittliche Tempo einer kleinen Karawane ist meistens 70 bis 
$75 \mathrm{~m}$ in der Minute. In einer Entfernung, in welcher der Kompass durch die Waffen und die an den Koffern befindlichen Eisenteile eine Ablenkung nicht mehr erfährt, schliesst man den Tross. Die Flagge gilt nicht nur als åusseres Zeichen einer deutschen Expedition in den Dörfern und Städten, sondern erfüllt zugleich auch einen äusserst wichtigen Zweck bei den Aufnahmen. Bei den engen Pfaden ist man gezwungen, bei den Aufnahmen ein besonderes System inne zu halten, nach welchem, wenn man die Zeit als Maasseinheit nimmt, mindestens alle 5 Minuten der Kompass, sowie die Uhr, abzulesen ist. Häufig wird es dann auch bei einer scharfen Aenderung der Richtung notwendig, die auffälligsten Krümmungen der Wege noch besonders durch den Kompass festzustellen. Andere haben sich das Schrittmaass zur Norm gemacht und zählen die Schritte, wobei sie bei einer bestimmten Zahl derselben ihre Ablesung vornehmen. Letzeres System ist nur bei kleinen Märschen anzuwenden; man ist gezwungen, die Zahlen, welche einem zugleich die Uhr ersetzen, selbst mechanisch nachzuzählen und wird durch diese mühsame und lästige Arbeit von jeglicher Beobachtung auf dem Marsche abgelenkt.

Was die Kisten und Koffer zum Aufbewahren der auf einer solchen Reise notwendigen Gregenstände anbetrifft, so erweisen sich am praktischsten die Blechkoffer mit Gummieinlage, welche infolge ihres hermetischen Verschlusses die Sachen vor der Feuchtigkeit des Klimas sowie vor Regen vollkommen schützen. Gewöhnlich befindet sich bei einer solchen kleinen Karawane noch die sogenannte Kochlast, welche ein paar Töpfe, sowie die notwendigsten Teller, Messer und Gabeln enthält, und ferner mit einigen europäischen, für die Dauer fast unentbehrlichen Delikatessen, wie Butter, Thee, Oel, Zucker, Salz, Pfeffer und sonstigen Kleinigkeiten ausgerüstet ist. In dieser Zusammenstellung marschiere ich mit insgesamt I 3 Trägern, einem Jungen, der mir zugleich als Dolmetscher in der Evhesprache dient, sowie einem kleinen Kochjungen, der allerdings nicht viel von den Finessen einer europäischen Küche versteht.

In der Frühe, nachdem von den Bekannten Abschied genommen ist; geht es auf der Misahöhestrasse aus Lome heraus. Bald haben wir auf dem $4 \mathrm{~m}$ breiten Wege die ausgetrocknete Lagune erreicht, in der noch hin und wieder kleine Löcher mit Wasser zurückgeblieben sind. Die anwohnenden Schwarzen dieser wasserarmen Zone kommen meilenweit her, um aus diesen Sumpflöchern, die teilweise noch ausgegraben und erweitert werden, das trübe Wasser für ihren Haushalt zu holen. Gleich hinter der Lagune steigt der Weg'steil an und ist infolge seines rot gefärbten Lateritbodens weithin sichtbar. Wir steigen ungefähr $40 \mathrm{~m}$ in die Höhe; hier blicken wir noch einmal zurück, um auf lange 


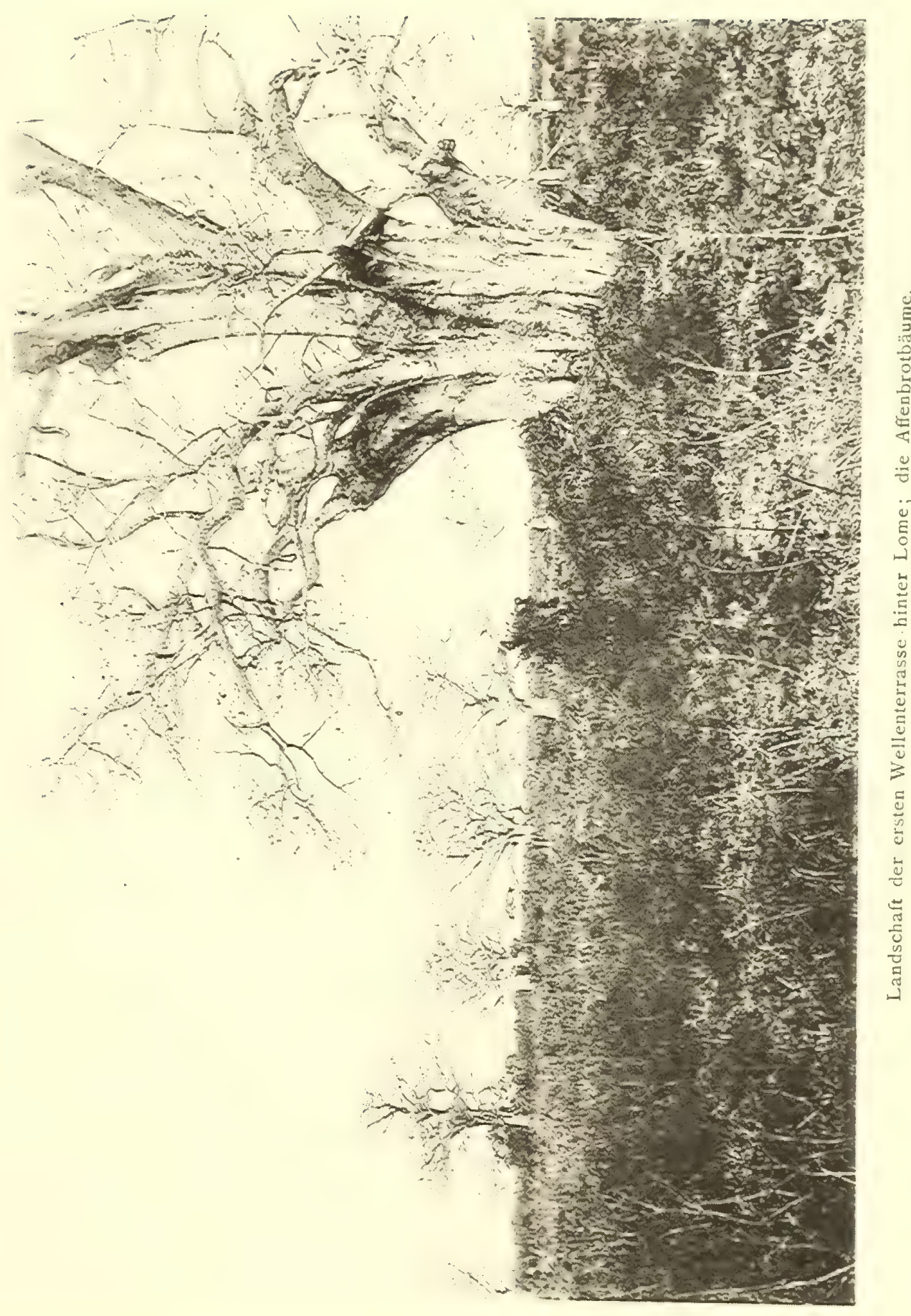



Zeit Abschied von der Küste zu nehmen, welche mir durch Arbeit und Freundschaftsbande lieb geworden war. Noch immer hört man das Brausen des Neeres; hinter uns liegt nun die grosse weite Lagune; dann kommt ein kleiner Palmengürtel, in dem Amutive, Be und die anderen kleinen Ortschaften nahe an der Küste liegen und weit hinter dem Busch setzen sich, von den Strahlen der Sonne beleuchtet, die blendend weissen Dächer von dem tiefen Blau des Meeres ab. Wellenförmig zieht sich nun der breite Weg in gerader Richtung durch den Busch dahin. Die ersten $3 \mathrm{~km}$ unseres Marsches auf diesen Höhenzügen bildet die Zone der uns schon bekannten Affenbrotbäume. Der Boden ist von niederem Gras und Gestrüpp bewachsen. Je weiter wir uns von der Küste entfernen, desto höher wird der Busch. Von der Höhe einer Terrasse sieht man wie der Weg durch das Thal in einem Bogen bis zur nächsten Wellenterrasse führt; immer hofft man von der folgenden Terrasse eine weitere Fernsicht in das Innere dieses dunklen Erdteils zu erhalten, aber stets erblickt man wieder neue Wellenterrassen, welche den Blicken des Reisenden Halt gebieten, bis man endlich diese wellenartigen Höhen überwunden hat und sich auf dem langsam ansteigenden Plateau befindet. Von Südwest nach Nordost hin ziehen sich die langen Thäler, welche bei hoher Regenzeit schöne grüne Wiesen aufweisen. Zu beiden Seiten des Weges liegen häufig Kassawafelder mit Papayabäumen, von einem $2 \mathrm{~m}$ hohen Busch umgeben. Rechts und links befinden sich kleine Dörfer, zu denen diese Felder gehören und welche durch den den Weg einfassenden Busch fast gänzlich den Blicken der Karawane und Passanten entzogen sind. Diese Dörfer merken nichts von der Belästigung und Störung, welche die grossen Karawanen häufig verursachen; trotzdem haben sie doch von den vorüberziehenden Reisen Vorteile, indem sie am Wege überall kleine Verkaufsstellen angelegt haben, wo die Frauen die Produkte des Landes zur Erfrischung des Reisenden feilbieten. Hier werden hauptsächlich Papaya, Erdnüsse, ja auch Wasser und Palmwein für einige Kauris rerkauft.

Wir befinden uns nun auf dem Plateau, welches so arm an Wasser ist, dass, wie bereits vorher erwähnt, solches überall weit hergeholt werden muss; dasselbe ist meistens nur schmutziges trübes Lehmwasser und käuflich zu haben. Oft begegnet man auf dieser grossen Strasse Karawanen von Frauen, Kindern und Mädchen, welche alle grosse Thontöpfe oder aus Kürbissen hergestellte Kalabassen mit Wasser tragen; hâufig müssen sie dieses von den 4,5 auch $6 \mathrm{~km}$ entfernten Wasserplätzen an der Küste herholen. Bisweilen kommt es auch vor, dass grössere Karawanen den ihnen begegnenden wehrlosen Mädchen und Frauen die Wasserkrüge leeren, um ihren Durst zu löschen. 
Ein reges Leben herrscht oft an solch einer Verkaufsstelle, denn hier rasten sowohl die Karawanen, welche aus dem Innern kommen, als auch diejenigen, welche von Lome in ihre Heimat gehen. Den grössten Absatz hat der Palmwein, der vollkommenen Ersatz für das schlechte lehmige Wasser bietet. In einer Reihe an dem Wege entlang sitzen die schwarzen Weiber, vor sich riesengrosse Kalabassen, in denen der weisse Palmenwein aus der nahe gelegenen Palmzone hergebracht wird. Daneben stehen grosse und kleine Kalabassen aus Kürbissen, welche die Trinkgefässe ersetzen. In einer anderen Kalabasse werden die für die Waren eingelösten Kaurimuscheln aufgespeichert. Zwischen den Weibern und auf dem Wege sitzen die Träger, zumeist ärmlich gekleidet, oft nur mit einem kleinem Stück Zeug, welches um die Hüften gelegt ist, während andere Händler von der Küste, zum Teil europäisch mit Hosen, ja sogar mit Schuhen bekleidet sind: andere wieder tragen ein grosses Umschlagetuch, während die Haussas mit ihren langen blauen oder weissen Toben und dem über die Schulter hängenden grossen Schwert vorteilhaft von der schwarzen Menge abstechen. Wieder andere Karawanen sind mit Gummi aus dem weiten Hinterlande herunter gekommen und tragen die Zeichen der echten Buschleute; ihre Frisuren haben zum Theil äusserst komische Formen Die einen tragen kleine Löckchen an der Seite, in denen Fetische, wie Knochen oder Kaurimuscheln eingeflochten sind, während andere den glatt rasierten Kopf, auf dem an der Stirn ein Schopf stehen geblieben ist, mit roten Papageienfedern geschmückt haben. Kleine Mädchen, welche besonders gern zum Tragen von leichteren Lasten verwendet werden, haben sich mit einer gelben Perlenschnur und einem roten Schlips geschmückt; ihre hauptsächlichste Toilette besteht in Perlenschnüren, welche auch häufig am Unterschenkel getragen werden. Ferner sieht man hier neben den behäbigen und dicken Marktweibern, von langen Märschen und Entbehrungen ermattete Weiber sitzen, die nur mit einem kleinen Schamtuch bekleidet sind und von dem Staub der Strasse grau aussehen. Kasten und Koffer, sowie die verschiedensten Lasten, grosse Töpfe und Kalabassen versperren den Weg. Die Güte des Palmweins durch Kosten prüfend, gehen die Käufer der Reihe nach an den Marktweibern vorbei, um erst nach langem Feilschen das Geschäft abzuschliessen. Mittelst einer an einem langen Stabe befestigten kleinen Kalabasse, schöpft dann die Verkäuferin den flüssigen Inhalt aus ihrer grossen, oft $1 / 2 \mathrm{~m}$ hohen Kalabasse; welche die Gestalt eines riesengrossen, eiförmigen Kürbisses besitzt. Eine kleine Trinkschale nimmt den weisslich-grünen, köstlichen Met auf, welcher dann unter den Schwarzen herumkreist. Viel werden auch hier die Erdnüsse, sowohl geröstet wie ungeröstet, verkauft. Meistens ist den über dem Feuer 
gerösteten Nüssen eine kleine Portion Salz beigemischt, wodurch sie einen angenehmen Geschmack bekommen; dagegen sind die nicht gerösteten ziemlich weichlich und mehlig. Oefters werden dic gerösteten Erdnüsse mit kleinen Maiskörnern vermengt und bilden in dieser Zubereitung einen vorzüglichen Leckerbissen für unsere schwarzen Brüder.

Nach einer Rast, wobei wir reichlich unseren Durst und unsere Leute auch den Hunger gestillt hatten, geht es wieder vorwärts. Immer üppiger wird die Vegetation und statt der dürftigen Kassavafelder sieht man häufig grosse Maisfarmen, sowie schöne Erdnussfarmen, die von weitem unseren Kleefeldern gleichen. Dazwischen sind Papaya und Bananen gepflanzt und geben diesen Negerfarmen noch ein bunteres Gepräge. Der Busch wird höher, grössere Bäume werden sichtbar, die ihre Kronen hoch über den Busch emporstrecken. Immer häufiger werden die Farmen; an Stelle des strengen roten Lateritbodens und des alles verwehenden Dünensandes tritt ein humusreicher lehmiger Sandboden und die Vegetation erhält mit jedem Schritt ein üppigeres Aussehen. Statt der Kokospalmen erscheinen zuerst vereinzelt die Oelpalmen mit ihren dunklen grossen Blättern; sie verdichten sich bald zu einem wahren Hain, der unserem Weg nun auch den nötigen Schatten spendet. Zu beiden Seiten des Weges zieht sich dieser grosse undurchdringliche Palmenwald hin; überall sieht man an den Blattscheiden die schönen grossen roten Früchte schwer herunterhängen, während der Boden des düstern Waldes, der infolge der Stacheln der Palmen fast ungangbar ișt, von grossen Farrenkräutern bedeckt wird. Nur selten sieht man noch eine Farm, welche dann herrlich von dem dunklen Grün der Palmen absticht. Namentlich Bananen, vermischt mit diesen Palmen, geben ein wahrhaft tropisches Vegetationsbild ab. Häufig sind die Blätter der Bananen vom Winde ganz zerfetzt und verstümmelt so dass ihre schöne Fächerform fast nicht mehr zu erkennen ist. Doch an geschützten Plätzen, wie hier inmitten dieser Oelpalmhaine, bildet die Banane ihres schönen Blattes wegen eine wahre Zierpflanze.

Wir befinden uns nun in der eigentlichen Zone der Oelpalmenregion, welche sich wie ein breites Band entlang zieht. Die Oelpalme ist das hauptsächlichste Ausfuhrprodukt dieses Landstriches. Wir haben schon gesehen, in welcher Weise sich der Handel an der Küste fast ausschliesslich um die Kerne und das Oel, welches diese Pflanze so reichlich liefert, dreht und dass bei einer Missernte die Händler schwer geschädigt werden. Die Kerne bilden hier als solche ein besonderes Produkt; sie werden getrocknet und dann zur Küste zum Verkauf gesandt. Erst in Europa werden sie $z u$ feinen Oelen verarbeitet und aus den Rückständen dieser Kerne wird der sogenannte Palmkernkuchen, ein 
beliebtes Viehfutter, hergestellt. Das Fleisch, welches diese Kerne einschliesst, wird von den Schwarzen durch Stampfen in grossen mit Steinen ausgepflasterten Gruben von dem eigentlichen Kerne gelöst und das Oel wird dann durch Kochen und Sieden von den Fasern der Pulpa geschieden. In grossen Kalabassen wird demnächst das Oel zur Küste transportiert, wo es, wie schon vorher erwähnt, von den Kaufleuten häufig nochmals in eisernen Kesseln, die auf den Faktoreihöfen stehen, durchgekocht wird, um es noch besser von Fasern und Schmutz zu reinigen und einen angemessenen Preis für das Produkt zu erzielen.

Aus diesem Oel werden hauptsächlich unsere guten Stearinkerzen hergestellt.

Weiter geht unser Marsch; überall liegen zu beiden Seiten des Weges die abgeschlossenen hohen Dörfer und Farmen der Schwarzen, angezeigt durch das Krähen der Hähne, sowie durch die an der Strasse liegenden Verkaufsplätze. Wiederum hat man kleinere Terrainwellen zu überschreiten. In den dazwischen liegenden Thälern wachsen auf dem humusreichen Boden in dichten Waldungen die Oelpalmen, während die Lateritflächen meistens mit Busch- oder Kassawafarmen bestanden sind. Ein grosser Wollbaum zeigt uns die letzte Höhe vor Akeppe, dem ersten grösseren Negerdorfe. Wir besteigen nun das Plateau und grosse Kassawafarmen, die mit Oelpalmen und Bananen bestanden sind, deuten uns die Nähe des Dorfes an. Nachdem wir noch einen kleinen Oelpalmenhain durchschritten haben, sehen wir endlich auf der Höhe das Dorf Akeppe liegen. Noch eine halbe Stunde dauert auf der geraden Strasse in fast westlicher Richtung der Marsch und nach insgesamt $6 \%$ Stunden haben wir glücklich den ersten grösseren Rastplatz, Akeppe, erreicht.

Akeppe Akeppe ist der erste bedeutende Ort, welcher von der Küste aus an dieser grossen ins Innere führenden Strasse liegt. Gleichzeitig ist es die letzte grössere Station der Karawanen, die weit aus dem Innern Waren an die Küste nach Lome führen. Deshalb entfaltet sich hier ein reges Leben. Hart an der Strasse hat sich ein grosser Markt etabliert, auf dem neben den bekannten Lebensmitteln noch verschiedene Stoffe und Zeuge verhandelt werden. Letztere werden hauptsächlich von dem überall Geschäfte treibenden und reisenden Haussa feilgeboten, der als gewiegter Handelsmann weiss; dass hier mit solchen Sachen ein Geschäft zu machen ist. Denn hier versorgen sich vielfach die weit aus dem Innern zurückkehrenden Träger, die nach gethaner Arbeit den Verdienst für dieselbe eingeheimst haben. Bervor sie nach Hause zurückkehren, ergänzen sie ihre Zeuge und mancher von ihnen kauft ein neues Lavalava oder eine fertige Hose, um so geschmückt in seine Heimat wieder einzuziehen und sich seinen Verwàdten und Freunden oder auch seiner 
sweetheart, wie der technische Ausdruck der englisch sprechenden Schwarzen an der Küste für die Geliebte lautet, in diesem neuen Schmucke vorzustellen.

Auch für die Mädchen ist für den nötigen Putz gesorgt. Häufig sieht man an einer primitiven Schnur Kopftücher, wozu sich die bunten Taschentücher vorzüglich eignen, sowie Perlenschnüre und allerhand Kattunstoffe in den grellsten, auffallendsten Farben für den ankommenden Fremdling aufgereiht. Da die schwarzen Schönen, was den Putz anbelangt, ihren Kavalieren in keiner Beziehung nachstehen wollen, so ergänzen sie hier ebenfalls ihre Toilette. Ein neuer Kattunstoff wird erstanden und bildet, um die Hüften geschlungen, die neue Robe. Eine gelbe oder rote Perlenschnur wird um den Hals gehangen und die Toilette für die erwartungsvollen Verwandten oder Verehrer ist fertig. Es ist sozusagen ein kleiner fliegender Reisebazar für diese schwarzen Reisenden, welche auf den grossen Fussmärschen ihre Sachen ganz anders verbrauchen, als ihre europäischen Kollegen, welche in einem Wagenabteil dritter oder vierter Klasse bequem in ein paar Stunden das Land durchfliegen. Hier heisst es alles, auch die nötigen Lebensmittel auf dem Kopfe getragen durch Sümpfe oder Flüsse mitzufuhren. Das wissen die geschäftskundigen Haussas ganz vorzüglich auszubeuten. Nicht selten wird der halbe mühsam erworbene Verdienst von diesen Leuten ausgegeben, denn sie müssen hier die Sachen doppelt so teuer bezahlen, als an der Küste.

Akeppe liegt fast in einem Oelpalmenhain und so macht auch der kleine Markt, der sich nördlich an den Ort anschliesst und beinahe unmittelbar auf dem Wege unter den Palmen liegt, einen einladenden Eindruck. Das rege Leben, durch die durchziehenden Karawanen veranlasst, bietet auch für das verwöhnte Auge eines Europäers einige Abwechselung. Ueberall sieht man Träger aus den verschiedenen Gegenden auf ihren Lasten sitzen. Hier die echten Buschleute, welche sich durch ihr bescheidenes Wesen vorteilhaft von den Küstennegern unterscheiden; dort ein Händler von der Küste mit seinen Leuten in europäischer Kleidung, der sich vermöge seines Geldbeutels und auch seiner Stellung erhaben über das gewöhnliche schwarze Volk dünkt und höchstens geruht, sich mit einem Haussahändler über die Preise und Verhältnisse der durchreisten Gegenden zu unterhalten.

Das Dorf, welches im Süden des Marktes liegt, besteht nur aus armseligen kleinen Hütten, die wenig von den durchreisenden Fremden benutzt werden, da das nahe gelegene grosse Dorf Noëppe ganz andere Bequemlichkeiten bietet.

Die Leute, welche in Akeppe ständig wohnen, unterhalten einen ausgiebigen Handel mit Lome, wo sie gegen ihre Produkte Stoffe ein- 
tauschen oder solche auch in Geld umsetzen. Die Stoffe werden dann häufig wieder an die Durchreisenden verkauft und ergeben einen doppelten Gewinn.

Belästigungen von den Trägern oder Karawanen haben die Einwohner von Akeppe weniger zu fürchten, da, wie schon erwähnt, das eigentliche Nachtquartier in Noëppe ist; nach einer kurzen Rast oder dem Einkauf der Waren geht es weiter, um endlich nach langem Marsch das ersehnte Ziel zu erreichen. Nachdem ich mir in dem kühlen Schatten an einer Kalabasse Palmwein gütlich gethan hatte, marschierte ich ebenfalls mit meinen Jungen und Dolmetschern, sowie etlichen Trägern, die ich hier glücklich eingeholt hatte, weiter nach unserem nächsten Nachtquartier.

Die grosse Strasse hat bei Akeppe ihre westliche Richtung vollkommen geändert und führt fast in einem rechten Winkel nach NordNordwest. Schon von Akeppe aus sieht man, wie in schnurgerader Richtung der breite Weg durch die weite, aber flache Thalmulde wieder zur Höhe hinaufführt und schnell eilen wir durch den herrlichen geschlossen dichten Oelpalmwald der Höhe zu. Auf dieser angelangt, zeigen uns schon die hohen, die Palmen weit überragenden Bäume das erlösende Ziel an. Noch eine kleine Mulde ist bald durchschritten. Grosse schöne Haine von Bananenfeldern passieren wir und in $3 / 4$ Stunden haben wir das Dorf Noëppe erreicht. Wir begeben uns hier sofort zum Gehöft des Häuptlings und werden von diesem gastlich empfangen. Ein kleines Gehöft mit einigen Hütten wird mir angewiesen, aber leider sind zu meinem grossen Aerger meine Lasten noch nicht angelangt. Bald kommt der Häuptling mit seinen Geschenken, die in ein paar Bananen, Yams nnd etwas Kassava für meine Leute bestanden.

In den Orten an der grossen Strasse, welche von vielen Reisenden und Europäern passiert werden, ist ein solches Nachtquartier ein vorzügliches Geschäft für den Häuptling. Der Weisse ist hier nichts Neues mehr, die Geschenke fallen daher spärlich aus. Dagegen sind die Leute in Bezug auf Gegengeschenke von den Europäern in unerhörtem Masse verwöhnt worden, denn es ist allmählich zur Gewohnheit geworden, dass man für etliche Bananen und für das Quartier in der Lehmhütte, die einem für die Nacht zur Verfügung steht, Geschenke im Werte von zwei Mark macht. Indessen bringt es einmal der Gebrauch mit sich, bei dem Häuptling des Ortes sein Quartier aufzuschlagen, andererseits sind auch ihre Hütten besser und grösser gebaut, als die der anderen Bewohner. Nahe an der Küste ist man in dieser Hinsicht immer noch im Vorteil, da man mit Geld bezahlen kann und dadurch wenigstens die Kosten für das Tragen der auszutauschenden Gegenstände spart. Infolgedessen habe ich mich gleich den übrigen Reisenden bemüht, auch im Hinterlande 
wenn möglich statt der Tauschwaren Geld einzuführen und dadurch den ganzen wirtschaftlichen Verhältnissen eine andere Basis zu geben.

Leider wird an den Küstenplätzen, hauptsächlich in Noëppe, welches viel von englischen Händlern aus Kitta besucht wird, das englische Geldl dem deutschen bei weitem vorgezogen.

So kam es häufig zu kleinen Unzuträglichkeiten mit den Leuten, welche natürlich schon der deutschen Sache wegen von den Reisenden mit deutschem Gelde bezahlt werden. Grerade in Noëppe ereignete es sich öfters, dass einer oder der andere Träger sich beschwerte, dass ihm die Leute nichts fur deutsches Geld verkaufen wollten. Hiergegen wurde mit Erfolg eine sehr einfache Methode angewandt, indem nämlich die Käufer erst nach Empfang der Ware mit deutschem Gelde bezahlt wurden. Verweigerten die Verkäufer die Annahme des Geldes, so behielten die Käufer die Waren, den Händlern aber wurde anheimgestellt, deutsches Geld zu nehmen oder garnichts zu erhalten. Nach langem Palaver über den Wert des deutschen Geldes fügten sich die Händler, jedoch wurden, wie ich vermute, die Preise bei Bezahlung mit deutschem Gelde etwas erhöht. Auf diese Weise wurde deutsches Geld kursfähig. Leider wird die Verbreitung des englischen Geldes, speziell an der Küste noch durch unsere Kaufleute an den grossen Küstenplätzen gefördert. Durch das englische Abkommen muss sowohl englisches wie deutsches Geld linksseitig des Voltagebietes zu gleichem Kurs bei Steuererhebung in Zahlung genommen werden. Der einzelne Kaufmann würde allerdings bei dem ausschliesslichen Handel mit deutschem Gelde häufig in die üble Lage kommen, auf Kosten dieses seinen Verdienst geschmälert zu sehen, da der Schwarze solche Faktoreien bevorzugen würde, welche ihm die Waren mit englischem Gielde bezahlen oder für englisches Geld verkaufen Andererseits hat bei der Auszahlung in englischem Gelde der Kaufmann einen Nachteil, da er wiederum das in Europa häufig in geringerem Kurs stehende deutsche Geld annehmen muss. Es würde ein grosser Fortschritt sein, wenn diesem Uebelstande abgeholfen werden könnte Ein Leichtes wäre es, wenn die Handelskåmmer sich darüber einigen und gemeinsam in dem Punkte vorgehen wollte, dass sämtliche deutsche Firmen nur mit deutschem Gelde handeln müssten. Die eigentlich gebräuchliche Scheidemünze im Togogebiet ist die Kaurimuschel, jedoch sind, mit Ausnahme des weiteren Hinterlandes, europäische Scheidemünzen schon sehr verbreitet. Die beliebteste Münze ist der englische Sixpence, auch der Schilling und das Zweischillingstück; ausserdem wird noch der minderwertige amerikanische Dollar in Zahlung genommen. Von deutschem Gelde geht vorzugsweise das Fünfpfennigstück, welches „Kopper“ genannt wird. Ferner werden auch gern unsere Fünfzigpfennigstücke, welche schlankweg mit "deutschem Sixpence" bezeichnet"werden, so wie unsere 
deutsche Mark, welche dem Werte nach dem Schilling gleichgestellt wird, in Zahlung genommen. Merkwürdigerweise gehen aber Zehnpfennigstücke gar nicht, weil sie wegen ihrer Grösse fälschlich als Fünfzigpfennigstücke ausgegeben wurden und weil sie ferner durch eine schwarze Falschmünzerbande in Akoda nachgemacht und entwertet worden sind. Dieselben sind in einer nachgebildeten Form zwischen zwei Muscheln aus Blei gegossen worden. Thalerstücke werden fast gar nicht genommen und auch Zweimarkstücke gehen sehr schwer, während deutsches Gold bei grossen Handelsabschlüssen oder auch bei grösseren Zahlungen an die Träger gern Abnahme findet.

Noëppe. Wir kehren nach dieser Abschweifung zu unserem Dorf Noëppe zurück. Dasselbe ist westlich von der Strasse in einem grossen Palmenhain gelegen. Viele hohe Bäume stehen auf den Plätzen und zahlreiche Bananen und auch Kokospalmen sind in den Gehöften angepflanzt. Auf dem grossen viereckig angelegten Markt ist ein reges Treiben an den bestimmten Markttagen, an denen die Leute karawanenweise ihre Produkte dorthin bringen und wo ein grosser Teil derselben von den Händlern des nahe liegenden englischen Gebietes gekauft wird. Die Nähe des englischen Gebietes hat leider, namentlich in früheren Jahren, zur Folge gehabt, dass ein Teil der Produkte, welche auf unserer angelegten Strasse aus dem Innern kommen, von hier aus infolge des bestehenden Zollvertrages ungehindert auf englisches Gebiet übergingen. An den Tagen, an welchen kein Markt abgehalten wird, ist Noëppe verhältnismässig ein stiller Ort; der grosse Marktplatz, der zu Zeiten so bevölkert ist, liegt einsam da und bildet nur einen Spielplatz für die Kinder. Ausser diesen bevölkern ihn noch eine Menge Schweine, welche grunzend den Boden durchwühlen; hierzu gesellen sich noch eine Anzahl Ziegen und Schafe, welche dort grasen oder in dem Schatten ihrer Ruhe pflegen.

Der Tag ging zur Neige, die Nacht brach an und noch immer war nichts von meinen Trägern zu merken, die mein Feldbett sowie die Kochlast und das übrige Gepäck ausser einigen Blechkasten, die ich glücklich in Akeppe abgefangen hatte, mit sich führten. Auf einer kleinen grünen Ginkiste sass ich vom Marsche ermüdet in der Lehmhütte, welche mein Junge mit einer geborgten Oellampe erleuchtet hatte. Eine solche Oellampe besteht eigentlich nur aus einer kleinen, plump aus Thon geformten Schale, welche Palmöl mit einem Docht von Baumwolle, enthält. Natürlich ist, wie man sich denken kann, solch eine Situation nicht gerade angenehm, denn leicht gekleidet, wie man ist, und durch die brennende Hitze am Tage gewissermaassen verwöhnt, erscheint einem der Abend und die Nacht mit ihrem Thau kühl. Unter diesen Umständen nahm ich mit Vergnügen den Vorschlag meines hungrigen Jungen an, und liess mir von demselben etwas 
Yams kochen, sowie den sogenannten Fufu herrichten; als besondere Delikatesse wurden noch ein paar Eier serviert. Trotz riesigen Hungers musste dieses Mahl für heute gleichzeitig Mittag- und Abendbrot bilden.

Aus einigen geborgten Tüchern stellte ich mir auf einer Strohmatte das Lager her und ich muss sagen, dass ich trotz dieses primitiven Lagers infolge des unter den hiesigen Verhältnissen ungewöhnlich langen Marsches von fast $28 \mathrm{~km}$ ausgezeichnet geschlafen habe. Den nächsten Morgen zog ich ohne Träger weiter, in der Hoffnung, dass sie mich in Keve einholen oder dass ich sie dort schon antreffen würde. In gerader Richtung geht der Weg durch den schönen Palmenhain weiter und alle Gräser und Blätter glitzern noch von dem reichlich am Morgen gefallenen Tau. Wir passieren die Farmen, in welchen neben Bananen viele Papayabäume stehen und deren Boden von der Kassava vollkommen beschattet wird. Ueberall führen seitlich durch den dichten Palmenwald kleine Pfade zu den Farmniederlassungen. An der Strasse befinden sich viele kleine Verkaufsstellen, bei welchen Palmwein in grossen Kalabassen feilgeboten wird; ab und zu sieht man einen Farmer an dem Wege oder in dem Palmenhain oder in einer Farm eine Oelpalme fällen, um von ihr den schäumenden Wein zu gewinnen. Der Stamm wird möglichst tief abgehauen; dann wird nach zwei bis drei Wochen an dem oberen Ende ein Loch in denselben geschlagen und darunter eine kleine Kalabasse gehängt, welche bestimmt ist, den Palmwein aufzunehmen. Ueber die Kalabasse werden Palmblätter oder Blätter von Bananen gelegt, welche das Einfallen von Staub oder Schmutz verhindern sollen. Später wird das Loch durch Ausschneiden vergrössert und reingehalten, auf welche Weise der Wein respektive der Saft bis nahezu 6Wochen fliessend erhalten werden kann. Der Wein von jungen Palmen ist süss, während er von alten Stämmen herb schmeckt. Den besten Palmwein erhält man des Morgens, wenn er in der Nacht abgekühlt ist und frisch von der Farm gebracht wird; meistens wird der Palmwein morgens und nachmittags, bei Sonnenuntergang, von den Farmen geholt. Er ist eine hellgraue Flüssigkeit, welche moussiert und von einem weisslichen Schaum bedeckt ist. Der Wein hat einen nicht unangenehmen, süss-säuerlichen, prickelnden Geschmack. In der ersten Zeit der Gewinnung ist er weniger berauschend, während er schon nach ungefähr zehn Tagen stärker und herber wird und nach einer Zeit von sechs Wochen die berauschendste Wirkung ausübt. Sehr häufig wird er mit Wasser versetzt getrunken. Der Palmwein leistet auch unserer europäischen Küche gute Dienste, denn in Ermangelung von Hefe verwendet der Koch zur Herstellung des Brotes altgegorenen Palmwein. Leider ist mit der Gewinnung des Weines eine erhebliche Ausrottung der Palmenbäume verbunden, denn ein Baum giebt nicht mehr als einige Liter Wein. Ein Segen ist es, dass die KI.OSE, Togo 
Palme pflanzungsfähig ist und dass sie bei der tropischen Vegetation sich bald wieder vermehrt. Aber jedenfalls wäre es für die wirtschaftlichen Verhältnisse unseres Gebietes vorteilhaft, wenn diesem Verfahren auf gesetzlichem Wege gesteuert werden würde.

Wir setzen unsern Weg weiter fort und treffen ab und zu noch Nach dem grosse schöne Maisfarmen der naheliegenden Dörfer an. Noch eine Marktflecken Strecke geht es durch Oelpalmenhaine, dann verlassen wir dieselben in Badja. einer kleinen Niederung, in welcher die Vegetation ein anderes Aussehen erhält. Aus den schönen Palmenwäldern tritt man in eine grosse Baumsavanne ein, welche mit Schilfgras weithin bedeckt ist und nur einen spärlichen Baumwuchs aufweist. An den tiefer gelegenen Stellen dieser Niederung ist sie mit hohem Schilfgras bestanden, in der uns nach langer Zeit wieder vereinzelt die grossen und schlanken Agobims begegnen. Die Niederung wird gewissermaassen durch das Thal des Aka gebildet und ist häufig den Ueberschwemmungen desselben ausgesetzt. Der breite Weg ist hier auf einem Damm weiter geführt, an dessen Seiten grosse Gräben ausgehoben sind, welche die Strasse vor Ueberflutung schützen. Der Weg durch dieses Thal bietet keine Abwechselung, bis man langsam zu den kleinen Höhenzügen ansteigend, welche den Aka begleiten, aus dieser Niederung und Baumsavanne herauskommt und wieder in einen schönen Oelpalmenwald gelangt. Dieser begleitet uns bis an die Farmen, welche die Nähe des nächstgelegenen grösseren Dorfes und Marktplatzes Badja ankündigen. Auch hier liegen grosse Maisfarmen von Oelpalmenwald eingerahmt und ein dichter Urwald führt uns in das Dorf hinein, welches in einer Lichtung zu beiden Seiten des Weges liegt. In der Mitte befindet sich ein grosser Marktplatz, der quer über die Strasse führt und von wahren Prachtexemplaren grosser Schattenbäume umgeben ist. In diesem waldumgebenen, idyllischen Orte machen wir halt und lassen uns auf dem Marktplatz auf einer Bank nieder, wo sonst gewöhnlich der hohe Rat zu tagen pflegt und sich des Abends die Bewohner des Dörfchens versammeln, um bei einem Topf Palmwein ihre Pfeife Tabak zu schmauchen. Hier hat sich ebenfalls wegen der vielen durchgehenden Karawanen eine Schar von Marktweibern niedergelassen, welche die Bedürfnisse der schwarzen Reisenden befriedigen.

Auf dem Marktplatze befindet sich das Haus des Häuptlings, der zugleich den Fetischpriester vertritt und dadurch ein besonderes Ansehen in dem Orte und in der Umgegend besitzt. Hier sah ich zum ersten Male eine Prozession, die einen drolligen Eindruck auf mich machte. Vorweg schritten Knaben und Mädchen in ihrem grössten Staat, welche Palmenwedel trugen, dahinter kam eine junge Frau, welche weiss bemalt war und ebenfalls ihren grössten Staat angelegt hatte; 
dieser folgte eine Menge Volk. Ich erkundigte mich nach dem Zweck dieses sonderbaren Aufzuges und erfuhr, dass es eine Wöchnerin sei, welche nach der Geburt des Kindes ihren ersten Ausgang machte und unter gewissen Zeremonieen dem Fetisch für die glückliche Entbindung opferte, womit auch eine Waschung und Reinigung der Frau verbunden sein soll. In diesem Hauptfetischorte bemerkte ich ferner eine schwarze Schöne in höchst seltsamem Aufputz. Sie gehörte wahrscheinlich zu den Fetischpriesterinnen; wenigstens machte ihr weiss bemalter Körper mit der sonderbaren Kleidung, den vielen Kaurimuscheln, den Amuletten und roten Papageifedern auf mich ganz den Eindruck, obwohl die Leute mir angaben, dass sie sich zum Tanze geschmückt habe. Das Sonderbarste an dem ganzen Schmuck war ausser der geringen Kleidung ein Spiegel, welchen sie auf dem Rücken trug.

Die Natur, welche in Afrika alles bedeutet, hat Badja mit seinen schönen, das ganze Dorf zierenden Bäumen zu' einem lieblichen Orte gemacht. Ein hoher Flaggenmast trägt die schwarz-weiss-rote Flagge, welche gewöhnlich zu Ehren der durchreisenden Beamten oder Offiziere aufgezogen wird. Häufig ist sie auch ein äusserliches Erkennungszeichen für die Gesinnung des Häuptlings. Sobald man den Ort betritt, an dessen Eingang ein mächtig hoher Baum steht, sieht man schon von weitem die deutschen Farben durch das helle Grün schimmern und fühlt sich dadurch noch ganz besonders bewogen, auf dem schönen schattigen Platze Rast zu machen. Nachdem wir genügend der Ruhe gepflegt haben, brechen wir auf, um in einigen Stunden das grosse Negerdorf Kevega zu erreichen. Wir marschieren durch den hohen Wald, der Badja umgiebt und passieren am Ende des Dorfes wie am Eingang einen grossen Thonfetisch, welcher unter einem Grasdach aufgestellt ist. Diese Figuren in sitzender Stellung, nur plump aus Thon geformt, sind mitunter weiss bemalt; die Augen sind aus Kaurimuscheln hergestellt, öfters ist auch der Oberkörper damit versehen. Häufig liegen alte Ginflaschen und Kalabassen mit kleinen Kaurimuscheln gefullt neben der Fetischfigur, die an ein dem Fetisch gebrachtes Opfer erinnern.

Von Badja führt uns nun der breite Weg weiter auf einem hohen Damme, durch das bei hoher Regenzeir überschwemmte Thale der Zuflüsse des Aka, des Atete und des Gayethoë. Diese beiden Gewässer bilden in der grossen Baumsavanne, die bald hinter Badja wieder ihren einförmigen Charakter annimmt, ein grösseres sumpfiges Terrain, weshalb hier eine mit grossen Kosten verbundene Aufschüttung des Dammes vorgenommen werden musste. Bei Trockenzeit ist auch dieses Terrain wie selbst die Ueberschwemmungsgebiete der Flüsse, der kleineren Flüsschen und Bäche vollständig ausgetrocknet und glühend brennt dann die Sonne auf das armselige Schilfgras und den niedrigen Baumwuchs. 

Eingeborenen verursacht werden, um neue Farmen herzustellen, tragen nicht wenig zur Verödung der Vegetation bei und lassen auch keinen höheren Baumwuchs zu; denn alljährlich werden die Bäume infolge der Brände fast ihrer ganzen Kraft und ihres Blätterschmuckes beraubt. So sieht man in solchen Ebenen meistens nur niedrige verkrüppelte Bäume und niedriges Strauchwerk. Ab und zu ragen dazwischen ein paar Riesenbäume, deren Natur alle diese Hindernisse überwunden hat, hoch über den kümmerlichen Busch hinaus. Unglaublich verändert sich das ganze Landschaftsbild nach solchen Bränden; man glaubt die Gegend nicht wieder zu erkennen; alles ist kahl und man denkt sich unwillkürlich in unsere Winterlandschaft versetzt, nur dass der Schnee fehlt und statt dessen weithin schwarze Asche die Fluren bedeckt. Bäume und Sträucher starren ohne Blätterschmuck aus dem verkohlten Grase hervor; schon weithin macht sich ein brandiger, unangenehmer Geruch bemerkbar. Mitunter wird man von dem Brande selbst überrascht, dicke Qualmwolken steigen empor; stickender Dunst erfüllt die Luft und fast wie Schneeflocken fliegen die Bestandteile der Asche umher und schwärzen das Gesicht des Wanderers, wie die Lasten. Bisweilen ist man, um den Marsch nicht zu verzögern, gezwungen, seinen Weg durch diesen Brand fortzusetzen. Dass die Hitze, die er verursacht, bei der schon an und für sich hohen Temperatur von 30 Grad Celsius nicht eben angenehm ist, kann man sich leicht vorstellen. Bei dem breiten Wege hier ist natürlich wenig Gefahr, Brandwunden davon zu tragen, zumal noch ein kleiner Nebenpfad vorhanden ist. Es geht dann mit marsch, marsch durch die Flammen, welche zur rechten und linken Seite des Weges emporlodern und in dem frischen Holz ein Geknatter wie Gewehrfeuer erzeugen. Das Absengen ist bei den Eingeborenen mit ihren primitiven Feldgeräten, die nur aus einer Hacke bestehen, die einfachste Methode für die Anlegung einer neuen Farm. Dieses Verfahren erübrigt eine grosse Arbeit bei dem Ausroden und der Freilegung des Busches und gewährt auch den anzubauenden Pflanzen an den verkohlten Ueberresten wertvolle Stoffe zur Düngung des Bodens. Die kleineren stehengebliebenen Büsche werden dann noch mit der Hacke ausgerodet; während die grösseren Stämme einfach stehen bleiben. Das Land wird bei Beginn der Regenzeit mit der. Hacke aufgelockert, und zur Einsaat fertig gestellt. Nach der Regenzeit erfolgt die Einsaat, an welcher sich ausser den Männern auch: die Frauen und Kinder beteiligen. Die kleinen Kinder werden auf dẹm Rücken der Frau mitgeführt und nur ein Tuch, welches den kleinen schwarzen Weltbürger einhüllt, hält denselben auf dem Rücken der Frau fest. So sieht man die Frauen mit ihren Jüngstgeborenen alle Arbeiten verrichten. 
Da wir uns gerade im Bereich der Farmen befinden, so wollen wir Ackerbau. näher auf der eigentlichen Anbau der Pflanzen in diesen Gegenden eingehen. Der Grund und Boden ist im Besitz der ersten Familien, welche sich hier angesiedelt und dadurch gewissermaassen das Land in Besitz genommen haben. Es ist somit das Eigentum der alteingesessenen Gemeinde. Dieser grosse Grundbesitz vererbt sich immer wieder vom Vater auf den ältesten Sohn, während die unbebauten Territorien zum Niessbrauch und zur Urbarmachung an andere Familienangehörige abgegeben werden. Bei der grossen Ausdehnung der Ländereien der einzelnen Ortschaften und dem verhältnismässig kleinen bebauten Terrain bleiben noch weite bebauungsfähige Strecken übrig. Aus diesem Grunde ist es auch später zugezogenen Familien ermöglicht, leicht Land zum Anbau zu erhalten. Die Erlaubnis wird ohne Schwierigkeiten erteilt, und so haben häufig reiche Leute, welche sonst keinen eigenen Grundbesitz haben, vermöge ihrer Sklaven und vielen Frauen grössere und ergiebigere Farmen, als die Besitzer des Landes. Die einzelnen Ländereien sind allerdings in manchen Gegenden nicht genau abgegrenzt; häufig bilden Flussläufe, kleine Bäche oder auch grosse Bäume die Merkmale der Grenzen. Stellenweise, namentlich im Gebirge, werden die Grenzen durch gewisse Gräser, welche an denselben ausgesät werden, gekennzeichnet und festgelegt. Die perennierenden Pflanzen sind den Bewohnern sowie den Nachbarn genau bekannt und werden bei Grenzstreitigkeiten von den Parteien gewissermaassen als Grenzpfähle des Gebiets oder der einzelnen Besitztümer anerkannt.*) Falls die Grenzen nicht genau feststehen, so ist unser schwarzer Ackerbauer behufs Feststellung derselben auf eine einfache Methode verfallen. Er fällt auf dem zweifelhaften Gebiete einfach eine Palme; falls nun in längerer Zeit von den Nachbarn kein Einspruch erhoben und das Terrain, auf welchem die Palme gefällt ist, nicht als ihr Eigentum beansprucht wird, so sieht der betreffende Farmer dasselbe als seinen Besitz an. Es werden dann auf dem Gebiete Farmen angelegt und damit sind alle Ansprüche eines anderen auf dieses Terrain ausgeschlossen. Wir haben gesehen, in welch einfacher Weise der schwarze Ackerbauer das Land rodet. Während der Trockenzeit wird der Busch in Brand gesteckt, die stehengebliebenen Bäume und der Busch werden mit der Hacke ausgegraben und ansgerodet, während die nutzbringenden Bäume fürsorglich verschont werden. Ebenso werden Schattenbäume für gewisse Pflanzen unberührt gelassen. Grosse alte ehrwürdige Riesen, die dem Bauer im Wege stehen, werden zu Fall gebracht, indem an die Wurzeln oder an den unteren Stamm Feuer gelegt wird. Der Baum

*) Nach Spieth. 
verkohlt langsam und der übrig gebliebene Teil des Stammes wird noch als Feuerungsmaterial verwendet. Die einzelnen Zweige und Dornen werden als Schutz vor dem Wilde um die Farm gelegt. An den einzelnen offenen Stellen dieser Dornenhecke werden von dem schlauen Bauer und Jäger Fallen für das Wild aufgestellt. Die Asche der verkohlten Pflanzen bildet eine wertvolle mineralische Düngung. Die Pflanzen werden meistens nur ein Jahr auf derselben Fläche angebaut. Allerdings bleiben gewisse Pflanzen wie Kassawa mehrere Jahre stehen und liefern so ebenfalls ihren Ertrag. Gewöhnlich wird jedoch jedes Jahr eine neue Farm angelegt. Der Boden bleibt dann sehr häufig noch einige Zeit zur Oxydation brach liegen und wird bei Beginn der Regenzeit gelockert und bebaut. Es sind somit zwei Saatzeiten und zwar beginnt die Frühjahrssaatzeit im Februar und endigt im Mai. Die Frauen besorgen mit den Sklaven die Einsaat für das Frühjahrsgemüse. Es gehören hierher vorzugsweise Erdnüsse, Bohnen, Erderbsen, süsse Kartoffeln, Zwiebeln, Pfeffer, ferner Spinat und die sogenannten Gardeneggs. Diese Gemüsearten bilden mit eine grosse Einnahmequelle der Frauen, da ihnen allein der Erlös aus denselben zukommt. Mit diesem Taschengeld bestreiten sie zumeist allein ihre Ausgaben für Tücher, Schmuck- oder Toilettengegenstände. Auf einem der nächsten Märkte wird die Ernte verhandelt und von dem Erlöse die neue Equipierung angeschafft. Ausser diesen Gemüsepflanzen wird noch im März und April namentlich in der Ebene in grosser Menge Mais, Yams dagegen im Mai oder Juni, häufig auch noch in der Sommersaatzeit angebaut. Der Yams wird in kleinen Stücken in Löchern, mitunter auch in kleinen Häufchen verpflanzt, die zum Schutze vor dem Wilde mit Reisig oder Gras eingredeckt werden. Die Sommersaatzeit beginnt vor der Regenzeit und dauert von Juni bis August. In dieser Zeit werden meistens die Reisfarmen angelegt und an der Küste die alten Kassawafarmen durch neue Felder ersetzt. Die Kassawafelder, welche fast drei Jahre Erträge liefern, werden, falls es die Zeit erlaubt, in der Frühjahrssaatzeit angelegt. Ist auch die Einsaat vollendet, so dauert doch die Mühe und Arbeit bis zur Ernte der Pflanzen. Das Reinhalten der Felder ist keine Kleinigkeit bei dieser tropischen Vegetation, wo das Unkraut zum Verdrusse der schwarzen Bauern noch weit mehr als bei uns in Europa wuchert. So sind die Frauen und Kinder, meistens auch die Sklaven in den Farmen das ganze Jahr über eifrig mit dem Ausjäten des schädlichen Unkrautes beschäftigt. Yams ủnd Reis erfordern im allgemeinen eine höhere Kultur; man sieht daher diese Farmen fast immer wohl bestellt und von Unkraut frei. In den sandigen Küstengegenden, wo überall die dürftige Kassawa angepflanzt wird, nimmt man es mit der Reinhaltung der Felder nicht so genau. Eine solche Kassawafarm sieht dann häufig wild aus, während 
ab und zu dazwischen einzelne Bananen oder auch Oelpalmen das romantische Bild beleben.

Während der Zeit der Feldbestellung verlassen zum grossen Teil die jungen Familien das Dorf und lassen sich in der Farm nieder, wo sie während der ganzen Zeit in einigen kleinen Grashütţen hausen. Mitunter kann man auf den Farmen auch kleine Wächterhütten sehen, welche den während der Ernte die Felder bewachenden Leuten als Unterkommen dienen. Jeder Dieb, der es wagt, auch nur ein paar Yamsknollen oder Reisstauden auszureissen, wird rücksichtslos von dem Eigentümer der Farm niedergeknallt, denn nach den überlieferten Rechtsanschauungen der Eingeborenen ist jeder Eigentümer berechtigt, einen auf der That ertappten Felddieb ohne weiteres niederzuschiessen. Auch schützen die Leute ihre Felder gegen Vögel oder Wild durch Vogelscheuchen, die in kleinen Klappern oder Eisenglocken bestehen.

Später wollen wir auf die Eigentümlichkeiten des Ackerbaues in anderen Gegenden eingehen und werden dabei sehen, dass in den fruchtbaren Thälern der Gebirgsgegenden die Kultur vorgeschrittener als in den Küstengegenden ist.

Zwei bis drei Jahre wird das Land zum Anbau benutzt, alsdann wird wieder frisches Land in Bestellung genommen. Zu diesem Zwecke wird ein neuer Busch in Brand gesteckt, während die' alten Farmen bald wieder zum undurchdringlichen Busch verwildern.

Wir haben nun die Farmen, auch eine solche Buschfarm, passiert In der Landund gelangen zuerst über eine Brücke, auf welcher wir den kleinen Bach schaft Keve. Atete überschreiten. Grosse Fächerpalmen und Schilfgras bezeichnen die in der Regenzeit überfluteten Stellen und das kleine Thal des Baches. Von hier geht es weiter über eine kleine Anhöhe und auf einer zweiten Brücke über den Bach Gayetoë. Der Weg steigt nun mässig bergan und weithin bis an die Höhe zieht sich die öde Baumsavanne, welche auf diesem breiten Wege dem Reisenden nur wenig Schatten und Abwechselung bietet. Freudig begrüssen wir die Maisfarmen, welche das erste Anzeichen für die Nähe von Kevega bilden. Wir kommen wieder in einen dichten Oelpalmenwald, an denselben schliesst sich ein hoher undurchdringlicher. Buschwald an, der die mannigfaltigsten Arten von hohen Bäumen und Sträuchern aufweist und in dem die Oel. palmen mit diesen abwechseln. Es ist dies eigentlich der erste höhere geschlossene Wald, welchen wir seit dem Verlassen der Küste antreffen und der uns, abgesehen von den Palmen, an einen niedrigen verwilderten Laubwald in der Heimat erinnert. In schnurgerader nordwestlicher Richtung fuhrt uns der Weg durch den schattenspendenden Wald und nach sëchsstündigem scharfen Marsche haben wir das Dorf Keve erreicht, welches sich mit seinen armseligen Hütten an der Ostseite des Weges 
dahin zieht Diese sind ziemlich rerfallen und machen einen dürftigen Eindruck, da die Bundigkeit des Bodens geschwunden ist und der sandige Lehmboden ein weniger gutes Material für den Huttenbau bildet, als der reine Lehmboden. Häufig sieht man das Flechtwerk der Wände, aus welchem die meisten Evhehütten gebaut sind, zu Tage treten; die eigentliche Lehmwand zeigt grosse Lücken und wird nur von dem Geflecht gehalten.

Keve war einst ein grosser Stützpunkt des Fetisches, denn hier befand sich mitten auf dem Wege ein sogenanntes Fetischhaus,

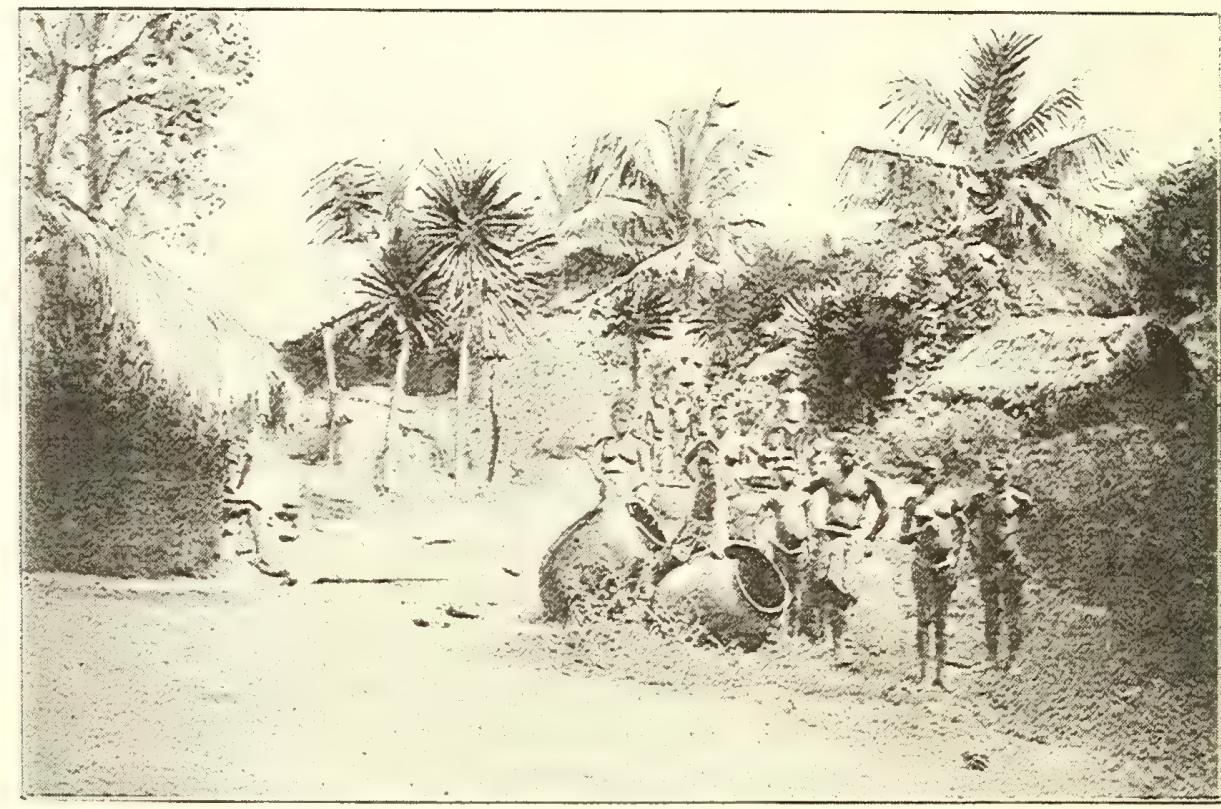

Das Dorf Kevega mit den grossen Wasserbehältern.

in welchem die zukünftigen Jünger und Priester des Fetisches in den Arzeneikünsten unterrichtet und in die Geheimnisse und Tänze eingeweiht wurden. Da der Weg, welcher zum grössten Teile von Herrn Leuschner ausgefuhrt wurde, direkt auf dieses Gehöft stiess, wurde die Hütte, ungeachtet des Widerspruches der Bewohner und der Fetischpriester abgebrochen und damit gleichzeitig dem Heidentume entgegengearbeitet. Heute befindet sich an der Stelle, wo früher das Gehöft stand, nur noch ein kleines $\mathrm{I}^{\mathrm{T}} / 2 \mathrm{~m}$ hohes Fetischhäuschen, welches aus Lehm gebaut und gleich den Evhehütten mit einem Strohdach eingedeckt ist. Ein kleines weisses Stück Zeug verschliesst die Oeffnung des Häuschens; eine rote Schranzfeder des grauen Papageis schmückt 
das weisse Tuch und zeigt zugleich einen Fetischplatz an. Wahrscheinlich werden auch in diesem Hause kleine Thonfetische aufgestellt sein.

Wir marschieren an dem Dorfe vorüber und gelangen plötzlich an eine breite Strasse, rechts rom Wege, die ron weiss gekalkten Steinen flankiert wird und durch ein grosses schön gezimmertes Thor in das Innere eines kleinen Schlosshofes hineinführt; im Hintergrunde desselben steht ein weisses, von Säulen umgebenes grosses, fast nach europäischem Styl gebautes Haus, welches mit seiner Rampe ganz den Eindruck eines Landschlösschens inmitten eines Parkes macht. Es ist dieses ein grosses Lehmhaus, welches Herr Leuschner bei dem Wegebau errichtet und das ihm lange Zeit als Wohnung gedient hat. Die Wände sind aus starken Lehmmauern aufgeführt; ein glattes Wellblechdach deckt das ganze Gebäude ein und ringsherum läuft eine Veranda, ebenfalls aus Lehmpfeilern und Lehmwänden errichtet. Der Fussboden ist zementiert und so bildet dieses Gehöft mit seinen Wirtschaftsgebäuden, der Küche und dem Stall zur Unterbringung der Pferde während der Trockenzeit für die durchreisenden Weissen, welche hier zu rasten pflegen, einen schönen Aufenthalt. Aber schlimm ist es, dieses Haus in der Regenzeit zu betreten, denn die Lehmmauern sind wenig durch das platte Dach geschützt, so dass die häufigen Tornados schon manches Loch in die Wände gerissen haben.

Als ich mit den übrigen Herren der Expedition hier das letzte Mal übernachtete, wurden wir arg enttïuscht, denn man war bei dem heftigen Tornado und dem strömenden Regen fast seines Lebens nicht mehr sicher. Alle Augenblicke fiel ein aufgeweichter Klumpen Lehm herunter und platschte auf den Boden, so dass man fortwährend befürchten musste, dass irgend ein Pfeiler zusammenstürzen würde. Infolgedessen hielt es unser Expeditionsmeister, Herr Hoyer, für angezeigt, sein Logis nach dem Pferdestall, der mit Gras eingedeckt war, zu verlegen.

Auf meiner ersten Durchreise wohnte noch Herr Leuschner hier, welcher mich liebenswürdig aufnahm und mir in seiner bewunderungswürdig eingerichteten Häuslichkeit Erholung von den überstandenen Mühen gewährte; so war es mir vergönnt, wieder im Bett der Ruhe pflegen zu können. Herr Leuschner hatte auch mit primitiven Instrumenten ein Bohrloch von gewaltiger Tiefe anlegen lassen, jedoch war diese Arbeit leider erfolglos, da trotz der grossen Tiefe noch keine Spur von Wasser zu finden war; in Ermangelung besserer Instrumente musste das angefangene Werk wieder aufgegeben werden.

Hier wurde mir unter anderem ein rorzüglicher Antilopenbraten aufgetischt. Ein grosser Wildreichtum von Antilopen scheint überhaupt in dieser Gegend rorhanden zu sein. Ausser der kleinen Zwergantilope kommt häufig die Schirantilope vor, welche von den Jägern vielfach 
erlegt wird. Das Fleisch derselben wird etwas angeräuchert und in der Sonne getrocknet. Auf diese Weise präpariert, wird es dann in einzelnen kleinen Portionen auf dem Markte oder in grösseren Orten verkauft.

Totenfeste. In Keve wurde des Nachts die Ruhe öfters durch die vielen Totenfeste, die hier gefeiert wurden, gestört. Ein ungeheures Getrommele, sowie das Knallen der Flinten, konnte man bei mondhellen Nächten öfters vernehmen. Natürlich ist ein solches Fest mit einem grossen Trinkgelage verbunden. Nachdem der Tote in dem Gehöft oder bei grossen Leuten auch im Hause in sitzender Stellung begraben ist, beginnt erst die richtige Totenfeier. Diese gestaltet sich je nach dem Vermögen des Verstorbenen und seiner Familie verschiedenartig, der letzteren Pflicht ist es, eine des Verstorbenen würdige Feier zu veranstalten. Zu diesem Feste werden alle Verwandten und Bekannten im Ort und in den benachbarten Dörfern eingeladen und alles strömt nun in dem Gehöft des Verstorbenen, dessen Haus nach dem Tode nicht betreten wird, zusammen. Von weit her kommen die jungen Burschen mit den bekannten Daneguns - Steinschlossflinten — bewaffnet, sowie die jungen Mädchen in grossem Staat, mit ihrem sämtlichen Schmuck behangen, zu diesem Totenfeste. Die Familie muss je nach der Wohlhabenheit Hühner oder Schafe schlachten und Fufu oder sonstige Speise für ihre Gäste zubereiten. Natürlich darf auch hier nicht der Palmwein fehlen, der in reichlichen Mengen vertilgt, häufig aber auch durch den Gin ersetzt wird. Sobald die Dunkelheit eingetreten ist, beginnt der Tanz. Die grossen Trommeln des Ortes werden zu diesem Zweck herbeigeschafft und ein oder zwei Trommler, auf einem Stein oder niedrigen Schemel sitzend, bearbeiten mit beiden Händen, mit einer bewunderungswürdigen Ausdauer, die Holztrommel, welche sie mit den Knieen festhalten. Diese Trommeln haben meistens eine längliche Form und bestehen aus einem ausgehöhlten Holzklotze, welcher mit einem Schaffell überzogen ist.

Die übrige Menge steht im Kreise herum und schlägt mit den Händen den Takt, während ein oder zwei junge. Leute unter den unglaublichsten Gliederverrenkungen den Tanz vorführen, welcher von dem eintönigen Gesang der Neger begleitet wird und mit einem von der umstehenden Menge ausgestossenen Freudengeschrei schliesst. Das nächste Paar, zwei junge Mädchen, beginnt darauf den Tanz. Er besteht ebenfalls aus den vorher beschriebenen Gliederverrenkungen, wobei die Arme in eintönigem Takt bewegt werden. Inzwischen schiessen die jungen Burschen mit ihren Donnerbüchsen unaufhörlich in die Luft und wetteifern gegenseitig im Erzielen eines grösseren Knalleffektes. Diese Feste dauern häufig ein bis zwei Tage und Nächte hindurch und 
sind für den Europäer wegen dem damit rerbundenen fortwährenden Lärm eine reine Schreckensplage.

Inzwischen hatten sich in Keve glücklich meine Träger eingefunden und nachdem ich mich mit vielem Dank von Herrn Leuschner verabschiedet hatte, brach ich am nächsten Tage mit denselben auf, um jetzt in geschlossener Kolonne meinen Marsch weiter nach Misahöhe fortzusetzen. Es war mir, wie bereits erwähnt, eine Warnung für meine künftigen afrikanischen Reisen, mich nicht von den Trägern zu trennen. Von jetzt ab marschierte ich stets, wenn es anging, unmittelbar hinter der Kolonne, um jeden Nachzügler oder Drückeberger sofort durch einen kräftigen Denkzettel an seine Pflicht erinnern zu können.

Im Jahre I 894 , als ich das erste Mal ins Innere ging, war der Weg nur teilweise bis Keve fertig gestellt. Damals musste man den Negerpfad ron einem Orte zum andern benutzen; jetzt führt eine breite Strasse in gerader Richtung weit ins Innere und so gelangt man nach $3 / 4$ stündigem Marsch durch den grossen schönen Urwald mit hohen Seidenwollbäumen, aus denen die Eingeborenen ihre Kanoes herstellen, nach Assahun, einem wichtigen Marktplatz. In Assahun entwickelt sich an den festgesetzten Marktagen ein reges Leben. Es kommen hier hauptsächlich Lebensmittel jeder Art zum Verkauf. Der Markt giebt im allgemeinen ein schönes Bild ab; unter den grossen Bäumen sieht man ein buntes Gewimmel von schwarzen Käufern und Verkäufern. Erdnüsse, Yams, Kassava, Bananen, Palmwein, gerösteter und ungerösteter Mais, allerhand Esswaren, wie die beliebten Maisbrote, sowie getrocknete Fische von der Küste her, Glasperlen, Tücher, hauptsächlich europäischen Ursprunges, Apfelsinen und Citronen werden hier in grossen Mengen feilgeboten.

Nach kurzer Rast marschierten wir in schnurgerader Richtung die Strasse weiter. Trotz des regen Verkehrs, welcher auf dieser grossen Strasse herrscht, war der Weg stellenweise mit Gras bewachsen und nur ein enger Pfad führte darauf entlang. Ich habe auf dieser Strasse häufig an einem Tage Karawanen von 20 bis 30 Personen angetroffen, welche hauptsächlich Palmkerne, Palmöl, Wein, zum Teil auch Mais, sowie weit her von Atakpame Gummi und andere Produkte nach der Küste herunterbrachten.

Es ist originell, wie man häufig schon von weitem an dem Aeusseren der Karawanen erkennen kann, woher sie kommen. So sind die Buschleute aus dem weiten Hinterlande, die man allerdings nur selten antrifft, sehr wenig und ärmlich bekleidet, die Haussas dagegen, welche meistens in kleineren Trupps herunterkommen, tragen weite blaue Toben. Die Mädchen, welche öfters zum Tragen von leichten Gummilasten verwendet werden, haben die ty pischen Frisuren der Kotoki- 
Leute, welche darin besteht, dass zu beiden Seiten des Kopfes die Haare durch Scheitel abgeteilt sind. Sie tragen auch einen kleinen Schurz wie die Evhe-Mädchen, doch fehlen ihnen häufig die sogenannten Schnüre unterhalb des Knies. Anders erscheinen die Lèute aus den Weberdistrikten, die ein buntgestreiftes Hemde oder eine Jacke aus dem von den Eingeborenen angefertigten haltbaren Stoffe tragen. Die Grussi- oder die Mussi-Sklaven erkennt man sofort an den mannigfachen Tätowierungen auf der Backe, welche aus breiten, fast vom Ohre bis zur Mundspalte herunterreichenden Schnitten bestehen. Die massenhaften Karawanen mit ihren verschiedenartigen Typen beleben die einförmige Landschaft der Gras- und Baumsavanne.

Bei hoher Regenzeit ist dieser Weg Ueberschwemmungen ausgesetzt und schwer zu passieren, weil die Wassermassen häufig die Strasse in einen wahren Morast umwandeln. Bis an die Kniee watet man dann im Schlamm und erreicht so das Thal des Baches Aië, welcher trotz seiner unscheinbaren Gewässer, die während der Trockenzeit vollständig verschwinden, die Strasse oft unpassierbar macht. Auf dem letzten Marsche, auf welchem ich und die übrigen Mitglieder der grossen Expedition diese Stellen zu Pferde bei der Regenzeit passieren mussten, brachten wir mit Mühe und Not unsere bis an den Bauch versinkenden Pferde vorwärts. Hier trafen wir grosse $5 \mathrm{~m}$ hohe Gneisfelsblöcke an. Nach dem Alter der von Südwesten nach Nordosten streichenden Ueberreste des Gesteins zu urteilen, kann sich ein uralter Bergrücken tief unterhalb der Erdschicht hinziehen, der nur ab und zu in den Thälern der Flussniederungen in Gestalt dieser grossen Blöcke zu Tage tritt. Zwischen dem Aië und einem kleinen Nebenbach desselben. finden wir wieder einen galerieförmigen Oelpalmenhain, welcher die Ufer einfasst. Auf einer kleinen Brückè, die nach europäischer Art, allerdings nur primitiv aus Baumstämmen gebaut ist, überschreitet man die Bäche. Die Strasse führt in nordwestlicher Richtung zwischen Oelpalmen, durch Busch- und Baumsavannen weiter. Zwei Kilometer von Tove biegt sie plötzlich nach Nordosten $a b$ und führt in kleinen Windungen direkt nach dem fast 360 Hütten zählenden Negerdorf Tove. An dieser Strasse hat sich ebenfalls ein Markt etabliert, welcher kleine Erfrischungen für die Reisenden bietet; sehr oft sind auch hier die Haussas anzutreffen, die auf ihrem Wege zu oder von der Küste ihr fliegendes Warenlager mit bunten Zeugen und Perlen zum Kaufe aufgestellt haben.

In Tove pflegt der Reisende zu übernachten, denn es ist zwischen Gbin und Keve der einzige grössere Ort, der an der Strasse liegt und Lebensmittel für grössere Karawanen zu liefern im Stande ist. Die Gehöfte sind meistens auf einen kleinen Raum dicht zusammengedrắngt; 
niedrige Hütten umgeben dieselben. Zum Teil haben sie einen Vorbau oder Vorraum, der hauptsächlich bei Regen gute Dienste thut. Auch ich benutzte öfters bei schönen warmen Nächten solchen Vorraum, um mein Feldbett aufzuschlagen und darin zu übernachten. Uebrigens bieten die armseligen Hütten, welche hier wenig gepflegt werden, auch im Innern nur einen primitiven Schutz, da die Grasdächer häufig grosse Löcher aufweisen.

Grosse Kokospalmen verschönern etwas die engen, sehr schmutzigen Gehöfte, auf denen Hühner, Ziegen, Schafe und Schweine friedlich zwischen den Bewohnern einherwandern. Die Hühner haben sozusagen einen engeren Verkehr mit der Familie, man wird daher diese unverschämten Gäste in seiner Hütte fast gar nicht los. Es ist eine kleine unansehnliche Hühnergattung, die infolge der Inzucht, wie auch die Ziegen und Schafe, degeneriert ist. So sorgfältig auch die Einwohner ihre Hühner und übrigen Haustiere pflegen, welche öfters ihr ganzes Vermögen ausmachen, so sind sie doch oft kindisch grausam gegen dieselben. Häufig ziehen sie einem Huhn etliche Schwanz- oder Flügelfedern aus, um sich damit zu schmücken, ferner finden sie eine ganz besondere Freude daran, einem Huhn die Federn zum Teil auszuraufen und das gequälte Tier halbnackt herumlaufen zu lassen. Auch werden die Hühner oft schon vor dem Schlachten gerupft. Der naive Neger, der in dieser Beziehung ganz wie ein Kind denkt, sieht darin keine Grausamkeit und wundert sich, wenn der Weisse seinen Angestellten diese Tierquälerei verbietet. So gut wie der Neger seine Tiere sonst behandelt, so ist er doch bei dem Schlachten derselben vollständig gefühllos, so dass ein Tierschutzverein hier ein reiches Feld für seine Thätigkeit finden würde. In den Gehöften trifft man bisweilen Kornspeicher, sowie kleine Ställe für Ziegen, Schafe und Schweine. Die aus Lehm gebauten Kornspeicher bestehen aus einem fast trichterförmigen Behälter, der auf Steinen ruht und durch Stangen gestützt ist. Ein rundes, kegelförmiges Grasdach schützt die Vorräte vor den Unbilden der Witterung. Die Ställe für das Kleinvieh sind zumeist nur Vèrschläge von Knüppelholz.

Die Leute in Towe sind zum grössten Teil Ackerbauer, welche viel Mais und grosse Felder mit Erdnüssen anbauen; die Ernteerträge werden dann in den oben erwähnten Speichern aufbewahrt.

Die Wasserarmut des Gebietes von der Küste bis nach Bin ist bei grosser Trockenzeit eine ganz entsetzliche Plage für das Land; mit jedem Tröpfchen Wasser wird sparsam umgegangen und in den trockenen Zeiten nur das nötigste zum Lebensunterhalt verbraucht. Natürlich ist das Wasser zum Waschen zu kostbar und so sind diese armen Leute bei weitem nicht so reinlich wie die in dieser Beziehung gesegneteren 
Küstenneger, welche sich jederzeit durch ein frisches Bad erquicken können. Man kann sich denken, wie unangenehm es für den Weissen ist, in der Trockenzeit diese wasserarme Zone zu passieren. Obwohl ihm mitunter als kostbare Gabè Wasser geschenkt wird, er es auch für Geld und gute Worte aufkauft, so erhält er doch häufig nur eine kleine Kürbisschale mit grauem, schmutzigem Waschwasser; und doch muss er froh sein, wenn er sich damit oberflächlich Hände und Gesicht von Staub und Schweiss reinigen kann. Erst in Misahöhe, jetzt allerdings schon in Palime, ist es möglich, sich tüchtig zu waschen und an kaltem Wasser zu erfrischen. Man kann sich lebhaft vorstellen, wie ein solcher Fussreisender aussieht, der mit rotem Staub bedeckt ist und alle. Augenblicke einen Sumpf zu passieren hat, der die Beine bis an die Kniee schwarz färbt. Augen, Ohren und Nase sind von Schmutz verklebt und er empfindet keinen sehnlicheren Wunsch, als endlich wieder einmal klares Wasser zu haben. Um diesem Mangel einigermaassen abzuhelfen, fangen die Eingeborenen den Regen, der aber in der Trockenzeit nur selten das Land beglückt, auf. $\mathrm{Zu}$ diesem $\mathrm{Zweck}$ haben sie grosse Thontöpfe aufgestellt, weite runde Gefässe, die fast ${ }^{\mathrm{T}} / 2 \mathrm{~m}$ hoch sind und welche an den Gebäuden und häufig auch unter der Traufe des Daches angebracht sind. Diese Töpfe sind nur von geringer Haltbarkeit, da die Eingeborenen in diesem Gebiet eigentlich keine umfassende Töpferei betreiben. Ueberhaupt haben hier die europäischen Waaren das einheimische Gewerbe beinahe ganz verdrängt.

Der Ort Tove war in früherer Zeit weit und breit dadurch gefürchtet, dass die Einwohner Sklaven abfingen, welche von ihrem berüchtigten Häuptling in Ketten gelegt wurden. Seit Einführung der europäischen Herrschaft ist natürlich ein solches Verfahren an dieser grossen Strasse unmöglich und die Leute können jetzt ungehindert weit ins Innere reisen.

Früh am anderen Morgen brach ich wieder mit meiner Karawane auf. Unser nächstes Ziel ist das nun endlich Wasser besitzende Dorf Gbin. Der Weg geht von Tove etwas bergab durch eine endlose Baumsavanne nach dem kleinen Thal des $5 \mathrm{~m}$ breiten Flusses Egu und fuhrt dann wieder etwas bergan, immer in schnurgerader nordwestlicher Richtung, bis zu den Ruinen des verlassenen Negerdorfes Wodunu. Früher passierte man auch auf dem Buschpfad das östlich gelegene, verlassene Dörfchen Klabonu. Ausser der endlosen Baumsavanne, in welcher viele Mimosen vorkommen, die eine Akazienart sind und unserer auf Sandboden häufigen Akazie gleichen, trifft man ab und zu einen kleinen Galeriewald von Oelpalmen und einige Buschparzellen an. Von den Sträuchern ist der sogenannte Kalabassenstrauch zu erwähnen. Die grossen, rauhen Blätter dieses Strauches bilden einen wichtigen 
Gebrauchsartikel der schwarzen Hausfrau. Die Blätter werden nämlich wegen ihrer Rauheit zum Scheuern der grossen Kalabassen und kleineren Kürbisschalen benutzt. Sie wirken fast wie Sandpapier und sind daher vorzüglich zur Reinigung der Gefässe zu verwerten. Ferner befinden sich unter den Sträuchern eine ganze Menge solcher Arten, welche zu Medizinzwecken benutzt werden. Von einzelnen werden die Blätter zu Thee abgekocht und wirken abführend, während die Früchte anderer Sträucher das Gegenteil bewirken; noch andere Blätter werden zum Verkleben und Verbinden von Wunden benutzt. Man sollte nicht glauben, welche ausgedehnten. Kenntnisse die Leute in Bezug auf die Verwendung der einzelnen Sträucher besitzen. Viele von diesen Heilmitteln sollen nach Aussage von Aerzten ganz vorzüglich sein.

Wir erreichen nun das verlassene Wodunu, welches heute leider nur noch eine Ruine ist. Kahle zerfallene Mauern, welche aus dem Grase emporragen und vereinzelt stehen gebliebene Papayabäume erinnern an die einstige Niederlassung. Merkwürdig ist, wie schnell ein solcher Ort vollständig mit Gras und Dornbüschen bewachsen wird, durch welche man sich mit Gewalt Bahn brechen muss. Infolge des erhöhten Verkehrs an dieser Strasse haben die Bewohner ihre frühere Heimstätte verlassen und sich weiter abseits im Busche angesiedelt. Namentlich die kleineren Ortschaften waren häufig wehrlos gegen die grossen Karawanen, welche in unverschämter Weise ihre Ueberlegenheit ausnutzten, die Felder plünderten oder auch gelegentlich Hühner oder Schafe raubten. Dieses hat die Bewohner fast sämtlicher kleinerer Ortschaften, an denen die grosse Strasse vorbeiführt, bewogen, ihre Wohnplätze zu verlassen. Früher, als die Strasse noch nicht bis hierher führte und der Verkehr noch nicht seine jetzige Höhe erreicht hatte, schlug ich mit besonderem Vergnügen in diesen kleinen Orten mein Nachtquartier auf. Hier konnte man so recht das Leben und Treiben der Eingeborenen beobachten. Des Tags über waren sie fast ganz verlassen, da die Männer und Frauen dann auf ihrer Farm arbeiteten, die Männer auch der ergiebigen Jagd nachgingen, welche in diesen wildreichen Gegenden von den meisten Bewohnern mit Erfolg betrieben wird.

Tagelang stellen die eingeborenen Jäger unermüdlich dem Wilde nach. Auch giebt es passionierte Jäger, welche längere Zeit ausserhalb des Dorfes in kleinen Hütten im Busch oder an den Farmplätzen leben und dem Wilde auflauern. Jedoch stehen diese Leute in keinem grossen Ansehen bei der übrigen Berölkerung und werden als faul und arbeitsscheu angesehen. Die Ausrüstung eines solchen Jägers macht einen drolligen Eindruck, wenn derselbe früh am Norgen würderoll zur 
Jagd geht oder des Abends zurückkehrt. Eine Kappe, welche fast wie- ein rundes Körbchen aussieht und von Flechtwerk hergestellt ist, bildet das Hauptbekleidungsstück. Ein armseliger, häufig zerfetzter Lappen ist um die Hüfte geschlungen, um die Scham zu bedecken, während ein breiter, grosser Gurt aus Leder die Munition in sich birgt. Dieser Gürtel enthält, ähnlich dem eúropäischen Patronengürtel, Holzgetässe in kleinen Ledertäschchẹn, welche mit grobem Negerpulver gefüllt sind. An der Seite hängt ein kleiner Beutel aus Leder oder Zeug, in welchem die Geschosse, die aus gehacktem Blei oder auch aus kleinen runden Steinchen bestehen, aufbewahrt werden. Ferner sind an dem Gurt kleinere Messer zum Ausweiden des Wildes befestigt. Mitunter trägt auch ein solcher schwarzer Jägersmann an einem Bindfaden ein Paar Amulette, welche ihm Glück bringen sollen und aus einem Paar Leopardenzähnen oder aus einigen Antilopenhaaren oder aus den Federn eines Raubvogels bestehen. Eine grosse Steinschlossflinte bildet die eigentliche Waffe, welche in der Regel geschultert getragen wird. Jedoch wird sie an dem nach vorn gerichteten Lauf angefasst, so dass der schwere Kolben, welcher mit verschiedenen Glück bringenden Jägerfetischen, wie Kaurimuscheln, Büffelschwänzen u. dgl. geschmückt ist, seines Gewichts halber nach hinten getragen wird. In dieser Weise ausgerüstet, sucht der Jäger die Spuren des Wildes auf, welches sich namentlich in dieser Gegend bei der Trockenzeit an den in geringer Anzahl vorhandenen Wasserplätzen aufhält. Tage und Nächte lang liegt er nun, ohne sich durch die Insekten und die lästigen Moskitos stören zu lassen, regungslos auf dem Anstand, um die Beute zu erhaschen. Was für eine Ausdauer dazu gehört, kann man daraus entnehmen, dass wir Europäer trotz unserer weittragenden vorzüglichen Gewehre nur sehr selten, mitunter garnicht zum Schuss gelangen; dass diese Leute mit ihrer nur 20 bis 30 Schritt tragenden Donnerbüchse überhaupt Erfolg haben, verdanken sie ausser ihrer Geduld hauptsächlich der Zeit, welche sie darauf verwenden und ihrer vollkommenen Unempfindlichkeit gegen Moskitos und andere derartige unangenehme Gäste. Hauptsächlich erlegen sie in dieser Gegend die fast überall vorkommenden Antilopenarten, wie Schir-, Zwerg-, Pferdeund Kuhantilope, auch werden zuweilen Büffel und Leoparden erbeutet. Aber auch noch auf andere Art wird die Jagd auf dem Anstande ausgeübt. Es werden Steinschlossflinten an den Stellen ausgelegt, wo das Wild verkehrt, dort werden Fäden gezogen, welche mit dem Schloss der Flinte in Verbindung stehen, in der Richtung des Laufes gehen und bei der geringsten Berührung die ausgelegten Flinten entladen. Das ahnungslose Wild, welches diese Fäden passiert, wird dann durch die ausgelegten Flinten zur Strecke gebracht. Dieses Verfahren 
hat namentlich für den Europäer, der sich selbst auf der Pürsche betindet und die Warnungszeichen nicht kennt, grosse Gefahren. Die Wrarnungszeichen bestehen darin, dass das Gras an dem Pfade zu einem Knoten zusammengebunden wird. Unterlässt der Jäger, ein solches TVarnungszeichen anzubringen, so trifft ihn, falls dadurch ein Unglüch herbeigeführt wird, die volle Schuld. Trotz dieser Maassregel komnit es doch noch vor, dass Schwarze, namentlich alte Weiber, welche Feuerholz sammeln, unverhofft von dem Geschoss getroffen werden. Zur Erbeutung grösserer Tiere werden auch öfters tiefe Gruben angelegt, die vorsichtig mit Laub und Erde verdeckt sind. Den kleineren Tieren wird mit Fallen nachgestellt; diese bestehen aus einigen einfachen Knüppelgerüsten, an denen ein mit Steinen beschwertes Fallbrett angebracht ist. Geht ein Tier in diese Falle, so fällt das Gerüst zusammen, das Tier wird ron der Last der Bretter und der Steine erschlagen oder festgeklemmt und so zur Strecke gebracht. Meistens werden diese Fallen, welche gleichzeitig einen Schutz gegen Feldschaden bilden, an den $\mathrm{Zu}$ yängen zu den Farmen in den Dornenhecken gelegt. Eine grosse Freude herrscht natürlich im ganzen Orte, wenn ein Jäger das Glück gehabt hat, ein grösseres Wild, z. B. eine Kuh- oder Pferdeantilope zu erlegen. Fast das gesamte Dorf ist an einem solchen Ereignis beteiligt, da selbstverständlich Verwandte und Freunde Teile von dem erlegten Wild erhalten, dem Häuptling aber sein rechtmässiger Teil in Gestalt einer Hinterkeule abgegeben wird.

So wie das ganze Leben und Treiben der Evheleute rom Fetischglauben durchdrungen ist, so spielt auch der Aberglauben bei der Jagd und den Jägern eine ganz bedeutende Rolle. Infolgedessen wird die Erlegung eines Tieres meistens nicht der Geschicklichkeit und Ausdauer des Jägers, sondern übernatürlichen Verhältnissen zugeschrieben. Hat ein Jäger ein Tier erlegt, so eilt er nach Hause und holt sich Rat bei den erfahrenen und alten Jägern, die häufig auch Fetischpriester sind, was er zum Schutze gegen den bösen Geist des Tieres thun soll. Der Tod des Tieres wird dann als gerechte Strafe dafür ausgelegt, dass es Hühner gestohlen oder Schafe zerrissen habe. Die Seele des Tieres lebt nach dem Glauben der Leute weiter fort wie die des Menschen. Die Tierseele soll auch die Fähigkeit besitzen, den Jäger zu blenden, so dass derselbe z. B. auf der Jagd ein Buschtier für einen Menschen ansieht und umgekehrt in Gefahr kommt, in diesem Zustande einen Menschen für ein Tier zu halten. Auch soll der Jäger, im Busche verirrt, die Fähigkeit verlieren, den Heimweg zu finden. Der Unglückliche, der sich bei einer derartigen Gelegenheit eine fahrlässige Tötung zu Schulden kommen lässt, wird als verblendet erklärt und in die Sklaverei verkauft. Seine Hütten und Farmen werden dann zerstört und dem KLose, Togo. 
Erdboden gleich gemacht. Zum Schutze gregen solche Torkommnisse muss or gewisse Ceremonieen durchmachen, welche den bei dem Todo eines Verwandten üblichen ähnlich sind ${ }^{*}$ ) I)em Jäger wird ein (xrashalm in den Mund gelegt, zum Zeichen, dass er bei der yanzen Ceremonic nicht mehr sprechen darf Bei der Erlegung grösserer Tiere, wie " B eines Leoparden, wird die Trommel gerührt, und nun zieht alles in den Busch, um die Beute in feierlichem Zuge einzuholen Dem Leoparden werden mit einem Tuch die Augen verbunden, derselbe wird an einer Stange angebunden und so im Triumph nach Hause gebracht Der Jäger, der Held des Tages, wird auf den Schultern zweier kräftiger Männer seiner Beute nachgetragen Linter Lobgesang bewegt sich der Zug nach den Hütten des Häuptlings, der Aeltesten und andercer angesehener Männer. Diese beschenken alle den Jägrer und winschen ihm Glück Nach diesem feierlichen Limuge wird die Beute an einem Baume aufgehangen, abgehäutet und zerlegt Dabei werden leider oft die wertwollen Felle in der Hitze des (iefechtes zerschnitten und vernichtet. Zu dem darauf folgenden Mahle wird der Jäger häufig, namentlich in clen Gebirgsgegenden; festlich geschmückt und zieht in diesem Aufzuge durch die Strassen des Dorfes Eine Seite des Körpers wirl mit weissen und gelben Farben bemalt, so dass die schwarze Haut des Jägers dem Fell des erlegten Tieres ähnelt Die Augenlider werden ebenfalls weiss angestrichen und selbst die Jägerkappe erhält einen entsprechenden Anstrich. Die Hände, die Füsse und der Hals sind mit allerhand Jagrdtrophäen, wie Leopardenzähnen oder Klauen, die zugleich fetischembleme vorstellen, weschmückt In diesem phantastischen Aufruge läuft der Jäger auf allen Vieren mit einem Bogen bewaffnet, brüllend durch die Strassen und ahmt die Geberden des erlegten Tieres nach Zwei seiner Spiessgesellen begleiten ihn, mit Lanze und Knippel versehen, ebenfalls in gebückter Stellung Der Jäger und sein Anhang hat das Recht, alle Hühner, welche er auf diesem Irege antrifft, totzuschlagen und für sich in Anspruch zu nehmen

I)er Häuptling erhält ron der Jasclbeute zuerst seinen Anteil, während später auch die Vornehmen und Aeltesten des Dorfes mit einem Stuck Fleisch beschenkt werden Die übrigen Teile, die Eingerreide und selbst die Knochen. Werden dann von den anderen Einwohnern verspeist Die Zähne sowie die Klauen und der Kopf des erlegten Tieres bleiben als Jagdtrophäe dem glücklichen Jäger Aus diesem Grunde sind auch meistens an den Fellen, die man zu kaufen bekommt, die Krallen leider nicht mehr vorhanden Grössere Tiere, wie Elefanten und Buffel werden nicht herumgetragen, sondern mestens vor der Hütte

*) Nach Spieth 
des fïgers zerlegt und zerteilt. Bleibt noch Fleisch übrig, so kommt dem läger ausser den Stosszähnen oder Hörnern auch noch der Erlös für dieses zu.

Vachrlem das Tier zerlegt und verspeist ist, beginnt für den Jäger fast dieselbe Ceremonie wie bei den Trauerfeierlichkeiten Verstorbener. Der fïger muss, um sich vor dem Geist des erlegten Tieres zu schützen, besondere Maassregeln treffen*). Er darf einige Tage die Hütte nicht rerlassen, auch während dieser Zeit nicht sprechen oder Kleider anlegen; er muss ferner 12 Tage hindurch gewisse Speisen, wie Fische, meiden und darf während dieser Zeit nur die Speisen mit Salz greniessen. I) Tagre hindurch kann der Jäger sämtliche Hühner, die er in clem Dorfe antriff, zu seinem Gebrauche nehmen. Nach dieser eigentümlichen Fasten- und Einsiedlerzeit ist der Jäger wieder frei. Wahrscheinlich hat nach dem Glauben der Leute dann die Seele des erlegten Tieres im Reich der Toten Ruhe gefunden. Ein grosses Fest sämtlicher Dorfbewohner beschliesst diese Zeit Ein Gelage findet bei Tan\% und Cicsang statt, wobei bestimmte Jägertänze aufgeführt werden. Dabei stellen die Jäger dar, wie sie die Spur des Wildes finden, wie sie plötzlich auf dasselbe stossen und sich heranzupürschen suchen, ferner, wie der Leopard horcht und sich windet, wie er sich zum Sprunge bereit hält, endlich wie der Jäger feuert und fehlt, und die Beute schliesslich durch die im Hinterhalt liegrenden (ienossen noch im letzten Augenblick erlegt wird

Auch verehren die Jäger ihre besonderen Fetische, so wurde mir gesagt, dass in dem Orte Soluga, wo ich seiner Zeit einen neuen Wey anlegte, ein Jägerfetisch sei I)erselbe bestand aus + bis 5 kleinen Thonfiguren, ron denen die grösste nicht höher als ungefähr $50 \mathrm{~cm}$ war und an welche sich die ubrigen wie Orgelpfeifen anreihten Diese Fetischfiguren standen unter einem (jrasdach und ror denselben lagen die Tribute der Jägrerei: Büffel- und Antilopenhörner, die mit Kaurimuscheln besetyt waren Kleine Amulette waren angehangen, sowie die Krallen ron Leoparden und Raubrögeln und die ebenfalls als Fetisch bekannten Leopardenzähne Leider konnte ich ron den abergläubischen Leuten keinen näheren Aufschluss erhalten und musste mich mit der Thatsache begnügen, dass es ein Jägerfetisch sei, zu welchem diese weit und breit aus der Umgegrend pilgrern um Gilück für die Jaggd zu erflehen

Nach dieser Abschweifung kehren wir zu dem kleinen Ort VIodunu Häusliches zurück, welcher bei meiner ersten Reise noch an der Strasse lag Hier Leben in den machte ich, wie schon gesagt, gerne Rast, um der Nachtruhe zu pflegen Jäger-und Mitunter bekommt man in diesem Jägerort einen frischen Antilopenbraten Farmdörfern

\&) Nach Spieth 
zu kaufen. Natürlich wird derselbe mit ganz besonderer Freude erstanden, denn bis jetzt stand auf dem einförmigen Speisezettel nur Huhn und wieder Huhn. Ein solcher Antilopenbraten ist allerdings kein solcher Hochgenuss wie bei uns ein gut zubereiteter Rehbraten, denn wenn auch das Fleisch wenig dem eines Rehs nachsteht, so ist doch leider die mangelhafte Kücheneinrichtung, sowie die Kunst des schwarzen Kochs wenig dazu greeignet, einen wohlschmeckenden Braten zu bereiten. Wenn man Musse hat, versucht man es selbst mit der Kochkunst, aber der Erfolg pflegt so gering zu sein, dass man seine Zeit besser wichtigeren Sachen zuwendet.

In dem kleinen Orte Wodunu hat man so recht Einblick in das Treiben der genügsamen Schwarzen. Ein Antilopenbraten ist natürlich für sie ein ganz besonderer Leckerbissen, da er nur selten rorkommt. Meist können nur die Reicheren ihn sich leisten, während die Jäger ihn so rorteilhaft wie nur irgend möglich zu verkaufen suchen. Sie räuchern das Fleisch etwas und lassen es dann in der Sonne trocknen. In dieser Form kommt es in kleinen Partieen zum Verkauf und bringt einen schönen Erlös. Von einer Antilope ist binnen kurzer Zeit auch nicht mehr die Spur vorhanden. Eingeweide und Geschlinge werden von den Bewohnern selbst sofort zu einer Art Frikassee gemacht und sogar die Knochen werden verwerthet, indem sie theilweise zerstampft und zu Suppe gekocht oder zu einer Sauce für den Fufu verwendet werden. Das Gehörn wird verkauft oder dem Fetisch geweiht, selbst die Zähne und Klauen werden häufig als Amulett getragen und sollen dem Jäger Glück bringen. Das Fell wird auf dem Rasen ausgespannt und in der Sonne getrocknet und kommt alsdann entreder zum Verkauf an die Küste, oder es wird ron den reichen Schwarzen als Lagerstätte oder Teppich benutzt.

So ausgestorben der Ort am Tage erscheint, um so mehr Leben herrscht des Abends in den einzelnen Haushaltungen. Die Mädchen und Frauen tragen in grossen Töpfen das Wasser herbei, während die alten Weiber tagsüber Feuerholz gesammelt haben und dieses für die Bereitung der Hauptmahlzeit, die bei unseren Schwarzen nach Sonnenuntergang eingenommen wird, herbeibringen. Es beginnen nun die kleinen Herdfeuer zu rauchen, welche sich in der Trockenzeit meistens vor der Hütte, in der Regenzeit aber im Innern derselben befinden. Der Transport des primitiven Herdes ist leicht zu bewirken, da er häufig nur aus drei grossen Steinen besteht oder auch aus einem kleinen Thonkegel hergestellt ist, welcher den grossen Kochtopf stützt. Einen traulichen Eindruck macht der Feuerschein ror sämtlichen Hütten. An dem Herdfeuer sitzen die Familien und plaudern über die Ereignisse des Tages, während die Frau emsig das Feuer schürt und in einem grossen 
primitiven Thontopf das Wrasser siedet. Die Mädchen schälen den Yams und schneiden ihn in Stücke, dann wird er in grossen Töpfen gekocht und ron da aus wandert er in die grossen Holzmörser, in denen er von den Frauen zu Brei zerstampft wird. Ueber einem anderen kleinen Feuer wird eine Sauce ron Kräutern und Palmöl bereitet und bald ist das frugale Mahl für die Familie hergerichtet. In einer grossen, flachen Schüssel aus Thon wird nun der allbeliebte Fufu aufgetragen, daneben steht eine kleinere mit Kräutersauce; mitunter wird das Mahl noch durch

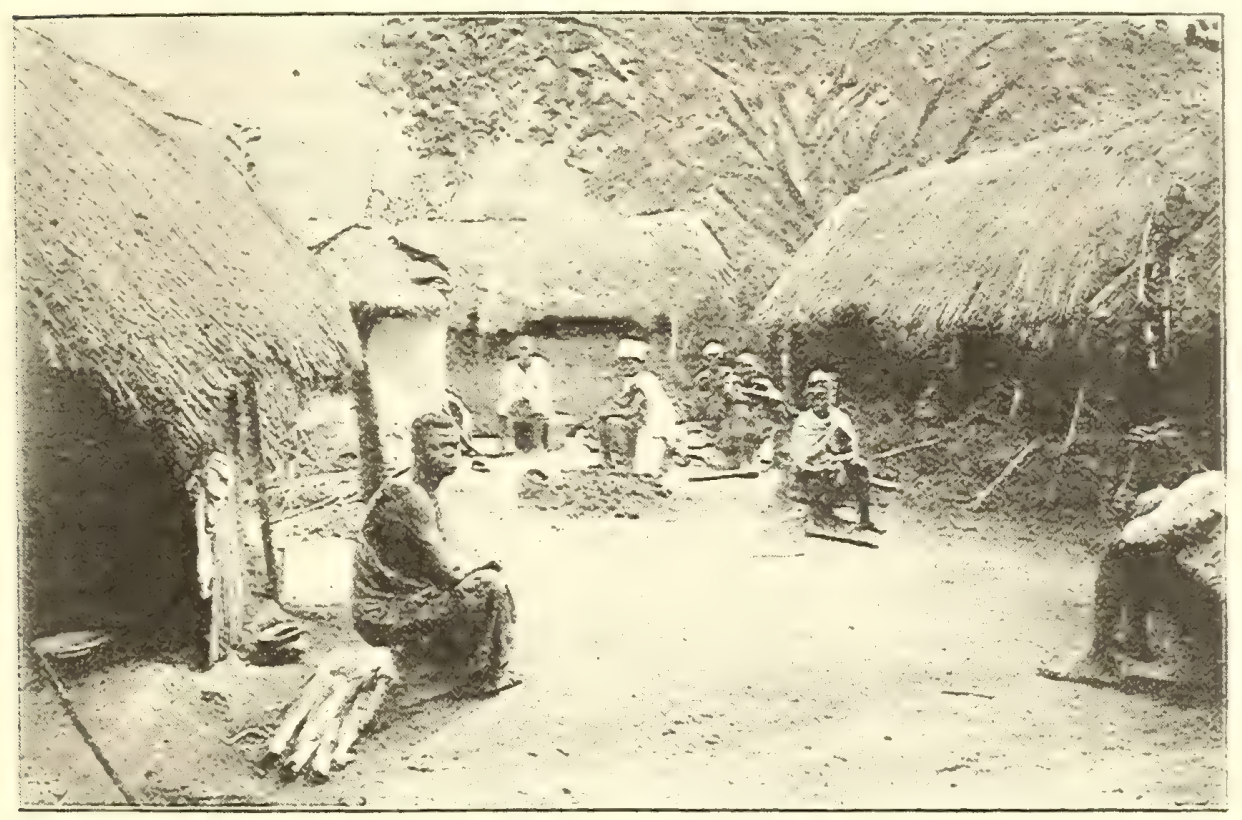

Ein Gehöft der Evhe-Neger

ein Huhn oder einige Stinkfische ron der Küste vervollständigt. Alle hocken im Kreise auf der Erde, die Kniee hoch angezogen bis an das Kinn, um die Tafel und jeder greift decent mit den Fingerspitzen der rechten Hand nach dem Fufu, formt ihn geschickt zu einer Kugel und fährt damit in die meistens sehr stark gepfefferte Kräutersauce, um der Speise die nötige Würze zu verleihen. Der Bissen wird nun mit Andacht und V'erständnis verzehrt und zu bewundern ist, wie jeder bei dem Mahl zu seinem Rechte gelangt. Keiner sucht dem andern zurorzukommen oder ihn in irgend einer Weise zu schmälern. Die Finger werden nach jedem Mahle sauber gewaschen und gereinigt. Häufig lässt man die Feuer noch weiter brennen, um sich nach dem Mahle am Herde zu erwärmen. 
Heute ist leider auf der ganzen Strecke zwischen Tore und Gbin kein einziger Ort mehr, der an der Strasse liegt und so muss man ohne wrössere Rast den Marsch auf der grossen Strecke ron Tore bis Gbin zurücklegen.

Nachdem wir die Ruinen von dem alten Wodunu passiert haben, greht es clurch die grosse Baumsavanne weiter, an den niedrigrer gelegenen Strecken wechseln Oelpalmen mit anderen höheren Buscharten ab. Zur Seite des Weges liegen vereinzelte kleine Koffis, geschützt von dem umgebenden Busch, allmählich steigt das Terrain bis zum Ueberschwemmungsgebiete des Gibin an. Fon den höchsten Punkten hat man einen flüchtigen Ausblick auf den grossen Aguberg, welcher im Norden vor uns liegt; nur $a b$ und zu schimmern seine ( $i$ ipfel durch die lichten Stellen der endlosen Saranne Bald kommen wir in clas grosse Ueberschwemmungsgebiet des Gbin, wo Schilfgras und zahlreiche Waldpartieen, die hier einen höheren Wuchs haben, beweisen, dass der Boden mehr Fruchtbarkeit besitzt und daher ein besseres Gedeihen der Pflanzen bewirkt.

In der Die grosse Ebene, in der der (xbin fliesst, soll bei Hochwasser in Gbin-Ebene. einer Breite von fast $2 \mathrm{~km}$ überschwemmt werden In dieser Zeit bildet der Fluss mit seinem Ueberschwemmungsgebiet ein grosses V'erkehrshindernis; tagelang muissen die Karawanen liegen bleiben und das Fallen des Wassers abwarten, um dann erst das weite sumpfige Terrain passieren zu können. Heute führt die Strasse auf einem Damm bis an den Gbin heran und ist dadurch mehr vor der Leberschwemmung geschützt als früher. Leber den (ibin fuhrt jetzt eine nach europäischer Art errichtete Brücke, infolgedessen hat man es nicht mehr nötig, wie in früheren Zeiten, diesen Fluss auf einem übergeworfenen Baum, auf welchem man mühsam entlang kriechen musste, zu uberschreiten Der Gibin hat ziemlich steil abfallende Uferränder, die ca 2 bis $2^{1} / 2 \mathrm{~m}$ hoch sind und bei Hochflut ron der ( Nur der hohe Galeriewald, der sich zu beiden Seiten des Ufers dahinzieht, hält das eigentliche bett in seinen Grenzen. Baumwurzeln starren häufig an dem Lfer frei heraus und nicht selten kommt es ror, dass bei grossem IVasser ein baum der Gewalt der Flut weichen muss und in oder über den Fluss fällt. Infolgedessen wird auf diesem Flüsschen so grut wie yar keine Schiffahrt betrieben Aber so getährlich der Fluss bei der Regrenzeit sein soll, so unbedeutend ist er bei der Trockenzeit. Nur ein ciewässer von etwa 6 bis $7 \mathrm{~m}$ Breite und $3 / 4 \mathrm{~m}$ Tiefe floss träge in dem Flussbett dahin, als ich ihn im Jahre 1894 passierte. Nach den schrecklichen trockenen Jahren Ende des Jahres I 897 , fand ich sogar das Bett vollkommen trocken ror, so dass ich im ersten Augenblick im Zweifel war, ob es wirklich der (ibinfluss sei Nur weit unten, südwestlich des Dorfes, befanden sich kleine Wasserlachen in 
dem Bette, fast $1 \% \frac{1}{2} \mathrm{~km}$ weit mussten die Bewohner pilgern, um aus schmutzigen Pfützen die Wasserüberreste zu schöpfen.

In schnurgerader Richtung führt nun die Kunststrasse durch den II ald, welcher den Gbin umgiebt, und weiter durch die Savanne, welche sich westlich ron dem Dorfe Gbin hinzieht. Auf einer kleinen Anhöhe liegt das etwa 60 Hütten zählende Dorf Gbin, welches durch seine höhere lage ror der Ueberschwemmung des Flusses geschützt ist. Der Weg fuhrt an dem Nordwestausgange des Dorfes vorbei; an demselben befindet sich jetzt eine kleine Baracke, welche Herrn Leuschner während der Herstellung des Weges als Wohnung gedient hat. Ein hoher Busch umgiebt das kleine Dorf im Osten und im Norden. Zusammengedrängt liegen die wenigen armseligen Hütten, welche häufig als Logis und Nachtyuartier für die vielen Karawanen dienen Es ist der erste grössere Ort, welcher bei normalen Zeiten frei ron dem schrecklichen Wrassermangel ist; hier ist es einem vergönnt, ein lang ersehntes und erquickendes Bad in dem (ibinfluss zu nehmen. Die Lage der Baracke inmitten des hohen Busches abscits rom Dorfe gewährt nach den Strapazen des Marsches einen angenehmen und schönen Ruheplatz. Auch bietet diese Behausung mit den aus Palmblattrippen hergestellten Hutten grösseren Komfort, als die häutig eingeräucherten Negerhütten. Da das Dorf sehr nahe am Wege liegt, und Leute bald zur Hand sind, ist der Ort in jeder Hinsicht einer der bequemsten Rastplätze für den Europäer. Hier rasten die Karawanen, welche ron Agu sowie von den umliegenden Gegenden und aus dem westlichen Teile des Agomegebirges kommen, nebeneinander. Die Höfe sind dann ron Fremden belagert und durch die Lasten der Träger sleichsam in Wrarenlager umgewandelt.

Die Kleidung der Gbin-Bewohner macht schon einen weniger europäischen Eindruck; namentlich in dem jetzt zerstörten Klonu waren viele Weber anzutreffen, weil die Hausweberei eine besondere Industrie der (iebirgsgegenden ist und sich hier auch länger gegen die Konkurren, der (lurch die Trägerkosten verteuerten europäischen Waren halten konnte. Allerdings nimmt mit den Jahren infolge der besseren Verkehrsmittel und mit der Anlegung von Nebenfaktoreien der Handel mit europäischen Kattunzeugen im Hinterlande einen grösseren Aufschwung. In Gibin sieht man sehr viel Elfenbein, welches zu allerhand Schmuckgregenständen verarbeitet wird, wie z. B. zu I 5 bis $20 \mathrm{~cm}$ langen Manschetten, welche statt der Armringe getragen werden, sowie zu kleinen Reifen, mit denen die Damen den Oberarm zieren; oftmals tragen auch die Veiber breite Elfenbeinringe um die Fesseln. Die grossen Stulpen an den Beinen und Armen verleihen dem watschelnden Körper noch einen plumperen und schwerfälligeren Gang. Das Elfenbein soll aus der grossen unbekannten Ebene des Gbin und des Sio herrühren, welche sich 
nordwestlich weithin in das Land erstreckt und fast ganz unbewohnt ist. In den grossen Galeriewäldern, welche die Flüsse und deren Niederungen umgeben, sollen nach Aussage der Eingeborenen noch Elefanten hausen. Dieses fand ich bestätigt durch den Reichtum an Elfenbeinschmuck, rlen die Leute in der Gegend tragen, wie durch die Aussagen eines Dolmetschers der Regierung, Amussu Bruce, der persönlich einen Elefanten dort erlegt haben will. Bruce, der bei meiner letzten Reise Dolmetscher auf der Station Kpando war, erzählte mir noch mit grossem Feuer dieses Jagderlebnis, auf welches er sich mit Recht nicht wenig einzubilden schien. Da die Eingeborenen, namentlich aber die Jäger, fürchten, dass der Weisse ihnen ins Handwerk pfuschen könnte, so erfährt man leider wenig ron ihren Jagden und von dem Versteck des Wildes. Jedenfalls muss man den Schneid der einzelnen Jäger bewundern, die es ragen, mit ihren schlechten Steinschlossflinten die Jagd auf diese Riesenticre aufzunehmen. Aber der Gewinn des kostbaren Elfenbeins ist ein grosser Ansporn und wiegt ihnen die Gefahr, welcher sie sich aussetzen, bei weitem auf. Das erbeutete Elfenbein wird teils durch Händler zur Küste gebracht, teils wird es ron den Eingeborenen zu Schmuckgegenständen verarbeitet.

Nachdem ich in dem sogenannten Wegehause bei Gbin der Ruhe gepflegt und mich des Abends vorher an einem frischen Bade im Gbin erquickt hatte, marschierte ich am nächsten Tage mit meinen Trägern weiter durch die grosse Ebene. Eintönig zieht sich der Pfad durch die grosse Baumsavanne etwas ansteigend bis zu dem grossen Negerdorfe Assahun hin. Von Gbin ab hört die grosse Strasse auf, und wir rerfolgen einen kleinen Negerpfad, der sich zwischen dem Grase und den Bäumen hindurchschlängelt. Dieser Weg lehrt recht die Vorteile der grossen europäischen Kunststrassen erkennen; wenn man früh durch das hohe Gras marschieren muss, wo alles mit Thau bedeckt ist, so ist man binnen fünf Minuten bis auf die Haut nass. Grosse Pfützen, die sich nach einem Regen in dem muldenförmigen, ausgetretenen, häufig nur $20 \mathrm{~cm}$ breiten Pfade angesammelt haben, versperren den Weg. Die Neger, die zum grössten Teile einwärts gehen und auch mehr an solche Pfade gewöhnt sind, empfinden diese Unbequemlichkeiten weniger als die beschuhten Europäer.

Das Gras erreicht in dieser Ebene fast $1 \mathrm{~m}$ Höhe und hat einen schilfigen Charakter. Die Bäume, welche mit Ausnahme der besonclers grossen Stämme in diesen weiten Ebenen unter den vielen Feuerbränden, welche die Eingeborenen zur Herstellung ihrer Farmen entzünden, zu leiden haben, sind |sozusagen degeneriert. Der Savannenbaum erreicht eine durchschnittliche Höhe von 3 bis $4 \mathrm{~m}$ und gehört zumeist den Morinda- und den Mimosenarten an. Man hat 


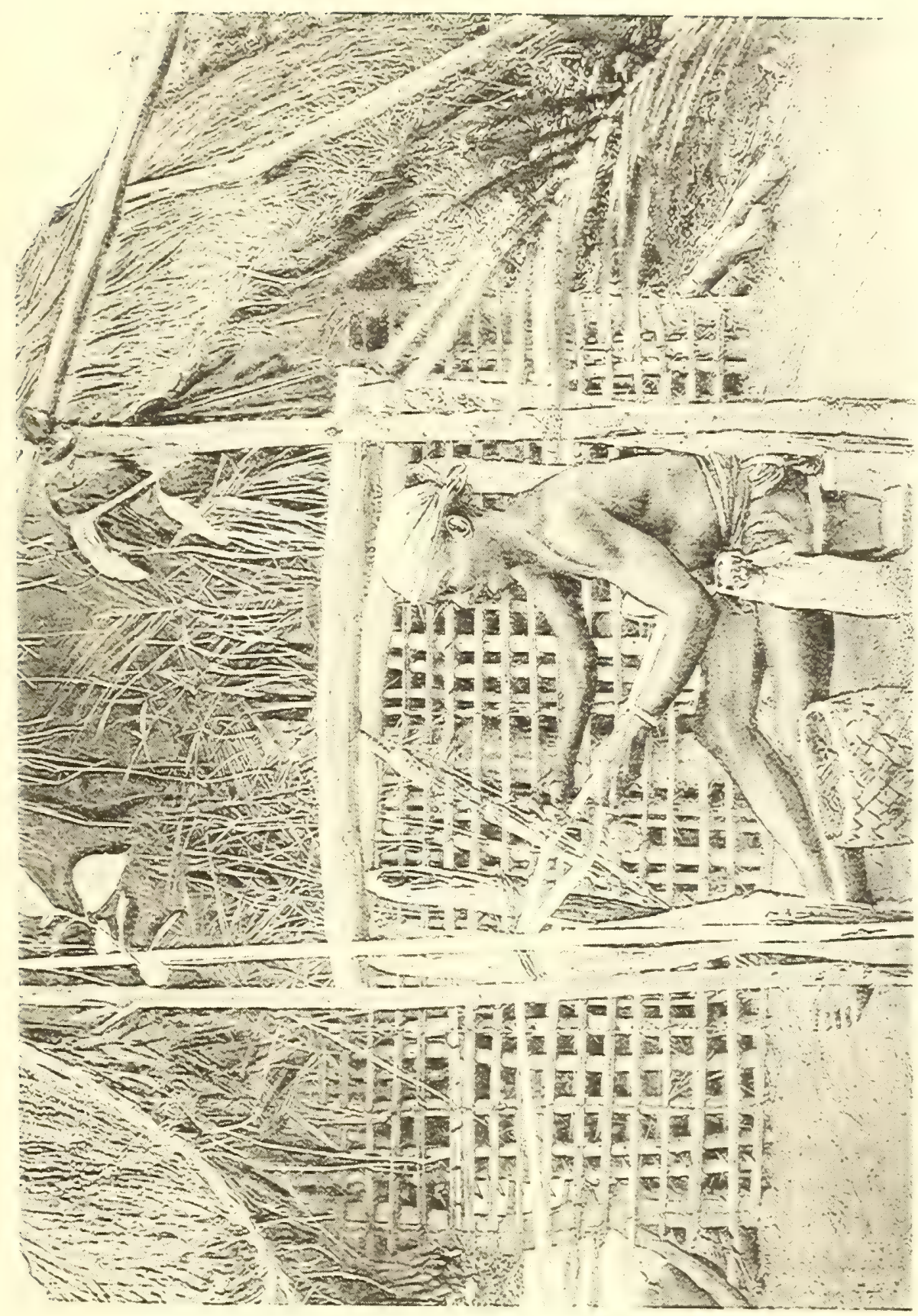



den Eindruck, durch einen vollkommen verwilderten, alten Obstgarten zu wandern.

Wrir überschreiten jetzt die kleinen rechtsseitigen Zuflüsse des Gbin, die während der Trockenzeit ganz ausgetrocknet und leicht zu passieren sind. Sie bieten einige Abwechselung in dieser grossen, sich fast immer sleich bleibenden Savanne. Kleine Wälder mit Palmbäumen zeigen schon von weitem die Wrasserläufe an und erfreut begrüsst man die schattigen Bäume, welche dem Reisenden einen erwünschten Ruheplat» in dieser grossen sonnigen Ebene gewähren. Auch die Träger sincl froh, ihre Bürde auf einige Minuten los zu werden und neben derselben ihre müden Glieder in dem kühlen Schatten ausstrecken zu können.

Alte Träger, die oft die Strecke Lome-Misahöhe zurückgelegt haben, kennen die Wasserstellen, welche hier und da in dem ausgetrockneten Flussbette zurückgeblieben sind. Der jüngste Träger muss natürlich Wasser herbeiholen und alles labt sich an dem trüben, unansehnlichen Nass. Aber nur eine kleine Rast kann den Trägern gegönnt werden und unwillig nehmen sie die Lasten wieder auf; einer hilft dem andern dieselbe auf dem Kopf zurecht zu legen, und weiter geht es durch die endlose Baumsaranne. Karawanen kommen und gehen und man erkundigt sich gegenseitig nach dem nächsten Wasserplatz oder dem nächsten zu erreichenden Ziel, dem Dorfe Assahun. Die zuverlässigste Uhr, die hier die Leute besitzen, ist die Sonne; sie richten sich einfach nach ihrem Stande. Diese Art der Orientierung ist in diesen dem Aequator nahegelegenen Orten sehr leicht, da die Sonne mit geringen Abweichungen um 6 Uhr früh aufgeht und des Abends zu derselben Zeit hinter dem Erdball verschwindet.

Auf dem Marsche, namentlich des Morgens und des Abends, taucht plötzlich aus einem kleinen Seitenpfad die Gestalt eines Jägers auf, der mit seiner grossen Flinte auf den Anstand geht, oder ron demselben nach seinem Heim zurückkehrt. Häufig sieht man auch ganze Familien ron den Farmen zurückkehren, die teils wegen der Bodenverhältnisse, teils wegen der plündernden Karawanen weit ron dem Dorfe und abseits der Strasse in dem Busch angelegt sind. Kinder und Frauen mit Säuglingen auf dem Rücken, mit Hacken versehen, kommen ron den Farmen und tragen die geernteten Feldfrüchte auf dem Kopfe zur Bcreitung des Abendmahles. Vorweg schreitet der Mann mit einer grossen Steinschlossflinte, oft jedoch ohne Munition, denn der blosse Anblick dieser Mordwaffe genügt schon für einen schwàrzen Bruder aus dem Nebendorfe, um ror etwaigen Angriffen zu schützen. In diesen Küstengebieten ist fast jedes grössere Dorf ein Königreich für sich, und wenn einige Dörfer in Streit kommen und sich gewissermaassen den Krieg erklären, so wird dieser nicht durch blutige Schlachten ausgeglichen, 
sonclern durch Abfangen ron Leuten, welche zu Sklaven gemacht werden oler durch Wegnahme von Yieh oder Feldfrüchten Aus diesen Gründen, führen die Leute auf dem Felde Waffen mit, um schon durch den kriegerischen Findruck etwaigen Uebergriffen vorzubeugen

Der Weg fuhrt noch immer durch die Savanne; nur die niedrigen Stellen sind durch höheres. Schilfgras und durch Agobims gekennzeichnet. Dann beginnt er etwas zu steigen und die ersten Vorläufer des Agomegebirges Werden zum ersten Mal sichtbar I Jer Weg wird steinig, das (iras höher; und bald haben wir die Farmen von Assahun erreicht. Kleine Fetische, welche gregen Felddiebstahl schützen sollen, stehen an den Gemarkungen der Felder. Fs sind Frdhügel mit einem kleinen darauf gesteckten Stab, welcher die Fetischembleme, Federn, Kauris oder dergleichen enthält, diese Fetische werden ron den abergläubischen Nogern respektiert und erfullen so ihren Zweck

I) Dorf VIriederum überschreitet man ein kleines Nebenflüsschen des Gibin Assahun und gelangt alsdann in das grosse, fast zoo Hütten zählende Negerdorf in der Land-Assahun, das eigentlich aus drei kleinen zusammenhängrenden Dörfern schaft besteht. Is ist ein wichtiger Plat\%, da er seit der Zerstörung von Klonu und Towe der letzte Rastplatz ror dem Ciebirge und der einzige Ort ist, welcher zwischen Cibin und Palime an der grossen Karawanenstrasse liegt. Kleine, viereckige Hütten, deren Wände statt von Lehm auch öfters von zusammengefügten Rippen der Oelpalmblätter hergestellt sind, umgeben die (iehöfte, welche von einem, ebenfalls aus Palmblattrippen errichteten Zaune umgeben sind. Ein reger Karawanenverkehr belebt den Ort, auch eine verhältnismässig grosse Textilindustrie ist hier zu bemerken. Auf dem grosisen, mit Schattenbäumen bestandenen Narktplatz des nördlich velegenen Dorfes sind Bänke aufgestellt, hier werden die Versammlungen des hohen Rats abgehalten, auch ist hier clie Stätte für die Zusammenkïnfte der I)orfbewohner, welche die Ereignisse des Tayes besprechen. I)ie Bänke bestehen aus ẹnem grosien Baumstamm und einer Rücklehne, die von zwei Stützen gehalten wird Auch wir lassen uns hier nieder.

IS ist von der Küste aus der erste Ort, der noch viele charakteristische Eigentumlichkeiten der Eingeborenen aufweist. Die Leute tragen den Stempel der richtigen Huschleute, ihre Frisuren haben, selbst bei den Männern, die eigentümlichsten furmen Manche tragen bei glatt abrasiertem Kopf nur einen Schopf an der Stirn und an den Seiten, andere wieder wahre Muster von ausrasierten Scheiteln auf dem Kopf. Auch finclen wir die Weberei wie Flechterei überall in diesem Orte vertreten Hier sitzt eine Frau, die emsig an einer gewöhnlichen Spule die Batumolle zu groben Fäden spinnt, dort ein Weber, der die Fäden an cinem primitiven Webstuhl zu Streifen ron 3 bis + Zoll Breite zusammenwelot, in einem anderen Gehöft bemerkt man Leute, welche Matten und 
Körbe aus Grätsern oder aus den Blättern der l'alme flechten. Lin solcher Vebstuhl ist äusserst primitiv. Er besteht aus einem (ierust ron rohen Stangen, in welchem der betreffende Weber auf einem Schemel sitzt. Die Hochkämme werden durch eine Schnur mit dem liusse bewegt, während die Kreuzfäden mittels eines Schiffchens mit der Hand durchgezogen werden Die einzelnen Streifen werden nicht breiter als 3 bis + Zoll. Die Fäden hält ein Stein fest, der bei dem Vorwärtsschreiten der Arbeit nachgezogen wird. Die grösseren Tücher entstehen dann durch Zusammennähen dieser einzelnen Streifen Zum Flechten wird meistens das hohe Schilfyras verwendet. Man stellt daraus einfache Matten zum Schlafen, sowie Körbe oder Säcke zum Autbewahren ron Wehl her Dic einzelnen Halme der Gräser werden flach auf den Boden gelegt und dam in der Quere durchflochten, wobei erstere ron dem Schwarzen mit dem fusse festgehalten werden, während er die Querstreifen mit der Hand durchzieht.

Auch an diesem Orte kommt noch viel Elfenbeinschmuck ror; mitunter tragen die Schönen des Ortes aber auch unterhalb des Knöchels, auf dem Fusse aufliegend, Bänder aus Messing. Nicht wenig beliebt sind Perlen, welche, je weiter ron der Kuste entfernt, desto seltener und begehrenswerter werden. Es herrscht hier die eigentümliche Sitte, dass die Männer häufig weisse, um die Stirn gewundene Kopftücher tragen. Infolgedessen ist es bisweilen ron weitem schwer, die Männer von den Frauen, die an der Küste fast immer solche Tücher tragen, zu unterscheiden. Leberhaupt ist es fur einen Europäer in der ersten Zeit nicht leicht, die verschiedenen (ieschlechter von einander zu trennen. I)ie schwarze Farbe und die aufgeworfenen Lippen treten in den Vordergrund und die individuellen Züge entgrehen dem Neuling vollkommen. Erst nach einiger Zeit, wenn der Weisse mehr in das Leben und die Sitten dieser Leute eingedrungen ist, lernt er die Verschiedenheit der Geschlechter sowohl in geistiger wie in körperlicher Beziehung kennen. Natürlich machen die schwarzen I)amen mit dem eingebogenen Rückgrat, den wulstigen Lippen und den bei verheirateten Frauen häufig übermässig grossen herabhängenden Brüsten keinen schönen Eindruck. Aber mit der Zeit rewöhnt man sich an den Anblick; die Empfindung des Hässlichen schwindet und man kann dann sehr wohl unterscheiden, ob ein Mann oder eine Frau nach Negrerbegriffen schön oder hässlich ist.

Der Geldwert in Assahun hat infolge der Entfernung von der Küste schon verhältnismässig abgenommen. Es gereicht daher den Trägern und Händlern zum Vorteil, wenn sie Perlen oder dergleichen Tand von der Küste mitfuhren und hier gegen Lebensmittel oder anderes Aequivalent eintauschen. Oft werden in Assahun von den Trägern auf eigene Rechnung noch Hilfsträger angenommen, welche ihnen die Lasten bis 
Tove oder Palime abnehmen. Durch den höheren Wert der Tauschártikel können sich die Träger diesen Luxus gestatten, da sie die Hilfsträger oft nur mit den leicht mitzuführenden Perlenschnüren belohnen. Bei dem hohen Wert der Waren in dieser Gegend und dem verhältnismässig geringen Einkaufspreis an der Küste machen die Träger bei dem Lohne ron fast durchșchnittlich I M. täglich immer noch ein gutes Geschäft.

Auf dem Markte liegen meistens die Karawanen mit ihren Lasten, um der Ruhe zu pflegen oder auch Nachtquartier zu nehmen und am folgenden Tage in aller Frühe ihre Reise weiter fortzusetzen. Es entfaltet sich dann unter den grossen schattigen Bäumen, die ihre knorrigen IV urzeln weit über den Platz erstrecken, ein reges Treiben. Die Leute von der Küste können sich nur schwer mit den Bewohnern verständigen, da in Assahun schon ein anderer Dialekt der Evhe-Sprache gesprochen wird. Ueberhaupt sind die Sprachbezirke in dem Togogebiet sehr begrenzte. Selbst die Evhe-Sprache, die ron der Küste fast bis zum 7. nördlichen Breitengrade heraufreicht, hat viele Dialekte, so dass z. B. an der Küste in Klein-Popo ein anderer Dialekt herrscht, als in dem etwa $50 \mathrm{~km}$ davon entfernten Lome. Obwohl die Togoleute ein grossartiges Sprachtalent besitzen, so ist es doch oft schwer für sie, sich verständlich zu machen. Unter den Karawanen jedoch finden sich immer Leute, die diese Gegend schon bereist haben und als Dolmetscher dienen können. Auf dem grossen Marktplatze vereinigen sich denn auch die verschiedenen Sprachkundigen zu einzelnen Gruppen. Infolge dieser Umstände schliesst sich der sonst übermütige Küstenneger, der dem clurch vielen Verkehr überlegenen Buschneger vollkommen stumm gregenübersteht, enger an seinen weissen Herrn an, was die Führung erleichtert. Mitunter geschieht aber auch das Gegenteil, indem die verschiedenen Sprachen Missverständnisse hervorrufen und es infolgedessen zu kleinen Reibereien kommt, die jedoch durch ruhiges İingreifen eines älteren, vernünftigen Mannes oder des Weissen bald greschlichtet werden.

Zwischen den einzelnen Gruppen auf dem Markte tummeln sich kleine Heerden von Schafen mittlerer Grösse mit weissem, glatthaarigem Fell, welches von dem schwarzen Kopfe auffallend absticht. Drollig sehen die kleinen schwarzen Ziegen aus, welche neugierig die Lasten beschnuppern; sie sind kaum ${ }^{\mathrm{r}} / 2 \mathrm{~m}$ hoch und besitzen ein schwarzes Fell, welches nur $a b$ und $z u$ einen kleinen weissen Spiegel hat. Ziegen sowohl wie Schafe werden nur ausnahmsweise bei Festlichkeiten geschlachtet. Ihre Felle sind ein begehrter Artikel bei den Schwarzen, sie werden als Teppiche oder auch als Thürvorhänge verwendet oder zum Schutze gegen den Regen über die Tragekörbe gespannt. Das 
Fell wird, nachdem es abgezogen ist, zunächst präpariert, alsdann zwischen kleine Holzstäbe grespannt und zum Trocknen in die Sonne grelegt. Hühner sind auch hier in allen Arten anzutreffen und als der treueste Begleiter des Menschen auch der Hund. Als Wächter in den Gehöften findet man eine mittelgrosse Hunderasse von hellgelber Farbe ror. Eigentümlich ist es, dass diese afrikanischen Hunde nicht bellen wie unsere Hunde, sondern nur heulen. Der Hund, der natürlich nach Negrerart launisch behandelt und häufig mit Steinen geworfen oder mit Füssen gestossen wird, ist feig und kriechend und steht somit unseren edlen europäischen Hunderassen bedeutend nach. Bei jeder Gelegenheit zieht er den Schwanz ein und sucht Deckung hinter den Zäunen der Gehöfte.

Nachdem man die Nacht in Assahun verbracht hat, geht es früh am andern Morgen weiter, um womöglich am späten Nachmittag Palime d zu erreichen Die Träger haben Hilfsträger genommen und unsere Karawane hat eine stattliche Anzahl erreicht; ein buntes Durcheinander, Müdchen und Frauen, sowie Männer mit ihren Kopftüchern, gehören derselben an. Gleich hinter dem Dorfe beginnen die Schluchten und Bergketten und ein scharfes Geröll bedeckt den schmalen Fusspfarl. Tiele von den Trägern haben jetzt Sandalen angelegt, um ihre Füsse ror den spitzen Steinen zu schützen. Obwohl die Neger barfuss laufen und infolge der grossen Märsche eine Hornhaut haben, die fast einer Schuhsohle gleicht, so scheint doch diese dem Gestein in Gebirgsgegenden keinen genügenden Widerstand zu bieten. Die Sandalen, welche sie anlegen, bestehen oft nur aus einem nach dem Fusse geschnittenen Stück Fell, welches durch etliche Schnüre über dem Spann gehalten wird. Die meisten dieser Sandalen werden von den Haussas in den mannigfaltigsten Arten geschickt angefertigt. Die I andschaft hat sich inzwischen verändert. Anstatt durch kurzes Gras und Baumsavannen führt der Weg durch $2{ }^{\mathrm{x}} / 2$ bis $3 \mathrm{~m}$ hohes, dichtes Rohrgras. An Stelle der weiten kahlen Ebene treten bewaldete Schluchten und Bergketten und mühsam schlängelt sich der Pfad bald bergauf, bald bergab. Die kleinen Zuflüsse des Heso, eines linken Nebenflusses des Todjie, welcher in die Kitta-Lagune mündet, bilden bizarre Schluchten in der Richtung nach Südwesten. Man marschiert auf diesem Pfade in den Niederungen der kleinen Zuflüsse des Heso fast wie in einem Wald ron Gräsern. Viermal überschreitet man tief eingeschnittene, oftmals nur 2 bis $+\mathrm{m}$ breite Zuflüsse, welche sämtlich ron den nahe gelegenen Bergzügen des Agu herzukommen scheinen. Diese kleinen Gebirgsgrewässer haben tiefe Rinnen gerissen, die bei der Regenzeit, wie alle afrikanischen Flüsschen und Bäche, verhältnismässig grosse Wassermengen führen, während sie bei der Trockenzeit dem 
Reisenden nur durch ihre tiefen Schluchten und das Auf- und Abklettern an ihren Ufern beschwerlich werden Vorzugsweise ist dies der Fall, wenn man, was allerdings selten rorkommt, den Weg zu Pferde zurücklegt.

Die afrikanischen Pferde sind fast gar nicht eingresprungen, sondern nehmen alle Hindernisse durch Klettern. Bei solchen eingeschnittenen Bächen wäre es für Pferd und Reiter ein Leichtes, dieselben im Sprunge zu nehmen, doch leider läuft man Gefahr, was mir später noch häufig passiert ist, mit dem ängstlichen Pferde in den Graben hineinzufallen und ein unangenehmes Bad in dem Norast zu nehmen Nur mühsam rutscht das Pferd den Abhang hinunter und erklimmt dann ebenso das ansteigende, steile, oft nachgebende, ausgewaschene L'fer

Der Pfad geht jetzt öfters steil bergan, der Busch nimmt mehr und mehr zu und wird zu einem undurchdringlichen Walde, bis man eine Höhe von ungefähr $200 \mathrm{~m}$ erlangt hat und eine tiefe Schlucht vor sich sieht Wieder geht es etwa $60 \mathrm{~m}$ bergab, der Weg füht über Geröll und kleine Steine, welche den Marsch unserer unbeschuhten Träger erschweren und wieder befindet man sich in einem Walde von Gras, der die Lfer des kleinen Baches und die Ebene umgiebt Immer steiler werden die kleinen Höhenzuge, bis man an den Tata, den bedeutendsten Bach, der aber auch nur eine bieite ron $+m$ hat, grelangt; ron hier weht es wiederum bergauf im hohen Busch bis zum nächsten Höhenzug, auf welchem jetat verweist und verlassen das einst so schöne, grosse Negrerdorf Klonu liegt Dasselbe wurde mit Recht in dem Tove-Aufstand, Welchem es sich hartnäckig und widerspenstig angreschlossen hatte, von ven Truppen, zumal alle Eingeborenen den Ort verlassen hatten und gegen dieselben keine andere Strafe rerhängt werden konnte, abgebrannt Wie schnell ein solcher Ort vollkommen verfällt und verwildert, davon hat man hier wiederum ein trauriges Beispiel Die einzelnen Mauern, welche von dem Brande noch verschont greblieben sind, ragen kaum noch aus dem hohen Dornbusch und dem wuchernden Unkraut hervor Nur einzelne Papaya-, hananen- und Limonenbäume sind stehen geblieben und zeugen ron der fruheren Stätte menschlicher Arbeit.

Als ich bei meiner ersten Reise, im Jahre s 994 , durch dieses 1)orf Klonu kam, war es noch ein gefürchteter Ort Das erste Gebirgsclorf auf clen Vorlïufern des Agromegebirges, lag es $210 \mathrm{~m}$ über dem Meeresspiegel und roo $m$ über dem Spiegel der nahen Gebirssbäche Schon zu jener Zeit benahmen sich die Leute wenig freundlich gregen den Weissen und durchziehende Karawanen Nur mit Wühe konnte man hier Bescheid erhalten und musste seine ganze Autorität aufbieten, um bei den Einwohnern etwas fur die Träger oder für sich selbst eintauschen zu können In der Lmgebung des Dorfes, namentlich nördlich ron 
Klonu, fand man zahlreiche schöne wrosse Yamsfarmen, während die dürftige Kassava nur selten rorkam Auch beginnen hier auf dem besseren Boden grössere Farmen ron schönen Erdnussfeldern. In Klonu, schon vereimelt in Assahun, sah ich zuerst die sogrenannten Kappengeier, welche sich auf den Vorhöhen des Cxebirges in grösserer Zahl zeigten lis gelang mir dann auch zum Vergnügen der Einwohner auf grosse Entfernung einen solchen Vogel zu schiessen, was ich wohl allerdings weniger meiner Schiesskunst, als dem Zufall und der (iüte meiner Büchse zuzuschreiben hatte.

Heute ist leider auf der Strasise ron Assahun nach Agome-Palime kein Ort, der zu einer grösseren Rast sich eignet. Aber trotzdem rasten die Karawanen gewohnheitsmässig noch in den Ruinen des alten Klonu und lassen sich die reifen Papayafrüchte sowie die Limonen, welche dort noch zwischen den Trummern gedeihen, gut schmecken. Yur ein alter Fetisch ist am Nordausgang des zerstörten Dorfes stehen geblieben und bewacht die Trümmer Es ist eine sonderbare, grosse, sitzende Thonfigur, die in aussergewöhnlicher Weise mit vielen weissen Punkten bemalt ist und einen grossen Kaurischmuck trägt.

Wir verlassen Klonu und marschieren weiter; es geht jetzt wieder bergab zu einem kleinen Nebenflüsschen, dem Tovië Die Höhen zwischen den Bächen, welche alle in den Heso, der hier den Namen Ähä fuhrt, münden, steigen sanfter an. Die kleinen Schluchten, die häufig hier bioss I bis $2 \mathrm{~m}$ breit sind, schneiden weniger tief in die Höhen ein, statt de. hohen Grases rahmen nunmehr Oelpalmen die Bäche ein, und auf den Höhen der einzelnen Züge tritt an Stelle des dichten Waldes ein lichter Busch. Von den Hügeln, welche zu beiden Seiten des Ảä sich langziehen, hat man den ersten schönen Ausblick auf die weit sich hinzichenden Ketten des Agomegebirges, und ein wundervolles Bild entfaltet sich ror den Blicken des Wanderers, im Hintergrunde erscheinen die vom Horizonte begrenzten blauen Berge, während vor denselben der Agu seine dunklen Spitzen erhebt Jedoch nur kurze Zeit ist dem Reisenden dieser schöne Anblick rergönnt, denn wieder sreht der Pfacl bergab zu dem Thal des Hauptflusses, des Ähä, der alle kleinen Bäche und Flüsschen dieser Gegend aufnimnt lïn grosser hoher Busch, dazwischen viele Oelpalmen, bildet den Galleriewald und eine schöne gezimmerte Brücke, die ron der Station Misahöhe hier angelegt ist, fuhrt über den fast I $_{5} \mathrm{~m}$ breiten thäfluss Grosse erratische Blöcke sind in dem hett desselben ausgewaschen, und Lianen, die uiber den Bach herüberhängen. abgefallene Aeste und Zweige versperren häufig dem kleinen Gewässer. welches krystallhell über die Felsen dahinrinnt, den $W^{\prime}$ eg. Einen schönen tropischen Anblick gewährt der Fluss, über dem sich der IIald wie eine I aube schliesst. 
Wieder fuhrt der Pfad auf die Höhe, wieder ist in seinen Konturen clas Agome-Gebirge fur Augenblicke in Sicht, um dann hinter dem dichten Busch, der hier vermengt mit hohem Rohrgras zu beiden Seiten des Weges steht, zu verschwinden. In diesem dichten Busch geht es auf steinigem Wege weiter, bis man das zerstörte Dorf Tove-Djibe erreicht, welches der eigentliche Herd der Aufständischen war. Auch hier starren heute aus dem Unkraut nur Trümmer hervor, obwohl schon neue Ansiedelungen im Entstehen begriffen sind. Die durch den

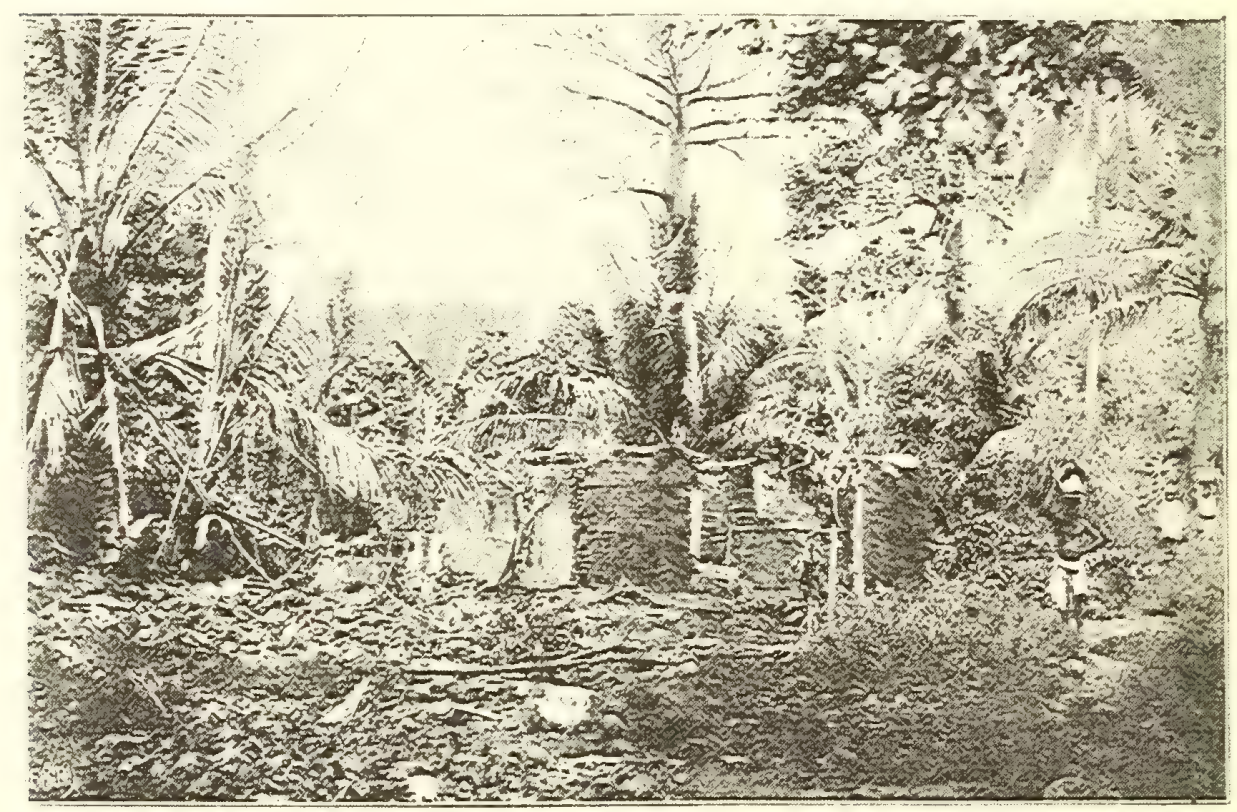

Das zerstörte Dorf Tove-Djibe

Aufstand zerstreuten Leute haben, nachdem sie ihre Strafe abgebüsst, um Erlaubnis gebeten, sich an den alten Wohnstätten wieder ansiedeln zu dürfen, um ihr Handwerk, die Töpferei, die einst weit und breit bekannt war, wieder aufzunehmen.

Töpferei. Die günstigen Bodenverhältnisse von Tove-Djibe haben das Töpferhandwerk gezeitigt, welches in Afrika, trotz der primitiven Handwerkzeuge, zu einer gewissen Blüte gelangt ist. Die vielen Scherben, die noch heute in grossen Haufen zwischen den Wänden und dem Schutt der Mauern liegen, zeigen, welche Ausdehnung einst dieses Handwerk hier gehabt hat: Bei meinem ersten Hiersein besass das mittelgrosse Dorf in der Mitte einen grossen viereckigen Marktplatz, der ron hohen Schattenbäumen überragt war und auf dem man viele Schafe und Ziegen sich 
tummeln sah. Ueberall wurden in der Nähe des Dorfes Töpfe gebrannt oder gestrichen. Hier wurden die grossen Thongefässe in einer durchschnitlichen Höhe von to bis $50 \mathrm{~cm}$ und einem 1)urchmesser von etwa 25 bis $35 \mathrm{~cm}$ hergestellt, die in den regenarmen Gegenden als Wasserbehälter dienen. Kleine und grosse Schüsseln im Durchmesser ron $x_{5}$ bis $30 \mathrm{~cm}$, sowie kleine Näpfe und Schalen kamen zum Verkauf. Tiele dieser Thonwaren waren wit einer roten Erdfarbe grestrichen, während andere schwarz gefärbt wurden. Fast das ganze Gebiet des Agome(;ebirges und weit darüber hinaus wurde von Tove-Djibe aus mit diesen wichtigen Hausgeräten versorgt. Interessant war es mir immer, auch später noch in Kpando, die Art der Anfertigung der grossen Thontöpfe anzusehen.

Meistens bemerkte ich Frauen, die mit grosser Handfertigkeit und (ieschicklichkeit, ohne eine Drehscheibe zu benutzen, nur mit den gewöhnlichsten Handwerkzeugen, wie einigen Holzstäben oder geglätteten Steinen, diese Arbeit ausführten. Ein grosser Haufen Thon und die nötigen Wassertöpfe standen an der Arbeitsstätte und emsig knetete eine Frau den Thon zu einer bündigen Masse, der wegen der allzugrossen Strenge des fettigen Bodens oft noch Sand beigemischt wurde. Eine andere Frau sass auf dem Erdboden und formte mit grosser Geschicklichkeit und Fingerfertigkeit aus einem Stück Thon den unteren Teil des Topfes mit dem Boden; vermittels kleiner Holzstäbchen gab sie ihm die richtige Form, und mit geglätteten Steinen wurde dann das Gefäss poliert. Der obere Teil wurde einzeln in Angriff genommen. Auch diesen formte die frau mit erstaunlicher Geschicklichkeit aus freier Hand. Der Rand wurde umgebogen, der ganze obere Teil geschabt, geglättet, alsclann mit dem unteren Teil zusammengefügt und so das Géfäss fertig gremacht

Gewöhnlich werden die Töpfe zum Gebrauch glatt hergestellt, nur selten werden kleine Verzierungen in Schlangenlinien um denselben gezogen. Die kleinen Schüsseln und Gefässe bestehen aus einem Stück und dienen besonders als Saucenschüsseln für die bekannte Palmölsauce; während für die Aufnahme des Fufu grössere flache Schüsseln benut/t werden. Die Schüsșeln erhalten häufig einen schwarzen Anstrich, der aus Russ und Palmöl hergestellt wird. Auch werden die Muster und Verzierungen oftmals noch mit bunten Farben bemalt.

Die Gefässe wurden nicht in unmittelbarer Nähe des Dorfes, sondern, um der Feuersgefahr rorzubeugen, ausserhalb des Bereichs der leicht entzündbaren Hütten in einem grossen Feuer gebrannt Während des Tagges wurden sie durch die glühenden Sonnenstrahlen ausgetrocknet und zum Brennen rorbereitet. I)es Abends, nachdem die andere Arbeit eingestellt war, wurde ein grosser Haufen Reisig zusammengetragen, in 
Brand gesteckt und häufig noch mit einer Lage von Gras oder feuchtem Rohr gedeckt, um die Bildung einer zu starken Hitze zu vermeiden und das Springen der Töpfe zu verhüten. Auf diesen Haufen wurden nun die Töpfe gestellt und gleichfalls mit einer Lage von Gras bedeckt, damit die Hitze auch auf den oberen Teil der Gefässe wirken konnte. Farbige Gefässe wurden erst an dem Feuer erwärmt und später gestrichen und bemalt. Nach diesem Verfahren wurden die bemalten Töpfe und Schüsseln wieder dem Feuer übergeben und nun erst fertig gebrannt. Ein dicker Qualm stieg zum Himmel empor und verkündete schon von weitem durch seinen brandigen Geruch, dass hier die Töpferei betrieben wurde. Waren die Töpfe fertig gebrannt, so wurden dieselben mittels grosser Stöcke aus dem glühenden Haufen hervorgeholt und nach der Abkühlung zum Verkauf oder Gebrauch bereit gehalten.

Da es sich wenig lohnt, die zerbrechlichen Thongefässe von Europa $z u$ importieren, auch die von den Eingeborenen angefertigten einfachen Thongefässe schliesslich denselben $Z$ weck erfüllen, so ist die Töpferei im Gegensatz zur einheimischen Weberei noch immer im Vorteil, obwohl die Haussas auch schon in dieser Beziehung Konkurrenz machen und die an der Küste gekauften Blech- oder Messingschüsseln mit gutem Profit im Hinterlande umsetzen. Das Wasser bleibt in porösen Thontöpfen kühler als in Kalabassen, deshalb ist das Töpferhandwerk bei weitem ergiebiger, als die Anpflanzung und Bearbeitung von Kürbissen, deren Gedeihen sehr von der Witterung abhängt. Diese letzteren werden häufig zur Aufbewahrung von Maiskörnern oder Erdnüssen verwendet, auch auf Reisen den weniger haltbaren Thongefässen vorgezogen. Den Haushalt einer Negerfrau ziert eine Galerie von Thontöpfen, Näpfen und Schalen, und so wie bei uns die Frauen ihren Stolz in dem Besitz von feinem Porzellan und Geschirr finden, so setzt auch die Negerfrau etwas darein, die grossen Töpfe rein zu erhalten und immer wieder zu ergänzen, um bei Festlichkeiten darin den Palmwein zu kredenzen, oder den Fufu und die mit grosser Kochkunst hergestellte gepfefferte Oelpalmensauce ihren Gästen vorzusetzen.

Ursachen des ToveAufstandes.
Leider mussten diese Stätten der Negerindustrie in dem Aufstande der Bewohner gegen die Regierungsorgane von den Truppen zerstört werden, um die Autorität der Regierung auf dieser Hauptkarawanenstrasse nach dem Innern wieder herzustellen. Schon immer wurden die Karawanen von den aufsässigen Eingeborenen, die von den Fetischpriestern aufgehetzt waren, belästigt und häufig ihrer Waren beraubt. Aber da Tove-Djibe und Klonu bequeme Rastplätze waren, so wurden sie, namentlich von den von der Küste kommenden Karawanen und Reisenden nach der Ueberwindung der Vorhöhen des Gebirges doch gern als Ruheplatz oder als Nachtquartier benutzt, zumal auch das im 
Nurden ron einem grossen schönen Laubwald umgebene Tore sehr schön liegt. Bei dieser Gelegenheit gab es nun beständig Scherereien, da die Häuptlinge die Weissen als Feinde betrachteten und ihnen allc Hindernisse in den Weg zu legen suchten. Wenn man in diese Orte kam, rermisste man sehr oft die schwarz-weiss-rote Flagge, jenes Zeichen, das jedem echten Deutschen schon von vornherein Sympathie für die Bewohner einflösst. Meistens zeigte sich bei der Ankunft der Europäer kein Häuptling, auch kein Sprecher desselben war aufzutreiben; wenn man in die Hütte des Häuptlings schickte, so hatte er sich in der Regel verborgen, und irgend ein Mitglied der Familie erklärte mürrisch dem Dolmetscher, dass er nach einer entfernten Farm gegangen oder zu einer Festlichkeit, ciner Totenfeier oder dergleichen verreist wäre. In solchen Fällen musste man sich natürlich dann selbst Rat schaffen, namentlich wenn man sehr ermüdet vom Marsche war, die Träger keine Lust mehr verspürten, weiter zu marschieren, oder der Abend bereits hereingebrochen war. Man suchte sich selbst eine Hütte aus und quartierte sich darin ein, trotz cles Sträubens der Leute. Diese wurden allerdings durch den enormen Preis von 2 M. für das Quartier entschädigt und freuten sich dann über den Gewinn, obwohl sie von ihren Landsleuten scheel anzresehen und dazu aufgehetzt wurden, künftig dem Reisenden keine Unterkunft zu gewähren. Aber auch in der Verproviantierung stellten sich Schwierigkeiten ein, denn Hühner oder Yams waren gar nicht oder im günstigen Falle nur für einen sehr hohen Preis zu haben. Die Jungen und die Träger bekamen dann mit den aufgehetzten Leuten öfters kleine Krawalle, die jedoch bald wieder geschlichtet wurden. Hatte man einige Soldaten zur Begleitung, die mit den Leuten umzugehen verstanden und sich mit Hilfe ihres Führers den nötigen Respekt verschaffen konnten, so war der Aufenthalt in diesen Orten weniger unerfreulich. Anders jedoch, wenn ein unbeschützter Reisender, namentlich ein Neuling, in diese Gegend kam; er musste sich allen Launen der Leute fügen, schenkte womöglich ihren Aussagen, der Häuptling sei auf die Farm gegangen, nøch Cilauben und wartete ungeduldig seine Rückkehr ab, um ihn entweder erst nach langer Zeit oder überhaupt nicht zu Gesicht zu bekommen Die Hühner waren meistens in ihren Ställen eingesperrt, der Yams war noch auf den Farmen und musste erst geholt werden, das Wasser und das Feuerholz waren in der Regel schon im eigenen Haushalt verbraucht, und so gab es hundert Ausreden, die der ahnungslose Reisende für bare Münze nahm. Im besten Falle fand sich dann ein vernünftiger alter Mann oder ein altes Weib, welche einiges Mitgefühl besassen, und so kam er zuletzt mit Geld und guten Worten zu einem Stück Yams oder einigen Eiern.

Der Fetisch, welcher ein Feind jeglicher Kultur ist und in ihrem Vordringen seinen Untergang sieht, hat alle Ursache, die Leute 
gegen das Eindringen ron europäischen Waren aufzuhetzen und den Fremdlingen Hindernisse in den $\mathrm{Weg}$ zu legen Selbstrerständlich ist der Widerstand gegen die Weissen und die europäischen Waren in den Industriebezirken der Schwarzen grösser, denn die billigen Zeuge und Stoffe von der Küste drücken den Wert der einheimischen Waren bedeutend herab. Die rerhältnismässig reichere Kleidung der Küstenneger und der Tand an Perlen besticht indessen doch die Schönen dieser Buschvölker, das Begehren nach diesen Artikeln und, wie schon vorher gresagt, der im V'erhältnis niedrige J'reis, verdrängt trot\% allen Widerstandes des Fetisches die einheimische Industrie und ruft eine innere Gïhrung und Revolution auch bei diesen naiven Negervölkern hervor

Der Hauptfetisch in dieser (iegrend liegt, wie öfters in den (jebirs.s. gregenden, auf den höchsten Gipfeln der Berge, Bergkegel oder einzelne hervorragende Berge sind ron fietischsagen umwoben und werken gewissermaassen als heilig verehrt Ausser dem Fetischpriester darf sie kein Sterblicher betreten Dieses erklärt sich daraus, dass bei den Naturölkern alle Naturereignisse oder grosse Naturschöpfungen, wie grrosse Ströme oder Berge, als Attribute des Fetisch angesehen werden So liegt auch in dieser (iegend der Hauptfetisch auf dem Agu Weithin beherrscht der Agu die Thäler südlich des Agomegebirges und seinc höchsten Gipfel ragen über den Busch und die kleinen lorberge empor

Aus dem Angeführten haben wir ersehen, worin der Grund zu dem Aufstande dieser lölker las Es grenügte cine kleine äussere Lirsache. um ren fufstand $\%$ entflammen

Tove- Zu jener Zeit hatte der inzwischen der Malaria zum Opfer gefallene Aufstand Botaniker Baumann von der Station Misahöhe aus mit einigen Trägem und Jungen ohne militärischen Schut\% eine kleine Exkursion nach dem Agu unternommen Die Leute, die sich in der Mehrahl befanden und sich laher ihrer Macht bewusst waren, verweigerten ihm Lebensmittel sowic Interkunft, machten sich in der frechsten Ireise uber seine Anordnungen und Forderungen lustig, verlachten und verhöhnten ihn Baumann, der wohl einsah, dass hier der Klügere nachgeben musste, stelle sich, um ernste Zwischenfälle \%u vermeiden, als wenn ihn diese schlechte Behandlung nicht berühre Abends, als er sich zur Ruhe begeben hatte, umtanzten die Leute sein Bett, schnitten Grimassen und pfiffen und belästigten ihn auf die schmählichste Art Baumann that, als ob er im Schlafe rom diesem ganzen Torfall nichts gremerkt hätte und marschierte am andern Tage nach seiner Station Nisahöhe zurück Hier angrelangt, schickte er sofort eine Patrouille mit scharfen Patronen nach dem Orte, um die Rädelsführer festzunehmen und gebührend zu bestrafen Ein (iefreiter mit + Mann hatte den Auftrag und führte ihn trot\% des Widerstandes der Lente prompt aus, er verhaftete die ihm angegebenen Missethäter und 
hielt sich die Bewohner der Ortschaft rom Leibe, indem er drohte, sofort Feuer zu geben, wenn sie ihn mit den Gefangenen nicht frei abziehen liessen. Einge alte Leute hielten denn auch die Menge daron ab, die Soldaten anzugreifen. Nachdem sich unsere schwarze Polizei den nötigen Respekt durch einige Kolbenstösse verschafft hatte, konnten sie ungehindert den Marsch bis nach Tove-Djibe fortsetzen. Hier ruhten sie aus; bald aber sammelte sich eine neugierige Menge, die von den (iefangenen aufgefordert wurde, sie zu befreien und die Soldaten zu misshandeln. Ein Wort gab das andere, die Soldaten wurden immer dichter umringt, die Gefangenen suchten, ermutigt, ihre Fesseln abzustreifen und sich zu befreien. Als einige übermütige Tove-Leute sie mit sich fortreissen wollten, trat ihnen der energische Gefreite in den Wreg und drohte jeden zu erschiessen, der einen Gefangenen befreien würde. Nachdem er sich freie Bahn geschaffen, suchte er mit den Gefangenen und seinen Leuten das Dorf zu verlassen und weiter zu marschieren. Unglücklicherweise kam es jedoch zwischen einigen rauflustigen Patronen zum Handgemenge; die vier tapferen Soldaten pflanzten ihre Seitengewehre auf und hielten sich durch ihr energisches Auftreten die Menge vom Leibe Doch die aufgeregte Menge griff trotz der Ermahnung der alten Leute zu den alten Steinschlossflinten und bei dem darauf folgenden Handgemenge erhielten einige Leute mit den Seitengewehren blutige Köpfe. Als einmal Blut geflossen war, drangen die Leute auf die Soldaten ein und saben auf einen derselben, der ihnen den Weg abschneiden wollte, Feuer

In der Notwehr erwiderten die Soldaten selbstverständlich sofort das Feuer. Leider traf ein feindlicher Schuss den schneidigen Gefreiten in's Bein, so dass er kampfunfähig wurde Mit Freudengeschrei raste nun die ungestüme Menge auf die paar Mann los, welche die Gefangenen aufgeben und sich in den Busch zurückziehen mussten. Als sie bis Palime gekommen waren, wo sie sich sicher fühlten, vermissten sie ausser den entflohenen Gefangenen ihren Führer, den Gefreiten, einen stämmigen, schönen, grossen Neger. Angstvoll warteten sie in Palime bis zum Abend und erfuhren dann durch die Leute, die von Tove kamen, das Schicksal ihres armen Kameraden. Derselbe konnte, rerwundet, nicht flüchten und geriet so in die Gewalt der erbarmungslosen, blutdürstigen Burschen, die ihm nach vorangegangenen Misshandlungen den Kopf abschnitten. Der Neger kennt im gereizten Zustande kein Erbarmen und ist ron der höchsten Grausamkeit gegen die in seine Macht gegebenen Gefangenen, wie ihm überhaupt nur Gewalthätigkeit imponiert Jede Nachgiebigkeit legt er ron seinem Standpunkte als Feigheit aus. - 
Dieser Torfall, sowie der Umstand, dass die Eingeborenen den Verkehr auf der ganzen Strasse bei jeder Celegenheit hemmten, insbesondere auch einem Boten, welcher nach der Station Misahöhe geschickt war, die Kehle durchschnitten, zwangen natürlich die Regierung, Maas:regeln gegen diese Uebergriffe zu treffen. Baumann sandte eine stärkere Patrouille nach Tore, welche den Häuptling einfangen und die Rädelführer der gerechten Strafe überliefern sollte. Der Führer hatte jedoch die Weisung, falls die Rädelsführer nicht gutwillig ausgeliefert würden. nicht einzuschreiten, sondern sofort nach der Station zurückzukehren Da letzteres geschah und die Leute darin einen fluchtartigen Rückzus erblickten, kam der Aufstand zum Ausbruch. Die Eingeborenen, in der fireudigen Ueberzeugung, dass sie die Soldaten zurückgeschlagen hätten und der Weisse gegen sie machtlos sei, hielten nun erst recht die Karawanen an, schnitten vollständig den Verkehr mit der Küste ab und feierten ron dem geraubten Gut Gelage und andere Feste. Diestbewirkte, dass sich das benachbarte Dorf Klonu mit den Bewohnern ron Tove verbündete und an der Plünderung der. Karawanen beteiligte Ja, sie hatten sogar die Absicht, die Station Misahöhe zu stürmen. Baumann hatte jedoch sofort auf Umwegen einen Eilboten an die Küste gesandt und die etwa so Mann starke Truppe zu Hilfe herbeigerufen Unter dem stellvertretenden Führer der Truppe, Polizeimeister Gerlach, der früher Feldwebel bei den Cardejägern war. marschierte mit noch zwei anderen Weissen die Truppe in Eilmärschen ron der Küste ab. Dort waren die fabelhaftesten Gerüchte über den grossen Aufstand, die Niedermetzelung der Weissen und die Einnahne der Station rerbreitet worden Inzwischen war aber der "Sperber", ron Kamerun kommend, in Klein-Popo vor Anker gegangen, was bei der Küstenbevölkerung den nötigen Eindruck nicht rerfehlte Bei dem Gerücht ron dem Anmarsche der Truppen wurden fast alle Dörfer verlassen und in Klonu sowie in Tove war kein Mensch, selbst nicht einmal alte Weiber, anzutreffen, was die Verpflegung der Truppe ganz auswerordentlich erschwerte Dieselbe kam, nachdem sie in anstrengenden Märschen durch die verödeten Dörfer schnell die Strecke bis Agome zurückgelegt hatte, auf der Station Misahöhe an. Baumann forderte nun nochmals die Leute von Tove-Djibe auf, ihnen den Häuptling zu senden, aber vergebens; er wartete noch einige Tage und marschierte dann vereint mit Gerlach und dessen Truppe gegen Tove los. Als sie dort ankamen, wurden sie von einzelnen Bewaffneten in dem Busch angegriffen, welche jedoch bald die Flucht ergriffen oder erschossen wurden. Das leere Tove wurde besetzt, in der Nacht loderten grosse Wachtfeuer und Jatrouillen umgingen den Ort, damit kein Ueberfall stattfinden könne, Am nächsten Tage in der Frühe wurde Tove abgebrannt und num 
marschierte die Truppe auch nach Klonu, welches chenfalls rerstört mal verbrannt wude Assahun, welches auch nicht ganz schuldlos war wurde durch dieses energische Vorgehen rollkommen eingeschüchtert und suchte seine freundschaft gegen die Weissen durch Geschenke und Kundschafterdienste zu bezeugen. Dicse wurden natürlich angenommen and mit ihrer Hilfe dic Farm der Tove-Leute, wohin sich dieselben seflüchtet hatten, aufgesucht. Die Verbrennung der Dörfer wäre fü die I. eute keine angemessene Strafe gewesen, weil die Hütten für sie wenig. Wert haben und in einigen Wrochen ganze Gehöfte wieder neu aufrebaut werclen. Das ganze Hab und (iut wird in solchen kriegerischen Zeiten in einigen Kalabassen geborgen und mit dem wenigen Vieh. weiches aus etlichen Hühnern und Schafen bestcht, schnell auf der Farm in Sicherheit gebracht. I'm nun ein fur alle Mal solchen Excessen rorzubeugen und einen grösseren Aufstand für die Folge zu verhindern, salt es, die Leute in ihren Schlupfirinkeln aufusuchen und sie sorrohl clurch Zerstörung der Farmen, sowie durch Wegnahme ihres Hab und Guts nachdrücklich zu bestrafen Ein Menschenleben wird bei diesen Vaturölkern wenig geschätzt, es ist für sie die emptindlichste Strafe. weit empfindlicher als der Tod cines Bckannten oder Verwandten, Wenn sie in ihrem kleinen Viehbestande geschädigt werden. Mit Leichtigkeit "urde der Widerstand der einzelnen I,eute überwunden und wer nicht floh, den traf die grerechte Strafe Nur Weiber und Kinder, sowie alte T.eute wurden durch die cnergische I)isziplin, welche die Führer aufrecht arhielten, verschont

Die Niederwerfung dieses Aufstandes hat den Leuten die Macht. welche der Wreisse zu entwickeln vermag, klar for Augen geführt und (o) ist durch diesen Zwischenfall einem umfangreichen Aufstande und weiteren Kämpfen vorgebeugt worden Dic Leute baten bald um Frieden. Aer ihnen auch nach Auferlegung eines Tributes als Sühne gewährt wurde Natürlich war dieser Tribut gering, da die Leute alle zerstreut und ihres Besitztums beraubt, ausser Stande waren eine grössere Abgabe zu zahlen Der jetzige Stationsleiter, Herr Wegner, bat denn auch im Interesse der Leute die Landeshauptmannschaft, ron dieser Abgabe abzustehen und dic Sache auf sich beruhen zu lassen lir hat daclurch bewirkt, dass die Leute freiwillig darum einkamen, sich wieder ansiedeln zu dürfen Diese neuen Ansiedelungen werden wir später noch antreffen

Nach dieser Abschweifung kommen wir nun wieder zu unserem Màrsch \%uruck. Wir verliessen Tore-Djibe und kamen sofort nördlich de. l)orfes in einen grossen, schönen, lichten Laubwald. In diesem Mralde sah ich zum ersten Mal wild den für das (xebirge typischen weissschenkligen Seidenaffen. Einer meiner I,eute machte mich darauf aufmerksam, dass in den bïumen ein wrosser Affe sitze; ich schlich mich heran, doch 
schon hatte mich das possierliche Tier bemerkt und sprang von einem Cripfel des Baumes zum andern, bis es mein Schuss erreichte und es etwa 20 Schritt vor mir zu Boden fiel. Einer meiner Jungen wollte sich clem Tiere nähern, jedoch stellte sich dasselbe auf die Hinterhände und machte sich zum Angriff bereit, so dass sich die hinzukommenden Leute nicht heranwagten. Leider hatte ich die letzte Patrone verschossen, die ich im Augenblick bei mir trug, und wie es sehr häufig der Fall ist, war der Träger der Patronentasche nicht gleich zur Stelle; ehe ich daher noch zum Laden kam, um dem Tiere den Fangschuss zu geben, hatte es sich rom Schreck erholt und war im Nu in den dichten Busch geflüchtet. Eine starke Schweissspur wurde zwar bei dem Absuchen des Terrains vorgefunden, doch war das Tier selbst wie rom Erdboden verschwunden. Da ich mich nicht länger aufhalten konnte, so setzte ich den hinzugelaufenen Toveleuten eine Belohnung aus, wenn sie mir cien Affen oder sein Fell bringen würden Jedoch verging lange Zeit, bis ich Tove wieder berührte und etwas von dem verschwundenen Affen zu hören bekam. Einige Leute bestätigten mir dann, dass der Affe aufgefunden worden und das Fell im Besitz des Häuptlings sei. Dieser jedoch bestritt es mir gegenüber unter höhnischem Grinsen, woraus man ersieht, wie wenig diese Leute trutz der gebotenen hohen Belohnung geneigt sind, dem Weissen Gefälligkeiten zu erweisen. Die schwarzen Seidenaffen, die in den Gebirgen unseres Togolandes häufig sind, haben wegen ihres schönen sammetartigen, langhaarigen Felles ein hubsches Aeussere. Das Fell, welches bei der Herstellung von Muffen gern verwendet wird, wie auch andere wertrolle Pelze bilden ein gewinnbringendes Ausfuhrprodukt nach der dem 'Togogebiet benachbarten englischen Goldküsten-Kolonie. In neuerer Zeit wird auch von einigen deutschen faktoreien unseres Schutzgebietes die Ausfuhr von Fellen betrieben Es wäre wünschenswert, dass unsere deutschen Kaufleute von den Engländern lernten, aus dem Handel mit diesen kleinen Nebenprodukten Gewinn zu ziehen.

Der Weg führt nun weiter an dem rechten Ufer des Ahä entlang, der in einem dichten Haine dahinfliesst. Häufig müssen kleine Zuflüsse passiert werden. In Windungen schlängelt sich der schmale Pfad durch den wunderschönen schattigen Oelpalmenhain, der über ihm zusammenschlägt. Das lichte Laub grosser Farrenkräuter, die in dem Schatten der Palme vorzüglich gedeihen, belebt das tiefe Dunkel des tropischen Haines. Lianen und Schlingpflanzen verweben sich mit den Palmen zu einem dichten Netz; vermorschte Stämme und Aeste versperren häufig den Weg und das Murmeln des Ähä-Flusses begleitet den Wanderer durch diese wildromantische Landschaft. So geht es weiter, bis man den kleinen Ahä-Bach auf einer von der Station hergestellten Brücke 
überschreitet; hier verlässt man wieder den Buschpfad und der Weg führt auf einer von der Station Misahöhe aus nach der Kuiste zu angelegten Kunststrasse weiter. Früher marschierte man auf dem oben erwähnten idyllisch schönen Pfade weiter und kam unbemerkt in das kleine, damals noch bescheidene Dörfchen Agome-Palime

Es bestand zu jener Zeit nur aus armseligen Negerhütten, jedoch machte sich auch schon hier ein reger Verkehr bemerkbar und der Handel und Unternehmungsigeist der Leute, ron den Weissen der Station angeregt, wird von dem jetzigen Häuptling Gidde-gidde unterstützt. Der kleine Markt war damals bereits ein Centralpunkt fur die in der Nähe grelegenen Orte. In dem anstossenden Walde wurden die wrösseren Märkte des Dörfchens abgehalten. Lnter dem Schatten der hohen schönen Bäume sassen die Marktweiber mit ihren Produkten, die hauptsächlich aus Lebensmitteln bestanden; nur spärlich wurde der Handel mit Stoffen betrieben. Heute ist Agome-Palime durch die Faktoreien und durch die Haussa-Kolonie, die dort entstanden ist, eine Grosshandelsstadt geworden. Den Aufschwung, den dieser Ort in den letzten zwei Jahren genommen hat, verdankt er der Rührigkeit und selbstlosen Tätigkeit des Botanikers Baumann Derselbe hat es verstanden, während seiner Leitung der Station Misahöhe, durch unermüdliche Remühungen den Handel des Gebietes auf diesen Ort zu konzentrieren und den Grund zu dem jetzt hervorragenden Handelsplatze zu legen. Wiederholt sandte er, nachdem er mit Gidde-gidde über die festzusetzenden Markttage verhandelt hatte, zu den Häuptlingen der benachbarten Dörfer, um die Eingeborenen zu bewegen, den Markt an diesen Tagen zu besuchen Auch der Stationsleiter, Dr. Cruner, hatte schon vorher die Kaufleute an der Küste veranlasst, dort Nebenfaktoreien und kleine Handelsniederlassungen zu gründen, um durch diesen rorgeschobenen Posten den vielfach auf englisches Gebiet übergehenden Handel zu sewinnen und speziell hier einen Vorort für den Linkauf des aus den nördlichen Gegenden kommenden Gummi zu schaffen Die ersten Faktoreien, die sich fast zu gleicher Zeit entschlossen hatten, hier kleine Niederlassungen zu gründen, waren die Bremer Faktorei von Vietor und diejenige von C. Goedelt aus Lome. Zuerst mieteten sich die Weissen, welche die Faktoreien anlegten, einige Hütten, diese wurden in Läden umgewandelt, und in einer derselben schlug der Weisse seine primitive Wohnung auf. Naturlich leistete die Station den Kaufleuten in jeder IVeise die erbetene Unterstützung Es war nicht ungemütlich in diesen kleinen Hütten, zumal die Bewohner den Weissen zugethan waren und ein freundliches Wesen hatten. Ihre Spiele und Tänze, die häufig zu Ehren cler ankommenden Weissen veranstaltet wurden, boten eine schöne Abwechselung. Auch hier musste erst die Macht des Fetisch gebrochen 
werden, was jedoch bei der grösseren Intelligenz der Bewohner mit nicht allzugrossen Schwierigkeiten rerknüpft war Die Bewohner der Gegend besitzen durch den steten Umgang mit den Weissen auf der Station, sowie durch das Reisen mit Beamten und Offizieren ein viel höheres Verständnis für den Handel sowohl wie für die Kulturarbeit. Es ist deshalb erklärlich, dass die Kaufleute willige Unterstützung fanden, bald wurden auch Gummihändler aus Adele herangezogen, so dass sich die beiden genannten firmen genötigt sahen ihre Niederlassung zu rergrössern und dort mehrere İuropäer zu stationieren

In dem schönen Walde liegen zu beiden Seiten des schattigen Narktplatzes die für afrikanische Verhältnisse stattlichen Crebäude clieser Faktoreien. Jede derselben hat in dem Gebäude grosse und ausredehnte Läden, welche ganz nach dem Muster der sogenannten Stores in Lome eingerichtet sind. Selbstredend wird in der Auswahl der Waren besondere Rücksicht auf den Geschmack der schwarzen Bewohner dieser I andesteile genommen. Durch den Aufschwung ron Palime, das gewissermaassen einen Vorort des Handels auf der grossen Strasse nach dem Innern bildet, sahen sich aber auch noch andere Kauflente aus Lome veranlasst, dort schwarze Angestellte $z$ u stationieren, welche die Interessen der verschiedenen Faktoreien wahrzunehmen haben. Diese haben ihre Waren zum Teil in kleinen Buden auf dem Markte ausgestellt und selbst die Haussa, welche durch ihre Sklaven die Waren billiger heranschaffen können, konkurrieren flott mit den europäischen Kaufleuten Vatürlich haben auch hier, wie gewöhnlich, die Haussa das einträgliche Fleischerhandwerk für sich in Anspruch genommen Heute hat diese Haussakolonie einen Häuptling, der die Streitigkeiten, die seine Landsleute auszufechten haben, schlichtet und ihnen nicht ohne allzugeringen Torteil Wohnung und Kost gewährt, sie auch, wenn er seinen Nutzen daron hat, in den Handelsgeschäften unterstützt.

Der Ort rergrössert sich fast zusehends in staunenswerter Weise Leberall an der grossen Strasse und am Markte sieht man ron primitiven Zäunen umgebene Gehöfte, sowie neue Häuser und Hütten der unternehmenden schwarzen Händler entstehen. Heute hat der Ort infolge seiner wachsenden Bedeutung vollkommen sein äusseres Aussehen verändert Neben den einfachen Negerhütten bemerkt man jet»t schon kleine Lehmhäuser, nach europäischem Muster mit Fensterläden und Thüren versehen, die an armselige Bauernhäuser meiner Heimatsprovinz Posen erinnern, aber mit den abgegrenzten kleinen Gehöften immerhin einen freundlichen Eindruck machen Mit der Crösse des Ortes hat selbstverständlich auch der Handel, namentlich in der allerneuesten Zeit, bedeutend zugenommen So bringen den Gummi heute nicht nur die Eingeborenen der Gummidistrikte oder die Akkrahändler und Haussas 
herunter, sondern es gehen jetzt auch ganze Karawanen ron Händlern aus Palime selbst herauf. Zu meiner grossen Freude habe ich später viele Erheleute in den Adeledörfern getroffen. Anfangs 1898 hat auch der neue Stationsleiter von Misahöhe, Premierleutnant Wegner, in dankenswerter Weise eine grosse Strasse von Palime aus zu bauen angefangen, welche die wenig bekannten Gebiete des Agu und seine Umgebung erschliessen und die Bewohner einander näher bringen soll. In letzter Zeit endlich haben, durch die Erfolge veranlasst, cinzelne Firmen begonnen, weit im Innern Stationen anzulegen. Als Frucht dieser Bestrebungen sind bereits Handelsniederlassungen in Kipando entstanden

Interessant ist es, zu beobachten, wie sich mit den Verhältnissen auch die Leute und ihre Sitten ändern. Früher liess es sich der Häuptling (iidde-gidfe nicht nehmen, den Weissen feierlich zu empfangen. Zu diesem Staatsakt trug er ein hellgrünes Hüftuch, einen stark abgenutzten Frack und einen alten abgelegten Chapeau claque, den eine deutsche Kokarde zierte. Heut dagegen trägt Cidde-gidde bei solcher Gelegenheit nach Landessitte nur ein grosses Umschlagetuch, während er bei Besuchen auf der Station oder den Faktoreien häufig in einem weissen DandyAnzuge erscheint Gidde-gidde war nämlich mittlerweile an der Küste und hat sich dort die Sitten und Gebräuche der schwarzen Händler angeeignet. Als er abreiste trug er noch den oben beschriebenen Anzug, aber bei seiner Rückkehr erschien er zu unserem grossen Erstaunen als schwarzer Gentleman. Würderoll ging er in weissem Anzuge, gelben Gigerlschuhen und einem grossen Hut zur nicht geringen Bewunderung seiner Landeskinder in seiner Residenz einher. Um aber auch den Gelehrten herauszukehren, wie es die schreibkundigen Schwarzen an der Küste thun, hatte sich Gidde-gidde mit einer blauen Brille versehen. Als wir ihn bei seiner Ankunft auf der Station Misahöhe befragten, ob er plötzlich schlimme Augen bekommen hätte, gab er an, class er auf der Reise sich ein Augenleiden zugezogen hätte. Aber man konnte von einem Uebel nichts bemerken und wenn man ihn in seiner Behausung plötzlich besuchte, fand man ihn behaglich in seiner alten Kleidung ohne Brille. Gidde-gidde hat sich merkwürdigerweise durch seine Schlauheit emporgearbeitet; eigentlich war er weder Häuptling noch Sprecher in seinem Dorfe. Doch trat er durchziehenden Reisenden gregenüber stets als solcher auf, während der eigentliche Häuptling stumpfsinnig als Puppe daneben sass und auch sonst in keiner Weise die Achtung seiner Landsleute genoss. Gidde-gidde wurde erst Sprecher für den König, leitete die Geschäfte für denselben und wurde dann schliesslich mit der Zustimmung der Dorfbewohner von der Station zum Häuptling gemacht 
Nachdem ich mich an dem vorzüglichen Palmwein, welchen Giddesidde mir und meinen Leuten verabreichte und wofür ich ihm als Tribut ein Stück Zeug schenkte, erquickt hatte, zoggen wir unter dem fröhlichen Johlen der Dorfbewohner durch das damals noch kleine Dorf und setzten unseren Weitermarsch fort. Heute führt die grosse Strasse durch einen hohen schönen Busch schnurgerade weiter nach Kussuntu. Ausser Yams, Bananen und Oelpalmen wird seit dem Einzug der Haussa auch das Sorghum, oder, wie es hier genannt wird, das Guineakorn angebaut, ein beliebtes Körnerfutter fur die Pferde. Die kleinen Zuflüsse des thä werden hier auf Brücken nach europäischer Art überschritten; rechts und links rom Wege liegen üppige grosse Erdnussfelder und in lem Thal des Ähä kommt man durch grosse schöne Reisfelder, denen ich hier zum ersten Nale begegnete. Zu beiden Seiten dieser Ebene befinclen sich hohe schöne Bergketten; wir treten somit in das eigentliche Agome-Cebirge ein und zwar befinden wir uns in dem grossen Thal, desisen fettes Schwemmland und grüne Matten sich ringsum ausbreiten. Im Hintergrunde wird das Thal von hohen schroff abfallenden, in der Ferne blau schimmernden Felsen begrenzt. Bald haben wir Kussuntu, ein wichtiges Landdörfchen, erreicht und werden dort ron dem alten Häuptling mit Freude empfangen Derselbe besitzt zwar bei weitem nicht die geistigen Fähigkeiten wie Cridde-gidde, meint es aber um so ehrlicher und ist schon seit Herolds Zeiten eine bekannte Persönlichkeit auf der Station Misahöhe. Sein graues Haar und sein Knebelbart, welcher stets eingefettet und wohlgedreht ist, sowie sein joviales Gesicht mit der wohlgeformten Nase verleihen diesem alten Mann ein ehrwürdiges Aeussere Die sämtlichen Einwohner des Dorfes hatten sich auf der Hauptstrasse, die mitten durch das Dorf führt, gruppiert. Auf dem Markte stehen ausser einem grossen roten Thonfetisch viele Kornspeicher, welche die Fruchtbarkeit dieses schönen Thales erkennen lassen Diese Speicher sind ziemlich plump gebaut und bestehen aus einem viereckigen Oberbau ron Lehm, der als Behälter für die Körner client Dieser Bau steht auf einem primitiven Lnterbau von Stangen und ist mit (iras eingedeckt Interessant ist die verschiedenartige form dieser Speicher in den einzelnen Orten. In Tove haben die Speicher, wie schon beschrieben, die Form eines umgekehrten Kegels, der direki auf einem kleinen Fundament von Stein ruht, während der ganze Bau an den Seiten durch Stützen gehalten wird. In anderen Farmdörfern, wie \%. B. in Badjakowhe giebt es primitivere Speicher, welche aus einer Art von (ieflecht hergestellt werden. Dieselben sind meistens lileiner und hängen yewissermaassen in einem Gestell ron Stangen. Sehr häufig sind in diesen kleinen Farmdörfern auch die Hütten aus Flechtwerk hergestellt. Das eigentliche Gerüst der Hütte wird dann mit Palmblätterrippen 
ausgeflochten. In Gibin ist noch eine andere Art von Speicher zu erwähnen; ein cylinderartiger Lehmkegel als Behälter, welcher mit Gras eingedeckt ist, ruht auf einem Untergerüst von Pfählen. Im allgemeinen scheinen die Leute bei der Anlegung ihrer Speicher das Prinzip zu haben, dass die Lagerräume nicht direkt auf dem Boden stehen dürfen, sondern eine Unterlage, wenn auch nur von Steinen, besitzen müssen. Es geschieht dies wohl um einerseits die Feuchtigkeit des Boden. andererseits die Termiten ron dem Getreide abzuhalten.

Nachdem wir uns nach kurzer Rast von dem Häuptling verabschiedet hatten, wurde der Marsch weiter fortgesetzt. An dem Ausgang des Dorfes steht ein grosser Baum, dessen Stamm mit Bändern geschmückt und ron einem kleinen Zaun aus Palmblattrippen umgeben ist. i)ies ist auch ein sogenannter Fetisch Der abergläubische Negrer sieht in allen Sachen, welche ihm entweder durch Grösse imponieren oder an welche sich ein Ereignis knupft, ein höheres Wesen, das in demselben wohnt In schnurgerader Richtung marschieren wir auf kleinen Brücken über die Zuflüsse des Ähä, welche hier den Boden sehr fruchtbar machen und besonders für den Reisbau günstigr sind. Hellgrüne Reisfelder ziehen sich weit in dem feuchten Thale dahin, ein dichter Busch, in welchem ausser Oelpalmen auch viele Dattelpalmen vorkommen, rahmt die kleinen Bäche ein. Allmählich rücken die hohen Bergketten näher und verengen das Thal, schon zeichnen sich in nordwestlicher Ferne die einzelnen Berge und Kuppen des Gebirges ab und in tiefen Einschnitten markiert sich der François-Pass, an dessen Fusse Misahöhe liegt und dessen Höhen die Quellen des Ähä bergen. Der Pass schliesst somit das Thal des Baches im Norden ab und bildet gewissermaassen die Wasserscheide der nördlichen und südlichen Bäche und Flüsschen.

Weiterhin auf der Strasse begegnen wir einem mächtigen Erdhügel, der gleich einer Pyramide über das hohe Gras und das Gebusch hinwegragt Bei einiger Phantasie könnte man glauben, dass dieser Kegel der Ueberrest eines alten gotischen Bauwerks sei. Es ist aber nichts anderes als ein Termitenhügel, der in dieser (jegend häufig anzutreffen ist und den die gefürchteten grossen, weissen afrikanischen Ameisen mit der Zeit aufgeführt haben. Bei steter, jahrelanger Arbeit ist der Bau mit seinen kunstrollen Höhlen und Gängen, in denen diese gefürchteten Insekten hausen, entstanden. Der Zerstörungstrieb der Termiten ist allgemein bekannt; ihr unterirdisches Treiben ist häufig mit einer grossen Gefahr für die Gebäude und Hütten der Neger verbunden. Namentlich zerfressen sie die Gerüste und Pfähle der Hütten, so dass die Bewohner oftmals gezwungen sind, diese einzureissen und ron neuem aufzubauen. Sie scheuen ängstlich das Tageslicht und arbeiten nur in verdeckten Gängen, welche sie mit Lehm bedecken. In diesen Gängen bringen sie auch 
Nach dem Dorfe lo

Schmiedehandwerk ihre Eier unter. Nur ganz feste Holzarten bleiben von ihnen verschont, so wird das schöne rote Odumholz von ihnen nicht angegriffen. Infolgedessen benutzt man das Holz dieses Baumes, obwohl es schwerer zu bearbeiten ist, vorzugsweise zu den Stationsbauten. Hierbei sei das Verfahren erwähnt, durch welches es dem Stationsassistenten Rosenhagen in Kete-Kradji gelang, die Termiten fernzuhalten. Er strich den Schuppen, in welchem die Lasten der Expedition lagerten, insbesondere den Erdboden und die Wände, bis zu einer gewissen Höhe mit Steinkohlenteer an. Aber die Termiten sind es nicht allein, welche Schaden anrichten, auch die Kakerlaken, grosse etwa einen Zoll lange Schwaben, sind ein Schrecken für die Europäer. Unbemerkt kriechen sie in die Kisten und Kasten und zerfressen binnen kurzem alles, namentlich wollene Sachen Man kann sich freuen, wenn man diese gefährlichen Feinde noch rechtzeitig entdeckt, um den Rest vor der Zerstörung retten zu können.

Immer höher werden die Berge und schon sieht man durch lichte Stellen des Busches den Kamm des Hausberges und den Kegel der Moltkespitze. Zwischen ihnen liegt die grosse Mulde des Passes und auf halber Höhe sieht man die Anlagen der Station wie weisse Punkte hervorleuchten. Iron hier aus bietet sich eine herrliche Aussicht auf clen Thalkessel des Agome-Gebirges und im Rücken auf den weit in der Ferne vorgelagerten hohen Agu. Bald haben wir Yo erreicht und hiermit den engeren Bezirk der Station, denn hier wohnen die meisten Arbeiter. Grosse Bäume beschatten den Marktplatz, der rings von Hütten umgeben ist. Aus einer derselben, die nur aus einem Gerüst zu bestehen scheint, sehen wir Rauch emporsteigen; gleichzeitig tönt uns der Schlag eines Hammers entgegen und lässt uns in dieser Hütte sofort eine Schmiede vermuten.

Das Schmiedehandwerk ist im allgemeinen verbreitet. Die kleine offene Hütte, in der es betrieben wird, besitzt eigentlich nur ein Schattendach. Nach dem Markt zu ist das Innere durch Wände von Palmblattrippen geschützt. Die Seiten nach dem Gehöft sind vollkommen offen und lassen bei der hohen Temperatur, die in einer solchen afrikanischen Schmiede herrscht, den nötigen Luftzug ein. Hier schwingt nun der schwarze Meister regelrecht seinen Hammer und der Geselle zieht emsig den Blasebalg. Fast alle Werkzeuge, die man in dieser afrikanischen Schmiede bemerkt, sind europäischen Fabrikats. Jedoch liegt gerade hierin insofern Interesse, als man daraus ersieht, wie weit schon die europäische Kultur vorgedrungen ist und in welcher Weise die Werkzeuge von den schwarzen Meistern gehandhabt werden. Wir bemerken in der Hütte einen Ambos, einen Schraubstock und einen Blasebalg. Auch finden wir hier schon Blecheimer, in denen das nötige Wasser zur Abkühlung des erhitzten Eisens bereit gehalten wird. Ueberall liegen Steinschlossflinten 
und Hacken zur Reparatur umher. Linter den Schlägen des Hammers werden meist Messer oder Hacken zur Bearbeitung des Bodens angefertigt oder geschärft. Mit dem Zunehmen der Einfuhr von Flinten aus Europa liegt natürlich auch dem Schmiedehandwerk die Instandhaltung dieser grossen Steinschlossflinten ob. Der Schmied in Yo schien zwar nur ein einfacher Arbeiter zu sein, machte aber doch auf mich einen höchst intelligenten Eindruck. Das kluge Gesicht war von einem Knebelbart seschmückt, seine sehnigen Arme und die Muskeln, die aus dem leichten

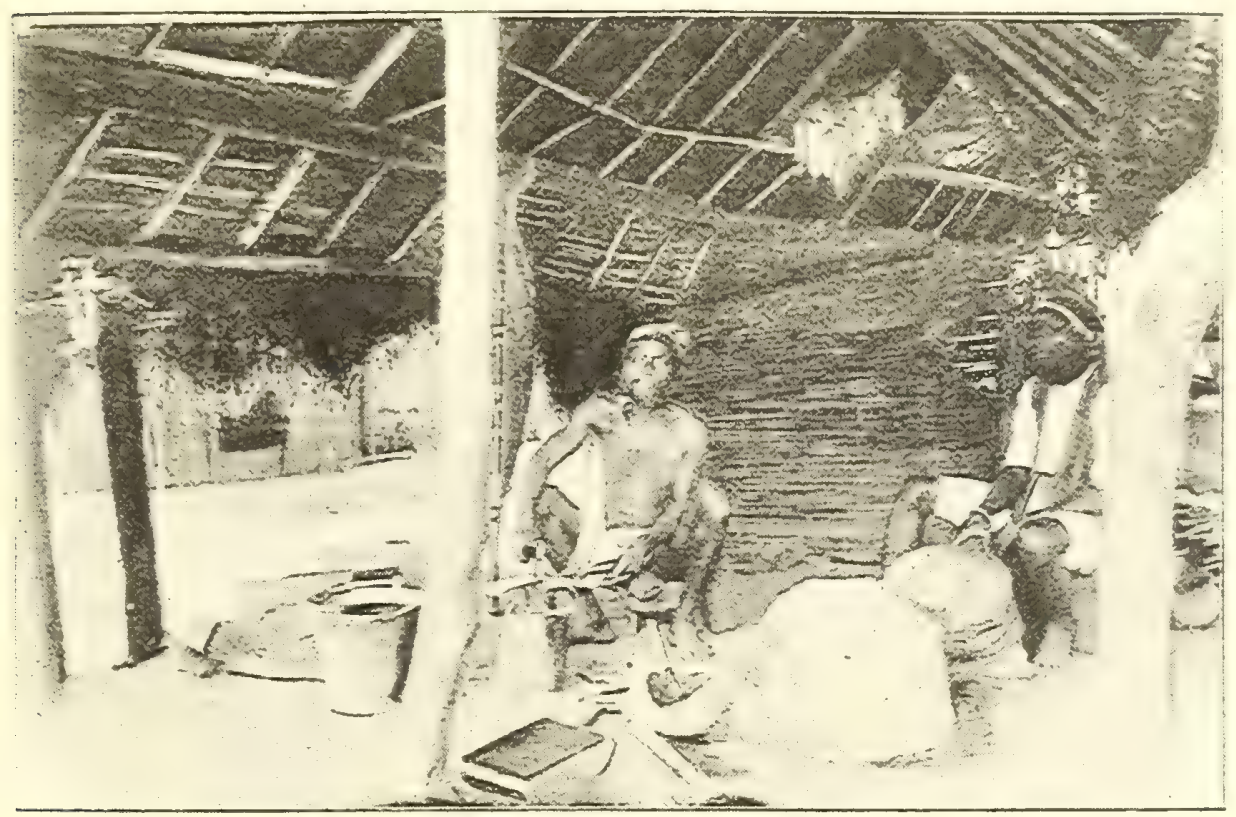

Schmiedewerkstatt in dem Dorfe Yo.

Zeugschurz bei jeder Bewegung hervortraten, zeugten von der nervigen Kraft, die dieses Handwerk erfordert. Unvorteilhaft nahm sich dagegen das stupide Gesicht seines Gehilfen aus, der mechanisch den Blasebalg bewegte. Der Meister gab mir sofort über sein Handwerk in freundlicher Weise Auskunft und liess sich gern bei seiner Arbeit ron mir photographieren.

Fast alle Schmieden bestehen, wie wir schon gesehen haben, nur aus einem kleinen Schattendach, unter welchem die primitiven Geräte aufgestellt sind. Die meisten sind jedoch nicht so reich ausgestattet, wie die beschriebene Schmiede in Yo. Der Ambos besteht häufig nur aus einem grossen Stein; der Blasebalg ist aus einigen Ziegen- oder Schaffellen mühsam zusammengeflickt, während allerdings europäische 
Hämmer und Zangren fast in allen Schmieden des ganzen Evhe-Gebietes und darüber hinaus Eingang gefunden haben. Aber auch mit dem primitiven Handwerkszeug verstehen die Leute es geschickt, Messer, Schwerter, Ackergerätschaften, häufig auch Schmucksachen aus eingeführten Metallen, Messing oder Silber zu verfertigen. Auch zeugen die grossen, durchbrochenen Fetischschwerter von der hohen Geschicklichkeit dieser schwarzen Schmiede. Unser Bild veranschaulicht gleichzeitig, in welcher Weise die Eingebornen zum Teil ihren Mundvorrat aufheben.

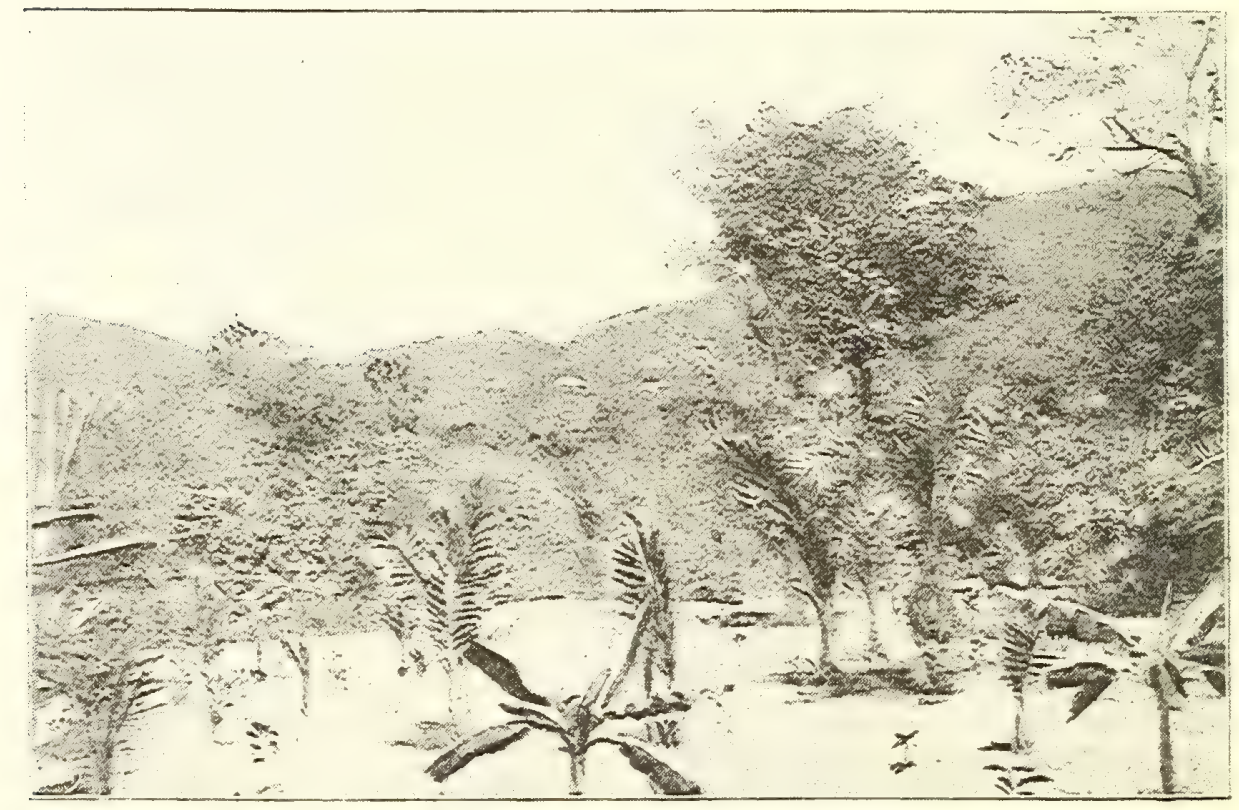

Der François-Pass und die Station Misahöhe von der Kaffeeplantage aus gesehen

Hoch an der Decke werden die Maiskolben, die ein begehrenswerter Naschartikel sind, aufgehangen und ohne weitere Zuthat mit der Zeit geräuchert

Anstieg nach

Von Yo aus hat man einen schönen Ausblick auf das ror uns

Misahöhe. ansteigende Gebirge und auf die Station, von der einzelne Häuser sichtbar sind und deren Flagge uns schon weithin aus dem dunklen Grün der bewaldeten Berge entgegen weht. In gerader Richtung führt nun der Wey ansteigend in dem schmalen Thale entlang. In den schroff abfallenden Bergketten und Schluchten hausen unzählige Affen. Zu beiden Seiten des Weges wächst hohes Rohrgras, welches für die Güte des Bodens spricht und uns fast die Aussicht benimmt. Bald entfaltet sich aber vor uns ein tropisches Bild; wir erreichen eine grosse schöne 
Plantage. Es ist ein Versuch, den der Gründer der Station, Hauptmann Herold, mit dem Anbau von Kaffee gemacht hat und der seitclem fortgesetzt worden ist. Zwischen den einzelnen Kaffeebäumchen, die hier prachtvoll gedeihen und schon schöne Trauben angesetzt haben, stehen Bananen in voller Pracht, da sie hier vor dem Winde den nötigen Schutz haben. Mit ihnen wechseln grosse Oelpalmen ab und die ganze Anlage gewährt ein schönes Beispiel von der Fruchtbarkeit und Fülle tropischer Vegetation. Der jetzige Stationsleiter, sowie sein Vorgänger haben sich durch die Anlage einer grossen Kolaplantage verdient gemacht. Die Nüsse waren fast alle angegangen, die kleinen Pflanzen schienen sich zum Teil kräftig $z u$ entwickeln und versprachen einen guten Erfolg. Der Weg führt nun nochmals über einen kleinen Zufluss des Ähä, der fast den Fuss des ansteigenden Gebirges begrenzt und dann geht es steil bergan. Auf den Hängen ziehen sich die Kolafarmen entlang und auf der ersten etwa $350 \mathrm{~m}$ hoch gelegenen Terrasse liegt der Gemüsegarten der Station, sowie ein Teil der Hütten der auf der Station beschäftigten Weiboys. Immer steiler wird der Pfad, die Abhänge sind mit grünem Gras bedeckt, das von der Station ausgesät wird. Auf hohem Bergkegel und fast wie an den Felsen angeklebt, liegt die schön ausgebaute Station Misahöhe vor uns. Hier werden wir von den Weissen der Station begrüsst, die uns schon lange von der Terrasse des stattlichen Gebäudes aus mit Gläsern verfolgt haben und denen unsere Ankunft bereits gestern gemeldet war. Denn wie im Fluge verbreitet sich in Afrika von Mund zu Mund die Ankunft eines Europäers. Allerdings ist in dieser Gegend der Weisse keine grosse Seltenheit und so bringt sein Herannahen mit Truppen oder einer Karawane nicht mehr die ganze Gegend in Aufregung.

\section{DIE STATION MISAHÖHE.}

In Misahọhe fühlt man sich nach langer Zeit fast wieder in europäische Verhältnisse versetzt. Das grosse schöne Wohnhaus, welches aus Steinquadern von dem Pflanzer Goldberg angelegt und von Dr. Gruner weiter aufgebaut worden ist, enthält einen geräumigen Saal und zwei Nebenzimmer, in denen man es sich bequem machen kann. Die grossen Fenster führen auf die Veranda, die rings um das Gebäude herumläuft und ron einem breiten Schindeldach beschattet wird. Das Haus und die ganze Anlage erhebt sich auf einem Plateau, das zum Teil erst auf den Hängen geschaffen worden ist. Das Hauptgebäude liegt auf einer 
Bastion, die ebenfalls aus Steinen, dem Material der Berge, aufgefuhrt ist und dem Gebäude einen erhöhten Standpunkt und ein imposantes Aussehen verleiht Auf der breiten, zementierten Veranda werden ron den Weissen die freien Stunden rerbracht und während der Trockenzeit werden auch hier die Mahlzeiten eingenommen. Einen wunderschönen Blick hat man von dieser Veranda atis auf das weite, rom Ähä gebildete Thal, welches tief in das Gebirge einschneidet. Auf der Nordseite wird dasselbe von den schroff abfallenden Felswänden der nördlichen Bergkette eingefasst, während die südlichen Hänge lieblicher und sanfter gewölbt sind und sich nach Süden hin plötzlich öffnen; vor uns liegt die Ebene, in der sich der Ähä dahinschlängelt und die Dächer der kleinen Dörfer aus dem Busch hervorlugen, während weit im Hintergrunde der Agu mit seinen drei hohen Kegeln das breite Thal abschliesst. Auf den bewaldeten Höhen ist der Wohnsitz der Affen. Die Paviane, deren Geschrei, „Hö, Hö“, man des Abends bis zur Station herüberhört, halten sich vorzugsweise in den kahlen Schluchten zwischen schroffen Felsabhängen auf, während der uns schon bekannte weissschenklige Seidenaffe hauptsächlich die Gipfel der Bäume belebt. Den nördlichen Teil der Station bildet die alte Herold'sche Station, wie sie hier genannt wirl

Bedeutung der Statione und Hauptverkehrs. strassen.
Leutnant Herold war der verdienstvolle Gründer dieser ersten Station in dem westlichen Teile unseres Togogebietes. Wir haben schon gesehen, wie früher die alte Strasse im Osten des Gebiets an der französischen Grenze entlang durch Atakpame nach Adele und nach der Station Bismarcksburg fuhrte Es war dies der erste Pfad, den die tüchtigen Forscher Kling, Wolff und François von Klein-Popo aus in das Hinterland gebahnt hatten. Derselbe erschloss diese Gegend dem Handel und brachte einen Aufschwung in den Verkehr auf dem östlichen Gebietc. Obwohl sich auch hier grosse Schwierigkeiten den ersten Reisenden entgegenstellten und dieselben mit jedem Häuptling wegen des Durchzuges erst verhandeln mussten, so entstand doch allmählich aus dieser Strasse ein Verkehrsweg nach der noch heut zweitgrössten Handelsstadt Popo an der Ostkuste Aber der Krieg in Dahome hatte einen ungünstigen Einfluss auf diese Karawanenstrasse und der Handel zog sich, ztierst langsam, später schneller, nach der Westküste unseres (iebietes, nach unserer jetzigen Netropole Lome. Der damalige Landeshauptmann ron Puttkamer, der einsah, dass durch die Verlegung det Hauptverkehrsstrassen nach dem Westen des (iebietes ein grosser Teil der Produkte unseres Hinterlandes zum Nachteil unserer Kolonieen auf englisches Gebiet überging, suchte dem entgegenzutreten, indem et Strassen in das Innere anlegte und auch fur den nötigen Schut\% derselben durch Stationen sorgte Seiner Initiative haben wir also die Anlegung der Station Misahöhe, sovie der grossen Strasie, die im 
Westen unseres (iebietes weit ins Hinterland führt, zu clanken. I)ic Inlage der Srasse hatte den erhofften Erfolg, denn ein grosser Teil des Handels, der früher nach englischem Gebiet ging, wurde auf unsere jetzige Hauptstadt Lome abgelenkt, was der vermehrte Verkehr, der Umsatz, sowie das mächtige Anwachsen dieser Metropole am besten beweisen. Bei der grossen Wichtigkeit der Strassen und Stationen für das Hinterland muss ich nochmals auf die schon erwähnten Verkehrsstrassen im Osten unseres Gebietes zurückkommen. Leider musste der Weiterbau der weniger wichtigen Strasse, welche von Sebbe schon über Anfoi herausgebaut war, aus Mangel an Mitteln zu gunsten der westlichen grossen Strasse nach Misahöhe aufgegeben werden. Wenn wir jetzt auch im Osten durch den letzten Pariser Vertrag eine I'asserstrasse nach dem Hinterlande haben, so würde es doch für unser östliches Gebiet und speziell für die Hebung ron Klein-Popo von grosser Bedeutung sein, wenn die begonnene Strasse entweder weitergefuhrt oder von unserem jetzt deutschen Topli aus über die neu angelegte Station in Atakpame, Bismarckburg und weiter nach Tshautscho heraufgefuhrt werden könnte. Is würden damit das jetzt so unzugängliche, rinderreiche Atakpamegebiet und die nordöstlichen reichen Gummidistrikte dem Handel mehr erschlossen und nutzbar gemacht werden; ferner würden auch die verödete Station Bismarcksburg und die Gebiete im Osten neu belebt sowie dem Nangel an Trägern und Arbeitskräften auf der westlichen grossen Karawanenstrasse wesentlich abgeholfen werden. Der Verkehr, der sich auf der grossen Strasse im Westen immer mehr steigert, liegt im Osten dieses Gebietes fast darnieder. Mit der Anlegung einer Strasse im Osten würde dann auch die jetzige grosse Strasse im Westen entlastet werden und die Karawanen, die heute den grossen Umweg von Tshautscho und den nördlichen Kotokolilanden über Kratyi machen müssen, hätten es bedeutend näher, wenn sie von Tshautscho aus direkt nach dem Süden zur Küste marschieren könnten. Diese Strasse wirde also fü das ganze östliche Gebiet sowohl in kommerzieller als auch in kultureller und in strategischer Beziehung ron ganz hervorragender Bedeutung sein. Durch die vorerwähnten Grủnde bewogen, ging seiner Zeit der frühere Landeshauptmann $v$. Puttkamer mit dem jetzigen Hauptmann Herold und dem Stabsarzt Dr Wicke im Mesten des Gebietes ron Lome aus auf dem damaligen Buschpfad über Gbin bis Agome, wo auf halber Höhe des Cíebirges in dem Ahä-Thal der Platz für die heutige Station Misahöhe wegen seiner gesunden und schönen Lage bestimmt wurde.

Hauptmann Herold wurde mit der Anlage der Station beauftragt, er Die Aufgabe ist daher der eigentliche Gründer und Erbauer des heute so schön der Station entwickelten Misahöhe. Hauptmann Herold hat mit bescheidenen Mitteln Misahöhe. den jetzt noch nach ihm benannten Teil erbaut. Zumeist sind es Lehm- 
häuser, welche weiss angestrichen und mit einem Hol\%- oder Pappdach eingedeckt sind Ein bescheidenes Häuschen, welches auf einer Bastion von Steinen erbaut ist und ron dem man einen schönen Ausblick auf das Thal geniesst, bildete die einfache Wohnung des verdienstvollen Gründers. Der andere Teil enthält die Arbeitsräume, die Wache, das Gefängnis, die Apotheke und eine schöne Dunkelkammer, in der ich den grössten Teil meiner Evhe-Photographieen hergestellt habe. In der neueren Zeit sind noch eine aus Steinen aufgeführte Küche, sowie ein langes einstöckiges Gebäude errichtet worden, in dem die Dolmetscher wohnen und sich verschiedene Arbeits- und Lagerräume befinden. Die Hänge nach dem Thale zu sind

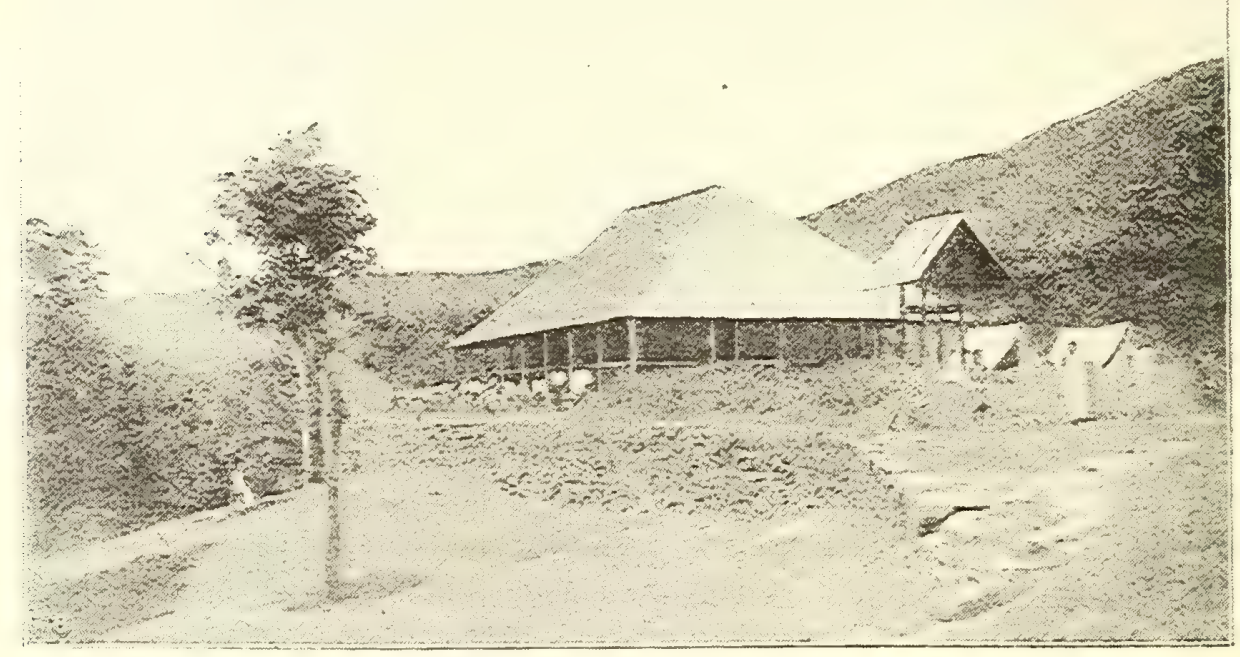

Hauptgebäude der Station Misahöhe

alle mit kurzem Gras eingesät worden und bilden für die Stationshercle eine schöne Weide. Die ansehnliche Herde hat allerdings viele Wechselfälle erlebt, bald war sie zu einer stattlichen Anzahl angewachsen, bald wieder durch Krankheit, lie nach den Angaben des Botanikers Baumann von der Tsetsefliege herruhren soll, dezimiert. Heute fuhrt auch ron dem Quell, der sich oberhalb der Station auf dem Wege nach dem François-Pass befindet, eine primitive Wasserleitung hinunter, welche sowohl für den Haushalt als auch fur die schöne Badeeinrichtung klares kaltes Wasser liefert. Wisahöhe ist, was die Wasserverhältnisse anbetrifft, der idealste Ort unserer Togokolonie Die höhere Lage und infolgedessen die Frische der Temperatur, welche bei der Regenzeit bis auf $\mathrm{I} 2{ }^{\circ}$ Celsius heruntersinkt; sowie das helle klare 
Trinkwasser machen die Station zu cinem der gesündesten Punkte in unserem Hinterlande. Die Station ist auch ron politischer und strategischer Bedeutung, da sie den einzigen Pass, der in dieser Gegrend uber das Gebirge fuhrt, vollkommen beherrscht. Alle Karawanen müssen auf der Strasse, die hier an den Hängen der Schlucht heraufgebaut ist und sich über den François-Pass bis nach dem im Thale liegenden Ort Tongbe erstreckt, die Station berühren. Hauptmann Herold hatte in der ersten Zeit mit dem Widerstand der einzelnen Häuptlinge und der

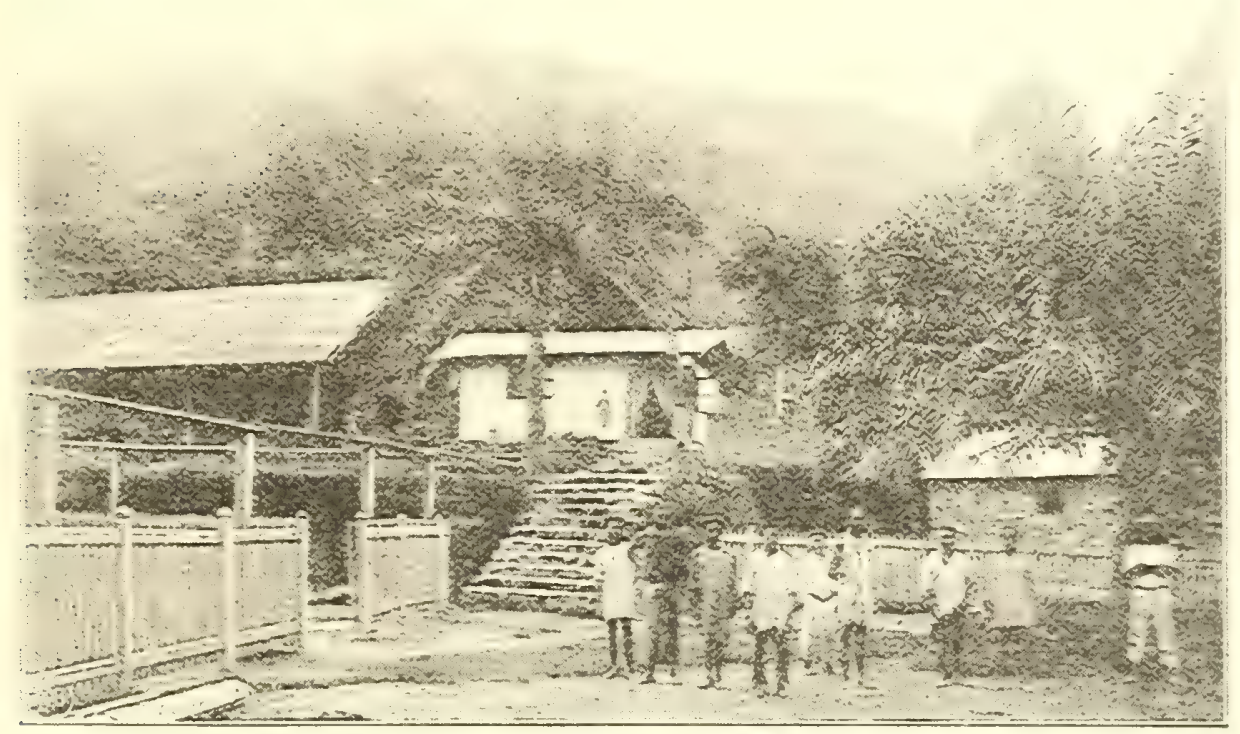

Die Wirtschaftsgebäude der Station Misahöhe.

Eingeborenen, die sich jeglichem Einflusse von Seiten der Station zu entziehen suchten, nicht unerheblich zu kämpfen. Sie gefährdeten die Pfade, belästigten die Karawanen und Händler und erhoben von ihnen Tributzahlungen. Die erste Aufgabe des damaligen Leiters bestand daher darin, diesem Treiben ein Ende zu machen. Es kam soweit, dass die Station von den Kumaleuten förmlich belagert wurde. Sie besetzten die Höhen und schossen von dort aus auf die Station herunter, die der Hauptmann Herold mit seiner kleinen Nannschaft verteidigte. Durch die günstige Position der Eingeborenen war die Station sehr gefährdet und nur der Mut des Führers und die Ueberlegenheit der Feuerwaffen schlugen den Feind zurück. Den grössten Widerstand leisteten die Bergrölker, die sich in ihren geschützten Thälern sicher wussten und 
durch nichts einzuschüchtern waren, bis auch sie endlich teils mit (iewalt, teils durch friedliche Unternehmungen dem Handel und der Kultur gewonnen wurden Heute bilden diese Leute einen wichtigen Stamm der Arbeiter der Station, ihre grosse Körperliraft und Ausdauer haben sie zu gesuchten Trägern gemacht, dic den Lastenverkehr zwischen Misahöhe und Lome und auch den nördlich gelegenen Stationen, wie Kratyi und Kpando vermitteln helfen In ihren Farmen haben sie mit Erfolg den Kaffee angebaut, welcher ihnen durch den Hauptmann Herold fast aufgedrungen werden musste, heute aber bereits den Kumaleuten schöne Erträge abwirft. Wurch die Anlage von Wegen ist auch die nördlich gelegene Kette, auf der der Hausberg liegt, passierbar gemacht und jetzt fuhrt auf den Kamm der Bergkette ein schöner Pfad, der den Verkehr mit den nördlich gelegenen Kumathälern ganz erheblich erleichtert Auf der höchsten Stelle dieses nördlichen Bergzuges ist ein Steinhäuschen mit einer kleinen meteorologischen Station erbaut worden Yon hier aus hat man eine wunderschöne Aussicht auf das breite Thal, das zwischen dem Gebirge und der Küste liegt Deutlich tritt der majestätische Agu aus der Ebene heraus, während man weit nach Sưdwesten hin die Gebirgskette verfolgen kann, die in einzelne kleine Höhen übergeht, über welche weit der Adaklu hervorragt. Im Norden sieht man in die Kumuthäler und in die Thäler ron Leglebi hinein, weiter nördlich in nordwestlicher Richtung in das Thal des Danyi und seiner Tebenflusse, welches die Höhen ron Lavanyo abschliesst; weiter daruber hinaus in der Ferne crheben sich als höchste Spitzen die Rerge von Kunya und ron Wurupong und setzen der Fernsicht ein Ziel.

Die Station hat nicht allein eine politische Bedeutung, sie hat auch an der wissenschaftlichen Erforschung des Agomelandes und weiter daruber hinaus einen ganz bedeutenden Anteil. Schon Hauptmann Herold hat uns durch seine zahlreichen ethnologischen Schriften mit den dortigen Völkern bekannt gemacht, während Dr. Gruner und Baumann einen hervorragenden Anteil an der geographischen Erforschung dieser Gebiete haben Durch zoologische und botanische Sammlungen ist die Kenntnis von der Fauna und Flora unserer Kolonie gefördert worden Auch die meteorologischen und klimatischen Verhältnisse wurden durch fortlaufende Beobachtungen festgestellt Die zahlreichen von hier aus aufgenommenen Routen führten zur Erschliessung fast aller Dörfer und Orte der Lmgegend. Durch eine wohlangelegte Triangulation des Assessors Leutnant Plehn ist ferner eine Basis fur alle geographischen Fixpunkte bis zur Kuste hin geschaffen und letztere an das trigonometrische Netz, welches sich bis Bismarcksburg hinzieht, angeschlossen worden Wenn Misahöhe jetzt auch infolge der weiter im Hinterlande angelegten Stationen an politischer Bedeutung verloren hat und die 
Erichliessung und wissenschaftliche Erforschung des (iebietes weit vorgeichritten ist, so ist doch noch nicht alles gethan und es ist heute die besondere Aufgabe des jetzigen Leiters, Oberleutnant Wegner, die wirtschaftliche Bedeutung dieser Gebiete in jeder Weise durch Anlegung ron Strassen und ron Versuchsplantagen sowie durch Gründung neuer Handelsbeziehungen zu heben. Ist schon durch die Stationsbauten und durch die hingebende Unterstützung der Bremer-Mission ein Stamm ron Handwerkern, wie Tischler, Naurer und Zimmerleute geschaffen worden, so muss dieser mit der Zeit immer noch vermehrt werden. Dank der Thätigkeit der Mission bildet sich allmählich bei den Schwarzen ein wohlhabender Handwerstand neben dem des Handels heraus. Die wanze Station, welche fast ausschliesslich ron solchen Leuten erbaut worden ist, spricht fur die Leistungsfähigkeit der schwarzen Handwerker. Der Dachstuhl des Hauptgebäudes ist sorgfältig aus regelrecht bearbeiteten Odumhölzern zusammengefugt, während die Herstellung der Decken und Dielen, sowie der inneren Einrichtung, der Schränke, Stühle, Iraschtische, Bettstellen, Tische und anderer kleiner Tischlerarbeiten beredtes Zeugnis ron den Fähigkeiten der Schwarzen ablegt. 1)ie Einrichtung europäischer Faktoreien in Palime hat, wie wir gesehen haben, einen bedeutenden Handelsverkehr gezeitigt, der in dankenswerter Weise von dem jetzigen Leiter durch den Bau neuer Strassen und Anknüpfung neuer Handelsbeziehungen gefördert und unterstützt wird. Durch die Anlage kleiner Versuchsplantagen auf der Station ist den grossen anzulegenden Plantagen im Hinterlande gewissermaassen vorgearbeitet worden, ebenso können auch speziell die neuen Versuche, welche mit Kolanussplantagen gemacht wurden, von grosser wirtschaftlicher bedeutung für unsere Kolonieen werden. Die Kolanusse werden, wie bei uns der Tabak und die Zigarren, ron fast sämtlichen Haussas, sowie ron den mit ihnen im Verkehr stehenden Völkern als narkotisches Mittel gebraucht. Sie sollen nach ihrer Behauptung gegen Müdigkeit und Durst schuitzen, was nach meiner Wahrnehmung allerdings der Fall ist, da sie nervenanregend wirken. Die Goldküste, an welcher namentlich der Ort Ateobu mit vielen Kolabäumen gesegnet ist, hat einen gewaltigen Export dieser Nüsse. Von weit her aus den Haussakolonieen kommen kleine Karawanen, welche nicht selten Vieh und Pferde herunterbringen und diese dann gegen die Kolanuss eintauschen. Grosse Karawanen von Haussas, meistens mit Schafen, überschreiten bei Kratyi den Volta, um an Ort und Stelle in Ateobu und den benachbarten Gegenden die mitgebrachten Schafe gegen Kolanüsse zu verhandeln. Sie bilden die Zwischenhändler und führen diese Kolanussware auf die grossen Märkte, wie Kratyi, Salaga und Tshautsho u. a. m., wo sie gegen allerhand Waren, wie Pferde, Esel, Elfenbein, Eingebornentücher oder Leder- 
atbeiten aus den Haussastädten eingetauscht werden Auf diese Weise gelangt eine ganz ungeheure Menge ron Kolanussen in den Handel. Auch hat sich in den letzten Jahren der Export der Kolanuss nach Europa erheblich gesteigert Sie wird zur Herstellung der verschiedensten Arzneimittel, zum Beispiel der Kakaopräparate und der Kolaliqueure benutzt. Ihre Verwendung zu derartigen Präparaten hat in den letzten Jahren so stark zugenommen, dass der Export nach Europa noch bedeutender zu werden verspricht. Hierin liegt ein grosser wirtschaftlicher Torteil fur unsere Togokolonie, weil sie, wie die Nachbarkolonie der englischen Goldkuste, die Heimat der Kolanuss, einen günstigen Boden fur das Gedeihen derselben besitzt. Die Anlage von grossen Kolanussplantagen würde demnach die wirtschaftlichen Verhältnisse wesentlich heben und uns auch den Handel an einheimischen Produkten, wie Gummi, Elfenbein, Stoffen, Pferden und Rindvieh, der heut in die englische Kolonie ubergeht, zufuhren Wie die verhältnismässig kleinen Kolanussfarmen der Eingeborenen in Tappa und die Versuche mit Kolanüssen in Bismarcksburg, sowie die allerneuesten Anpflanzungen in Misahöh beweisen, kann man mit Recht in gewissen Teilen des Hinterlandes unserer Kolonie auf ein guinstiges Resultat rechnen.

Ausser der wirtschaftlichen Thätigkeit haben die Stationen Misahöhe wie auch die ubrigen Stationen im Hinterlande eine ganz besondere Bedeutung fur unsere Expeditionen und denLastenverkehr. Sie ermöglichen es selbst grossen Expeditionen, die Reise ohne Mitnahme des sonst unvermeidlichen Ballastes an Waren und vielen Trägern zu machen, da sie stets die Zufuhr von Proviant von der Kúste vermitteln können. Misahöhe ist die erste Station, welche die Lasten in Empfang zu nehmen und zu ordnen hat und sie dann mit Hülfe neuer Träger bis zur nächsten Station Kratyi weiter befördert Da die Träger von der Kuste aus bis Misahöhe ohne weitere Bedeckung wandern können, werden hierdurch grosse Kosten erspart. Auch wird durch diesen Verkehr eine stete Fủhlung mit den einzelnen Stationen aufrecht erhalten. Häufig kommen in Misahöhe den Tag uber 30 bis 50 Lasten an, welche alle geordnet und weiter befördert sein wollen, so dass die Beamten beständig mit der Herbeischaffung von Trägern beschäftigt sind.

Umgebung Um ron der Anlage und näheren Umgebung der Station ein von anschauliches Bild zu geben, sei zunächst gesagt, dass der ganze Gebäudekomplex der Station sich terassenförmig an den Hängen des FrançoisPasses hinzieht. Auf der ersten grösseren Terrasse liegt die schon geschilderte eigentliche Station, während ein grosser Arbeitsschuppen fur die Zimmerleute, sowie die Huitten der Arbeiter und Soldaten sich oberhalb dieser Anlage befinden. Das Ganze gewährt ein romantisches Bild; rorn präsentieren sich vorteilhaft das grosse Hauptgebäude und die 
weissen Nebengebüude der Station, während im Hintergrunde an der Berglehne die kleinen Hütten liegen; hinter diesen erhebt sich eine die Station noch foo $\mathrm{m}$ überragende, steil abfallende Bergkette mit dem Hausberg. Nördlich führt der Pfad an der Schlucht des thä und dem François-Pass vorbei, während südwestlich das tief einschneidende Thal die Station von den westlichen Bergketten und der Moltkespitze trennt. So rauh die nördliche Kette erscheint, so lieblich sieht die Moltkespitze aus. Der Aufstieg zu clerselben ist schwierig und unbequem. Auf dem Hausberg sind refeinzelt Leoparden und auf der Moltkespitze auch Büffelheerden gesehen worden, welche zwischen den nördlich oder nordöstlich liegenden Bergen und der Moltkespitze in dem Thal des Ahä wechseln sollen. Die Aussicht auf eine erfolgreiche Buffeljagd, sowie die Gelegenheit, den südwestlichen Gebirgszug etwas näher kennen zu lernen, reizten mich, einen Streifzug auf die Moltkespitze zu machen. Mit Geld und guten Worten warb ich einen eingeborenen Jäger aus Yo an. Wir brachen in aller Frühe auf und marschierten in der grossen Schlucht des Ähä bis zu den Heroldfällen, welche dieser kleine Bach bildet und die nach ihrem Entdecker ihren Namen erhalten haben, um ron hier aus auf kleinen unausgetretenen Jägerpfaden und über die Wasserrinnen, welche die Zuflüsse des Baches bilden, die Spitze zu erklimmen. Fast undurchdringlich wurde zuweilen der Busch und häufig konnten wir uns nur schrittweise den Weg bahnen. Zahlreiche grosse Raubvögel und Milane umkreisten die Gipfel mit unheimlichem Geschrei. In den Kronen und Zweigen der Bäume schaukelten sich munter ganze Heerden von schwarzen Seidenaffen. Lange schaute ich zu, wie diese schlanken schönen Tiere in grossen Sätzen über die Schluchten und Felsen von einem Ast der überhängenden Bäume zum andern sprangen. Sie prügelten und balgten sich wie eine Schar wilder Knaben. Bald suchte ein kleiner Affe mit einer Frucht, die er in der einen Hand trug, das Weite; aber schon im nächsten Augenblick hatte ihm ein stärkerer den Weg abgeschnitten, ihm die Beute abgenommen und sich nun zu dem Schmause den Blicken seiner Kumpane entzogen. Endlich hatten wir nach mühevollem Aufstieg den obersten Kegel erreicht. Aber ach! statt der schönen grünen Matten, die wir von unten zu sehen vermeinten, stellte sich uns ein undurchdringlicher Wald von hohem Gras entgegen. Schrittweise drangen wir vor, ohne irgend eine Aussicht nach rechts oder links zu haben. Da stiessen wir plötzlich auf schmale zerstampfte Pfade, in denen wir deutlich die Spuren ron Büffeln erkannten. Nur zwei bis drei Schritte konnten wir ror uns sehen; aber von dem Wunsche beseclt, das Wild zu erspähen, verfolgten wir die Büffelpfade, bis wir dann auch die Lagerstätte der wilden Gesellen entdeckten. Nahe Geräusche und ein dumpfer Schlag auf dem Boden liessen 
vermuthen, dass die Heerde nicht fern sei Aber clas hohe Gras versperrte jeden Ausblick, so dass wir ihrer nicht ansichtig werden konnten. Es war ein gewagtes Unternehmen, in diesem hohen undurchdringlichen Gras eine Pursche abzuhalten, ich kann von Glück sagen, dass ich der Gefahr entgangen bin, unerwartet von einem dieser gefährlichen Tiere uberrannt zu werden Wir verfolgten die Spur noch weiter und fanden ein verlassenes Lager sowie die frische Fährte und Losung dieser Tiere Jetzt befindet sich auf dem Kegel des Berges ein kleines Gerüst, welches von Leutnant Plehn in den letzten Jahren zum Zwecke der Triangulation errichtet worden ist. Im Jahre 1894 , als ich diese Expedition unternahm, wechselten noch kleine Rudel von Buffeln in der thä-Ebene und wurden ab und zu erlegt Auch erzählte mir Herr Baumann, dass er fruher auf dem Hausberg unverhofft einen Leoparden angetroffen hätte. Obgleich ohne Gewehr, verlor er doch nicht die Geistesgegenwart und ging direkt auf die Bestie los Der Leopard räumte erst langsam und dann in offener Flucht das Feld. Durch den gesteigerten Verkehr und die Anlage neuer Pfade und Wege verschwinden natülich auch diese Tiere, um sich in die sicheren Schlupfwinkel des Busches und der Wälder zurückzuziehen.

\section{REISE NACH DEM AGU.}

Bei meiner zweiten Reise im Jahre r 897 hatte ich auf meinem Ruckmarsche (xelegenheit, den Agu und seine Umgebung kennen zu lernen. Ich beteiligte mich an der kleinen Reise, welche Leutnant Wegner und der stellvertretende Landeshauptmann, Assessor Gleim, nach dem Agu machten, um die dortigen Verhältnisse näher kennen zu lernen. Wir marschierten mit einer kleinen Karawane von Misahöhe auf der Strasse über Kussuntu, Agome-Palime, Tove, den fruheren Ort Abesia nach Nyambo am Fusse des Agu Abesia, welches im Aufstande vollkommen zerstört worden war, wurde jetzt wieder seitens der Leute eifrig aufgrebaut, da sie die Erlaubnis erhalten hatten, sich hier wieder niederzulassen. Am Ảhä-Fluss, in einer günstig gelegenen Ebene waren sie beschäftigt, ihre kleinen Huitten zu errichten und den Busch für neue Ansiedelungen abzubrennen und zu roden. Weiter ging es durch das alte Dorf von Abesia nach Ueberschreitung des thä, der hier bei mittelhohem Wasserstande eine Breite von etwa 6 bis $8 \mathrm{~m}$ und eine Tiefe von $\mathrm{x} / 2 \mathrm{~m}$ hat, aber, wie alle afrikanischen Flusse und Bäche, bei der Regenzeit nicht ohne Schwierigkeit zu passieren sein soll. Der Pfad 
fuhrt durch hohen Busch In der Ferne erheben sich wischen kleinen, in den thä mündenden Bächen niedrige Rücken und Hügel, die gleichsam als Vorhöhen den Lebergang aus der Ebene zu dem Agugebirge bilden

Wir überschreiten den $5 \mathrm{~m}$ breiten Bach Adeye und kommen in das Bereich der reichen Farmen von Nyombo, einem der Hauptplätze in dieser Gegend. Leppige Mais- und grosse Yamsfelder, sowie Erdnussfarmen sind am Fusse des Agu angelegt. Zwischen den Bächen liegen grosse Haine ron Oelpalmen, in denen wir uns auf einem zweiten Marsche in der Nacht verirten. Die Träger stolperten in der Finsternis und es ging nur langsam vorwärts, weil die kleinen $W$ asserbäche mit ihren zerrissenen steilen Ufern ein grosses Hindernis bildeten. Als wir fast nicht mehr aus noch ein wussten, versuchten wir mittels des Kompasses auf engen Jägerpfaden die Hauptstrasse wieder zu gewinnen. Mein unerschrockener Meppo leuchtete mit einer grossen Laterne voran. Bald sahen wir ein grosses Feuer, gingen auf dasselbe zu und gelangten glücklich nach dem grossen Dorfe Nyambo. Hier wurden wir wie immer von dem Häuptling freundlich aufgenommen und quartierten uns bei ihm ein. Nyambo liegt am Fusse des Berges und zieht sich herauf bis zu einer Höhe von $830 \mathrm{~m}$ über dem Meeresspiegel; der höher gelegene kleinere Teil wird Alt-Nyambo genannt. Nyambo ist ein Dorf ron etwa 200 bis 300 Hütten, während Alt-Nyambo nur etwa 50 bis zo Hütten zählt. Auf halber Höhe des Berges liegt eine kleine Aussenstation der norddeutschen Mission, die hier eine Schule unter der Aufsicht eines schwarzen Lehrers eingerichtet hat. Auf der höchsten Spitze des Berges, die sich ungefähr $980 \mathrm{~m}$ über dem Meeresspiegel erhebt und von der man eine herrliche Aussicht auf das weite Thal und auch auf das Gebirge haben soll, befindet sich der Fetischplatz der ganzen Gegend. In Nyambo selbst wird der Markt abgehalten, auf dem die Produkte noch zu verhältnismässig billigen Preisen abgesetzt werden, da die versteckten, ron der grossen Verkehrsstrasse abseits liegenden Orte wenig Absatzgebiete haben und auch die Ansprüche der Eingeborenen bedeutend geringer sind, als an denjenigen Plätzen, welche an der grossen Karawanenstrasse liegen. Nur ab und zu kommen schlaue Händler hierher, welche den Reichtum dieser Gegend erkannt haben und an die Leute mit grossem Vorteil europäische Waren gegen Oelpalmprodukte absetzen. Hier werden auch Felle von Leoparden verhandelt. Die westlich gelegenen Striche des Agu sind durch ganz besondere Fruchtbarkeit ausgezeichnet und werden durch kleine Bäche genügend mit Wasser versorgt. Grosse Yamsfarmen zeugen von der Ueppigkeit des Bodens und die eigentümlichen grossen Speicher, welche häufig auf dem Felde erbaut sind, sprechen für die reichen 
Ernten, die der Ackerbau liefert. Diese Speicher bestehen aus einem Gerüst von Stangen und Knüppeln, welches ganz demjenigen der Evhehütten ähnelt und mit einem Grasdach eingedeckt ist. Zwischen den Querbalken sind ron der Mittelrippe der Oelpalmblätter Geflechte ausgefuhrt, welche in einzelnen Etagen die grossen Yamsknollen aufnehmen So werden diese Früchte in offener Hütte unter sicherem Grasdach vor Regen geschutzt und durch den Luftzug vor dem Dumpfigwerden bewahrt. Diese Aufbewahrungsmethode habe ich an keinem andern Ort

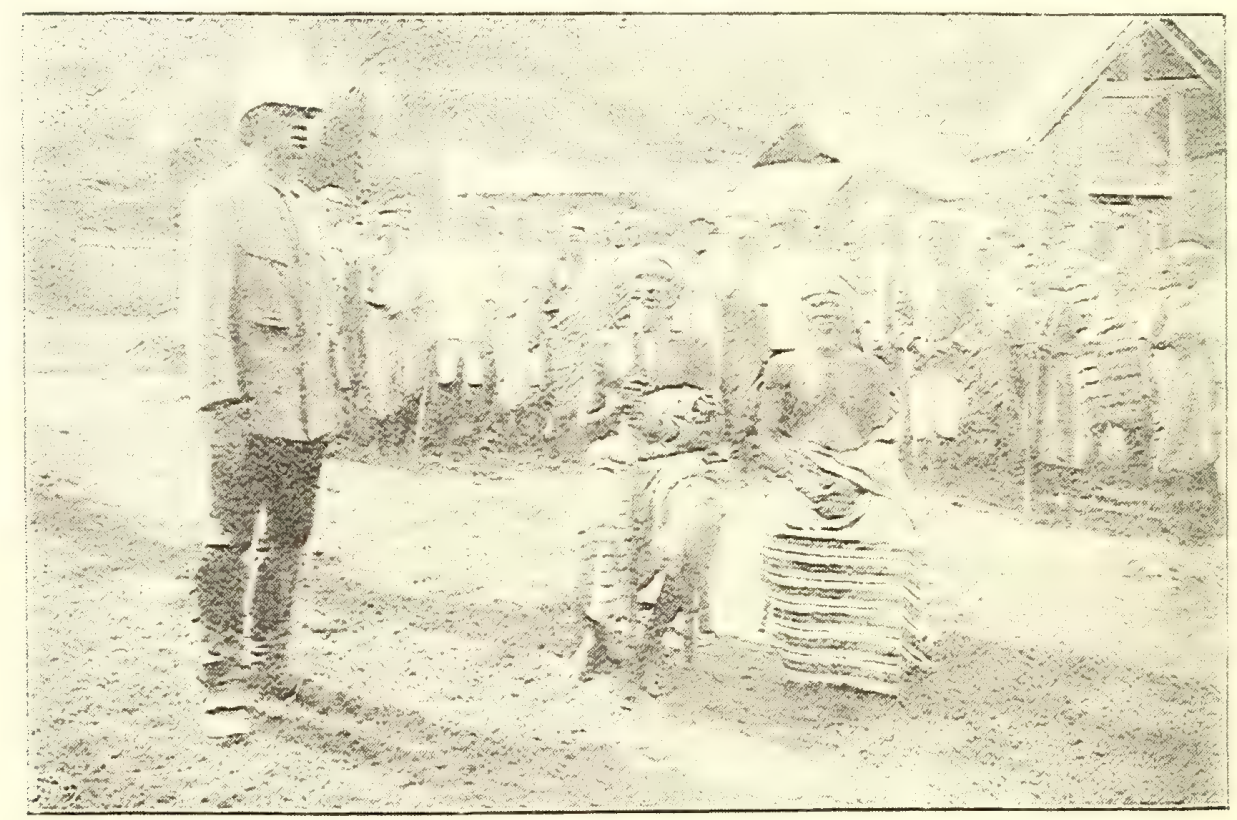

Häuptling und Leute vom Agu Bei einem Palawer auf der Station Misahöhe.

angetroffen, in anderen Gegenden werden sehr häufig die Yamsfrüchte auf einem Gerüst, welches unter dem Dache der Hütte angebracht ist, aufbewahrt. In Nyambo ist der Besuch eines Weissen noch eine grosse Seltenheit und deshalb auch die Neugierde der Eingeborenen bei der Ankunft eines solchen Gastes nicht gering. Ueberall umstehen und begaffen sie ihn und nur mit Mühe kann der Häuptling die Aufdringlichkeit seiner neugierigen, häufig sehr dürftig bekleideten Unterthanen abwehren. Die Schule, welche auf einer schönen freien Fläche in halber Höhe des Berges liegt, enthält ausser dem Schulzimmer noch die Wohnung des schwarzen Lehrers. Von hier aus hat man auch eine wunderschöne Aussicht auf die Ebene und Gebirgskette, sowie auf das Thal mit den schönen Farmen. Weiter hinauf kam ich leider nicht, 
weil ich durch ein heftiges Fieber abgehalten wurde. Infolgedessen konnte ich auch nicht die Attribute des Fetisch Bagba, welcher in dem Agu seinen Sitz haben soll, selbst in Augenschein nehmen.

Dieser Fetisch hat eine grosse Bedeutung fur die ganze Gegend und ihm wird die Macht zugeschrieben, Regen zu spenden oder zu versagen. Auch ist er Herr über die Winde und den Harmattan. In grossen Töpfen soll der Priester dieses Fetisches die Winde verschlossen halten. Ein Gehöft, welches dem Fetischpriester gehört, steht oben auf dem höchsten Punkt des Berges und eine Hütte soll die Kleinodien des Fetischs bergen, welchem von den Eingeborenen so gewaltige Kraft zugeschrieben wird. Auch sollen ihm einzelne grosse Ziegenböcke mit langen Bärten gehören. Der Fetischpriester, der eine grosse Macht hat und eigentlich auch zugleich Häuptling des Landes ist, darf nach der Vorschrift des Fetischs nie den Berg verlassen und muss sein ganzes Leben auf den Höhen des Agugebirges zubringen. Nur einmal des Jahres darf er herabkommen, um Einkäufe auf dem Markte zu besorgen; er darf jedoch nicht die Hütte eines anderen Sterblichen betreten und ist gezwungen, an demselben Tage wieder in seine Verbannung zurückzukehren. Die Regierungsgeschäfte in den Orten und Dörfern werden von Unterhäuptlingen, welche von dem Fetischpriester bestellt werden, erledigt. Auf dem Agu befindet sich ein grosser erratischer Felsblock, welcher von den Eingeborenen mit ganz besonderer Ehrfurcht betrachtet wird und den sie den Stein ihres grossen Gottes Mawu nennen. Der Fetischpriester macht nicht geringe Geschäfte mit Amuletten in Gestalt von Leopardenzähnen und Leopardenkrallen. Auf unsere Bitte sandte er uns eine Anzahl dieser Fetischembleme zum Kauf.

Die Bewohner des grossen schönen Dorfes Nyambo sind meistens Ackerbauer; daneben treiben sie auch Viehzucht, wie fast alle Evheneger und halten Ziegen und Schafe für den eigenen Bedarf. Von Nyambo aus ist ron Leutnant Wegner in schnurgerader Richtung ein direkter Pfad nach Agome-Palime angelegt worden, welcher höchstens halb so lang ist, als der Weg über Tove. Der Häuptling in Nyambo nahm uns gut auf und beschenkte uns mit grossen Kalabassen Palmwein Dieser war jedoch von geringer Güte, weil es hier zu Lande auf den Beschluss des Rates der Alten üblich ist, den Palmwein halb mit Wasser vermischt zu trinken.

Den nächsten Tag verliessen wir Nyambo und marschierten nach Norden über kleine Flüsse, die alle in den Ähä münden, am Fusse des Gebirges entlang. Ueberall sind die schmalen Ränder der Bäche mit Oelpalmen besetzt, während im Busche massenhaft Baumwollsträucher wild wachsen. Der Boden ist ein sandiger Lehmboden, welcher genügende Feuchtigkeit aus den kleinen Bächen und Zuflüssen des Agu-Gebirges

Fetisch Bagba.

Günstige Bodenverhältnisse ür Plantagen. 
aufnimmt. In der wasserreichen Ebene der Landschaft Nyambo und an den Hängen des Agu ist das Erdreich vortrefflich zu Plantagen geeignet. Ausser dem liberianischen Kaffee, der hauptsächlich in den Thälern anzubauen wäre, würden sich in den höher gelegenen Gegenden ganz besonders die arabischen Kaffeesorten zum Anbau eignen, während die feuchten Thäler vielleicht den Anbau von Kakaó gestatten könnten. Es würde ferner lohnend sein, hier grössere Versuche mit Kola und mit Baumwolle zu machen, deren Sträucher, wie wir gesehen haben, wild im Busch wachsen. Die Baumwolle wird auch in den Farmen von den Eingebornen angepflanzt und gedeiht neben den übrigen Pflanzen bei geringer Pflege verhältnismässig gut. Tüchtige und geschickte Arbeiter für die Plantage würden leicht zu haben sein, da sich die Leute dieser Gegenden bei den bisher gemachten Versuchen auf der Station als brauchbar und willig erwiesen haben. Durch Versuche mit Gummibäumen würde sich die Rentabilität dieser Plantagen vielleicht noch steigern lassen. Die nahe gelegenen Faktoreien von Palime, sowie die Station von Misahöhe würden für die weissen Pflanzer bei ihren Unternehmungen von grossem Nutzen sein. Natürlich können solche Anlagen nur dann von Erfolg gekrönt sein, wenn damit wirkliche Fachleute, die lange als Pflanzer in den Tropen gearbeitet haben, betraut werden.

Im Osten und Süden des AguGebirges.

Wir verlassen nun die Landschaft Nyambo und wenden uns in nordwestlicher Richtung nach Vhegbe. Der Weg ist mit Geröll bedeckt und vielfach zerklüftet von den grossen Wasserrinnen, die in der Regenzeit hier herabkommen. Die Vegetation wird dürftiger; an Stelle der grossen schönen Farmen treten weite Flächen, die meistens Busch aufweisen und spärlich bebaut sind. In Vhegbe übersieht man die grosse Ebene des Sio und den nordwestlichen Haupthöhenzug des sogenannten AgomeGebirges, der in der Landschaft Gbele unserem Auge entschwindet. Nach Osten ist die Sio-Ebene von kleinen Bergketten begrenzt. Der Weg führt über Vhegbe nach Akplolo, einem grossen Dorfe. So spärlich der nördliche Teil des Agu von Wasserrinnen durchzogen ist, so wasserreich ist der Osten und Süden dieses Gebirgsstockes. Wir betreten zunächst das Thal des Sio und weiterhin das des Ave, eines linken Nebenflüsschens des Sio, welcher einen kleinen vorgelagerten Gebirgsstock, den Didodemeberg von dem Hauptgebirgsstock des Agu trennt. Hier wird die Vegetation wiederum uppig; grosse Palmenwälder umgeben den Bach; nach einem schönen Marsch durch die Vorhöhen gelangen wir zu dem in einem grossen Palmenhain liegenden Dorfé Akplolo. Von hier aus marschieren wir auf schmalem Pfade durch einen fast undurchdringlichen Urwald zu dem Sio, um diesen in Augenschein zu nehmen und uns durch ein Bad zu stärken. Der Sio besitzt hier eine ungefähre Breite von ro $\mathrm{m}$ und hat ein schönes klares Wasser, 
welches murmelnd über die grossen erratischen Felsblöcke dahin fliesst. Fast das ganze Bett in diesem Teile des Sio besteht aus Gestein, welches häufig tief zerklüftet ist und terrassenförmig nach Süden zu abnimmt.

Da das Wasser sehr niedrig war und die grossen Felsblöcke aus demselben herausragten, so wurde auf einem solchen mitten im Flüsschen ein frugales Frühstück eingenommen, was uns nach dem Bade und dem anstrengenden Marsche nicht wenig mundete. Durch den dichten Urwald ging es wieder zurück nach Akplolo und von hier aus in südlicher Richtung weiter nach Aguibo, wo wir übernachteten, um am nächsten Tage unseren Marsch nach Gadja fortzusetzen. Ueberall merkte man in diesen Orten die Abgeschlossenheit und den nur spärlichen Verkehr auf den Pfaden. Aufdringlich scharten sich in den Ortschaften die Leute um unsere kleine Karawane, um ihre Neugierde zu befriedigen. Trotz der Weberei und Spinnerei, welche hier betrieben wird, ist die Bekleidung sowohl des weiblichen als auch des männlichen Geschlechts des Tags über bei der Arbeit eine dürftige. In der Morgenkühle erschienen die Leute in ein selbst gewebtes Tuch eingehüllt, um den Abzug der Karawane zu sehen. Massenhaft waren, besonders in den östlich gelegenen Dörfern, die Kokospalmen vertreten, so dass wir uns und unseren Leuten mit den reifen Früchten einen langentbehrten Genuss verschaffen konnten. In den Dörfern sah man viele Hutten, deren Wände nur aus einem Gerüst von Palmzweigen bestanden; auch fand man häufig grosse, auf Stützen ruhende Grasdächer, die in Ermangelung grösserer Bäume den nötigen Schatten gewährten Schwärme wilder Tauben bevölkerten die Wipfel der Bäume. So marschierte ich mit den beiden genannten Herren bis nach Gadja, wo ich mich von ihnen trennte und meinen Warsch nach Süden zu, nach Gbin, der grossen Ebene des Gbinflusses weiter fortsetzte. Der Weg führte durch einen dichten Busch, in dem $z u$ beiden Seiten die Farmen ron Gadja lagen; im Rücken hatten wir den Agu, der uns noch mit seiner höchsten Spitze, der BaumannSpitze, die nach dem verdienten Forscher ihren Namen erhalten hat, grüsste. Der Busch wurde höher und wir gelangten in den breiten Galeriewald des Gbinflusses. Tief eingerissen windet sich das Bett des Flusses durch diesen dichten Urwald, ab und zu erhält er kleinere Zuflüsse von Westen her, die alle aus den Vorbergen des grossen Gebirgszuges heraustreten. Alle diese Bäche, wie der Gbin selbst, waren total ausgetrocknet, so dass ich glaubte, an einer Schlucht und nicht an dem Bette des bei der Regenzeit so mächtigen Flusse. angelange zu sein. Allerdings lernte ich den oberen Fluswiauf auf meiner letzten Reise, Ende des Jahres 1897 , kennen, wo nach mehreren verhältnismässig trockenen Jahren grosse Wassersnot im ganzen Lande 
herrschte. Ich überschritt das vollkommen ausgetrocknete Bett des Flusses zweimal und erreichte so zuerst die Farmen von Gbin, sodann den Ort selbst, wo ich mich in dem uns wohlbekannten Wegehause wieder häuslich niederliess. Auf dem ganzen Wege von Gadja bis Gbin ist auch nicht ein Dorf oder eine grössere Niederlassung anzutreften.

\section{IM NORDWESTLICHEN EVHE-GEBIET.}

\section{REISE NACH KPANDO.}

Ueber- Kpando habe ich sowohl.im. Festschmuck als auch im alltäglichen schreiten des Leben bei grösseren und kleineren Expeditionen näher kennen gelernt. Gebirges. Die Strasse nach Kpando führt nordwestlich über das Agome-Gebirge in das Thal des Volta. Der Weg, der von der Station angelegt ist, führt in Windungen in der grossen Schlucht des Ähä bis auf den FrançoisPass. Zu beiden Seiten des Weges ziehen sich die 700 bis $800 \mathrm{~m}$ hohen Bergzüge entlang und ziemlich steil fällt die tiefe Schlucht ab, die hier der Ähä bildet. Ein dichter Laubwald bedeckt die Höhen und in grossen Kehren führt der ziemlich breit angelegte Weg trotz der Steigung verhältnismässig bequem auf den Pass. Eine lange Holzrinne leitet das Quellwasser bergab. Vor dem Wanderer türmen sich die steilen Höhen auf, hinter ihm entfaltet sich ein herrliches Landschaftsbild. Von den einzelnen Absätzen, die den Weg unterbrechen, hat er Gelegenheit, einen Rückblick ins Thal zu werfen und von den Bergen von Agome Abschied zu nehmen. In einer Höhe von fast $600 \mathrm{~m}$ liegt die grosse Schlucht des Ähä vor ihm, die nach Süden hin den Gebirgsstock teilt; zu seinen Füssen blinken ab und zu die winzigen Häuser der Station und weithin ziehen sich die Bergketten, bis sie allmählich in das weite Thal übergehen. In zauberhafter Ferne erglänzt der Agu und belebt mit seinen hohen Gipfeln die weite Ebene, welche den Horizont abschliesst. Plötzlich öffnen sich die Berge nach Norden hin und wir befinden uns auf dem kleinen Plateau des Passes. An den nördlichen Abhängen liegen noch kleine Hütten, in denen die Handwerker der Station wohnen. Wir berühren hier die hördliche und südliche Wasserscheide und verlassen somit die Thäler des Ähä; vor uns nehmen die Quellen des Tii oder Kolli ihren Lauf zur Ebene und durchschneiden in tiefen Schluchten die Gebirgsketten in fast nördlicher Richtung. 
Der Hauptgebirgszug im Süden wäre nun überschritten. Schroff fält die Kette nach Norden ab, bis sie sanft in das kleine Thal des Tii ubergeht, im Norden von einem Höhenzuge begrenzt, den der Bach in einer tiefen Schlucht durchbricht. Mässig senkt sich vom FrançoisPass aus die grosse Strasse nach dem Thal des Tii-Baches und fuhrt an diesem weiter entlang. Schöne Bäume und dichter Laubwald umgeben den kleinen Bach; die Gewässer plätschern murmelnd über das steinige Bett, grosse erratische Blöcke hemmen seinen Lauf und kleine Katarakte bilden mannigfache Strudel. Die Bergketten zu beiden Seiten werden höher; grosse Odumbäume beschatten den Pfad, alte vermorschte Stämme liegen quer über dem Bach und immer tiefer schneidet er sich, mühsam vorwärts dringend, in die unterhöhlten Ufer cin, die von den Wurzeln grosser Bäume durchzogen sind. Der Pfad fuhrt in gerader Richtung an den Abhängen der Schlucht hinauf. Nachdem man auf etlichen Brücken die kleinen Bäche passiert hat, erklimmt man wieder mit Mühe die letzte Höhe des Kammes. Vor uns öffnet sich das breite Thal des Kolli und seiner Zuflüsse, die einen Kessel bilden. Westlich rahmen die Höhen Amedjorhe mit ihren schroffen Felsen diesen Thalkessel ein, während ihn nach Norden hin das Kame-Gebirge abschliesst. Auf dem steilen zickzackförmigen Wege geht es in das Thal hinab, in welchem malerisch, dicht am Bache mitten in einem Hain von Kokospalmen das Dorf Tongbe liegt.

Durch das hellgrüne Laub der Palmen schimmern die von dem Rauch und der Witterung geschwärzten Dächer der Hütten dieser Bergbewohner. Grosse Farmen von Mais und Yams umgeben das Dorf und ziehen sich an den Hängen empor. Ausgedehnte Reisfelder heben sich hell von den dunkelgrunen Matten ab. Dies sind die ersten Reisfelder, die mir an Gebirgslehnen in einer Höhe von $400 \mathrm{~m}$ begegnet sind Es ist der sogenannte Bergreis, welcher diese Höhenlage verträgt und im Gegensatz zu dem Sumpfreis die Gebirgsregionen liebt Eine grosse, schön gezimmerte Brücke, die von der Station hergestellt ist, führt über den $\mathrm{x} 8$ bis $20 \mathrm{~m}$ breiten Kolli $z u$ dem vorher genannten Dorfe. Auf dem Marktplatz, den grosse Kokosnussbäume beschatten, machen wir Halt. Die grossen Palmen sind von unzähligen kleinen grünlichgelben Webervögeln belebt, welche emsig bei munterem Gezwitscher an ihren schönen und kunstvollen Wohnungen bauen. Friedlich und zutraulich wie bei uns die Schwalben, leben diese Vögelchen mitten in dem Dorfe und lassen sich nicht durch das Geräusch der ankommenden Karawanen stören. Zierlich sind die kunstvollen Nestchen mit einem seitlichen Eingange gebaut. Eins hängt neben dem andern, kleinen Körbchen ähnlich, an den Aesten in dem 
Laub der Palmen. Tongbe stellt die Träger und Arbeiter für die Station; ausser dem Ackerbau ist hier noch die Weberei und Spinnerei zu Hause. Unsere Träger sind schnell zu ihren Verwandten geeilt, um noch einen kleinen Mundvorrat für die Reise herauszuschlagen. Erdnüsse, Bananen und geröstete Yams werden auf solchen Reisen vielfach von den Trägern mitgeführt. Die ganże Bewohnerschaft versammelt sich auf dem Marktplatz und wünscht noch diesem oder jenem Verwandten und Bekannten eine glückliche Reise und gute Heimkehr. Nachdem sich alles gestärkt hat, wird die Reise fortgesetzt und es beginnt der mühsamste Marsch, die Ueberschreitung des nördlichen überaus schroffen und rauhen Gebirgszuges.

In der letzten Zeit ist über diesen Gebirgszug von der Station aus ein Weg angelegt worden, der an den Höhen des Kollibaches entlang führt und dem Reisenden das wiederholte Passieren des Baches, sowie das Herunterklettern an den steil abfallenden Hängen ersparen soll; doch ist dieser Weg der vielen Bäume, Schlingpflanzen und massenhaften Wurzeln wegen beschwerlich und der alte Eingeborenenpfad immer noch vorzuziehen. Als ich bei meiner ersten Anwesenheit in Afrika hier reiste, existierte dieser Weg noch nicht; aber auch jetzt wird er von den Eingeborenen und Trägern noch fast garnicht benutzt und konnte ich die Leute nur mit Mühe bewegen, auf ihm zu marschieren. Obwohl er infolge der Schluchten grosse Steigungen und Senkungen aufweist, so wird er doch nach gänzlicher Fertigstellung, nach Ausrodung der Wurzeln, Schlingpflanzen und Bäume einen ganz hervorragenden Vorteil gegenüber dem alten Pfade gewähren, denn dieser ist eine der schwierigsten Passagen, welche der Reisende aus dem weiten Hinterlande zu überwinden hat, um das Gebirge zu überschreiten und zur Küste zu gelangen. Viele von den Leuten scheuen sich, die schweren Lasten über das Gebirge zu befördern und so kommt es häufig vor, dass sie es im Westen umgehen und die Produkte über Kpando und Anfóë in das englische Gebiet herunterführen. Es ist daher die Anlegung der verhältnismässig bequemen Strasse über das Gebirge ein nicht zu unterschätzender Gewinn. Der Anschluss der weiten VoltaEbene durch eine bequeme Kunststrasse über das Gebirge an die grosse Strasse zur Küste würde den Verkehr ganz erheblich steigern und neue Handelsbeziehungen in unserem Gebiet ins Leben rufen.

Wir nahmen von Tongbe aus noch den alten Weg, der quer über das Gebirge nach Kame und Leglebi und dann in der Ebene nach Kpando führt. Von Tongbe geht es auf einem schmalen ausgetretenen Pfade durch viele Mais- und Reisfarmen, die häufig von grossen schönen Bananen beschattet werden, bis man den Kolli erreicht, der hier in tiefer Schlucht die sanft ansteigende Hochebene durchschneidet und jenseits 
derselben in schroffen steilen Abhängen das felsige Gebirge zerklüftet. Erst jetzt beginnt der beschwerlichste Pfad, der bald in das tiefe Thal des Kolli, bald auf die steilen Höhen zu dem etwa $400 \mathrm{~m}$ hohen KameGebirge führt, welches dem Wanderer einen wildromantischen Anblick gewährt. Ein schöner Urwald beschattet unsern Weg; überali findet man eine Art wildwachsender Mangopflaumenbäume, deren abgefallene gelbe Früchte auf dem Boden liegen und den Wanderer zum Essen einladen. Dieselben besitzen einen terpentinartigen Geschmack und werden gern von den Eingeborenen zum Löschen des Durstes genossen. Unten im Grunde murmelt der Tiibach, den man fünfmal zu überschreiten hat. Steil führt der Weg über Felsblöcke und Geröll den Bach hinunter, welcher den Reisenden öfter zu einem unfreiwilligen kalten Bade zwingt. So geht es eine Weile über grosse Felsblöcke an dem Bache entlang, der sich durch die Felsen hindurchzwängt, oft kleine Wasserfälle bildend; dann plötzlich muss man wieder 300 bis $400 \mathrm{~m}$ steil aufwärts, um nach wenigen Minuten nochmals in das Thal des Baches herabzusteigen. Grosse Felsblöcke und Wurzeln erschweren den Marsch und mühsam gleitet der Träger mit seiner schweren Last, welche jeden Augenblick herunter zu fallen droht, den steilen Pfad herab. Oftmals sind meterhohe Felsen zu übersteigen und mit Anstrengung kämpft man sich an den Wurzeln und Aesten der Bäume vorbei in dem ausgetretenen Pfade vorwärts. In der Trockenzeit fliessen die Bäche nur spärlich; in der Regenzeit dagegen ist ihre Ueberschreitung nicht gefahrlos. Die reissende Strömung, welche grosse erratische Blöcke und Baumstämme mit sich führt, reicht häufig dem Wanderer bis an die Brust und nur mühsam können dann die Lasten durch das Wasser befördert werden. Nach zweistündigem Marsche auf diesem Pfade erreichen wir das Bergdorf Kame, das ganz auf der Höhe liegt; wir begrüssen es als eine Erlösung von den überstandenen Mühen. Urwüchsige, schöne und kräftig gebaute Leute empfangen den Reisenden freundlich grüssend, und bieten ihm herrliches, krystallhelles Quellwasser zum Trunke an. Das Dorf liegt einsåm und verlassen auf einem kleinen Plateau mitten zwischen hohen Bergen und Felsen, umgeben von dichtem Urwald. Kleine, viereckige Hütten ziehen sich an der Strasse entlang, an der unter schattigen Bäumen der Marktplatz mit seinen primitiven, aus alten Baumstämmen hergestellten Bänken liegt. Auch wir machen hier Rast, um nach den Strapazen und Anstrengungen des Marsches einige Zeit der Ruhe zu pflegen.

Mit der Erreichung des Dorfes Kame haben wir die grösste Schwierigkeit beim Ueberschreiten des Gebirges, welches uns von der Küste und rom Hinterlande trennt, so gut wie überwunden. Von Kame führt der Weg nach Nordwesten herunter in das grosse Thal des Danyi- 
Flusses. Dieser trennt mit seinen Nebenflüssen gewissermaassen das Lavanyo-Gebirge und die Berge von Kunya von dem Agome-Gebirge. Der Weg führt nun an den nördlichen Abhängen des Gebirges über kleine Thäler und Bergketten nach dem hart am Fusse des Gebirges gelegenen und von Vorbergen umschlossenen Bergdorf Leglebi sowie nach der Landschaft gleichen Namens. Es ist eine Berglandschaft im wahren Sinne des Wortes, denn nach Süden erstreckt sie sich mit ihren kleinen Bergdörfern weit in das Gebirge hinein. Diese Landschaft besitzt drei Orte mit dem Namen Leglebi und zwar Leglebi-Duga und Leglebi-Fiapi, an welchem uns unser Weg vorbeiführt, während das südlich gelegene Leglebi-Abesia heisst. Eingeschlossen von Bergen und Höhen macht der Ort mit den massenhaften Oelpalmen, die die Ufer der kleinen Gebirgsbäche zieren, einen äusserst freundlichen Eindruck. Leglebi ist auch der Sitz einer Aussenstation der norddeutschen Mission, welche eine von einem schwarzen Lehrer geleitete Schule hat. Die Mission entfaltet hier eine segensreiche Thätigkeit, die Schule ist äusserst gut besucht und viele Familien sind bereits zum Christentum übergetreten. Ueberall wo diese norddeutsche Mission sich niedergelassen hat, hat auch das Handwerk seinen Einzug gehalten. Wir finden hier Tischler, die von der Mission herangebildet sind und auf der Missionsstation sowie Regierungsstation Verwendung finden. Ferner hört man überall, wie bei uns zu Hause in den Gebirgsgegenden, den Webstuhl klappern, denn neben dem Ackerbau wird in diesen Dörfern auch die Weberei betrieben. Ein grosses, schönes aus Lehm gebautes Schulhaus, welches mit Fensterläden versehen und mit einem Grasdach eingedeckt ist, ist von der Mission erbaut worden und bietet dem Reisenden eine gute Unterkunft. Die Hütten der Eingeborenen in diesen Gebirgsgegenden schienen mir alle massiver und solider gebaut zu sein als in dem Küstenlande. Sie sind zwar etwas kleiner, aber dafür reinlicher gehalten. Die Wände sind geglättet und meistens mit einer gelben Thonfarbe angestrichen, währrend die Thüröffnungen mit roter Farbe schön bemalt sind. Der Fussboden ist fest gestampft, häufig ist auch der Sockel des Gebäudes bis zu einer gewissen Höhe schwarz angestrichen. Das Dach ist gut erhàlten und fast garnicht vom Rauch geschwärzt, da die Leute meistens in dem Gehöft ihren kleinen Herd aufgebaut haben. Derselbe besteht nur aus einem runden Lehmkranz und hat an der einen. Seite eine kleine Oeffnung, durch welche das Holz zur Feuerung hineingeschoben wird.

Marsch in der Am nächsten Tage marschieren wir weiter und passieren den kleinen Danyi-Ebene. Ort Leglebi-Fiapi. Mit ihm verlassen wir die Gebirgsthäler und betreten die Ebene des gewaltigen Danyi-Flusses. Die Vorberge treten zurück und das weite Thal öffnet sich vor unseren Blicken. Wir überschreiten kleine Zuflüsse und Bäche, die vom Gebirge in die Ebene. 


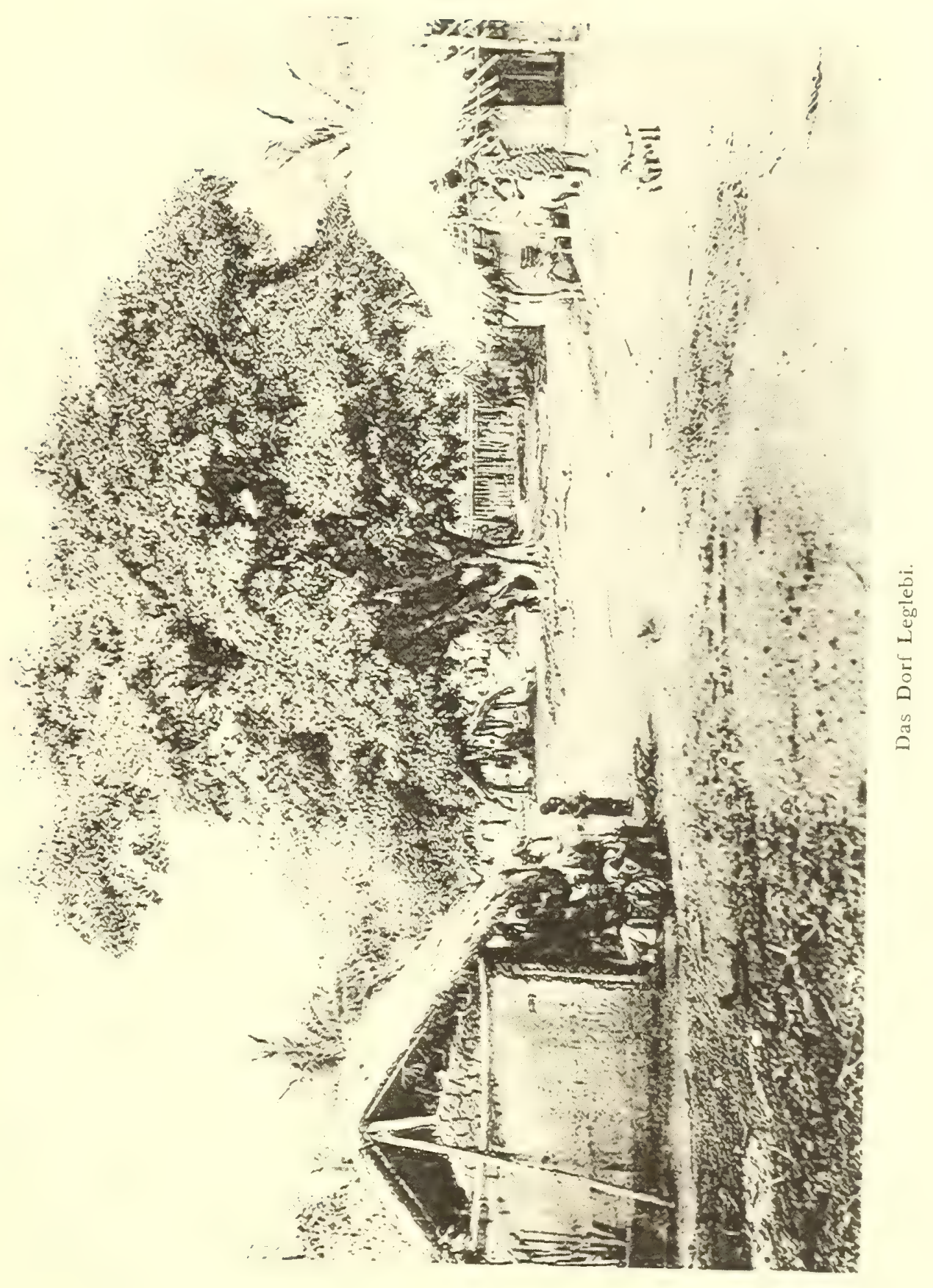



fliessen und gelangen in die Landschaft $V^{r}$ e und in den ziemlich grossen Ort Vedemme, den Sitz des Häuptlings dieser Landschaft. Crosse Zäune, die von der Mittelrippe des Oelpalmblattes hergestellt sind, umgeben die Gehöfte und überall begrenzen den Weg sowie das Dorf die grossen Yamsfarmen der Bewohner dieser Ortschaften. So freundlich einem in Leglebi die Leute begegneten, so scheu und ablehnend wird man hier empfangen. In weitem Kreise umstanden uns die Leute; der Häuptling, der grosse Macht besitzt, war ein alter Mann, der immer Palaver vorzutragen hatte und stets in Fehde mit den angrenzenden Häuptlingen stand.

Hier soll auch ein Hauptherd des berüchtigten heidnischen YeweOrdens sein. Es war der Grossvater des Evangelisten Stephan, Hiob Yewe-Orden Kuadzo, der in Ve den Yewekultus einführte und diesen Ort im Norden des Gebirges zu einem Hauptstützpunkt des verbrecherischen heidnischen Ordens machte. Seinem Enkel, der selbst Priester des Ordens war, später aber in der norddeutschen Mission erzogen worden und zum Christentum übergetreten ist, verdanken wir eine Schrift, welche das abscheuliche Treiben dieses, dem Christentum und der Zivilisation so gefährlichen Ordens aufdeckte und uns einige Kenntnis von dem Kultus desselben verschaffte. Auch die von einigen Missionaren auf Grund der Angaben des Kuadzo angestellten Nachforschungen blieben nicht erfolglos und drangen noch tiefer in die Geheimnisse dieser Ordensgesellschaft ein. Das Verdienst jedoch, alle diese Schriften gesammelt, handlich zusammengestellt und erläutert zu haben, gebührt H. Seidel, der unsere Togolitteratur schon durch so manche Schrift bereichert hat. Nach seinen Ausführungen soll dieser Orden aus dem nahe gelegenen Dahome-Gebiet stammen und sich schnell an der Küste entlang über Klein-Popo und Lome und weiter bis zur Kitta-Lagune und darüber hinaus nach Westen verbreitet haben. Nach Norden hin soll er über das ganze untere und mittlere Siogebiet sowie hinauf bis nach Atakpame ausgedehnt sein. Auch hat er Keve sowie Tove in sein Gebiet gezogen und sich sogar bis hier nach Ve verpflanzt. Aus den Angaben des Kuadzo, aus der Schrift Seidels und aus den Mitteilungen der Missionare Härtter, Spieth und des verstorbenen Pater Hoffmann entnehmen wir Folgendes über den Kultus des heidnischen Yewe-Ordens. Yewe bedeutet nach Kuadzo nichts anderes, als Ayewe, d. h. "Schlauheitsgraben", weil, wie Kuadzo erklärt, der Yewe-Orden einem künstlich lockenden Graben gleicht. Der Yewe-Kultus besteht aus mehreren Fetischen, die ihre bestimmten Funktionen haben, die sich jedoch alle wiederum in der Yewe-Gottheit vereinigen. Eine dieser Gottheiten ist Xebieso oder kurzweg So, der Blitzgott, der die Blitze auf die Erde herunterschleudert in Gestalt von runden oder axtförmigen Steinen, welche die Sosteine, d. h. die Steine 
des Gottes Xebieso oder So, genannt werden. Diese Steine sollen nach dem Glauben der Leute die bösen Menschen töten. Ein ähnlicher Aberglauben herrscht auch bei uns auf dem Lande, wo die sogenannten Donnerkeile irrtümlicherweise für Meteore gehalten werden. Diese kleinen Sosteine, die meistens eine runde Form haben und in der Mitte durchlöchert sind, sind wahrscheinlich weiter nichts als prähistorische Steine, die früher bei irgend einem Gewerbe benutzt worden sind. Einige vermuten, dass sie möglicherweise zur Beschwerung der Fischernetze gedient haben; andere behaupten, dass sie beim Spinnen als Spule benutzt wurden, noch andere versichern, dass sie als Schmuckgegenstände Verwendung gefunden haben. Trotz aller Nachforschungen herrscht bis jetzt über die frühere Verwendung dieser Steine ein völliges Dunkel. Durch Zufall bin ich in den Besitz einiger Exemplare gelangt. Eines Tages bemerkte ich vor der Thür meines Hauses in Misahöhe einige Steine, deren Form mir auffiel; ich hob sie auf und stellte Nachforschungen über sie an, die jedoch vollkommen resultatlos blieben. Erst später erfuhr ich von meinem kleinen Diener Meppo, dass sein Vater ihm solche Steine gezeigt und ihm gesagt habe, dass dieselben vom Himmel fielen und böse Menschen töteten. Ich nahm die sagenhaften Steine mit und übergab sie später dem Museum für Völkerkunde, wo sie heute ausgestellt sind. Der Blitzgott bestraft mit seinen Blitzen die Abtrünnigen oder die durch Uebertretungen schuldigen Menschen; er zerstört die Wohnungen derselben und zerschmettert die grössten Bäume des Waldes. Da der Orden von der Küste ausgegangen ist, werden natürlich auch Gottheiten verehrt, welche über die Tierwelt des gewaltigen Meeres herrschen. Eine solche Gottheit ist, seinem Abzeichen, einem Seetiere, nach, der Gott Agbui. Ein dritter Untergott, der eine giftige Schlange als Abzeichen führt, heisst Voduda. Er soll aber nicht identisch sein mit dem grossen Schlangengott Danhgbi, dem nur ungiftige Reptilien heilig sind. Dieser Schlangenkult, der hauptsächlich aus Dahome in unser Gebiet herübergekommen ist, äussert sich auch in der Ornamentik und den Skulpturen, namentlich an den Schnitzarbeiten an der Küste. So sind die geschnitzten Häuptlingsstöcke häufig mit Schlangen gekrönt; auch die Füsse der Stühle sowie die Kalabassen sind mit Schlangenverzierungen geschmückt. Ferner wird noch ein Fetischgott Aw'leketi verehrt, der ebenfalls als Meeresgott bezeichnet wird und dem als solchem das Zeichen eines Hais beigegeben ist. Ausser den hier angeführten Gottheiten sollen noch mehrere Fetischgötter existieren, die sämtlich den grossen heidnischen Yewegott unterstützen.

Die Priester, welche den Verkehr der gewöhnlichen Sterblichen mit dem Yewegott vermitteln, besitzen eine ansehnliche Macht. Ihnen allen ist ein Oberpriester überstellt, der in der Yewesprache den Namen Hubono führt und den die Yewemänner, die Husunuo, sowie die Yewe- 
frauen oder Wodusio untergeordnet sind. Ferner unterstehen ihm die Geheimmitglieder, die Hundeo oder Spione, welche die Verleumder und Verräter der Gemeinde aufzuspüren und neue Mitglieder durch List oder Tücke heranzuziehen haben. Ihnen liegt auch der Bau neuer Hütten, sowie die Instandhaltung derselben für die Klöster des Ordens ob. Sie bilden den untersten Grad dieser Mitgliederschaft und gehören eigentlich zur Gemeinde. Hundeo, welches der Plural ist, wird im Singular mit Hundé ausgedrückt. Alle die Priester und Mitglieder dieses Oŕdens verständigen sich in einer gewissen Geheimsprache, die Nichteingeweihten vollkommen unbekannt ist. Die Weiber dieses Ordens werden in drei Klassen eingeteilt, je nach den Untergottheiten, denen sie dienen und zwar in Soweiber, welche den Blitzgott So, in Agbuiweiber, die den Gott Agbui und in Vodudaweiber, welche den Gott Voduda speziell verehren. In dem Yewegehöft wohnen die verschiedenen Klassen der Weiber in getrennten Hütten; jede dieser Klassen besitzt eine besondere Geheimsprache, die aber einander sehr ähnlich sind und von denen die leichteste die Agbuisprache ist. Letztere ist somit auch die allgemeine Verkehrssprache der Yewe-Mitglieder.

Der Eintritt eines neuen Mitgliedes in den Yeweorden wird unter gewissen Zeremonieen vollzogen. Der Betreffende geht zu dem Oberpriester und teilt ihm seinen Wunsch mit, in den Orden aufgenommen zu werden. Bevor er von dem Oberpriester angenommen wird, muss er sich verpflichten, mit Leib und Seele dem Orden zu dienen, für den grossen Gott Yewe Hütten zu bauen, sowie auch neue Mitglieder für denselben anzuwerben. Er muss ferner geloben, nie etwas von den Zeremonieen oder dem Kultus des Yewe-Ordens an Nichtmitglieder zu verraten, da er sonst fon dem grossen Gott Yewe getötet wird. Das neu eintretende Mitglied wird alsdann in die Geheimnisse des Yeweordens eingeweiht. Es werden ihm ein mit Leinwand umhülltes Eisen, das den Yewe bedeuten soll, ferner eine zweischneidige Axt, die Axt des So, ein Widderhorn, ein schlangenförmig gewundenes Eisen, wahrscheinlich das Abzeichen des Fetischgottes Vodudu, ein durchlöcherter Stein des Blitzgottes So und endlich ein länglicher Stein, welcher die Axt des grossen allmächtigen Gottes Yewe vorstellen soll, rorgezeigt. Der Priester taucht diese Geräte in geweihtes Wasser und fährt mit dem Stein des grossen Blitzgottes So über den Rücken des Novizen. Der Priester warnt ihn dabei, irgend ein Geheimnis des Ordens zu verraten oder demselben abtrünnig zu werden, sonst würde der grosse Gotte Yewe ihn durch den Blitzstein in zwei Hälften zf-spalten. Ferner wird ihm das Widderhorn gezeigt und er wird darauf hingewiesen, dass er von einem Widder getötet werden wird, wenn er dem Yewe abtrünnig werden sollte. Weiter wird dem Novizen noch 
ein zungenförmiger Stein vorgeführt, wobei man ihm droht, dass ihm, wenn er dem Yewe untreu wird, bei Donner und Blitz die Zunge aus dem Munde treten und er elendiglich sterben wird. Ferner wird ihm noch die gewundene eiserne Schlange gezeigt, welche wahrscheinlich das Attribut des Fetischgottes Vodudu oder des Meergottes Aw'lekete bildet, deren Zusammengehörigkeit noch zweifelhaft ist. Man umkreist nun mehrmals den Novizen und der Priester sagt ihm feierlich, dass ihn, wenn er irgend etwas verrät, das Wasser bei Regen umgeben und er darin ertrinken wird. Um den armen Neuling noch mehr einzuschüchtern, werden ihm die Augen verbunden und zum Schluss wird noch ein ganz tolles Experiment mit ihm vorgenommen. Es wird ihm Pulver auf das Knie gestreut und dieses plötzlich entzündet, wobei ihm der Priester zuruft, dass ihn Yewe auf diese Weise töten würde, falls er sich des Verrates an dem Orden schuldig machen sollte. Nach diesen Zermonieen, die das Vorspiel bilden, wird der Novize durch den Yewetrank gewissermaassen für die Aufnahme in den Orden würdig gemacht. Es wird ihm eine Kalabasse mit geweihtem Wasser gereicht, die er austrinken muss. Dadurch zieht nach dem Glauben der Leute der Gott Yewe in den Körper des neuen Mitgliedes ein. Alsdann erhält er seinen neuen Yewenamen. Der ehemalige Name des Betreffenden darf nicht mehr genannt werden, weil sonst dieses Yewemitglied „verwildert", worauf ich später noch zurückkommen werde. Das neue Mitglied wird nun mit den Pflichten und Geboten des Ordens bekannt gemacht, nach welchen er sich des Genusses einiger Fische, wie Karpfen, Welse und des Schweinefleisches enthalten muss; auch ist es ihm verboten, eine gewisse Krebsart, sowie ein bestimmtes Gemüse und das abfliessende Regenwasser zu geniessen. Ferner darf er bei Todesstrafe keine Steine auf dem Kopfe tragen, da der grosse Gott Yewe selbst in der Gestalt eines Steines gedacht wird. Endlich wird dem neuen Mitglied aufgetragen, unter allen Umständen Mitglieder des Ordens in jeder Weise zu unterstützen, auch jede ihm zu Ohren kommende Unternehmung oder Rede, die von Fremden gegen den Orden oder den Yewe geplant oder geführt wird, sofort dem Oberpriester zu melden.

Das zügellose Leben und der freie Verkehr zwischen den Yewemännern und -Weibern bei Festlichkeiten lockt alljährlich viele zum Eintritt in den Orden. Auch ist der Yeweorden eine Freistätte für Mörder, welche die Blutrache der Verwandten des Ermordeten fürchten und ihr so zu entgehen suchen. Weiter suchen bedrängte Schuldner häufig $\mathrm{Zu}$ flucht in dem Yeweorden, um auf diese bequeme Weise ihre Gläubiger los zu werden. Nach dem Glauben und den Lehren der Priester werden die Leute von dem grossen Yewegott selbst in den Orden geleitet und sind infolgedessen unantastbar. Häufig suchen die Yeweweiber oder 
Männer Streit mit einem Lneingeweihten anzufangen und clieser tritt clann aus Furcht vor der Strafe und dem langwierigen Prozess, der ihm von den Yewepriestern gemacht wird, in den Orden ein. Bisweilen wird auch ein Mädchen, welches einem sogenannten "Hundé" in die Arme läuft, unter den Vorspiegelungen von dem schönen und freien Leben in dem Orden zum Eintritt bewogen. Man lockt sie bei Nacht in das Yewegehöft und nimmt sie unter den vorher erwähnten Zeremonieen in den Orden auf. Das Mädchen wird hierauf wieder entlassen und es wird ihm, um den Schein zu erwecken, als ob es der Yewegott selbst in das Gehöft des Fetischplatzes geführt hätte, aufgetragen, mit lautem Geschrei wie besessen aus dem Hause seiner Eltern zu laufen, sich vor dem Eingang des Gehöftes niederzuwerfen und tot zu stellen. Es wird ihm dabei gesagt, dass es, falls es diesen Rat nicht befolge, sterben müsse. Auch Frauen, welche mit ihrem Manne in Unfrieden leben und diesen gern los sein möchten, sowie Leute, denen wegen irgend eines Vergehens ein darauf hindeutender Name beigelegt worden ist und welche sich davon befreien wollen, treten in den Orden ein. Mitunter werden sogar Mädchen mit Gewalt von den Yewemännern in das Kloster geschleppt und dort ror den Verwandten versteckt. Die Eltern rennen dann in ihrer Angst nach dem Yewegehöft, um Auskunft über ihr Kind zu erhalten. Nach einem Tribut von zwei Flaschen Gin und einer Anzahl Kauris, gewöhnlich sieben Strings im Werte von sieben Pfennigen, sowie eines Quantums Maismehls wird den Eltern mitgeteilt, dass Yewe, der Fetischgott, das Kind in seinen Schutz genommen und hierher geführt habe. Ferner werden noch zwei weisse und zwei schwarze Hühner, sowie sechs Flaschen Gin als besondere Opfergabe beansprucht. Das Blut eines weissen Huhnes wird sodann auf den Kopf des Mädchens gegossen, das damit als Yeweweib in den Orden aufgenommen ist. Die Aufnahme wird sieben Tage lang durch ein Fest bei Trommelschlag und Tanz gefeiert. Die neuaufgenommene Vodusio wird am ganzen Körper rasiert und muss darauf ein kaltes Bad nehmen, nach welchem sie mit Oel eingesalbt wird. Ferner erhält sie von dem Priester ein weisses Stück Zeug, welches sie um die Lenden schlingt, das jedoch in Ermangelung eines solchen auch durch ein Bananenblatt ersetzt werden kann; auch wird ihr zum Zeichen ihres Grades ein we'isser Faden um den Hals gebunden. Nach dieser feierlichen Zeremonie erhält das betreffende Mädchen ihren Yewenamen, den sie von nun an ausschliesslich zu führen hat. Dle Eltern des Mädchens haben nun einen abermaligen Tribut an Kauris an den Oberpriester zu zahlen und müssen für das Kind sechs Monate hindurch das Essen liefern, da während dieser Zeit dasselbe in die Geheimnisse des Ordens eingeführt wird und das Yewegehöft nicht verlassen darf. Innerhalb dieser Zeit lernt es die Yewesprache, ferner die Bereitung einiger Gifte sowie 
Tanz und Gesang, und darf mit keinem Uneingeweihten, auch nicht mit irgend einem Angehörigen seiner Familie sprechen. Mädchen, welche sich trotzdem weigern in den Orden einzutreten und jeglicher Versuchung widerstehen, sollen nach der Angabe unseres Gewährsmannes Kuadzo von den Mitgliedern getötet werden und es heisst dann, dass sie Yewe selber getötet habe. Verheiratete Frauen, die in den Orden eintreten, brauchen auf ihren Wunsch nur mit ihren Männern zu verkehren und falls diese den Verkehr verlangen, müssen sie einen gewissen Tribut an den Oberpriester entrichten und auch selbst in den Orden eintreten. Die Kinder, die in dem Fetischhause geboren werden, gehören ebenfalls dem Orden an. So wie der Eintritt eines Mädchens in den Orden gefeiert wurde, so wird auch nach sechs Monaten die Beendigung der Lehrzeit gefeiert. Es wird ein grosses Fest, an dem fast das ganze Dorf Teil nimmt, von den Mitgliedern des Ordens veranstaltet, wobei die Verwandten und Angehörigen des Mädchens die ganzen Kosten zu tragen und für den nötigen Branntwein sowie für die Speisen Sorge zu tragen haben. Bis zu dem Feste haben die Eltern ihr Kind nicht wiedergesehen. Erst am folgenden Tage wird ihnen dasselbe vorgeführt, nachdem sie noch einen abermaligen Tribut von I 2 M. und einer Ziege an den Oberpriester abgeliefert haben. Bevor dies jedoch geschieht, bestreicht, wie der Missionar Spieth berichtet, der Priester den Scheitel des Mädchens mit dem Blute eines zum Opfer dargebrachten Huhnes; alsdann werden ihr nochmals die Gebote des Ordens eingeprägt und neue, von den Eltern übersandte Kleider angelegt. Nun erst wird es seinen Eltern und Verwandten vorgestellt. Erst am siebenten Tage darauf wird das Mädchen von einigen Mitgliedern des Ordens in das - elterliche Haus zurückgebracht, wo es vier Monate hindurch kein Evhe sprechen darf. Acht Tage nach dieser Frist macht die Yewedienerin ihre Besuche bei den Mitgliedern der Familie. Ueberall grüsst sie unter Kniefall in der Geheimsprache, worauf ihr von den Verwandten einige Kauris geschenkt werden, welche sie nach der Klosterregel dreimal abzuweisen und erst beim vierten Mal anzunehmen hat. Der Verwandte besprengt dann das Mädchen mit dem mitgebrachten, von dem YeweOrden geweihten Wasser, indem er dabei sagt, dass es jetzt eine YewePriesterin geworden sei und dass Yewe es mit toten Ohren hören möge, falls er irrtümlich seinen alten Namen rufen sollte.

Das Ver- Wird ein Yewe-Mitglied von irgend einem Unbeteiligten beschimpft wildern von oder bei seinem alten Namen gerufen, so ist dies eins der besten Mittel, Yewe- dem Orden einen neuen Verdienst zukommen zu lassen. Das betreffende Mitgliedera. Mitglied „verwildert" angeblich und man nennt ein solches in der Yewesprache eine Alaga, d. h. eine Rasende. Eine solche Alaga wird scheinbar rasend, läuft wie besessen umher, demoliert die Zäune und Dächer 
der Hütten und zerschlägt die Töpfe oder sonstigen Gebrauchsgegenstände ihres Beleidigers. Dann läuft sie schreiend und rasend in den Busch und nach dem Glauben der Leute, welcher durch die Machinationen des Ordens peinlich erhalten und verbreitet wird, soll eine solche Alaga oder Verwilderte, falls sie nicht bald wieder heimgebracht wird, sich in einen Leoparden verwandeln. Der Beleidiger und die Angehörigen der betreffenden Alaga laufen nun, von Schrecken und Angst erfullt, zu dem Oberpriester und bitten ihn um seinen Beistand, damit die betreffende Verwilderte wieder zurückkehrt. Der Beleidiger wird in einem offenen Palaver zur Sühne für die zugefügte Beleidigung zu einer Geldstrafe, sowie zur Hergabe von Leinen und Zeugen, häufig bis zu einem Werte von 240 M. verurteilt. Oft muss ein Mann, der von diesem Richterspruch betroffen wird, seine eigenen Kinder verpfänden oder verkaufen, um seinen Peinigern, die ihm mit dem Tode drohen, zu entgehen. Mitunter geschieht es auch, dass ein solcher Mann es schliesslich vorzieht, selbst in den Orden einzutreten, um auf diese Weise die für ihn verhängnisvolle Angelegenheit zu beenden. Den nächsten Tag, nachdem das Opfer in den nötigen Geschenken und Geld gebracht ist, soll nun die Alaga von Priestern wieder eingeholt werden. Während des Verwilderns soll die Alaga die ganze Zeit hindurch im Busch, ohne Essen und Trinken, leben, in Wirklichkeit wird sie von ihren Kumpanen reichlich, natürlich heimlich, mit Speise und Trank versorgt und ruht auch des Nachts gemütlich in einer der Yewehütten. Vor dem Einholen der Alaga wird sie am ganzen Körper mit rotem Thon beschmiert, ihre Haare werden mit klebrigem Pflanzensaft zusammengeklebt und ein künstlicher Schwanz aus einer Schlingpflanze wird ihr angebunden; dieses verleiht der ganzen Person ein scheussliches Aussehen und erweckt bei den Leuten den Glauben, dass sie wirklich im Begriff steht, sich in einen Leoparden zu verwandeln. Unter Trommeln, Singen und dem nötigen Lärm werden am andern Tage die sämtlichen Mitglieder aufgeboten; so ziehen sie schreiend und tanzend in den Busch. um die Alaga aufzusuchen. Die Mitglieder finden sie auch bald an dem natürlich vorher verabredeten Platz, nehmen sie in ihre Nitte und unter Trommelschlag und Gesang ziehen sie wieder in das Yewegehöft zurück. Bald geht die Kunde im Dorfe, dass nach dem Aussehen der Rasenden sie wirklich bald ein Leopard geworden wäre. Die Alaga wird nun gewaschen, gereinigt und mit neuen Tüchern bekleidet. Alsdann zeigt sie sich wieder der verwunderten Menge und ein grosses Fest beschliesst den glücklichen Ausgang dieser Komödie.

Es giebt verschiedene Arten der Verwilderung. Eine Art läuft des Nachts wie ein Leopard schreiend herum, begleitet von zwei Hundeo, mit denen sie gewöhnlich ein unkeusches Leben führt. Eine andere Art lauert auf einsamen Pfaden Marktleuten auf, raubt ihnen die Waren 
an Speise und Trank, die sie zu Markte führen, und wirft, falls sie diese nicht gutwillig geben, mit Steinen nach ihnen. Da eine solche Verwilderte unantastbar ist, so macht sie ein ganz gutes Geschäft, weil die Leute lieber etwas von ihrer Ware geben als dass sie sich den Verfolgungen der Yewepriester aussetzen. Eine dritte Art hat die wenig appetitliche Beschäftigung, sich im Schmutz und Kot herumzuwälzen und fortwährend mit Geschrei den Namen ihres Beleidigers zu rufen.

Das Einholen der Besessenen wird gern mit irgend einem den Verhältnissen angepassten Wunder verbunden. Wird z. B. einem Mitgliede

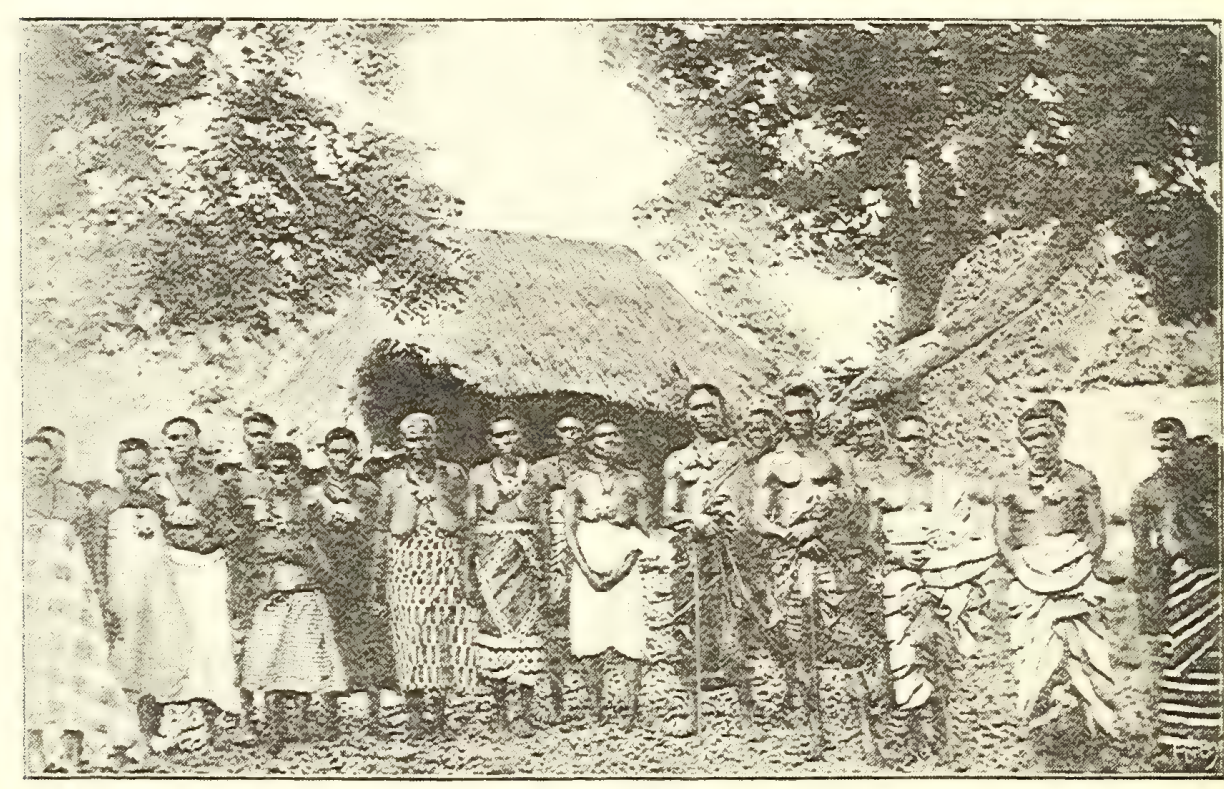

Felisch-Priesterinnen.

von irgend einem Ahe, d. h. einem Nichteingeweihten, ein nach den Ordensregeln verbotener Fisch zum Essen vorgesetzt, von welchem Verbot der Unbeteiligte meistens keine Ahnung hat, so wird derselbe zunächst natürlich beschuldigt, das betreffende Mitglied verführt und seine Verwilderung herbeigeführt zu haben. Es wird dann mit dem Verwilderten ein ganz besonderer Prozess vorgenommen. Man setzt ihm eine Suppe von der verbotenen Fischgattung vor, und giebt ihm dabei kleine Fische derselben Art, die er in der Mundhöhle vor dem Volke verbergen muss. Er kommt nun wie besessen vor die Menge und tanzt vor derselben bei Trommelschlag, um dann plötzlich einzuhalten und zum grössten Erstaunen der Menge sowohl die Suppe als auch die kleinen lebendigen Fische von sich zu geben. Natürlich wird dadurch in dem 
Volke der Glaube an den grossen Yewegott, der solche Wunder an einem seiner Diener geschehen lassen kann, gestärkt. Häufig wird aber auch dem Volke noch eine andere Vorstellung gegeben, denn dieser Orden hat hierin für Abwechselung gesorgt. Ausser der Verwilderten, die aus dem Busch geholt wird, giebt es, namentlich bei der Küstenbevölkerung, noch eine einen grösseren Eindruck machende Alaga, die in ihrer Verwilderung in das Meer gesprungen ist und auf dem Meeresgrunde ihr Wesen treibt. Die Hundeo finden unter grossem Geschrei am Strande die Schmuckgegenstände und Kleider der ins Meer gesprungenen Alaga. Ein von dem Orden bestochener Ahe wird in das Geheimnis eingeweiht und zum sofortigen Eintritt in den Orden gezwungen. Er fügt sich gewöhnlich, denn er kennt die Schrecken, die ihn treffen, wenn er irgend etwas von der Sache verrät; der Orden würde ihm entweder seine Hütte anzünden oder ihn von anderen Mitgliedern totschlagen lassen. An dem zur Auffindung der Verwilderten bestimmten Tage wird dieselbe von einem Hundé noch vor Tagesanbruch von dem Yewegehöft, wo sie inzwischen versteckt gehalten wurde, an eine einsame Stelle am Strande geführt; sie geht hier in das Meer, zur bestimmten Stunde stellt sich der gedungene Fischer ein, wirft seine Netze aus und fischt die im Wasser in gebückter Stellung versteckte Person auf. Nach dem verabredeten Zeichen erhebt er ein kolassales Geschrei und die schon benachrichtigten und harrenden Mitglieder strömen von allen Seiten herbei. Schnell hat sich in dem Orte die Kunde von dem Ereignis verbreitet, das Volk kommt an den Meeresstrand gelaufen, um sich von dem Wunder, welches Yewe aus dem Meeresgrunde hervorgezaubert hat, zu überzeugen. Die Alaga, welcher vorher die Kopfhaare abrasiert worden sind, hält dieselben in einer Kalabasse in der Hand und bestärkt so den Glauben der Leute, dass der Yewegott selbst sie in das Meer hineingezogen und ihr das Haupt rasiert habe. Man bringt nun die Alaga in feierlichem Zuge unter Trommelschlag und Tanzen der Vodusi in die Stadt und endlich wieder in das Yewegehöft zurück.

Ein anderes Mittel dient dazu, angesehene und reiche Familien zum Auffindung

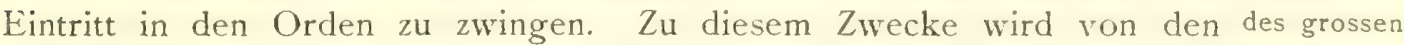
Mitgliedern des Ordens an der Stelle, wo der begehrenswerte Ahe seine Yewe-Gottes. Farm baut, ein kleiner verschlossener Topf, der die roten Schwanzfedern des grauen Papagei sowie das Kopfband einer Vodusi enthält, vergraben. Dieses nennt man den Yewe, da in dem Gefäss der grosse Gott Yewe selbst wohnen soll. Am nächsten Tage findet natürlich der nichts ahnende Farmer beim Durchgraben seines Ackers den Topf. Da die Neger, wie alle Naturvölker abergläubisch sind, lässt er vor Furcht seine Hacke fallen und läuft schnurstracks in das Dorf zurück, um seinen Angehörigen und Bekannten den sonderbaren Fund zu melden. Alsbald 
wird er von einem Mitgliede des Bundes über den Vorfall aufgeklärt und es wird ihm gesagt, dass er Yewe gefunden habe. Der nächste Oberpriester wird benachrichtigt, lässt den Finder des Topfes zu sich rufen und macht im klar, dass er von Yewe selbst ausersehen sei und zunächst ein weisses und ein schwarzes Huhn sowie Branntwein und Kauris opfern müsse, bevor er über die Bedeutung dieses Ereignisses volle Aufklärung erhalten könne. Selbstverständlich folgt der in Angst versetzte Mann dem weisen Rat des Oberpriesters und bringt den erwünschten Tribut, worauf der Priester erklärt, dass ihn Yewe selbst zu seinem Priester ausersehen habe. Der so geprellte Mann lässt sich von diesem Zauber bethören; ein grosses Fest wird von dem Oberpriester angesetzt, bei welchem feierlich bei Trommeln und Gesang das Kleinod von den sämtlichen Yewedienern und Priestern von dem Felde eingeholt, das neu aufzunehmende Mitglied in den Kultus des Ordens eingeweiht und durch den Fetischtrank zum Priester geweiht wird.

Der neue Priester baut nun auf seinem Hofe eine kleine Hütte, in welcher der erwähnte Topf seine Aufstellung findet. Er giesst dann aus einer Kalabasse Mehlwasser auf den zur Hütte führenden Weg und betet, wie uns Missionar Spieth übermittelt hat: "Yewe, Du, den ich gefunden, gieb mir Gesundheit, damit ich Dir dienen kann, " oder „damit mein Fleisch stark bleibe, dass ich Dir dienen kann“. Der so eingeweihte neue Priester hat ferner auch für ein Kloster zu sorgen, in welchem die Yeweweiber sowie die übrigen Mitglieder Unterkunft finden. Ein solches Kloster besteht aus einigen Lehmhütten, welche von einem grossen Zaun aus Palmblattrippen oder auch, je nach der Gegend, von einer Lehmmauer umgeben sind. Einige dieser Hütten sollen der Länge nach durch eine Lehmwand in zwei Räume geteilt sein; in der Mitte dieser Wand soll sich ein Hohlraum befinden, zu dem eine kleine Oeffnung führt, durch welche sich grerade ein Mensch hineinzwängen kann. Dieser Raum bietet ein geeignetes Versteck für die geraubten Mädchen oder die verwilderten Yeweweiber. In dem vorderen Raume liegen auf einem kleinen hölzernen Gerüst veschiedẻne geopferte Fetischembleme, die als Amulette verwandt werden. Die Fetischembleme bestehen aus Knochen, Kaurimuscheln oder sonstigem Plunder. Jede dieser Hütten soll noch zwei Eingänge besitzen. Ferner sind noch Fetischembleme der Gottheiten, wie die zweischneidige Axt des Blitzgottes, die Sosteine, sowie die übrigen Attribute der Gottheiten in diesem Gehöft aufgestellt. Ein Erdkegel, der den Altar vorstellt, befindet sich ebenfalls dort. Auf demselben finden die Opfer statt, wobei die Federn weisser Hühner mit ihrem Blute angeklebt werden. Nun muss sich auch der neue Priester nach Mitgliedern für das neu entstandene Kloster umsehen. Zu diesem Zwecke werden einige Hundéo oder Yewemänner beauftragt für die nötigen 
Frauen oder Vodusi zu sorgen. Bei Nacht wird dann irgend einem Mädchen in der Nähe des Dorfes aufgelauert und dieses häufig mit Sträuben in das Yewegehöft geschleppt, wo es anfangs in der vorerwähnten Höhlung in der Wand der betreffenden Hutte verborgen gehalten wird. In dem Yewegehöft wird es dann wie die vorerwähnten neu erworbenen Mitglieder behandelt. Der erste Fang einer solchen Vodusi wird durch eine siebentägige Feier festlich begangen.

Ein ähnliches Verfahren, um dem Orden neue Priester zu gewinnen, wird namentlich bei Fischern angewandt, indem man ihrem Handwerk entsprechend eine Kalabasse mit den geheiligten Attributen des Yewegottes an der Stelle ins Wasser senkt, wo der Fischer gewöhnlich seine Netze auswirft. Auf die schon geschilderte Weise wird dieser dann in das Garn des verbrecherischen Ordens gezogen.

Oefters soll es jedoch auch vorkommen, dass Leute freiwillig Priester dieses Ordens zu werden wünschen. Diese müssen die kleinen durchlöcherten Blitzsteine sammeln und in einen Topf mit Wasser legen. Der Topf wird dann verschlossen auf dem Felde vergraben. Wenn nach einiger Zeit die betreffenden Leute ihre Farm bearbeiten, stellen sie sich, als ob sie den Topf gefunden hätten. Sie machen dem Oberpriester oder Hubono von dem Funde Mitteilung und werden dann nach den üblichen Zeremonieen ebenfalls in den Orden aufgenommen.

Der Orden kann auch durch Ankauf der zur Errichtung eines neuen Klosters nötigen Attribute in andere Gegenden oder Ortschaften verpflanzt werden. Zu diesem Zweck muss der, welcher dieses Unternehmen wagt, eine Kalabasse mit Wasser mit dem darin befindlichen So-Stein und der zweischneidigen Axt des Blitzgottes Xebieso für einen verhältnismässig hohen Preis von einem Oberpriester des Yeweordens erwerben. Bei passender Gelegenheit, bei Krankheit, Seuchen, anhaltender Dürre oder sonstigen Notlagen der Gegend verkündet nun der Betreffende unter dem Volke, dass er eine Abhilfe wisse; der grosse Yewe habe zu ihm gesprochen, dass er das Uebel heben werde, wenn ein Kloster an diesem Orte erbaut würde. Das bedrängte Volk hofft, aus seiner Not befreit zu werden und geht zu der neuen Lehre über. Sò entstehen plötzlich neue Niederlassungen des heidnischen Ordens. Die alten Götzen werden bei Seite gethan und schnell verbreitet sich der neue Kult in der Gegend. Die Attribute, die zu einer solchen Gründung nötig sind, werden mit Vorliebe besonders mächtigen Orden abgekauft. So soll Anyoro in unserem deutschen Gebiet einer der bedeutendsten Verkaufsplätze dieser sonderbaren Handelsartikel sein.

Der grosse Yewegott soll auch die Macht besitzen, Tote zu erwecken und wieder auferstehen zu lassen. Aus diesem Grunde werden Personen, die auf dem Sterbebette liegen, oder solche, die bei einer

Totenerweckung durch den Yewe-Gott. 
Schlägerei verletzt worden sind, gewissermaassen zur Pílege dem Yeweorden anvertraut. Die Mitglieder suchen dann alle Mittel anzuwenden, um den Schwerkranken am Leben zu erhalten. Dem Volke und den Angehörigen wird verkündigt, dass der Mann gestorben sei und dass nur der grosse Fetischgott die Macht habe, ihn wieder ins Leben zurückzurufen. Die Verwandten kommen nun zu dem Oberpriester mit Geschenken, was natürlich der Hauptzweck des ganzen Schwindels ist, und bitten ihn, bei dem grossen Gott ein Wort einzulegen, damit dieser durch seine Gnade den Toten erwecken möge. Sobald nun der Priester den Zeitpunkt für günstig hält, lässt er durch Yeweweiber und die übrigen Mitglieder in der Stadt laut verkünden, dass Yewe den Toten wieder erwecken werde. Es sammelt sich bald eine grosse Volksmenge vor dem Gehöft des Fetischordens an; ein Toter wird herbeigebracht, der wie üblich auf einem Brette liegt und in weisse Leinwand eingewickelt ist und dessen Körper, nach dem starken Geruch zu urteilen, in Verwesung übergegangen zu sein scheint; der Tote wird von den Mitgliedern des Ordens auf den Schultern in feierlicher Prozession herumgetragen und unter Trommelschlag und Tanz der Yeweweiber bewegt sich der Zug durch die Strassen des Ortes, bis er wieder in dem Yewegehöft angelangt ist. Dieses ist das Vorspiel für das nichtsahnende Volk, das durch den Leichengeruch vollkommen von dem Tode des Mannes überzeugt ist. Thatsächlich ist die Sache nicht so tragisch, da der Leichnam nur der Kadawer eines toten und in Verwesung übergegangenen Hundes ist. Was im Gehöft selbst vorgeht, entzieht sich den Blicken der Menge, da nur die Eingeweihten und Priester das Recht haben, diese geheiligte Stätte zu betreten. Ungeduldig und harrend der Dinge, die da kommen sollen, steht das unwissende Volk vor dem Gehöft, bis endlich die angebliche Zeremonie des Oberpriesters, der die Vorbereitung fur die Auferstehung trifft, beendigt ist. Wieder erscheint der Zug mit dem Leichnam und unter Kreischen und Tanzen der Yewe-Weiber und -Männer bewegt sich derselbe nochmals durch die Strassen des Dorfes. Häufig wird der Tote um seine eigene Achse gedreht und mit demselben so lange im Kreise herumgetanzt, bis der Zug wieder in dem Gehöfte angekommen ist. Dort wird der angeblich Tote von seinen Leichentüchern befreit und erscheint wohl und munter vor der Menge, die ihn jubelnd umgiebt und nicht mehr an der Allmacht des Yewe zweifelt. Im Volke flüstert einer dem andern ins Ohr: Wahrhaftig, Yewe ist der grösste Gott. Auf diese und ähnliche Weise wird das arme Volk bethört und von dem heidnischen Orden auf Abwege geführt. Selbst wenn ein Mitglied der Sache überdrüssig ist und den ganzen Betrug durchschaut, so muss es ihn doch mitmachen, da es weiss, dass ihm der Austritt aus dem Orden sein eigenes Leben sowie möglicherweise auch das seiner Familie kosten würde. 
Ueber Abtrünnige oder Verräter wird von dem Orden die Todesstrafe verhängt. Der Verräter wird von einem angeblichen Freunde des Nachts in den Busch gelockt und dort oder an irgend einer abgelegenen Stelle auf dem Felde von den Mitgliedern des Yeweordens erbarmungslos totgeschlagen. Die Leiche wird dann häufig an einem Baum aufgebahrt und mit weisser Leinwand bedeckt. Am nächsten Morgen verkünden schreiend alle Yewe-Weiber, dass Yewe die gerechte Strafe an einem Manne vollzogen hat, weicher Schlechtes ron ihm geredet und sich gegen ihn aufgelehnt habe. Die Leute strömen herbei und sind von Schrecken erfullt uiber das Gericht, welches der Yewegott über den Verräter gehalten hat. Auch werden Abtrünnige durch Gift in das Jenseits befördert. Hat der Orden aber nicht die Absicht, den Tod des Schuldigen herbeizuführen oder kann er ihm mit diesen Mordmitteln nicht zu Leibe gehen, so sucht er ihn an seinem Gut zu schädigen. Es werden z. B. bei einem Gewitter die leicht entzündlichen Grasdächer seiner Hütte von den Mit. gliedern des Ordens in Brand gesteckt; sofort laufen alsdann alle YeweWeiber und -Männer im Dorfe umher und verkünden schreiend, dass Yewe durch den Blitzgott Xebieso So-Steine und feurige Blitze vom Himmel heruntergesandt und die Dächer entzündet habe. Jeder, der diesem Brande Einhalt thun wollte, würde sich gegen die Maassnahmen des grossen Gottes vergehen. Natürlich hütet man sich davor und so geht denn das ganze Gehöft in Flammen auf; der angeblich Schuldige aber wird durch diese niederträchtige gemeingefährliche Sippschaft um sein Hab und Gut gebracht. Die Trümmer seines Gehöftes werden durch die Yewemänner dem Erdboden gleich gemacht und alles, was nicht durch den Brand zerstört ist, wird ihm geraubt. Die Zerstörung begründen die Yewediener damit, daśs sie unter den Trümmern der Gebäude nach den bekannten So-Steinen suchen, welche der grosse Blitzgott Xebieso vom Himmel herunter geschleudert hat. Sobald ein Sühnegeld an den Oberpriester gezahlt worden ist, wird die Brandstelle von einem Priester mit Wasser von neuem geweiht, auch die Bewohner, die eine so harte Strafe getroffen hat, müssen sich wieder reinigen und mit geweihtem Wasser waschen. Bisweilen wird nun auch wirklich ein Gehöft durch den Blitz in Brand gesetzt; natürlich entgeht dann erst recht nicht der durch den Brandschaden betroffene Mann der Habgier der Yeweleute und muss noch trotz des erlittenen Verlustes seinen Tribut bei dem Oberpriester abladen.

Die Yewepriester suchen sich meistens mit dem König und Schutz der Häuptling des Landes ins Einverständnis zu setzen. Oefter wird deshalb, Yewemitgliebevor der Oberpriester seinen Urteilsspruch verkündet, noch der Rat der durch den und die Meinung des weltlichen Oberhauptes des Dorfes eingeholt, um richterlichen dıe Vollstreckung des gefällten Urteils zu sichern. Natürlich fällt bei Priester. 
dieser Beratung eine ansehnliche Entschädigungssumme für den Häuptling $\mathrm{ab}$ und so leben oft Oberpriester und Häuptlinge in gutem Einvernehmen. Aber auch Häuptlinge, die persönlich dem Orden nicht geneigt sind, müssen mit ihm rechnen, da sie sonst seine Rache auf sich laden würden.

Nicht selten entscheidet der Yewepriester Beleidigungsprozesse, die zwei Nichtmitglieder gegen einander führen. Auch wenden sich Gläubiger, welche eine bestimmte Summe gegen einen Schuldner einklagen, an die Gerichtsbarkeit des Yeweordens. In einem solchen Falle werden Verwandte des Schuldners von den Hundeo festgenommen und erst nach Bezahlung der Schuldsumme und eines Tributs an die Hundeo und an den Fetischorden freigelassen. Hierbei muss erwähnt werden, dass es im allgemeinen üblich und gewissermaassen Gesetz ist, dass der Gläubiger die Verwandten des Schuldners bis zur Begleichung der Schuld als Pfand bezw. als Sklaven behalten kann.

Festlichkeiten An bestimmten Festtagen, welche der Orden feiert, darf niemand im Orden. bei einem Mitgliede rauchend oder mit bedecktem Haupte vorbeigehen. Ziegen und Schafe werden zu den Festen den Bewohnern einfach gestohlen und dann gemeinsam verspeist. Bei solchen Gelegenheiten geht es hoch her; an Branntwein und Essen fehlt es nicht und ein unsittlicher Verkehr zwischen Männern und Weibern des Ordens spielt dabei die Hauptrolle. Die Weiber gehen in dem Fetischgehöft und auch ausserhalb desselben vollkommen nackt umher, wovon man sich in Adjido, wo ein solcher Orden ist, überzeugen kann. Auch sollen die Mitglieder bei solchen Gelagen es für vornehm halten, sich unanständig aufzuführen und darin gegenseitig wetteifern, indem sie, wie unser Gewährsmann Kuadzo schreibt, Nawe, Nawe schreien. Zur Teilnahme an diesen Freudenfesten, die namentlich junge Leute verfuhren, in den Orden einzutreten, sind nur die Mitglieder befugt. Wehe dem Unglücklichen, der es wagt, die geheiligte Stätte zu betreten, wehe sogar dem, der sich irrtümlich verläuft; er wird, abgesehen von den nicht geringen Strafen, welche ihm später durch den Prozess entstehen, von den Yewe-Männern und -Weibern, die sich wie Hyänen auf ihn stürzen, durchgeprügelt und kann froh sein, wenn er mit dem Leben davon kommt.

Ausstossung Die Ordensregeln und -Gebote werden scharf durchgeführt und aus dem orden. jede Uebertretung wird streng geahndet; Uebertretungen werden mit Geldbussen bestraft und in schwereren Fällen wird der Schuldige aus dem Orden ausgestossen. An dem Tage, an welchem die Ausstossung erfolgt, werden sämtliche Mitglieder wild und teilen dieselbe schreiend und wie besessen durch die Strassen laufend dem Volke mit. Dem Schuldigen wird vor dem versammelten Volke unter Trommelschlag und Tanz der Kopf rasiert, man ruft ihn zum Spott mit seinem früheren Namen, 
weil bei Strafe niemand den Yewenamen aussprechen darf. Nach einer ardentlichen Tracht Prügel wird der Ausgestossene fortgejagt, denn der Yewe ist, wie sich die Mitglieder ausdrücken, aus dem Kopfe des Schuldigen herausgenommen.

Stirbt ein Mitglied, so findet die Totenfeier, wie bei allen Negern, durch ein besonderes Fest und Gelage statt, nur dass bei einem Yewemitglied die Hundeo allein den Toten beerdigen dürfen, während dieses Vorrecht sonst den Familienmitgliegern väterlicherseits zusteht. Als ganz besonderes Zeichen der Trauer wälzen sich die Priester und Priesterinnen des Yewe im Koth und Schmutz, um dann ein gemeinschaftliches Reinigungsbad zu nehmen. Jeder der Angehörigen muss alsdann einen Topf mit Wasser in das Haus des Verstorbenen bringen, welches der Priester weiht. Mit diesem geweihten Wasser besprengt der Priester das Haus und bannt dadurch den Geist des Verstorbenen, der in dem ganzen Lande sehr gefürchtet ist und nach dem Glauben der Leute eine eigentümliche Zauberkraft besitzt. Das Totengelage wird selbstverständlich von der Familie bezahlt; die Sachen und Kleider des Verstorbenen verbleiben dem Orden als Erbteil.

Die Aufklärung über das verbrecherische Treiben des Ordens haben wir, wie nochmals erwähnt sei, vor allem unserem aufrichtigen Gewährsmann Kuadzo, sowie den Bemühungen der Missionare und der Schrift des H. Seidel zu verdanken; die Regierung ist dadurch in den Stand gesetzt, dem verbrecherischen Treiben des Ordens entgegen zu treten.

Wir verlassen nun den Fetischort Ve, der uns Anlass zu obigen Schilderungen gegeben hat und setzen unseren Marsch nach Kpando fort.

Der Weg füht in nordwestlicher Richtung über die kleinen Vororte Weitcrmarsch von Ve-Demme, über Vime, während zur rechten Seite des Weges das nach Kpando Farmdörfchen Agbome liegen bleibt. Wir passieren grosse Farmdörfer und grüne Fluren von Erdnüssen, Mais und Yams; ab und zu steht mitten in den Farmen eine kleine Hütte, umgeben von den schon früher beschriebenen Kornspeichern, die bestimmt sind, die reiche Ernte aufzunehmen. Der Yams wird hier häufig in kleine Erdhügel gepflanzt, dic mit der Hacke aufgeworfen und gelockert sind; später wird ein Stock in den Hügel gesteckt, an welchem sich der Yams emporrankt, während er sonst auf dem Erdboden entlang kriecht. Meistens wird er aber sich selbst überlassen und überzieht dann das ganze Feld mit einem schönen frischen Grün.

Immer spärlicher wird der Baumwuchs in dieser weiten Ebene; eine grosse Grassavanne breitet sich vor uns aus und der schmale, unebene Pfad nähert sich dem Ufer des Danyiflusses. In der Ferne erhebt sich ein neues Gebirge, das mit seinen vielen kleinen Kuppen ein 
wechselvolles Bild gewährt. Es ist das Lavanyo-Gebirge, welches wir schon fruher von den Höhen des Agome-Gebirges begrusst haben. Das Gras wird schilfiger und härter; $a b$ und $z u$ sind sumpfige Stellen zu überwinden. Wir überschreiten einen kleinen Nebenfluss des Danyi, Aflabó, und erreichen den Ort Bevi, der an den Ufern des Danyi liegt. Hier machen wir unter den grossen Fikusbäumen, die einen schönen breiten Marktplatz beschatten, Halt, um nach einer kurzen Ruhepause wieder aufzubrechen und den Fluss zu passieren. Als Brücke über den fast ${ }_{5} \mathrm{~m}$ breiten Fluss dient ein Baumstamm. Die Eingeborenen

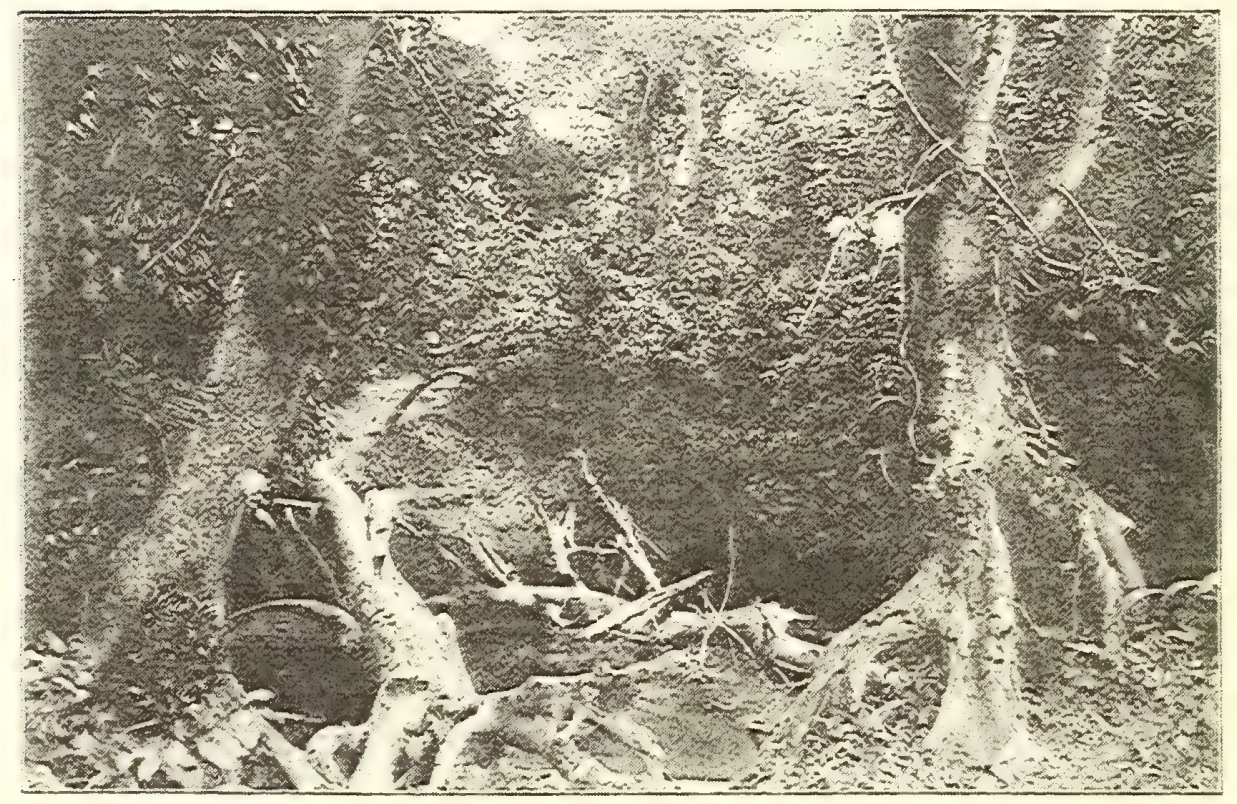

Flussübergang im Hinterlande.

stellen solche Brücken mit Vorliebe her, da sie ihnen nur geringe: Arbeit verursachen. Ein grosser Baumstamm, der dicht am Ufer steht und dessen Wurzeln gewöhnlich schon durch die Gewalt des Wassers untergraben sind, wird mit wenig Mühe von den Wurzelteilen losgelöst und alsdann gefällt, so dass der Stamm quer über den Fluss zu liegen kommt. Einige kleine Aeste werden dann noch abgehauen und die primitive Brücke ist fertig. Im allgemeinen erfullt sie bei den durchschnittlichen Wasserverhältnissen vollkommen ihren Zweck; nur bei Hochwasser werden häufig die Stämme überflutet oder weggerissen, so dass dann der ganze Verkehr auf diesen Strassen stockt und die Karawanen gezwungen sind, so lange Halt zu machen, bis das Wasser 
wieder gefallen ist. Auch wir kletterten einer nach dem ardern über diese Eingeborenenbrücke.

Bei dieser Gelegenheit muss ich auf die Galanterie der schwarzen Kavaliere gegen das weibliche Geschlecht zu sprechen kommen. Der Schwarze benutzt ein solches Ereignis ganz wie bei uns, um sich seiner Dame angenehm zu machen. Schnell springt einer der sonst nicht allzufleissigen Träger herzu, nimmt ihr die Last ab und trägt sie leichtfússig hinüber. Ein anderer ist ihr behilflich, über die Aeste und Wurzeln zu klettern und wieder ein anderer reicht der schwarzen lady beim Ueberschreiten des Stammes galant seine biedere Rechte, wobei es, wie bei unseren Damen, nicht ohne ängstliches Geschrei und Gekicher abgeht.

Inzwischen baden sich noch schnell und ungeniert die übrigen Träger in dem klaren Wasser des Flusses, um sich vor dem Aufbruch der Karawane von dem Schweiss und Schmutz des langen Marsches zu reinigen. Mit Mühe wird dann die Gesellschaft wieder zusammengebracht; schwerfällig werden die Lasten aufgenommen und der Marsch in der grossen weiten Grassavanne wird fortgesetzt. Immer näher rücken die südlichen Ausläufer des Lavanyo-Gebirges, kleine Hügel begleiten den Weg und bald sehen wir von der Höhe das nächste Dörfchen Gradja, welches schon zu der Landschaft Kpando gehört. Hier wie in fast allen Orten empfängt uns der Häuptling und ist erstaunt, dass ein Weisser so plötzlich, ohne vorher angekündigt zu sein, in seinem Orte erscheint. Schnell sendet er Boten voraus, um den König Dakadu, seinen Herrn, noch rechtzeitig von der Annäherung des Weissen zu benachrichtigen. Gewöhnlich haten diese schwarzen Häuptlinge ein schlechtes Gewissen und fürchten, dass man sie überrumpeln und festnehmen könnte, denn sie haben immer so viel auf dem Kerbholz, dass sie sich nie ganz sicher fühlen.

Auf einem Damme, der Gadja mit dem nächsten kleinen Farmdorf Sobuësante verbindet, führt nun der $\mathrm{Weg}$ in südöstlicher Richtung über kleine Terrainwellen direkt nach der grossen Haupt- und Residenzstadt des Negerfürsten Dakadu. Schon von weitem hört man das Gesumme der Volksmenge und die Trommeln, welche der König bei der Ankunft eines Weissen schlagen lässt, um die Häupter und Würdenträger der Stadt beim Empfange um sich zu scharen. Ein kleiner schmutziger Steg führt durch eine enge Strasse $z u$ dem grossen Versammlungsplatz, der im Osten der Stadt liegt und an welchem sich das Palais des Königs Dakadu befindet. Unsere kleine Truppe, voran die ${ }_{5}$ Soldaten mit der schwarz-weiss-roten Flagge, dahinter die Träger mit ihren Lasten, um, geben von einer Masse Volk, die uns begleitet, marschiert direkt nach der Empfangshalle des Königs, wo wir unter unaufhörlichem Trommeln von Dakadu empfangen werden. Dr. Gruner, mit dem ich damals reiste- 
begrüsste Dakadu und teilte ihm mit, dass wir hierher gekommen wären, um ihn zu besuchen und sein Land zu sehen. Dakadu sass auf einem erhöhten Platze in der Vorhalle, umgeben von den Würdenträgern, die in der Nähe des Thrones Platz genommen hatten; neben ihm stand der Sprecher mit dem Königsstock, der die Würde seines Amtes anzeigte. Dakadu hatte ein grosses Eingeborenentuch umgeschlagen und den sogenannten Fetischhelm aufgesetzt, einen alten Tropenhelm, der schwarz gestrichen ist und an dem allerhand Fetischembleme angebracht sind, um den Träger vor feindlichen Geschossen zu schützen. Er ist ein mittelgrosser, hagerer, alter Mann, dessen pockennarbiges, aber ziemlich wohlgebildetes Gesicht scharfe und energische Züge aufweist. Ein grauer Backenbart, der sehr selten bei den Evhenegern vorkommt, rahmt das schwarze Gesicht ein, aus dem lebhafte, listige Augen hervorblicken. Dakadu ist der erste Häuptling im ganzen Evhegebiet, der eine wirkliche Herrschaft über seine Unterthanen führt. Seine Regierung dürfte manche Grausamkeiten aufzuweisen haben Die Unterhäuptlinge in dem Kpandogebiet haben wenig zu sagen und sind vollkommen abhängig von dem Willen ihres energischen Gebieters. So fuhrte auch Dakadu in dem Palaver eigentlich allein das Wort, welches sein Sprecher weiter verkündete. In polterndem, selbstbewusstem Tone liess er uns fragen, warum wir ohne vorherige Anmeldung nach Kpando grekommen wären. Dr. Gruner erwiderte ihm, dass der Weisse marschiere, wenn er gerade Zeit hätte und dass er nicht immer vorher den Tag der Ankunft angeben könne. Bald war die Empfangsfeierlichkeit vorbei und wir wurden in ein benachbartes Gehöft geführt, das uns und unseren Leuten angewiesen wurde. Dieses Gehöft war von allen vier Seiten von kleinen Hütten umgeben, der Eingang fuhrte durch eine Hütte, welche nach dem Hofraum zu offen war. Daran stiess eine grössere Hütte, die sogar mit Fensterladen versehen war und die einen Tisch, eine Bettstelle und einen Stuhl enthielt. Dieses Mobiliar war von einem einheimischen Tischler gezimmert worden. Darauf folgte eine kleine Hütte, zu deren Eingang einige Stufen führten und die von aussen sauber mit roter Farbe gestrichen, auch sonst gut gebaut und innen reinlich erhalten war. Eine Thür und Fensterladen verschlossen auch diese europäische Negerhütte. Diese beiden Hütten nahmen Dr. Gruner und ich in Beschlag. Unsere Leute wie auch der Koch richteten sich in den anderen Hütten, die wie gewöhnlich ohne Unterbau direkt auf die Erde gebaūt waren, häuslich ein. Den Tag über gewährte bei der glühenden Sonnenhitze in dem Hofe eine offene Halle mit grossem Grasdach einen angenehmen Aufenthalt.

Das Palais des Königs ist natürlich nichts anderes als eine grosse lange Hütte, die nach aussen hin geschlossen ist und in der Mitte 
eine eingezogene $W^{r}$ and besitzt, wodurch die Königshalle gebildet wird; in der Mitte derselben ist der Thronsessel aufgestellt, während an den Seiten die grossen Trommeln stehen und an den Wänden überall Fetischembleme wie Knochen, Federn und Hörner angebracht sind; auch ein kleiner Kriegsfetisch, mit einem Schwert in der Hand, steht darin, dessen eine Hälfte schwarz, die andere weiss bemalt ist. Die weisse Farbe bezeichnet fast im ganzen Afrika bei den eingeborenen Stämmen den Krieg, während die rote Farbe als Friedenszeichen gilt. Zu der Königshalle führen einige Stufen herauf, auf welchen bei Festlichkeiten die Häuptlinge und Grossen des Landes nach Rang und Würde ihren Sitz einnehmen. Die übrigen Seiten des Gehöftes sind ebenfalls von Hütten umgeben, deren Eingänge alle nach dem Grehöft zu liegen und die als Wohngebäude der Sklaven und Frauen des Königs, sowie als Wirtschaftsgebäude dienen. Auf dem grossen viereckigen Platze vor dem Palais werden die Palaver und Festlichkeiten abgehalten; grosse Schattenbäume grewähren den einzelnen Gruppen Schutz, die der König zu empfangen wünscht. Die übrigen Seiten des Platzes nehmen die Hütten und Gehöfte der grossen Würdenträger oder reichen Händler ein. An diesen Platz stösst, đurch eine kleine Strasse verbunden, das Terrain, auf dem die Wochenmärkte, sowie auch die kleineren Märkte abgehalten werden.

Ein reges Leben und Treiben entfaltet sich auf diesem Markt, denn Kpando als Kpando ist einer unserer grössten Handelsplätze in diesem Gebiet. Handelsplatz. Durch seine günstige Lage, nur ungefähr 7 Kilometer von dem grossen Voltastrom entfernt, ist Kpando schnell aufgeblüht und bildet eigentlich bis in neuere Zeit einen Stapelplatz für die englischen Waren, welche infolge des billigen Wassertransports von der Küste bis nach Dogbadja auf deutsches Gebiet oder auch nach Gabé auf dem gegenüberliegenden Volta-Ufer auf englisches Gebiet gebracht werden. Dogbadja bildet den eigentlichen Vorhafen von Kpando und grosse Vorräte an Pulver und Salz liegen dort aufgestapelt. Ausser dem schon früher erwähnten Adda-Salz ist hier auch europäisches Salz in Massen vorhanden. Zumeist sind alle diese Waren von dem englischen rechtsseitigen Voltagebiet eingeschmuggelt; sie werden meistens in Adda eingekauft und dann mittelst Kanoes den Volta heraufgebracht. So beherrschen die englischen Händler vollkommen den grossen Markt von Kpando und der englische Einfluss ist in sämtlichen, an den Volta grenzenden Gebieten wahrzunehmen. Da wie schon vorher erwähnt, die linksseitigen englischen Gebiete des Volta mit unserem deutschen Gebiet ein und dieselbe Zollkonvention haben, wonach die englischen Waren aus diesen Gebieten zollfrei in unsere deutsche Kolonie eingehen und umgekehrt unsere deutschen Waren wieder zollfrei in das linksseitige englische Voltagebiet eingeführt werden dürfen, während das rechtsseitige grosse Gebiet der 
englischen Goldküstenkolonie dem allgemeinen Zoll unterliegt ist natürlich dem Schmuggel Thür und Thor geöffnet. Aus diesem Grunde wurde eine Zollstation in Kpando eröffnet, welche schon jetzt eine erhebliche Einnahme aus dem Zoll der eingefuhrten Waren hat. Durch die Station, sowie durch Ursprungsatteste ist in neuerer Zeit dem Schmuggel gründlich entgegengetreten worden. Trotzdem ist es natürlich mit Rücksicht auf die Konvention und bei der Nähe der englischen Grenze nicht möglich, ihn gänzlich zu verhindern. Auf dem Kpandomarkte werden, wie auf allen anderen grossen Negermärkten, allerhand Lebensmittel und Produkte feilgeboten. Viele Zeuge und Stoffe, sowie Pulver und Gewehre, vor allen Dingen Salz, werden von englischen Händlern verkauft. Selbst die Haussas fehlen nicht und haben in den Grasdachhallen und den angrenzenden Hütten -ihre bunten Stoffe, Messingschüsseln und anderen Verkaufsartikel zum Kauf ausgestellt.

Auch die Bremer Faktorei aus Lome hat an diesem Markt eine Niederlassung und einen Laden. Sie führt dieselben Waren, die wir schon an der Küste in den sogenannten Stores vorgefunden haben und die hier einen guten Absatz finden. Der Unkosten wegen ist vorläufig nur ein schwarzer Angestellter der Firma mit der Verwaltung dieser Verkaufsstelle beauftragt und bis auf weiteres hat auch die Firma von der Errichtung von Häusern nach europäischer Art Abstand genommen.

Stadı und Umgebung ron Kpando

Kpando selbst dehnt sich nach Norden und Westen weithin aus und die kleinen Vorstädte wie Aloë hängen fast ganz mit der Hauptstadt zusammen. Im Osten der Stadt liegt die Station der Baseler Missionsgesellschaft. Die Mission wird von einem schwarzen Lehrer verwaltet. In der Schule wird in der Evhe- und in der Tshisprache unterrichtet. Auch hier erfreut sich die Missionsschule eines regen Besuches, da die Eingeborenen im allgemeinen wissbegierig sind und danach tràchten, lesen und schreiben zu lernen. Unter den Negern gilt ein Schriftkundiger als Gelehrter und steht in grossem Ansehen. Auf dem platten Lande werden häufig Schriftzeichen oder Schriftstücke als Fetisch betrachtet. Dagegen findet die Lehre des Christentums infolge des Verbots der Polygamie weniger Eingang. Ausser der Missionsschule ist noch eine sogenannte Haussaschule vorhanden, welche die Kinder der mohamedanischen Haussa-Kolonisten besuchen und in welcher ein mohamedanischer Priester die Schüler den Koran lesen lehrt und in der arabischen Schrift unterrichtet. Ueberall wo Haussas sich niederlassen, bringen sie einen Priester mit und ernennen auch einen eignen Häuptling, der ihre Streitigkeiten zu schlichten, sowie die Kolonie bei dem eingeborenen König zu vertreten hat. Lange Zeit herrschte hier der alte Profoyetu, den wir schon auf unserer Reise an der Küste bei Bagidá angetroffen haben. Infolge von Zwistigkeiten, welche unter 


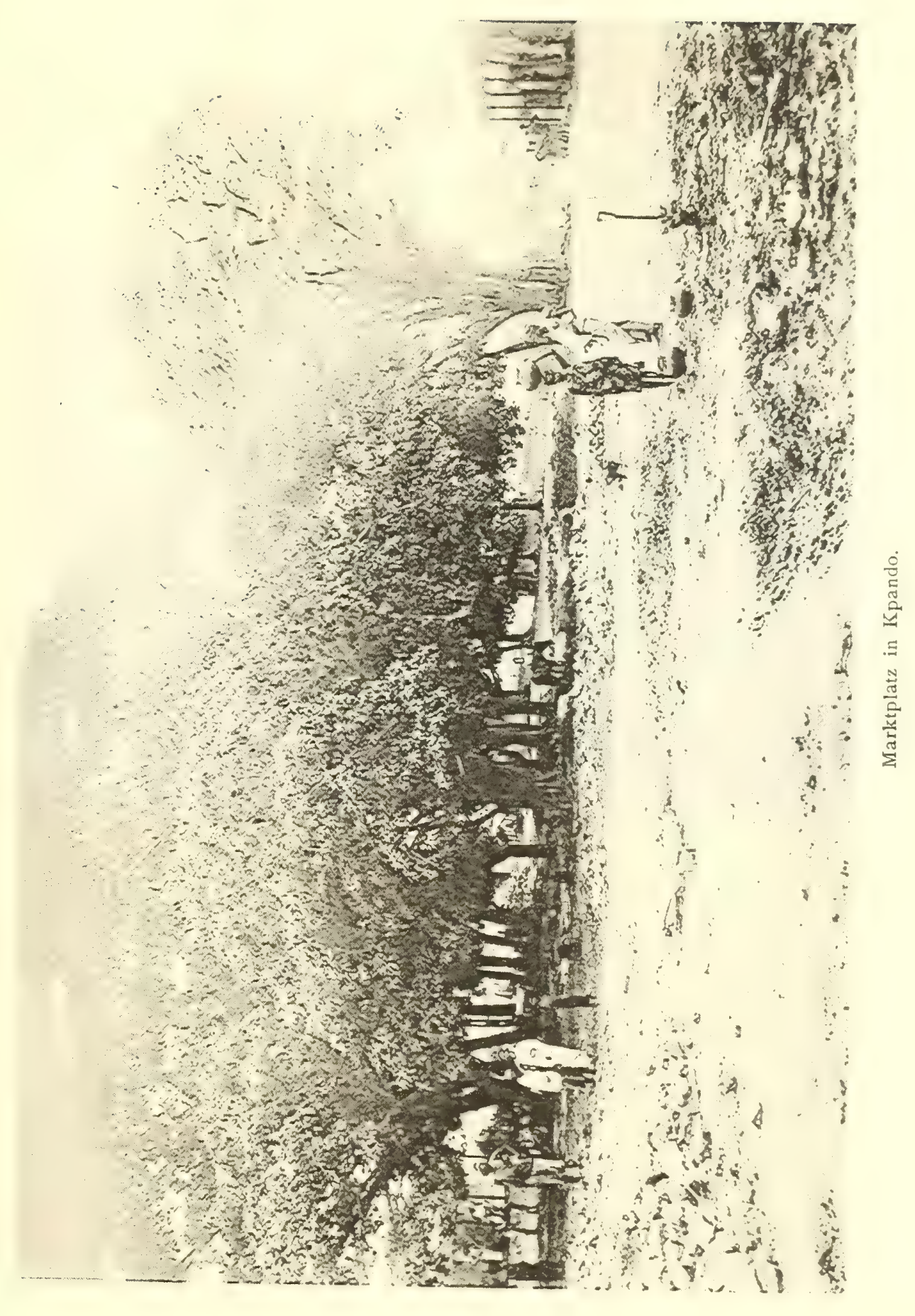



den reichen Haussa-Familien entstanden sind, musste der alte Profoyetu einem andern Chief weichen.

Die ganze Stadt Kpando hat das Gepräge einer Handelsstadt. Ueberall sieht man englische Händler in Gruppen über dieses oder jenes Geschäft beratschlagen, überall bieten Haussa-Händler ihre bunten Kattunwaren oder Perlen oder auch die beliebten Messingstangen, aus denen die Eingeboren die glänzenden Armbänder herstellen, zum Kauf an. Lange, mit einem Grasdach versehene Lehmhütten dienen in Kpando

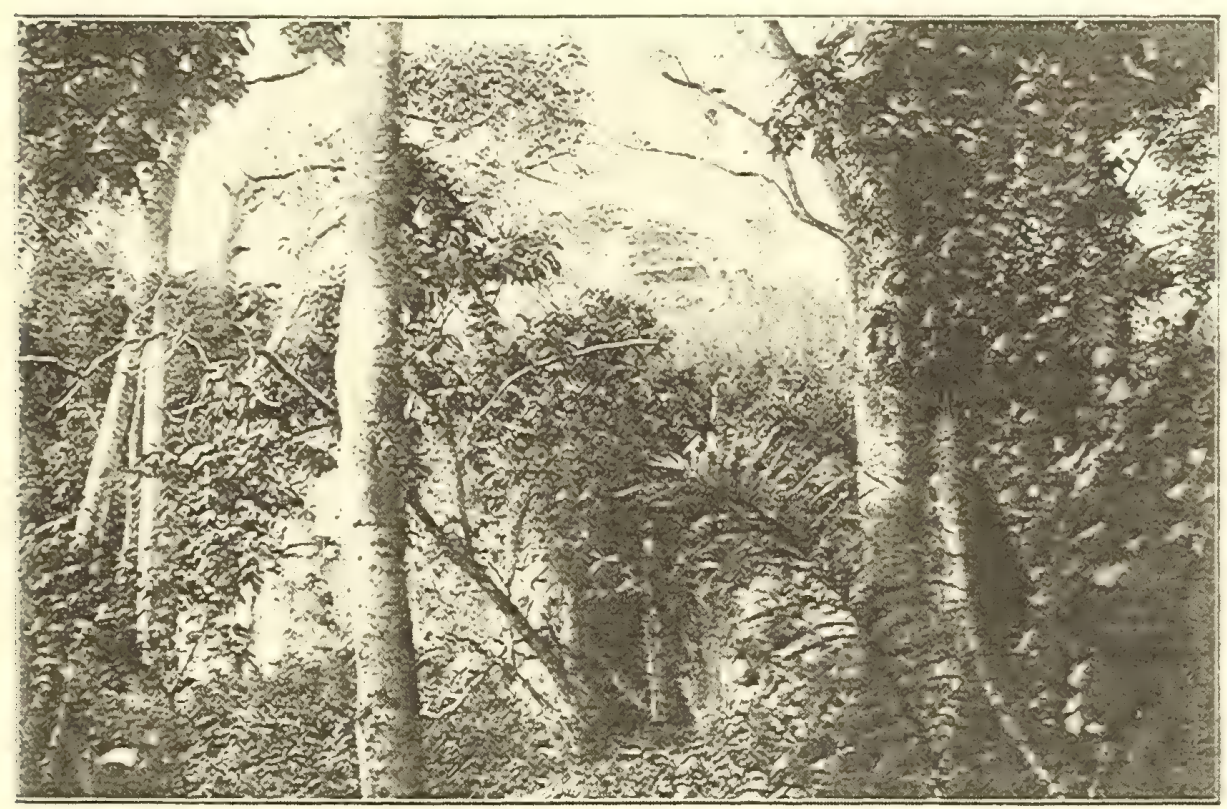

Die Zollstation Kpando

den Fremden als Gasthaus; der innere Raum ist in mehrere Abteile eingeteilt, zu welchen je ein besonderer Eingang führt.

Rings um Kpando herum liegen die Farmen der Ackerbauer. Im Nordosten der Stadt zieht sich ein kleiner Höhenzug mit grossen erratischen Steinblöcken von etwa $20 \mathrm{~m}$ Höhe entlang, auf dem die Regierungsstation angelegt ist. Dieselbe ist in viereckiger form von dem. Techniker Stöhr erbaut. Bei meinem letzten Aufenthalt im Jahre 1897 bestanden die Gebäude aus grossen Lehmhütten nach Art der Eingeborenen. Ein schöner grosser Hofraum, zugleich der Exerzierplatz der Station, war von den Hütten, die als Wohnungen für die Soldaten und Arbeiter und als Aufbewahrungsorte dienten, begrenzt. Auf der Ostseite der Station war auf den Felsen, welche hier steil abfielen, eine kleine Bastion 
errichtet und auf diesem Felsplateau sollte das Wohnhaus für die Europäer erbaut werden. Von hier aus hat man einen schönen Blick auf die Stadt Kpando selbst, welche. sich mit ihren rooo Hütten nach Osten erstreckt. Weiterhin überblickt man die grosse Ebene des Danyi-Flusses und die Berge und Ketten des Agome-Gebirges, welche das Thal abschliessen. Auf dem kleinen Bergzuge an der Station entspringt in unmittelbarer Nähe ein klarer Quell, der die Station mit dem nötigen Trinkwasser versorgt. Nicht weit von der Stationsanlage zieht sich die Strasse über die Felsblöcke nach dem schon erwähnten Hafenplatz Dogbadja am Volta hin. Dieser Weg, der die eigentliche Strasse der Händler bildet, die ihre Waren auf dem Volta aus dem englischen Gebiet einschmuggeln, wird von dieser ausserordentlich wichtigen Zollstation vollkommen beherrscht.

Ausser Handel und Ackerbau wird in Kpando in kleinem Maassstabe die Weberei, sowie in grösserem Umfange die Töpferei betrieben. Der grosse Markt in Kpando, der die Bewohner der umliegenden Ortschaften und weiterher anzieht, bietet für die fast in jeder Wirtschaft unentbehrlichen Töpferwaren einen guten Absatz.

Kpando ist im Norden die letzte Landschaft des Evhestammes, wo die Evhesprache gesprochen wird, aber auch die Tshisprache, welche von den meisten aus dem Aschantie-Gebiete kommenden Händlern gesprochen wird, hat Eingang gefunden. Neben dieser ist die Haussa-Sprache und vereinzelt die Guan-Sprache, welche in der im Norden angrenzenden Landschaft Kunya gesprochen wird, im Gebrauch.

König

Dakadu und seine

Herrschaft

Als ich das erste Mal mit Dr. Gruner in Kpando war, handelte es sich darum, die Landschaft unter deutsche Flagge zu stellen. Durch den englischen Vertrag gehörte sie ja thatsächlich schon lange zu deutschem Gebiet, aber König Dakadu betrachtete sich als vollkommen selbständig und unabhängig, obwohl er dem Einfluss, den die englischen Händler von der Goldküste auf ihn ausübten, nicht widerstand. Dakadu zog natürlich von diesen den grössten Gewinn, da er bei Palavern und sonstigen Gelegenheiten einen ansehnlichen Tribut forderte; so unterstützte er z. B. den englischen Schmuggel auf jede Weise, so dass infolgedessen nur wenig Waren oder Produkte zur deutschen Küste gelangten. Die englischen Händler dominierten in Kpando vollkommen, während die aus deutschem Gebiet erst in zweiter Linie kamen. Die Mittel gestatteten es in der ersten Zeit unserer neuen Kolonie nicht, ohne weiteres gegen einen so mächtigen Häuptling wie Dakadu vorzugehen. So war es erst nach der Befestigung der Station Misahöhe Dr. Gruner vorbehalten, Kpando die deutsche Flagge zu geben. Lange Palaver fanden zwischen Dakadu und uns statt, wobei Dakadu häufig eine sehr herausfordernde Sprache führte. Wie stark damals noch sein Selbstgefühl war, zeigte 
sich bei folgendem Vorfall. Ein Soldat hatte einem Verwandten won Dakadu zufällig eine kleine Thonpfeife zerbrochen, worauf Dakadu dem Soldaten sagen liess, dass er ihm den Kopf abschlagen würde. Der Soldat gab dem Boten zur Antwort, er habe keine Furcht, Dakaclu solle es nur versuchen. Damit die Leute bei dem mehrtägigen Aufenthalt nicht müssig blieben, hielt ich mit meinen ${ }_{5}$ Mann ein strammes Exerzieren auf dem grossen Platze vor der Königshalle ab. Bei dieser Gelegenheit liess ich den schuldigen Soldaten vor die Front treten, rügte seine Handlungsweise, lobte ihn aber zugleich öffentlich, dass er dem König auf seine anmaassende Herausforderung eine beherzte Antwort erteilt hätte und gab meiner Freude darüber Ausdruck, dass er Vertrauen zu seinem Führer habe. Auch der König mit seinem ganzen Stabe hatte sich vor seinem Palaste eingefunden und musterte die Exerzitien unserer Soldaten. Es wurde Gefechtsexerzieren und das sogenannte Buschgefecht geübt und zum Schluss wurde mit aufgepflanztem Seitengewehr unter lautem Hurra ein Sturm auf das königliche Schloss ausgeführt. Bei diesem Anblick erschrak die ganze königliche Umgebung und der gefürchtete König zog sich schleunigst in seine Halle zurück. Als jedoch noch vor dem Palaste Halt geblasen und das Kommando "Gewehr ab" gegeben wurde, erhellten sich die Gesichter wieder und Dakadu erklärte mir erfreut, dass die deutschen Soldaten gut exerzieren könnten. Nach Austausch der Geschenke, die einen ganz besonderen Einfluss auf den habgierigen Dakadu ausübten, versprach dieser den deutschen Handel zu schützen und nachdem ihm noch eine Jahresrente garantiert worden war, nahm er feierlichst die deutsche Flagge an. Hiermit war unsere Mission beendet und wir kehrten wieder nach unserer Station Misahöhe zurück.

\section{MILITÄREXPEDITION ÜBER KPANDO NACH KRATYI.}

Ende des Jahres 1895 kam ich mit der grossen Militärexpedition, die unter Leitung des Oberleutnants v. Döring zwecks Anlegung der Station Kratyi über Kpando ihren Weg nahm, wieder an diesen Ort. Die Marschordnung einer derartigen Expedition in sicheren und friedlichen Gegenden ist die folgende. Meistens marschiert die Truppe voran, an der Spitze sechs Spielleute, die bein Passieren eines Ortes trommeln und pfeifen. Dahinter kommt die grosse Trägerkolonne und den Schluss 
bilden wieder einige Soldaten mit einem gewandten Unteroffizier, der am Queu die Ordnung aufrecht erhält. Falls mehrere Weisse bei der Expedition sind, schliesst öfters ein solcher den Zug. Bei der Expedition nach Kratyi waren drei Weisse, Oberleutnant v. Döring, ich selbst und der seitdem verstorbene Botaniker Baumann, welcher damals auf der Station Misahöhe stationiert war. Der Landeshauptmann v. Puttkamer wollte diese Expedition persönlich leiten, wurde jedoch durch die Versetzung nach Kamerun an der Ausführung seines Planes verhindert; an seiner Stelle wurde v. Döring mit den Funktionen eines Landeshauptmanns ausgestattet und mit der Expedition nach Kratyi gesandt. Lange Zeit vorher war der Besuch des obersten Beamten der Kolonie den Häuptlingen angekündigt, welche sich darauf freuten, insbesondere wegen der Geschenke, die sie zu erhalten hofften. Der Expedition war auch eine ansehnliche Geldsumme und ausserdem Geschenke für die Häuptlinge zur Verfügung gestellt, in der richtigen Erkenntnis, dass die Freundschaft des Negers, sowie Macht und Ansehen der Europäer von diesen Mitteln abhängen. Wir waren sämtlich beritten, aber die Pferde waren unser Eigentum, da die Regierung damals kein Geld zum Ankauf von Pferden bewilligt hatte.

Empfang Unter Trommeln und Pfeifen, voran die schwarz-weiss-rote Flagge, der Expedition. Von der Königshalle wehte auf einem hohen Mast eine grosse deutsche Flagge. Ganz Kpando war natürlich auf den Beinen und sammelte sich auf dem Platze. Die grossen Trommeln wurden gerührt und wir wurden feierlich von Dakadu empfangen. Ein grosses Zelt wurde unter den hohen Bäumen auf dem Markte aufgestellt, davor stand die Flagge und in langen Reihen die Gewehrpyramiden der 120 Mann starken Truppe. Ein Unteroffizier zog täglich auf Wache und ein Posten vor Gewehr hatte die Fremden von dem Platze fernzuhalten und Aufsicht über die Waffen zu führen. Ueber den Gewehrpyramiden hingen die Patronentaschen und Seitengewehre eines jeden Soldaten. Diese Maassnahme ist getroffen, um etwaigen Ausschreitungen der Soldaten gegen die wehrlosen Eingeborenen vorzubeugen. Ein Spielmann, der ebenfalls stets auf Wache ist, ist verpflichtet, bei einem Alarm sofort die Truppen zu den Gewehren zu rufen.

Am nächsten Tage kam Dakadu und brachte seine Geschenke, die aus einer ungeheuren Menge von Yams, Bananen, Papaya, Mais und anderen Lebensmitteln bestanden. Auch Ziegen und Schafe wurden von den Farmen herbeigeholt und uns von Dakadu zum Geschenk gemacht. Der Neger zeigt in dieser Beziehung ein gewisses Feingefuhl, denn er überreicht die Geschenke, selbst wenn die Gabe noch so gross ist, immer mit der Entschuldigung, dass er leider nicht mehr hätte und 
bäte, die kleine Crabe zur Beköstigung der Leute anzunehmen. Alle Geschenke werden aber in der Hoffnung gegeben, dass der Weisse dieselben drei- und vierfach vergelten wird. Dem König Dakadu wurde vielmals für die Spenden gedankt und durch v. Döring gleichzeitig energisch klar gemacht, dass alle bisherigen Anmaassungen und Uebergriffe, deren er sich schuldig gemacht hätte, vergessen sein sollten, dass er aber fortan den Anweisungen der Regierung bei Termeidung harter Strafen Folge zu leisten hätte. Angesichts der vielen Gewehre und Soldaten, die bei dem prahlerischen Dakadu ihren Eindruck nicht verfehlten, war er ziemlich kleinmütig geworden. Sein polterndes Wesen und seine Drohungen mit Krieg und Kopfabschneiden hörten ganz auf. Er gelobte, in Zukunft die Befehle der deutschen Regierung zu befolgen und in jeder Lage treu zu ihr zu stehen. Ihre Macht, welche er zum ersten Mal in dieser Weise entfaltet sah, hatte sowohl auf Dakadu, wie auf die Berölkerung eine heilsame Wirkung ausgeübt. Die falsche Vorstellung, welche die englischen Händler von derselben verbreitet hatten, war damit hinfällig geworden. Der Neger lässt sich leicht durch äussere Machtentfaltung imponieren und unterwirft sich ihr ohne weiteres, da er im allgemeinen ängstlich und um sein Leben besorgt ist.

Am nächsten Tage war grosser Empfang der sämtlichen Häuptlinge Grosser Aufder Kpando-Landschaft und schon am frühen Morgen sassen die zug Dakadus. einzelnen Sendboten vor dem Palais des Königs, um diesem die Ankunft ihrer Herren und Gebieter anzuzeigen. Dakadu kam mit einigen Würrdenträgern, bald nachdem wir aufgestanden waren, zu uns, wünschte uns guten Morgen und erkundigte sich, wie wir die Nacht in seiner Residenz geschlafen hätten. Eine grosse Kalabasse mit Palmwein wurde herbeigebracht und nach Negersitte trank uns der König aus einer kleinen Kürbisschale zuerst zu. Er hatte an dem Tische vor dem Zelte Platz genommen und nun machte die Palmweinschale zuerst bei uns Weissen und dann bei den Würdenträgern des Königs die Runde. Der König hatte inzwischen seine Pfeife mit dem von uns geschenkten Tabak in Brand gesteckt; eine Sklave stand zu ihrer Bedienung hinter ihm; auch führte der König eine kleine aus einer Kokosnuss gearbeitete Schnupftabaksdose mit sich und sprach derselben sehr stark zu, so dass sein stattlicher Bart, sowie seine Nase Spuren des Schnupftabaks trugen. Auch uns bot der König, freundlich grinsend, eine Priese an, wir dankten jedoch höflichst für diese Aufmerksamkeit. Der König, sowie die übrigen Würdenträger, welche sich auf kleinen Schemeln oder auf der Erde hockend, um unseren Tisch gruppiert hatten, waren in ein grosses Tuch eingewickelt, welches sie vor der für afrikanische Verhältnisse kühlen Morgentemperatur schützte. Nachdem der alte Dakadu seine Kehle angefeuchtet hatte, war der drückende Alp, der Tags zuvor auf ihm 
gelastet hatte, geschwunden. Er versicherte uns nochmals seine, Freundschaft und kam dann bald wieder auf die alten Palaver zurückr erzählte uns alle Schlechtigkeiten der benachbarten Häuptlinge und bat uns, energisch gegen dieselben einzuschreiten, in der Hoffnung, durch die Freundschaft mit den Weissen zu grösserem Ansehen gegenüber den mächtigen Häuptlingen zu gelangen. Nachdem wir ihm einige Cognacs kredenzt hatten, auf die er offenbar schon lange gewartet hatte, $20 \mathrm{~g}$ er sich in seine Gemächer zurück, um die weiteren Regierungsgeschäfte und Vorbereitungen für den offiziellen Aufzug zu erledigen. Die Sonne war schon zur halben Höhe gestiegen, als allmählich unter unaufhörlichem Trommeln die Häuptlinge teils in einer Hängematte getragen, teils zu Fuss unter einem riesengrossen roten oder gelben Schirm vor dem Palais des Königs Dakadu anlangten. Eine Menge Volk war herbeigeeilt, fast der ganze Platz war besetzt und nur mit Mühe konnte unsere Wache die Menge in gebührender Entfernung halten. Plötzlich trat Ruhe ein, Trommeln fielen ein und der König trat auf die Stufen der Halle, um die Häuptlinge zu begrüssen und in feierlichem Zuge zu den Weissen zu begleiten. Unter unaufhörlichem Trommeln bewegte sich der Zug über den Platz, voran Dakadu unter einem rotseidenen Schirm, mit einer Art phrygischen Mütze und mit einem grossen gelbseidenen Tuche bekleidet, welches er einst von einem Weissen zum Geschenk erhalten hatte. Ihm folgte sein ganzer Stab, der Sprecher mit dem Königsstock, sowie der Rat der Alten, der Haussa-Häuptling Profoyetu, in langem weissen Haussa-Gewand und mit einem Turban von weiss-rotem Musselin auf dem Kopf. Hieran schlossen sich die einzelnen Abordnungen, nach der Grösse der Dörfer und Städte geordnet, voran die Häuptlinge unter Baldachinen mit Stabträgern an der Spitze. Hinter dem Zuge endlich wurden die Geschenke gebracht, grosse Kala bassen mit Mais, Yams, Reis, Bananen und Ananas; daneben wurden an kleinen Seilen Schafe und Ziegen nachgeschleppt.

Als der Zug hielt, teilte uns Dakadu mit, dass die Häuptlinge gekommen wären, um uns $\mathrm{zu}$ sehen und zu begrüssen. Die meisten hatten sich auf kleinen Schemeln, welche von Sklaven herbeigeschafft wurden, häuslich niedergelassen. Wir drückten jedem einzelnen die Hand und sprachen unseren Dank für die schönen Geschenke aus. Bei der Begrüssung entblösst der Neger vor einem Höhergestellten die rechte Schulter. Bei dem Handreichen wird mit den beiden Mittelfingern ein knallender Ton hervorgebracht. Untergebene fallen vor dem Häupt. ling auf die Kniee, das Gesicht zur Erde gebeugt, so dass sie mit dem Kopfe den Erdboden berühren, klatschen dann einige Mal in die Hände und stammeln: "Donna, Donnalo" (Ich danke, ich danke sehr). Als Gruss zwischen Gleichgestellten auf dem Marsche, namentlich wenn sich 
die Leute häufiger sehen, ruft einer dem andern zu: "Wie geht es zu Hause, ich danke sehr, wie geht es bei Dir zu Hause?" "Wie geht es Deinen Kindern?", worunter nicht nur diese, sondern auch Weiber und Sklaven gemeint werden. „Home-tolle? Ole-do? Dewi-ole? Elle? "Haben sich die Leute längere Zeit nicht gesehen, so findet natürlich noch ein Austausch von Fragen nnd Antworten statt: "Woher kommst Du, wohin gehst Du?" ets. Nachdem die Häuptlinge ermahnt worden waren, ihrem Oberhäuptling Dakadu stets Folge zu leisten und ihnen nochmals der Dank für ihr Erscheinen ausgesprochen war, wurde die Versammlung entlassen.

Die ansehnlichsten Häuptlinge wurden bei Dakadu selbst einquartiert. Die grossen Baldachine fanden neben den Trommeln vor der Königshalle ihren Platz; sie gaben infolge ihrer bunten Farben ein malerisches Bild ab. So verschieden die Häuptlinge in grüner, gelber oder roter Seide gekleidet waren, so verschiedene Farben hatten auch die Baldachine. Ein solcher Baldachin ist ein grosser Schirm, der bei feierlichen Aufzügen nur von den Häuptlingen benutzt werden darf. Er wird meistens aus roter oder gelber Seide oder auch aus Tuch hergestellt und ist eine besondere Eigentümlichkeit der Evhe-Neger. Ein weiteres Abzeichen der Häuptlinge ist der Stab des Königs, der aus Ebenholz oder anderem harten Holz schön geschnitzt ist. Oefter ist der $\mathrm{I}^{\mathrm{I}} / 2 \mathrm{~m}$ lange Stab an der Spitze mit einer schönen Schnitzerei in Form einer Schlange oder einer sonstigen Figur verziert.

Nachmittags wurden mit den Dolmetschern die Geschenke für die einzelnen Häuptlinge ausgesucht und je nach dem Grade und dem Rang des zu Beschenkenden bemessen. Für die grossen Häuptlinge besteht das Haugtgeschenk aus einem Stück Seide. Perlenschnüre, kleine Spiegel und Messingstäbe werden für die Frauen beigelegt. Der Weisse ist gezwungen, Geschenke zu geben, da er sonst für geizig gilt und Schwierigkeiten hinsichtlich der Verpflegung seiner Leute haben würde. Die Vernachlässigung dieser Sitte hat schon oft zu Unzuträglichkeiten, sogar zu kleinen Gefechten geführt und viele Kosten verursacht. Aus diesem Grunde wählt man von zwei Uebeln das kleinere. Namentlich ist diese Regel in dem weiteren Hinterlande zu befolgen, wo einmal die Macht des Weissen weniger bekannt, ausserdem aber auch die Verpflegung bei weitem schwieriger ist.

Des Abends bei hellem Mondschein riefen die Trommeln die tanzlustige Menge auf den grossen Platz und bei Gesang, dem taktmässigen Schlage der Trommel und Händeklatschen traten die Tänzer und Tänzerinnen hervor, darunter auch Frauen mit Kindern auf dem Rücken.

Festliche

Tanzaufiührungen in Kpando. Unsere Leute, Träger sowohl wie Soldaten, beteiligten sich an dem Tanze und waren unter den Damen besonders beliebt. Jeder wetteiferte

Austausch ron Geschenken 
das Herz einer schönen Schwarzen zu gewinnen, indem er ihr beim Tanz ein schönes Tuch und ein Paar Pèrlenschnüre zuwarf. Nach Landessitte dürfen eigentlich nur die wirklichen Bürger und Freien des Ortes den Tanz mitmachen. Bei dem zweierlei Tuch wurde jedoch auch hier zu Lande eine Ausnahme gemacht und so war die Harmonie zwischen unseren Leuten und dem Kpando-Volk vollkommen hergestellt. Auch König Dakadu, welcher bis zum Abend das nötige Quantum Alkohol vertilgt hatte, führte mit einem seiner Weiber einen Tanz auf. Er hatte zu dieser feierlichen Gelegenheit seinen ganzen Maskenstaat herausgeholt, so zierte ausser den grossen seidenen Tüchern auch ein alter Admiralshut sein Haupt. Die Trommelschläger boten ihre ganze Kunst auf, um den König bei dem seltenen Tanze rythmisch zu begleiten und die Menge wetteiferte im Händeklatschen und im Gesange. Der Tanz und das Fest währten die ganze Nacht hindurch unter unaufhörlichem Trommelschlag. Das Geschrei und der Lärm raubten uns gänzlich die Nachtruhe. Auch nötigten ụns einige Excesse mehrmals unser Lager $z u$ verlassen und nach dem Rechten zu sehen. Meistens handelte es sich um eine kleine Familienszene, weil die Träger oder Soldaten sich zu weit mit den Töchtern des Landes eingelassen hatten und nun von deren Verwandten durchgeprügelt oder zum Hause hinausgeworfen wurden. Natürlich standen ihnen einige animierte Kameraden hilfreich bei und so entspann sich ganz wie bei uns in der Heimat eine grosse Prügelei. Die Wache wurde herbeigerufen und die Störenfriede bis zum andern Morgen in Sicherheit gebracht, wo ihrer die gerechte Strafe wartete. Alle Ausschreitungen müssen selbstverständlich hart bestraft werden, insbesondere Raub und Erpressung, um ein abschreckendes Beispiel zu geben, denn nur durch feste Disziplin ist die Truppe einer solchen Expedition zusammen zu halten. Am Morgen nach einem solchen Feste fällt natürlich der Marsch bezw. Dienst den an den Folgen ihrer Ausschweifungen leidenden Leuten ebenso schwer wie unseren Soldaten in der Heimat und die meisten bitten um einen Ruhetag, der eigentlich nie gewährt werden sollte, da er gewöhnlich nur zu einem neuen Trinkgelage benutzt wird.

Maassnahmen

Während der Festlichkeiten waren wir nicht unthätig geblieben gegen Dogbadja und Anfoë. und hatten Boten nach Dogbadja, sowie nach Anfoë gesandt, um die Häuptlinge zu einer Rücksprache über einige wichtige Punkte zu bestellen. Beide liessen uns sagen, sie dächten gar nicht daran, uns aufzusuchen; wenn wir etwas haben wollten, sollten wir nur zu ihnen kommen, im übrigen gingen die Deutschen sie gar nichts an. Noch am selben Tage wurde beschlossen, des Nachts vor Morgengrauen die Truppe zu alarmieren, nach Dogbadja sowie nach Anfoë zu marschieren und eventuell die Schuldigen zu bestrafen. Oberleutnant von Döring, sowie Botaniker 
Baumann zogen am frühen Morgen zum grossen Staunen des geängstigten Kpando-Volkes mit der Hälfte der Truppe nach Dogbadja, während ich zur selben Zeit mit 60 Mann nach Anfoë aufbrach. Als v. Döring und Baumann in Dogbadja ankamen, waren trotz der Geheimhaltung aller Pläne die Eingebornen bereits nach Gabé auf dem gegenüberliegenden Volta-Ufer geflüchtet. Eine Menge eingeschmuggelter Pulvervorräte wurde in den Hütten vorgefunden. Da der Häuptling, welchen v. Döring rufen liess, sich weigerte, aus seinem Schlupfwinkel hervorzukommen, auch die zurückgebliebenen Händler sich frech benahmen und keine Aufklärung über das eingeschmuggelte Pulver geben wollten, so machte v. Döring kurzen Prozess und liess die unrechtmässig eingeführten Waren einfach verbrennen. Soldaten wurden mit brennenden Grasbündeln an die Hütten gesandt und steckten die Dächer derselben in Brand. Nicht lange dauerte es, so gingen sämtliche Pulverfässer in die Luft und eine grosse Rauchwolke verkündete den Schmugglern die gerechte Strafe. Am andern Tage kam der Häuptling von Dogbadja und versprach, dass er von nun an nicht mehr Schmuggler in seinem Dorfe dulden werde.

Der Marsch nach Anfoë ging ohne Schwierigkeiten von statten. Ich marschierte auf direktem Wege über Akhnavhe und Soviëvhe nach nach Anfö̈ Anfoë, der Haupt- und Residenzstadt des Häuptlings der Landschaft gleichen Namens. Ueberall wurden wir von den Bewohnern von Akhnavhe und Soviëvhe empfangen und von den Häuptlingen begrüsst, mit welchen wir bei den grossen Festen in Kpando bereits Freundschaft geschlossen hatten. Der Marsch führte durch eine reiche Gregend mit vielen Yams und Maisfarmen, die auf den Lehnen der kleinen Höhenzüge angelegt waren. Es sind die südlichen Ausläufer des Lavanyo-Gebirges, welches sich in südwestlicher Richtung bis an den Volta herunterzieht. Die kleinen Bergketten setzen sich dann auf dem linken Ufer des Volta weiter nach Süden fort, bis sie sich mit den südlichen Ausläufern des AgomeGebirges vereinigen und in den Aframamebergen bei Akwamu ihr Ende erreichen. Gleich hinter Kpando marschierten wir durch hohes Schilforas und hinter Akhnavhe gelangten wir zu den vorerwähnten kleinen Bergketten, über welche wir unseren Weg nehmen mussten. In einer Höhe von hundert Metern begrenzten einzelne Kuppen im Westen unseren Pfad. Eine grosse Fruchtbarkeit war überall in den Thälern zu bemerken. Am Fusse dieser kleinen Berge liegt die nächstgrössere Stadt Soviëvhe. Massenhaft standen an den kleinen Wasserrinnen und Gebirgsbächen selten schön entwickelte Oelpalmen. In Soriërhe erkundigte ich mich genau nach der Grenze der Landschaft Anfoë, sowie nach dem Weg und der Lage des Ortes. Bereitwilligst wurden uns Führer zur Verfügung gestellt und bald setzten wir uns wieder in Bewegung, damit uns keine Boten vorauseilen und die Anfoë-Leute von unserer Ankunft benachrichtigen 
konnten. Zu diesem Zweck hatte ich sowohl in Aknavhe als auch in Soviëvhe bei meiner Ankunft die Wege, welche nach Anfoë führtén, durch Posten gesperrt, denn in Afrika verbreitet sich die Nachricht von den Bewegungen einer Karawane oder Expedition und der Ankunft eines Weissen mit ausserordentlicher Geschwindigkeit. Durch ein plötzliches Erscheinen wird bei diesem kopflosen Negervolk viel gewonnen, denn der Neger braucht viel Zeit zur Ueberlegung, ehe er handelt. Dies machen sich auch die arabischen Sklavenräuber zum Vorteil, eine kleine Schaar überfällt noch vor Morgengrauen das Dorf und alle waffenfähigen Männer verlassen schlaftrunken unter Zurücklassung ihrer Waffen in eiligster Flucht ihre Wohnungen. So kann man durch einen Eilmarsch manchem Gefecht und Kampf vorbeugen.

Noch ehe wir die Grenze des feindlichen Gebietes überschritten hatten, kam der schwarze Sergeant Mollu zu mir und sagte in seinem Negerenglisch: "Massa, I think we send one spitze". Der vorsichtige Mollu hatte nicht Unrecht; ich liess daher die Truppe halten und sandte eine Spitze unter einem schwarzen Unteroffizier voraus, der genau den Weg zu untersuchen hatte, während drei Leute auf dem schmalen Pfade die Verbindung mit dem Haupttrupp aufrecht erhielten. Der Sergeant Mollu befehligte in Ermangelung eines Weissen das Gros, während ich mich selbst an die Spitze begab. Nachdem so die Truppe formiert war, liess ich scharf laden und marschierte weiter über den kleinen Bach Sadome, einen linken Nebenfluss des Danyi. Viele Farmen, die noch zu Soviërhe gehörten, wurden passiert und bald überschritten wir die Grenze von Kpando. Ein dichter Busch umgab den schmalen Pfad; indessen erreichten wir unbehindert den Marktplatz von Anfoë, Adame. Die Kinder und Weiber flüchteten schleunigst und warfen ihre mit Wasser angefüllten Kalabassen auf die Erde.

Verhandlung

In Geschwindschritt drangen wir in das Dorf selbst ein, wo ich auf mit dem einem ziemlich grossen Platze vor der Königshütte die Truppen in zwei Häuptling von Gliedern aufmarschieren liess. Teils ängstlich, teils neugierig schaute Antoë das Volk in einiger Entfernung diesem militärischen Treiben zu und bald war die Kunde von unserem Erscheinen durch den Ort und zu den benachbarten Dörfern gedrungen. Sogleich war auch der König benachrichtigt und nahm mit seinen Grossen und Würdenträgern vor seiner Hütte auf der anderen Seite des Platzes gegenüber den Soldaten Platz. Auf der Seite meiner Soldaten liess ich mir meinen Feldtisch und Stuhl aufklappen und setzte mich ebenfalls, während ein Posten vor Gewehr die neugierige Menge abhielt. Die Soldaten waren abgetreten, hatten jedoch die strikte Weisung, sich direkt hinter den Gewehrpyramiden aufzuhalten, um jeden Augenblick an die Gewehre treten zu können. Unterdessen hatte der König einen englischen 
Händler, der als Dolmetscher fungierte, zu mir mit der Nachricht resandt, dass er bereit sei, mich zu empfangen. Um nun sufort einen Trumpf gegen das hochfahrende Wesen des Häuptlings auszuspielen, liess ich ihm erwidern, dass ich ron dem weiten Marsche zu ermüdet sei, um zu ihm zu kommen und dass er gut thun würde, sich zu mir zu begeben, da ich mit ihm ein ernstes Wort zu reden habe. Angesichts der rerhältnismässig vielen Soldaten wurde der grosssprecherische Häuptling kleinmütiger und auch die Familienoberhäupter schienen in der Mehrzahl dafür zu stimmen, dass der König nachgeben und mir zuerst den Besuch machen sollte. Die jüngeren Leute waren jedoch anscheinend dagegen und so wurde ein ziemlich heftiges Palaver gefuhrt, bis schliesslich doch der Rat der alten Leute die Oberhand gewann. Der König schickte wiederum seinen Dolmetscher zu mir, um mir zu sagen, dass er bald kommen würde. Ich liess ihm danken und forderte ihn auf, sich ein wenig zu beeilen, da ich nicht lange Zeit am Orte zu bleiben beabsichtige. Dieses that ich, um schon vor dem Palaver einen gewissen Einfiuss auszuüben und den König gefügiger zu machen. Ich hatte hierzu allen Grund, da der Häuptling früher den Grafen Pfeil, welcher damals vertretungsweise in Togo als Reichskommissar fungierte, bei seiner Anwesenheit in Anfoë hart bedrängt hatte. Graf Pfeil hatte żu jener Zeit nur wenig Soldaten bei sich und als er dem Häuptlinge wegen der Schwierigkeiten, welche er den Händlern aus dem deutschen Gebiet in den Weg legte und wegen dem Vorschub, den er den Hetzereien der englischen Händler leistete, Vorstellungen machte, kündete er dem Grafen Pfeil an, dass derselbe sofort den Ort und die Landschaft zu verlassen hätte, anderenfalls er ihn angreifen würde. Eine Flaggenhissung wurde kategorisch von ihm abgelehnt, da er die englische Flagge gewählt habe. Die englische Flagge wurde gehisst und nur durch baldigen Abzug konnte Graf Pfeil sich aus der Affaire ziehen. Ueberall in diesem deutschen Gebiet hatte sich der englische Einfluss unrechtmässig breit gemacht, die englischen Händler verteilten selbst englische Flaggen und spielten sich als Herren des Landes auf, während sie die deutschen Händler rollkommen verdrängten.

Infolge meines energischen Auftretens besuchte mich der König mit seinen sämtlichen Würdenträgern, die sich um ihn geschart hatten. Eine grosse Menschenmenge füllte den weiten Platz und eine gewisse Aufregung und Spannung machte sich bei dem ganzen Volke bemerkbar. Der König trug ausser einem grossen Eingeborenen-Tuch viele Fetischembleme um den Hals und an den Armen. Ich fragte ihn zunächst, warum er nicht unserer Aufforderung gemäss nach Kpando gekommen wäre, worauf er sich damit entschuldigte, dass er nach der Aussage des Boten geglaubt habe, es handle sich darum, sich Dakadu unterzuordnen. 
Er sei aber ein freier Häuptling und wolle sich nicht unter die Herrschaft von Kpando stellen lassen. Dakadu nämlich hatte die Gelegenheit benutzen wollen, um für sich Propaganda zu machen und hatte absichtlich eine falsche Nachricht nach Anfoë gesandt, während er uns berichtete, dass der Häuptling unsere Bestellung erhalten habe, aber nichts mit den Weissen zu thun haben wolle. Damit war der Irrtum aufgeklärt und den Häuptling traf keine Schuld. Ich machte sodann den Häuptling darauf aufmerksam, dass die Landschaft deutsches Gebiet sei. Aus diesem Grunde forderte ich ihn auf, sämtliche englischen Flaggen, die sich in der Stadt befänden, innerhalb einer Stunde herauszugeben, damit sie der englischen Regierung zurückgesandt werden könnten, anderenfalls ich jeden in dem Orte streng bestrafen würde, bei dem ich eine englische Flagge fände. Der Häuptling versicherte mir hoch und teuer, dass er wohl früher englische Flaggen aufgezogen habe, dass sich aber jetzt keine mehr in dem Orte befänden. Ich liess es dabei bewenden. Da er mich nach Negerart beeinflussen wollte, wurden mir reichliche Geschenke, Schafe und Ziegen, Yams und Reis dargeboten. Ich dankte ihm und entliess ihn mit der Mitteilung, dass ich nach einer Stunde das Palaver fortsetzen würde und dass er sich bis dahin überlegen möge, was er nun, nachdem ihm die Sachlage klar wäre, zu thun gedenke. Inzwischen nahm ich das aus Kpando mitgenommene Frühstuick ein und notierte mir einige Reiseskizzen über den zurückgelegten Weg. Nach Verlauf von ungefähr einer Stunde machte ich dem König einen Gegenbesuch und übergab ihm einige Geschenke als Erwiderung fur die seinigen.

Flaggenrissung in Anfoë
Mein Dolmetscher war über den ganzen Gang der Ereignisse vollkommen orientiert und meldete mir, dass der König mit den Familienoberhäuptern beratschlagt habe, ob sie die deutsche Flagge annehmen sollten oder nicht. Es, war ihnen mittlerweile doch klar geworden, dass die deutsche Regierung eine grössere Macht besässe, als die englischen Händler behaupteten; schliesslich entschied sich der König dahin, um die deutsche Flagge zu bitten. Ich hielt ihm zunächst alle seine früheren Vergehen vor und sagte ihm, er verdiene zwar unsere Flagge nicht, der deutsche Kaiser sei aber so mächtig, dass er gegenüber einem so kleinen Häuptling Gnade für Recht ergehen lassen würde. Nachdem dann der Häuptling noch eine Urkunde unterschrieben - hatte, in welcher er gelobte, stets treu zur deutschen Flagge zu stehen, die deutschen Interessen zu wahren und den Handel zu fördern, willigte ich in die Uebergabe der Flagge. Zaghaft unterzeichneten noch einige Würdenträger zur Bekräftigung das Protokoll. Von dem Dolmetscher unterrichtet, berührten sie ängstlich mit der Hand den Federhalter, worauf der Dolmetscher unter das Protokol ${ }^{\ddagger}$ drei Kreuze als Namenszeichen setzte. 
Am Nachmittage wurden nun die Vorbereitungen zu der feierlichen Flaggenhissung getroffen. Ein mächtiger Stamm wurde vor dem Gehöft des Königs eingegraben und daran eine Schnur befestigt, die die Flagge halten sollte. Die Trommeln des Königs hatten das Volk schnell herbeigerufen und der Platz hatte sich mit einer grossen Menschenmenge gefüllt. Die Soldaten waren unter Gewehr getreten und hatten gegenüber dem Flaggenstock Aufstellung genommen. Auf der anderen Seite stand der König mit seinen Würdenträgern und nun begann der feierliche Akt. Es wurde "Stillgestanden" kommandiert, das Gewehr übergenommen, ich bestieg als echter Kavallerist meinen Gaul und unter präsentiertem Gewehr und Trommelwirbel der Spielleute wurde die Flagge gehisst. Ein dreimaliges Hoch auf Seine Majestät wurde von mir ausgebracht, das die Menge mit Jubelgeschrei beantwortete. Ich schüttelte nun nochmals dem Häuptling zur Bekräftigung der Freundschaft unter wiederholter Ermahnung, treu zur deutschen Flagge zu stehen, die Hand; dann erfolgte das Kommando: „Hoch legt an!" - „Feuer!“ — und eine dreimalige Salve dröhnte in dem von Bergen umgebenen Thale. Bei dieser Gelegenheit war mein sonst zahmer Gaul unruhig geworden und da den kleinen Pferden unsere Sattelgurte nicht ordentlich passen, rutschte ich bei dem Steigen meines mutigen Afrikaners unvorhergesehen auf die Kruppe desselben. Schnell sprang ich aus dem Sattel und kommandierte die nächste Salye zu Fuss. Da der Unfall ziemlich glatt verlief und keine Störung verursachte, so glaubten natürlich die Eingeborenen, die eine solche Zeremonie noch nicht mit erlebt hatten, dass mein unfreiwilliger Abstieg mit zu dem ganzen Schauspiel gehöre. Nur einzelne grinsende Gesichter meiner Soldaten verrieten den wahren Sachverhalt, während der Häuptling und die übrigen Würdenträger andächtig dem sanzen Vorgang folgten. Leider hatte ich durch meinen starken Händedruck den armen Häuptling schwer geschädigt und gekränkt, was ich aber erst später, als ich zur Küste zurückgekehrt war, erfuhr. Der Häuptling von Anfoë beschwerte sich nämlich bei der Landeshauptmannschaft darüber, dass ich ihn seines Fetischnagels an dem kleinen Finger beraubt hätte. Dieser Nagel wird peinlich behütet und darf nicht abgebrochen werden weil sonst nach dem Volksglauben ein Unglück über den Besitzer hereinbricht. Dèr Nagel soll auch bei dem sogenannten Fetischtrinken eine bedeutende Rolle spielen, weil in demselben häufig das tötliche Gift verborgen, von dem Fetischpriester ungesehen in das Trinkgefäss hineingeworfen und alsdann dem ahnungslosen Opfer zum Trunke gereicht wird. Inzwischen hatte sich das Gerücht von der Annäherung eines Weissen mit vielen Soldaten verbreitet und bald war auch die Flaggenhissung in Anfoë weit im Umkreis bekannt. Eine Ueputation der Landschaft Tafi mit dem Häuptling erschien und bat um die deutsche Flagge. 
Naciidem auch dieser die Oberhoheit der deutschen Regierung anerkannt hatte, übergab ich ihm für die Landschaft Tafi eine Flagge; da ich des Abends wieder in Kpando sein musste und keine Zeit hatte, selbst die Flaggenhissung vorzunehmen. Ich kehrte noch an demselben Tage mit der Truppe zurück und gelangte auch glücklich nach Kpando, wo Oberleutnant v. Döring mit dem Botaniker Baumann meine Ankunft erwarteten Noch an demselben Abend machte Dakadu seine Aufwartung, um zu fragen, wie uns die Reise bekommen wäre. Eigentlich wollte er nur Näheres über den nach afrikanischen Begriffen grossen Kriegssug erfahren; statt dessen erhielt er aber eine Rüge für seine Lügen und Intriguen.

Marsch von

Wir beschlossen am nächsten Tage aufzubrechen und weiter über Kpando nach Kunya nach Kratyi zu marschieren. In aller Frühe wurde Reveille der Land- geblasen; die Koffer, Kisten und Kasten wurden schnell zusammenschaft Kunya. gepackt, das Zelt abgebrochen und bald war alles zum Abmarsch bereit. Wir gingen noch früh zum König Dakadu und nahmen von ihm in förmlicher Audienz Abschied. Noch ein Mal erwiderte Dakadu mit seinen Würdenträgern unseren Besuch, wünschte uns glückliche Reise und bat uns, recht bald wiederzukommen und das nächste Mal längere Zeit bei ihm zu verweilen. Die Häuptlinge sind nämlich unter sich eifersüchtig und misstrauisch, wenn der Weisse einem von ihnen mehr Freundschaftsbezeugungen erweist als dem andern; die Macht und das Ansehen eines bevorzugten Häuptlings werden gehoben, wenn der Weisse in seiner Stadt länger und öfter verweilt. Andererseits locken ihn auch die Geschenke. Nachdem zum Aufbruch geblasen and die Truppe angetreten war, marschierten wir unter dem Spiel der Trommler und Pfeifer: "Muss i denn, nuss i denn zum Städtle hinaus" in der Kolonne zu zweien auf der verhältnismäsșig grossen Strasse nach dem Vorort Aloë aus der Residenz des Königs Dakadu heraus.

Im Westen des Weges ziehen sich die Vorberge des Lavanyogebirges hin, während im Nordosten dieses selbst sich erhebt. Bald hatten wir die nächste Vorstadt Abahung erreicht und gelangten durch eine hohe Grassavanne und einen dichten Busch bis zu dem Dorf Fesi, wo eine kleine Rast gemacht wurde und Träger wie Soldaten ihren Durst mit dem bereitwilligst herbeigebrachten Wasser stillten. Als wir aus dem Orte marschierten, lief ein altes ärmlich bekleidetes Weib unserer Karawane nach und bat die Soldaten um Schutz. Wir erfuhren von diesen, dass die Frau eine Sklavin sei, die von ihrem Herrn verkauft werden sollte und es vorgezogen habe, ihm zu entlaufen. Auf die flehentlichen Bitten der Alten liessen wir sie mit uns ziehen. Sie kochte von nun an für die Soldaten und machte sich im Lager durch Feuermachen, Wassertragen und andere Arbeiten nützlich. SolcheVorfälle 
sehen die Träger und Soldaten recht gern, geben aber gewöhnlich dem Weissen erst nach einigen Tagen davon Kunde, wenn die Reise bereits so weit fortgesetzt ist, dass man die Hilfe suchende Person mitführen muss, um sie nicht völlig preiszugeben. Unser Weg führt nun durch üppigen Busch und über die Quellflüsse des kleinen Flüsschens Ekpenne Weiter; wiederum berühren wir in dieser bevölkerten Gegend ein kleines Dorf Agbonohué. Die Quellflüsse kommen alle von dem Lavanyogebirge, welches sich jetzt im Osten steil erhebt, während im Westen die kleinen Berge und Hügel mehr an die Strasse herantreten. Wir wandern über kleine Erhebungen durch einen schönen Oelpalmenhain, der die kleinen Bäche einrahmt und sich fast bis zu dem Orte Dafo erstreckt. Dafo ist der letzte Ort, welcher im Norden der Landschaft Kpando an dieser Strasse liegt. Mit ihm verlassen wir die Landschaft Kpando und das ron uns durchreiste Evhegebiet.

Nach kurzer Zeit haben wir die Grenze erreicht, in einer grossen hohen Grassavanne marschieren wir in die Landschaft Kunya ein und schon der Gruss der Eingeborenen zeigt uns an, dass wir das neue Sprachgebiet der Kyerepong- oder Guanisprache betreten haben. Noch des Abends gelangen wir in die Hauptstadt von Kunya, um sodann in die Residenz des Königs der Landschaft Kunya, Ntshumuru, einzurücken. An einem mächtigen Flaggenstock wehte uns schon von weitem die deutsche Flagge entgegen, was uns hier in der Wildnis des schwarzen Erdteils eigentümlich berührte und in freudige Stimmung versetzte. Der alte Häuptling empfing uns vor seinem Gehöft und brachte uns eine grosse Anzahl von Geschenken, darunter die üblichen Ziegen und Schafe und einen sehr guten Palmwein, denn er war weit und breit als Feinschmecker bekannt. Sein Sprecher war ein grosser schöner Mann mit einem mächtigen Henri-quatre, der nicht echt, sondern künstlich verlängert und mit Fett elegant und spitz gedreht war. Wir schlugen auf dem kleinen Platz vor dem Gehöft des Häuptlings unser Lager auf und ausserdem stand uns ein kleines aber sauberes Gehöft des Königs zur Verfügung. Bald nach unserer Ankunft bestiegen wir wieder unsere Pferde, um dem schwarzen Missionar Mr. Hall einen Besuch abzustatten. Mr. Hall ist ein intelligenter Mann, der in der Baseler Mission ausgebildet und gleich den weissen Missionaren Pfarrer der Baseler Missionsstation ist, die in Kunya ihren Sitz hat. Er spielt bei vorkommenden Gelegenheiten liebenswürdig den Dolmetscher zwischen dem Häuptling und den durchziehenden Weissen.

Der Abend war herangebrochen und wir sassen friedlich vor dem Zelte àn unserem Feldtisch. Der Koch hatte uns mit einer gebratenen Hammelkeule überrascht, welche uns sehr gut mundete. Wir waren in bester Laune und unterhielten uns über die auf unserem weiteren 
Marsche zu treffenden Maassnahmen, als ein Bote mit einem Briefe ankam. Derselbe wurde sofort geöffnet. In schlechter englischer Schrift wurde uns von einem Händler im Namen des Häuptlings von Tafi mitgeteilt, dass die Ortschaften Biakpa und Vhane der LandAvatime an Tafi den Krieg erklärt hätten, weil Tafi die deutsche Flagge genommen und Peki, das auf englischem Gebiet liegt, verraten habe. Der Häuptling von Peki hatte früher die Herrschaft über die nördlich liegenden Landschaften, wie Tafi und Avatime und über die Häuptlinge dieser Landschaften. Da die Handelsinteressen derselben, wie wir gesehen haben, sich früher ausschliesslich nach dem Süden hin in das englische Gebiet erstreckten und die englischen Händler sowie der mächtige Häuptling von Peki die englischen Interessen unterstützten, so betrachteten sich die Häuptlinge von Tafi und Avatime als englische Unterthanen. Man wollte deshalb die Landschaft Tafi, welche die deutsche Flagge genommen hatte, bestrafen. Im Grunde jedoch beabsichtigten die Häuptlinge von Biakpa und Vhane ihre alte Fehde gegen den benachbarten Tafi-Häuptling auszufechten und glaubten, gestützt auf die englische Macht, gegen denselben einen vorteilhaften Raubzug ausfuhren zu können.

Zug gregen

Bialipa und

Vhane zur

Unterstützung des

Häuptlings von Tafi

Wir beschlossen natürlich sofort, unserem jüngsten Bundesgenossen in Tafi jegliche Hilfe angedeihen zu lassen, ganz früh am Morgen aufzubrechen und in einem Dauermarsch über Kpando nach dem bedrängten Tafi zu eilen. Wir hatten uns geeinigt, den Marsch ohne weiteres Gepäck zu machen und ausser den erforderlichen Küchenvorräten und den nötigen Patronen alles Entbehrliche in Kunya unter Aufsicht des Mr. Hall, der uñs darin liebenswürdig unterstützte, zurückzulassen. Die Bevölkerung von Kunya, die als leichtsinnig bekannt ist, feierte unsere Ankunft bei Trommelschlag, Tanz und Gesang. Bald wiegten sich unsere Soldaten und Träger in frölichem Tanz mit den schwarzen Schönen und manches Herz wurde gebrochen, denn auch der schwarze Soldat denkt: „And're Städtchen, and're Mädchen." Aber am frühen Morgen störte das wohlbekannte Alarmzeichen die Freude und der unvermeidliche Dienst forderte seine Rechte; mancher junge schwarze Krieger musste sich erbarmungslos von der Seite seiner schnell eroberten Angebeteten losreissen. Bald standen die Soldaten in Reih und Glied, Gewehr bei Fuss, während die Träger, nichts Gutes ahnend, grosse Lust verspürten sich zu drücken. Mit Mühe und Not wurden 12 Träger, welche die Patronenkisten tragen sollten, herangeholt und von Soldaten bewacht, clamit sie nicht bei irgend einer Gelegenheit das Weite suchten.

Ganz Kunya war in grosser Aufregung und der König fragte, was wir vorhätten und ob wir etwas gegen ihn unternehmen wollten. Wir versicherten ihm, dass wir dazu keine Ursache hätten, unsere sämtlichen 
Lasten bei ihm lassen und bald wieder zurückkehren würden. Iie Veugier und Angst des Volkes war gross. Ueberall guckten die aus dem Schlafe geschreckten Eingeborenen hinter ihren Zäunen und Mauern hervor und umdrängten unsern Zug. Bei trübem Mondschein zog sich im sogenannten Gänsemarsch die grosse Karavane hin, lautlos und schweigend rückten wir durch das friedliche Terrain; wir drei Europäer hinter der Karawane, un etwaige Ausreisser und Nachzügler sofort festhalten zu können. Bald wurde das Schweigen und das bedrückende Gefühl, das sich der ganzen Truppe bemächtigt zu haben schien, durch den Gesang des auch unseren Schwarzen wohlbekannten Liedes: „Ich hat einen Kameraden" - unterbrochen und als auch die Spielleute und die alten Lnteroffiziere, die das Lied oft an der Küste gehört hatten, einfielen, trat eine fröhliche und gehobene Stimmung in der ganzen Kolonne ein. Die Leute, welche das Lied nicht auf deutsch nachplappern konnten, sangen auf ihre Weise in Evhe oder auch in Haussa, gerade wie ihnen der Schnabel gewachsen war, ihre heimatlichen Kriegslieder. Sie ahnten allmählich, um was es sich handelte; die gefüllten Patronentaschen, sowie die Massenmunition liessen auf einen Kriegszug schliessen. Die Truppe, welche bis dahin noch keine eigentliche Feuertaufe erhalten hatte, brannte in dem Bewusstsein ihrer Ueberlegenheit darauf, sich auszuzeichnen und auch die Hoffnung auf Beute erhöhte ihre Kampfbegier. Beschwerlich war der Marsch über die kleinen Rinnen und Bäche, welche den Busch durchzogen und alle Augenblicke stolperten einige Leute über Baumwurzeln oder Steine. Obwohl wir den Soldaten den Befehl erteilt hatten, in den Dörfern sich ruhig zu verhalten, so waren doch durch das unvermeidliche Geräusch, das eine grosse Karawane verursacht, die Leute zum grossen Teil aus ihrem Schlaf aufgeschreckt; sie flohen unter Zurücklassung ihrer ganzen Habe in den Busch und nur einige beherzte Männer sowie alte Weiber, die nicht so rasch fortkommen konnten, blieben in den Dörfern zurück. Die Zurückgebliebenen wurden jedoch bald beruhigt und sogar mit Geschenken zum Häuptling gesandt, um unsere friedliche Absicht kund zu thun. Alsbald erschien der Häuptling, um sich zu bedanken und auch das Volk kehrte in die Hutten zurück.

Die Wege an unseren Rastplätzen waren vorher durch Machen gesperrt worden, damit sich die Nachricht von unserem Zuge nicht weiter verbreitete. Der Tag fing an zu grauen, als wir wieder Fesi erreichten. $\mathrm{Zu}$ meiner Ueberraschung bemerkte ich beim Tageslicht, dass das Pferd des Herrn ron Döring seine Farbe verändert hatte; der alte Fliegenschimmel hatte bei näherer Betrachtung eine gelbbraune Jacke bekommen. Der Pferdejunge wurde ins Verhör genommen und es ergab sich, dass er das Pferd nach Haussaart mit Tabakslauge ein- 
geschmiert hatte, um die lästigen Zecken abzuhalten. Diese Schmarotzer, welche in Afrika besonders zahlreich auftreten, entziehen dem Pferde die Lebenskraft; man hat daher sehr darauf zu achten, dass es beim Putzen von dem Ungeziefer befreit und namentlich die Mähne, die Schwanzwurzel und das Innere der Ohren genau besichtigt werden. Da sich die Blutsauger besonders an diesen Stellen festsetzen, ist es praktisch, die Mähne nach englischer Manier kurz zu schneiden. Der gute Haussajunge hatte uns durch seine Manipulation auf lange Zeit grosses Vergnügen bereitet.

Mit Tagesanbruch zogen wir wieder in die Hauptstadt ron Kpando ein. Eine grosse Menschenmenge begleitete unseren Zug und die alten Bekannten gaben ihrer Freude Ausdruck, uns nach so kurzer Zeit schon wieder zu sehen. Der gütigen Einladung des schwarzen Missionars entsprachen wir gern, da wir noch nichts Warmes genossen hatten. Auf dem Königsplatze wurde-das Lager aufgeschlagen und auch den Soldaten und Trägern eine kurze Zeit zum Abkochen gegeben. Auch hier hatte sich sofort, da im Süden -der Stadt die Ausgänge gesperrt wurden, die Nachricht ron einem Kriegszuge verbreitet. Das Gerücht von der kriegerischen Haltung der Avatime-Ortschaften Biakpa und Thame gegen Tafi und der Hịlferuf des Tafihäuptlings an uns war schon bis Kpando gedrungen. Dakadu empfing uns, liess die Trommel ruhren und bald waren sämtliche Würdenträger um ihn versammelt, die nun unter sich über die Ereignisse berieten. Dakadu bat uns, wieder zu einem Palarer zu erscheinen, da er uns etwas Wichtiges mitzuteilen hätte Wir folgten der Einladung und vor der Königshalle wurde nun in üblicher Weise das Palaver abgehalten. Dakadu teilte uns mit, er habe gehört, dass wir dem Häuptling von Tafi zu Hilfe zögen und denselben in dem Kriege gegen Biakpa und Thame unterstützen wollten. Er drückte sein Bedauern aus, dass wir ihm, als Bundesgenossen, nicht Mitteilung davon gemacht hätten, da er doch als unser Freund verpflichtet wäre, mit uns zu ziehen. Er wolle dies noch jetzt thun und ebenfalls gegen unsern Feind kämpfen. Der ganze Rat stimmte der Rede des Königs bei und bestätigte dies durch ein lang gedehntes "Ähä, Ähä", d. h. "Ja, so ist es gut". Da uns nicht genau bekannt war, wie weit die Peki-Leute bei dieser Sache engagiert waren, so nahmen wir Dakadus Anerbieten an und gestatteten ihm uns zu folgen. Der schlaue Dakadu sagte sich ohne $Z$ wreifel, dass der, Weisse der Stärkere sei und deshalb eine gute Beute für ihn und seine Leute abfallen würde. Andererseits aber wollte er den Weissen auch unterstützen, um seinem mächtigen Nachbarrival von Paki eine Niederlage zu bereiten.

Nachdem unsere Soldaten abgekocht hatten, marschierten wir weiter über Kudjora und den Danyifluss nach Tafi. Letzterer wurde auf 
einem grossen baumstamm passiert, wobei manche drollige Scene sich ereignete. Der glatte Baumstamm war nur fur sehr geschickte Leute cine sichere Passage. Viele Träger und Soldaten zogen es deshalb vor, den Fluss, der zur Zeit ziemlich seicht war, zu durchwaten. Zu diesem Zwecke entledigten sie sich ihrer Uniformen, banden sie mit dem Seitengewehr und den Patrontaschen in ein Bündel zusammen und trugen das Ganze auf dem Kopfe durch den Fluss. Es war ein Freudenfest für unsere Leute, wieder einmal ein schönes Bad nehmen zu können, denn der Küstenneger ist bekanntlich sehr reinlich und tummelt sich, sobald es seine Zeit erlaubt, entweder im Meere oder in der anstossenden Lagune. Einige Leute versuchten auf dem Stamm reitend den Fluss zu passieren und purzelten dabei häufig unter allgemeinem Gelächter kopfüber ins Wasser. Auch die Haussa, die aus dem Innern kommen und sich im Wasser weniger zu Hause fühlen, nahmen in ihren grossen Pumphosen und der langen Haussatobe auf dem Baumstamme reitend das Hindernis. So bot, dieser Uebergang eine aufheiternde Abwechselung auf dem langen Marsche. Es ging dann auf einem engen Pfade in gewundener Linie durch einen grossen, fast undurchdringlichen Busch über kleine Nebenflüsse und Bäche, welche der Danyifluss von Osten her aufnimmt. Die Sonne neigte sich schon bedenklich zum Untergange, als wir endlich die Farmen erreichten; menschliche Stimmen, sowie das Gebell der Hunde kündigten die Nähe ron Tafi an.

Ohne weiteren Aufenthalt marschierten wir in die Stadt ein und Feldlager in machten auf dem Marktplatze Halt, wo uns jubelnd eine grosse Menge Volks erwartete. Viele Leute hatten Kriegsschmuck angelegt, sie waren mit Messern, Patronentaschen sowie mit den uns wohlbekannten Daneguns, den alten dänischen Steinschlossflinten, ausgerüstet. Viele Krieger trugen auch sogenannte Kriegskappen, welche mit Kauris geschmückt waren und wie runde, aus Flechtwerk hergestellte Körbchen aussahen. Der Häuptling des Ortes, welcher wenig Intelligenz besass, hielt es nicht für nötig, uns zu begrüssen oder ein Quartier durch seinen Sprecher anweisen zu lassen. Wir gingen daher mit unserm Dolmetscher zu seinem Gehöft, wo er vor einer Hütte unter einem alten Grasdach stumpfsinnig und teilnahmslos dasass. Einige Händler, die als Dolmetscher fungierten, schienen die Regierung zu fuhren und den König vollkommen zu beherrschen. Nach langem Hin- und Herreden wurde uns schliesslich ein Gehöft zum Quartier angewiesen und eine so geringe Menge Yams als Geschenk gegeben, dass sie kaum für uns drei Europäer hinreichte. Ich liess den Häuptling bitten, dass er die Leute anweisen solle, Yams Reis und andere Lebensmittel ron den Farmen zu holen und sie zu den ühlichen Landespreisen an die Soldaten und mitgebrachten Kpandoleute 
zu verkaufen. Leider wurde dieser Aufforderung von dem Könige und dem Volke nicht entsprochen, da es fürchtete, die Lebensmittel umsonst hergeben zu müssen. Mittlerweile war ein frugales Abendbrot, das wir unter einem grossen Feigenbaum auf dem Marktplatze einnahmen, in der Gestalt einiger gekochter Hühner ohne irgend welche Beigabe, hergerichtet. Sogar das Salz fehlte. Zu unserem nicht geringen Verdruss hatte nämlich der Träger, welchem die Kochlast anvertraut war, aus Angst vor den kommenden Ereignissen dieselbe in den Busch geworfen und war heimlich verschwunden. Etwas Fufu ergänzte unseren Speisezettel. Ein weiterer Disput über die zu ergreifenden Maassregeln liess uns übrigens wenig Zeit an lukullische Genüsse zu denken.

Bald nach dem Einmarsch wurde durch Unteroffizierpostén, sowie durch eine Vorpostenkette und Patrouillen die Sicherung von Tafi hergestellt. Im allgemeinen ist die Sperrung eines solchen Ortes ziemlich einfach, da nur wenige Wege zu den umliegenden Ortschaften führen und diese meistens nur kleine, 2 Fuss breite Pfade sind, welche sich durch den undurchdringlichen Busch hinwinden. An diese Strassen werden nun die Unteroffizierposten gelegt, welche ihrerseits wieder durch eine Vorpostenkette vor einem Ueberfall gesichert sind. Die Hauptstrassen, welche wir zu sperren hatten, waren die Strassen nach Yogbe, welches schon in Avatime liegt, und nach Tafi-Mando, welches weniger gefährdet schien, da Mando noch zur Landschaft Tafi gehört. Während wir noch bei Tische unter dem grossen Baume sassen und von den Strapazen des Marsches ausruhten, hörten wir von weitem Trommelschlag und bald wurde uns gemeldet, dass der König Dakadu mit vielen Kriegern im Anmarsche auf Tafi sei. Das Trommeln kam immer näher und bald marschierte die Truppe der Krieger in die Stadt ein. Dakadu hatte nach unserer Schätzung 300 bis 400 Krieger gesammelt und war uns so schnell wie möglich auf dem Kriegspfade gefolgt. Einen eigentümlichen Anblick gewährten die einzelnen Gruppen, die alle im Kriegsschmuck mit Gewehren und Speeren, sowie mit ihren Fetischemblemen auf dem Marktplatz an uns vorüberzogen. Voran marschierten die Leute von Kpando selbst in stattlicher Menge; vorweg die Trommelschläger des Königs mit grossen Kriegstrommeln, an denen die Köpfe ron besiegten Feinden als Trophäen angebracht waren. Grausig sah es aus, wenn die Schädel beim Trommeln nickten. Dahinter kam in würdiger Haltung unser alter Freund Dakadu, angethan mit dem Kriegsschmuck, dem früher erwähnten Fetischhelm und einem alten Kriegswams der Haussaleute. An dem Haussahemd waren ausser den Amuletten der Haussa viele Fetischembleme in Gestalt von Kauris, Leopardenzähnen und Klauen angenäht. Auf den Schultern hatte der gute Dakadu gleich unseren Achselstücken als königliches Abzeichen 
weisse Straussenfedern befestigt. In kleinen Trupps folgten die einzelnen Kpando-Ortschaften mit ihren Häuptlingen an der Spitze. Crruppen zu vier und fünf Mann marschierten würdig und siegesbewusst im Kriegsschmuck an uns vorüber, als wollten sie salutieren, meistens nur mit einem kleinen Schamtuch bekleidet, welches um die Hüften geschlungen und zwischen den Beinen durchgezogen war. Viele hatten Patronengürtel und die uns wohlbekannte, aus Binsen geflochtene Kriegskappe angelegt; fast jeder trug ein Messer im Gürtel, die meisten waren mit der Steinschlossflinte bewaffnet, deren Kolben mit vielen Fetischemblemen über die Schulter in die Luft ragte. Einzelne waren nur mit Haumessern rersehen, während andere einen Kriegsspeer in der Hand trugen. Die Nacht war hereingebrochen und überall loderten auf dem Marktplatz in dem Dunkel der Nacht die kleinen Lagerfeuer empor. Bald jedoch stellte sich infolge der Unklugheit und des Starrsinns dés Häuptlings von Tafi, der einen Krieg ohne jedes Opfer fuhren zu können glaubte, der Mangel an jeglichen Nahrungsmitteln für die grosse Anzahl der Krieger heraus, was zu Tumulten und schliesslich zu kleinen Schlägereien zwischen den Eingeborenen und Kpandoleuten führte. Wir wollten uns gerade in einem armseligen Gehöft zur Ruhe begeben, als Dakadu mit den übrigen Häuptlingen zu uns kam und uns um eine Rücksprache betreffs der Verpflegung bat. Dakadu erklärte uns, dass, wenn der Häuptling von Tafi die Herausgabe von Nahrungsmitteln verweigere und wir nicht einschritten, er seine Leute von Plünderung, sowie von Mord und Totschlag nicht zurückhalten könne. Wir versammelten darauf sämtliche Krieger und unsere Leute auf dem grossen Marktplatze und liessen ihnen verkünden, dass niemand das Recht hätte, sich gewaltsam Nahrungsmittel zu verschaffen, sie sollten sich gedulden, bis wir Rat geschafft hätten. Wir versprachen dafür zu sorgen, dass jeder das Nötige erhalten würde. Hierauf begaben wir uns sofort zu dem Häuptling von Tafi und machten ihm klar, dass, da er uns zu Hilfe gerufen habe, er auch verpflichtet sei, für den nötigen Proviant der Leute zu sorgen. Als er dennoch hartnäckig die Verabfolgung von Nahrungsmitteln verweigerte, liessen wir ihm sagen, dass wir den Kriegern, sowie unseren Leuten seine Yams- und Maisfarmen preisgeben müssten, dass wir ihn jedoch später entschädigen würden. Dieser Beschluss wurde mit lauter Stimme von dem Dolmetscher auf dem Markte verkündet und mit unglaublicher Freude von den Kriegern und unseren Leuten aufgenommen. Alles strömte hinaus auf die Farmen, um ansehnlichen Vorrat an Yams und Mais herbeizuschaffen. Wir glaubten nun Ordnung geschaffen und das Notwendigste gethan $z u$ haben, um einem Unfrieden vorzubeugen. Die Kriegsfurie war aber einmal entfesselt und mit ihr die Habgier der Negergesellschaft; Raub und Plünderung kannten nun keine Schranken mehr. 
Wir Europäer hatten uns vorgenommen, uns in zweistündiger Wache abzulösen, um die Posten zu revidieren und einen Ueberfall, sowie etwaige Ausschreitungen zu verhindern. Aber sobald die Leute mit dem Proviant von den Farmen zurückgekehrt waren, hatte die Ruhe ein Ende. Schnell hatten sich einige Ringe auf dem Markte gebildet, die das Feuer von neuem anfachten und nun ihren Yams und sonstige Früchte zu kochen begannen. Alsbald entstand Lärm und Geschrei im Ort; Weiber und Mädchen kreischten, Schlägereien fanden zwischen den Eingeborenen statt und die raubgierig gewordene Bande begann Schafe, Huhner und alles, was sie sonst noch auftreiben konnten, zu plündern und aus den Hutten der Eingeborenen wegzuschleppen. Hier liefen etliche brutale Burschen einem vor Angst schreienden und sich sträubenden Mädchen nach, dort stritten sich die Leute um die Töpfe und Kalabassen zum Kochen, andere suchten die davonlaufenden Hühner zu erhaschen, wieder andere machten sich eiligst mit einem halben, eben getöteten und noch dampfenden Schaf davon, um es über dem Feuer.zu braten und mit den Genossen zu verzehren; an anderer Stelle machten sich die Leute eine kleine Ziege streitig, so dass sie das Tier auseinander zu reissen drohten, da jeder es fur sich beanspruchte. Gegen diese Uebergriffe mussten wir einschreiten. Wir durchstreiften mit Patrouillen die Stadt, um die Ordnung herzustellen und die Eingreborenen vor der Habgier der Kpandoleute zu schützen. Einige kräftige Fusstritte und Kolbenstösse unserer mitgeführten Patrouille thaten gute Dienste, aber erst als wir verkündeten, dass jeder, den wir beim Plündern anträfen, erschossen werden würde, und einige Ruhestörer wirklich festnahmen, trat Ruhe ein. Wir hatten die ganze Nacht gewacht und erwarteten sehnlichst den Tagesanbruch.

Gefechts- Um 5 Uhr ertönte die Reveille und bald entfaltete sich in dem bereiter Orte eine rege Thätigkeit. Die Wachen wurden eingezogen und das Marsch in den Signal rief die Soldaten an die Gewehre, welchem Beispiele auch die feindlichen Getreuen Dakadus folgten, der würdig wie ein Feldherr, Heerschau Landschaft über seine Krieger auf dem Marktplatze hielt. Oberleutnant von Avatime Döring übernahm die Führung des Ganzen, ich die Avantgarde und der Botaniker Baumann befehligte die Nachhut und die irregulären Truppen des Königs von Dakadu. Ich rückte nun mit der 4o Mann starken Avantgarde auf der Strasse nach Yogbe ab, während von Döring mit dem Gros von 6o Mann und dahinter Baumann mit den übrigen Kriegern folgte. Der Unteroffizierposten, der immer noch die Strasse nach Yogbe deckte, bildete die Spitze. Unser schneidiger Unteroffizier Issar mit vier ausgesuchten Leuten hatte diesen Auftrag erhalten. Drei Verbindungsleute hielten die Fühlung auf dem schmalen Buschpfade mit meiner Avantgarde aufrecht, während fünf weitere 
Leute die Verbindung mit Premierleutnant von Döring bewerkstelligten. lch selbst ritt an der Spitze, um sofort bei einem Ueberfall die trantgarde zusammenziehen und mit einem energischen Feuer dem Feinde entgegentreten zu können. In dem undurchdringlichen Busch und den weitabliegenden vereinsamten Pfaden war es unmöglich, den Marsch durch Seitenpatrouillen zu decken, was irrtümlicherweise in Europa häufig als Fehler bezeichnet wird. Die schmalen Pfade lassen den Marsch nur in der Kolonne zu einem zu und bei dem dichten Busch ist ein Abweichen rom Wege oder ein Absenden ron Seitenpatrouillen gar nicht denkbar. Dadurch gestaltet sich dic afrikanische Kriegsfuhrung wesentlich anders als in Europa. Dort können die auf den grossen Strassen marschierenden Truppen bei jedem Angriff ihre Fronten entwickeln und aufmarschieren, während alle diese Maassnahmen und Vorteile in Afrika fortfallen und man gezwungen ist, sich auf engem Pfade so gut wie möglich in der Kolonne einzeln zu rerteidigen. Eine kleine Schar beherzter Neger könnte in einem solchen Defilé durch einen plötzlichen Ueberfall eine noch so gut bewaffnete Truppe vollkommen vernichten, denn der undurchdringliche Busch lässt kaum die Handhabung des Gewehres zu; ausserdem kann man auf gewundenen Negerpfaden öfters nur zehn Schritt weit sehen. Auf solchen Strassen ist dann die einzige Verteidigungsweise die, dass man, falls noch Zeit ist, rechts und links Salven in den Busch abgiebt. Bei clieser Gelegenheit macht auf das Kommando: "zum chargieren halt" die Truppe halt und die Leute abwechselnd rechts und links um, indem sie das Gewehr zum Anschlag bereit halten.

Dás nahe gelegene kleine Dorf Yogbe gehört schon zu Tafi; es wurden deshalb alle. Vorbereitungen getroffen, um einem etwaigen Angriff begegnen zu können. Man hörte bereits das Summen menschlicher Stimmen, so dass ich vorzog, einen Augenblick halt zu machen, um von Döring zu benachrichtigen. Ich meldete, dass ich meine Avantgarde zusammenziehen würde, um im Marsch-Marsch einen freien Platz im Dorfe zu gewinnen, auf dem sich die Truppe entwickeln und Aufstellung nehmen könnte. Mit aufgepflanztem Seitengewehr ging es lautlos im Laufschritt vorwärts, bis wir glücklich in dem kleinen Dorfe einen freien Platz erreichten, auf dem ich sofort die Truppe aufmarschieren liess. Währenddessen hatten sich die Bewohner mit grossem Geschrei in die dahinter liegenden Strassen geflüchtèt. Viele Leute waren mit Flinten bewaffnet und ich war gerade im Begriff anlegen und eine Salve abgeben zu lassen, als plötzlich ein Mann in einer alten Husaren-Attila hervorsprang, seine Mütze in die Höhe schwenkte und mit lauter Stimme herüberschrie: "Massa we beg pardon, we beg pardon". Sogleich gab ich das Kommando: "Setzt ab" und liess den Mann zu mir 
kommen, um mit ihm zu reden. Es war ein alter Zimmermann, ehemaliger Missionsschüler und Arbeiter von der Station Misahöhe, der hier lebte und durch seinen weisen Rat im letzten Augenblick seinen Heimatsort vor dem Kriegsunglück bewahrt hatte. Ich sandte ihn zu von Döring, um diesen als Führer der Expedition zu benachrichtigen und besetzte selbst schnell die Ausgänge des Ortes, um zu verhüten, dass sich die Nachricht von unserer Ankunft weiter verbreitete. Bald marschierte von Döring mit der Truppe in das kleine Dorf ein und liess den Häuptling kommen, der demütig um Verzeihung bat.

Nach einer kurzen Rast setzten wir unseren Marsch in einer weiten Baumsavanne fort; vor uns erstreckte sich von Südwesten nach Nordosten die grosse Kette der Gebirgszüge von Avatime. Das Gebirge bildet hier die Wasserscheide der kleinen Nebenflüsse des Danyiflusses im Norden, während sich nach Süden zu von den Kämmen des Gebirges die kleinen Zuflüsse und Bäche des Todjië ergiessen. Die Marschordnung wurde wie vorher innegehalten und im nunteren Tempo bewegte sich die ganze Truppe nach dem nächsten Ort, Fume, vorwärts. Da ich mich von der Beschaffenheit des Terrains überzeugen wollte und damals noch ein schönes Reitpferd besass, sprengte ich weit voraus, um gleichzeitig die Stellung des Feindes, der uns nach den Angaben der Yogbeleute vor den Dörfern erwarten sollte, auszukundschaften. Ich hatte schon, ohne etwas zu bemerken, eine ganze Strecke im Galopp zurückgelegt, als ich zu meinem Erstaunen hinter mir den braven Unteroffizier Issa mit seinen Leuten gewahrte. Auf meine Frage, warum er so gerannt und nicht auf seinem Posten geblieben wäre, antwortete er mir in seinem Negerenglisch: „Massa, wohin Du gehst, gehen wir auch, wir wollen Dich nicht allein lassen". Inzwischen war auch Leutnant ron Döring an die Spitze gekommen und im Marsch-Marsch ging es nach Fume, wo uns die Leute schon mit einer grossen schwarz-weiss-roten Flagge entgegenwinkten und ebenfalls um Frieden baten. Auch hier wurde der Häuptling verwarnt und nachdem die Flagge, welche die Leute sich noch in der letzten Stunde von der Mission geborgt hatten, unter Präsentieren und Trommelwirbel an einem grossen Flaggenstock gehisst war, ging es weiter nach Biakpa und Vhame, dem eigentlichen Herd des Aufstandes.

Mit dem Eintritt in das Gebirge begannen erst die Schwierigkeiten des Marsches. Wir hatten einige Bäche, die einem linken Nebenfluss des Danyi angehörten, zu überschreiten. Zwischen diesen kleinen Bächen lagen die Kämme des Avatimegebirges. Auf einem schmalen, mit Geröll und Steinen bedecktem Pfade ging es bergan; häufig mussten grosse erratische Blöcke genommen werden, so dass wir von den Pferden steigen und zu Fuss unseren Marsch fortsetzen mussten. Besonders 
für unsere unbeschuhten Mannschaften war der Marsch auf den mit spitzen Steinen besäten Pfaden, über die Felsen und Klippen des Gebirges sehr beschwerlich. Die Sonne stand schon ziemlich hoch, als wir mit Mühe endlich den Höhepunkt des Kammes erreicht hatten; aber die vorgelagerten Züge und einzelnen Ketten, sowie der Busch liessen leider keine weite Fernsicht zu. Nach Angabe des Botanikers Baumann sollte man von der Höhe aus das Dorf Biakpa rollkommen übersehen können. Es wurde für den Fall, dass eine grosse Kriegermenge dort sichtbar würde, beschlossen, ihr unseren ersten Gruss durch eine wohlgezielte Salve herunterzusenden. Wir marschierten nun bergan, doch konnten wir kein Dorf entdecken; dann ging es wieder bergauf, um einen kleinen Querkamm zu überschreiten und nochmals bergab in das Thal.

Vergebens spähten wir nach irgend einer Ortschaft aus, bis wir Einrücken in plötzlich auf Farmen stiessen, die uns die Nähe ron Biakpa rerrieten. Biakpa. $\mathrm{Ab}$ und $z \mathrm{u}$ sah man schon ron weitem Krieger, mit Flinten bewaffnet, scheu in den die Farmen umgebenden Busch huschen und alles deutete darauf hin, dass hier der Zusammenstoss stattfinden würde. Ich zog die Avantgarde eng zusammen, nur eine kleine Spitze blieb vor der Kolonne, bei der wir uns mit gezogenem Säbel befanden, um beim Angriff sofort die gebotenen Maassregeln treffen und durch ein energisches Feuer der Avantgarde dem Feinde die Spitze bieten zu können, oder diesen wenigstens so lange aufzuhalten, bis das Gros der Truppe herangekommen wäre. Wir passierten einen Dornenbusch, der vorzüglich zut Verteidigung geeignet war und wo wir deshalb einen Ueberfall erwarteten. Doch blieb alles still und wir befanden uns plötzlich mitten in dem Dorfe. welches wie ausgestorben erschien Das Kommando: „Marsch Marsch, Aufmarschieren" ertönte und alles kam im Sturmschritt an, um seinen Platy einzunehmen und den Aufmarsch zu bewerkstelligen. Ausser einigen alten Männern und Weibern, die in der Eile nicht weiter gekonnt hatten. war in dem Dorfe Biakpa kein lebendes Wesen mehr zu entdecken Flehentlich baten die Zurückgebliebenen um Schonung und erzählten uns, dass der Häuptling ron Thane allein an dem Lngluck Schuld habe und durch den Häuptling ron Peki immer wieder gegen die Deutschen aufgehetzt werde. Der ganze Ort wurde abgesucht, doch nichts Ver dächtiges weiter bemerkt Inzwischen war der Haupttrupp herangekommen. Ton den irregulären Truppen war jedoch noch nichts zu sehen. Sie liessen sich Zeit, da ihnen weniger daran gelegen war, in einen Kampf rerwickelt zu werden, als sich nach demselben der Beute zu bemächtigen. Das Plündern spielt bei afrikanischen Kriegern eine wichtige Rolle und geschieht zum Teil deshalb, weil durch das Abbrennen der armseligen Grasdächer die Leute so gut wie garnicht, 
jedenfalls nicht nachdrücklich genug geschädigt werden. Wenn die Autständischen dem Feinde nicht Stand halten können und sich ihm durch die Flucht entziehen, so betrachten sie sich nicht als besiegt. Sie bauen dann bald wieder ihre Hütten auf und da sie ihr Vieh schon vorher in Sicherheit gebracht haben, so erleiden sie durch den Krieg keinen wesentlichen Schaden. Sie beginnen, durch die Fetischpriester oder sonstige der Regierung feindlich gesinnte Organe aufgehetzt, den Aufruhr einfach von neuem. Aus diesem Grunde ist das Plündern durch irreguläre Truppen von afrikanischen Negerstämmen in den Fällen, wo die gänzliche Niederwerfung des Feindes notwendig ist, entschuldbar. Bald wurde uns von den alten Leuten ein vorzüglicher Palmwein verabreicht und wir stillten guten Mutes den brennenden Durst mit dem kühlen Trunke. Die alten Leute wurden zum Teil als Geiseln und Führer mitgenommen und bald waren wir wieder auf dem Marsche gegen den Hauptort Vhane, wo sich nun sämtliche Krieger der Umgegend um den Häuptling von Vhane geschart haben sollten.

Besetzung Nach einem ermüdenden Marsche in dem bergigen Terrain kamen von Vhane. wir schliesslich an die Farmen von Vhane, wo wir den Truppen vor dem voraussichtlich bevorstehenden Kampfe eine kleine Ruhepause gönnten. Dann wurde unter Vorsichtsmaassregeln im Eilmarsch der Weg fortgesetzt. Sobald wir die ersten Häuser erreicht hatten, wurde aufmarschiert und in breiter Front auf das Dorf vorgegangen; doch bevor wir noch zum Angriff auf eine grosse Menschenmasse, die teils bewaffnet, teils unbewaffnet alle Strassen und Plätze des Dorfes besetzt hielt, übergehen konnten, erschien am Eingange des Dorfes eine grosse schwarzweiss-rote Flagge, als Zeichen des Friedens und der Unterwerfung. Bis an den Marktplatz wurde vormarschiert und derselbe von zwei Seiten von unseren 120 Mann umstellt. Ehe wir noch mit jemandem verhandeln konnten, hatten uns schon die Missionare von Amedjovhe, an der Spitze Herr Seeger, von weitem begrüsst und boten uns zum Beweise der Freundschaft und des Friedens zwischen den Avatime-Leuten und uns die Hand.

Noch am Morgen des letzten Tages war es den Bestrebungen der Missionare gelungen, die Leute von einem feindlichen Vorgehen abzuhalten. Sie waren, wie uns die Missionare erzählten, anfangs sehr kriegerisch gesinnt gewesen, da ein Bote, welcher den Leutnant v. Döring und mich mit vier Mann gesehen haben muss, dem Häuptling die Nachricht überbracht hatte, dass nur zwei Weisse und vier Soldaten ankämen. Die Missionare waren natürlich besser unterrichtet und lachten den Häuptling aus, dass er an ein solches Märchen glauben könne. Das Volk war denn auch nicht wenig erstaunt, als die Kette der Soldaten kein Ende nehmen wollte und schliesslich noch 400 bewaffnete Krieger 
Dakadus mit ihren grausigen Kriegstrommeln'folgten. Die Soldaten standen mit Gewehr bei Fuss und konnten jeden Augenblick mit der Waffe eingreifen. Währenddessen hatte das Palaver mit dem Häuptling begonnen. Derselbe sass in einer grossen offenen Halle, die aus Palmblättern und Gras hergestellt war, umgeben ron seinem Hofstaat. Die Missionare waren so gütig die Dolmetscher zu spielen, so dass wir bald mit den Leuten fertig wurden. Dem Häuptling wurde ordentlich ins Gewissen geredet und eröffnet, dass er und seine Leute eine exemplarische Strafe verdient hätten. Da er wohl einsah, dass er bei einem Kampfe den kürzeren gezogen hätte, unterwarf er sich röllig unter der Bedingung, dass wir ihn und sein Volk schonen wollten. Insbesondere versprach er, von nun an treu zur deutschen Regierung zu halten, so wie er bis jetzt zu seinem Oberhäuptling, dem Häuptling von Peki und dessen Herrn, der englischen Regierung, gehalten hätte. Er wies darauf hin dass er bis jetzt geglaubt habe, England anzugehören, da er dem Häuptling von Peki verpflichtet und dieser englischer Unterthan sei. Die Flagge wurde auf einem grossen Maste vor der Königshalle gehisst. Dem Häuptling wurde als Sühne ein Tribut ron Yams, Ziegen, Schafen und anderen Lebensmitteln für unsere Soldaten und Dakadus Krieger auferlegt; es war dies eine gerechte Strafe für die vielen Unzuträglichkeiten, welche er der deutschen Regierung sowie den deutschen Kaufleuten bereitet hatte.

Während des Palavers hatten unsere Soldaten im Uebermut die Geiseln aus Biakpa, welche in kleinen Zöpfchen Fetischamulette trugen, ihrer Locken beraubt und ihnen die Bärte verschnitten. Diese Scene erregte bei den übermütigen Kameraden viel Heiterkeit; innerlich mussten auch wir über das veränderte Aussehen unserer Geiseln lachen, aber die Schuldigen bekamen eine Rüge und militärische Strafen. Die Geiseln wurden dann entlassen und zogen freudig, wenn auch ihres Haarschmuckes beraubt, wieder ihren heimischen Penaten zu. Durch das verdienstvolle Eingreifen der Bremer Missionare von Amedjovhe nahm somit unser Kriegszug ein friedliches Ende. Derselbe war aber, obwohl er unblutig verlief, doch von grosser Bedeutung für unsere Machtstellung in den westlichen, an der Grenze gelegenen Gebieten und für den Handel der deutschen Kaufleute.

Nach allen diesen Vorgängen folgten wir gern der liebenswürdigen Ruhetag auf Aufforderung der Missionare, hoch oben in Amedjorhe auf ihrer Station der Missions. mit unseren Soldaten und Leuten unser Quartier aüfzuschlagen. Dakadu blieb mit seinen Leuten in Vhane und that sich dort gütlich an dem als station Tribut herbeigeschafften Vieh und den Produkten des Landes. Nachdem sich unsere Soldaten vollauf verproviantiert hatten, marschierten wir unter Hörnerklang und Trommelschlag in Reih und Glied aus Thane 
heraus. Dakadu liess es sich jedoch nicht nehmen, uns mit seinen Würdenträgern noch bis hinter die Farmen der Stadt zu begleiten. Nachdem wir uns vielmals für seine Hilfe bedankt hatten, verabschiedeten wir uns von dem alten Rauhbein mit einem freundlichen Händedruck. Unter Vorantritt der Missionare ging es nun in dem Thale des Kala entlang. Ein bequemer Weg, der von den Missionaren angelegt war, führte von dem fast $500 \mathrm{~m}$ über dem Meeresspiegel gelegenen Dorfe Vhane noch etwa $270 \mathrm{~m}$ höher auf die Missionsstation herauf. Einen schönen Rückblick gewährten die Thäler; zu unsern Füssen lagen Biakpa und Vhane, im Norden erhob sich der Gemmi mit seinen $800 \mathrm{~m}$ hohen Kegeln. Bald war das. Dorf Amedjorhe erreicht und mit klingendem Spiele ging es durch dasselbe hindurch, wo uns die Bewohner freudig begrüssten und die ganze Dorfjugend das Geleite gab. Die grösste Anziehungskraft üben wie in der Heimat auch bei dieser schwarzen Gesellschaft die Trommler und Spielleute, denn taktmässig marschieren die Jungens stramm neben den Soldaten. Thre kleinen schlanken Glieder ohne jegliche Bekleidung zeigen oft ein wunderschönes Ebenmaass. Die Schulkinder werden sämtlich von der Mission europäisch bekleidet und machen einen guten Eindruck. Fast die Mehrzahl der Bewohner ron Amedjovhe sind Christen und Angehörige der Bremer Missionsstation. Viele von ihnen sind Handwerker und leisten bei den Missionsbauten Hilfe.

Wir verlassen das Dorf Amedjovhe und erreichen in wenigen Minuten die auf dem Gipfel thronende Station. Auf dem grossen Hofe derselben wird halt gemacht; zunächst werden die Wachen und Posten eingeteilt und die Leute mit der nötigen Instruktion versehen. Dann betreten wir das geräumige grosse Wohnhaus und Schulgebäude der Mission und begrüssen hier in der Wildnis europäische Damen und ein trauliches deutsches Familienheim. Angenehm ist es, inmitten des weiten Busches die so lang entbehrten Bequemlichkeiten eines europäischen Hauses vorzufinden. An einem langen Tisch wird gemeinschaftlich das Mahl eingenommen. Die fleissigen Hände der Hausfrau haben aus den afrikanischen Erzeugnissen sowie aus selbst gezogenen Früchten und Gemüsen ein Menu hergestellt, das uns zur Freude unserer gastfreien Wirte vorzüglich munder. Das traute Familienleben, das belebende Element der Damen wirkte erfrischend auf unser Gemüt und gab uns neuen Mut für die Zukunft.

Entwicklung Das grosse geräumige Gebäude ist ein Beweis ron dem Fleiss, und mit welchem die Missionare die ganze Anlage geschaffen haben. Alles ist an Ort und Stelle angefertigt, nichts von Europa eingeführt. In der unteren Etage befinden sich die Schule und die Kirche, während in der oberen die verheirateten Missionare wohnen; ausserdem stehen einige Gastzimmer für die Aufnahme durchreisender Missionare oder anderer 
Weisser zur Verfügung. Da Amedjovhe hoch liegt und infolgedessen ein gutes Klima hat, wird es auch häufig von den in weniger günstig gelegenen Orten stationierten Missionaren zur Erholung aufgesucht. Das schöne Haus ziert eine rings um dasselbe laufende geräumige Veranda, auf welche sich grosse Fenster und die Ausgänge der einzelnen Zimmer und Wohnungen öffnen. Von dieser Veranda hat man einen wunderschönen Ausblick auf das sich weithin erstreckende Thal des Todjië, auf die vorgelagerten Höhenzüge des Dodome-Gebirges im Südosten, die Berge ron Vhane im Süden, sowie im Norden und Osten auf den Hauptgebirgsstock der Landschaft, den abgerundeten Kegel des Gemmi und die sich anschliessenden Gebirgsketten und Thäler ron Logba und Kpedse. In dem Thal des kleinen Ahavobaches, zwischen der Station und dem Gemmi, liegt vor uns in dem Busch, in Bananen und Oelpalmen eingebettet, das etwa roo Hütten umfassende Dorf Amedjovhe. Neben dem Missionsgebäude befinden sich auf dem verhältnismässig kleinen Plateau noch einige Wirtschaftsgebäude. Unter der Leitung handwerkskundiger Missionare hat es gerade die Bremer Mission verstanden, sich mit unermüdlichem Fleiss einen Stamm von Arbeitern, wie Tischlern, Zimmerleuten, Glasern, ja auch Drechslern, Maurern ḩeranzubilden und hat damit zum Segen der schwarzen Bevölkerung den Grund für die Weiterverbreitung des Handwerks in unserer Togokolonie gelegt. Ausser diesen Handwerkern werden in den Missionsschulen Dolmetscher und Lehrer herangebildet, welche meistens der englischen Schrift und Sprache kundig und dadurch bei weitem ihren übrigen Landsleuten und Genossen überlegen sind. Ferner ist es ein Verdienst der Missionare, dass sie durch Anlegung von Plantagen und Versuche mit Sämereien und Früchten den Ackerbau und die Produktionsfähigkeit deș Landes heben. So haben sie in Avatime ausgiebige Versuche mit liberianischem und arabischem Kaffee gemacht, auch Kakao angepflanzt und in ihren Gärten die verschiedensten Arten europäischer Früchte und Gemüse mit Erfolg gezogen. Auch die Eingeborenen haben, ron der Mission unterstützt, Kleine Kaffeeplantagen angelegt, so dass bereits Kaffee von Avatime auf den Bremer Markt gebracht worden ist. Die Bremer Mission wirkt hauptsächlich auf dem Sprachgebiet des Evhestammes, in dessen Sprache sie lehrt und predigt, während die Baseler Mission in den Sprachen des Tshi und Guan und den damit verwandten Sprachen unterrichtet. Die Norddeutsche Mission hat drei Hauptstationen in Ho, in Amedjorhe und in Lome. Der Hauptstation Ho unterstehen die Aussenstationen Nyogbo, Akorierhe, Matse, Abutia; Abuadi und Waya. I) Station Amedjorhe hat ihre Aussenstationen in Gbasémme, Leglebi, Anfoë und Woadse. Die Aussenstation der neu gegründeten Hauptstation Lome befindet sich in Tore. Alle diese Aussenstationen haben Schulen, 
welche mit schwarzen Lehrern besetzt sind, während die Hauptstationen Europäer und ausserdem noch schwarze Lehrer und Lehrerinnen als Gehilfen haben. In Amedjovhe ist ferner in der letzten Zeit noch ein Seminar sowie eine Mittelschule zur Ausbildung der schwarzen Lehrer errichtet worden. Ausserdem werden begabte junge Schwarze, welche die vorerwähnten Schulen durchgemacht haben, zu ihrer weiteren Verwendung in der Mission in dem Seminar in Hall in Württemberg als Lehrer ausgebildet. So haben im Jahre I 897 drei junge schwarze Leute dort ihren Kursus beendigt und sind in ihrer afrikanischen Heimat als Lehrer angestellt worden.

Mit unseren Truppen hielt ein militärisches Leben und Treiben in die Missionsstation Amedjovhe seinen Einzug. In langen Reihen standen auf dem Missionshofe die Gewehrpyramiden, eine Wache sorgte für die Ruhe und Ordnung, des Abends zum Zapfenstreiche ertönte weithin in die Thäler und Berge das Hornsignal und der Wirbel der Trommeln und bei threm Klange erinnerten sich auch die Missionare mit Freuden ihrer Soldatenzeit. Nachdem wir uns gestärkt hatten, wurde noch ein Aufstieg auf den Gemmi gemacht, von dessen höchster Spitze wir einen wunderschönen Ausblick auf die tiefer liegenden Vorberge und die einschneidenden kleinen Gebirgsthäler sowie auf die Missionsstation genossen. Auf dem Gipfel des Gemmi, der wie ein Kegel über die anderen Berge hinausragt und die Form eines alten Vulkans besitzt, fanden wir unzählige Eisenschlacken, die angeblich von den Schmieden der Bayas herrühren, welche sich dort vor vielen Jahren auf der Flucht niedergelassen und das Schmiedehandwerk betrieben haben sollen. Nachdem wir den Abend in fröhlichem Zusammensein auf der gastfreien Station zugebracht und uns durch eine ungestörte Nachtruhe erquickt hatten, ertönte des Morgens die Reveille: „Du hast ja schon genug geschlafen“. Das Signal mahnte zum Aufbruch; mit vielem Dank verabschiedeten wir uns von unseren freundlichen Wirten und verliessen unter klingendem Spiel, voran die schwarz-weiss-rote Flagge, die Station, um über Fume, Jogbe, Kpando unsern Rückmarsch nach Kunya anzutreten.

Ackerbau in Auf unserem Marsche fielen mir die vielen grossen Reisfarmen auf, den Gebirgs- die sich an den Berglehnen und in den Gründen hinzogen. Ein wundergegenden von schönes, saftiges Hellgrün bedeckte die'weiten Fluren und emsig sah Avatime. man die Leute in den Farmen mit dem Jäten von Unkraut oder mit der Einsaat neuer Früchte beschäftigt. In Avatime finden wir wieder den eigentümlichen Gebrauch, die Grenzen durch bestimmte Gewächse zu kennzeichnen, welche um die Gemarkungen herumgepflanzt werden; ganze Ortschaften kennzeichnen die Grenzen ihrer Gebiete durch solche perennierenden Pflanzen, welche in dem ganzen Avatimegebiet als wirk- 
liche Grenzzeichen anerkannt werden. Infolge der guten Bodenbeschaffenheit hat der Landbau hier eine ganz hervorragende Bedeutung erhalten. In Avatime wird nach der ersten Maisernte der Acker wieder von neuem umgebrochen und mit einem sichelartigen Instrument für den Anbau von Bergreis vorbereitet. Im Monat Juli und August wird dann mit der Reiseinsaat begonnen; der Reis wird mit der Hand ausgesät und darauf mit dem vorher erwähnten Instrument etwa $5 \mathrm{~cm}$ tief in den Boden gebracht. Die Reisaussaat wird nur mit der besonderen Erlaubnis der Fetischpriester vorgenommen. Der Bergreis hat in diesen Gebirgsgegenden eine ganz besondere Verbreitung erfahren, so dass die Ernte nicht nur den eigenen Bedarf deckt, sondern auch schon Reis nach der Küste exportiert worden ist, wo er in Lome und anderen grossen Handelsplätzen billiger als der importierte Reis verkauft werden soll. In Avatime soll es nach den Aussagen des Missionars Spieth nicht weniger als 16 Yamsarten geben. Für den Yams sind hier zwei Saatzeiten rorhanden, die eine, wie in der Ebene, im Frühjahr, von April bis Anfang Mai, die andere von Mai bis Juni. Bei der Einsaat von Yams ist rorher nicht, wie bei der Einsaat von Reis, die Erlaubnis des Fetischpriesters einzuholen. Beim Pflanzen bedienen sich die Leute einer zugespitzten Stange, mit welcher sie den Boden, in welchen der Pflänzling eingelegt werden soll, umbrechen und dann sorgfältig von Wurzeln und Steinen reinigen. In die offene Stelle werden die einzelnen Yamsstücke eingelegt, mit dem sichelartigen Instrument verscharrt und um die Pflänzlinge herum der Boden gelockert. Es wird also für jeden Ptlänzling ein kleines, tiefes Saatbett besonders hergestellt. Jeder dieser Pflänzlinge wird darauf noch behäufelt und die kleinen Haufen werden zum Schutze gegen Vögel und Wild mit Gras, Reisig oder Dornen bedeckt. Für die emporschiessenden Triebe und Ranken werden auf jedem Haufen kleine Stäbchen errichtet. Werden die Ranken zu hoch, so werden die kleinen Stäbchen durch grössere Stangen ersetzt. Von weitem gleicht ein solches Feld ganz unseren heimatlichen Weinbergen.

Neben dem Ackerbau wird in diesen Gebirgsdörfern die Weberei sowie das Schmiedehandwerk eifrig betrieben. Auch wird die Jagd auf Leoparden und Antilopen gepflegt. Ferner ist die Seifensiederei in Avatime in hohem Schwunge. Aus den Früchten eines hohen Baumes, der zur Gattung der Sapindaceen gehört, kochen die Eingeborenen die Seife, welche in kleinen, schwarzen, faustgrossen Ballen zu nicht unerheblichen Preisen auf den Markt gebracht wird. In allen diesen Gebirgslanden wächst in den Gründen und an den Bächen die Oelpalme, die an diesen abgelegen Orten leider weniger ausgenutzt wird, weil der geringe Preis die Unkosten und der Transport auf dem beschwerlichen Wege nicht deckt. Durch die Anlage von Strassen und Plantagen 
könnte die Produktion des Landes noch bedeutend gesteigert und der Ertrag erhöht werden. Namentlich würde es sich lohnen, in diesen Gegenden bei dem fruchtharen Boden und dem verhältnismässig grossen Verștändnis der Bewohner für den Ackerbau, grössere Plantagen anzulegen, da hier mit Leichtigkeit schon mit den Bodenverhältnissen vertraute und geschulte Arbeiter zu finden wären. Ausser den erwähnten Kulturpflanzen soll noch in diesen Gebieten eine minderwertige Kolanuss vorkommen, die jedoch wegen ihrer geringen Qualität weder zum Verkaut noch zur Ausfuhr gelangt.

Wieder- Auf unserem Rückmarsch bekamen wir allerlei Klagen über die eintreffen in Kpandoleute zu hören. Dieselben hatten alle Orte, welche keine deutsche Kpando und Flagge führten, heimgesucht und ausgeplündert. Namentlich hatte die Weitermarsch Ortschaft Fume darunter sehr zu leiden gehabt und ihr Häuptling bat nach Kratyi. uns, den König Dakadu zu bestrafen. Dieser Vorfall war den Leuten jedoch eine gute Lehre, wie wichtig es sei, bei Streitigkeiten auch äusserlich durch die Flagge ihre deutsche Angehörigkeit zu zeigen. Die anfangs wenig beachtete Flagge kam nun plötzlich zu Ehren und die Mission in Amedjovhe wurde um deutsche Flaggen bestürmt. Bald hatten wir wieder Kpando erreicht, wo uns Dakadu schon freudig begrüsste Wir beschlossen hier einen Rasttag einzulegen und am nächstfolgenden Tage weiter nach Kunya zu marschieren. Am Abend war wiederum grosser Tanz auf dem Königsplatze. Am nächsten Morgen verabschiedeten wir uns von Dakadu und erreichten Kunya, wo wir alles in guter Ordnung vorfanden und von unseren Trägern, die hier so lange geschwelgt hatten, jubelnd empfangen wurden. Dem Missionar Mr. Hall, dem Häuptling von Kunya, spendeten wir unseren Dank für die geleistete Hilfe und für die Unterstützung, welche er unseren Leuten in unserer Abwesenheit hatte zu teil werden lassen. Sodann marschierten wir weiter nach Kete-Kratyi, wo wir später die Station errichtet haben. Ich habe diese Militärexpedition vorweg beschrieben, da ich nachher nicht mehr auf diese südlichen Gregenden zurückkomme. Wir kehren nun zurück nach der Station Misahöhe, dem Ausgangspunkt meiner nächsten Reise.

\section{CHARAKTERISTIK DES EVHESTAMMES.}

Anthropologische Eigenschaften.
Während meines Aufenthaltes an der Küste sowie in Misahöhe hatte ich Gelegenheit, einigermaassen die Eigentümlichkeiten des Evhevolkes kennen zu lernen. Der Stamm der Evhe erstreckt sich von der Sklavenküste aus zwischen dem Volta und dem Monofluss ungefähr bis 
zum 7. Grad nördlicher Breite. Die Körperformen dieses Volksstammes kann man im allgemeinen als wohlgebildet bezeichnen. Die Mānner sind hübsche, schlanke Gestalten mittlerer Grösse, während die Frauen durchweg etwas kleiner und schwächlicher gebaut sind. Das Gesicht ist verhältnismässig schön, da die Leute an der Küste im grossen und ganzen nicht die plattgedrückte Nase und die aufgeworfenen Lippen haben, welche dem Negertypus eigentümlich sind. Diese Erscheinung erklärt sich wahrscheinlich dadurch, dạss die Sklavenküste, wie ihr Name andeutet, schon vor mehreren Jahrhunderten, zuerst durch die Portugiesen und Holländer wegen ihrer beliebten schwarzen Ware heimgesucht worden ist. Die Küstenbewohner kamen dadurch in Berührung mit europäischen Rassen; später waren es die Engländer und schliesslich die Deutschen, welche sich an der Küste ebenfalls ansiedelten und einen gewissen Einfluss auf die Bevölkerung ausübten. Durch die Ansiedelungen hat sich europäisches Blut mit demjenigen der Bewohner dieser Küstenstriche vermischt und derselben den Stempel und Ausdruck europäischer Gesichter aufgedrückt. Im Innern finden wir diese wohlgeformten Gesichter weniger und der eigentümliche Negerty pus tritt deutlicher hervor. Die Hautfarbe ist in allgemeinen tiefschwarz, obwohl auch braune und hellere Schattierungen nicht selten sind. Durch das Einreiben der Haut mit Fett und Oel erhält sie meistens einen eigentümlichen speckigen Glanz. Beide Geschlechter haben gewöhnlich als Kennzeichen aus den oberen mittleren Schneidezähnen ein kleines Dreieck ausgefeilt; häufig, namentlich bei den Küstenbewohnern, ist dieses Dreieck sehr klein und kaum zu bemerken.

Bei den Frauen haben anscheinend einzelne Gebräuche und Sitten eine gewisse Entstellung der Körperformen herbeigeführt. Da sie es für eine besondere Schönheit halten, wenn die Brüste schlaff herunterhängen, so tragen nicht selten schon die jungen Mädchen ein Tuch über dieselben gebunden, welches die Brüste herunterpresst und ihnen bald die gewünschte Form verleiht. Durch Zerren sowie durch das lange Säugen der Kinder werden die Brüste unverhältnismässig lang und reichen häufig bis zum Nabel herab. Auch habe ich bei sämtlichen Negerfrauen, welche ich gesehen, ein auffallend eingebogenes Kreuz bemerkt, so dass der Hinterteil bedeutend hervortritt. Unwillkürlich wird man bei dem Anblick an die Stratopygie der Hottentottenweiber erinnert. Entweder ist diese Deformation durch das Tragen der Kinder auf dem Rücken herbeigefuhrt oder die Natur hat schon von altersher diesen natürlichen Sattel als Sitz für die Säuglinge vorgesehen. Ausser diesen Deformationen werden die Körperformen durch Einschneiden von Stammeszeichen oder Schutzzeichen oder besonderen Schönheitsmalen entstellt. So tragen fast alle Frauen des Evhestammes drei kleine senkrechte Narben auf der 
Stirn zwischen den Augenbrauen und je drei auf jeder Backe, die ebenfalls senkrecht stehen und sich auf der Vorderwange befinden. Die

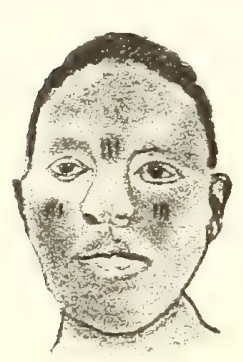
Narben sind meistens nur I $\mathrm{cm}$ lang und mit Indigo bläulich gefärbt. Im allgemeinen sind sie wenig auffällig und heben sich nur durch ihre bläuliche Farbe ron der schwarzen oder braunen Haut ab.

Die Männer des Evhestammes haben meistens gar keine Stammesabzeichen oder sonstige Tätowierungen. Nur wenn sie als einziger Knabe den Eltern zurückgeblieben sind, wird ihnen gewissermaassen eine Schutzmarke auf der rechten Wange unterhalb des Jochbogens eingeschnitten. Sie besteht aus einem kleinen, ungefähr $2 \mathrm{~cm}$ langen Querschnitt, der aber nicht, wie die Marken bei dem weiblichen Geschlecht, gefärbt ist. Die Marken sollen bei dem Mädchen von der Mutter eingeschnitten und gefärbt werden. Bei dem Knaben macht diese Schutzmarken der Vater in dem Glauben, dass der Knabe dadurch vor einem frühen Tode oder sonstigem Unheil geschützt ist.

Geburt

Die Frauen sollen, wie bei allen Naturvölkern, sehr leicht gebären und nur selten wird eine alte Frau zugezogen, die bei der Entbindung behilflich ist. Die Nabelschnur wird bei dem kleinen Weltbürger häufig sehr lang abgeschnitten oder trocknet auch nicht selten von selbst ein. Es entstehen dadurch häufig grosse Nabelbrüche, welche allerdings seltener bei den Evhenegern, öfter jedoch bei den Stämmen im Hinterlande von Togo rorkommen. Die neugeborenen Kinder sind, wie bei allen Negerstämmen, weiss und erhalten erst nach einigen Tagen die schwarze Hautfarbe. Sie werden sorgfältig gepflegt, täglich in warmem Wasser gebadet und mit zärtlicher Liebe von den Angehörigen und der Mutter gehütet.

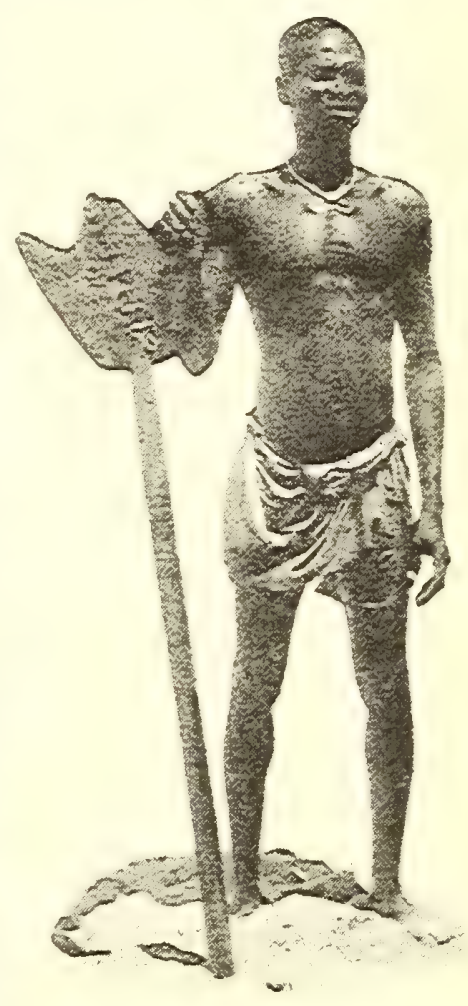

Evhe-Neger von der Küste mit Ruder. Auch werden dem kleinen Kinde später aus Fürsorge von der Mutter ein paar geweihte Kaurimuscheln in den Haarwirbel eingeflochten, welche es vor Unheil schützen sollen. Das Kind erhält von dem Vater die Namen und nach einigen Wochen findet, falls es ein 
Knabe ist, die Beschneidung desselben statt. Schwangere Frauen gehen öfters vor dem Gebären zum Fetischpriester, dem sie den nötigen Tribut zahlen, damit er den grossen Gott Nawu um Segen und eine glückliche Entbindung anflehe. Auch wird zuweilen vor der Niederkunft ein kleiner Thonfetisch als Symbol des zu erwartenden Kindes vor der Hütte aufgestellt. Schon vor der Geburt wird häufig das Kind, falls es ein Mädchen sein sollte, mit Zustimmung des Fetisch dem Sohn eines nahen Bekannten oder Verwandten zugesprochen, so dass es gewissermaassen schon verlobt ist, ehe es das Licht der Welt erblickt hat. Ist es nun wirklich ein Mädchen, so arbeitet der Jüngling für seine spätere Frau und legt den Verdienst bei seinen zukünftigen Schwiegereltern nieder. In Betanase soll ein Fetisch Nana Kombi existieren, welchem die Macht zugeschrieben wird, die glückliche Geburt eines Kindes herbeizuführen. Die besorgten Frauen gehen zu diesem Fetisch und bitten ihn unter Ueberreichung von Opfern, das Leben des neugeborenen Kindes zu schützen, das sie gewissermaassen dem Fetisch weihen. Ein solches Kind ist äusserlich kenntlich, weil demselben bis zum sechsten Lebensjahr das Haupthaar nicht geschnitten werden darf; auch verpflichtet sich die Mutter des Kindes, sich bis zum sechsten Jahre nach der Geburt des Kindes nicht berühren zu lassen. Hat das Kind das sechste Lebensjahr vollendet, so bringt es die Mutter zum Zeichen der Dankbarkeit zu dem Fetischpriester. Der Priester schneidet nun dem Kinde das Haar ab, während die Mutter dem Fetisch in Gestalt von Ziegen oder Schafen ein Opfer bringt und damit ihr Gelübde und das Kind einlöst. Einige eigentümliche Gebräuche sollen bei der Geburt eines Knaben in Avatime vorkommen. Der Vater des neugeborenen Kindes darf nach der Sitte in diesen Gebirgsgegenden am Tage der Geburt seine Hütte nicht verlassen. So wie die Mutter das Wochenbett hüten muss, so muss auch der Vater dadurch, dass er die Hütte nicht verlässt, seine Vaterschaft anerkennen. In Avatime und in den nördlichen Gegenden von Kunya ist die Beschneidung nicht üblich; auch wird dem Kinde erst nach einigen Wochen der Name gegeben; während dieser Zeit wird das Kind beobachtet und erhält nach den mutmaasslichen Charaktereigenschaften seinen Namen. Im allgemeinen werden den Kindern die Namen des Tages ihrer Geburt gegeben; häufig bezieht sich der Name auch auf zufällige am Tage der Geburt eingetretene Ereignisse.

Die kleinen Kinder machen mit ihren grossen schwarzen Augen und der wohlgebildeten Nase und Lippen meistens einen hübschen Eindruck. Erst später entwickeln sich die letzteren Organe in der dem Negertypus charakteristischen Weise und verunzieren durch ihre übergrossen Formen das Gesicht. Die Kinder werden häufig drei Jahre lang von der Mutter genährt, und es überrascht anfangs, wenn man die grossen

Kindererziehung: 
Kinder noch immer an der Mutterbrust säugen sieht. Bei allen Gelegenheiten, bei der Arbeit wie auf der Reise, werden die kleinen Kinder von der Mutter auf dem Rücken getragen; sie nehmen auf dem Hinterteil der Frau den Reitsit\% ein und werden durch ein Tuch, das vorn zusammengebunden ist, festgehalten Wenn das Kind ungeduldig erwacht oder zu schreien anfängt, wird es einfach nach vorn geschoben und stillt dann nach Herzenslust seinen Durst. Wird das Mädchen grösser, so muss es sich durch kleine Dienste im Haushalt nützlich machen. Es holt das nötige Wasser und. Feuerholz herbei, muss zuweilen das Kochen beaufsichtigen und der Mutter beim Waschen der Tücher und der Kalabassen helfen. Der Knabe folgt, wenn er grösser geworden ist, mehr dem Vater und wird ron diesem in dem Anbau der Früchte unterrichtet; auch wird er auf die Jagid und den Fischfang mitgenommen und so allmählich in die Beschäftigung des Mannes eingeführt.

Brautwerbung.
Bei reifem Alter beider Geschlechter werden die Ehen eingegangen Die Wahl der Gattin ist je nach den Gegenden und Verhältnissen verschieden An der Küste in den grossen Städten und häufig in einzelnen Landschaften im Innern wählt der junge Mann frei seine zukünftige Gattin im Einverständnis mit den Eltern derselben, welchen er je nach den Vorzügen oder der Schönheit seiner Erkorenen einen gewissen Tribut zahlt. Mit dem Eingehen der Ehe verlässt der Mann das Haus seiner Eltern, baut sich eine Hütte und gründet einen eigenen Hausstand Wenn er seine Wahl getroffen hat, schickt er einen Freund zu dem Vater des Mädchens, der diesem die Angelegenheit vorträgt und gewissermaassen über das Geschäft verhandelt. Ist dasselbe abgeschlossen, so macht auch der junge Freier seine Aufwartung und der Hochzeitstay wird festgesetzt; vorher hat jedoch der Bräutigam den Tribut für das Mädchen bei dem Vater zu entrichten, wogegen dieser das Hochzeitsfest veranstaltet und die Gäste zu bewirten hat. Der Bräutigam hat ferner noch für die Ausstattung seiner Braut zu sorgen und schenkt ihr zu diesem Zweck Tücher, Perlenschnüre und andere Kostbarkeiten, welche sie am Tage der Hochzeit anlegen muss. Weiter im Innern, wo, wie wir gesehen haben, die jungen Mädchen von Kindesbeinen an einem jungen Mann versprochen sind, ist das Zugeständnis zur Heirat seitens der Eltern des jungen Mädchens einfacher und ein besonderer Kaufpreis wird dann nicht mehr gefordert, da der Bräutigam schon die ganze Zeit hindurch für seine Braut gearbeitet hat. Tritt die Reife des jungen Mädchens ein, so wirbt der Bräutigam um dasselbe, indem er den Eltern eine Kalabasse mit Fufu und Palmöl und ein kleines Geschenk an Kauris überbringt und diese bittet, das Mädchen nun als Frau heimführen zu dürfen Mitunter ereignet es sich jedoch, dass das junge Mädchen ihrem Verlobten abgeneigt ist. Kommt an dem bestimmten Tage der hoffnungs- 

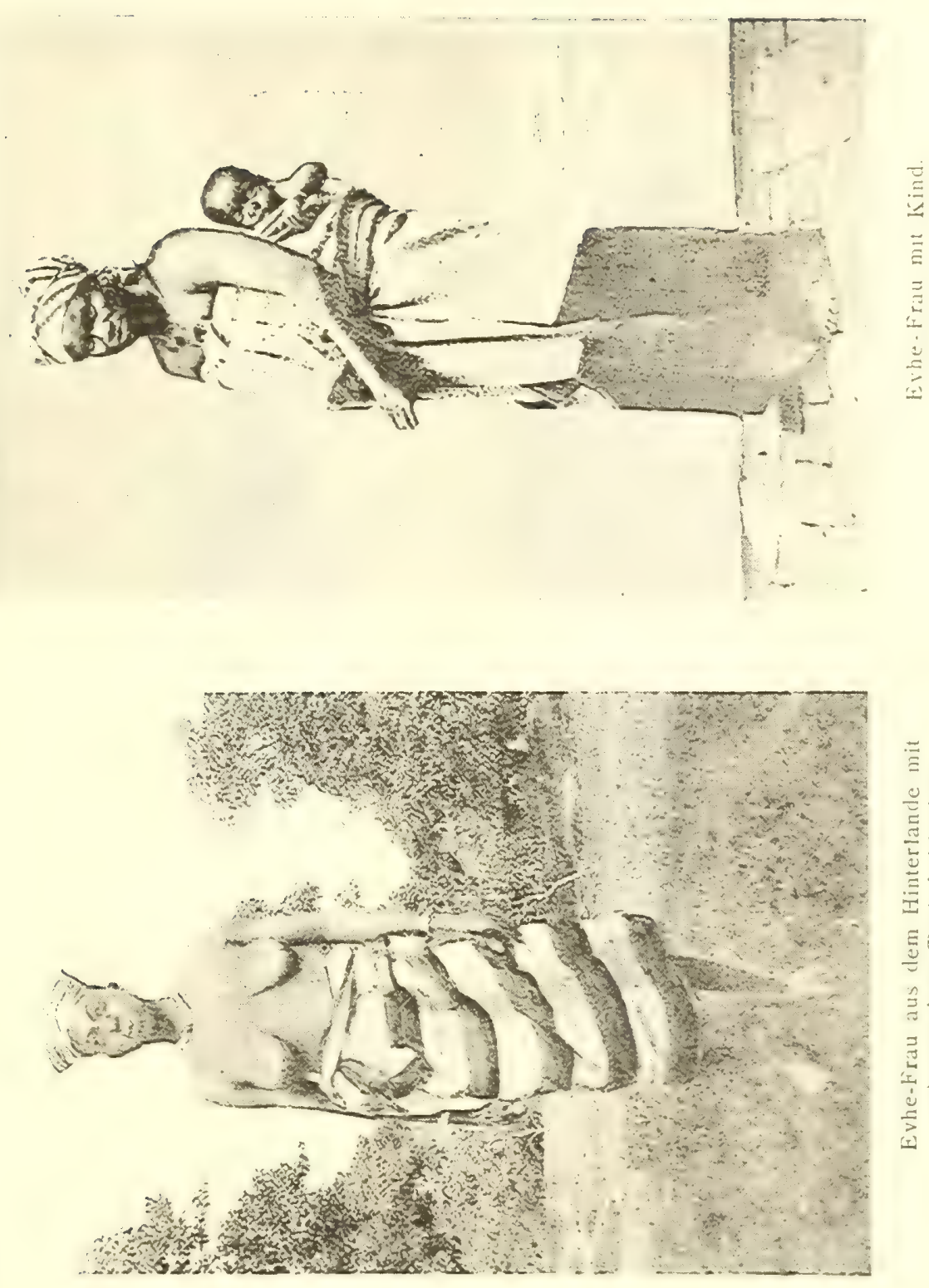

volle Bräutigam in das Haus der Eltern, um seine Braut heimzuführen, so verlässt diese heimlich das Dorf, läuft in den Busch, oder hält sich für einige Zeit bei Bekannten oder Verwandten verborgen. Oft hat ein solches Familiendrama einen traurigen Ausgang für den Bräutigam, welcher die Schande nicht überleben zu können glaubt und seinem Leben durch Selbstmord ein Ende bereitet. Bisweilen jedoch hat der Bräutigam zu einem solchen Schritt keine Lust und entschädigt sich für
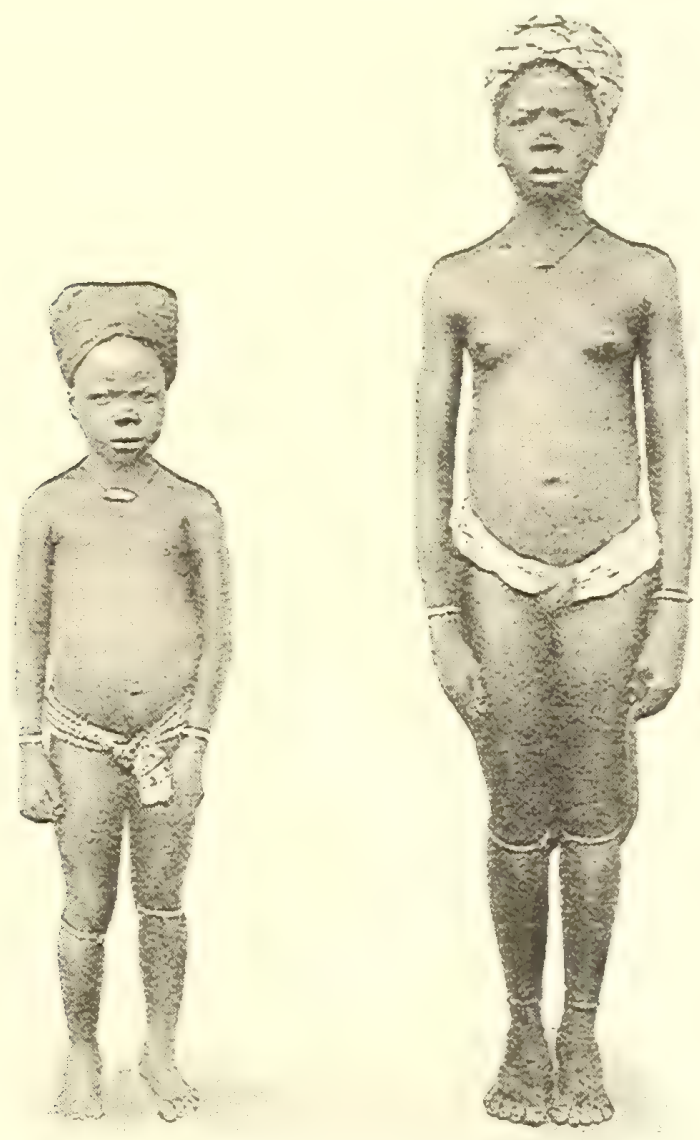

Evhe-Mädchen im Putz

die viele Mühe und Arbeit, der er sich seiner undankbaren Braut wegen unterzogen hat, indem er die Sache mehr ron der praktischen Seite ansieht und das ihm verpflichtete Mädchen einfach als Sklavin verkauft. Der Erlös sowie ein Pauschquantum, welches die Eltern als Sühne für die Geschenke und die geleistete Arbeit an den verlassenen Bräutigam 
zu zahlen haben, tröstet denselben über den Verlust der Braut und giebt ihm gleichzeitig Gelegenheit, ein anderes Mädchen zu freien.

Hochzeits- Die Hochzeitsfeste werden unter Trommelschlag und Gesang mehrere gebrăuche. Tage hindurch bei Tanz und Schmaus und einem ordentlichen Zechgelage gefeiert. Die Braut ist bei der Hochzeit fast überladen mit Schmucksachen, welche sie aber als junge Frau bis zur ersten Niederkunft ablegen muss. Das junge Ehepaar zieht sich des Abends in seine Hütte zurück und eine alte Frau untersucht gewissermaassen als Zeugin Tags darauf das ausgebreitete weisse Tuch unter dem Lager und zeigt dieses mit den gefärbten Spuren als Beweis der vollzogenen Ehe den Bekannten vor. Zuweilen wird aber auch von der gutmütigen Alten einem Hahn der Garaus gemacht, um den Vollzug der Ehe nachzuweisen; das Fest wird dann durch keinen Misston gestört und fröhlich weiter gefeiert.

Die Ehe Die Frau ist nicht, wie oft angenommen wird, bei den Negern nur eine dienende Magd, sondern spielt häufig eine grosse Rolle in dęm Familienleben. Es giebt also unter den afrikanischen Verhältnissen eben so viel Pantoffelhelden wie bei uns in dem zivilisierten Europa. Je mehr Kinder die Frau hat, desto grösser ist ihr Einfluss und.ihr Ansehen. Ist die Ehe kinderlos, so wird der Fetisch um Hilfe angerufen. Der Priester schreibt der Frau gewisse Opfer und Verhaltungsmaassregeln vor, welche sie befolgen muss. Von dem grossen Gotte Mawu ist dem Untergotte Kewu die Macht verliehen worden, der Frau Fruchtbarkeit zu verleihen und sie vor Fehl- oder Totgeburten zu schützen, während andererseits die Mutterliebe die Evhefrauen selbst bis in das benachbarte Kunya-Gebiet zu dem Fetisch Nana Kombi treibt, dem die Erhaltung der kleinen Kinder obliegt. Gebiert die Frau ein Kind, so nährt sie dasselbe mit der Muttermilch meistens mehrere Jahre lang, innerhalb welcher Zeit sie nach Landessitte unberührt bleiben muss. Gewisse religiöse Gelübde zwingen die Frau aber unter Umständen sogar fünf Jahre den geschlechtlichen Verkehr mit dém Manne zu meiden. Daher erklärt sich auch die Polygamie der Negerstämme. Bei den Evhenegern hat ein Mann, der imstande ist, mehrere Frauen zu ernähren, gewöhnlich zwei bis drei. Meistens ist dann die Lieblingsfrau die jüngere, welche sich putzt, nur zum Vergnügen des Mannes dient und das Kommando über die übrigen Frauen hat. Während die begünstigte Frau ihrem Vergnügen nachgeht, müssen die übrigen Frauen des Mannes, schon ihrer Kinder wegen, den Haushalt besorgen und das Essen bereiten.

Ehebruch. Trotz der im allgemeinen guten Sitten, ist die Treue der Frau, namentlich in den Küstengegenden, eine recht laue. Häufig kommt es vor, dass die Frau auf einem Fehltritt von dem Manne ertappt wird, was zu Zerwürfnissen und Unzuträglichkeiten zwischen den Ehehälften 
und schliesslich zur Anklage gegen den Thäter führt. Derselbe muss sich in Gegenwart des Häuptlings ror der versammelten Menge verantworten und, falls er für schuldig befunden wird, das Vergehen mit ciner Geldstrafe sühnen. Ist die Frau verstockt, so führt sie der Mann zu dem Häuptling, der sie dann verurteilt, von einem Priester des Giftgottes Nanyo, der seinen Hauptsitz in Aneho hat, den sogenannten Fetischtrank zu nehmen, wodurch ihre Schuld oder Unschuld festgestellt wird. Die Frau ist somit der Gnade oder Ungnade des Priesters verfallen, der ihr je nach Gunst oder Ungunst der Verhältnisse entweder den Giftbecher oder einen Becher mit unschädlichem Wasser überreicht. Aber auch der Giftbecher hat bei diesen Gottesurteilen eine rerschiedene Wirkung, da das Gift meistens ein Pflanzen- und Herzgift ist, welches eine brecherregende Wirkung besitzt. Tritt die Wirkung des Giftes sofort ein und wird es wieder ausgebrochen, so ist die Angeklagte gerettet und gilt für unschuldig

Die Ehe ist bei den Negern im allgemeinen für das ganze Leben verbindlich und gewährt dem Manne wie der Frau gewisse Rechte, die sich, wie alle Rechte dieser Naturvölker, durch mündliche Ueberlieferung erhalten und vererben. So hat der junge Ehemann an der Küste das Recht, seine Frau sofort in das elterliche Haus zurückzusenden und ron den Schwiegereltern die Geschenke und den Kaufpreis zurückzufordern, wenn sich bei der Hochzeit herausstellt, dass sie nicht mehr Jungfrau war Im Innern weicht man von dieser Auffassung häufig ab, in der Annahme, dass ein Mädchen, das vorher keinen geschlechtlichen Umgang mit Männern hatte, keine Anziehung für die Männerwelt besitze. Kommt das Vergehen eines Mädchens in die Oeffentlichkeit, so ist es fur dieses und die Familie eine grosse Schande. Der Mann hat ferner das Recht, wenn er seiner Frau abgeneigt ist und diese nicht mehr bei sich behalten will, sie in das elterliche Haus zurückzusenden. In diesem Falle werden dem Manne weder die Geschenke noch sonstige Andenken zurückerstattet; indessen ereignet sich der Fall selten, da er dem Manne keinen Vorteil bringt. Die Frau ist nach dem Begriff der Eingeborenen gewissermaassen Eigentum des Mannes und deshalb hat er das Recht, dieselbe zu verschenken oder auch für eine bestimmte Summe einem anderen zu überlassen. Der Mann begiebt sich in diesem Falle sämtlicher Anrechte auf die Frau und auf die Kinder, welche dieselbe später mit einem anderen Manne haben sollte. Besitzt die Frau eine Abneigung gegen ihren Mann, so gestattet er ihr wohl gewöhnlich in das elterliche Haus zurückzukehren, giebt jedoch dadurch nicht seine Rechte auf und betrachtet sie, wenn er dabei einen materiellen Nutzen hat, immer noch als sein rechtmässiges Weib. Bekommt z. B. die Frau ein uneheliches Kind, so meldet sich häufig der rechtmässige Gatte und erhebt Anspruch 
auf dasselbe. Ihm steht nach dem Begriff der Eingeborenen das rechtmässige Eigentum des Kindes zu und deshalb lässt der Mann diese günstige Gelegenheit selten vorüber gehen, seine Familie zu vermehren und sich dadurch zu bereichern. Bei den weiten Strecken brachen Landes besteht nämlich der Hauptreichtum des Negers in einer grossen Anzahl von Familienmitgliedern. Er hat dann ausreichende Arbeitskräfte im Hause und auf dem Felde und braucht keine Sklaven zu erwerben. Ein kinderreicher Familienvater kann daher grössere Strecken Landes urbar machen, Farmen anlegen, seine Kinder mit Produkten auf die Märkte senden, Handel treiben und sein Vermögen bedeutend vergrössern. Man kann deshalb in Afrika im wahren Sinne des Wortes noch von einem Kindersegen reden. Stirbt eine Frau, die ihren Mann mit dessen Zustimmung verlassen hat, während der Schwangerschaft, so hat der rechtmässige Mann das Recht von dem Liebhaber seiner Frau nicht nur fur diese, sondern auch für das noch nicht geborene Kind eine entsprechende Entschädigung zu fordern. Stirbt der Mann, so kehrt die Frau meistens sofort in das Trauerhaus zurück und macht wie die übrigen Frauen die üblichen Zeremonieen mit, weil sie den Geist des verstorbenen Mannes fürchtet. Die Trauer dauert aus diesem Grunde nur so lange, bis der Geist des Mannes in das Reich Mawus aufgenommen ist und nicht mehr umherirrt. So frei im allgemeinen der Verkehr der jungen Mädchen mit Männern ist, so achtet doch der Mann, so lange die Frau nicht von ihm geschieden ist, darauf, dass dieselbe ihm die eheliche Treue bewahrt. Wenn er die Frau bei einem Fehltritt ertappt, so hat er, wie ich erwähnt habe, das Recht, dieselbe von sich zu weisen und den Kaufpreis ron den Schwiegereltern zurückzufordern, dagegen kein Anrecht auf eine Entschädigung, wenn nur Abneigung und nicht eheliche Untreue vorliegt. In den meisten Fällen macht der Mann weniger die Frau als den Verführer verantwortlich und sucht von diesem eine Sühne in Gestalt von Geld oder sonstigen Wertobjekten zu erhalten. Geht der Betreffende nicht gutwillig darauf ein, so wird er durch den Häuptling und die Aeltesten im öffentlichen Palaver zu der Sühne verurteilt.

Reinlichkeit. Was im allgemeinen die Reinlichkeit der Evheneger anbetrifft, so kann man sie in dieser Beziehung auf eine hohe Stufe stellen. Der Trieb zur Reinlichkeit ist allerdings in denjenigen Landstrichen, die an Wassermangel leiden, namentlich zur Trockenzeit, weniger vorhanden, desto grösser aber an der Küste und in den wasserreichen Gegenden. Die Evheneger baden, wenn es irgend möglich ist, häufig mehrere Male am Tage und seifen dabei ihren Körper tüchtig ab. Auch das kurz geschnittene Haar erhöht noch die Sauberkeit. Stundenlang baden die kleinen Jungen und Mädchen an den Küstenplätzen in der 


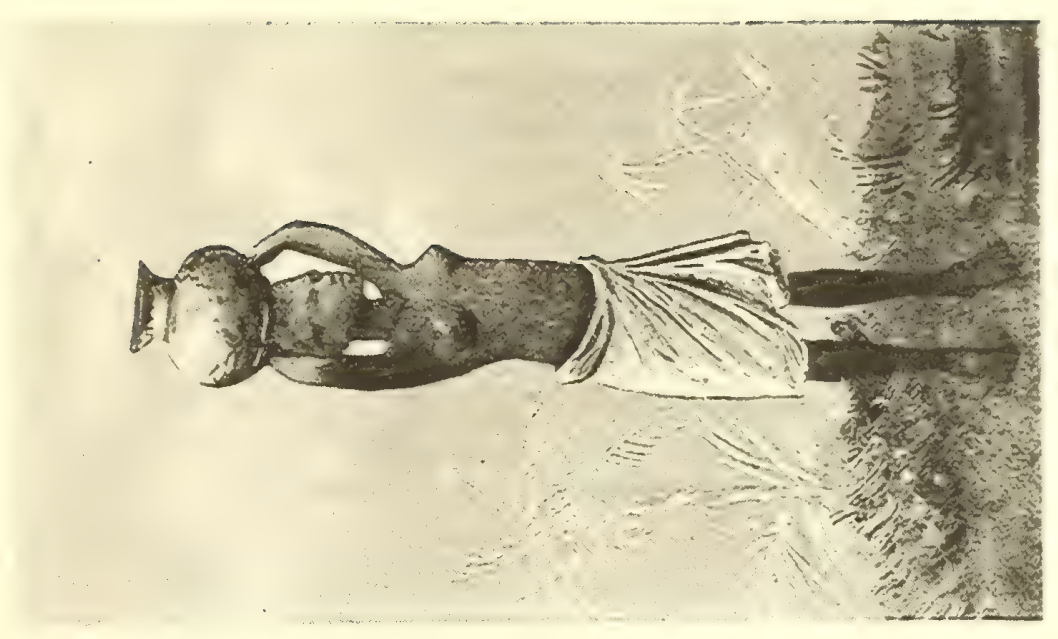

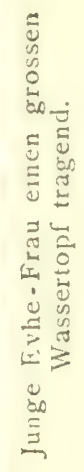

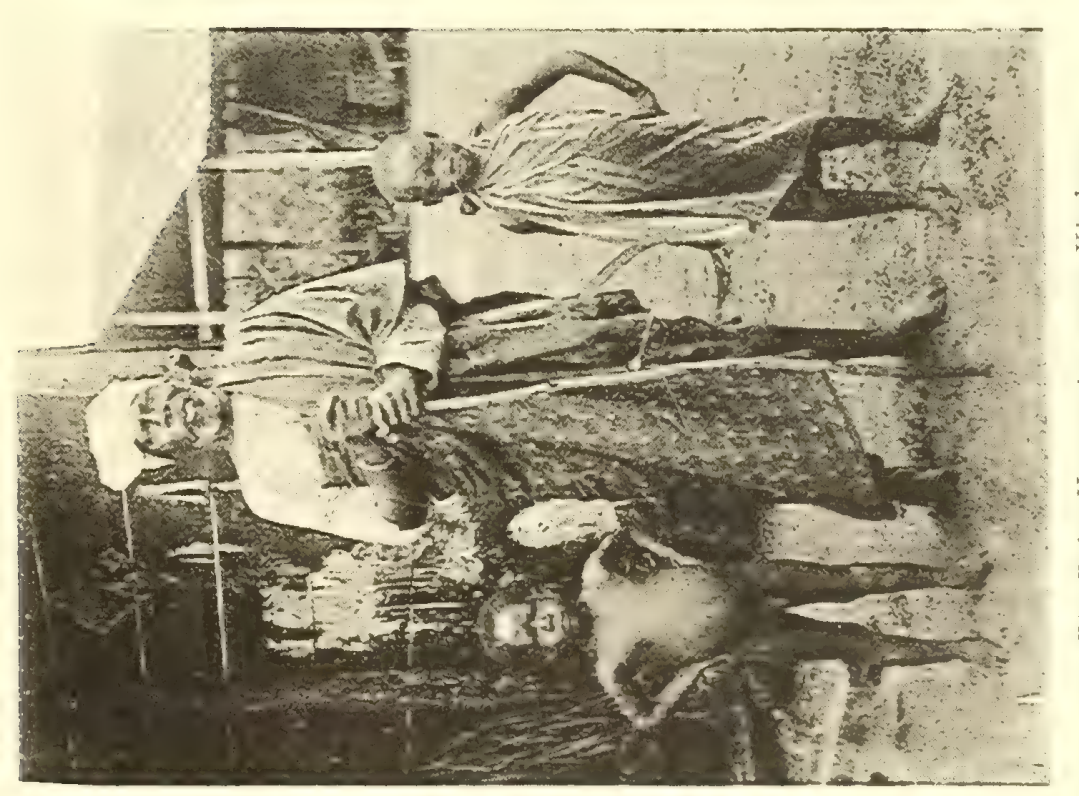



See und in der I agune. Es ist eine Freude, dem muntren Treiben des kleinen schwarzen Volkes im Wasser zuzusehen, namentlich wenn die Knaben, auf einem Brett sitzend, die hohe Brandung passieren. Ueberall sieht man in der Lagune die Frauen mit ihren Kindern im Wasser stchen und sie trotz Sträubens und Schreiens tüchtig mit Seife und VIasser bearbeiten. In den von Gewässern entfernter gelegenen Gegenden hat jedes Gehöft seinen kleinen Waschplatz, der sich in einem Winkel des Hofes befindet und mit Matten abgegrenzt ist. Des Abends, wenn der Mann bestaubt von der Feldarbeit zurückkehrt, stellt die Frau einen Topf mit warmem Wasser bereit, damit der Mann in dem Waschraum ein erquickendes Bad nehmen kann. Dann erst legt er reine Tücher an und begiebt sich zu dem fertig gestellten Mahle. Die Frauen ölen, namentlich bei feierlichen Gelegenheiten, ihren Körper nach dem Bade mit Fett ein, damit die Haut glänzend erscheint. Die Haare werden mit allerhand Pomaden und Fetten eingerieben, die allerdings nach unseren Begriffen wenig zur Reinlichkeit beitragen. Lavendelwasser und andere wohlriechende Parfümerieen, sowie Seifen gehören zu den Lieblingstoilettegegenständen.

Die Kleidung der Neger ist an der Küste sehr verschieden; neben dem schwarzen Gigerl im Chapeau bas, gelben Nanking-Hosen, hohen Vatermördern und schwarzem Frack sieht man den verachteten Buschmann, welcher nur mit einem kleinen Tuch seine Scham bedeckt hat Auch bei den schwarzen Damen fehlt es nicht an europäischen Kleidungsstücken. Selbstverständlich machen sie in dem europäischen Anzug keinen vorteilhaften Eindruck, da die starken Hüften, der watschelnde Gang und die langen schlenkernden Arme wenig zu dieser Kleidung passen; bei weitem besser steht ihnen die heimische Tracht. Europäische Kleidung sieht man allerdings nur in den grossen Küstenstädten, während im allgemeinen die Tracht der Leute aus einem grossen Umschlagetuch besteht, unter welchen die Frauen den sogenannten Schlips, d. h. ein kleines Schamtuch tragen. Dieser Zeugstreifen, der die Scham deckt, ist hinten und vorn an einer Hüftschnur, auf der Perlen oder weiter im Innern auch geschnitzte Plättchen aus Kokosnussschalen aufgereiht sind, hergestellt. Die Männer dagegen tragen unter dem Tuch einen kleinen Lappen, der zwischen den Beinen durchgezogen und um die Hüften gebunden ist. Bei den jungen unverheirateten Frauen fehlt das grosse Tuch und auch die jungen Burschen gehen nur mit dem Schamtuch bekleidet aufs Feld zur Arbeit. Frauen und Mädchen tragen bei feierlichen Gelegenheiten farbige Tücher um den Kopf gewunden. Die Kinder laufen nackt umher; mitunter wird ihnen von der Mutter ein kleines Liebeszeichen, bestehend aus einem Armband oder einer Halskette oder auch einer kleinen Perlenschnur als Schmuck 
angelegt. Während die Männer bei der Arbeit nur das Schamtuch tragen, haben die Frauen ausser demselben noch ein kleines Tuch, welches um den Leib gebunden bis zu den Knieen herunterhängt. Wenn ein Weisser oder eine höher gestellte Persönlichkeit des Weges

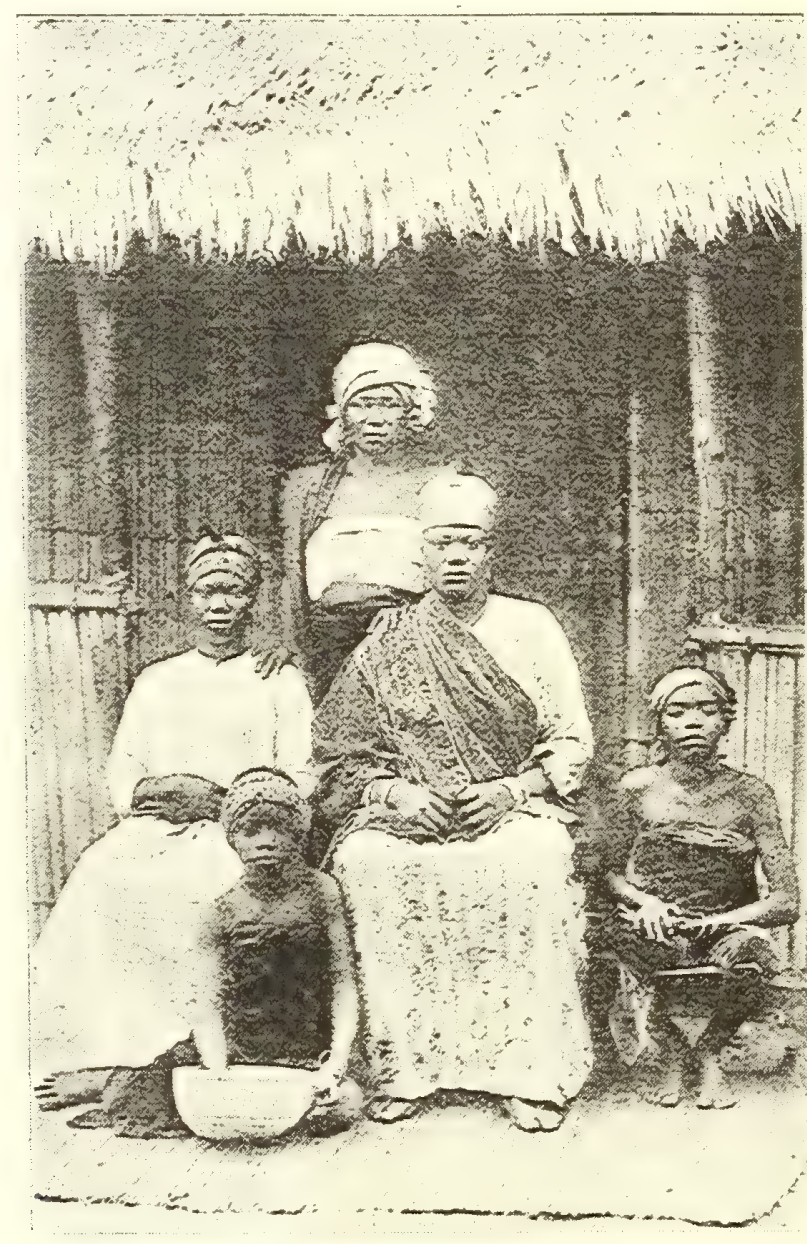

Reiche Evhe-Frauen von der Küste.

kommt oder ein Festzug vorbeizieht, wird das Tuch aufgerollt und damit die Brust bedeckt. Ausser den erwähnten Kleidungsstücken pflegen sich die schwarzen Frauen, wie wir gesehen haben, noch mit Armbändern und sonstigem Putz zu schmücken.

Ackerbau und Im Verlaufe der Reise habe ich wahrgenommen, auf welcher hohen Handel Stufe im allgemeinen der Ackerbau bei dem Stamme der Evhe steht. 
Obwohl noch andere Erwerbszweige in Frage kommen, liegt doch das Hauptgewicht auf dem Ackerbau, welcher zum Teil in grossem Stil betrieben wird. Die reichen Yams-, Mais- und Reisfarmen, welche wir auf unseren Märschen gesehen haben, lassen auf die Fruchtbarkeit des Bodens, die intensive Kultur desselben, sowie auf den Fleiss dieser Bevölkerung gegenüber anderen Negerstämmen schliessen. Ausser dem Ackerbau ist der Handel erwähnenswert. Fast alle Evheneger sind ausgesprochene Händler, welche auf Märkten und an Wegen ihre Waren feilhalten, mit Beharrlichkeit anpreisen und um jeden Pfennig unermüdlich feilschen. Bemerkenswert ist, dass auch die Frauen neben ihren häuslichen Arbeiten dem Handel obliegen, um sich durch diesen Nebenverdienst oftmals selbständig zu machen und ihre persönlichen Bedurfnisse zu bestreiten.

Die Viehzucht hat mit der hohen Kultur des Ackers in keiner Weise Schritt gehalten. Allerdings ist in dieser Beziehung den Evhenegern keine Schuld beizumessen, weil einer reellen Viehzucht in dem Küstengebiet elementare Hindernisse entgegenstehen. So ist die Pferdeund Rindviehzucht in den Gebieten, die wir durchstreift haben, teils wegen der Wasserverhältnisse, teils wegen des Mangels an geeigneten Weideplätzen und vor allem wegen der Tsetsefliegen bis jetzt fast ausgeschlossen. Es giebt in diesem Gebiete, wie in Adjido, nur sehr wenige Oasen, welche diesen schädlichen Einflüssen nicht unterliegen. Nächst der Küste ist Atakpame die einzige Landschaft, in welcher eine ergiebige Rindviehzucht mit Erfolg betrieben wird und welche in dieser Hinsicht für die Zukunft einen nicht $z u$ unterschätzenden wirtschaftlichen Faktor bilden kann. Hoffentlich werden diese misslichen Verhältnisse, besonders was die Weideplätze anbelangt, mit den Jahren durch die fortschreitende Kultur beseitigt und durch Anpflanzung von süssen Gräsern geeignete Weideplätze geschaffen werden. Dass dieselben gedeihen können, beweist die Anlage der Weiden an den Abhängen der Station Misahöhe, wo mit süssen kurzhalmigen Gräsern recht gute Resultate erzielt worden sind. Die Wasserverhältnisse können sich durch die Anlage von Brunnen und Cisternen bessern. Eine geeignete Zuchtwahl, sowie eine passende Körnerfütterung könnten auch die Tiere in Bezug auf schädliche Einflüsse widerstandsfähiger machen, so dass wir nicht ganz die Hoffnung aufzugeben brauchen, dass in dieser Beziehung die Hindernisse mit der Zeit beseitigt werden können.

Was das Kleinvieh anbetrifft, welches sich bedeutend genügsamer in der Nahrung und widerstandsfähiger erweist, so haben wir auf unseren Reisen durch die Gebiete fast überall Schafe und Ziegen, auch häufig Schweine angetroffen. In einigen Orten werden zahme Tauben gehalten, während Hühner selbst in den ärmsten Orten zu finden sind. Die Schafe 
und Ziegen sind durch mangelhafte Ernährung und Inzucht vollkommen degeneriert und mit unseren europäischen Vertretern dieser Rasse garnicht zu vergleichen. Die Tiere laufen im allgemeinen frei herum und suchen sich ihre Nahrung so gut es geht in den umliegenden Grassavannen oder halten sich auch manchmal an irgend einer der nahegelegenen Farmen schadlos. Natürlich ist unter diesen Umständen eine Zuchtwahl vollkommen ausgeschlossen und, da die Tiere alle zusammenleben und wenig frisches Blut in die Heerden kommt, von einer Auffrischung des letzteren nicht die Rede. Diese Inzucht hat zur Folge, dass die kleineren schwarzen, glatthaarigen Ziegen, welche wir so häufig angetroffen haben, im Durchschnitt nicht höher als $40 \mathrm{~cm}$ sind.

Die Ziegen werden gewöhnlich nur bei feierlichen Gelegenheiten als Schlachtvieh benutzt. Die Schafe finden häuptsächlich bei den Opfern für die Fetische Verwertung und werden seltener wie die Ziegen als Schlachttiere verwendet, da sie teurer sind. Eine Wollproduktion existiert meines Wissens nicht, da Wollschafe im eigentlichen Sinne überhaupt nicht vorhanden sind. Die Wolle der afrikanischen Schafe kann nur als Haar bezeichnet werden. Mit der Einführung anderer Arten und Veredlung derselben liesse sich wohl die Schafzucht heben. Die Schafe, im allgemeinen genügsam und auch mit geringerem Futter zufrieden, könnten mit der Zeit in unserem deutschen Togogebiet vielleicht noch ein bedeutendes Wollquantum liefern. Die einheimischen Schafe sind durchschnittlich nicht höher als $\mathrm{r} / 2 \mathrm{~m}$ und machen wie die übrigen Tiere meistens einen dürftigen Eindruck. Ausser den Wollschafen, wenn man sich so ausdrücken darf, giebt es aber noch eine Rasse, welche vollkommen glatthaarig ist und zum grössten Teil eine weisse Grundfarbe besitzt, während der Kopf und der Hals schwarz sind. Sie gleichen fast den bekannten Somalischafen, nur dass sie bedeutend kleiner sind.

Die hier vorkommenden Schweine sind, was ihre körperliche Entwickelung anbelangt, nicht die schlechtesten Haustiere. Auch sie müssen meistens ihr Futter selbst suchen; jedoch finden sie viel Nahrungsstoff in dem massenhaften Unrat der Dörfer und sind deshalb mit Recht an der Küste bei den Europäern verpönt; auch im Innern gelten sie allen Mohamedanern als Haram.

Was das Geflügel anbetrifft, so ist das gewöhnliche Haushuhn überall verbreitet; aber auch dieses ist zu einer winzig kleinen Art verkümmert und bietet dem Europäer, der auf manchen Strecken fast das ganze Jahr hindurch nur Huhn auf dem Tisch sieht, einen zweifelhaften Genuss. Die Eier werden von den Eingeborenen garnicht gegessen, sondern nur zur Brut benutzt, so dass man häufig unter einer Mandel Eier ro bis 12 angebrütete findet. In einigen Ortschaften giebt es Perlhühner. Sie stammen direkt von dem wilden afrikanischen Perlhuhn ab, 
das in diesen Gegenden weit verbreitet ist. Diese zahmen Pcrlhühner sind $i m$ grossen und ganzen nicht so degeneriert wie die Haushühner. Durch ihre Beweglichkeit scheinen sie sich leichter aus den anliegenden Feldern Nahrung verschaffen zu können, vielleicht ist auch eine Auffrischung durch das Blut der wilden Vertreter ihrer Rasse nicht ausgeschlossen.

Wie in allen Weltteilen der Hund ein treuer Freund und Begleiter der Menschen ist, so finden wir ihn auch hier in Afrika bei den Negern wieder. Diese betrachten ihn allerdings nicht bloss als Hausfreund, als Wächter und Hüter der Hütten, sondern geniessen auch sein Fleisch. Die Hunderasse in diesen Gegenden ist meistens von mittlerer Grösse; der Kopf ist länglich, die Schnauze spitz. Der Körper ist schlank, sodass der ganze Rumpf einem Bastard von Spitz und Windhund ähnlich sieht. Die Ohren sind klein und herabhängend, während der Schwanz aufrecht gerollt, ziemlich lang und glatt ist. Das fiell ist glatt und gewöhnlich hellgelb, die Pfoten und die Schwanzspitze weiss. Eigentümlich ist, dass die afrikanischen Hunde durchaus nicht bellen können, sondern nur ein Geheul anschlagen. Sie sind im allgemeinen nicht hässlich, jedoch öfters durch die Räude, von welcher hier die Hunde ganzer Ortschaften befallen werden, entstellt. Der Grund für das häufige Auftreten dieser Krankheit scheint in der mangelhaften Ernährung, sowie in der schlechten Haltung der Tiere zu liegen. Natürlich wird ihrer Verbreitung durch das freie L'mherlaufen der Tiere Vorschub geleistet.

Die Jagd sowie Sitten und Gebräuche der Jäger habe ich bereits geschildert und gezeigt, dass der Fetisch-Orden auch auf diesem Gebiet und Fiscberei. von Einfluss ist. Zu erwähnen ist hauptsächlich, dass nach dem Glauben der Evheneger die Seele des Tieres, gleich der des Menschen, im Jenseits weiter fortlebt. Es werden daher die Geister der erlegten Tiere gefürchtet und durch die geschilderten Gebräuche, welche denen bei der Bestattung eines Verwandten annähernd gleichkommen, gewissermaassen beschworen, damit sie dem Jäger nichts Böses zufügen.

Die Fischerei wird hauptsächlich an der Küste betrieben. Das weite Meer und die Lagune, welche wegen ihrer schmackhaften Fische gerühmt wird, bieten den Küstennegern reichliche Gelegenheit zum Fischfang, von dem sich viele Familien ernähren. Weiter im Innern findet der Fischfang nur in den grösseren Strömen und Flüssen statt. Die kleineren Flüsse und Bäche in Afrika haben natürlich so gut wie gar keine Fische, da sie in der Trockenzeit kein Wasser führen. Triel aber trägt zur Ausrottung der Fische auch die Raubfischerei der Neger bei, da sie keine Schonzeit kennen. Der Neger fischt und angelt alles, rom kleinsten bis zum grössten Fische; denn auch die kleinsten Fische 
werden geräuchert und getrocknet und sind eine beliebte Delikatesse. Durch diese unüberlegte Wirtschaft nimmt der Fischreichtum selbstverständlich mit der Zeit ab; nur geeignete Gesetze über die Ausübung der Fischerei könnten diesem Uebelstand abhelfen.

Gewerbe Das verbeitetste Gewerbe in ganz Afrika ist das der Schmiedekunst. Wir haben bereits gesehen, dass die Leute im Innern des Landes ihre Bedarfsgegenstände, wie Messer und Schwerter selbst schmieden, wie sie auch selbst früher verstanden haben, Eisen zu gewinnen, was noch heute in manchen Ortschaften an den zurückgebliebenen Schlacken zu bemerken ist. Auch die Instandsetzung von Gewehren liegt einheimischen Schmieden ob und einen besonderen Beweis für ihre Kunstfertigkeit liefert die Verarbeitung von Silber- und Nickelmünzen zu Armbändern und sonstigen Schmuckgegenständen. An der Küste sind die Leistungen der Schmiede um so erstaunlicher, als sich dieselben zur Arbeit primitiver Werkzeuge bedienen. Hier werden mit Geschick die in der letzten Zeit beliebt gewordenen, sogenannten Afrikaringe aus dem weit hergebrachten Gold des Hinterlandes, sowie auch vielfach aus europäischem Golde geschmiedet. Sie stellen meistens die Sternbilder des Tierkreises dar, welche mühsam einzeln gearbeitet und auf einen Goldreif aufgelötet werden. Auf dieselbe Weise werden auch Broschen und Armbänder hergestellt. Da in Togo nur wenig Goldschmiede sind und die Sachen meistens von den sogenannten Schwarzschmieden ausgeführt werden, so werden diese Arbeiten hauptsächlich von Goldschmieden in Akkra verfertigt. Hoffentlich gelingt es, auch in unseren Gebieten Goldadern aufzufinden, dadurch diesen Industriezweig zu noch grösserer Blüte zu bringen und den Wert der Kolonie bedeutend zu erhöhen. Das gewöhnliche Schmiedehandwerk ist bei den Evheleuten sehr verbreitet und fast in jedem grossen Ort befindet sich ein Dorfschmied.

Weberei und Obwohl heute die Weberei in den Küstengebieten durch die billigen Spinnerei. europäischen Stoffe und Zeuge sehr verdrängt ist, so haben wir auf unserer Reise doch viele Dörfer angetroffen, in denen noch der Webstuhl klappert. Die Hauptproduktion der Weberei sind Tücher, welche aus schmalen Streifen zusammengenäht sind; die einzelnen Streifen werden in einer Breite von etwa Io bis $13 \mathrm{~cm}$ auf den schon früher beschriebenen Webstühlen angefertigt. Die schönsten Erzeugnisse dieser EingeborenenWeberei bilden die überall verbreiteten und beliebten Hängematten, welche weit fester als die europäischen Hängematten sind. Sie bestehen meistens aus einem grauen, dicht gewebten, mit roten oder blauen Fäden durchschossenen Stoff. Wenn auch die Weberei bei weitem nicht so intensiv betrieben wird wie das Schmiedehandwerk, so giebt es doch noch einzelne Weberfamilien, die dieses Gewerbe für den Handel aus- 
üben; meistens aber weben die Leute fur ihren eigenen Bedarf. Eng mit der Weberei verknüpft ist die Spinnerei, die dort, wo noch Baumwollkultur herrscht, die hauptsächlichste Beschäftigung der alten Frauen ist. Aber auch die Spinnerei ist durch die Einführung europäischer Garne und Zwirne sehr verdrängt worden; nicht selten verwenden daher die eingeborenen Weber europäische Garne zu ihren Geweben.

Die Töpferei bildet gewissermaassen das Monopol einzelner Plätze, Töpferei und welche infolge ihres bündigen Bodens für dieses Handwerk besonders Schnitzerei geeignet sind. So hat Tove, wie wir gesehen haben, in dieser Beziehung eine ganz besondere Bedeutung gehabt; ebenso soll auch Bolu an der Küste ein grosser Marktplatz für Töpferwaren sein. Bemerkenswert ist die Fingerfertigkeit der eingeborenen Töpfer, die, wie bereits geschildert, mit dem primitivsten Handwerkszeug, wie Holzstäbchen und geschliffenen Steinen, die Form und Verzierung der verschiedenen Gefässe ausführen. Die Drehscheibe, welche bei uns die Arbeit in hohem Grade erleichtert, ist bei allen diesen Negervölkern noch unbekannt.

Die Schnitzerei verdient ebenfalls erwähnt zu werden. Die schönen symbolischen Häuptlingsstöcke mit Figuren und Verzierungen, sowie die künstlich geschnitzten, durchbrochenen Königsstühle und Schemel der Eingeborenen, die sämtlich aus einem Stück gearbeitet sind, sprechen für die grosse Kunstfertigkeit der Schnitzer, welche oft nur mit einem einfachen Buschmesser arbeiten. Das Untergestell der Königsstühle ist häufig in Form von gewundenen Schlangen hergestellt oder besteht in kleinen, durchbrochenen und verzierten Säulen. Auch fertigen die Leute kleine Löffel sowie Kämme, ein Lieblingsartikel der Frauen, an. Ferner werden aus der harten Kernschale der Kokosnuss die bei den Negern häufigen Ketten gearbeitet, welche hauptsächlich als Hüftschnur um den Leib getragen werden und zur Befestigung der kleinen Schamtücher dienen. Aus der harten Schale werden geschickt kleine runde Blättchen ausgeschnitten, geschabt, durchlocht und auf einen Faden gezogen. Die auf diese Wreise hergestellte Schnur wirkt wie eine Kette aus stumpfen schwarzen Glasperlen. Auch Hausgeräte aller Art werden geschnitzt. So findet man in jeder Haushaltung die unentbehrlichen Kalabassen aus Kürbissen, welchen schon während der Zeit des Wachsens künstlich eine bestimmte Form gegeben wird. Der Schnitzer entfernt dann das Mark des Kürbisses und glättet die Innenseite desselben. Diese Gegenstände sind in allen Formen vorhanden, von den grössten Vorratsschalen bis zu den kleinsten Wassernäpfen. Die Kalabassen und Schalen werden mit allerhand Mustern verziert. So sind meistens auf den Kalabassen Abbildungen von einheimischen Tieren eingeschnitzt; namentlich Schlangen, die auch in dem Fetischleben eine grosse Rolle spielen, sind in allen Formen vertreten. Vielfach werden Eidechsen auf diesen Gefässen an- 
gebracht, jedoch ist die Form derselben, wenn man ihre Entstehungsgeschichte nicht kennt, kaum erkennbar. Sie sind nur noch eine Art Ornament, dessen erster Ursprung auf diese Tiere zuruickzufuhren ist. Endlich werden auch Vögel, wie Reiher zu der Verzierung der Kalabassen benutzt. Aus den Kürbissen werden Vorratsschalen, Wassernäpfe, Schöpflöffel, kleine Esslöffel, aus der Kokosnuss Schnupftabaksdosen und andere Gebrauchsgegenstände angefertigt. Ausser den angeführten Gegenständen werden, jedoch seltener bei den Evhes, auch noch vereinzelt an den Küstenplätzen Kanoes und andere kleine Fahrzeuge sowie Ruder aus Holz gearbeitet, obwohl der Kanoebau mehr eine Spezialität der Kunyaleute ist, da in dem Kustenbezirk die dazu notwendigen grossen Seidenwollbäume fehlen. Wir haben aber schon gesehen, wie gut sich unsere Evheneger für Zimmer- und Tischlerarbeiten eignen und in welcher Weise sich besonders die Missionen mit der Ausbildung dieser Handwerker beschäftigt haben. Dieser segensreiche Einfluss der Missionen auf das Handwerk ist bei allen Europäerbauten von nicht zu unterschätzendem Nutzen gewesen.

(erberei Einen besonderen Industriezweig bildet die Lederarbeit, welche den Evheleuten nicht unbekannt ist, wenn auch die eigentlichen Meister der Gerberei in unseren Gebieten hauptsächlich die Haussas sind. Doch werden auch von den Evheleuten Felle gegerbt, um damit ihre Trommeln zu überziehen; ausserdem stellen sie sich aus gegerbtem Leder oder Fell Patronentaschen her. Zu ihren kleinen Messern haben sie häufig schön gearbeitete und verzierte Lederscheiden. In der Sonne getrocknete Felle werden nicht selten als Thürvorsetzer oder als Teppiche, sowie zur Eindeckung von Traglasten, Pulver und sonstigen gegen Feuchtigkeit zu schützenden Gegenständen benutzt. Leider gehen bei der Zerlegung des erlegten Wildes viele Felle verloren, da die Eingeborenen es nicht der Mühe wert halten, die erlegten Tiere vorher abzuziehen. An den Küstenplätzen in Togo ist die Nachfrage nach Fellen gering, an der englischen Goldküste dagegen der Handel und die Ausfuhr der Felle recht bedeutend.

Flechterei Die Flechterei wird überall nebenbei betrieben. Aus langen Rohrgräsern und aus Palmblättern werden schöne Schlafmatten, sowie kleine Taschen und Körbe zur Aufbewahrung von Mehl oder Körnern geflochten; ferner werden Thürvorsätzer, an der Küste auch die erwähnten grossen Regenhüte, Kriegshelme und Kappen angefertigt.

Hüttenbau. $\quad$ Zu der wichtigsten Beschäftigung der Evheneger gehört unstreitig der Bau ihrer Hütten. Jeder Evheneger baut sich seine Hütte und sein Gehöft selbst auf. Er lernt dies schon in der Jugend,. da er wie die übrigen Familienmitglieder bei dem Bau der Hütten des Vaters fleissig mitarbeiten muss. Der Bau der Hütten ist im allgemeinen zwar ein sehr 
einfacher, indessen erfullen sie rollkommen ihren Zweck und halten gut Stand gegen die Unbilden der Witterung. Dic Form ist bei den Evheleuten ausschliesslich viereckig; sie sind gewöhnlich $3 \mathrm{~m}$ breit, 5 bis $6 \mathrm{~m}$ lang und werden von einem grossen Giebeldach eingedeckt. Jede Hutte hat einen Eingang, der zugleich das Licht einlässt, da bei den wirklich typischen Eingeborenen-Hütten weder Läden noch Fensteröffnungen rorhanden sind. Meistens enthält die Hütte nur einen, selten mehrere Räume. Die Hütten werden in der Art gebaut, dass zuerst ein Gerüst von rohen Pfeilern und doppelten Querleisten aufgefuhrt wird,

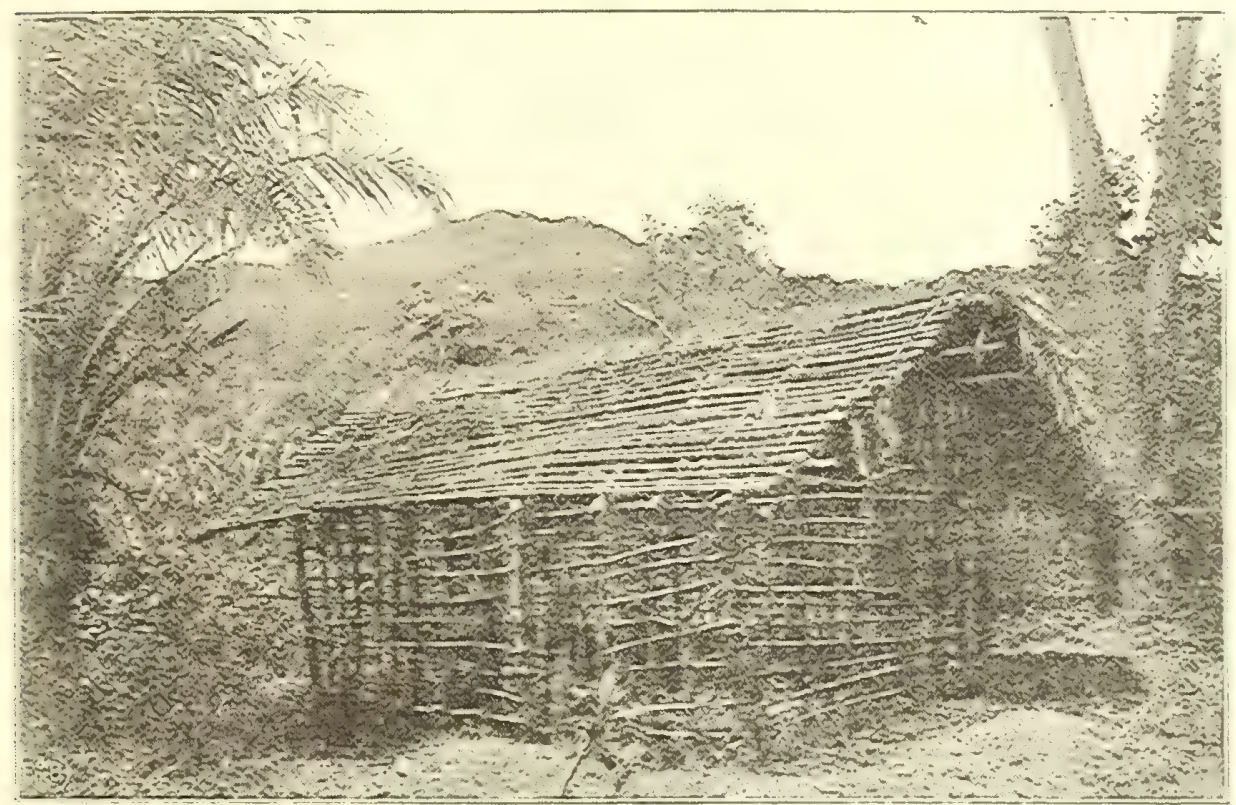

Eine im Bau begriffene Hütte der Evhe-Neger.

dessen ungefähr $2 \mathrm{~m}$ hohe Seitenwände aus rohen Stangen bestehen. Die Giebelseiten sind etwas höher, bis 3 und $3 \frac{\mathrm{x}}{2} \mathrm{~m}$ aufgeführt. Die Dachsparren sind, wenn Bambus vorhanden ist, aus diesem Material angefertigt, während die Querleisten des Daches aus Blattrippen der Wein- und Oelpalme bestehen. Die Wände werden zwischen den doppelten Leisten mit Lehm ausgefullt, wozu öfters wegen ihrer Festigkeit Termitenhaufen verwendet werden. Um den Luftzug in der Hütte zu ermöglichen, bleibt zwischen dem Dach und den Giebelseiten ein freier Raum. Das Dach wird mit Gras eingedeckt, das ziegelartig übereinander liegt und auch dem stärksten Tornado Widerstand leistet. Der Fussboden wird aus Lehm zu einer Tenne festgestampft. Bei luxuriösen Bauten werden die Wände des 
Hauses mit hellgelber Erdfarbe, sowie die Kanten und die Einfassung der Thür mit einer roten Thonfarbe gestrichen. In den besseren Hütten findet man eine sogenannte Schlafbank, d. h. ein Brett, welches auf vier Pfählen ruht und auf dem eine 3 bis 4 Zoll starke, aus Gras geflochtene Schlafmatte liegt. Interessant ist es, wie der Neger sich auch ohne Moskitonetz in der Hütte gegen die Ueberfälle der Moskitos zu schützen weiss. Er hüllt sich vollkommen, selbst den Kopf, die Arme und Beine in sein grosses Tuch ein und ist auf diese Weise vollständig geschützt. Ein Weisser würde in dieser Lage bei der grossen Hitze fast ersticken und mehr leiden, als durch die Stiche der Moskitos, gegen welche man mit der Zeit fast unempfindlich wird. Bei den reichen Händlern findet man roh gezimmerte Holzbettstellen mit Moskitovorhängen aus europäischem Kattun; ihre Häuser haben auch schon Fensterluken, die mit Holzläden verschlossen werden. Die Eingänge zu den Hütten werden des Nachts mit Vorsetzern verschlossen. Die Vorsetzer bestehen gewöhnlich aus zusammengefugten Palmblattrippen. Das Dach wird zuweilen über die Seitenwände herabhängend durch Stützen gehalten und auf diese Weise ein Vorraum geschaffen, welcher gegen Sonne und Regen schützt. Wie wir schon fruher erwähnt haben, befinden sich die Feuerstätten entweder vor der Hütte oder unter einem kleinen Grasdach, seltener in der Hütte selbst. Ferner findet man in jedem Gehöft den bekannten hölzernen Trog zum Fufustampfen, sowie Ställe für das Kleinvieh. Die Ställe sind in der Regel nichts weiter als ein kleiner Raum, der durch Knüppelhölzer abgesperrt ist und in welchem die Tiere des Nachts gehalten werden. In einer Ecke des Gehöfts ist auch häufig noch ein kleiner Raum zum Waschen abgeteilt. In ölreichen Gegenden findet man in den Gehöften kleine runde, gepflasterte Gruben, welche zur Aufnahme und Gährung der Oelpalmenfrüchte dienen. Die Dörfer besitzen gemeinsam sogenannte Reiben, auf denen die Frauen Korn, Maiskörner, Pfeffer sowie andere Früchte zerreiben. Diese Reiben bestehen aus einem viereckigen Lehmblock von ungefähr I $m$ Höhe, der oben mit einem grossen Stein versehen ist, auf welchem die Früchte mittelst kleiner Steine zerrieben werden.

Religion. Die Religion der Evheveger ist nicht bloss reiner Götzendienst und Fetischverehrung. Sie verehren vielmehr, wie wir schon gesehen haben, in ihrem Gotte Mawu, wie auch selbst in dem Yewe, ein höheres Wesen, das über dem Menschen steht und die Welt erschaffen hat. Interessant ist es, wie die Evheneger sich die Erschaffung des Menschen vorstellen. Der grosse Gott Mawu hat bei der Schöpfung auch den Menschen erschaffen und zwar ein weisses und schwarzes Paar. Darauf stellte Mawu den beiden Paaren zwei Körbe zur Verfügung, einen kleineren und einen grösseren. Das schwarze Paar stürzte sich sofort auf den grossen Korb, 
Wïhrend der kleine Korb für das weisse Paar übrig blieb. In dem srossen Korbe waren Hacke, Axt und Buschmesser, Geräte für den Ackerbau, enthalten, während sich in dem kleinen Korbe nur ein Buch befand. Das schwarze Paar ging nun bald seiner Arbeit, dem Ackerbau, nach; das weisse Paar dagegen fing in dem Buche an zu lesen und war bald den schwarzen Brüdern an Schlauheit überlegen. Aus Rache bedrückte das schwarze Paar das andere, bis sich Mawu erbarmte und ein grosses Seil rom Himmel liess, mit welchem er das weisse Paar über das grosse Wasser setzte. - Auch glauben die Anhänger dieser Religion an eine Seelenwanderung und ein Wiedersehen im Jenseits. Diese Crrundgedanken sind allerdings von vielen Nebenerscheinungen und Zeremonieen, welche die selbstsüchtigen Fetischpriester rorschreiben, durchkreuzt, welche das ganze Leben dieser Schwarzen beeinflussen und die Entwickelung der Kultur hemmen.

Ausser dem Yewe-Kultus, der fast die ganze Küstengegend beherrscht, finden wir weiter im Innern und besonders in den Gebirgsgegenden die alte Religion mit ihren Göttern und Gottheiten vor. Dieselbe ist noch immer sehr verbreitet, scheint aber im allgemeinen, obgleich einzelne Züge daraus bei dem Yewe-Kultus wiederkehren, mit weniger verbrecherischen Mitteln 'zu arbeiten wie der Yewe-Kultus. Dieser lässt kein Mittel unbenutzt und schreckt selbst vor Mord und Totschlag nicht zurück, um sein Ansehen zu vergrössern. Es ist ihm daher auch gelungen, die alten Götter verhältnismässig schnell zu verdrängen. Y'eber den Yewe-Orden, seine Sitten und Religionsgebräuche habe ich bereits gesprochen; ich glaube nun noch über die alten Götter und Religionsgebräuche etwas mitteilen zu müssen. Mawu wird als der grosse Gott gedacht, der die Erde und die Menschen erschaffen hat und der nun als König über den anderen Göttern steht. Nach den Begriffen der Neger braucht er nicht mehr zu arbeiten, sondern hat seine Funktionen den einzelnen Gottheiten übertragen. Mawu selbst kann hiernach den Menschen nichts Böses zufügen. Er ist gewissermaassen in seinen Handlungen beschränkt und ron den Untergottheiten abhängig. Nur diese, oder die Geister der Verstorbenen können den Menschen schädigen. Deshalb werden auch nur den Untergöttern Opfer gebracht, was aber nur dann geschieht, wenn man von dem betreffenden Fetischgott irgend etwas fordert, z. B., dass derselbe Regen machen oder irgend eine Krankheit verscheuchen soll. Ein allgemeines Dankgefuhl gegen Mawu als den höchsten Gott, kennt der Neger nicht. Da er ron ihm nichts fordern und dieser ihm Nichts Böses zufügen kann, so werden ihm auch keine.Opfer dargebracht. Die vielen Fetische und Thonfiguren, welche wir in den Dörfern, an den Wegen und Pfaden bemerkt haben, sind nur Opfer, welche für den betreffenden Fetisch bestimmt sind. Sie seibst 
werden keineswegs verehrt, sie sind nur ein symbolisches Zeichen. Es ist gewissermaassen die Stätte, an welcher der Fetisch durch den Priester gerufen werden kann. Der Priester hat das Amt, mit den Untergotheiten oder Fetischen in Verbindung zu treten und näher mit ihnen $z u$ verkehren; er ist also der Vermittler zwischen den Menschen und den Fetischen. Ist ein Fetisch beleidigt, so muss er durch ein Opfer, welches der Fetischpriester vorschreibt, wieder versöhnt werden.

Die Opfer bestehen hauptsächlich in Hühnern oder Schafen. Der Fetischpriester verteilt die geopferten Tiere unter gewissen Zeremonieen, wobei der Löwenanteil fưr ihn abfällt, während dem Fetisch nur die Gedärme oder einige innere Teile des Tieres dargebracht werden, welche der Priester vor die Fetischfiguren oder an geweihten Plätzen niederlegt. Bisweilen werden diesem Opfer noch einige Flaschen Gin oder Feldfrüchte beigefügt. Die Opfer bestehen nicht immer in Tieren und Abgaben, sondern sehr häufig in Thonfetischen, die wir überall in den Ortschaften angetroffen haben. Letzteres Opfer wird in der Regel dargebracht, wenn die Geister der Verstorbenen oder böse Krankheiten von dem Dorf oder der Hütte ferngehalten werden sollen. Der Fetisch lässt dann durch den Priester verkünden, dass diè bösen Geister durch ein solches Opfer versöhnt werden können. Der Priester des Fetisch vergräbt an der betreffenden Opferstelle ein kleines Fetischzeichen, das aus Leopardenzähnen, Knochen oder dergleichen besteht. Ueber diesen Fetischgegenstand wird dann die Thonfigur errichtet. Lange ausbleibender Regen soll von Zauberern oder bösen Geistern zurückgehalten werden, welche dann ebenfalls durch bestimmte Opfer versöhnt werden müssen. Die bekanntesten der symbolischen Fetischfiguren sind, wie bereits erwähnt, die grossen menschenähnlichen Thonfiguren, welche vor den Dörfern aufgestellt sind. Mit dem ihnen beigegebenen Knüppel halten sie die Feinde, sowie die bösen Geister der Verstorbenen fern, welche noch nicht in der Welt der Toten Eingang gefunden haben und unstet umherirren.

Die Was den Aufenthaltsort der Fetische anbelangt, so wohnen sie Untergötter angeblich hauptsächlich in den Wolken; bisweilen sollen sie aber auch is dienstbare ihren Wohnsitz in der Erde haben. Die Funktion der einzelnen Fetische Geister des Mavu. ist sehr begrenzt und es kommt daher öfters vor, dass ein Hilfesuchender von einem Fetisch an einen anderen gewiesen wird. So schickt $z$ B. der allwissende Fetisch Afa den Bittenden zu dem Fetisch Bagba auf dem Aguberge, um von diesem Regen zu erflehen, weil Bagba den Harmattan, den Regen und die Winde beherrscht, welche er in verschlossenen Töpfen bereit halten soll. Auch ist ein Fetisch mächtiger als der andere, sie unterstützen sich gegenseitig und holen von einander 
Rat ein.*) Afa ist der Fetisch der Allwissenheit, er verkündet, wer oder was an dem einen oder anderen L'ebel schuld ist; doch kann er selbst häutig das Uebel nicht abstellen. I)ie betreffende Gemeinde muss dann zu einem andern Fetisch gehen und diesen bitten. Der Fetisch Alenka besitzt die Macht Städte und Dörfer vor ansteckenden Krankheiten zu schützen; cine ähnliche Macht besitzt der Fetisch Ananasi; den Fetisch Hewioso haben wir bereits gewissermaassen im Yewe-Kultus als den Blitzgott Xebieso kennen gelernt, der die Blitze in die menschlichen Wohnungen schleudert. Ihm wird geopfert, wenn ein Tornado losbricht. Wir haben ferner gesehen, wie der Fetisch Kewu von schwangeren Frauen besucht wird. Der Fetisch Arsekete hat die Gewalt, verirrte Menschen auf den richtigen Weg zurückzufuhren, sowie flüchtige Diebe in dem Busch aufzufinden. Diesem gleich kommt der Fetisch Buboyabo in Adjido, dem man ein Schaf und ein paar Hühner opfert, damit er die Diebe bestrafe.*) Der Priester giebt alsdann dem Bestohlenen etwas Maismehl, welches derselbe im Dorfe umherstreut. Wenn der Dieb auf dieses ausgestreute Mehl tritt, schwellen ihm die Gliedmaassen an und er verfällt schliesslich dem Tode. Der Priester zeigt nach einiger Zeit dem Bestohlenen an, dass der grosse Fetisch Buboyabo den Dieb bestraft und getötet habe und dass ihm ein neues Opfer dafür gebracht werden müsse. Der zugleich Geprellte und Bestohlene leistet auch pflichtschuldigst das Opfer in Gestalt von Hühnern und Schafen, die gewöhnlich von weisser Farbe sein müssen. Der Priester schert darauf dem Bestohlenen das Haupthaar und dieser dankt dem Fetisch, indem er sich vor ihm auf die Erde wirft, in die Hände klatscht und den Erdboden mit dem Kopf berührt. Aehnlich wie die alten Griechen Terpsichore als Muse des Tanzes verehrten, ebenso feiern auch die Togoneger den Fetisch Agboë als Beschützer der Tänze und Spiele. In Aneho soll Agboë auch als der Urheber des Donners gedacht werden.

Einer der gefürchtetsten Fetische ist in Ancho an der Küste der Gottesurteile schon vorher erwähnte Fetisch Nanyo, der treulose Frauen durch den des Fetisch. Priester mit dem Giftbecher bestraft. Derselbe wird, namentlich bei Mördern, wenn die Gerichte die Schuld oder Unschuld des Betreffenden nicht zu entscheiden vermögen, angerufen, um gewissermaassen ein Gottesurteil zu fällen. Der Priester des Nanyo fragt den Angeschuldigten, ob er den Mord begangen habe oder nicht; gesteht dieser die That nicht ein oder verweigert er die Aussage, so wird er dazu durch den Trank des Fetisch grezwungen. Bei dieser feierlichen Zeremonie werden dem Angeschuldigten die Haare sowie die Nägel an den Fingern und Füssen beschnitten. Der Fetischpriester holt alsdann

*) Nach Heroldt. 
einen Fetisch aus seiner Hütte und vergräbt ihn, sowie die Haare und Nägel, vor der Fetischhütte. Er beschwört darauf nochmals den Angeschuldigten, die Wahrheit zu gestehen, widrigenfalls er von dem grossen Fetisch getötet werden würde. Der Priester ruft den Fetisch herbei und bittet um seine Unterstützung. Darauf wird dem Angeklagten eine Kalabasse mit dem Fetischtrank gereicht, welche dieser leeren muss. Stirbt er von dem Gift, welches der Priester bereitet hat, innerhalb acht Tagen, so hat Nanyo durch den Tod die Schuld des Angeklagten gesühnt. Ein Totenfest wird nicht gefeiert, weil der Geist des Toten zur Sühne noch umherirrt. Die Leiche wird auf einem Gestell von vier Pfählen in den Busch oder an einen abgelegenen Ort getragen und den wilden Tieren und Geiern preisgegeben. So sieht man in den sumpfigen Gegenden bei Degbenu öfter die gebleichten Totengerippe solcher Opfer. Ferner wird häufig freiwillig von zwei Leuten oder Parteien, die sich streiten und den Beweis der Wahrheit antreten wollen, der Giftbecher getrunken. Auch auf andere Weise kann die Schuld von Dieben oder kleineren Missethätern durch den Fetisch bewiesen werden. Der Priester stellt eine Schüssel mit siedendem Oel auf, in diese wird ein Ring geworfen und der Verdächtigte gezwungen, den Ring aus der Schüssel herauszunehmen. Bevor er jedoch dieses Exxperiment ausfuhrt, taucht er die Hände in eine andere Schüssel, die eine Abkochung von verschiedenen Pflanzengiften enthalten soll. Wahrscheinlich schützen diese vor der Verbrühung; doch glauben die Leute fest daran, dass der Schuldige sich trotz dieses Präservativs verbrüht. Der Beschädigte wird als schuldig befunden und verurteilt. Wird jemand einer Lüge beschuldigt, so wird er ebenfalls vor den Fetischpriester geführt und dieser beweist zuweilen durch ein Wunder die Schuld oder Unschuld des Betreffenden und gleichzeitig die Macht des Fetischgottes. Im öffentlichen Palaver wird der Angeklagte von dem Fetischpriester beschworen, die Wahrheit zu gestehen; sagt er nach Ansicht der Leute nicht die Wahrheit, so werden ihm von dem Priester die Augen mit einem ätzenden Gift eingerieben. Das Gift beginnt alsbald $z u$ wirken; in diesem Zustande wird dann der Gepeinigte nochmals verhört und ihm von dem Priester angekündigt, dass ihn, falls er die gewünschte Aussage macht, der grosse Fetisch von den Schmerzen erlösen würde. In dieser Hoffnung sagt der Betreffende alles aus, was von ihm verlangt wird und so fällt er schuldig oder unschuldig seinem Ankläger und dem Fetisch zum Opfer. Der Priester befreit ihn nun von den Schmerzen, indem er ihm die Augen mit einer Flüssigkeit auswäscht, welche die Wirkung des Giftes wieder aufhebt. Ist der Unglückliche jedoch nicht willig, gegen seine Ueberzeugung zu sprechen, so wird er seinem Schicksal überlassen und verliert oftmals für 
immer sein Augenlicht. Wenn andererseits der Fetischpriester durch Geschenke und Opfer bestochen ist, so führt er durch ein Wunder des Fetisch die Freisprechung des Angeklagten herbei. Unter Vornahme der uns bereits bekannten Zeremonieen und Anrufung des Fetisch wird der Angeklagte zur Aussage der Wahrheit ermahnt. Der Priester bestreicht nun auch seine Augen, aber nicht mit Gift, sondern mit einem unschädlichen Wasser, und zieht schliesslich zur grossen Verwunderung der umstehenden Menge Kaurimuscheln aus den Augen des Angeschuldigten, wodurch seine Nichtschuld erwiesen wird. Dieses Taschenspielerstückchen wird auf folgende Weise ausgeführt: Der Fetischpriester, welcher, nachdem er den Angeklagten ermahnt hat, nichts mehr spricht, bläst ihm mit einer Fertigkeit, welche die Umstehenden verblüfft, aus seinem Munde eine Kaurimuschel ins Gesicht und zeigt diese dann dem betrogenen Volke. Ein solcher Vorgang ist bei einem Palaver von einem Missionar beobachtet und so der Betrug aufgedeckt worden. Ausser den eigentlichen Fetischpriestern giebt es noch, namentlich an der Küste, wie in dem Dorfe Akoda an der Lagune, Zauberer, die ebenfalls durch ihre Künste Gottesurteile herbeiführen. Namentlich sollen sie bei Mord den Thäter feststellen können. Zu diesem Zwecke nehmen sie ein mit Kaurimuscheln besetztes Blaserohr (Yakatu), streuen in dasselbe ein aus Pflanzen hergestelltes Gift (Eti) in Pulverform und blasen dasselbe in die Luft, wobei sie das Rohr gegen die Sonne richten und die Namen des mutmaasslichen Mörders rufen. Bei dem Namen des wirklichen Mörders soll sich nach Ansicht der Leute das Pulver in Blut yerwandeln und als solches niederfallen.

Ausser den bereits erwähnten Göttern und Nebengöttern spielt namentlich an der Küste der Fetisch Legba eine ganz bedeutende Rolle. Derselbe wird als Teufel gedacht, der den Menschen nur Böses zufügt. Nach Missionar Prietze soll Legba der oberste Fetisch sein, dem auch die Erschaffung des Menschen zugeschrieben wird. Bei meinen Erkundigungen, sowie auch bei Hauptmann Heroldt, dem wir eingehende Mitteilungen über Religion und Rechtsgebräuche der Evheneger verdanken, welche mir hauptsächlich als Grundlage gedient haben, bin ich letzterer Auffassung nie begregnet, sondern stets nur der, dass Mawu der Schöpfer der Erde und des Menschen sei. Legba wird hingegen überall als Teufel bezeichnet und mit dessen Attributen ausgerüstet dargestellt. Dem Fetisch Legba wird meistens auf freien Plätzen ein Opfer in Gestalt einer grossen menschenähnlichen Thonfigur gebracht beziehungsweise errichtet und unter dieselbe nach der Angabe von Prietze ein Hunde-, ein Tiger-, ein Löwen- und ein Schlangenkopf vergraben. Auch werden ihm Opfer in Speisen gebracht und öfters sieht man bei dem Fetisch allerhand Scherben und alte Tücher als Opfergaben herumliegen. 
Aus den vorangegangenen Schilderungen geht hervor, wie schändlich die Priester ihre Macht missbrauchen, um bei dem abergläubischen Volke zu Ansehen zu gelangen; sie haben sehr oft eine grössere Macht wie die Häuptlinge selbst und zwingen diese, sich ihrem Willen zu fügen. Das ganze Leben der Leute ist von der Furcht vor den Fetischen und Geistern durchdrungen und abhängig. Wir wollen jedoch hoffen und wünschen, dass durch die unermüdliche Thätigkeit der Missionare sowie durch das Fortschreiten der Kultur die Macht der Priester und Götter gebrochen und das Volk dem Christentum zugefuhrt werden wird.

Die Priester und Priesterinnen des Fetisch

Begräbnisfeierlichkeiten.
Was die Fetischpriester anbetrifft, so sind es gewöhnlich Männer, bisweilen aber auch Frauen, welche diese einträgliche Stellung einnehmen. Ihre Abzeichen bestehen aus mit Kaurimuscheln besetzten Schmuckgegenständen. . Oft sind die Priester gleichzeitig Medizinmänner und haben nicht nur eine grosse Kenntnis von den Medizinkräutern, sondern auch von der Bereitung von Giften aus giftigen Kräutern. Um Fetischpriester zu werden, müssen die Mädchen oder Knaben einen dreijährigen Kursus durchmachen, in welchem sie im Tanz und in der Fetischsprache unterrichtet werden.

Eng im Zusammenhange mit der Religion stehen natürlich auch die Zeremonieen bei den Begräbnissen und Totenfeiern Verstorbener. Sobald der Tod eingetreten ist, laufen alle Verwandten und Frauen des Verstorbenen zusammen und stimmen die Totenklage an. Die Frauen eilen durch den Ort und verkünden durch ihre Klagen den Tod ihres Mannes den Bewohnern des Dorfes. Der Tote wird alsdann von den Verwandten gewaschen, in schöne neue Tưcher eingehüllt und, wie im Schlafe liegend, in seiner Hütte, den Kopf mit der Hand gestützt, aufgebahrt. Bisweilen wird ihm noch die Pfeife als Zeichen des Friedens in den Mund gesteckt. Die Verwandten kommen von nah und fern herbei, nehmen Abschied von ihm, lassen ihre Angehörigen im Jenseits grüssen und häufig die verstorbenen Geister fur das ihnen etwa zugefügte Leid um Verzeihung bitten. Falls der Verstorbene durch einen Zauberer oder bösen Geist abberufen ist, versprechen sie ihm, seinen Tod zu sühnen, oder, wenn ein Mord vorliegt; an dem Mörder zu rächen. Bei einzelnen Stämmen glaubt man überhaupt nicht an einen natürlichen Tod und so hat sich bei allen Evhenegern die Sitte herausgebildet, dass ein Fetischpriester oder ein Totenbeschwörer vor der Bestattung erst die Ursache des Todes feststellen muss. Der Priester oder die Priesterin beschwören den Geist des Verstorbenen und nennen dann öfters die Landschaft oder das Dorf, wo der mutmaassliche Mörder wohnt, deuten also nur die Persönlichkeit desselben ohne Angabe des Namens an. Oft verkünden sie auch, dass der Tote vor Altersschwäche gestorben und in das Reich des Mavu abberufen worden sei. In Angome hat die 
Priesterin einen grossen Haarwedel, mit welchem sie die Leiche schlägt und hierauf wird mit demselben Instrument ein grosses Fetischarmband aus Kaurimuscheln berührt.*) Durch diese Zeremonie beschwört sie den Greist des Toten, ihr den Mörder anzugeben. In einigen anderen Landschaften und Dörfern der Evheneger wird der Leichnam unter Vorantritt des Totenbeschwörers auf einem Brette durch die Strassen und Plätze des Dorfes getragen. Der Geist des Toten soll dann durch den Priester die Hütte oder das Gehört seines Mörders angeben können. Der Priester bleibt mit dem Leichnam vor der Hütte oder dem Gehöft des angeblichen Mörders stehen und bezeichnet ihn auf diese Weise dem Volke und der Familie. In den nächsten Tagen wird der Tote mit seinen Kleidern in Matten gehüllt und in schlafender Stellung in ein ungefähr zwei Fuss tiefes Grab in seiner Hütte, mit dem Gesicht nach dem Ausgang derselben, beerdigt. Jeder der Leidtragenden wirft wie bei uns ein paar Hände voll Erde in das Grab. Dem Toten werden Haumesser und Dolche beigelegt, damit er auf seiner Reise nach dem Reiche der Toten die bösen Geister, die sich ihm in den Weg stellen, töten kann. Ferner werden ihm häufig noch Zeuge oder Schmuckgegenstände mitgegeben, damit er sich bei dem Eintritt in das Totenreich wurdig und festlich schmücken kann; mitunter auch eine Flasche Gin oder Palmenwein zur Stärkung auf die Reise. Ausserdem legen die Verwandten eine Anzahl Kaurimuscheln in das Grab, damit der Tote den alten Fährmann Akotia, welcher die Verstorbenen in seinem Kanoe über den breiten Fluss Assisa zum Reich der Toten übersetzt, für die Mühe belohnen kann. Die Sage von dem Fährmann erinnert an die Mythologie der alten Griechen, bei denen Charon auch die abgeschiedenen Seelen über den Styx übersetzt. In dem Reiche der Toten leben die Geister der Verstorbenen nach der Ansicht des Volkes ganz wie auf Erden, nur dass sie keine Arbeit mehr zu verrichten brauchen und ihnen weder ein Fetisch noch ein böser Geist irgend ein Leid zufügen kann. In dem Jenseits begrüsst der Verstorbene die Geister der vor ihm Verstorbenen und feiert das Wiedersehen mit seinen Verwandten und Bekannten. Nach der Bestattung findet das eigentliche Totenfest statt. Es wird von den Anwesenden der Totentanz ausgeführt, der in den üblichen Gliederverrenkungen besteht, während die bewaffneten Männer Böllerschüsse abgeben. Das Fest dauert bis in die Nacht hinein und unter Tanz, Gesang und fortwährendem Schiessen werden ungeheure Quantitäten Gin und Palmwein vertilgt. Es ist Pflicht der Verwandten, diese Festlichkeiten herzurichten und es gilt als grosse Schande für die ganze Familie, wenn ein solches Totenfest nicht den Verhältnissen des Ver-

*) Nach Heroldt. 
storbenen angemessen gefeiert wird. Schuldner und Verbrecher werden, wie wir gesehen haben, ohne jede Feierlichkeit in dem Busch ausgesetzt. Nach dem Glauben der Leute gehen die Geister der Verstorbenen nur in das Reich der Toten ein, wenn sie unter den betreffenden Zeremonieen feierlich bestattet worden sind; die Geister Nichtbeerdigter dagegen können nicht zur Ruhe kommen und müssen in der Nacht als weisse Gestalten auf der Erde umherirren. In einzelnen Gegenden werden die Toten nicht in der Hütte, sondern im Busch begraben und ihnen mitunter Schüsseln und Näpfe mit Speisen und Trank zur Nahrung für den herumirrenden Geist mitgegeben Man findet deshalb bei den im Busch liegenden Gräbern oft Schüsseln und Näpfe, ferner alte Gebrauchsgegenstände, wie Stühle und ein Brett, worauf der Geist des Verstorbenen sich ausruhen kann.

Stirbt der Mann, so muss die Frau sechs Wochen in der Hütte am Grabe desselben trauern. Sie darf während dieser sechs Wochen die Hütte am Tage nicht verlassen und höchstens des Nachts herausgehen, um die nötigsten Obliegenheiten zu besorgen. Von dem Fetischpriester wird der trauernden Frau das Haupthaar abgeschnitten, auch werden ihr sämtliche Tücher und Schmucksachen während der Trauerzeit genommen, weil sie zum Zeichen der Trauer vollkommen entblösst gehen muss. Des Nachts liegt sie in der Hütte mit einem Knüppel bewaffnet, damit sie den Geist ihres verstorbenen Mannes verscheuchen kann, da sie nach dem Aberglauben der Leute bei einem etwaigen ehelichen Verkehr mit demselben ebenfalls dem Tode verfällt. Ferner wird in der Hütte ein Feuer unterhalten, in welchem stark riechende Kräuter verbrannt werden, deren Geruch ebenfalls den Geist von der Hütte fern halten soll.*) Verlässt die Frau des Nachts für einige Augenblicke die Hütte, so geht sie mit einem Stock bewaffnet und muss nach der Sitte die linke Hand auf die rechte Schulter legen. Während der sechswöchentlichen Trauer darf die Frau nur gewisse Speisen geniessen; sie streut auf dieselben stets etwas Asche, damit der Verstorbene nicht an dem Mahl teilnimmt, weil eine gemeinsame Mahlzeit, sowie jede andere Gemeinschaft mit dem Toten ihren Tod herbeiführen würde. Nach Ablauf der ersten sechs Wochen darf die Frau wieder die Hütte verlassen, muss jedoch noch stets den Knüppel bei sich führen und darf sich nur mit einem kleinen Schamtuch bedecken. Die Fastengebote, sowie auch die Vorsichtsmaassregeln gegen jegliche Gemeinschaft dauern noch sechs Monate fort, jedoch darf die Frau während dieser Zeit ihrer früheren Beschäftigung nachgehen. Zum Schluss muss die Frau ein Reinigungsbad nehmen und damit legt sie die Trauer ab. Die Verwandten und

*) Nach Heroldt 
Bekannten beschenken die Witwe mit Tüchern und Schmuckgegenständen; sie macht alsdann im festlichen Gewande ihre Dankbesuche, wobei ihr meistens Kauris oder sonstige Gegenstände verehrt werden.

Die Trauer eines Mannes um seine Frau geht unter denselben Zeremonieen vor sich, jedoch kann derselbe schon nach sieben Tagen die Hütte verlassen. Die Trauer dauert für beide Geschlechter etwa sechs Monate, weil der Geist des Verstorbenen diese Zeit gebraucht um in das Reich der Toten und damit zur ewigen Ruhe zu gelangen. Nach Ablauf der Trauerzeit dürfen die Witwe und der Witwer wieder heiraten.

Alle Gesetze und Rechtsgewohnheiten haben sich durch mündliche Ueberlieferung vererbt und bei dem Volke erhalten. Der oberste Richter und Hüter des Gesetzes ist gewöhnlich der Häuptling oder König des Stammes, während andererseits, wie wir schon gesehen haben, häufig die Fetischpriester eine grosse Rolle bei Rechtsstreitigkeiten, oder bei Bestrafung der Schuldigen spielen, sowie die letzte Instanz bilden und das Machtwort als Richter abgeben.

Das Familienrecht ist bereits in seinen Grundzügen bei der FamilienBehandlung der Ehe im allgemeinen berührt worden. Das älteste Glied verhäitnisse der Familie ist auch zugleich das Oberhaupt derselben. Dieses, sowie die übrigen Mitglieder haften für jedes einzelne Glied der Familie und können bei Schuldpalavern für die Schulden eines Familienmitgliedes verantwortlich gemacht werden. Es hat dann die Pflicht, für die übrigen Familienmitglieder die Schulden zu bezahlen, hat aber ebenfalls unumschränkte Gewalt über die einzelnen Mitglieder. Es kann dieselben verpfänden oder verkaufen, um die Schulden mit dem Erlös zu decken.

Heirat oder ein geschlechtlicher Verkehr zwischen rechten Geschwistern findet im allgemeinen nicht statt und wird als schimpflich erachtet. Auch wird die eigene Mutter von ihren Kindern in hohem Ansehen gehalten, während Stiefsöhne nach dem Tode des Vaters ihre Stiefmutter gewissermaassen als Nachlass erben.*) Ein Verkehr mit Stiefmüttern, sowie mit Stiefgeschwistern gilt nicht als schimpflich, sondern als vollkommen rechtmässig. Die Kinder, welche der Mann mit Sklavenfrauen erzeugt hat, gelten im allgemeinen als frei und werden wie die übrigen Kinder der Familie angesehen, nur dass dieselben später nicht das Recht besitzen, Häuptling zu werden oder an dem Rat der Familienhäupter bei Palavern teilzunehmen. Wir haben schon bei der Ehe hervorgehoben, dass der Mann gegenüber der Frau grosse Rechte besitzt und sogar die Kinder, welche die geschiedene Frau mit einem anderen Liebhaber hat, als sein rechtmässiges Eigentum in Anspruch nehmen kann.

*) Nach Heroldt 
Was die Erbschaft anbetrifft, so erbt der älteste Sohn meistens die Würden und Rechte des Vaters. Auch erbt er gemeinschaftlich mit den übrigen Söhnen dès Verstorbenen die Aecker und Ländereien, sowie die Frauen des Vaters. Jedoch erbt nie ein Sohn seine eigene Mutter. Den ganzen beweglichen Nachlass, wie die Sklaven, Wirtschaftsgegenstände und das Vieh erhält der älteste Sohn der Schwester des Verstorbenen. Das Familienoberhaupt, der älteste Sohn des Verstorbenen, verwaltet den Barschatz, welcher zurückgeblieben ist und dessen Niessbrauch den Geschwistern des Verstorbenen zusteht. Das eigentliche Vermögen darf nicht angegriffen werden und dient nur zur Erhaltung des Gemeinwohls der Familie. Durch dieses Familienvermögen erklärt sich auch die Haftbarkeit der Familie für jedes einzelne Mitglied, da die Schuld aus dem Familienfonds bezahlt wird. Jedes Familienmitglied hat ferner Anteil an der Bewirtschaftung des Landes und steht jedem das Recht zu, ein Stück Acker zur Bestellung und zu seinem Niessbrauch zu nehmen, wogegen das Eigentum des Grund und Bodens den Söhnen zusteht. Stirbt eine Frau, so erben ihre Kinder das gesamte Vermögen; lässt sie jedoch keine Kinder zurück, so erben die Brüder und Schwestern der Verstorbenen. Die Leiche einer Frau, die nicht aus demselben Dorfe stammt, wird nach dem Ort gebracht, wo ihre Familie ansässig ist und derselben zur Bestattung übergeben. Beim Tode von Kindern, welche Vermögen besitzen, wird dieses zur Veranstaltung der Totenfeste und Begräbnisfeierlichkeiten verwendet. Stirbt ein Sklave, so bleiben seine Kinder Sklaven des ehemaligen Herrn; sowie auch das Eigentum eines verstorbenen Sklaven auf dessen Herrn übergeht. Kinder von Sklavenfrauen sind Eigentum ihres Besitzers.

An der Küste sind seinerzeit von dem stellvertretenden kaiserlichen Kommissar Grafen Pfeil nach den beschriebenen Rechtsgewohnheiten bei der Erbschaft folgende Grundsätze aufgestellt worden: Sämtliche Neffen des verstorbenen Mannes erben das bewegliche Vermögen, während die Söhne das unbewegliche Vermögen, wie den Grund und Boden und die Hütten erben. Die Frauen können thun, was sie wollen. Die Sklaven werden mit dem Tode ihres Herrn sämtlich frei, jedoch können sie in dem bisherigen Verhältnis bleiben, wenn sie wollen. Ist das Barvermögen zu gering, um die Schulden des Verstorbenen zu decken, so können mit den zurückgelassenen Sklaven die Schulden bezahlt werden. Bei dem Tode einer Frau erben ihre Eltern, Brüder und Schwestern das bewegliche Vermögen, während die Kinder die Grundstücke erben. Sind Brüder und Schwestern der Verstorbenen nicht vorhanden, so erben auch das bewegliche Gut die Kinder derselben. Sklaven der Betreffenden werden mit dem Tode ihrer Herrin frei. 
Die bewegliche Habe bildet im allgemeinen bei dem Neger den Hauptbesitz. Die Bevorzugung der Neffen gegrenüber den Söhnen bei der Erbschaft wird durch eine kleine überlieferte Legende erklärt, welche mit der Geschichte und der Einwanderung der Evheleute verknüpft sein soll. Vor tausend Jahren sollen unsere Evheleute aus Nodshie ausgewandert sein, weil der herrschende Häuptling ein grausames Regiment führte und seine Unterthanen sehr unterdrückte. Unter dem Häuptling Folli verliessen die Evheleute ihre Heimatsstadt. Um jedoch ihr Vorhaben nicht zu erkennen zu geben, entfernten sie sich rückwärts laufend von der Stadt. Als sie nun schon eine Weile unterwegs waren, wurde Folli gewahr, dass er seinen Königsstuhl vergessen habe. Er beauftragte seinen Sohn, ihn zu holen, doch die Mutter liess es nicht zu, aus Furcht vor dem Könige von Nodshie. Der Häuptling bat daher seine Schwester, einen ihrer Söhne zurückzusenden, um den Stuhl holen zu lassen. Der Sohn der Schwester führte den Auftrag glücklich aus. Zum Danke für diese That soll nun der Häuptling Folli als der Stammvater des neuen Evhegeschlechts bei seinem Tode alle seine bewegliche Habe seinen Neffen und Nichten vermacht haben. Auf diese Weise soll sich dieser Brauch herausgebildet haben, der noch heutigen Tages bei den Evhenegern geübt wird.

Den Schutz, welchen der einzelne für seine Person nach den überlieferten Rechtsanschauungen in Anspruch nimmt, ist im allgemeinen ein geringer und hängt häufig von der Willkür der Häuptlinge oder Fetische ab. Der Mord wird fast immer mit dem Tode bestraft, auch ist die Blutrache allgemein verbreitet. So hat ein Angehöriger des Ermordeten gewissermaassen die Pflicht und das Recht, den Mörder zu töten. Falls er es nicht thut, kommt er mit den religiösen Anschauungen in Konflikt und hat den Geist des Ermordeten sein ganzes Leben lang zu fürchten. In der Regel jedoch wird der Mörder ergriffen und, falls die That desselben gewiss und vor Zeugen geschehen ist, von dem Häuptling vor den Rat der Familienoberhäupter gebracht und zum Tode verurteilt. Er wird dann in den Busch geschleppt und von den Familienoberhäuptern, denen allein das Recht zusteht, getötet. Auch ist die Familie des Mörders verpflichtet, die Familie des Ermordeten zu entschädigen. Ist die Schuld des Mörders ungewiss, so wird er, wie wir schon vorher erwähnt haben, zu dem Fetischtrank verurteilt. Die Mörder haben keinen Anspruch auf ein ehrliches Begräbnis oder auf Begräbnisfeierlichkeiten und wird ihnen so der Eintritt in die Welt der Toten versagt. Sie werden meistens auf dem erwähnten Gerüst im Busche aufgebahrt. Bei fahrlässiger Tötung werden die Thäter meistens in die Sklaverei verkauft. Der Erlös für die verkauften Sklaven wird der geschädigten Familie als Busse überwiesen. 
Diebstahl. Diebstahl wird bei den Evhenegern, wie überhaupt bei allen Naturvölkern verhältnismässig hart bestraft. Diebe, welche bei der That abgefasst werden, können ohne weiteres von dem Bestohlenen getötet werden. Der getötete Dieb wird dann zu Schimpf und Schande der Familie mitten auf die Dorfstrasse gelegt, wodurch sein Vergehen öffentlich bekannt gegeben wird. Diẹ geringsten Felddiebstähle werden oft mit dem Tode geahndet, wenn der Besitzer den Dieb auf dem Felde ertappt. Wird der Dieb später überführt, so ist die Strafe naturgemäss bedeutend geringer. So übermittelt uns Missionar Spieth Strafen gegen junge Burschen, die beim Diebstahl angetroffen wurden. Bei dem ersten Falle nimmt sich des Burschen sein Onkel an, der ihn verwarnt und ihm eine nicht zu geringe väterliche Züchtigung angedeihen lässt. Im Wiederholungsfalle werden dem Dieb die Augen mit scharfem Pfeffer eingerieben. Beim abermaligen Vergehen erfolgt, falls der Verbrecher als unverbesserlich erkannt wird, der Verkauf. Mit dem Erlöse entschädigt dann die Familie des Diebes die Bestohlenen, und es erlischt jeder weitere Anspruch eines Geschädigten an die dafür haftbare Familie.

Auch für die Schulden eines Familienmitgliedes ist die ganze tilgung. Familie haftbar, sogar der Onkel wird für seinen Neffen verantwortlich gemacht, weil er die Pflicht hat, sich um seine Angehörigen zu kümmern. So wird meistens aus dem Barvermögen, falls solches vorhanden ist, die Schuld der betreffenden Familienmitglieder bezahlt. Sind keine Mittel vorhanden, so wird der Schuldner in die Sklaverei verkauft oder selbst seinem Gläubiger als Sklave in Zahlung gegeben. Familienoberhäuptern sowie Häuptlingen steht aber auch das Recht zu, andere Familienangehörige $z u$ verkaufen oder sie statt eigner Schulden in Pfand zu geben. Mit dem Tode eines Schuldners erlischt gewissermaassen der Anspruch des Gläubigers. Allerdings steht dem Schuldner dann kein rechtmässiges Begräbnis zu und der Verstorbene wird auf die erwähnte Art im Busch ausgesetzt. In den meisten Fällen jedoch zahlt die Familie, wenn sie irgend kann, die Schulden des Verstorbenen oder setzt sich mit den Gläubigern auseinander, damit der Verstorbene begraben werden kann und sein Geist in dem Totenreiche Ruhe findet. Sind die Schulden des Verstorbenen unbekannt und stellen sich dann mit dem Tode die Gläubiger ein, so müssen diese den Beweis der Wahrheit antreten, indem sie Wasser trinken, mit welchem dem Verstorbenen der Mund ausgewaschen worden ist. Falls sie die Unwahrheit gesagt haben, sollen sie sofort sterben, anderenfalls wird ihre Forderung als richtig anerkannt. Findet sich in dem Nachlass des verstorbenen Schuldners Vermögen vor, so werden die Schulden davon bezahlt.

Diebstahl wie Schulden werden, wie wir gesehen haben, streng geahndet, falls das Vergehen in dem eignen Dorfe oder Stamme 
begangen worden ist. Gehört der Geschädigte zu einem anderen Dorfe oder zu einer anderen Gemeinschaft, so geht der Betreffende frei von Strafe aus, falls der Geschädigte sich nicht durch Macht sein Recht verschafft oder die betreffende Gemeinde durch Wegfangen von Leuten des anderen Stammes sich schadlos hält. Bei dieser Gelegenheit wird nicht der Schuldner oder Dieb selbst oder ein Familienmitglied weggefangen, sondern gerade derjenige des betreffenden Stammes, dessen man am besten habhaft werden kann. Häufig einigen sich jedoch später in einem Palaver die betreffenden Ortschaften über die Einlösung der Gefangenen, indem bei einer solchen Ausgleichung Pulver, Gewehre, Wild und Tücher zu verhältnismässig hohen Preisen abgegeben werden. Kommt es jedoch zu keinem Vergleich, so wird zwischen beiden Parteien der Krieg erklärt. Jede Ortschaft sucht sich gegenseitig Leute abzufangen und es kommt schliesslich so weit, dass dadurch die Strasse für die betreffenden Stammesangehörigen gesperrt ist und Handel und Wandel darunter leiden. Natürlich ist es Pflicht der Regierung, falls sie davon erfährt und an dem betreffenden Orte die nötigen Mittel zur Verfügung hat, gegen diese Uebelstände einzuschreiten.

Der Grund und Boden gehört im allgemeinen den alt eingesessenen Grundbesitz. Familien, welche darauf von Alters her durch ihre Farmen und Jagdgründe ein Besitzrecht erworben haben. Die Söhne erben den Grundbesitz und sind somit die rechtmässigen Eigentümer desselben. Sie haben das Recht, nach ihrem Willen Farmen auf demselben anzulegen; auch können sie überall nach ihrem Belieben das Jagdrecht ausüben. Sie haben aber andererseits die Pflicht, den einzelnen Familienmitgliedern die Erlaubnis zur Anlegung von Farmen für ihren Gebrauch zu gestatten; auch ist diesen das Schlagen von Palmen und die Entnahme von Palmwein für ihren eigenen Haushalt erlaubt. Die Söhne dagegen verfügen frei über die Ausbeutung des Landes und der Jagdrechte.

Der oberste Kriegsherr und Richter ist zugleich der Häuptling des Ortes, welcher wiederum häufig dem gemeinschaftlichen Oberhäuptling der ganzen Landschaft untersteht. Oefters regiert ein solcher Oberkönig nur nominell und die einzelnen Häuptlinge thun und lassen was sie wollen. Der Häuptling wird bei den Evheleuten gewöhnlich aus der Familie des Königs gewählt, welcher dieses Recht vermöge alter Tradition zusteht. Die Wahl wird ron den Familienoberhäuptern vollzogen; oft wird derjenige zum Häuptling gewählt, der den Wünschen der Familienältesten am meisten willfährt. Weniger kommt es bei dieser Wahl auf die Klugheit oder sonstige Eigenschaften des Betreffenden an, als darauf, ob er den Familienoberhäuptern bequem ist. Aus diesen Gründen ist auch die Macht des Häuptlings eine sehr verschiedene. Meistens ist ein solcher Dorfhäuptling, namentlich an der Küste, eine Puppe, 
welche Repräsentationspflichten hat, sonst aber im allgemeinen ihren Willen demjenigen der Aeltesten unterordnen muss. Bisweilen kommt es allerdings auch vor, dass sich die Wähler täuschen und der Häuptling ein strammes Regiment zu führen versteht, namentlich wenn derselbe reich und dadurch unabhängig von dem Wohlwollen seiner Ratgeber ist. Letzteres finden wir meistens weit im Innern; so haben wir in Dakadu einen Oberhäuptling, welcher seine Macht und sein Recht auch bei den Unterhäuptlingen zu wahren weiss. Ist jedoch ein kleiner Dorfhäuptling seinen Leuten unbequem und besitzt er nicht die Macht sich zu halten, so wird er einfach durch Beschluss der alten Leute abgesetzt und diese wählen dann aus der Königsfamilie einen anderen Häuptling. Eigentümliche Gründe kommen mitunter bei der Wahl eines allgemein beliebten Anwärters in Betracht. So sind Aeusserlichkeiten, wie grosse Ohren oder eine grosse Nase, Gründe, den Betreffenden von der Wahl auszuschliessen, da er nach den Begriffen der Neger nicht für repäsentationsfähig gilt. Er könnte von anderen Stämmen wegen seiner Schönheitsfehler verspottet werden oder eventuell zu einem Spottnamen herausfordern.

Bei der Repräsentation spielt der König die Hauptrolle, denn der Neger liebt es im allgemeinen, Prunk und Ansehen zu entfalten. Stellt jedoch ein solcher Dorfhäuptling eine Forderung an die Gemeinde, z. B. dass sie den Weg reinhalten oder irgend welche Dienste leisten soll, so stösst er häufig auf nicht geringen Widerstand und ist ohnmächtig, die geringsten Forderungen durchzusetzen. Lebt der Häuptling in gutem Einvernehmen mit den Familienoberhäuptern, welche ihm bei jedem Palaver zur Seite stehen und versteht er, sich ihres Vertrauens würdig zu machen, so ist damit seine Macht und sein Ansehen begründet.

Die Rechtsprechung durch den

Hāuptling und den Fetischpriester.

Aber auch der Fetischpriester ist für den Häuptling eine bittere Persönlichkeit, mit der er es halten muss, wenn er Frieden haben will. Häufig ist der Einfluss der Fetischpriester bei weitem grösser, als derjenige des Häuptlings. Vor den Häuptling und die Familienoberhäupter kommen die Palaver, wobei der Häuptling der oberste Schiedsrichter ist, falls er es nicht vorzieht, die Angelegenheit dem Fetischpriester zu übergeben und der Entscheidung des Fetisches zu überlassen. Der Gang bei solchen Schiedsgerichten ist meistens der folgende: Der Kläger begiebt sich zu dem Häuptling und trägt ihm seine Sache vor. Dieser, falls er nicht allein über den Fall entscheiden kann, ruft den Rat der Familienältesten zu einem Palaver zusammen, wobei beide Parteien erscheinen. Darauf zieht sich der Rat der Aeltesten zurück und beschliesst über den Fall, indem der Häuptling bei Meinungsverschiedenheit den Ausschlag giebt und durch seinen Sprecher den Richterspruch verkünden 
lässt. Diese Palaver sind für die streitenden Parteien meistens mit grösseren Kosten verbunden und der Häuptling schöpft daraus seine Haupteinnahmen. Im allgemeinen wird ein Palaver oder eine Forderung an die Gemeinde erst dann als rechtskräftig und bindend angesehen, wenn der Häuptling zusammen mit den Familienoberhäuptern den Beschluss gefasst hat.

Wir haben nun die Sitten und Gebräuche der Evheneger kennen gelernt und sind auch tiefer in das Leben dieses Volkes eingedrungen. Aus alledem geht hervor, dass diese Leute trotz ihrer mitunter eigentümlichen Anschauungen auf einer höheren Kulturstufe stehen. Mit der Einführung passender Werkzeuge und Maschinen, der Verbreitung des Handwerks, sowie der intensiveren Unterweisung in demselben, dürfte dieses Volk noch einer blühenden Zukunft entgegengehen. Durch Anlegung ron Eisenbahnen und Wegen könnten die vielen brach liegenden Gründe und Triften mit blühenden Plantagen bebaut werden. Ebenso würden die vielen unverwerteten Naturprodukte durch die Anlegung von Verkehrsmitteln eine grössere Verbreitung finden, die Produktionsfähigkeit dieser Landschaften gefördert und der Wert der Kolonie bedeutend gesteigert werden. 

ZWEITER TEIL.

\section{DAS HINTERLAND \\ UND DER DEUTSCHE SUDAN.}





\title{
IM WESTEN DES HINTERLANDES.
}

\author{
REISE ÜBER KETE-KRATYI \\ NACH SALAGA.
}

Der Vertrag, nach welchem nördlich des 8. Grades ein Teil des Politische Hinterlandes zu einem neutralen Gebiet zwischen Deutschland und Eng- Umtriebe in land gemacht worden ist, hat für unser Hinterland grosse Nachteile. der neutralen Das neutrale Gebiet umfasst zum grössten Teil das Königreich Salaga Zone. sowie das Reich der mächtigen Dagomba. Major v. François gebührt das Verdienst in erster Linie, im Jahre r 888 einen Freundschaftsvertrag mit dem alten Sultan Mama von Salaga geschlossen zu haben; ausser ihm war es Kling, welcher später Salaga besuchte und die Freundschaftsbeziehungen noch fester knüpfte. Neben diesen deutschen Reisenden waren einige Engländer beziehungsweise in englischen Diensten stehende Schwarze und Mulatten in Salaga, welche den Sultan bestimmen wollten, mit England einen Vertrag zu schliessen. Zum Teil mögen ihnen von dem bedrängten Sultan Konzessionen gemacht worden sein, doch hat der Vertrag von François das Vorrecht sowie die Form eines Schutzvertrages und ist somit maassgebend für uns, so dass wir bei einer Verteilung des Gebietes verbürgte Rechte auf eine Besitzergreifung von Salaga haben. Seitdem nun die neutrale Zone besteht, ist eine Vertragsschliessung innerhalb dieser von beiden Mächten ausgeschlossen. Trotz dieser Vereinbarungen mit dem englischen Kabinett haben es die Engländer immer wieder versucht, neue Verträge mit den betreffenden Häuptlingen und Sultanen zu schliessen und den englischen Einfluss auf dieses Gebiet auszudehnen. So sandten sie im Jahre I 894 den englischen Mulatten-Offizier Ferguson nach Salaga, um dort einen neuen Schutz. vertrag für England abzuschliessen. Allerdings hatte das englische Kabinett vorher mit dem unsrigen vereinbart, dass es einen englischen Offizier nach Salaga schicken wolle, um einen Vertrag im Interesse Deutschlands und Englands zu schliessen, wonach andere Mächte verhindert werden sollten, einen Schutzbrief über diese Gebiete auszustellen. Die Franzosen nämlich waren in dem letzten Jahre mit grosser An- 
strengung und bewundernswerter Energie auf dem schwarzen Kontinent und auch in unserem Hinterlande politisch thätig gewesen. Diese wollte man durch eine gemeinschaftliche Vereinbarung abhalten, ihre Interessensphäre über die neutrale Zone auszudehnen. Doch war über den ganzen Plan in der gesamten Kolonie nichts bekannt und nicht einmal der damalige Landeshauptmann war davon unterrichtet. Es war somit ein grosses Verdienst des Afrikareisenden G. A. Krause, dass er die Regierung von dem verdächtigen Treiben des Mulatten Ferguson in Salaga benachrichtigte. Krause hielt sich damals in Kratyi auf und hatte infolge seiner guten Beziehungen durch schwarze Händler sowie durch die Haussas erfahren, dass Ferguson mit einer Anzahl Soldaten in Salaga liege und den Sultan sowie die Grossen dazu gedrängt habe, einen englischen Schutzvertrag abzuschliessen. Auch hatte er die Absicht, die englische Flagge zu hissen, stiess jedoch dabei auf Schwierigkeiten. Die älteren Leute nämlich wussten von den Freundschaftsbeziehungen zu der deutschen Regierung und wollten, bevor sie sich zu diesem Schritte entschlossen, dieselbe davon in Kenntnis setzen. Ferguson war infolgedessen mittlerweile nach Yendi gezogen, um dort sein Glück zu versuchen, hatte jedoch die Absicht, auf seinem Rückmarsch wieder nach Salaga zu kommen und dann die Flaggenhissung mit Gewalt durchzusetzen. Als Krause dies in Kratyi erfuhr, schickte er sofort einen Eilboten mit einem Briefe nach der nächsten Station Misahöhe, um diese von dem Vorhaben der Engländer in Kenntnis zu setzen und damit ihren Anschlag zu vereiteln. Dr. Gruner, der damalige Chef der Station, kam sofort zu mir und wir berieten noch spät $\leqslant m$ Abend, was zu thun sei. Meine Ansicht war, dass sofort einer von uns nach Salaga aufbrechen müsse, um gegen die Uebergriffe der Engländer zu protestieren. Dr. Gruner, der damals schon Vorbereitungen zu seiner grossen Expedition traf, hatte selbst wenig Zeit dazu, andererseits waren aber auch die Mittel, welche uns zur Verfügung standen, äusserst gering. Sieben Soldaten befanden sich auf der Station, die andern waren auf Patrouille oder krank; ebenso schlecht stand es mit den Geldverhältnissen, da sich in der Stationskasse nur $300 \mathrm{M}$. befanden. Ich erklärte mich jedoch angesichts einer für uns so wichtigen Ehrensache schliesslich bereit, mit den vorhandenen Mitteln am andern Morgen mit zwei Soldaten, vier Trägern, meinem Jungen und einem Evhe-Dolmetscher aufzubrechen und alles daranzusetzen, um den Engländern zuvorzukommen. Dieser Plan fand die Zustimmung des Dr. Gruner und so verliess ich am nächsten Morgen, am 30. September 1894 , die Station Misahöhe.

Abmarsch Meine Ausrüstung war nicht eben glänzend. Sie bestand aus zwei von Misahōhe. Blechkoffern, welche meine ganzen Habseligkeiten nebst den spärlichen Geschenken für die Häuptlinge enthielten. Ausser diesen führte ich noch 
ein Feldbett sowie eine Kinchlast mit den allernötigsten Materialwaren, bestehend aus Zucker, Essig, Oel und Salz, sowie eine Flasche Cognac mit. Nach einem kurzen Abschied von der Station ging der Marsch rüstig vorwärts über den François-Pass. Noch einen Blick sendeten wir rückwärts auf das weite Thal und den Agu, dann verschwanden hinter uns die Station und das Vorland. Wir befanden uns bald wieder auf dem bekannten Kamewege mitten im Gebirge zwischen Bergen, Schluchten und Thälern. Bald war unser erster Rastplatz, das Bergdorf Kame, erreicht, wo wir alte Bekannte begrüssten und uns an einem Topf frischen Palmweins ${ }^{\circ}$ zur Weiterreise stärkten. Nach einem kurzen Aufenthalt brachen wir auf; ziemlich steil ging es von diesen Bergen in die Thäler hinab, die der schon bekannte Danyifluss mit seinen Nebenflüssen und Bächen in einer weiten Ebene bildet. Der Weg führt an den Schluchten und Bergen vorbei, die dem Gebirge vorgelagert sind und bald begrüsst uns der sagenreiche Gipfel des Bogli. Auf diesem einzeln daliegenden Kegel soll nach dem Glauben der Leute eine höhere Macht thronen und von hier aus den Verkehr der Bewohner der Thäler mit dem obersten Fetischgotte vermitteln. Leider ist mir über den Bogli und seinen Fetisch nichts Näheres bekannt geworden, nur weiss ich, dass seine Zugänge ängstlich behütet und jedem fremden Eindringling verheimlicht werden.

Nach einem einstündigen Abstieg gelangen wir zu dem freundlichen Das GebirgsGebirgsdorf Liati, welches uns mit seinen hohen Bäumen, unter welchen dorf Liati. der Rat des Dorfes zu tagen pflegt, zu einer kurzen Ruhepause einladet. Das Dorf besteht aus zwei Teilen, die in der letzten Zeit durch eine breite Strasse, welche die Bewohner aus eigenem Antriebe ausgebaut haben, mit einander verbunden sind. Grosse Palmenhaine umgeben die beiden Ortschaften, die etwa $200 \mathrm{~m}$ von einander entfernt liegen. Die Eingeborenen empfangen den Reisenden freundlich. Es ist gewöhnlich für sie ein Freudenfest, wenn Expeditionen und Karawanen nach überstandenem Marsche hier eintreffen, um vor dem Gebirge und der Station Nisahöhe das letzte Nachtquartier aufzuschlagen.

Manche Mutter und mancher Vater sucht dann Nachricht ron dem Elternliebe. als Soldat oder Träger in der Ferne weilenden Sohn zu erhalten, oder begrüsst den nach langer Reise und überstandenen Gefahren Heimkehrenden und bringt den besten Palmwein, die reifsten Früchte herbei, um ihn zu erquicken. Man kann häufig in den Augen der Alten lesen, wie gross die Freude des Wiedersehens ist. Allerdings gehört dazu eine gewisse Kenntnis des Negercharakters, da der Schwarze seine Freude äusserlich nur wenig zeigt; doch auch an den Gaben, welche er seiner geringen Habe entnimmt, erkennt man die Lebhaftigkeit seiner Empfindung. Die meisten Söhne und Kinder des Dorfes sind als Arbeiter, als Soldaten 
oder auch als Träger in dem Dienste der Station Misahöhe und vermitteln so den Verkehr zwischen Misahöhe und Kete-Kratyi. Auch hier sieht man wieder den günstigen Einfluss der Bremer Mission. Einige Familien sind ganz zum Christentum übergetreten, während andere ihre Kinder nach Leglebi zur Missionsschule senden und dort unterrichten lassen. Man findet Leute, welche das Tischlerhandwerk erlernt haben, einige Hütten sind mit Thüren und Fensterläden versehen und nicht selten trifft man eine gezimmerte Bettstelle in der Behausung an. Das hübsche, reinliche Dorf liegt geradezu idyllisch an den hohen Bergzügen des Agomegebirges; fast überwältigend starren die braunen Fels๋wände des Bogli auf den kleinen Ort herab. Die Hütten sind meistens gut und dauerhaft gebaut, das Grasdach ist sorgsam geflochten, die Oelpalme bildet ein wertvolles Material zu den Dachsparren. Beim Verlassen des Ortes bleiben die reichen Gründe des Gebirgsthales hinter uns und wir betreten die grosse Ebene des Danyi. Der Boden nimmt an Güte bedeutend ab; wir passieren noch einige Kassavafarmen und kommen nun in eine weite Savanne, welche nur von niedrigem Schilfgras bedeckt ist. Einige Buschdschungeln, sowie einzelne dürftige Bäume beleben die Ebene. Nach einem zweistündigen Marsche gelangen wir auf einem schlechten holprigen Pfade an die ärmlichen Kassavafarmen von Kollem.

Kollem unter Von hohem Maste begrüsst uns schon weit in der Ebene die deutsche deutscher Flagge, welche hier durch den verstorbenen Botaniker Baumann gegen Flagge, den Protest der englischen Händler feierlich gehisst worden ist. Ein grosser Busch umgiebt die Stadt. Auf schmalem Pfad gelangen wir bald mitten in dieselbe und machen auf dem geräumigen Marktplatz Halt. Hier fallen uns die zum Teil nach europäischer Art gebauten Hütten auf, -welche mit Fensteröffnungen, Läden und Thüren versehen sind. Ferner kann man an einzelnen Hütten eine Art Veranda aus Lehm bemerken. Einige christliche Familien sowie einige englische Händler haben hier ihren Wohnsitz aufgeschlagen. In diesen Gebieten hat sich der $Z$ wischenhandel mit Gummi nach Adeli hin ausgebreitet; deshalb finden wir einzelne wohlhabende Leute, welche sich die erwähnten Luxusbauten gestatten können.

Soldaten- So schwer sich die Alten dem deutschen Einfluss haben fügen spiele der können, um so rascher hat die Jugend hier an unserem Militärwesen Negerjugend. Gefallen gefunden. So überraschte mich, als wir auf dem Markte in Kollem von dem langen Marsche ruhten, plötzlich das taktmässige Trommeln und die Kommandostimmen einer anscheinend heranmarschierenden Truppe. Ich war im ersten Augenblicke überzeugt, dass es ein Trupp Soldaten wäre, der von irgend einer Expedition heimkehre und unter Trommelschlag in die Stadt einrücke. Doch bald wurde ich eines anderen belehrt; zur allgemeinen Belustigung marschierte die 
Dorfjugend stramm in Reih und Glied, mit Hozsäbeln und Holzgewehren bewaffnet, unter Führung eines älteren Jungen auf dem Marktplatz auf, um uns ihre Kriegskünste vorzuführen. Es wirkte äusserst komisch, die Ordnung, den Ernst und die Würde dieser schwarzen Jungen zu sehen, welche im Alter von $\mathrm{I}_{5}$ bis hinunter zu 6 und 5 Jahren das Kommando in strammer Haltung ausführten. Die Kommandos wurden in deutscher Sprache nachgeahmt; die Griffe wurden mit den kleinen Holzgewehren erakt nachgemacht und jedes Versehen wurde von dem Kommandierenden mit einem Kopfstück oder einer kleinen Prügelstrafe geahndet. Die Kleinen nahmen ihre Strafe hin, ohne eine Miene zu verziehen, so dass man sich wirklich über ihre Disziplin wundern musste. In .Europa würde ein Junge unter ähnlichen Umständen sofort geweint und mit dem üblichen: „ich spiel' nicht mehr mit“ den Platz verlassen haben.

Die Stadt Kollem gehört noch zur Landschaft Ve und liegt hart Die Ebene des an dem Flusse Kolli, den wir nach dem Verlassen von Kollem passierten. Der-Kolli ist ein linker Nebenfluss des Danyi und vereinigt sich nicht weit südwestlich von dem Orte mit demselben; er ist ungefähr $20 \mathrm{~m}$ breit und hat nicht allzusteile Ufer. Ueber diesen Fluss führt eine sogenannte Eingebornenbrücke, die aus einem grossen Kanoebaum besteht; man überschreitet darauf auch bei hoher Regenzeit bequem das $2 \mathrm{~m}$ tiefe, träge dahinfliessende Gewässer. Die Ufer werden von einem schönen Galeriewald eingerahmt, der mit seinen hohen Kanoebäumen einem kleinen Urwald gleicht. Der Weg führt auf einem holprigen, schlechten Pfade weiter nach Norden durch die Savanne. Wild und dürftig breitet sich die mit niedrigem Gras und Baumwuchs bestandene Ebene vor uns aus. Bald überschreiten wir die Grenzen von Ve und betreten die Landschaft Lavanyo.

Meistens werden die Grenzen durch die Natur selbst bestimmt, indem Gebirge oder Flüsse Stämme und Landschaften scheiden; jedoch findet man auch in Ermangelung dieser Naturgrenzen grosse unbebaute und unbewohnte Ebenen, die wie ein Gürtel das Land umgeben und die einzelnen Gebiete von einander trennen. Die Vegetation wird nun allmählich üppiger, statt des Sandbodens tritt ein schwarzer, dunkler Moorboden auf und bald befinden wir uns in dem unmittelbaren Ueberschwemmungsgebiet des Danyi. Der zunehmende Morast und das Schilfgras erschweren den Weg ganz erheblich; zuweilen fällt ein Träger mit der gesamten Last in den Schmutz. Bis an die Knie im Wasser, geht es Schritt für Schritt vorwärts, bis man in den grossen und wilden Urwald, der den Fluss umgiebt, eintritt. Wurzeln und umgefallene Baumstämme versperren den schmalen Pfad und bereiten unserer kleinen Karawane noch grössere Hindernisse. Endlich haben wir die Ufer des reissenden Danyi erreicht. Auch 
hier führt eine primitive Eingeborenenbrücke über den Fluss. Ein Baum mit sämtlichen Aesten und Wurzeln ist einfach quer über denselben gefällt. Bei hoher Regenzeit ist eine solche Brücke häufig unpassierbar. In dieser öden Gegend, wo weit und breit weder ein Kanoe noch ein menschliches Wesen anzutreffen ist, sieht man sich dann zu einem unfreiwilligen Halt gezwungen. Wild wie der Urwald und die Umgebung dieses Flusses wälzt er seine nicht unbeträchtlichen Wassermengen in dem verhältnismässig engen Bett schnell über Felsblöcke und querliegende Baumstämme in den Volta hinab. Meine schwarzen Begleiter kletterten, bis über die Brust im W'asser, über den Baumstamm und mit wahrhaft erstaunlicher Geschicklichkeit brachten auch die Träger ihre Lasten hinüber. So glückte es uns bei dem Hinmarsch noch den Fluss verhältnismässig leicht zu passieren. Später auf dem Rückmarsch wurde jedoch meine Hoffnung, das Hindernis ebenso schnell zu überwinden, gründlich vereitelt. Hoch über sämtliche Baumstämme wälzten sich die gewaltigen Fluten und unsere Anstrengungen, den Fluss zu überschreiten, waren vergeblich. Endlich, nach sechsstündiger Arbeit, hatten wir aus Lianen ein Seil hergestellt, welches uns in Verbindung mit unseren Blechkoffern als Fähre diente. Der Schwimmer hat in diesen reissenden Flüssen weniger die Krokodile zu fürchten, als die Aeste und Baumstümpfe, an denen er bei der reissenden Gewalt des Wassers unter Umständen leicht aufgespiesst werden kann. Bei Trockenzeit ist der Danyi, wie alle kleineren afrikanischen Flüsse, ohne weitere Schwierigkeiten zu durchwaten. Eine Reise bei Trockenzeit ist daher nicht annähernd mit den Schwierigkeiten verbunden, wie bei der grossen Regenzeit. Flüsse und Bäche, die nur 2 bis $3 \mathrm{~m}$ breit sind und in der Trockenzeit bloss eine ausgetrocknete Rinne bilden, müssen in der Regenzeit häufig bis an die Schultern im Wasser passiert werden. Oft erkennt man einen Fluss, den man bei Hochwasser überschritten hat, bei der Trockenzeit kaum wieder. Unser Marsch geht nun auf dem jenseitigen Ufer weiter durch den mächtigen Urwald, in dem Mangroven mit Oelpalmen abwechseln. Grosse, durch den Wind umgestürzte Baumriesen erschweren den Marsch. Bald gelangen wir aus dem Ueberschwemmungsgebiet des Danyi heraus und passieren einen Buschwald, bis wir endlich wieder in die Baumsavanne gelangen und uns nun in der Landschaft Lavanyo befinden. Im Norden erblickt man in weiter Ferne die etwa 4 bis $500 \mathrm{~m}$ hohen Berge von Lavanyo, die hier die natürliche Grenze zwischen dem uns wohlbekannten Evhe-Volke und den nördlich wohnenden Guan-Völkern bildet.

Abschied in Der Häuptling von Lavanyo residiert in Kpemme, wohin wir nun Kpemme vom unsere Schritte lenken. Wir verlassen die Ebene und überwinden einige Evhestamme. Höhen. Im Norden tauchen die Vorläufer des Kunyagebirges auf. 
Eine herrliche Parklandchaft breitet sich zu unseren Füsssen aus, wo in saftig grünen Wiesen dichte Boskets mit Oelpalmen abwechseln. Die Vegetation hat sich ganz verändert, man sieht wieder üppige Yamsfarmen und wohlgepflegte Maisfelder. Abwechselungsvoll schlängelt sich der Weg über die einzelnen Berge und weithin sieht man nach Süden hin die Ebene sich erstrecken. Schöne Erdnussfelder und die stellenweise angebauten Ranken des Yams beleben die Hänge. Inmitten dieses schönen Geländes liegt die kleine aber anmutige Königsstadt Kpemme, in der wir unser Nachtquartier aufschlagen. Von hier aus sieht man in der Ferne noch einmal die Berge von Agome und nimmt zugleich Abschied von dem Stamm der Evheneger. In Kpemme, das vollkommen im Busch und hart an der Südlehne des LavanyoGebirges gelegèn ist, wird beim Scheiden noch ein Trunk Palmwein genommen, welcher aus den ungemein ergiebigen Palmen der Umgegend gewonnen wird. Munter klappert hier schon am frühen Morgen der Webstuhl und emsig sieht man die Leute auf den üppigen Farmen beschäftigt. Unser Marsch führt zu dem Pass hinauf, der über das Gebirge nach Norden weiterführt. Bald befinden wir uns in den Bergen von Kunya, welche nach Nordosten gewissermaassen die Fortsetzung des Lavanyogebirges bilden. Gleich nördlich hinter Kpemme überschreitet man einen Sattel des Gebirges; noch einmal grüssen wir nach Süden die Dörfer und Auen, um uns dann nach Norden den Bergen und Thälern der Landschaft Kunya zuzuwenden.

Das Gebirge, welches sich nach Norden hinzieht, erreicht seinen Im Gebiet der Höhepunkt in den steilen Bergen von Wurupong. Unser Marsch führt Guanvölker in direkt nach der Königsstadt Kunya herunter, vorbei an der Baseler Missionsstation, wo uns Mr. Hall, der schwarze Pfarrer dieser Station, der Landschaft mit seinen Kindern freundlich empfängt. In liebenswürdiger Weise begleitet er uns und macht bei dem König den Dolmetscher. Vor allem ist uns natürlich daran gelegen, uns nach dem langen, ermüdenden Marsche für die Nacht häuslich einzurichten und dann bei dem stets bereiten Mr. Hall über Land und Leute Erkundigungen einzuziehen. Trotz aller Ermüdung sind leider die lästigen Begrüssungszeremonieen bei dem -immerhin ziemlich bedeutenden Häuptling nicht zu vermeiden. Die Träger und meine Leute, die sämtlich Evhe sind, scharen sich nun um mich herum, da dieses der erste Ort ist, wo ihre Sprache ziemlich versagt; nur $\mathrm{ab}$ und $\mathrm{zu}$ finden sich einige Eingeborene oder Haussa, die der Evhesprache kundig sind und dann meistens mit gutem Torteil bei Einkäufen oder sonstigen kleinen Anliegen die Verständigung mit den übrigen Bewohnerrn herbeiführen. Einige Hülfe gewährt auch das Tshi das hier und weithin nach Norden die Handelssprache bildet, da die englischen Händler meistens aus dem Aschanti-Lande stammen und diese 
Sprache weit über ihre Grenzen hinaus verbreiten. In Kunya wird, wie wir schon vorher erwähnt haben, ein Dialekt der Guan-Sprache, die sogenannte Kyerepong-Sprache, gesprochen. Mit dem Verlassen des Evhe-Gebietes kommen wir in einen Wirrwarr von Sprachen und Dialekten, was den Verkehr und das Reisen sehr erschwert. Auch hat die Baseler Mission viele Mühe unter diesen Verhältnissen für die Verbreitung des Christentums zu wirken. Wir wollen später auf die Thâtigkeit dieser Mission zurückkommen, doch müssen wir zunächst den neuen Stamm und seine Wohnsitze etwas näher betrachten.

Kunya und seine Bewohner.

Die Stadt Kunya besteht eigentlich aus fünf Ortschaften, die beinahe zusammenhängen und deren jede ihren Häuptling hat. Ntshumuru ist der Hauptort und der Sitz des Oberhäuptlings der Landschaft Kunya; jedoch ist dieser Häuptling nur König dem Namen nach und steht vollkommen unter dem Einfluss des Fetischpriesters des heidnischen Gottes Sia zu Wurupong, der zugleich auch Häuptling dieses Ortes ist. Ganz Kunya macht im Vergleich zu den Evhedörfern einen fremdartigen Eindruck. Die Strassen sind ziemlich eng, doch sind zwischen den einzelnen Stadtvierteln grosse freie Plätze vorhanden, auf denen heute auch schon der nie fehlende Haussahändler seine Stoffe und Waren ausgebreitet hat und mit der eingeborenen Bevölkerung im Handel von Produkten wetteifert. Die Bevölkerung nährt sich hauptsächlich von Ackerbau. Grosse Farmen von Reis und Yams sieht man überall. In Wurupong ist sogar eine schöne Kaffeeplantage von den Eingeborenen angelegt; obwohl sie ziemlich wild aufwächst und von den Eingeborenen gewissermaassen als Busch betrachtet wird, hat sie doch schöne, grosse Beeren und liefert den Beweis, dass die Bodenverhältnisse für eine derartige Anpflanzung günstig sind. Natürlich kann sich wegen der allzugrossen Entfernung von der Küste und den geringen Verkehrsmitteln der Anbau vorläufig nur für die Eingeborenen selbst lohnen. Der Grund zur Anlegung dieser Farm ist, wie auch in Misahöhe selbst und in einzelnen Teilen des Evhegebietes, von dem Gründer der Station Misahöhe, dem verdienstvollen Hauptmann Heroldt, gelegt worden. In den Farmen und rings um die Dörfer stehen häufig Bananen und Limonenbäume, auch die Oelpalme ist in üppiger Fülle überalt anzutreffen. Hier gewinnen die Leute einen ganz vorzüglichen Palmwein, der auch bei den Festen des Sia eine hervorragende Rolle spielt. Der Topf Palmwein bei dem Häuptling von Kunya ist allen Reisenden, die jemals dort Aufenthalt genommen haben, wohlbekannt. In Bezug auf dieses edle Getränk giebt es hier wahre Feinschmecker. Der Wein vòn jungęn Palmen ist süss und verhältnismässig leicht; er wird deshalb von dem weiblichen Geschlecht und Kindern bevorzugt. Der Wein von älteren Palmen schmeckt herber und bildet das Getränk der Männer. Ganz frischer Palmwein ist, selbst 
bei älteren Bäumen, leichter, während er nach dem Cährungsprozess erheblich berauschender und herber wird und schliesslich stark moussiert. Ein solcher Wein ist eins der üblichen Geschenke des Häuptlings, welcher, wie alle Kunyaleute; gründlich die Weinkalabasse zu schwingen versteht. Palmkerne und Oel gehen im allgemeinen von hier wegen der grossen Transportkosten weniger zur Küste, doch ist das Palmöl ein wesentliches Nahrungsmittel. Ausser der Oelpalme ist aber noch für die Landschaft von besonderer Wichtigkeit der grosse und mä̀chtige Seidenwollbaum, aus dem besonders die Kunyaleute mit einem Haumesser, Stemmeisen und

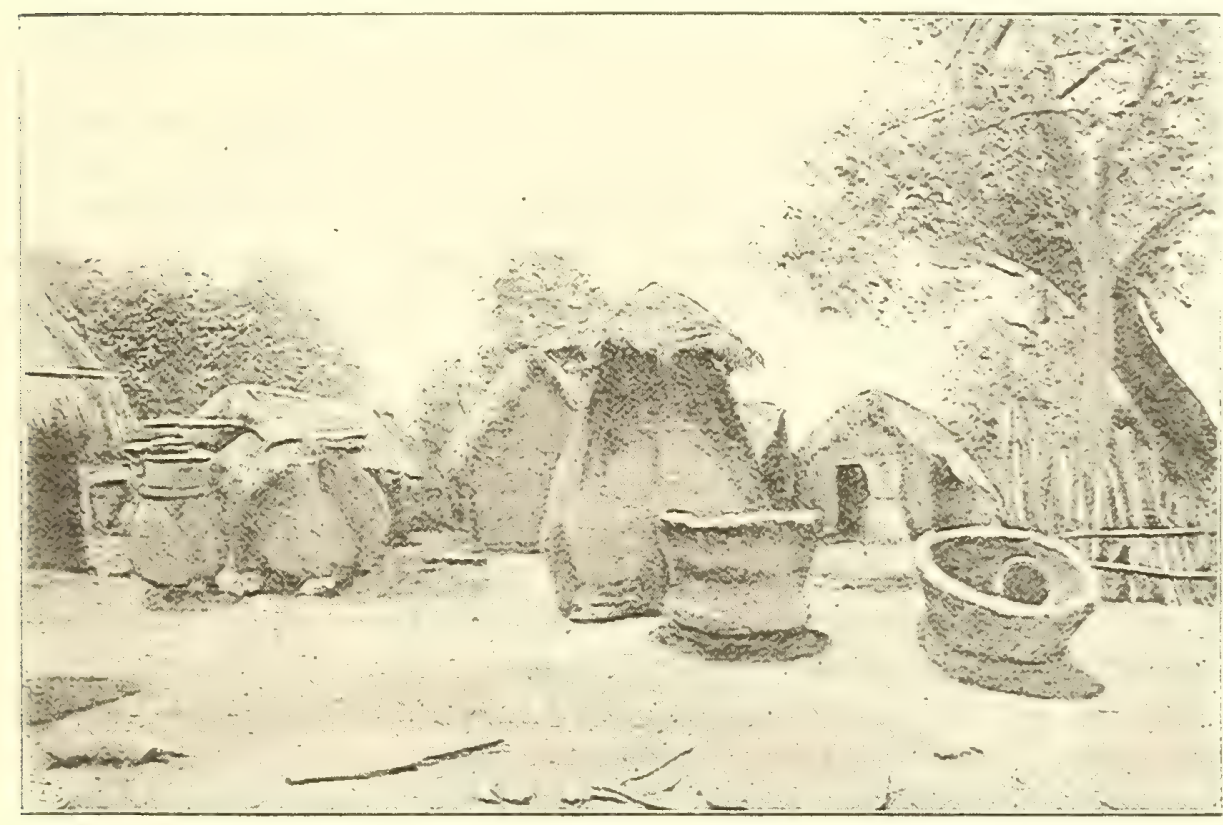

Dorfstrasse mit Kornspeichern in Kunya-Ntshumuru

ähnlichen rohen Instrumenten geschickt grosse Kanoes herzustellen verstehen. Was die Viehzucht anbetrifft, so wird dieselbe nur in geringem Maasse betrieben; Hühner zum eigenen Gebrauch sowie einige Schafe und Ziegen, mitunter auch noch ein paar Schweine, bilden den Viehstand. Auch liegen die Eingeborenen dem Fischfang und der Jagd ob. Letztere wird häufig durch Stellen von Fallen ausgeübt. Die vielen eigenartigen Kornspeicher, die typisch für diese Landschaft sind, zeugen von der Ertragsfähigkeit des Bodens. Man trifft sie überall in den Strassen an, Sie sind gross, rund und plump, aus Lehm erbaut, etwa $2 \mathrm{~m}$ hoch und mit einem. Dach von Palmblättern eingedeckt. Der Rumpf steht auf 
plumpen, ebenfalls aus Lehm gefertigten Füssen. Diese Speicher, welche keiner Farm fehlen, tragen sehr zur Verengerung der an sich schmalen Strassen bei.

Die fünf Städte: Kunya-Ntshumuru, Kunya-Sevhetihoë, KunyaAhenkuro, Kunya-Klobá und Ekplé haben alle denselben Typus. Grosse Fikusarten stehen auf den freien Plätzen und Märkten; in ihren Gipfeln treiben die zahlreich vorhandenen Kappengeier und Milane ihr Wesen. Die Hütten sind meist kleiner als die der Evheneger und nähern sich mehr der quadratischen Form. Auch pflegt das Gehöft selbst durch diese Hütten eingeschlossen zu sein. Man findet deshalb seltener die grossen Mattenzäune als in den Orten der. Evheneger. Anstatt der kleinen Zäune werden häufig dicke $\mathrm{I}^{\mathrm{T}} \mathrm{I}_{2} \mathrm{~m}$ hohe Lehmmauern errichtet.

Der gutmütige Typus der Evheneger ist bei den Kunyaleuten weniger anzutreffen; aus tiefen Augenhöhlen leuchten hinterlistige Augen mit scheuem Blick hervor. Dẻr Weisse wird misstrauisch betrachtet und von den Eingeborenen gemieden. Der Fetischkult, der hier die ganze Gegend beherrscht, bringt es mit sich, dass die Leute den Weissen fürchten, weil er ihre Verbrechen aufdeckt und bestraft. Gegen diese heillosen Gebräuche zu Felde zu ziehen, ist vor allen Dingen die Baseler Mission berufen, welche auch höchst segensreich in dieser Hinsicht wirkt.

Wir haben schon früher die Thätigkeit und das Verbreitungsgebiet der katholischen Steyler-, sowie der evangelischen norddeutschen Bremerund der Wesleyanischen Mission kennen gelernt. Nunmehr wollen wir auch auf die Baseler Mission eingehen, welche schon weit in unser Hinterland vorgedrungen ist. Während die drei vorgenannten Missionen fast ausschliesslich im Evhegebiet ihre Thätigkeit entwickeln und somit in sprachlicher Hinsicht geringere Schwierigkeiten zu überwinden haben als die Baseler Mission, so hat diese ihren Wirkungskreis mehr in das Hinterland verlegt. Schon im Evhegebiet nördlich des Lavanyogebirges begininen in Vaakpo und in Kpando, sowie in Lavanyo und in einigen anderen kleinen Zwischenstationen die ersten Glieder der Stationskette, welche sich durch Kunya und Boëm bis nach Adèle heraufzieht. Das Hauptgewicht der Baseler Mission liegt allerdings auf englischem Gebiet, wo sie in Akkra an der Küste einen Hauptstützpunkt hat. Vorzugsweise ist somit das Sprachgebiet der Aschanti und deren verwandten Stämme das Feld ihrer Thätigkeit. Aus diesem Grunde legt sie hauptsächlich Wert auf die Tshisprache. Trotzdem hat sie es verstanden, ihre Missionsthätigkeit mit Erfolg auch auf andere Sprachgebiete auszudehnen. Sie lehrt in dem Evhegebiet in Evhe, während sie in den nördlicher gelegenen Stationen Guan und Tshi als Unterrichtssprache gebraucht. In Worra-Worra, in Boëm sowie in Borada wird der Unter- 
richt in Tshi abgehalten, während in den anderen Stationen in der L efanasprache unterrichtet wird. Natürlich hat die Mission bei dieser Menge von Sprachen und Dialekten grosse Mühe, geeignete Lehrkräfte zu finden; sie ist daher im allgemeinen gezwungen gewesen, ihren Unterricht in der Tshisprache zu erteilen. Obwohl, wie wir bereits gesehen haben, diese Sprache sich weit in das Innere hinein als Handelssprache einen Weg gebahnt hat, so wäre es vielleicht für unsere Togokolonie vorteilhafter, wenn wenigstens in den Schulen und Missionen eine einheitliche Unterrichtssprache herrschte. Für einen grossen Teil unserer Togokolonie wäre die am weitesten an der Küste bis hinter das Gebirge verbreitete Evhesprache wohl die geeignetste, während für unser deutsches Hinterland Guań oder Haussa in Frage käme. Der Verkehr zwischen den Eingeborenen und den Weissen würde dadurch erheblich erleichtert werden. Der Handel unter den verschiedenen Sprachstämmen würde sich beleben und die häufig durch Missverständnis hervorgerufenen Streitigkeiten würden jedenfalls bedeutend abnehmen. Es würden sich dann in sprachlicher Beziehung Verhältnisse wie in Ostafrika herausbilden, wo die Suahelisprache von der Küste weit in das Land hinein bis zu den Seeen alș Verkehrssprache und als Sprache der Gebildeten gilt. Ein in dieser Sprache vorgebildetes Beamtenpersonal würde auch ganz anders wirken und das Leben der Eingeborenen verstehen können.

Was das Personal der Baseler Mission, das in unserem Hinterlande thätig ist, anbetrifft, so hat der frühere Missionar Mischlich als erster die Gegenden von Kratyi bis herauf nach Adele und Tshautscho bereist und dann in der letztgenannten Landschaft bei Ketschenke etwa eine Stunde von unserer alten Regierungsstation Bismarckburg entfernt, im Jahre 1896 eine neue Station angelegt. Die Baseler Mission wird in Adele einen dankbaren Boden für ihre Thätigkeit finden, da das Volk von früher her an die Weissen gewöhnt ist und noch späterhin, nach Aufgabe der Station Bismarckburg, dankbar der Ordnung und Ruhe gedachte, welche der weisse Mann auf der Station aufrecht zu erhalten verstand. Die Baseler Mission hat auch im vorigen Jahre den Missionar Pfisterer ins Togogebiet herausgesandt, um in Boëm eine geeignete Europäerstation zu errichten. Der Hauptzweck dieser Station soll eine Erziehungsanstalt zur Heranbildung geeigneter Lehrkräfte für die Station sein. Hoffentlich wird auch diese Station die Sprachschwierigkeiten durch die Ausbildung geeigneter junger Leute aus den verschiedenen Stämmen bald überwinden. Wie grosse Vorteile die Heranziehung geeigneter schwarzer Elemente für die Verbreitung der Mission gewährt, zeigt gerade die Baseler Mission an einem hervorragenden Beispiel, dem in Basel ausgebildeten und erzogenen schwarzen Missionar Clerk, der vollkommen auf derselben Bildungsstufe steht wie unsere gebildeten 
weissen Missionare. Nur hat er den Vorteil, dass ihm die Schwarzen wohl seiner Hautfarbe wegen zutraulicher begegnen, als dem Weissen. Der Nativepfarrer Hall, den wir schon vorher erwähnt haben, ist in ähnlicher "Weise in Ntshumuru thätig; jedoch hat Missionar Clerk eine vollständig deutsche Erziehung genossen und sein ganzes Wesen ist daher von einer deutschen Gesinnung durchdrungen. Ich werde nie die angenehmen Plauderstunden vergessen, welche ich mit Herrn Clerk auf der einsamen Station Kete-Kratyi verbracht habe. Ich befand mich damals lange Zeit ganz allein auf der Station. Tagsüber musste ich mich natürlich des sogenannten Negerenglisch bedienen und nur des Abends bekam ich von meinem kleinen Diener einige deutsche Brocken zu, hören. Eines Tages liess sich plötzlich Missionar Clerk anmelden und wenige Stunden darauf trat derselbe ein. Er war mir als gebildeter Mann geschildert worden; ich ging ihm infolgedessen entgegen und empfing ihn in englischer Sprache. Als mir bei der nun folgenden Unterhaltung einmal ein englisches Wort fehlte, fiel er $z u$ meinem Staunen in geläufigem Deutsch ein und ich hatte nun die grosse Freude, mich nach so langer Zeit wieder in meiner Muttersprache über meine verschiedenen Reisen und die afrikanischen Zustände unterhalten zu können.

sprachtalent Was die Erlernung der deutschen Sprache anbetrifft, so habe ich der Togoneger. mich selbst überzeugt, dass sie bei dem Sprachentalent, welches der Mein kleiner Neger im allgemeinen besitzt, nicht so schwierig ist, wie es im ersten Diener Augenblick erscheint. So habe ich ein eklatantes Beispiel an meinem Meppo. kleinen Diener Meppo, welchen ich in verhältnismässig kurzer Zeit ziemlich weit in der deutschen Sprache gebracht habe. Ich bekam den Knaben, der nur seine Muttersprache Evhe kannte, als er siebenjährig war und hatte anfangs Mühe, mich mit ihm zu verständigen. Ich nahm mir aber fest vor, nur deutsch mit ihm zu sprechen. Anfanğs war dies ungemein schwer; alle kleinen Verrichtungen und die gebräuchlichsten Gegenstände musste er mir mechanisch nachplappern. „Ein Glas Wasser" und dergleichen waren die ersten Exerzitien, welche der Bube bald begriff; so ging es weiter, bis er erst Worte und später kleine Sätze sprechen konnte. Endlich aber kam ich so weit mit ihm, dass er, als wir an die Küste zurückkehrten, sich überall so ziemlich in deutsch verständigen konnte. Ich nahm ihn wegen seiner Anhänglichkeit mit nach Deutschland, wo er ein halbes Jahr blieb und weiteren Unterricht in der deutschen Sprache nahm; nach diesem halben Jahr konnte er Briefe schreiben, lesen und rechnen. Auch liess ich ihn in der Franzis. kaner-Kirche in Posen taufen. Er erhielt die Namen „Karl, Wilhelm“; der letztere war sein Rufname und er war nicht wenig stolz, darauf, denselben Namen zu führen wie der deutsche Kaiser. Ich lasse umstehend einen Brief folgen, den der kleine Wilhelm Bruce geschrieben hat. 

Linlone Dloseffien.

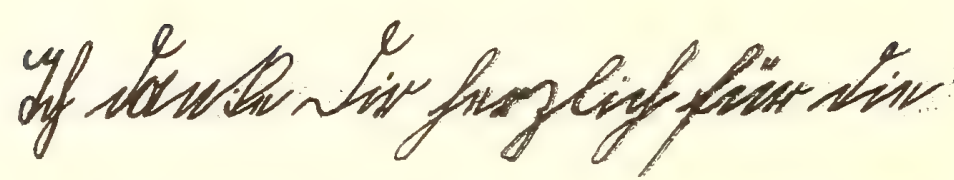

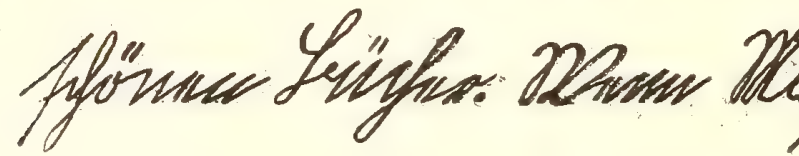

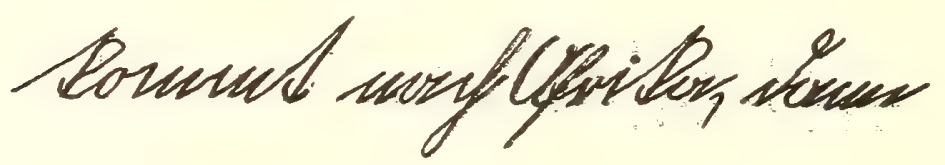

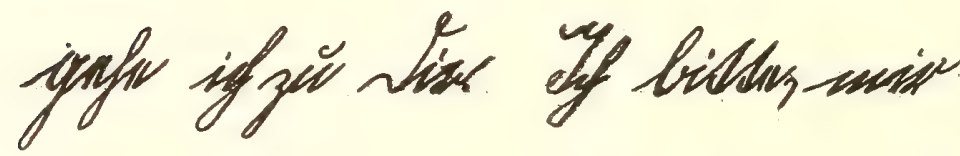

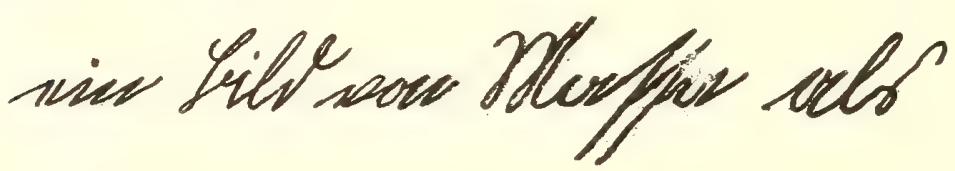

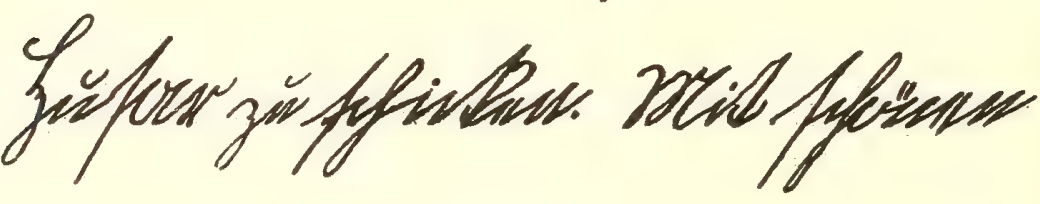

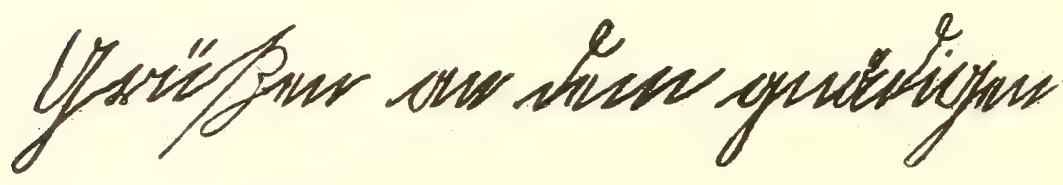




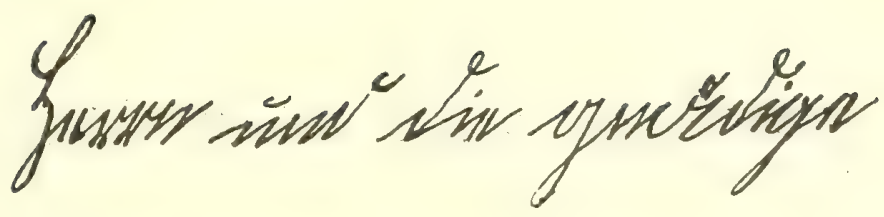
crevine in Pofhes surit one tif sives

Derfielsw. 

Auf meiner letzten Expedition begleitete mich Meppo wieder weit bis nach Sugu herauf und trug durch sein rergnügtes Wesen zur allgemeinen Heiterkeit bei; wenn meinen Leuten der Mut sank, pflegte er sie zu verspotten oder zu ermuntern, indem er ihnen zurief: „wo Massa hingeht, da fürchte ich mich nicht". Dem Expeditionsmeister, Herrn Hoyer, war er in der ersten Zeit bei dem Verkehr mit den Schwarzen ein wertvoller Dolmetscher. Auch verwandte ich ihn häufig, wenn der Dolmetscher der Expedition zufällig nicht anwesend war, als solchen bei kleineren

DolmetscherPalavern, bei denen er meine Ermahnungen an

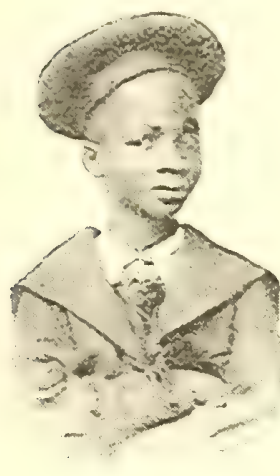

Meppo in Europa. die eingeborenen Häuptlinge in drolliger Wreise mit demselben Accent und würdevoller Miene wiederholte. Es geschah dies jedoch nur als Notbehelf, denn im allgemeinen ist es schwarzen Häuptlingen gegenüber nicht thunlich, einen unbedeutenden Knnaben als Dolmetscher zu verwenden. Nach dem Brauche der Schwarzen ist der Sprecher des Häuptlings oder Königs auch sein erster Berater und Minister. Als Zeichen seiner Würde trägt er den Häuptlingsstab für den König und wird infolgedessen auch meistens von den Weissen als Stabträger bezeichnet. Ein mächtiger König oder Häuptling pflegt selten bei Palavern oder Versammlungen selbst zu dem Volke zu sprechen; er lässt sein Wort oder sein Urteil durch den sogenannten Sprecher verkünden. Diese Sitte hat ihren guten Grund, denn ist ein übereiltes Wort oder ein zu scharfes Urteil gefallen, so kann es bei näherer Besprechung, namentlich dem Weissen gegenüber, als Missverständnis des Sprechers dargestellt werden. Auf diese Weise lassen sich Schwierigkeiten, die zu grossen Verwicklungen hätten führen können, bei einigem guten Willen der Parteien leicht beilegen. Infolgedessen muss auch der Weisse einen würdigen Repräsentanten als Dolmetscher haben, und ist gezwungen, einen älteren Mann zu nehmen, der auch bei seinen Landsleuten etwas gilt und seinen Herrn dementsprechend vertreten kann. Der Lohn eines Dolmetschers ist nicht gering; gewöhnlich wird er in Togo monatlich mit 60 Mark und auf dem Marsche noch mit 25 Pfennig Verpflegungsgeld pro Tag bezahlt.

Es war erstaunlich, in welch kurzer Zeit unsere Bengels in Kratyi in der Kratyisprache mit den Leuten verhandeln konnten; auch lernten sie bald von den Haussajungen und den Händlern etwas Haussa, so dass sie sich zur Not in dieser Sprache weiter helfen konnten. Obwohl ich mit Wilhelm nur deutsch sprach, so hatte er doch von den übrigen Jungens sehr schnell etwas englisch gelernt. Auch ist die Sprachen- 
kenntnis der Dolmetscher, die meistens Akkrahändler sind, ganz erstaunlich. Nicht selten sprechen diese Leute zwei bis drei Sprachen ausser ihrer Muttersprache. Von den europäischen Sprachen ist es naturgemäss die englische, die fast alle diese Leute sprechen, häufig auch gut schreiben. Von den eingeborenen Sprachen sprechen sie nicht selten Ga, Tshi und Evhe, so dass sie also vier Sprachen beherrschen. Alles dieses zeugt von dem ungemein grossen Sprachtalent, welches die Schwarzen im allgemeinen besitzen. Daher muss es binnen kurzem gelingen, neben der einheitlichen Negersprache des Evhe einen Stamm zu schaffen, welcher nicht nur an der Küste, sondern auch in Innern unserer deutschen Kolonie die deutsche Sprache gelernt hat. Es würde hervorragenden politischen Vorteil haben, wenn sich unter den Eingeborenen Leute befänden, die der deutschen Sprache mächtig und somit auch für deutsche Sitte und Gesinnung emptänglicher wären. Bis jetzt ist es im Hinterlande nur der englische Händler, welcher den gebildeten Mann spielt und damit selbstverständlich englische Interessen vertritt. Er preist, wenn nur irgend möglich, die englische Ware im Gegensatz zur deutschen an, selbst wenn "Made in Germany" darauf steht, was der Schwarze natürlich nicht versteht. Wir haben gesehen, wie gut das Personal der Baseler Mission im Innern des Landes in der deutschen Sprache ausgebildet ist, und so kann und wird es ihr hoffentlich nicht schwer fallen, wenigstens einen kleinen Stamm von begabten Zöglingen in der deutschen Sprache weiter fortzubilden. Ist erst ein deutsches Lehrpersonal vorhanden, welches in der deutschen Sprache weiter unterrichtet, so könnten wir, ähnlich wie in englischen Kolonieen, wenigstens die Händler und gebildeten Schwarzen mit unserer Sprache vertraut machen. Statt der englischen würde dann die deutsche Sprache als Verkehrssprache in unserer Kolonie gelten.

Weitermarsch Nachdem ich in Ntshumuru ausgeruht hatte, besuchte ich noch nach die Baseler Mission und deren Schule, in welcher Mr. Hall unterWurupong richtet. Die Schüler lasen und schrieben in Tshi, während sie in Kyerepong (Guań) mündlich unterrichtet wurden; auch sangen sie einzelne Lieder in dieser ihrer Muttersprache. Die ganze Klasse ist je nach den Leistungen in mehrere Abteilungen geteilt. Nach einem freundlichen Abschied von Mr. Hall und dem Könige, der an dem Tage so krank war, dass er zu meiner Begleitung bis an die Grenzen der Königsstadt nur seinen Stabträger mitschickte, setzten wir unsere Reise fort. Der Stabträger hatte sich zur Feier des Tages seinen Knebelbart um ein ganz beträchtliches Stück künstlich verlängert und mit Fett spitz eingedreht, so dass er einen ganz martialischen Eindruck machte. Bei entsetzlichem Regen, der alle Bäche füllte, zog ich mit 
meiner kleinen Karawane weiter und bald hatten wir das nächste Dörfchen, welches eigentlich nur als Vorstadt ron Ntshumuru zu betrachten ist, Kadjevi, erreicht. Im Westen erheben sich die kleinen Torberge des Kunyagebirges, während im Osten sich in steilen Felsen das eigentliche Gebirge dahinzieht. Der Urwald besteht aus mächtigen Baobabs, welche mit Fikusarten und Oelpalmen abwechseln. Kleine Scharen von Affen beleben den Wald, während Völker von Perlhühnern sich durch ihren eigentümlichen Schrei bemerkbar machen. Massenhafte Habichte und die uns schon bekannten Kappengeier umkreisen die hohen Fielsen. Wir passieren das Dorf Antomda, welches in der Mitte einen mächtigen Marktplatz hat und wo ich vereinzelt vollkommen quadratische Hütten bemerkte. Nach einer kurzen Ruhepause marschieren wir weiter und von nun an begleitet uns im Osten der nördliche Ausläufer des Kunyagebirges, das Wuruponggebirge, mit seinen schroffen, bizarr nach Westen abfallenden Felsen. Beim Ausgange des Dorfes gelangen wir wieder in einen schönen Hain. Die kleinen Wasserrinnen sind bei dieser hohen Regenzeit mit Wasser gefüllt, so dass man alle Augenblicke ein unfreiwilliges Bad nehmen muss. Der Pfad schlängelt sich durch wunderbar schönen Laubwald. Zur rechten werden die Berge immer schroffer, während sich zur linken kleine Höhen und die Vorberge des Gebirges hinziehen. Bald haben wir das Oertchen Täpo erreicht und gelangen nach einem kurzen Marsch durch hohen Laubwald nach dem grossen Fetischorte der Kunyaleute, nach Wurupong. Die Einwohner benehmen sich scheu und geben nur ungern Bescheid auf die Frage, wo der Häuptling des Ortes wohnt, der hier zugleich der oberste Priester des grossen Fetischgottes Sia, des Nationalgottes der Kunyaleute ist. Zuerst lässt sich der Häuptling wie gewöhnlich verleugnen und es wird mir mitgeteilt, dass er zur Farm gegangen sei. Es ist dies ein Kniff, dén wir schon kennen gelernt haben und der uns meistens eine nicht gerade wohlwollende Aufnahme der Bevölkerung und des Häuptlings verkündigt Auf meine Versicherung, dass ich nur gekommen sei, um den Häuptling zu begrüssen und ihm vor allem Geschenke zu überreichen, wurde ich schliesslich vorgelassen und ging zu dem Gehöft des mächtigen Oberpriesters.

Es war ein alter hagerer Mann mit stierem Blick und einem kleinen Besuch beim grauen Bart. Er trug nach Art der übrigen Leute das sogenannte LavaLava, ein grosses Umschlagetuch, nur dass seiner Würde gemäss noch ein alter Strohhut seinen Kopf bedeckte. Er war sichtlich erleichtert, als er merkte, dass ich eigentlich weiter nichts als ein Nachtquartier für mich und meine Leute haben wollte, namentlich als ich ihm ankündigte, Fetischpriester und Häuptling vor Wurupong dass ich morgen wieder weiter zu ziehen gedächte. Wahrscheinlich erwartete er nichts Gutes, zumal er wohl wusste, dass der Weisse Mord 
und Totschlag sowie andere Verbrechen, welche dieser hohe Priester im Namen seines Fetischgottes verübt, zu bestrafen pflegt. In dem kleinen Gehöfte, welches dicht gedrängt voll Menschen war, standen in der Mitte eigentümliche kleine runde, mit Brettern eingedeckte Thongetässe. Wahrscheinlich waren sie Heiligtümer des Fetischgottes Sia, denn als ich mich in Ermangelung eines Stuhles auf einen dieser heiligen Schreine setzen wollte, bedeutete man mir ängstlich und erstaunt, dass dieses nicht anginge und brachte mir sofort einen Schemel. Nach der Ueberreichung der Geschenke von Yams und einem Huhn wurde ich in das von dem Häuptling für mich bestimmte Gehöft geführt. Es war von stattlicher Grösse und überall von kleinen, gut gebauten Hütten umgeben. Die Hütten in dem ganzen Dorfe sind sämtlich viereckig, nur dass die Längsseiten im Verhältnis zu den Seitenwänden kürzer sind, als bei den Evhe-Hütten. Im allgemeinen sind gerade die besser gebauten Hütten kleiner als die der Evhe. Die Mauern sind häufig ohne Holzgerüst nur aus festem Lehm erbaut. Meistens steht die Hütte nicht direkt auf der Erde, sondern ein kleiner fusshoher Sockel aus festgestampftem Lehm bildet den Boden. Die Wände sind häufig mit roter und gelber Erdfarbe bemalt. Der ganze Ort liegt reizend; umgeben von einem hohen Fikuswalde und im Osten hart an das hohe schroffe Felsgebirge gelehnt, ist er von der Natur im höchsten Grade begünstigt und soll nach der naiven Anschauung dieser Naturvölker gewissermaassen zum Wohnsitz ihres Fetischgottes Sia geschaffen sein. In den hohen Gipfeln der Bäume des Waldes rauscht es unheimlich; viele Geier, Habichte und andere Raubvögel bewohnen den hohen Horst.

Aehnlich allen Völkern längs des Volta sind auch die Bewohner des Sia. Kunyalandes vollkommen dem Fetisch ergeben und von seinen Priestern beherrscht. Sia scheint nach allem, was ich gehört habe und auch nach den Angaben des Herrn Hall ihr höchster Gott zu sein, der alles erschaffen hat und gleich dem Evhegotte Mavu wieder seine Untergötter und sonstige dienstbaren Geister besitzt. Jedoch fordert er, im Gegensatz zu Mavu, grausame Opfer. Bei den grossen Festen, die meistens nach der grossen Regenzeit im Oktober abgehalten werden und nach dem Berichte des Herrn Hall 36 Tage währen, müssen Menschen geopfert werden, da der grosse Sia nach dem Glauben dieser fanatischen Leute den dargebrachten Opfertrank nur aus Trinkschalen annehmen darf, die aus Menschenschädeln verfertigt sind. Es sollen deshalb an dem Tage vor dem eigentlichen Feste überall vereinsamte Fremdè aufgegriffen und totgeschlagen werden; um ihre Hirnschale dem Fetischgotte Sia zu opfern. Die Hirnschale darf nur von einem Fremden, keinesfalls aber von einem Kunyamanne herstammen. Es erklärt dies das häufige Verschwinden von Händlern oder einsamen Wanderern in dieser Gegend. 
Nach den Angaben des verstorbenen Reisenden Baumann sollen auch Fremde, die zufällig bei dem Feste anwesend sind, zu diesem Zwecke dem Fetischgotte Sia geopfert werden. Ferner sollen ausser diesen Schädeln bei den Fetischtänzen andere menschliche Körperteile von den Priestern symbolisch gebraucht werden. Die Mörder, welche dem Fetisch diese Trophäen darbringen, werden hoch geachtet und dürfen bei dem Fetischtanz, welchen sonst nur die Priester ausführen, mit tanzen. Nach Herrn Halls Angaben soll der Oberpriester den Tanz beginnen, indem er mit einem Bündel Reisig symbolisch alles zusammenkehrt, d. h. alle Feinde zusammenscharrt, darauf mit einer Lanze danach sticht und gleichsam die Feinde des Landes tötet und rernichtet. Inzwischen schlagen die grossen Fetischtrommeln den Takt und auch die ber*ozzugten Mörder sollen ihren Tanz unter dem Jauchzen des Volkes ausführen. Die grossen Trommeln, die ebenfalls mit menschlichen Schädeln geschmückt sind, bilden das Hauptinstrument dieser Festmusik. Sie sind I m hoch und mit einem Kalbfell überzogen, welches mit den Schädeln in Verbindung steht, so dass sie bei dem Rühren der Trommel taktmässig nicken. Ausser diesem Opfer fordern der Gott und natürlich auch die Priester Ziegen, Schafe und Hühner zum Opfer. Diese werden dann gemeinschaftlich in dem heiligen Hain geopfert und verzehrt. Bei dem Feste des Sia findet auch die Reinigung der Witwen oder Witwer statt, ähnlich wie bei den Evhenegern. Hier jedoch fällt mit diesem Feste die Befreiung von dem toten Geiste des Mannes zusammen. Die Witwen haben nach dem Tode des Mannes ebenfalls gewisse Zeremonieen durchzumachen. Sie dürfen während der Trauerzeit ihr Haus nicht verlassen und müssen zum Zeichen der Trauer sich rot bemalen, den Kopf rasieren und sämtliche Kleider ablegen. An dem Tage des Siafestes werden sie von den Priestern mit Fetischwasser besprengt. Damit sind sie jedes weiteren Zeremoniells enthoben und dürfen wieder frei umhergehen, sowie ihre Besuche bei den Verwandten machen, von denen sie dann beschenkt werden.

Neben dem grossen Gotte Sia ist einer der hauptsächlichsten Untergötter Fetische der Fetisch Kombi, welcher in Bätanase seinen Sitz haben soll und, wie es scheint, hauptsächlich zum Schutze gegen Giftmischerei dient. Er hat darin eine gewisse Aehnlichkeit mit dem Giftgott Nanyo des Sia Der Fetisch des Evhevolkes, der, wie wir gesehen haben, bei Giftmorden zur Ermittelung des Mörders angerufen wird. Bei dem Siafeste werden auch sämtliche andere Götzen und Fetische angerufen und durch Opfer verehrt. Gleich nach den Festen zu Wurupong, die dem grossen Gotte Sia gelten, begeben sich alle angesehene Männer, der Häuptling an der Spitze, von Kunya nach Bätanase zu dem Fetischgotte Kombi, der wahrscheinlich nur ein Lntergott des Sia und dessen Werkzeug ist, 
ähnlich wie bei den Evheleuten der grosse Fetischgott Mavu Untergötter besitzt. Weiber und Kinder werden ängstlich zu Hause gehalten. Bei den feierlichen Zeremonieen wird der Fetischgott Kombi nach dem Geschick jedes einzelnen Familienmitgliedes befragt. Vor der Verkündigung des Wahrspruches wandern sämtliche Männer unter Vorantritt der Priester und des Häuptlings aus der Stadt heraus, um gewissermaassen alles Unglück aus den Mauern der Stadt herauszutragen.*) Die feierliche Prozession begiebt sich zu einem grossen Seidenwollbaum, unter dem sich die sämtlichen Grossen und die übrigen beteiligten Männer den Körper abreiben, worauf sie sich von aller Schuld befreit zu haben glauben. Hierauf wird der Baum mit einer Axt angeschlagen und dabei der Name einer Person ausgerufen. Fällt die abgeschlagene Rinde des Baumes mit der inneren Seite nach oben auf den Boden, so bringt es der betreffenden Familie oder der Person, deren Name aufgerufen ist, für das nächste Jahr Glück, geschieht das Umgekehrte, so bedeutet es Unglück und ruft dann grosse Trauer hervor. Die Späne werden, wie Mr. Hall weiter ausführt, von einem jeden nach Hause getragen, wo sie mit Ausnahme von drei Rindenstücken zerstampft, mit Wasser angerührt und alsdann auf dem Wege nach dem Abort in einer grossen Kalabasse aufgestellt werden; ein jeder muss sich damit waschen, wahrscheinlich um sich noch nachträglich von allem Uebel zu reinigen und so ein Unglück abzuwenden. Die zurückgelassenen drei Rindenspäne werden von den Priestern nach dem Heiligtum des Kombi gebracht und in der Kalabasse, in welcher der Fetischgott seinen Sitz haben soll, aufbewahrt, bis sie zu dem feierlichen Tranke des Gottes Kombi benutzt werden. In feierlicher Prozession begiebt sich darauf der Zug mit sämtlichen Priestern des Fetisches und den Häuptlingen zu den übrigen Götzen, um auch diesen Opfer zu bringen und das Fest des Sia noch mit dem Tranke des Kombi zu beendigen. Die Kürbiskalabasse mit ihrem mysteriösen Inhalt, welche mit einer weiss-roten Erdfarbe bestrichen ist, wird aus dem Fetischhause hervorgeholt und mit Palmwein abgewaschen, wobei ein jeder Teilnehmer an dem Feste mit der Farbe der Kalabasse auf der Stirn gezeichnet wird. Der Wein, der zu dieser Waschung und später zum Trank benutzt wird, wird aus gutem Palmwein hergestellt; die drei aufbewahrten Rindenstücke werden zu Pulver zerrieben und hineingethan. Nachdem die Kalabasse abgewaschen ist, wird sie wieder mit der weiss-roten Erdfarbe bestrichen und auf diese Weise neu geweiht, um bis zum nächsten Feste in dem Fetischhause aufbewahrt zu werden. Jeder Kunyamann muss sich an dem allgemeinen Umtrunke beteiligen, da bei dem Volke der Glaube

*) Nach Hall. 
herrscht, dass jeder, der einen Giftmord begangen hat, sofort durch den Trank getötet wird. Es entspricht dieses dem Cxiftbecher des Nanyo, nur mit dem Unterschiede, dass dieser meistens tötlich wirkt, während jener ungetährlich ist. Trotzdem ist der Glaube so tief eingewurzelt, dass jeder, welcher sich dem Tranke entzieht, rückhaltlos als Giftmischer betrachtet wird. Was die sonst noch üblichen Gebräuche bei dem Feste anbetrifft, so darf während der Zeit des Siafestes weder eine Trommel gerührt noch ein Totenfest abgehalten werden oder ein Gesang ertönen. Nur das Fest selbst wird mit Gesang, rauschender Musik und Tanz gefeiert. Ich erinnere mich deutlich der verschiedenen Male, an welchen ich Kunya passiert habe; auf dieser ersten Reise nach Salaga im Oktober herrschte eine unheimliche Totenstille in der ganzen Landschaft. Als ich dagegen im Frühjahre 1897 durchzog, fiel mir der Ort durch das lockere Leben, welches die Eingeborenen führten, gerade im Gegensatz zu früher auf. An den verschiedenen Marktplätzen wurde getanzt und getrommelt und das Gejohle und Geschrei dauerte fast bis zum Morgengrauen.

Was die übrigen Götzen anbelangt, so sind sie mir weniger bekannt; auch habe ich in der Litteratur nirgends etwas Näheres darüber finden können, nur dass es wie bei den Evhenegern eine ungewöhnlich grosse Zahl von kleinen Göttern und Hausgötzen geben soll. In der That sieht man überall die schon vorher erwähnten Fetische aus Lehm an den Strassen und vor den Hütten, sowie die sogenannten kleineren Hausfetische innerhalb der letzteren. Nach den Angaben des Hauptmanns Heroldt sollen auch die menschlichen Unterkiefer dem Gotte Kombi zu Bätanase geweiht und zu diesem Zwecke dorthin gebracht werden. Nach dem Glauben der Leute sollen nämlich dieselben dem grossen Gotte Kombi als Grundlage für einen neuen Menschen dienen. Daher soll auch die Sitte herrschen, den besiegten und getöteten Feinden die Unterkiefer abzunehmen und sie nach Bätanase zu bringen.

Wras im allgemeinen die Anthropophagie betrifft, so ist sie, wie Kanibalismus es scheint, fast überall im Hinterlande bis herunter zur Küste vertreten. So haben wir bei den Evhenegern an den Kriegstrommeln die Schädel gefallener Feinde bemerkt. Aber auch dies hängt wohl nicht bloss mit der Rache gegen die gefallenen Feinde, sondern wahrscheinlich mit einem Aberglauben zusammen. Wir finden diesen Missbrauch der menschlichen Körperteile in einem Bericht des Hauptmanns Heroldt über eine Gerichtsverhandlung wieder. Es stand unter Anklage ein Akpossomann, der einen Händler aus Gbele weggefangen und ermordet hatte. Akposso und Gbele führten mit einander Krieg und fingen sich nach der üblichen Sitte gegenseitig Leute ab. Nach diesem Brauch wird, wie wir schon früher gesehen haben, ein Gefangener einfach Sklave seines 
Vergewaltigers und dieser hat dann auch als solcher das Recht, über Leben und Tod seines Sklaven zu verfügen. In den meisten Fällen allerdings ist der Neger viel zu berechnend, um sich durch das Beiseiteschaffen einer so wertvollen Ware einen materiellen Verlust zuzuziehen, so dass er eher einen ihm unbequemen Sklaven verkauft als tötet. In dem oben erwähnten Fall jedoch schienen andere Beweggründe rorzuliegen und handelte es sich wahrscheinlich um ähnliche Fetischgebräuche, wie wir sie in Kunya bei dem Siafeste kennen gelernt haben. Der Akpossomann hatte seinem Opfer den Kopf abgeschnitten, den Schädel durch Kochen präpariert und aus demselben eine Trinkschale hergestellt. Dieselbe war mit weissen Flecken bemalt und höchstwahrscheinlich zu Fetischzwecken verwandt worden. Hände und Herz des Getöteten hatte der Mörder in der Sonnie getrocknet und als Trophäe in seiner Hütte aufgehangen. Auch nach den letzten Berichten des Hauptmanns Heroldt vom Jahre 1898 wurde in Togo der Kanibalismus geübt. So sollen in dem Tafievekriege im März I 888 gefallene Haussasoldaten von den feindlichen Tafievekriegern thatsächlich in Stücke geschnitten, in grossen Töpfen gekocht und verzehrt worden sein. Die Tafieveleute wurden dabei von den zurückkehrenden englischen Haussasoldaten betroffen. Wahrscheinlich hängt diese abscheuliche That mit dem Aberglauben zusammen, dass nach der Meinung der Leute die Kraft der verzehrten Feinde in sie übergeht. Ferner ist mir von den Missionaren ein Fall erzählt wọrden, wonach einem vom Blitz erschlagenen Manne einige Gliedmaassen, sowie das Herz genommen und präpariert worden sein sollen. Vermutlich waren diese letzteren Gebräuche gewissermaassen mit einem Opfer für den Blitzgott Xebieso, der bei dem Yeweorden eine so grosse Rolle spielt, verbunden. Das Abschneiden des Kopfes bei gefallenen Feinden finden wir überall, daher trifft man auch bei den Evheleuten so zahlreiche Schädeltrophäen an. Der letzte mir bekannte Fall, der mit der Bestrafung der Toveleute endigte, wurde I895 an einem Gefreiten der Polizeitruppe verübt. Derselbe wurde verwundet und kam so in die Gewalt der wütenden Leute, die ihm erbarmungslos den Kopf abschnitten. Das Abnehmen des Unterkiefers, der bei dèn Kunyaleuten, wie wir gesehen haben, dem Untergotte des Sia, dem Kombi, geweiht wird; der unter den Evheleuten herrschende Glaube, dass er zur Erschaffung eines neuen Menschen erforderlich ist; ferner die vielen Amulette, die sehr häufig aus Tierknochen hergestellt sind, sowie die Aufbewahrung der Unterkiefer erlegter Tiere weisen sämtlich darauf hin, dass die Leute weniger durch Grausamkeit zum Morde verleitet werden, als vom Aberglauben. Auch das Töten durch Gifttrank bei den Gottesurteilen, sowie das Töten von Zwillingen, auf das wir später zurückkommen werden, sind 


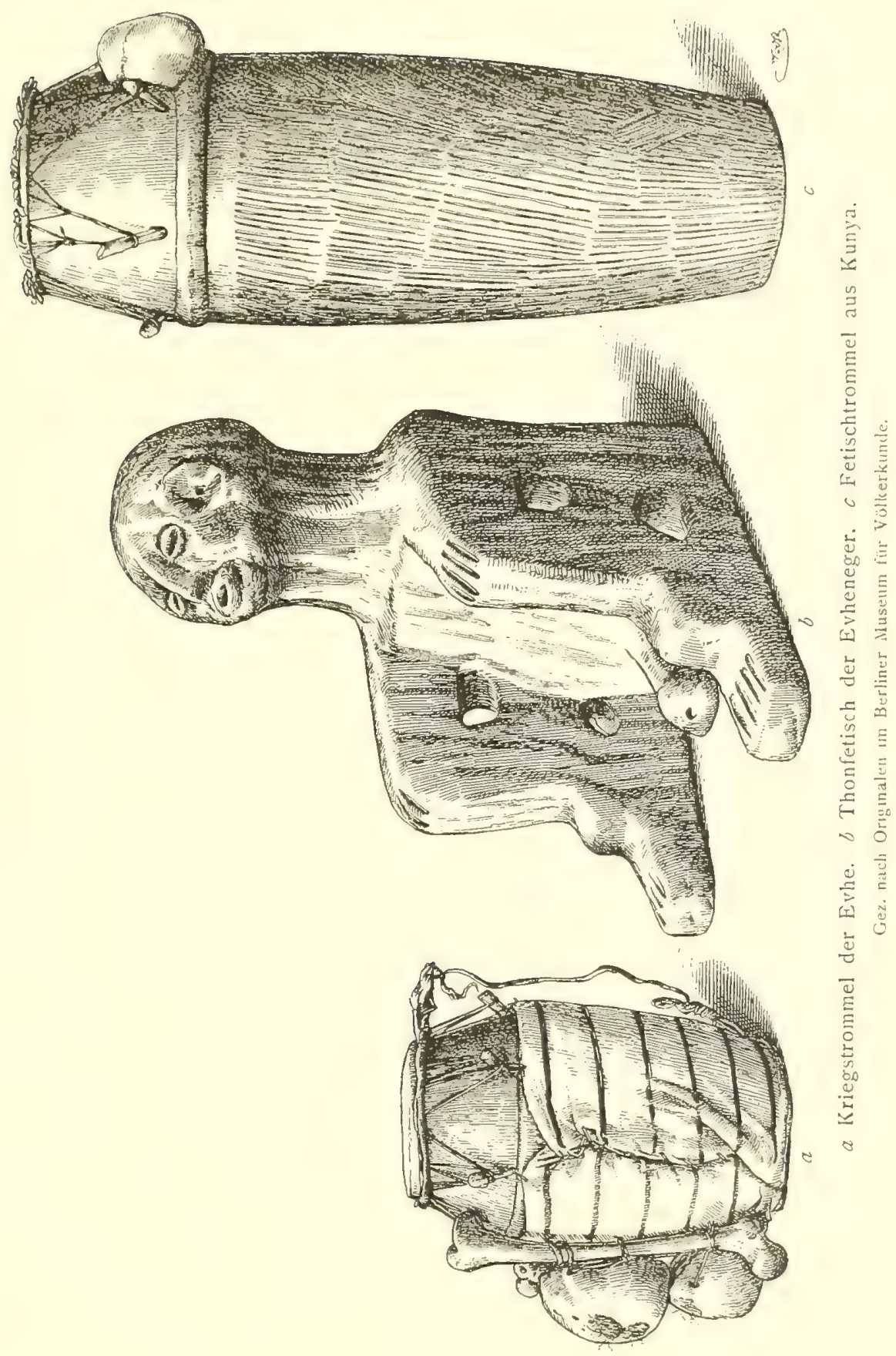


lediglich Folgen des Aberglaubens. Aus alledem geht hervor, dass der Neger bei weitem nicht so grausam ist, wie er scheint und dass oft nur seine kindliche Unwissenheit an seinen Verbrechen schuld ist. Durch das Vordringen der Kultur und des Christentums wird zweifellos allen diesen Gräuelthaten ein Ziel gesetzt werden.

Am nächsten Tage früh verlassen wir Wurupong. Der Weg führt Weitermarsch durch schönen Fikuswald bergauf und bergab. Das Gebirge ragt ${ }^{\text {von Wurupong }}$ durch Boëm. noch hoch über riesenhafte Baobabs, Seidenwollbäume und die übrigen Gipfel des Laubwaldes hinaus. Viele Wasseradern und kleine Bäche haben das Erdreich zerklüftet und führen ihre Gewässer den Flüssen $z u$, welche sich schliesslich in dem grossen Voltastrome vereinigen. Alle diese Rinnsale, die in der Trockenzeit nur an ihren tiefeingeschnittenen Ufern kenntlich sind, bilden in der grossen Regenzeit häufig ein ausgedehntes Ueberschwemmungsgebiet. Auf den Fusspfaden rieselt das Wasser oft kilometerweit, ehe es einen Abfluss findet. Stundenlang hat man dann in diesen kleinen Wasseradern zu marschieren, was natürlich äusserst beschwerlich ist. Alle Augenblicke muss man ein zerklüftetes Flussbett bis an die Brust durchwaten, um mühsam an dem andern Ufer wieder heraufzuklettern. Auch die Lasten leiden auf solchen Wegen, da es öfter vorkommt, dass die Träger in dem schmutzigen, aufgewühlten Wasser zusammenbrechen. Häufige Tornados sorgen dafür, dass der Oberkörper nicht einseitig trocken bleibt. Natürlich wird das Schuhwerk des Europäers entsetzlich mitgenommen, aber etwaige Luftlöcher in den Stiefeln bewerkstelligen wenigstens den Abfluss. Selbst in der Trockenzeit durchnässt der fallende Tau den Wanderer gründlich und so marschiert er oft, im wahren Sinne des Wortes wie aus dem Wasser gezogen, stundenweit, bis die liebe Sonne Erbarmen fühlt und mit ihren heissen Tropenstrahlen seine Kleider wieder trocknet. Alles dies ist noch zu ertragen, am unangenehmsten aber ist in diesen Regenzeiten die Aufnahme der geographischen Lagen. Für den Neuling ist eine richtige Beurteilung der Wasserverhältnisse der Flüsse oder Bäche fast unmöglich. Doch allmählich gewinnt man ein besseres Urteil, namentlich, wenn man Gelegenheit gehabt hat, denselben Marsch in der Trockenzeit zu wiederholen. Ströme, wie bei uns die Oder, können dann nicht selten zu Fuss passiert werden und führen höchstens ${ }^{\mathrm{I}}{ }_{1}$ o des Wassers, welches sie in der hohen Regenzeit besitzen. Unser Marsch führt weiter durch den Wald; an den Bächen findet man überall die Oelpalme und in den Niederungen gesellen sich $z u$ den Bambussträuchern die mannigfaltigsten Pandanusarten. Kleine Gruppen ron Affen, meistens Meerkatzen, begleiten häufig auf den hohen Gipfeln der Bäume die Karawanen und treiben dort ihr lustiges Spiel. Weiter nach Norden marschierend, 
gelangt man auf ein Plateau, welches einen mehr sandigen Boclen aufweist und mit niedrigem Grase, auch ab und zu mit kleinen Baumgruppen und Sträuchern bestanden ist. Von diesem Plateau hat man einen schönen Rückblick auf das nach Nordosten sich hinziehende Wuruponggebirge mit dem weithin sichtbaren Ebo. Dieser ist ein hoher Felsen, der nach Westen hin steil abfällt und wegen seiner eigentümlichen, einem Hute ähnlichen Form, auf grosse Entfernung von den übrigen Bergen und Gipfeln zu unterscheiden ist.

Durch Nach einem anstrengenden $3 \frac{x}{2}$ stündigen Narsche gelangt man an das Gebiet von den Kleinen Konsufluss, welcher die Grenze zwischen der Landschaft Konya und der von Boëm bildet. An dem linken Ufer dieses Flüsschens liegt das Dörfchen Konsu, welches eigentlich nur zwei Familien birgt, die bei Regenzeit die Fähre über diesen kleinen, etwa $20 \mathrm{~m}$ breiten, aber reissenden Gebirgsfluss bedienen. An dem tief eingeschnittenen Bette des Flusses zieht sich ein niedriger Galeriewald entlang, da anscheinend grössere Bäume in diesem felsigen Untergrunde keine tieferen Wurzeln zu schlagen vermögen. Die steilen Ufer erschweren den Transport der Waren sehr, namentlich in der Regenzeit, wo der Fluss den Charakter eines wild dahinbrausenden Gebirgsstromes annimmt. Nur mit Anstrengung wird unsere kleine Karawane in den schlechten Kanoes hinüber befördert. Später haben wir hier auf einer Expedition mit dem verstorbenen Reisenden Baumann eine kleine Abhilfe geschafft, indem wir mit Dynamitpatronen den Thonschiefer sprengten. Der Konsu soll von Nordosten kommen und seinen Ursprung auf dem Gebirge gleichen Namens, dem Konsugebirge, haben Auch er fuhrt bei Trockenzeit nur ein kleines Gewässer, welches durch die Felsen hindurchsickert. Mit dem Betreten des rechten Konsuufers verlassen wir das Kunyaland und erreichen nach einem kurzen viertelstundigen Marsche das erste kleine Dorf der Landschaft Boëm, Kwamikrum, dessen Mittelpunkt allerDas Empor- dings hauptsächlich aus einer Haussakolonie besteht. Der Ort selbst, blühen welcher auf einer freien Anhöhe liegt, ist ein armseliges Dörfchen, Kwamikrums welches von Boëmleuten bewohnt wird. Dasselbe hängt eigentlich von durch den dem reichen Haussa Abu-Karimo ab, der es verstanden hat, den Haussa Abu - Karimo. Ort durch die Anlegung eines grossen Fremdenlogis und eines Marktplatzes lebensfähig zu machen. Die Boëmleute liegen dem Ackerbau, der Jagd und der Fischerei ob. Ihr V'iehbestand setzt sich nur aus einigen Hühnern, Ziegen und Schafen zusammen. Ihre Landprodukte, wie Yams, Kassava oder Bananen, sowie etliche Hühner und Schafe verwerten sie, indem sie dieselben bei den vielen Fremden, welche hier Rast machen und bei Abu-Karimo übernachten, absetzen. Es ist fabelhaft, wie sich dieser Ort in einigen Jahren gehoben hat. Ich war erstaunt, als ich nach längerer Abwesenheit wieder durch Kwamikrum marschierte 
und dort anstatt der kleinen Kolonie eine grosse, schöne Haussaniederlassung vorfand, in deren Mitte ein geräumiger freier Platz geschaffen war, wo die Eingeborenen Lebensmittel und die fliegenden Haussahändler ihre Stoffe und Waren dem Fremden zum Kaufe anboten. Der schlaue Haussa Abu-Karimo hat mit dem ihm eigenen Scharfsinn an dem Zentralpunkt der Karawanen, welche aus Adele sowie aus dem boëmlande hier zusammentreffen, für ein treffliches Unterkommen gesorgt. Es war gewissermaassen ein Bedürfnis auf der langen Strasse, die von Konfokrum über Kwamikrum nach Wurupong führt, einen Rastpunkt fur die vielen durchziehnden Karawanen zu finden. Der Weg von Lionfokrum, der zum Teil noch über die Tappaberge führt und ziemlich beschwerlich ist, geht fast ohne Unterbrechung durch Busch und Wald, ohne dass man an irgend einem grösseren Orte vorbeikommt, der sich zu einem Aufenthalt für Karawanen oder Expeditionen eignet. Daher wird das isolierte Kwamikrum von allen Reisenden mit Freuden begrüsst. Abu-Karimo ist es gelungen, ein wirklich eigenartiges, grosses Gasthaus für die Reisenden einzurichten. Natürlich besteht ein solches Hotel nach afrikanischem Muster nur aus einfachen, langen, schmalen I.ehmhütten. Dieselben sind in viele kleine Abteilungen geteilt, in denen die Fremden einquartiert werden. Ausser diesem Fremdenlogis hat aber der schlaue Abu-Karimo noch ein Salzlager angelegt. In diesen salzarmen Gegenden ist das Salz einer der begehrenswertesten Tauschartikel. Ein solches Lager bildet daher für diesen Marktflecken einen nicht zu unterschätzenden Anziehungspunkt und die Fremden werden, wenn sie nach der Heimat zurückkehren, oft noch bestimmt, hier ihren Salzbedarf zu decken.

Natürlich war Abu-Karimo anfangs den Feindseligkeiten der englischen Händler ausgesetzt, die in diesem Haussa mit Recht einen gefährlichen Konkurrenten sahen. So kam es, dass er mich bei meiner ersten Reise um den Schutz der Regierung und zum Zeichen desselben um eine deutsche Flagge bat. Da ich die Befugnis hatte, deutsch gesinnte Häuptlinge in den Schutz der Regierung zu stellen und ihnen clie schwarz-weiss-rote Flagge zu geben, so hielt ich es für angebracht, auch diesem intelligenten Haussa formell durch die Verleihung der deutschen Flagge den Schutz gegen die englischen Händler zu gewähren. Damit war zugleich eine Kontrollstation gegen die Schmuggler aus dem englischen Gebiete geschaffen. Abu-Karimo ist ein äusserst gewiegter Kaufmann und hat seine Erziehung in Akkra genossen, wo er Haussasoldat war und es bis zu einem Native-Offizier gebracht haben will. Auch war er in London, an welche Zeit er sich gern erinnert. Er ist ein wurdiger Repräsentant seines Geschlechts; seine Figur, mit der yrossen Tube bekleidet, sein schlaues Gesicht und sein ganzes Auftreten 
sind charakteristisch für den richtigen Haussa-Gentleman. Ich war erstaunt, mich mit ihm über die Verhältnisse des Landes und seines Handels recht gut unterhalten zu können.

In der Land. Nachdem ich mich bei einer guten Verpflegung mit Huhn und schaft Tappa. Yams von den Strapazen des vorhergehenden Tages ausgeruht hatte, brach ich mit meiner kleinen Karawane am anderen Tage früh morgens auf. Das Plateau, auf dem wir weiter marschieren, gewährt einen schönen Blick auf das Thal des Konsu, sowie auf das sich in der Ferne nach Nordosten hinziehende Baika- und Konsugebirge, welche nach meiner ungefähren Schätzung die Höhe von $400 \mathrm{~m}$ erreichen. Der Weg führt nun nach Norden an den Osthängen des Plateaus entlang. Ueberall stösst man auf felsigen Untergrund, welcher nur mit einer geringen Erdschicht bedeckt ist. Die Vegetation hat sich ganz verändert und statt der üppigen Gebirgswälder mit ihren hohen Baumwollbäumen und Oelpalmen umgiebt uns eine weite Baumsavanne, welche mit meterhohem Grase bedeckt ist und auf der vereinzelt die von nun ab für uns typisch werdenden Savannenbäume, Schibutterbäume und Mimosen abwechseln. Auf diesem Plateau wandert man ungefähr drei Stunden nördlich, bis man vor sich einen grossen Thalkessel erblickt, der im Norden und Nordwesten von den Bergen von Worawora eingefasst ist. Es gewährt einen schönen Anblick, wie sich die einzelnen Kegel in typischer Pyramidenform abheben. Bald haben wir die südwestlichen Vorberge des Tappagebirges erreicht, in welche das Plateau, auf welchem wir uns befinden, übergeht. Von diesem Plateau geht es auf steilem Pfade durch dicht bewaldete Schluchten, welche einen wildromantischen Charakter tragen, in das Thal des Asioko (Asuokoko), eines linken Nebenflusses des Volta, hinunter. Nach Ueberwindung einiger kleiner Bäche, die alle in den Asioko führen, gelangt man nach einem $\mathrm{I}^{\mathrm{I}} / 2$ stündigen Marsche, kleine Koffis passierend, nach dem Fetischort Konfokrum (Komfokokokrum). Hier residiert die Fetischfrau Koko, die zugleich Gebieterin dieses kleinen Dorfes ist. Der Name Konfokrum soll in der Eingeborenensprache weiter nichts bezeichnen, als einen Ort, welcher der Wahrsagerin Koko geweiht ist. Gleich beim Betreten des Dorfes stossen wir auf einen grossen Opferkegel, der dem Fetisch Odente zu Kratyi heilig ist. Er steht in der Mitte auf dem Marktplatz zwischen den armseligen Hütten und besteht aus einem grossen Schutzdach, unter welchem ein Erdkegel von ungefähr $\mathrm{I}^{\mathrm{T}} / 2 \mathrm{~m}$ Höhe errichtet ist, auf dem eine kleine Opferschale steht. Rings um den Markt befinden sich die Gehöfte der Eingeborenen, während weiter abseits die Fetischfrau in ihren zum Teil kleinen aber schönen Hütten haust. Meistens erhält der Weisse auf seine Nachfrage die Antwort, dass sie nach Tappa zu dem Oberhäuptling gegangen sei; doch hatte ich einmal die Ehre, von ihr 
empfangen zu werden. Sie ist ein stupides altes Weib, welches mit Fetischemblemen behangen ist und äusserlich eine blosse Puppe zu sein scheint. Ihr Sprecher, ein unverschämter junger Bursche, führt allein das Wort und scheint, was die weltlichen Angelegenheiten dieser Hohenpriesterin betrifft, das Heft in der Hand $z u$ haben. In Konfokrum begregnen wir zum ersten Mal dem grossen Fetisch Odente, dessen Reich im Süden mit dem Fetisch der Koko beginnt. Wie wir gesehen haben, hört mit der Landschaft Kunya die Herrschaft des mächtigen Siafetisches auf. Meistens reichen diese Fetische nur so weit, wie das Sprachgebiet, dem sie angehören. Wir befinden uns nun hier im Bereich der Boëmsprache, die in der ganzen Landschaft Boëm gesprochen wird. Diese hat jedoch ziemlich verschiedene Dialekte und der uns bekannte Missionar Clerk teilt sie in nicht weniger als vier Sprachgebiete ein. Im übrigen ist in diesen Gegenden die Tshisprache überall verbreitet, so dass man sie für die eigentliche Landessprache halten könnte. In allen Gegenden der Landschaft Tappa, welche ich bereist habe, konnte ich mich vorzüglich durch meinen Dolmetscher in der Tshisprache verständigen, ja selbst herauf bis Kratyi und fast bis Salaga traf man Leute, die der Sprache vollkommen mächtig waren. Es ist kein Wunder, dass die Tshisprache in allen diesen Ländern verbreitet ist, da dieselben früher teils zu dem mächtigen Reich der Aschantis gehörten oder wenigstens vollkommen unter dem Einflusse dieses mutigen und kriegslustigen Nachbarstammes standen. Auch der Handel der Aschanti ist weit in das I and hineingedrungen. Alle die alten Handelsbeziehungen, welche früher durch das Vordringen der Aschanti geknüpft wurden, sind sorgfältig von den Aschantihändlern aufrecht erhalten und mit aller Energie von der englischen Regierung unterstützt und gefördert worden. Aus diesem Grunde gehen auch jetzt noch die meisten Produkte des Hinterlandes, wie Gummi, Vieh und andere Erzeugnisse zum Schaden unserer Kolonieen und der deutschen Kaufleute, die an den Küstenplätzen ansässig sind, aus unseren Hinterländern in das englische Aschantigebiet. Zu alledem kommt noch der Umstand, der auch jetzt noch von einschneidender Bedeutung für uns ist, dass die Wasserstrasse des Volta und seiner Nebenflüsse eine Hauptbedingung für die Ausbreitung des Handels war. Aber, wie wir schon früher hervorgehoben haben, ist auch das Addasalz ein hervorragender Faktor in dieser handelspolitischen Entwickelung gewesen. Obwohl sich natürlich alle diese Verhältnisse durch die Entstehung unserer jungen deutschen Kolonie Togo und die damit verbundene Sicherung der Strassen, die Anlegung von Wegen und den Schutz, welchen wir Händlern aus dem Evhegebiet und anderen Teilen unserer Kolonie gegen die Uebergriffe der übermütigen Aschantihändler aus dem englischen Gebiete, besonders von Adda und Akkra 
gewähren, zu unseren Gunsten geändert haben, so müssen wir uns doch fortdauernd mit aller Energie bestreben, diese fur unsere Kolonie ungesunden Zustände vollends aus der Welt zu schaffen. Durch Anlegung von Bahnen und mit Anspannung aller unserer Kräfte können wir, wie ich schon früher erörtert habe, der Wasserstrasse des Volta den Rang streitig machen.

Handel in

Tappa und die Kolanuss.

Was nun die Landschaft Tappa im engeren Sinne betrifft, so bildet sie für den Händler einen Centralpunkt. Hier ist es vor allen Dingen der Kolabaum, welcher den Handel anzieht und von den Eingeborenen in Farmen angepflanzt wird. Die Kolanuss, eines der beliebtesten narkotischen Mittel der Haussa, bildet, wie wir bereits gesehen haben, einen Handelsartikel, der sich bis weit in die Haussaländer hinein erstreckt. Jedoch steht die Nachfrage zu dem geringen Angebot in keinem annähernden Verhältnis; bei einer rationellen Anpflanzung der Kola könnte Tappa zu einer ganz hervorragenden wirtschaftlichen Bedeutung gelangen. Die Landschaft Tappa und in dieser hauptsächlich Konfokrum werden ron rielen Viehkarawanen durchzogen, welche das Vieh aus den Hinterländern von Sugu, auch selbst von Borgu auf direktem Wege zur Küste bringen. So bildet sich ein reger Verkehr in dieser Landschaft heraus Auch kommen zur Regenzeit, wenn es die Höhe des Wasserstandes des Asioko gestattet, direkte Kanoeladungen mit Salz bis zu dem Wasserplatz von Odei herauf, wo dann mit dem Addasalz auch geringere Produkte eingetauscht werden. So liefern die immer noch reichen Bestände der Oelpalmen in den Bergen Palmkerne, deren Ausfuhr nach der Küste sich infolge des Wassertransports in grossen Kanoes zu gewissen Jahreszeiten noch immer lohnt. Hier, wie in den ganzen Ländern am Volta, sowie an dessen grösseren Nebenflüssen ist auch der Kanoebau, welchen wir schon früher erwähnt haben, zu Hause. Auf meiner Reise durch das Gebirgsland Tappa habe ich in den Wäldern Gummilianen bemerkt. Trotzdem ist vorläufig von den Leuten an eine Ausbeutung dieser ertragreichen Pflanze noch nicht gedacht worden. Obwohl sie hier wohl kaum in dem Maasse vorkommt wie im Adeligebirge, würde sie doch bei vernünftiger Ausnutzung den Bewohnern ganz bedeutende Einnahmen bringen. Nach dem Bericht des Grafen Zech kommen am Asioko auch vereinzelt Mahagonibäume vor, welche später für die Landschaft einen wertvollen Handelsartikel bilden können.

Konfokrum liegt nicht weit von Asioko in einem schönen Hain, welcher Mimosen und grosse Seidenwollbäume birgt. Die Hütten zeigen überall die rechteckige Form; jedoch unterscheiden sie sich von den vorher beschriebenen Evhehütten häufig dadurch, dass sie ausser den Giebeldächern mit sogenannten Walmdächern eingedeckt sind und 
sich der quadratischen Form nähern. Die Bewohner treiben reben dem Ackerbau eine mässige V'iehzucht, die ausser Hühnern hauptsächlich aus Schafen besteht, da dem Fetisch Odente, wie wir später sehen werden, Ziegen verhasst sind und deshalb an dieser heiligen Stelle nicht geduldet werden. Auserdem aber liegen sie auch dem Fischfang in dem nahen Asioko und dessen Nebengewässern ob; auch haben sie (ielegenheit zur Jagd in den umliegenden Wäldern und Gebirgen. Die Landschaft Tappa ist im allgemeinen von einem rauhen, unbeugsamen Gebirgsstamm bewohnt, welcher zwar nominell und seiner Sprache nach zu Boëm gehört, sich sonst aber wenig um den König in Borada kümmert und sich nur seinem eigenen Häuptling unterordnet. Ich will hier eine Begegnung, welche ich später mit dem Häuptling von Tappa hatte, vorwegr nehmen.

Ich hatte den Befehl erhalten, den Häuptling von Tappa zur Rede zu stellen, weshalb er nicht einem auf Veranlassung des Oberleutnants v Döring ihm ron dem König von Boëm erteilten Befehle Folge geleistet habe. Bei dem Einzuge $r$ Dörings in Borada, der Hauptstadt ron Boëm, hatte der König nämlieh alle Häuptlinge seines Reiches auffordern lassen, nach Borada zu kommen, um ihm und der deutschen Regierung Treue zu geloben. Alle waren erschienen, bis auf den Häuptling von Tappa Ausserdem hatte der König, wie gewöhnlich, allerhand Klagen darüber zu führen, dass sich die Boëmleute durch Wegfangen von Leuten und durch Unbotmässigkeit unliebsam machten. Zu diesem Zwecke marschierte ich über Konfokrum hinauf in die rauhen Berge von Tappa. Der Asioko und seine kleinen Nebenflüsse, welche ihr Bett in die steilen Felsen eingegraben haben, mussten überschritten werden; der Marsch ging auf steilem Pfad die Berge hinauf durch Urwald und Gestrüpp. Erstaunlich war es, hier überall gewaltige Massen ron Ananassträuchern wie Unkraut stehen zu sehen, so dass sie nicht selten den Weg versperrten und unseren Marsch erschwerten. Aber trotz dieser Fülle von Sträuchern und einer grossen Menge von Knospen und Blüten, sowie unreifen Früchten hatte ich doch nicht Gelegenheit, mit einer reifen Frucht meinen brennenden Durst zu stillen. Die Eingeborenen besitzen eine ganz besondere Findigkeit, Früchte, die nur einigermaassen reif sind, sobald als möglich einzuheimsen.

Ich begab mich mit meiner kleinen Karawane, welche aus i 3 Mann Soldaten und einigen Trägern bestand, direkt nach dem Häuptlingsdorfe Tappa, um mich so schnell als möglich meines Auftrages zu entledigen. Schon auf dem steilen Gebirgspfade kamen mir Händler entgegen, welche mich ermahnten, mich in acht zu nehmen, da die sämtlichen bewaffneten Tappaleute sich in dem Ort versammelt hätten und wüste Reden gegen den Weissen führten. Auch habe in Odeï, einem kleinen Ort, der am Fusse des Gebirges im Thale des Asioko liegt, ein Totenfest 
stattgefunden, wo sich die Gemüter erhitzt hätten. Noch aus der Tiefe her erdröhnte das Geknall und Geschrei aus Odeï zu uns herauf, während wir unsererseits Mühe hatten, die steilen Felsen und Blöcke und querliegende grosse Baumstämme zu überwinden. Endlich waren wir in der Nähe des Dorfes, welches hoch oben auf dem Kamme des Gebirgszuges liegt, angekommen; ich hielt es infolgedessen für ratsam, die Gewehre laden zu lassen, kündigte den Leuten die Gefahr an, welcher wir entgegen gingen und machte sie darauf aufmerksam, dass sie mich immer im Auge behalten sollten. Wir marschierten durch den kleinen Ort auf den Marktplatz, wo unter den mächtigen Bäumen der Häuptling mit seinen Getreuen, wie es schien, in kriegerischer Stimmung versammelt war. Ich marschierte mit meiner kleinen Anzahl Leute in die Menge hinein, welche wütend die Steinschlossflinten schwang und eine drohende Haltung annahm. Dann liess ich die Leute direkt hinter mir mit Gewehr bei Fuss aufmarschieren und begrüsste den Häuptling, wobei trotz des vorhergehenden Lärms eine unheimliche Totenstille eintrat. Ich fragte ihn nun, warum er dem Befehl der Regierung und seines Oberhäuptlings zu Borada nicht nachgekommen sei und forderte ihn auf, sich zu verantworten. Ein Höllenlärm entstand und der kritische Moment schien gekommen zu sein. In diesem Augenblick trat ich auf den Häuptling zu und fragte ihn, ob er wirklich König in seinem Lande sei und ob man in demselben einen Fremden in dieser Weise zu empfangen pflege; ich habe bis jetzt nur von der Schönheit und Grösse seines Reiches gehört und sei erstaunt, nun einen Häuptling vor mir zu sehen, der so wenig Macht über seine Unterthanen habe, dass sie nicht einmal auf seinen Befehl einen Grast ehrten, welcher gekommen sei, um ein herrschendes Missverständnis aufzuklären und Freundschaft zwischen seinem Volke und der deutschen Regierung zu schliessen. Der Sprecher des Königs, welcher nun Ruhe gebot, konnte jedoch wenig Ordnung schaffen, bis sich schliesslich die alten Leute ins Mittel legten und die Oberhand über

Flaggenhissung in Tappa. den Pöbel erlangten. Der König sagte mir, dass es immer sein Wunsch gewesen sei, mit der Regierung Freundschaft zu schliessen, dass er auch wie der König von Borada und die anderen deutschen Häuptlinge eine Flagge haben möchte, dass er jedoch sein Land selbst regieren wolle, wenn er auch bereit sei, den Befehlen der Regierung nachzukommen und stets zu derselben zu halten. Die Stimmung im Volke war auf einmal umgeschlagen und nur noch die Alten debattierten, während die junge Gesellschaft sich ruhig verhielt. Um nun sowohl mir nichts $z u$ vergeben, als auch der Sache zu nützen, ermahnte ich ihn, vor allem sämtliche Wege freizugeben und zu versprechen, dass Streitigkeiten mit den Nachbarn vermieden würden und jeder frei durch das Land ziehen dürfe. Nach vielem Hin- und Herreden willigte der Häuptling endlich 
ein und so wurde aus dem kriegerischen Vorspiel ein Freudenfest für Tappa. Bald wurden Geschenke herangeholt und auch der übliche Palmwein fehlte nicht, der nun bei dem Häuptling und den Grossen kreiste. Mit dem ersten Trunk wurde die Freundschaft besiegelt. Ich erhielt eine Menge Yams und Essen für meine Leute und wurde selbst mit einem solchen Uebermaass von Schafen und Hühnern überschüttet, dass ich wegen Gegengeschenken in Verlegenheit kam. Vor allen Dingen überreichte ich dem Häuptling die Flagge und sagte ihm, dieses sei das grösste Geschenk, das ich ihm geben könnte, da es das Zeichen der Freundschaft zwischen ihm und der deutschen Regierung bedeute. Es wurde nun schnell unter dem Jubel der Schwarzen ein grosser Bambus als Flaggenstock vor dem Gebäude des Häuptlings aufgerichtet und bald wehte hoch auf dem Berge von Tappa die schwarz-weiss-rote Flagge. Wie bei allen ähnlichen Gelegenheiten ging die Flagge unter präsentiertem Gewehr hoch und mit dem Hoch auf Se. Majestät, in welches natürlich meine kleine Truppe einstimmte, war der feierliche Akt beendet. Der Häuptling aber war noch nicht befriedigt, sondern verlangte, dass ich, wie bei den übrigen Häuptlingen auch schiessen lassen sollte. Notgedrungen war ich nun gezwungen, mit den noch scharfgeladenen Gewehren den Salut zu geben. Ich nutzte aber diesen Umstand aus, indem ich ihm sagte, dass diese Ehre bis jetzt noch keinem der Häuptlinge zu teil geworden sei und bedeutete die Leute, dass sie sich nicht fürchten sollten, da die Soldaten hoch in die Aeste hineinschiessen würden. Ein dreifacher donnernder Salut hallte in den Bergen wieder und zum grossen Staunen der Menge fielen einige dicke Aeste von den hohen Bäumen hernieder. Bald darauf zog ich über Akamin wieder zur Station Kete-Kratyi zurück. War der Aufstieg schwierig gewesen, so gestaltete sich der Abstieg noch schwieriger, da er gewissermaassen sprungweise von Fels zu Fels bis Akanim ausgeführt werden musste. Nicht wenig Mühe machte es, die geschenkten Schafe mitzuführen, jedoch wollte ich sie bei dem häufigen Mangel an Proviant nicht missen.

Nach dieser kurzen Abschweifung kehren wir wieder nach Heiligabend Konfokrum zurück. Es sei mir gestattet, eine kleine Feier zu beschreiben, welche wir drei Weisse hier begingen. Es war das Weihnachtsfest I 895 auf der grossen Expedition, welche unter Oberleutnant von Döring, dem Botaniker Baumann und mir gegen das feindliche Kete-Kratyi gerichtet war. Wir wollten auch fern von der Heimat den alten deutschen Brauch eines Weihnachtsbaumes nicht missen und so wurde in Ermangelung des Tannenbaumes eine schöne Mimose ausgesucht, die am Abend auf dem Marktplatze neben dem Fetisch ihre Aufstellung fand und bei einbrechender Nacht durch Wachskerzen erleuchtet wurde. Aengstlich 
umstand das Volk den eigentümlichen Fetisch des Weissen, wie sie den Baum nannten. Während wir an die Heimat und unsere teuren Anverwandten daheim dachten, sangen wir das Weihnachtslied: „Stille Nacht, heilige Nacht", in welches zu unserer grossen Freude und Ueberraschung ein Teil unserer Träger in der Evhesprache mit einstimmte. Es waren sämtlich ehemalige Schüler der Mission, welche sich an das Christfest in ihrer Heimat erinnerten. Wohl überkommt einen eine gewisse Wehmut, wenn man fern von zu Hause in der Wildnis das Weihnachtsfest feiert; andererseits aber verleiht einem das Bewusstsein, deutsche Sitte und deutsche Kultur in ferne Erdteile tragen zu dürfen, ein Gefühl patriotischer Erhebung, welches jegliches Heimweh besiegt. Zur Feier dieses Abends beschenkten wir alle Christen unter unseren Leuten mit einer Mark. Natürlich wollten die meisten Christen sein, selbst unsere Haussa waren bereit, an diesem Tage ihren Allah zu verleugnen.

Marsch nach der Landschaf Apai.
Akroso im Gebiet der Tshisprache

Am nächsten Morgen ging es weiter, dem nächsten Ziele Akrossu am Asioko zu Der Weg führte über zahlreiche kleine Zuflüsse des Asioko. Sie waren bei der gerade herrschenden grossen Regenzeit angeschwollen, so dass wir häufig ganze Strecken sumpfiges Terrain durchwaten mussten, bis wir wieder den eigentlichen Pfad erreichten. Wir marschierten nun an dem linken Ufer des Asioko weiter. Ein grosser Galeriewald umgiebt den Asioko, welcher zu unserer Zeit seine gewaltigen Fluten langsam über die Felsen dahinwälzte. Er führte eine ungeheure Wassermasse, die sich bei dem Einfluss in den Volta fast staute. Hohe Seidenwollbäume rahmen den Asioko ein. Auch sieht man hier viel Odum-Bäume, welche ein wertvolles Material für den Bau von europäischen Häusern in den Tropengegenden bilden. Bei starkem und unangenehmem Regenwetter überschritten wir nach dreistündigem Marsch auf Kanoes den Asioko, um nach dem nächsten Rastplatz Akrossu, auf dem rechten Ufer zu gelangen. Der Asioko bildet die Grenze zwischen Boëm und der Landschaft Apai und mit dem Ueberschreiten desselben kommt man in clas eigentliche Gebiet der Tshisprache.

Akroso ist ein kleiner Ort, der leider halb verlassen und verfallen ist; jedoch hat er in der letzten Zeit wieder einen Aufschwung genommen. Er ist ein Hauptrastplatz für die Karawanen und seine Bewohner sind auf den Fremdenverkehr angewiesen. Eine Haupteinnahmequelle bildet die Fähre, welche sich bei hohem Wasserstande einer grossen Frequenz erfreut. In Akroso liegt das Grab des hoffnungsvollen Reisenden Dr. Küster, der hier nach kurzer, aber reger Thätigkeit fern von der Heimat seine Ruhestätte gefunden hat. Auch Dr. Küster wurde auf der Reise das Opfer des Malariafiebers, welches schon so viele kostbare Menschenleben in den Tropen gefordert hat. Akroso soll nach den Angaben der Leute durch eine Epidemie niedergegangen sein, was die verfallenen Ueberreste 
zahlreicher Hütten bekunden. Die Bevölkerung soll sich damals zum grössten Teil in Krobo auf dem rechten Volta-Ufer auf englischem (jebict angesiedelt haben. Die Leute sprechen wie in der ganzen Landschaft Apai, zu welcher auch Akroso gehört, hauptsächlich Tshi; jedoch ist es nicht ausgeschlossen, dass sie, namentlich in den kleineren Orten und Farmdörfern, ausser der Tshisprache noch eine eigene Sprache besitzen. Es ist für den Reisenden ungemein schwierig, alle Sprachgrenzen zu erkennen und scharf zu trennen. So giebt es in Boëm eine ganze Reihe von Orten, in denen, ausser der Muttersprache, im Verkehr fast ausschliesslich Tshi gesprochen wird. Ausserdem sind noch viele Geheimsprachen im Gebrauch, wie wir sie schon z. B. bei dem Yewe-Orden kennen gelernt haben. Was die Stammesabzeichen oder vielleicht auch

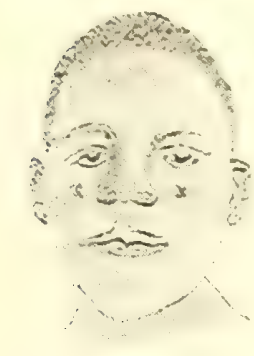
Schönheitsmarken anbetrifft, so habe ich in Akroso, sowie weiter hinauf bis an den Oti bei den Frauen ein und dieselbe Tätowierung bemerkt Es sind zwei kleine Querschnitte in der Gegend der Backenknochen, die einen kleinen Stern bilden

Da mir in Akroso genügend Zeit übrig blieb, Kanoefahrt mietete ich mir ein Kanoe, um den Einfluss des auf dem Asioko in den Volta festzustellen. Der Asioko ist Asioko und durchschnittlich ungefähr 40 bis $50 \mathrm{~m}$ breit und bei dem Volta.

durchschnittlich etwa $4 \mathrm{~m}$ tief. Als ich jedoch später bei der Trockenzeit denselben Fluss passierte, führte er nur ein seichtes Gewässer, das sich mühsam durch die Schnellen und Felsen hindurcharbeitete. In einem kleinen, aber schlanken Kanoe erreichte ich ungefähr zwanzig Minuten westlich die Einmündung in den Volta. Die Strömung war sehr schwach und wurde durch den hohen Masserstand des Volta, wie ich schon vorher erwähnt hatte, förmlich gestaut. Der Asioko sowie der Volta waren hier von einem hohen Galeriewald umgeben. Hohe Fikusarten und von Lianen umwundene Mangroven bildeten den Tummelplatz der Affen. Hauptsächlich waren hier kleine Meerkatzen vertreten, während ich, allerdings an dem oberen Lauf bei Konfokrum, vereinzelt auch kleine Trupps von Seidenaffen bemerkte. Nashornvögel machten sich überall durch ihr Kreischen bemerkbar und flatterten hoch über den Wasserspiegel dahin. Drollig war es anzusehen, wie possierlich dreinschauende Affen unser Kanoe verfolgten und dann plötzlich auf ein gegebenes Zeichen in kleinen Trupps, die Grossen voran, sprungweis am Ufer unseren Vortrab bildeten. Bei der Einmündung des Asioko in den Volta weist der Volta eine majestätische Breite von 400 bis $500 \mathrm{~m}$ auf. Mit reissender Geschwindigkeit wälzte der Strom seine gewaltigen Wassermassen vorwärts und gestattete uns nur, unser Kanoe mühsam 
am Ufer von Ast zu Ast stromaufwärts zu ziehen. Auf dem gegenüberliegenden Ufer sah man Krobo liegen. Leider mussten wir die Fahrt bald aufgeben, da wir der gewaltigen Strömung mit dem kleinen Kanoe nicht gewachsen waren. Später habe ich den Asioko auch bei Trockenzeit von Konfokrum bis Akrossu befahren. Die Fahrt war allerdings wegen des niedrigen Wasserstandes sehr schwierig, da wir nur mit Mühe zwischen den Felsen durchkormmen konnten und unser Kanoe über jede Stromschnelle wegstossen mussten. Trotzdem will ich diese herrliche Fahrt nicht unerwähnt lassen. Die hohen Bäume schlugen fast mit ihren Kronen über dem Fluss zusammen; grosse Felsblöcke versperrten den Weg und krystallhell rauschte das Wasser über die kleinen Schnellen;

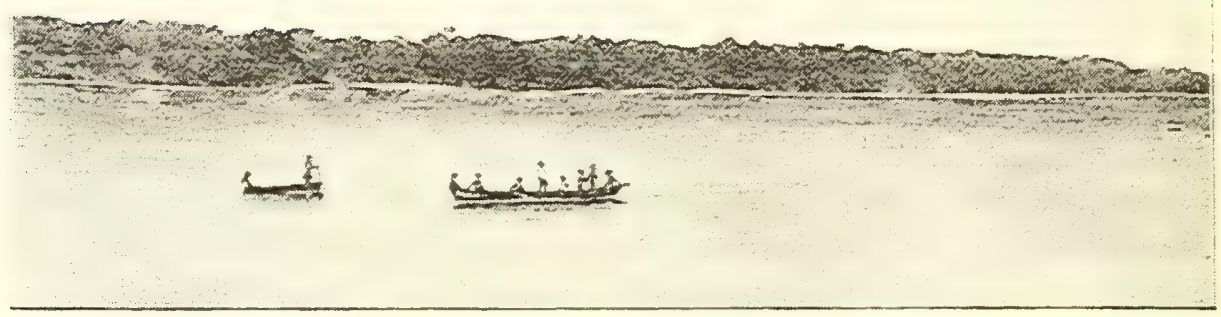

Der Voltastrom.

wiederum begleiteten uns an den malerisch schönen Ufern muntere Affenschwärme. Auf den wasserumspülten Felsen stolzierten die originellen kleinen Lappenkiebitze, auch waren überall die verschiedensten Reiherarten zu bemerken, wobei uns besonders ein grosser Schattenreiher durch seine aschbraune Farbe auffiel. Derselbe stand wie angewurzelt; als wir näher herankamen und ich schon meine Büchse zum Schuss erheben wollte, bemerkten wir plötzlich, dass er sich in einer Schlinge befand. Baumann, mit dem ich damals diese Fahrt machte, freute sich nicht wenig über den seltenen Fang. Auch hatten wir Gelegenheit, massenhaft kleine Eisvögel und Finkenarten, sowie einige der damals noch wenig bekannten Lappenkiebitze zu erlegen. Ein grosser Seeadler, der durch seine schwarz-weisse Farbe weithin erkennbar ist, bildete das Hauptstück unserer Beute. Zum Schluss der Fahrt gelangten 
wir nach Akroso, wo wir emsig daran gingen, die erlegten Tiere für die Museen zu präparieren und zu konservieren.

In Akroso übernachtete ich und hatte dort Gelegenheit, die Nachtquartier Leiden, welche die Moskitos ihren Opfern verursachen, vollauf kennen in Akroso. zu lernen. Als Neuling in afrikanischen Gebräuchen hatte ich bei Moskitodem schnellen Aufbruch leider mein Moskitonetz vergessen, was ich plage. in der Volta-Niederung bitter bereuen sollte. Nach den anstrengenden Strapazen des Tages, wo ich mich nicht selten i 2 Stunden auf dem Marsche befand, dann des Abends totmüde das Lager in einer Hütte aufsuchte, konnte ich, besonders in Akroso, von den Stichen der Moskitos gepeinigt, kein Auge schliessen. Sumpfiges Terrain, Wasser und Urwald sind die Heimat dieser entsetzlichen Quälgeister. Auf Höhen oder freiliegenden Ortschaften dagegen, wo der Wind oder der Tornado freien Zutritt hat, bleibt man gewöhnlich einigermaassen von ihnen verschont. Die Eingeborenen sind, wie wir schon früher gresehen haben, bedeutend besser gestellt, als wir Europäer, da sie sich vollständig in ihr Tuch einwickeln, so dass nichts von ihrem Körper zu sehen ist. Ich zog mir aus dieser Nacht eine Lehre und kaufte mir, als sich die Gelegenheit in Kratyi darbot, ein allerdings recht schlechtes, aus geringem Leinenstoff hergestelltes Moskitonetz, wofür ich einen unerhörten Preis erlegen musste. Die Haussa kennen eine solche Notlage ganz genau und ziehen daraus natürlich ihren Vorteil. Für ein Netz, welches vielleicht an der Küste nur mit 3 Mark bezahlt wird, musste ich damals in Kete nicht weniger als ${ }_{5} 5$ Mark opfern. - Auch in Akroso war am Ende des Dorfes ein Opferkegel des Fetischgottes Odente aufgestellt. Es berührt tief schmerzlich, wenn man am Anfang des Dorfes, aus hohem Grase das verlassene Grabkreuz Dr. Küsters hervorblicken sieht. Bevor ich am andern Tage von Akroso Abschied nahm, liess ich noch so gut wie möglich das Grab und Kreuz in Ordnung bringen.

Nach der schlaflosen Nacht trat ich am nächsten Morgen ermüdet meinen Weitermarsch an. Der Weg führte zunächst durch eine ziemlich grosse Grassavanne, in welcher vereinzelt die Farmen der AkrosoLeute liegen. Diese Ebene, die von mittelhohem Grase und einzelnen Buschdschungeln bestanden ist, ist das Revier der Schirr-Antilopen, die hier in Rudeln äsen und an deren Anblick man sich erfreuen kann. afrikanischen Nur selten findet man in dem ganzen Vorland ron Togo niedrige Jagd. baumlose Grassavannen, welche einen weiten Fernblick gewähren. Daher ist auch die Jagd so ungemein schwierig, da man meistens kein genügendes Schussfeld hat. Hierzu kommt noch die grosse Scheu des afrikanischen Wildes, so dass man sich auf Expeditionen aus Mangel an Zeit mit der Jagd so gut wie gar nicht befassen kann. Nur Flugwild

Marsch auf der Karawanenstrasse rach Apaso. Schwieriglieiten der 
auf Flüssen wird erlegt; sonst ist man, namentlich bei der Antilopenjagd, gezwungen, nach Eingeborenenart sich nächtelang auf die Lauer zu legen, um eine Jagdbeute zu erlangen. Ich nahm die Gelegenheit hier wahr, pürschte mich heran, konnte aber, da ich erst auf eine verhältnismässig grosse Entfernung schiessen konnte, nichts erlegen. Bei hoher Regenzeit ist die Ebene auf weite Strecken unter Wasser. Ein kleiner Bach durchzieht sie, der bei Hochwasser durch seine Tiefe dem Reisenden manche Unbequemlichkeiten bereitet. Um nicht gleich am fruhen Morgen total nass zu werden und sich einzuschmutzen, lässt man sich häufig durch einen kräftigen Träger über solche kleine Cräben forttragen Jedoch kann man auch gerade den umgekehrten Zweck erreichen, wenn der Träger strauchelt und man dann mit seinen ganzen Habseligkeiten, Kompass, Barometer und Büchern, in diesem Schlamm ein Bad nehmen muss. Gott sei Dank stecken die meisten Instrumente in starken Lederfutteralen und die Tropensonne ist so intensiv, dass sie bald wieder trocken werden. Man kann sich denken, wie schnell die Instrumente auf solcher Reise sich abnutzen und fehlerhaft werden; doch kann man durch stetige Kontrolle die Fehler wieder ausgleichen. Wir folgten nun bei einer Gabelung zweier Wege naturgemäss dem grösseren, im Glauben, den Hauptpfad getroffen zu haben. Doch sahen wir uns bald enttäuscht, denn wir gelangten nur auf eine Farm, wo der Weg sein Ende erreichte. Mühsam erkletterten wir eine der felsigen Höhen, um Ausschau zu halten, doch der Busch hinderte uns daran. Während ich mich auf einer Felsplatte niederliess, um den Trägern eine kurze Rast zu gewähren, hatte ich viel Spass an den Affen, welche, von der Neugier an diese einsame Stelle getrieben, die sonderbaren Eindringlinge mit erstaunten Blicken musterten und jeden Handgriff scharf beobachteten. $\mathrm{Zu}$ meinem Verdruss mussten wir uns nun mühsam durch das Gehölz durcharbeiten, um auf die verfehlte Hauptstrasse zurück zu gelangen. Ich erwähne diesen Zwischenfall nur, um zu zeigen, wie leicht solche Pfade Anlass zu Verirrungen geben und wie schwierig es oft ist, den richtigen herauszufinden. Die Eingeborenen machen nämlich sehr häufig zu den Farmen Wege, die viel breiter und gepflegter sind, als die grossen Karawanenstrassen, welche in das Innere führen. Auf diesen Strassen wird keine Hand angelegt und nur der ausserordentliche rege Verkehr erhält sie. Meistens sind sie so schmal, dass man nur in der Rinne laufen kann, wenn man die Fusse vor einander setzt: Letzteres ist für den Neger nicht schwierig, dem Europäer dagegen wird es nicht leicht in der während der Regenzeit vom Wasser ausgespulten Mulde zu marschieren. Es ist gewöhnlich gerade ein Kennzeichen fur solche Karawanenpfade, dass sie tief ausgelaufen sind. Nachdem wir wieder den eigentlichen Pfad erreicht 
haben, geht es bergauf und bergab über die felsigen Höhen, welche sich am Volta entlang zichen und das eigentliche Ueberschwemmungsgebiet desselben begrenzen. Auf diesen Höhen tritt häufig kahler Fels zu Tage, der hier meistens aus Konglomeraten und Raseneisenstein besteht. Durch kleine Gewässer werden Schluchten gebildet, deren Waldungen dem Wanderer den erwünschten Schatten gewähren. Von diesen Anhöhen kommt man nun wieder in die für die Volta-Ebene typische eintönige Baumsavanne. Dieselbe ist meistens mit mittelhohem Grase und abwechselnd mit dem Schi-Butterbaum und mit Mimosen bestanden, während nur vereinzelt Fikusarten, sowie auch der Senegal(xummibaum rorkommen. In den kleinen Galeriewäldern der Flüsse und Bäche treten noch spärlicher die Oel- und Dattelpalmen auf. Nach einem 6 stundigen Marsche gelangt man in das Dorf Apaso, den Apaso und grössten Ort der Landschaft Apai. Er besteht nur aus einer breiten die Bewohner Strasse, die zugleich den Marktplatz bildet. Hier überwiegen schon die quadratischen Hütten mit Walmdächern; auch trifft man zum ersten der Landschaft Apai. Male seit der Küste mehrere runde Hütten mit den sogenannten Kegeldächern an. Wit diesen Hütten beginnt die verbreitetste Bauart der Eingeborenen, welche fast in dem ganzen Hinterlande die vorherrschende ist. Im allgemeinen schreibt man die Bauart der viereckigen Hütten dem europäischen Einflusse und einer höheren Kultur zu. Andererseits haben aber auch die auf einer bedeutend höheren Stufe stehenden Haussa und andere Völker im Sudan runde Hütten, welche vielfach dauerhafter und besser als die viereckigen Hutten gebaut sind Durch ihre runde form und das kegelförmige abschüssige Dach widerstehen sie besser der Witterung und namentlich den starken Regengüssen der heftigen Tornados. Auch kommt bei diesen Hütten die Wetterseite lange nicht so in Frage als bei den viereckigen. Eigentümlich fielen mir in Apaso die vielen und besonders grossen Schafe auf, welche viel Aehnlichkeit mit dem Samoli-Schafe haben. Vor allem ist die Grösse dieser Tiere gegenüber den kleinen Schafen im ganzen Küstenlande hervorzuheben.

In Apaso nähren sich die Leute von der Jagd und Fischerei; ausserdem.macht die Nähe des Volta diesen Platz zu einem Haltepunkt und Stapelplatz für die englischen Händler, welche per Kanoe den Volta heraufkommen. Besonders ist aber in Apaso der Kanoebau im Flor. Derselbe hängt mit der Schnitzerei innig zusammen. Es werden deshalb hier wie auch weiterhin in Ahinkru die grossen Trommeln angefertigt, welche uns bei öffentlichen Aufzügen und Fetischtänzen oft begegnet sind. Das Gestell zu diesen Trommeln wird aus dem Querschnitt eines Baumstammes angefertigt. Bisweilen sind diese Gestelle mit Arabesken und Skulpturen versehen, welche mit einem einfachen Messer 
kunstvoll eingeschnitten werden. Ferner werden hier Kämme für Frauen, sowie die öfters kunstvoll geschnitzten Königsstühle hergestellt. Das Untergestell dieser Stühle ist meistens durchbrochen oder sonst.mit Zierrat, wie Schlangen oder Arabesken, versehen, während der obere Teil in der Regel eine einfache glatte Mulde bildet.

Beschleunigte Am nächsten Morgen verliess ich Apaso, um in einem Dauermarsch Reise nach noch am Abend Kratyi zu erreichen. Endlos führt der Weg durch die Kratyi. eintönige Baumsavanne, wir erreichen bald den kleinen Königsort des Landes, Apai, welcher abseits von der Strasse liegt, lassen denselben liegen und marschieren direkt unserm nächsten Ziele, Otisu am Oti, zu. Nach mehrstündigem Marsche gelangen wir zu dem kleinen Gehöft von Atafre, dem einzigen Rastpunkt, welcher auf dem Wege zwischen Apai und Otisu liegt. In entgegenkommender Weise bringen dort die Leute den Karawanen Wasser, auch fallen mitunter für die Träger einige Bananen und etwas Yams ab. Ich kaufte hier für mich einen sogenannten Königsstuhl, welcher in diesem kleinen verlassenen Orte ganz besonders gut hergestellt werden soll. Nach kurzer Rast geht es weiter und nach einem zweistündigen Marsche erreichen wir das schön gelegene Dorf Otisu. Schon von den Aṇhöhen aus, welche man vor Otisu zu passieren hat, erkennt man an den grossen Bäumen den Galeriewald des mächtigen Otiflusses, welcher sich weit in der Savanne dahinzieht und in welchem hohe Laubbäume mit Oelpalmen abwechseln. Von diesem Galeriewald Das Dorf umgeben, liegt hart auf steiler Anhöhe das Dorf Otisu und vor uns Otisu am fliesst majestätisch der Otifluss mit seinen gewaltigen trübgelben WasserOtilluss. massen, umgeben von undurchdringlichem Urwald, dahin. Das Dorf Otisu ist ein schöner idyllisch gelegener Ort. Hier sind die länglichen Giebelhütten schon seltener und die runden Hütten werden vorherrschend. Ein Hain von Bananen lehnt sich an den Galeriewald und bilcet durch sein helles Grün einen schönen Kontrast zu dem Dunkel des Waldes. Allerhand Reiher und Wasservögel bevölkern die Ufer und das Wasser des gewaltigen Stromes. Selbst der Ibis fehlt nicht. Aber neben dieser friedlichen Fauna lauert auch in den Wasserhöhlen, die das Wasser gerissen hat, das Krokodil auf seine Beute; nicht selten kommt es vor, dass den Eingeborenen von ihrem geringen Viehstande ein Schaf oder eine Ziege weggeschnappt wird und dem scheusslichen Reptil zum Opfer fällt. Im Oti ist auch die Wohnstätte der grossen Flusskolosse, der Nilpferde. Bei hoher Regenzeit ist der Oti ein majestätischer I $70 \mathrm{~m}$ breiter Strom, der mit reissender Schnelle seine gewaltigen Wassermassen zum Volta hinabwälzt. Die vielen Stromschnellen, die in der Tiefe des Wassers verborgen sind, machen sich durch ihr dumpfes Getöse bemerkbar. Ganz anders erscheint dieser mächtige Strom bei der Trockenzeit. Trotzdem gewährt er auch dann 
durch seine Breite immer noch einen mächtigen Anblick und bietet auch mehr Abwechselung durch seine Stromschnellen, die Felsen, welche aus dem Wasser hervorragen, und seine Katarakte. Die Ufer selbst sind ziemlich hoch und steil und überall mit dichtem Gebüsch und hohem von Lianen umschlungenen Wald umgeben. Ausser Vögeln und Wassertieren, welche hier ihr Stillleben führen, treiben auch Affen in den Baumwipfeln ihr munteres Wesen. Den schon vorher erwähnten Meerkatzen gesellen sich die komischen Paviane zu. Ferner birgt der Galeriewald und der grosse Busch, welcher den Strom viele Meilen weit hinauf begleitet, ein freies, reiches Jagdgebiet, wo auch der Leopard an Antilopen und anderem Wildbret seine Beute findet. Der Otistrom erstreckt sich in nördlicher Richtung bis nach Gurma herauf und fliesst nicht weit entfernt von der neu entstandenen Station Sansane-Mangu vorbei. Er ist leider infolge seiner Katarakte, namentlich in der Trockenzeit, für grosse Strecken nicht schiffbar, während bei hoher Regenzeit Kanoes bis nach Yendi und Mangu heraufgehen sollen.

Was die Bewohner von Otisu anbetrifft, so sind sie meistens Farmer, Jäger und Fischer. Gerade die Jagd, besonders aber die Fischerei am Einfluss des grossen Oti in den Volta bringt ihnen einen äusserst reichen Ertrag. Es werden die verschiedensten Methoden des Fischfanges angewandt, die wir auch schon früher an der Küste gesehen haben. Auch hier legt man häufig des Nachts, namentlich auf die Felsen der Stromschnellen im Volta, Feuerbrände und sticht dann die auf diese Weise angelockten Fische. Einen geradezu geisterhaften Eindruck macht es, wenn man sich des Abends in einem Kanoe auf dem Flusse treiben lässt und dann plötzlich den Oti wie durch eine Feuerkette abgesperrt sieht. Ausser diesem Fischfang wird jedoch nach Graf Zech noch eine andere Methode angewandt, die bedeutend ergiebiger sein soll. Man entzieht einem grossen Baum, einer Euphorbienart, den Saft. Diese weisse Flüssigkeit wird in den Fluss gegossen und wirkt betäubend auf die Fische, so dass sie auf der Seite liegend an der Oberfläche des Wassers hintreiben und mühelos erbeutet werden können. Der Häuptling vion Otisu unterhält mit seinen Leuten eine Fähre über den Oti. Bei dem massenhaften Verkehr, der auf der grossen Karawanenstrasse zur Küste geht, ist diese Fähre ein einträgliches Geschäft für den kleißen Ort. Jedoch muss der Häuptling einen Teil des Verdienstes als Tribut an den Oberhäuptling von Kratyi abgeben. Nach der Anlegung der Station Kratyi wurde Otisu sowie die ganze Landschaft Apai, welche früher unter dem Ober-Häuptling des auf englischem Gebiet liegenden Kodiabe stand, durch den damaligen Stationschef v. Döring dem Häuptling von Kratyi unterstellt. Auch wurde die Höhe des Fährgeldes geregelt und eine gesetzmässige Taxe von der Station aus festgesetzt. 
Uebersetzen über den Oti in und Weitermarsch über Ahinkru

Im engeren Kratyi - Gebiet.
Wir verlassen nun Otisu und setzen in grossen Kanoes, welche hier immer zur Ueberfahrt bereit stehen, über den breiten Fluss. Trotzdem reichlich für Kanoes gesorgt ist, müssen die Leute bei grossen Karawanen häufig längere Zeit warten, bis sie über den Strom befördert werden können. Einen wunderschönen Anblick gewährt vom jenseitigen Ufer das kleine Dorf, das mit seinen runden und viereckigen Hütten im Rahmen des Waldes hoch an dem steilen Ufer liegt. Noch einmal werfen wir einen Blick zurück und rüstig geht es vorwärts über Ahinkru, die letzte Stadt der Landschaft Apai. Hier finden wir wieder die langen grossen Giebelhütten, die von der im Tshigebiet üblichen viereckigen Form abweichen. Mir wurde berichtet, dass Leute von Boëm hier eingewandert wären und den typischen Hüttenbau von Boëm nach der neuen Heimat Ahinkru verpflanzt hätten. Da die Sonne sich schon bedenklich dem Horizont nähert, passieren wir schnell Ahinkru und kommen nach Dentemarso, einem kleinen Ort, welcher schon ganz im Gebiet von Kratyi liegt und wohl nach dem Fetischgotte Dente seinen Namen erhalten hat. In Kratyi sind viele Ortschaften dem Oberpriester Bossumfo des Odente-Fetisch untergeordnet; so dass innerhalb des Kratyigebietes eigentlich noch ein zweites Reich, das des Fetischpriesters, besteht. Nach einer Erfrischung zog ich mit meiner kleinen Karawane weiter und passierte noch einige kleine Farmenortschaften. Ueber die eintönige Baumsavanne senkte sich das Dunkel der Nacht. Leider machte dies meinen geographischen Aufnahmen ein Ende und ich konnte nur noch roh die Kompassablesungen nach der Windrose aufzeichnen, bis auch schliesslich hierfür das Licht versagte, so dass ich mich über die Richtung lediglich nach den Sternbildern orientieren konnte.

Bald erreichten wir Pampani, den letzten grösseren Ort vor Kratyi. Hier sassen die Leute friedlich an den Feuern vor ihren Hütten und bereiteten das Abendmahl. Wir wurden nicht wenig angestaunt und mit besonderer Freude von einer Haussa-Karawane begrüsst, welche ebenfalls am andern Tage nach Kratyi wollte. Man riet mir dringend $a b$, des Nachts nach Kete zu marschieren; aber was half's; mein Hauptziel war, dem Ferguson und einer englischen Flaggenhissung in Salaga zuvorzukommen. Und so galt es natürlich alle Anstrengungen zu machen, um zunächst wenigstens Kratyi, wo unser Gewährs- und Landsmann G. A. Krause sich als Haussa-Händler aufhalten sollte, zu erreichen. Vor allen Dingen hoffte ich bei ihm eine kräftige Unterstützung zu finden und mit ihm gemeinsam nach Salaga zu marschieren, um unsere verbürgten Vertragsrechte gegen die Eingriffe des Ferguson zu schützen. Diesen Beweggründen gegenüber wichen alle Schwierigkeiten und ich marschierte im Dunkel der Nacht weiter 
dem uns damals noch feindlich gesinnten Kratyi zu. Der Wreg durch Marschdie Savanne schien endlos und meine Träger waren so ermüdet, dass beschwerden. sie fast mit den Lasten zusammenbrachen. Auch der Sternenhimmel verschwand und ein tiefes Dunkel schloss jegliche Fernsicht aus; es begann in mächtigen Strömen zu regnen und je weiter die Stunde vorrückte, um so schwieriger wurde das Fortkommen. Zu alledem kam bei meinen Trägern und Leuten noch die Angst vor dem allgemein gefürchteten Kratyi und seinem allmächtigen Fetisch. Auch wussten sie sehr wohl, wie feindselig die Stimmung der Kratyi-bevölkerung und ihres Fetischpriesters Bossumfo gegen die verhassten Weissen war. Durch Zureden und Versprechungen und durch Annahme fremder Hilfskräfte, welche ich glücklicherweise noch vereinsamt auf dem Pfade traf, gelang es mir jedoch, die Leute von der Umkehr abzuhalten, und zum Weitermarsch nach Kratyi zu bewegen. Durch Kratyi selbst wollten sie aber auf keinen Fall hindurch, obwohl es der nähere Weg war, und so entschloss ich mich, einen kleinen Umweg zu machen und ungesehen nach Kete, der uns befreundeten Haussastadt, zu marschieren Der lange Marsch von Apaso, ron früh um sechs bis spät in die Nacht gegen neun Uhr, hatte natürlich unsere Kräfte auf das Aeusserste angespannt. Langsam, aber stetig, trotteten wir durch die weiten Farmen, welche Kratyi umgeben und in denen viele kleine eigenartige Hütten liegen, welche von den die Felder bearbeitenden Sklaven bewohnt werden. Abubukari, einer von meinen beiden Soldaten, welcher aus Salaga stammte, aber Haussa war, machte den Führer, doch auch ihn verliess bei der Finsternis sein Ortssinn. Häufig waren kleine Bäche und Wasserrinnen zu durchwaten und nicht selten fiel ein Träger mit seiner ganzen Last hinein. Schliesslich verliefen wir uns noch und gelangten zu unserer Verzweiflung an eine kleine Farm, wo uns die Leute wieder auf den richtigen Weg wiesen. Immer weiter marschierten wir, über Steine, Stöcke und Wurzeln und der ganze Unwillen der Leute entlud sich auf meinen armen HaussaSoldaten, welcher immer vorgab, dass wir bald den Ort erreichen müssten. Trotzdem schien auch er sich in der Entfernung getäuscht zu haben und hielt wohl nur seine Behauptung aufrecht, um die Leute $z u$ ermuntern. Mittlerweile hatte sich indessen der Himmel aufgeklärt, der Mond war aus den Wolken getreten und beleuchtete zu unserer Freude den Weg. Immer dichter wurden die Farmen; endlose Mais-, Yamsund Erdnussfelder bedeckten das leicht gewellte Terrain. Endlich erkannten wir an Igrossen Felsblöcken und dem Gebell der Paviane in dem Fetischhain von Kratyi die Nähe unseres Zieles. Lautlos marschierten wir weiter, bis wir auf die Höhen kamen, welche sich zu beiden Seiten des Volta entlang ziehen und hinter denen die grosse Handelsstadt Kete direkt in der Thalniederung des Volta-Flusses liegt. Vor uns 
bemerkten wir starken Feuerschein am Horizont, der von den vielen Năchtlichešs Feuerstätten des Ortes herrührte. Auch Gesang und Trommelschall Eintreffen in tönten zu uns herüber und bald sahen wir von dem Hügel aus im Kete. Mondschein cirka 2000 Hütten vor uns liegen. Fast unbemerkt betraten wir die engen, schmutzigen Gassen der Stadt und gelangten auf einen kleinen Platz, abseits von dem grossen Markte, auf dem, wie es schien, beim Mondenschein ein nächtlicher Tanz der Haussa-Jugend stattfand. Auf diesem Platze machte ich Halt; im Nu lagen alle Lasten auf der Erde und neben ihnen streckten die ermüdeten Träger ihre Glieder aus. Auch ich war vollständig erschöpft und setzte mich auf einen meiner Blechkoffer, um von den Strapazen des Tages auszuruhen. Dann sandte ich Abubukari zu dem Haussa-Häuptling Sofo, um ihm ankündigen zu lassen, dass ein deutscher Offizier hier sei und mit seinen Leuten bei ihm zu übernachten wünsche. Bald hațte sich in der Stadt das Gerücht von der Ankunft eines Weissen verbreitet und in der nächsten Minute waren wir von Haussa und Eingeborenen umringt.

Begrüssung Zum Glück erschien bald Sofo, der uns von der aufdringlichen durch Sofo Gesellschaft befreite und sich ungemein freute, einen Weissen bei sich und die Haussa aufnehmen zu können. Er führte, mich sofort nach seinem Gehöft, wo ich in einer schönen, grossen, viereckigen Hütte mein Quartier fand. Auch meine Leute wurden in einer Hütte mir gegenüber untergebracht und Sofo liess von seinen Frauen und Sklaven Yams, Mais- und Hirsebrote und Wasser herbeischaffen. Bald brodelte ein lustiges Feuer unter den Töpfen, wo der Yams gekocht oder geröstet wurde. Als Sofo sah, dass ich auf eine gute Verpflegung meiner Leute Wert legte, gab er sich in dieser Beziehung alle Mühe und auch einige Haussa, die in Lome und in der Küstengegend bekannt und der Evhesprache kundig waren, unterhielten sich mit ihnen, zum Teil wohl aus Neugierde, um zu erfahren, was die plötzliche Reise des Weissen zu bedeuten hätte. Sobald ich mich etwas gereinigt hatte, setzte ich mich unter das Schattendach vor der Hütte und nach und nach füllte sich der ganze Hof mit Notablen, Haussa und anderen Händlern, die von meiner Ankunft gehört hatten. Sie warteten jedoch in respektvoller Entfernung, bis Sofo mir einen oder den anderen vorstellte. Die Fragen, woher ich so unbemerkt käme, nahmen fast kein Ende, wurden aber durchaus nicht aufdringlich gestellt, sondern so, wie 'es der feine und gewandte Ton, der diesen Schwarzen eigen ist, mit sich bringt. Indessen fiel es Sofo doch auf, dass ich mit einer so kleinen Karawane marschierte und schien bei ihm den Verdacht żu erwecken, dass ich als Abgesandter der deutschen Regierung käme. Er fragte mich: „Wenn Du ein deutscher Offizier bist, -wo hast Du denn Deine Trompete?" Denn da alle übrigen Expeditionen, welche er gesehen hatte, Signalhörner mit sich führten, glaubte er, dass 
dieses Instrument ein Attribut des deutschen Offiziers oder Beamten sei. Ich erklärte ihm, dass ich mir so wenig Leute mitgenommen habe, um Vereitelung desto schneller vorwärts zu kommen, da ich keine Zeit habe. Natürlich des Planes erkundigte ich mich auch gleich nach Herrn Krause. Nicht wenig über- durch die Abraschte mich die Nachricht, dass dieser nach dem Süden zur Goldküste gegangen sei. Damit war mein Plan durchkreuzt und die Hoffnung, mit wesenheit des p. Krause. Krause gemeinschaftlich nach Salaga zu marschieren, vereitelt. Von Sofo erfuhr ich, dass Krause vollkommen der Haussa-Sprache mächtig sei und auch in der Tracht derselben ginge. Er sagte mir: "Wenn Du Malamusa", wie Krause von den Eingeborenen genannt wurde, „sprechen hörst, so glaubst Du, er wäre selber ein Haussa".

Da ich dringend der Ruhe bedurfte, erklärte ich den Notablen, dass ich alle weiteren Verhandlungen am nächsten Morgen erledigen werde. Sofo hatte mir inzwischen eine fette türkische Ente zum Geschenk gemacht; ausserdem erhielt ich noch Yams und Erdnüsse. Schnell wurde die Ente gerupft und in den Topf gesteckt; obwohl sie thranig und zäh war, erschien mir das Mahl bei meinem Heisshunger opulent. Nach dem Essen verabschiedete ich mich von Sofo und dankte ihm für die gute Unterkunft, welche er mir und meinen Leuten gewährt hatte.

\section{DIE HANDELSSTADT KETE.}

Da es schon spät - es war mittlerweile Mitternacht geworden - und mein altes hölzernes Feldbett, welches ich mitführte, sehr defekt geworden war, so legte ich mich auf Sofos Ruhestätte. An der hinteren Seite der Hütte befand sich auf dem festgestampften Boden eine kleine Erhöhung, auf der das Lager ausgebreitet war. Es bestand aus einer gut geflochtenen Grasmatratze, welche etwa ${ }_{5} \mathrm{~cm}$ dick und am Kopfende etwas erhöht war. Ueber derselben lagen einige grosse Grasmatten, welche das Lager bildeten. Vor diesem Lager war gewissermaassen àls Teppich ein langhaariges Schaffell ausgebreitet. Auch an einer Lampe fehlte es nicht; sie bestand aus einem Thongefäss, das mit Palmöl gefüllt war, während der Docht durch Wolle ersetzt wurde. Auch besass Sofo ein paar Eingeborenen-Stühle; eine grosse Truhe und einige europäische Blechkoffer schienen die Habseligkeiten, sowie die reichen schönen Gewänder des Haussahäuptlings zu enthalten. Mein Schlafgemach war durch eine Thüröffnung mit einer anderen Abteilung der Hütte verbunden; vor der Oeffnung hing eine geflochtene Matte von Palmenzweigen. Nach der gehabten Anstrengung schlief ich -trotz meiner Aufregung über die in den nächsten Tagen bevorstehenden Ereignisse ganz vorzüglich. Schon beim Morgengrauen hörte man das 
Gebet des Priesters, welcher von der Moschee aus seinen Morgengruss zu Allah emporsandte. Die Weiber schrieen mit eintönigem "KaffaKaffa" die beliebte Erdnusssuppe und gebackene Reis- und Maisbrote zum Frühstück aus. Bald entwickelte sich überall in der Stadt ein reges Treiben und viele Landbewohner zogen mit ihren Produkten, wie Mais, Reis, Erdnüssen und Yams von den Farmen zum grossen Markte. Auch ich erhob mich früh, um gleich bei Tagesanbruch die Stadt und das Treiben derselben in Augenschein zu nehmen. Während ich eine Tasse Thee zu mir nahm, gab ich dem Dolmetscher meine Befehle und Aufträge für den Tag. Währenddessen war auch Sofo aufgestanden und verrichtete in einer Ecke des Gehöftes sein Morgengebet mit dem Gesicht nach Osten grewandt. Vorher hatte er in einer kleinen messingenen Schüssel die vorgeschriebene Fusswaschung vorgenommen, die dem dreimaligen Gebet am Tage, früh, mittags und abends, stets vorangeht. Mit blossen Füssen kniet der Haussa andächtig auf einem kleinen Fell nieder, berührt mit seiner Stirn den Erdboden, steht dann plötzlich auf, streckt die Hände zu Allah empor, betet seinen Koranspruch, sinkt wieder in die Kniee und berührt dann dreimal den Boden mit seiner Stirn, zum Zeichen dass er sich vor Allah in den Staub legt und auch wieder zu Staub wird. Nichts stört oder hindert einen Muselmann in dieser Zeremonie; sei es in seinem Gehöfte, sei es auf der Strasse oder auf dem Pfade im Busch, überall kommt er seiner religiösen Bauliche Ein- Pflicht nach. - Ich betrachtete nun das Gehöft von Sofo, welches für richtung der die Wohnstätte eines Haussa-Häuptlings typisch ist. Durch eine lange HaussaGehöfte viereckige Vorhalle, die aber sonst in der Regel rund ist, betritt man das Gehöft. In dieser Halle stehen meistens die Reitpferde auf der einen Seite, während sich nicht selten auf der andern Seite ein erhöhter Sockel aus Lehm befindet, der bei den Palavern dem Häuptling als Thronsessel dient und mit einem grossen Leoparden- oder Kuhfell belegt wird, auf welchem der Häuptling nach orientalischer Sitte mit gekreuzten Beinen sitzt. Neben ihm nehmen die Würdenträger und Aeltešten Aufstellung. Aus dieser Halle gelangt man in ein grösseres Gehöft, in welchem, wie wir gesehen haben, eine viereckige Hutte Sofo selbst als Wohnung dient, während die anderen Hütten die Sklaven und den männlichen Teil des Haushaltes aufnehmen. Hier werden auch häufig des Tages über die Pferde, wenn sie nicht auf der Weide sind, eingestellt. Sie sind an den Vorderfüssen mit einem Strick gefesselt, welcher an einem kurzen, in die Erde geschlagenen Pfahl angebunden ist. Hinter diesem Gehöft liegt gewöhnlich bei den Notablen und Vornehmen der Waschraum und gleichzeitig der Abort, der aus einer grossen Grube besteht, welche oben eingedeckt ist und als Sitz einen alten Topf ohne Boden hat. Von diesem Gehöft aus betritt man durch 
eine kleine runde Vorhalle ein zweites, welches sich durch seine vielen runden Hüttten von dem ersteren unterscheidet. Hier betindet sich das Domizil der Haussa-Frauen, von denen jede ihre besondere kleine Hütte hat. Zwischen dem ersten Gehöft und diesem Gehöft der Frauen liegt die Küche, welche ebenfalls aus einer runden Hütte besteht. Die Feuerstätte ist ein einfacher kleiner Lehmofen, welcher aus einem Lehmkranz besteht, auf den das Gefäss zu stehen kommt. Ein solcher Komplex ist in Kete meistens von einem grossen Mattenzaun umgeben.

Nachdem ich das Gehöft in Augenschein genommen hatte, war mein erster Gang mit Sofo und meinem Dolmetscher durch die Hauptstrassen der Stadt auf den Marktplatz. Die Handelsstadt Kete ist eine ${ }^{\text {F }}$ grosse Fremdenstadt, welche nur zu gewissen Zeiten, in welchen die Karawanen durchkommen, voll bevölkert ist. Eine halbe Stunde südlich von Kete liegt, hart am Volta, die eigentliche Eingeborenenstadt Kratyi, die Residenz des Königs Odukru und des Fetischpriesters Bossumfo. Ein schöner breiter Pfad verbindet beide Ortschaften. Während in Kratyi nur heidnische Bevölkerung wohnt, ist Kete das erste Bollwerk des Islams in diesem westlichen deutschen Sudan. In Kete wohnen fast ausschliesslich muhamedanische Fremde oder ansässige Haussa. Kete selbst liegt tief in der Niederung, etwa 20 Minuten rom Voltastrom entfernt, und kommt somit weniger in das engere Ueberschwemmungsgebiet des Flusses. Es ist ein glühend heisses Thal, da der Untergrund, auf welchem Kete steht, nur mit einer dünnen Humusschicht bedeckt ist, unter der grosse Felsen lagern und kein Baum oder Strauch die Strahlen der Sonne abhält. Die Gehöfte sind dicht nebeneinander erbaut und bilden, von Mattenzäunen umgeben, 3 bis $4 \mathrm{~m}$ breite, oft aber auch sehr enge Strassen, welche infolge des grossen Verkehrs an Reinlichkeit viel zu wünschen lassen. Kete zertällt in mehrere Teile. Im Centrum der Stadt wohnt die eigentliche Bevölkerung, welche aus eingewanderten Haussa besteht. An der Peripherie liegen die einzelnen Kolonieen der verschiedenen Stämme, welche sich hier zeitweise zum Handel oder auch auf dem Durchmarsche niederlassen. Es sind dies Leute aus Salaga, Yendi im Reiche der Dagomba, aus Sugu, Tshautsho, Borgu, ja selbst aus Cano und Bornu. Die meisten Hütten sind klein und rund, haben einen Durchmesser von 4 bis $5 \mathrm{~m}$ und sind mit einem Kegeldach versehen, dessen Spitze zur grösseren Haltbarkeit des Daches häufig ein Topf ziert. Diese Hütten sind meistens aus Lehm ausgeführt, bestehen aber auch nicht selten aus Matten. In den engen Strassen sieht man überall muhamedanische Bettler hocken, die ihre Gebrechen zur Schau tragen und auf diese Weise das mitleidige Herz der Vorübergehenden zu enveichen suchen. Sonst herrscht in dieser Handelsstadt ein reges Treiben; Kara- 
wanen kommen an, die nach den Gesichtsmarken der Leute weither aus dem Norden stammen und bepackte Esel versperren oft vollständig den Fusspfad.

Marktverkehr Wir lenken unsere Schritte nach dem. Marktplatz, welcher den in Kete. Mittelpunkt des kaufmännischen Verkehrs bildet. Rings um diesen Wertvolle Handelsartikel von einheimischen Hier werden alle Waren feilgeboten, die ein Negerherz begehren kann. und euro- Neben den europäischen Stoffen von der Küste nehmen die Produkte aus păischen Stoffen. dem Innern, grosse Haussa-Toben und Burnusse aus den Haussa-Staaten, den ersten Rang ein. Es sind häufig wertvolle Stücke, meistens von blauem oder weissem Tuch, mit weiten Aermeln und schönen Bruststickereien. Neben diesen giebt es aber auch Toben von Seide. Nicht selten ist der Preis einer solchen Tobe 40 bis 60 Schilling; einfachere sind aber schon für Io bis 30 Schilling zu haben. Ausser den einheimischen Stoffen werden auch europäische Stoffe zu den Haussa-Toben verwandt. Diese Toben sind für einen Nichtkenner kaum von den echten zu unterscheiden, nur dass ihr Preis und wahrscheinlich auch ihre Haltbarkeit bedeutend geringer ist. Ausser den Toben vervollständigen den Anzug eines Haussa ungemein weite Hosen, welche infolge der Stoffmenge ein teures Kleidungsstück sind. Auch sind phrygische Mützen von Stoff und Sammet, sowie ferner die einfachen weissen Haussa-Hemden zu haben. Häufig sieht man in diesen Buden den fleissigen HaussaSchneider sitzen, welcher an Ort und Stelle seine Kunst ausübt, meistens jedoch werden die Toben schon fertig auf den Markt gebracht. Ueberall liegen wertvolle blauseidene Ballen in den Buden, da blau die Lieblingsfarbe der Haussa .ist. Auch werden für die eingeborene Bevölkerung gedruckte englische Printstoffe von Kattun in allen möglichen Mustern und Farben feilgeboten. Gewöhnlich sind diese zu Ballen zu I2 Yards gerollt und werden hier für bis zu 6 Schilling verkauft, während sie an der Küste nur einen Preis von 3 Mark erzielen. Ausser diesen sogenannten Printstoffen giebt es aber noch haltbarere, bessere Stoffe, meistens deutsches Fabrikat, die hauptsächlich aus Lome kommen und den Stempel "Made in Germany" tragen. Auffallend stechen von diesem europäischen Fabrikat die schönen, blau und weiss gestreiften, derben Stoffe der einheimischen Industrie ab. Sie werden weither aus den Haussa-Staaten zum Verkauf und Eintausch durch Karawanen hierhergeführt. Der beliebteste Artikel in dieser Branche ist in Kete-Kratyi der Stoff, welcher im Sudan und bei den muhamedanischen Völkern zu ihrem Alltagsanzug, zu Toben und Hemden, sowie auch Hosen und Mützen, verarbeitet wird, nämlich der sogenannte englische Greybafts. In der Regel ist dieser Stoff zu 30 Yards in 
Ballen gerollt und für 7 Mark das Stück in den Faktoreien an der Küste zu kaufen. Doch hier in Kratyi steigt meistens der Preis um ein Drittel. $\mathrm{Zu}$ all diesen Stoffen treten noch die weissen und roten Musselins, aus denen der Turban hergestellt wird, welchen bei feierlichen Gelegenheiten die Notablen der muhamedanischen Welt zu tragen pflegen. Neben den Toben dekorieren die inneren Wände dieser Buden häufig die beliebten Taschentücher, welche der hier ansässigen KratyiBevölkerung, namentlich den Frauen, als Kopfschmuck dienen. Auch werden in allen Buden Blau- und Rotgarne, europäisches sowie einheimisches Fabrikat, ferner Baumwolle zum Spinnen feilgehalten. Damit sind aber noch lange nicht alle Verkaufsartikel dieses Krammarktes erschöpft. Jeder Laden umfasst neben den angeführten Toben und Tüchern auch Waffen, grosse Haussa-Schwerter mit schönen gepressten ledernen Scheiden, bunte Wehrgehänge mit roten Quasten, Speere, Griffmesser, sowie Armbänder aus Holz, Eisen und Messing.

Die Lederindustrie der Haussa kann man am besten nach den Erzeugnisse hier ausgestellten mannigfaltigen Waren beurteilen. Die schönsten und der afrikabesten Lederwaren kommen weither, meistens aus dem Innern der nischen Haussa-Staaten; so die schönen Satteltaschen, welche meistens mit LederinduLeopardenfellen oder auch mit buntem Leder verziert sind; ferner schön gedrehte Zaumzeuge und Zügel für die Haussareiter. Ueberall findet man verschiedenartig geformte Sandalen und Schuhe, welche von den Haussa auf ihren Märschen und von der einheimischen Bevölkerung in gebirgigen Gegenden getragen werden. Neben den einfachsten Sandalen aus Ziegenfell, die nur aus einer Sohle und einem Paar Lederstreifen zum Binden bestehen, sind hier die gut und fest gearbeiteten HaussaSchuhe, häufig mit dreifacher Sohle, mit schön gepresstem Oberleder in gelber, grüner und anderer Farbe für 2 bis 3 Mark zu haben. Es fehlen selbst nicht die grossen Reiterstiefeln, welche die Haussa beim Reiten anzulegen pflegen. Es sind dies aus braunem Leder gepresste Gamaschen, an denen Schuhe mit Sporen aus gezacktem Eisen befestigt sind. Grosse Taschen aus rohem Leder, die von der Schulter herabhängend getragen werden und zum Aufnehmen des Reisegeldes, der Kauris, dienen, schön gearbeitete grosse, aus Rindsfell hergestellte Tragkörbe für Esel, sowie gegerbtes Ziegenleder in roter, grüner und brauner Farbe und kunstvoll gearbeitete Zaumzeuge geben Zeugnis von der Mannigfaltigkeit und Blüte der Lederindustrie.

Messer, die man im Haushalt zum Zerschneiden des Fleisches Artikel des gebraucht, werden hier in Kete in den Schmieden hergestellt und eben- einheimischen falls auf den Markt zum Verkauf gebracht; neben diesen sieht man Schmiedeschön gearbeitete Kandaren mit langen Scheeren und Pferdegebisse. handwerkes. Auch Bassari ist mit seiner Eisenindustrie vertreten. Grosse, runde, 
geschmiedete Eisenplatten sind vorrätig, welche in den Schmieden verarbeitet oder auch bei der Feldarbeit direkt als Hacke benutzt werden, indem man sie einfach in einen Holzstiel steckt. In dieser Beziehung ist den Gebräuchen in den verschiedenen Gegenden Rechnung getragen. So finden wir neben diesen glatten runden Eisen die grossen dreizackigen Hacken, welche ebenfalls aus Bassari kommen und besonders in Atakpane allgemein verwendet werden. Der Preis für eine solche Eisenplatte beträgt hier ungetähr 25 Pfennige. Weiter sind kleine Schwerter, sowie Verteidigungsäxte aus Mossi, welche von den Leuten auf Reisen über der Schulter getragen werden, für etwa 35 Pfennige käuflich zu haben.

Einheimische Flechtwaren, Gebrauchs. und Schmuckgegenstānde.
Wertvolle Landesprodukte. Gold und Elfenbein.
Sogar europäische Rasiermesser, kleine Nadelbüchsen und europäische Nadeln, Toilettegegenstände für die schwarzen Schönen, europäische Seifen, Lavendelwasser, Graphitstifte in schönen kleinen zierlichen, aus Rindsfell gedrehten Büchschen, auch die bei den Haussa-Frauen sehr beliebte Schminke, das Henna und das Antimon, fehlen in diesen Verkaufsläden nicht. Schlafmatten aus Sugu und aus Kete, meistens von Suguleuten hergestellt, die einfachsten Grasmatten bis zu den grossen geflochtenen Matten, die als Zäune oder als Seitenwände der Hütten dienen, ferner bunte, schön geflochtene Matten, die als Rouleaux zu den Eingängen benutzt werden, kleine aus Gras geflochtene Teller und Körbchen in den verschiedensten Farben, zierlich und häufig wasserdicht gearbeitet, werden hier verkauft. Zumeist werden diese kunstvoll gearbeiteten Tellerchen in Mossi angefertigt und kommen mit MossiKarawanen herunter oder werden von den Haussa-Händlern dort aufgekauft und hier zum Verkauf gestellt. Der Preis ist für die kunstvolle Arbeit sehr gering, man bekommt schon für 50 Pfennige einen schön geflochtenen Teller. Kalabassen jeglicher Art, aus Kürbissen gearbeitet, werden zum Preise von ro bis 50 Pfennigen, auch bis zu I Mark angeboten. Aus Gras geflochtene Siebe zum Sortieren des Mehles liegen ebenfalls zum Preise von 25 Pfennige zum Verkauf aus. Ringe aus Messing, zum grossen Teil von den Dagombas gefertigt, werden für 20 Pfennige verkauft. Perlen aller Art von Glas, namentlich kleine blaue, auch schwarze und sonstige bunte Glasperlen, böhmisches Fabrikat, sowie kleine herzförmige Kolliers für Haussa-Frauen vervollständigen die Reihe der Schmuckgegenstände. Aber auch Achatperlen, sowie die beliebten blauen wertvollen einheimischen Groundbeads werden von den Reichen des Landes gekauft. Neben kleinen gedrehten Arm- und Fussringen aus Eisen und Messing giebt es auch schwere Hals- und Fussschellen für Sklaven.

Das wertvollste Produkt, welches auf den Markt von Kete gebracht wird, ist der Goldstaub. Derselbe kommt allerdings nur in geringen Mengen vor und soll weit aus dem Hinterlande von den Quellflüssen des Volta und aus dem Mossi-Gebiet stammen. Elfenbein wird weniger 
auf dem Marktplatz verhandelt, als in den Gehöften der Haussa-Händler aufgestapelt. Wunderbar sieht eine mit Elfenbein aus dem Innern kommende Karawane aus; die einzelnen Zähne sind in Matten regelrecht verpackt und werden von einem Träger, öfter aber auch wegen ihrer ungeheuren Schwere von zweien zugleich getragen. Ich sah hier häufig Exemplare, die ein Gewicht von 50 Pfund, nicht selten sogar ron jo Pfund hatten. Meistens werden die Elefantenzähne von den HaussaHändlern in Kete zur Küste getragen und in den Faktoreien verhandelt. Nicht selten jedoch werden sie schon von Küsten-Händlern in Kratyi angekauft und leider vielfach in Kanoes den Volta herunter in englisches Gebiet gebracht. Das Elfenbein, das die Mossi- und Haussa-Karawanen bringen, wird bei der Ankunft von den auswärtigen Haussa-Händlern in Kete mit Beschlag belegt und gegen andere Waren eingehandelt. Häufig wird es, wie schon erwähnt, in Kete an die Zwischenhändler in Pausch und Bogen nach Taxe oder auch nach Gewicht, wo das Pfund einen Preis von etwa 3 Mark erzielt, verkauft.

Ausser diesen wertvollen Produkten ist der Kautschuk erwähnenswert, welcher aus Adele kommt und zum Teil hier gegen Salz, Stoffe und Pulver eingetauscht wird. Neben dem Detailgeschäft findet auch ein Handel en gros statt. Diese Gummi-Engros-Geschäfte werden hauptsächlich in Kratyi selbst abgewickelt, weil die englischen Akkra-Händler ihre Salzlager aus Adda in der Nähe des Volta haben und dasselbe ohne Schwierigkeit gegen Kautschuk umtauschen und auf dem Volta nach dem englischen Küstengebiet verschiffen können. Leider geht dadurch der Gummi zum grössten Teil dem deutschen Küstengebiet verloren. Zum Glück wird indessen jetzt ein Teil unseres AdeleGummis auf dem Landwege über Boëm nach Lome heruntergeführt. Hauptsächlich vermitteln dieses Geschäft in der letzten Zeit die EvheHändler und besonders die Träger aus Agome.

Ein nicht zu unterschätzender Artikel auf dem Markt in Kratyi sind die Rinds-, Schaf- und Ziegenfelle, welche zum Teil aus Mossi, zum Teil aus den Haussa-Ländern kommen. Diesen reihen sich noch Leopardenfelle, sowie die Felle von Affen und Wildkatzen an. Ferner werden, wenn auch in geringeren Mengen, Straussenfedern, vereinzelt auch junge lebende Strausse von den Karawanen nach Kete auf den Markt gebracht.

Ueberall liegen am Markt in grossen Haufen die sogenannten Road- Europäische brass, die beliebten Messingstangen, welche ein Hauptartikel in den Hinterländern sind. Sie werden in den einheimischen Schmieden zu den Messingwaren mannigfaltigsten Schmuckgegenständen, zu Finger-, Arm- und Fussringen, häufig auch zu Ringen an den Zehen verarbeitet und nicht selten sieht man eine schwarze Dame, die neben ihrem knapp handbreiten Schamtuch über und über an Arm- und Fussgelenken mit dem blank geputzten 
Messingschmucke beladen ist. Einer der beliebtesten Handelsartikel in muhamedanischen Gegenden, der in keinem wohlhabenden Hausstand fehlen darf, sind die grossen schönen Messingschalen, welche aus Europa kommen und bis in das Innere von Afrika verhandelt werden. Diese Messingschüsseln dienen, wie auch die Kürbisschalen, zum Aufbewahren von allerhand Lebensmitteln und Vorräten.

Waffen und Auch findet man hier überall neben den Schwertern und DolchPulver. messern die grossen schwerfälligen Daneguns, welche die begehrenswerteste Waffe der heidnischen Bevölkerung bilden. In langen Reihen sieht man häufig kleine Pulverfässer aufgestapelt. Sie enthalten meistens das grobkörnige Negerpulver, welches ein ganz hervorragender und begehrenswerter Tauschartikel in Afrika ist.

Alkohol. Ebenso gross wie der Umsatz in Pulver und Gewehren ist die Nachfrage der heidnischen Bevölkerung nach dem so sehr beliebten Alkohol. In grossen viereckigen verlöteten Blechbüchsen ist hier der Fusel ausgestellt. Derselbe wird im Detailhandel zu unerhörten Preisen in vierkantigen kleinen gepressten Glasflaschen zum Kaufe angeboten. Für den Schnaps opfert der Neger alles; obwohl er Palmwein sowie verschiedene Hirsebiere selbst herstellt, so ist doch der höchste aller seiner Genüsse der verderbliche Fusel. Selbst der Muhamedaner, der Haussa, widersteht in seiner Hütte, wo er sich unbeobachtet weiss, dem Schnapsteufel nicht; öffentlich dagegen enthält er sich jeglichen Genusses von Alkohol. - Auf dem Markte sind ferner grosse und kleine Trommeln, das Hauptmusikinstrument aller afrikanischen Völker, verkäuflich.

Gemüse- und Wir haben uns nun glücklich durch die feilschenden Gruppen von Fruchthandel einer Bude zur andern gedrängt und betrachten die Mitte des Marktes, wo sich der eigentliche Produktenhandel und Grünzeugmarkt des Landes befindet. Die schwarzen Hökerweiber sitzen vor ihren Kalabassen und Matten, auf denen sie Yams, Reis und Hirse ausgebreitet haben und machen sich durch ihr Gekreisch bemerkbar. Häufig haben sie Matten aufgestellt, um sich und ihre Waren vor den glühenden Sonnenstrahlen zu schützen. Ueberall werden von den Hökerweibern die sogenannten Leims, kleine Limonen, Ananas, Papaya, die Früchte des Melonenbaumes, aber auch Brennholz, geröstete und ungeröstete Erdnüsse und Maiskörner, Erđerbsen, Zwiebeln, Tomaten, Suppenkräuter, Maismehl, Schibutter in Zuckerhutform, zum Schutz gegen die Sonne mit Blättern umwunden, u. s. w. feilgehalten.

Narkotische Auch für den narkotischen Genuss ist gesorgt. Man sięht hier Genüsse Tabak, welcher von der Küste hergebracht wird, in Strähnchen liegen, und Gewürze. sowie den in kleine Päckchen gerollten einheimischen Tabak; daneben liegt in Körben mit Blättern verpackt, das beliebteste Erfrischungsmittel 
der Haussa, die Kolanuss, sowie andere Gewürze. Salz ist in kleinen Haufen auf Matten ausgebreitet; ausserdem sieht man Tamarinde sowie Blätter und Kräuter zur Bereitung der beliebten Kräutersaucen.

Auch einheimische Seife, die zu schwarzen kleinen Kugeln geformt ist, kommt auf den Produktenmarkt. Die Seife wird aus Bananenasche, Schibutter oder Palmöl grewöhnlich von Frauen im Haushalt selbst hergestellt. Neben diesen Seifen liegen häufig die ebenfalls in kleinen Kugeln zusammengeballten Indigofasern, zur Herstellung der beliebten blauen Farbe der Haussa.

Zucker ist bei den Negern ein sehr beliebter Artikel. Obwohl wilder Honig, wie auch das Zuckerrohr einen Ersatz bieten, wird der europäische Zucker allem anderen vorgezogen. Er wird hier in kleinen Würfelstücken Genuss- und Nahrungsverkauft und zwar häufig das Stück zu dem unerhörten Preise von $5{ }^{\circ} \mathrm{Pfg}$. Aber er kommt auch in kleinen Paketen auf den Markt und ist dann im Engros-Geschäft verhältnismässig billiger als bei stückweisem Verkauf.

An allen Strassen und Ecken und auf dem Markte sitzen die Weiber, welche fertige Speisen feilbieten. So ist allerhand $z u$ haben, namentlich des Morgens die rotbraune dickflüssige Hirsesuppe, welche aus den roten Rispen der Hirse, mit Wasser gekocht, hergestellt wird. Sie hat einen angenehmen säuerlichen Geschmack und vertritt gewissermaassen die bei uns beliebten Mehlsuppen. Ueberall wird sie mit dem Rufe: „Kaffa, Kaffa" ausgeboten. Dazu kommen gekochter Yams, geröstete und un-

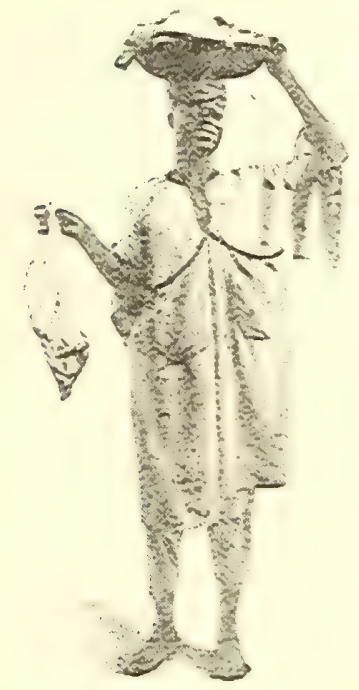

Ein Haussafleischer. geröstete Erdnüsse, Honigbier, ungepfefferter Reis und gepfefferte Oel-, Hirse- und Bohnenkuchen. Die in Schibutter oder Palmöl gebackenen Kuchen schmecken nicht übel, jedoch sind sie für einen europäischen Gaumen zu stark gepfeffert und auch schwer verdaulich.

Auf der westlichen Seite des Platzes hat Fleischmarkt sich der Fleischmarkt niedergelassen, der sich durch einen nicht gerade angenehmen Geruch schon von weitem bemerkbar macht. Meistens wird das einträgliche Fleischerhandwerk von den Haussa betrieben. Würdig übersieht der Chiefbutcher oder Serkipower, wie ihn die Haussa nennen, sein Bereich. Auf grossen, auf der Erde ausgebreiteten Matten liegt in grossen und kleinen Portionen Schaf-, Ziegen- und Ochsenfleisch, das aber von Millionen von Fliegen bis zur Unkenntlichkeit besäet ist. Feine Scheiben, die an der Sonne gedörrt sind oder kleinere Fleischstücke, die auf langen Holzspiessen über dem Feuer geröstet werden, dienen zum sofortigen Genuss. Die 
ausgespannten Felle der geschlachteten Tiere liegen zum Trocknen daneben; Klauen, Hörner, Köpfe und Knochen werden gieichfalls verwertet. Auf den Dächern der umliegenden Hütten sitzen die gierigen Kappengeier, wie bei uns die Krähen, und recken ihre langen, nackten Hälse spähend nach dem Abfall.

Marktbilder und Scenen

Nicht selten hat sich auf dem. Markte eine kleine Musikbande niedergelassen, welche das Gewirr und den Tumult durch den eintönigen Trommelschlag noch bedeutend steigert. Die meisten Buden und grösseren Verkaufsstellen sind von Haussa-Händlern besetzt, während die Höker und Grünzeugweiber mehr der einheimischen Bevölkerung angehören. Dieses bunte Durcheinander verleiht dem Negermarkt einen eigentümlichen Reiz. Die schlanken Gestalten der Haussa heben sich vorteilhaft von dem Gewühl der Eingeborenen ab. Langsam und würdig durchschreiten sie, in schöne weisse oder blaue Burnusse und Toben gehüllt, auf dem Kopf den hochumwundenen Turban oder Fez, die feilschende und schreiende Menge. Hier sieht man ärmliche alte Weiber, denen nur ein kümmerlicher Schurz die Scham bedeckt, mit Feuerholz sitzen, während daneben eine Haussafrau, in schöne blaue Tücher gekleidet, ebenfalls ihre Waren feilbietet. Dralle Mädchen kokettieren mit jungen Burschen und tragen, in grelle rote Tücher gehüllt, Arme und Füsse mit Messingringen geschmückt, alle Reize ihrer Jugend zur Schau. Mossiträger und Dagomba in anliegenden weiss und blau gestreiften Taillenhemden, sowie Kratyileute mit einem dürftigen Schamschurz, die Lasten auf dem Kopfe tragend, wimmeln durcheinander. Hoch über diesem bunten Getümmel weht heute in der Mitte des Marktes, Achtung gebietend und Schutz verkündend, die schwarz-weiss-rote deutsche Flagge. Bevor hier diese Flagge wehte, wurden auf dem Markte von den Fremden und Marktbesuchern willkürlich Tribut und Abgaben seitens des allmächtigen Fetischpriesters des Dente erhoben. Seine Sklaven forderten einfach von den Händlern einen Teil ihrer Verkaufsgegenstände und falls sie diese nicht freiwillig hergaben, wurden sie ihnen gewaltsam genommen und die Eigentümer noch körperlich misshandelt. Den Hökerweibern wurden, falls sie dem Verlangen nicht nachkamen, ihre Körbe umgeworfen, so dass die Ware verdarb. Heute ist es mit dieser willkürlichen Herrschaft vorbei und jeder fremde Ankömmling, der die Flagge von weitem über die Tausende von Hütten flattern sieht, weiss, dass sie für seine persönliche Freiheit und seinen Schutz bürgt und begrüsst sie schon deshalb aus der Ferne mit Freuden.

Viehmarkt. Nordwestlich von diesem Markte, dicht an der alten Moschee, unter den Schattenbäumen, befindet sich der Viehmarkt. Neben den kleinen Rindern, die aus Sugu und Borgu herunterkommen, stehen die grossen 
grauen Buckelrinder der Mossi zum Verkauf, dancben betinden sich Ziegen und Schafe; von letzteren sind die grossen hochbeinigen Salagaschafe, sowie die mittelgrossen zottigen Landschafe mit den typischen Halsklunkern vertreten. Trotz der Masse von Vieh, die hier zum Markte kommt, übersteigt die Nachfrage das Angebot. Denn allein in Kete werden täglich Io bis 15 Rinder geschlachtet, um den Bedarf der etwa 8000 muhamedanischen Einwohner zu decken. Ausserdem geht abcr noch häufig Vieh zur Küste herunter. Auf diesem Viehmarkt, der sich, wie der Fleischmarkt, keiner besonderen Reinlichkeit erfreut, sind auch Matten und Flechtwerke aus Gras zum Kaufe ausgestellt.

Häufig sitzen in den Strassen der Stadt Mattenflechter bei der Arbeit, sowie auch Haussa oder Mossileute, welche geschickt auf dem primitiven Webestuhl die gestreiften Zeuge herstellen. An den Strassenecken halten sich fliegende Barbiere auf, welche auf Kunden warten und Das Handwerk und Geverbe auf den in einer Ledertasche ihr ganzes Handwerkszeug bergen. Die Geschicklichkeit dieser schwarzen Barbiere steht der unserer europäischen wenig nach, da die Eingeborenen nicht selten grosse Ansprüche an sie stellen. Die Frisuren sind häufig kompliziert und bilden wahre Muster auf ihrem Schädel. Eine der häufigsten Frisuren der heidnischen Bevölkerung: besteht aus drei bis. vier Tollen, welche stehen bleiben, während die Zwischenräume ausrasiert sind. Die Muhamedaner dagegen rasieren ihr Haupthaar glatt, wie es ihre Sitte vorschreibt. Ausser dem geschilderten grossen Markte befinden sich noch im Norden der Stadt kleine Viktualienmärkte, die meistens dann frequentiert werden, wenn der grosse Grünzeugmarkt nachmittags geschlossen ist und nur die Verkaufshallen und grössere Geschäftsstellen geöffnet bleiben.

Die eigentliche Scheidemünze auf dem Markt sind die Kaurimuscheln, wovon hier ungefähr 2000 Stück für eine Mark zu haben sind, während an der Küste 4 ooo Stück den Wert einer Mark repräsentieren. Natürlich Geldverkehr. haben sich auch in dieser Beziehung die Verhältnisse gegen früher geändert; so war es erstaunlich, wie mit Anlegung der Station das deutsche Geld in Aufnahme kam. Im Jahre .1894, auf meiner geschilderten Reise nach Salaga, wurde deutsches Geld überhaupt nicht angenommen. Es gelang mir mit Mühe und Not, dasselbe bei einem reichen HaussaHändler umzuwechseln und ich erhielt damals für eine deutsche Mark nur neun Pence oder nach unserem Gelde fünfundsiebenzig Pfennige. Im Jahre I 897 dagegen war fast das umgekehrte Verhältnis eingetreten, indem eine deutsche Mark, namentlich in Fünfpfennig-Stücken fast einen Schilling und drei Pence wert war. Damals beherrschten nur englische Händler von der Küste den Markt, während heute auch Händler aus unseren deutschen Gebieten und schwarze Agenten aus den Faktoreien von Lome den Markt besuchen. Mit der Anlegung der Station hat sich 
in kurzer Zeit die deutsche Münze eingebürgert und neben dem englischen Sixpence und dem Schilling ist unsere deutsche Mark, das FünfzigpfennigStück und der sogenannte Copper, unser deutsches Fünfpfennig-Stück, die Lieblingsmünze geworden. So wird häufig schon der Wert auf dem Markte nach diesem Fünfpfennig-Stück berechnet. Oft hört man bei einer Frage nach dem Preise die Antwort: „Five copper, Ten copper, Twenty copper". In einer sehr einfachen Art wird mitunter von den grossen Händlern bei dem Abschluss eines Geschäfts verfahren. Die geforderte Summe, die in Kaurimuscheln nicht selten ein grosses Gewicht ausmacht, gelangt nicht gleich zur vollen Auszahlung, sondern das Geschäft wird im Wege der Diskontierung erledigt, indem der Verkäufer eines Ochsen die Summe bei dem Käufer stehen lässt und dann beim weiteren Einkaut von Kolanüssen sein Guthaben dem Verkäufer der letzteren überweist. Aus dieser Schilderung des Marktes und des Verkehrs geht deutlich hervor, dass Kete ein Haupt-Stapel- und Sammelplatz für alle Karawanen und Erzeugnisse unseres Hinterlandes und des Nigerbogens geworden ist. Mit dem Niedergange von Salaga hat sich Kete noch bedeutend gehoben, weil es gewissermaassen an die Stelle des eingegangenen grossẹn Marktplatzes von Salaga getreten ist.

Verdeckter Sklavenhandel.

Handelsvertreter aus dem Hinterlande.

Wenn auch vor allem die Erzeugnisse des Landes und der Eintausch derselben gegen europäische Waren in Betracht kommen und nicht, wie in Salaga, die Sklaven die Hauptware auf dem Markte bilden, so ist es doch trotz aller Verbote und Maassnahmen nicht möglich, den heimlichen Handel mit Menschen vollkommen zu unterdrücken. Selbstredend werden die Sklaven ängstlich den Blicken der Weissen entzogen, aber die verschiedenen Stammesmarken bei den häufig jugendlichen Trägern, Mädchen und Knaben, weisen darauf hin, dass sie von den Karawanen als Sklaven mitgeführt werden. Mitunter sind diese Sklaven, welche nach Haussaart frisiert gehen und auch das Haussahemd tragen, in den langen Trägerkolonnen kaum von den Haussa zu unterscheiden. Fern von der Heimat und eingeschüchtert von ihren Herren, geben sie keinen Aufschluss über ihr Los; auch wenn sie frei herumlaufen und ihre Arbeit verrichten, erfährt man wenig über das Schicksal dieser Fremdlinge. Meistens heisst es, dass sie von einem Freunde den Haussa oder Karawanen mitgegeben worden seien, um Salz oder andere Produkte nach ihrer Heimat zu bringen.

Was die Stadt Kete anbetrifft, so haben wir gesehen, dass sie, wie früher Salaga, einen grossen Fremdenverkehr hat. Zur Regenzeit aber ist sie weniger besucht, denn die Karawanen aus Mossi, den HaussaStaaten und anderen Ländern sind dann schon schwer beladen in ihre Heimat zurückgekehrt, um zur Trockenzeit mit neuer Zufuhr zu erscheinen. Nur einzelne Agenten und Vertreter der Kolonieen sind zurückgeblieben, um während der Regenzeit Waren aufzukaufen und die Geschäfte für ihre 
[ andsleute auszukundschaften. So hat, gewissermaassen als Abgesandte des Königs der Dagomba, eine Prinzessin aus Yendi in Kete ihr Hoflager aufgeschlagen. Auch die Mussi und andere Kolonisten aus den verschiedensten Landschaften sind vertreten.

Zwei Moscheen dienen der Haussa-Kolonie, sowie den übrigen Der Islam in Muhamedanern als Grotteshäuser. Jeden Freitag sieht man die ganze Kete muhamedanische Bevölkerung in neuen weissen Burnussen und Turbanen zu den Moscheen wallfahren, vor welchen häufig Bettler sitzen und Frömmigkeit heucheln, um auf diese Weise, namentlich an den Freitagen, den Festtagen der Muhamedaner, Almosen zu erlangen. Hin und wieder durchreist auch ein frommer Mekkapilger diese muhamedanischen Kolonien, wo er als solcher von seinen Glaubensgenossen während seines Aufenthaltes als Gast gut aufgenommen und verpflegt wird. Diese Pilger sind leicht an ihrem lang herabhängenden Haar kenntlich, welches sie der Sitte gemäss während ihrer ganzen Mekkafahrt als Erkennungszeichen wachsen lassen. Die grössere und ältere Moschee liegt nahe dem Markte und ist ein viereckiges, aus Lehm errichtetes Gebäude mit einem hohen Giebeldach aus Gras. Für die Priester ist aus Lehm eine Art Kanzel hergerichtet. In neuerer Zeit jedoch hat Sofo gewissermaassen zum Lobe Allahs eine neue Moschee gebaut, die kleiner, aber viel schöner und interessanter als die alte zerfallene ist. Sie hat gleichfalls Lehmmauern, in denen oben kleine Oeffnungen angebracht sind, welche das Licht hereinlassen. Das Dach ist platt, auf einer kleinen Lehmtreppe kann man auf dasselbe gelangen und hat von hier aus einen schönen Ausblick auf das aus mehr als 2000 Hütten bestehende Kete. Im Innern ist diese Moschee ebenfalls mit einer Art Lehmkanzel versehen, welche am Ende des Hauptschiffs gelegen ist, während sich an den Seiten, durch Lehmmauern getrennt, kleine Nischen für die einzelnen Gläubigen befinden.

Im übrigen besteht die Stadt aus kleinen winkligen Strassen, an Bauart und denen sich die Gehöfte mit ihren meistens in runder Form mit Kegeldach erbauten Hütten entlang ziehen. Vor den Hütten befinden sich zum Teil die grossen, mit Giebeldach versehenen viereckigen Hallen der Vornehmen. Wie in jeder muhamedanischen Stadt herrscht in den Strassen und auf den Plätzen ein ekelerregender Schmutz, da kein Mensch daran denkt, die dem allgemeinen Verkehr dienenden Strassen zu säubern. $Z \mathrm{u}$ diesem Schmutz gesellen sich noch mit dem Einzug der Karawanen die Pocken, welche sich hier ab und zu einnisten, so dass man gerade in Kete auf den grossen Marktplätzen vielen pockennarbigen Gesichtern begegnet. Die einzige Sanitätspolizei, welche sich dieser vor Schmutz starrenden Strassen erbarmt, nimmt, wie in allen grossen Städten, die Reinigung in der Nacht vor. Wenn die geschäftigen Kaufleute ihre Buden geschlossen und die Bewohner sich in ihre Hütten

sanitäre Verbältnisse

Sanitătspolizei. 
zurückgezogen haben, dann rücken die Reinigungskolonnen in Gestalt von gefleckten Hyänen und Schakalen an, um wenigstens die gröbsten Ueberreste zu vertilgen. Ausser dieser Beute fällt ihnen nicht selten der Kadaver eines gefallenen Esels oder Pferdes zu, welchen die Bewohner einfach auf die Steinfelsen bei der Stadt tragen und den nächtlichen Aastieren überlassen. Was im übrigen die sanitäre Lage von Kete-Kratyi anbetrifft, so ist sie durchaus unbefriedigend, einerseits wegen der hohen Temperatur in der schattenlosen Volta-Ebene, andererseits deshalb, weil das Ueberschwemmungsgebiet des Volta fast bis an den westlichen Teil der Stadt Kete heranreicht. Schädlich wirken namentlich die beim Fallen des Volta nach der Regenzeit zurück-bleibenden Sümpfe, welche bei der brennenden Sonnenglut Miasmen ausströmen und den Keim zu Malaria-Erkrankungen legen.

Geo-

graphische Lage von

Kete und die

Erweiterung der Verkehrs.

mittel.

In geographischer Hinsicht dagegen ist Kete für einen grossen Handelsplatz sehr geeignet, da es an den grossen Karawanenstrassen aus dem Innern zur Küste und in unmittelbarer Nähe des Voltastroms liegt, dessen Hauptquellflüsse sich nördlich von Kete vereinigen. Der dadurch ermöglichte Verkehr auf Kanoes aus dem Innern, besonders von Kratyi ab, erleichert und fördert bedeutend den Handel. Bis Kratyi herauf kommen sogar bei Hochwasser Dampfschiffe von der Küste mit Salz und anderen Gütern, welche hier gewissermaassen die Speicher für die Handelsstadt Kete fúllen. Trotz dieser günstigen Verhältnisse und obwohl uns leider die Wasserstrasse des Voltastromes zur Küste nicht gehört, so ist doch nicht zu verkennen, dass Kete erst durch die deutsche Schutzherrschaft und mit dem Niedergange von Salaga zum Centralpunkt des Handels sich emporgeschwungen hat. Um uns die Produkte des Hinterlandes auch für die Zukunft zu sichern und nutzbar zu machen, wird der Bau einer Eisenbahn bis zur Küste unabweislich notwendig sein. Der Volta versorgt fast I oooo Seelen, die umliegenden Farmen und Ortschaften eingerechnet, mit nach afrikanischen Verhältnissen immerhin gutem Trinkwasser. So leidet wenigstens Kete nie an Wassermangel, wie dies in Salaga der Fall war, wo die Eingeborenen genötigt waren, Cisternen zu bauen und sich mit dem schmutzigen Wasser derselben zu begnügen. Auch ist für die Eingeborenen und

Der Bade- Reisenden ein schöner und grosser Badeplatz vorhanden, wo sich in den und Wasser- Morgen- und Abendstunden ein buntes Treiben entwickelt. In langen platz in Kete. Kolonnen wandern Frauen, Mädchen und Sklaven im Gänsemarsch, alle mit grossen Kalabassen und Kürbisschalen auf dem Kopf, zu dem Wasser. Auch Knaben und Männer finden sich ein. Es ist gewissermaassen ein internationales Bad, denn viele Völkerstämme: Mossi-, Yoruba-, Grussi-, Haussa-, Kratyi-Leute treffen hier zusammen und Männer und Frauen baden einträchtig mit einander. Neben den Menschen, die sich hier lustig in den 
Fluten tummeln, nehmen auch die Tiere an den Wohlthaten des Badens teil; Pferde, Schafe und Esel werden zur Schwemme und Tränke gebracht. Hier hat eine fürsorgliche Mutter ihren kleinen, Zeter und Mordio schreienden Bengel eingeseift, was den Spott und das Gelächter seiner älteren Kameraden hervorruft; dort sieht man die Weiber emsig beschäftigt, die in grossen Kalabassen mitgeführte Wäsche in den Fluten des Volta zu spülen. Von dem erhöhten Ufer übersieht man den gelblichen Strom, den ein dichter und schöner Urwald, besonders auf dem westlichen Ufer, einrahmt. Die hohen Bäume spiegeln sich im Wasser wieder und in dem Gebüsch entfaltet sich ein reges Leben von Strandläufern und Eisvögeln, während Affen ihr munteres Spiel in den Wipfeln treiben. Grosse beladene Kanoes kommen den Volta herunter; Fischer ziehen mit ihren kleinen Fahrzeugen und Netzen am Ufer entlang. Aber auch dieses lustige Treiben wird nicht selten durch ein herannahendes Krokodil gestört, welches mitunter unerbittlich sein Opfer in die Tiefe hinabzieht. So habe ich, als ich später auf der Station Kete-Kratyi stationiert war, ein Krokodil geschossen, welches, nachdem es einen allzurorwitzigen Haussa weggeschnappt hatte, mit grosser Dreistigkeit die Badestelle gesperrt hielt. Da das Baden unter diesen Umständen nicht möglich war, baten mich die Leute, sie von dem Untier zu erlösen. Ich entsprach gern ihrem Wunsche und stellte mich an der bezeichneten Stelle auf den Anstand, wo ich es leider an dem ersten Abend zweimal fehlte; am nächsten Morgen jedoch erreichte die Kugel ihr Ziel und zerschmetterte dem Saurier die Schädeldecke. Sofort überschlug sich das Tier und zeigte seine weisse Bauchdecke. Nur durch einen Kopfschuss ist dem Krokodil beizukommen, sein Leben ist so zäh, dass es durch keinen anderen Schuss, selbst mit dem Modell 88, getötet wird. Auch wenn es tötlich verwundet ist, hat es immer noch Kraft, auf den Grund zu gehen und sich dort festzubeissen. Im Triumph wurde der böse Feind mittelst Kanoes ans Land gebracht und später mit grossem Behagen von den Leuten der Station verspeist. Ich reservierte mir der Wissenschaft wegen ein Rippenstück und liess es auf verschiedene Weise von dem Stationskoch zubereiten. Das Fleisch hat leider einen unangenehmen Moschusgeschmack, sonst hat es Aehnlichkeit mit dem unseres Stockfisches. Die im oberen Volta am häufigsten vorkommende Species scheint nach meinen Beobachtungen die grüne spitzmäulige Art zu sein.

\section{DIE KÖNIGS- UND FETISCHSTADT KRATYI.}

Nachdem wir die grosse Fremdenstadt Kete kennen gelernt haben, begeben wir uns nach dem nahe gelegenen Kratyi, der Residenz des Königs Odukru und des mächtigen Fetischpriesters des Dente, Bosumfo 
genannt. Ein schöner, breit ausgetretener Pfad führt etwa eine halbe Stunde südlich über eine kleine Erderhebung nach dem hart am Voltaufer gelegenen Kratyi. Schon von weitem sieht man den grossen heiligen Fetischhain, von welchem dieser geheimnisvolle Ort eingefasst ist. Geradezu malerisch schön ist die Lage dieses Platzes. Der grosse Hain spendet dem etwa 400 Hütten zählenden Orte seinen Schatten, während auf der anderen Seite sich der Volta in Stromschnellen über die Felsblöcke ergiesst. Hoch türmen sich unterhalb der Schnellen und des Wasserfalles, dicht bei Kratyi, die Felsen auf und gebieten wie Scylla und Charybdis den Schiffern ein kategorisches Halt; es müssen deshalb alle Lasten der Kanoes an dieser Stelle ausgeladen und im Falle eines Weitertransports auf dem Strome oberhalb der Schnellen bei dem Wasserplatz von Kete wieder verladen werden. Hier wird auch von dem König von Kratyi eine Fähre unterhalten, welche die Karawanen mit Vieh, namentlich mit Schafen, auf das jenseitige englische Ufer der Aschanti hinüberbringt. Die Karawanen, welche meistens aus Haussas bestehen, führen massenhaft Schafe in die Kolagegenden zum Eintausch gegen die Kolanuss, welche sie auf demselben Wege über Kratyi zurückbringen. Vor der Stadt wird meistens Halt gemacht, da der Fetisch den Aufenthalt von Pferden oder Eseln in seinen heiligen Mauern verbietet. Die Haussa steigen vom Pferde und legen zu Fuss den Weg zum Könige oder zu einem der Händler zurück. Eng aneinander gedrängt stehen die kleinen runden Hütten wie angeklebt auf dem Fels. Gleich am nördlichen Ausgange der Stadt hat der König sein Hoflager in einem kleinen Gehöft, welches aus kümmerlichen Lehmhütten besteht, aufgeschlagen; daneben liegt das Gehöft des mächtigen Oberpriesters. Einige grosse Boababbäume stehen im Süden der Stadt auf einem freien Platze. Hier fanden die gefürchteten Gottesurteile und mit ihnen die vielen Giftmorde statt, welche sich der mächtige Priester und seine Gehilfen zu Schulden kommen liessen. Nahe an den Ufern des Volta liegen die grossen Salzlager und Speicher der Akkrahändler, bestehend aus kleinen runden Hütten, die bis oben an das Kegeldach mit Säcken angefüllt sind, in denen je zu einer Last das kostbare Addasalz verpackt ist. Die ganze Stadt macht einen eigentümlichen Eindruck; die fanatischen Kratyileute stehen ganz unter dem Einfluss des Fetisch und betrachten jeden Fremden als Eindringling. Ihr Blick ist scheu und unstät und die fahlschwarze Hautfarbe des nur durftig bekleideten Körpers, sowie die prognatische Gesichtsbildung wirken abstossend.

Der Fetisch- Einen komischen Anblick gewährt die Fütterung der grossen gott Odente. Paviane und Affen, welche hier als heilig gelten, weil sie den heiligen Hain bewohnen; sie scheinen auf ganz vertrautem Fusse mit den Eingeborenen zu stehen. Ueberall auf den Plätzen und in der Nähe der 
Hütten werden um die Mittagszeit Kalabassen und Thonschalen mit Yams aufgestellt, um die zahlreichen zur Mahlzeit erscheinenden Affen zu füttern. Grosse und kleine Affen speisen gemeinsam und ganze Affenfamilien, Vater, Mutter und Kind, sitzen possierlich um eine Schüssel herum, ohne sich bei ihrer Arbeit stören zu lassen. In dieser seltsamen Stadt sieht man nur wenig Vieh, denn ausser einigen Hunden und Schafen ist dem armen Volke das Halten von Vieh von dem Fetisçh verboten. Namentlich die weissen Schafe werden zu Opferzwecken verwendet und dem mächtigen Fetisch Odente bei den Festen dargebracht. Da Odente Ziegen hasst, so ist auch den Anhängern des Kratyi-Fetisch das Gelübde auferlegt, kein Ziegenfleisch zu geniessen; ebenso soll jeder dem Tode verfallen sein, welcher in den Kot dieser vom Fetisch verdammten Tiere tritt.*) Neben den Ziegen sind dem Odente, wie wir vorher gesehen haben, auch Pferde und Esel verhasst; deshalb ist ausserhalb von Kratyi ein besonderer Weg für Karawanen mit solchen Tieren angelegt worden. Da die Kratyileute und ihr König sich das einträgliche Geschäft mit der Fähre nicht entgehen lassen, andererseits aber dem Gebote ihres grossen Fetischgottes nachkommen wollten, so musste dieser Ausweg gefunden werden. Der König hat wenig Macht und ist ganz ron dem Oberpriester und dessen Launen abhängig. Das Kratyivolk steht wie alle fanatischen Heidenvölker vollkommen unter Die Willkürdem Einfluss der Fetischpriester und muss die von ihm geforderten herrschaft der Abgaben unweigerlich leisten. So werden in Kratyi die Hühner Fetischeigentlich nur zu Opferzwecken gehalten, weil dies der Fetisch gebietet. priester. Natürlich müssen die Leute bei jeder Gelegenheit grössere Tribute zahlen und für die Fetischpriester Schafe, ja selbst Stiere zum Opfer bringen. Was die Furcht vor den Götzen bei solchen Naturvölkern vermag, sehen wir daraus, dass sie dem Götzen Odente auf sein Verlangen selbst Menschen zum Opfer bringen. Aber auch noch andere Gebräuche sind den Leuten von dem Fetischpriester vorgeschrieben. So darf kein Mensch den Ort, wo dieser Fetisch herrscht, im Dunkeln mit Licht passieren, damit der Geist des Fetisch, welcher in der Nacht über diese Orte dahin schweben soll, nicht in seiner Ruhe gestört wird. Am Tage soll der grosse Fetisch seinen Wohnsitz in einer Felsenhöhle haben, welche dicht am Volta in dem geheiligten Haine liegt. In diesem Hain ist alles heilig, nicht nur die Affen, wie wir schon bemerkt haben, sondern auch alle anderen Tiere und kein Jäger darf es wagen, hier ein Tier zu erlegen, wenn ihm sein Leben lieb ist. Als ein nichtsahnender Händler einst einen Affen in diesem heiligen Hain tötete ${ }_{5}$ sollen die Kratyileute den Leichnam des Tieres gerade wie den eines Menschen

*) Nach Rottmann. 
Verbreitung des Odentefetisch und seine Opfer stätten

begraben und ihm eine Totenfeier mit dem bei Menschen üblichen Schiessen bereitet haben. Der Händler selbst war zu seinem Glück schleunigst entflohen. Natürlich war der Ort Kratyi von Fremden gefürchtet, weil sie in jeder Weise der Willkür dieses fanatischen Volkes und der Fetischpriester ausgesetzt waren. Wenn ein Fremder den Hain passierte und nur irgend einen Ast oder Zweig knickte, so wurde er unweigerlich vơr Bosumfo in Kratyi geführt, um sich wegen dieses Gottesfrevels zu verantworten. Dies war für den Fetischpriester eine gute Gelegenheit, einen möglichst hohen Gewinn herauszuschlagen und der Betreffende musste froh sein, wenn er sich durch Auslieferung seiner Waren Leben und Freiheit erkaufen konnte. Ein besonderer Vertrauter des Fetischpriesters war ein früherer Grussisklave Okla, welcher gewissermaassen das Amt des obersten Exekutivbeamten dieses grausamen Herrschers bekleidete. Derselbe erhob häufig eigenmächtig Tribut in den vielen Fetischdörfern, welche alle von Sklaven des Oberpriesters bevölkert waren und direkt unter diesem, nicht unter der Herrschaft des Königs standen. Oefters sollen auf einsamen Pfaden kleineKarawanen von Okla und seinen Helfershelfern überfallen worden sein; die Waren wurden ihnen abgenommen und wer sich wehrte, wurde niedergeschlagen, während Kinder und Frauen als Sklaven in irgend ein Fetischdorf gebracht wurden.

Die Herrschaft dieses Fetisch reicht auf dem linken Voltaufer von Akroxa bis zum Daka, während sie sich auf dem rechten Voltaufer bis Akwapim, dem Ausgangspunkt des Fetischkultus, nahe der Goldküste erstrecken soll. In allen diesen Dörfern und Ortschaften sieht man die Altäre dieses Götzen, bestehend aus einem stumpfen, etwa $2 \mathrm{~m}$ hohen Erdkegel, zu welchem meistens einige Stufen führen. Auf dem Erdkegel steht gewöhnlich eine Schale, in der nicht selten Gin oder Rum geopfert wird; der Kegel selbst ist mit weisser Farbe besprengt, mit dem Blut von Opfertieren beschmiert und mit den weissen Federn geopferter Hühner beklebt. Auch werden Knochen von geopferten Schafen vor dem Kegel niedergelegt. Ueber ihm befindet sich ein Schattendach aus Gras, welches die geheiligte Stätte vor den Unbilden der Witterung schützen soll. Diese Ausstattung giebt der Opferstätte ein grausiges und geheimnisvolles Aussehen. Wird ein solcher Fetisch in einem Dorfe neu errichtet, so kommen die Leute sehr häufig von weit her nach Kratyi, dem Sitz des Götzen, um von dem Fetischpriester gegen einen hohen Preis geweihte Erde in Empfang zu nehmen. Natürlich verbreiten die Priester den Glauben, dass diese Opferstätten dem grossen Odente besonders angenehm sind, und schreiben ihnen auch besondere Wirkungen zu. Bevor der Bau auf dem dazu für würdig befundenen Platze errichtet wird, soll unter dem Fundament desselben als Opfer für Odente Menschenblut geflossen sein und der Leichnam des Opfers vergraben werden. 
Die herbeigeschaffte Erde wird mit dem Blut des Opfers und mit Lehm geknetet und auf diesem Fundament der eigentliche Opferaltar errichtet. In Ermangelung eines Menschen sollen sich die Priester aber auch, wie mir erzählt worden ist, mit dem Opfer eines Ochsen oder Schafes begnügen.

Ausser dem Oberpriester und seinen Priestern gchören noch zu Verhängnis. dem Orden die sogenannten Wahrsager und Wahrsagerinnen, welche rolle Folgen wiederum von Sklaven und kleinen Mädchen in ihren priesterlichen der WegFunktionen unterstützt werden. Auf meinem Rückmarsch geschah es in nahme eines dem kleinen Fetischdorfe Dadiase, dass meine Leute, als ich am Fieber krank darnieder lag, für mich ein Huhn fingen, weil ihnen freiwillig nichts verkauft wurde. Ich selbst lag im Bett ohne etwas von dem ganzen Vorgange zu wissen, als ich plötzlich durch einen Höllenlärm geweckt wurde und sofort, nichts Gutes ahnend, notdürftig bekleidet vor die Hütte trat, um zu sehen, was vorging. Meine Leute waren in einen Streit mit den Eingeborenen verwickelt, welche alle mit Messern und Flinten bewaffnet waren und einen der Unsrigen ergriffen hatten; ich griff natürlich sofort zu meinem Karabiner, trat unter die Streitenden und befreite mit einem kräftigen Kolbenstoss den Bedrängten. Damit war aber die Sache noch nicht erledigt, denn wütend drang die Schar auf meine unbewaffneten Leute ein. Ich konnte sie nur abhalten, indem ich ihnen erklärte, dass ich jeden über den Haufen schiessen würde, der es wagen sollte, sich an einem meiner Leute zu vergreifen. In diesem Augenblick trat einer meiner besten Träger, Sapavi, an mich heran und flüsterte mir zu: „Massa, I beg you, shoot not, we are all lost.“ Es war auch meine Ansicht; so lenkte ich ein und versprach den Leuten die Sache ganz nach ihrem Wunsch zu erledigen. Das Huhn, dem schon der Kopf umgedreht war, konnte ich natürlich nicht ins Leben zurückrufen, indessen besänftigte ich den Eigentümer desselben für den Augenblick mit einem grossen Lösegeld. Der gefährlichste von allen war der Fetischpriester, der fortfuhr, seine Leute aufzureizen und immer wieder mit den meinigen Streit suchte. Als Grund gab er an, dass die Hühner nur für Opferzwecke bestimmt seien. Trotz aller Ueberredungskünste konnte ich die Eingeborenen nicht ganz von der Unschuld meiner Leute überzeugen. Schliesslich gewann ich den Häuptling und die Aeltesten, indem ich ihnen drohte, ich würde, falls mir oder meinen Leuten in dem Dorfe etwas zustiesse, mit vielen Soldaten kommen und den Ort in Brand schiessen. Hierauf wurde ich nicht mehr behelligt und der Häuptling schickte mir sogar, um mich zu versöhnen, etwas gekochten Yams. Ich hatte aber den Verdacht, dass derselbe vergiftet sei und in der That weigerte sich der Ueberbringer mit mir davon zu essen. Ich schickte also den Yams mit Dank dem Häuptling zurück und liess ihm sagen, er möge, wenn er mir ein Geschenk geben wolle, selbst zu mir 
Fetisch- kommen. Abends hörte ich von meinen Leuten, dass die Wahrsager, Auguren. gleich den römischen Auguren, aus dem Fallen der Kaurimuscheln mein Urteil verkünden sollten. $\mathrm{Zu}$ diesem $Z$ weck hatten sie sich mit den Fetischleuten in einer Hütte vereinigt; eine Hand voll Kaurimuscheln wurde in die Höhe geworfen und aus dem Fallen der Muscheln sollte hevorgehen, ob ich in guter oder böser Absicht gekommen sei. Fällt die Mehrzahl der Muscheln mit der Narbe nach oben, so hat der Betreffende eine offene Brust und führt nichts im Schilde, sondern kommt in guter Absicht. Fällt dagegen die Mehrzahl der Kaurimuscheln mit der Narbe auf den Boden, so hat der Mann eine verdeckte Brust, führt also böses im Schilde, oder kommt mit schlechten Absichten. Sind die Würfel gefallen, so wird das Urteil gesprochen und die Strafe kann an dem Opfer vollzogen werden. Dasselbe Hazardspiel wird von fast allen Negern zum Vergnügen gespielt. Wahrscheinlich fielen in diesem Falle die Würfel zu meinen Gunsten, da ich nicht weiter belästigt wurde. Aber schlimm ergeht es den armen Schwarzen, ja selbst den Anhängern des Fetisch, wenn sie in Ungnade bei dem Fetischpriester gefallen sind. Nicht selten liegt ihr Leben und Gut in seiner Hand und sie müssen Strafen den Giftbecher leeren. Allerdings entscheidet zuletzt die Organisation des Fetisch des menschlichen Körpers immer noch selbst, indem der Magen unter Umständen das Gift nicht behält. Häufig jedoch soll das betreffende Opfer, ehe noch die Wirkung des Giftes eintritt, mit Knütteln und Messern von den Helfershelfern des Priesters und der fanatischen Menge totgeschlagen werden. Noch schlimmer ist es, wenn der Fetischpriester dem Angeklagten verkündet, dass der Fetisch nur durch seinen Tod versöhnt werden könne. Das betreffende Opfer soll dann mit Rum und Gin in einen trunkenen Zustand versetzt, in den Busch gebracht und ihm dort ein Danegun in die Hand gedrückt werden. Bevor der so Verurteilte noch zur Besinnung kommt, befördert er sich entweder selbst vom Leben zum Tode, oder es ist ihm auch noch bei diesem Akt jemand behülflich, der ihm den Finger zum Abzug des Gewehres führt. Die Fetischfrauen werden häufig nach der obersten Wahrsagerin, Koko, Kokofrauen genannt. Die Feste dieses Fetisch bestehen hauptsächlich in grossen Gelagen, wobei Unmengen von Rum und Gin vertilgt und Tänze aufgeführt werden, bei denen, wie ich selbst in Kratyi gesehen habe, die sogenannten Tänzerinnen der Kokofrau eine besondere Rolle spielen. Es sind meistens junge Mädchen, die durch ihre schlüpfrigen Tänze den Glanzpunkt des Festes bilden. In einem engen Gehöft zwischen den runden kleinen Hütten drängt sich das Volk von Kratyi zusammen, alles befindet sich durch den Branntweingenuss in animierter Stimmung, und bei eintönigem Gesang und Trommelschlag tanzt in der Mitte ein kleines, ganz in weiss gekleidetes Mädchen der Koko, 
inclem es rorsingt, worauf dann. der ganze Chor mit Ciesang und Händeklatschen einfällt.

Was die Entstehungsgeschichte des Fetisch Odente anbelangt, so Geschichte lasse ich dieselbe des allgemeinen Interesses halber und zum besseren und Herkunft Verständnis dieses Kults hier folgen. Ich stütze mich dabei auf die Berichte des Fetisch des verdienstvollen Missionars Rottmann, welcher durch seine kleine Schrift Odente. im Evangelischen Missions-Magazin einiges Licht über den so weit ausgedehnten Odente-Kultus verbreitet hat und andererseits uns zeigt, was Aberglaube und Einbildungskraft bei diesem Negervolke vermögen.

Es lebte, schreibt Rottmann, in der Ortschaft Date in der Landschaft Akwapim an der Goldküste ein Götze, namens Konkom. Dieser Götze war in der ganzen Lmgegend als Wahrsager berühmt und so strömte das ganze Volk der Landschaft Akwapim nach Date, um ihm seine Opfergaben darzubringen. Konkom wohnte in einer Höhle, ror welcher alle die dargebrachten Früchte niedergelegt wurden. Ein paar beherzte Männer, welche doch schliesslich sehen wollten, wo alle diese Opfergaben blieben, stellten sich auf die Lauer und bemerkten, wie ein Arm aus der Oeffnung der Höhle herausgestreckt wurde, um den dargebrachten Yams hereinzunehmen. Sie erfassten eiligst den herausgestreckten Arm und zogen das Wunder an das Tageslicht. Aber siehe da, es war ein Mann mit nur einem Arm und einer zerfressenen Nase und die Leute überkam ein Schrecken, da sie ihn nicht für einen gewöhnlichen Menschen hielten. Sie eilten davon und erzählten den Bewohnern des Ortes Date, was ihnen zugestossen sei. Diese liefen voll Angst zu der Höhle und baten den Götzen, nicht weiter zu zürnen, da sie alles thun wollten, was er verlangte. Konkom erwiderte, dass der Fetischgott nur versöhnt werden könnte, wenn sie ihm sämtliche Früchte der Ernte als Opfer weihten. Der Fetischgott würde ihnen später alles wieder vergelten. Die Leute opferten wirklich ihre gesamte Ernte und hofften auf den Segen, der da kommen sollte. Aber sie warteten vergebens, denn von dem Götzen war seit der Zeit nichts mehr zu hören. Derselbe war in einer schönen Nacht nach Kratyi am Volta entflohen, wo er von dem abergläubischen Volke gut aufgenommen wurde und sein Wesen von neuem zu treiben begann. Bald hatte der Kult in Kratyi Verbreitung gefunden und alles Volk strömte herbei, um an den Festen teilzunehmen und Erlösung von seinen Leiden zu finden. Inzwischen war in Date grosse Hungersnot ausgebrochen. Das Volk meinte darin den gerechten Zorn des Götzen für die an ihm verübte Frevelthat zu erkennen und glaubte nur durch ihn davon befreit werden zu können. In diesem Augenblick trat ein Mädchen, genannt Koko, auf, welches durch einen Wahrsager von Konkom aus Kratyi in die Geheimnisse des Kultes ein- Wahrsagerin geweiht war. Es verkündete dem bedrängten Volke, dass Konkom 
wiederkommen würde, falls sie ihm Altäre und Opferstätten bereiteten. Ferner müssten die Leute sich zu Opfern verpflichten, welche dem grossen Götzen angenehm seien. Bald erlangte die Wahrsagerin Koko eine grosse Macht; man that alles, was sie wünschte, da man von ihr allein die Rettung erhoffte. Auf diese Weise entstanden die zahlreichen Opferstätten, welche wir kennen gelernt haben. Bald verlangte Koko statt der Opfer von Schafen und Gin auch Rinder und Rum; ja die Wahrsagerin des teuflischen Fetisch schreckte nicht davor zurück, in seinem

Menschen- Namen Menschenopfer zu fordern. $\mathrm{Zu}$ diesem $Z$ weck wurde von weither opfer. ein Sklavenknabe heimlich gekauft. Obgleich die Leute zögerten, setzte Koko ihren grausamen Plan durch. In einer dunklen Nacht wurde die verbrecherische That verübt; kein Eingeweihter durfte auf Kokos Machtspruch hin die Hütte verlassen. Der arme Knabe wurde an die Opferstätte gebracht, wo ihm trotz allen Flehens von den Mordgesellen das Genick gebrochen wurde, indem man ihn mit dem Gesicht auf den Boden warf und über seinen Nacken eine Stange legte, auf welche zwei Männer traten, während andere den Körper rückwärts bogen. Auf diese scheussliche Art soll das unglückselige Opfer von den fanatischen Leuten gemordet worden sein. Der Körper wurde nun in die Erde eingegraben, so dass nur der Kopf darüber hinausragte, und auf diesem wurde der Teufelskegel errichtet. So entstand die Opferstätte und der Denkstein für den Götzen Konkom, welcher von nun an seinen Hauptsitz in Kratyi aufschlug und dort als Fetischgott Odente fortleben soll. Den Namen Odente hat der Götze Konkom nach der Ortschaft Date erhalten, von wo er gekommen war; aus dem Worte Date entstand fälschlich Dente. Nach Date kehrte der Götze trotz dieses scheusslichen Opfers natürlich nicht zurück und dessen Bewohner sollen noch heute auf seine Wiederkunft warten, während andere nach Kratyi ausgewandert sein sollen. Durch Streitigkeiten der Bewohner des Ortes aber wurde die Sache vor das englische Gericht gebracht und so ereilte die Mordgesellen ihre gerechte Strafe. Eine englische Gerichtskommission stellte den Thatbestand an Ort und Stelle fest und fand zu ihrem Entsetzen, als nachgegraben wurde, unter dem mysteriösen Fetischkegel den Schädel und das Gerippe des unglücklichen Opferknaben. Zur Bestätigung dieser Geschichte giebt uns Missionar Rottmann das Datum an, an welchem am 4. April r 887 die Verbrecher in Akkra an der Goldküste von der englischen Gerichtsbarkeit durch den Strang hingerichtet wurden.

Anthropologische Eigenschaften.

\section{CHARAKTERISTIK IER KRATYILEUTE UND DER HAUSSA.}

Die Kratyileute sollen nach der Legende ursprünglich aus Date in der Landschaft Akwapim gekommen sein und sich in Kratyi niedergelassen haben. Sie sprechen einen eigenen Dialekt, die sogenannte 
Kratyisprache, welche unser Sprachforscher Christaller zu den Guańsprachen zählt. Doch ist die Tshisprache, namentlich als Handels- und Verkehrssprache, in der ganzen Voltaebene gebräuchlich. Die Kratyileute standen früher, wie alle die benachbarten Volksstämme, unter dem Einfluss des Aschantikönigs. Deshalb hat die Tshisprache hier vielfach Wurzel gefasst.

Die Kratyileute scheinen auch ihrem äusseren Typus nach mit den Aschantis nahe verwandt zu sein; sie besitzen dieselben scharfen und markanten Gesichtszüge, nur dass ihr Körperbau mehr den Stämmen im Innern der grossen Ebene gleicht. Männer und Weiber scheinen im allgemeinen kleiner zu sein als die Gebirgsstämme und Küstenbewohner. Die Schultern sind schmäler und die Brust flacher, die Beine und Arme sind weniger fleischig, aber häufig sehniger und kräftiger, als die wulstigen Gliedmaassen der Evhe. Die Hände und Füsse sind schmal und trocken, der ganze Körperbau schlank. Das krause. schwarze Haar tragen Männer wie Weiber kurz geschoren, nur die jungen heiratsfähigen Burschen und Dandies lassen häufig vorn an der Stirn und zu beiden Seiten der Schläfen eine höhere Haartolle stehen. Nicht selten sieht man auch bei abergläubischen Leute eine kleine Locke, die auf dem Kopfe stehen geblieben ist und in die ein Fetischamulett aus Federn, Kauris, Knochen oder dergleichen eingeflochten wird. Dieses Amulett soll gegen Kopfschmerz, Zahnschmerz und ähnliche Krankheiten schützen. Direkte Stammeszeichen tragen die Kratyi-Leute eigentlich nicht; nur die Frauen haben die verschiedensten Tätowierungen, welche als Schmuck dienen. So tragen sie, wie bei den Aschantis, kleine kreuzweise gestellte Querschnitte, die gleichsam einen Stern bilden, auf den Backen. Auch bemerkte ich auf der rechten Backe in der Gegend des Backenknochens zwei kleine kreuzweise Einschnitte; während auf der linken Backe zwei kleine Querschnitte und darunter drei senkrechte Einschnitte vorhanden waren. Andere wieder trugen auf der rechten Backe vier kleine, durch Querschnitte erzeugte w whts |link: Sterne, die senkrecht untereinander standen, während sich $\times \quad \overline{\mathrm{III}}$ auf der linken Backe nur zwei solche Sterne befanden. $\underset{x \times}{x} \quad x_{x} \quad$ Auch sieht man auf beiden Backen drei kleine Querschnitte $x_{x} \quad x^{x}$ mit je einem Stern. Ausser diesen Tätowierungen sind bei $\equiv \times \quad x \equiv$ Frauen und Männern häufig die Zähne gefeilt und zwar ist, wie bei den Evheleuten, ein Dreieck zwischen den mittleren

oberen Schneidezähnen ausgefeilt; während ich andererseits vielfach die spitze Form bemerkte.

Die Kleidung der Kratyileute ist im allgemeinen schon durch das Kleidung und Gebot des Fetisch eingeschränkt und geradezu dürftig zu nennen. Die Hüttenbau. Männer tragen meistens an einer um den Leib gebundenen Schnur ein 
kleines Schamtuch, welches zwischen den Beinen durchgezogen ist. Als Schmuck tragen sie häufig noch aus Eisen oder Holz gefertigte Armringe und um den Hals nicht selten eine von der Küste gebrachte bunte Perlenschnur. Umschlagetücher werden überwiegend nur von reicheren und höher gestellten Personen getragen. Die Weiber tragen ausser einem kleinen Schamtuch, welches wie bei den Evhefrauen meistens an einer Perlenschnur um den Leib gehalten wird, noch ein kleines dürftiges Hüfttuch um die Lenden, welches eine Handbreit oberhalb der Knie abschliesst. Häufig tragen sie auch noch ein buntes Tuch um den Kopf geknüpft und zieren ihren Arm mit einer Menge der beliebten Armbänder von blankem Messing oder von Kaurimuscheln, was aber meistens nur bei den Reichen der Fall ist.

Die Hütten der Kratyileute sind fast durchweg rund mit Kegeldach, während sich vereinzelt noch quadratische mit sogenannten Walmdächern vorfinden. Verheiratet sich ein junger Mann und gründet einen eigenen Familienherd, so baut er sich natürlich auch eine neue Hütte. Ein solcher Hüttenbau wird grösstenteils von den Familienangehörigen selbst vorgenommen. Nachdem der Bauplatz gereinigt und ein Kreis abgesteckt ist, wird die Lehmmauer meist auf einem kreisrunden, ungefähr einen Fuss starken Fundament von Stein aufgebaut. Zu diesem Zwecke wird Lehm herbeigeschafft, und nicht selten ein Termitenhaufen dazu verwandt. Der Lehm wird geknetet und zu kokosnussgrossen runden Ballen geformt, mit denen nun der Aufbau der Mauer beginnt. Aber nur $1 / 2 \mathrm{~m}$ hoch werden die einzelnen Lagen der Mauer aufgeschichtet und dann so lange in der Sonne getrocknet, bis dieselben eine genügende Festigkeit haben, um die nächste Lage zu tragen. Auf diese Weise wird die Mauer dann meistens bis zu I $1 / 2 \mathrm{~m}$ Höhe aufgeführt. Nachdem sie genügend ausgetrocknet ist, werden die Dachsparren, welche aus Bambus oder anderen rohen Stangen bestehen, an der Krone durch Gabeln zusammengefügt und mit Bast verbunden, so dass das ganze Dach eine kegelartige Form erhält. Die Stangen werden noch mit Querhölzern befestigt und alsdann wird das ganze Dach mit gut geflochtenen kreisrunden Grasmatten, die schuppenartig übereinander gelegt sind, eingedeckt. Die Kegelspitze des Daches krönt in der Regel ein alter bodenloser Topf, welcher die an der Krone zusammengebundenen Grasmatten besser zusammenhalten soll. Eigentlich geschlossene Gehöfte besitzen die Kratyileute nicht; die Hütten, welche zusammengehören, stehen um einen kleinen Platz herum, auf den die einzelnen Ausgänge der Hütten münden. Die Ausgänge bestehen, wie bei allen übrigen Hütten, nur aus einer kleinen Oeffnung, die oben abgerundet ist und zugleich das Licht hereinlässt. Des Nachts oder auch am Tage, wenn die Hütte verlassen ist, wird der Eingang 
mit einer aus Gras geflochtenen Watte verstellt. Der Boden einer solchen Hütte ist, wie bei den Evhenegern, aus Lehm zu einer Tenne festgestampft. Der Bau der Hütten kann natürlich nur in der Trockenzeit vorgenommen werden, da sonst die heftigen Tornados, welche die Regenzeit mit sich bringt, sofort das Gebäude zerstören würden.

Die Hauptbeschäftigung der Kratyileute ist neben der Jagd, dem Fischfang, sowie in geringem Umfange der Hausindustrie, der W'eberei und Flechterei, vor allem der Ackerbau. Sie haben die Aufgabe, die Massen von durchziehenden Fremden und Händlern und vor allem die grosse Negerstadt Kete, sowie den ausgedehnten Markt mit Vieh, Lebensmitteln und Feldfrüchten zu versorgen. Die grossen, schönen Farmen, durch welche man stundenlang, namentlich im Süden von Kratyi, marschiert, zeugen von der intensiven Thätigkeit der Kratyileute. Man begegnet hier seltener wilden Farmen, in denen Mais, Bananen und Yams durcheinander wachsen, sondern mächtigen, wohlgepflegten Yamsfeldern, welche von Unkraut gesäubert sind und wo der Yams, entweder auf der Erde oder an Stöcken gezogen wird. Ueberall sieht man in den Farmen Leute beschäftigt, welche die einzelnen Stauden behäufeln oder durch Jäten das Unkraut vertilgen. Grosse Reis- und Hirsefelder, wie das sogenannte Guineakorn wogen im Winde; dazwischen dehnen sich die grünen Matten der Erdnussfelder. Gelbe Bohnenfelder, Bataten, Pfeffer und Zwiebeln, sowie Baumwollsträuche, ergänzen die Fülle der angebauten Früchte. Mitten im Grünen liegen die kleinen Farmgehöfte mit ihren fremdartigen, bienenkorbähnlichen Hütten.

Nähert man sich den Hütten, so findet man plötzlich Leute, welche eine fremde Sprache sprechen. Die grossen Tätowierungen quer über die ganze Backe lassen die Leute als Grussi erkennen. Aber ausser diesen bemerkt man auch häufig die verschiedenen Stammeszeichen der Mossi, daneben Leute aus den heidnischen Ländern von Kapre und Bassari; alle sind hier emsig in den grossen Farmen der Kratyileute thäftig. Sie sind meistens Sklaven des Königs ron Kratyi, des Fetischpriesters oder sonstiger reicher Ackerbauer. Die grossen Felder und Farmen, die den Bedarf an Feldfrüchten von Kete decken, können nicht alle von der im Verhältnis zu diesem ausgedehnten Ackerbau geringen Anzahl eingeborener Kratyileute bestellt werden; sie lassen daher ihre Farmen durch Haussklaven anpflanzen. Das Loos dieser Leute ist, abgesehen von der dürftigen Bekleidung, nicht schlechter als das unserer Feldarbeiter. Sie bewohnen eigene Hütten und rerrichten tagsüber auf den ihnen angewiesenen Farmen frei ihre Feldarbeit. Auch führen sie häufig ein glückliches Familienleben, da sie gewöhnlich schnell verheiratet werden, um ihnen das Entlaufen zu erschweren. Ton dem, was das Land hervorbringt, sowie von den von ihnen selbst gezüchteten 
Hühnern erhalten sie soviel, als sie zu ihrem Lebensunterhalt brauchen, so dass sie bei ihrer Bedürfnislosigkeit ein ganz behagliches Leben führen. In einer Beziehung sind sie sogar besser gestellt, als unsere Bauern, die selbst für ihren Unterhalt bedacht sein müssen, während der Sklave auch bei Missernte von seinem Herrn erhalten werden muss.

Sitten und Gebräuche.
Die eingewanderten Haussa. Anthropologische Eigenschaften.
Was die Sitten und Gebräuche der Kratyileute anbetrifft, so sind sie denjenigen der Evheleute ähnlich. Auch die Kratyileute feiern ihre Totenfesté durch ein grosses Gelage, nur dass hier Rum und Gin dem bei den Evheleuten üblichen Palmwein vorgezogen wird. Ein unaufhörliches Schiessen findet ebenfalls bei allen derartigen Festen statt. Die Rechtsprechung liegt den Häuptlingen und dem Könige ob, aber auch hier ist die Justiz zum grossen Teil in die Hand des Fetischpriesters gegeben, welcher häufig Gottesurteile anordnet und den Giftbecher trinken lässt. An der Strasse, die von Kratyi nach Kete führt, bemerkt man eine Menge Gräber der Opfer, die durch Gift von dem Fetischpriester getötet worden sind. Ausserdem ist bei diesem verblendeten Volk der Kindesmord nicht selten. Man glaubt, dass bei Zwillingsgeburten ein böser Geist seine Hand im Spiele gehabt habe und aus diesem Grunde tötet man die unschuldigen Kinder in unbarmherzigerWeise. Hat eine Frau das Unglück zum zweiten Male ein Zwillingspaar zu gebären, so sollen die Leute sogar nicht davor zurückschrecken, die unschuldigen Kinder einem Ameisenhaufen zu übergeben; denn nur auf diese Weise meinen sie, sei einer weiteren Zwillingsgeburt vorzubeugen.*) Es ist merkwürdig, dass die meisten Naturvölker Zwillingsgeburten als ein böses Omen betrachten, an dem ein böser Geist schuld ist. Vielleicht erklärt es sich daraus, dass sie es für unnatürlich halten, wenn eine Mutter zwei Kinder ernähren soll, da eine künstliche Ernährungsweise der Kinder nicht bekannt ist.

Einen Gegensatz zu den heidnischen Kratyileuten bilden die mohamedanischen Haussa, welche bis zur Küste vorgedrungen sind. Ihren hauptsächlichsten Wohnsitz in der Togokolonie haben sie in der grossen Handelsstadt Kete: Die Haussa besitzen; wie die westafrikanischen Neger, eine ebenholzschwarze Hautfarbe. Sie sind meistens grosse, schöne und kräftige Gestalten, welche schon durch ihren Körperbau vorteilhaft von der sie umgebenden heidnischen Bevölkerung abstechen. Auch die Gesichtszüge sind gegenüber denen der Kratyileute geradezu schön zu nennen; edlere Formen und mandelförmige Augen verraten, trotz der schwarzen Hautfarbe, eine stärkere Beimischung hamitischen Blutes. Nase und Lippen sind weniger aufgeworfen, der Ausdruck ist intelligent, die Augen blicken listig, während der Neger häufig stumpfsinnig vor sich hin brütet. Mitunter erinnern die Züge des Haussa an den semitischen

*) Nach Clerk. 


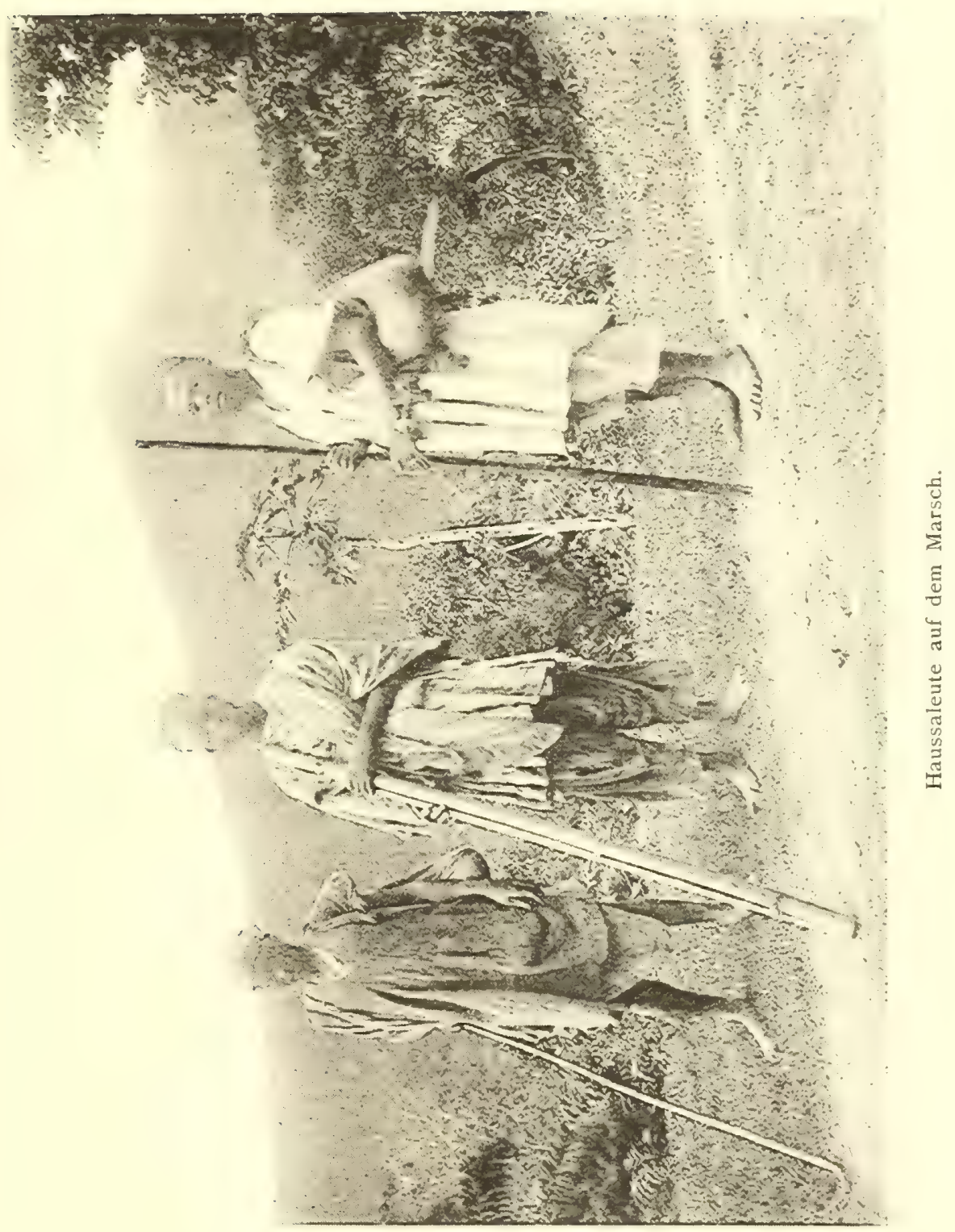


Typus. Die Frauen sind durchschnittlich gross im Verhältnis zu anderen Negerrassen. Die Männer tragen nicht selten zwei bis vier lange, dünne Längsstreifen von der Schläfe bis zum Mundwinkel als Tätowierung. Ihre Kleidung ist ebenso reichhaltig wie eigenartig. In dieser Beziehung bleiben die Haussa, wo sie sich auch befinden, ihren Sitten und Gewohnheiten treu. Die Vornehmen und Reichen tragen einen grossen, weiten Burnus, mit schön gestickten Brusttaschen, weite, perlgraue Pluderhosen und Sandalen. Aber auch die ärmere Klasse mit ihren aus Greybaft hergestellten Toben, Hemden und Hosen, unterscheidet sich vorteilhaft von den fast unbekleideten Eingeborenen. Das Haar der Haussa ist glatt rasiert, während ihr Gesicht häufig ein kleiner Knebelbart ziert. Die Frauen, welche nicht so abgeschlossen leben wie die mohamedanischen Frauen im Orient, wären keineswegs hässlich, wenn sie sich nicht durch Schmuck und Schminke entstellten. Ihre Frisur ist ziemlich kunstvoll und sieht in der Form einem bairischen Raupenhelm nicht unähnlich. In dem rechten Nasenflügel tragen sie eine kleine Koralle, die Augenbrauen sind mit Graphit und die Augenlider mit Antimon gefärbt. Ihre Zähne sind von dem Genuss der Kolanuss gelb, die Finger und Fingernägel werden mit Henna rot gefärbt. Der vornehme Haussa, der sich's leisten kann, hat meistens drei bis vier Frauen. Die Frauen tragen gewöhnlich ein aus einem europäischen oder einheimischen Tuch bestehendes blaues Hemde, sowie ein grosses blaues Umschlagetuch. Ausserdem tragen sie Armringe und Armbänder aus Messing oder auch nicht selten aus Silber. Sogar die Männer tragen öfters an ihren Fingern schwere Ringe, die glatt, bisweilen jedoch auch mit einem kunstvoll gearbeiteten Aufsatz geziert sind. Für einen Mann, der mit den Händen etwas schaffen will, müssen diese riesenhaften Fingerringe geradezu ein Hindernis sein. Die jungen Mädchen legen für gewöhnlich ausser dem Schmuck nur ein Hüfttuch um, während die Burschen der besseren Familien ein Haussahemd und eine phrygische Mütze tragen.

Was die Beschäftigung der Haussa anbetrifft, so sind sie haupt-Beschäftigung sächlich gewiegte Handelsleute, welche weite und beschwerliche Reisen nicht scheuen, wenn ein vorteilhaftes Geschäft abzuschliessen ist. Daneben und giebt es aber auch unter ihnen Gewerbetreibende, vor allem Fleischer, die in allen Haussakolonieen, selbst in Lome an der Küste eine wichtige und einträgliche Stellung einnehmen; auch Schmiede und Mattenflechter haben wir vereinzelt auf dem Markt von Kete angetroffen. Bei meiner öfteren Anwesenheit in Kete hatte ich Gelegenheit, ihre Spiele und Tänze kennen zu lernen. Die Haussamädchen führen einen eigentümlichen Tanz auf, wobei sich eine grosse Reihe von Mädchen hintereinander aufstellt. Zwei von ihnen tanzen dos-à-dos und treten dann wieder in die Reihe, um von zwei anderen Tänzerinnen abgelöst zu werden. Die 
ganze Menge begleitet den Tanz und die Trommelschläge mit Händeklatschen und Gesang. Eine kleine Oellampe erhellt den Tanzplatz und das lustige Spiel hält die junge Mädchenschar bis spät abends zusammen. Einen schönen und sinnreichen Schwerttanz führen die Haussaburschen auf. Es bildet sich ein grosser Kreis von jungen Leuten, welche alle mit Stöcken oder Schwertern bewaffnet sind. Jeder der Burschen nimmt eine Fechtstellung ein und ficht mit seinem Nebenmann. Der ganze Kreis bewegt sich nun in der Runde und abwechselnd pariert der einzelne die Schläge seines Vordermannes, während er sich im nächsten Augenblick gegen die Schwertstreiche seines Hintermannes den Rücken deckt. Diesen Schwerttanz führen die Haussa, als passionierte Reiter, bei hohen Festlichkeiten auch zu Pferde aus, indem sie in einem Kreise reiten. Bei den Haussafesten treten berufsmässige Sänger und Clowns auf; sowohl das weibliche als auch das männliche Geschlecht beteiligt sich daran. Jede grössere Karawane hat, wie wir gesehen, ihre Spielleute, welche entweder an der Spitze der Karawane mit Trommelschlag den Einzug in die Dörfer eröffnen oder vor dem Grossherrn als Gaukler tanzend und sein Lob singend, einherziehen. Mir zu Ehren wurde auch einmal von einer Haussadame ein Festtanz vorgeführt. Die Tänzerin war nicht mehr jung, erntete aber von der weit im Kreise herumstehenden Menge reichlichen Beifall. Sie schnitt Grimassen, verdrehte die Augen, stampfte mit den Füssen, machte lascive Bewegungen und gebärdete sich geradezu wie eine Wahnsinnige. Das Ganze machte einen abscheulichen und ekelhaften Eindruck; nur um kein Spielverderber zu sein, harrte ich geduldig bis zum Schlusse des Tanzes aus.

Mohamedani- Was die Erziehung der Haussajugend betrifft, so giebt es in allen sche Schulen Kolonieen Schulen, welche von den Haussapriestern geleitet werden. Die Knaben lernen in arabischer Schrift lesen und schreiben, wobei der Koran als Unterlage dient. Auch auf der Reise werden die Schreib- und Leseübungen fortgesetzt; die Knaben führen ihre Schreibtafeln, auf der Schulter hängend, mit sich, während sie auf dem Kopfe ihre kleine Last tragen. Die Schreibtafeln sind aus Holz gearbeitet; sie schreiben darauf mit einem zugespitzten Holzgriffel, der in eine eigens präparierte schwarze Tinte getaucht wird. Die Priester nehmen bei den Haussa eine der höchsten Stellen ein, denn sie sind zugleich die Gelehrten und Schriftkundigen.

\section{VERZÖGERTER AUFENTHALT IN KETE.}

Da Herr Krause von Kratyi abwesend war, suchte ich nun unter allen Umständen Sofo zur Mitreise zu gewinnen, um durch seinen Anhang meine Karawane zu verstärken und zugleich einen schwarzen Repräsentanten zu haben. Aber nur durch grosse Versprechungen, durch Ge- 


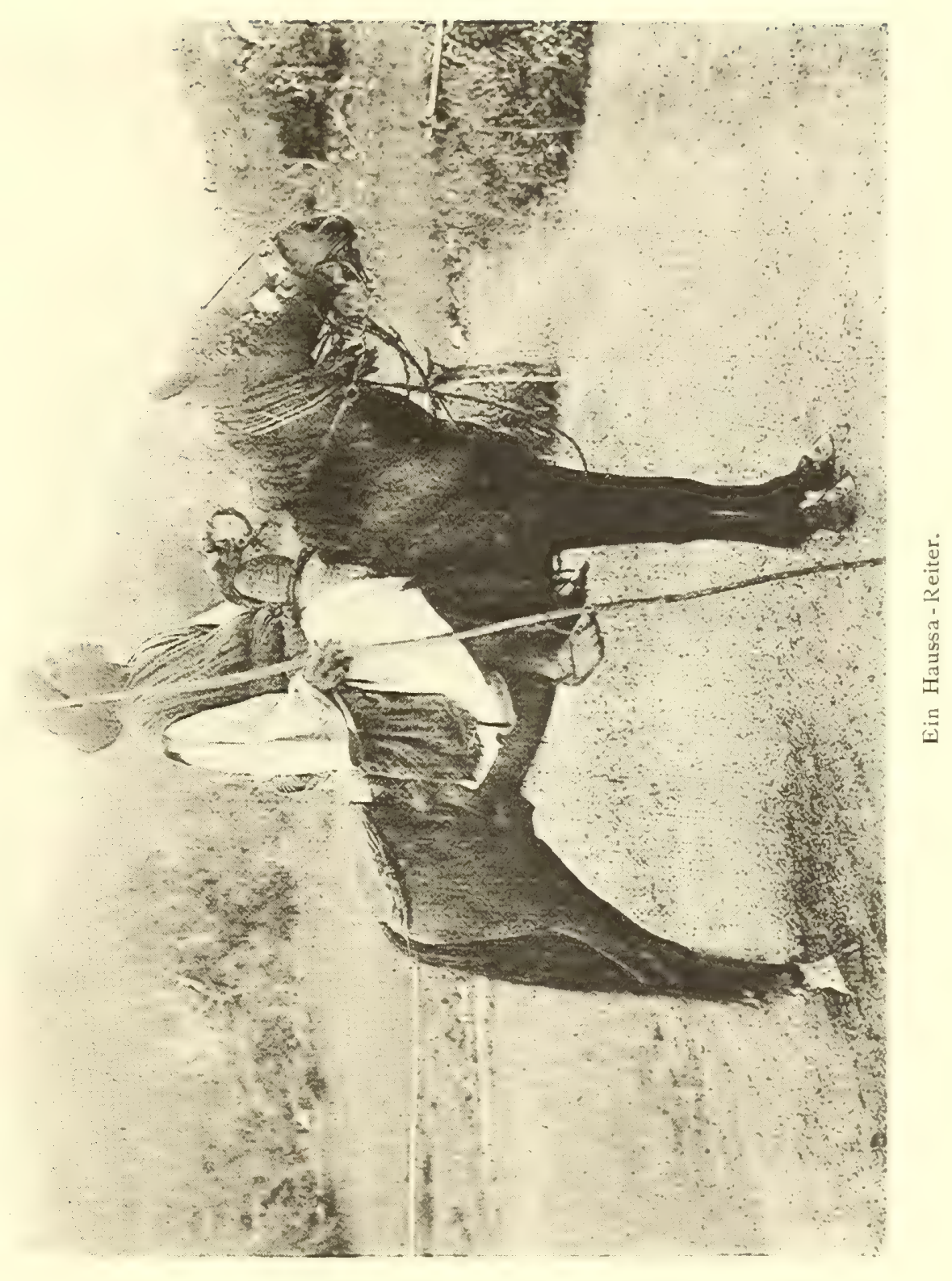



währung aller seiner Wünsche und durch Geschenke gelang es mir, seine Zustimmung zu erlangen. Obwohl ich darauf brannte, so schnell als möglich von Kratyi wegzukommen, musste ich volle vier Tage liegen bleiben, bis Sofo seine Reisevorbereitungen beendet hatte. Täglich hatte er neue Einwände gegen die Abreise vorzubringen und stundenlang verhandelte ich mit ihm vor der grossen viereckigen Hütte, welche mit ihrem Schattendach nach aussen eine Art Veranda bildete und uns tagsüber vor den Strahlen der Tropensonne schützte. Unter dieser Veranda ist der Platz, wo intime Vérhandlungen mit Freunden und guten Bekannten stattfinden. Wie man bei uns mit der Tabakspfeife des Abends gesellige Stunden verbringt, so sitzt auch hier bei der Kolanuss, die überall dem Gaste angeboten wird, der Haussa mit seinen Freunden und Bekannten auf grossen Rindsfellen oder kleinen einheimischen, geschnitzten Stühlen bei munterem Gespräch über die Tagesereignisse. Daneben stehen meistens die Pferde an Pflöcken, an den Vorderbeinen mit einem Strick gefesselt; an der Halfter hängt gewöhnlich eine Art Glocke, ähnlich unseren Schweizer Kuhschellen, und harmonisch erklingt in der Stille des Abends das Geläute in dem friedlichen Gehöft. Im übrigen wurden mir diese in Kratyi verlebten Tage nicht lang, denn ich hatte von früh bis spät den Besuch der Haussa-Notablen, sowie Deputationen mit Geschenken an Schafen, Ziegen und Yams zu empfangen. Auch Bier von den Jendileuten, sówie Milch von den Kühen, die hier von einzelnen Haussas gehalten werden, waren bei dem gänzlichen Mangel an europäischen Genussmitteln nicht unwillkommen.

Die Festlichkeiten habe ich bereits erwähnt, welche die Haussa mir zu Ehren veranstalteten. Eine der interessantesten Belustigungen für mich war das Wettrennen, welches von fast allen berittenen Haussa und zufällig anwesenden Dagomba- und Tshautsholeuten veranstaltet wurde. Dieses Rennen, zu welchem alle Haussa ihr festliches Reitergewand angelegt, sowie die Pferde mit buntem Geschirr aufgezäumt und die Sättel mit schönen Decken belegt hatten, bildete entschieden den Glanzpunkt der Festlichkeiten. Es wurde einfach in der Strasse vor meiner Wohnung abgehalten. Sofo selbst an der Spitze der Reiter eröffnete in fliegender Karriere das Rennen und jeder suchte in einzelnen Abständen so schnell als möglich vorbeizujagen. Romantisch nahmen sich diese schwarzen Haussareiter auf ihren buntbehangenen, mittelgrossen Pferden aus. Die weissen Toben flatterten im Winde und unter dem-hohen Turban oder Fez mit dem heruntergeschlagenen Litwan leuchteten die schwarzen Augen der Reiter hervor, als sie in den engen Strassen an mir vorübersprengten. Die hohen Reiterstiefel mit den Pluderhosen, der arabische tiefe Bocksattel mit schweren metallenen Steigbügeln, die grosse Kandare mit ihren langen Scheren und hier und da die KLose, Togo.

Pferderennen. 
mit dem Speer zum Wurfe erhobene Rechte vereinigten sich zu einem malerischen Bilde.

Pferdekauf. In Kete erstand ich auch ein Pferd fur 260 Mark. Es war ein hübscher Rotschimmèl, ungefähr 5 Fuss hoch und hatte nach seiner Bauart arabisches Blut in den Adern. Zur grossen Freude der Haussajugend taufte ich den feurigen kleinen Hengst mit dem Namen „Hassan“ (der Schreckliche). Das Einreiten desselben machte mir allerdings nicht wenig zu schaffen, denn er war ein so bekannter Steiger, dass Sofo mich durch einen Dolmetscher gegen den Ankauf warnen liess. Aber gerade das spornte mich an, obwohl ich schon beim Vorreiten des Pferdes bemerkte, dass Sofo nicht Unrecht gehabt hatte. Um die Unart des Tieres zu rerbergen, sagte mir der Besitzer, der Reiter wolle mir zeigen, was für Kunststücke das Pferd verstände. Das Tier war aber vollkommen verrissen und nur der beste Reiter in Kete, der es vorritt, konnte es einigermaassen beherrschen. Aus diesem Grunde wollte auch der Besitzer, ein reicher Haussahändler, das sonst vollkommen gesunde Pferd verkaufen; der Haussa ist im Pferdeschacher noch viel geriebener als unsere Pferdehändler in Europa; er verkauft nur lahme oder kranke Pferde an Europäer, da er weiss, dass man sich in einer Notlage befindet und um jeden Preis ein Pferd für die Weiterreise haben muss. Ich setzte mich nun trotz des Abratens meines Dolmetschers selbst auf das Pferd, da ich wohl sah, dass es nur weichmäulig und durch das Annehmen der scharfen Kandare verrissen war. Das Pferd versuchte natürlich mit mir dieselben Kapriolen, da ich weder Sporen noch eine Reitgerte hatte; beinahe wäre ich mit ihm rückwärts in eine Hütte hineingeraten, was mir zuerst den Spott der Umstehenden zuzog. Als ich mir aber eine Haussapeitsche hatte geben lassen, wurde ich bald Herr über den kleinen Wildfang, wofür mir grosser Beifall von den Haussa gespendet wurde. Sofo sagte mir: „Es ist doch richtig, dass die deutschen Offiziere auch reiten können, was ich früher nicht geglaubt habe, da sie nur langsam reiten." Es ist diese Ansicht sehr erklärlich, da die Haussa Der Haussa wohl passionierte Reiter sind, aber ihre ganze Force in eine tolle Karriere als Reiter und setzen, welche vom Fleck aus geritten und ebenso wieder auf dem Fleck Pferdepfleger. pariert wird. Nur Schritt und Galopp ist ihnen bekannt, während Trab nie von ihnen geritten wird. Durch das plötzliche Anreiten sind die Pferde gewöhnlich auf den Hinterbeinen kaput, und durch die scharfe Parade die Vorderbeine ruiniert. Aus diesem Grunde findet man bei längere Zeit gebrauchten Pferden selten, dass sie gut auf den Beinen sind, vielmehr sehen sie, wenn sie ihres äusserlichen Schmuckes beraubt sind, abgetrieben und kümmerlich aus. Die Haussa züchten in Kete nur sehr selten Pferde; diese werden meistens aus Mossi, sowie aus Sugu und Tshautsho heruntergebracht. Es sind 
hier meistens zwei Pferderassen vertreten: eine kleinere Art, welche sehr ausdauernd und zäh sein soll und meistens als Packpferd gleich den Eseln benutzt wird. Sie gleicht sowohl in ihrem Aussehen als in ihrem Temperament unseren kleinen polnischen Bauernpferden. Das eigentliche Reit- und Kriegspferd ist eine grössere und stärkere Art, welche etwa 5 Fuss im Durchschnitt hat, aber auch nicht selten die Grösse von 5 Fuss 4 Zoll, ja sogar bis 5 Zoll erreicht. Kastriert werden die Pferde nicht und nur der Hengst der grösseren Art wird bei den

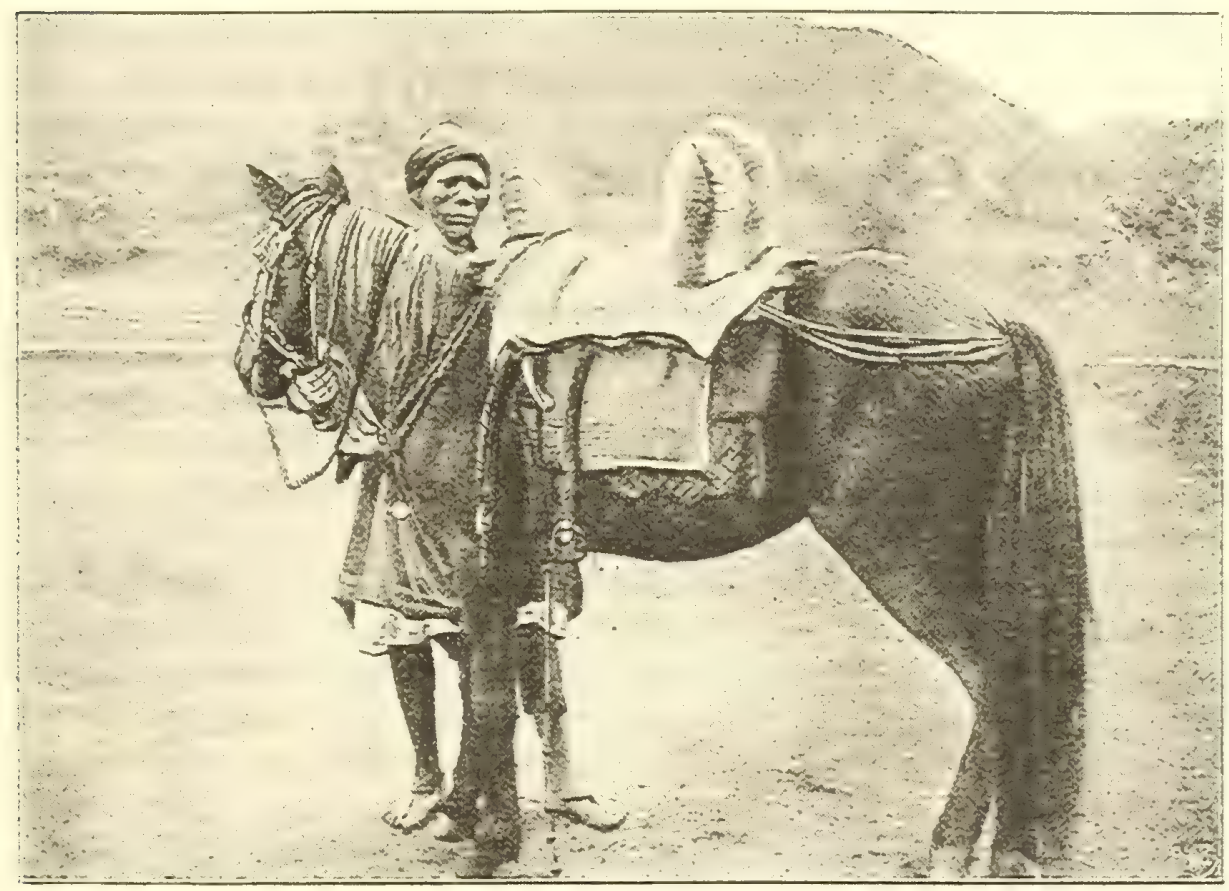

Gesatteltes Haussapferd.

Haussa als Reit- und Kriegspferd benutzt, während die Stuten nur zur Zucht gehalten werden. Tagsüber werden die Pferde sehr häufig auf die grosse Wiese südlich von Kete gețrieben, wo sie zusammen mit anderen Tieren, wie Eseln und den vorübergehend gehaltenen Rindern grasen.

Die Esel, welche mit den Karawanen aus Mossi herkommen, sind von einer schönen, mittelgrossen Art. Ihre Farbe ist zumeist hellgrau und über den Rücken zieht sich ein schwarzer Längsstreifen nebst zwei schwarzen Querstreifen. Häufig sind diese Tiere in ganz empörend roher Weise durch Marken gekennzeichnet, indem ihnen Zeichen an den Hinterschenkeln eingebrannt sind oder das eine Ohr abgeschnitten 
ist. Die Rinder werden hauptsächlich zum Verkauf oder zum Schlachten kurze Zeit gehalten.

Da die Haussa passionierte Reiter sind, so kämpfen sie auch meistens zu Pferde. Ihre Hauptbewaffnung besteht aus sechs bis sieben Speeren, welche sie in einem Futteral unter dem Gesäss am Sattel führen. Beim Kampfe sollen sie, wie ich gehört habe, den Gegner in Karriere anreiten und im Vorbeireiten die Speere auf denselben schleudern. Zu Fuss fuhren sie meistens ein langes Schwert, welches in einer kunstvoll gearbeiteten Lederscheide steckt und auf dem Marsch an einem Bande über der linken Schulter getragen wird.

Sattelung und Interessant ist die Aufzäumung und Sattelung der Haussapferde. Zăumung Der Sattel besteht aus einem hohen Holzblock mit Lederüberzug und hat einen sehr hohen Vorderzwiesel, sowie eine mächtige Rückenlehne. An geflochtenen Lederstrippen hängen mächtige Steigbügel, aus Eisen oder Messing gearbeitet, in welche der ganze Fuss hineingeht. Unter den Sattel werden grosse Unterlegdecken von den verschiedensten grellen Farben gelegt, während auf demselben häufig eine schön gestickte rote Schabracke ausgebreitet wird; nicht selten zieren den Sattel noch schöne Packtaschen aus Leopardenfell oder aus kunstvoller Lederarbeit. Das Zaumzeug ist aus geflochtenem Leder, an dessen Stirnriemen lange Ledertroddeln zum Schutze der Augen angebracht sind. Ferner hängen an dem Zaumzeug rote, gelbe und blaue Ledertäschchen, in welchen Koransprüche eingenäht sind. Eine scharfe Kandare, die roh aus Eisen gearbeitet und mit langen Scheren versehen ist und bei der eine bewegliche Eisenstange unsere Kinnkette ersetzt, dient mit einem geflochtenen Zugel zur Führung des Pferdes.

Deputation Es war ein bewegtes Leben, das ich in dieser Negerstadt fuhrte, alter Haussa- sodass ich kaum Zeit hatte, mir Notizen über all das Gesehene und Soldaten. Erlebte, sowie ethnographische und geographische Aufzeichnungen zu machen. Am ersten Tage ging es noch verhältnismässig ruhig zu und ich nahm, wie wir schon gesehen haben, die Gelegenheit wahr, mir Kete und seinen grossen Markt anzusehen. Schon früh am zweiten Tage erschien eine Deputation der Veteranen, welche einst in der englischen Haussatruppe in Akkra gedient hatten. Alle zeigten mir als Ausweis ihre Pässe und schienen stolz darauf zu sein, einst als Soldat gedient zu haben. Jeder gedachte der Zeit mit Freuden und schien es aus alter Anhänglichkeit an das Soldatenhandwerk als Pflicht anzusehen, meine beiden Soldaten als Kameraden zu bewirten und aufzunehmen. Wie die Haussa ritterliche Künste lieben, so sagt ihnen auch das Soldatenhandwerk zu; sie bilden sowohl bei uns wie auch bei den Engtändern den besten Stamm der Truppe. 
Kaum hatten mich die alten Krieger verlassen, als der mohamedanische Priester, Malam genannt, anrückte, um mich zu begrüssen und den Segen Allahs für meine Weiterreise auf mich herabzuflehen. Er war ein gewandter und hübscher Mann mit schwarzem Bart, welcher durch sein ruhiges und besonnenes Wesen mir ganz besonders gefiel.

Abudu-Bedde und die einzelnen Kolonieen in Kete schickten ihre Vertreter mit Geschenken; besonders die Dagomba waren durch ihre Prinzessin, eine Tochter des mächtigen Sultans von Jendi, vertreten. Sie brachte mir grosse Kalabassen mit Honigbier eigenen Gebräus zum Geschenk, welches garnicht übel schmeckte. Diese Prinzessin unterhält hier gewissermaassen ein Hotel in ihrem mit vielen Hütten bebauten Gehöft und vertritt die politischen wie auch die Handelsinteressen der Dagombaleute. Da sie die Repräsentantin des Sultans ist, wird sie bei allên Festlichkeiten als selbständiger Häuptling behandelt und von den schlauen Haussahäuptlingen, welche ihre hohe Verbindung mit Jendi zu schätzen wissen, mit Freundschaftsbezeugungen überschüttet. Aber wie die Haussa versteht auch diese Jendiprinzessin ihren geschäftlichen Torteil, und das in Kete seltene Bier, welches sie für die Fremden bereitet, bringt ihr einen erheblichen Nebenverdienst ein. Auch wurde in der Stadt gemunkelt, dass Sofo ihr ausgesprochener Liebling und Verehrer sei. Da es meine Absicht war, über Salaga auch nach Jendi zu reisen, so musste ich mich natürlich um die Gunst der hohen Frau bewerben. Ich machte ihr meinen Gegenbesuch mit Sofo und den übrigen Häuptlingen der Stadt und zeichnete sie ihrer Stellung und Würde gemäss vor den übrigen schwarzen Damen aus. Dieses war mir in der That von wesentlichem Nutzen, denn als sie hörte, dass ich nach Jendi wollte, gab sie mir an ihren erlauchten Vater und Gebieter ein Empfehlungsschreiben mit, worin sie ihn ihrer Freundschaft für mich versicherte. Auch sandte sie mein Schreiben an den Sultan durch einen ihrer eigenen Leute.

Ich schrieb dem Sultan ungefähr folgenden Brief, der in die arabische Sprache übersetzt wurde:

\section{Dem König Adami ron Jendi. \\ Grosser König!}

„Da ich schon viel von Deinem reichen Lande und Deiner Freundschaft für das deutsche Tolk gehört habe, so will ich Dich, grosser König, besuchen. Ich sende Dir daher zuerst durch diesen Boten meinen Gruss und melde Dir meine Ankunft in Jendi an. Hier in Kete hatte ich schon die Freude Deine Tochter und die Leute Deines Tolkes zu sehen, mit denen ich gut Freund geworden bin. Ich freue mich dahèr schon sehr, Dich und Deine Stadt zu sehen; bis dahin sei gegrüsst." 
Aufzug des Fetischpriesters Bosumfo.
Obwohl ich bei meinen geringen Machtverhältnissen einer Zusammenkunft mit dem Könige und dem mächtigen Fetischpriester Bosumfo gern ausgewichen wäre, so brachten es ihre eigenen Besuche mit sich, dass ich mit ihnen in Berührung treten musste. Aus oben angeführtem Grunde hatte ich vorher meinen Dolmetscher an den König und an den Fetischpriester geschickt mit Grüssen und dem Auftrage, mich zu entschuldigen, dass ich sie nicht besuchen könnte, da ich sowohl von den Strapazen der Reise zu sehr angegriffen wäre, sowie auch meine Vorbereitungen für den baldigen Weitermarsch treffen müsste. Ich liess ihnen ferner sagen, dass ich mich freuen würde, sie auf dem Rückmarsch besuchen zu dürfen. Am dritten Tage jedoch, als ich mich im Gespräch mit Sofo über die Vorbereitung zu unserer Reise befand, ertönten von weitem die grossen Trommeln und bald wurden unsere eigenen Worte von unaufhörlichem Trommelschlag und von dem Stimmengewirr einer herannahenden grossen Volksmenge übertönt. Es war der mächtige und gefürchtete Fetischpriester, welcher wohl teils aus Neugierde kam, andererseits auch nicht den Haussahäuptlingen nachstehen wollte. Ein imposanter Zug entfaltete sich in den engen Gassen der Negerstadt, gefolgt von tausenden von Leuten, denn ganz Kratyi und auch die Bewohner von Kete waren zusammengelaufen, um den feierlichen Aufzug zu sehen. An der Spitze marschierten die Trommler und Spielleute; vor dem Fetischpriester wurden die Fetischembleme getragen, während Bosumfo selbst sich in einer mit roter Seide ausgeschlagenen Sänfte von seinen Sklaven tragen liess. Ihn umgaben die Priester und. Wahrsager, welche verschiedene Amulette, wie kleine Hühnerknochen, Leopardenzähne, Kaurimuscheln und dergleichen mehr am Halse trugen. Gleichsam als Ratgeber und Marschall, welcher allen Befehlen seines Herrn mit bewaffneten Sklaven Achtung und Nachdruck verschaffte, schritt neben der Sänfte der Grussisklave Okla, welcher sich zu dieser einflussreichen Stellung emporgeschwungen hatte und nicht viel weniger Ansehen besass, als der Fetischpriester selbst, jedenfalls aber mehr, als der vom Oberpriester abhängige König des Landes. Eine grosse Menge von Sklaven, die meistens mit langen Dänenflinten bewaffnet waren, sonst aber geringe Spuren von einer Uniform trugen, bildeten den miltärischen Tross. Es war ein eigentümliches Bild. Zwischen den schwarzen nackten Gestalten wimmelte es von weissen Burnussen und blauen Haussatoben und in diesem bunten Volksknäuel bildete die rot ausgeschlagene Hängematte mit dem priesterlichen Despoten in seiner phantastischen aber wertvollen Bekleidung den Mittelpunkt. Der Fetischpriester trug zur Feier des Tages seinen königlichen Schmuck, grüne seidene Hosen, sowie ein grosses hellgelbes seidenes Lava-Lava um seine Schultern. Okla dagegen trug nach Haussaart eine wertyolle 
blaue gestickte Tobe. Der Fetischpriester war alt und gebrechlich; seine markanten Gesichtszüge, die tiefliegenden, aber listigen und stechenden Augen, der hagere Körper, die trockenen Gliedmaassen und wadenlosen Beine waren typisch für einen alten Kratyimann. Sein Marschall Okla dagegen war eine imposante grosse und kräftige Figur, welche in dem langen Haussagewand noch grösser erschien.

Bei der Annäherung des Fetischpriesters erkannte man deutlich Furcht vor die Unruhe, welche sich meiner Leute sowie des ganzen sonst so dem Fetischfriedlichen Grehöfts des Sofo bemächtigte. Die Haussa verkündeten uns ängstlich, dass der Fetischpriester mit allen seinen Sklaven heranziehe. Ihre Besorgnis war nicht ganz unbegründet, denn im Frühjahr desselben Jahres hatte derselbe Fetischpriester einen nächtlichen Ueberfall in dem Gehöft des Sofo auf Oberleutnant r. Doering geplant, obwohl derselbe eine Karawane von vierzig bewaffneten Trägern mit sich führte. Nur durch seine Entschlossenheit und Energie gelang es v. Doering, den verbrecherischen Anschlag des Fetischpriesters zu vereiteln. Er hatte, wie er mir später erzählte, zum Glück einen angesehenen und dem Oberpriester verwandten Kratyimann wegen eines Verbrechens als Gefangenen bei sich und drohte, als er in der Nacht geweckt und von dem Plan unterrichtet wurde, den Gefangenen zu töten, sobald der erste Schuss fiele. Um ihren Stammesbruder zu retten, zogen die Verschwörer es vor, wieder umzukehren und so missglückte der Ueberfall. Es leuchtete ein, dass ich mit drei Gewehren und neun Mann in keiner Weise die Macht besass, erfolgreichen Widerstand zu leisten. Jedoch liegt bei dem abergläubischen und schreckhaften Negervolke der Vorteil häufig auf der Seite desjenigen, der furchtlos und entschlossen auftritt. In dieser Erkenntnis war es für mich die Hauptsache, in jeder gefährlichen Lage durch Ruhe das Vertrauen meiner Leute, und in dem vorliegenden Falle auch das der befreundeten Haussa zu gewinnen. Ich sass in Ermangelung eines Stuhles auf einem meiner Blechkoffer und trank, um den Tropendurst zu stillen, kalten Thee. Sofo und mein Dolmetscher baten mich, dem Fetischpriester entgegen zu gehen, während meine kleine Schar sich ängstlich um mich drängte. Sofort stellte ich einen Posten vor das Gehöft, um jedem Unbefugten den Eingang zu versperren. Sofo erwiderte ich auf seinen gut gemeinten Rat, dass der Fetischpriester mich aufsuchen möge, wenn er etwas ron mir haben wolle. Endlich langte der Zug an der Pforte an und Sofo und mein Dolmetscher fragten mich ängstlich, ob sie den Priester empfangen sollten. Ich liess mich in meinem Gespräch über die Weiterreise nicht stören und rauchte, auf meinem Koffer sitzend, eine Zigarre, was bekanntlich über manche V'erlegenheit hinweghilft. Inzwischen marschierte der imposante $\mathrm{Zug}$, die Trommeln roran, in 
das Gehöft ein. Ich blieb ruhig sitzen und liess mir in keiner Weise durch die frech auftretenden Kratyileute imponieren. Es war eine unheimliche Stille eingetreten. Der Fetischpriester hielt im Gehöft und liess mir sagen, er wolle mich besuchen; ich erwiderte ihm durch den Dolmetscher, dass ich mich freue ihn zu sehen und dass ich ihn erwarte. Nun entstand ein drolliger Etiquettenstreit, denn die Mehrzahl meinte, ich müsse an die Sänfte herantreten und den in dieser sitzenden Oberpriester begrüssen. Da ich aber keine Miene machte, meinen Platz zu verlassen, musste doch der peinlichen Situation ein Ende gemacht werden. Der Priester machte endlich auch Anstalten, aus der Sänfte zu steigen, was die Leute stark erregte, da sie besorgten, er könne dadurch seiner Würde etwas vergeben. Trotz dieser Bedenken gewann er aber zuletzt die Oberhand und liess sich aus seiner Sänfte herausheben. Er schritt auf mich zu, reichte mir die Hand und nahm, wie jeder gewöhnliche Sterbliche, neben mir auf einem Eingeborenenschemel Platz. Ich behandelte ihn freundlich, da mir in diesem Falle nichts anderes übrig blieb und es die Vorsicht gebot. Er brachte mir Geschenke, Schafe sowie eine Menge Yams, wofur ich ihm dankte. Natürlich war es für ihn die Hauptsache, den eigentlichen Zweck meiner Reise zu erfahren, da er mit Recht besorgt sein mochte, dass seine Schandthaten und Verbrechen bekannt würden. Wenn er auch meine kleine Karawane nicht zu fürchten brauchte, so war doch immerhin sein Misstrauen geweckt worden. Ich teilte ihm mit, dass ich mich auf der Durchreise nach Salaga befände, um dort den König zu besuchen und kundigte ihm ferner die bevorstehende Anlage einer grossen Station in Kratyi selbst an. Diese Nachricht rief natürlich grosse Freude bei den Haussa hervor, während das Kratyivolk die Ankündigung von der Anlegung einer Station mit Misstrauen aufnahm. Nachdem wir uns noch gegenseitig nach Möglichkeit die Unwahrheit gesagt und unserer Freude über die gegenseitige Bekanntschaft Ausdruck gegeben hatten, verabschiedete sich Bosumfo und kletterte wieder in seine Sänfte, um nach Kratyi zurückzukehren. Alles atmete befreit auf und jeder ging wieder ruhig seiner Arbeit nach, während ich fortfuhr die weiteren Eventualitäten der Reise mit Sofo zu besprechen, der ihr beständig Hindernisse in den Weg legte. Bald war es Freitag, ein Tag, an dem natürlich kein Mohamedaner eine Reise antreten kann, bald hatte er wieder einen anderen Vorwand ersonnen, und jedesmal wurde die Abreise mit dem üblichen "Inschallah" auf den nächsten Tag verschoben.

Ein Tornado. Am Nachmittag entlud sich, wie fast alle Tage um dieselbe Zeit, ein furchtbarer Tornado, den zu schildern ich bei dieser Gelegenheit nicht unterlassen möchte. Die Sonne verfinstert sich, der Himmel färbt sich dunkel und eilig, ziehen kleine abgerissene Wolken von dem Volta her über die 
Stadt. Die ganze Natur ist wie abgestorben, denn alles hat sich in die Hütten geflüchtet. Auch die Vögel sind verstummt und jene dumpfe Stille tritt ein, welche immer einem grossen Unwetter vorangeht. Einzelne Windstösse künden den Sturm an und in wenigen Minuten hat er den Ort erreicht. Hohe Staubwolken, vermischt mit abgerissenen Blättern und Zweigen, wirbeln empor und der Himmel verfinstert sich immer mehr. Tiefschwarze Wolken wälzen sich heran, Blitze zucken daraus hernieder und unmittelbar darauf folgen krachende Donnerschläge. Das Unwetter tobt gerade über uns. Grosse Tropfen beginnen zu fallen, erst vereinzelt dann stärker, bis in wenigen Vinuten sich ein Wolkenbruch über Stadt und Land ergiesst. Immer kürzer werden die Pausen zwischen Blitz und Donner und gewaltige Schläge bohren sich in das Erdreich, oder fällen die Riesen des Urwaldes, begleitet von dem Krachen des entfesselten Elementes. So rasch wie das Unwetter Schrecken verbreitend hereinbricht, so rasch geht es auch vorüber. Aber noch lange zucken Blitze aus den in der Ferne abziehenden Wolken. Der Regen wird schwächer, erquickt Menschen und Tiere und spendet den nach Feuchtigkeit lechzenden Tropenpflanzen die ersehnte Nahrung. Schon nach Verlauf einer Stunde lacht gewöhnlich die Tropensonne wieder am blauen Firmament. In der Regel setzen die Tornados in Kete während der Regenperiode im Oktober fast mit der Genauigkeit einer Uhr zwischen vier und fünf Uhr nachmittags ein. Wer um diese Zeit bei einer Temperatur von etwa $30^{\circ} \mathrm{C}$. im Schatten unter Dach und Fach sitzt, erfreut sich der Abkuhlung. Wen aber ein solcher Tornado unterwegs auf der Reise trifft, der ist nach wenigen Minuten bis auf die Haut durchnässt. In kurzer Zeit schwellen alle kleinen Bäche an, die Wege sind durchweicht und bei jedem Schritt vorwärts rutscht man um einen Viertelschritt zurück. Die Stimmung des Negers ist unter solchen Umständen sehr gedrückt; kein Scherz belebt die Trägerkolonne und mutlos, dem Wetter grollend, schreitet sie ihrem nächsten Ziele zu. Zündet ein Blitz, so ist es interessant zu beobachten, wie verschieden sich der Haussa und der Eingeborene gegen das Feuer verhalten. Bei einem Brand in Kete habe ich bemerkt, dass die heidnischen Eingeborenen alles noch $z u$ retten suchen, was $z u$ retten ist. Frauen und Kinder schreien, alles schleppt Wasser herbei und ein heilloser Spektakel begleitet das Löschungswerk. Während dieses geschäftigen Treibens stehen die Haussa regungslos und stumm daneben, alles dem unerbittlichen Fatum preisgebend. Unthätig und träge sehen sie dem Spiel der Flammen zu und halten womöglich noch die Eingeborenen von der Rettung ab, in der Meinung, dass Allah es so gewollt habe und er allein dem Feuer Einhalt gebieten könne. 
r.esuch des Königs Odukru.

Die vertriebene Salagaprinzen.
Der König Odukru, welcher von dem oben geschilderten Besuche des Fetischpriesters gehört hatte, wollte diesem nicht nachstehen und machte ebenfalls seine Aufwartung. Auch er kam mit grossem Gefolge, voran der alte Stabträger, der das Nahen des Königs ankündigte. Er benutzte, wie der Fetischpriester, bei solchen feierlichen Aufzügen ebenfalls eine Hängematte, nur dass dieselbe nicht aus Seide bestand, sondern aus dem weniger kostbaren, im Lande selbst gewebten, haltbaren, grauroten Stoffe. Um seine Hüften trug er ein schönes Umschlagetuch, ebenfalls ein Artikel der einheimischen Hausindustrie; auch die grossen Trommeln fehlten nicht, welche bei allen Aufzügen in diesem Lande eine wichtige Rolle spielen. König Odukru war ein sehr alter, gebrechlicher Mann mit grauen Haaren. Ich empfing ihn freundlich, da ich wusste, dass er wenig Schuld an den Verbrechen hatte, welche Kratyi gefurchtet machen, und nur eine Puppe in den Händen des Fetischpriesters war. Er brachte mir Yams, Schafe und einige höchst willkommene Ananasfrüchte zum Geschenk. Er versicherte mich seiner Freundschaft, während ich ihn ermahnte, den Befehlen der Regierung nachzukommen, zumal er als König des Landes für alle Schandthaten verantwortlich sei; ferner machte ich ihn darauf aufmerksam, dass er besonders die deutschen Händler, die aus dem deutschen Gebiete nach Kratyi kämen, zu schützen habe, und legte ihm auch eindringlich den Schutz der Haussa, als unserer Freunde, ans Herz. Als Gegenleistung sicherte ich ihm den Schutz der deutschen Regierung gegen alle inneren und äusseren Feinde seines Landes zu. Auch kündigte ich ihm den Bau einer grossen Station in Kete an, die bestimmt sei, seine Autorität zu unterstützen und seinen Befehlen innerhalb seines Reiches Achtung zu verschaffen. Nach dieser Besprechung winkte der König und es traten einige stattliche alte Gestalten, mit blauen Haussatoben und phrygischen Mützen bekleidet, hervor, welche mir als Prinzen des vertriebenen und getöteten Königs Mama von Salaga vorgestellt wurden. Das Auftreten dieser vornehmen alten Leute machte einen würdigen Eindruck, namentlich im Gegensatz zu dem hochmütigen Fetischpriester und dem unbedeutenden König Odukru. Sie baten mich flehentlich um Schutz für den Sohn ihres getöteten Königs, sie seien überall in dem grossen Gonyareiche herumgezogen, um Hilfe zu suchen, aber stets von den Anhängern des jetzigen unrechtmässigen Königs Isafa und von den im Lande sich herumtreibenden Dagombahorden verfolgt worden. Ihr Gut und ihre Sklaven seien ihnen geraubt und viele ihrer Anhänger getötet worden. Ich sagte ihnen den Schutz der deutschen Regierung zu, da sie sich auf deutschem Boden befänden, wo immer Gerechtigkeit geübt werde. Darauf wurde ein etwa I6-I7jähriger junger Mann geholt, der nur dürftig mit einem Schamtuch um seine Lenden bekleidet war und dessen 
Backen eine Tätowierung von drei langen Einschnitten von den Schläfen bis zu den Mundwinkeln, ähnlich der Tätowierung der Haussa, aufwiesen. Dieselben Zeichen hatten auch die übrigen Prinzen. Dieser junge Mann wurde mir als der Sohn und rechtmässige Erbe des Königs von Salaga vorgestellt. Schüchtern und angstvoll kniete er zum Grusse nieder nach Art der Eingeborenen, wenn sie einem Häuptling ihren Dank äussern wollen. Dieser junge Mann war der Prinz Lempo, ein Name, den er noch heute im Volksmunde führt. Er hat jetzt unter dem Namen Sulemana als König des grossen Gonyareiches seinen Sitz in Kratyi aufgeschlagen und das rechtmässige Erbe seines Vaters angetreten. Ich wurde inständigst gebeten, den unrechtmässigen Sultan Isafa, mit dem Spottnamen Kapaki, aus Salaga zu vertreiben und Lempo auf den angestammten Thron zu setzen. Es war allerdings ein seltsames Ansinnen, dass ich mit zwei Soldaten und drei Gewehren gegen Salaga ziehen sollte. Und doch hätte mich der Anblick dieser ehrwürdigen alten Salagaleute dazu begeistern können, für den rechtmässigen Erben das Schwert in die Wagschale zu werfen und an der Spitze eines Haussaund Gonyaheeres gegen Salaga zu ziehen, um auch in Afrika dem guten deutschen Rechte Geltung zu verschaffen. Aber ideale Ziele mussten hier der Zweckmässigkeit und nüchternen Erwägung weichen. Auch hatte ich vor allem die neutrale Zone zu respektieren. Ich erwiderte also den Salaga-Prinzen in der öffentlichen Versammlung, in der sowoh! Gegner als Freunde der Sache sein konnten, dass ich nichts für sie thun könne, solange Salaga nicht deutsches Land sei. Dagegen erklärte ich nochmals vor der ganzen Versammlung, dass es niemand wagen solle, seien es Dagomba- oder Gonyaleute, den Flüchtlingen ein Haar zu krümmen, solange sie auf deutschem Boden wären und dass die Regierung Zuwiderhandlungen streng bestrafen würde. Die Prinzen bat ich, mich später aufzusuchen, um ihre Angelegenheit ohne Zeugen zu verhandeln. Bei dieser Unterredung versprach ich ihnen, dass ich nach meiner Rückkehr aus Salaga für sie eintreten würde, sagte ihnen auch für später jede Unterstützung zu, wenn die Station erst errichtet sein würde. Zunächst sollten sie ihre Boten zu den versprengten Prinzen und Anhängern des Königs Mama schicken, damit ich dieselben alle bei meiner Rückkehr von der Reise in Kratyi empfangen und sprechen könne; bis auf weiteres sollten sie sich hier ansiedeln. So entstand nachmals die Kolonie Neu-Salaga bei Kete. Später bei der Gründung der Station wurde dann Lempo als rechtmässiger König von Gonya mit dem Namen Sulemana gekrönt. Durch den Fall und Niedergang von Salaga hat Kratyi, was den Handelsverkehr betrifft, zum grössten Teil die Erbschaft von Salaga angetreten, ist durch neuen Zuzug stetig gewachsen und schliesslich ein Centralpunkt des Handels geworden. 
Der Thronfolgestreit in Salaga.

Zum besseren V'erständnis der politischen Lage und des Erbfolgestreites von Salaga ist es erforderlich, auf die Königsgeschichte sowie die Ursache zu den Thronstreitigkeiten näher einzugehen. Das eigentliche Königreich Gonya soll vor Jahrhunderten durch das Vordringen der Mandingo südlich des grossen Nigerbogens begründet worden sein. Wahrscheinlich ist dieses Königreich ein Ueberrest aus der Blütezeit

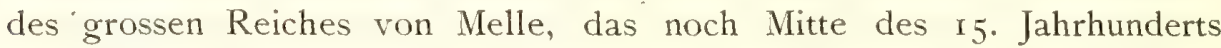
seine grösste Ausdehnung im westlichen Sudan besass und im I6. Jahrhundert durch die Sonrhays verdrängt wurde. In diese Zeit scheint auch die Gründung des Gonyareiches zu fallen, wo es wahrscheinlich aus den Trümmern des Melle-Reiches unter einer Mandingo-Dynastie entstand. - Seit der Gründung dieses Königreichs, welches mit seiner Hauptstadt Salaga zu einer hervorragenden Blüte gelangt ist, sollen einige zwanzig Könige geherrscht haben. Man kann also die Entstehung des Reiches, wenn man die Regierung eines jeden Königs im Durchschnitt auf I $_{5}$ Jahre veranschlagt, in das 16. Jahrhunderts verlegen, was mit dem Zerfall des Melle-Reiches ungefähr zusammenfallen würde. Die Reihe der uns bekannten Könige beginnt mit dem König Mama von Salaga, den Major von François zuerst im Jahre I888 besucht und mit dem er einen Freundschaftsvertrag für das deutsche Reich geschlossen hat. Unter König Mama entstand ein Thronfolgestreit, indem der Häuptling von Kabaki schon beim Regierungsantritt des Königs Mama die rechtmässige Thronfolge für seine Familie in Anspruch nahm. Die Königswürde soll, wie mir in Kratyi erzählt wurde, nach einer Reihe von Jahren unter den Mitgliedern der Königsfamilie abwechseln. Aus diesem Grunde soll Kabaki den Thron für sich in Anspruch genommen und später, im Jahre I892, mit Hilfe der Dagomba den alten König Mama gestürzt und sich auf den Thron geschwungen haben. Den Dagombakönig in Jendi konnte Kabaki nur für diesen Schritt gewinnen, indem er sich seiner Oberhoheit unterwarf. Kapaki nahm als Sultan von Salaga den Namen Isafa an und regierte seit I 892 unter den schwierigsten Verhältnissen und der Ungunst seines Volkes. Als seine letzten Anhänger von ihm abzufallen drohten, vergiftete er sich zu Anfang des Jahres 1897. Der Afrikareisende G. A. Krause war gerade in Salaga anwesend, als der Thronfolgestreit eintrat. Er schildert das Anrücken des dem Thronprätendenten zu Hilfe eilenden Dagombaheeres als ein so plötzliches, dass kein Mensch es wagte, den 800 Kriegern, wovon 200 Reiter, irgendwelchen Widerstand zu leisten. So ergriff alles, auch der König selbst mit einigen Getreuen die Flucht, wobei die meisten nur ihr nacktes Leben retten konnten. Ihre ganze Habe fiel den raubsüchtigen Dagombahorden anheim. Ueber die Flucht des Königs Mama sind die verschiedensten Legenden im Volke verbreitet. Die einen behaupten, dass er auf seinem Rückzuge mehrere Gefechte geliefert 
habe, dabei von seinen Feinden gefangen und getötet worden sei. Andere wollen wissen, dass der König als Sklave in Dagomba lebe; wieder andere sagen, dass er freiwillig den Tod in dem Grenzflusse Daka gesucht habe und seine Seele dort in ein Krokodil gefahren sei. Das Wahrscheinlichste jedoch ist, dass König Nama in einem Gefecht gefallen und getötet worden ist.

Der Jendikönig soll seinen Leuten streng verboten haben, Salaga zu zerstören und zu plündern; er soll nur den Befehl erteilt haben, den König Mama gefangen zu nehmen und Kapaki auf den Thron zu setzen. Die Horden stürzten sich jedoch mit Habgier auf die Stadt und den Königssitz Pembi, zerstörten und plünderten alles, und machten nieder, was sich ihnen widersetzte. Salaga wurde bis auf wenige kahle Mauern vollkommen vernichtet und dem Erdboden gleich gemacht. Auch die übrigen Städte südlich von Salaga bis zum Daka, wo Mama und seine Anhänger etappenweise hingeflohen waren, wurden in einzelnen Gefechten angegriffen und teilten das Los der Hauptstadt des Landes.

Bevor ich Kete verliess, gelangte an den König Odukru die Nach-Gegenbesuch richt, dass der nunmehrige Sultan Isafa von Salaga Abgesandte an ihn beim König geschickt hätte mit der Aufforderung, nach meinem Abrücken Lempo, den Sohn des früheren Königs ron Salaga auszuliefern oder den Krieg zu gewärtigen. Als ich dies erfuhr, bestieg ich sofort meinen Hassan und bat Sofo, mich als Zeuge zu dem König nach Kratyi zu begleiten. Gleichzeitig gedachte ich vor der Abreise dem Könige meinen Besuch und Dank für die zweifelhafte Gastfreundschaft, die ich in seinem Lande genossen hatte, abzustatten. Viele vornehme Haussa aus der Stadt hatten sich auf schönen, gesattelten Pferden mit ihren Pferdehaltern. und Sklaven vor dem Gehöft des Sofo versammelt, als sie hörten, dass ich nachmittags um ${ }_{1}^{1} / 2$ Uhr meinen Besuch bei dem König ron Kratyi angemeldet hätte. Um die festgesetzte Zeit ritt ich mit einem imposanten Gefolge von Reitern und daneben herlaufenden Sklaven nach der Königsstadt Kratyi. Alles stieg vor Kratyi vom Pferde, da der Fetischpriester keine Pferde in seiner Stadt duldet. Nur ich ritt als einziger in die Stadt ein, während mir die Haussa zu Fuss folgten. Hier fand ich Odukru in seinem Gehöft vor, welcher mich mit seinem ganzen Gefolge und seinen Leibsklaven unter einem kleinen Schattendach vor seiner Hutte empting. Zur Fëier des Tages hatte Odukru an der Hütte Bilder aufgehangen, in denen ich $z u$ meiner Ueberraschung und Freude Porträts Kaiser Wilhelms I und Kaiser Friedrichs erkannt. Grosse Aehnlichkeit hatten diese von der Witterung stark mitgenommenen Gemälde nicht mehr, doch erinnerte mich ihr Vorhandensein daran, dass früher deutsche Reisende hier in patriotischer Weise gewirkt hatten.

Odukru sass auf einem schön geschnitzten Königsstuhl, um ihn herum kauerten die Stadträter ebenfalls auf kleinen Holzschemeln und 
daneben standen seine Leibsklaven, welche einen sonderbaren, aus Baumwolle gefertigten, schwarz gefärbten Shawl um die Lenden und die Scham gewunden hatten. Die Enden dieses Shawls waren mit einer Quaste und Messingringen versehen und hingen hinten weit herunter. Da die übrige Gestalt sonst vollkommen nackt war, hätte man, namentlich von weitem, im ersten Augenblick glauben können, geschwänzte Menschen vor sich zu haben.

Ich dankte Odukru nochmals für seine Geschenke und erinnerte ihn an sein Versprechen, den Salagaflüchtlingen Schutz zu gewähren. Er war durch die Drohungen Kapakis wieder wankend geworden und ich hatte alle Mühe, ihn von einer Auslieferung des Königssohns abzuhalten. Ich sagte ihm, dass ich mit meinem Kopf für sein Leben, er aber mit dem seinen für das Lempos hafte. Widerstrebend willigte er endlich ein und nachdem er mir noch Glück zur Reise gewünscht hatte, schüttelten wir uns zum Abschied kräftig die Hände.

Vor- Mit den Vorbereitungen zur Abreise wurde nun endlich Ernst bereitungen gemacht. Sofo, welcher wie alle Haussa, mit der Reise ein gutes zur Geschäft verbinden wollte, hatte einen grossen Vorrat von Kolanüssen Weiterreise aufgekauft und diese sorgfältig mit Blättern in Tragkörbe verpackt. Mittlerweile hatte sich noch eine ganze Anzahl anderer vornehmer Haussa gefunden, welche sämtlich die Reise nach Salaga mitmachen wollten. Als alles fertig war und ich zum Abmarsch drängte, erschien noch Malam, der mohamedanische Priester. Alle Teilnehmer der Reise und andere Haussa hatten sich vor dem Gehöft von Sofo versammelt. Der Priester segnete sämtliche Reisenden ein und flehte zu Allah, dass er ihnen gnädig sein möge. Es war auch für mich als Christen ein ergreifendes Schauspiel, die Haussa mit ihren Schwertern und Gewändern, die Weiber Sofos uud die ganze übrige Versammlung im Gebet auf den Knieen liegen zu sehen. Der ehrwürdige alte Priester kam auch zu mir und wünschte mir, dass Allah mich in seinen Schutz nehmen möge. Obwohl die Haussa nicht gerade zu den fanatischen und strenggläubigen Mohamedanern gerechnet werden können, so halten sie doch selbst auf ihren weiten Reisen an allen religiösen Vorschriften fest.

\section{VON KETE NACH SALAGA.}

Nachdem nochmals Abschied von den Zurückbleibenden genommen war, stieg alles zu Pferde; fast sämtliche berittene Haussa von Kete hatten sich eingefunden. Bald hatte sich die kleine Karawane geordnet, voran marschierten Soldaten, dahinter meine wenigen Träger und diesen folgten die Träger der mitreisenden Haussahonoratioren. Alle waren mit schweren Lasten beladen, welche meistens Kolanüsse enthielten, 
während die Frauen des Sofo mit ihren Sklaven und Kindern fast den ganzen Hausvorrat, Kalabassen, Maisbrote und Töpfe für das Lager mit sich führten. Natürlich fehlten auch nicht die Trommler und Lobsänger, welche unter Trommelschlag den Ruhm des grossen Haussahäuptlings zu verkünden hatten. Obwohl Sofo mir sagte, dass er die Leute nur mir zu Ehren mitgenommen hätte, wurde ich im Vergleich zu Sofo spärlich mit Lobeshymnen bedacht. Unter unaufhörlichem Trommeln und Gesang setzte sich die stattliche Karawane in Bewegung, welcher ich mit Sofo und der übrigen bunten berittenen Haussasuite folgte. Es gewährte einen malerischen Anblick, als wir durch die engen kleinen Strassen zogen, welche von Neugierigen dicht besetzt waren. Hinter allen Zäunen und Hütten lugten die Leute hervor und riefen uns einen Abschiedsgruss nach. Die berittene Suite begleitete uns bis an die Grenzmarken der Stadt. Hier nahm auch sie mit besten Wünschen Marsch durch Abschied. Obwohl unsere Zahl dadurch beträchtlich zusammenschmolz, die Savanne hatte meine Karawane jetzt immerhin ein anderes Aussehen, als bei dem Einmarsch in Kratyi. Die Sitte der Vornehmen verlangt es, dass in diesen Gegenden der Weisse, der Vertreter einer Regierung, reitet, falls er nicht eine Hängematte mit sich führt. Ueberall in der Nähe von Dörfern und Hütten liess der Haussatrommler seinen eintönigen langgedehnten Gesang vernehmen, indem er dabei unermüdlich das Kalbfell seiner Trommel bearbeitete. Der Marsch führte zuerst durch die eintönige Ebene, dann auf die Höhenzüge des Volta, von denen man mehrmals im Westen das Voltathal erblickte, während sich im Osten die etwa $300 \mathrm{~m}$ flach ansteigenden Höhen von Abudjiro hinziehen. Auf diesem Wege begegnete mir zum ersten Male ein Sklave, der im Halseisen ging und die Last seines Herrn, des ihn begleitenden Haussa, trug. Ich drohte der fremden Karawane, auf sie Feuer geben zu lassen, wenn sie nicht sofort den Sklaven freigäbe. Der auf diese Weise befreite Sklave leistete mir später in der Gegend, in der er zu Hause war, gute Führerdienste. Die Vegetation nahm nun wieder den eintönigen Savannencharakter an, in dem verkrüppelte Tshibutterbäume mit Mimosen abwechseln. Nach dreistündigem Marsche gelangten wir glücklich nach Tariasso, einem kleinen Dorfe, welches nicht mehr als dreihundert Hütten zählt. Dieses Dorf gehört gewissermaassen zu der Domäne des Fetischpriesters in Kratyi. Nach einer kurzen Rast auf dem kleinen schattigen Marktplatze marschierten wir weiter und erreichten das grosse Sklavendorf Bombatá. Hier wurde ich mit grossem Jubel von der Bevölkerung aufgenommen, da der befreite Sklave seinen Landsleuten sogleich seine Rettung berichtet hatte. Sie gaben ihrer Freude und ihrem Dank durch kleine aber wohlgemeinte Geschenke Ausdruck. 
Das Sklaven- In Bombatá übernachteten wir, um am anderen Morgen nach dorf Bombatá. Bayamso weiter zu marschieren. Bombatá hat erst in der letzten Zeit sich zu einem stattlichen Dorfe entwickelt. Die Bewohner sind fast alle Sklaven, die sich vor der Schreckensherrschaft der Aschantis auf das diesseitige Ufer des Volta geflüchtet hatten. Verschiedene Stämme sind hier bunt durcheinander gewürfelt, Grussi-, Mossi-Leute und andere wohnen friedlich nebeneinander. Der ganze Ort besteht aus drei kleinen Flecken, die nahe aneinander liegen und zwischen denen sich schöne Felder mit Erdnüssen, Mais-, Reis- und Guineakorn ausdehnen. Die Hütten sind alle rund, zum Teil aus Lehm, zum Teil aber auch aus Grasmatten erbaut.

Am anderen Morgen früh sechs Uhr brach ich mit Sofo wieder auf und marschierte durch die grosse Baumsavanne über Kwashikrum. Hier ist von den Reisenden ein kleines Lager von Laubhütten aufgeschlagen, was den Karawanen auf der grossen Strasse nach Salaga als Rast- und Nachtlager dient. Der Weg führte nun über einen grossen, schönen, von vielen kleinen Gewässern durchzogenen Wiesenplan. Diese Bäche fliessen alle in den Volta und verleihen der Gegend, in der nicht weit vom Wege der aus nur wenigen Hütten bestehende Ort Baforre liegt, ein heiteres und fruchtbares Aussehen. Bald erreichten wir das Flüsschen Bado, welches auf einem Baumstamme überschritten wurde, und nach einer Stunde auch den Schwesterfluss Djem, der infolge seiner flachen Ufer die Savanne weithin unter Wasser gesetzt hatte und uns nötigte, einen kleinen Umweg über die Höhen und ein Farmdorf, welches schon zu Bayamso gehört, zu machen. Nun befanden wir uns wieder inmitten üppiger Farmen. In der Savanne und auf den Wiesen grasten eine schöne Rinderherde sowie eine Anzahl Pferde der hierher geflüchteten Salagaleute.

In Bayamso, das aus etwa 500 Hütten besteht, wurden wir von dem Häuptling und den Flüchtlingen auf dem Marktplatze empfangen. Wir schlugen hier unser Nachtquartier auf und blieben bis zum nächsten Tage. Bayamso hat infolge des Erbfolgestreites und des Krieges mit Salaga an Bedeutung ganz erheblich gewonnen, da es einen Zuzug durch die Salagaleute erfahren hat und ferner der letzte grössere Ort auf der Strasse nach Salaga ist, wo die Karawanen gezwungen sind, ihre Vorräte an Proviant zu ergänzen. Auch bildet Bayamso einen Knotenpunkt der verschiedenen Strassen in der Landschaft Ntshumuru, in welcher es im Süden unstreitig die bedeutendste Stadt ist; von hier gehen ebenfalls verschiedene Wege nach dem englischen Gebiet, sowie nach der neutralen Zone des rechtsseitigen Voltaufers. Eine Fähre über den Volta vermittelt den Verkehr mit der grossen englischen Strasse, welche am rechten Ufer des Voltas entlangführt. Bayamso liegt noch 


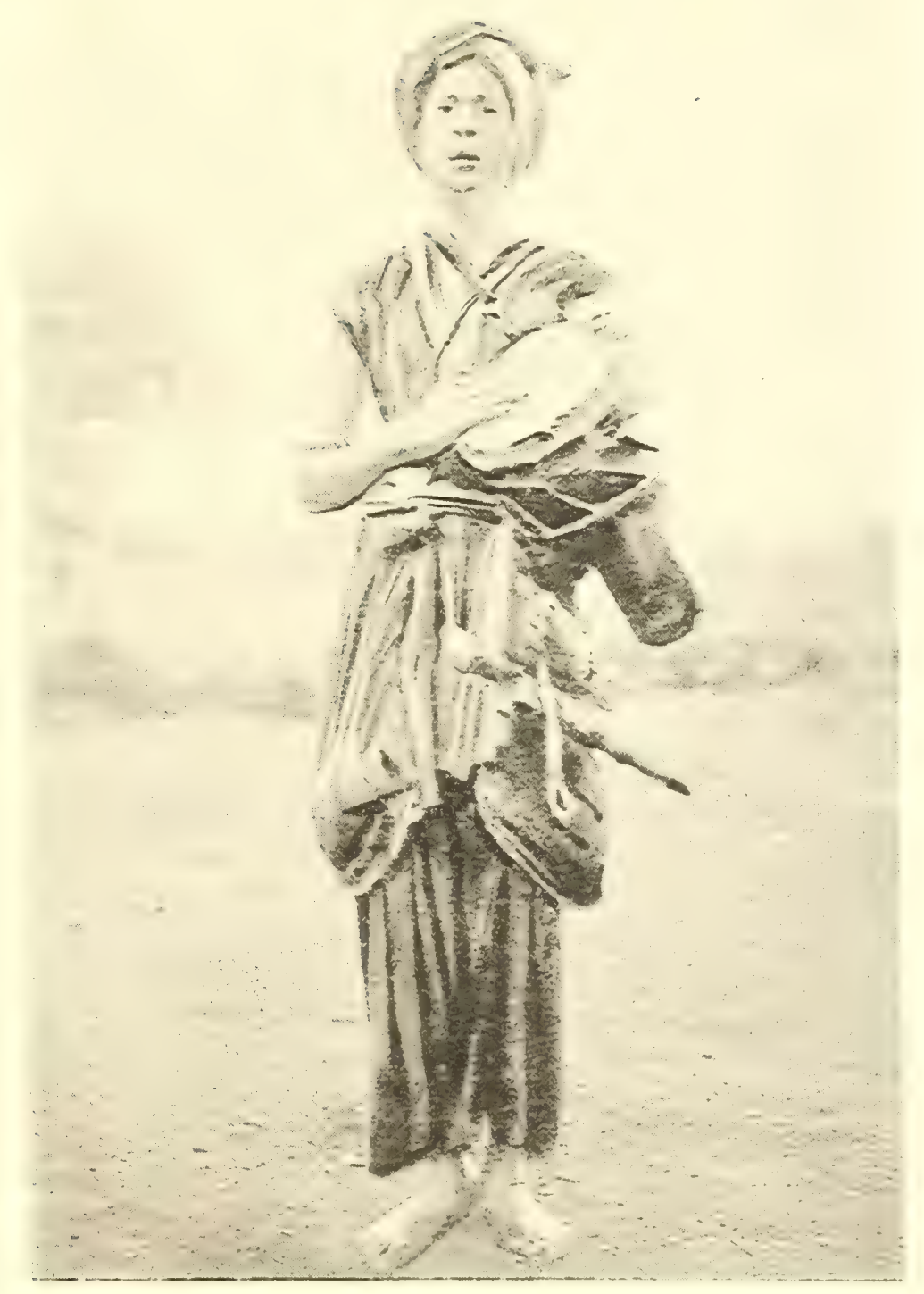

Fabrender Sänger mit Trommel bei mohamedanischen Fürstenhöfen. 
auf deutschem Gebiet und gehört zu dem Kratyireiche; auch hier hat der Fetisch des Dente Wurzel gefasst und ein hoher Fetischkegel begegnet uns schon am Eingange der Stadt. Wie überall in der Landschaft Ntshumuru sind hier kleine runde Lehmhütten mit Kegeldach üblich. Die Leute in der Landschaft Ntshumuru beschäftigen sich hauptsächlich mit Feldarbeit, aber auch mit der Fischerei im Volta und dessen Nebenflüssen sowie mit der Jagd. Bayamso selbst ist mit seinen engen Strassen und den auf einen kleinen Fleck zusammengedrängten Hütten ein schmutziger Ort. Die vielen frei herumlaufenden Schafe, Ziegen und Schweine tragen nicht wenig zur Unsauberkeit bei.

Kaum hatte ich es mir in einem kleinen Gehöft, welches mir vom Häuptlinge angewiesen war, bequem gemacht, so kam auch schon eine weitere Gesandtschaft der geflüchteten Salagaprinzen, welche meinen Schutz anrief. Gleich darauf erschienen die in Bayamso eben eingetroffenen Gesandten und Krieger des neuen Sultans Isafa, welche stürmisch die Auslieferung der Prinzen und Flüchtlinge verlangten. Ich erwiderte, dass ich nichts dagegen hätte, wenn dieselben freiwillig mit ihnen gehen wollten, dass ich aber nicht befugt wäre, sie auszuliefern, da jeder im deutschen Gebiete frei wäre und unter dem Schutze des Reiches stände; es sei mir eine Freude, sie als Gäste auf deutschem Gebiet zu begrüssen, ich müsse sie jedoch auffordern, auch hier die Gesetze des Landes zu respektieren, falls sie nicht einen Ḱrieg heraufbeschwören wollten. Einige Geschenke an Tabak und Rum sicherten mir ihre Freundschaft und dadurch auch die ihres Herrn, welchen sie natürlich sofort von der Angelegenheit sowie von meiner Ankunft benachrichtigt hatten. Die Flüchtlinge übergab ich dem persönlịchen Schutze des Häuptlings von Bayamso und bat sie, bei meiner Rückkunft nach Kratyi sich dort einzufinden.

Früh am nächsten Tage, nachdem ich meine Vorräte ergänzt hatte, Marsch durch marschierte ich, von den Salagaleuten bis hinter die Stadt begleitet, das verwüstete weiter. Die grosse Savanne schien sich ins Endlose auszudehnen. Hier und dort wurden einige Buschhühner aufgescheucht und auch Perlhühner machten sich durch ihren eigenartigen Ruf bemerklich. Gegen Mittag hatten wir endlich den kleinen Bach Boka erreicht, welcher nach den Angaben der Leute die Grenze zwischen Kratyi und Salaga bilden soll. Ein kurzer Marsch brachte uns nach dem kleinen Fischerort Banda, welcher dicht am Daka, einem rechten Nebenflusse des Volta, -liegt. Hier rasteten wir. Banda gehört schon zu Salaga und war auf meiner Route der einzige Ort, der wegen seiner Lage auf dem linken Ufer des Daka von der Verwüstung der Dagomba verschont geblieben ist. Die Leute betreiben Jagd und Fischerei. Andererseits werfen ihnen auch die durchziehenden Karawanen, die hier ihren Vorrat an Yams ergänzen, sowie die Fähre über den Daka eine schöne Einnahme ab.

Weitere Salagaflücbtlinge

Königreioh Gonya. 
Um Salaga schnell zu erreichen, wurde der Marsch trotz allen Sträubens Sofos, der an ein bequemeres Reisen gewöhnt war, weiter fortgesetzt und der Daka auf kleinen Kanoes überschritten. Der Daka besass damals eine Breite von $50 \mathrm{~m}$ und seine Tiefe war bei weitem grösser als die der vorher genannten Flüsse. Er ist tief, in hohe und sandige Ufer gebettet und hat ein schwaches Gefälle. Der Marsch fuhrt über kleine Anhöhen, welche den Daka begleiten, an verlassenen und zerstörten Hütten vorbei. Nach einer halben Stunde gelangten wir durch eine wilde Busch- und Baumsavanne nach dem ebenfalls verlassenen Orte Kurupi. Dieser Ort war gänzlich zerstört bis auf das Fetischgebäude, das anzutasten die Dagombaleute nicht gewagt hatten. Es dient heute den kleinen durchreisenden Karawanen als Herberge. Da dieses Fetischhaus von Fremden schon dicht besetzt war, mussten wir uns nach einer anderen Unterkunft umsehen. Schliesslich fanden wir $z u$ unserer grossen Freude noch einige kleine Hütten, die nicht ganz der Verwüstung anheimgefallen waren und deren Dächer wenigstens einigen Schutz gegen den Landregen boten, der sich inzwischen zu unserem grossen Missbehagen eingestellt hatte. In der einen Hütte schlug ich mit Sofo mein kümmerliches Quartier auf, während unsere Leute sich teils in das Fetischhaus, teils in die zweite halbverfallene Hütte flüchteten. Unsere Pferde konnten wir leider nur im Freien vor

Gestörte Nachtruhe durch Löwengebrüll.

unseren Hütten anbinden. So verbrachten wir eine schaurige Nacht unter den Trümmern des einst blühenden Negerdorfes. Die einst ausgetretenen Pfade waren überall bewachsen; auf den Ruinen und zwischen den stehen gebliebenen Mauern wuchsen Gras und hohe Dornen. In dieser Einöde hatte sich, wie uns schon die Eingeborenen von Banda berichteten, ein Löwenpaar eingenistet. Wir fanden ihre Fährte, welche zum Wasserplatz des Daka führte. Kein Mensch wagte sich bei der finsteren Nacht heraus und zum Schutze unserer Pferde wurde in der halb zerfallenen Hütte ein grosses Feuer aufrecht erhalten; die Soldaten hatten den Befehl, abwechselnd zu wachen. Es war Mitternacht geworden, doch liess uns der unaufhörliche Regen, der durch das schadhafte Dach in die Hütte tröpfelte, nur wenig zur Ruhe kommen. Plötzlich wurden wir durch das Wiehern unserer Pferde aufgeschreckt. Da ich meine Kleider nicht abgelegt hatte, trat ich, nichts Gutes ahnend, hinaus. Die Leute wåren natürlich eingeschlafen, das Feuer drohte zu erlöschen, die Pferde zitterten und stampften unruhig. Ich weckte die Leute und liess das Feuer wieder in Brand bringen. Als ich mich eben wieder auf das nasse Feldbett strecken wollte, wurde ich durch ein gewaltiges Gebrüll aufgeschreckt. Auch meine Leute waren mit einem Male munter geworden und stürmten mit dem Rufe: „Massa, Massa, one lion!" in meine Hütte. Nun war auch der schlaftrunkene Sofo mit einem 
Satze auf den Beinen. Noch einmal ertönte ein gewaltiges Brüllen, begleitet ron dem ängstlichen Gewieher unserer Pfercle. Ich griff sofort zu meinem Karabiner und forderte meine Leute auf, mit mir den Busch abzusuchen. Aber keiner verspürte irgend welche Lust dazu und selbst Sofo hielt es für ratsam, bei diesem Regenwetter die Hütte nicht zu verlassen, obwohl dieser Grund ziemlich hinfällig war, da wir alle schon durch die Traufe des Daches bis auf die Haut nass waren. Ich wählte meinen Träger Sapavi und den Soldaten Mama, die bei solchen Gelegenheiten immer den meisten Mut gezeigt hatten, bewaffnete sie mit Karabinern und patrouillierte den Pfad ab, welcher zum Daka führte. Aber die Nacht war so finster, dass man kaum drei Schritt weit sehen konnte. Unaufhörlich fiel der Regen nieder, in tiefer Stille lagen die Ruinen und der Busch; trotz gespannter Aufmerksamkeit hörte man nichts als die Stimmen vereinzelter Nachttiere und das Rauschen der Baumwipfel. Endlich sagte mir Sapavi, der etwas Negerenglisch radebrechte: "Massa, I think it is better we go at home, it is too dark." Sapavi hatte nicht unrecht und so gab ich, wiewohl ungern, die Jagd auf, ohne den Löwen gesichtet zu haben. Natürlich konnten Sapavi und Mama ihren Landsleuten nicht genug davon vorprahlen, wie sie jeden Augenblick bereit gewesen wären, den geladenen Karabiner anzulegen und abzudrücken; und es wurde mir erst nachträglich klar, dass ich bei diesem Streifzug in dem dichten Busch in der grössten Gefahr geschwebt hatte, von diesen Jagdhelden angeschossen zu werden.

Am nächsten Morgen hatte der Regen aufgehört und so nahm ich, Besichtigung bevor wir weiter marschierten, den stehengebliebenen Fetischtempel in eines FetischAugenschein. Es war eine 5 bis $6 \mathrm{~m}$ lange und ungetähr $4 \mathrm{~m}$ breite hauses. Giebelhütte aus Lehm, deren Wände eine Höhe von ungefïhr $2 \mathrm{~m}$ hatten. Das vermorschte Dach war innen durch rohe Holzpfeiler gestützt; die Wände waren schwarz angestrichen. Auf diesen befanden sich merkwürdige rohe Tierzeichnungen, die mit weisser Farbe aufgetragen waren und die Umrisse von Schildkröten, Antilopen und Schlangen erkennen liessen. Ausser diesen Zeichnungen scheint alles von den Priestern vor dem Kriege in Sicherheit gebracht worden zu sein. Diese

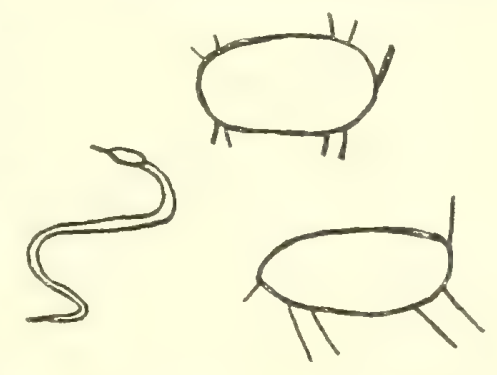
Figuren lassen darauf schliessen, dass hier entweder ein Tierkult stattgefunden hat oder wenigstens ein Fetisch verehrt wurde, der als Symbol diese Tiere im Wappen führte, ähnlich den Göttern an der Küste, welche wir bei dem Evherolke kennen gelernt haben. 

des Marsches durch eine grosse, schattenlose Baumsavanne, vorbei an den kleinen, durch Fieber ebenfalls verlassenen und zerstörten Dörfern von Alafi und Tsabodiga. Auf den vergrasten Mauern des Dorfes befanden sich massenhaft alte vermorschte Antilopenhörner. Ob diese einem Fetischzweck dienen sollten oder irgend eine andere symbolische Bedeutung hatten, konnte ich leider nicht ermitteln. Jedenfalls deuten diese Hörner auf einen grossen Wildreichtum in dieser Gegend hin. Inzwischen hatten der ermüdende Marsch, die Aufregung, die mangelhafte Proviantierung, die stets wechselnde Witterung und das beständige Durchwaten von Bächen und Sümpfen meinen sonst so widerstandsfähigen Körper erschöpft. Schon am frühen Morgen hatte ich ein Unwohlsein verspürt, welches der Vorbote eines heftigen Fiebers war, das sich auch bald, begleitet von starkem Kopfschmerz und unaufhörlichem Erbrechen, einstellte. Ich musste meine Aufnahmen auf Abstände von Io Minuten beschränken und endlich ganz einstellen, da mein Zustand sich so verschlimmert hatte, dass ich mich nicht mehr aufrecht halten konnte und mich lang auf das Gras in die brennende Sonne legen musste, um mich wenigstens von dem ermüdenden Marsche zu erholen. Endlich hatten meine Leute etwas Wasser gefunden, welches meinen krankhaft brennenden Durst einigermaassen löschte und es mir ermöglichte, den Marsch wieder eine Zeit lang fortzusetzen. So ging es etappenweise sehr langsam vorwärts. Mit dem Eintreten der Abendkühle besserte sich mein Zustand; aber mein Plan, Salaga noch an diesem Tage zu erreichen, musste infolge der vorgerückten Stunde aufgegeben werden. Da in dieser Gegend alle unvorhergesehenen Begebenheiten als Fetisch oder Fatum angesehen werden, verbot ich meinen Leuten, über den $Z$ wischenfall zu sprechen.

Begrüssung durch die Eskorte des Sultans von Salaga.
Schon war die Dämmerung eingetreten, die in den Tropen nur einen kurzen Uebergang zur Nacht bildet, als plötzlich meine Karawane hielt und mein nicht eben beherzter Dolmetscher Heinrich atemlos zu mir an die Queu gelaufen kam, mit dem Ausruf: "Herr, viele Reiter kommen angesprengt, sie werden uns töten". Ich ritt sofort an die Spitze und liess mir meinen Karabiner nebst Patronen bringen, als auch schon meine Leute schreiend auseinanderstoben und in Windeseile zwei Reiter mit erhobenen Speeren an mir vorbeijagten. In diesem Moment erschien auch mir die Lage kritisch, ich liess Halt machen, sammelte die Leute und hielt mich mit den Soldaten schussbereit. Doch bald fand das Rätsel seine Lösung. Sofo, der zurückgeblieben war, kam mit den Reitern vorgesprengt und erklärte, dass der Hofmarschall des Königs Isafa mit einer Eskorte von Reitern und Kriegern in dem nahe gelegenen Kurupi auf uns warte, um uns nach Salaga zum Sultan zu geleiten. Binnen kurzem hatten wir das verlassene Kurupi erreicht, wo 
uns die Feuer einer rastenden Karawane durch den Busch entgegen leuchteten. Es war ein eigentümliches und bezauberndes Bild, welches sich unseren Blicken darbot. Rings um den grossen mit hohen Seidenwoll- und Fikusbäumen umstandenen Marktplatz lagen die mit Gras überwucherten Ruinen des alten, durch den Krieg zerstörten Kurupi. Vor den kleinen Laubhütten brannten Feuer, um welche die schwarzen Reisenden kauerten. Auf dem Platze unter den hohen Bäumen hatte eine Anzahl Reiter in weissen Toben und phrygischen Mützen, mit langen Speeren bewaffnet, sowie mehrere Krieger mit langen Steinschlossflinten Aufstellung genommen. Die lodernden Flammen erleuchteten phantastisch die tiefe Wildnis. In Karriere ritt der Führer dieses Trupps auf mich zu, parierte sein Pferd auf dem Fleck, so dass es durch das plötzliche Anziehen der Kandare sich bäumte, während sein Reiter nach Haussaart, ähnlich unserem militärischen Grusse, mit der Hand salutierte. Er teilte mir durch Sofo, welcher den Dolmetscher machte, mit, dass der Sultan ihn mir entgegengesandt habe, um mir den Weg zu weisen; auch frische Pferde für mich und Sofo führe er mit. Da ich in meinem ermatteten Zustande keineswegs aufgelegt war, in der Nacht noch einen vierstündigen Marsch zu machen, so erwiderte ich dem Hofmarschall, dass ich erst morgen weiter zu reisen gedächte, zumal ich den Sultan nicht so spät in der Nacht stören und auch gern bei Tage in die schöne Königsstadt Pembi einziehen wolle. Meine Absicht sei, in aller Frühe aufzubrechen und um zehn Uhr in Salaga ein zumarschieren. Der Hofmarschall erklärte, dass er Befehl habe, mich zu geleiten und bereit sei, drei Wochen auf mich zu warten, wenn ich es verlange.

Die Salagakrieger trugen sämtlich ein Kriegswams, das aus einem kurzen grauen wattierten Haussahemd bestand und überall mit roten, schwarzen und grünen Ledertäschchen besetzt war. Diese enthielten Koransprüche, welche gegen feindliche Kugeln schützen sollen. Mit ihren phrygischen Mützen, hohen braunen Ledergamaschen und langen Speeren, machten die Reiter auf ihren ebenfalls mit bunten Amuletten behangenen Pferden einen kriegerischen Eindruck.

Die Krieger zu Fuss trugen fast dasselbe Gewand, jedoch keine Reiterstiefel; anstatt der Speere waren sie mit langen Steinschlossflinten bewaffnet, an deren Schaft, als königliches Abzeichen, ein langer Rossschweif hing.

Leider war ich auf diesen Aufenthalt in keiner Weise vorbereitet Nachtlager in und so fehlte mir und meinen Leuten jeglicher Proviant. Infolgedessen Kurupi. waren wir auf die Gnade der die Hütten mit uns teilenden Ashantikarawane angewiesen, welche uns für teures Geld etwas Yams abliess. Mittlerweile war es stockfinster geworden; die meisten Feuer waren 
erloschen und die Leute hatten sich zur Ruhe begeben, bis auf einige Wachen für die Pferde zum Schutze vor Leoparden und Hyänen. Auch ich legte mich in einer der primitiven Laubhütten nieder, konnte aber yor Fieberhitze und Ermüdung, sowie wegen des vielen Ungeziefers, das sich in diesen Hütten eingenistet hatte, nur wenig schlafen. In der Nacht hörte man häufig das Brüllen der Leoparden und das Heulen der Hyänen, Geräusche, welche einem in Afrika mit der Zeit bekannt werden. Mit Freuden begrüsste ich den ersten Morgenschimmer. Vor Tagesanbruch wurde Feuer angezündet, um die letzten Ueberreste des Yams in der glühenden Asche zu rösten. Die Sterne prangten noch am Himmel, während sich im Osten schon das Frührot zeigte. Allmählich begannen die dunklen Schatten der Nacht zu weichen, die Vögel belebten die Stille der Natur durch ihr Gezwitscher und dieses freundliche Stimmungsbild bot uns Ersatz für die überstandenen Strapazen und Entbehrungen des Marsches.

\section{IN DER RESIDENZSTADT PEMBI UND DER HAUPTSTADT SALAGA DES KÖNIGREICHS GONYA.}

Einzug in die

Mit Sonnenaufgang wurde aufgebrochen; Sofo bestieg das ihm Königsstadt entgegengesandte Pferd des Sultans, während ich beschloss meinen Pembi. Hassan, der mich so lange getragen hatte, auch bei dem feierlichen Einzuge in Salaga zu reiten. Nach einem vierstündigen Marsche durch die Baumsavanne sahen wir endlich Pembi, die Königsstadt, vor uns liegen. Nun ordnete sich der Zug; voran marschierte die Esskorte, der ich mit Sofo und meinem Dolmetscher Heinrich folgte. Letzterer war nicht wenig stolz, ein Pferd des Sultans reiten zu dürfen. Hierauf folgten sämtliche Träger mit ihren Lasten. In der Nähe der Stadt wurde der imposante Zug noch durch eine Reiterschar, welche uns in fliegender Karriere entgegensprengte, vermehrt. Es waren die Haussa, welche sich hier als Händler aufhielten und bei dem Gerücht von unserer Ankunft sich schnell beritten gemacht hatten, um mir wie ihrem stammverwandten Häuptlinge Sofo den ersten Gruss vor den Thoren zu entbieten. Wir ritten bis vor die Stadt, wo uns bedeutet wurde, dass wir warten müssten, bis der König seine Erlaubnis zu unserem Einzuge gegeben haben würde. Wahrscheinlich imponierte ihm meine kleine Karawane nicht, und er wollte mich seine Macht fühlen lassen. Da ich aber keineswegs gewillt war, mich bei meiner schwierigen Mission von der Laune dieses schwarzen Usurpators abhängig zu machen, erklärte ich dem Hofmarschall, dass ich als Abgesandter Sr. Majestät des deutschen Kaisers und als Gast des Sultans nicht beabsichtige, vor den Thoren der 
Stadt zu warten. Entweder der Sultan solle mir sofort die Erlaubnis erteilen einzuziehen oder ich würde auf einen Empfang seinerseits verzichten und, ohne ihn weiter zu berücksichtigen, durch sein Land zu dem grossen König der Dagomba nach Jendi marschieren, welchem ich meinen Besuch angesagt und der mir durch reitende Boten seine Freude hierüber habe ausdrücken lassen. Diese Erklärung verfehlte ihre Wirkung auf den übermütigen Sultan nicht. Im fliegenden Galopp kam der Hofmarschall zurück und brachte mir die Nachricht, dass der König sich nur zu einem feierlichen Empfange vorbereite, und dass mir als seinem Gast stets der Einzug in seine Stadt freistünde. Aus alledem ging hervor, wie ängstlich der Sultan, trotz dieser äusserlichen Zeremonieen, besorgt war, dass ich ihn übergehen und seinem Oberherrn, dem Sultan ron Jendi, berichten könne, welche Verwüstungen die raubsüchtigen Dagombahorden gegen seinen Befehl unter der Anführung Isafas in dem ganzen Gebiet angerichtet hätten. Wir ritten nun in Pembi ein, wo ebenfalls die meisten Hütten zerstört waren. Nur der eigentliche Königsplatz und die rings um diesen gelegenen Gehöfte waren erhalten; fast alle Einwohner dieses halbverlassenen Ortes waren auf den Beinen und die dumpfen Klänge der grossen Trommeln verkündeten, dass der Sultan seine wenigen Getreuen zu sich berief. Bald befanden wir uns vor dem Königlichen Palast, welcher aus etwa 20 runden Lehmhütten mit Kegeldach bestand. Die grosse Vorhütte, durch welche der Eingang in das Gehöft führte, war durch die hohe Spitze des Kegeldaches als Häuptlingshütte erkennbar. Alles stieg vom Pferde, da nur der König das Torrecht hat, hoch zu Ross einzureiten.

Ein unaufhörliches Pauken erdröhnte und die Musik, die aus den Empfang beim verschiedensten Instrumenten zusammengesetzt war, intonierte gewisser- Sultan Isafa. maassen einen Tusch. Zum Schrecken meines ängstlichen Dolmetschers blieb ich aber zu Pferde und sprengte auf meinem Hassan bis auf den Festplatz, wo der Sultan in der grossen offenen, mit einem Grasdach eingedeckten Königshalle, deren drei Seiten aus geflochtenen Matten bestanden, mit seinen Grossen und Sklaven versammelt war. Isafa sass zwischen drei grossen, bunten Lederkissen auf einer schönen Decke; vor ihm hockten seine Leibsklaven, von denen der eine einen grossen Spucknapf bereit hielt, wenn seine schwarze Majestät geruhte, sich $\mathrm{zu}$ räuspern. Der Sultan selbst trug ein schönes Haussagewand und über demselben den roten wollenen Königsmantel. Ueber den Kopf hatte er die Kapuze des Mantels geżogen, von deren Spitze eine Troddel über das schwarze Gesicht hing. Einer seiner Grossen sass neben ihm und hielt, seiner Würde als Sprecher und Ratgeber des Sultans gemäss, einen mit Leopardenfell benähten Königsstab in der Hand. Sämtliche Grossen umgaben den Sultan in der Halle und waren, 
wie er, mit schön gestickten Haussahemden und Toben bekleidet, nur dass die meisten eine Art phrygische Mütze aus Sammet oder Tuch trugen, oder wie der Kriegsminister Mama, das Haupt mit einem Fez bedeckt hatten.

Musikkapelle bei den

Haussa und an den mohamedanischen Fürster.

höfen.

Neben dieser Halle war die königliche Hofkapelle aufgestellt, welche mit bewunderungswürdiger Ausdauer ihre Instrumente bearbeitete. Bei dieser Kapelle spielte, wie bei allen afrikanischen Konzerten, die Trommel die Hauptrolle. Im übrigen bestand sie aus denselben Instrumenten, wie

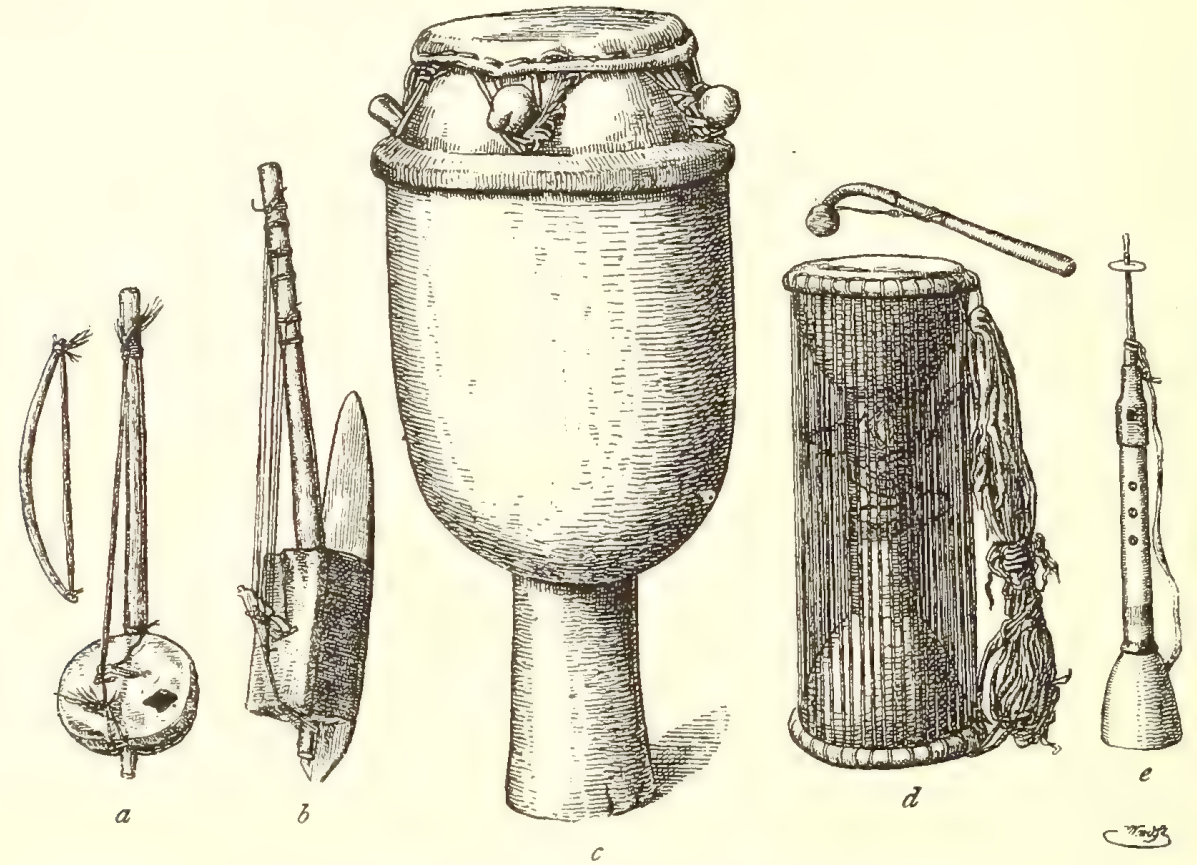

Im deutschen Sudan gebräuchliche Musikinstrumente.

a Haussageige aus Kete. $b$ Cuitarre der Banyau, $c$ Signaltrommel aus Salaga. $d$ Marschund Kriegstrommel aus Kete. e Klarinette der Haussa aus Kete.

Gez. naclı Originalen im Berliser Museum für Völkerkunde

die Haussakapellen. Den Mittelpunkt bilden zwei riesige Trommeln, welche von einem Trommler abwechselnd, wie unsere Kesselpauken, mit Paukenschlägeln geschlagen werden. Die grossen Trommeln werden durch viele kleinere Marschtrommeln begleitet. Einige dieser kleinen Trommeln können durch Spannschnüre gestimmt werden; sie werden unter dem Arm getragen, durch den Druck des Armes abgetönt und meistens mit einem kleinen Schlägel gerührt. Die grossen Trommeln dienen wie bei verschiedenen anderen Stämmen im Hinterlande von Togo als Signaltrommeln, auf denen Fremde schon von weitem von einem Ort zum anderen angemeldet werden, oder durch welche eine drohende Gefahr 
oder ein wichtiger Befehl des Häuptlings bekannt gegeben werden kann. Jedoch scheint diese Trommelsprache hier nicht in dem Naasse ausgebildet zu sein, wie im Hinterlande von Kamerun. $\mathrm{Zu}$ den Instrumenten gehört ferner ein wegen seiner Form "Alligator" benanntes Blasinstrument, welches unserer Klarinette ähnlich ist, da ihm durch Oeffnen und Schliessen der Schalllöcher verschiedene Töne entlockt werden. Auch entbehrt die Musik der Haussa keineswegs der Seiteninstrumente. So ist im allgemeinen eine Art Guitarre gebräuchlich; dieselbe besitzt einen aus einem Holzkasten hergestellten Resonanzboden, der mit einer gegerbten Haut überspannt ist. Das Griffbrett besteht aus einem mit Darmseiten bespannten Bogen. Die Krone dieser Instrumente ist aber die Geige. Sie ist allerdings kein Cremonenser Fabrikat, sondern wird von dem Musiker selbst hergestellt und vererbt sich vom Vater auf den Sohn, welcher auch von diesem in der Handhabung des Fiedelbogens unterrichtet wird. Ganz wie bei uns liegt der Wert der afrikanischen Geige in ihrem Alter. Die Geige ist ähnlich gebaut wie die Guitarre, nur ist sie kleiner, der Resonanzboden besteht gewönhnlich aus einem Kürbis und die Saiten sind aus starken Pferdehaaren hergestellt.

Vor der Königshalle sprang ich schnell aus dem Sattel und durchschritt die Reihe der vor dem König liegenden Sklaven, welche mir gewissermaassen zur Abwehr die Hände entgegenstreckten, was jedoch wenig Erfolg hatte. Nachdem ich einem derselben kräftig auf die Füsse getreten hatte, machten sie mir mit Respekt Platz und ich konnte ungehindert meinem königlichen Gästgeber die schwarze Rechte schütteln und ihm die Grüsse meiner Regierung übermitteln. Der König gebot sofort seiner Kapelle Schweigen und liess mir durch seinen Sprecher und meinen Dolmetscher mitteilen, dass er sich freue, mich in seiner Stadt empfangen zu können. Ich erklärte ihm offen, dass ich gekommen sei, um gegen die Uebergriffe des englischen Schwarzen Ferguson zu protestieren. Derselbe treibe ein falsches Spiel und vertrete nur seine eigenen Interessen. Ich könne nicht glauben, dass die befreundete Regierung Ihrer Majestät der Königin von England Deutschland gegenüber einen Vertragbruch begehen würde; ein solcher sei aber das Vorgehen des Ferguson. Salaga sei dem Vertrag nach ein Deutschen und Engländern gleich befreundetes, unabhängiges Königreich unter einem selbständigen Sultan, dessen Rechte nicht geschmälert werden dürften. Ferguson habe keine Befugnis, ohne weiteres mit vielen Soldaten durch das Land zu ziehen. Ich habe nur zwei Soldaten zu meinem persönlichen Schutze mitgenommen, um den Sultan als Freund der deutschen Regierung zu ehren. Ferguson hatte, wie ich mich überzeugte; eine kleine Besatzung von zwölf Haussasoldaten zurückgelassen. Der Sultan fürchtete sich wahrscheinlich, in der grossen Ver-

\footnotetext{
Protest vor dem Sultan gegen die englischen Intriguen in Salaga.
} 
sammlung öffentlich seine Missfallen über das despotische Auftreten des Ferguson zu äussern, zumal sich einige englische Händler und Soldaten unter der Volksmenge befanden. Er erwiderte daher, dass er heute nur seiner Freude Ausdruck geben wolle, den Abgesandten der deutschen Regierung bei sich zu begrüssen. Bald darauf fielen wieder die grossen Trommeln ein und damit war der feierliche Empfang beendet.

Austausch

von Ceschenken.
Es wurde mir und meinen Leuten ein kleines Gehöft angewiesen, in welchem wir uns in die Hütten teilten. Sofo und die übrige Haussabegleirung fanden Aufnahme bei den ihnen befreundeten Haussà. Leider stellte sich bei mir wieder das Fieber ein und nötigte mich, eine Schwitzkur vorzunehmen. Doch wurde ich bald gestört, da die Besuche der einzelnen Würdenträger und Notablen begannen. Zunächst erschien der Hofmarschall des Sultans mit dem Greschenk seines Herrn, das in einem jungen schönen Stier bestand. Mit Mühe und Not wurde das unbändige Tier vorgefuhrt und nicht viel fehlte, so hätte es die ganze Gesandschaft über den Haufen gerannt. Ferner erschien der Liman, der oberste mohamedanische Priester, der am Hofe von Salaga stets eine der einflussreichsten Stellungen inne hatte. Er brachte mir ein Schaf zum Geschenk mit und wünschte mir, dass Allah mich in Salaga unter seinen Schutz nehmen möchte. Mama, der Kriegsminister, an dem ich bald einen Freund erworben hatte, machte mir ebenfalls seinen Besuch. Mama war ein Dagombamann und fiel mir sofort durch seine äussere Erscheinung auf. An Grösse überragte er die ganze Versammlung. Sein Körperbau war kräftig und wurde durch die kleidsame Tracht, das lange weiss und blau gestickte Haussagewand und den roten Fez, noch gehoben. Die lebhaften schwarzen Augen verliehen dem wohlgeformten Gesicht, welches von einem schwarzen Bart umrahmt war, einen angenehmen und klugen Ausdruck. Mama folgte meinen Reden und denen des Sultans stets mit grosser Aufmerksamkeit und beteiligte sich auch bei kritischen Momenten an der Debatte. So nickte er mir zu, als ich bei meinem ersten Empfange öffentlich gegen die Uebergriffe des Ferguson protestierte. Die Haussakolonie brachte mir Geschenke von Yams und einigen Eiern, was mir bei der Teuerung und der geringen Zufuhr an Lebensmitteln sehr willkommen war. Auch der Chief von Salaga machte mir mit einigen Salagaleuten, die dort nach der Zerstörung wieder ihr Heim aufgeschlagen hatten, seinen Besuch.

Gegen Abend sandte ich durch Sofo und meinen Dolmetscher dem Sultan und den übrigen Grossen meine Gegengeschenke. Bei meiner spärlichen Ausrüstung war es mir zu meinem Verdruss unmöglich, die vielen Geschenke hinreichend zu erwidern. Ein paar Stücke Seide und Stoffe, welche ich zu unerhörten Preisen noch in Kratyi erstanden hatte, 
bildeten nebst Gin, Rum und Kolanüssen, welche Sofo mitgenommen hatte, meine Gegengeschenke. Natürlich machte Sofo aus meiner Verlegenheit sofort ein Geschäft und forderte unverschämte Preise für seine IVare. Ausserdem zwangen er und der Volmetscher der Tshisprache mich, ihnen eine hohe Belohnung an Geld zu geben, widrigenfalls sie drohten, nicht weiter mit dem Sultan zu verhandeln, sondern nach Kratyi zurückzukehren. Nach vielen V'ersprechungen gelang es mir schliesslich, Sofo zu gewinnen und damit den Dolmetscher von seinen augenblicklichen Forderungen abzubringen. Mit 300 Mark war es nicht ganz leicht, allen Verpflichtungen nachzukommen; sonst hatte ich, ausser dem Träger und

Ausnutzung meiner bedrängten Lage Koch Sapavi, der mir zwar in kritischen Momenten tapfer zur Seite stand, aber gar kein Verständnis für die. Vorgänge hatte, niemanden, auf den ich bei einer unglücklichen Wendung der Dinge rechnen konnte. Mein Dolmetscher Heinrich, der nur deutsch und Evhe sprach, mir also hier nicht mehr nützen konnte, und auch stets in Angst vor den kommenden Ereignissen schwebte, gereichte mir mehr zur Last als zum Vorteil. So war ich ganz auf Sofo und den Dolmetscher der Tshisprache angewiesen, welche nur auf ihren eigenen Vorteil bedacht, in jeder Weise meine bedrängte Lage auszubeuten suchten. Nan kann sich leicht vorstellen, wie schwierig unter diesen Umständen meine Situation war. Das Fieber, die Entbehrung jeglicher europäischer Genussmittel und die Strapazen der Reise hatten meine Stimmung sehr gedrückt. Alle Augenblicke musste ich von den Eingeborenen hören, wie freigebig Ferguson Seide und englisches Geld ausgeteilt habe, während ich nur mit Mühe und Not die mir dargereichten Geschenke annähernd zu erwidern vermöge. Die allgemeine Stimmung neigte daher natürlich dem Engländer zu. Erst später gelang es mir, die Zuneigung einiger einflussreicher Leute zu erwerben, wodurch sich auch die Stimmung des Volkes zu meinen Gunsten veränderte. $\mathrm{Zu}$ alledem kam noch die Ungunst der Witterung, die mich tagsüber an die kleinen rauchigen Hütțen fesselte. Die Preise für Lebensmittel waren unerhört; so wurde z. B. für ein Huhn der Preis ron 2 Mark bezahlt.

Der Sultan machte mir bald einen Besuch, dankte mir fü die Geschenke und bat mich um meinen Rat, wie er die durch den Krieg. zerstörten Städte wieder aufbauen könne. Ich erwiderte ihm, dass ich zuvor Salaga in Augenschein nehmen müsse. Dieses schien ihm wenig zu behagen, denn er beantwortete alle meine Fragen in Betreff von Salaga ausweichend und obgleich er mich zum Schluss bat, ihn in Kenntnis zu setzen, wann ich nach Salaga reiten wollte, da er mir einen Führer mitgeben und Vorbereitungen zu meinem Empfange veranlassen wolle, so merkte ich am nächsten Tage sehr wohl an seinen Ausflüchten, dass er meine Besichtigung ron Salaga zu hintertreiben 
suchte. Ich schwang mich also kurz entschlossen mit Sofo und meinem Dolmetscher aufs Pferd, sprengte zur Königsstadt Pembi hinaus und erreichte in einer halben Stunde, nachdem wir einige Erdnuss- und Guineakornfelder passiert hatten, das früher so berühmte Salaga.

Salaga Meine Vorstellung von der grossen Handelsstadt wurde gleich zerstört, als ich in die kläglichen Ueberreste dieser einst so stolzen Negermetropole einzog. Salaga, kann man wohl sagen, hatte aufgehört als solches zu existieren. Nur spärliche Trümmer ragten aus dem Grase hervor und erinnerten an die Zeiten einstiger Blüte. Zwischen den Ruinen sah man ab und zu tiefe Löcher, die früher Wasserzisternen gewesen waren. Da Salaga in der Ebene, weder an einem Bach noch an einem Fluss gelegen ist, so war es, namentlich in der Trockenzeit für Trink- und Kochwasser auf diese Zisternen angewiesen. Noch unappetitlicher sollen die Wasserverhältnisse dadurch gemacht worden sein, dass die Zisternen häufig gleichzeitig als Kloaken benutzt wurden. Hier herrschten auch fruher unter dem von allen Seiten zuströmenden Volke stets die Pocken. In Pembi liegen die Verhältnisse ähnlich. Ich bin dort leider selbst gezwungen gewesen, dieses nichts weniger als reine Wasser zu benutzen. Nur ein kleiner Teil des Platzes, auf dem einst so viele Sklavenmärkte abgehalten wurden, ist erhalten geblieben. Die meisten Hallen stehen leer und nur hier und da werden Erdnüsse, etwas Fleisch, Yams, Maiskolben, Gewürze, Speisen, sowie einige Schmuckgegenstände feilgeboten. Die wenigen Gehöfte, die zum Teil verschont geblieben sind, haben durchweg runde Hütten mit $\mathrm{I}^{\mathrm{T}} / 2$ Fuss starken Lehmmauern, an deren Eingängen kleine Fresken, auch nicht selten Kaurimuscheln und Scherben von alten Tellern zur Verzierung angebracht sind. Die Hütten sind im allgemeinen gross, haben einen Durchmesser von etwa $4 \mathrm{~m}$ und eine Höhe von $3 \mathrm{~m}$ und ein solides aus Gras geflochtenes Kegeldach. Als ich die verlassenen Ruinen durchritt, wurde ich von einem Haussa angerufen, der mich Malamusa nannte und in mir unseren Landsmann G. A. Krause vermutete. Bei dem Anblick dieser Trümmer musste ich unwillkürlich an die frühere Herrlichkeit nnd das alte Schlagwort "Salaga" denken, das noch heute auf allen Lippen schwebt und in der Negerphantasie der abgelegeneren Stämme seinen Zauber noch immer nicht verloren zu haben scheint.

Kurze Die Sprache der Bewohner von Salaga und des Königreichs Gonya Charak- ist ein Dialekt der grossen Guansprache. Ausser der Königsfamilie und teristik der einigen Würdenträgern sind die Gonyaleute meistens Heiden, während Gonyaleute die Fürstenfamilien, wenigstens dem Namen nach Mohamedaner sind. Sie üben die Beschneidung aus und der mohamedanische Priester, Liman genannt, hat an ihren Fürstenhöfen stets eine hohe und einflussreiche Stellung. Nicht selten gehören die mohamedanischen Priester in dem 
Gonyareiche der Königsfamilie selbst an. Obgleich die Bekenner des Islam sich streng an die äusseren Formalitäten halten, achten sie seine Gebote wenig. So lieben die meisten den Alkohol und auch bei Isafa hat der Trunk nicht wenig zu seinem Untergange beigetragen. Sämtliche Mitglieder der Königsfamilie sind durch eigenartige Tätowierungen erkennbar, welche auf beiden Backen aus drei parallelen, von der Schläfe bis zu den Mundwinkeln hinabreichenden fein eingeritzten Strichen bestehen. Ausser diesen Erkennungszeichen haben sie noch die mannigfaltigsten Tätowierungen, welche gewissermaassen als Schmuck auch von der übrigen Gonyabevölkerung getragen werden. Obgleich die Mitglieder der Königsfamilie als Mandingoleute eigentlich Fremdlinge in dem Gonyareiche sind, sind sie doch in Sprache und Sitten vollkommen darin aufgegangen. Auch ist die Bevölkerung ron

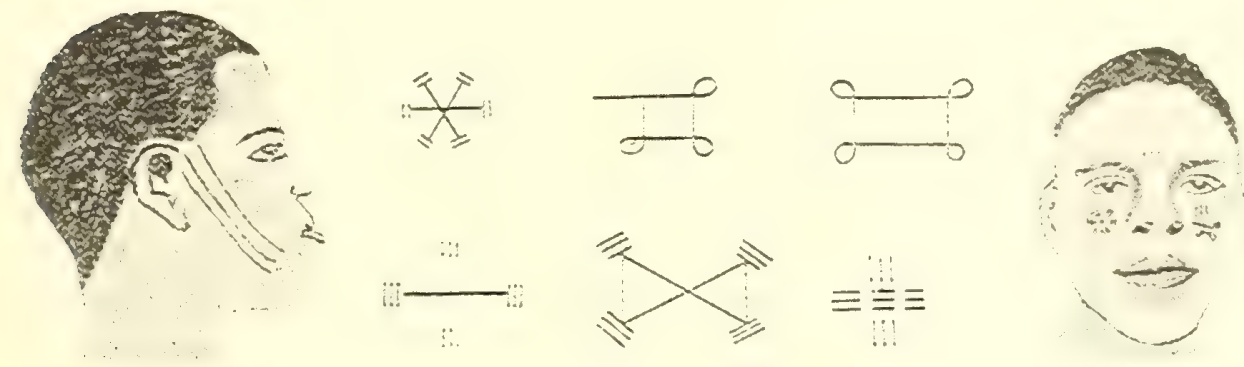

Gonya nicht so sehr ein einheitlicher Tolksstamm als vielmehr ein Konglomerat von Völkern, die politisch eine Zusammengehörigkeit bilden und sich schliesslich aus den Sprachstämmen des Guan einen eigenen Dialekt gebildet haben. Bei den massenhaften Sklaven, welche hier aus den verschiedensten Gegenden zusammenströmen, ist natürlich eine Vermischung der Rassen nicht ausgeblieben. So zeichnen sich die Gonya nicht, wie viele andere Volksstämme durch besondere Stammeszeichen aus, sondern jeder trägt eine andere Tätowierung auf Brust, Arm und Backen. Einzelne Gonyaleute tragen auf beiden Seiten zwischen Augen und Ohren ein dunkeltätowiertes Dreieck, die Frauen zeichnen sich besondèrs durch die mannigfaltigsten Tätowierungen auf beiden Seiten der Backen aus. Auch bemerkte ich bei einigen. Frauen, dass Arme, Hals und Brust bis zur Magengegend reich tätowiert waren. Besonders beliebte Motive sind Sterne, Schleifen und nicht selten mit diesen in Verbindung drei nebeneinander laufende Striche. Leider ist es mir bei der kurzen Zeit meines Aufenthalts in Salaga nicht vergönnt 
gewesen, die Sitten der Gonyaleute näher kennen zu lernen, da fast sämtliche Dörfer, welche ich passierte, zerstört oder verlassen waren. Ich kann daher über ihre Industrie wenig berichten. Ausser der Feldarbeit und dem Anbau der verschiedensten Hirsesorten und von Mais habe ich wenig von ihrer Thätigkeit gesehen. Dass die zu dem Gebiete gehörigen Ntshumuruleute ebenfalls dem Ackerbau und speziell der Fischerei und Jagd obliegen, wurde bereits gesagt. Das Hauptprodukt des Landes, mit dem die Bewohner Handel treiben, ist die Schibutter, welche noch heutigen Tages als Ausfuhrgut bis an die Küste geht und in Zuckerhutform in Blättern verpackt, auf allen Märkten des Landes anzutreffen ist. Die Gewinnung der Schibutter ist eine einfache. Die Früchte werden im Feuer geröstet, darauf in Holzmörsern zerstampft und in grossen Töpfen gekocht. Das obenauf schwimmende Fett wird abgeschöpft und ergiebt in geronnenem Zustande das fertige Produkt. In geringerem Maassstabe wird auch Sesamsaat aus dem Gebiete von Gonya ausgeführt.

Die Sklaverei. Salaga hat seinen Aufschwwung und seine Blütezeit nur dem SklavenSklavenraub handel zu verdanken. Seine geographische Lage ist in manchen und Sklaven- Beziehungen besser als die von Kete, es liegt weiter nördlich im Niger-
handel. bogen, näher am Niger selbst und an den Quellflüssen des grossen Voltastromes, ist wegen seiner weiten Entfernung unabhängig von der Kuste und wegen seiner Neutralität weniger von politischen Ereignissen beeinflusst. Salaga ist im westlichen Sudan ein Hauptstapelplatz der Erzeugnisse der inneren afrikanischen Industrie gewesen, welche durch Sklaven leicht und unbehindert auf den Markt gebracht wurden. Aus denselben Gründen war es ein Zentralpunkt des Sklavenhandels, von wo aus die schwarze Menschenware noch immer wie zur Zeit der Portugiesen, wenn auch jetzt heimlich, auf versteckten Pfaden durch die von Europäern besetzten Gebiete bis an die Gold- und Sklavenküste heruntergeführt wurde. Früher wurden auf dem Markt von Salaga, nach der Schätzung älterer Reisender, etwa I5 000 Sklaven jährlich umgesetzt. Meistens waren es Dagomba, welche aus dem nördlich gelegenen Teil, namentlich aus Grussi, aber auch aus den angrenzenden Gebieten die Leute raubten und zu Sklaven machten. Vermöge ihrer guten Reiterei überfielen die Sklavenjäger plötzlich ein Dorf, steckten dasselbe in Brand, schlugen alles was sich wehrte nieder und trieben namentlich Weiber und junge Mädchen zum Verkauf nach Salaga. Auch die an den Grenzen der Kafir zerstreut liegenden mohamedanischen Kolonieen beteiligten sich an dem Sklavenraub. Mossikarawanen brachten die Erzeugnisse ihres Landes, Wollstoffe und Elfenbein auf den Köpfen der Sklaven nach dem Markt und machten auf diese Weise ein doppeltes Geschäft. Sie transportierten ihre Produkte fast umsonst und verkauften zugleich mit den Waren das 
Transportmittel fur einen hohen Preis. Ein Sklave soll je nach seinem Alter und Körperbau einen Preis ron circa 80 bis r 20 Mark erzielt haben. Andererseits ist die Sklaverei, wie aus der ganzen Cierichtsbarkeit der Eingeborenen hervorgeht, häufig nichts anderes, als die in Afrika geset7mässige Strafe für Verbrecher.

Selbstverständlich ist die Sklaverei von unserem Standpunkt aus Lie Sklaverei verwerflich und muss ausgerottet werden, indessen ist die Lage der als wirtschaftSklaven eine bessere als man im allgemeinen annimmt. Nur der Sklaven- licher Faktor. raub bringt Schrecken mit sich und bildet wirtschaftlich den Ruin fur Afrika. Mord und Brand ist bei diesem Geschäft die Parole. Grosse Dörfer und Landstrecken veröden und werden durch die Sklavenjagden entvölkert. Obwohl heute die schwarze Menschenware nicht mehr überseeisch ausgeführt werden kann, so brauchen doch die mohamedanischen Höfe immer noch eine grosse Anzahl von Sklaven. Aber auch fast sämtliche Häuptlinge und Wohlhabende in unserem Togogebiet halten eine grosse Anzahl von Sklaven, welche ihre Felder lind Aecker bewirtschaften und auf diese Weise die arbeitende Klasse bilden. In der Natur des Negers liegt es nicht, sich freiwillig einer Arbeit zu unterziehen, er will gewissermaassen mit Gewalt dazu gezwungen werden. Wie sollten bei den jetzigen primitiven Verhältnissen Produkte aus dem innern Afrika transportiert werden, wenn es nicht hauptsächlich auf den Köpfen von Sklaven geschähe? Es gilt deshalb in Afrika nicht für ein grosses Verbrechen, auf diese Weise die menschlichen Kräfte nutzbar zu machen. Im übrigen werden Haussklaven keineswegs so schlecht gehalten wie man gemeinhin glaubt, die Leute gehen häufig ganz in dem Stamme und der Familie des Herrn auf und nehmen sogar unter Umständen an den Höfen der Häuptlinge und Priester einflussreiche Stellungen ein, wie beispielsweise der bereits erwähnte Grussisklave Okla.am Hofe des Bossumfo, des Fetischpriesters in Kratyi. Meistens sind sie durch Heirat an den Stamm gefesselt. Auch erbt nach afrikanischem Gesetz der Sklave, falls nach dem Tode seines Herrn keine näheren Verwandten vorhanden sind, dessen ganzes Vermögen und wird mit seinem Tode frei. Es ist demnach klar, dass mit der Sklaverei bis jetzt die ganze Existenz und das Wohl der afrikanischen Volkswirtschaft steht und fällt.

Der Fetisch erstreckt seine Nacht auch auf diese Verhältnisse. In PlötzlicheAb. der Regel wird dem neuen Sklaven vom Fetischpriester ein Trank über-schaffung der reicht, welcher in Wirklichkeit unschädlich ist, ihm aber den Tod bringen soll, wenn er einen Fluchtrersuch wagt. Obwohl es Pflicht der Regierung, sowie der Beamten und Missionare ist, den Sklavenraub, sei es unter dem Zeichen des Kreuzes, sei es mit Feuer und Schwert, auszurotten, so ist es andererseits weder ratsam, noch überhaup: 
möglich, die Sklaverei als solche plötzlich aus der Welt zu schaffen. Tausende von Existenzen würden mit einem Schlage brotlos werden, da die Mehrzahl der Leute noch viel zu unselbständig ist, um sich selbst zu ernähren. Die zügellosen Massen würden eine Umwälzung sämtlicher, seit Jahrhunderten bestehender Einrichtungen herbeifuhren und Mord und Totschlag würden in erhöhtem Maasse platzgreifen. Nur bei einem allmählichen, nach Grundsätzen geordneten Vorgehen kann einem solchen Unglück vorgebeugt werden. Auch ist es ganz unmöglich, die Sklavenhändler nach europäischen Rechtsbegriffen zu bestrafen, vielmehr muss man darin den afrikanischen Verhältnissen Rechnung tragen. Vor allem ist es schwierig, die Mohamedaner zu beeinflussen, da ihnen ihre Religion heidnischen Völkern gegenüber die Sklaverei erlaubt.

Obwohl die von der Küste eindringende Kultur segensreich wirkt, so ruft sie doch einen Niedergang der afrikanischen Industrie und damit einen vorübergehenden Verlust für das einheimische Gewerbe hervor. Es ist daher anzunehmen, dass auch in bezug auf die Sklaverei ein plötzlicher Uebergang zu anderen Verhältnissen sich nicht ohne grosse Schädigung der wirtschaftlichen Interessen der eingeborenen Bevölkerung vollziehen dürfte. Indessen wird sowohl der Sklaverei, wie den Schrecken des heidnischen Glaubens durch den Sieg des Christentums allmählich aber sicher Einhalt gethan werden. Die christliche Mission ist berufen unter dem Schutze einer starken Regierung, als Apostel und Kulturträger sämtlichen damit verbundenen Uebelständen ein Ende zu machen.

Verbandiungen mit dem Sultan Isafa.
Abgesehen von diesem einen Ausfluge von Pembi nach Salaga war ich nun täglich von morgens bis mittags und häufig noch nachmittags bis spät abends beschäftigt, mit dem Sultan Isafa zu verhandeln. Da bei der hohen Regenzeit die Temperatur für afrikanische Vèrhältnisse sehr niedrig war und morgens und abends bis auf $15^{\circ}$ herunterging, sass ich mit dem Sultan in einem seiner Privatgemächer, einer kleinen runden Hütte in dem hinteren Gehöft. Der Sultan war dort nur von einigen seiner Vertrauten umgeben; meistens waren der Liman, der Kriegsminister und der Hofmarschall zugegen. Nicht selten befand sich auch seine Lieblingsfrau dabei. Ich war gewöhnlich von Sofo und meinem Dolmetscher begleitet. Meist war in der kleinen schwarzen Hütte ein Holzfeuer angezündet, um welches wir alle, die dem hohen Rate mitangehörten, hockten. Der Sultan bat mich wiederholt, bei ihm zu bleiben und ihm bei dem Wiederaufbau der verwüsteten Dörfer und Städte zu helfen. Er erzählte beständig, wie Ferguson ihn gedrängt habe, die englische Flagge zu hissen und sein Gebiet unter englischen Schutz zu stellen; wie er selbst aber diese Aufforderung stets abgelehnt 
und sich auf die deutsche Regierung berufen habe. Die Luft in der kleinen Hütte war durch den Qualm des Holzfeuers erstickend. Obendrein quälte mich Isafa fortwährend, aus einer kleinen Schnupftabaksdose eine Prise zu nehmen, so dass ich schliesslich, blos um ihn los zu werden, tapfer mitschnupfe. Ausser diesem narkotischen Genuss war der Sultan, trotz den Geboten seiner Religion, dem Alkoholgenuss nicht abhold. Von Zeit zu Zeit kreiste die Schnapsflasche, welche ich standhaft verweigerte, was mir Isafa, da es sein Vorteil war, nicht zu verargen schien. Hierzu kam ab und zu die feierliche Spucknapfscene, während seine Lieblingsfrau ihn vor jeder kritischen Rede durch Rückenkratzen zu neuem Mut anzuspornen schien. So verstrichen sechs Tage unter beständiger Wiederholung derselben Punkte.

Unter anderem fragte mich der Sultan, ob Ferguson im Einverständnis mit der deutschen Regierung handele, wie er behauptet habe. Ich verneinte natürlich diese Frage und wiederholte nochmals, was ich ihm in der öffentlichen Versammlung über Ferguson schon gesagt hatte. Inzwischen hatten sich unsere Beziehungen von Tag zu Tag freundschaftlicher gestaltet und so vertraute er mir eines Tages an, dass er mich wegen eines Papiers um Rat fragen wolle. Er holte aus einer Bundes- Der unrechtlade ein Schriftstück hervor, welches er mir zeigte, und fragte mich, ob mässige die deutsche Regierung, wie ihm von Ferguson mitgeteilt worden sei, Vertrag von ein solches Papier erhalten habe. Meine Aufregung stieg aufs höchste, jedoch suchte ich sie äusserlich möglichst zu unterdrücken. Durch dieses Schriftstück sollte ich hinter die Ränke kommen, welche Ferguson gegen unsere Regierung geschmiedet hatte, und den Zweck meiner Mission vollauf erreichen. Es war ein Freundschafts- und Handelsvertrag mit England, in dem sich Isafa, von Ferguson gezwungen, unter die Schutzherrschaft von England stellte. Ich durchflog den in englischer Sprache abgefasstem Vertrag und machte Isafa darauf aufmerksam, dass das Schriftstück nur ron Ferguson selbst, nicht einmal von dem Gouverneur der Goldküste unterzeichnet sei, dass Ferguson also jedenfalls auf seine eigene Verantwortung gehandelt habe. Isafa beteuerte mir, dass er nicht englisch verstehe und daher garnicht wisse, was er gezwungen worden sei zu unterzeichnen. Er bat mich, ihm mitzuteilen, was dieses Schriftstück eigentlich bedeute. Als ich ihm klar machte, dass es gegen die bestehenden Verträge zwischen Deutschland und England verstosse und dass er darin gewissermaassen unfreiwillig sein Land an England abgetreten habe, war er entrüstet, derartig betrogen worden zu sein, und bat mich, dies der deutschen Regierung mitzuteilen. Habe er doch Geschenke von Stieren nach Misahöhe gesandt; um der deutschen Règierung seine Freundschaft zu beweisen. Ich faltete darauf dieses für mich so wertvolle Schriftstück, das alles enthielt, was die Uebergriffe des Ferguson 
bestätigte, zusammen und war glücklich, es in meiner Tasche bergen zu können. Isafa versicherte ich, dass ich das Schriftstück meiner Regierung übergeben würde, und dass er keinen besseren Boten dazu finden könne als mich. Als besonderes Zeichen meiner Freundschaft beschenkte ich den Sultan, da ich von allen anderen Mitteln entblösst war, mit meinem eigenen Revolver, was ihm nicht wenig Freude machte, zumal die Waffe durch reiche und schöne Verzierung und Vernickelung schon für einen Europäer ein wertvolles Geschenk gewesen wäre. Auch eine Schachtel - Patronen mit 25 Stück fügte ich diesem Geschenke hinzu und unterwies Isafa im Laden und Abfeuern der Waffe. Um mein Gewissen wenigstens etwas von der Verantwortung zu befreien, die darin lag, einem schwarzen Häuptling eine immerhin gefährliche Waffe in die Hand gegeben zu haben, wollte ich durch schnelles Feuern die Anzahl der Patronen um ein bedeutendes vermindern; doch Isafa erklärte mir beim zweiten Schuss, dass er nun vollkommen instruiert sei und lieber die Patronen behalten wolle, da ohne diese das ganze Ding keinen Wert habe. Auch musste ich ihm bestimmt versprechen, dass ich ihm mehr Patronen von der Küste senden würde. Der Sultan bat mich, nun die deutsche Flagge $\mathrm{zu}$ hissen, er wolle sich mit den Grossen und seinem ganzen Volke unter deutschen Schutz stellen. Dadurch glaubte er, sich vor den Uebergriffen Fergusons und seiner Soldaten zu sichern. Ich schlug ihm aber natürlich diese Bitte ab und verlangte, er solle die englischen Soldaten auffordern, die Stadt Pembi zu verlassen und nach der Küste zurückzukehren, was auch später geschah. Isafa bat mich ferner, wenigstens Fergusons Rückkehr aus Daboya abzuwarten und ihn vor diesem in Schutz zu nehmen. Es lag aber garnicht in meinem Interesse, nach diesem Erfolge Ferguson abzuwarten, zumal dieser seine Mission in Salaga durch den abgeschlossenen Vertrag erledigt glaubte und jedenfalls garnicht daran dachte, jetzt dahin zurückzukehren. Aus diesem Grunde, sowie aus Mangel an jeglichen Lebensmitteln, wollte ich von Salaga den Rückmarsch wenigstens bis Kratyi antreten, um dort eine Anleihe in Geld zu machen, mich mit Tauschartikeln und Geschenken $z u$ versehen und alsdann eventuell über Bimbilla nach Yendi zu marschieren. Ich sollte aber nicht ganz ungehindert fortkommen, denn der bedrängte Sultan war entschlossen, mich um keinen Preis ziehen zu lassen.

Als ich daher für den nächsten Tag meine Abreise ankündigte, stiess ich auf heftigen Widerspruch. Der Sultan warf mir Furcht vor Schwierig- Ferguson vor, was ich energisch zurückwies, mit dem Bemerken, dass keiten beim ich jeden niederschiessen würde, der mich angriffe. Meine wenigen, Abmarschvon aber guten Gewehre seien imstande, mehrere Mann mit einem Schuss zu
Salaga. Boden zu strecken. Ich fragte, ob es Sitte am Hofe von Salaga sei, 
Gäste in dieser Weise zu behandeln und drohte, seinem Oberherrn, dem Sultan von Yendi, zu erzählen, wie es mir ergangen wäre. Diese Worte wirkten, der Sultan bat mich um Verzeihung und erklärte nur im Scherz gesprochen zu haben. Mittlerweile war es Nacht geworden und ich zog mich zurück mit der Erklärung, dass ich am anderen Tage früh wiederkommen würde, um von ihm Abschied zu nehmen. Noch an demselben Abend packte ich meine Sachen, legte das wertvolle Schriftstück in einen meiner Blechkoffer, welchen ich dem zuverlässigen Sapavi anvertraute, liess dann meine Leute, ausser Sofo und dem Tshidolmetscher, zusammenrufen und versprach ihnen eine Belohnung, wenn sie sofort lautlos aufbrechen und in der Nacht nach Krupi vorausmarschierten, wo sie mich am nächsten Tage unter allen Umständen erwarten sollten. Ungehindert und ungesehen ging auch, Gott sei Dank, ihre Abreise vor sich.

Am nächsten Tage bemerkten Sofo und der Dolmetscher das Fehlen der Träger und Soldaten und es verbreitete sich das Gerücht, dass sie nach Yendi abmarschiert seien. Sofort erschien der Marschall des Sultans bei mir, um sich darnach zu erkundigen. Ich liess ihn bei dem Glauben, dass ich meine Leute zwar nach Yendi vorausgeschickt habe, mich aber erst entschliessen wolle, ob ich nach Yendi gehen oder nach Zurückholung der Leute mit diesen gemeinsam nach Kratyi marschieren würde. Auch Sofo und der Dolmetscher baten mich, noch in Pembi zu bleiben, da Sofo seine mitgenommenen Kolanüsse und den Gin noch losschlagen wollte. Ich erklärte ihnen jedoch, dass ich auf jeden Fall Pembi heute verlassen müsse und begab mich zum Sultan, um mich von ihm zu verabschieden; inzwischen sollten die Pferde gesattelt werden und Sofo seine Leute zum Aufbruch bereit halten, anderenfalls drohte ich ohne ihn abzumarschiëren. Der Sultan suchte mich noch immer unter allerhand Vorwänden zurückzuhalten. Schliesslich musste ich ihm versprechen, bald wiederzukommen und dann längere Zeit bei ihm zu bleiben.

\section{RÜCKMARSCH ÜBER KRATYI.}

Die Sonne stand schon ziemlich tief, als ich den Sultan verliess. Vor meiner Hütte erwarteten mich meine wenigen Leute mit den gesattelten Pferden. Schnell sandte ich sie voraus, nur den Dolmetscher behielt ich bei mir. Dann bestieg ich trotz des Einspruches der Häuptlinge meinen feurigen Hassan und sprengte, indem ich ihnen ein "Auf Wiedersehen" zurief, durch die Strassen. An der Grenze der Stadt wurde ich plötzlich von einer Schar Sklaven des Sultans angerufen, welche ihre Speere und Gewehre emporhielten und mir den Weg ver- 
sperren wollten. Ich liess mich aber nicht beirren, sondern gab meinem Hassan die Sporen, sprengte auf sie zu und hätte sie unfehlbar umgeritten, wenn sie nicht Platz gemacht hätten. Niemand wagte es, mich anzugreifen, und so kam ich glücklich davon. Bald hatte ich meine vorausmarschierenden Leute erreicht und nun ging es in der Finsternis dem verabredeten Ziele, Krupi, in Eilmärschen zu. Die Nacht war stockfinster, und ein unheimliches Gefühl bemächtigte sich meiner bei dem Gedanken, von den Sklaven des Sultans verfolgt zu werden. Aus diesem Grunde forcierte ich unseren Marsch aufs äusserste. Es war seit langer Zeit das erste Mal, dass ich wieder den geladenen Karabiner schussbereit umgehangen trug. Sofo war natürlich, seinen Geschäften treu, in Salaga geblieben und so hatte ich von meinen acht Leuten ausser dem Dolmetscher nur noch drei bei mir. Durch die stete Spannung der letzten Wochen, sowie durch das Fieber waren meine Nerven vollkommen zerrüttet, so dass die geringsten Ereignisse mich in Aufregung versetzten. So ging es vorwärts in der finsteren Nacht, deren Stille nur durch das Rauschen des Laubes, das Brüllen eines Leoparden und das unaufhörliche Bellen der Hyänen unheimlich unterbrochen wurde. Letzteres begleitete uns fast bis an den Lagerplatz von Kurupi, den wir in nun doppelt beschleunigtem Tempo in drei Stunden erreichten. Ein Gefuhl der Sicherheit überkam uns, als wir von weitem die Feuer durch den Busch lodern sahen und wieder menschliche Stimmen vernahmen. Noch grösser war unsere Freude, als wir dort Sapavi mit den übrigen Leuten und sämtlichen Lasten antrafen. Leider stellte sich in diesem verlassenen Orte die alte Kalamität, das Fehlen von Nahrungsmitteln, wieder ein. Den Salagaochsen, welchen ich vom Sultan zum Geschenk erhalten hatte, wollte ich nicht opfern, weil ich hoffte, in Kratyi Geld dafür zu erhalten.

Noch vor Morgengrauen marschierten wir von Krupi ab und nach einem 5 tägigen Eilmarsch gelangte ich mit meinen Leuten, aller Mittel

Wiederein treffen in Kete und peinliches Strafgericht. bar, wieder nach Kete, wo ich von den Haussa mit Freuden empfangen wurde. Aber noch sollte ich mich nicht der wohlverdienten Ruhe erfreuen, denn man schleppte mir einen blutüberströmten Haussahändler herbei, welcher von einem Eingeborenen mit Gewalt seines Gutes beraubt worden war. Fast sämtliche Haussa von Kete hatten sich versammelt und baten mich inständig, den Frevler zu bestrafen, da ich ihnen den Schutz der deutschen Regierung versprochen habe. Gern hätte ich mich dieser unangenehmen Aufgabe entzogen, doch hielt ich es für meine Pflicht, einzuschreiten. Der Thäter wurde bald herbeigeschafft; es war ein grosser kräftiger Neger, welcher sich noch seiner That zu freuen schien und mir grinsend zur Antwort gab, einem Haussa könne solche Behandlung nichts schaden. Ich verurteilte ihn zu der 
wohlverdienten Strafe von 25 Hieben und zum Ersatz des geraubten Gutes. Nach diesem Urteilsspruch wurde mir aber mitgeteilt, dass es ein Sklare des Königs Odukru sei. Die Situation wurde hierdurch kritischer, denn mittlerweile hatten sich eine Menge Kratyileute, sowic die bewaffneten Sklaven des Königs eingefunden und vor dem Gehöft des Sofo, wo der Prozess verhandelt wurde, Aufstellung genommen. Sie forderten stürmisch die Auslieferung des Missethäters und drohten, ihn mit Gewalt zu befreien. Die Haussa waren auf einmal sehr kleinlaut geworden und fast jeder scheute sich, meinen Leuten bei der Exekution behiflich zu sein. Als ich dies bemerkte, erklärte ich ihnen, dass ich sofort die Stadt verlassen und sie der Willkür ihrer Machthaber Preis geben werde. Ausserdem schalt ich sie ,feige Kerle" die zwar Schwerter hätten, sie aber nicht gebrauchen könnten. Das half, und bald hatten die meisten Haussa ihre Schwerter umgürtet, um auf jeden Fall für einen Gewaltakt gerüstet zu sein. So wurde dann die Strafe vollzogen. Der Verurteilte, der bis zuletzt auf seine Genossen gerechnet zu haben schien, lächelte anfangs, aber schon nach einigen Streichen zeigte sich die weichliche Negernatur, er schrie und bat um Verzeihung. Ganz ohne Zwischenfälle sollte indessen auch dieser Staatsakt nicht von statten gehen. Noch während die Strafe vollzogen wurde, entstand ein Tumult um das Gehöf, das ich abgesperrt hatte, gleichzeitig ertönten einzelne Schreckschüsse, welche von den Sklaven über das Gehöft gefeuert wurden. Es war jedoch nur eir blinder Lärm, da sie sowohl ihren König Odukru, als auch den Fetisch des weissen Mannes zu sehr fürchteten. Noch lange hielt der Tumult an, doch gegen Abend hatte sich die Menge verlaufen. Der Uebelthäter hatte inzwischen sein freches Wesen abgelegt und konnte nun, in Fesseln gelegt, über seine Frevelthat nachdenken. Ich machte sofort dem Könige Anzeige ron dem Vorfall und bat ihn, da der Sklave mittellos war, als Herr desselben, das geraubte Gut im Werte ron 28 Schilling zu ersetzen, widrigenfalls ich den Verbrecher in Ketten mit zur Küste nehmen würde. Der König erwiderte mir, dass er zwar die Berechtigung der Strafe anerkenne, sich aber nicht verpflichtet fühle, für seinen Sklaven aufzukommen.

Inzwischen war mir der Befehl zugegangen, meinen Rückmarsch anzutreten. Obwohl ich schon eine Anleihe bei einem Haussahändler beinahe abgeschlossen hatte und mich eben von neuem zu einem Marsche Rückmarsch nach Yendi rüsten wollte, musste ich diesem Befehl unverzüglich nach- zur Küste, kommen. Der Gefangene war mir leider entwischt. Wahrscheinlich Verhandlung hatten ihn die Soldaten aus Furcht vor einem Ueberfall laufen lassen. und Abschied Ich verkündete nun, dass ich morgen zur Küste aufbrechen, vorher aber noch von Odukru Abschied nehmen und denselben nötigen würde die ron König Odukru. 
Entschädigung für das geraubte Gut zu zahlen. Die Haussa sahen angstvoll meinem Abmarsch entgegen und hätten mich am liebsten dort behalten. Als sie aber erkannten, dass mein Entschluss unerschütterlich feststand, schickten sie sich an, mich feierlich zu Ross bis zur Grenze des Stadtgebietes von Kratyi zu begleiten. Nachdem ich am nächsten Morgen von Kete Abschied genommen, begab ich mich, von fast sämtlichen Haussa zu Pferde gefolgt, nach Kratyi zu dem Könige Odukru, trug ihm noch einmal die Angelegenheit bezüglich des Sklaven vor und bedeutete ihm, dass er als Herr des Sklaven nicht bloss Rechte, sondern auch Pflichten gegen denselben zu erfüllen habe. Odukru entgegnete mir schelmisch, dass der Sklave ja garnicht mehr in meinem Besitz sei; hierauf erwiderte ich, dass ich befohlen habe, er solle später von den Haussa zur Station Misahöhe gebracht werden. Ich erklärte Odukru ferner, dass, wenn er unser Freund bleiben wolle, er, als König sich vor allen Dingen den Gesetzen der Regierung fügen müsse und gezwungen sei, für die Schuld seines Sklaven einzutreten. Da ich mir nicht jede Brücke zu einem Rückzuge abbrechen wollte, so stellte ich ihm eine Frist bis zu meinem Wiedereintreffen in Kratyi; bis dahin sollte er sich entschieden haben, ob er unsere Feindschaft oder unsere Freundschaft vorziehe. Schliesslich willigte Odukru zu meiner grossen Freude ein, die 28 Schilling in Kauris zu bezahlen. Hierauf schieden wir in Freundschaft und ich marschierte zunächst nach Misahöhe, wo ich die Herren der Togo-Hinterland-Expedition noch vor ihrem Aufbruch begrüssen konnte. Nach einigen Tagen Rast marschierte ich direkt zur Küste und gelangte, durch die überstandenen Strapazen um 40 Pfund leichter an Körpergewicht, über Lome nach Sebbe, wo ich dem Landeshauptmann v. Puttkammer den mir von Isafa ausgehändigten Vertrag überreichte, und ihm über den Verlauf meiner Reise Bericht erstattete.

\section{DIE STATION KETE-KRATYI.}

Ende des Jahres 1894 fand die Gründung der so wichtigen Station Kete-Kratyi statt. Die Dispositionen hierzu erfuhren insofern eine Veräuderung, àls der damalige Landeshauptmann v. Puttkamer infolge seiner Versetzung nach Kamerun die von ihm geplante Reise nach Kratyi nicht mehr selbst ausführen konnte. Er übertrug dann die Führung der Expedition nach Kratyi dem Oberleutnant v. Doering, welchem ich zugeteilt war. Die Oberleitung der Kolonieen übernahm der neu ernannte 
Landeshauptmann von Togo, Köhler, und während seiner Amtsthätigkeit fanden die späteren Expeditionen nach dem Hinterlande statt. Auch gelangte in dieser Zeit die Deutsche Togo-Hinterland-Expedition unter Führung des Dr. Gruner, des Leutnants von Carnap-Querenheim und des Dr. Doering zur Ausführung.

Wir befinden uns wieder in Kratyi, wo am Sylvester das Terrain der Station unter Flaggenhissung in Besitz genommen und der rechtmässige Erbe von Salaga, Lempo, unter dem Namen Sulemana auf dem Markt von Kete als Sultan von Salaga mit seinem Sitz in Kratyi anerkannt und feierlich gekrönt wurde. Die Zeremonieen, welche bei dieser Krönung stattfanden, dürften nicht uninteressant sein und so will ich sie hier schildern. Unter dem Trommelwirbel unserer Spielleute, präsentiertem Gewehr unserer etwa I 20 Mann starken Truppe und einer dreimaligen Salve wurde in Kete auf dem Platz vor dem Gehöfte des Häuptlings Sofo feierlich die deutsche Flagge gehisst. Lempo war nach Haussaart grekleidet und ron den sämtlichen alten Prinzen von Salaga umgeben. Er gab nun vor uns drei Weissen, Leutnant v. Doering, dem Botaniker Baumann und mir, vor den Prinzen und dem Liman das feierliche Versprechen ab, dass er stets treu zu der deutschen Regierung halten und bis die Wirren in Salaga beendigt wären, bei Kratyi residieren würde. Hier ist er auch, wie bereits erwähnt wurde, geblieben, wodurch dann Neu-Salaga gewissermaassen als ein neues Stadtviertel ron Kete entstand. Nach diesem Versprechen wurde Lempo unter dem Namen Sulemana von den ältesten Prinzen zum Könige ausgerufen. Es wurde ihm der rote Königsmantel über die Schultern gelegt, ein Schwert überreicht und ein silberner Ring an die rechte Hand gesteckt; so geschmückt, wurde er auf ein schön aufgezäumtes, mit Amuletten behangenes Pferd gesetzt und durch die Strassen von Kete geführt. Schliesslich wurde er vor seinem Gehöft von sämtlichen Prinzen unter unaufhörlichem Pauken und dem Jubel der Bevölkerung beglückwünscht und in den inneren Räumen seiner Wohnung von der ihm erst kürzlich angetrauten Gattin empfangen, so dass das Volk zugleich mit dem Sultan auch eine Sultanin erhielt.

Seit meiner Abreise hatten sich die Verhältnisse in Kratyi, sehr zu unseren Gunsten geändert. Bosumfo und sein Helfershelfer Okla waren von der Togo-Hinterlands-Expedition ihres verbrecherischen Treibens wegen vor Gericht geladen und standgerichtlich erschossen worden. Kete-Kratyi war somit von seiner grössten Plage befreit. Kete war infolge dessen dem Handel der Haussas freigegeben und die willkürlichen Tributforderungen jener mächtigen Fetischpriester hatten aufgehört. Allerdings hatte inzwischen die Anmaassung der englischen Händler immer mehr zugenommen; sie unterdrückten die von Lome

Krönung des Sultans Sulemana.

Handelsverbältnisse in Kratyi und Uebermut der englischen Händler. 
kommenden deutschen Händler und spielten sich als die Herren von Kete auf. Der Schmuggel kannte keine Grenzen mehr. Sämtliche Erzeugnisse, auch von dem rechten Voltaufer, aus dem englischen Gebiet von Adda und Akkra, gingen einfach zollfrei gegen den Eintausch wertvoller Landesprodukte, wie Vieh, Pferde, Gummi, Elfenbein u. s. w. zur englischen Küste. Auf diese Weise wurde fast der ganze Handel des deutschen Hinterlandes von Lome abgezogen und kam den englischen Faktoreien in Akkra und Adda zu gute. Deutsches Geld war verpönt und deutschgesinnte Eingeborene wurden verhöhnt. Der Uebermut der englischen Händler war so weit gegangen, dass sie dem deutschen Unterhändler Amason, einem Eingeborenen, die Flaggenhissung untersagt hatten. Der englische Händler Yomoku hatte mit Gewalt das Reichspanier in Kete heruntergerissen und dabei Amason mit dem Tode gedroht, falls er versuchen sollte, es noch einmal zu hissen. Es war somit die höchste Zeit, dem gefährdeten deutschen Handel einen kräftigen Schutz zu teil werden zu lassen und auch andererseits der deutschen Regierung im Hinterlande Achtung zu verschaffen, sowie den Uebergriffen der Dagomba- und Salagaleute, welche die Strassen nach Kete durch herumziehende Räuberbanden sperrten, ernstlich zu steuern. Auch bot die Station Kete-Kratyi einen geeigneten Rückhalt für die fast zur selben Zeit in das Hinterland entsandte deutsche Togoexpedition, welche durch den Zuzug der Karawanen aus dem Hinterlande mit Kete noch immer einigermaassen in Fühlung bleiben konnte. Mit der Anlage der Station war daher einem fühlbaren Bedürfnis für jetzt sowie für künftige Zeiten abgeholfen.

Dem Oberleutnant v. Doering lag es nun als Chef und Begründer der Station zuvörderst ob, für den baldigen Aufbau der Stationsanlage Sorge zu tragen. Die Höhe, welche zwischen Kete und Kratyi an der Verbindungsstrasse dieser beiden Orte gelegen ist, bot dafur den passendsten Platz, da von hier aus die Strasse von Kete und Kratyi, sowie ein breit angelegter Weg zum Wasserplatz an dem Volta beherrscht wird. Auch kann man Kete von dieser Höhe übersehen, während Kratyi allerdings durch den Busch und den Fetischhain mehr gedeckt liegt.

\section{EXPEDITION NACH YEGI.}

Schon in den ersten Tagen, während mit dem Buschbrande begonnen wurde, intriguierte Ferguson mit Erfolg wider unsere Abmachung mit England ohne Berücksichtigung der neutralen Zone auf der rechten Seite des Volta. Als wir hiervon Nachricht erhielten, sandte mich r. Doering sofort mit so Soldaten nach Yegi, um auch dort das Treiben ron Ferguson oder Mr. Faxen, wie ihn die Eingeborenen nannten, auf- 
zudecken und die Handelsverbindungen, welche Yegi früher mit Kratyi unterhalten hatte, wieder anzuknüpfen, sowic den Leuten klar zu machen, dass sie nichts hindere, auf die linke Seite des Volta zu kommen. Auch sollten sich wieder Dogombahorden bei Bayamso gezeigt haben und die Strasse unsicher machen. Endlich hatte ich den Auftrag, den Rebellen Yomoku, wekcher wie schon vorher erwähnt, den deutschen Agenten mit dem Tode bedroht hatte, in Yegi festzunehmen, weil er auch dort wiederum gegen die deutsche Regierung agitierte und sämtliche Händler aufhielt, welche nach Kratyi in das deutsche Gebiet wollten.

Ich marschierte von Kete über Bayamso und Akandim, überschritt den Daka und Volta, passierte das zerstörte Temkranku und gelangte auf dem rechten Toltaufer nach Neu-Temkranku. Wie auf meiner Reise nach Salaga durch das Gonyagebiet, so fand ich auch hier alles verwüstet und verödet. Sämtliche Einwohner der Ortschaften in der Landschaft Ntshumuru und Kulubu hatten sich aus Furcht ror der Kriegsfurie auf die rechte Voltaseite geflüchtet und hier in der Landschaft Bron die Ortschaften Neu-Temkranku und Padyai gegründet. Da die Leute hauptsächlich Fischer sind, haben sie hier ihre gewrohnte Arbeit wieder gefunden. Der Weg führt immer auf der rechten Seite des Volta durch Galeriewald. Ueberall fand ich eine reiche Tierwelt; Meerkatzen und Paviane bevölkerten den Wald, grosse Kropfstörche, Ibisse, Kraniche und die verschiedensten Reiherarten den Fluss und sein Ueberschwemmungsgebiet. Dann überschritt ich auf Kanoes, wahren Seelenverkäufern, den langsam und schwertällig dahinfliessenden, aber tiefen, etwa $40 \mathrm{~m}$ breiten Pru. Das Uebersetzen dauerte lange; fast schien es fraglich, ob das winzige Fahrzeug ausser dem Fährmann noch mit einer Person besetzt werden könne. Ich war glücklich, als ich alle meine Leute wohlbehalten auf dem anderen Ufer hatte. Hiermit war auch der Einfluss des Pru in den Tolta festgelegt. In Eilmärschen ging es weiter und gegen Abend hatte ich zur grossen Verwunderung der Einwohner Yegi erreicht. Ueberall wurde ich für einen Engländer und meine Soldaten für englische Haussatruppen angesehen. Man hielt es für unmöglich, dass deutsche Offiziere und Soldaten hierherkommen könnten, da die Engländer mit Erfolg verbreitet hatten, dass alles Gebiet rechtsseitig des Tolta englisch sei. Es gab dann erstaunte Gesichter, wenn ich die Leute auf die von der englischen abweichende Lniform der Soldaten und die schwarz-weiss-rote Fahne aufmerksam machte.

Sobald ich in Yegi eingerückt war, liess ich mir das Gehöft ron Einrücken in Yomoku zeigen, umstellte es und suchte nach dem Rebellen. Aber Yegi leider war das Nest ausgeflogen. Ich fand nur seine Frau ror, welche ich nach einer kurzen Ternehmung wieder entliess, während ich etwas 
Gim und Kolanüsse, die Yomoku in der Eile zurückgelassen, in Beschlag nahm. Trotz aller meiner Vorsichtsmaassregeln hatte Yomoku Kenntnis von meinem Marsch erlangt, obwohl keiner meiner Leute irgendwie den Zielpunkt oder den Zweck der Expedition kannte. Auch hatte ich stets in den Dörfern, welche ich zum Aufenthalt benutzte, die Ausgänge nach dem Norden zu besetzen lassen, damit kein Bote die Ankunft der Expedition vorher melden könnte. ihre Existenz hauptsächlich dem Handel. Wie Kratyi war sie der Vorhafen für Salaga, da das Addasalz, welches in Kratyi häufig neu verladen wird, auf dem Volta in Kanoes bis hierher heraufkommt. Yegi liegt auch an der grossen Karawanenstrasse, welche von Ateobu, dem Hauptmarktplatz für Kolanüsse, nach Salaga und von dort weiter in die nördlich gelegenen Hinterländer führt. Ferner soll über Yegi, namentlich in der letzten Zeit seit dem Untergang von Salaga, der Weg nach den Goldgefilden von Vasepe gehen. Der Goldstaub kommt indessen in Yegi nur in geringen Mengen zum Verkauf und wird dann vorzugsweise gegen Addasalz eingetauscht. Der grösste Teil des Goldstaubes geht nach Kintambo und wird dort hauptsächlich gegen Kolanüsse, sowie auch gegen Greybaft, Perlen und Stoffe verhandelt. Heute hat Yegi bedeutend zugenommen und ein grosser Marktplatz nach Art desjenigen von Kete ist hier etabliert. Ausser den genannten Waren, Roadbrass und Addasalz von der Küste, finden wir hier alle die einheimischen Produkte wieder, welche die Haussahändler nach Kete führen. Der Markt gewährt auch äusserlich einen ähnlichen Anblick wie der in Kete. Neben den Haussas in ihren langen Hemden und Toben sieht man dürftig bekleidete Eingeborene und viele alte Salagaleute. Die Haussas haben sich auch hier kleine Verkaufsbuden eingerichtet, in denen sie ihre Waren feilbieten.

Die Bewohner von Yegi un Was die Bevölkerung der Landschaft Bron anbetrifft, so unterder Landschaft Bron. scheidet sie sich wenig von den Ntshumuruleuten. Ihre Sprache ist dieselbe; vermutlich gehören sie zu dem sprachverwandten Stamm der Guan, obwohl man auf dem Markt von Yegi die Aschantihändler mit den Eingeborenen auch in der Tshisprache verhandeln hört. Die Brońleute bauen ihre Hütten meist rund mit Kegeldach, wie wir sie schon häufig angetroffen haben. Auch werden vereinzelt viereckige Hütten mit Giebeldach errichtet, wie sie speziell die Aschanti zu bauen pflegen. Interessant und charakteristisch aber sind für Yegi die grossen, langen, schmalen, viereckigen Lehmhütten in der eigentlichen Stadt, die nicht, wie gewöhnlich, ein Giebeldach aus Gras, sondern ein flaches Dach haben, das mit Erde eingedeckt ist. Wahrscheinlich erklärt sich 
diese Bauart aus dem Mangel an langem Gras, da die Steppe, wie es mir schien, ein kurzes, besseres WVeidegras und nicht wie in den nördlicher gelegenen Gegenden, hohes Riedgras trägt.

Meine politische Mission in Yegi war bald erledigt. Ich kon- Englische statierte, dass Ferguson auch hier und zwar mit viel grösserem Erfolg Umtriebe und als auf dem anderen Voltaufer der neutralen Zone ausgesprengt hatte, dass alle auf dem rechten Voltaufer gelegenen Landschaften englisch An. seien. Den Leuten erklärte ich öffentlich, dass sie vorläufig weder Engländér noch Deutsche wären und dass sie nach wie vor noch unter

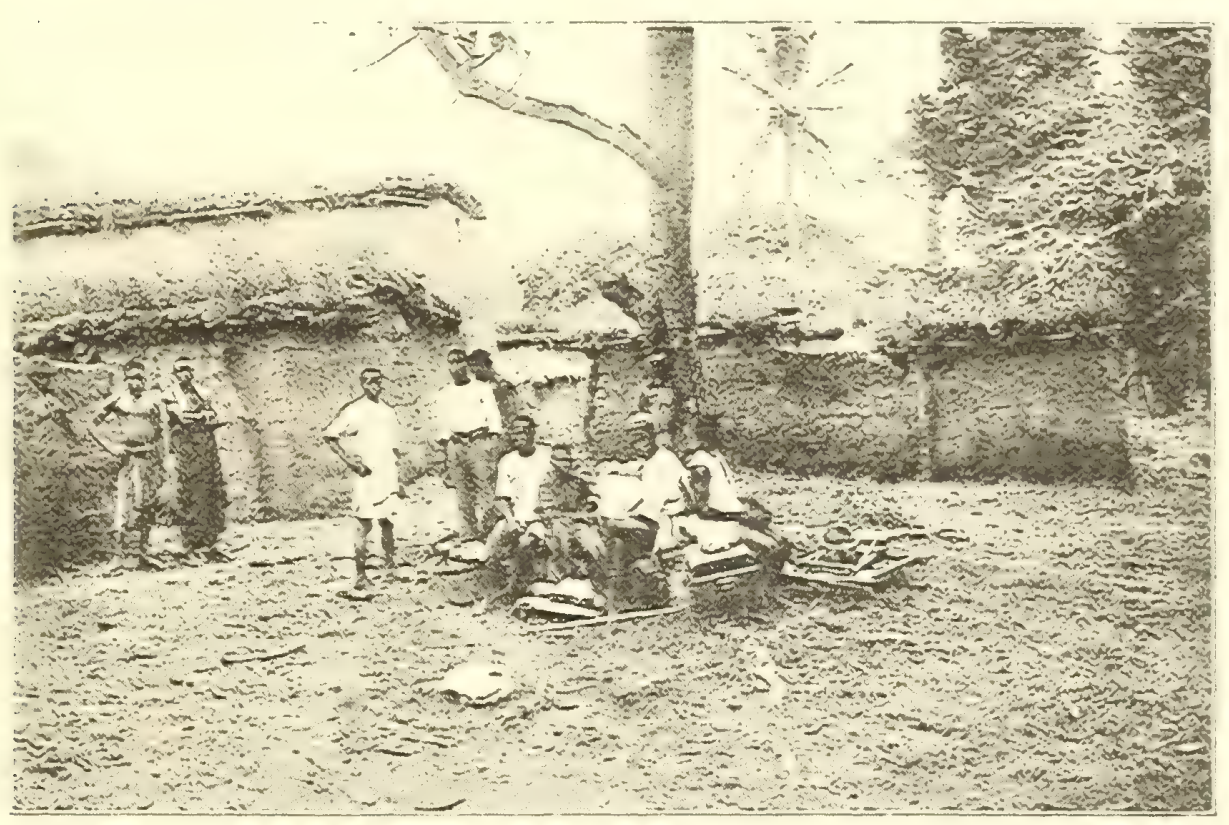

Hüttenform mit platten Dächern

der Oberhoheit des Häuptlings Odukru in Kratyi ständen. Der Häuptling von Yegi schien wenig Macht zu besitzen, während sein Sprecher vollkommen unter dem Einfluss englischer Händler stand. Diese berichteten mir eine Fabel von der bevorstehenden Ankunft einer englischen Expedition, wahrscheinlich in der Hoffnung, mich dadurch zum baldigen Abmarsch zu bewegen. Sehr verwundert schienen sie, als ich mich bereit erklärte, dieselbe abzuwarten und zu begrüssen. Die Akkrahändler waren auch hier äusserst übermütig und frech. So drängte sich des Abends, als ich bei einem frugalen Mahle aus gekochtem Huhn vor meiner Hütte sass, ein Kerl ohne irgend welche Veranlassung an mich heran mit den Worten: „Massa, I am no german subject, Massa, 
I am english subject, you can me nothing do." Ich wies ihn fort, aber trotzdem der vor Gewehr aufgestellte Posten ihm wehrte, kam er immer wieder. Schliesslich riss mir die Geduld, ich liess den Kerl festnehmen und ihm einige Hiebe verabreichen. Als er sah, dass die Sache ernst wurde, rief er schon nach den ersten Streichen: „Massa, I beg you, it is not true, I am no english, I am german subject." Die umherstehende Menge verhöhnte ihn ob dieses raschen Stimmungswechsels und ich hatte für diesmal die Lacher auf meiner Seite. Am zweiten Tage brach ich von Yegi wieder auf mit dem tröstlichen Gefühl, nicht ganz umsonst dort gewesen zu sein, denn die meisten Häuptlinge und Händler versicherten mir, mich in Kratyi besuchen zu wollen und gaben mir das Geleite noch weit über die Stadt hinaus Ich marschierte auf demselben Wege zurück, auf dem ich gekommen war, um einige meiner geographischen Aufnahmen zu ergänzen. Noch vor Kete traf ich v. Doering, der mir entgegengeeilt war, um mich zu begrüssen.

\section{POLITISCHE VERHÄLTNISSE IN KRATYI.}

v. Doering erzählte mir, dass Ferguson inzwischen auf der anderen Seite des Volta, gegenüber Kratyi, in der kleinen Niederlassung Unsomero mit einer grossen Expedition eingetroffen sei, und auf jede Weise die Kratyileute zu bereden suche; ihre Wohnplätze auf das rechtsseitige Ufer zu verlegen. Wahrscheinlich beabsichtigte er, durch die Entvölkerung von Kete den ganzen Handel nach Unsomero herüberzuziehen und so an Stelle des alten ein neues Kete auf englischem Gebiet zu gründen. Da König Odukru darüber klagte, dass er beständig von Abgesandten des Ferguson bedrängt werde, stellte v. Doering des Nachts Posten aus, welche die Aufwiegler ergriffen und zur Station brachten, wo sie in Eisen gelegt wurden. Ferguson suchte nun andere Mittel um die Kratyileute zu zwingen, ihre Wohnplätze aufzugeben. Er drohte ihnen, sie in Eisen legen zu lassen, Wenn sie auf dem Volta

Schutzmaass- fischten oder den Wasserplatz benutzten. v. Doering liess darauf Ferguson regeln gegen erklären, dass er Posten längs des Volta aufgestellt habe mit dem Befehl, englische jeden zu erschiessen, der es wagen würde, die Kratyileute beim WasserUebergriffe. schöpfen zu belästigen oder sich an den auf dem Wasser liegenden Kanoes zu vergreifen. Ferguson erkannte die Uebermacht unserer Truppe, welche auch auf die Kratyileute ihren Eindruck nicht verfehlt hatte, sah die Nutzlosigkeit seiner Intriguen ein und räumte das Feld, um zur Küste zurückzukehren. Durch seine Manipulationen war es ihm aber doch gelungen, Kete wenigstens vorübergehend zu schädigen, da er viele englische Händler bewogen hatte, auf das rechtsseitige Ufer zu ziehen. Dadurch wurde der Schmuggel gefördert, während die Haltung 
der englischen Akkrahändler eine immerwährend drohende Gefahr für die friedliche Entwicklung des Handels bildete. Leider sind wir bei Festlegung der deutsch-englischen Grenze bei Kratyi von den Engländern insofern übervorteilt worden, als nicht der Voltastrom, sondern laut Vertrag das linke Voltaufer die Grenze bildet. Somit ist uns natürlich die Schiffahrt genommen, obgleich es aus menschlichen Gründen ausgeschlossen erscheint, dass bei diesen pr̈imitiven Verhältnissen den angrenzenden Bewohnern die Nutzniessung des Wassers für ihren Lebensbedarf willkürlich versagt werden könnte. Hoffentlich werden wir bei der Regelung unserer Westgrenze das Recht einer neutralen Schiffahrt, wenigstens zwischen den beiden Nachbarkolonieen, noch nachträglich èrlangen und so den einmal begangenen Fehler wieder gut machen.

\section{AUFBAU DER STATION.}

Die Station hatte sich während meiner Abwesenheit in überraschender Weise verändert. Das Terrain war gereinigt worden, inmitten desselben wehte von hohem Mast die deutsche Flagge und daneben erhob sich eine kleine Baracke aus Holz und Segelleinwand, welche uns von nun ab fast ein Jahr hindurch als Wohnung dienen sollte. Diese kleine Tropenbaracke war aus Europa bezogen und von der Firma Chevallier \& Comp. mittelst Kanoe den Volta direkt bis nach Kratyi heraufgebracht worden. v. Doering hatte auch von einem Ziegler aus Gridji eine kleine Feldziegelei errichten lassen, wo die Ziegreln für den Bau des künftigen Stationsgebäudes flott gebrannt wurden. Die Erdmassen für das Fundament des Gebäudes waren bereits ausgehoben. Ein grosser Lehmschuppen wurde provisorisch zur Aufnahme unserer sämtlichen Lasten und Güter erhaut, als Küche diente uns eine kleine Hütte aus Matten und Gras mit einem aus einigen Steinen hergestellten Kochherd. So war vorläufig notdürftig für unser Unterkommen gesorgt. Während v. Doering die übrigen Sachen von der verlassenen Station Bismarckburg holte, baute ich aus Matten, so gut es ging, noch Pferdeställe, Schuppen und ein Wachtlokal für die Mannschaften, ein Gefängnis, sowie eine hohe Ziegelmauer rings um die Station, die an den Seiten mit kleinen Thüren versehen wurde. Diese Mauer, welche nach Angabe v. Doerings aufgeführt wurde, sollte unseren Soldaten als Ab-und Brustwehr bei einem etwaigen Ueberfall dienen. Cement, Kalk und Wellblech wurden ron der oben genannten Firma auf dem Volta bis nach Kratyi gebracht. Oft fehlte es uns an Zimmerleuten, da dieselben nur von der Station Misahöhe oder von der Mission herangezogen werden konnten. Grossen Aufenthalt verursachte auch die Beschaffung von Brettern aus der Odumeiche. $\mathrm{Zu}$ Maurern wurden schnell ein paar geschickte 
Schwarze angelernt und so entstand allmählich unter mancherlei Hindernissen und Wechselfällen ein grosses Stationsgebäude mit einem Dach aus Wellblech und einer Veranda, welche auf gemauerten Pfeilern ruhte. Leider waren die Ziegel nicht gut durchgebrannt, infolgedessen wurde das schnell aufgeführte stattliche Haus sehr bald durch die Witterung zerstört. Bei meiner letzten Anwesenheit in Kratyi im Jahre i 897 fand ich zu meinem grossen-Bedauern ein unbrauchbares, baufälliges und unbenutztes Gebäude vor. Der Aufenthalt darin war fast unmöglich, da das Grasdach über dem Wellblech fehlte und die glühende Sonne in den Räumen eine unerträgliche Hitze erzeugte. Der jetzige Stationsleiter, Graf Zech, hat nun die einheimische Bauart vorgezogen und von den ansässigen Jeorubaleuten und Haussa nach seinen Angaben grosse Häuser aus Lehm aufführen lassen, welche mit einem soliden Grasdach nach einheimischer Art eingedeckt sind. Ein solcher Bau geht unter stetem Pauken und Gesang vor sich. Einige kneten Lehm, andere errichten die Wände, wieder andere flechten Matten und die Bauunternehmer erklären, ohne diesen unaufhörlichen Lärm keinen Bau ausführen zu können. Obgleich aber diese Bauart anscheinend geringfügige Mittel erfordert, ist sie nicht dauerhaft und verursacht durch die wiederholten Erneuerungen und Aenderungen mit der Zeit doch erhebliche Kosten und Arbeit. Aus diesem Grunde würde es vielleicht praktischer sein, fertige, aus Holz gezimmerte Tropenhäuser kommen zu lassen, wie es die Kaufleute zu thun pflegen. Bei Kratyi z. B. wäre der Transport auf dem Volta leicht zu bewerkstelligen. Der günstige Einfluss wohnlicher Gebäude auf dié Gesundheit der Europäer würde allein die Ausgabe lohnen. Auch könnten erhebliche Kosten erspart werden, wenn ein von der Regierung angestellter Zimmermeister und Maurerpolier den Bau leiteten und dadurch Misserfolgen wie den unsrigen vorbeugten.

Aufnabmen in Während v. Doering sich den Bau der Station angelegen sein der liess, nahm ich, so gut es ging, die Umgebung von Kratyi auf. Jeden Umgebung zweiten Tag ritt ich des Morgens früh, von einem der Sprache kundigen von Kratyi. Soldaten begleitet, von der Station fort, um eine Verbindung mit diesem oder jenem Ort herzustellen, die Tour dem Routennetz anzuschliessen und in einer Schleife die Station wieder zu erreichen. Da mir keine Gelder für diesen Zweck zur Verfügung standen, war ich natürlich darauf angewiesen, zur Nacht immer wieder nach Kratyi zurückzukehren. Meistens nahm ich bis zu einem bestimmten Dorfe oder Fixpunkte die Strecke bis nachmittags um vier Uhr auf, um dann abends wieder allein im Trabe durch den finsteren Busch den Rückweg anzutreten, während mein Begleiter vorzog, in einem der Dörfer zu übernachten. Oft konnte ich mich in der Dunkelheit auf den schmalen Buschpfaden nur nach den Sternen orientieren. Auch verritt ich mich häufig und konnte mich 
dann nur dadurch zurechtfinden, dass ich Eingeborenen den Namen Kratyi nannte. War man einmal auf einer der grossen Karawanenstrassen, so konnte man Kete selbst bei Nacht nicht verfehlen, denn alle ausgetretenen Pfade führten strahlenförmig dorthin. $v$. Doering war mitunter in der ersten Zeit sehr besorgt, wenn ich erst spät abends, oft erst um neun oder zehn Uhr nach der Station zurückkehrte. Am nächsten Tage vervollständigten und konstruierten wir die Routen gemeinschaftlich und schufen so binnen vier Wochen ein grosses Xet? um Kratyi.

\section{ZOOLOGISCHES.}

Ausser diesen geographischen Arbeiten wurden auf der Station Ketc. Kratyi, wie auf allen anderen wissenschaftlichen Stationen, auch zoologische Sammlungen veranstaltet. Wie sich Hauptmann Kling und Dr. Büttner in Bismarckburg und Baumann in Misahöhe in dieser Beziehung grosse Verdienste erworben haben, so zeichnete sich in Kratyi Graf Zech durch seine zoologischen Forschungen aus. Mir persönlich war es nur in geringem Maasse vergönnt, daran teilzunehmen, weil meine vielen Reisen, die mit der Gründung der Station zusammenhängenden Geschäfte und das Anlernen des Personals, mir wenig Zeit übrig liessen. Wenn ich etwas zu den zoologischen Sammlungen beitrug, waren es meist Jagdtrophäen, die ich von kleinen Vergnügungs- und Erholungstouren im Busch oder auf dem Volta mitbrachte. Die erlegten Tiere wurden nach einem bestimmten Schema gemessen, Farbe, Augen, Abzeichen und nähere Bestimmungen, falls solche möglich waren, wurden notiert. Dann wurden sie durch Wilhelm, meinem Konservator, vorsichtig abgezogen, der Balg hergestellt und zur Konservierung inwendig mit sogenannter Arsenikseife bestrichen. Hierauf wurde der ganze Balg in der Sonne getrocknet und schliesslich, mit Nummern und Marke rersehen, in eine verlötete Blechschachtel verpackt, um bei Gelegenheit dem naturhistorischen Museum zu Berlin übermittelt zu werden.

Ich fuhr gewöhnlich in Begleitung meines Jungen im Kanoe den Fauna des Volta hinauf. Dabei begegneten wir grossen Mengen von Wasserrögeln. Voltastromes. Enten der verschiedensten Art zogen über den Fluss dahin, kleine Strandläufer trippelten am Ufer entlang und schillernde Eisvögel, ron dem grossen Königsfischer bis zu den kleinsten Arten, schlüpften ron Ast zu Ast oder lauerten regungslos auf ihre Beute. Der heilige Ibis flatterte pfeifend über das Wasser, während hoch in der Luft der sogenannte schwarz-weisse Geier-Seeadler seine Kreise zog. Reiher jeder Art, der kleine weisse Silberreiher und auch der braune weissrückige Nachtreiher, spazierten auf den kleinen Inseln umher. Weiter oben am Volta, namentlich bei Jegi, wimmelte es von Kranichen und den langbeinigen grossen Kropf- 
störchen, welche an Grösse alle Vertreter dieser Vogelgattung überragen. Auch der Königskranich stolziert an den Ufern des Volta. An den Stromschnellen und Katarakten oberhalb Kratyi trifft man in den angrenzenden Büschen zahllose kleine rote Würger und bunte Finkenarten; in den hohen Wipfeln der Galeriewälder gurrt die Ringeltaube; auch tummeln sich dort Scharen von Affen, namentlich Meerkatzen und kleinere Pavianarten, während die grossen Paviane den Fetischhain bei Kratyi bevorzugen. Der Voltastrom wimmelt von Krokodilen, die sich von der Strömung Schwärme kleiner Weissfische in den gähnenden Rachen treiben lassen. Die Fischer stellen einer grossen schönen, hechtähnlichen Fischart nach, die ein vorzügliches Gericht abgiebt; neben diesen und einer Menge anderer essbarer Fische sollen auch Welse, insbesondere der längliche Zitterwels, ferner die gefleckten Katzenfische im Volta vorkommen. An den Ufern bemerkte ich nicht selten die grosse, scheussliche Warneidechse.

Ein herrliches Bild gewährt der majestätische Strom namentlich bei untergehender Sonne, wenn sich der Galleriewald in den Fluten wiederspiegelt. Ab und zu fährt ein Fischer nach Hause oder die einzelnen Wasserplätze werden von einigen menschlichen Gestalten belebt. Nichts unterbricht die lautlose Stille als das dumpfe Rauschen des Volta zwischen den Felsen, die Stimmen der Affen und Vögel, oder das dumpfe Wiehern und Plätschern eines Flusspferdes.

Flusspferdjagd.
Die Jagd auf diese Tiere ist ungemein aufregend. Ich befand mich einmal im Kanoe auf dem Volta, als ich bei einer grossen Alisbuchtung oberhalb Kete plötzlich eine Flusspferdfamilie bemerkte, welche sich bei unserem Herannahen aus dem hohen Grase des jenseitigen Ufers in das Wasser begab. Obwohl ich gerade an diesem Tage nur einige Stationsarbeiter bei mir hatte, die wenig mit dem Strom vertraut waren, liess ich doch den Kurs ändern und fuhr direkt auf die Flusspferde zu. Gespannt folgte ich dem Zuge der Tiere, welche sich anfangs nur durch das Kräuseln des Wassers verrieten, während sie später $a b$ und zu mit ihren Köpfen über der Oberfläche auftauchten, um Luft zu schöpfen. Sie schwammen, ihren Kurs ändernd, direkt auf unser kleines Kanoe $z u$, als wollten sie uns in voller Fahrt nehmen. Vorn schwammen die Alten, während zwei ziemlich ausgewachsene junge Tiere folgten. Als mir der Augenblick günstig schien, feuerte ich, aber die erste Kugel schlug vor den Tieren ins Wasser. In demselben Augenblick waren auch alle vier Köpfe verschwunden. Jetzt hiess es aufpassen, um nicht von den Tieren überrannt zu werden. Auch ein zweiter Schuss fehlte. Leider gewährte das schwankende kleine Kanoe keinen festen Stützpunkt und bei dem Rückschlag des Karabiners musste man sich vorsehen, nicht das Gleichgewicht zu verlieren und das Gefährt zum Umschlagen zu bringen. Inzwischen waren die Tiere fast auf $180 \mathrm{~m}$ herangekommen 
und es war die höchste Zeit, ihren Angriff abzuwehren. Ab und zu tauchten ihre grossen Köpfe vor uns auf und einen günstigen Augenblick erfassend, feuerte ich zum dritten Mal auf eins der Jungen. Diese Kugel schien getroffen zu haben. Das Tier bäumte sich auf; ein dumpfer Ton, ein wütendes Schnauben und Plätschern und sämtliche Flusspferde waren wieder verschwunden. Nur die kleinen Wellen auf der Oberfläche des Wassers zeigten, dass sie sich gewandt hatten und nun mit der Strömung nach Süden schwammen. Es that mir leid, die begehrenswerte Beute aufgeben zu müssen. Aber die Sonne stand bereits beträchtlich tief, auch wollte ich v. Döring durch meine späte Rückkehr nicht in Unruhe versetzen. Ohnehin war das Büchsenlicht verschwunden und die meisten Tiere hatten sich schon zur Ruhe begeben. Traumversunken liess ich in der Abendstille das kleine Kanoe von der Strömung unserem Ziele zutreiben. Plötzlich aber wurde ich aus diesem Traume herausgerissen. Ein gewaltiger Stoss erschütterte das Kanoe, das Wasser schäumte auf und der steuernde Neger stiess einen Angstschrei aus. „Massa, look, look one beast, it kill us so" riefen fast alle Insassen des Bootes. Ein zweiter Stoss drohte das Kanoe umzuschlagen. In demselben Augenblick gewahrte ich den Rücken eines gewaltigen Flusspferdes. Zum Glück hatte ich noch meinen Karabiner geladen und feuerte zwei Schüsse ab. Ein Stöhnen, ein Aufplätschern des Wassers, ein Wellenschlag, der unser Boot gefährdete, folgten, und im nächsten Augenblick sah man nur noch die Wellen sich kräuseln, während unser Kanoe langsam den Fluss hinuntertrieb. Meine Leute, vom Schreck gelähmt, waren unfähig, ein Ruder zu bervegen. Auch ich muss gestehen, dass mir der Schreck in die Glieder gefahren war und ich mich erst nach einer ganzen Weile erholte. Ein Haussa, Blaima Abuki, den ich nur zufällig mitgenommen hatte, versicherte mir, dass er nie wieder eine Flussfahrt mit mir unternehmen würde, und auch die übrigen Bootsleute konnten zu Hause nicht genug von der überstandenen Gefahr erzählen. Nach einigen Tagen sagte mir Blaima Abuki, dass ein junges Flusspferd bei Unsumero angeschwemmt und von den Leuten des Dorfes in Beschlag genommen worden seien. Trotz aller Bitten und Geldversprechungen konnte ich aber leider nicht die Stosszähne als Jagdtrophäen für mich retten.

Es herrschen, was die Flusspferde anbetriff, sehr verschiedene Ansichten. Die einen behaupten, sie greifen nicht an, während andere wieder sagen, dass sie kleine Kanoes und Böte zu kentern suchen und ihre Opfer auch mit den Füssen treten. Nach meinen Beobachtungen kann ich nur sagen, dass die Tiere nur dann Boote anzugreifen scheinen, wenn sie selbst angegriffen und verwundet werden. Sie nähern sich unter Wasser dem Boote, heben es mit ihrem gewaltigen Rücken und Kopf in die Höhe und bringen es so zum Kentern. 
Buschwild. Ausser dem Galeriewald und dem Strome bietet auch der Busch, sowie die grossen um Kratyi gelegenen Farmen ein schönes Jagdterrain. Leider ist das afrikanische Wild sehr scheu, deshalb die Beute gering und die Jagd höchst beschwerlich. Während Antilopen, wie die Kuh-, Schirr-, Streifen-, Schopf-, Pferde- und Zwergantilope, welche sämtlich im Togogebiet vorkommen, wegen ihrer Scheuheit nur äusserst selten von Weissen erlegt werden können, so hat die Jagd auf Meister Lampe in Afrika immerhin noch Erfolg. Man trifft ihn gewöhnlich, wenn man die Felder bei der Hühnerjagd durchkreuzt; plötzlich tauchen hinter einem Hügel oder Strauche seine grossen Löffel auf und eiligst ergreift er die Flucht. Der afrikanische Hase ist bedeutend kleiner als der europäische und gleicht mehr unserem grauen wilden Kaninchen; insofern ist er auch schwieriger zu schiessen und liefert an Qualität ein geringeres Wildbret als unser Hase.

Raubtiere. Die um Kratyi massenhaft verbreiteten Hyänen, Schakale und Leoparden sieht man selten. Dagegen hörten wir fast täglich beim Morgengrauen die Hyänen heulen, während wir des Nachts mitunter durch das fürchterliche Brüllen eines Leoparden aus dem Schlafe gestört wurden. Häufig rissen sich dann unsere Reitpferde los, irrten in der Nacht umher und mussten mühsam von unseren Leuten wieder eingefangen werden. Einmal drang sogar ein Leopard bis in unseren primitiven Pferdestall ein, indem er die Mattenzäune des Gebäudes niederriss; jedoch wurde er durch das Feuer und den Lärm der Soldaten verscheucht. Auch den Togo-Serval habe ich, allerdings nur aus den zu Markte gebrachten Fellen, kennen gelernt, während Löwen und Elefanten mehr in den grossen. Steppen nördlich und östlich von Kratyi und schwarze und rote Büffel, wie wir gesehen haben, mehr in der Nähe der Gebirge und in der angrenzenden Ebene von Misahöhe sich aufhalten. In dem Gebirge von Adele sind die verschiedenartigsten Wildkatzen und Ziebetkatzen zu Hause; desgleichen Wild- und Stachelschweine.

Hühnerjagd Eine dankbare Jagd in dem Busch bilden die sogenannten Buschhühner, welche in der Farbe unseren Feldhühnern gleichen, nur dass sie etwas grösser sind und bei jeder Gefahr aufbäumen; das Hähnchen, welches ęinen grossen Sporn trägt, lässt bei Annäherung eines Jägers hoch vom Gipfel eines Baumes seinen Warnungsruf ertönen. Gut zu jagen sind diese Hühner in den Yamsfeldern, wie bei uns in den Kartoffeln. Auch sie suchen hinter den einzelnen Yamshügeln Deckung, um dann eilig davon zu laufen und in einiger Entfernung aufzugehen. Ausser den Hühnern trifft man in kleinen Schwärmen, besonders um Kratyi, eine grünschillernde grosse Taube, die sogenannte Papageientaube, die verhältnismässig leicht zu schiessen ist und einen guten Braten liefert. Auch eine grössere braunrote Taube kommt vereinzelt vor. Neben 
diesen Buschhühnern und Tauben ist die Jagd auf Perlhühner die ergiebigste; ich habe dieselhen in ganzen Völkern, sowohl in den Galeriewäldern, als auch überall auf den hohen Bäumen der Baumsavanne und Gefilden unseres Hinterlandes, angetroffen. Auch sie bäumen bei Gefahr fast immer auf und sind selten auf dem Boden anzutreffen, eigentlich nur, wenn sie ihre Nahrung suchen. Bei der Jagd kommt es hauptsächlich darauf an, die Perlhühner zu zersprengen, um sie dann einzeln abzuschiessen. Durch ihr trompetenartiges Geschrei verraten sie sich und sind deshalb verhältnismässig leicht zu erlegen.

Bei der Wanderung durch den Busch wird man häufig durch den Wald-und Schrei und das plötzliche Aufflattern des mächtig grossen, schwarzen, Sumpfvögel. mit roter Kappe versehenen Hornraben erschreckt. Auch grün schillernde Stare, schön gefiederte Mandelkrähen, der Riesenturako und der grüne Helmvogel, sowie Kuckucke und Wiedehopfe sind vertreten; überall hört man diese Vögel krächzen, welche meistens hoch in der Luft über die Gewässer flattern, während in dem Busch der Stundenvogel unaufhörlich seinen eintönigen Ruf erschallen lässt. An den kleinen Bächen hausen viele Finkenarten, Würger und Meisen, auch begegnet man der munteren kleinen Bachstelze mit wippendem Schwanz. Zu ihr gesellen sich die Bienenfresser mit ihren langen Schwanzfedern, die prachtvoll in allen Farben schillernden Nektariden und Paradiesvögel. Spechte und andere Klettervögel in verschiedenen Grössen hämmern an den morschen Stämmen. Auch der Pirol wiederholt in der weiten Baumsavanne seinen Namen, und unser frecher Strassenjunge, der unvermeidliche Sperling, wird in den Dörfern durch Finken und Webervögel ersetzt, während die verschiedensten Arten unserer zutraulichen Schwalbe auch in Afrika die Luft mit ihrem Geschwätz erfüllen. In dem Geäst der Bäume, häufig mitten in den Dörfern, wimmelt es von Schwärmen niedlicher Werbervögel, deren verschiedene Arten sich durch ihre kunstvoll gebauten Nester unterscheiden. Kleine grüne Papageien, die in grossen Familien einträchtig zusammen leben und in der Gefangenschaft die Trennung nicht ertragen können, schwirren durch die Luft. Kuckuckgrosse, schöne grüne Papageien mit schwarzem Kopf und orangefarbigen Bäckchen bevölkern paarweise und in kleinen Familien die nördliche Baumsavanne, wo ich sie, besonders auch bei Bassari, in der Freiheit gesehen habe. Sie sind in der Gefangenschaft äusserst zutraulich, sprechen aber leider garnicht, während der in Togo vorkommende graue, grosse Papagei mit weisslichem Kopf und rotem Schwanz ein gelehriges Tier ist und in der Gefangenschaft nach kurzer Zeit einige Worte, ja sogar Sätze nachplappert; doch muss ich bemerken, dass ich ihn nie in Freiheit angetroffen, sondern nur im Hinterlande von Togo bei Aschanti-Händlern gesehen habe, wo er flott in der Tshi-Sprache parlierte. Des Abends 
kreisen in der Luft allerhand Fledermäuse, von der kleinsten Art bis zu dem fliegenden Hunde. Daneben flattern grosse unheimliche Nachtschwalben umher; die langen Schwungfedern mit büschelartigem Ansatz verleihen ihnen ein charakteristisches Aussehen. Ihnen gesellen sich bei dem Dunkel der Nacht die mannigfaltigsten Käuze, sowie die schön gefiederte Ohreule zu.

Raubvögel. Die Raubvögel haben ihr Revier hauptsächlich bei den grossen Dörfern und Städten aufgeschlagen, über welchen sie in zahllosen Scharen kreisen, um nach Beute zu spähen. Wo man hinblickt, sitzen auf den Dächern von Kratyi die Kappengeier, wie bei uns die Krähen. Sie sind die Träger des Ungeziefers, namentlich von massenhaften Vogelläusen. In grossen Schwärmen zog über der Station der sogenannte Schmarotzermilan, welchen die Eingeborenen mit grimmiger Feindschaft verfolgen. Trotz unserer Gewehre, die wir bei jeder Gelegenheit anwandten, um diese Raubvögel aus der Luft zu holen, ging ihre Frechheit so weit, dass sie unverhofft zu unseren Füssen niederstiessen und ein Küken von der Henne wegholten. Pfeilschnell flogen sie dann mit ihrer Beute davon, um sich auf der Krone eines hohen Baumes daran zu delektieren. Hühnerhabichte, Falken und Sperber leben alle von dem Raub junger Hühner und Tauben, so dass wir selbst auf der Station einen ganz immensen Verlust in der Aufzucht junger Hühner hatten. In den hohen Horsten im Gebirge halten sich die verschiedensten Adler auf. Ausser dem Geier-Seeadler wird diese Familie durch einen grossen braunen Adler würdig repräsentiert. Bei den primitiven Feuerwaffen, deren sich die Eingeborenen bedienen, ist natürlich an ein Abnehmen dieser Raubtiere nicht zu denken. Andererseits vertilgen sie aber auch viele schädliche Tiere, besonders die massenhaften Ratten und Mäuse, welche sie meistens bei Grasbränden zu erjagen suchen, noch ehe sie einen neuen Schlupfwinkel gefunden haben. In dieser Beziehung teilen die Adler den Geschmack der Eingeborenen, welche sich nicht scheuen, dieses Ungeziefer zu verspeisen und ihm mit eigens dazu hergerichteten Fallen nachstellen. Als Leckerbissen gelten den Eingeborenen auch geröstete Heuschrecken, Eichkatzen und Eidechsen, namentlich eine grosse feuerrote Art. Ausser diesen bevölkern aber auch graue, gelbe und grüne Eidechsen die Dächer der Hütten, sowie die in den Dörfern befindlichen Bäume. Sie leben mit den Eingeborenen friedlich zusammen und sind zutrauliche Tierchen, welche man gleichsam

Insekten und deren

Plage als Haustiere betrachtet.

Die Insektenwelt ist geeignet, dem Reisenden, der sich über solche Unannehmlichkeiten nicht hinwegzusetzen versteht, das Leben zu verbittern. So spielen namentlich an den kleinen Bächen unzählige Fliegenschwärme, welche dem Wanderer meilenweit das Geleite geben, um gierig den 
Schweiss aufzusaugen, wobei sie ihm häufig in die Augen geraten; dann wieder umsummt ihn ein einzelner Mistkäfer oder er gerät unabsichtlich in einen Schwarm wilder Bienen oder Wespen, bei welcher Gelegenheit die unbekleideten Träger ihr Heil in schleuniger Flucht suchen müssen. Auf bündigem Lehm- oder Thonboden findet man überall die Pyramiden der Termiten. Eine der unangenehmsten Plagen ist die unerträglich bissige kleine braune Baumameise, welche sich vom Baum herabfallen lässt und überall ihren Weg unter die Kleider findet. Dagegen erfreuen durch ihren Anblick farbenreiche prächtige Schmetterlinge, welche die Blüten und Knospen umgaukeln, während über den kleinen Bächen massenhaft in bunten Farben schillernde Libellen flattern.

Kehrt man des Abends müde und hungrig auf die Station zurück und hofft in der Kühle gemütlich beim Mahle über die Ereignisse des Tages plaudern zu können, so zwingen einen nicht selten die Mosquitos zur Flucht in die tagsüber durchwärmte Baracke. Denn erst am anbrechenden Abend entwickelt die Insektenwelt ihre volle Thätigkeit. Unzählige Nachtfalter und Motten, Eintagsfliegen, fliegende Ameisen sowie allerhand Käfer und Termiten umschwärmen das Windlicht, um in der Flamme den sicheren Tod $z u$ finden. Würmer und pflanzenähnliche Insekten, wie wandelnde Blätter und Zweige bedecken den Tisch. Hat man das Zelt, in dem man häufig unterwegs bivakiert, nicht mit einem Graben umgeben und Asche gestreut, so kann es geschehen, dass ein ganzes Heer. von Ameisen durch dasselbe seine Marschroute nimmt oder gar darin sein Quartier aufschlägt. Aus diesem Grunde waren bei unserer kleinen Baracke in Kratyi an den Säulen, auf dem sie ruhte, zum Schutze Behälter angebracht, in welche Wasser oder Oel hineingegossen wurde. Trotzdem fanden doch die mannigfaltigsten Raupen, Ameisen und grosse langbeinige Spinnen ihren Weg in das Innere. Oft entdeckte man bei einer Revision der Blechkoffer, dass sich bei einem zutälligen Offenlassen des Deckels die unangenehmen Kakerlaken eingefunden und grosse Löcher in die Sachen hineingefressen hatten. Sogar Ratten und Mäuse hatten die Dreistigkeit des Nachts unsere mit Fett eingeschmierten Stiefel anzuknabbern, so dass wir dieselben schliesslich frei aufhängen mussten. Auch Schlupfwespen und Termiten verderben durch ihre Nester und Kanäle, welche sie häufig quer durch eine Holzkiste legen, die darin enthaltenen Sachen. Einer der gefährlichsten Feinde der aus Holz erbauten einheimischen Hütten sind die Holzbohrer, welche ihre Gänge in die Holzteile einbohren und schliesslich vereint mit den Termiten die Hütte zu Fall bringen, so dass die Eingeborenen gezwungen sind, ihre Bauten immer wieder zu erneuern. 
Giftige Amphibien, Schlangen und Skorpione.

Bei dem Stationsbau in Kratyi wurden unsere Leute öfters durch giftige Schlangen gefährdet, welche bei dem Säubern des Terrains aus ihrem Schlupfwinkel aufgescheucht werden. Die Leute erschlugen sie, worauf wir sie konservierten. Grosse verschiedenartig gezeichnete Schlangenhäute, welche meist von den Fetischleuten getragen werden, lassen auf die Häufigkeit dieser Reptilien schliessen. Riesenschlangen sollen nicht selten die Pfade unsicher machen und auf hohen Bäumen lauernd vereinzelt sogar Menschen anfallen. Ausser diesen Landschlangen hausen in den kleinen Höhlen der Uferwände auch massenhafte Wasserschlangen. Nicht selten traten die unbeschuhten Eingeborenen auf einen Tausendfuss, was ihnen einen brennenden Schmerz verursachte. Unter den Steinblöcken, welche wir zum Bau der Station wegräumten, wurden von den Leuten viele Skorpione gefunden und getötet; mehrmals wurden auch Arbeiter von diesen gefährlichen Tieren verwundet. Gewöhnlich haben wir die verwundete Stelle sofort mit einem Messer aufgeschnitten, das Blut ausgedrückt und die Wunde, wenn nichts Besseres zur Hand war, mit glühender Zigarrenasche ausgebrannt, worauf den Leuten noch ein gehöriges Quantum Schnaps verabreicht wurde. Auf diese Weise wurden sämtliche Leute in einigen Tagen geheilt; mir ist wenigstens kein Fall bekannt, wo ein Schwarzer nach dieser Behandlung an den Folgen des Stiches gestorben wäre. Damit wäre wohl im grossen und ganzen, ausser den schon erwähnten Haustieren, die Fauna unseres Gebietes im Hinterlande von Togo erschöpft.

\section{LEBEN AUF DER STATION UND GESTALTUNG DER POLITISCHEN VERHÄLTNISSE.}

Das Leben auf der Station Kete-Kratyi war in jeder Beziehung ein abwechselungsvolles und ereignisreiches. Da aus fast allen Gebieten des Hinterlandes Karawanen und Händler nach Kete kamen, fehlte es uns niemals an politischen Nachrichten. Durch Briefe und Posten waren wir in steter Fühlung mit der Togo Expedition und hatten sogar nicht wenig Mühe mit dem Nachsenden der Lasten und Depeschen, was von der damals am weitesten vorgeschobenen Ståtion Kete-Kratyi besorgt wurde. Fast jeden Abend sass ich mit v. Doering zusammen, um die Ereignisse und die Nachrichten, welche aus dem Hinterlande zu uns drangen, zu besprechen und darauf Pläne für die Zukunft zu bauen. Am Freitag machten König Lempo und die mohamedanischen Häuptlinge, sowie die vornehmen Haussa mit ihrem Gefolge hoch zu Ross ihren Besuch, welchen wir dann in der Regel Sonntags erwiderten. Tagsüber füllten die mannigfaltigsten-Geschäfte, Palaver und Besuche 
die Zeit vollkommen aus. Nur die Mittagshitze war häufig unerträglich und trieb den Thermometerstand, selbst im Schatten, in unserer Baracke bis auf $38^{\circ} \mathrm{C}$. in die Höhe. An Komfort liess die kleine Baracke für einen Europäer überhaupt manches zu wünschen übrig, denn sie gewährte kaum genügenden Platz für uns beide. Doch hatten wir bei unserer interessanten und angespannten Thätigkeit kaum Zeit, an solche Kleinigkeiten zu denken. Auch bot uns die kleine Menagerie, welche sich schliesslich zusammengefunden hatte, einige Abwechselung und Belustigung. Ein grosser Pavian, der Aerger des Kochs, dem er durch seine Diebstähle manchen Verdruss bereitete, erfreute uns durch seine drolligen Einfälle. Ausserdem belebten die Station zwei grosse Strausse und ein Papagei, bei dem wir fast Unterricht in der Tshisprache nehmen konnten und der uns jeden Morgen mit dem Grusse: „Aku madjiro" (Guten Morgen, mein Väterchen) begrüsste, uns auch, friedlich und einträchtig mit unserem Affen Anton bei den Mahlzeiten Gesellschaft leistete. Unseren Tisch versorgte ein Hühnerhof, sowie eine kleine Herde von Schafen und Ziegen, später auch Rinder. Trotzdem war das Leben ziemlich hart, denn während des bereits oben geschilderten Toveaufstandes fehlten uns Während des alle europäischen Genussmittel. Selbst der Zucker, der bei der Zubereitung von Speisen und Getränken viel unentbehrlicher ist, als man ohne weiteres annehmen würde, war uns ausgegangen. Fast $1 / 4$ Jahr lang konnten wir unseren Arbeitern und Soldaten kaum die Löhnung zahlen. Die Disziplin war infolgedessen sehr gelockert und Diebstahl und Erpressungen fanden bei den Eingeborenen häufig statt. Unter den Umständen konnten wir sie kaum bestrafen und auch den Schaden der Eingeborenen nur mit den letzten Resten unseres erschöpften Vorrats decken. Dabei waren die Nachrichten, welche durch Karawanen oder Händler zu uns kamen, nichts weniger als ermutigend; bald hiess es, die Toveleute hätten die Station Misahöhe überfallen, dann wieder die ganze Truppe sei heraufgekommen und habe die Toveleute geschlagen. So widersprachen sich die Nachrichten fortwährend. Da sich die.Hiobsposten über den Toveaufstand wiederholten und wir von jeder Verbindung mit der Küste abgeschnitten waren, marschierte ich, weil v. Doering am Fieber darniederlag, mit der etwa 25 Mann starken Besatzung und einigen Patronenträgern nach der Station Misahöhe ab, um dieselbe eventuell zu entsetzen und zur Küste durchzustossen. Unterwegs erhielt ich die Nachricht, dass Misahöhe von den Toveleuten eingenommen und der Weisse, Botaniker Baumann, mit der Besatzung ermordet worden sei. Natürlich beschleunigte ich nun meinen Marsch und der Eifer, mit dem meine Soldaten ihre gefallenen Kameraden zu rächen strebten, machte es mir möglich, trotz der Gebirge die Strecke von etwa 200 Kilometern in 4 Tagen zurückzulegen. Auf der Station angelangt, wurden 
wir zu unserer Freude von Baumann, dem Polizeimeister Gerlach und der gesamten Truppe mit einem Hurra, welches in den Bergen und Schluchten wiederhallte, empfangen. Der ganze Aufstand war glücklich beendet und die Toveleute hatten sich schon ergeben. Da ich diesen Aufstand bereits geschildert habe, will ich hier nicht weiter darauf eingehen, sondern nur erwähnen, dass ich reich mit Proviant und Geld versehen zur nicht geringen Freude des Stationsleiters v. Doering auf die Station zurückkehrte.

Die deutsche Hier waren inzwischen auch neue Nachrichten von Dr. Gruner und Togo- der Hinterland-Expedition eingetroffen. Die Togoexpedition war durch Expedition und unsere Interessensphäre

Dagromba über Yendi, Mangu nach Gurma marschiert, wohin v. Carnap vorausgeeilt und so der französischen Expedition zuvorgekommen war. In Gurma befanden sich zwei Herrscher, welche beide ein Anrecht auf den Thron zu haben behaupteten; Dr. Gruner schloss seinen Schutzvertrag mit dem Häuptling von Madjakwale, während die Franzosen sich mit dessen Gegner vertrugen, den eine andere Partei in Fada-N-Gurma unterstützte. In Mangu war die Expedition besonders freundlich aufgenommen worden, deshalb hatte Dr. Gruner Sansane-Manggu zu einer grösseren Rast gewählt, um hier auf dem Rückmarsch wieder einen Stützpunkt zu finden. Das Ergebnis dieser grossen Togo-Expedition war nicht bloss wissenschaftlich, sondern auch politisch ein günstiges. Es wurden Oberhoheits- und Schutzverträge in den Landschaften ManguPama und Gurma geschlossen und die Expedition wurde später, im Februar 1895, in das grosse Königreich Gando am Niger bis zu der Stadt Sai, ungefähr beim I3. Grad nördlicher Breite, weitergeführt. Von hier aus ging sie südlich vom Niger bis Giris und nördlich nach der Hauptstadt des Königreiches Gando. Hier schloss Dr. Gruner mit dem Sultan einen Schutzvertrag über das Grebiet von Gando ab, in welchem sich der Sultan mit seinem ganzen Reich, welches sich am Niger vom 8. Grad bis ungefähr I4. Grad nördlicher Breite erstreckt, unter den Schutz des deutschen Reiches stellte. Die Engländer haben diesen Vertrag zwar anğefochten unter der Behauptung, dass Gando zu dem Sultanat von Sokoto gehöre und dass, der Sultan von Gando nicht das Recht habe, ohne Genehmigung - des Sultans von Sokoto sich in den Schutz einer anderen Macht zu begeben; für uns ist es jedoch maassgebend, dass der Sultan von Gando in seinem Reiche überall anerkannt wird und sich als unabhängiger Herrscher ausgiebt. Dass frühè ein Abhängigkeitsverhältnis zwischen Gando und Sokoto existiert hat oder Gando später mehr oder weniger von Sokoto abhängig geworden ist, kann auf unsern Vertrag keinen Einfluss haben. Wenn wir ferner in dem mit Frankreich abgeschlossenen Vertrage Pama und Gurma den Franzosen überlassen haben und somit die deutsche Grenze bis zum 
elften Grad nördlicher Brcite reicht, "so ist Gando keinesfalls in diesen Vertrag mit einbegriffen und wir haben alle Ursache, unsere Rechte auf dieses grosse Königreich zu wahren. Obgleich wir auch im Norden rom Niger abgeschnitten sind, können wir, wenn die Neutralität des letzteren gewahrt wird, gut nach Gando gelangen und dort unsere Interessen vertreten. Sollte aber wegen der isolierten Lage von Gando die Regierung auf den Erwerb desselben keinen Wert legen, so müsste uns doch England, welches auf Gando reflektiert, bei der Abgrenzung ron Togo ein entsprechendes Aequivalent für dieses grosse Ländergebiet bieten.

Leider musste die deutsche Togo-Expedition wegen Ausbruchs der Pocken umkehren und den Marsch zur Küste antreten. v. Carnap hatte die schwere Aufgabe, die Kranken mittelst Booten auf dem Niger zur Küste zu bringen und sie von dort wieder über See nach ihrer Heimat Togo zurückzuführen. Dr. Gruner marschierte mit Dr. Doering und dem gesunden Teil der Expedition von Gando über die Städte Giris und Ilo, durch Borgu über Kandi und Kwande nach Sansane-Mongu, und von da über Yendi, Bimbila und Kratyi, wo ich sie empfing, zur Küste zurück.

Inzwischen begannen die englischen Händler zu empfinden, dass es Maassnahmen mit ihrer Alleinherrschaft auf dem Markt von Kete vorüber war. Am gegen den Tolta wurde durch einen kleinen Posten eine Zollkontrolle ausgeübt und Schmuggel die Adda-Händler, welche bis dahin, alle deutschen Gesetze missachtend, einen flotten Schmuggel betrieben hatten, wurden massenhaft abgefasst. Auch wuchs nnter dem Schutze der deutschen Flagge die Konkurrenz der deutschen Küstenhändler und das englische Geld beherrschte nicht mehr ausschliesslich den Markt. Durch die vielen Arbeiter, Soldaten und Träger, welche die Station unterhielt und denen ihr Lohn, wenn angängig, in deutschem Gelde ausgezahlt wurde, kam deutsches Geld in Aufnahme. Bald hatte das deutsche Silber und vor allem unser 5 Pfennig-Stück als Scheidemünze den Markt erobert, so dass in KeteKratyi die kleinen Werte nur in Koppers - darunter versteht man das deutsche 5 Pfennig-Stück - angegeben wurden. Die Kauris mussten wenigstens teilweise unserem Nickel bis zum Werte ron 5 Pfennigen weichen, ebenso fiel auch indirekt der Kurs des englischen Geldes, da ausser Silber und Gold keine andere Scheidemünze als jene im Hinterlande gangbar war. So z. B. hatte eine Mark in 5 Pfennig-Stücken den Wert von einem Schilling und drei englischen Pence.

Aus allen diesen Gründen machten die englischen Händler noch einmal den Versuch, ihren alten Plan durchzusetzen und Kete auf das rechte Voltaufer zu verlegen. Sie wanderten auf englisches Gebiet aus, etablierten dort einen flotten Handel und suchten die Leute in Kete, besonders die Eingeborenen ron Kratyi, und auch den alten König 
Odukru gegen die deutsche Regierung und die Weissen der Station aufzuhetzen. Hiergegen musste energisch eingeschritten werden. Eine Unmenge von Kanoes, welche mit grossen Quantitäten von Addasalz, Gin und Rum, sowie Pulver und Gewehren den Volta heraufkamen und diese Waren bei Nacht einzuschmuggeln suchten, wurden von den Posten mit Beschlag belegt und konfisziert. Schliesslich sahen die Händler das Vergebliche ihrer Bemühungen ein, baten um Erlaubnis, sich wieder in Kete niederlassen zu dürfen und versprachen, von nun $a b$ sich den deutschen Gesetzen zu fügen. Nach einem Monat wurde die Sperre aufgehoben und auch der englische Händler respektierte jetzt die deutsche Flagge.

Sofo, der seine Häuptlingswürde dem englischen Kommissar Mr. Firminger verdankte, welcher ihn an Stelle von Abudu-Bedde eingesetzt hatte, spielte bei allen diesen Angelegenheiten eine äusserst zweifelhafte Rolle, so dass er schliesslich abgesetzt und der frühere Häuptling der Haussa von Kete, Abudu-Bedde, wieder eingesetzt wurde. Derselbe ist jetzt Statthalter von Kete. Leider hat in jüngster Zeit, wie der Stationsleiter, Graf Zech, berichtet, das englische Intriguenspiel neue Früchte gezeitigt. So erhebt die englische Regierung bei Kratyi ein Fährgeld von 5 Schilling für je 5o Pfund englischer Waren, welche den Volta auf deutsches Gebiet passieren. Infolgedessen geht die Kolanuss heute nicht mehr in der Menge wie früher von Ateobu (Atebobu) über Kete, sondern über Yeggi und weiter über Salaga in das Hinterland. Am fühlbarsten aber dürfte für den Handel von Kete sein, dass das Hauptprodukt, das Addasalz, ebenfalls diesem Fährzoll unterworfen ist. Um so dringender wäre es geboten, durch eine Bahn oder neue Strassen diesen misslichen Verhälnissen abzuhelfen und bei einem neuen Gebietsvertrag im Hinterlande die Neutralität der Schiffahrt auf dem Volta zu sichern.

Eine recht einsame Zeit begann für mich, als v. Doering seinen Heimatsurlaub antrat. Meine Gesundheit war stark angegriffen und der stete Verkehr mit den teilnahmlosen Schwarzen war wenig geeignet, meine Gemütsstimmung zu heben. Mein kleiner Meppo war der einzige, mit dem ich $a b$ und zu ein deutsches Wort sprechen konnte. Allein die stets wechselnden Ereignisse liessen mir keine Zeit zu trüben Betrachtungen und hielten meine Thatkraft immer rege.

Einfluss der Die Station hatte allmählich immer mehr Fühlung mit den NachbarStation auf die staaten bekommen und ihr Einfluss erstreckte sich weit über das Reich politischen Dagomba hinaus bis Mossi und im Osten bis Sugu und Tshautsho. Die

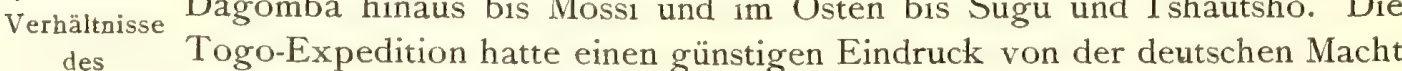
Hinterlandes. hinterlassen. Fremde Karawanen suchten jetzt den Schutz der deutschen 
Flagge in Kete; ja häufig baten sie darum, dass man ihnen auf der Rückreise die deutsche Flagge mitgeben möchte, da sie sich unter ihr gegen etwaige Angriffe der Dagomba oder anderer feindlicher Stämme sicherer fühlten. Natürlich war dieser starke Einfluss der Station dem Sultan von Yendi wenig willkommen. Dieser hatte die Gewohnheit, von den reichen Karawanen, welche sein Reich berührten, einen Tribut $z$ u erheben. Häufig liess er durch bewaffnete Dagomba-Horden die Karawanen anfallen, und ihnen einen Teil der Ware abnehmen, oder auch die Träger der Lasten zu seinen Sklaven machen. Besonders war die Strasse über Salaga nach Kete durch die Leute des Sultans Isafa gefährdet, da er im Vertrauen auf die Macht der Dagomba und auch wohl im Einverständnis mit dem König derselben willkürlich die nach Kete ziehenden Karawanen plünderte und Sklaven raubte, um den Handel nach Kete lahm zu legen und sich so dafür zu rächen, dass die deutsche Regierung den rechtmässigen Thronerben von Salaga als König mit dem Sitze in Kete anerkannt hatte.

Eines Tages erhielt ich die Nachricht, dass Malami als Abgesandter Anmaassung des Königs Isafa von Salaga nach Kete kommen wolle, um der Station einen Besuch abzustatten. Malami war ein schlauer Haussa, der als Unterhändler des Königs in Salaga lebte und sich nach Aussage der und Vebergriffe durch Eingeborenen an der Plünderung der Karawanen und dem Sklavenraub beteiligt hatte. Malami kam auch wirklich in Begleitung seiner Sklaven und einiger Dagombas, auf einem schön gezäumten Pferde, mit der weissen Tobe und dem Turban angethan, auf die Station gesprengt, wo sich eine Menge Volk aus Kete und Kratyi angesammelt hatte. Er entbot mir siegresbewusst vor der versammelten Menge den Gruss des Sultans Isafa und erklärte, dass er im Auftrage des Sultans gekommen sei, um den Unwillen desselben darüber auszudrücken, dass wir Lempo als König von Salaga anerkannt hätten. Der Sultan verlange als alleiniger Herrscher von Salaga anerkannt zu werden und fordere die Auslieferung Lempos. Ich liess Malami ruhig ausreden. Dann aber hielt ich ihm alle Missethaten vor, die Isafa und er selbst an den Karawanen verübt hätten, wobei ich sieben Fälle von Plünderung und Sklavenraub namhaft machte. Ich sagte ihm, er solle dem Sultan melden lassen, dass sein Abgesandter sich in Ketten auf der Station Kete befände, und dass, falls er die Räubereien nicht unterliesse, auch er der gerechten Strafe nicht entgehen würde. Malami drohte nun mit dem König von Yendi, seinen Oberherrn, in dessen Namen er spreche. Dessen ungeachtet und trotz der Intervention von Sofo, welcher die Unschuld Malamis beteuerte und mir versicherte, dass die Dagomba gegen uns zu Felde ziehen würden, nahm ich Malami vorläufig in Lntersuchungshaft, 
bis alle Zeugen vernommen sein würden, welche ihn angeklagt hatten und erklärte ihm, dass er bestraft werden würde, wenn ich ihn nach ihren Aussagen für schuldig befände. Ich riet ihm ferner, seine Leute nach Hause zu senden, den Sultan Isafa von seiner Haft in Kenntnis zu setzen und ihm mitzuteilen, dass, falls er die Räubereien nicht einstelle, er bei der nächsten Gelegenheit durch eine Expedition bestraft werden würde; wolle er sich aber eines Besseren besinnen, so möge er mir dies durch einen anderen Gesandten mitteilen.

Falsche DagombaGesandtschaften, Intriguen durch Sofo und die YendiPrinzessin.

Aufregende Nachricht über das angebliche Anrücken eines

Dagombaheeres.

Schon vorher waren zu dem Stationsleiter v. Doering ab und zu Abgesandte des Dagomba-Königs auf die Station gekommen, um in höflicher Weise für Isafa einzutreten und die Freundschaft des Königs von Yendi zu beteuern. Sie wurden dann reich mit Geschenken beladen, entlassen, damit sie uns eine freundliche Gesinnung am Hofe von Jendi bewahren sollten. Auch hatte sich seit den letzten Vorgängen das Verhältnis zwischen Sofo und der Yendiprinzessin auffallend intim gestaltet, während beide gegen die Station kühler wurden. Namentlich die Prinzessin hatte schon lange ihre Besuche bei uns und die Geschenke von Honigbier aus ihrer Brauerei eingestellt. Kurz, alle Anzeichen sprachen dafür, dass Sofo der Urheber der Intriguen sei. Wahrscheinlich gedachte er, da seine Partei immerhin noch ziemlich stark war, uns durch sein Verhalten zu zwingen, ihn wieder als Häuptling anzuerkennen. Nach der Festnahme von Malami drang von neuem die Kunde von einer Dagombagesandtschaft zu uns und bald darauf wurde Kete durch die Nachricht in Aufregung versetzt, dass sich ein grosses Dagombaheer nähere. Lempo fand sich als einer der ersten bei mir ein und wollte nach der Küste fliehen. Kurz darauf kamen viele Notablen und Einwohner von Kete händeringend zu mir und baten um meinen Rat, wie sie sich schützen und wohin sie flüchten sollten. Ich kann nicht leugnen, dass auch mir anfangs die Situation ernst erschien, da alle Anzeichen dafür sprachen, dass wirklich etwas Aussergewöhnliches vor sich ginge. Natürlich lenkte sich sogleich mein Verdacht auf Sofo und die Yendiprinzessin, von denen das Gerücht ausgegangen sein sollte; doch beteuerten beide, von dem Anrücken eines Heeres nichts zu wissen. Sie wollten nur gehört haben, dass eine kleine Gesandtschaft des Königs unterwegs sei; die Nachricht von dem Anzuge eines Heeres wollten sie auf dem Markte von Kete nur gerüchtweise vernommen haben. Zunächst beruhigte ich die erschreckten Leute und versicherte ihnen, dass ich sie mit meinem Leben gegen die Dagomba schützen wolle. Falls sich das Gerücht bestätigen sollte, was ich nicht glaube, so sollten sie alle ihr Hab und Gut auf die Station bringen und Kete räumen. Dem Haussahäuptling Abudu-Bedde erteilte ich den Befehl, sich mit 
sämtlichen Haussa bei herannahender Gefahr bewaffnet auf der Station einzufinden. Denselben Befehl erteilte ich dem König Odukru. I)ie Haussa schienen eher zu einem Kampfe geneigt, während Odukru meinem Befehl nur in dem Falle der äussersten Not gehorcht hätte. Noch an demselben Tage sandte ich drei gut berittene und mir als kampflustig und intelligent geschilderte Haussa nach der Grenzstadt Bayamso, um auszukundscliaften, ob sich das Gerücht bestätige. Auch liess ich Sofo und das Gehöft der Yendiprinzessin von einigen mir ergebenen Haussa bewachen. Meine kleine Truppe von 25 Mann zog ich in ihr Lager bei der Station zusammen und verbot jedem, dasselbe ohne Erlaubnis zu verlassen. Auch die Wache wurde verstärkt und stündlich wurden während der ganzen Nacht Patrouillen nach Kete und darüber hinaus auf den Pfad nach Salaga gesandt, um uns vor einem etwaigen Ueberfall zu sichern. Den nächsten Morgen schon kam einer der abgesandten Haussareiter auf die Station zurückgesprengt und meldete, dass sich in Tariasso mehrere Dagombaleute aufhielten, während sich in Salaga ein grosses Dagombaheer befinden solle. Es fiel mir gleich auf, dass der Vortrab eines grossen Dagombaheeres nur aus einigen Leuten zu Fuss, worunter sogar Yendiprinzen, bestehen solle. Auch sollten sich die Leute als Unterhändler für den König von Yendi ausgegeben haben. Die Aufregung in Kete nahm indessen zu. Ich begab mich daher zu Pferde nach der Stadt und suchte die Bevölkerung durch einen Haussachief und meinen Dolmetscher $\mathrm{zu}$ beruhigen.

Mit grosser Spannung erwartete ich fast schlaflos den nächsten Eintreffen der Morgen. Hierauf wurde mir die Ankunft einer aus etwa zehn Personen vermeintbestehenden Gesandtschaft aus Yendi gemeldet, welche mir durch Sofo lichen Yendiihren Gruss entbieten liess. Jetzt wurde auch mein Dolmetscher stutzig, denn es schien höchst unwahrscheinlich, dass Yendiprinzen mit einem so geringen Aufwand an Sklaven und Trägern und ohne Pferde als Abgesandite des mächtigen Königs reisen würden. Abudu-Bedde vertraute mir gleichfalls heimlich an, dass nach seiner Ansicht diese Dagombaleute keine richtigen Prinzen seien. Bald darauf erschien die Gesandtschaft, von Sofo, der Yendiprinzessin und der ganzen Dagomba-Kolonie gefolgt, auf der Station. Fast ganz Kete war hier versammelt. Ich empfing sie vor dem Zelte, aber ihr ärmliches Aussehen bestärkte mich in dem Verdacht, dass sie keine Prinzen seien. Sie brachten mir vorgeblich den Gruss des Königs von Yendi und erklärten mir, dass er über die Einsetzung des Lempo als König Sulemana von Salaga sowie über die Festnahme von Malami sehr erzürnt sei. Er verlange die Auslieferung beider und Sofo solle dabei als Agent des Königs den Unterhändler spielen. Ich bedeutete ihnen vor der ganzen Volksmenge, dass der 
König von Yendi wohl in seinem Reiche unumschränkt zu gebieten vermöge, dass aber die deutsche Regierung auf ihrem Gebiete thun könne, was ihr beliebe und dass sie es ablehne, ihm Rechenschaft über ihre Maassnahmen zu geben, obwohl sie seine Freundschaft zu schätzen wisse. Hierauf drohten die Gesandten, von denen sich zwei als Prinzen ausgaben, dass der König ein grosses Heer gegen Kratyi und die Station senden würde. Ich erwiderte ihnen jedoch unumwunden, dass ich sie vorläufig als meine Kriegsgefangenen betrachten und so lange hierbehalten würde, bis ich die wirkliche Absicht ihres Königs erfahren habe. Dann stellte ich die Namen der angeblichen Prinzen fest, obwohl sie sich anfangs weigerten, dieselben anzugeben und ihre Aussagen sich widersprachen. Schliesslich gaben sie sich als die Prinzen Salim und Muhammed Karki aus.

Entlarvung der falschen Gesandtschaft.

Rãubereien

Auch die Yendiprinzessin und Sofo verwickelten sich in Widersprüche und gaben zu, dass die Gesandten eigentlich keine Prinzen wären, sondern nur als Boten des Königs so genannt würden. Ich nahm also die angeblichen Prinzen trotz des Protestes von Sofo und der Yendiprinzessin, gefangen, versprach ihnen jedoch, den König von Yendi davon unterrichten zu lassen und, falls sich ihre Mission bewahrheitete und der König sich der deutschen Regierung füge, sie mit Geschenken zu entlassen. Auch stellte ich ihren Begleitern frei, ihre Prinzen zu einer bestimmten Zeit auf der Station zu besuchen. Doch schon am selben Abend wurde mir berichtet, dass die angebliche Gesandtschaft aus Kete spurlos verschwunden sei. Gleichzeitig trafen von Bayamso Nachrichten ein, dass man von einem Dagombaheere nichts wisse und die ganze Angelegenheit erwies sich als ein Betrug. Die angeblichen Dagombaprinzen, die schon früher einen ähnlichen Streich mit Erfolg ausgeführt hatten, waren gewöhnliche Dagombaleute, welche nie etwas mit dem Hofe von Yendi zu thun gehabt hatten und wahrscheinlich von Sofo durch Geschenke zu dieser Komödie verleitet worden waren. Letzteres konnte zwar nicht erwiesen werden; doch wies der König von Yendi in einem an mich gerichteten Antwortschreiben jede Verantwortung für sie zurück. Die falschen Prinzen verbüssten hierauf ihre Strafe in Kete. Der ganze Vorgang beweist, wie überraschend und unglaublich schnell in Afrika Gerüchte verbreitet werden und wie fast jeder Tag eine neue Wendung bringt, so dass Afrika mit Recht das Land der Ueberraschungen genannt werden kann. Sofo, dem eine direkte Schuld nicht bewiesen werden konnte, stell $\downarrow$ diese feingewobene Intrigue als echtem Haussa ein Schlauheitsattest aus, zeigt aber auch die Hinterlistigkeit und Durchtriebenheit seines Charakters.

derDagomba. Boten liessen übrigens erkennen, dass er gegen uns verstimmt war. 
Auch nahmen die Räubereien der Dagomba immer mehr zu und das Verhältnis zwischen der Station und dem Yendikönig wurde immer gespannter. $r$. Carnap gelang es noch auf seinen verdienstvollen und weiten Reisen im Hinterlande freundschaftlich mit den Häuptlingen zu unterhandeln. Dagegen wurde später der Durchmarsch der Expedition unter Dr. Gruner nach Sansane-Mangu von dem Könige beanstandet. Es kam zu einem Kriege, der von dem tapferen Führer der Schutztruppe v. Massow siegreich geführt wurde und mit dem glücklichen Durchmarsch der Expedition endete. Nach dem Abzuge der Truppé liess aber der König von Yendi die Karawanen wieder in der früheren Weise plündern. Leider ist es der Regierung nicht möglich, diesen misslichen Verhältnissen dauernd abzuhelfen, da ein Durchzug von Truppen oder die Anlegung einer Station wegen des Neutralitätsvertrages mit England nicht angängig ist.

Je schroffer sich im Norden die Beziehungen zu der Dagombaleuten Gesandtschaft gestalteten, desto enger und intimer wurden diejenigen zu den sogenannten Kotokolilanden im Nordosten. Mit dem Verfall von Salaga kam wegen der räuberischen Ueberfälle der Dagomba die direkte Karawanenstrasse zwischen dem Hinterlande von Tshautsho, Sugu und Borgu sowie aus den entfernten Haussastaaten nach Kratyi immer mehr in Aufnahme. Der Häuptling von Sugu sandte seinen Sohn mit einer Karawane nach Kete, um dort neue Handelsbeziehungen anzuknüpfen und in nähere Verbindung zu der deutschen Regierung zu treten, da er viel unter dem Drucke der französischen Regierung zu leiden hatte. Unter dem Geleit von Abudu-Bedde und Sofo besuchte mich der Königssohn auf der Station und übermittelte mir die Grüsse des Königs von Sugu. Er brachte mir als Geschenk ein grosses schönes Leopardenfell und bat mich gleichzeitig den Karawanen von Sugu den Schutz der deutschen Regierung zu gewähren. Ferner liess mich der König einladen nach Sugu zu kommen, da er die Freundschaft mit den Deutschen zu erneuern wünsche. Ich versprach, den König in Sugu zu besuchen, sobald ich Zeit hätte und sandte sofort einen Eilboten zur Küste nach Lome an den damaligen Landeshauptmann mit der Bitte, mir die Erlaubnis hierzu zu geben und mir einen Betrag von I 200 Mark zu bewilligen, um eine Reise über Bassari nach Sugu und eventuell auch nach Borgu zu unternehmen. Es war mein Plan dann, wenn möglich, von Borgu aus durch das Kabreland nach Yendi und von da zurück nach Kete zu marschieren.

Den günstigsten Zeitpunkt, nach Sugu und Borgu vorzudringen; hatten wir leider, als die Franzosen im Jahre I 893 und auch noch 1894 mit dem König Behanzin von Dahomey im Kriege lagen, aus Mangel an Geldmitteln verfehlt. Aber unsere deutsche Togo-Expedition wett- 
eiferte nun im Hinterlande von Gurma mit der französischen. Die Gebiete von Sugu und Borgu waren von der französischen Expedition bis dahin nur gestreift und der französische Einfluss hatte noch kaum Wurzel gefasst. Es war daher vielleicht noch möglich, die von den Reisenden Dr. Wolf und Kling in den Jahren 1889 und $189 \mathrm{r}$ in Sugu angeknupften Freundschaftsbeziehungen wieder aufzufrischen, einen Schutzvertrag mit dem Herrscher von Sugu zu schliessen und durch $\mathrm{Zu}$ rücklassung kleiner Militärposten der französischen Okkupation zuvorzukommen. Obwohl ich mir nicht verhehlte, dass die Reise nach Borgu mit ganz erheblichen Schwierigkeiten verbunden gewesen wäre, wollte ich doch den Versuch machen bis nach Kwande, der Residenz des Sultans von Borgu, vorzudringen, um dort für uns noch neue Vertragsrechte zu erlangen. Auch wäre die Reise wissenschaftlich von Erfolg gewesen, da ich hoffen durfte, geographische Aufnahmen in dem gänzlich unerforschten Kabregebiet zu erzielen. Aber obwohl mein Vorschlag für wichtig und richtig anerkannt wurde, musste er leider wegen Mangel an Geldmitteln unausgeführt bleiben.

Erst nach Ablauf eines Jahres wurden der Graf Zech und später Freiherr von Seefried in die Gebiete von Sugu gesandt, wo sie wissenschäftlich thätig waren, überall kleine Posten zurückliessen, Stationen von einigen Hütten anlegten und so im letzten Augenblick die Franzosen Der Pariser hinderten, noch weiter nach Westen zu greifen. Fast zwei Jahre später, Vertrag und im Jahre I897, wurde mit verhältnismässig viel grösseren Mitteln die dieBedeutung Station Sugu angelegt, wo zuerst provisorisch ein Weisser, Zollassistent der Station Wegner, stationiert war, welcher dort leider der Dysenterie erlag. Später ging, fast zu gleicher Zeit mit unserer privaten Douglas-Expedition, Dr. Kersting mit einem Unteroffizier nach Sugu. Aber auch Dr. Kersting musste nach Abschluss des Pariser Vertrages vom Jahre 1897 die Station wieder räumen. Nach der Rückkehr der Togo-Expedition I 896 und infolge der Aufhebung von Bismarckburg als Europäerstation dehnte die Station Kratyi, hauptsächlich durch die Reisen von Graf Zech, ihre politische und wissenschaftliche Thätigkeit auf die grosse Interessensphäre im Norden aus. Zuvor ist ihre Thätigkeit durch die Anlage der neuen Stationen Sansane-Mangu, Paratau und Bassari, sowie durch den Pariser Vertrag begrenzt, indessen bleibt sie noch heute als Stützpunkt. der vorgeschobenen Posten unentbehrlich. Von hier aus treten sämtliche Expeditionen nach den neu angelegten entfernten Stationen ihren Weg an und die Posten und Proviantkolonnen werden von hier aus expediert. Da ferner das benachbarte Kete noch heute der Knoten- und Sammelpunkt aller Karawanen ist, wird die Station Kratyi ihre Bedeutung auch in Zukunft behalten und für die weitere Erschliessung und Entwickelung des Hinterlandes segensreich wirken. 
Infolge des Fiebers war meine Gesundheit so erschüttert, dass ich um Versetzung in eine andere gesundere Gegend einkam. Kurz darauf traf Graf Zech ein, welcher die Station übernahm, während ich zur Küste marschierte. Hier verschlimmerte sich mein Zustand derart, dass ich + Wochen in dem Krankenhause von Klein-Popo zubringen musste. Nach meiner Genesung wurde mir die Küstenmessung und eine Aufnahme von Klein-Popo übertragen. Im April 1896 war meine zweijährige Dienstzeit beendet und ich trat die Heimreise an.

\section{DAS ÖSTLICHE HINTERLAND.}

\section{REISE NACH BASSARI UND SUGU.}

Die Besitzergreifung und wissenschaftliche Erforschung unserer Kolonieen hat weite Landstrecken für die Kultur erschlossen. Der nächste Schritt aber muss darin bestehen, das Interesse deutscher Grosskapitalisten für die wirtschaftliche Hebung dieser neuen Gebiete zu wecken. Dadurch allein kann dem eigentlichen $Z_{\text {weck }}$ unserer Kolonieen näher getreten werden. Glücklicherweise haben sich in neuerer Zeit nationalgesinnte Männer gefunden, die einsehen, dass ihr Kapital, wenn auch, wie bei jedem neuen Unternehmen, mit Risiko, doch mit Vorteil in den neuen Kolonieen angelegt werden könne. Diese haben sich durch die Gründung von Plantagengresellschaften, sowie durch grosse Handelsunternehmungen, die noch in der Bildung begriffen sind, namentlich in Kamerun, um die Kolonialsache in hohem Grade verdient gemacht. Aber auch für Togo ist mit der wirtschaftlichen Erschliessung und der Anlage von Plantagen eine neue Aera angebrochen. So entsandte die Familie Douglas im Jahre r897 eine Expedition nach dem Hinterlande von Togo, welche ursprünglich wirtschaftlichen Zwecken dienen sollte, zunächst aber eine politische Mission zu erledigen hatte. Anfang des genannten Jahres wurde mir die Ausrüstung, später auch die Führung derselben übertragen. Im Frühjahr war die Expedition zum Abmarsch von der Küste bereit. Wir standen damals noch vor dem Abschluss des Pariser Vertrages und, da die Expedition seitens ihrer Unternehmer auch der Regierung zur Verfügung gestellt war, so wurde sie noch im letzten Augenblicke dazu benutzt, um im Osten, tief im Hinterlande, in die staatliche Interessensphäre vor- 
zudringen. $\mathrm{Zu}$ diesem $\mathrm{Zweck}$ erhielt die Expedition den Auftrag, den kleinen Posten Bassari, westlich von der grossen französischen Station Bafilo, zu besetzen und dort eine provisorische Europäerstation zu gründen. Die geologische Erforschung des Landes von der Küste aus nach dem Innern, sowie die Erwerbung geeigneten Areals in der Nähe der Küste zu Plantagenzwecken musste daher aufgegeben werden. Statt dessen wurden die geologischen Untersuchungen weit im Norcien des Gebietes begonnen und schrittweise bis zur Küste fortgesetzt. Zunächst will ich über die Znsammensetzung und Ausrüstung einer solchen grossen Expedition einige Worte vorausschicken.

\section{AUSRÜSTUNG.}

Feldbett.

Der grösste Teil der Ausrüstungsgegenstände wurde in Berlin bei der Firma v. Tippelskirch besorgt. Was die Gebrauchsgegenstände anbetrifft, so ist nach meiner Ansicht das Hauptaugenmerk auf ein bequemes und allen Anforderungen entsprechendes Feldbett zu legen. Dasselbe darf vor allen Dingen nicht schwerer sein als eine Last, also etwa 50 Pfund, andererseits muss das Bettgestell ein Ganzes bilden und nicht in einzelne Teile zerlegbar sein, da diese auf der Reise leicht verloren gehen können. Auch muss es zusammengelegt eine geringe Ausdehnung haben, da es sonst in dem Busche auf dẹn engen Pfaden fortwährend anstösst und dem Träger grosse Unbequemlichkeiten bereitet. Es darf höchstens $50 \mathrm{~cm}$ breit und $80-90 \mathrm{~cm}$ lang sein. Ferner muss das Bett und namentlich die Leinwandmatratze die nötige Spannung haben, damit sich keine Mulde beim Liegen bildet. Endlich muss die Matratze eine erhöhte Kopflage besitzen. Die nötige Leichtigkeit erzielte ich, indem ich das Gestell aus Gasrohr anfertigen liess. Das ganze Bettgestell mit den Mosquitonetzhaltern wog nicht mehr als 25 Pfund. Es konnte auseinandergeklappt werden und alle Teile, bis auf die Mosquitonetzhalter waren durch Charniere miteinander verbunden, so dass es binnen einigen Minuten aufgeschlagen werden konnte. Eine doppelt gelegte, dicht imprägnierte Segelleinwand bildete die Matratze; sämtliche Eisenteile waren verzinnt, um sie vor Rost zu schützen. Das Lager wurde durch eine wasserdichte, sogenannte Lagerdecke vervollständigt, welche als Unterlage diente und je nach der Witterung und der Temperatur auch zum Einhüllen verwendet werden konnte. Ein grosses, gutes Rosshaarkissen in der Breite des Bettgestells mit wasserdichtem Ueberzug diente als Unterlage für den Kopf. Der Reinlichkeit wegen fanden noch rohleinene Bettlaken, sowie einige Kissenüberzüge, ferner eine billige italienische Seidendecke und für kältere Nächte eine Woll- oder Kameelhaardecke Verwendung. Ein leichtes Mosquitonetz beschloss die Ausrüstung des Tropenbettes. Eine starke, 
aus Leinwand hergestellte und mit Leder benähte Tasche hatte den Zweck, das Bett mit sämtlichen Decken und Kissen für den Marsch aufzunehmen und vor Regen zu schützen. Nach meiner Erfahrung wie der der übrigen Teilnehmer der Expedition hat sich dieses Bett vorzüglich bewährt, so dass wir es selbst in den Faktoreien der grossen, schweren Holzbettstelle vorgezogen haben.

Von grosser Wichtigkeit ist es ferner, zusammenlegbare Tische und

Tische und

Stüble

Stühle mitzunehmen. Man glaubt nicht, wie schwer es ist, längere Zeit ohne Tisch zu leben und rom Boden zu essen, sowie grössere Berichte auf den Knieen zu schreiben. Wenn es angängig ist, empfiehlt es sich, mehrere Stühle für jede Person mitzunehmen und zwar einen gewöhnlichen kleinen Stuhl, der bei der Arbeit und beim Essen benutzt wird und einen bequemen Deckstuhl, oder sogenannten englischen Stuhl zum ausruhen. Dann gehört unbedingt zur Ausrüstung jeder Expedition eine Menage, die ineinander gelegt werden kann und das Geschirr aufnimmt.

Bei umfangreichen Expeditionen ist natürlich auch ein grösseres Zelt erforderlich. Jedoch ist ein solches eher entbehrlich, als die vorher erwähnten Gegenstände, da man überall Dörfer und Hütten antrifft. Ausserdem sind die Hütten der Eingeborenen vom sanitären Standpunkte aus einem Zelte unbedingt vorzuziehen. Die ausgetrockneten Lehmhütten haben wegen ihrer dicken Lehmmauern und guten Grasdächer eine gleichmässigere Temperatur, während in dem Leinwandzelt die Temperatur bei Tag und Nacht mit der Aussentemperatur wechselt. Am Tage, wenn die Tropensonne ihre Strahlen auf das Leinwandzelt sendet, ist die Hitze darin fast unerträglich, während es sich nachts ebenso schnell abkühlt und man häufig, namentlich in der Harmattanzeit, des Morgens geradezu in seinem. Bette friert. Natürlich schwankt die Temperatur bis zu einem gewissen Grade auch in einer Hütte, doch nicht in dem Maasse, wie in einem Zelte. Jedenfalls ist nach meiner Anschauung in den Tropen nur ein Zelt mit doppeltem Dach verwendbar. Abgesehen von diesem Uebelstande bildet sich auch im Zelt trotz einer Bodendecke durch die Ausdünstungen des frischen Bodens eine verhältnismässig grosse Feuchtigkeit.

Was die Beleuchtung anbetrifft, so thut man am besten, sich mit einer einfachen Petroleumlaterne zu versehen, und für den Fall, dass das Petroleum ausgeht, einen Vorrat von Stearinkerzen mitzuführen. Natürlich gehört zu der Ausrüstung eine kleine Apotheke, welche von den gebräuchlichsten Arzneien, wie Chinin, Kalomel etc., grössere Dosen enthalten muss.

Zur persönlichen Ausstattung wähle man Anzüge von dem be- Ausrüstung. kannten weissen und braunen Drell, während die Unterkleider am besten aus feiner Baumwolle bestehen. Alle Kleidungsstïcke sowie alle
Beleuchtungs. material.

Persönliche 
dem Witterungseinfluss unterworfenen Gegenstände werden in durch Gummi luftdicht abgeschlossenen Blechkoffern verpackt. Trotz des hohen Preises dieser Koffer machen sie sich sehr bald bezahlt, da sie, wie schon erwähnt, den einzigen Schutz gegen die Feuchtigkeit und die massenhaft vorhandenen Insekten, Termiten, Bohrkäfer etc. bilden. Ganz besonders unentbehrlich sind ausser den allgemein bekannten Gegenständen wie Tropenhelm, Schuhwerk etc., eine Gummibadewanne und ein Waschbecken. Ferner ist zur Aufbewahrung von getragener Wäsche ein wasserdichter, verschliessbarer Sack notwendig.

Bewaffnung

Was die Bewaffnung anbelangt, so ist für Europäer der Karabiner, und Reitzeug. Modell 88, sowohl zur Verteidigung als auch zur Hochwildjagd die beste Waffe. Die Munition für Hochwild ist noch mit einer Bleispitze versehen, die einen grösseren Blutverlust und somit eine raschere Wirkung des Geschosses herbeiführt. Neben diesem Karabiner sind Schrotflinten mitzuführen, die jedoch untereinander behufs Vereinfachung der Munition von demselben Kaliber sein sollen. Ausserdem sind noch zur Verteidigung ein paar Revolver mit grossem Kaliber erforderlich. Bezüglich der Bewaffnung der Leute ist es streitig, ob Karabiner oder Gewehr zweckmässiger ist. Jedenfalls herrscht in unseren deutschen Kolonieen nur eine Stimme des Lobes über die Bewaffnung mit unserem Mausergewehr, Modell 7I. Durch die Einfachheit und Solidität der Konstruktion ist es selbst für einen Schwarzen leicht zu reinigen und entspricht auch den immensen Anforderungen, welche in dem feuchten Tropenklima auf einer Expedition an ein Gewehr gestellt werden. Bei der Bewaffnung der Lasten-Träger ist wegen des geringeren Gewichtes, sowie wegen der besseren Handhabung in dem Busch der Karabiner dem Gewehr oder der Jägerbüchse bei weitem vorzuziehen. Bei der Bewaffnung von Soldaten dagegen ist, trotz der angeführten Vorzüge des Karabiners, die Jägerbüchse, Modell 7 I, nach meiner Erfahrung die gegebene Waffe. Der Vorteil besteht hauptsächlich darin, dass die Soldaten bei einem Sturm oder Nahkampf das Seitengewehr aufpflanzen können, was auch schon wegen des äusseren Eindrucks den Schwarzen gegenüber nicht zu unterschätzen sein dürfte.

$\mathrm{Zu}$ diesen Ausrüstungsgegenständen kommen bei Reisen nach dem Hinterlande von Togo noch Sättel und Zaumzeuge, welche in den Kolonieen schwer und nur für hohes Geld zu haben sind.

Wissen- Die wissenschaftliche Ausrüstung umfasst zunächst alle Instrumente schafliche für geographische Messungen: Kompasse, Theodoliten, Aneroïde, BandInstrumente maasse und vor allen Dingen die verschiedensten Uhren. Alle diese feinen und Karten. Instrumente müssen sämtlich möglichst sorgtältig verpackt werden, wobei ein mit Gummi verschlossener Blechkoffer wieder als die praktischste Art der Verpackung erscheint. Ausser diesen, für geographische Aufnahmen 
bestimmten Instrumenten sind Werkzeuge und Instrumente für andere wissenschaftliche Zwecke notwendig, wie Seziermesser und Gifte für zoologische Präparate, Messinstrumente für anthropologische Aufnahmen und ein guter photographischer Apparat, der bei keiner grösseren wissenschaftlichen Expedition fehlen sollte. Natürlich müssen sämtliche vorhandenen Routen und Karten der zu durchwandernden Gegenden aufs Eingehendste geprüft und mitgenommen werden. Auch darf man auf keinen Fall einen festen Schreibkasten vergessen, der zur Aufbewahrung aller wichtigen Notizen und Schriftstücke dient.

Grössere Geschenke für Könige oder Sultane werden im allgemeinen Grössere Geschon von Europa mitgenommen. Am beliebtesten sind für diesen Zweck fantastische Zaumzeuge, Schabracken, Goldbrokatstoffe, Kaiserbilder, Schwerter, Hirschfänger, Uhren, Spiegel, Spieldosen, Becher, Fuchsschwänze als Fliegenwedel, und bunte und weisse Decken. $\mathrm{Zu}$ sogenannten Königsmänteln eignen sich vorzüglich rot gefärbte Bademäntel. Für das Hinterland ist besonders gangbar, namentlich an den reichen mohamedanischen Fürstenhöfen und bei den Haussahändlern, der MariaTheresien-Thaler, dessen Wert von der Küste nach dem Innern zu bedeutend zunimmt. Er wird noch heute in der Münze in Wien für afrikanische $Z$ wecke geprägt und ist bei grösserer Abnahme für 2,30 Mark $z u$ haben. Während er in Kete von den Haussa mit 4 Mark bewertet wird, hat er schon in Tshautsho einen Wert von 5 bis 6 Mark und weiter am Niger soll er sogar einen Wert von 7,50 Mark erzielen. Der Maria-Theresien-Thaler hat schon früher durch Reisende seinen Weg in das Innere gefunden. So erwähnt unser berühmter Nachtigal den Kurs der Theresien-Thaler in Central-Afrika in Bornu, und in der grossen Handelstadt Cano. Dieser Thaler hat sich so eingebürgert, dass selbst der König Menelik von Abessinien eine ähnliche Münze mit seinem Bildnis für sein Land hat prägen lassen.

Alle übrigen Tauschartikel kauft man am besten in den afrikanischen Faktoreien, die dem Geschmack und der Nachfrage der einzelnen Gegenden Rechnung tragen. Zum Eintausch von kleineren Gegenständen eignen sich am besten Perlen, die je nach der Gegend ihre besondere Form, Farbe und Grösse haben müssen, ferner kleine Handspiegel, auch Messingstäbe zu Schmuckgegenständen, bunte Taschentücher zu Kopftüchern, für Frauen allerhand minderwertige Pomaden und das allbeliebte sogenannte Lawendelwasser. Gin in Flaschen, auf welchen die Etikette mit dem Elefanten nicht fehlen darf, und ganz besonders Tabak, der verhältnismässig leicht zu verpacken und wenig dem Einfluss der Witterung ausgesetzt ist, erweisen sich ebenfalls als praktisch. Der Tabak ist ungemein beliebt und selbst gangbar in den Gegenden, wo Tabak gebaut wird. Kleinere Dienstleistungen werden mit einigen Blättern 
bezahlt und ein head Tabak, der an der Küste nur einen Preis von 25 bis 30 Pfennigen hat, erzielt z. B. auf dem Markt in Akpande und in den von Kratyi nördlich gelegenen Gegenden einen Preis von I Mark. Ferner werden kleine weisse Thonpfeifen gern gesehen. Ich habe deshalb für das Tabakskollegium eines grossen Häuptlings lange Pfeifen aus Europa mitgenommen, welche der schwarzen Hoheit eine unbändige Freude bereiteten. Als Tauschartikel können auch wertvollere Sachen verwendet werden, wie die verschiedensten Seidenstoffe, Baumwollzeuge und Kattune.

Mitzu-

Was die mitzuführenden Lebensmittel anbetrifft, so liegen die Verführende hältnisse in dieser Beziehung in dem reichbevölkerten Hinterland von Lebens- und Genussmittel Togo ziemlich günstig, da man fast jeden Tag ein Dorf erreicht, wo Hühner, Schafe und Ziegen, weiter im Innern auch Rinder zu haben sind. Ab und zu bringt die Jagd eine Antilope oder ein paar Tauben, Busch- oder Perlhühner. Beim Durchschreiten eines grösseren unbevölkerten Busches werden für einige Tage die nötigen Hühner mitgenommen. Ausserdem findet man fast überall Yams, Kassava, Reis, Bohnen oder Hirse, so dass man so gut wie gar keine Konserven braucht und nur für die Zuthaten und vor allem, bei den schlechten Wasserverhältnissen, für Getränke zu sorgen hat. $\mathrm{Zu}$ diesem Zweck muss man Butter, Fette und Oel in genügenden Mengen mitnehmen. Essig ist garnicht und Pfeffer nicht überall käuflich, wogegen Salz, wenn auch teuer und in einheimischer Form, überall zu haben ist. Von Getränken ist Kakao. Kaffee und besonders Thee mitzuführen, da fast sämtliches Wasser aus Vorsicht gekocht und häufig kalt mit Theezusatz genossen wird. Eine grosse Rolle spielt dabei, wie ich schon erwähnt habe, zur Ergänzung der Kohlenhydrate, sowie zur Verbesserung der Schmackhaftigkeit, der Zucker. Geht dieser aus, so ist das für die ganze Expedition eine empfindliche Entbehrung. Als Getränke sind zur Erhaltung und Stärkung der Körperkräfte, namentlich nach Fiebern, bei der Hitze Bordeauxweine und Sekt sehr empfehlenswert. Von Alkoholen ist Cognac anzuraten, wovon ein geringes Quantum für eine verhältnismässig lange Zeit ausreicht.

Die

Zusammensetzung der Expedition.

Die Zusammensetzung der Expedition bestand im ganzen aus drei Weissen. Wir teilten uns in die einzelnen Funktionen. Bergassessor Hupfeld lag selbstverständlich die geologische Forschung ob, während Unteroffizier Hoyer zum Expeditionsmeister ernannt wurde. Ich selbst übernahm die Führung und Ausrüstung der Expedition, sowie die geographischen Aufnahmen und ethnologischen Aufzeichnungen und die damit verbundenen Arbeiten. Die Schwierigkeiten bei Anwerbung des erforderlichen Personals lagen hauptsächlich darin, einen tüchtigen und zuverlässigen Dolmetscher, sowie einen mit dem Expeditionsleben ver- 
trauten Koch zu gewinnen. Ferner galt es schnell eine kleine Truppe für die Expedition auszubilden und auch einen Stamm von zo Trägern für die Reise zu schaffen. Bei allen diesen Vorarbeiten wurde ich von der Regierung, sowie von den Kaufleuten an der Küste in anerkennenswertester Weise unterstützt. Ausser diesen verdanke ich es aber hauptsächlich der Hingabe und dem Eifer meiner Reisegefährten, dass es mir gelang, in einer verhältnismässig so kurzen Zeit meine Aufgabe zu bewältigen und den Marsch in das Innere antreten zu können.

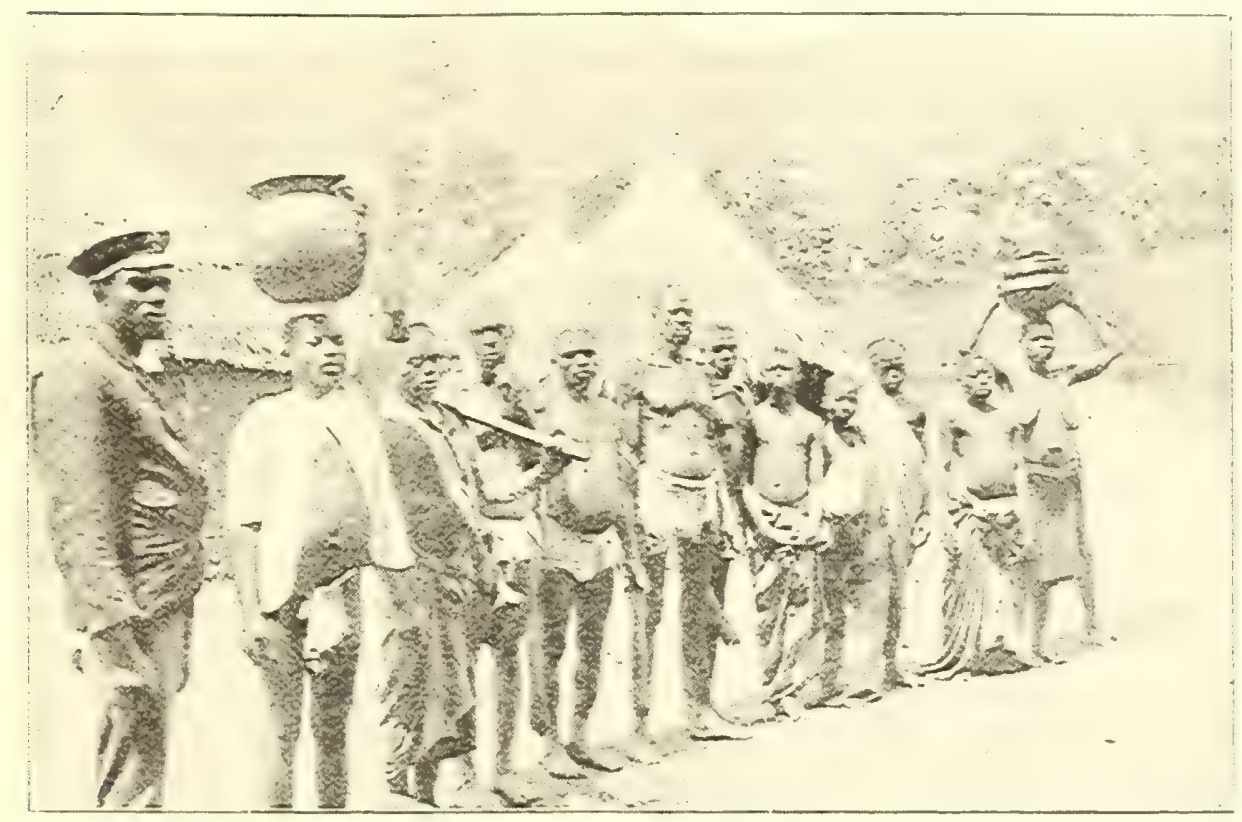

Träger von dem Evhestamm.

Was die Lohnverhältnisse der Leute anbetrifft, so bekam unser Dolmetscher Johnson Garver 6o Mark und der Koch Hans Naku 35 Mark monatlich. Ausser diesen beiden Leuten engagierte ich einen Schmied, Johnson Almeida, fur die Instandhaltung der Werkzeuge und als Hetman für die Leute für einen Monatslohn von 45 Mark. Garver und Almeida gehörten beide den vornehmsten und reichsten, an der Küste ansässigen schwarzen Geschlechtern an, was ihnen den schwarzen Trägern und Soldaten gegenüber ein gewisses Ansehen verlieh, andererseits auch für ihre Sicherheit bürgte, da nach der Rechtsanschauung der Eingeborenen, wie bereits erwähnt, die ganze Familie für jedes Vergehen ihrer Angehörigen haftet. Die Träger warb ich meistens aus dem Dorfe Gridyi bei Klein-Popo an und zahlte ihnen pro Tag 75 Pfennige Lohn, die 
Soldaten nahm ich aus den Freiwilligen desselben Orts und liess sie so schnell wie möglich ausexerzieren. Herr Hoyer mit zwei schwarzen Unteroffizieren von der Truppe bildeten die an Grösse alle Träger weit überragenden zwölf Rekruten in erstaunlich kurzer Zeit so weit aus, dass sie wenigstens einigermaassen für ihren nunmehrigen Beruf zu verwenden waren. Auch ein Hornist wurde noch in Eile ausgebildet. Um das richtige Soldatenmaterial zu bekommen, musste ich den Leuten dieselbe Löhnung geben, welche die Soldaten der Schutztruppe erhielten und zwar pro Tag und Mann I Mark. Sämtliçhe Leute der Expedition bekamen auf dem Marsche einen Verpflegungszuschuss von 25 Pfennig pro Tag. Im allgemeinen sind die Trägerverhältnisse, besonders an der Küste und im ganzen Evhegebiete, ausserordentlich günstige. Die Leute vermieten sich gern, jedoch meistens nicht über Misahöhe bezw. von Agome bis über Kratyi hinaus. Der Lohn für eine Last von 50 bis 60 Pfund von Lome bis nach Misahöhe beträgt nur 5 Mark, dagegen von Misahöhe bis Kratyi 8 Mark. Natürlich musste ich bei dem Risiko, welches die Leute auf einer so langen Reise in fremden, ihnen unbekannten Gegenden eingingen, mehr zahlen, um sie überhaupt für den Zweck zu gewinnen.

\section{ABMARSCH VON DER KÜSTE UND MARSCHORDNUNG.}

Ende Mai 1897 waren alle Vorbereitungen beendet und nachdem wir noch unter den Klängen der Kapelle bei festlichem Mahl Abschied von der Küste genommen hatten, marschierten wir am 29. Mai früh von Lome ab. Die ganze Expedition hatte folgende Marschordnung. An der Spitze wehte die deutsche Flagge, welche von dem grössten Soldaten, Agbemedy, getragen wurde; dahinter marschierte die kleine Truppe, welcher sich der lange Zug von Lastträgern anschloss. Hierauf folgte der Stab der schwarzen Eskorte, der Dolmetscher, ein Hornist und etliche Soldaten, welche aufzupassen hatten, dass keiner der Träger zurückblieb. Assessor Hupfeld hatte meistens die Tète, während der Expeditionsmeister Hoyer, wegen der seiner Aufsicht anvertrauten Schwarzen am Queu ritt; ich selbst machte den Beschluss, um durch meine Routenaufnahmen und das wiederholte Einstellen des Kompasses die ganze Kolonne nicht unnutz aufzuhalten. Auch gewährt die voranmarschierende Trägerkolonne immer ein Objekt zur Anpeilung und giebt durch ihr gleichmässiges Tempo eine Norm für die Marschgeschwindigkeit. In dieser Hinsicht hat die Routenaufnahme zu Pferde grosse Vorteile, da man die voranmarschierende Karawane durch einen kleinen Trab schnell wieder einholen kann. Die zurückgelegten Strecken bleiben dann bei gleicher Ablesungszeit die gleichen und die Länge der Route kommt auch ohne astronomische Ortsbestimmungen der wirklich zurückgelegten Strecke annähernd gleich. 
Die ganze Proviantierung und Zufuhr der Expedition wurde durch zweimonatliche Trägerkolonnen von der Küste her über die Stationen Misahöhe und Kratyi nach Bassari wo wir unseren Stützpunkt hatten, nachgesandt. Nur durch einen verhältnismässig langen Aufenthalt in Bassari konnte dieser Nachschub von Proviant und Tauschartikeln bewerkstelligt und so die erheblichen Kosten eines grossen dauernden Trägermaterials gespart werden.

Die ganze Expedition, mit welcher wir bis nach Bassari marschierten, bestand aus etwa i 30 Köpfen. Von den hundert Trägern machten nur 30 die ganze Expedition mit, während die übrigen etappenweise von einer Station bis zur andern gedungen wurden.

Unser Marsch nach Kratyi ging glatt von Statten. Bis hierher ist Aufbruch von es im allgemeinen leicht, Träger zu erhalten, da man, wie schon erwähnt, nur mit Evheleuten marschiert. Ueber die Station Kratyi hinaus gehen jedoch die Leute verhältnismässig selten und die Furcht vor den Dagomba und den nördlichen Völkern ist leider noch immer so gross, dass Leute welche schon fest engagiert sind, in Kratyi vor dem Weitermarsch desertieren. Aus diesem Grunde ist hier gewöhnlich ein längerer Aufenthalt geboten, um ein grösseres Trägermaterial, meistens Kratyileute, neu einzustellen. Die meisten Träger waren damals von den Stationen Sansane-Mangu und Sugu engagiert, so dass wir es nur der Güte des damaligen Stationsassistenten Rosenhagen zu verdanken hatten, dass wir bald unseren Weitermarsch antreten konnten. Um den Abmarsch zu beschleunigen, sandte ich die Hälfte der Träger, ungefähr fünfzig, bis Dutukpene voraus. Von dort aus beabsichtigte ich mit sämtlichen Trägern geschlossen weiter zu marschieren, da die Gegend von da ab unsicher sein sollte. Zwei Tage darauf verliessen wir mit dem Gros der Expedition ebenfalls Kete und marschierten über Abudjiro bis Padji, wo wir unser erstes Nachtquartier aufschlugen. Noch einmal begrüssten wir von den Höhen, nordwestlich von der Stadt Kete, die südlichen Gebirge von Boëm. Dann folgten wir der grossen Heerstrasse, welche nach den Kotokolilanden führt, durch die eintönige Buschsavanne, die wir bereits auf dem Wege nach Salaga kennen gelernt haben.

Neue Träger, welche noch nicht an die Marschdisziplin gewöhnt sind, machen dem Aufsichtspersonal, dem Dolmetscher, dem am Queu marschierenden Soldaten und dem Expeditionsmeister nicht wenig zu schaffen. Bald verweigert ein Träger den Weitermarsch, ein anderer behauptet, seine Last sei ihm zu schwer, wieder ein anderer sucht den Umtausch einer ihm unangenehmen Last zu erzwingen, indem er absichtlich stolpert und sie zu Boden wirft. Das sind harte Gedulasproben für clen pflichttreuen Weissen, der für die Aufrechterhaltung der Disziplin und den Verlust der Lasten verantwortlich gemacht wird. 
Häufig bedarf es seiner ganzen Energie, um die Leute im Guten oder Bösen zum Weitermarsch zu bewegen. Erst wenn sie eingesehen haben, dass sie ihren Willen nicht durchsetzen, fügen sie sich und nach etlichen Tagen geht der Marsch ordnungsmässig von statten.

Unterkunft in Unsere Karawane erreichte bald Abudjiro und die Vorläufer der Padji. Höhenzüge, welche bei Padji den Volta begleiten. Auf kleinen TerrainVersuchter wellen ging der Marsch bei strömendem Regen weiter bis Padji, das auf Diebstahl einer Anhöhe nahe am Oti liegt und aus zwei Dörfern mit etwa je $5^{\circ}$ Hütten besteht. Von hier aus übersieht man das Thal des mächtigen Oti, welcher, den dunklen Galeriewald durchschneidend, in einer Mulde zwischen kleinen Hügelketten dahinfliesst. Padji selbst ist ein viel besuchter Ort. In der Nacht wird er von grossen Haussakarawanen umlagert, welche in kleinen Laubhütten, nahe dem Dorfe, ihr Quartier aufschlagen. Wir marschierten an einem unwirtlichen Regentage in die Stadt ein und fanden alle Hütten dicht belegt. Infolgedessen wurde rasch von den damit vertrauten Soldaten das Zelt aufgeschlagen, in welchem wir unser gekochtes Huhn mit grossem Appetit verzehrten.

In der Nacht ereignete sich ein charakteristischer Zwischenfall. Da wir die grosse unbewohnte Baumsavanne zwischen Kratyi und Adele passieren mussten, hatte ich einen uns von König Lempo in Kratyi geschenkten Stier sowie mehrere Schafe und Hühner als Schlachttiere mitgenommen. Plötzlich meldeten mir meine Soldaten: „Massa, the cow run away." Sogleich bot ich alle Leute auf und wir Weissen voran mit der Laterne suchten bei strömendem Regen im Busch und in der Nähe der Ortschaften den Stier. Alle Augenblicke ertönte ein kräftiger Fluch durch die Dunkelheit und nicht ohne Grund, denn gewöhnlich hatte der Betreffende seiner ganzen Länge nach mit dem nassen Erdboden Bekanntschaft gemacht. Schliesslich meldete sich der gesuchte Stier selbst durch sein Blöken. Er befand sich mitten unter dem Vieh einer Haussakarawane. Natürlich leugneten die Haussa, ihn dort hingebracht zu haben und behaupteten, dass er sich freiwillig zu ihrem Vieh gesellt habe. Da der Fall nicht klar lag, musste ich von einer Bestrafung absehen, indessen bin ich überzeugt, dass die schlauen Haussa einen Diebstahl beabsichtigt hatten.

Uebergang Am nächsten Morgen überschritten wir in grossen Kanoes, mit über den Oti denen die Padjileute die Fähre unterhalten, den Oti. Der Fluss war bei Padji. bei der Regenzeit hoch angeschwollen und wälzte seine gelblichen Fluten in dem tief eingeschnittenen Bett in einer Breite von $120 \mathrm{~m}$ dem Volta zu. Der Abfall der steilen Uferränder erreichte eine Höhe von Io bis $12 \mathrm{~m}$. Ein grosser schöner Galeriewald bedeckte zu beiden Seiten die sanften Höhen. Alles, was von der Expedition des Ruderns kundig war, wurde mit Paddeln bewaffnet und unterstützte die Fährleute. 
In etwa sechs Kanoes wurde die Ueberfahrt bewerkstelligt. Ijie meiste Sorge machte der Transport der Pferde. Ein paar beherzte Soldaten nahmen in den Kanoes Platz und hielten das Pferd am Zügel, während andere das Kanoe mit dem schwimmenden Pferde hinüber zu rudern suchten. Bei ruhigen Pferden gelingt dieses Experiment gewöhnlich, doch bei aufgeregten Tieren ist es bei der gewaltigen Strömung nicht ohne Gefahr für die Insassen. Leider mussten auch wir die Erfahrung machen, dass eins unserer Tiere ein Boot umwarf, in welchem sich zu unserem grossen Kummer auch eine Last Zucker befand, die nun anstatt unseren Kaffee, die Fluten des Oti und den Krokodilen das Leben versüsste. Glücklicherweise fanden wir unterhalb der Fähre eine Furt, wo wir unsere drei Streitrosse hinüberbrachten. In etwa zwei Stunden war das Uebersetzen beendet und nach einer kurzen Rast marschierten wir weiter. Ueberall passierten wir provisorische Haussalager, die sich längs des Pfades dahinzogen; vor den erst kürzlich verlassenen Laubhütten sah man stellenweise noch die Feuer glimmen. Der Weg führte über kleine Terrainwellen und eingeschnittene Bäche durch eine endlose Baumsavanne. An den sumpfigen Stellen begegnen wir vereinzelten Oelpalmen und hohem Schilfgras. Ab und zu starrt ein Termitenhügel aus dem Busch hervor; die Strasse ist belebt von langen Karawanen mit vielen Lastträgern, die entweder Gummi aus dem Adelegebiet herunterbringen oder weither aus Sugu und Tshautsho Pferde, Vieh und Schafe mit sich führen. Viele Lasten werden auf Eseln und kleinen Dagombapferden in Körben transportiert. Die Haussa grüssen freudig mit dem Zuruf "nussa-nu, kaka-dina" — "lafia, lafia" und erkundigen sich, wie es ihren Verwandten in Kete geht. Sie sind glücklich, nach so langer Abwesenheit ein bekanntes Gesicht oder einen Verwandten zu sehen. Auch unsere Evheleute treffen ab und zu einen ihrer Landsleute aus Agome, der die eingetauschten Waren über Kete zur Küste bringt. Gewöhnlich schlagen allerdings diese Leute den Weg von Adele durch Tribu und Boëm über das uns bekannte Kwamikrum ein. Das „hometolle?" („wie geht es zu Hause?") und „deviolle?" („wie geht es Deinen Kindern?") wird mit „Oledo!" und „Elle!" beantwortet und zum Zeichen der Freude kauern die Weiber nieder und klatschen in die Hände.

Alle diese Karawanen unterscheiden sich durch ihr Aeusseres von einander. Die Haussakarawanen sind schon von weitem kenntlich, teils durch die typische Tracht und die grossen Lasten, teils dadurch, dass sie mit ihrem ganzen Haushalt, Weibern, Kindern und Sklaven reisen. In der langen Reihe der Träger befinden sich viele Mädchen mit ausrasiertem Scheitel und Kopftuch, während die Frauen einen ganzen Haushalt von Kalabassen und Schalen, mit Lebensmitteln angefüllt auf 
der typischen hohen Frisur tragen. Alle Männer tragen auf der linken Schulter das lange Haussaschwert und einen schönen, in Leder eingebundenen Koran; an derselben Stelle führen die Knaben ihre Schreibtafel aus Holz und den Griffel mit sich und brüsten sich mit ihrer Kenntnis des arabischen ABC. Hinter dieser Karawane reitet gewöhnlich der Herr und Gebieter auf einem schön angeschirrten und gesattelten Pferde. Anders sieht eine Haussakarawane aus, welche weiter aus dem Innern kommt; an Stelle der vielen Träger treten dann kleine Packpferde und Esel und die Sklaven, namentlich die Grussileute, tragen

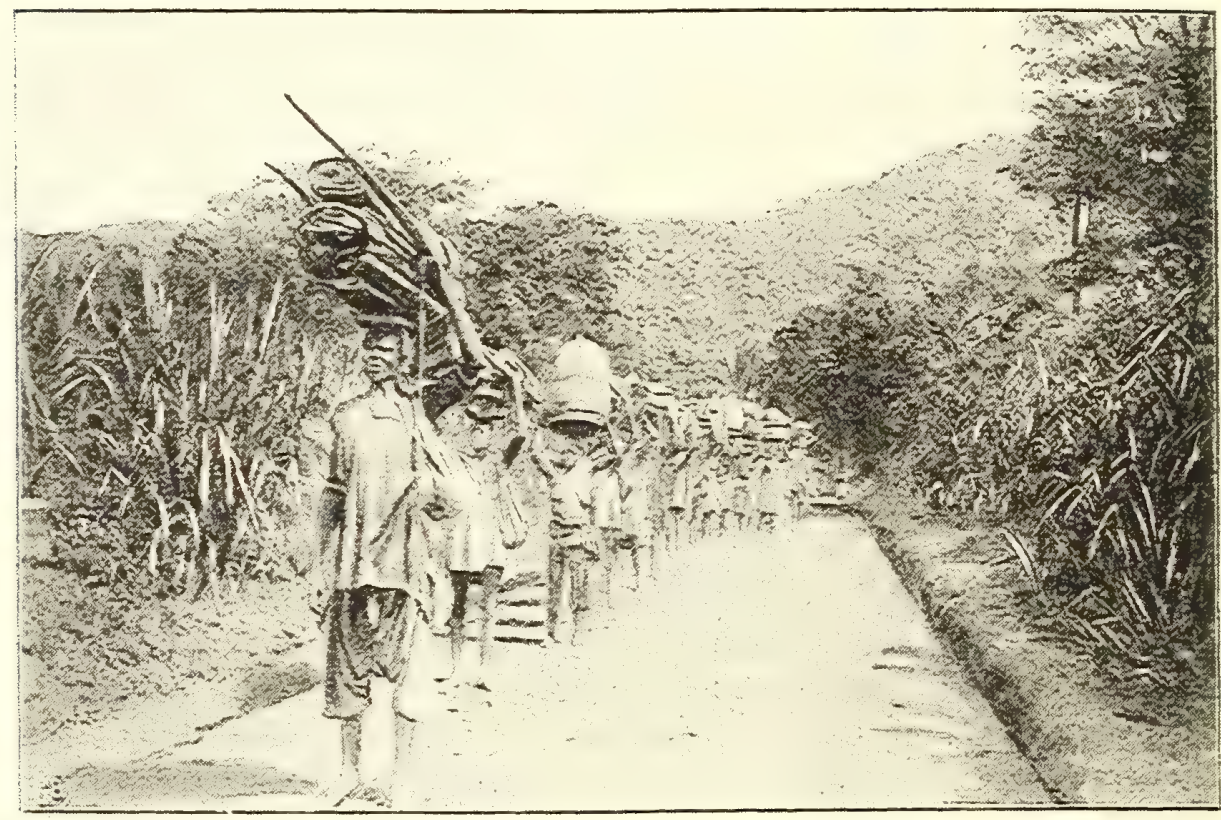

Haussakarawane.

breite Gesichtsmarken, an denen man ihre verschiedene Herkunft erkennt. Einige Karawanen führen Stoffe mit sich, andere Vieh oder Pferde. Aus den näher gelegenen Landschaften zieht aber auch die einheimische heidnische Bevölkerung mit ihren Produkten nach Kete, um dort gegen Schafe, Gummi oder andere Landesprodukte, Eisen, Seife, Salz etc. einzutauschen. Eine solche Karawane kennzeichnet sich von weitem durch die Scheu der meist hageren, nur mit einem kleinen Suspensorium bekleideten Träger, die gewöhnlich ihre vergifteten und gefürchteten Pfeile in kleinen Holzköchern mit dem scharf gespannten Bogen über der Schulter tragen. Ab und zu wird eine solche Karawane von einem Buschsoldaten begleitet, wie ihn meine Soldaten höhnisch 
namten, einem gross gewachsenen Neger, der stolz über der Schulter, den Kolben nach oben, die bekannte Steinschlossflinte, mit einem Büffelschwanz und anderen Fetischemblemen verziert, trägt. Anders wieder sehen die Karawanen aus, welche von Küstenhändlern, meistens Akkraleuten, geführt werden. Die Leute zeichnen sich durch ihr freies Auftreten und die luxuriösere Kleidung aus; nicht selten tragen sie Kattunhosen oder sogar genähte Jacken. Hinter der Karawane marschiert häufig der Küstenhändler als Dandy mit europäischen Hosen und Jacke und ist zum Zeichen seiner Würde als afrikanischer Grosskaufmann mit einem grossen Sonnen- oder Regenschirm bewaffnet, welcher ihm natürlich in dem Busch wenig nützt.

Beim Vorbeimarschieren tauschen unsere Soldaten nicht selten Blicke mit den Schönen anderer Länder, um dann schliesslich auf einem gemeinsamen Rastplatz das Herzensband enger zu knüpfen. Das alte Sprichwort, welches den deutschen Blaujacken nåchgesagt wird: „Anderes Städtchen, anderes Mädchen," trifft also auch bei unseren afrikanischen Soldaten zu.

Die Spur dieser grossen Karawanenstrasse ist überall durch die Karawanengebleichten Gerippe gefallener Lasttiere gekennzeichnet. Der Neger kennt keine Rücksicht gegen andere; er lässt das Tier dort, wo es fällt, einfach liegen und vermodern. Ein solcher Kadaver verpestet den Weg oft mehrere Kilometer weit und gewährt einen scheusslichen Anblick für die Vorüberreisenden. Die Gedärme sind von den zahllosen Aasgeiern, welche alle diese Plätze mit Gekrächz umschwärmen, weit aus dem Körper herausgezerrt; gierige Nachttiere haben das Tier zerfleischt und die einzelnen Glieder verschleppt und deutliche Spuren von Leoparden und anderen Wildkatzen zeigen, dass dieselben ihre nächtlichen Streifzüge vom Adelegebirge aus durch den Busch und die Steppe ausdehnen, um den in den letzten Zügen liegenden Tieren den Tod zu erleichtern.

Nach einem anstrengenden Marsche gelangen wir schliesslich zu Aufschlagen dem grossen Lager, welches die Haussa Songorimi nennen und welches und Beziehen ungefähr auf ${ }^{2} / 3$ des Weges zwischen Padji und Dutukpene liegt. Ein des Lagers kleiner Bach spendet hier in der Trockenzeit nur aus einigen SchöpfSongorimi. stellen ein schmutziggraues Wasser. Es war ein romantisches Bild, welches sich inmitten dieser wüsten Einöde únseren Augen darbot. Verschiedene Karawanen hatten sich um die kleinen Laubhütten gruppiert; in der Mitte des Kreises loderte das Feuer und in grossen Töpfen dampften der Yams oder sonstige Leckerbissen, während die Pferde und Esel neben den Lasten gekoppelt grasten. Lange Kolonnen von Mädchen mit grossen Wassertöpfen auf dem Kopfe kamen und gingen, die Frauen schürten das Feuer und sammelten emsig Holz, um den bei 
den Lasten liegenden ermüdeten Trägern das Mahl zu bereiten. Fast alle Laubhütten waren schon besetzt und nur aus Gutmütigkeit räumten schliesslich einige Leute zu unseren Gunsten einen grösseren Rastplatz. Nun begann unser Personal so schnell wie möglich das Lager aufzuschlagen und einzurichten. Den Trägern fiel die Aufgabe zu, den Platz zu reinigen und die Lasten in den Hütten unterzubringen. Währenddessen waren die geübten Soldaten mit der Errichtung des Zeltes beschäftigt, Tische, Stühle und Feldbetten wurden von unserem kleinen Jungen aufgestellt, während der Koch mit Hilfe der ihm zugewiesenen Träger seine primitive Küche in Ordnung brachte und die Vorbereitungen zu dem Mahle traf. Einige Träger sammelten Feuerholz, während andere das nötige Wasser herbeiholten.

Bei dieser Einteilung war das Lager bald fertig. Mitten darin stand das Zelt, vor dem wir meistens auf unseren Feldstühlen an dem transportablen Tisch Platz nahmen, während unsere Leute im Kreise an den verschiedenen Feuern lagerten nnd gruppenweise, je nach ihrer Stammesangehörigkeit, ihr Abendbrot bereiteten. In der Mitte wehte neben einem grossen Wachtfeuer die deutsche Flagge. Eine Wache, sowie ein Posten vor Gewehr, der, wie bei uns, zweistündig abgelöst wurde, hatten die Ruhe und Ordnung im Lager aufrecht zu erhalten und waren verantwortlich für etwaige Diebstähle. Jeden Abend bei Sonnenuntergang um sechs Uhr ertönte der deutsche Zapfenstreich und früh um 5 Uhr die Reveille, was uns stets, auch mitten in der Wildnis, an die ferne Heimat erinnerte. Mit Rücksicht auf die grosse Anstrengung, welche der lange beschwerliche Marsch allen Beteiligten bereitet hatte, wurde zur Freude des ganzen Lagers der mitgefuhrte Stier geschlachtet. Binnen wenigen Minuten war der Stier Abbruch des spurlos verschwunden.

Lagers und Marsch nach Dutukpene.

Früh am anderen Morgen, noch vor Tagesgrauen, regte es sich in dem ganzen grossen Lager; alles war mit dem Aufbruch und mit Abkochen beschäftigt und die Haussa verliessen als die ersten, noch im Dunkeln, den Rastplatz. Natürlich lässt sich ein mit Zelten und allem möglichen Komfort ausgestattetes Lager wie das unsrige nicht so schnell abbrechen wie ein Eingeborenenlager; wir marschierten daher ziemlich als die letzten aus dem Songorimi ab. Still und verlassen lag der grosse Platz da, nur die Holzstösse glimmten noch; bald aber wimmelte der Ort von unzähligen Tauben, welche in den zurückgebliebenen Abfällen ihre Nahrung suchten. Eine kleine rotbraune Art war am zahlreichsten vertreten; auch die Ringeltaube, sowie eine grössere rotbraune Art nahmen emsig an dem Mahle teil. Mit einigen Schüssen verschafften wir uns für den nächsten Tag einen schönen Braten. Dann wurden die Pferde vorgeführt und mit dem Signal zum Auf- 
bruch und Abmarsch ging es über kleine Bäche dem nächsten Ziele, Dutukpene zu. Bevor ich den Weitermarsch schildere, will ich noch bemerken, dass Dr. Gruner in diesem Busche auf einem anderen Pfade, absaits von dem grossen Lager, einige Lehmhütten aufgebact hat, welche von einem Schwarzen bewohnt werden und einen Rastpunkt für die durchziehenden Weissen oder andere Karawanen gewähren. Auch ich kehrte dort auf meinem Rückmarsch ein, doch knüpfen sich leider an diesen Aufenthalt trübe Erinnerungen. Als einziger Europäer, nur von Buschleuten, Bassari-Trägern und meinem kleinen treuen Meppo begleitet, erkrankte ich im Busch an einem schweren Fieber. Da sämtliche Pferde gefallen waren und ich den Marsch durch die grosse unbewohnte Steppe zu Fuss zurücklegen musste, versagte mir schliesslich die Kraft und ich musste mich im Reitsitz auf dem Buckel der gutmütigen Bassarileute bis zu diesem Lager schleppen. Hierher sandte mir Herr Rosenhagen, den ich von meiner Lage benachrichtigt hatte, in dankenswerter Weise ein Reitpferd, auf dem ich dann meinen Weg fortsetzen konnte. Wenn man krank und hilflos im Busch liegt, von keinem verstanden als von einem kleinen Jungen und umgeben von șchwarzen Trägern die über den langen Aufenthalt murrend einen auch noch $\mathrm{zu}$ verlassen drohen, erscheint ein solches Lager in ganz anderem Lichte, als wenn man es in Gemeinschaft mit einer grossen, wohlausgerüsteten Expedition besucht.

Unser Weitermarsch in der ebenen Baumsavanne bot geringe Abwechselung, bis wir zu einem schönen Galeriewald kamen, welcher den in grossen Schlangenwindungen dahinfliessenden, etwa ro $m$ breiten Fluss Yalaga umgiebt. Das tiefeingeschnittene Flussbett führt ein schönes klares Wasser.

Am Yalaga und in der grossen Savanne, welche wir durchschritten haben, sollen sich grosse Mengen von Antilopen, Leoparden, sowie auch Elefanten aufhalten. An den Flussläufen waren in der That deutliche Spuren von Elefanten zu bemerken. Auch hier begegneten wir unter den hohen Bäumen kleinen Lagern. Die Vegetation wird üppiger, an den Ufern der kleinen Bäche wachsen Palmen, die Terrainwellen mehren sich und von den Anhöhen erblickt man in der Ferne wie in Nebel eingehüllt die Umrisse des Adelegebirges Immer näher treten die bizarren Formen des steil nach Westen abfallenden Gebirgzuges und endlich breitet sich in voller Majestät das ganze Adele-Gebirge vor uns aus. Das Krähen der Hähne und menschliche Stimmen verkünden die Nähe von Dutukpene; zur Seite des Weges lagern verschiedene Karawanen vor den typischen Laubhütten; die Weiden sind von ihren Herden belebt und der Weg fuhrt nun bergan zu dem Königsplatz von Dutukpene. 


\section{DURCH DIE KAUTSCHUKDISTRIKTE DER LANDSCHAFTEN}

\section{VON ADELE UND ATYUTI.}

Ankunft in Dutukpene

Tanz der Adeleleute

Auf dem Marktplatz wurden wir von dem Häuptling Kwadyo, dem alten Freunde der Reisenden Wolf und Kling, unter den riesig-grossen Schattenbäumen des Marktes gastlich empfangen. Sofort wurden uns unsere Quartiere angewiesen und unter einem mächtigen Fikusbaum wurde inmitten des Dorfes auf dem Marktplatz unser Zelt aufgeschlagen. Unsere Lasten wurden in einer grossen viereckigen Hütte mit Walmdach untergebracht, welche so zu sagen das Rathaus bildete. Fast alle Adeledörfer besitzen eine Hütte, die für gewöhnlich freisteht und zur Aufnahme der grossen Trommel und des übrigen Gemeingutes des Dorfes dient. Als besondere Ehrenbezeugung wird diese Hütte bei dem Besuch eines Weissen diesem zur Wohnung gegeben. Die Hütten, die ungefähr $4 \mathrm{~m}$ hoch sind, sollen denjenigen in Adakpame ähnlich sein. Das hohe Dach ist meistens der Tummelplatz zahmer Tauben, welche ich sowohl in Dutukpene wie in Odumase bemerkt habe und welche teils eine blaue, teils eine weisse Farbe haben. Obwohl die Hutten in der Landschaft Adele zum grössten Teil rund und mit Kegeldach versehen sind, so finden sich doch auch in Dutukpene quadratische Hütten mit Walmdach und Veranda vor, welche wohl auf den Aschanti-Einfluss zurückzuführen sind, da ganz Adele, sowie auch die übrigen Kautschuk gewinnenden Landschaften von Aschantihändlern überschwemmt sind. Die Dörfer besitzen keine geschlossenen, von Zäunen oder Mauern umgeben Gehöfte, sondern die einzelnen Hütten, deren Thüröffnungen in der Regel nach Innen führen, sind meistens zu einem Gehöft zusammengruppiert.

Der alte Kwadyo nahm uns sehr gut auf und beschenkte uns reichlich mit Kassava und Yams. Er ist ein alter hagerer Mann, welcher in seinem Dorfe und der Umgebung ziemlich viel Macht und Ansehen besitzt. Unter einem kleinen Grasdach sitzt er tagsüber über und erledigt seine Regierungsgeschäfte. Wie zur Zeit von Wolf und Kling, trägt er noch heute mit Würde als königliches Abzeichen einen abgelegten Tropenhelm, der jedoch seiner Gesichtsfarbe entsprechend schwarz angestrichen ist. Seinen Sitz bildet ein schön geschnitzter, sogenannter Königsstuhl, der ihm stets vorangetragen wird und sein Herannahen durch das Geläute der am Stuhle befestigten Klingeln verkündet. Kwadyo veranstaltete uns zu Ehren des Abends einen grossen Tanz, welcher beim Scheine der Oellampen unter der Mitwirkung des Häuptlings und seiner Gemahlin auf dem Marktplatze stattfand. Fast das ganze Volk versammelte sich dort und umstand im Kreise den kleinen Tanzplatz. Einzelne Tänze werden in der Weise ausgeführt, 
dass sich Männer und Frauen abwechselnd entgegentanzen. Beim langsamen Vorwärtstanzen werden besonders mit dem Oberkörper Grliederverrenkungen ausgefuhrt, welche darin bestehen, dass sie fast mit dem Ellenbogen im Rücken zusammenstossen und die Schultern auf- und abwärtsziehen, so dass sämtliche Muskeln des Oberkörpers vibrieren. was im ganzen einen unästhetischen Anblick gewährt. Als Zeichen besonderer Anerkennung wird häufig den Tanzenden ein Tuch von irgend einer Schönen zugeworfen; auch ein Schlag in die erhobene, hohle Hand gilt als besondere Auszeichnung. Der Tanz wird von der umstehenden Menge mit Händeklatschen begleitet, wodurch den Tanzenden der Takt angegeben wird. Eine grosse Trommel fehlt auch hier nicht und bildet die eigentliche Tanzmusik. Sie wird von einem Trommler, der gewissermaassen auf ihr reitet, mit zwei Schlägeln bearbeitet. Ausser dieser grossen Trommel werden mehrere kleine Trommeln, die eine konische abgerundete Form haben, mit den Händen gerührt. Anstatt der Rasseln, welche wir bei dem Evhevolke kennen gelernt haben, wird der Tanz von den Männern durch Aufeinanderschlagen zweier kleinen Holzstückchen im Takte begleitet. Der ganze Tanz hat eine grosse Aehnlichkeit mit dem der Evheneger, welcher auch in unästhetischer Gliederverrenkung gipfelt.

Die Adeleleute sind von mittlerer Grösse und haben im allgemeinen nicht den kräftigen Körperbau, der sonst die Grebirgsvölker auszeichnet. Adele-Volk In den feuchten Thälern im Westen des Grebirges trifft man viele Leute mit oft riesengrossem Kropfe, auch solche, die an Atrophie, besonders der unteren Gliedmaassen, leiden. Direkte Stammeszeichen habe ich bei den Adeleleuten nicht bemerkt; nur $\mathrm{ab}$ und $\mathrm{zu}$ fand ich bei einzelnen Frauen Tätowierungen von kleinen Schleifen und Sternen zum Schmuck, und bei den Männern mitunter einen kleinen Querschnitt in der Nasenlippenfalte. Ihre Tracht unterscheidet sich nicht wesentlich von der der Evheleute, nur dass sie eine grosse Vorliebe für Messingringe besitzen, worin auch ein schwungvoller Handel durch Austausch gegen Kautschuk betrieben wird. Viele junge Frauen und Mädchen sind mit spiegelblank geputzten Arm- und Beinringen förmlich beladen. Die Beschäftigung der Adeleleute besteht in der Kautschukgewinnung, im Ackerbau und in der Viehzucht fur ihren eigenen Bedarf. Ausser Yams bauen sie in grösseren Mengen Kassawa. An Vieh züchten sie nur die schon erwähnten kleinen Ziegenrassen sowie mittelgrosse Schafe. Ausserdem ist in Adele eine mittelgrosse, hellgelbe Hunderasse mit weissen Pfoten und weisser Schwanzspitze fast überall anzutreffen.

Das Gebirge und die grosse Ebene bilden ein weites ergiebiges JagdundVorJagdterrain. Im Gebirge besonders hausen die verschiedensten Wild-kommen von katzen und von dort unternimmt der Leopard seine nächtlichen Streif- Elefanten. 
züge in die Ebene. In der grossen Baumsavanne und in den Urwäldern an den Flüssen hält sich der Elefant auf, welcher mit Erfolg von den Adeleleuten gejagt wird, wie die vielen Kinnladen und Elefantenschädel beweisen, welche den Bewohnern auf dem Markte von Dutukpene als Sitzplätze dienen. Auch werden $a b$ und zu hier von Gummihändlern aus Akkra Elefantenzähne eingetauscht. Leider werden die in verhältnismässig geringer Anzahl vorhandenen Elefanten durch die Schusswaffe, welche schon bis tief im Innern bekannt ist, immer mehr ausgerottet. Es wäre daher endlich an der Zeit, Maassregeln gegen ẹne gänzliche

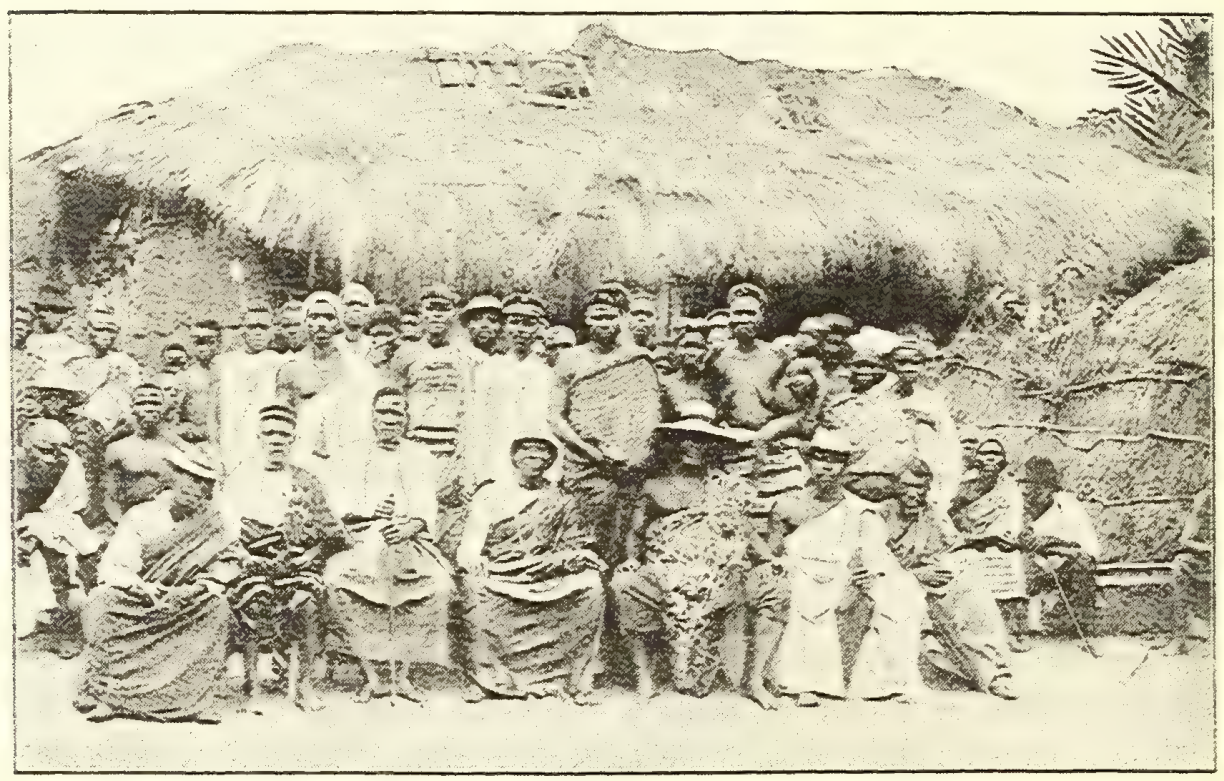

Gummihändler von der Küste.

Ausrottung zu ergreifen. Ein Schongesetz für Elefanten oder ein Verbot der Jagd ohne Jagdschein würde in dieser Beziehung gute Dienste thun. Für die Erforschung Afrikas und die uns hier obliegende Kulturarbeit ist die Zähmung des afrikanischen Elefanten von ganz hervorragender Bedeutung. Die ersten Versuche mit der Zähmung und Verwendung der Elefanten als Lastenträger haben die verdienstvollen Väter von Kautschuk- Fernan-Vaz in Gabun gemacht. Was den Kautschukhandel betrifft, so handel und scheint heute der Hauptmarkt für diesen Artikel in Adiuti in Goklon der Zuzug fremder Völker narh dem Adelegebiet zu liegen, wo es von Händlern, namentlich aus Akkra, geradezu wimmelt. Durch den vielen Verkehr mit Fremden und Küstenleuten und mit der früheren Station Bismarcksburg sind die Leute Fremden, auch Weissen gegenüber, zutraulich. Die verschiedenen Orte, welche an der grossen 
Heeresstrasse westlich des Gebirges liegen, bilden gewissermaassen grosse Fremdenherbergen. Im grossen und ganzen wohnen die Adeleleute, abgesehen von den Verkehrscentren, zerstreut in dem Busch auf Farmen, wo sie ihr Land bebauen, den Kautschuk sammeln und an ihrer Scholle kleben. Trotz der Anregung, welche ihnen durch die Händler geboten wird, trotz des fruchtbaren Bodens und des Kautschuks, den ihnen die Natur liefert, können sie sich nicht zu eigener Thatkraft aufraffen und den Handel selbst in die Hand nehmen, sondern stehen vollkommen unter dem Einfluss fremder Händler. Das Adelevolk hat kein geschlossenes Gemeinwesen, wird vielmehr in den einzelnen Dörfern von kleinen Dorfhäuptlingen regiert, deren Macht nicht weit über die Grenzen ihres engen Dorfbezirkes hinausreicht.

In den Gebirgen haben dagegen die Fetischpriester eine grössere Gewalt. Der oberste Gott soll nach Wolf Neyo sein, der alle Wünsche und Bitten der Menschen erfüllen, aber auch im Gegensatze zu dem obersten Gotte der Evhe, Mavu, die Bösen strafen kann. Der Totengott Frikku soll die Macht haben, in seinem Haine bei Dadease die Geister Verstorbener $z u$ beschwören und ihren Angehörigen zu zeigen. Ferner besitzt das Adelevolk, wie die meisten Naturvölker, einen Regengott, Nikotta, der auf die Bitten der Menschen den fruchtbringenden Regen spendet. Die Vermittlung zwischen Menschen und Göttern besorgen auch hier Priester und Priesterinnen, welche sich dem Fetisch geweiht haben. Das höchste Priesteramt des grossen Fetischgottes Neyo wird in Perëu von einer Oberpriesterin verwaltet.

Die Sprache der Adeleleute soll mehrere Dialekte haben. Im Gebirge soll sie besonders rein gesprochen werden, während in der Ebene fremde Einflüsse bemerkbar sind. So wird dort viel Tshi gesprochen, während in Ketshebi teilweise die Tribusprache vorherrscht. Ausser diesen Sprachen wird auch vielfach Evhe verstanden. In ähnlicher Weise prägt sich der Einfluss der Aschanti, besonders in Odumase, in der Bauart der Hütten aus. Die Einwirkung aller dieser fremden Elemente macht, dass der ganze westliche Teil des Adelelandes in der Ebene kaum als ein zusammengehöriger Volksstamm angesehen werden kann. Eigentlich sind nur die Landesgrenzen maassgebend, während im östlichen Gebirgsteil die Rasse weniger gemischt sein soll.

Nach dem anstrengenden Marsch durch die grosse Buschsavànne lag Marsch in der fast unser ganzes Personal an Malaria krank darnieder. Erst nach einigen Landschaft Tagen konnten wir langsam unsern Weg fortsetzen. Derselbe führte Adele. auf der grossen Heeresstrasse am Gebirge in nördlicher Richtung weiter. Im Westen dehnt sich die grosse Savanne aus, während im Osten, etwa $600 \mathrm{~m}$ von Dutukpene entfernt, das steil nach Westen abfallende, etwa \$oo m hohe Gebirge sich hinzieht. Die Kette dieser Gebirgszüge wird 
von kleinen Bächen und Flüssen unterbrochen, welche durch grosse Schluchten und Thäler ihren westlichen Lauf zum Oti nehmen. Die meisten dieser Gebirgsbäche führen bei der Trockenzeit gar kein oder nur wenig Wasser; dagegen haben grössere Bäche, wie der Urubu, schnellfliessendes, kristallhelles Wasser. An den Ufern enfaltet sich eine üppige Tropenvegetation; neben der Oelpalme tritt vereinzelt Raphia vinifera auf. Die Savanne dagegen zeigt ausser einigen hohen Fikusarten noch immer die charakteristischen verkrüppelten Savannenbäume, darunter viele Mimosen und Tshibutterbäume. Der Pfad führt auf den kleinen Vorläufern des Gebirges weiter. Im Osten begleiten uns kammartige Gebirgszüge, welche ein stets abwechselndes und schönes Panorama bilden. Bald haben wir den $20 \mathrm{~m}$ breiten Tshai erreicht, dessen tief eingeschnittenes, von undurchdringlichem Galeriewald eingefasstes Bett nur ${ }^{\mathrm{I}} / 4 \mathrm{~m}$ tiefes Wasser führt.

DasAdeledorf Das Dorf Kedyevi liegt auf einer kleinen Anhöhe, von welcher Kedyevi und man einen schönen Rückblick auf das Gebirge hat. Vor dem Dorfe der Fremden- sind Laubhütten für die Reisenden aufgeschlagen, aber auch das Dorf verkehr selbst gleicht einem Karawanenlager. Auf dem Markt kauern Haussa mit Glasperlen, wertvollen Achaten vom Kirotashi am Niger und den sogenannten Groundbeads, welche in unserem Hinterlande gegraben werden, stumm und regungslos vor ihren Kalabassen. Die verschiedensten Stämme, Aschanti, Tshautsholeute, selbst Leute aus Tribu und Akposso befinden sich hier auf der Durchreise; andere haben sich dauernd niedergelassen und leben von den Karawanen, welche gewöhnlich Gummi aus Adele und Atyuti holen. Neben den eigentlichen runden Adelehütten sieht man quadratische Hütten mit Walmdach und auch vereinzelte Giebelhütten mit einer durch das vorgebaute Dach gebildeten Veranda. Durch diese Verschiedenartigkeit seiner Bauten macht der ganze Ort, der nicht mehr als 3 oo Hütten zählt, schon äusserlich einen zusammengewürfelten Eindruck. Zwischen den einzelnen Hütten, die keine geschlossenen Gehöfte bilden, treiben sich mitten unter den Menschen massenhaft die Lasttiere der Karawanen, wie Esel und Pferde, herum.

Ich hatte hier Gelegenheit ein eigentümliches und hübsches Kinderspiel zu beobachten, welches die zusammengelaufene Kinderschar ausführte. Einem Kinde wurden die Augen verbunden, dann tanzte die ganze kleine Gesellschaft im Kreise um dasselbe herum und sang dazu ein Lied, welches mit einem Refrain endigte, worauf sie plötzlich auseinander stob, um sich zu verstecken; das Kind mit den verbundenen Augen löste nun die Binde und suchte eins der Kinder zu erhaschen, worauf dann das Spiel von neuem begann.

In den Hütten fand ich verschiedene Fetischwerkzeuge; eines derselben dient dazu, um Diebe zu bestrafen. Es besteht aus zwei kleinen 
rotgefärbten Hölzern, die mit einer langen Schnur umwickelt sind. An dem Ende der Schnur sind Kaurimuscheln und Tierhaare befestigt. Vermöge eines Spruches, der beim Bewickeln dieser Hölzer hergesagt wird und der alle möglichen Verwünschungen enthält, soll der Missethäter verhext und an Füssen und Händen gelähmt werden.

Am nächsten Tage marschierten wir durch das schöne Thal des Tshai nach dem letzten Adeleorte, Odumase. Noch einen Rückblick an den Westwerfen wir auf den langen Gebirgszug bei Dutukpene. Die Skizzen der abhăngen des einzelnen Gebirge und Kegel mehren sich in meinem Aufnahmebuch, so gebirges nacb dass ich kaum mit meiner Arbeit der Marschgeschwindigkeit der Odumase. Karawane folgen kann. In gebirgigem Terrain treten bei den Routenaufnahmen ganz unglaubliche Schwierigkeiten an den Aufnehmenden heran. Ausser den Kompassablesungen, die sich gerade hier durch die massenhaften Windungen, die der Weg macht, häufen, fordert auch der Aneroïd eine erhöhte Aufmerksamkeit, da sich mit jedem Schritt in diesem gebirgigen Terrain das Höhenniveau ändert. Zahllose Bäche und Flüsschen stürzen von den Höhen herab und durchkreuzen den Weg; alle diese wollen ihrem Namen, ihrer Richtung, ihrer Tiefe und Breite nach festgestellt und gemessen sein. Nebenbei müssen aber auch zur Festlegung der Route und des Gebirges die mannigfaltigen Kuppen und Kegel angepeilt und, damit man über die Form einigen Aufschluss erhält und die Fixpunkte wiedererkennt, alle Gebirgszüge im Sattel skizziert werden.

Nach einem kurzen Marsch gelangen wir auf schattigem Pfad DasAdeledorf nach dem kleinen, aber verkehrsreichen Ort Odumase, welcher unter mächtigen Bäumen in dem Galeriewald am Tshai liegt. Mitten unter den kleinen Hütten steht das Gemeindehaus von derselben hohen Bauart wie das in Dutukpene. Die Hütten haben meistens eine quadratische oder viereckige Form und wegen des vorgebauten Daches einen kleinen gedeckten Vorplatz. Sie erinnern an die Bauart der Aschanti. Die meisten Leute sprechen Tshi, auch sind zum Teil hier reine Aschantifamilien ansässig. Wieweit die Trägheit und Indolenz der Eingeborenen geht, beweist folgendes Beispiel: Auf dem Marktplatz in nächster Nähe der Hütten lag der Kadaver eines halbverwesten Esels, welcher den ganzen Ort mit seinem Geruch verpestete. Als ich meinem Erstaunen hierüber Ausdruck gab, meinte der Häuptling, die Geier würden ihn mit der Zeit schon fortholen. Auf meine Bitten hin liessen sich die Leute doch endlich bewegen, den Kadaver wegzuräumen, so dass wir auf dem idyllisch gelegenen Marktplatz unter den hohen Bäumen unser Zeltlager aufschlagen konnten.

In Odumase traf ich auf dem Rückmarsch zur grossen Freude Handelsmeiner Evheleute eine Karawane von Evheleuten aus Palime, welche karawanen bis nach Adele und Atyuti marschiert waren, um dort Gummi gegen aus Agome. 
Im Atyutilande.

Nyambo und seine Bewohner.
Stoffe und Messingstäbe einzutauschen. Angeregt durch die Erfahrungen, welche sie als Träger für die Station Misahöhe gemacht haben und durch die Faktoreien in Palime, rüsten einzelne Evhehändler, wie die Haussa, mit geschultem Trägermaterial kleine Karawanen aus, um aus Akposso, Kebu und Tribu, sogar aus Adele und Atyuti, Gummi zu holen. Die Atyutiund Adeleleute selbst sind zu träge, um ihre Produkte an die Handelscentren zu bringen und begnügen sich mit dem geringen Erlös, welchen sie an Ort und Stelle von den Händlern bekommen. Die meisten Händler sind Aschantileute, aber auch viele Haussa und Evheleute betreiben den einträglichen Handel mit dem Kautschukprodukt. In den bisher durchreisten AdeleOrtschaften hatte ich bereits verhältnismässig viele Leute mit Kropf angetroffen. In Odumase aber bemerkte ich ungewöhnlich viele Leute, welche mit dieser Krankheit in ganz auffälliger Weise behaftet waren.

Am nächsten Tage setzten wir unseren Weg fort, überschritten hinter Odumase die Grenze des Adelelandes und gelangten in die Landschaft Atyuti. Der Marsch führte über kleine Terrainwellen und viele kleine Bäche, deren Ufer mit Oelpalmen, Dattelpalmen und Fikusarten bestanden waren. Massenhafte Gummilianen, Landolphia, umschlangen die hohen Bäume und in den Wäldern wuchsen üppige Farrenkräuter. Ab und $z u$ traten Raseneisenstein und Gneisblöcke $z u$ Tage. Nach einem vierstündigem starken Marsch gelangten wir an grosse Farmen mit Yams, Guineakorn und Kassawa, in denen Sklaven, Männer und Frauen arbeiteten.

Auf einer Anhöhe liegt das Dorf Nyambo, von wo aus man wieder einen Blick auf das Gebirge gewinnt, besonders auf den Bossom-Berg. In einem kleinen anstossenden Haine sieht man hier und da Gruppen von hohen Dattelpalmen. Nyambo, ein verkehrsreiches Dorf, ist, wie alle Atyutidörfer, die an der grossen Karawanenstrasse und in den Gummibezirken liegen, von fremden Händlern überfüllt; auch befindet sich hier, wie überall, wo Handel und Verkehr blühen, eine Haussakolonie, die man sofort an den grossen runden Hütten erkennt, welche in einem runden geschlossenen Gehöft, dessen Eingang durch die typische Vorhalle führt, zusammen liegen. Die Hütten der Atyutileute sind ebenfalls rund; doch sind hier unter den Einfluss fremder Stämme, namentlich der Aschanti, auch quadratische und andere viereckige Hütten entstanden. Der Häuptling und die zahlreichen anwesenden Haussa bereiteten uns einen grossen Empfang.

Der schöne Zustand der Farmen um Nyambo beweist, dass der Anbau des fruchtbaren und ergiebigen Bodens reiche Erträge bringen könnte; doch ist namentlich in den dem Gebirge näher gelegenen Orten wie Goklon, Keri und Paua die Kautschuk-Gewinnung die Hauptbeschäftigung der Eingeborenen. Sie macht im allgemeinen weniger 
Mühe und bringt auch durch den schnellen Umsatz einen grösseren sofortigen Verdienst. In diesen Kautschukbezirken kursieren die Gummibälle wie Geld. Es scheint, dass Nyambo mit seinen Farmen einen grossen Teil der Lebensmittel für diese Gegend produziert. Neben der kleinen, allgemein bekannten schwarzen Ziege bemerkte ich in Nyambo, sowie in den übrigen Ortschaften, eine grössere Schafrasse und Schweine, während an Hühnern bei dem kolossalen Verbrauch durch die Fremden stets Mangel zu herrschen scheint. Die Atyutileute haben ihre eigene Sprache, doch wird viel Aschanti und auch schon Temu gesprochen.

Der westliche Teil des Atyutilandes steht unter dem Einfluss der Der Einfluss Häuptlinge der einzelnen kleinen Ortschaften, während in dem östlichen Gebirgslande noch bis vor kurzem der Fetischpriester des Fetisch Landesfetisch Buruku herrschte. Die Macht der letzteren erstreckt sich weit über die Grenzen des Landes hinaus, so dass sich die Fetischpriester anderer Orte, selbst des Dente aus Kratyi in schwierigen Fällen bei ihm Rat geholt haben sollen. Auch sollen die Fetischgötter von Adele dem Fetisch von Buruku unterstanden haben. Diesem mächtigen Fetisch, welcher angeblich in dem schönen Bergdorf Siare seinen Sitz hat, gehorcht auch ein Kriegsfetisch Gagon, der in Shirina residiert. Der Oberpriester des Fetisch Buruku galt zugleich als der König des Landes und war sehr gefürchtet, weil er, wie die meisten anderen Fetischpriester, den Gifttrank reichte. Lange Zeit war Buruku der Wallfahrtsort der Könige ron Aschanti, der Dagomba, der Häuptlinge ron Tshautsho und Salaga und anderer, welche sich vor Beginn eines Krieges oder einer Fehde von dem Fetisch den Ausgang prophezeien liessen. Dank der Entschlossenheit des Grafen Zech ist dem Treiben des Fetischpriesters im Oktober I 896 durch einen kuhnen Zug ein Ende bereitet worden. Er nahm den Fetischpriester gefangen und setzte auf den Wunsch der Atyuti-Bevölkerung den Häuptling Kwadyo von Paua zum König des Landes ein, nach dessen Tode sein Sohn Kwaku folgte.

Bevor wir Nyambo verlassen, will ich noch das eigenartige Tanzspiel schildern, das uns die Bevölkerung des Dorfes veranstaltete. Am Abend versammelte sich die ganze tanzfähige Jugend, Männer und Weiber, nachdem sie schon lange vorher durch grosse Trommeln zum Tanze zusammengerufen worden war. Diese Trommeln haben am unteren Ende des hölzernen Resonanzbodens einen Fuss, auf welchem sie, an einen Baum gelehnt, stehen. Daneben ertönen noch eine Anzahl kleinerer Trommeln, welche ebenfalls durch Schlägel gerührt werden. Das Orchester wird durch Antilopenhörner vervollständigt. Den Takt giebt der sogenannte Gongon, die bekannte Kuhschelle, welche überall, auch im Evhegebiet, zum Ausschellen der Befehle des Häuptlings dient. Der Tanz beginnt, indem sich die Tänzer in einem Kreis aufstellen. Sobald

Musikinstrumente und der Serpentintanz der Atyutileute. 
die Musik anhebt, wird in raschem Tempo ein Kreislauf ausgeführt, wobei die Tänzer die Knie beugen und ihre grossen Umschlagtücher von den Hüften nehmen. Diese Tücher werden mit ausgestreckten Armen ausgebreitet und flattern dann wie bunte Flaggen der Beifall spendenden Menge zu. Der Tanz erinnerte mich sofort an die in Europa bekannten Serpentintänze. Dieser Tour folgt dann gewöhnlich ein langsamer Tanz unter den üblichen Gliederverrenkungen.

Am nächsten Morgen mit Tagesanbruch verliessen wir Nyambo, um über Goklon nach Paua zu marschieren. Unser Weg führt näher an die hohe Bergkette heran. An Stelle der langen Gebirgskämme treten uns mehr einzelne spitze und steilabfallende Kuppen und Kegel entgegen, welche der eigentlichen Gebirgskette vorgelagert sind. Wir betreten nun das Handelscentrum des Kautschuks, Goklon.

Kautschuk und dessen Gewinnung.
In Goklon, welches etwa roo Hütten zählt, herrscht ein mannigfaltiges Treiben. Ueberall in den Hütten der Bewohner sieht man Gummi in kleineren oder grösseren Ballen aufgestapelt; alle Höfe sind mit Aschanti- oder Haussahändlern erfült. Die letzteren haben wieder ihre fliegenden Läden mit bunten Zeugen und Tüchern, sowie besonders mit Messingstangen und Ringen zu Schmuckgegenständen errichet. Leider spielt aber in diesem mit Gummi gesegneten Lande auch der Schnaps eine ganz hervorragende Rolle. An Stelle der Kaurimuscheln werden hier häufig Gummibälle als kursierendes Geld von den Eingeborenen verausgabt. Ein Gummiball von 4 bis $7 \mathrm{~cm}$ Durchmesser hat einen Wert von 5 bis Io Pfennigen. Für grössere Posten werden häufig besondere Bälle angefertigt. Das kleine Dorf hat ganz den Charakter einer Handelsstadt. Die Händler stammen meistens aus Aschanti, doch kommen sie in neuerer Zeit, seit Einfuhrung der sogenannten Gummischeine, auch von der deutschen Küste. Auf meiner Rückreise traf ich beispielsweise dort eine reiche Grosshändlerin aus dem Evhegebiet, die zur Feier des Tages ihren ganzen Seidenstaat angelegt hatte. Oft wird man als Europäer wenig von diesem Gummihandel gewahr, da die Händler meistens ein schlechtes Gewissen haben und die vorgeschriebenen Handelsscheine nicht besitzen. So waren, als wir mit der grossen Expedition durch den Ort marschierten, alle Gummivorräte bei Seite geräumt. Erst auf meinem Rückmarsch bekam ich einen Einblick in die Verhältnisse. Die Bauart des Dorfes ist im allgemeinen keine einheitliche. In der Regel bilden viereckige oder runde Hütten ein Gehöft, in das man durch eine Vorhalle gelangt. Neben der Atyutisprache wird von den zum Teil auf der Durchreise befindlichen, zum Teil ansässigen Fremden Tshi, Temu und Haussa gesprochen. Die Bevölkerung widmet sich im wesentlichen der Kautschukgewinnung und dem Handel mit demselben, während der fruchtbare Boden wenig 
ausgenutzt wird. Gewöhnlich bauen die Leute nur soviel Feldprodukte, als sie zu ihrem Lebensunterhalt gebrauchen.

Das Einsammeln des Gummisaftes besorgt gewöhnlich die Dorfjugend, während die Männer und Frauen dem Handel, dem Haushalt und der geringen Feldarbeit obliegen. Den grössten Teil des Tages verbringen sie aber mit Nichtsthun, wozu der Schnapsteufel nicht wenig beiträgt. Mit fröhlichem Gesang zieht die Jugend des Dorfes früh am Morgen aus, um den Saft der Kautschukliane zu gewinnen. Auf besonderen, nur den Eingeborenen bekannten, abseits gelegenen und wenig betretenen Pfaden dringen die Kautschuksammler tief in den Busch vor, wo sie in den Galeriewäldern der Flüsse und Bäche ihre Ernte halten. Leider werden bei der Gewinnung des Saftes häufig aus Unverstand und Bequemlichkeit ganze Lianenstämme umgebrochen und mit der Wurzel ausgerissen. Auf diese Weise ist schon ein grosser Teil der Kautschukliane in der Nähe der Dörfer ausgerottet und es liegt die Befürchtung nahe, dass diese wertvolle Pflanze allmählich vertilgt werden könnte, wenn dem bisherigen Unwesen nicht gesteuert wird. Die Rinde der Lianen wird zum Zweck der Gewinnung des Saftes an mehreren Stellen angeschnitten, worauf dann der herausquellende weisse Milchsaft in Gefässen aufgefangen und mit Limonensaft oder auch mit Salz zum Gerinnen gebracht wird. Am Abend wird zu Hause die zähe Masse, welche sich wie Harz in Fäden zieht, zu einem faustgrossen Ball gewickelt. Bei dieser Gelegenheit kommt es häufig vor, dass in den Gummi Steine und Sand mit eingerollt werden, um den Preis zu erhöhen. Der vorsichtige Kaufmann schützt sich jedoch gegen diesen Betrug, indem er einzelne Probebälle durchschneidet.

Bis jetzt ist, obwohl der Gummi für unsere Togokolonie Gewinn Gummihandel bringt, wenig oder garnichts zum Schutze und zur Hebung der Kautschuk- und Schutz. kultur gethan worden. Die Bestimmung über die Handelsscheine mit Gummi in dem deutschen Schutzgebiet wird von den englischen Händlern unbeachtet gelassen, da in den grossen Gummibezirken nicht ein einziges Organ vorhanden ist, welches eine Kontrolle ausüben könnte. Die maassregeln gegen die Raubwirtschaft. Händler dominieren in diesen Gebieten vollkommen, erledigen für hohes Geld Regierungsgeschäfte, halten die Palaver der Eingeborenen ab und treffen selbständige Entscheidungen. Gleichzeitig schädigen sie das Handelsgeschäft, indem sie die Eingeborenen übervorteilen und durch Verabreichung von Schnaps und Vorschuss die Leute zum Nichtsthun verleiten. Da der Neger nie an die Zukunft denkt und gewissermaassen von der Hand in den Mund lebt, so kommt es ihm nicht in den Sinn, neue Lianen anzupflanzen oder bei der Ernte die Pflanzen zu schonen. Aus allen diesen Gründen würde in den Gummibezirken von Bo, Atyuti, Adele, Tribu, Kebu und Akposso ein erfahrener, von der 
Regierung angestellter Pflanzer, der besonders mit tropischen Pflanzenkulturen und mit der Anpflanzung von Gummibäumen vertraut ist, ein segensreiches Feld der Thätigkeit finden. Er könnte die Eingeborenen durch Anbauversuche zu einer rationellen Gummikultur anregen. Wahrscheinlich könnten ausser der Kautschukliane auch Gummibäume, wie Maniohot, Glaziovic und Kickxia africana mit Vorteil zum Anbau gelangen. Versuche mit den beiden ersteren haben bereits in verschiedenen Plantagen an der Küste Erfolg gehabt. Auch müsste der willkürlichen Ausrodung von Gummipflanzen durch ein Gesetz energisch entgegengetreten werden.

Paua und Wir verlassen nun das Dorf Goklon und marschieren über den dessen Wild-kleinen Atyutiort Keri, unseren letzten Rastplatz in dieser Landschaft, reichtum. dem Dörfchen Paua zu. Zur Rechten begleiten uns hohe, steil abfallende Gebirgsketten. Viele ausgetrocknete Wasserrinnen und Bäche durchkreuzen unseren $W e g$ und, ehe wir Paua erreichen, überschreiten wir das Gebirgsflüsschen Quam, welches die Wasserstelle für Paua ist. In den Wäldern wächst überall die Oelpalme, sowie Raphia und die verschiedensten Fikusarten, während Pandanus-Arten, Farnkräuter und hohes Gras den Boden bedecken. Das Dörfchen Paua ist schon ziemlich weit von dem Handelscentrum entfernt, die kleinen runden Hütten sind daher in dem typischen Stil der Atyuti-Leute erbaut. Das Gehöft des Häuptlings ist durch einen mit Matten geschlossenen Hofraum gekennzeichnet, während der Eingang durch eine grosse Vorhalle führt, in welcher Trommeln und andere Utensilien aufbewahrt werden In der Regel wird Paua nicht als Nachtquartier benutzt, sondern die Karawanen gehen bis Kuëda durch. Der Ort ist deshalb wenig belebt. Die Jagd ist hier ausserordentlich ergiebig, wovon ich Gelegenheit hatte mich zu überzeugen, zumal Antilopen sich ganz nah an das Dorf heranwagten. Ausser der Zwergantilope soll auch die Kuhantilope in diesen Gebieten häufig sein. Ferner sollen hier Leoparden ihr Unwesen treiben, so dass mich die Leute auf meinem Rückmarsch in Abrionko davor warnten, den Ort bei Nacht zu verlassen. Man erzählte mir, dass die Leoparden aus dem nahen Gebirge ihre Streifzüge bis an das Dorf Abrionko ausdehnen und dass ihnen zwei Kinder zum Opfer gefallen seien. Das eine, ein Knabe von zehn Jahren, sei sogar aus einer abseits gelegenen offenen Hütte von seiner Schlafstelle weggeholt worden.

\section{IM GEBIET DER LANDSCHAFT BO.}

Am nächsten Morgen verliessen wir Paua, überschritten bald hinter dem Dorfe die Grenze und gelangten in die Landschaft Bo. Auf kleinen Terrainwellen, welche dem steil-abfallenden Gebirge vorgelagert sind, 
geht es hinunter zu dem Thale des Kuë, welches an dieser Stelle die Doppelkette des Bogebirges durchbricht. Ueberall treten uns steile Kegel entgegen, welche sich beim Weitermarsch in kleine Ketten mit vorgelagerten Gipfeln auflösen.

Der Kuë ist ein Nebenfluss des Bassa und durchschneidet die grosse Gebirgskctte von Westen nach Osten. Er hat ein breites Thal und fliesst in einem Bett von etwa $45 \mathrm{~m}$ Breite. Zu meiner Zeit führte er nur ungefähr r $m$ tiefes Wasser und war somit ohne Hindernisse zu überschreiten. Ein üppiger Galeriewald mit zahlreichen Oelpalmen, grossen Bambussträuchern, Fikusarten und Farnkräutern fasst die Ufer ein. Von den hohen Stämmen hängen Lianen herab und in den Gipfeln tummeln sich die mannigfaltigsten Affenarten.

Mit dem Thal des Kuë öffnet sich das Gebirge, wir marschieren in diesem entlang und gelangen in einen Thalkessel, der durch den eigentlichen Höhenzug und durch die vorgelegte Bergkette gebildet wird. Dieser wunderschöne, rings von Bergen umgebene Thalkessel, hat von Gehirge aus mehrere kleine Zugänge. Im Osten wird er von einer etwa $400 \mathrm{~m}$ hohen, steilen Bergkette begrenzt und liegt sozusagen in einem Längsthal, welches durch eine zweite Kette von sanft ansteigenden etwa roo $m$ hohen Bergen im Westen abgeschlossen wird. Nicht weit von dem Flüsschen Kuë liegt mitten in diesem Thal das kleine Dorf Kuëda. Ueber den Namen dieses Ortes liegen von verschiedenen Reisenden verschiedene Angaben vor. Nach unseren Erkundigungen lautet er "Kuëda“, was weiter nichts bedeutet als Ort am Kuë. Andererseits wurde uns auch der Name "Urinyao", d. h. „Königsstadt" genannt; als wir jedoch nach dem meist auf den Karten verzeichneten Namen „Kumaso" fragten, sagte der Häuptling spöttisch: „Nur der weisse Mann nennt diesen Ort so". Ich nehme daher an, dass Kuëda der richtige Name ist.

In der Landschaft Bo macht sich bereits der mohamedanische Einfluss geltend. Der Häuptling und ein Teil der Aeltesten hatten beispielsweise bei unserem Empfange Haussa-Hemden und phrygische Mützen angelegt. Auch waren einige Haussa und Leute aus Tshautsho anwesend, welche den durchreisenden Karawanen Lebensmittel und aller-Verkauf von hand Leckerbissen verkauften. Früh am Morgen schon ertönte der Nahrungsbekannte Ruf: „Kaffa, Kaffa", mit welchem dampfende Hirsesuppe feilmitteln geboten wird. Durch kleine aus Raphia-Piassawa geflochtene Siebe, die wie Körbchen aussehen, wird die rote breiige Masse, welche vorzugsweise aus dem sogenannten Guineakorn und roter Rispenhirse bereitet wird, hindurchgedrückt. Die Hirssesuppe ist ein Hauptnahrungsmittel dieser Gegenden; jedoch wird sie meist nur des Morgens genossen, während man des Abends gekochten und gestossenen Yamsbrei, das im Evhegebiet so beliebte

Mohamedanischer Einfluss. 
Fufu, zu sich nimmt, das mit einer gepfefferten Kräutersauce gewürzt wird; mit dieser Sauce werden auch Klösse aus Guineakorn gegessen. Zuweilen wird dem Fufu etwas Fleisch von Huhn, Ziege oder Schaf beigegeben. Als Leckerei gelten geröstete Maiskörner und Erdnüsse. Aufenthalt in Um die von der Expedition mitgeführten Sachen in Ordnung zu Kuëda bringen, die Lasten neu zu verschnüren, und die Gewehre putzen zu lassen, beschlossen wir in diesem idyllisch schön gelegenen Thale fur einige Tage unser Lager aufzuschlagen, zumal auch der Bergassessor Hupfeld das Terrain für geologische Untersuchungen und Sammlungen

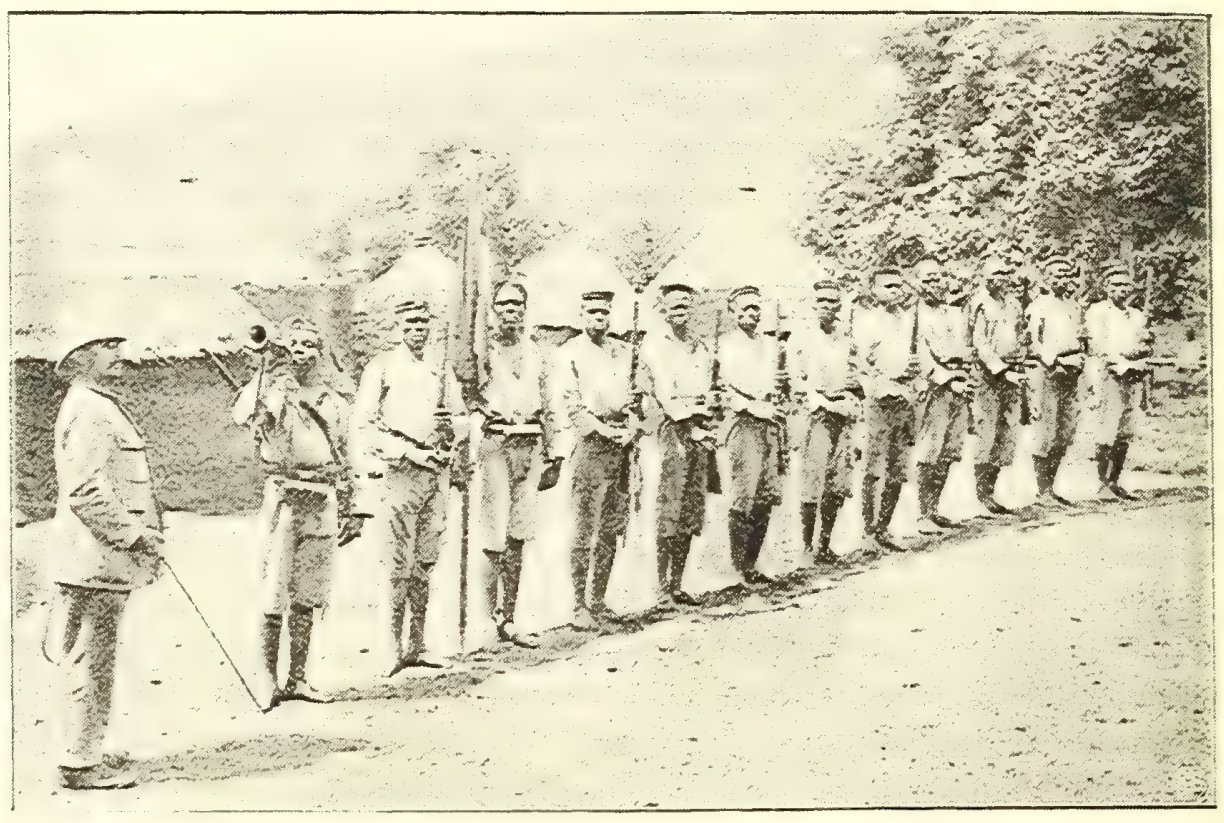

Expeditions-Soldaten un:er Befehl des Expeditionsmeisters Hoyer.

fur geeignet hielt. Die üppigen Reis- und Hirsefarmen lieferten hinreichenden Proviant, den der Häuptling durch Geschenke von Ziegen, Schafen und Huhnern noch vervollständigte.

Kuëda ist ein freundliches Dorf, dessen fleissige Bewohner in den fruchtbaren Thälern einen einträglichen Ackerbau treiben. Yams, Guineakorn, Erdnüsse, in geringerem Maasse auch Kassava und verschiedene Bohnenarten zieren die wohlgepflegten Farmenfelder. Grosse Kornspeicher, die fast in der ganzen Landschaft Bo, in Bassari und zum Teil auch in den nördlich gelegenen Temu-Ländern gebräuchlich sind, dienen zur Aufnahme des Guineakorns. Diese eigentümlichen Behälter haben eine trịchterähnliche Form, sind aus Holzstäben und Grasgeflecht 
hergestellt und werden von starken Holzpfeilern gestützt. Den ganzen Behälter schützt ein kegelförmiges Grasdach.

Nachdem wir uns hier häuslich eingerichtet, unser Zelt auforeschlagen und die runden Hütten bezogen hatten, gingen wir an die Arbeit. Der Expeditionsmeister Hoyer beschäftigte sich mit der weiteren Ausbildung der noch ungenügend geschulten Soldaten. Kleine Felddienstübungen wurden abgehalten, an welchen auch die mit Gewehren ausgerüsteten Träger, Dolmetscher und sonstigen Bediensteten der Expedition teilnehmen musste, um bei einem etwaigen Angriff oder Gefecht die Truppe zu verstärken.

Assessor Hupfeld unternahm kleine geologische Exkursionen, während ich geographische Aufnahmen, Höhenmessungen und sonstige Skizzen ausführte. Dabei zeigte sich, dass einzelne Punkte des Hauptgebirges eine relative Höhe von $400 \mathrm{~m}$ erreichen, während die ganze Kette in der Nähe von Kuëda eine durchschnittliche Höhe von $35^{\circ} \mathrm{m}$, die kleineren vorgelagerten Züge hingegen nur eine Höhe von 50 bis $100 \mathrm{~m}$ haben. Die geologischen Untersuchungen ergaben, dass die Felsen meistens aus Quarzgestein bestehen. Der Kuë selbst wies bei mehrmaligen Waschungen des Flusssandes hauptsächlich Quarzsand, Glimmer und Schwefelkies auf. Ausserdem fand Assessor Hupfeld auf den kleinen Bergkegeln überall in grosser Menge Eisenschlacken vor, welche auf eine frühere grosse Eisenindustrie in diesen Gegenden schliessen lassen. Das Vorkommen von Brauneisenstein in der ganzen Gebirgskette bestätigt diese Vermutung. Bis jetzt ist es leider nicht gelungen, Gold nachzuweisen, doch hoffen wir, dass es der Zukunft vorbehalten bleibt, in den grossen Quarzgebirgen eingesprengte Goldadern zu finden.

Am Abend nach gethaner Arbeit wurden wir durch den fröhlichen Tanz und Gesang der Eingeborenen erheitert. Die Texte dieser Negerlieder, welche mir der Dolmetscher übersetzte, waren häufig geradezu rührend. Sie besagten, dass, seit der weisse Mann in ihr Land gekommen sei, der Sklavenfang aufhöre und priesen die Macht des Weissen und ihres grossen Königs.

Nach mehrtägiger Rast brachen wir auf, marschierten auf der Marsch nach westlichen Seite des Grebirges nach Norden und überschritten das 25 bis Tashi, west$30 \mathrm{~m}$ breite Bett des Bassa, der die hohe Gebirgskette durchschneidet und sich bei Regenzeit bis an die Uferränder auf fast roo $m$ Breite erweitert. Ein grosser Galeriewald begleitet das Flussbett. Es gewährt ein schönes Bild, wie der Bassa im Osten aus einer tiefen, dunkelrot gefärbten Felsenschlucht, von Wald umgeben, heraustritt, um im Westen die nun abnehmende, sanft gewellte Hügelkette zu umfliessen. Ohne längeren Aufenthalt passieren wir das kleine Dorf Kadya; die vorgelagerte Hügelkette verläuft sich in der grossen Savanne, die zum Teil mit Tshibutterbäumen und Parkia africana bestanden ist. Nur ab und zu findet die Hügelkette ihre Fortsetzung in einzelnen kleinen Erhöhungen, 
die westlich von Tashi auftreten und dem Geographen erwünschte Anhaltspunkte für seine Aufnahmen gewähren. Die grosse Gebirgskette im Osten nimmt nun einen bizarren Charakter an. Der Anstieg von etwa 20 wird schroffer und beträgt von jetzt ab ungefähr $30^{\circ}$. Bis zur halben Höhe fallen die steilen Quarzfelsen in deutlich ausgeprägten, durch das Eisen rötlich getärbten Schichten, fast senkrecht ab. Eigentümlich heben sich dagegen Reihen weisser Quarzgesteine ab, welche als bequeme Marken die Uebersicht der endlosen Gebirgskette erleichtern. Der Weg führt uber kleine hüglige Ausläufer und tief eingeschnittene Gebirgsbäche, bis wir an eine Gruppe kegelförmiger, kleiner Berge gelangen, die wie Vulkane isoliert von dem Gebirge in der Ebene liegen In wenigen Minuten erreichen wir die kleine, aus einigen runden Hütten bestehende Regierungsstation bei Tashi. Dieselbe wurde als Tribut von den Boleuten errichtet, als sie unter ihrem König Urabaya im Frühjahr r 896 bei Tashi dem Grafen Zech den Durchzug verweigert hatten und von diesem geschlagen worden waren, wobei ein grosser Teil des Dorfes zur Strafe niedergebrannt wurde.

Tashi als Kreuzungspunkt der Handelsstrassen

Suruku, die Vorstadt von Akpande.
Dicht am Fusse des steilen Gebirges liegt etwas nördlich von der Station das Dorf Tashi selbst, von dem nach dem Gefechte nur ein kleiner Teil wieder aufgebaut worden ist. Eine grosse Anzahl von Ruinen lässt auf die frühere Grösse des Ortes schliessen. Heute zählt Tashi nur noch ungefähr 200 Hütten. Der Ort ist ein Knotenpunkt des Verkehrs und ein Rastplatz für durchziehende Karawanen, da er an dem Kreuzungspunkt der Routen über Jerepanga nach Dagomba, sowie an dem über das Bogebirge und Fasau nach Tshautsho führenden Passe und an der Hauptstrasse nach Bassari liegt. Die Hütten liegen, wie in den übrigen Dörfern der Landschaft Bo, in geschlossenen Gehöften zusammen und sind rund.

Am ṇächsten Morgen setzen wir unsern Marsch in nördlicher Richtung fort. Im Osten zieht sich ein etwa $300 \mathrm{~m}$ hoher Gebirgskamm mit schroff abfallenden Felsen hin. Im Westen hat man eine schöne Aussicht auf die grosse Baumsavanne und die vereinzelt vorgelagerten Berge von 50-Ioo $\mathrm{m}$ Höhe. Nach einem einstündigen Marsch erreichen wir Suruku, in dem Thale des Flüsschens Sako. Suruku liegt noch ganz in der Ebene, während die Königstadt Akpande mit Kissinti hoch oben auf dem Abhange des Gebirges erbaut ist. Suruku selbst ist eine Stadt mit etwa 300 Hütten. Zum ersten Male bemerkte ich hier an den Eingangshallen grosse aus Bambus hergestellte Thüren, welche sich in Angeln bewegten. . Die Hütte des Häuptlings krönte ein Straussenei. Auf dem Marktplatz vor der Häuptlingshütte wurden wir von dem Häuptling und den Grossen der Stadt empfangen und mit Schafen beschenkt. Der Häuptling trug ausser der phrygischen Mütze und dem Haussahemde, mit dem auch die meisten Notablen bekleidet waren, wie fast alle Häuptlinge eine aus Flechtwerk hergestellte grosse Kappe, 
die mit Amuletten, kleinen Täschchen aus Fell und rotem Tuch, benäht war. Obwohl in der Landschaft Bo fast gar keine Mohamedaner ansässig sind, pflegen die Häuptlinge bei feierlichen Gelegenheiten mohamedanische Tracht und Sitten äusserlich anzunehmen.

Auf meinem Rückmarsch begegnete es mir in Suruku, dass sich neben Behandlung der Hütte, in der ich übernachtete, in einer anderen Hütte ein Irrsinniger eines Geistesbefand. Es ist dies der einzige Fall von Geisteskrankheit, den ich im kranken Hinterland von Togo beobachtet habe. Der Irre schien nicht gemeingefährlich zu sein, störte mich aber die ganze Nacht durch seinen nicht gerade melodischen Gesang, welcher zuweilen in ein heiseres Krächzen und Schreien ausartete, so dass er schliesslich in einer anderen Hütte untergebracht werden musste. Sein starres, stupides Gesicht verriet den Geisteskranken, obgleich sein Körper wohlgepflegt war. Die Leute lachten zwar heimlich über ihn, verhöhnten und reizten ihn aber nicht, sondern behandelten ihn im Gegenteil schonend und freundlich. Im Anschluss an ein Gespräch erfuhr ich, dass gefährliche Geisteskranke in einer Hütte untergebracht werden, deren Eingänge man vermauert, so dass nur eine kleine Oeffnung übrig bleibt, durch welche dem Kranken das Essen zugereicht wird.

Nach einem kurzen Aufenthalt marschierten wir weiter der nahe- Der Wassergelegenen Königstadt Akpande zu und erreichten bald den ro $\mathrm{m}$ fall des Sako breiten Fluss Sako, wo sich uns ein eigenartiges Naturschauspiel darbot. Von dem etwa $300 \mathrm{~m}$ hohen Kamm des Gebirges stürzt der Sako in einer tiefen Felsschlucht von etwa $70 \mathrm{~m}$ Höhe herab. Wie ein weisser Silberfaden hebt sich der Wasserfall von dem dunkelrot gefärbten Fels der Schlucht ab, während die bewaldete Bergkette den ganzen kleinen Thalkessel umkränzt. Kein Wunder, dass die Naturvölker dieser Schöpfung gewissermaassen eine höhere Macht zuschreiben und in den Wasserfall und die romantische Felsschlucht den Sitz ihres Fetischgottes verlegen.

Unser Weg führte nun steil bergauf zu den vorgelagerten Hängen des Gebirges mit der weithin sichtbaren Königstadt des Landes Akpande. Hier wurden wir mit dem ganzen Pomp eines Negerfürsten von dem Oberhäuptling der Landschaft Bo empfangen. Die Spitze der langen Kolonne hatte die Residenz noch nicht erreicht, als uns der König auf einem schönen braunen, nach Haussaart gesattelten Hengste entgegengeritten kam und uns zum Grusse seine biedere Rechte bot. Er trug nach Art der mohamedanischen Sultane über seinem Haussagewand einen roten Königsmantel, während ein roter Fez sein Haupt zierte. Vor dem Gehöft des Königs hatten sich alle Grossen seines Reiches aufgestellt. Die meisten trugen zu diesem feierlichen Akt Haussatracht oder wenigstens lange Haussahemden. Der alte Oberhäuptling Urabaya hatte ein imponierendes Aeussere, seine grosse schlanke Gestalt, sein hageres

Empfang durch den Oberhäuptling Urabaya. 
Gesicht mit scharfen, energischen Zügen und lebhaften Augen, verliehen ihm etwas Selbstbewusstes und Grebieterisches. Er stellte uns einige Gehöfte zur Verfügung, wo zu unserer Ueberraschung bereits alles für unsere Aufnahme vorbereitet war.

Urabaya Die ganze Dorfbewohnerschaft war vor dem Gehöft des Königs als Herrscher. zusammengeströmt. Vor dieser grossen Versammlung hiess uns Urabaya willkommen und bat uns, unseren Leuten zu sagen, dass sie nichts eigenmächtig nehmen möchten. Er habe angeordnet, dass die zu unserer Verpflegung erforderlichen Mengen von Yams und Guineakorn aus den Farmen geholt würden. Ich gab ihm durch den Dolmetscher das öffentliche Versprechen, dass keiner meiner Soldaten oder Träger sich an irgend etwas vergreifen würde und dass ich denjenigen streng bestrafen würde, welcher sich irgend eine Ausschreitung zu Schulden kommen lasse. Dass wir als Freunde gekommen seien, beweise ja schon unsere Flagge, deren Farben mit der seinigen übereinstimmten. Von einem hohen Flaggenmast vor dem Häuptlingsgehöft wehte nämlich weithin sichtbar die deutsche Flagge, welche Urabaya einst so hartnäckig zurückgewiesen hatte. Schon Kling musste im Jahre 1890 vor Akpande umkehren, weil ihm Urabaya den Durchmarsch durch sein Land verweigerte. Erst dem Grafen Zech war es nach dem Gefecht bei Tashi I 896 gelungen, Urabaya zur Unterwerfung und zur Annahme der deutschen Flagge zu zwingen. Auch den vordringenden Dagomba soll Urabaya in seinem Berglande stets siegreich widerstanden haben und selbst seine Abhängigkeit von dem mächtigen König Dyabo von Tshautsho war in den letzten Jahren nur eine scheinbare. Erst mit der Unterwerfung Urabayas unter die deutsche Macht ist es gelungen, ihn zu bewegen, die Oberhoheit Dyabos wieder insoweit anzuerkennen, dass er ihm einen Tribut von Vieh und Produkten nach Paratau sandte. Es lag im Interesse der deutschen Regierung, die Macht Dyabos in jeder Weise zu stärken, da es eine künftige Verwaltung der vereinigten Temuländer bedeutend erleichtern würde, wenn hier geordnete Zustände herrschten. Urabaya versicherte mir, dass er jetzt ein Freund der deutschen Regierung sei. Er hielt dann eine Ansprache an das versammelte Volk, in welcher er erklärte, dass laut meinem Versprechen keiner meiner Leute etwas nehmen werde, ohne es zu bezahlen, und befahl, genügend Yams und Korn zum Verkauf zu bringen.

Austausch der Nach dieser Versammlung liess der König von seinen Frauen eine Geschenke. Menge von Kalabassen und Schüsseln mit fertig zubereiteten Speisen, der beliebten Guineakornsuppe, Kaffa, Fufu, Kräutersauce und Hirseklössen füllen und brachte sie uns zum Geschenk als ersten willkommenen Imbiss. Später schenkte er mir noch zwei schöne Stiere, eine Menge Yams und Guineakorn. Mittlerweile war unser Zelt aufgeschlagen 
worden, von dem man einen herrlichen Blick auf die Ebene und Suruku hatte. In demselben liess ich die für Urabaya bestimmten Geschenke auslegen. Ein grosser, rotgefärbter Bademantel kam uns hier trefflich zustatten und hatte in diesen Gegenden einen Wert von ungefähr 3o Nark. Auch ein alter Kürassierpallasch fand grossen Beifall bei Urabaya. Die Kaiserbilder wurden mit Interesse betrachtet, wobei Urabaya sein Wohlgefallen an dem Bildnis der Kaiserin äusserte. Die Bilder erhielten einen Ehrenplatz in der grossen Vorhalle, in welcher Urabaya bei schlechtem Wetter seine Regierungsgeschäfte erledigte. Er erhielt ferner Tabak, lange Tabakspfeifen und eine Flasche Madeira. Seinen Kindern schenkte ich Tambourins, Okarinas und Flöten, während seine Frauen mit Tüchern, Pomaden und Lawendelwasser reichlich bedacht wurden. Um uns eine besondere Freude zu bereiten, veranstaltete Urabaya an dem mondhellen Abend ein Konzert seiner Hofkapelle, an welches sich ein Tanz anschloss. Bei dieser Gelegenheit traten wieder die bekannten grossen Trommeln in Thätigkeit, aber den grössten Effekt machten Elfenbeinhörner von fast I Meter Länge, welche mit Leopardenfell überzogen waren. Sie hatten an der Seite ein einfaches Mundstück und gaben stossweise einen monotonen, dumpf dröhnenden Ton von sich. Auch Antilopenhörner werden in ähnlicher Weise zu Instrumenten verwendet. Die ganze Musik machte ein furchtbares Getöse, das in den Bergen wiederhallte. Bei dem Tanze kamen hauptsächlich die Trommeln zur Geltung. Urabaya selbst eröffnete unter dem Beifall der Menge den Tanz, welchem sich die Grossen des Reiches anschlossen. Es war ein Solotanz, wobei die Tänzer unter den üblichen Gliederverrenkungen im Kreise herumtanzten und sich in langsamem rythmischem Takt vorwärts bewegten. Zum Schluss wurde durch eine Kniebeuge und durch Ausstrecken der Arme dem Könige eine Art Huldigung dargebracht. Frauen wie Männer beteiligten sich an dem Tanze, der die Menge noch lange belustigte.

Die Boleute sind mittelgross und die Bewohner der Städte westlich des Gebirges zeichnen sich, soweit ich sie kennen gelernt habe, keineswegs durch einen besonders kräftigen Körperbau aus, wie andere Gebirgsvölker. In der Landschaft Bo sah ich mehrere Albinos mit graublauen Augen und rötlich-weissem Kopfhaar. Diese Abnormität gewährt in Verbindung mit dem Negertypus einen geradezu widerwärtigen Anblick. Auch kommt häufig Nabelbruch vor.

Die Stammeszeichen, oder vielleicht besser gesagt, die gebräuchlichsten Tätowierungen sind in der Landschaft Bo bei Männern und Frauen, wie bei der Königsfamilie von Gonya, drei bis vier feine Längsschnitte, die auf beiden Backen von der Schläfe bis zum Kinn reichen. Meistens ist diese Tätowierung so fein, dass man sie von

Tanzfestlich

keiten am

Hofe

Urabayas
Charakteristik der Boleute. 
weitem kaum bemerkt. Seltener sind die Tätowierungen zu kolossalen wulstigen Striemen angeschwollen, welche das Gesicht geradezu entstellen. Ausser den am häufigsten vorkommenden Längsstreifen werden auch kleine Querschnitte oberhalb und parallel der Nasenlippenfalte entweder auf einer oder auf beiden Backen, sowie bei Männern und Frauen eine Art Knopfreihe quer auf der Stirn angebracht. Es werden aber, besonders von den Frauen, aüch noch andere Tätowierungen, ähnlich wie in Salaga, zum Schmucke getragen.

Haartracht.

Die Haartracht der Boleute ist, wie in fast allen Temuländern, keine einheitliche, sondern unterliegt den mannigfaltigsten Variationen. Viele Männer und Frauen tragen das Haar kurz geschoren. Die Männer haben häufig den Kopf glatt rasiert und lassen nur oberhalb der Stirn eine kreisrunde Stelle mit kurz geschnittenem Haar stehen. Andere wieder tragen nur am Wirbel einen runden Haarkreis. Auch werden öfters auf einem rasierten Kopf drei solcher Haarkreise längs der Kopfnaht hintereinander stehen gelassen. Die Männer haben vielfach eine Haarzotte längs der Kopfnaht, die an einen bayrischen Raupenhelm erinnert und daher anfangs komisch wirkt. Die Frauen tragen nicht selten drei längs der Kopfnaht und zu beiden Seiten netzartig zusammengeflochtene Wülste, von denen auf jeder Schläfe ein kleines geflochtenes Zöpfchen herunterhängt. Die kleinen Mädchen haben gewöhnlich kurz geschorenes Haar, wobei verschiedene ausrasierte Scheitel das Haar in vier Kreise auf beiden Seiten des Kopfes, oberhalb der Stirn und oberhalb des Nackens, abteilen. Grössere Mädchen tragen häufig an den Schläfen die längeren Haare zu Zöpfchen geflochten, was den Uebergang zu der vorher beschriebenen netzartigen Frisur der Frauen bildet.

Die Temusprache.

Kleidung.
Die Sprache der Boleute gehört zu dem grossen Sprachstamme der Temuvölker, die alle unter der Oberhoheit des Königs Dyabo von Tshautsho stehen. Diese bewohnen im grossen und ganzen die Landschaften Bo, Fassaú, das engere Tshautshoreich, die selbständigen Bezirke von Dako und Bafilo, sowie die Landschaft Adye. Im übrigen hat sich durch die Macht und das Vordringen des Tshautshokönigs Dyabo die Temusprache auch stellenweise in die Nachbargebiete verpflanzt.

Die Kleidung der Männer besteht meist aus dem Haussahemde und der phrygischen Mütze, andere tragen nur eine aus Zeug gewebte, nach vorn herunterhängende Schürze und unter dieser eine Art Suspensorium. Die ansässige mohamedanische Bevölkerung, die auf kleinen Handweben und Webstühlen die Weberei betreibt, geht fast durchweg nach Haussaart gekleidet. Die Männer in den weiter nördlich gelegenen Ortschaften sind noch nicht so weit in der Kultur vorgeschritten; da hier keine mohamedanischen Weber wohnen, tragen sie meist nur ein 
kleines gegerbtes Fell, welches die Scham bedeckt, oder auch ein langes getrocknetes Schaf- oder Ziegenfell, welches vorn wie eine Schürze herunterhängt und mit den Vorderpfoten über der Schulter verknüpft wird.

Die Frauen tragen meist ein blaues oder weisses, seltener ein rotgefärbtes Tuch um die Hüften. Beliebt sind schwarz-weiss-blau gestreifte Tücher, welche auch von den Männern getragen werden. Diese Tücher bestehen aus 4 bis 5 Zoll breit gewebten Streifen, welche, wie bei den Evheleuten, zu einem Tuch zusammengenäht werden. Neben der meist von Mohamedanern ausgeübten Weberei wird die Spinnerei und der Anbau von Baumwolle betrieben. Die weissen Baumwolltücher werden mit Indigo sowie mit verschiedenen Farbhölzern bunt gefärbt. Die Frauen tragen besonders in den grösseren Städten wie Akpande, Tashi und Suruku eine Anzahl Messingarmbänder, häufig auch eine rote Perlenschnur um den Hals. Achate aus Kirotashi und die bekannten Groundbeads dienen den reichen und vornehmen Frauen als Schmuck. Seltener tragen sie Ohrringe in den durchlöcherten Ohrläppchen. Dieselben bestehen aus kleinen Markstückchen von der Staude des Guineakornes, welche gefärbt eine täuschende Aehnlichkeit mit Glasperlen haben; diese Markstückchen werden auch, zu kleinen Kettchen vereinigt, um den Hals getragen.

Die jungen Mädchen haben sämtlich eine Hüftschnur, die zum Teil aus Glasperlen, häufig aber nur aus aufgereihten und flach geschliffenen Plättchen von Palmenkernen besteht. Ein ganz ähnlicher Brauch besteht bei den Evhenegern an der Küste, welche aus der Schale der Kokosnuss eine Art Perlen herzustellen pflegen. Meistens besteht diese Hüftschnur aus mehreren einzelnen Schnüren und ist mit europäischen Glàsperlen verziert. Ein kleines handbreites Tuch, welches nach vorn $z$ wischen den Beinen durchgezogen ist, deckt notdürftig die Scham. Häufig jedoch sind sogar heiratsfähige Mädchen nur mit den erwähnten Schmucksachen und einer Hüftschnur bekleidet. Die Kinder gehen alle nackend.

Die Häuptlinge tragen hier, wie in vielen anderen Landschaften des grossen Tshautshoreichs, eine kronenartige, geflochtene Kappe, welche mit Amuletten oder kleinen bunten Tuch- oder Felltäschchen benäht ist, in denen sich nach Mohamedanerart Koransprüche befinden.

Die Bewaffnung der Boleute besteht einerseits aus den bekannten Berraffnung Steinschlossflinten, andererseits aus Pfeil und Bogen. Auch sah ich in dieser Landschaft Leute mit dem sogenannten Griffmesser. Die Hütten in der Landschaft Bo sind meistens rund und in einem Gehöft zusammenhängend gebaut, dessen einzelne $Z$ wischenräume durch eine $I^{x} / 2 \mathrm{~m}$ hohe 
Mauer getrennt sind. Der Eingang ist häufig durch eine Thür aus Bambusstäben verschlossen, die sich in einer Angel dreht, und führt durch eine grössere Halle. Die Thüröffnungen dieser Halle sind grösser als die Eingänge der übrigen in dem Gehöft liegenden Hütten. Die grössere Vorhalle wird nicht bewohnt, sondern dient gewöhnlich dazu, das nicht im Gebrauch befindliche Hausgerät aufzubewahren. Nicht selten wird die Vorhalle auch, wie bei den Haussa, als Pferdestall benutzt und dient den Häuptlingen zur Abhaltung ihrer Palaver. Gewöhnlich ist das Kegeldach dieser Hütte, welches in eine lä̀ngere Spitze verläuft, mit einem Straussenei gekrönt. Alle diese runden Hütten sind mit einem Kegeldach versehen.

Der ăussere In Akpande hatten die heidnische und die mohamedanische Einfluss des Bevölkerung getrennte Quartiere. Akpande ist die Königsstadt und Mohame- wird fast nur von der heidnischen Bevölkerung bewohnt, während danismus und Kissinti die eigentliche Handelsstadt und der Hauptwohnort der nische Reli- mohamedanischen Bevölkerung, sowie der Aufenthaltsort der durchgion der Ein- reisenden Händler ist. Suruku, welches im Thale liegt, wird sowohl geborenen. von Heiden als von Mohamedanern bewohnt.

Der Mohamedanismus ist bei der einheimischen Bevölkerung mehr äusserlicher Natur, hauptsächlich haben sie die Tracht und einzelne Sitten der Mohamedaner ang’nommen. Meistens sind die Häuntlinge und Fürstengeschlechter, sowie einzelne Grosse in den Temulandschaften Mohamedaner, während das Volk im allgemeinen heidnisch ist.

In Akpande soll der alte Urabaya noch der oberste Fetischpriester gewesen sein. Der Sitz des Fetisches der Boleute befindet sich, wie schon erwähnt, in dem Wasserfall oder eigentlich in dem Quell des Sako, der ihnen vielleicht bei früheren Kämpfen mit den Dagomba gute Dienste geleistet hat. Im übrigen wird der Sitz des Fetisch, wie bei den Evhe- und anderen Negerstämmen, in hervorragende Berge oder sonstige Naturerscheinungen verlegt. Alljährlich soll in Akpande von dem Felsen, von dem der Sako herabfällt, ein Esel heruntergestürzt werden, wobei der Felsen, auf welchen der Wasserfall aufschlägt, als Opferstein gedacht ist.

Ackerbau. Die Boleute treiben hauptsächlich Ackerbau und Viehzucht. Die grossen fruchtbaren Gründe und Thäler, die von dem Sako und Bassa - bewässert werden, liefern einen guten Boden zum Anbau von Feldprodukten. Andererseits erfüllen die saftigen Hänge und Weiden an dem Gebirge mit ihren Gebirgskräutern, sowie die hohe luftige Lage, welche von der Tsetsefliege verschont wird, alle Bedingungen zu einer rentablen Viehzucht. Von den Feldfrüchten werden ausșer Yams besonders Hirse, vorwiegend rote Rispenhirse, das sogenannte Guineakorn, aber auch weisse und gelbe Kolbenhirse, Okro zu Suppenkraut 
und Pfeffer angebaut. Ausserdem ist meistens noch ein Feld mit Kürbissen bestellt, welche zur Fabrikation von Kürbisflaschen und Kalabassen dienen.

Eine Haupteinnahmequelle bildet, wie schon vorher angedeutet, die Viehzucht, welche ich auf meiner Reise von der Küste ins Innere eigentlich erst hier im grösseren Maassstabe angetroffen habe. Leider haben die Leute kein Prinzip in der Aufucht und so ist eine Zuchtwahl ausgeschlossen. Die freie Zucht befördert aber die Missbildung der Tiere. So sah ich z. B. tragende Stuten, die zur Zucht gehalten wurden und vollkommen missgestaltet waren. Namentlich kommen geradezu unglaubliche Senkrücken bei den Pferden vor. Auch degenerieren die Herden häufig durch Inzucht. Die Pferde sind meistens von mittlerer Grösse. Die Hengste werden, wie bei den Haussa, hauptsächlich zum Reiten benutzt, während die Stuten nur zur Aufzucht gehalten werden. Mittelgrosse schöne Rinder, welche unserem Gebirgsschlag ähnlich sehen, beleben die Hänge und Wiesen und sind von früh bis spät auf der Weide; morgens und abends durchziehen diese Herden die engen Strassen der Stadt; zu ihnen gesellen sich Ziegen, Schafe, Schweine, Pferde und Esel, $\mathrm{ab}$ und zu auch Maulesel. Alle laufen frei auf der Strasse umher, was nicht gerade zur Reinlichkeit des Ortes beiträgt. Infolgedessen sind die Strassen bei Regenwetter kaum zu passieren, wenn man nicht bis an die Knöchel im Schmutz waten will. Grosse Ställe giebt es eigentlich nicht. Die Tiere werden des Nachts nahe bei dem Gehöft oder in demselben an Pflöcken angebunden, bei schlechtem Wetter nicht selten auch in der Vorhalle oder in einer Hütte eingestellt.

Auf die Pflege des Viehes verwenden die Leute ziemlich viel Sorgfalt; sie geben namentlich den Pferden neben der Weide Guineakorn, welches sie zu diesem Zweck in grossen Feldern anbauen. Mit der Pflege sind meistens Knaben betraut, sie weiden, füttern und putzen die Pferde. Die kleineren Kälber werden nicht mit auf die Weide getrieben, sondern verbleiben in einer Hütte. Morgens, mittags und abends werden sie zur Mutter gelassen, die meistens um diese Zeit schon brüllend im Trabe von der Weide ins Dorf gelaufen kommt. Milch geben die Kühe verhältnismässig wenig; sie ist nur eine Delikatesse für die Reichen. Das Vieh ist im allgemeinen ziemlich störrisch und es ist schwer, ein Stück allein von der Herde wegzutransportieren. Im grossen und ganzen wird es mehr zu Verkaufs- als zu Schlachtzwecken gehalten. Es wird häufig von Haussahändlern aufgekauft und nach Kete in Kratyi gebracht, wo es gegen Salz, Stoffe u. s. w. eingetauscht wird. Auch gehen namentlich Ziegen und Schafe in das englische Gebiet nach Ateobu, wo sie von den Haussahändlern gegen Kolanüsse verhandelt werden. Ausser diesen Tieren werden auch Hunde, Hühner, Tauben und türkische Enten als Haustiere gehalten. 
Der Markt und die Landesprodukte.

Gelirauchsgegenstände und Handelsartikel

Ausflug nach Yerepangá.
Der Markt in Akpande wird auf einem freien Platz nahe der Handelsstadt Kissinti abgehalten, auf dem eine Menge grösserer Steine den schwarzen Hökerweibern als Schemel dienen. Der hauptsächlichste Verkaufsartikel ist Hirse, welche in dreierlei Arten vorkommt. Die rote Rispenhirse, das Guineakorn, wird meistens zu der Morgensuppe, dem sogenannten Kaffa, die weisse Hirse zu den beliebten Hirseklössen und die gelbe Hirse zur Bierbereitung verwendet. Ausserdem gelangen zum Verkauf Palmöl, Schibutter, Pfeffer und Suppenkräuter, sowie die mannigfaltigsten zubereiteten Speisen, Suppen, Hirseklösse und Pfeffersaucen, geröstete Erdnüsse, und als besonderer Leckerbissen auch geröstete Heuschrecken. Gewöhnlich werden die Speisen von den Käufern an Ort und Stelle mit dem nötigen Appetit verzehrt. Dazu tritt noch das unentbehrliche Salz. Dieses kommt in Bo meist in der schmutzigen grauen Form des Addasalzes vor, jedoch wird auch schon hier, namentlich in der Regenzeit, französisches Salz eingeführt. Es geht als sogenanntes "rock salt" von Gross-Popo den Mono herauf und dann von Atakpame über Land durch Pedji und Anyana nach Tshautsho, von wo es dann in dem Hinterlande verbreitet wird.

Ausser diesen Lebensmitteln findet man die von den Haussa gewebten Tücher, Baumwolle, sowie die zum Färben der Tücher dienenden Farbhölzer und Indigo. $\mathrm{Zu}$ den einheimischen Stoffen kommen noch "Greybaft"-Stoffe und in geringerem Maasse Kattunzeuge von der Küste. Ein wichtiger Bekleidungsartikel sind die von fast allen Frauen und Mädchen getragenen Hüftschnüre aus geschliffenen Palmkernen und Muschelschalen vom Mono. Seltener werden Hüftschnüre aus Glasperlen, wie sie an der Küste üblich sind, getragen. Für den Schmuck der schwarzen Schönen ist durch das sogenannte Roadbrass sowie durch fertige Armringe aus Messing gesorgt. Die Haussa bringen kleine rote Perlen von der Küste, welche als Kette um den Hals getragen oder zum Besatz von Hüftschnüren verwendet werden und verkaufen auch Achate von Kirotashi und die begehrten und wertvollen Groundbeads. Letztere bilden wie bei den Evheleuten den Schmuck der Reichen und Vornehmen. An Geräten für den Haushalt kommen schöne, aus Pandamuspflanzen und Palmblättern geflochtene Matten, kleine aus der Raphia geflochtene Teller und Siebe, kunstvoll geschnitzte Kürbisflaschen, und mit den verschiedensten Verzierungen versehene Kalabassen in allen Formen auf den Markt. In grosser Auswahl sind Thonwaren vertreten, welche auch hier in besonderen Töpfereibezirken angefertigt werden.

Während unseres kurzen Aufenthaltes in Akpande unternahm ich mit Assessor Hupfeld eine kleine Streiftour nach dem Orte Yerepangá, welcher westlich in der Ebene liegt und noch zur Landschaft Bo gehört. Ueber Yerepangá führt von Akpande aus die alte Klingsche Route 
durch Dagomba über Bimbila im Gonyareich nach Yendi oder nach Salaga. Assessor Hupfeld war es darum zu thun, geologische Aufschlüsse über die kleinen vorgelagerten Berge der Gebirgskette zu erhalten, während ich selbst von diesen aus wichtige Fixpunkte für das Gebirge anpeilen konnte. Yerepangá ist ein Doppelort mit schönen, grossen Farmen. Sonst trägt der Ort im kleineren Maassstabe dasselbe Gepräge wie die Hauptstadt Akpande.

Als ich auf meinem Rückmarsch Akpande passierte, war der Ort totenstill; die deutsche Flagge, welche den Reisenden sonst schon von weitem begrüsste, war nicht gehisst und nur der kahle Flaggenstock starrte ihm hoch vom Felsen entgegen. Der Ort schien ganz verwandelt, alles Leben und Treiben fehlte, denn der alte Urabaya lag im Sterben. Ich wurde noch zur Hilfe gerufen, um ihm Erleichterung zu verschaffen, doch konnte ich zu meinem Bedauern als Laie nichts thun, als ihm zur Kräftigung meine letzte Flasche Rotwein opfern. Er war zu einem Skelett abgemagert und das Ende stand unmittelbar bevor. Die Leute gingen und kamen aus allen Orten; man konnte ihnen ansehen, welchen Anteil sie an ihrem alten Häuptling nahmen. Sie hatten den Verdacht, dass er infolge seines Besuches bei dem König Dyabo von Tshautsho erkrankt sei. Aber auch Dyabo hat Urabaya nicht lange überlebt und ist ungefähr ein Jahr später gestorben. Da ich vor meinem Abzuge noch eine Breitenbestimmung machen wollte, musste ich gerade an dem Todestage Beobachtungen anstellen. Dies erweckte bei den Eingeborenen grosses Misstrauen. Sie betrachteten mich von weitem und fragten meinen kleinen Meppo aus, was ich für einen Fetisch vorhabe. Schon nahmen sie eine drohende Haltung gegen mich an, als es mir schliesslich gelang, einigen älteren Leuten Aufschluss zu geben und sie dadurch zu beruhigen.

Am Abend um ro Uhr zeigte mir das Wehklagen der Weiber und Kinder des Urabaya dessen Tod an. Den ganzen Abend kamen und gingen Leute, um näheres über den Tod ihres Häuptlinges zu erfahren. Der Sohn Urabayas erschien mit einer Deputation bei mir, kündigte mir den Tod seines Vaters an und stellte sich zugleich als König des Landes ror. Dass ich meiner Beobachtungen wegen erst spät am Abend speiste und verhältnismässig lange aufblieb, schien die Leute peinlich zu berühren. Wiederholt kamen sie und erkundigten sich, ob ich nicht bald zur Ruhe ginge, da sie für den Toten Fetisch machen wollten. Die Geschenke, welche ich Urabaya noch übersandt hatte, ein Stück Greybaft sowie ein paar Maria-Theresia-Thaler wurden dem Toten, wie ich später erfuhr, mit ins Grab gelegt. In den Greybaft soll Urabaya nach Art der Evheleute eingewickelt worden sein. Vor Morgengrauen fand das eigentliche Begräbnis unter Gesang statt. Wie mir meine

Tod des

Oberhäuptlings Urabaya

Bestattung des Hăuptlings 
Leute berichteten, soll Urabaya nicht in der Hütte, wie es bei den meisten Stämmen im Togo-Hinterlande Sitte ist, sondern an dem Fusse des Gebirges bestattet worden sein. Zwar kann ich für diese Angabe nicht bürgen, doch bemerkte ich auf dem Wege, welcher zu der angeblichen Begräbnisstätte führte, Spuren eines Opfers in Gestalt von Blut und weissen Hühnerfedern. Ausserdem wurden Stühle und Gefässe, welche Urabaya bei Lebzeiten in Gebrauch hatte, nach dem Begräbnisplatz getragen.

Marsch längs Wir verlassen nun die schöne Bergstadt Akpande und marschieren des Bo- westlich vom Gebirge nach Norden über kleine Vorberge, welche durch gebirges nach tiefeingeschnittene Gebirgsbäche eingeschnürt werden. Diese Bäche Kadiumbara scheinen nur bei Regenzeit Wasser zu führen; ihre Ufer sind von hohen Bambussträuchern und Oelpalmen umgeben. Zur Rechten läuft wieder das hohe Bogebirge, während zur Linken kleine Hügelketten vơn etwa $50 \mathrm{~m}$ Höhe sich dahinziehen. Die Hauptkette des Gebirges nimmt wieder sanfte Formen an und fällt nach Norden $z u$ ab, bis sie durch das Thal des Mo begrenzt wird. Die durchschnittliche Höhe der Kämme beträgt nördlich von Akpande nur noch etwa 200 bis $250 \mathrm{~m}$. Infolge des hügeligen Terrains wird der Weg beschwerlich. Er geht fortwährend bergauf und bergab über hügeliges Vorland und kleine zerrissene Flussbetten. Der Weg ist mit herabgespültem Geröll und kleinen Quarzsteinchen bedeckt. Auch der in grossen Flächen zu Tage tretende Raseneisenstein erschwert dem unbeschuhten Träger und unseren unbeschlagenen Pferden das Vorwärtskommen. Nach vierstündigem Marsche erreichen wir Kadiumbara, einen kleinen Ort, der hart am Gebirge liegt und aus drei Plätzen mit zusammen ${ }_{5}{ }^{\circ}$ Hütten besteht. Grosse schattige Affenbrotbäume beschirmen gleichsam die kleinen Hütten, die sich inmitten der Berge und des mächtigen Waldes wie Kinderspielzeug ausnehmen.

Im Gebiet der

Wir sind nun im wahren Sinne des Wortes im Bereich der BuschBuschvölker, leute. Die Männer haben ein unwirtliches und barsches Aeussere und Das Dorf erschienen mir grösser als in den vorerwähnten Plätzen der Landschaft Kadiumbara. Bo. Sie tragen als einzige Bekleidung ein Ziegen- oder Schaffell, welches mit den Vorderfüssen zusammengeknüpft wird. Die Frauen tragen meistens ein rotgefärbtes Tuch, das von Mohamedanern gewebt und hierher gebracht wird.

Jedes der kleinen Gehöfte ist mit einer wohlerhaltenen Lehmmauer umgeben, der Zugang führt durch eine Vorhalle. Die Hütten sind fest, klein und rund, mit glatt gestrichenen Wänden und kleinen Oeffnungen, die als Eingang dienen. Es wirkt drollig, wenn der Europäer auf allen Vieren hineinkriecht. Der Boden der Hütten ist fast so hart wie Asphalt. Die Wände und der Boden innerhalb der Gehöfte sind mit farbigen 


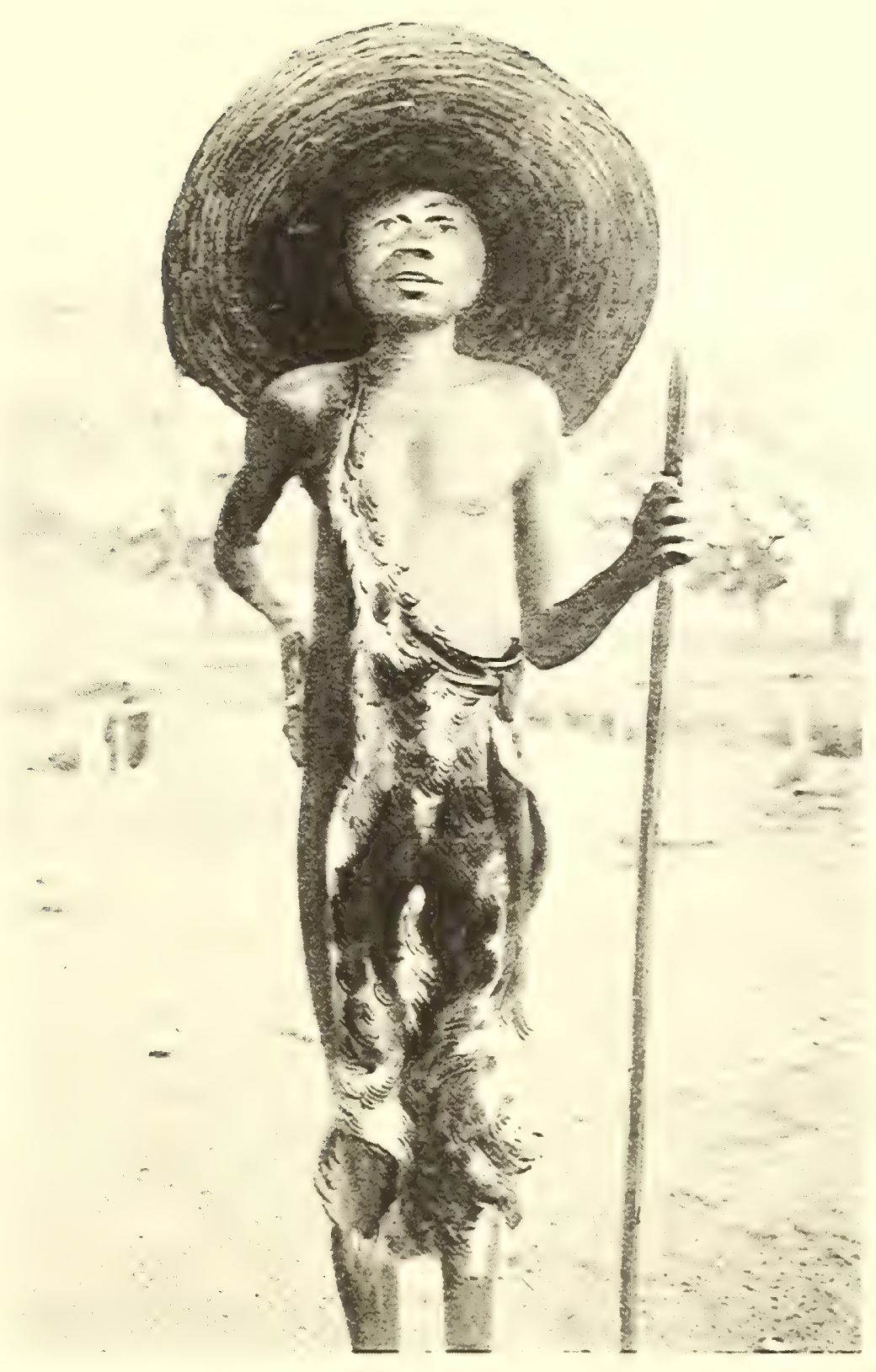

Ein Vornehmer aus Kadiumbara. 

Steinen und Muscheln ausgelegt, was an Mosaikarbeit erinnert. Schöne Rinder, Ziegen, Schafe und Schweine treiben sich frei unter den Bewohnern herum. Die Bewaffnung der Leute besteht zumeist aus Pfeil und Bogen. Ihre Hauptbeschäftigung ist natürlich die Viehzucht; auch war die schöne Rinderherde, welche sich allerdings in lästiger Weise zwischen unseren Lasten herumtrieb, keineswegs zu verachten.

Unter den grossen schattigen Bäumen schlugen wir vor dem Gehöft des Häuptlings unser Zeltlager auf, um am nächsten Tage unseren Marsch

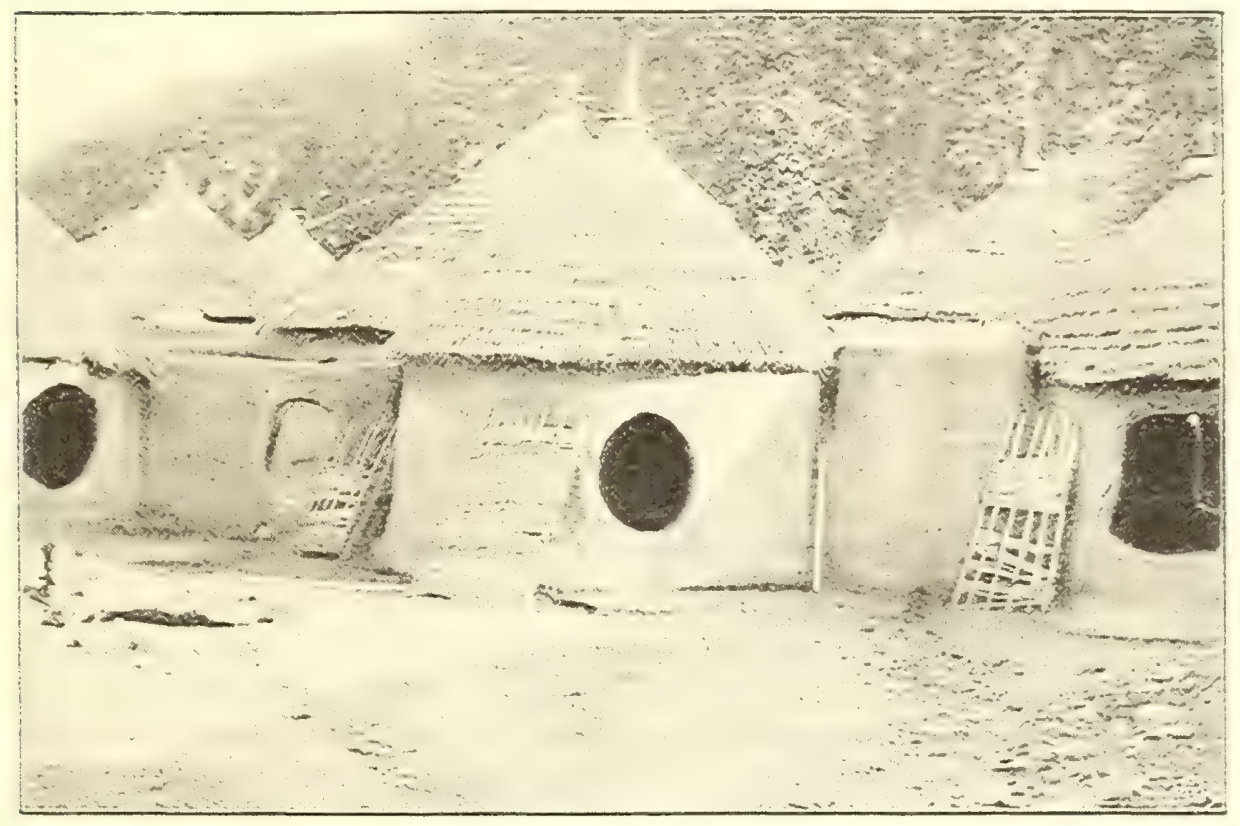

Hütten in Kadiumbara

fortzusetzen. Trotz der Scheu, welche die Leute in den kleinen Bodörfern an den Tag legten, wurden wir doch dank der Fürsorge des alten Urabaya überall gut aufgenommen. Auf der ganzen Route hatte Urabaya von Akpande aus Abgesandte vorausgeschickt, welche uns in jedem Dorfe nebst den Häuptlingen und Aeltesten des Dorfes mit Geschenken erwarteten. Als königliches Abzeichen trug der Führer der Gesandtschaft ausser der Steinschlossflinte einen ehemaligen französischen Uniformrock, der über einer Schamschürze getragen, ungemein komisch wirkte.

Am nächsten Tage marschierten wir über den kleinen Ort Fale, wo wir ebenfalls schönes Vieh bemerkten, weiter nach Norden und erreichten nach $\mathrm{I}^{\mathrm{x}} / 2$ stündigem Marsch über welliges Terrain das kleine 
Das Dorf Bolo. Es ist der letzte Platz vor dem stattlichen Mofluss. Bolo Grenzdorf besteht nur aus etwa 60 Hütten und ist der Rastplatz der Karawanen, Bolo am Mo welche von Bassari kommen oder dorthin gehen. Hier rüstet sich alles zum Ueberschreiten des Mo oder geniesst die Ruhe nach dem anstrengenden Marsch durch die weite Baumsavanne und das bergige Bassariland. Bolo liegt hart an der Gebïgslehne, was dem Dörfchen einen eigentümlichen Reiz verleiht. Die armseligen Hütten beherbergen ein bedürfnisloses zufriedenes Buschvolk, das zu seiner Bekleidung und Ernährung nichts braucht, als ein kleines Fell und selbst gebauten Yams. Früher lag ein Dorf, Kulum, auf halber Höhe des Gebirges, wo noch jetzt der Versammlungsplatz und die Ueberreste zerfallener Hütten zu erkennen sind. Die Bewohner sollen nach Angabe der Boleute wegen einer schweren Krankheit diesen Platz verlassen haben. Durch den verlassenen Ort Kulum geht ein kleiner, wenig betretener Gebirgspfad nach Kabambore, wo er sich an die grosse Route, welche von Tashi noch Tshautsho führt, anschliesst. Jedoch scheint dieser Pfad nur von den Boleuten als Verbindungspfad benutzt zu werden. Von Haustieren bemerkte ich nur Ziegen, Schweine, Hunde und Hühnèr. Rinder habe ich in Bolo nicht gesehen.

Nach Bassari Am 7. Juli verliessen wir Bolo und mit ihm das schöne Bogebirge. Wir wählten nicht den direkten Weg nach Bassari, da man auf diesem weder ein Dorf noch eine Farm antrifft, sondern gingen über Dyodjega, um den langen Marsch durch ein Nachtquartier zu unterbrechen. Nach einem einstündigen Marsch durch die Farmen von Bolo gebot uns der

Fluss- stattliche Mongofluss, der in seinem Oberlauf Mo heisst, ein kategorisches übergang Halt. Der Fluss war zu damaliger Zeit etwa $40 \mathrm{~m}$ breit und $\mathrm{I} / 2 \mathrm{~m}$ tief. über den Mo. Die Uferränder sind steil und zerrissen, und das tief eingeschnittene Bett enthält grosse Glimmerschieferblöcke und Quarzitfelsen. Im ersten Augenblick standen wir ratlos vor der mächtigen Strömung, da weder ein Kanoe noch irgend ein anderes Fahrzeug vorhanden war. Ich liess den Fluss durch zwei gute Schwimmer untersuchen, jedoch schien es unmöglich, ihn ohne Vorsichtsmaassregeln zu passieren. Wir liessen daher ein starkes Seil auf dem einen Ufer befestigen; da jedoch das Seil nicht lang genug war, mussten einige Leute auf dem gegenüberliegenden Ufer dasselbe halten. Dieses Seil gab unseren Trägern hinreichenden Halt, um der starken Strömung Widerstand zu leisten. So wurde mit vieler Mühe in ungefähr zwei Stunden der Uebergang ohne Unfall bewerkstelligt. Die Leute scheinen hier Kanoes nicht zu kennen, haben auch kein Interesse daran, das Passieren ihrer Grenzen und Flüsse zu erleichtern. Sie scheinen sich in ihrer Abgeschlossenheit nur um so sicherer und wohler zu fühlen. Bei hoher Regenzeit sind der Mo, sowie die übrigen grossen Flüsse nicht mehr zu 
Fuss passierbar und man ist gezwungen, ein Floss zu Hilfe zu nehmen. Die Haussa, die häufig mit ihrem ganzen Haushalt reisen, und sich weder durch Flüsse, noch durch Strapazen von ihren Handelsgeschäften abhalten lassen, sollen, wie mir von Augenzeugen mitgeteilt wurde, ihre breiten Kürbisschalen und Kalabassen zum Uebersetzen benutzen. Die Waren werden in den Kalabassen durch einen Haussa, der hinterherschwimmt, von dem einen Ufer zum anderen befördert. Die Frauen dagegen sollen auf folgende Weise übergesetzt werden. Die Frau ergreift die eine Seite der Kürbisschale, der Mann die andere. Beide gehen bis zur Hüfte ins Wasser; die Frau wird dann, von der Kurbisschale und ihrem Mann unterstützt, auf die andere Seite des Flusses gesteuert. Diese Kürbisschalen, die häufig I Meter breit sind, dienen auf der Reise als Wasserbehälter und Truhen. Der Mongo entspringt aus den Bergen von Aledjo-Kadara, wo wir ihn als Mo überschritten haben. Ebenso wie südlich des Flusses sind auch nördlich desselben überall Haussalager, wo die Haussa übernachten oder bei allzu hohem Wasserstande das Fallen des Wassers abwarten.

\section{IM BASSARILANDE.}

Wit dem Ueberschreiten des Mongo befinden wir uns in dem Bassarilande und marschieren nun in dem Flussgebiet des Oti, zu welchem auch der Mongo gehört, über kleine Hügel nach Norden. Diese Hügel bilden eine Fortsetzung des Bogebirges und reichen in einem welligen Terrain fast bis zu den Bassaribergen. Der Weg führt durch eine dichte Baum- und Grassavanne, die überall Spuren von Wild aufweist, so dass man einen grösseren Wildreichtum in diesen Gegenden voraussetzen darf.

Nach einstündigem starken Marsch erreichten wir die erste Bassari- Das Farmdorf ortschaft Dyodjega, ein armseliges Farmdorf, dessen Bewohner sich rom Dyodjega. Ackerbau, von der Jagd und zum Teil auch vom Fischfang im Mongo ernähren. In Dyodjega verabschiedeten sich die Abgesandten des Häuptlings Urabaya, welche wir mit Geschenken für diesen und für sie selbst dankend entliessen. Kaum hatten wir das Lager bezogen und unsere Leute mühsam in dem kleinen Dorf untergebracht, so kam es zu Streitigkeiten mit den als rauflustig bekannten Bassarileuten. Meist ist an solchen Streitigkeiten die Verschiedenheit der Sprache schuld, da in den kleinen Farmendörfern ausser der Bassari- 
sprache weder Temu noch irgend eine andere Sprache gesprochen wird. Gewöhnlich handelte es sich darum, dass die Bewohner sich weigerten, unseren Leuten gutwillig etwas zu verkaufen. Ein Palaver nach dem anderen musste zur Begleichung von Zwistigkeiten abgehalten werden; auch hatte unsere Wache einen schweren Stand, da häufig Männer und Frauen drohend in unser Zelt hineinstürmen wollten. Erst die Nacht brachte die erwünschte Ruhe mit sich.

Am nächsten Tage verliessen wir bei strömendem Regen Dyodjega, um unser Endziel, Bassari zu erreichen. Der Pfad führte durch einen. endlosen Busch, der von kleinen Wasserrinnen durchkreuzt wurde. Niedrige Hügel und Berge boten zwar einige Abwechselung, erschwerten aber den Marsch, insbesondere bei dem ungünstigen Wetter. In Strömen peitschte der Tropenregen herunter und machte es mir fast unmöglich, meine Routenaufnahme fortzusetzen. Nur mit Mühe konnte ich mein Buch vor der Nässe schützen. Bald ging es über einen kleinen Bergsattel und auf dem Plateau winkten einige Farmhütten, in denen wir den Regen abwarteten. Alles drängte sich in den engen Räumen zusammen, um einen trockenen Platz zu finden. Gegen I I Uhr zerriss der Wolkenschleier, und der Regen liess nach, so dass wir wieder aufbrechen konnten. Auf beiden Seiten des Pfades zogen sich kleine Hügelketten von etwa roo bis $200 \mathrm{~m}$ Höhe entlang, bis wir in die Ebene und zugleich in das Bereich der grossen Farmen von Bassari gelangten, von wo wir das Bassarigebirge oder, besser gesagt, den grossen Bassariberg vor uns liegen sahen.

Einmarsch in den Bereich des eigentlichen Bassari.
Ein eigentümliches Gefühl der Unsicherheit hatte sich fast der ganzen Karawane bemächtigt. Weit und breit sind nämlich die Bassarileute als Raufbolde bekannt und wegen ihrer Schandthaten und Reibereien mit den übrigen Völkern gefürchtet. Eine kleine Terrainwelle benimmt uns noch die Aussicht auf die Bassariortschaften, welche zum grössten Teil den Fuss des Bassariberges umlagern. Bald ist auch diese Anhöhe erstiegen und die südlichen Dörfer liegen vor uns. Hoch türmt sich der etwa 200-30o Meter hohe Bassariberg mit seinen Schluchten und Ausläufern als ein geschlossener Gebirgsstock im Nordosten vor uns auf, während im Nordwesten der langgezogene etwa 200 Meter hohe scharfe Kamm des Nafineberges und weiterhin die einzelnen Kegel der Duadiorberge das Thal abschliessen, in welchem westlich und nördlich des Gebirges die Städte und Dörfer liegen. Zaghaft marschierten die Träger weiter und das Tempo verlangsamte sich immer mehr, bis wir endlich auf einem kleinen Grasplatz unter einem Baume, westlich des ersten Bassaridorfes Langondy, halt machten, um die Karawane für den Einmarsch neu zu formieren und frische Kräfte zu sammeln. In dem Dorf Langondy, das ungefähr 200 Hütten zählt, waren 


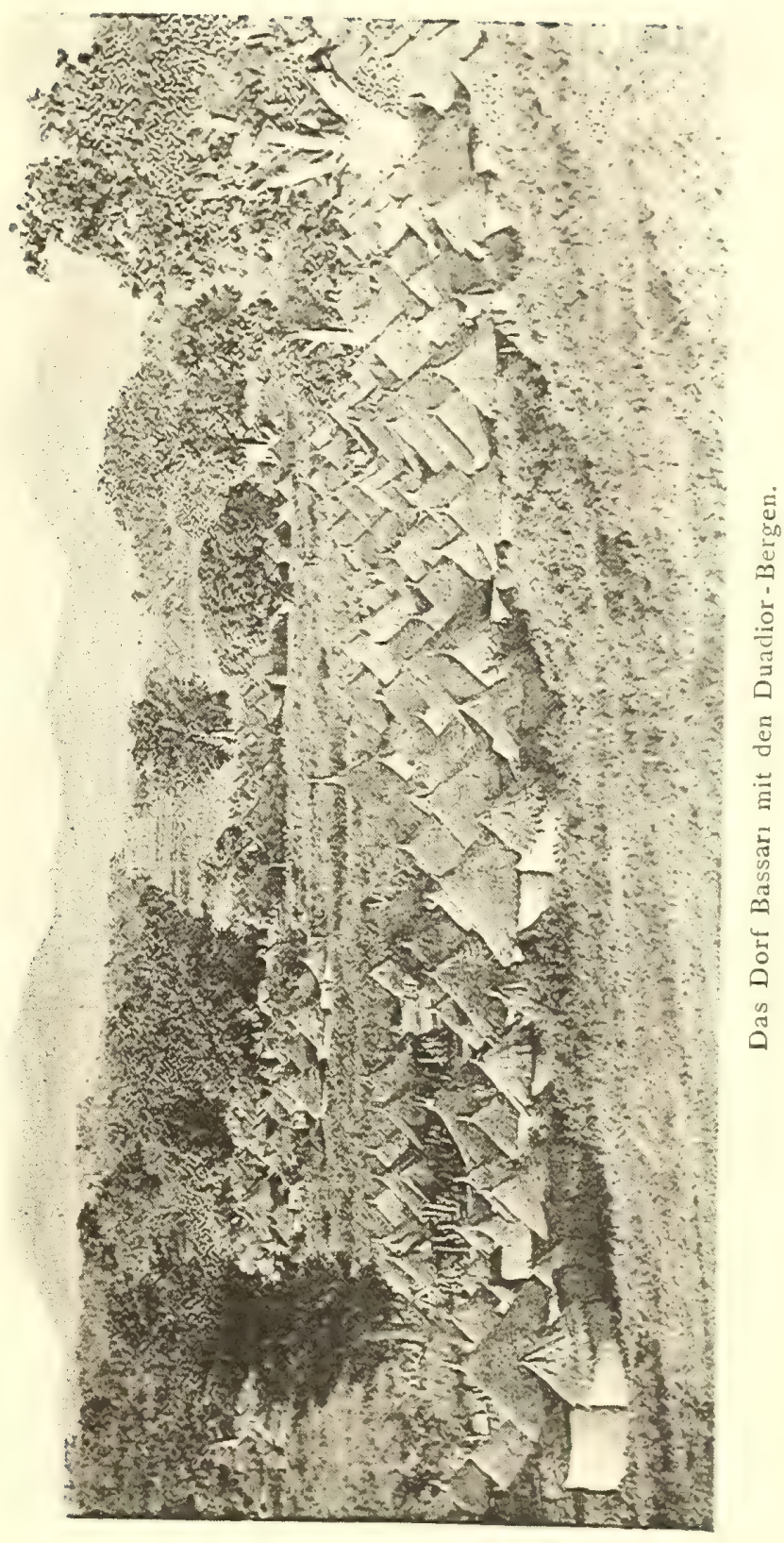


die Bewohner fast vollständig versammelt, doch hielten sie sich scheu und misstrauisch zurück, mit Ausnahme einer alten Frau, welche zu uns kam, uns begrüsste und etliche Yams und Erdnüsse zum Geschenke brachte. Nach einer kurzen Rast wurde aufgebrochen, vorweg die deutsche Flagge, dahinter die Soldaten, sowie unsere Gewehrträger, dann folgte die lange Trägerkette dicht geschlossen hinter einander, während etliche Bewaffnete den Beschluss machten. Das näckste grosse Dorf, welches wir an dem Fusse des Berges passierten, war das etwa 8 oo Hütten zählende Naparba. Hier begrüssten uns einige Haussa, welche gekommen waren, um eiserne Geräte zu kaufen. Sie sprachen Evhe und gaben sichtlich ihrer Freude über unsere Ankunft in Bassari Ausdruck. Die Bassarileute waren zwar begierig, die Karawane und die Weissen zu sehen, blieben jedoch abseits stehen und verhielten sich mürrisch und ablehnend. Die Dächer der Hütten, die kleinen Mauern, mit welchen die Gehöfte und Dörfer umgeben waren, und die grossen Bäume waren mit Zuschauern besetzt.

So marschierten wir lautlos an Benaualiba, einem Dorf von ebenfalls 800 bis rooo Hütten, vorbei durch einen ebenso grossen Platz, Wodande, über Kukunyave zu der kleinen vom Grafen Zech errichteten, aus einigen runden Lehmhütten bestehenden Station. Aber wer beschreibt unsere Ueberraschung, als wir hier auf hohem Flaggenmast die deutsche Flagge wehen sahen und ein reges Treiben und Leben wahrnahmen. Deutsche Soldaten, eine Menge Evheträger begrüssten laut schreiend und juchzend unsere Träger, ihre Landsleute, und das „Home tole" wollte kein Ende nehmen. Wir erfuhren nun, dass Dr. Gruner sich vor den Konkombo hierher zurückgezogen habe. Obwohl das Gerücht von einem Rückzuge Dr. Gruners schon lange zu uns gedrungen war, hatten wir doch nicht recht daran glauben wollen, bis wir ihn nun in Bassari mit seinem Assistenten, Sergeanten Britsch, begrüșsen konnten. Da die Station auf diese Weise schon besetzt war, schlugen wir in dem kleinen verlassenen Orte Yatré unser Lager auf.

Bald nach unserer Ankunft erschien der König des Bassarilandes, Tagba, mit seinen sämtlichen Würdenträgern und den Aeltesten der Ortschaften, um uns zu begrüssen und uns Geschenke zu überreichen. Tagba selbst ist ein wenig befähigter Mensch, der vollkommen unter dem Einfluss der Stadtältesten steht und wenig Ansehen besitzt. Seine Unterhaltung beschränkte sich, mit Ausnahme einiger Worte über die Geschenke, auf Ja und Nein. Schon das nichtssagende, von einem spärlichen Bart eingerahmte Gesicht mit den trüben Augen liess auf eine geringe Intelligenz schliessen. Tagba und sein Sprecher trugen Haussahemden und phrygische Mützen. Der König hatte über das Hemde noch einen grasgrünen, seidenen Umhang gezogen. Von der 
übrigen Gesandtschaft trugen einige Haussahemden, die meisten des hohen Rates aber waren nur mit einem langen Schurz aus Ziegen-, Kuh-; oder Leopardenfell bekleidet, welches über den Schultern mit den Vorderpfoten verknüpft war. Das Fell deckte also nur notdürftig die vordere Seite des Körpers. Der König, dem wir einen Stuhl angeboten hatten, thronte auf diesem, während der übrige Hofstaat im Halbkreise auf der Erde kauerte. Einige hockten. auf ihrem Fell, welches sie zwischen ihre Beine nach hinten gelegt hatten, andere

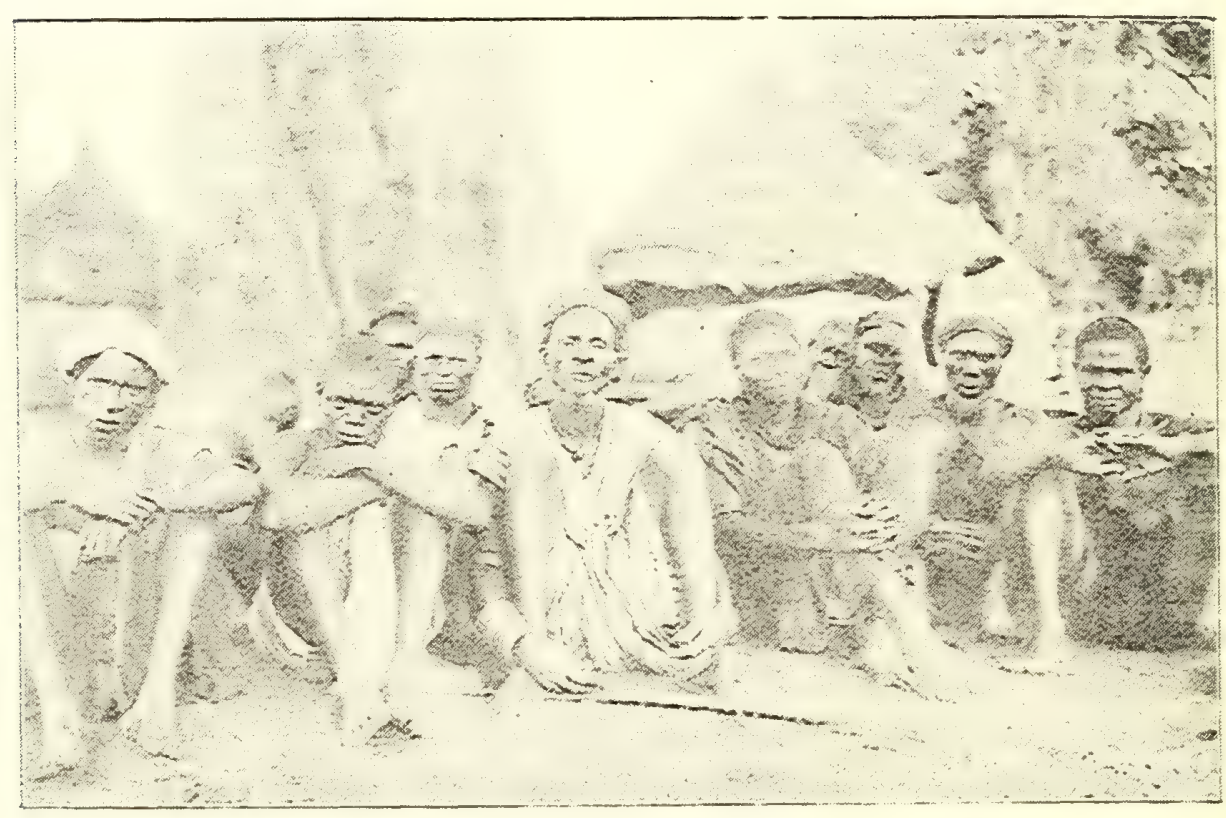

Ein Dorfhäuptling von Bassari mit seinen Getreuen.

führten winzig kleine Schemel mit sich, noch andere hatten ein Beil oder eine Feldhacke, auf deren Stil sie sich setzten. Da die meisten dieser hohen Herren ohne narkotische Mittel nicht leben können, führten sie fast sämtlich Schnupftabakdosen in Gestalt von faustgrossen Kürbisfläschchen bei sich. Diese werden in kleinen Felltaschen aufbewahrt, die aus Ziegen oder Hundefell, oder dem Fell der $Z_{\text {wergantilope bestehen }}$ und über die Schulter hängend getragen werden. Die Taschen sind nahtlos, weil das ganze Fell abgezogen und am Halse abgeschnitten wird; die Hinterbeine und der After sind zugebunden, während die Vorderpfoten als Tragriemen benutzt werden. Im allgemeinen dienen diese Taschen zur Aufbewahrung von Kauris. Die Hauptsache jedoch bildet die Schnupftabakdose, welche bei solchen Versammlungen in der Runde kreist. 
Nase und Schnurrbart des Schnupfers sind von dem zerstossenen Tabak rotbraun gefärbt und kontrastieren seltsam mit dem schwarzen Gesicht. Der Rat der Alten bestand zum grössten Teil aus ergrauten Häuptern, welche den König umgaben und nicht selten durch wildes Geschrei auch ihm gegenüber ihre eigene Meinung vertraten. Nachdem uns ein Stier, Yams und viele Kalabassen mit Hirse überreicht worden waren, beendigten wir den Empfang mit Dank und einem Händedruck.

Am nächsten Tage machten wir dem König unseren Gegenbesuch Gegenbesuch in der auf der Höhe gelegenen Königsstadt Kore. Zu diesem Zwecke bei Tagba zogen wir uns alle weiss an und ritten unter Voranmarsch unserer kleinen Truppe und unter Begleitung der Dolmetscher und einer grossen Volksmenge in die Stadt ein. Vor dem Königspalast, welcher, wie in der Königsstadt bei den meisten Negerfürsten, nur aus einigen Lehmhütten bestand, hatte Tagba unter grossen Schattenbäumen auf einem freien Platze mit seinem ganzen Hofstaat und den Würdenträgern des Reiches Platz genommen. Wir begrüssten ihn und erklärten öffentlich vor der Versammlung, zu welchem $Z$ weck wir gekommen seien. Es sei unsere Absicht, in Bassari eine Station zu gründen, auf dass jeder frei im Lande umherziehen und seinem Vorteil nachgehen könne, wodurch auch Bassari an Macht und Grösse zunehmen würde. Kaum war diese Erklärung abgegeben, so entstand ein gewaltiger Lärm und jeder wollte das Wort ergreifen. Dabei gestikulierte die wilde Gesellschaft mit Händen und Füssen und schrie derartig durcheinander, dass eine allgemeine Prügelei unvermeidlich schien. Sie seien die Väter der Stadt und wollten in ihrem Lande frei schalten und walten; niemand brauche sie zu bevormunden. Der Auftritt veranschaulichte so recht den streitsüchtigen Charakter der Raufbolde. Tagba selbst kam überhaupt nicht mehr zu Wort und wer am lautesten schreien konnte, blieb bei diesem Wortgefecht Sieger. Nachdem sich die Leute etwas beruhigt hatten, machten wir ihňen klar, dass wir gekommen seien, um ihren König zu besuchen und nicht, um uns mit jedem einzelnen Bassarimann herumzustreiten. Der Weisse sei an Ordnung gewöhnt und werde ihnen Achtung vor ihrem König beizubringen wissen; nur der habe zu sprechen, dem der König die Erlaubnis dazu erteile. Tagba und seine nächste Umgebung fühlten sich durch diese Worte-geschmeichelt und gewannen mehr Vertrauen zu uns. Wir überreichten ihm nun unsere Geschenke und damit schloss die feierliche Audienz. Im Laufe der nächsten Tage besuchten uns die Häuptlinge und Gesandtschaften der verschiedenen Bassariorte und brachten uns Yams, Ziegen, Schafe und Hühner, sowie in grossen Kalabassen das in Bassari allgemein beliebte Hirsebier. 


\section{LEBEN UND THÄTIGKEIT AUF DER STATION BASSARI.}

Einrichtung einer provi. sorischen

Station in

Bassari

Das erste was wir in Bassari thaten, war, uns so gut wie möglich in dem verlassenen Ort Yatré einzurichten. Unter den hohen Affenbrotbäumen und Fikusarten wurde unser Zelt aufgeschlagen; der ganze Umkreis wurde von Schmutz und Gras befreit, das Dörfchen, ungefähr aus fünfehn bis zwanzig Hütten bestehend, wurde darauf in verschiedene Teile geteilt und die bestehenden Verbindungsmauern in den einzelnen Gehöften wurden des bequemeren Verkehrs wegen niedergerissen. Dem Fremden ist es fast unmöglich, sich in einem solchen Gehöft

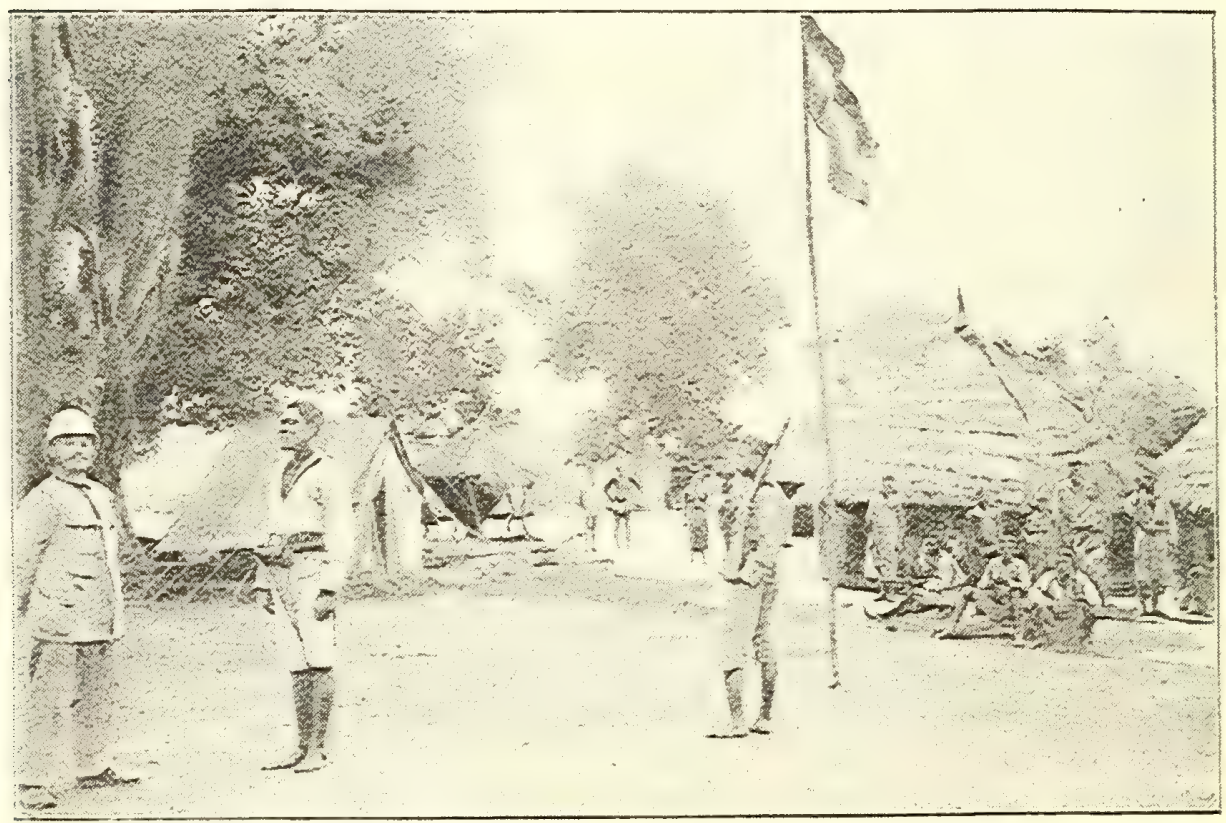

Die Station Bassari im Dorfe Yatré.

mit unzähligen kleinen Mauern und Hütten, aus dem man immer wieder in andere Gehöfte hineinkommt, zurecht zu finden. Wir teilten den ganzen Ort in drei Teile, von welchen der eine mit den grösseren Hütten als Wohnung "für uns und zur Unterbringung unseres Gepäcks und unserer Lasten diente, während in den beiden anderen die Träger und Soldaten einquartiert wurden. In die Vorhalle wurde die Wache mit Waffen und Munition gelegt. Unsere Pferde erhielten einen Stall aus geflochtenen Matten. Ausserdem bauten wir aus demselben Material eine kleine Halle zum Aufenthalt während des Regens, da man in den dunklen Hütten weder lesen noch schreiben konnte. Ein aus alten 
Kisten gezimmerter Tisch leistete uns bei unseren schriftlichen Arbeiten sowie bei den Mahlzeiten vorzügliche Dienste. Meistens hielten wir uns natürlich im Freien auf, wo uns die hohen Bäume den nötigen Schatten spendeten und der Anblick der lieblichen Natur über manchen Verdruss hinweghalf. Im Süden vor uns lag das schöne Gebirge mit steil abfallenden Felsen und Schluchten, an deren Abhang die im Wald eingebettete Dörfer mit ihren niedlichen Hütten zu kleben schienen. Im Norden dagegen erstreckte sich eine weite Ebene mit schönen Wiesen und fruchtbaren Feldern, abgeschlossen durch die Duadionberge, die uns wie eine sanfte Hügelkette mit grünen Matten erschienen.

Um unsere Träger zu beschäftigen und von den aufdringlichen und lästigen Bassarileuten fernzuhalten, wurde der ganze grosse Stationsplatz durch Zäune und Barrieren von Bambus abgeschlossen und eine Koppel für unsere Pferde angelegt. Auch hatten die Träger reichlich mit Wassertragen, Herbeischaffen von Feuerholz etc. zu thun, endlich wurden kleine Wege zu den nahe gelegenen Dörfern sowie zu dem Marktplatze angelegt. Die Soldaten wurden weiter ausgebildet. $\mathrm{Zu}$ diesem Zweck mussten sie einen kleinen Exerzierplatz, sowie einen Schiessplatz in einer Felsenschlucht anlegen. Die Scheiben wurden mit unserer Hilfe aus Greybaft auf einem Rahmen von Bambusstäben hergestellt und ein Soldat unserer Truppe als Zielpunkt darauf abgebildet, in dem die Truppe unseren besten Soldaten, Quaku, zu erkennen glaubte. Uebrigens wurde der grössere Teil der Träger in die Heimat nach Kratyi entlassen und nur ein kleiner Stamm nebst unserer Truppe zurückbehalten, so dass eine verhältnismässig ruhige Zeit für uns eintrat. Jeden Morgen um fünf Uhr, noch vor Tagesgrauen, wurde Wecken geblasen; die Träger wurden zur Arbeit eingeteilt, während die Soldaten exerzierten und in der ersten Zeit jeden Tag einzeln und auch in der Truppe auf dem Scheibenstand schossen, dass es dumpf dröhnend aus den Bergen wiederhallte. Häufig umstanden die Eingeborenen den Exerzierplatz und schauten aufmerksam dem Exerzieren der Soldaten zu. Ein Fullah trat als Soldat in unsere Truppe ein und leistete uns durch seine Kenntnis der Bassarisprache gute Dienste. Auch besorgte er uns für Geld und gute Worte manches Stück Käse, sowie Butter und Milch ron seinen im Lande zerstreut wohnenden Landsleuten. Mit dem Leben und Treiben auf den Stationen begann für Bassari eine neue Aera. Die Träger und Soldaten von Dr. Gruner, später auch von Herrn v. Massow, mussten mit Lebensmitteln versorgt werden. Dies zog eine Menge Tshautsholeute und Haussa nach Bassari, welche als Geldmakler und Dolmetscher zwischen unseren Leuten und dem einheimischen Volke vermittelten. 
In der ersten Zeit war die Verpflegung der Leute äusserst schwierig, Verpflegung da die Bassarileute absolut nicht zu bewegen waren, ihre Produkte gegen und die Ein- Geld herzugeben. So waren unsere Leute ganz der Willkür der Haussa lührung von

Geld. und Tshautshohändler, welche den Kurswert vorschrieben, ausgesetzt. Man bekam für eine Mark in der ersten Zeit häufig nur $75^{\circ}$ Kauris, während man an der Küste für eine Mark über den fünffachen Betrag, 4000 Kauris erhielt. Um unseren Leuten den Umtausch einigermaassen zu erleichtern, gaben wir ihnen Zeuge wie Graybaft und Perlen. Die Bassari nahmen nur Graybaft, Messingstäbe, kleine Spiegel, bunte Taschentücher, Kattun, kleine rote Perlen, mitunter auch unechte Korallenketten aus Glasperlen und Glasperlen, welche wie geschliffener Achat aussahen, in Zahlung. Für I Yard Graybaft wurden etwa 700 bis 800 Kaurimuscheln gezahlt, was dem dortigen Preise von etwa 7o bis 8o Pfennigen gleichkommt. Glücklicherweise erkannten die Haussa und Tshautshohändler bald in den von unseren Leuten auf den Markt gebrachten Tauschartikeln eine gefährliche Konkurrenz, infolgedessen gingen sie mit ihren Preisen herunter und zahlten nun ohne Schwierigkeiten für eine deutsche Mark wenigstens rooo Kauris. Fast ebenso drückten uns die Schlächter mit ihren Fleischpreisen. Für eine kleine Hammelkeule nahmen uns die Haussa in der ersten Zeit nicht weniger als 2 Mark ab und Rindfleisch war fast garnicht zu haben. Schliesslich erstanden wir gegen allerhand Waren, zuletzt auch für Geld, schöne, junge, ausgewachsene Stiere im Werte von 20 Mark und Schafe für 4 bis 5 Mark, und schlachteten, zerlegten und verkauften sie für den Selbstkostenpreis an unsere Leute. Ganz allmählich drang dann das Verständnis für den Wert des Geldes bei den Eingeborenen durch. Hauptsächlich durch unsere in den verschiedensten Münzsorten ausgeteilten Gegengeschenke wurde das Geld auf dem Markte von Bassari kursfähig, und schon nach zwei Monaten wurde lieber bar Geld als Ware in Zahlung genommen. Leider muss ich hier bemerken, dass ich trotz meiner Bemühungen deutsches Geld von der Küste zu erhalten, den grössten Teil in englischem Gelde erhielt, welches ich, nachdem das deutsche Geld verbraucht war, zu meinem Verdruss verausgaben und auf diese Weise englische Münze einführen musste. In dieser Beziehung muss ich es nochmals als wünschenswert und zweckmässig bezeichnen, in den Kolonieen eine einheitliche deutsche Münze als kurstähig einzuführen. Ich besuchte den Markt häufig, um auf diese Weise die verschiedenen Landesprodukte kennen zu lernen.

Der Markt Des Abends um 5 Uhr ziehen die Leute mit ihren Produkten auf von Kore und den grossen Markt in Kove oder auf den von Naparba. Unzählige Naparba. grosse Steine dienen dort den Verkäufern als Sitz. Eine Menge Feldprodukte, welche für den ausgedehnten Ackerbau sprechen, rote, weisse 
und gelbe Hirse, Pfeffer, Sesamsaat, Okro, Erdnüsse, Tomaten, Zwiebeln, Palmkörner, Palmöl und medizinische Kräuter werden in Kalabassen produkte und feilgeboten. Daneben giebt es lebende Hühner, auch Perlhühner, Schafe Nahrungsund Ziegen, das beliebte Kaffa, Dauadaua, in der Sonne getrocknetes Antilopen- und Schweinefleisch, Hirse-Klösse in Palmöl oder Tshibutter gebacken, Schaf- und Rindfleisch mit Kräutersaucen zubereitet, geröstete Erdnüsse, getrocknete und gebratene Fische, Austern aus dem Oti, Addasalz, rock salt und Feuerholz. Ausser den Eingeborenen trifft man Tshautsholeute, Haussa und Fulbe. Letztere bringen meistens Meiereiprodukte, wie angesäuerte Milch, Käse in grossen runden Formen von etwa $20 \mathrm{~cm}$ Durchmesser und 2 bis $4 \mathrm{~m}$ Höhe und als ganz besondere Delikatesse Butter zum Markte. In grossen Thongefässen und Kürbiskalabassen wird von den Frauen Hirsebier verkauft. Die Nachfrage ist so gross, dass die Käufer den Frauen schon auf dem Wege zum Markt auflauern und ihnen das Bier abnehmen.

Die Tshautsholeute oder besser gesagt die Mohamedaner aus den Temulandschaften, welche allein der Weberei kundig sind, bringen die bei den Bassarifrauen beliebten weissen, blauen, roten oder schwarz-weissblau gestreiften Baumwolltücher auf den Markt. Auch die dreieckigen Schamschürzen, welche die Bassarileute tragen, werden zum Kauf angeboten. Moande und andere südlich gelegene Orte sind mit grossen Thontöpfen und Schalen vertreten. Kürbisschalen und Kalabassen in allen Formen, Fufustampfen und grosse Holzmörser, in denen der Fufu bereitet wird, Schwämme aus Holzfasern, Matten aus Gras und Pandanusarten, geflochtene Körbchen und Teller von der Raphia, Besen, Thürvorsetzer, Tabak in langgedrehten. Rollen und Seifen in faustgrossen Kugeln, welche nur von Tshautsholeuten fabriziert werden, liegen zum Verkauf aus. Letztere werden zu einem hohen Preise feilgeboten. Vereinzelt kommt auch Kautschuk in kleinen Ballen vor, ebenso Rotholz, Indigo und andere aus Pflanzensaft hergestellte Farbmittel zum Färben der bei den Bassarifrauen gebräuchlichen roten Schamtücher. Zu den Bedarfsartikeln der Frauen gehören ferner die aus Palmkernen, seltener aus Muscheln hergestellten Hüftschnüre und die in Bassari von heiratsfähigen jungen Mädchen getragenen blaugefärbten Baumwollschnüre mit handgrossen, aus Baumwollfranzen bestehenden Schamschürzen. Haussa- und Tshautsholeute verkaufen kleine Quantitäten von korallenähnnlichen, roten und kleinen bunten Glasperlen, die wertvollen Groundbeads, seltener auch Achate. Ausserdem bringen sie von der Küste Graybaft, bunte Taschentücher und in geringerem Maasse andere Zeuge.

Das Schmiedehandwerk ist weniger vertreten, da seine Erzeugnisse an Ort und Stelle verkauft werden. Ab und zu sieht man die runden, 
zu Feldhacken verwendbaren Eisenscheiben, nicht selten auch aus Messingstäben gefertigte Armringe und eiserne Ringe.

Gewerbs- Ein eigentümliches Geschäft, welches die Bassari auf dem Markte mässige betreiben, ist das des Wahrsagens. Stundenlang sieht man das Volk Wahrsager. an der Seite des Marktes im Gespräch mit den mit Amuletten behangenen Wahrsagern. Aus den Zeichen, welche entstehen, indem ein Stock leicht auf dem Boden hin und hergeführt wird, sagen sie den Leuten auf Verlangen ihr Schicksal voraus. Der Marktplatz lag nicht weit von unserer Station und bot uns immer wieder von neuem ein abwechslungsvolles Bild.

Auflehnung Inzwischen beschäftigten uns die politischen Ereignisse vollauf. der Leutnant Thierry und die Station Sansane-Mangu waren durch eine AufKonkomba, lehnung des räuberischen Stammes der Konkomba vollkommen von der Küste und von jeglicher Verbindung abgeschnitten. Im Süden von Sansane-Mangu, in der neutralen Zone, wohnten die uns feindlichen Dagomba, welche den Durchzug nach Sansane-Mangu verweigerten und der einzige andere Weg dahin, über Kratyi-Bassari durch das Reich der Konkomba, war infolge des Aufstandes gleichfalls gesperrt. Oestlich von den Konkomba liegt das unerschlossene Gebiet der räuberischen Kabrevölker, welches bis dahin für kleinere Expeditionen noch nicht zugänglich war. Die Konkomba-Affaire hatte sich nach den Schilderungen Dr. Gruners folgenderweise zugetragen:

Der deutsche Agent des kleinen Polizeipostens in Bapure hatte Dr. Gruner in Sansane-Mangu gegen die Konkomba um Hilfe gebeten, da diese angeblich Bapure und den aus einigen schwarzen Polizisten bestehenden Posten dortselbst angegriffen und beraubt hätten. Dr. Gruner eilte mit etwa 30 Soldaten und mehreren eingeborenen Reitern und Trägern diesem kleinen Posten zu Hilfe, während Leutnant Thierry sich in der Landschaft Pama befand. Auf diesem Marsch wurde bei Bapure eine Patrouille Dr. Gruners durch die Konkombaleute vollkommen aufgerieben und einige seiner Soldaten durch vergiftete Pfeile getötet. Der Häuptling von Bapure, der angeblich auf Dr. Gruners Seite stand, war aus der Stadt verschwunden. Dr. Gruner bezog daher nach Aufgabe und Abbrennen des Bapurepostens, sowie nach Einziehung der deutschen Flagge ein Lager bei Bapure, da ihm der Aufenthalt in der Stadt zu unsicher schien. Das Lager wurde jedoch beständig von Konkomba-Patrouillen umschwärmt und die Kräfte der Expedition durch die vielen Nachtwachen so sehr angegriffen, dass Dr. Gruner, stetig von den Konkomba umgeben, sich nach Banyeli zurückziehen musste. Hier begegnete er seinem Assistenten Britsch, welcher von der Küste nach der Station Sansane-Mangu heraufgeschickt war und marschierte mit diesem vereinigt naç Bassari zurück, wo wir, wie schon vorher erwähnt, an demselben Tage einzogen. 
Dr. Gruner gab uns einige Aufschlüsse über das Buschvolk der Konkomba. Dieselben sollen über das ganze Land zerstreut auf ihren Farmen wohnen, Ackerbau und Viehzucht betreiben und, wie alle Naturvölker, geringe Ansprüche an das Leben stellen. Grössere Städte oder Dörfer sollen nicht vorhanden sein. Sie verfolgten Dr. Gruner, wie er mir erzählte, stets in einer ausgeschwärmten Schützenreihe in dem Busch und waren mit Bogen und vergifteten Pfeilen, sowie mit Messern ausgerüstet; am Daumen und Zeigefinger der rechten Hand trugen sie zwei kleine eiserne Fingerhüte, die wahrscheinlich zum Spannen des Bogens dienen und durch beständiges Klappen auf den eisernen Bogenspannern den einzelnen Kriegern die Fühlung mit der Reihe in dem dichten Busch ermöglichen. Die einzelnen Abteilungen der Krieger werden von einem Führer geleitet und durch Blasen auf einem Antilopenhorn wird den Kriegern das Signal zum Avancieren oder Halt gegeben. Das beständige Klappern der Bogenspanner soll, wie uns Dr. Gruner berichtete, seine Leute in steter Aufregung gehalten haben. Obwohl wir uns Dr. Gruner mit drei Weissen und unseren zehn Expeditionssoldaten zur Verfügung stellten und auch eine Verstärkung von Kratyi von etwa 20 Mann zu erwarten stand, so dass unsere Truppe 50 Soldaten und fünf Weisse stark gewesen wäre, hielt er es doch nicht für ratsam, den Vormarsch gegen Sansane-Mangu zu beginnen und durch das starkbesetzte Konkombagebiet die Verbindung mit der abgeschnittenen Station und Leutnant Thierry wieder herzustellen. Infolgedessen kam später die Truppe von der Küste mit vier Weissen nach Bassari herauf und stellte nach einem kurzen Gefecht und einem Angriff auf das Lager der Konkomba die Verbindung wieder her. Ab und zu kamen Konkombaleute als Spione bis nach Bassari, um sich dort von der Lage der Dinge zu überzeugen; sobald die Soldaten sie aber erkannten, wurden sie ergriffen und nur durch energisches Einschreiten der Weissen gerettet. Bei diesem Einfangen der Konkombaleute konnte ich mich von ihrer ungewöhnlichen Geschmeidigkeit überzeugen; immer wieder wussten sie sich den Händen der Soldaten zu entwinden, bis sie schliesslich gefesselt zur Station gebracht wurden.

Fortwährend beunruhigten uns sensationelle Gerüchte von dem Vormarsch der Konkomba und von der Aussendung einzelner Bogenschützen, welche die Weissen hinterrücks erschiessen sollten. Natürlich war unseren Wachen und Posten die grösste Aufmerksamkeit für die Nacht eingeschärft und sämtliche Leute der Expedition waren für einen Uebérfall vorbereitet. Zieht man indessen die Uebertreibung in Betracht, mit der selbst die unbedeutendsten Ereignisse in Afrika wiedererzählt werden, so war bei einem einigermaassen energischen Auftreten unsererseits unsere Lage nicht so gefährdet, wie es namentlich in der ersten Zeit den Anschein hatte. 
Wir konnten uns daher auch friedlichen Aufgaben zuwenden. So sche und geo- liessen wir von unseren Leuten neue Wege anlegen, die Station auslogische Auf- bauen und unternahmen kleinere Touren zur geologischen und geographischen Rekognószierung der Umgegend von Bassari. Auch Dr. Gruner baute mit seinen Leuten breite Verbindungsstrassen zu unserer Station, sowie nach dem grossen Dorfe Wodande, was bei den Eingeborenen solchen Anklang fand, dass der König selbst mit seinen Leuten im Anschluss an die grosse Strasse, welche die Station verband, einen Weg nach dem Königsplatz herstellen liess.

Rings um den Bassariberg wurden die verschiedensten Orte festgestellt. Interessant ist, dass man Bassari eigentlich nach seinen hauptsächlichen Erwerbszweigen in mehrere Bezirke einteilen kann. So wird in Kore und Nańbani, die sich durch schöne ausgedehnte Farmen auszeichnen, hauptsächlich Ackerbau betreiben. Der Norden und Nordwesten von Bassari selbst mit Wodande und Epássiba, in welchem grosse Weiden liegen, wird von Viehzüchtern bewohnt. Der Osten mit dem grossen Schmiededorf Naparba ist die Heimat der Eisenindustrie, während im Süden, in Nafine und Moande, Töpferei und Flechterei im grossen Maassstabe betrieben werden. Weiter im Norden, abseits von dem Bassariberge, in Mpampú, liegen die Eisenschmelzöfen. Natürlich sind die Bewohner aller dieser Industriebezirke nebenbei auch Ackerbauer und Viehzüchter.

Bassari im engeren Sinne gruppiert sich rings um den Bassariberg. Obwohl das eigentliche Bassariland sich bedeutend weiter erstreckt, sind die ungefähren Grenzen im Süden der Mofluss, im Westen der Katsha, ein rechter Nebenfluss des Mo, im Norden die Bezirke von Kabore und im Osten das Gebiet von Dako und der kleine Nebenfluss des Mo, Pempeu. Bassari ist also im Westen von den Dagomba, im Norden von den Kabrevölkern, im Osten und Süden von Tshautsho und den Temulandschaften eingeschlossen. Die grösseren Städte und Dörfer von Bassari zerfallen wieder in einzelne Bezirke und kleine Ortschaften, welche eigene Namen haben, so dass es sehr schwer ist, sich unter den verschiedenen Benennungen zurecht zufinden. Die Königsstadt Kore zerfällt in mehrere Teile und zählt etwa 800 Hütten, während Nańbani, Naparba und Wodande etwa je ıooo Hütten, Enongaliba oder Benaualiba etwa I 200 Hütten und Epassiba mit Dekotibaude etwa 2000 Hütten zählen. Ausser diesen Ortschaften muss man noch die kleinen, abseits liegenden Dörfer Nafine, Moande u. a. berücksichtigen. Demnach lässt sich die Hüttenzahl des engeren Bassari ungefähr auf $9000-10000$ schätzen, so dass die Einwohnerzahl von Bassari, wenn man etwa vier Köpfe auf eine Hütte rechnet, sich ungefähr auf $35000-40000$ belaufen würde. Assessor Hupfeld konnte auch hier leider nichts als Quarzit, sowie Eisenstein in grossen Mengen feststellen. 
Bei unserer Arbeit wurden wir nicht selten, namentlich in der ersten Zeit, durch streitsüchtige Bassari-Trunkenbolde belästigt. So drang eines Tages ein sogenannter Bigman, ein Dorfältester, in die Station ein, schlug wütend um sich, beschimpfte uns und warf uns ein Bündel Yamskraut vor die Füsse. Obgleich unsere Soldaten ihn zurückwiesen, liess er sich nicht abhalten, sondern fuhr fort, in drohender Weise zu toben, während eine Menge Volks die Station umgab und über den Helden jubelte. Da der Trunkenbold in grober Weise den herbeigeholten Dolmetscher verletzte und schliesslich die Soldaten der Wache, welche ihn wegbringen wollten, insultierte und stiess, liess ich ihn verhaften. Hierauf geberdete er sich wie wahnsinnig und rief seine Bekannten zu Hilfe, die sich jedoch, als die Sache ernst zu werden anfing, schleunigst entfernten. Trotz seines Sträubens wurde er gebunden und in der fur die Wache bestimmten Hütte eingesperrt, wobei sich die Soldaten für die erhaltenen Püffe stillschweigend revanchierten. Als sich der Mann einigermaassen beruhigt hatte, liess ich ihn durch den Dolmetscher vernehmen und stellte fest, dass ihm aus seiner Farm Yams gestohlen seien und dass angeblich unsere Soldaten an dem Diebstahl Schuld hätten. Am nächsten Tage verhörte ich ihn nochmals selbst. Indessen war er ausser Stande, mir die Zeugen zu nennen, die meine Soldaten bei dem Diebstahl betroffen haben wollten und brachte schliesslich nach langem Zaudern heraus, dass er von seinen Landsleuten im angetrunkenen $\mathrm{Zu}$ stande aufgereizt worden sei und gar nicht wisse, wer den Diebstahl begangen habe. Da er sein Unrecht einsah und bat, dass man ihm die Strafe erlassen möge, liess ich ihn laufen. Wahrscheinlich hatte er eine schwere Strafe oder wenigstens die Auferlegung eines hohen Lösegeldes erwartet, denn er zeigte sich sehr dankbar und brachte uns am nächsten Tage freiwillig Hühner und Bier zum Geschenk. Noch mehr überraschte es ihn, als er dafür ein Gegengeschenk erhielt. Auch unter sich beginnen die rauhen und rauflustigen Bassarileute bei jeder Gelegenheit, namentlich im trunkenen Zustande, Streit. Dieser Charakterzug, sowie ihre Raubgier und der Sklavenfang, haben sie bei den Nachbarstämmen so gefürchtet und verhasst gemacht, dass ihr Land gegen die übrigen Völker nahezu abgeschlossen ist.

Die Bassarileute sind im grossen und ganzen dem Trunk ergeben. So findet täglich nachmittags bei den Ratsversammlungen der Dorfältesten unter den grossen Schattenbäumen des Marktplatzes ein wahres Zechgelage bei Hirsebier, seltener bei Palmwein statt. Diese Beratungen verlaufen meistens sehr stürmisch, denn jeder hat seine eigene Meinung, die er in der Weise geltend macht, dass er mit wüstem Geschrei jedem anders Denkenden gegrenübertritt und schliesslich allen Beschlüssen zum Trotz thut, was er will. Jeden Augenblick glaubt man den Ausbruch

Zechgelage und Hazard. spiele der Bassarileute. 
einer Prügelei gewärtigen zu müssen. Nur der Schoppen Bier oder Wein und das Spiel versöhnen am Abend die erhitzten Gemüter. Bei untergehender Sonne findet meistens ein Gelage mit Bier statt, wobei ein Kaurispiel entriert wird. Zufrieden hocken dann die Väter der Stadt im Kreise mit bis zum Kinn angezogenen Knieen auf der Erde oder auf einem Stein. Ihre ganze Bekleidung besteht aus einem kleinen Schurz oder Lederfell. In der Mitte steht häufig eine grosse Kalabasse mit Bier, mit dem aus kleinen Schalen der Umtrunk gehalten wird. Daneben kreist die Tabaksdose und jeder schnupft nach Herzenslust. Jeder der Mitspielenden hat einen grossen

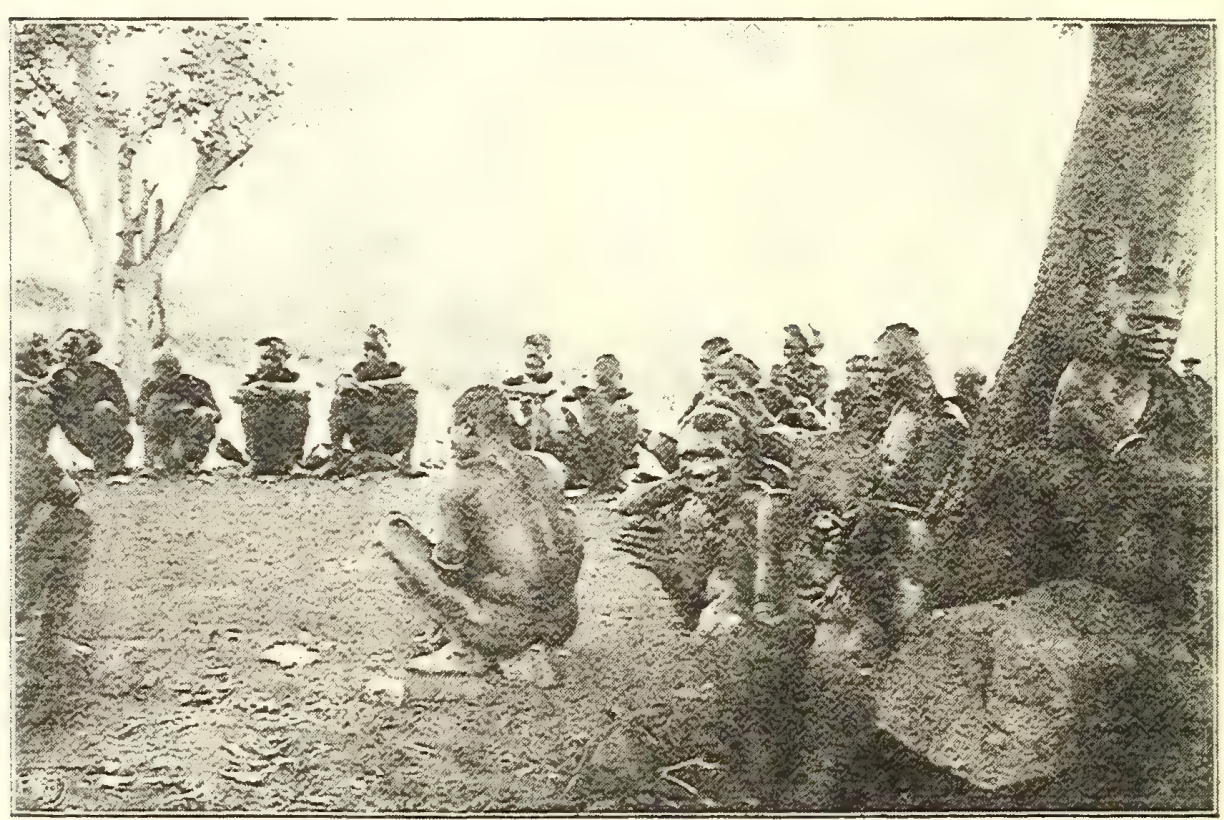

Kaurispiel der Bassari-Leute.

Haufen Kauris vor sich, von dem zu gleicher Zeit eine bestimmte Anzahl in die Mitte des Kreises geworfen wird. Je nachdem die Kauris auf die Narbe oder auf den Rücken fallen entscheidet sich das Glück des Spielers. Derjenige, dessen Kaurimuscheln in der Mehrzahl mit der Narbe nach oben liegen, ist der Sieger und heimst mit grinsendem Gesicht seinen Gewinn ein. So folgt ein Einsatz dem anderen. Besonders eifrige Spieler suchen dem Wurf durch Fingerschnalzen einen besonderen Nachdruck zu verleihen. Die Gewinnenden klatschen häufig in die Hände, während die Verlierenden nachdenklich ihr Haupt auf den Ellenbogen stützen. Jüngere Leute sehen dem Spiele zu und klettern nicht selten, um die Situation zu beherrschen, auf einen in der Nähe stehenden Baum. 
Der Wein wird aus der Raphia vinifera gewonnen; das Bier, das Wein- und eigentliche Nationalgetränk der Bassarileute, wird von der Frau meistens Bierbereitung im eigenen Haushalt zubereitet, und besteht vorherrschend aus gelber bei den Kolbenhirse oder Rispenhirse, die gekocht und mit dem Satz der Gährung Bassari, überlassen wird. Um das Bier besonders schmackhaft zu machen, wird ihm häufig Honig von wilden Bienen zugesetzt. Ein Zusatz von Luffa macht es, namentlich für die Trinkgelage, kräftig und berauschend. Vor dem Trinken wird es gewöhnlich umgerührt, damit der Satz sich mit der Flüssigkeit vereinigt. Der Geschmack des Bieres ist nicht übel und kommt unserem gewöhnlichen ungegohrenen Jungbiere am nächsten. Die Bierfabrikation wird von vielen Frauen, namentlich von Tshautshoweibern, in grossem Maassstab betrieben und dasselbe wird in riesengrossen Thontöpfen auf den Markt gebracht. Da meistens die Nachfrage grösser ist als das Angebot, hat das Bier einen verhältnismässig hohen Preis. Für 3 bis 4 Liter mussten wir 20 bis 25 Pfennig zahlen. Das Bier ersetzte uns in Bassari die europäischen Getränke; wir gewöhnten uns schnell an dasselbe, da es besonders auf Märschen erfrischender wirkt als Palmwein.

Die Feste nahmen in Bassari fast gar kein Ende. Ausser Spielen und Gelagen wurden bei der Grösse des Ortes öfter Totenfeiern in lärmender Weise abgehalten. Die ganze Nacht hindurch erdröhnten dann Flintenschüsse, welche in der felsigen Gegend durch das Echo verdoppelt wurden. Meistens war ein grosses Biergelage damit verbunden; die Teilnehmer kamen dann angetrunken an der Station vorüber und suchten die Posten durch ihr Geschrei zu reizen. Wollte man sich der lärmenden Raufbolde entledigen, so wurde häufig das Geschrei noch toller und gipfelte schliesslich in der Verherrlichung ihres Landes mit dem Rufe "Bassari“ — "Bassari“ — Bassari“. Thatsächlich sind die Leute nicht so unbändig, wie sie im ersten Augenblick erscheinen. Bei einem energischen und gemessenen Auftreten lassen sie sich sehr wohl anleiten und erziehen. Durch längeren Umgang lernte ich allmählich auch ihre guten Seiten kennen, zumal ich mich täglich mit ihnen beschäftigte, um in ihre Sitten und Gewohnheiten einzudringen, oder sie zu photographieren und anthropologisch zu messen. In der ersten Zeit hatte ich Mühe, ihnen richtige Angaben zu entlocken; häufig musste ich meine Gewährsmänner, an die ich ethnologische Fragen richtete, wieder fortjagen, weil ich sie bei Lügen ertappte. Endlich fand ich in Napui einen alten ehrlichen Koremann, einen sogenannten Bigman, welcher auch zu mir schliessilich Vertrauen fasste, als er merkte, dass ich nichts Böses vorhatte und nur durch ihn die Sitten des Landes kennen lernen wollte. Bei meinem Weggange beschenkte ich ihn mit Zeugen und Tabak; aber auch Napui zeigte sich erkenntlich und es war geradezu rührend, wie er mir beim Abschied wünschte, dass der 
Gott Unombote mich schützen, dass ich glücklich in meine Heimat zurückkehren und dass mir auf der Reise nichts zustossen möge. Als Geschenk gab er mir das Beste, was er geben konnte, ein Mittel gegen vergiftete Pfeile. In einem winzig kleinen Gefäss aus Tierhaut, welches die Bassarileute oft bei Reisen um den Hals tragen, befand sich, mit einem kleinen Holzstöpsel abgeschlossen, dieses Mittel. Es besteht aus einem schwarzen Pulver, welches zerstossener Holzkohlc nicht unähnlich sieht. Er erklärte mir, dass ich es folgendermaassen gebrauchen sollte: „Wenn du von einem vergifteten Pfeile getroffen wirst, so streue auf die wunde Stelle dieses Pulver und sauge dann mit dem Munde die Wunde aus; darauf musst du wieder das Pulver auf die Wunde streuen. Wenn du dieses thust, so wirst du nicht sterben." Ich kann nicht leugnen, dass es mir zuletzt wirklich schwer fiel, mich von den Leuten, mit denen ich so lange zusammen gearbeitet hatte, zu trennen.

Anthropo- Grosse Schwierigkeiten bereiteten mir die anthropologischen logische Messungen. Trotz aller Versprechungen konnte ich nur schwer einige Messungen. Leute dazu gewinnen. Selbst dann versagten sie noch im letzten Augenblick, wenn ich den Tasterzirkel benutzte, um Kopfmaasse zu nehmen. Ehe man sich's versah, waren sie, alles im Stich lassend, davongelaufen, und um keinen Preis zur Rückkehr zu bewegen. So gelang es mir nur mit der grössten Mühe, in der verhältnismässig kurzen und arbeitsreichen Zeit einige Leute zu messen.

Photo- Dagegen liessen sie sich willig photographieren. Bei dem ersten graphische Anblick des Zauberkastens zwar lief natürlich alles fort; nur ein paar Aufnabmen. beherzte Männer blieben und sahen dem Dinge misstrauisch zu. Aber ich photographierte anfangs nur leblose Gegenștände, wie Hütten oder Landschaften; diese Bilder machte ich vollständig fertig und zeigte sie den Leuten. So gewann ich den König und einige würdige alte Männer für mich. Bei ihren Besuchen auf der Station erklärte ich ihnen, dass der Kasten den Zweck hätte, solche Bilder zu machen, welche ich zu Hause meinen Landsleuten zeigen wolle, damit auch sie erführen, was furr ein grosses Dorf Bassari sei und wie seine Bewohner aussähen. Um sie von der Richtigkeit meiner Ausführungen zu überzeugen, zeigte ich ihnen Photographieen von Berlin, über die sie sich nicht genug wundern konnten; besonders staunten sie über die Grösse der Häuser und Strassen. Dann versprach ich dem König Tagba, auch von ihm ein Bild aufzunehmen und es ihm zu schenken. Hierauf machte der König mit seinem Hofstaat den Anfang und liess sich photographieren. Doch hatte ich unendliche Mühe, den Leuten klar zu machen, dass sie sich nicht bewegen dürften. Natürlich waren unsere Begriffe von Stillstehen verschieden. So hielt ein aufbrausender Bassarimann seinen übrigen Körper vollständig still, so grosse Ueberwindung es ihn auch kostete, 
begann aber, wenn ihm die Prozedur zu lange dauerte, jedesmal heftig zu schelten. Andere verzogen zu meinem Verdrusse das Gesicht. Ja, es war häufig sehr schwer, den Leuten begreiflich zu machen, dass sie nicht einmal die Nase rümpfen dürften. Schliesslich liessen sie sich sogar gern photographieren, auch Kinder, da ich sie meist mit einer Perlenschnur belohnte. Einige überängstliche Personen, welche überhaupt nur durch den Häuptling dazu gezwungen werden konnten, zitterten. Hierbei muss ich besonders eines riesenhaften, kräftig gebauten, mit einem grossen Danegun bewaffneten Bassarikriegers gedenken, der nur auf den kategorischen Befehl seines Häuptlings in Wodande sich photographieren liess und trotz seiner Hünengestalt so am ganzen Leibe zitterte, dass es unmöglich war, ein einigermaassen gutes Bild von ihm zu erhalten. Freilich spotteten hierüber sogar seine Landsleute und mein kleiner Meppo, der mich auf meinen photographischen Exkursionen bediente, jubelte über den tapferen Kriegsmann. Komisch wirkte es, wenn man den Leuten ihre eignen Bilder zeigte. Meist erkannten sie sich nicht, da sie keine Spiegel besassen und sich nie selbst gesehen hatten. Die Umstehenden dagegen erkannten das Bild recht gut und machten den Betreffender darauf aufmerksam, dass dies sein eigenes Bild sei Sein erstauntes Gesicht rief alsdann allgemeines Gelächter hervor. Mitunter führte aber die immer rege Einbildungskraft der Leute auch zu tragischen Scenen; so schrieb eine Frau den Tod ihres Kindes dem photographischen Fetisch des Weissen zu. Mit dem Expeditionsmeister Hoyer, der mich bei meinen photographischen Aufnahmen thatkräftig unterstützte, und meinen Jungen, die nit dem Aufbau und den Handreichungen vertraut waren, zog ich von einem Dorfe zum andern. Schon am Abend vorher wurden im Dunklen die zu exponierenden Platten in die Kassette eingelegt; häufig aber wurde auch wegen Mangel an Zeit am Tage ein Wechselsack benutzt. Es war keine kleine Aufgabe, bei der glühenden Hitze forwährend durch den Kasten zu sehen und die Leute zu stellen, welche sich natürlich so ungeschickt wie möglich benahmen. Eine Kalabasse mit Hirsebier war dann kein unwillkommenes Geschenk und mundete uns mindestens ebensogut, wie bei uns eine ächte Münchener.

Im allgemeinen ist es schwierig, bei dem häufigen Lichtwechsel Erfabrungen die richtige Expositionszeit zu treffen. Meistens sind die Bilder über- über die exponiert. Der günstigste Zeitpunkt für die Aufnahme ist um 4 Uhr photonachmittags oder um 8 Uhr früh. Doch muss man leider wegen Mangel an graphische Zeit auch andere Tageszeiten benutzen. Mein Apparat war ausziehbar und Technik in mit verschiedenen Linsen versehen, so dass ich Landschaften und Bildnisse aufnehmen konnte. Die Hauptschwierigkeit des Photographierens in den Tropen besteht in der feuchten und warmen Witterung und in dem Fehlen 
jeglicher Bequemlichkeit. Wenn die Platten nicht sehr gut in einzelnen Packeten zu höchstens I 2 Stück verlötet sind, werden sie schon vor dem Gebrauch feucht, häufig sogar ganz unbrauchbar, weil sich die Chemikalien zersetzen und die Platten schimmeln. Hat man selbst trockene Platten und lässt sie längere Zeit in den mit Leinwand ausgeschlagenen Kassetten, so kann man an einem feuchten Tage schon des Abends das Muster der Leinwand auf der Platte bemerken. Auch die zum Entwickeln der Platten dienenden Chemikalien zersetzen sich unter dem Einfluss des Klimas. Es ist deshalb ratsam, sie in kleinen Glaspatronen verpackt und in Kisten verlötet mitzuführen. Ich hatte der Einfachheit halber Bromsilber-Platten, sowie Papier und einen Metolentwickler mitgenommen, mit dem ich zugleich die Platten und das Papier entwickeln konnte. Heute würde man vielleicht besser Films benutzen, als die schweren Glasplatten. Der Einfachheit und Reinlichkeit wegen war das Fixiernatron auf meiner letzten Reise als Pulver in kleinen Blechkapseln verpackt; auf meiner ersten Reise hatte ich es als Krystallsalz mitgeführt, wobei ich leider die Erfahrung machen musste, dass es leicht schmilzt und alle mit demselben verpackten Sachen beschädigt.

Grosse Sorge bereitet dem Photographen in Afrika die Beschaffung einer guten Dunkelkammer. Auf einer dauernden, grossen Station kann man sich leicht eine solche erbauen, während man auf Expeditionen nur die dunklen Nächte zu Hilfe nehmen kann. Die leicht gebauten Hütten mit ihrem Grasdach, auf die man häufig allein angewiesen ist, lassen allzuviel Licht herein. Ich benutzte daher mit Vorteil mein Zelt als Dunkelkammer. Die dichte Segelleinwand lässt dann fast gar kein Licht hindurch. Um 7 Uhr begann die Arbeit, nachdem Meppo, der in allen Einzelheiten Bescheid wusste, schon vorher die Säuren und Schalen bereit gestellt hatte. Neugierigen gegenüber erklärte Meppo, dass er mit seinem Herrn heute Abend Fetisch mache. Da man, wie gesagt, in den Tropen sehr leicht überexponiert, ist es ratsam, etwas Brom mitzuführen, um damit das allzu schnelle Erscheinen des Bildes zu verhindern und die Details besser herauszubringen. Grosse Aufmerksamkeit muss man ferner auf das Wasser verwenden, welches oft trübe und zu warm ist. Bei einiger Ortskenntnis kann man gewöhnlich klares Wasser erhalten oder, wenn das nicht gelingt, muss man es durch Filterpapier giessen. Um kühles Wasser zu bekommen, ist es zweckmässig, dasselbe am Abend direkt vor Beginn der Arbeit holen zu lassen. Nachdem die Entwickelung und Waschung unter nicht geringem Schweiss in dem abgeschlossenen, heissen Zelte vor sich gegangen ist, spielt das. Trocknen der Platten noch eine grosse Rolle. Der Anfänger stellt meist in gewohnter Weise die Platten in den dazu angefertigten Gestellen senkrecht auf, um dann 
nach einiger Zeit zu seinem Schrecken zu entdecken, dass die Gelatine bei der Hitze heruntergelaufen ist. Infolgedessen legte ich später die Platten wagerecht ein; um sie vor Staub zu schützen, spannte ich ein Stück Kattun über ein altes Kistenbrett auf einem Gestell von gebogenen Messingstäben, sogenannten Roadbrass, die ich zu Tauschzwecken mitgebracht hatte. Sehr häufig erhält die Gelatine, da bei dem feuchten Klima die Trockenzeit ein bis zwei Tage dauert, durch die allzugrosse Hitze Risse und Blasen. Ist unter diesen erschwerenden Umständen wirklich ein geringer Prozentsatz von guten Platten fertiggestellt, so müssen dieselben vorsichtig in Papier und einer Kiste verpackt und diese noch auf das Sorgfältigste verlötet werden. Natürlich geht wiederum ein Teil durch Bruch auf dem Transport verloren, so dass schliesslich nur wenige die Heimat unversehrt erreichen. In dieser Eeziehung freue ich mich, besonders aus dem fernen Hinterland von Togo, eine Reihe von Aufnahmen unbeschädigt mitgebracht zu haben. Ich will nicht unerwähnt lassen, dass ich ausser einem grossen ausziehbaren Apparat einen kleinen mit unverschiebbarer Brennweite für schnelle Aufnahmen auf dem Marsche für unentbehrlich halte, da man häufig keine Zeit hat, den grösseren Apparat auf- und einzustellen.

Neben dem Entwickeln der photographischen Platten nahmen einen Teil des Abends und der Nacht die astronomischen und Ortsbestimmungen nomische Bein Anspruch. Gewöhnlich orientiert man sich des Abends zunächst nach stimmungen dem oft prachtvollen Sternhimmel und richtet sich auf freiem Felde ein primitives Observatorium ein, welches nur aus einem kleinen vom Gras gereinigten Platz und einigen Pflöcken und Stangen besteht, die von dem Aufstellungspunkt des Instrumentes ausgehend strahlenförmig die Windrose anzeigen. Diese Stangen werden schon am Tage mit Hilfe des Kompasses aufgestellt und so kann man leicht und praktisch die den Meridian und die Vertikale passierenden Sterne zu Zeit- und Breitenbestimmungen beobachten, ohne das Jahrbuch $z u$ benutzen oder eine Rechnung auszuführen. Meppo leistete mir auch hierbei die nötige Hilfe, indem er geschickt die Lampe hielt, um den Höhenkreis zu beleuchten, auch mit der Verpackung der Instrumente vertraut war. Allerdings musste ich ihn öfter, während ich die Sterne identifizierte, durch einen kleinen Denkzettel zur Aufmerksamkeit ermuntern. Wenn man sich eingearbeitet hat, gehen die Beobachtungen auf diese Weise gut von statten; wenn aber das Instrument versagt und sich Staub an dem Fadenkreuz angesetzt hat, ist die Not gross. Gewöhnlich versucht man erst, es vorsichtig zu reinigen; aber der Erfolg ist meist der, dass das äusserst feine Gewebe zerreisst. Die Not macht erfinderisch und man bemüht sich, ein neues Fadenkreuz zu konstruieren. Alle Versuche mit noch so feinen Haaren scheitern, weil die Haare in dem Fernrohr wie Balken erscheinen; schliesslich gelingt es, 
mit einem Spinnwebe ein primitives Fadenkreuz herzustellen. Um einer solchen Verlegenheit vorzubeugen, ist es jedenfalls ratsam, schon von Hause aus einen Ersatz für das Fadenkreuz mitzunehmen. Dieses besteht aus einer kleinen gravierten Glasplatte, welche anstatt des Fadenkreuzes eingesetzt wird. Der Fehler, welcher durch die Strahlenbrechung in der Glasplatte entsteht, kann später von einem Astronomen auf der Sternwarte durch Berechnung beseitigt werden. Praktisch erscheint mir noch die Mitnahme eines Sextanten zur Aufnahme von Monddistanzen für Längenbestimmungen, da diese Methode der Aufnahme von Mondhöhen vorzuziehen sein soll. Um jedoch eine grössere Sicherheit in den Aufnahmen zu erzielen, ist es ratsam, die Beobachtung nur mit Hülfe eines Stativs vorzunehmen.

\section{CHARAKTERISTIK DES BASSARIVOLKES.}

Einen grossen Teil des Tages nahmen die ethnographischen Ermittelungen in Anspruch, welche ich mit vieler Mühe den Bassarileuten und besonders meinem Freunde Napui aus Kore entlockte. Nach ihren Aussagen und meinen eigenen Beobachtungen, sowie denen früherer Reisender, kann ich im grossen und ganzen ungefähr Folgendes über dieses Volk berichten:

Die Gyamba-

Das Bassarivolk ist noch ein ächtes Buschvolk und gehört seiner sprache Sprache nach zu dem Gyamba-Sprachstamm. Derselbe umfasst wahrscheinlich auch die im Norden liegenden unabhängigen Städte Banyeli, Kuntum und Bapure und den Volksstamm der Konkomba, die sich alle untereinander gut verstehen. Besonders heimisch scheint die Sprache in Nagyamba zu sein, weshalb sie wohl den Namen Gyambasprache erhalten hat. Im allgemeinen scheint sie in dem Landstrich vorzuherrschen, der im Süden vom Abo, ungefähr vom 9. Grad nördlicher Breite, im Westen von Oti, im Norden und Nordosten vom Kara und im Osten von den Bergen von Dako begrenzt ist. Jedoch ist es nicht ausgeschlossen, dasss sich diese Sprache auch noch weiter nach Norden erstreckt. Nach Graf Zech wäre auch westlich von diesem Sprachgebiet die Sprache, welche in der Landschaft Tshamba gesprochen wird, zu dem Gyamba-Sprachstamm gehörig.

Anthropologische Eigenschaften der Bassari.
Die Bassarileute sind gut und kräftig gebaut und haben ein grosses Körpermaass. Ihr Typus ist der eines Gebirgsvolkes, kräftig entwickelter Körper mit breiter, gewölbter Brust und ausgebildeter Muskulatur. Der vorgeschobene grosse Unterkiefer, die aufgeworfenen 


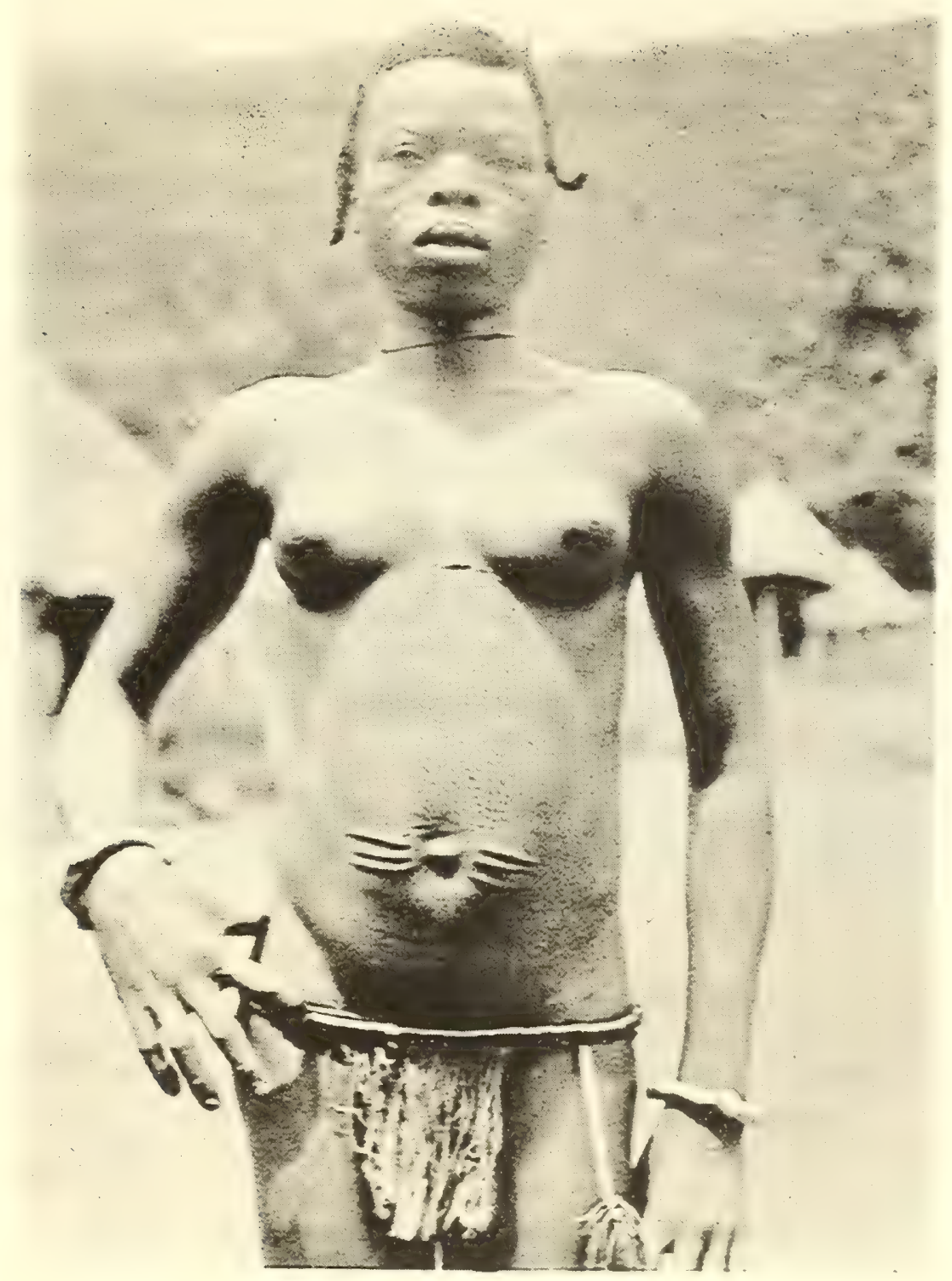

Bassari - Mädchen mit Tätowierung. 

Lippen und die breite Nase verleihen dem Gesicht ein prognathisches Aussehen. Die Männer haben nicht selten einen spärlichen Bartwuchs, dem sie die Form eines struppigen Knebelbartes geben. Im ganzen machen die jungen Männer mit ihrer kraftvollen Gestalt keinen schlechten Eindruck. Sie altern jedoch verhältnismässig schnell und Leute von t5 Jahren sind schon sehr gebrechlich, die vollen Körperformen schwinden, der charakteristische Knochenbau des Gesichts tritt mehr hervor, die Haut legt sich in Falten, die Augen werden häufig trübe und das Sehvermögen hat in diesem Alter bereits sehr gelitten. Der

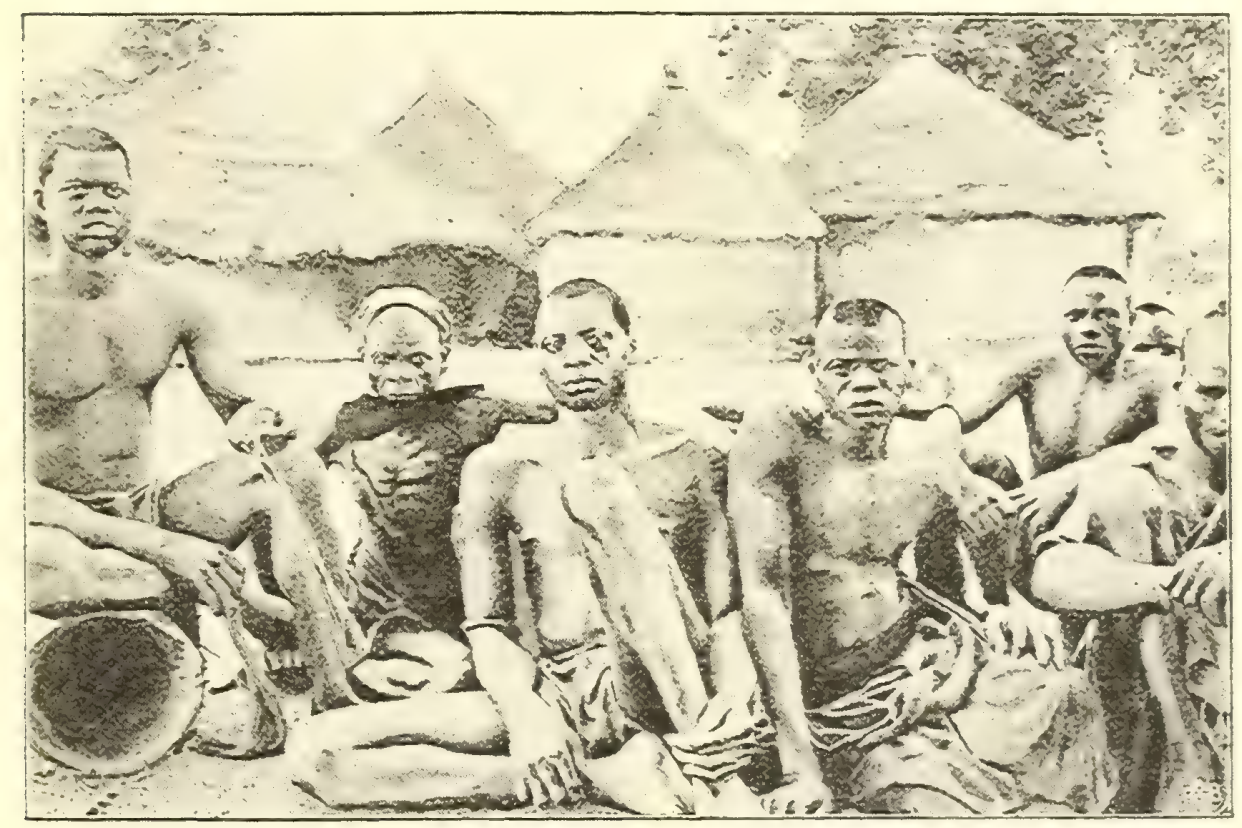

Bassari-Männer.

Kopf wird dagegen äusserst selten kahl, obwohl das Haar im hohen Alter ergraut. Die Leute werden selten über 5o Jahre alt. Die Mädchen mit ihren vollen Formen wirken ganz gefällig, während die älteren Frauen mit ihren runzligen Gesichtern und langen Brüsten geradezu hässlich sind. Auffallend sind gerade bei den Bassarifrauen die unverhältnismässig grossen und schlaff herunterhängenden Brüste, wahrscheinlich eine Folge des jahrelang fortgesetzten Säugens. Die Frauen sind im Verhältnis zu anderen Negerinnen mittelgross.

So schnell die Leute verblühen, ebenso schnell entwickeln sich auch die Kinder. Schon mit I 2 bis I 3 Jahren ist eine Jungfrau vollkommen entwickelt, jedoch ist es Brauch, dass sie erst mit ${ }_{5}$ Jahren heiratet. Auffallend sind 
bei den Kindern die häufig unverhältnismässig grossen Bäuche, welche wahrscheinlich von der aufschwemmenden Yams- und Hirsenahrung herrühren.

Die Tāto- Die eigentlichen Stammeszeichen der Bassarileute sind je ein Querwierung der schnitt oberhalb und parallel der Nasenlippenfalte. Da aber die Bassari-

Bassari. leute wegen ihres räuberischen Wesens und des Abfangens von Sklaven bei den Nachbarvölkern berüchtigt sind, fürchten sie in der Fremde erkannt und zu Sklaven gemacht zu werden, und lassen die Stammeszeichen oft ganz fort. Ausser den angeführten Querstrichen wird häufig

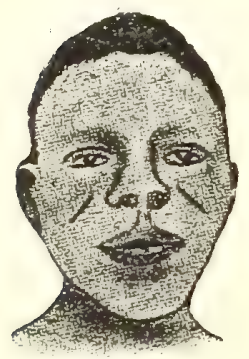
nur ein Querstrich auf der einen Backe gemacht, auch werden drei bis vier Längsstreifen von der Schläfe bis zum Mundwinkel getragen. Es sind dies die bekanntesten Stammeszeichen, wie sie in den Temulandschaften üblich und auch bei der Königsfamilie in Sugu

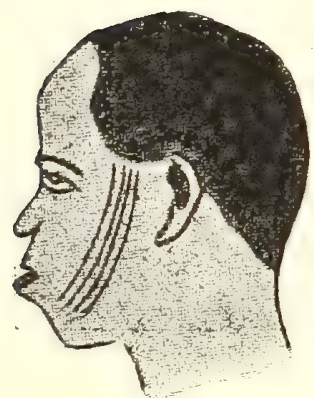

Bassari-Marken und Salaga gebräuchlich sind. Die Frauen tragen ausser dem Stammeszeichen die mannigfaltigsten Tätowierungen als Schmuck. So haben sie nach Art der Gonyaleute Sterne und Schleifen auf der Backe, nicht selten auch direkt über dem Brustbein kreuzweise zu einander liegende Einschnitte, ferner in der Magengegend die kompliziertesten Tätowierungen, welche sich häufig in einer Breite von ro $\mathrm{cm}$ von der Brust bis zum Nabel er-

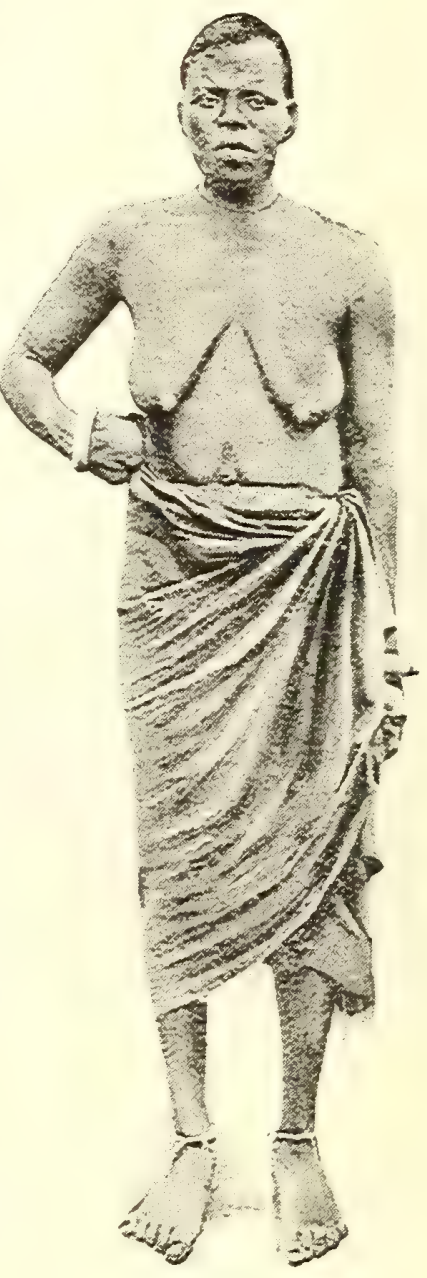

Bassari-Frau. strecken. Dieselbe Tätowierung ist oft auch auf dem Oberarm angebracht. Es ist ein Ornament, welches auch überall an den Hütten vorkommt und besteht aus übereinander liegenden, feinen, kleinen Einschnitten, die zu einem Muster geordnet sind und häufig kleine Quadrate oder andere Vierecke einschliessen. Eine allgemein übliche Tätowierung der Bassarimädchen und Frauen sind drei zu beiden Seiten des Nabels liegende 
Einschnitte. Diese Tätowierung tragen fast alle Mädchen, während ich bei Frauen auch noch oberhalb dieser eigentlichen Tätowierung mehrere wulstige, parallel laufende Einschnitte bemerkt habe.

Die Stammeszeichen der Bassarileute werden schon bei den Kindern im Alter von drei Jahren gemacht. Die Schmucktätowierungen dagegen werden im späteren Alter von berufsmässigen Frauen durch feine Einschnitte mit einem gewöhnlichen scharfen Messer hergestellt. Häufig werden diese Einschnitte noch mit feinem Pulver von Holzkohle ein-
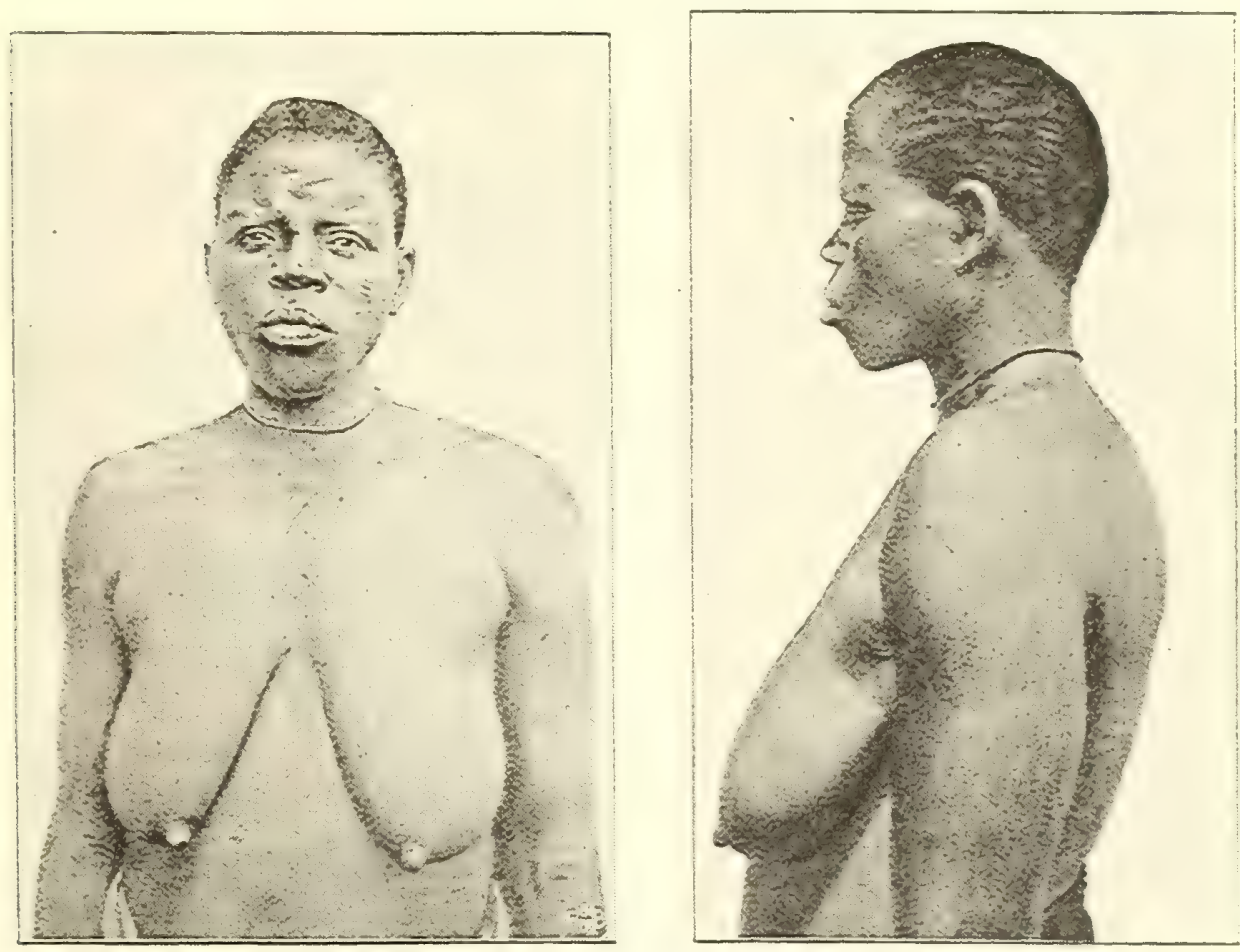

Bassari-Frau, Vorder- und Seitenansicht.

gerieben. Unglaublich ist es, was die Leute in dieser Beziehung der Eitelkeit zuliebe aushalten. So sah ich ein junges Mädchen, welches sich von einer Künstlerin wahre Muster einschneiden liess und, trotzdem sie am ganzen Körper mit Blut überströmt war, keine Miene verzog.

Bei den Bassarileuten sieht man auffällig viele Nabelbrüche. Die- Krankheiten. selben sind häufig so gross, dass sie den ganzen Körper entstellen und dem damit Behafteten bei manchen Arbeiten geradezu hinderlich sind. Wahrscheinlich rühren sie davon her, dass die Nabelschnur bei der Geburt nicht sorgfältig abgeschnitten oder in Ermangelung eines Messers 
abgerissen wird. Ausserdem tritt hier sehr häufig die Filaria sanguinis auf; sie besteht in einer Erkrankung des Zellengewebes der Hodensackhaut; häufig ist der Hodensack so angeschwollen, dass er den Leuten

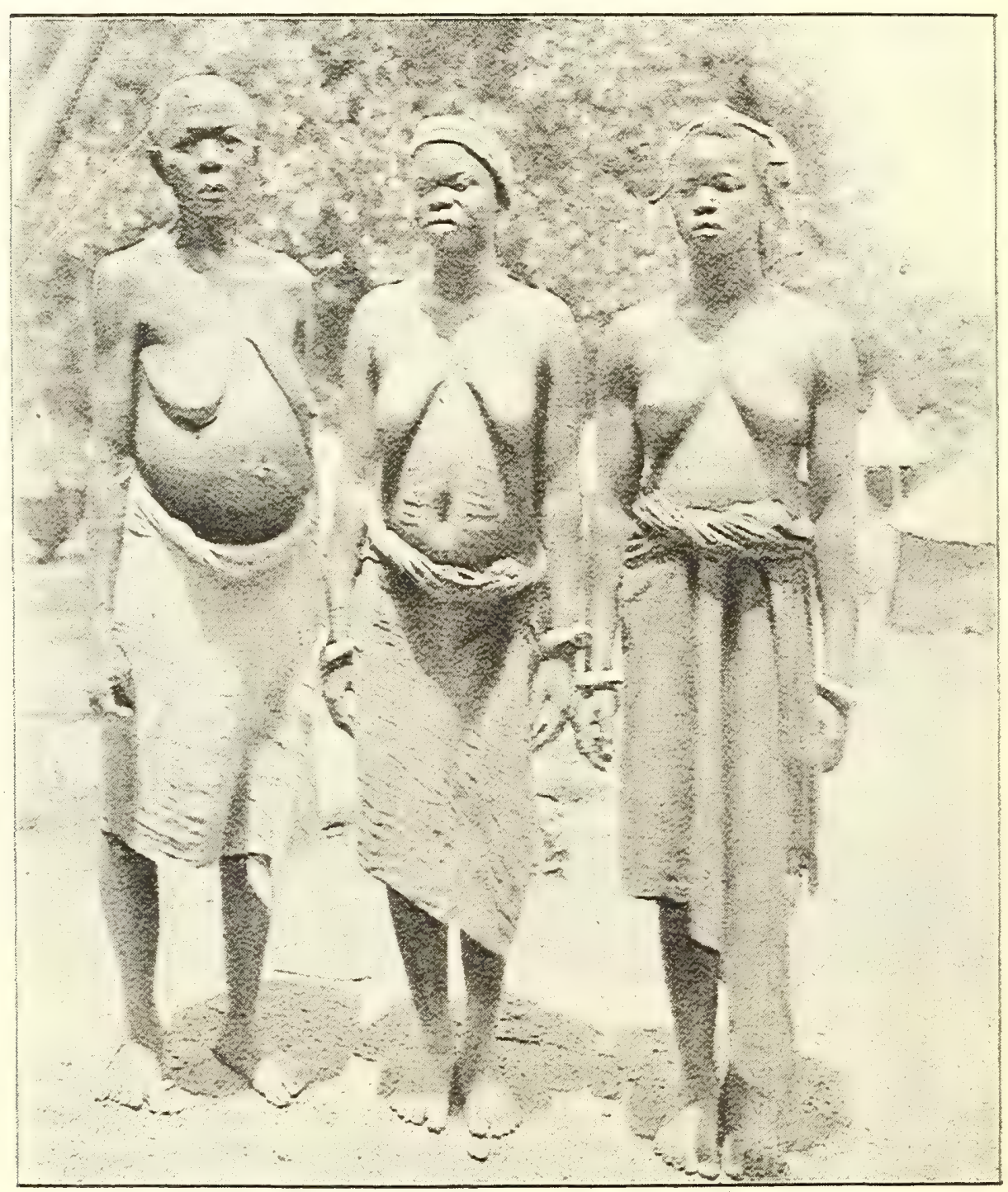

Drei Altersstufen von Bassari-Frauen.

beim Gehen hinderlich wird. Seltener habe ich in Bassari eine andere Form derselben Krankheit, die Elefantiasis, bemerkt, die eine Anschwellung der Füsse bewirkt. Das häufige Vorkommen der Filaria hängt wahrscheinlich mit der unzureichenden Kleidung der Leute zu- 

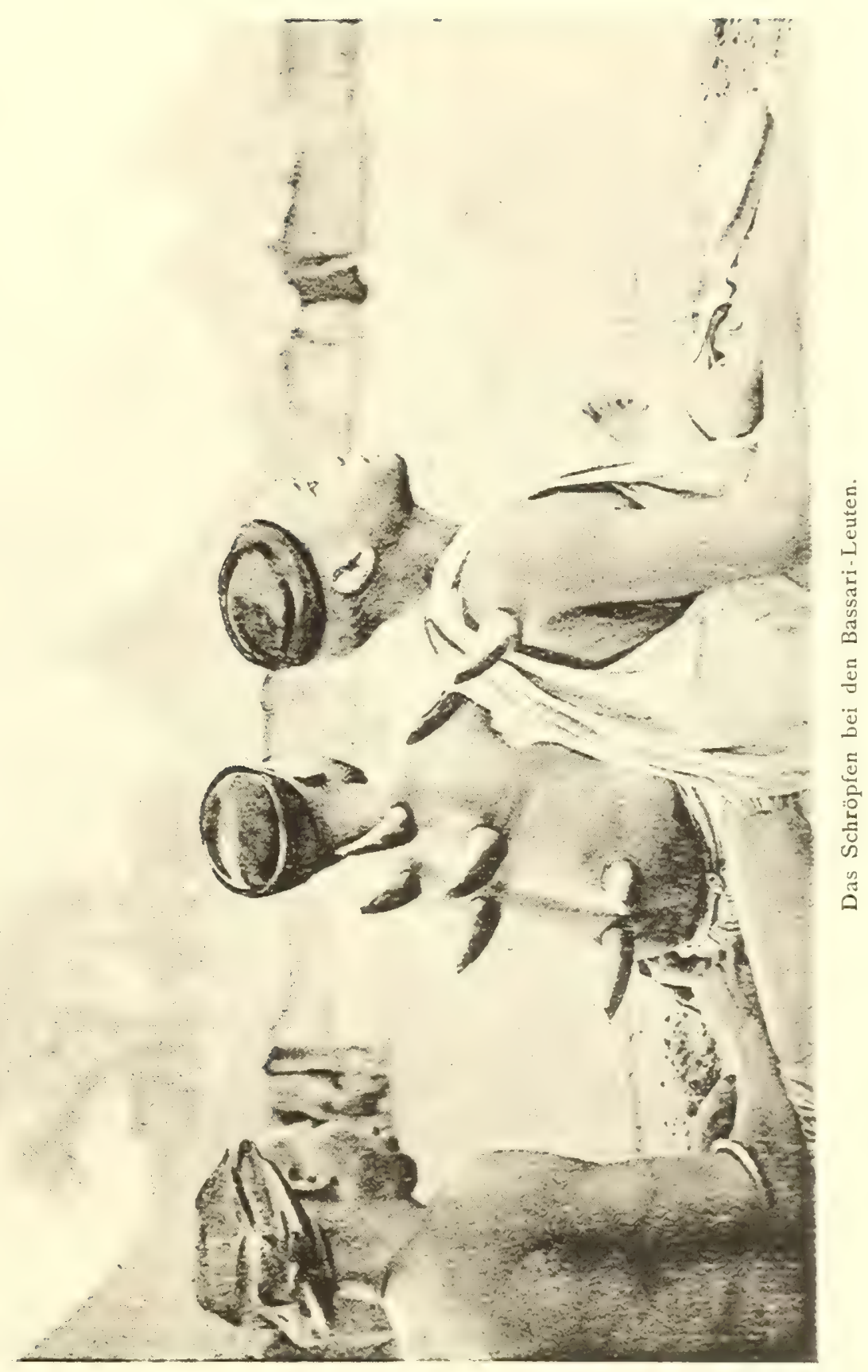

sammen, da der Krankheitserreger durch Moskitos übertragen werden soll. Ab und zu tritt auch bei den Bassarileuten der Kropf auf. Eigentümlich ist, dass die Fetischleute in Bassari nicht zugleich Medizinmänner sind, sondern dass, wie mir der alte Napui erklärte, nur weitgereiste Leute die ärttliche Praxis ausüben. Häufig sind es herumreisende mohamedanische Barbiere. Interessant war es mir zu sehen, wie die Leute Schröpfköpfe setzen. Ich hatte Gelegenheit, einen eingeborenen. Arzt, welcher zwei Personen zugleich bediente, bei der Arbeit zu beobachten und zu photographieren. Auf dem Rücken der Patienten wurden kleine Einschnitte gemacht, dann wurde ein abgeschnittenes Kuhhorn auf die Wunde gedrückt, durch das an der Spitze befindliche Loch das Blut angesaugt und schliesslich der luftverdünnte Raum an der Spitze des Hornes durch Baumwolle und Wachs abgeschlossen. So wurden 4-6 Schröpfköpfe gesetzt; das Ganze machte einen drolligen Eindruck, da die Leute aussahen, als wenn ihnen überall aus dem Rücken Hörner hervorsprossten. Bei Geburten werden auch Fetischpriester angerufen und verabfolgen den schwangeren Frauen Sympathiemittel.

Die Haartracht der Bassarileute ist eine mannigfaltige. Einige Männer tragen das Haar kurz geschnitten, andere haben den Kopf bis auf einen Haarkreis in der Haarwirbelgegend rasiert, wieder andere lassen nur einen Schopf oberhalb der Stirn oder einen Haarkamm längs der Kopfnaht stehen. In dem Schopf tragen die Leute mitunter einen Holzkamm. Frauen tragen das Haar meistens kurz geschoren und darüber ein turbanartig gewundenes Tuch. Junge Mädchen dagegen pflegen das Haar zu beiden Seiten der Schläfe abzuteilen und tragen dann die einzelnen Haarpartieen in drei Zöpfchen geflochten, welche zu beiden Seiten der Ohren und über den Nacken herunterhängen. Knaben gehen gewöhnlich kurz geschoren, während bei kleinen Mädchen mehrere Scheitel ausrasiert werden, wobei längs der Kopfnaht drei kreisförmige Haarbüschel stehen bleiben.

Die Reinlichkeit der Bassarileute lässt trotz Waschens und Badens viel zu wünschen übrig, da sie die Seifenfabrikation nicht selbst verstehen. Die Seife wird von hier ansässigen Tshautsholeuten oder aus anderen Gegenden eingeführt, was ihren Preis ganz ungewöhnlich erhöht, so dass nur reichere Leute sich diesen Luxus gestatten können. Die Leute haben daher viel Ungeziefer, von welchem sie sich in ihren Mussestunden gegenseitig zu befreien suchen.

Die Kleidung der Bassarileute ist im allgemeinen sehr primitiv, Kleidung und da sie selbst keine Weberei betreiben. Nur die ansässigen Tshautsho- Schmuck der leuten weben, aber meistens werden die gewebten Tücher aus den BassariTemulandschaften Dako oder Bafilo nach Bassari importiert. In den mănner. genannten Ortschaften wird die Weberei in grossem Maassstabe 
betrieben. Man findet dort häufig Weberkolonieen, wo ro bis 20 Webstühle nebeneinander aufgestellt und zu gleicher Zeit in Thätigkeit sind. Wahrscheinlich besteht aus diesem Grunde die Kleidung der Bassarileute hauptsächlich aus Tierfellen. Nicht unerwähnt möchte ich lassen, dass ich bei einer Karawane, welche aus Banyeli Eisenerz geholt hatte, eine alte Frau mit einem Rindentuch bemerkt habe. Obwohl die Leute angeblich in den Farmdörfern Rindenzeug herstellten, so konnte ich leider, da sich ihre Angaben widersprachen uud ich nur in diesem einen Falle in Bassari Rindenzeug gesehen haben, nichts Näheres darüber feststellen.

Die sogenannten Bigmen oder Familienoberhäupter tragen ein langes Leoparden-, Kuh- oder Schaffell, welches als Schurz einfach vorn herunterhängt und mit.den Vorderfüssen über der Schulter verknüpft ist. Die Schmiedemeister erkennt man dadurch, dass sie das Schurzfell über der Schulter nicht selten mit einer schweren eisernen Kette schliessen. Mitunter wird unter dem grossen Fell ein kleines gegerbtes Schaf- oder Ziegenleder zur Bedeckung der Scham getragen, welches um die Hüften gebunden und nach hinten gezogen wird. Jüngere und ärmere Leute tragen meist nur dieses kleine Schurzfell oder auch die bekannte dreieckige, schwarz-weiss-blau gestreifte Baumwollschürze aus Tshautsho. Sklaven gehen häufig nur mit einem kleinen Suspensorium bekleidet, das aus einem Baumwolllappen 'besteht. Bei den Männern ist die phrygische Mütze beliebt, welche wie ein Beutel herabhängt und zugleich zur Aufbewahrung von Kaurimuscheln oder sonstigen kleinen Gegenständen benutzt wird. Nicht selten tragen auch die Bigmen als Besonderes Abzeichen ihrer Würde einen grossen geflochtenen Haussa-Sțrohhut, dessen hohes Alter kaum seine eigentliche Herkunft erkennen lässt.

Häuptlinge, deren es nur wenige und für einzelne Orte giebt, da im allgemeinen die Aeltesten der Familienväter gemeinsam die Funktionen des Häuptlings ausüben, tragen mitunter ein Haussahemd und dazu wie im Thautshoreich eine Strohkappe ohne Krempe, die kronenartig aussieht, und, wie schon früher erwähnt, mit Amuletten von Tuch oder Felltäschchen benäht ist.

Sandalen sieht man selten. Sie bestehen meistens aus einer Sohle und werden mit kleinen Riemen an der grossen Zehe und dem Fussgelenk befestigt. Sie werden gewöhnlich vọn den Schmiedeleuten bei der Arbeit getragen. Zu dem primitiven Anzug der Bassarileute kann man. eigentlich auch einen kleinen Fellsack rechnen, den jeder einigermaassen wohlhabende Bassarimann bei sich führt und zur Aufbewahrung der unvermeidlichen Schnupftabaksdose und der Scheidemünze benutzt. 

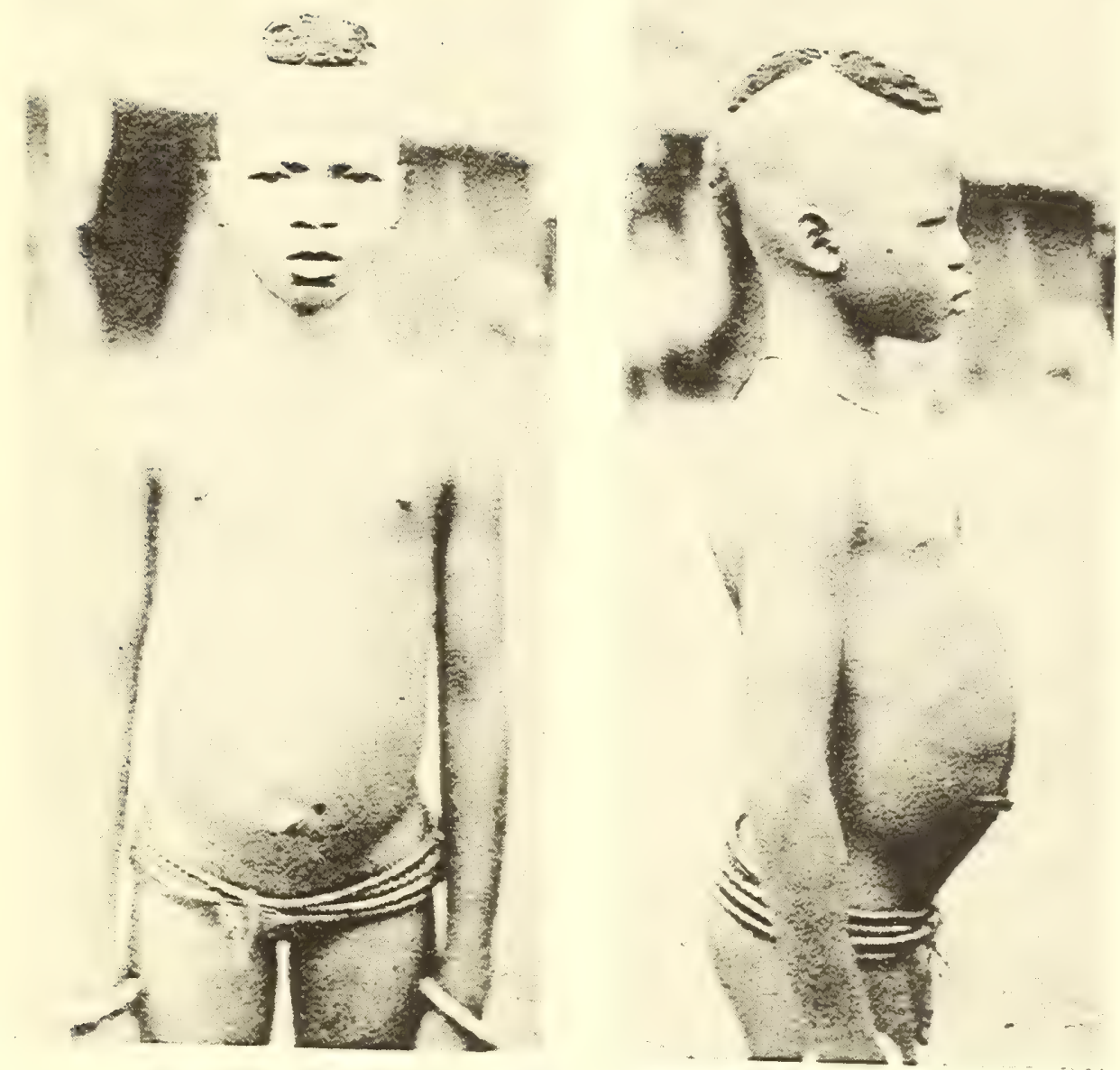

Haartracht Kleines Bassari-Mädchen.

Voulcransicht scitenan iuht 

Als Schmuck tragen die Männer häufig an dem Oberarm in Bassari geschmiedete, eiserne Armringe, die nicht selten mit Messingstäben zusammengedreht sind; vielfach werden auch glatt geschnitzte Holzreifen dazu verwendet. Vornehme alte Männer tragen oft eine Anzahl von Eisen- oder starken Messingringen um das Handgelenk. Reiche Leute ersetzen diese Metallringe durch einen aus Elefantenhaut geschnittenen Ring, der aus der Sohle verfertigt wird. Selten findet man bei den Männern Ohrringe, welche, wie bei uns, in den durchstochenen Ohrläppchen getragen werden und aus Grashalmen, kleinen Perlschnürchen oder Messingringen bestehen. Ebenso selten tragen sie eine kleine Schnur um den Hals, an der einige Perlen, wie Groundbeads aufgezogen sind.

Die Bekleidung der Frau besteht hauptsächlich aus einem einzigen, Kleidung und um die Hüfte geschlungenen Tuche, das von Tshautsholeuten angefertigt Schmuck der ist, und meistens ungefärbt in den Handel kommt. Zum grössten Teil werden jedoch diese Tücher von den Bassarifrauen nachträglich mit Rotholz gefärbt, indem sie die Rinde des Baumes zerschneiden, zerstossen und durch Zusatz von Wasser eine rotbraune Farbe herstellen. Diese Farbe scheint bei den Bassarileuten beliebt zu sein, da auch junge Mädchen sich zum besonderen Schmuck ihre Haut damit färben. Seltener werden weisse Tücher getragen, während bei Trauer dunkelblaue Tücher angelegt werden sollen. Ihre Handgelenke schmücken die Frauen mit schweren Messingringen, während sie um den Hals eine Perlenschnur aus den beliebten Groundbeads, unechten Korallen, roten europäischen Glasperlen oder Achatperlen vom Niger und von Kirotashi tragen. Vornehme Weiber stecken rote und blaue längliche Perlen als Pflock in die Ohrläppchen; ärmere verwenden zu diesem Zweck einen Grashalm oder ein Stück rot gefärbtes Hirsemark. Die jüngeren Mädchen gehen nur mit einer kleinen Hüftschnur bekleidet, von welcher eine aus Baumwolle hergestellte handbreite Franzenschürze herunterhängt, welche die Scham bedeckt.

Die Hüftschnüre bestehen aus den in den Temuländern rund geschliffenen Palmenkernen, auch aus den schon früher erwähnten, weissen, geschliffenen Muschelschalen. Oft werden als Schmuck zwei bis vier Hüftschnüre getragen, zu welchen auch mitunter europäische Glasperlen verwendet werden. Die Franzenschürze, welche mit einer Baumwollschnur befestigt wird, besteht aus einzelnen, dunkelblau gefärbten, zusammengedrehten Baumwollschnüren. Als besonderer Schmuck hängt manchmal an der Seite eine kleine Troddel herab.

Kinder, sowohl Mädchen wie Knaben, gehen vollkommen nackt, nur ausnahmsweise tragen kleine Mädchen ebenso wie die heiratsfähigen Frauen, Schmucksachen, etwa eine kleine Palmkern- oder Muschelschnur oder eine Perlenkette als Hüftschnur. 

Speerspitzen werden vergiftet. Zum Nahkampfe dienen ihnen Messer, Bassarileute. wobei das bekannte Griffmesser mit dem O-Griff gebraucht wird; häufig haben sie auch ein kleines, gebogenes Messer, welches mit einem Holzgriff versehen ist und in einer Leder- oder Fellscheide an einer Schnur über der Schulter getragen wird. Das Messer mit dem O-Griff wird dagegen meistens in der Hand getragen und soll mit zum Spannen des Bogens dienen. Die Pfeile sind gewöhnlich mit Widerhaken versehen und werden in einem kleinen Köcher aus Holz oder Fell aufbewahrt, der manchmal mit Kuhoder Büffelschwänzen verziert oder bemalt ist und über der Schulter hängt. Die Speere sind verschieden gearbeitet, teils mit Widerhaken, teils mit breiten, länglichen, schön ciselierten Spitzen, welche an einem etwa $\mathrm{I}^{1} / 2$ Meter langen Holzschaft befestigt sind. Letzterer ist durch eine eiserne Zwinge am untern Ende abgeschlossen. Zum grossen Teil sind aber schon von der Küste her Steinschlossflinten eingefuhrt.

Der grosse Bogen besteht aus hartem Holz und wird durch eine Sehne aus Darmseiten gespannt. Die Spannkraft wird häufig noch durch eiserne Ringe und Schienen, sowie durch Umwickeln mit Schlan-

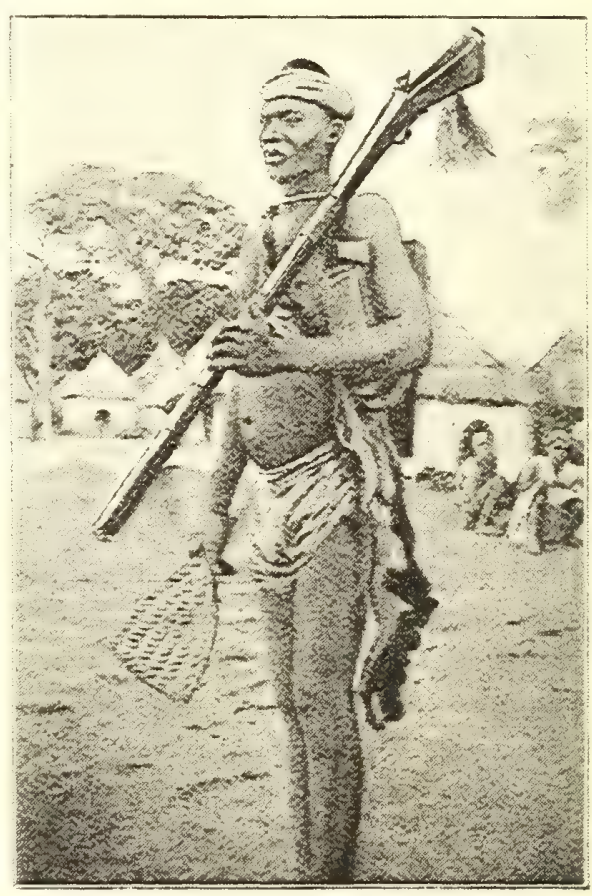

Ein Bassari-Krieger mit Steinschlossgewehr. gen- oder Eidechsenhaut erhöht.

Das Pfeilgift wird aus bestimmten Pflanzen, wahrscheinlich aus einer Strophantusart, von den Aeltesten, den Familienoberhäuptern, auf dem Bassariberge hergestellt. Der Ort der Bereitung wird vor den Frauen geheim gehalten; auch dürfen die Männer, welche bei der Giftbereitung thätig sind, während der Zeit nicht in Berührung mit Frauen kommen.

Um die Wirksamkeit des Giftes zu prüfen, werden Hühner geschossen, die nach Angabe meines Vertrauensmannes später gekocht und im festlichen Schmause bei Bier verspeist werden sollen. Wahrscheinlich ist mit dem Geniessen der Hühner der Aberglauben verknüpft, dass sie vor feindlichen Geschossen schützen. 
Die Hütten der Bassarileute sind, wie fast im ganzen Hinterlande, Gehöfte und rund und mit einem kegelförmigen Grasdach versehen; sie sind im Durch- Hütten in schnitt 3 bis $4 \mathrm{~m}$ breit, die Wände besitzen eine Höhe von etwa $\mathrm{r}^{2} / 2 \mathrm{~m}$, Bassari. während die ganze Hütte mit dem Grasdach, welches häufig in eine hohe Spitze ausläuft, nicht höher als 3 bis $4 \mathrm{~m}$ ist. Ganze Dorfviertel sind miteinander verbunden und nach der Aussenseite vollkommen abgeschlossen. Die Eingänge zu den einzelnen Gehöften liegen an der Dorfstrasse oder dem Dorfplatz. Ein grosses Gehöft ist wieder durch eine $\mathrm{I}^{2} / 2 \mathrm{~m}$ hohe

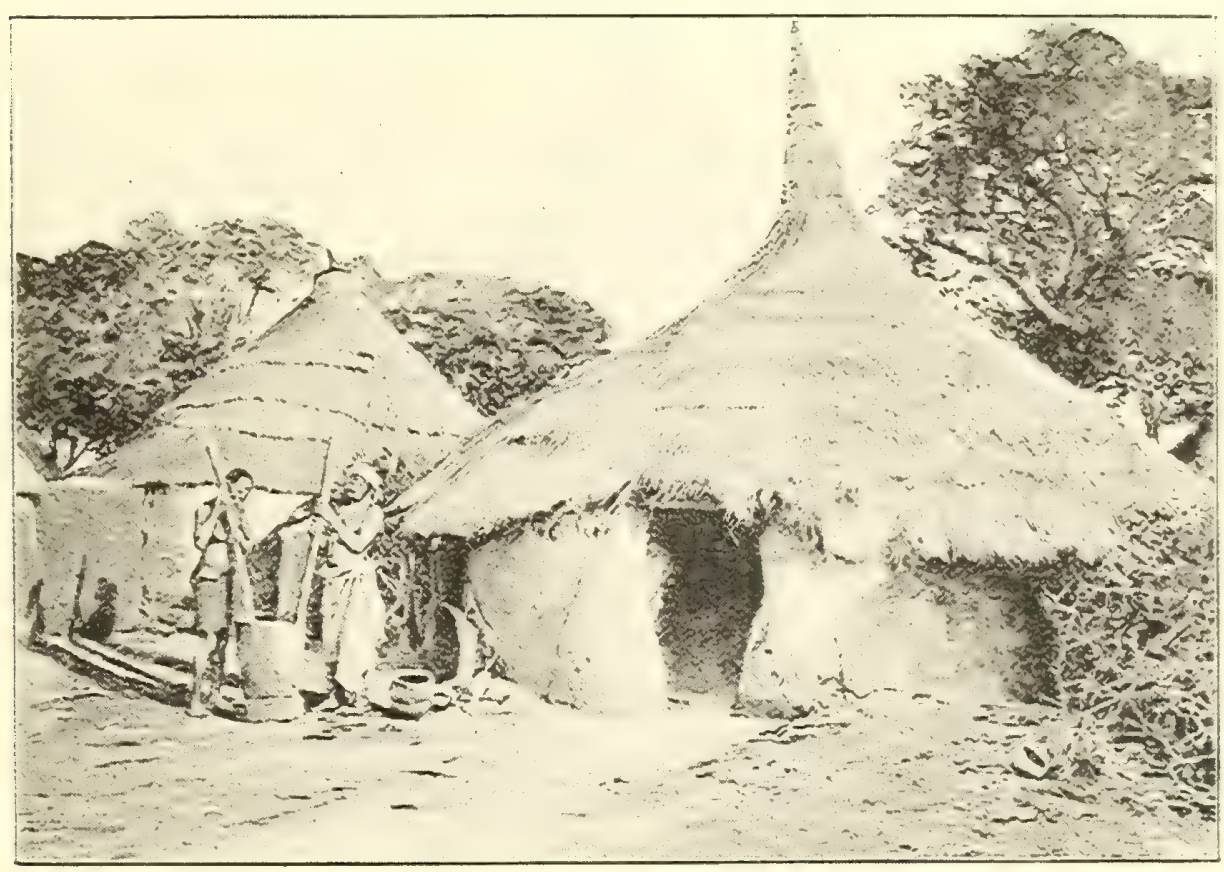

Eingangshütte in ein Håuptlings-Gehöft in Bassari.

Lehmmauer in einzelne Höfe geteilt, welche aus 3 bis 5 Hütten bestehen und von einer ganzen Familie bewohnt werden. Der Eingang in ein solches Gehöft führt durch die Vorhalle einer besonders grossen Hütte. Er ist $\mathrm{I}^{\mathrm{x}} / 2 \mathrm{~m}$ hoch und reicht bis an das Grasdach heran. Aus dieser Vorhalle gelangt man in den ersten Hof, um welchen die Hütten mit $3 / 4 \mathrm{~m}$ hohen und $1 / 2 \mathrm{~m}$ breiten, ovalen Eingangslöchern kreisförmig gruppiert sind. Durch ein kleines Loch in der Hofmauer gelangt man wiederum in einen anderen Hof, und so fort, bis man sich in einen Irrgarten versetzt glaubt. Die kleinen Eingänge waren uns Europäern anfangs lästig, da wir nur auf allen Vieren hineinkriechen konnten und uns Kopf, Arme und Beine stiessen. Natürlich wollten wir klüger sein und vergrösserten sie nach 
Bedürnis. Als aber die Regenzeit mit ihren Stürmen und Tornados einsetzte und uns das Wasser in die Hütten lief, sowie der Sturm ungemütlich darin hauste, sahen wir die Zweckmässigkeit dieser nicht gerade bequem angelegten Pforten ein. Die Eingänge sind etwa $40 \mathrm{~cm}$ über dem Erdboden angebracht, damit die Hütte nicht überschwemmt werden kann. Uebrigens kollidieren auch die Bassarileute trotz ihrer Geschicklichkeit mit den Lehmmauern, was wir daraus entnahmen, dass die Eingänge häufig unten und oben abgestossen waren. Die Hütten

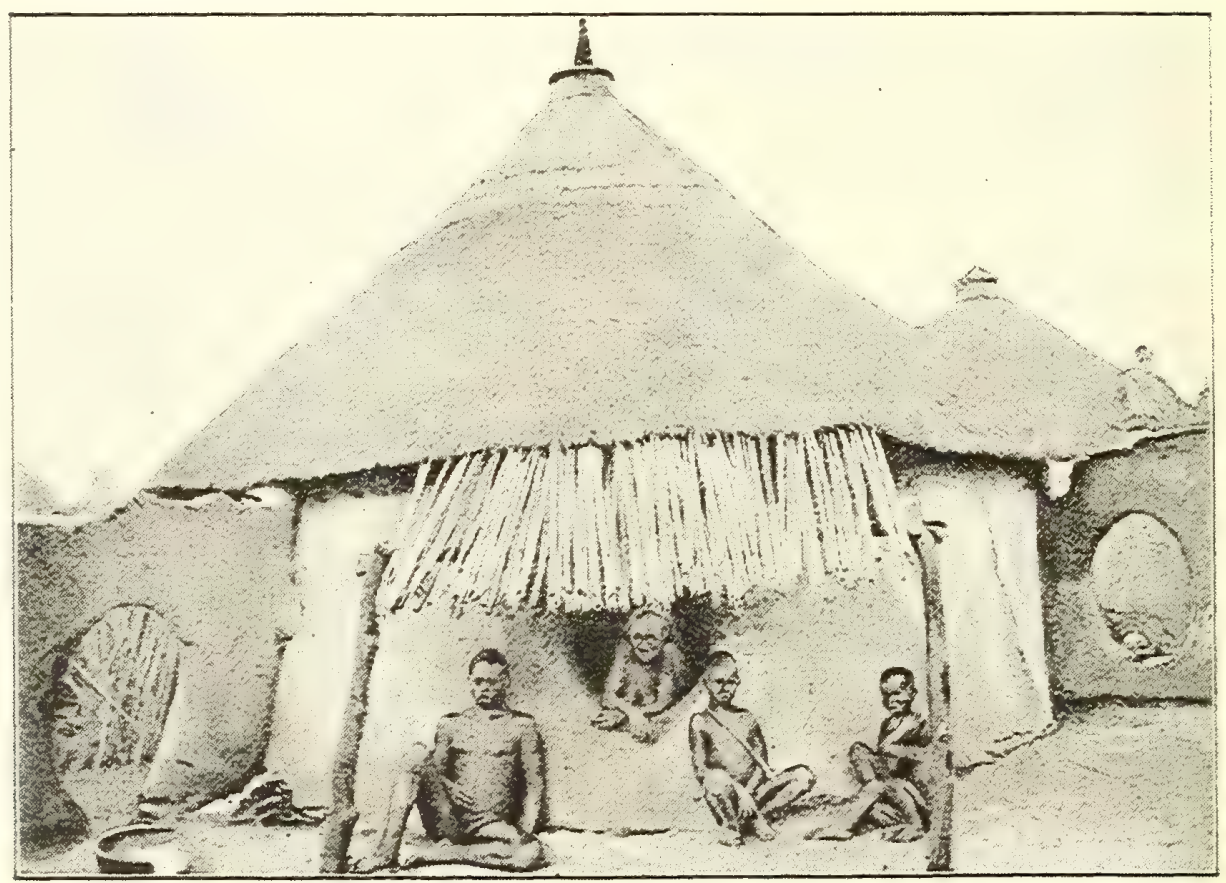

Das Innere eines Bassari-Gehöftes.

sind im allgemeinen gut und dauerhaft gebaut. Der Boden ist zu einer festen Tenne gestampft.

Verzierungen an den Hütten, sogenannte Graffiti.
An den Aussenwänden sind häufig merkwürdige Verzierungen angebracht. Diese Ornamentik, das sogenannte Graffito, war schon bei den alten Völkern gebräuchlich. Die eigentümlichen Muster bestehen aus kleinen, sich kreuzweise schneidenden Linien, die wiederum in einem Kreuzverbande Vierecke abschliessen. Sie sind mit scharfen Instrumenten auf schwarzem Grunde in die Lehmwand eingeritzt. Wie wir gesehen haben, kehrt dieselbe Form auch bei der Schmucktätowierung wieder, ebenso finden sie sich auf den Kalabassen der Bassarileute. Die Kegeldächer sind häufig noch oben an der Spitze umwunden und von einem 
bodenlosen Topf umgeben, der den Dachfirst zusammenhält. Die Häuptlingshütten mit den hochgewundenen Dachspitzen tragen nicht, wie in den Temulandschaften, ein Straussenei, sondern werden von einem kronenartigen, aus Holz geschnitzten Aufsatz geschmückt, der an ein gotisches Türmchen erinnert. Die grossen Eingangshallen besitzen mitunter eine Art Veranda, welche durch das weit übergebaute Dach gebildet wird. Nicht selten findet man bei grösseren Familienhütten ein kleines Schattendach, welches aus einigen Bambusstäben vor dem Ein-

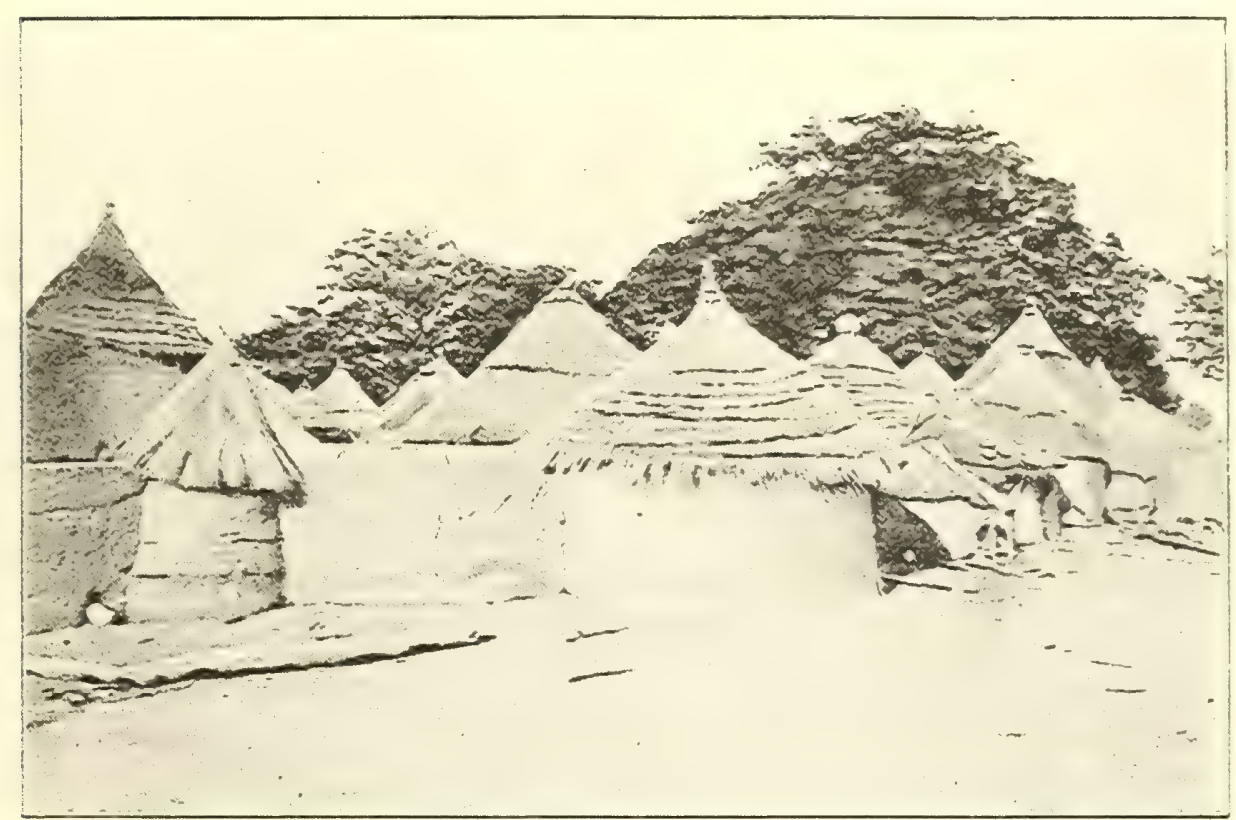

Rückseite eines Bassari-Dorfes,

gang errichtet ist. Bei den Häuptlingsgehöften ist die Vorhalle häufig durch einen Vorbau von grossen Säulen aus Lehm geziert.

In jedem Gehöft sind kleine runde Hütten eingebaut, welche als Ställe für die Hühner und das Kleinvieh dienen. Ausserdem finden wir, wie in Wodande und Epassiba, Viehkrale, welche aus grossen FelsStälle und Kornspeicher. blöcken hergestellt sind, auf denen zum Schutze eine Menge Dornenzweige liegen. Diese Viehkrale lehnen sich meistens direkt an das Gehöft an. Der Eingang in dieselben führt ebenfalls durch die Vorhalle und das Gehöft. Die Kornspeicher sind zumeist ebenso gebaut wie in den Temulandschaften und haben die Form von zwei aufeinander gestülpten Kegeln. 
Die heidnische Religion in Bassari

Die Bassarileute sind sämtlich Heiden. Mohamedanische Niederlassungen, wie Haussakolonieen, siedeln sich hier nicht an, da die Bassarileute sie durch ihr räuberisches Wesen vertreiben. Nur einzelne mohamedanische Händler aus Tshautsho, sowie durchreisende Haussahändler halten sich vorübergehend in Bassari auf. Obwohl mir die Bassarileute sagten, dass sie nur einen Gott, Unombotte, hätten, so wird derselbe wohl, wie Mavu bei den Evhes, kleinere Nebengötter haben, die den Verkehr mit den Menschen durch die Fetischpriester ver-

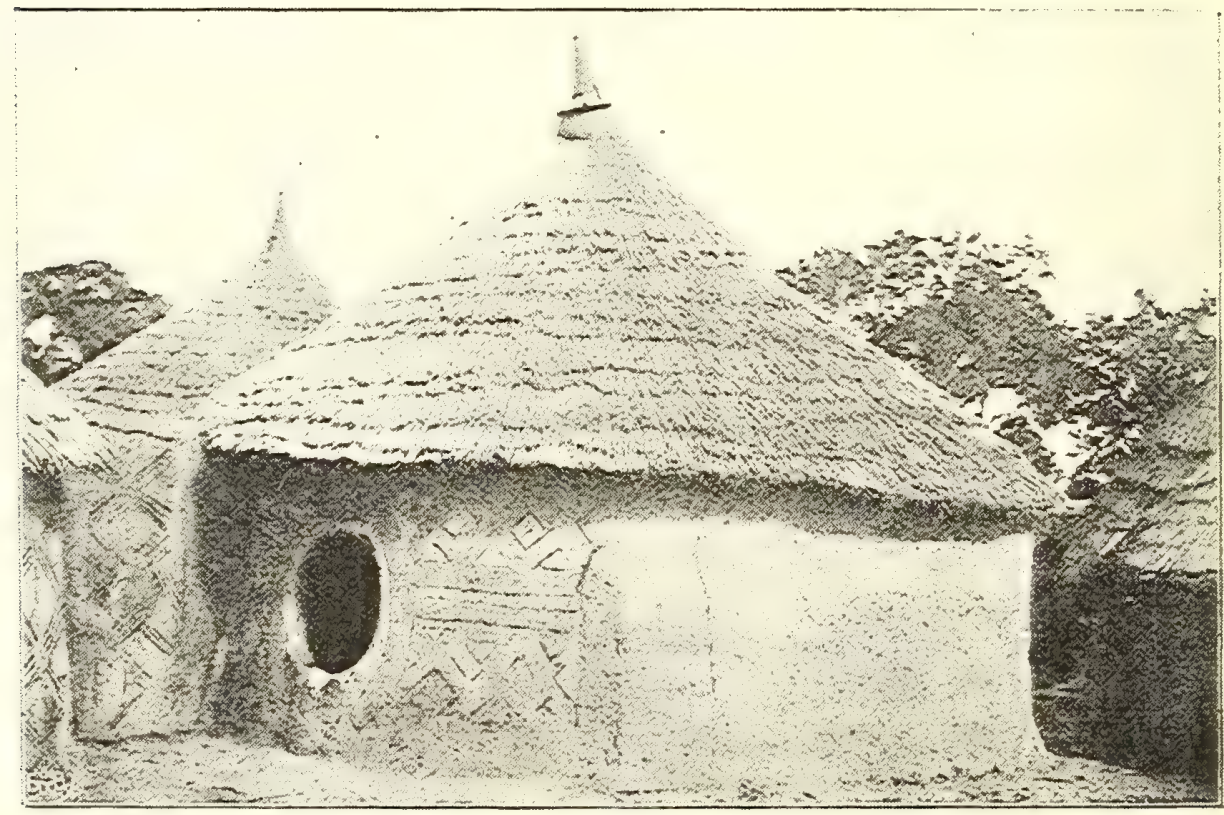

Die Graffito-Verzierungen an den Bassari-Hütten.

mitteln. Die Fetischpriester spielen auch hier eine grosse Rolle bei den Gottesurteilen, die ebenfalls mit dem Giftbecher entschieden werden. Ebenso werden sie bei Geburten zugezogen und erteilen der Frau, die gebären soll, Verhaltungsmaassregeln. Auch als Wahrsager haben wir sie auf dem Markt von Bassari kennen gelernt. Eigentumlich ist es, dass in Bassari derselbe Fetischkegel aus Lehm vorkommt, der in Kratyi von den Eingeborenen dem Fetischgott Odente als Opferaltar errichtet wird. Auch in Bassari werden an diesem Fetischkegel weisse Hühner und Schafe geopfert, wie die vielen mit Opferblut an dem Kegél festgeklebten, weissen Federn und die umherliegenden Knochen beweisen. $\mathrm{Ob}$ bei Errichtung dieses Kegels unter demselben Opfertiere oder Menschen begraben werden, wie bei dem 
Fetischkegel des Odente in Kratyi, konnte ich leider nicht feststellen. Im grossen und ganzen sieht man in Bassari, wie überhaupt im Hinterlande von Togo, seltener die symbolischen, fratzenhaften Fetischbildnisse, welche man auf Schritt und Tritt in den Küstengegenden antrifft. Die Bassarileute verlegen den Sitz ihres Fetischgottes in die Schluchten und Gipfel des Bassariberges. Obgleich bei ihren Geburten grausame Gebräuche üblich sind, scheint ihre Religion auf einem höheren Standpunkt zu stehen, als die vieler Küstenstämme. So riefen sie häufig zur

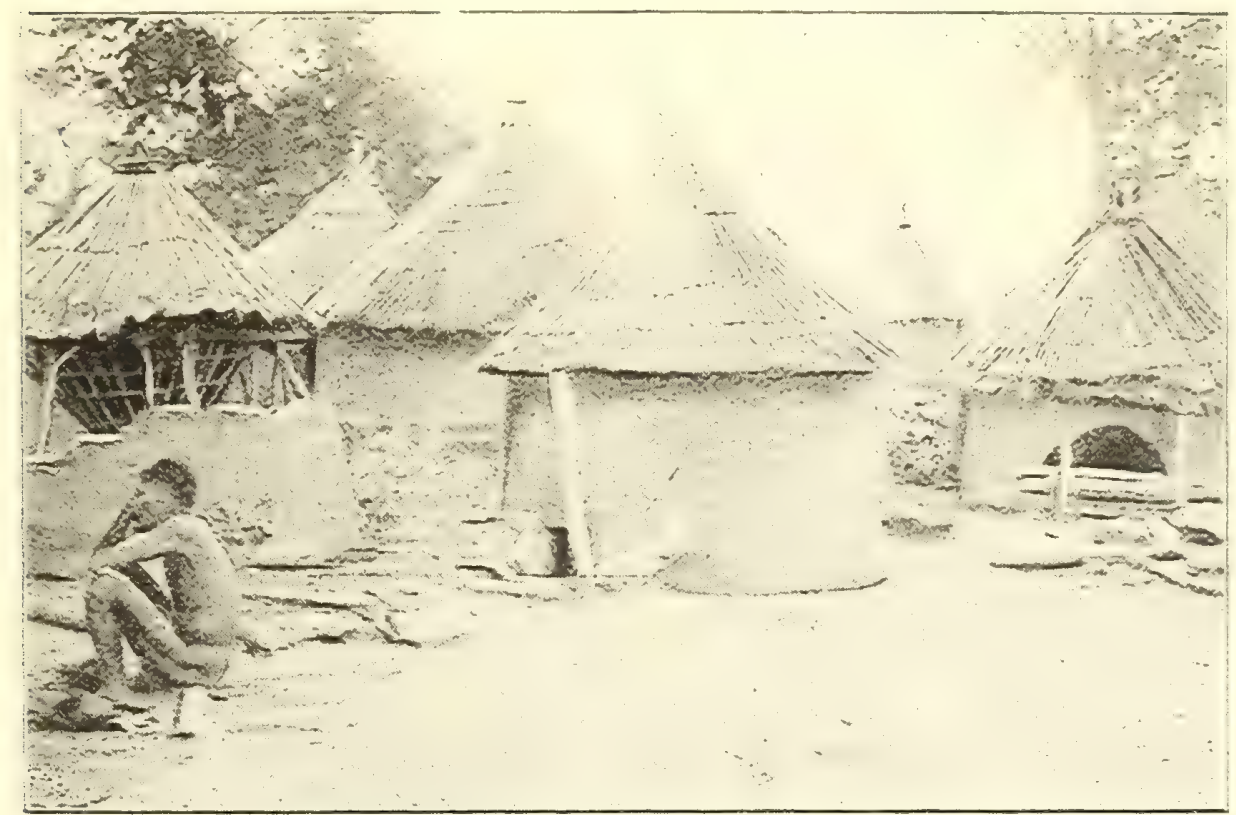

Ställe für Kleinvieh und Kornspeicher in Bassari

Bekräftigung ihrer Aussagen ihren Gott Unombotte an und wiesen mit der Hand nach dem Himmel.

Die Beschäftigung der Bassarileute besteht, abgesehen von mannig- Beschäftigung faltigen Industrieen, im Ackerbau, in der Viehzucht, der Jagd und dem Fischfang. Die grossen Farmen von Kore und Wodande tragen ausser dem Yams, der hier ebenfalls in Häufchen gepflanzt wird, besonders der Bassarileute. Ackerbau. reichlich Hirse. Die Yamsernte scheint, wie in dem Evhegebiet, von der Erlaubnis des Fetischpriesters abzuhängen. Die Hirse wird in drei verschiedenen Arten angebaut, Rispenhirse und Kolbenhirse mit weisser und gelber Frucht. Ausserdem werden Erdnüsse, Bohnen, Sesam und in grossen Mengen Okro und Taro gepflanzt; letztere Frucht habe ich hier zum ersten Male angetroffen. Im September sieht man überall 
dicht an den Dörfern kleine Beete, auf welchen Tabak gepflanzt wird, der sich in kurzer Zeit zu grossen Blättern entwickelt. Die Bearbeitung geschieht mit einer breiten eisernen Hacke, die in den Schmiedewerkstätten von Naparba hergestellt wird. Eine runde Eisenplatte wird etwas gebogen und in einem dazu gefertigten Holzstiel gesteckt. Zum Roden und Jäten dient ebenfalls eine Axt oder meisselförmige Hacke, die eine Holzgabel als Stiel umfasst.

Die Farmen werden vielfach von Sklaven bearbeitet und in Stand gehalten. Häufig sieht man, während sie mit Hacken und Jäten

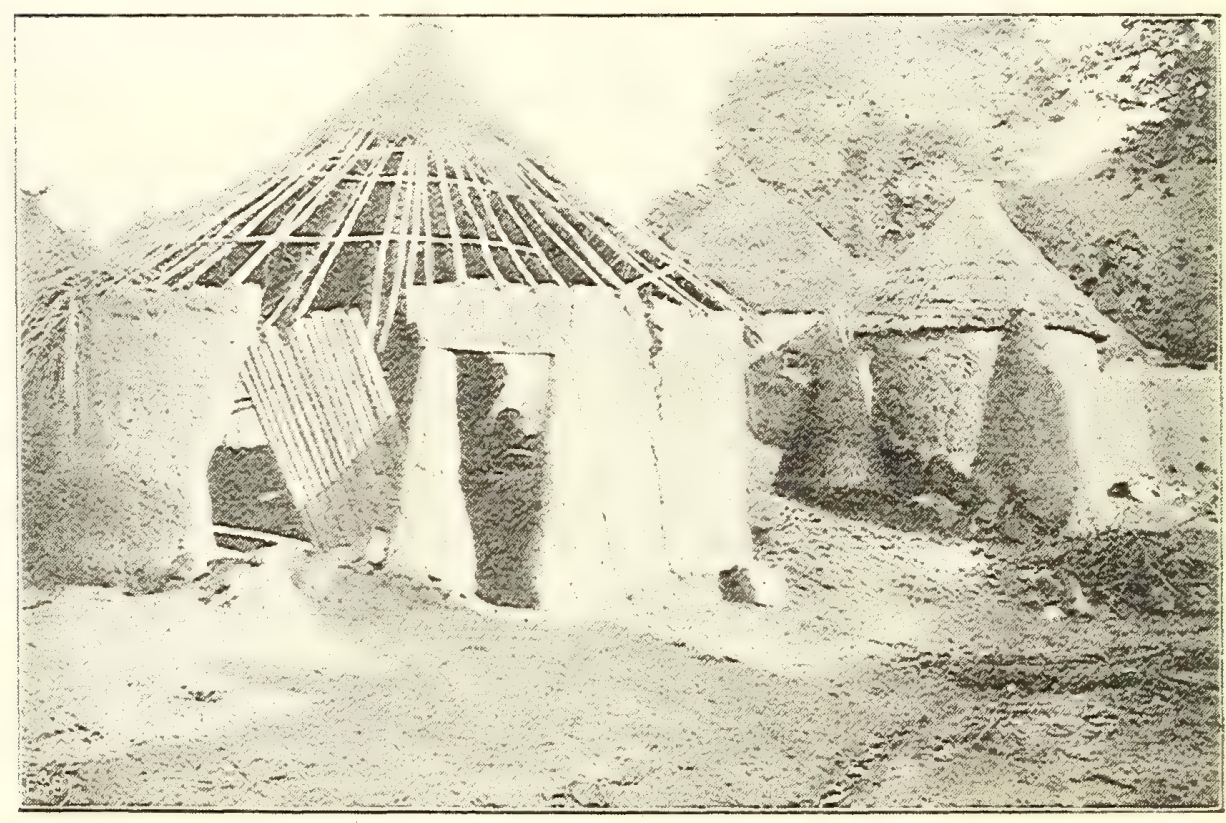

Eine zerfallene Hütte und Fetischkegel in Bassari.

beschäftigt sind, dass ihnen ein Haushuhn folgt, welches Larven und Würmer aufpickt. Dieses bildet das einzige Eigentum des Sklaven und wird ihm von seinem Herrn zur weiteren Aufzucht geschenkt. Es wird von dem Sklaven gewöhnlich in einem kleinen, besonders dazu aus Piassawa geflochtenen Korbe mit auf die Farm genommen, wo es seine Nahrung findet.

DieViehzucht Die Viehzucht ist namentlich in den westlich gelegenen Gegenden und die Fulbe zu Hause, wo die schönen Viehweiden von Bassari bei Wodande und in Bassari.

Epassiba liegen. Ausser Schweinen, Schafen und Ziegen züchten die Bassarileute eine kleine stämmige Rinderrasse. Die Pflege und Aufzucht 
des Viehs liegt häufig in den Händen von Fulbeleuten, die teilweise als Sklaven in diese Gegenden gekommen sind, teilweise aber auch aus freien Stücken sich hier niedergelassen und, weit entfernt von grösseren Ortschaften, ihre kleinen. Höfe errichtet haben. Niedrige, schlecht gebaute Hütten mit schmalen Eingängen, durch welche man nur auf Händen und Füssen ins Innere gelangen kann, sind für diese echten Viehzüchter charakteristisch. Ausser eigenem Vieh nehmen sie gegen Entschädigung auch Vieh von der einheimischen Bevölkerung in Pflege. Sie werden als gute Viehpfleger überall geschätzt und selbst die räuberischen Bassari lassen ihre friedlichen Niederlassungen unbehelligt.

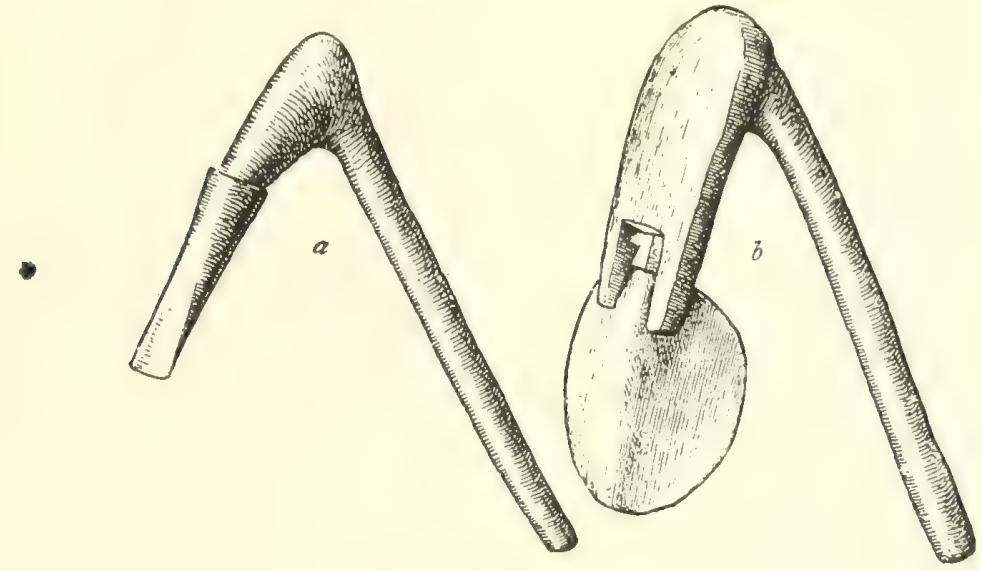

Ackergeräte der Bassari.

a Axt. $b$ Hacke.

Diese Fulbeleute, die das herrschende Geschlecht in den Haussastaaten bilden, kommen von dort in unser nördliches Hinterland und sind bis jetzt wohl südlich nur bis Bassari vorgedrungen. Vielleicht wäre es nicht unzweckmässig, diese harmlosen Hirten weiter südlich in Togo anzusiedeln und so die Viehzucht auch in den Küstengegenden zu heben. Von der Bevölkerung werden sie gegen Zahlung einer kleinen Abgabe an den König freundlich aufgenommen. In Bassari bringen sie dem König eine Kuh als Tribut, um die Erlaubnis zu ihrer Niederlassung zu erlangen. Bei ihren öfteren Besuchen auf unserer Station und durch die Einstellung eines Fulbemannes in unsere kleine Truppe hatte ich Gelegenheit, die Leute mehrfach zu beobachten. Es ist ein reines Nomadenvolk, welches von einem Ort zum anderen zieht, sobald die Weideplätze nicht mehr in hinreichender Fülle vorhanden sind. 
Der Trieb zum Wandern scheint ihnen im Blute zu liegen. So verlassen sie bei dem Tode irgend eines Familienmitgliedes mit ihrem ganzen $\mathrm{Hab}$ und Gut sofort das Land, um sich an einem anderen Ort wieder anzubauen.

Negroide Ihre Hautfarbe ist nicht so schwarz, wie die der westafrikanischen Eigenschaften Stämme, aber auch nicht so hell, wie die ihrer rein hamitischen Brüder, und Tracht der

Fulbehirten.

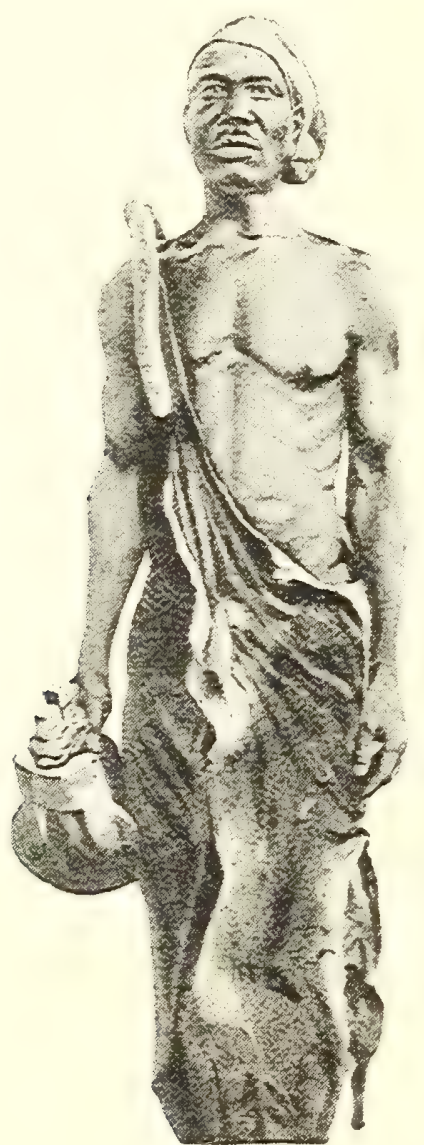

Bassari-Mann

mit Feldhacke und Axt

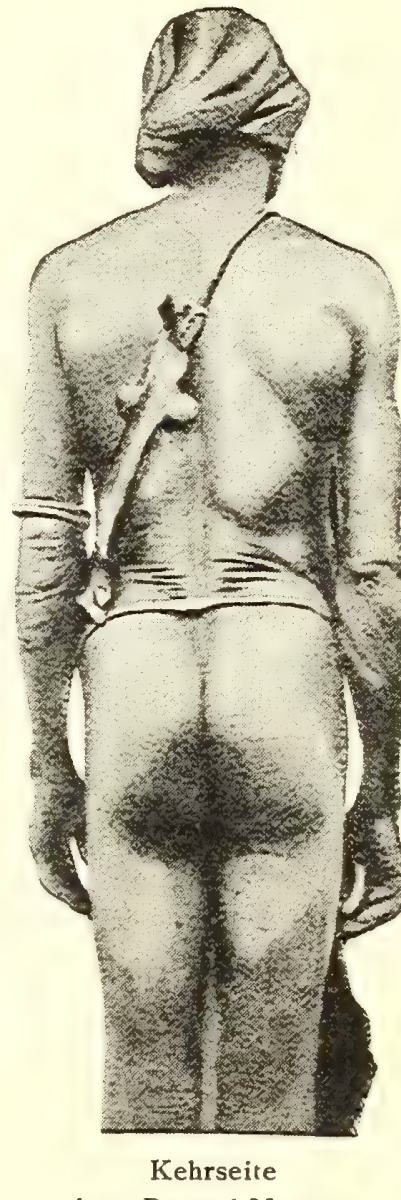

eines Bassari-Mannes.

sondern chokoladenfarbig. Ihr Haar ist weniger kraus als wellig zu nennen; die den reinen Hamiten ähnliche, arische Gesichtsbildung ist durch den negroiden Typus verdrängt. Ihre Gestalt dagegen ist zwar klein und schwächlich, aber wohlgeformt. Unter sich scheinen sie hauptsächlich in ihrer eigenen Sprache zu verkehren. Die Männer tragen das Kopfhaar gewöhnlich kurz geschoren, doch lassen sie zum Teil, wie die Bassarileute, auf dem rasierten Kopf einen Haarkamm stehen. Ihre kleinen, zierlichen 
Frauen tragen häufig zu beiden Seiten des Kopfes das Haar in Zöpfchen geflochten, welche sie nicht selten unter dem Kinn verknüpfen. Die Kleidung der Männer besteht aus einem langen weissen Hemd oder einem Tuch, während sie auf dem Kopf einen spitzen, kegelförmigen Hirtenhut mit grader Krempe tragen und in der Hand in der Regel einen grossen Hirtenstab führen. Die Frauen gehen ebenfalls meist mit einem weissen Tuch um die Hüften bekleidet.

Der Religion nach sind die Fulbe im allgemeinen eifrige Mohamedaner, jedoch sind unter denen, welche im Hinterlande von Togo als Hirten leben, auch vielfach Heiden anzutreffen.

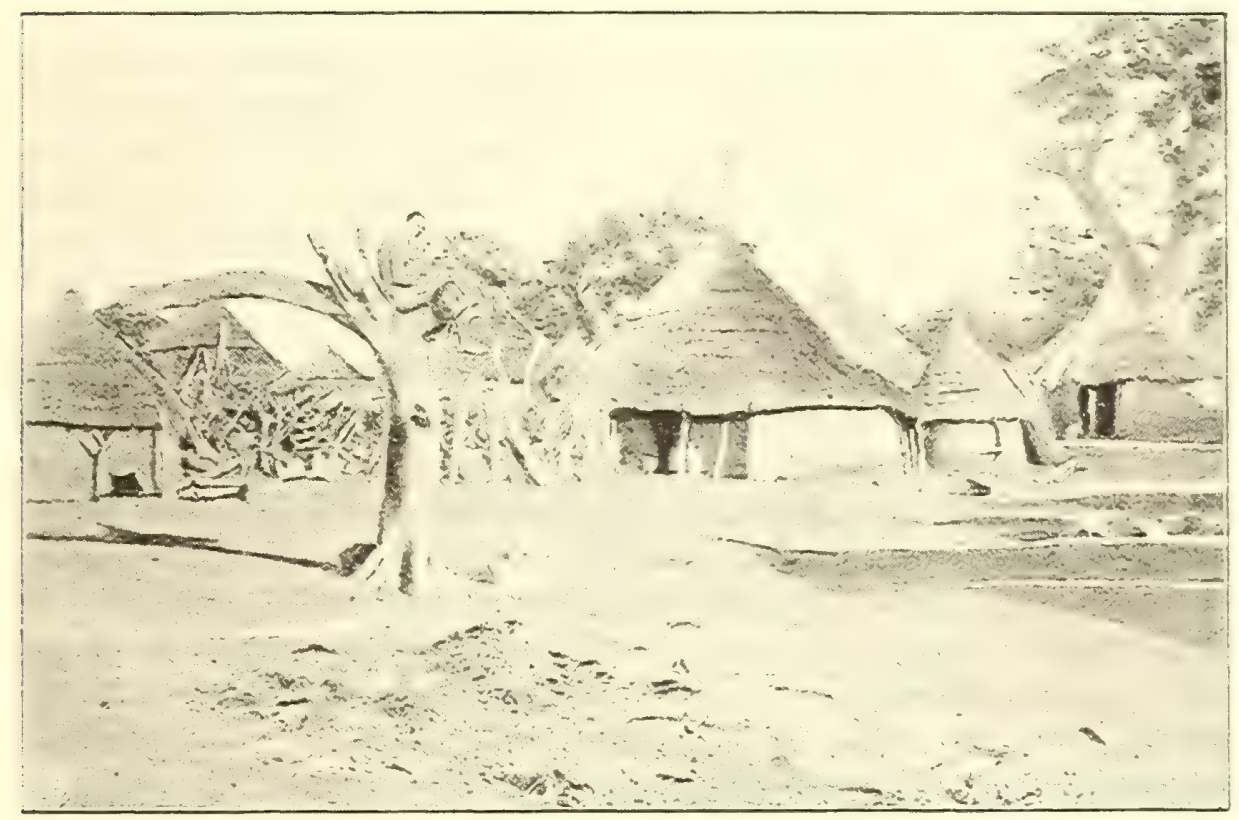

Geböft mit Viehkral in Bassari.

So anspruchslos und dürftig diese Leute leben, so intelligent sind Die Fulbe als sie in der Verwertung ihrer Molkereiprodukte und in der Aufzucht und Pfleger und Pflege ihres Viehs. Ackerbau betreiben sie so gut wie garnicht, sie Viehzüchter. bauen nur für ihren eigenen Lebensbedarf etwas Guineakorn. Ihr ganzes $\mathrm{Hab}$ und Gut besteht lediglich aus dem Vieh, welches ihnen die einheimische Bevölkerung für die Pflege und Wartung des eigenen Viehs als Entgelt geben muss. In Bassari erhalten sie für die Pflege der Kühe immer das zweite Kalb. Im grossen und ganzen wird das Vieh nur zur Aufzucht und der Milch wegen gehalten, so dass ausser einigen Zuchtstieren die Stiere zum Schlachten verkauft werden. Das 
Vieh wird früh auf die Weide getrieben und bleibt den ganzen Tag über auf derselben. Ueber Nacht wird es, wie bei den Bassarileuten selbst, in Viehhürden bei dem Gehöft eingetrieben oder auch, wie es sehr häufig bei den Fulbe geschieht, nahe bei dem Gehöft mit den Molkerei- Füssen an kleine Pflöcke angébunden. Die Kühe werden täglich geprodukte. molken und die Milch, welche bei der heissen Temperatur und den nicht immer allzu reinlichen Kalabassen bald sauer wird, kommt in angesäuertem Zustande auf den Markt. Auch bereiten die Leute Butter und Käse in einer grossen, runden, flachen Form, die einen Durchmesser von etwa 20 Centimeter und eine Höhe von 3 bis 4 Centimeter hat. Als uns in Bassari unser ganzer Proviant an Butter u. s. w. ausgegangen war, empfanden wir es sehr wohlthuend, an den Molkereiprodukten der Fulbeleute einigen Ersatz zu finden. Unser Fulbesoldat veranlasste seine Landsleute, uns reichlich zu versorgen. Da die Milch meistens schon gesäuert und daher nach unseren Begriffen weder zum Trinken noch zum Kochen zu verwenden war, liessen wir sie vollständig dickflüssig werden und bereiteten daraus den schönsten Weichkäse, der mit einem Zusatz von Kümmel und Salz trefflich schmeckte. Unser Koch Hans Naku buk uns dazu, so lange noch etwas Mehl in unserer Speisekammer vorhanden war, ein vorzügliches Schwarzbrot, bei dem die Hefe durch Palmwein oder Hirsebier ersetzt wurde. Die von den Fulbeleuten zubereitete Butter hat einen weichlichen Geschmack und geht sehr bald in Säuerung über, da die Leute bei der Bereitung kein Salz verwenden. Im übrigen ist sie zu Kochzwecken nicht schlechter, als die ranzige Konservenbutter, welche in der ersten Zeit der Schrecken aller Europäer in Afrika ist. Leider wird wegen des geringen Fettgehaltes der Milch nur wenig Butter gewonnen und sie kommt daher auch spärlich auf den Markt, wo sie eigentlich nur als Delikatesse für die Reicheren abgesetzt wird. Der Käse bildet das Hauptmolkereiprodukt der Fulbe und wird in grossen Mengen verkauft; er hält sich bei der hohen Temperatur verhältnismässig gut und schmeckt auch nicht übel, nur fehlt ihm die nötige Würze.

Die Jagd und Die Jagd wird in Bassari viel betrieben, das beweisen die Antilopender Fischfang und Leopardenfelle, mit denen die Leute sich bekleiden und zugleich in Bassari. ihren Stammesbrüdern gegenüber das Ansehen mutiger Jäger geben. Das Vorkommen grosser Elfenbeinhörner und zahlreicher Armringe aus Elefantensohle lässt auch auf die Ergiebigkeit der Elefantenjagd schliessen. Die Jagd scheint einen guten Ertrag abzuwerfen, da nicht selten getrocknetes Antilopenfleisch, sowie das getrocknete Fleisch einer Wildschweinart auf den Markt von Bassari kommt. Als Waffen dienen Pfeile und Bogen, ferner die zum Teil eingeführte Steinschlossflinte. Für uns waren die zahlreichen Perlhühner und Buschhühner in den weiten Farmen 
der Königsstadt ein willkommener Braten und boten uns auch in freien Stunden ein schönes Jagdvergnügen. Oft bemerkte ich auf meinen Streifzügen durch die Farmen eine kleine Hasenart, auch nicht selten in der Baumsavanne eine mittelgrosse, rotbraune schlanke, Affenart mit langem Schwanz, welche die Leute, gewissermaassen wie bei uns den Storch, schonen und heilig halten sollen. Ausserdem sah ich eines Tages flüchtig bei untergehender Sonne ein kleines Schuppentier, welches in den Löchern eines Grabenrandes verschwand. Von Papagaien bemerkte ich in der Savanne die wohlbekannte, mittelgrosse grüne Art mit schwarzem Kopf und gelbrötlichen Bäckchen. Von Interesse ist auch noch eine kleine stahlblaue Vogelart, welche man in Bassari auf den Weiden antrifft. Hier sitzt dieser Vogel furchtlos auf dem Rücken der weidenden Schafe, wo er das Ungeziefer aufliest und vertilgt. Ferner umkreisten grosse Habichte und verschiedene Adlerarten die Schluchten und Klüfte.

Den Fischfang betreiben die Bassari in der Weise, dass sie die Fische mit einem Fischgift betäuben, welches aus einer Euphorbienart gewonnen wird. Man sieht diesen Strauch in Bassari überall an den kleinen Flüssen und Bächen gewissermaassen in Baumschulen angepflanzt. Es fällt schon von weitem durch seine hellgelben Blüten auf, die sich später zu Schoten entwickeln. Die Blätter werden zu einem Brei zerstampft und in den Fluss geworfen. In der Landschaft Apai wird der Saft eines Baumes in ähnlicher Weise verwendet. Vielleicht ist dieser Baum, der ebenfalls zu den Euphorbien gehören soll, identisch mit dem Strauche.

Was die Industrie der Bassarileute anbetrifft, so steht das Schmiedehandwerk hier in hoher Blüte. Naparba ist ein ächtes Schmiededorf, in welchem die ganze Nacht hindurch in den kleinen Hütten das Feuer blinkt und der taktmässige Schlag des Hammers wiederhallt. Das Eisen, welches in Naparba verarbeitet wird, soll von ganz vorzüglicher Qualität sein und kommt meistens aus den Schmelzöfen von Banyeli oder Kabo; Bassari selbst liefert wenig, da sich nur in Mpampu einige Schmelzöfen befinden. Wegen seiner Güte wird das Eisen aus Banyeli besonders bevorzugt. Die Eisen-Schmelzöfen sollen einfache Lehmöfen von etwa 2 bis 3 Meter Höhe sein, die von oben gefüllt werden, während der Abzug sich unten befindet. Das Eisen soll hier durch Holzkohle reduziert werden, welche auch in den Schmiedewerkstätten gebraucht wird. Die Holzkohle wird von den Leuten in sogenannten Meilern hergestellt, welche wie bei uns, mit Gras und Erde eingedeckt werden. Bevor man nach Naparba kommt, sieht man schon von weitem den Rauch aus den Hütten aufsteigen und wird durch das Hämmern der Schmiedeleute an die Stätten in der Heimat erinnert, wo unser Eisen geschmiedet wird. Die runden Hütten sind verhältnismässig höher und breiter

Die Eisenindustrie in Bassari. Schmelzöfen.
BassariSchmiedemeister und Einrichtung ihrer Werkstätten. 
gebaut als die Wohnhäuser und haben meistens am Eingang ein Schutzdach gegen die Witterung. Das Feuer befindet sich in der Mitte der Hütte und wird durch einen primitiven Blasebalg angefacht, der aus zwei niedrigen, aufrechtstehenden Holzcylindern mit Fellüberzug besteht. Durch zwei senkrechte Holzstampfen wird der einfache Fellbalg von einem Lehrjungen in schnellen Stössen in Bewegung gesetzt. Letzerer muss, wie sein Herr, „im Schweisse seines Angesichtes“ sein Brot verdienen. Wegen der herrschenden grossen Hitze gehen die Leute, ausser einer phrygischen Mütze, die das Abzeichen des Meisters bildet, und einem paar Sandalen, gänzlich unbekleidet. Bei der hohen Temperatur ist dies ganz selbstverständlich und kein Mensch nimmt daran Anstoss, wenn die Frau ihrem unbekleideten Manne das Essen bringt. Auch der Verkehr mit den übrigen Leuten, die in der Werkstatt zu thun haben, ist vollkommen frei, was ausser dem Bereich der Werkstätte das Schamgefühl der BassariSteinerne leute empören würde. Ganz erstaunlich ist es, wie geschickt diese SchmiedeSchmiede- leute mit ihren primitiven Werkzeugen die zackigen Pfeile und Speere handwerk- herzustellen vermögen. Ihr ganzes Werkzeug besteht aus Quarzsteinen. Der zeuge. Amboss ist ein grosser Quarzblock, während in Reih und Glied an der Wand grosse und kleine Hämmer nebeneinander liegen, welche auch nur aus einfachen zugespitzten Quarzsteinen ohne jeglichen Stiel und Griff bestehen. Es ist merkwürdig, dass die Leute bei ihrer verhältnismässig grossen Handfertigkeit sich noch keinen Hammer aus Eisen hergestellt haben. Nur die Zange besteht aus zwei Eisenstäben, welche die Leute erstaunlich geschickt zusammen mit einem Stab, der ebenfalls zum Schüren Erzeugnisse des Feuers dient, zu handhaben verstehen. Unter den wuchtigen Schlägen des dieser Steinhammer entstehen runde eiserne Platten, die, an einem hölzernen Schmiede- Stiel befestigt, in Bassari, Kratyi und weit bis zur Küste hin als Hacke zur handwerkes. Bearbeitung des Feldes benutzt werden. Die Platten haben ungefähr einen Durchmesser von 20 bis 25 Centimeter und wiegen gewöhnlich \% Kilogramm. Doch wird auch den Anforderungen einzelner Gegenden entsprochen, da Bassari einen verhältnismässig grossen Export seiner geschätzten Eisenfabrikate besitzt. So wird in den Schmiedewerkstätten von Bassari die in Atakpame gebräuchliche zackige Hacke hergestellt. Das Eisen zu einer solchen Feldhacke, deren Stiel die Leute selbst fabrizieren, kostet auf dem Markte in Bassari I 300 bis 1400 Kauris, was einem Geldwerte von M. I,2O bis M. I,4O entspricht. Es werden ferner Messer als Waffe und zum häuslichen Grebrauch hergestellt; ebenso die in Bassari gebräuchliche Axt zum Roden und Holzhacken, die nur eine Breite von 3 bis 4 Centimetern hat und gewöhnlich an einem gebogenen Stiel über der Schulter getragen wird. Ganz besonders interessant ist die Anfertigung der kleinen vierkantigen, mit Widerhaken versehenen Pfeile. Die eisernen Pfeilspitzen werden zuerst roh in einem Durchmesser von 

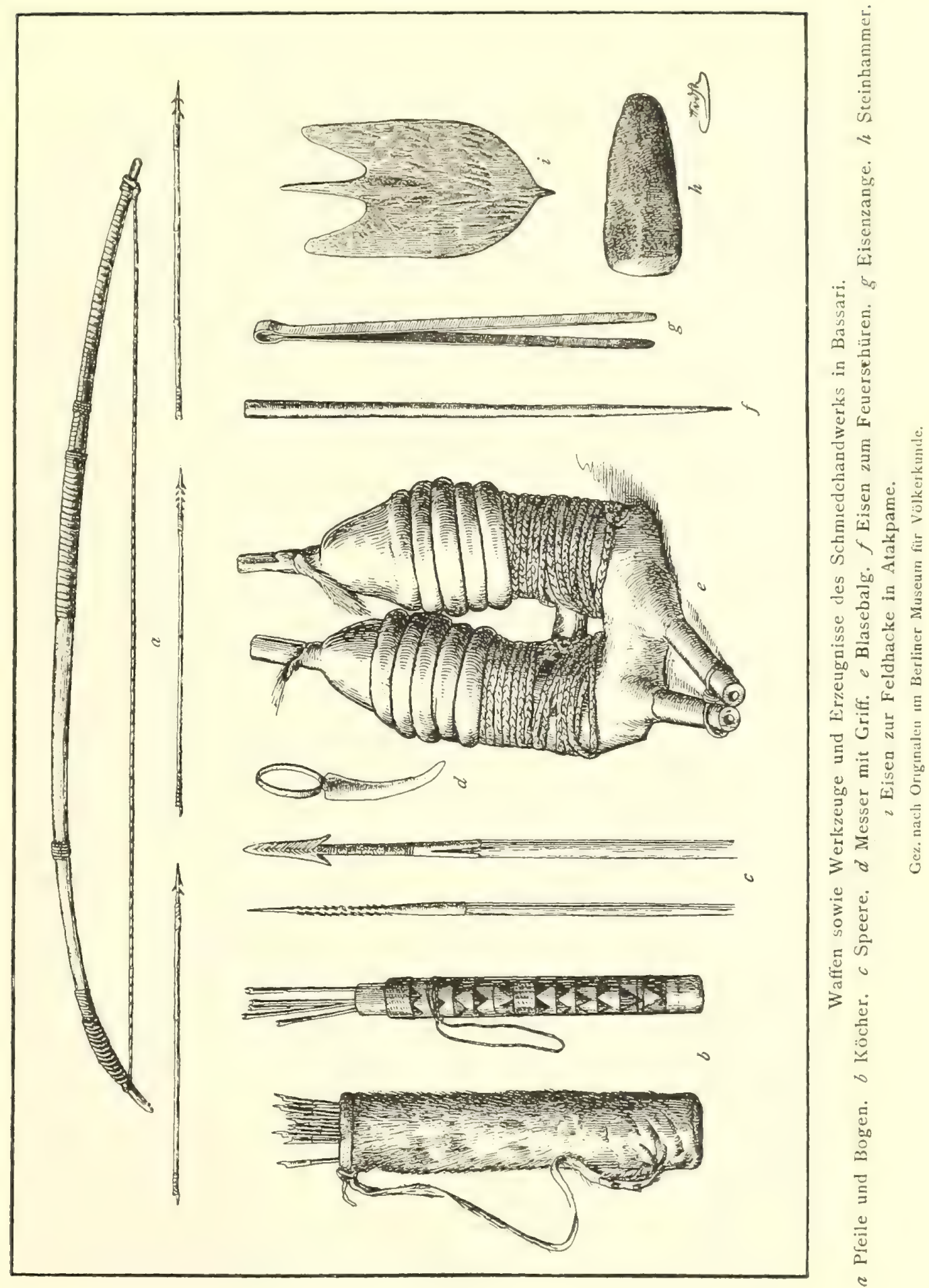
nicht mehr als 3 bis 4 Millimetern vierkantig geschmiedet. Dann wird das Eisen nochmals erhitzt, die Spitze geformt und mit einem eisernen Messer kleine Widerhaken in die Kanten geschlagen. Ebenso werden die Speerspitzen hergestellt, von denen ich hier zwei Arten bemerkte, eine kantige mit Widerhaken wie die Pfeile, und eine breite, häufig ciselierte, mit langer, lanzettförmiger Spitze. Auch werden die bekannten Griffmesser in allen Formen angefertigt. Die Eisenerzeugnisse des Bassarilandes sind bis jetzt die bekanntesten und hauptsächlichsten Industrieartikel des Landes.

Die Töpferei In den südlichen Orten von Bassari, in Moande, Kamkunde und in Bassari. Nafine wird die Töpferei betrieben. Die Form der Töpfe wird einfach mit der Hand hergestellt, die Töpfe selbst werden mit Steinen und glatten Hölzern geglättet. Es entspricht dies der Art, wie auch die Evhe das Handwerk ausüben, nur dass die Bassarileute die Töpfe auf eine andere Art brennen. Aehnlich wie bei unseren Holzkohlenmeilern wird ein Holzstoss von Reisig angezündet, die getrockneten Thontöpfe darauf gelegt und darüber eine Schicht von frischem Gras und Erde gedeckt, um ein allzu schnelles Brennen der Töpfe zu verhindern. Bei dieser Methode wird die Ware langsamer aber sicherer und besser durchgebrannt als bei dem offenen Feuer der Evhe.

Flechterei Neben der Töpferei beschäftigen sich die Leute mit der Flechterei. und

Schnitzerei der Bassarileute.

Aus Pandanusarten werden Matten, aus Raphia-Piassawa und Bast Thürvorhänge, Körbchen und allerhand andere Flechtarbeiten hergestellt. Die Schnitzerei kommt namentlich an den schön verzierten Kürbisflaschen und Kalabassen der Bassari zur Geltung. Die kunstvollen Ornamente werden mit dem einfachen Messer ausgeführt und bestehen meistens aus demselben Muster, welches wir in den Graffiti, als Verzierung der Hütten, und auch zum Teil in den Schmucktätowierungen der Bassarifrauen kennen gelernt haben.

Regierung Bassari ist ein Königreich, an dessen Spitze zu unserer Zeit der und König Tagba stand. In allen wichtigen Regierungsgeschäften wird er Verwaltung von dem Rat der Aeltesten unterstützt, der aus den freien Familiendes Lande. oberhäuptern besteht. Die meisten Ortschaften werden von den Aeltesten des Ortes vertreten und verwaltet. Der Häuptling des Ortes wird aus ihrer Mitte gewählt, was in einigen Ortschaften durch sie selbst, in andern durch den König geschieht. Je nach den Fähigkeiten und dem Reichtum des Häuptlings tritt er mehr oder weniger aus der Reihe der Aeltesten hervor. Die Familienhäupter spielen besonders in Bassari, wo noch das Faustrecht herrscht, eine ganz ungewöhnliche Rolle, so dass der König häufig ihnen gegenüber machtlos ist und schliesslich jedes Dorf, auch wohl jeder einflussreiche Familienvater, sich in engeren Grenzen sein eigenes Gesetz macht. Die Bassarileute haben, wie alle Völker, von alters her überlieferte Sitten und Rechtsgebräuche. Der 


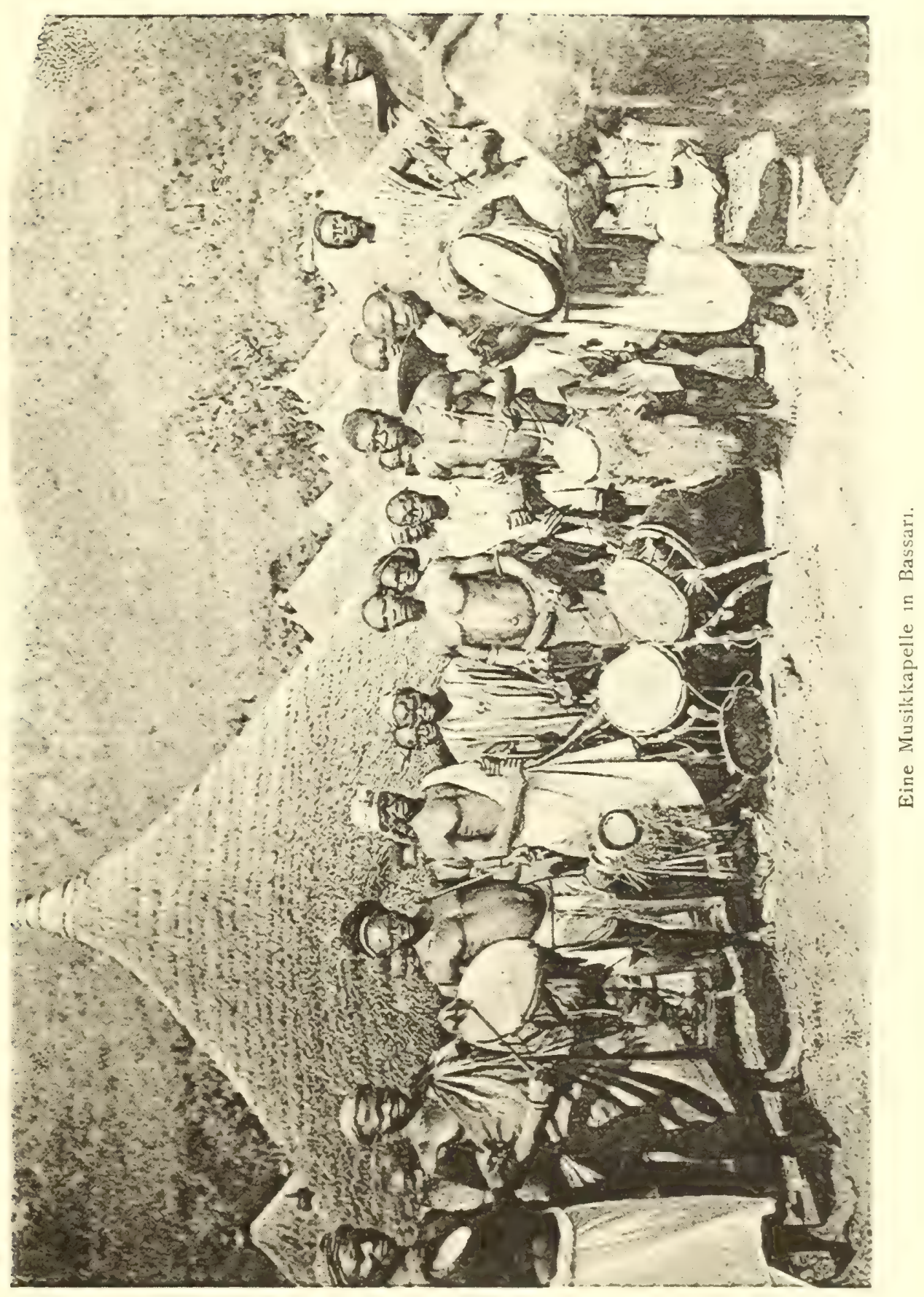



König von Bassari wird, wie mir berichtet wurde, von dem obersten Thronfolge Fetischpriester aus der Königsfamilie gewählt. Allerdings ist der in Bassari. Begriff „Familie“ ein sehr dehnbarer, da die alten ansässigen Bewohner eines Dorfes alle gewissermaassen zu einer Familie gehören. Nach den Rechtsanschauungen der Bassarileute ist bei der Verleihung von Aemtern und Ehrenstellen nur die Stellung des Vaters maassgebend. Derselbe muss Familienoberhaupt und ein freier Bassarimann sein, dagegen ist es unwesentlich, ob die Mutter eine Sklavin aus einem anderen Lande oder eine freie Bassarifrau ist. Der jetzige König Tagba ist der Sohn eines Bassarimannes aus der Königstadt Koré, während seine Mutter aus Tshautsho stammen soll. Die Eltern des Tagba lebten in Tshautsho, daher wurde Tagba in der TemuSprache erzogen. Erst nachdem er zum König von Bassari erkoren war, hat er sich die Bassari-Sprache angeeignet; er spricht heute ebenso gut Bassari wie Temu, trotzdem werden meistens die Verhandlungen durch den Sprecher des Königs, welcher ein Tshautshomann ist, geführt.

Nach dem Tode des Königs darf kein Mensch die Hütte desselben betreten. Das ganze Volk läuft zum Fetischpriester, welcher unter grosser Beteiligung an der Opferstätte dem Fetischgotte Unombotte Oel, Kauris, Mehl und weisse Hühner opfert.- Sämtliche Leute flehen dabei vereint zum Unombotte, dass er ihnen einen neuen König geben möge. Der Fetischpriester bestimmt nun heimlich den neuen König; dieser dringt Nacbfolgers. des Nachts in das Totenhaus des alten Königs ein und nimmt auf einem gewissen Stein, dem Ehrensitz des Königs, Platz. Das erstaunte Volk sieht den Königsthron wieder besetzt und jubelt dem neuèn König zu. Während des Interregnums soll ein aus dem Rat der Alten gewähltes Familienoberhaupt die Regierungsgeschäfte führen und dem neuen König noch drei Jahre lang zur Seite stehen. Ist der neue König durch den Fetischpriester eingesetzt, so beginnen die Krönungsfeierlichkeiten. Der König wird nach Nanbane in das Fetischhaus gebracht, wo er 30 Tage hindurch eine Prüfungszeit durchmachen muss, wobei er die Hütte nicht verlassen darf und unter verschiedenen Fetischzeremonieen gute Lehren vom Fetisch empfangen soll. Dann beginnt das eigentliche Fest, welches mit Tanz und Gelagen gefeiert wird. Der König wird unter Pauken und Hörnerklang von dem jubelnden Volke nach der Königsstadt Koré geleitet, wo er seinen feierlichen Einzug hält. Eigentümlich ist die Sitte, welche verlangt, dass der König gewissermaassen eine dreijährige Lehrund Probezeit durchzumachen hat. Während dieser drei Jahre repräsentiert er nur, wogegen der von den Familienoberhäuptern nach dem Tode des alten Königs eingesetzte Regent zusammen mit dem Rat der Alten weiter regiert. 
Kriegführung

Der

Dagomba krieg mit Bassari

Im Kriege ist der König der oberste Führer, er nimmt jedoch selbst nicht am Kampfe teil, sondern leitet ihn von einem nahen Hügel aus Napui berichtete mir, dass vor Beginn eines Krieges alle Kinder und Frauen auf den Bassariberg in Sicherheit gebracht werden. Zugleich werden Kundschafter in das Lager des Feindes geschickt und, wenn es geht, wird dasselbe in der Nacht überfallen. Die Bassarileute sollen in ausgeschwārmter Schlachtlinie, in dem hohen Grase kauernd, vorgehen, indem sie den Feind mit vergifteten Pfeilen zu beschiessen suchen. Sobald sie nahe genug sind und den Augenblick für günstig halten, werden die Elefantenhörner geblasen, die Trommeln geschlagen und der Angriff erfolgt mit Messern und Speeren. Feige werden verspottet, aus der Schlachtreihe fortgeschickt und als Weiber bezeichnet. Bei dem Abzuge des Feindes sollen sich auch die jungen Frauen und Mädchen mit dem ganzen Hofstaat des Königs an der Plünderung des Lagers beteiligen. Die Sklaven, sowie Kühe, Pferde und Gewehre fallen als Beute dem Könige zu. Weniger wertvolle Gegenstände, wie Tücher, Hörner, Ziegen oder Schafe, kann, wie mir mein Gewährsmann Napui erklärte, jeder fur sich selbst behalten. Die Kriegsgefangenen werden vom Könige in die Sklaverei verkauft und jeder, der einen Gefangenen abgeliefert

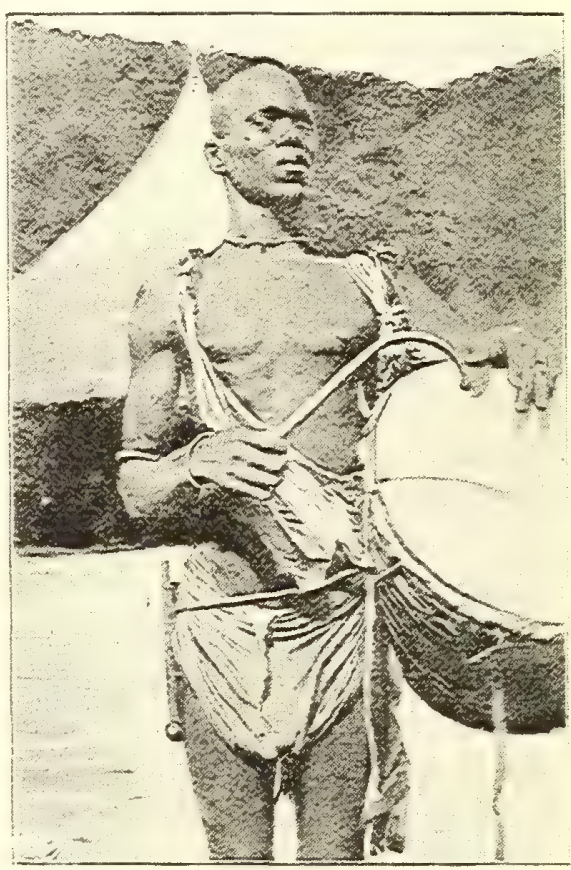

Ein Trommler mit der Kriegstrommel hat, erhält einen Anteil von dem Erlöse. Der Krieg der Bassarileute zielt natürlich, wie bei fast allen kriegfuhrenden Negerstämmen, nur auf die Erbeutung von Sklaven, Vieh und sonstigem Eigentum ihrer Nachbarn ab.

Bassari soll früher den Durchmarsch durch sein Gebiet vollständig gesperrt, alle Karawanen, die es zu passieren versuchten, angegriffen und die Leute zu Sklaven gemacht haben. So kam es auch unter dem König Abudulai der Dagomba, in den siebziger Jahren, zu einem heftigen Kampf mit Bassari, wobei zwar die Bassarileute geschlagen wurden, aber doch schliesslich Herren ihres Landes blieben. Sie flüchteten sich nämlich auf den Bassariberg, von wo ihnen noch versteckte Farmen und 
Wasserplätze zugänglich waren. Die Dagomba dagegen besetzten die Bassarihütten und sollen sich dort zum Teil drei Jahre lang gegen die steten Angriffe der Bassarileute behauptet haben. Infolge des langen Krieges brach indessen schliesslich eine Hungersnot unter ihnen aus, sie mussten Bassari aufgeben und unverrichteter Sache nach ihrem Lande zurückkehren. Während dieser drei Kriegsjahre hat Bassari sehr gelitten; es soll nach den Angaben der alten Leute vor dem Kriege viel grösser und bevölkerter gewesen sein als jetzt. Viele Bassarileute sollen nach Tshautsho und nach Sara übergesiedelt und nur zum Teil später wieder zurückgekehrt sein. Es giebt noch heute unter den alten Bassarileuten viele, welche der in Tshautsho herrschenden Temusprache mächtig oder mit Frauen aus Tshautsho verheiratet sind. Dadurch hat sich ein lebhafter Verkehr mit den Tshautsholeuten herausgebildet, die vielfach als Weber nach Bassari kommen, während der Verkehr zwischen Bassari und Dagomba ganz aufgehört hat. Auch sollen sich die Grenzen von Bassari früher weiter nach Norden erstreckt und Bapuré, Banyeli und Kabo umfasst haben, während diese Ortschaften heute von vollkommen selbständigen und unabhängigen Häuptlingen verwaltet werden. Im Süden sollen die Buschleute von Kadiumbara, Fale, Bolo und selbst Kabambore östlich des Gebirgszuges, welche auch denselben Typus wie die Bassarileute aufweisen, zu Bassari gehört haben. Tagba, welcher seine Macht im Norden über Banyeli und Kabo wieder auszudehnen suchte, hat in neuerer Zeit Sabermareiter in seinen Sold genommen, um diese Ortschaften zu erobern; jedoch ist es ihm nicht gelungen, sich Geltung zu verschaffen.

Die Sabermareiter sollen Söldner sein, die aus der Landschaft Die SabermaSaberma am Niger-Strom stammen und sich, wie in früheren Zeiten unsere Landsknechte, bei den einzelnen Staaten oder Häuptlingen verdingen. In der That sind sie aber weiter nichts als bezahlte Sklavenräuber, die weit und breit gefürchtet sind. $\mathrm{Zu}$ meiner Zeit waren sie noch in Sara, der nördlichsten Ortschaft von Bassari, in der Nähe von Kabo angesiedelt, von wo aus sie uns durch eine Deputation auf der Station Bassari begrüssen liessen. Ihre Bekleidung und Ausrüstung ist ziemlich dieselbe, wie die der Haussa-Reiter. Ihr Pferdematerial ist von mittlerer Grösse und durch die vielen Streifzüge, welche sie unternehmen, sind sowohl Reiter wie Pferde in gutem Training. Die Pferde sind häufig unansehnlich aber ausdauernd und dabei genügsam. DieLeute scheinen gute Reiter, sowie in der Führung der Waffen geübt zu sein. In der tollsten Karriere ritten sie uns ihre Pferde vor und machten dabei Waffenübungen mit dem Speer, indem sie ihn zum Stiche und Wurfe in die Luft erhoben. Durch die vielen Kämpfe und Gefahren, welche sie durchgemacht haben, sind sie rauhe Krieger geworden, die den gefüllten Becher mit Bier oder

$$
\begin{gathered}
\text { reiter } \\
\text { als Kriegs- } \\
\text { söldner. }
\end{gathered}
$$


Palmwein zu schwingen verstehen und für eine Flasche Gin ihr Leben einsetzen. Es gelang mir, sie zu überreden, sich photographieren zu lassen, wobei mir die Unruhe der Pferde und Reiter nicht wenig Schwierigkeiten bereitete.

Das

Richteramt des Bassarikönigs. und Einnahmen des Königs.

Der König ist in Bassari die höchste Instanz. Kleine Streitigkeiten werden von dem Häuptling oder dem Aeltesten des Gemeinderates unter Hinzuziehung von zwei Vertretern des letzteren erledigt. Sind jedoch die Beteiligten mit dem Urteil nicht zufrieden, so steht ihnen die Berufung an den König zu. Rechtsstreitigkeiten zwischen zwei Dörfern werden ebenfalls von dem König entschieden. Derselbe beruft $z$ u diesem Zweck die beiden streitenden Parteien und als Richter den Rat der Alten der betreffenden Dörfer. Die Kläger sowie die Verklagten bringen nun ihren Streit öffentlich zur Sprache, worauf sich dann die Richter jeder Partei besonders zurückziehen und über den Fall beraten. Nach Beendigung dieser Beratung kommen die Richter vor den König und geben durch einen Sprecher ihre Meinung über den Fall kund. Der König entscheidet alsdann den Streit und lässt durch seinen Sprecher öffentlich das Urteil verkünden. Für jede Gerichtssitzung, an welcher der König teil nimmt, erhält er von den Parteien 6000 bis 20000 Kauris, also 6 bis 20 Mark.

In einzelnen Dörfern, wie in Wodande, hat der König das Recht, besondere Häuptlinge zu ernennen, während in vielen Ortschaften, wie schon erwähnt, der älteste des Gemeinderates zugleich die Funktionen des Häuptlings ausübt. Jedes Dorf ist verpflichtet, für den König Farmen anzulegen, und bei dem Ausnehmen des ersten Yams dem König seinen Tribut an Feldfrüchten zu bringen. In langen Reihen kommen Männer, Weiber und Kinder zur Königsstadt gezogen, um Tagba gewissermaassen zu huldigen und ihren Tribut zu leisten. Ein königliches Dekret besagt, dass dieser Tribut nur alle zehn Tage gebracht werden darf, angeblich damit sich die Audienzen der einzelnen Ortschaften nicht zu oft wiederholen. Der eigentliche Grund wird wohl eher der sein, dass auf diese Weise die königliche Vorratskammer in gleichmässigen Abständen gefüllt wird. Bevor der König seinen Tribut erhalten hat, darf, wie mir die Bassarileute erklärten, kein Mensch von dem neuen Yams essen. In der That hängt aber auch hier die Yamsernte von der Erlaubnis des Fetischpriesters ab. Bevor nämlich der König selbst von dem neuen Yams geniesst, geht er zu dem Fetischpriester und opfert dem Fetisch einen Teil desselben, sowie zehn weisse Hühner. Diese gehören gewissermaassen zu dem Opfermahl, welches nach der Fetisch. zeremonie stattfindet und an welchem sich die Geber des Yams beteiligen. Mit dieser Zeremonie, welche in letzter Instanz vom Fetischpriester ausgeht, beginnt die Ernte des neuen Yams. Ausser dieser Abgabe an 


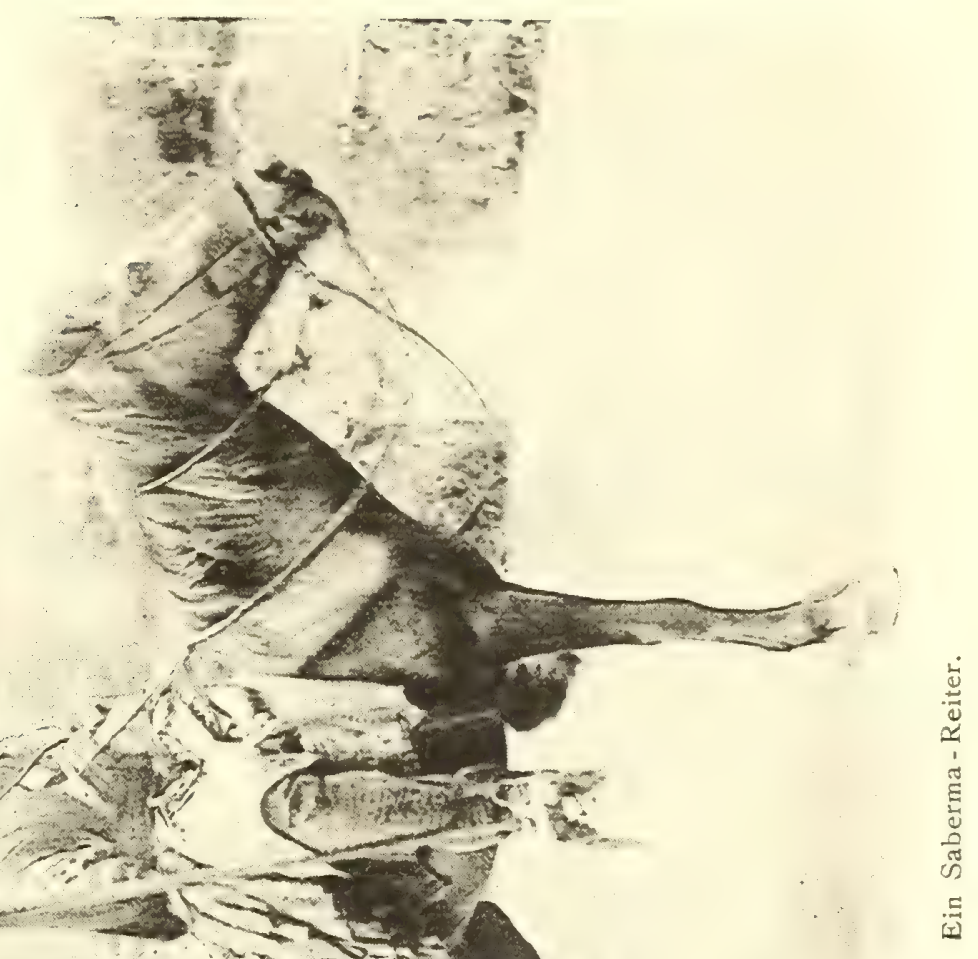



Feldprodukten und den hohen Prozessgebühren hat der König Anspruch auf einen Teil des erlegten Wildes.

Die Strafen in Bassari sind, dem rauhen Charakter des Volkes entsprechend, sehr hart und grausam. Mörder sind vogelfrei und jedes b Familienmitglied eines Gemordeten hat gewissermaassen die Pflicht, die Blutrache an dem Mörder auszuüben. Geschieht dies nicht, so wird der Mörder vor das Gericht des Königs und den Rat der Alten gebracht. Die Familie des Getöteten wird dann gefragt, ob der Mörder getötet oder ob er in die Sklaverei verkauft werden solle. Entscheidet sich die Familie für die Todesstrafe, so wird der Mörder von dem Könige einigen Vertretern des Gemeinderates übergeben, welche ihn in den Busch führen und dort mit einem Messer niederstechen. Der Körper wird in dem Busch liegen gelassen, wo ihn die Familie später ohne jegliche Totenfeier begraben kann. Entscheidet sich aber die Familie des Getöteten für den Verkauf in die Sklaverei, so wird er von dem Könige verkauft und der Erlös der Familie des Opfers übergeben. Ebenso gehört auch das Eigentum des Mörders der Familie des Getöteten.

Körperverletzungen, die bei den rauflustigen Bassaris nicht selten vorkommen, werden entweder mit Verkauf in die Sklaverei bestraft oder durch hohe Geldstrafen gesühnt. Diebstahl kann, wenn der Dieb bei der That ertappt wird, sofort mit dem Tode bestraft werden. In jedem Falle muss das gestohlene Gut ersetzt werden. Ist der Dieb hierzu nicht imstande, so wird er als Sklave verkauft und aus dem Erlöse der Bestohlene entschädigt.

Der Ehebruch wird in einer ungewöhnlich strengen Weise geahndet, da der Ehegatte der Frau das Recht hat, den Ehebrecher auf der Stelle zu töten. Anderenfalls hat die Familie des hintergangenen Gatten das Recht, den Ehegatten zu kastrieren. Bei dieser Gelegenheit zeigt sich so recht die Grausamkeit der Bassarileute, die dem Missethäter die Geschlechtsteile mit Steinen zerschlagen.

In zweifelhaften Fällen entscheidet bei den Bassarileuten das Gottes- Gottesurteile. urteil, welches durch den Fetischpriester herbeigeführt wird. Leugnet z. B. ein des Mordes Angeklagter die That, so wird er zum Trinken von Gift verurteilt, welches ihm der Fetischpriester reicht. Das Gift wird aus der Rinde eines Baumes gewonnen, der angeblich nicht in Bassari vorkommt. Der Verurteilte muss das Gift vor versammelter Volksmenge trinken. Speit er es bald aus, so wird er für unschuldig erklärt und durch Schiessen, Tanz und Gelage gefeiert. Giebt er dagegen das Gift nicht von sich, so wird er für schuldig befunden und dann, bevor die eigentliche Wirkung des Giftes eintritt, bei den ersten Zuckungen des Körpers, niedergeschlagen. Bei kleineren Vergehen oder gegenseitigen Beschuldigungen wird ebenfalls der Fetisch angerufen. Hierbei 
kommt dieselbe Methode zur Anwendung, wie bei den Evhe-Negern. Der Fetisch-Priester stellt eine Schüssel mit siedendem Oel auf und wirft seinen Ring hinein, den der Angeschuldigte herauszuholen hat. Derjenige, welcher sich dabei verbrüht, gilt als schuldig, während der, welcher unbeschädigt den Ring aus dem siedenden Oel herausholt, für

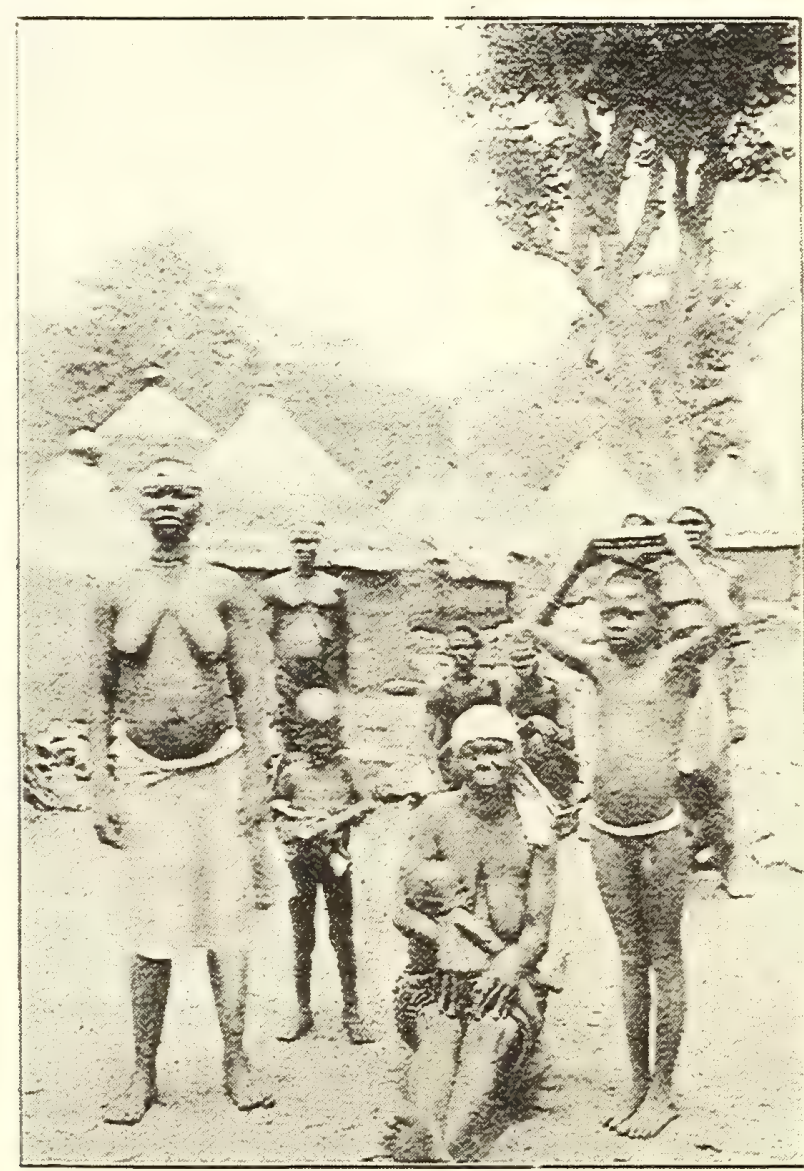

Ein Familien-ldyll in Bassari.

unschuldig erklärt wird. Wahrscheinlich hat auch hierbei der Fetischpriester seine Hand im Spiel und giebt dem Betreffenden, der für unschuldig erklärt werden soll, gegen gute Bezahlung irgend ein Mittel, durch welches die Hand vor dem Verbrühen geschützt wird.

Kinder-

Die Erziehung der Kinder liegt in den ersten Jahren der Mutter erziehung ob. Vier Jahre hindurch wird das Kind an der Brust genährt. Die Mutter trägt es deshalb, bis es laufen kann, bei jeglicher Verrichtung 
in einem Tuche festgebunden auf dem Rücken. Den Namen erhält das Kind gewöhnlich von der Mutter und zwar nach irgend welchen Ereignissen, die zufällig bei der Geburt mitgespielt haben. So wird häufig der Name des Wochentages, an welchem das Kind geboren ist, auch zuweilen der Name des Geburtsortes gewählt. Oft hat der Name die Bedeutung, dass alle früher geborenen Kinder vorher gestorben sind. Mit drei Jahren erhält das Kind gewöhnlich die Stammeszeichen; sie werden aber, wie wir gesehen, bei den Bassarileuten zuweilen weggelassen. Mit fünf Jahren werden die Kinder schon zu kleinen Arbeiten herangezogen. Der Knabe begleitet den Vater auf die Farm, wobei er ihm die Gerätschaften nachtragen muss und allmählich mit Feldarbeiten rertraut gemacht wird. Auch lernt er spielend die Handhabung der Vaffen, wozu ihm der Vater einen kleinen Bogen aus Bambus anfertigt. Mit sieben Jahren soll er schon soweit sein, dass er kleine Vögel erlegen kann. Das Mädchen hilft der Mutter in ihren häuslichen Verrichtungen, holt Feuerholz aus dem Busch, trägt das Wasser für den Haushalt heran, geht mit der Mutter auf den Wasserplatz zur Wäsche, und wird von ihr in der Kunst des Kochens und Bierbrauens unterrichtet. Das Stampfen des Yams und das Mahlen des Guineakorns besorgen die Frauen mit ihren Töchtern und weiblichen Sklaren im Hause, die eigentliche Feldarbeit dagegen besorgt der Mann, nur bei dem Pflanzen von Guineakorn und bei der Ernte desselben sind auch die Frauen auf dem Felde thätig.

Während die Männer und Knaben dem Fischfang und der Jagd obliegen, ziehen die Frauen mit ihren Töchtern auf den Markt, um dort Bier und Feldprodukte zu verhandeln. Mein Bassarigewährsmann Napui aus Okoré sagte mir, als ich ihn über die Verrichtungen der Frau und des Mannes befragte: "Gott hat die Frau gemacht, dass sie im Hause bleibe und Essen bereite für den Mann; den Mann aber, dass er in den Busch gehe, um Farm zu machen". Napui ist ein recht konservativer Bassarimann, der an dem Alten festhält und mit den neuen sozialen Verhältnissen, welche durch das Vordringen der Weissen in Bassari bedingt sind, nicht einverstanden ist. So erklärte er mir, dass mit der Ankunft der Weissen die Eltern die Autorität über ihre Kinder verloren hätten. "Jetzt," sagte er, "gehen die jungen Leute mit Ziegen und Schafen auf die Märkte und handeln dafür wertlose, teure Tücher ein und denken garnicht mehr daran, auf den Farmen zu arbeiten. Und der Erfolg davon ist, dass sie schliesslich doch nichts haben".

Schon mit sieben Jahren wählt häufig die Mutter für ihren Knaben ein kleines Mädchen aus der Bekanntschaft als Spielgefährtin aus, welches später gewöhnlich seine Gattin wird. Oft verrichtet der junge Mann, wie bei den Evheleuten, im voraus Feldarbeiten fur dasselbe, doch wird ihm

Brautwerbung. 
im allgemeinen die freie Wahl seiner Frau überlassen. Er wählt dieselbe häufig aus seinem Stamme oder kauft und heiratet eine Sklavin. Eine eigentliche Pubertätsfeier findet bei den Bassarileuten nicht statt, sondern ist mit der Hochzeit gleichbedeutend. Das Mädchen wird von den Eltern behütet, doch wird ein Fehltritt desselben weniger hart bestraft, als der einer Frau, es wird nur gebunden und geschlagen. In derselben Weise wird auch der jugendliche männliche Missethäter bestraft; Sklaven dagegen erfahren eine härtere Strafe, indem man sie mehrere Tage bindet, in Eisen legt und züchtigt. Mit I7 Jahren kann der junge Mann heiraten, während das Mädchen verhältnismässig spät, erst mit $\mathrm{I}_{5}$ bis $\mathrm{I} 6$ Jahren in den Ehestand treten darf. Der Bräutigam hält bei dem Vater um die Tochter an. Häufig verdienen sich auch Freunde gern den Kuppelpelz. Falls die Familie den Antrag annimmt, muss der junge Mann, wenn er nicht schon vorher für seine Zukünftige gearbeitet hat, den Eltern seiner Braut ein Hochzeitsgeschenk geben, das ungefähr den Wert von 45 Mark hat. Es besteht meist au einer Kuh und I 5 ooo Kauris, wovon der Vater des jungen Mädchens Tücher für die Braut kauft, während der Rest des Geldes unter die Familie verteilt wird.

Hochzeits- Die Hochzeit wird sieben Tage und Nächte hindurch bei Tanz und gebrẳuche Schmaus gefeiert. Vom ersten Hahnenkrähen bis 12 Uhr mittags wird und Familien- getanzt und ein grosses Gelage abgehalten. Von Mittag tritt dann, wie

teben. mir die Bassarileute erzählten, eine Pause zum Schlafen und Waschen ein, während beim Dunkelwerden der Tanz und das Fest wieder von neuem beginnt und die ganze Nacht hindurch in der üblichen Weise fortdauert. Mit der Verheiratung gründet das junge Paar seinen eigenen Hausstand und erhält eine eigene Hütte in dem grossen Familiengehöft. Das junge Paar unterstützt in der ersten Zeit, so lange es kinderlos ist, die Eltern des Mannes; der Sohn arbeitet auf der Farm für den Vater, während die Schwiegertochter für den Haushalt und das Essen sorgt "Zuerst", erklärte mir Napui, „erhält der Schwiegervater sein Essen, dann die Schwiegermutter und zuletzt der geliebte Gatte." Sind aber erst Kinder vorhanden, so wird ein eigner Haushalt geführt.

Der Junggeselle bleibt beim Vater und arbeitet für diesen. Junggesellen erfreuen sich bei den Bassaridamen keiner besonderen Achtung, gewöhnlich wird über sie das Urteil gefällt, dass sie überhaupt nicht im stande seien, zu heiraten. Wohlhabendere Männer besitzen mehrere, mitunter drei bis vier Frauen. Dies erklärt sich aus dem Umstande, dass bei den Bassarileuten, wie bei vielen anderen Negerstämmen, die Kinder bis zu vier Jahren gesäugt werden, in welcher Zeit die Frauen stets unberührt bleiben, eine Sitte, die von einem hoch entwickelten ästhetischen Gefuhl bei den Negervölkern zeugt. Sind mehrere Frauen vorhanden, so 


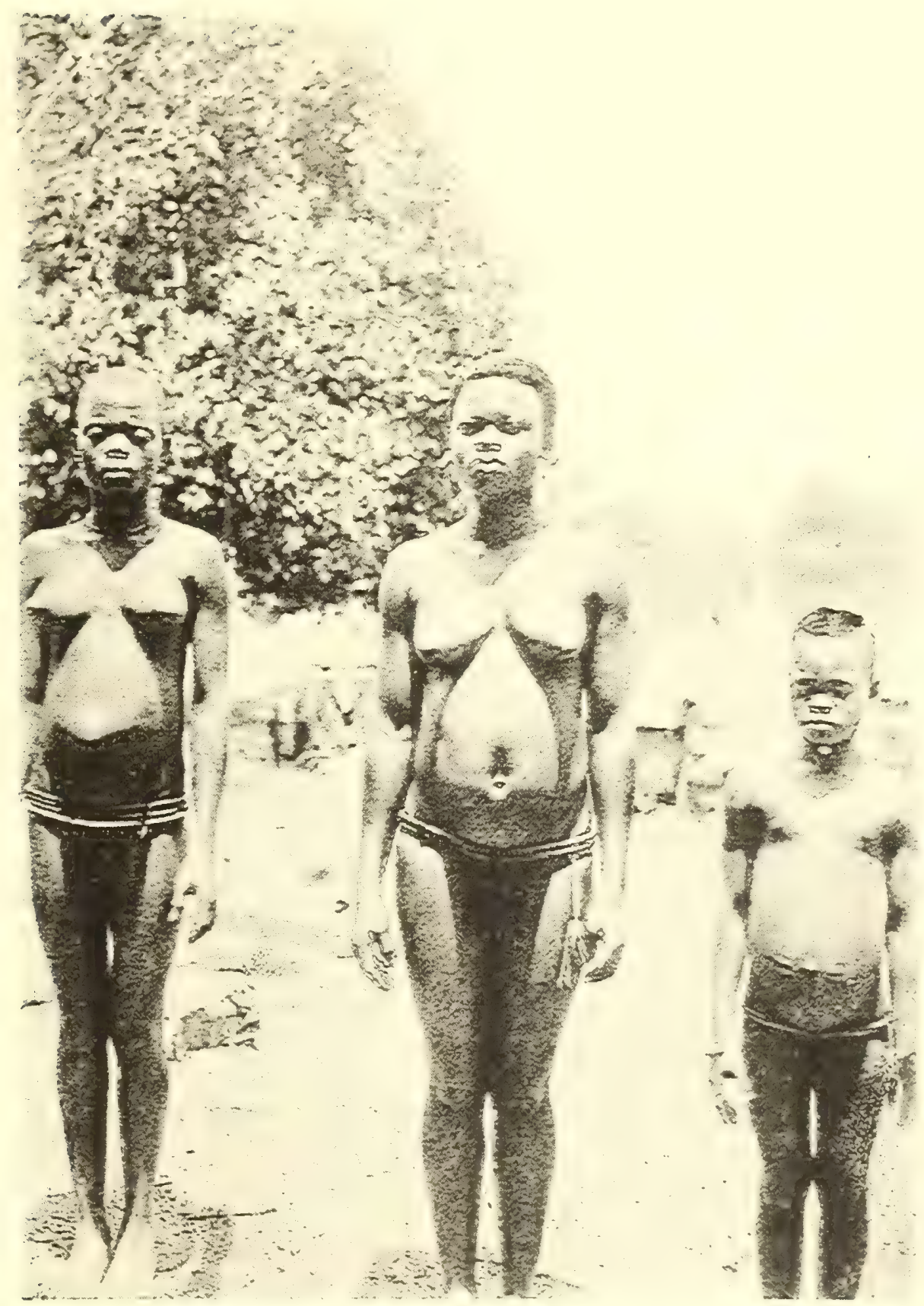

Bassari-Mädchen in drei Altersstufen. 

wird häufig eine derselben bevorzugt, sie hat mehr oder weniger die Aufsicht im Hause und über die Kinder und geht ihrem Vergnügen nach, während die übrigen Frauen die Arbeit verrichten müssen. Manchmal schwingt eine solche Lieblingsfrau den Pantoffel über ihren Herrn und Gebieter. Aber auch bei den Bassarileuten erntet der Pantoffelheld bei dem üblichen Dauerschoppen den wohlverdienten Spott. Der gewöhnliche Bassarimann hat meistens nur eine bis zwei Frauen, je nach seinen Vermögensverhältnissen.

In einem Familiengehöft wohnt in drei bis vier Hütten die ganze Familie, welche durchschnittlich aus drei bis vier Frauen und etwa acht Kindern besteht, so dass etwa vier Personen auf eine Hütte kommen. Napui besass drei Frauen, von denen er zehn Söhne hatte, welche sämtlich verheiratet waren und von denen jeder mehrere Kinder besass. Eigentümlich ist es, dass die Leute eine abergläubische Scheu haben, von ihren Kindern zu sprechen. Es soll dies davon herrühren, dass bei Zwistigkeiten Rache an den Kindern ausgeübt wird; auch werden häufig bei grossem Kinderreichtum einige der Kinder aus Neid vergiftet.

Die Geburt geht bei den Bassarifrauen, wie bei den meisten Naturvölkern, leicht von statten. Es kommt vor, dass hochschwangere Frauen ihrer Arbeit nachgehen und plötzlich auf dem Felde oder auf offener Strasse niederkommen; man sieht oft Frauen die plötzlich von Geburtswehen erfasst und nach Hause in ihre Hütte getragen werden. Bei der Geburt selbst ist gewöhnlich nur der Gatte und eine alte Vertrauensfrau zugegen, welche gewissermaassen die Hebeamme vertritt und die Nabelschnur abschneidet oder abreisst. Die Nabelschnur wird in der Wand der Hütte eingemauert, während die Nachgeburt unter dem Waschplatz vergraben wird. Bei schweren Geburten, die aber selten vorkommen sollen, wird der Fetisch angerufen. Der Fetischpriester opfert dann ein Huhn und scheint auch bei der Geburt mit Hand anzulegen. Operationen sollen nicht stattfinden, jedoch soll der Fetischpriester Mittel verordnen, welche die Geburt erleichtern. Er bereitet einen Thee aus Blättern, mit dem der Frau der Unterleib eingerieben und der ihr auch innerlich eingegeben wird. Für diese Bemühungen des Fetischpriesters soll ihm gewöhnlich eine Ziege geopfert werden.

Zwillinge gelten auch bei den Bassarileuten als ein böses Omen. Sind Zwillinge die Erstgeborenen, so wird ein Kind behalten, während das andere in einen grossen Topf gethan und lebendig begraben wird. Besteht das Zwillingspaar aus einem Mädchen und einem Knaben, so wird der Knabe behalten; bei gleichem Geschlecht wird, wie bei den Spartanern, der Stärkere von beiden am Leben erhalten. Um gewissermaassen die Zugehörigkeit der Zwillinge zu einander anzudeuten, wird 
Tot- und Missgeburten.
Sympathiemittel

des Fetischpriesters gegen Unfrucht. barkeit.

ein Huhn geopfert und in zwei Hälften geteilt. Die eine Hälfte wird dem zu begrabenden Kinde mitgegeben, die andere Hälfte wird in einem Topfe neben der Grabstätte des Kindes eingegraben. Dieses Opfer soll gleichsam den Fetisch versöhnen und den Geist des verstorbenen Kindes an die nahe Beziehung zu dem lebenden $Z$ willing erinnern, damit er sich nicht an ihm rächt. Nachgeborene $Z$ willinge werden ebenfalls lebend begraben. Später geht der Mann zum Fetischpriester, um dem Fetisch zu opfern und ihn zu bitten, dass er ihn vor einer Wiederholung des Unglücks behüten möchte. Frauen, die Zwillinge geboren haben, dürfen nicht mehr zur Einsaat und Ernte des Guineakornes auf die Farm gehen, da sie die Frucht des Feldes verderben könnten. Erst nach der Wiedergeburt eines Kindes erlaubt ihnen das Fetischgesetz wieder an den Feldarbeiten teilzunehmen.

Als ebenso verhängnisvoll werden Tot- und Missgeburten angesehen. Totgeborene Kinder dürfen, da sie gewissermaassen ansteckend wirken sollen, nur von alten Frauen begraben werden. Die Leute erzählten mir dass, wenn eine junge Frau ein totgeborenes Kind beerdige, sie sicherlich ebenfalls tot gebären werde. Missgeburten werden, da sie noch gefürchteter sind, vom Vater selbst in aller Stille im Busch begraben. Die Mutter von Tot- oder Missgeburten geht zum Fetischpriester und bringt dem Fetisch ein Sühnopfer, wobei der Priester gewisse Fetischzeremonieen vornimmt. Ein weisses Opferhuhn wird dabei an der Stelle begraben, wo sich die Frau zu waschen pflegt.

Bleibt die Ehe in den ersten Jahren kinderlos, so geht die Frau mit Opfergaben zum Fetischpriester und bittet ihn um ein Mittel. Dieser giebt ihr gewisse Verhaltungsmaassregeln; so darf die Frau z. B. bloss auf einem bestimmten Stuhl sitzen. Bekommt die Frau dann wirklich ein Kind, so wird der Knabe oder das Mädchen mit ${ }_{5} 5$ oder 17 Jahren zum Fetischpriester geführt und die Eltern bringen dem Fetisch ein Dankopfer. Die Opfergaben bestehen aus einem Perlhuhn, einem weissen Huhn, Guineakorn, Yams und Oel. Dem Knaben oder Mädchen wird das Haupthaar abgeschnitten, welches dem Fetischpriester verbleibt. Es ist dieses gewissermaassen das sichtbare Zeichen, dass die betreffende Person von dem Bann und der Verbindlichkeit dem Priester und dem Fetisch gegenüber befreit ist; wird dieses Opfer nicht gebracht, so gehört das Leben des Menschen dem Fetisch und derselbe soll vorzeitig sterben. Einen ähnlichen Gebrauch finden wir bei dem Tode einer verheirateten Frau wieder; die abgeschnittenen Haare derselben werden ihrer Familie als Zeichen des Todes übergeben.

Uneheliche Uneheliche Kinder werden von den Eltern der Mutter wie ihre Kinder. eigenen Kinder aufgezogen. Sie treten in dieselben Rechte wie die ehelichen Kinder. Ist der Vater des unehelichen Kindes bekannt, so 
muss er an die Eltern der Mutter denselben Wert zahlen, welchen das übliche Hochzeitzsgeschenk betragen haben würde. Aus diesem Grunde heiratet der Neger meistens schon aus pekuniären Rücksichten, obgleich er nach Zahlung der Abfindungssumme nicht mehr dazu verpflichtet ist. Ist eine verheiratete Frau ihrem Manne untreu, so hat der Gatte das Recht, sie den Eltern zurückzuschicken und das Hochzeitsgeschenk zurückzuverlangen. Wenn die Ehegatten mit der Scheidung einverstanden sind, muss die Frau das Hochzeitsgeschenk dem geschiedenen Manne zurückerstatten. Trennt sich aber der Mann von der Frau ohne ihren Willen, so hat derselbe keinen Anspruch auf den Ersatz des Hochzeitsgeschenkes. Wenn Witwen wieder heiraten, so bleiben die Kinder aus der ersten Ehe, solange sie Säuglinge sind, bei der Mutter, müssen aber später der Familie ihres ersten Mannes zurückgegeben werden. Im grossen und ganzen erfreuen sich Witwen, welche nicht wieder geheiratet haben, bei den Bassarileuten keines guten Rufes.

Da in Bassari Mangel an heiratsfähigen Mädchen herrscht, so nehmen die Bassarileute häufig Sklavinnen zur Frau. Für gewöhnlich jedoch heiraten sie Mädchen aus ihrem Stamme, da dieselben billiger sind, als eine Sklavin, die immerhin einen Geldwert in Kauris oder anderen Tauschartikeln von etwa 65 Mark repräsentiert. Die meisten Sklaven kommen aus dem benachbarten Kabrélande, wo angeblich ein grosser Ueberfluss an Menschen vorhanden sein soll. Die Kabréleute sollen häufig ihre eigenen Kinder zum Verkauf auf den Markt bringen oder fremde. Kinder abfangen und verkaufen, um ihre eigenen ernähren zu können. Auch die Häuptlinge bemächtigen sich ihrer eigenen Unterthanen und verkaufen sie in die Sklaverei. Doch mögen diese Angaben auf Uebertreibung beruhen, da die Bassarileute wahrscheinlich ihr Verhalten in der Sklavenfrage mir gegenüber beschönigen wollten. Der hauptsächliche Absatzort für die Kabrésklaven soll in Kabo sein, wo sie gegen Guineakorn an die Kaboleute verhandelt werden. Diese bringen sie auf die naheliegenden Märkte, wie auch nach Bassari, von wo aus sie dann weiter gehen. Häufig lassen sich die Haussahändler diesen guten Verdienst nicht entgehen und bringen die Sklaven als Träger oder, nach Haussaart frisiert, als ihre eigenen Kinder bis zur Küste. Nach Kabo hatten sich auch einzelne der herbeigerufenen Sabermareiter, die als Sklavenräuber gefürchtet sind, zurückgezogen. In Bassari sollen die Sklaven meistens für Kauris verkauft werden. Ein Kind soll mit 20 Mark, ein ausgewachsenes Mädchen oder ein junger Mann mit 65 Mark bezahlt werden, dagegen erzielt ein alter Mann oder eine alte Frau nur den unerhört geringen Preis von 6 Mark. Die Kabrésklaven haben äusserlich viel Aehnlichkeit mit den Bassarileuten. Ihre Tätowierungen bestehen aus drei kleinen, parallel zu einander laufenden, senkrechten 
Einschnitten oberhalb der beiden Brustwarzen und häufig auch am Oberund Unterarm. Die Gesichtsmarken sind ähnlich denen der Bassarileute, doch werden sie nur auf einer Backe getragen. Die Frauen tragen am Nabel, ähnlich wie die Bassarifrauen, drei bis vier Striche, die strahlenförmig nach vier Seiten ausgehen. Charakteristisch für die Kabrésklaven sind vor allem die Löcher in den Nasenflügeln, in welche sie in der Heimat Ringe oder Grashalme als Schmuck stecken. Die Kabréleute sind gewandte Schmiede. Häufig hatte ich in Bassari Gelegenheit, die zierlichen, schmiedeeisernen Halsketten zu bewundern, welche in Kabré hergestellt werden sollen.

Behandlung der Sklaven und ihre Rechte

Die Sklaven leben ganz in der Familie ihres Herren und werden von diesem häufig wie ihre Kinder betrachtet. Allerdings hat der Sklave kein Recht, Eigentum zu erwerben, er ist somit ein willenloses Werkzeug in den Händen seines Gebieters. Erst wenn der Sklave heiratet und Familie bekommt, wird ihm eine gewisse Selbständigkeit eingeräumt und mit dem Tode seines Herrn kann er, wenn dieser keine Erben hinterlässt, frei werden, unter Umständen sogar sein Vermögen erben. Die männlichen Sklaven werden gewöhnlich zur Feldarbeit benutzt, während die weiblichen Sklaven im Hause die Frauenarbeit verrichten und nicht selten die Zuneigung ihres Herrn in dem Grade erwerben, dass er sie heiratet. Der einzige persönliche Besitz, welcher dem Sklaven von seinem Herrn überlassen wird, ist ein Huhn, das ihn überall hin begleitet und dessen Nachzucht ihm auch als Eigentum ver-

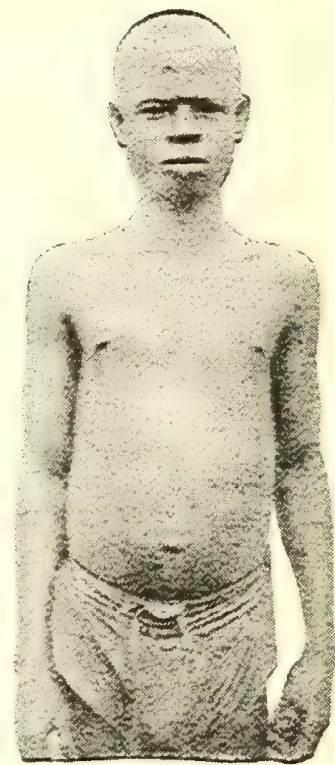

Ein Kabré-Sklave bleibt. Sklaven, welche das Heimweh nicht überwinden können, werden häufig durch Heirat an das neue Heim gebunden, damit sie nicht entlaufen. Die Strafen der Sklaven bestehen hauptsächlich darin, dass sie in Eisen gelegt und gezüchtigt werden. Die Todesstrafe wird gegen Sklaven fast nie verhängt, weil mit ihrem Tode ein materieller Verlust für ihren Herrn verbunden sein würde. Aus diesem Grunde zieht es der Bassarimann vor, einen nicht tauglichen Sklaven einfach zu verkaufen. Heiratet ein Sklave, so erhält er für sich eine eigene Hütte und arbeitet, wenn seine Familie Zuwachs erhält, nur noch 4 Tage in der Woche für seinen Herrn, während er die übrigen 2 Tage für seine Familie arbeiten darf. Die Woche der Bassarileute zählt nämlich nur 6 Tage und ein bestimmter Ruhetag wird in dieser nicht innegehalten. Die Sklavin wird durch Verheiratung mit einem Bassarimann frei und selbst 
wenn sie einen Sklaven heiratet, arbeitet sie nur noch für ihre Familie. Die Kinder von Freien und Sklaven, also aus Mischehen, sind frei, jedoch können Söhne, deren Vater Sklave war, keine Ehrenämter erhalten und somit auch nicht in den Gemeinderat kommen. Söhne von früheren Sklavinnen können dagegen die höchsten Aemter; selbst die Königswürde erreichen. Dieser Brauch lässt sich nur aus dem Mangel an Frauen und der Entvölkerung durch den Krieg, sowie dadurch erklären, dass die Bassarileute Wert darauf legen fremdes Blut in ihren Stamm aufzunehmen. Kinder aus einer Sklavenehe, deren Mutter und Vater also Sklaven sind, werden wieder Sklaven und sind Eigentum des Herrn ihrer Eltern. Die Sklaven vererben sich meistens auf den Sohn oder Bruder des verstorbenen Herrn. Mit dem Tode ihres zweiten Herrn werden sie jedoch nach dem allgemeinen Landesgesetz frei. Einheimische Freie werden wegen Schulden nicht selten zur Sklaverei verurteilt. Zwar haftet die Familie für die Schulden eines Familienmitgliedes und das Familienoberhaupt kann sie entweder mit einem Sklaven oder mit Familienangehörigen decken; ist aber die Familie hierzu nicht imstande, so wird der Schuldner Sklave seines Gläubigers.

Die Bassarileute erreichen, falls sie nicht durch den Gifttrank des Fetischpriesters oder durch Mord aus dem Leben scheiden, im Durchschnitt ein Alter von höchstens 50 Jahren. Schon mit 45 Jahren treten die Leute in das Greisenalter ein und mit 50 Jahren sterben sie an Altersschwäche. Bei dem Tode eines Bassarimannes spielt der Fetischpriester eine besondere Rolle. Er muss zuerst konstatieren, ob der Tod auf natürliche Weise erfolgt, oder ob er auf Mord oder Gift zurückzufuhren ist. In letzterem Falle fällt der Fetisch gewissermaassen einen Orakelspruch, indem er den Verdacht der Thäterschaft auf bestimmte Personen lenkt. Die Familie des Verstorbenen setzt eine Ehre darein, die Totenfeier und das Begräbnis des Verstorbenen den Vermögensverhältnissen entsprechend würdig zu gestalten. DieLeiche wird gewaschen, mit Rotholz eingerieben, auf ein Brett gebunden, mit weissen Tüchern bedeckt und in feierlicher Prozession umhergetragen. Bei einem Begräbnis, dem ich beiwohnte, sprangen die Leute mit der Leiche im Kreise herum, was einen höchst peinlichen Eindruck machte. Jedoch ist auch damit ein bestimmter Aberglaube verbunden, den ich leider nicht ermitteln konnte.

Der Verstorbene wird, sobald das Grab fertig ist, bei niedergehender Sonne in liegender Stellung von den Familienangehörigen unter feierlichen Gesängen begraben. Der Kopf wird mit der einen Hand gestützt, so dass der Tote das Aussehen eines Schlafenden hat. Verheiratete Leute werden in ihrem Gehöft begraben, während junge Leute, Sklaven und Kinder ihre Ruhestätte in dem Busch finden. Das Schurz- 
fell, welches der Verstorbene bei Lebzeiten getragen hat, wird ihm vor der Beerdigung abgenommen. Die Gräber, welche im Busch liegen, werden mit Dornen bedeckt, um sie vor Hyänen zu schützen. Nach der Beerdigung versammeln sich sämtliche Trauergäste in dem Gehöft des nächsten Anverwandten, wo sie festlich bewirtet werden und mit dem üblichen Schiessen das Totenfest feiern. Für einen Mann soll drei Tage, für eine Frau vier Tage lang geschossen werden. Der Körper des Verstorbenen gehört gewissermaassen der Familie des Vaters, welche ihn auch zu beerdigen hat; die Haare, welche dem Toten abgeschnitten werden, gehören dagegen der Familie der Mutter, welche dieselben ebenfalls weit im Busch vergräbt. Sobald sich die Kunde von einem Morde oder Totschlag verbreitet, sollen , sich die Familienangehörigen des Getöteten von der Mutter- und Vaterseite vereinigen, um über diesen Fall zu beraten. Die Uebersendung der Haare des Verstorbenen an die Familienmitglieder mütterlicherseits bedeutet gewissermaassen die Mahnung an dieselben, die Todesursache unparteiisch zu prüfen; die Annahme der Haare gilt als Anerkennung, dass der Verstorbene eines natürlichen Todes gestorben ist. Verheiratete Frauen, die aus anderen Dörfern stammen, werden häufig wegen der weiten Entfernung an dem Wege, welcher nach ihrem Heimatsort führt, begraben. Ihren Verwandten beziehungsweise ihrer Familie in der Heimat werden drei bis vier Bambusstäbe von der Hütte der Verstorbenen sowie ihre abgeschnittenen Haare mit einem Tuche bedeckt übersandt. Diese Gegenstände, welche gleichsam den Leichnam symbolisch darstellen, werden in dem Heimatsdorf der Verstorbenen feierlich beerdigt. Die Leichname von Schuldnern können nur mit Einverständnis sämtlicher Gläubiger begraben werden, andernfalls werden sie auf einem öffentlichen Wege an einen Baum gesetzt, und neben ihnen die wenigen Sachen, die sie hinterlassen haben, aufgestellt. Kommt dann ein Gläubiger und verlangt die Bezahlung seiner Forderung von der Familie, so weist diese ihn in den Busch zu dem Leichnam. Nur derjenige hat das Recht, einen Schuldner zu begraben, welcher die Schulden desselben bezahlen will. Auf diese Weise erlöschen also mit dem Tode die Schulden. Es gilt jedoch als eine grosse Schande für die Familie des Verstorbenen, wenn sie ihm kein würdiges Begräbnis zu teil werden lässt, und aus diesem Grunde kommt die Aussetzung eines Schuldners nur äusserst selten vor, auch wohl deshalb, weil der Glaube herrscht, dass der Geist unbeerdigter Leute keine Ruhe findet und unstät umherirrt.

Die Die eigentliche Trauer dauert in Bassari etwa I6 Tage. Während Trauerzeit. dieser Zeit dürfen die betreffenden Ehegatten ihre Hütte nicht verlassen und werden von Bekannten und Verwandten mit Essen versorgt. Die Frau legt zum Zeichen der Trauer ein dunkelblaues Tuch an. Am 
siebzehnten Tage wird der oder die Leidtragende im Busch gewaschen und kann dann wieder der Arbeit nachgehen. Vorher aber wird ein Besuch bei den Verwandten und Bekannten gemacht, um ihnen für das Essen sowie für die während der Trauerzeit geleistete Hilfe zu danken. Hierbei werden die Trauernden meist mit Kauris beschenkt, damit sie etwas für ihren nächsten Lebensunterhalt besitzen. Die Frau darf nämlich nichts von ihrem verstorbenen Mann an sich nehmen, da bei den Leuten der Aberglaube herrscht, dass sie dann auch sterben müsse. Während der Witwenzeit sollen die Frauen blaue Tücher tragen. Meistens jedoch heiraten sie bald wieder. Schon während der Trauerzeit pflegt derjenige, der sie heimzuführen gedenkt, die Fürsorge für die Witwe zu übernehmen und ihr das Essen zu bringen. Bald nach der Trauer zieht dann die Witwe in sein Haus und heiratet ihn.

Was das Erbrecht anbelangt, so erbt das Kind das ganze Vermögen, hat dann aber auch die Verpflichtung, für die Familie zu sorgen und übernimmt eventuell gleichzeitig die Schulden des V'erstorbenen. Sind Söhne vorhanden, so haben sie den Vorzug, der älteste Sohn wird Familienoberhaupt, er tritt auch in die Rechte des Vaters und erhält Sitz und Stimme in dem Gemeinderat, falls sein Vater Mitglied desselben gewesen ist. Hinterlässt der Verstorbene keine Kinder, so erben seine Geschwister. Alle diese Gebräuche haben eine gewisse Aehnlichkeit mit denjenigen der Evheneger.

\section{POLITISCHE VERHÄLTNISSE.}

Die politischen Verhältnisse waren vor und während unserer An- Die deutsche wesenheit in Bassari ungefähr folgende. Mossi im Norden war durch und eine Station in Wagadugu mit Franzosen besetzt, ebenso ein grosser Teil von französische Gurma, mit Ausnahme von Pama, welches durch den deutschen Offizier, Besetzung der Leutnant Thierry, mit zo Mann besetzt war. Die Station Sansane-Mangu streitigen war durch den Rückzug des Dr. Gruner augenblicklich von Weissen entblösst, dafür war aber durch unseren Einzug in Bassari dieses selbst mit fünf Weissen besetzt. Von Bapure war der kleine deutsche Posten zurück gezogen, während sich in Kabo ein Franzose mit einigen Schwarzen aufhielt. In Sara war die deutsche Flagge angeblich gestohlen und dieses schon zu unserer Zeit von den Franzosen durch einen Weissen mit zwölf Schwarzen besetzt. In Dako befand sich eine französische Station mit zwei Weissen, während in Bafilo der französische Resident auf einer grossen Station mit mehreren Weissen seinen Sitz hatte. Weiter im Norden war Semere von einem starken französischen Posten von Schwarzen besetzt, und in Sugu befand sich eine französische Station mit zwei Weissen. Im Süden war noch in Kirikri eine französische Station, die aus einem Weissen und einer kleinen schwarzen Besatzung bestand, welche auf König Dyabo von 
Tshautsho einen Druck ausüben sollte. Von deutscher Seite war Sugu mit einem Weissen und einer Besatzung von etwa dreissig Mann belegt, während sich in Semere und Sudu je ein schwarzer Agent befand.

Aus dieser kurzen Uebersicht geht deutlich hervor, dass uns die Franzosen an Stationen, kleinen Posten und Besatzungen überlegen waren. So waren, kurz vor unserem Einzug, in diesen streitigen Gebieten ständig nur drei deutsche Weisse stationiert, während von Seiten der Franzosen nach den ungefähren Angaben zehn bis zwölf Weisse thätig waren. Im letzten Augenblick vor Abschliessung des Pariser Vertrages, leider aber zu spät, wurden noch einige Weisse in das Hinterland gesandt, um streitiges Gebiet zu besetzen. So ging zu gleicher Zeit mit uns Dr. Kersting mit einem Assistenten nach Sugu und auch dem Dr. Gruner wurde ein Assistent zur Unterstützung beigegeben. Später sogar, nach Abschluss dieses Vertrages, traf noch die ganze Truppe von der Küste mit vier Weissen in Bassari ein. Während dieser Zeit setzten im Westen die Engländer ihr früheres Treiben in Salaga fort. Im Dagombareiche waren die Wege für Karawanen gesperrt und im Osten hatte sich auch der kleine Stamm der Konkomba zusammengerottet. Leider konnte aber die kleine Truppe gegen die feindlichen Dagomba nicht mehr in Wirksamkeit treten, da wir nunmehr die neutrale Zone respektieren mussten. Auf diese Weise konnte sie nur die Konkomba durch ein kleines Gefecht züchtigen und die Strasse nach Sansane-Mangu wieder frei machen.

\section{VON BASSARI NACH SUGU.}

Lange vor Ankunft der Truppe erhielten wir plötzlich von Dr. Kersting, der sich noch auf dem Marsche von Paratan über Kirikri nach Sugu befand, die Nachricht, dass der einzige Weisse in Sugu, Zollassistent Wegner, verstorben sei und die deutsche Besatzung infolge der Ränke

Bedrängnis der deutschen Besatzung in Sugu. der Franzosen durch den König von Sugu hart bedrängt werde. Der König drohte dem deutschen Dolmetscher und den Soldaten, dass er sie, falls sie nicht freiwillig die deutsche Flagge einzögen und abmarschierten, mit Gewalt vertreiben würde. Aus diesem Grunde bat uns Dr. Kersting, ihn zu unterstützen und $\mathrm{ihm}$ Antwort nach Sudu zu senden, wo er vorläufig die Dinge abzuwarten und mit dem König von Sugu friedlich zu verhandeln gedenke. Natürlich stand mit dem Eintreffen dieser Nachricht unser Entschluss fest, dem Dr. Kersting sofort mit allen verfügbar̨en, wenn auch nur bescheidenen Kräften, zur Hilfe zu eilen. Alsbald wurden 
die notdürftigsten Lasten zusammongestellt und die Gewehre der Soldaten gemustert. Auch von Dr. Gruner erhielten wir noch eine Anzahl Karabiner und uniformierte Träger, welche in den Augen der Schwarzen die geringe Anzahl unserer Soldaten bedeutend erhöhten. Ausser den allernotwendigsten Effekten und unseren Betten bestanden alle übrigen Lasten aus Patronen. Der Expeditionsmeister Hoyer musste zu seinem grossen Leidwesen zurückbleiben, um unsere Lasten $z u$ bewachen und uns erforderlichenfalls Munition und Proviant nachzusenden.

Nachdem wir uns von den Weissen in Bassari verabschiedet hatten, traten wir mit der aus etwa dreissig Köpfen bestehenden Expedition den Marsch an. Unser Personal befand sich in einer gedrückten Stimmung, da es den Bestimmungsort und Zweck der Reise nicht kannte; nur unsere kleinen Bengels, welche uns auch auf diesem Marsche begleiteten, waren wie immer guter Dinge. Unser Marsch war in der ersten Zeit wenig vom Wetter begünstigt, der Himmel schien alle seine Schleusen aufgezogen zu haben. Der Weg führte ungefähr nach Osten; hinter uns lag der Bassariberg und vor uns die kleinen Höhenzüge, welche schliesslich bei Dako in das Gebirge übergehen. Von grösseren Flüssen ist auf dieser Strecke nur der Kotokoli mit einer Breite von etwa i5 Metern zu erwähnen, an dem grössere Farmen zur Gewinnung des schon erwähnten Fischgifts lagen. Dagegen trafen wir häufiger kleine Bäche, welche die wiederholten Terrainwellen einschnürten und mit zahlreichen hohen Bambussträuchern eingefasst waren. Leider litt ich an diesem Tage an einem heftigen Fieber, welches mir bei dem strömenden Regen den Marsch und die geographischen Aufnahmen sehr erschwerte. Erst im Dunkeln erreichten wir den westlichen Ort von Dako, das Dorf Djavalim. Auf der Höhe erblickten wir die kleinen Feuer von Daude, unserem Nachtquartier. Bald hatten wir auch dieses erreicht und in einer grossen Hütte Unterkunft erhalten, da die Leute auf einen häufigeren Besuch von Weissen, wahrscheinlich von Franzosen, eingerichtet zu sein schienen. Am nächsten Tage liess ich mir die vier Dörfer von Dako zeigen, welche terassenförmig auf den Höhen liegen. Ausser Djavalim mit etwa 200 Hütten, welches am niedrigsten liegt, besteht Dako aus unserem Rastplatz Daude mit etwa 400 Hütten; weiter östlich aus Kadyerando mit etwa 300 Hütten und aus der auf der Höhe des Gebirgskammes gelegenen Königsstadt Soré mit etwa 7oo Hütten. In Soré war eine französische Station errichtet. Dako scheint ziemlich selbständig zu sein, wird aber als zu Bafilo gehörig angesehen. Die Leute sind mit einem Fell oder nur mit einem kleinen Schamtuch bekleidet, tragen aber auch viel eigengewebte Hemden. In Daude selbst besteht eine ganze Weberkolonie; man kann hier häufig zehn Webstühle in einer Reihe in Thätigkeit sehen. Im grossen und ganzen hat das 
Volk dieselben Eigentümlichkeiten wie das von Akbande. Dako gehört ebenfalls in das Bereich der Temusprache. Zu unserer Zeit stand Dako vollkommen unter französischem Einfluss und wir wurden daher als Deutsche mit Mișstrauen aufgenommen.

Am nächsten Tage marschierten wir nach dem Königsort Soré. Der Weg ging steil bergan, bis auf die etwa 520 Meter hohe Gebirgskette, auf der Soré gelegen ist.'Das Gebirge bei Dako besteht zum grossen Teil, wie das ganze Bo-Gebirge, aus Quarzgestein. Von dem Gebirgspfade nach Soré hat man einen schönen Ueberblick über die Ebene des Kará und weiterhin über die Berge von Kabré. Noch auf halber Höhe stockte plötzlich unsere Karawane; die Ursache war das Erscheinen einer Dagombakarawane, welche von Daude nach Soré reiste. Dieselbe schien sich, als sie die deutsche Flagge bemerkte, auf einen Angriff unsererseits gefasst zu machen und zog es nach kurzer Ueberlegung vor, das Weite zu suchen. Wahrscheinlich glaubte sie, dass der Deutsche Gleiches mit Gleichem vergelte, da die Dagombaleute nach dem Feldzuge alle Karawanen, welche aus deutschem Gebiet kamen, a ls ihre Feinde betrachteten, ausplünderten und die Leute zu Sklaven machten. In kurzer Zeit hatten wir die Königsstadt Soré erreicht und vor dem Gehöft des Häuptlingş Halt gemacht, welcher uns empfing und mit Palmwein bewirtete. Da wir unsėn Marsch nach Sugu vor den Franzosen verheimlichen wollten, zogen -wir nicht direkt über ihre grösste Station Bafilo, sondern auf einem anderen Wege über Aledjo-Kadara und Sudu. Gesellschaftliche Verpflichtungen hatten wir nicht gegen sie zu erfüllen, da die in Dako stationierten Weissen zu dieser Zeit verreist waren. Nur ein schwarzer französischer Agent befand sich auf der Station, welcher die französische Flagge hisste. Der Häuptling selbst begegnete uns äusserst misstrauisch und wollte uns zuerst keine Führer stellen. Nur durch energisches Auftreten und alle möglichen Versprechungen liess er sich dazu bewegen. Schon in Daude wurde uns abgeraten, direkt nach Aledjo-Kadara zu marschieren, da der Weg für Pferde nicht passierbar sei. Wir glaubten anfangs, dass die Leute uns nur aus Misstrauen diesen Pfad nicht zeigen wollten, jedoch mussten wir später einsehen, dass sie Recht hatten. Der Pfad führte quer über die

Ueber das Gebirge von Dako nach Aledjo-Kadara. Hänge des Dakogebirges und über die verschiedensten kleinen Bäche bergauf und bergab. $\mathrm{Ab}$ und zu lagen kleine Farmen von Yams und Erdnüssen an den Hängen und an den kleinen Thälern der Bäche, deren Ufer mit Oel- und Weinpalmen bestanden waren. Die Felsen und Höhenzüge, welche uns begleiteten, bestanden meistens aus eisenschüssigem Quarzit und Glimmerschiefer. Auch kamen an den Hängen grosse Mengen von Rot- und Magneteisenstein vor. Nach Ersteigung der Passhöhe befanden wir uns auf einem Hochplateau, welches mit 
niedrigem Buschwerk bewachsen war. Tor uns lag ein grosses breites Thal und die Führer teilten uns mit, dass Aledjo-Kadara nicht mehr weit entfernt sei. Aber jetzt zeigte sich erst die ganze Schwierigkeit dieses Marsches. Terassenförmig, auf einzelnen glatten Stufen, welche die Schieferplatten des Quarzit bildeten, ging es steil bergab in das Thal des Mo, welchen wir schon früher einmal bei Dyodjega als grossen Fluss unter dem Namen Mongo passiert hatten. Hier hat der Mo nur eine Breite von ro Meter und eine Tiefe von nicht mehr als $\% / 4$ Meter. Es ist ein schöner, raschfliessender Gebirgsstrom, welcher von dem Höhenzuge kommt, der sich zwischen Dako und Sudu von Westen nach Osten erstreckt. In diesem bis dahin noch nicht betretenen Gebiet konnten wir noch eine Menge anderer kleiner Wasserläufe feststellen und somit die Wasserscheide für eine Anzahl kleiner Bäche und Adern zwischen dem Mo im Süden und dem Kara im Norden finden. Dass bei dem nun folgenden steilen Abstieg keiner unserer Träger verunglückte und dass unsere Pferde auf kleinen Umwegen unbeschadet in das Thal gelangten, war wirklich ein Wunder. An dem schönen Mo, der von massenhaften Wein- und Oelpalmen umgeben ist und an dem sich im Westen schöne grüne Wiesen entlang ziehen, während im Osten das Gebirge schroff in's Thal abstürzt, machten wir Halt und pflegten eine Zeit lang der wohlverdienten Ruhe.

Hoch oben auf steilen Felsen, etwa 720 Meter über dem Meeres- Steiler Aufspiegel, lagen die kleinen Lehmhütten der Bewohner von Aledjo-Kadara. stieg und EinNach einer kurzen Rast begann der fast unüberwindbar scheinende Aufstieg über schroffe Felsblöcke, welche die Träger mit ihren schweren Lasten schrittweise zu erklimmen hatten. Auf halber Höhe der Felstrefien in Aledjo. Kadara. wand war von einem eigentlichen Pfade überhaupt nicht mehr die Rede, nur in einer engen ausgelaufenen Felsmulde konnte man sich von Stufe zu Stufe schwingen. Erstaunlich war es, wie die Leute diese Schwierigkeit trotz der Lasten überwanden. Auch ist es mir heute noch rätselhaft, wie das Pferd des Assessors Hupfeld, welches allerdings kleiner war, als das meinige, wenn auch ohne jegliches Gepäck diese Bergpartien hat nehmen können. Mein Pferd war nicht dazu imstande und ich musste es mitten auf der steilen Felswand stehen lassen. Nur mit Muhe erklomm ich mit einigen Soldaten, die bei mir geblieben waren, um das Pferd anzutreiben, Schritt für Schritt die hohen Felsen, während Assessor Hupfeld, der allerdings als geborener Bergbewohner mir im Klettern weit überlegen war, Aledjo-Kadara noch vor Sonnenuntergang erreichte. Die unglaubliche Gewandtheit, mit der die Bewohner von Aledjo-Kadara die Felswand erstiegen, erregte meinen Neid.

Schon lag das Thal des Mo und das gegenüber liegende Gebirge mit seinen weissen Quarzfelsen im Dunkel; der Mond stand am Firma- 
ment und warf lange Schatten über das Gebirge, als wir endlich das Hochplateau erstiegen und durch grosse Farmen von Guineakornfeldern in Aledjo-Kadara einzogen, wo Assessor Hupfeld schon das Nachtquartier besorgt hatte. Hoch über den kleinen runden Hütten wehte die deutsche Flagge. Die Leute waren meistens mit einem Fell und einer phrygischen Mütze bekleidet, nur die Grossen und Vornehmen trugen ein Haussahemd. Sie kauerten aut der Erde, schlugen mit der rechten Faust auf den Erdboden, und riefen beständig „ya he, ya he, ya he". Der Häuptling brachte uns eine Menge Yams und Guineakorn, auch unseren Leuten wurde Palmwein und Bier kredenzt, so dass die Anstrengungen des Tages bald vergessen waren. Nur der Gedanke liess mir keine Ruh, ob wohl mein Pferd, das ich schon verloren gègeben hatte, noch gerettet werden würde. Da die Leute gewandte Bergsteiger sind und selbst auf diesem Hochland Pferde halten, so setzte ich eine Belohnung aus, falls sie es mir gesund zuführten. Am nächsten Morgen wurden wir schon früh mit dem Gruss „ya he, ya he, ya he“, geweckt und unser Dolmetscher Garver meldete mir, dass mein Pferd heraufgebracht sei und munter Guineakorn fresse.

Das Bergdorf Aledjo-Kadara ist im wahren Sinne des Wortes ein verlassenes Aledjo- Räubernest. Von allen Seiten ist dieses kleine Plateau wie ein AdlerKadara horst durch hohe abfallende Felsen geschützt, nur von Norden her ist es erreichbar. Die Bewohner machen einen ebenso rauhen Eindruck wie die Bassarileute und der Häuptling von Aledjo-Kadara, ein ganz intelligenter Mann, ist weit und breit wegen seiner Sklavenräuberei berüchtigt. Aledjo-Kadara selbst besteht aus lauter kleinen, zerstreut liegenden Dörfern, die nach meiner Schätzung zusammen ungefähr I ooo Hütten besitzen. Die Stammeszeichen der Bewohner sind ziemlich dieselben wie in den meisten Temuländern, 3 bis 4 Längsschnitte über der Backe oder auch ein kleiner Querschnitt oberhalb und parallel der Nasenlippenfalte, der entweder nur auf einer Seite oder auf beiden vorkommt. Seltener findet man die langen Längsschnitte und die bezeichneten Querschnitte zusammen vor. Die Haartracht der Frauen ist ebenfalls dieselbe, wie in Akbande, auch werden hier häufig als Ohrschmuck von den Frauen kleine Grashalme oder buntgefärbtes Mark von Hirsestauden getragen. In diesem Gebirgshochland sieht man schöne Rinderherden, die jedoch meistens den Fulbe gehören, welche auch hier Niederlassungen besitzen. Schöne Wiesen mit saftigen Gebirgskräutern ermöglichen ausser der Viehzucht die Haltung von Pferden.

Am nächsten Morgen mussten wir trotz der vielen Fusswunden, welche sich unsere Träger bei dem Aufstieg zugezogen hatten, unsern Marsch wenigstens bis in die nächstgrössere Stadt Kumonde fortsetzen. In der Frühe sank auf diesem Hochplateau die Temperatur auf $15^{\circ} \mathrm{C}$. 
und die ganze Berglandschaft lag in dichtem Nebel, der sich als Regen niederschlug. Endlich durchbrach die Sonne den Wolkenschleier und binnen zwei Stunden hatte sich die Luft bis auf $24^{\circ} \mathrm{C}$. erwärmt. In Aledjo-Kadara bemerkte ich zum ersten Mal einen berufsmässigen Regenmacher, der aber diesmal den Regen, der schon zu lange gewährt hatte, wegzaubern sollte. Seine Kleidung trug geringe Spuren seines Fetischhandwerks; sie bestand nur aus einem kleinen gegerbten Schurzfell, und einer phrygischen Mütze. Er nahm auf einem erhöhten Punkte in dem Dorfe Aufstellung und fegte mit einer kleinen aus Raphiabast hergestellten Rute in der Richtung des Wolkenzuges den Regen fort. In der That hörte an diesem Tage der Regen auf, so dass die Leute für diesmal in ihrem Aberglauben bestärkt wurden.

Unsere Karawane wurde von Aledjo-Kadara aus von einigen Reitern begleitet, die mit Speeren bewaffnet waren und unter denen sich der Sohn des Häuptlings befand. Diese Leute machten denselben Eindruck wie die wilden Sabermareiter. Mit ihren geschickten Pferden sprangen sie in Karriere über Felsblöcke und Wurzeln auf und ab. Bald verengte sich das Plateau und 20 bis 30 Meter hohe Felsen schlossen einen kleinen Wiesenkessel ein. Mit einiger Phantasie konnte man in diesen Felsen aus Quarzit und Glimmerschiefer die eigentümlichsten Formen, wie Türme und Zinnen erkennen, so dass man unwillkürlich an das Elbsandsteingebirge oder an die Felsen von Adersbach und Weckelsdorf erinnert wurde. Unter andern gelangten wir zu einem Engpass zwischen den Felsenmauern, der durch einen künstlichen Steinwall bis auf einen schmalen Pfad vollkommen geschlossen war. Diese Steinwälle sollen im Kriege gegen Reiterangriffe schützen; wir finden sie in diesen Berglandschaften häufig wieder. Beim Weitermarsch öffnete sich wieder ein schönes Thal mit Wiesen und Hirsefeldern, die von hohen Felswänden eingeschlossen waren. Hier, nicht weit von dem Dorfe Peva, waren kleine Fels- und Erdmauern als Schiessstände für die Leoparden- und Hyänenjagd errichtet.

In Péva, einem Doppeldorf von etwa 600 Huitten, machten wir Halt. Wir wurden von dem Häuptling mit seinen Ratgebern empfangen und erhielten einen schönen Palmwein vorgesetzt, der aus der Raphia vinifera bereitet war. Da Péva unter der Oberhoheit des Königs Dyabo von Tshautsho stand und somit in unsere deutsche Interessensphäre fiel, wollten die Leute von der französischen Flagge, die hier unrechtmässiger Weise aufgezogen war, nichts wissen und als sie erfuhren, dass der mächtige

Flaggen hissung in Péra und Busiré, König Dyabo selbst unsere schwarz-weiss-rote Flagge führe, zogen sie die französische Flagge ein. Unter einem feierlichen Salut, der in den naheliegenden Felsen seinen Wiederhall fand, und unter dem Hurra unserer Leute stieg nun die deutsche Flagge in die Höhe. 
Nach dem Austausch von Geschenken und einer kurzen Rast verliessen wir Péva und gelangten nach dem kleinen Dorfe Busiré, wo die Leute ebenfalls um die Flagge baten. Der Weg führte bergauf und bergab über kleine Flussbäche, an deren Ufern Dattelpalmen, Oelund Weinpalmen standen. Die Farmen in dem weiten Felsenkessel waren meistens mit Hirse und Yams bestellt. Ueberall traten grosse quadratische Blöcke aus dem Erdboden hervor; auch die Farmen waren mit einzelstehenden turmartig aufragenden oder gruppenweise zusammenstehenden Felspartieen durchsetzt. Ab und $z u$ hatte man besondere Reitwege um

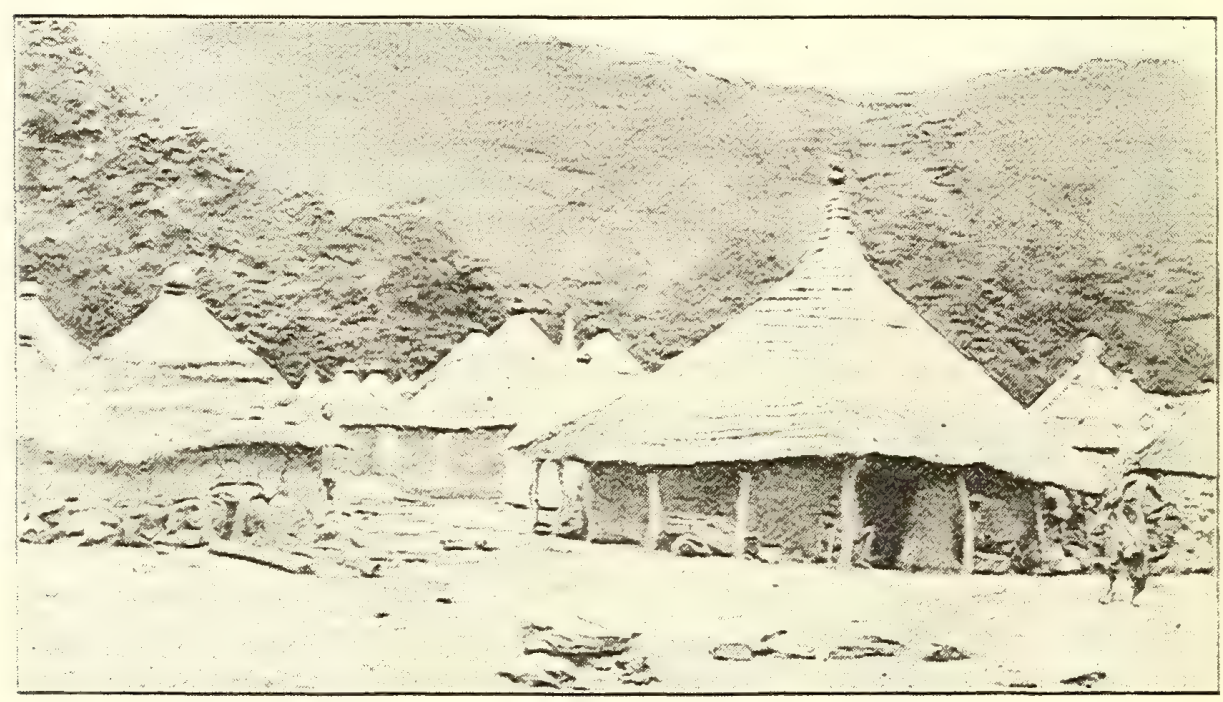

Häufig vorkommende Hüttenform in den Temu-Landschaften.

die Klippen herumgeführt, um den Pferden das Betreten der engen felsigen Fusspfade zu ersparen. Durch einen Engpass betrat man wieder. einen neuen Kessel, der gleichfalls durch eine Felswand gesperrt war. Der schmale, ausgetretene Pfad führte über Geröll und Steine immer bergauf, bis wir plötzlich durch zwei hohe Felsen, wie durch ein Festungsthor,

Die in die grosse Felsenstadt Kumondé gelangten. Die einzelnen Stadtviertel Felsenstadt schienen gleichsam in den Fels gehauen. Ein grosses Treiben entwickelte Kumondé sich vor unseren Augen in dem Zentrum der Stadt, auf dem grossen und ihre Marktplatz. Hier wurden, wie auf allen grossen Negermärkten, die verBewohner. schiedensten Waren bunt durcheinander feil gehalten, doch waren verhältnismässig wenig europäische Küstenprodukte zu bemerken. Leider konnten wir den Markt nicht näher in Augenschein nehmen, weil das Volk bei unserer Ankunft nach der Königsstadt eilte, wo wir im Gehöft 
des Königs unser I ager aufgeschlagen hatten. Bald waren wir umringt von einer dichten Menschenmenge. Ausser dem kleinen Platz vor dem Gehöft des Königs hatten die Leute auch die $20 \mathrm{~m}$ hohen Felsen, welche diesen Platz einschlossen, dicht besetzt, um unseem Treiben von dort aus zuzuschauen. Auf den Wunsch des Häuptlings von Kumondé wurde hier die deutsche Flagge gehisst. Bis Kumondé hatte uns der Sohn des Häuptlings von Aledjo-Kadara begleitet. In Péva und Busiré war er von den Häuptlingen freundlich aufgenommen worden, in Kumondé aber mussten wir ihn gegen die Angriffe der Leute schützen. Der Häuptling von Kumondé hält sich nämlich für den eigentlichen Herrn von AledjoKadara, wogegen der Häuptling von Aledjo-Kadara sich als vollkommen unabhängiger Herrscher fühlt und als solcher auch in Péva und Busiré anerkannt wird, die indessen dem Häuptling von Kumondé unterstehen.

Die Stadt Kumondé, die in verschiedene Stadtviertel zertällt, ist ihrer Lage nach eine der romantischsten Negerstädte, die ich gesehen habe, aber der 'Unrat und Schmutz und die übergrosse Hitze, welche die kahlen Felsen ausströmen, machen den Aufenthalt nicht gerade angenehm. Die Leute sind mit Fellen oder mit selbstgewebten Hemden bekleidet und tragen phrygische Mützen.

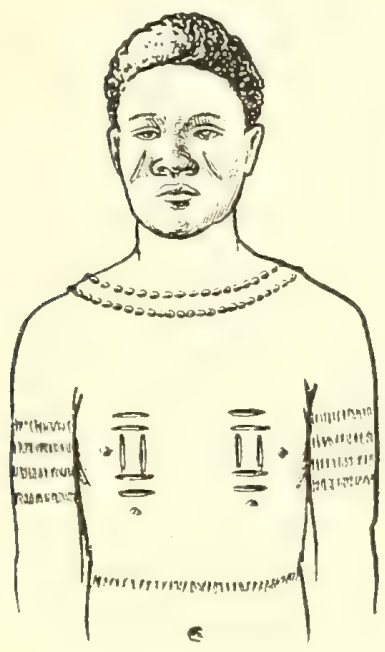
Die Frauen kleiden sich in einheimische Tücher, während die Kinder und Jungfrauen ausser einer Hüftschnur vollkommen unbekleidet gehen. Die Stammeszeichen sind, wie in den Temuländern, 3 bis 4 Längsschnitte vom Ohr bis zum Mundwinkel oder kleine Querschnitte oberhalb der Nasenlippenspalte. Ausserdem werden, wie in Akpande, mannigfaltige Schmucktätowierungen getragen. Bei den jungen Männern fielen mir einige Tätowierungen besonders auf. Mitten auf der Brust wurde ein Zeichen, ähnlich der römischen II getragen, während der obere Teil der Brust mit mehreren kleinen Knopfreihen, die Oberarme und der Bauch oberhalb der Hüften mit Zickzacklinien verziert waren. Die Hütten in Kumondé und in den Gebirgslandschaften, welche wir durchreisten, sind alle rund und mit Kegeldach versehen. Die Gehöfte, in welche man durch eine grosse Eingangshalle gelangt, sind geschlossen angelegt. Die Hütte des Häuptlings ist, wie in den Temulandschaften, häufig mit einem Straussenei gekrönt. 

Hochplateau selbe liegt etwa 600 bis $700 \mathrm{~m}$ über dem Meeresspiegel und zieht sich nach Sudu. von Kumondé bis nach Sudu hin. Die Farmen sind im allgemeinen dürftig; der Boden ist mit Felsblöcken und Steinen bedeckt; überall ragen vereinzelte, ro $\mathrm{m}$ hohe Felsen unvermittelt aus der Erde hervor. Die Vegetation ist ganz derjenigen unseres Hochgebirges ähnlich; statt des niedrigen Knieholzes wächst hier meterhohes Gestrüpp, dessen Stamm und fleischige, fingerartige Blätter einen milchweissen Saft haben. Die mageren Felder bedeckt in grosser Fülle eine schöne, lila blühende Blume, ähnlich unserem Alpenveilchen. Nur an den kleinen Bächen, die von dem Hochland in die Ebene führen, sieht man schöne Wiesen, auch vereinzelt Dattelpalmen. Sogar die Sennhütten fehlen nicht auf dieser Alp, denn die Fulbe haben in Bolo eine kleine Niederlassung von zwölt Hütten gegründet. Schöne Viehheerden weiden auf den Wiesen. Hinter Bolo überschreiten wir die Grenze von Kumonde und gelangen in das Bereich von Sudu. Das Hochplateau senkt sich etwas nach Osten, $\mathrm{ab}$ und zu tritt niedriger Busch auf; im Norden öffnet sich die grosse Ebene und das Thal des Kara, während in weiter Ferne die schwachen Umrisse des Kabrégebirges und des Berges bei Semere auftauchen. Einzelne Felsketten, die sich über das Hochplateau hinziehen, kreuzen unseren Weg, vereinigen sich bei Sudu und fallen gegen Norden steil ab. Natürliche Felsenthore, die nur einen engen Durchgang lassen, sperren die Felsenkessel ab und sind ausserdem noch durch Steinmauern gegen die Einfälle feindlicher Reiter befestigt.

Wir passierten nun den Ort Djalimde, welcher etwa 600 Hütten umfasst, und gelangten auf terrassenförmigen Felsplatten hinabsteigend zu der In der eigentlichen Königsstadt Sudu. Hier machten wir auf der kleinen deutschen befreundeten Station Halt, die aus einigen runden Lehmhütten besteht und nur durch die Königsstadt deutsche Flagge gekennzeichnet wird. Ein schwarzer Agent teilte uns zu Sudu. unserem grossen Leidwesen mit, dass Dr. Kersting über Semere nach Sudu abmarschiert sei. Bald darauf machte uns der alte Häuptling mit dem vom König von Tshautsho eingesetzten Reichsverweser seinen Besuch und hiess uns willkommen. Letzterer trug die kronenartige Kappe, welche die Häuptlinge des grossen Tshautshoreiches aufzusetzen pflegen. Sudu war infolge der engen Fühlung mit dem uns befreundeten Königshause von Tshautsho stets deutschfreundlich gesinnt. Aus diesem Grunde hatten die Franzosen trotz aller Anstrengung hier keinen Stützpunkt gefunden. Sudu besteht aus fünf Stadtbezirken, welche terrassenförmig an den Abhängen des Gebirges liegen. Die Bauart der Hütten ist dieselbe, wie in den Temulandschaften. Die einzelnen kleinen Stadtbezirke haben ungefähr eine Anzahl von je 250 Hütten, Sudu zählt also nach meiner Schätzung ungefähr I 200 bis I 300 Hütten. Ausser Djalimde sollen zu Sudu noch eine Stadt, 
die auf der Karte von Sprigade mit Kadyalóa bezeichnet ist, mit Iooo Hütten, ausserdem die Städte Gande mit 600 Hütten und $\mathrm{Agbandaude}$ mit 400 Hütten gehören. Unsere Leute hatten Mühe, sich die nötigen Nahrungsmittel zu verschaffen, da Geld überhaupt nicht angenommen wurde und auf dem Markt von unseren wenigen Tauschartikeln nur Greybaft, Messingstäbe und Perlen gangbar waren. Die Bekleidung der Suduleute unterscheidet sich nicht von der in den Tenulandschaften, nur dass hier viele vollkommen ausgewachsene Mädchen, unbekümmert um die vielen Fremden, gänzlich unbekleidet einhergingen. Auch sah ich in Sudu zum ersten Mal Zwerge. Da wir Dr. Kersting verfehlt hatten, beschlossen wir, über Semere den nächsten Weg nach Sugu zu nehmen.

Am nächsten Morgen brachen wir unter strömendem Regen mit einigen Führern von Sudu auf und befanden uns bald in der grossen Ebene des Kara, welche weithin mit Farmen bedeckt ist. Kolbenhirse, Yams, Rispenhirse und Okro waren hier in grosser Menge angebaut. Ueberall sah man in den Farmen Kornspeicher von derselben Art, wie wir sie in Kueda und Bassari angetroffen haben, was auf grosse Fruchtbarkeit des Bodens hindeutet. Auf den schönen Thalwiesen weidete das Vieh einiger Fulbeniederlassungen.

Nach Ueberschreitung der Grenze von Sudu kamen wir in das Be- Im Gebiet reich von Semere und an den kleinen Nebenfluss des Kara, den Pindi, von Semere. der etwa $15 \mathrm{~m}$ breit und $1 / 2 \mathrm{~m}$ tief war. Am Pindi begegnete uns eine kleine Karawane von Kabréleuten, welche in grosser Angst vor uns flüchtete. Die Kabréleute kommen an den grossen Markttagen nach Semere, wo sie, wie auch in Kabo, Eisen, wahrscheinlich aber auch Sklaven, gegen Salz, Yams, Guineakorn und andere Lebensmittel eintauschen. Männer und Frauen waren vollständig unbekleidet, nur einzelne alte Frauen trugen einen kleinen Schurz. Die Kabréleute zeigten sich ihren Frauen gegenüber als gewandte Kavaliere. Sie trugen dieselben mit grosser Sorgfalt über den Pindi, während unsere Küstenleute trotz ihrer Soldatenuniform viel weniger Gesittung bewiesen und die Kabréleute wegen ihrer Galanterie verspotteten.

Nach einer kurzen Rast marschierten wir weiter, passierten den kleinen, zerstörten Ort Bäu und erreichten am Nachmittag den Fluss Kara, der hier eine Breite von etwa 20 Metern und eine Tiefe von durchschnittlich I Meter aufwies. Die Strömung war so stark, dass die Träger sich aneinander klammern mussten, um nicht fortgeschwemmt zu werden. Der Weg führte durch eine grosse Baumsavanne, in der Diebefestigte uns der Berg von Semere als Wegweiser diente. Nach dem Ueber-Stadt Semere. schreiten des kleinen Flusses Peli kamen wir in das Bereich der Farmen von Semere; überall war Hirse, namentlich Kolbenhirse, angebaut. Bald hatten wir auch die Stadt selbst erreicht, konnten jedoch zunächst 
keinen Einblick in dieselbe gewinnen, weil sie von einer hohen Mauer und einer riesigen Hecke aus Mimosensträuchern umgeben ist. Ein enger Pfad führt durch die Mauer und die Hecke in das grosse Territorium von Semere. Die Stadt zertällt in einzelne Viertel, welche in grossen Hirse-, Yams-, Erdnuss- und Okro-Farmen zerstreut liegen und durch Dornhecken voneinander getrennt sind. Nach kurzem Marsch passierten wir in einem der südlichen Stadtteile den französischen Posten, der weithin durch seine Flagge erkennbar ist und von einigen Soldaten und einem schwarzen Agenten gehalten wird. Weiter nördlich gelangten wir durch Farmen und Hecken zu der eigentlichen Königsstadt, wo auf einem kleinen Hügel unsere, aus einigen Hütten bestehende Station lag. Schon von weitem flatterte uns die so anheimelnde schwarz-weiss-rote Flagge entgegen. Die Sonne stand schon ziemlich tief, als wir endlich die zum Theil von hohen Bäumen beschattete und durch Lehmmauern geschützte kleine Station betraten. Unser Agent Malami, welcher der deutschen Regierung schon öfters Dienste geleistet hatte, war in Semere ganz am Platze, weil er als vornehmer Haussa die schwierige Situation den Franzosen gegenüber beherrschte.

Thronstreitig keiten und Parteispaltungen in Semere

In Semere befanden sich zwei Parteien, eine deutschfreundliche und eine, die den Franzosen geneigt war. Infolge von Thronstreitigkeiten lagen einzelne Stadtviertel fortwährend im Streit, was auch zu der oben geschilderten Abgrenzung durch Dornhecken geführt hatte. Als wir Semere passierten, befanden sich sogar zwei Könige in der Stadt. Der eine wurde von den Franzosen anerkannt und herrschte über die kleineren südlichen Stadteile, während der andere mächtigere König von Dr. Kersting èngesetzt war. Als nämlich Dr. Kersting durch Semere nach Sugu zog, kam ihm, wie er uns mitteilte, schon vor der Stadt eine stattliche Anzahl von Reitern auf feurigen Pferden entgegengesprengt die zum grossen Teil nach vornehmer mohamedanischer Sitte den Turban trugen und mit einem Haussagewand bekleidet waren. Sie empfingen Dr. Kersting besonders freundlich und erklärten ihm, dass sie gerade mit der Königswahl beschäftigt wären, sich ảber über den zukünftigen König nicht einigen könnten, sie wollten deshalb ihm als Weissen die Entscheidung überlassen. Dr. Kersting wählte einen sehr wohlhabenden, einflussreichen Mann, welcher den grössten Anhang unter den Semereleuten besass. Dieser wurde nun zum König erhoben und war zuerst Alleinherrscher in Semere. Nicht lange darauf jedoch setzten die Franzosen einen Gegenkönig aus der ihnen ergebenen Partei ein, sodass die Zwistigkeiten und Thronstreitigkeiten von neuem begannen. Mit dem Abschluss des Pariser Vertrages und unsererem Abzug aus Semere und Sugu musste natürlich der von Dr. Kersting eingesetzte König dem französischen Einfluss weichen. Er stellte sich unter den Schutz des Dr. Kersting und 
begleitete diesen später mit einigen ihm treu gebliebenen Anhängern nach Kirikri, wo er ein neues Heim gründete.

Bald nach unserem Eintreffen in Semere besuchte uns der Galadima, Mohamedader Ministerpräsident des Königs; er brachte uns Ziegen, Schafe und Yams nischer zum Geschenk und meldete den bevorstehenden Besuch seines Herrn an. Fürstenhof in Kurz darauf erschien dieser mit seinem ganzen Hofstaat. In seiner Begleitung Semere befanden sich der oberste mohamedanische Priester, der Liman, sowie dessen Stellvertreter, der Naëmi. Zur Seite des Königs nahm als Sprecher der Galadima Platz. Alle waren nach mohamedanischer Art mit schönen Haussatoben, Turban und Sandalen bekleidet, welche letzteren sie nach mohamedanischer Sitte am Eingang des Gehöftes ablegten. .Der Takt und die Gewandtheit mit der sie in ihrer schwierigen Lage ihrer Freude über unsere Ankunft Ausdruck gaben, waren überraschend. Die eigentlichen Semereleute, welche eine eigene Sprache besitzen, sind grösstenteils noch Heiden, während die Grossen und die Könige von Semere schon seit vielen Jahren Mohamedaner sein sollen. An allen mohamedanischen Fürstenhöfen befindet sich im Gefolge des Königs ein Ministerpräsident der nach dem König die erste Stimme hat, während das mohamedanische Priestertum durch den Lima und den Naëmi vertreten ist. Nach den Ermittelungen des Grafen Zech, der das Verdienst hat, die kleinen deutschen Posten angelegt und viele Verträge geschlosssen zu haben soll die Königsdynastie in Semere von Gonyaleuten stammen. Diese sollen vor Zeiten von dem König von Pembi unterworfen und in den früheren Bewohnern von Semere aufgegangen sein. Heute jedoch bildet Semere ein eigenes, unabhängiges Gebiet.

Ausser den ansässigen Semereleuten finden wir hier grosse Haussaniederlassungen, die der Königsstadt ein mohamedanisches Gepräge verleihen. Auch andere mohamedanische Händler vom Niger, aus Dendi, suchen den Markt von Semere auf, wo sie sich infolge des jahrelangen Handelsverkehrs in ihrer Sprache verständlich machen können. Der

Handel und Gewerbe unter mohamedanischem Einfluss. mohamedanische Einfluss ist in Semere, sowie in den nördlich gelegenen Grossstädten vorherrschend. Der ganze Handel liegt in ihren Händen; ebenso wird die einträgliche Industrie der Weberei nus von Mohamedanern betrieben. Hier, wie in den Temuländern, werden die beliebten schwarz-weiss-blau gestreiften Tücher, daneben aber auch schöne durchbrochene, weisse Tücher erzeugt.

Die Mohamedaner sind durchweg nach Haussaart gekleidet, während Bevölkerung die heidnische Bevölkerung gegerbte Schurzfelle und die Frauen nur von Semere Tücher tragen. Die Bewaffnung besteht hauptsächlich aus Pfeil und Bogen, sowie aus Speeren und Schwertern. Gewehre scheinen nur wenig verbreitet zu sein. Die Pfeile werden vergiftet. Die Stammeszeichen sind im allgemeinen dieselben wie in Sugu und den Temu- 
Vegetation in den nördlichen Gebieten.

ländern, ebenso der Bau der Hütten und Gehöfte. Die Hütten der Leute sind rund und haben ein Kegeldach, die Häuptlingshütten haben dagegen spitze Dächer. Semere ist ein grosses Handelszentrum für Tshautsho und Sugu und wahrscheinlich auch ein grösserer Ausfuhrplatz für Sklaven aus den Kabrélanden, wie fast alle grossen Städte mit Haussaniederlassungen, die an den Grenzen dieser von jeder Kultur abgeschlossenen heidnischen Gebiete liegen. Eingehendere Beobachtungen konnte ich leider wegen der Kürze der Zeit nicht machen.

Wir marschierten schon am nächsten Morgen in nordöstlicher Richtung weiter. Bis an die Grenzen der Stadtmauer begleitete uns der König mit seinem Hofstaat. Der Weg führte durch ein sanft gewelltes Terrain, welches von kleinen Wasseradern, die zum Kara führen, durchzogen ist. Die Vegetation nimmt in der Ebene nördlich von Sudu einen ganz anderen Charakter an und unterscheidet sich wesentlich von derjenigen in dem südlichen Teil von Togo. An Stelle des eigentlichen Busches, welcher hauptsächlich in der Küstenzone vorkommt, und der Baum- und Grassavanne mit ihren massenhaften verkrüppelten Schibutterbäumen und Mimosen, welche mit dem $7^{\circ}$ nördlicher Breite bei Kpandu in den grossen Flussthälern beginnt und über den 9. Breitengrad hinaus reicht, tritt nunmehr eine weite Grassavanne, welche nur zum Teil spärlichen Baumwuchs aufweist. Auch die an der Küste und in dem Agomegebirge so mannigfaltig vertretenen Früchte sind nur spärlich oder garnicht mehr vorhanden. Mais und Kassava findet man selten, statt dessen wird Yams, Okro, Tabak in kleinen Parzellen, Hirse in den verschiedensten Arten und namentlich bei Sugu Reis angebaut. Ausser diesen Feldfrüchten ist die Banane in geringen Quantitäten vorhanden.

\section{IM GEBIET DER KYILINA-VÖLKER.}

Wir passieren die kleinen zerstörten Orte von Kunde, Soré und Kurde. In der Ferne heben sich in scharfen Konturen die Bergzüge von Kabré ab, während im Südwesten der Berg von Semere in blauem Nebel verschwindet. Unser Weg führt über welliges Terrain an kleinen Fulbeniederlassungen und Viehweiden vorbei, auf denen schöne Herden grasen. Weiter gelangen wir zu den Farmen von Barai, der ersten grösseren Stadt von Sugu in dem Bereiche der Kyilinavölker. Barai ist, ganz wie Semere, von einer Lehmmauer und einer mächtigen Dornenhecke umgeben, doch sind die einzelnen Stadtviertel nicht durch Dornenhecken getrennt. Mitten in dem Stadtbezirk von Barai liegt der Markt und das grosse Gehöft des Königs, welches von hohen Mauern eingeschlossen ist und ein wahres Labyrinth von Hütten in sich schliesst. In Barai hatte Dr. Kersting einen Soldaten stationiert, welcher bei der 
deutschen Flagge Wache hielt. Leider konnte ich wenig von der Stadt und seinen Bewohnern sehen, da wir erst bei Sonnenuntergang einzogen und nur die Nacht dort zubrachten. Eine grosse Menschenmenge hatte sich auch hier angesammelt und drängte sich in lästiger Weise an uns heran. Der Häuptling von Barai war, wie er uns durch seinen Sprecher mitteilen liess, durch Krankheit verhindert, uns zu begrüssen.

Schon in der Frühe des folgenden Tages marschierten wir auf dem nächsten Wege über sanft gewelltes Terrain und viele kleine Wasserrinnen direkt nach Sugu. Die Farmen, durch die wir kamen, waren meistens mit Yams und Hirse bestellt. In kurzer Zeit wurde das kleine, von dichtem Dornbusch umgebene Dorf Funa erreicht; dasselbe soll sich französischen Reisenden widersetzt haben und von diesen zerstört worden sein. Zwischen den Ruinen sind nur etwa ein Drittel der Hütten wieder aufgebaut. In Funa war ein kleiner französischer Posten stationiert, welcher bei unserem Durchmarsch die französische Flagge hisste. Ohne Aufenthalt passierten wir das Dorf und gelangten alsbald wieder in die grosse Grassavanne, welche ab und zu spärlichen Baumwuchs aufwies. Im Nordosten sah man in weiter Ferne die Berge von Pabegu, während sich vor uns und zur Seite des Weges zwischen den kleinen Wasserrinnen einzelne Hügel von vier bis acht Meter Höhe erhoben. Eine schöne Viehherde weidete auf der grünen Flur und mitten in dieser lag das Gehöft einer Fulbeniederlassung. Hier trafen wir zu unserer grössten Freude Dr. Kersting mit seinem Assistenten Schröder. Die etwa vierzig Mann starke Truppe salutierte unsere Expedition und erkannte Begrüssung jubelnd in unsern Evheleuten Stammesgenossen von der fernen Heimats- und Einzug in küste. Wir passierten den kleinen Ort Makantogon, um bald darauf die die deutsche deutsche Station Sugu zu erreichen. Schöne Hirse- und Yamsfarmen lagen zu beiden Seiten des Weges. Vor uns, mitten in der grossen Grassavanne, von einem dichten Walde umgeben, befand sich die grosse Stadt Sugu-Wangara, während uns nordwestlich von Wangara von einem hohen Hügel, auf dem die Station ihr kleines Zeltlager errichtet hatte, die deutsche Flagge entgegenwehte. Die Station beherrschte die weite Ebene, aus welcher im Norden die Berge von Pabegu auftauchten, während am Fusse des Hügels, von einer grossen Lehmmauer und Dornenhecke umgeben, die Stadt Wangara lag. Man konnte die französische Flagge auf dem Markt erkennen, dagegen wurde die Königs-Residenz Sugu-Kyilina durch den Wald unseren Blicken entzogen. Am Nordhange des Stationshügels lag das einsame, nur mit einem Kreuze geschmückte Grab des kurz ror unserer Ankunft im Dienste der Sache verstorbenen Assistenten Wegner. Derselbe ist kühn bis Sugu vorgedrungen, wo er in treuer Pflichterfüllung den weit vorgeschobenen Posten gegen die Franzosen hielt. Schon auf dem 
Marsche dorthin soll er einen Dysenterieanfall gehabt haben; später ist er, sich selbst überlassen, an Entkräftung gestorben.

Die Station selbst war wegen der weiten Entfernung von der Küste ler deutschen und der kurzen Zeit ihres Bestehens eigentlich nur ein kleines Lager.

Station Nur ein Teil der Leute war oben untergebracht, die übrigen befanden sich noch in Wangara. Dr. Kersting bewohnte mit seinem Assistenten zwei Hütten des verstorbenen Wegner, sowie ein paar mitgebrachte Zelte. Doch machte die Aufstellung der Zelte Schwierigkeiten, weil der Boden fast nur aus kahlen Felsen, hauptsächlich aus Brauneisenstein bestand. Des Tages über strömte die Felsmasse eine glühende Hitze aus und da weder Baum noch Strauch Schatten spendete, litten wir anfangs unter der Blendung. Doch schaffte Dr. Kersting bald hierfür Rat, indem er ein primitives Schattendach aus Segelleinwand errichtete. Des Abends war auf dem kahlen Hügel der Wind sehr empfindlich, auch machte sich der schnelle Temperaturwechsel zwischen Tag und Nacht ganz erheblich bemerkbar. Sonst aber war die Lage der Station vortrefflich gewählt, da sie sich ausserhalb des Stadtbezirkes befand und die Stadt vollkommen beherrschte.

Politische Was die politischen Verhältnisse in Sugu anbetraf, so hatte es

Verhăltnisse Dr. Kersting durch sein geschicktes Operieren bald dahin gebracht, dass in Sugu. die ganze Umgebung des hartnäckigen, französisch gesinnten Königs Peetoni III., zu den Anhängern der deutschen Partei zählte. Abgesandte aus Barai und anderen Städten des Sugulandes kamen zu ihm, um ihm $\mathrm{zu}$ begrüssen und ihm durch Geschenke von Reis, Hirse, Yams, Ziegen und Schafen ihre Freundschaft zu beweisen. Die mohamedanische Priesterschaft, die am Hofe grossen Einfluss besass, stand auf deutscher Seite. Der Liman und der Naëmi vermittelten zwischen Dr. Kersting und dem König, und der Galadima, der oberste Ratgeber des Königs, hatte diesen so weit gebracht, dass er dem Dr. Kersting einige prächtige Stiere und Feldfrüchte zum Geschenk machte. Dr. Kersting bestand jedoch darauf, dass der König ihn besuchen müsse, bevor er Geschenke von ihm annehme. Er verstand es auch ausgezeichnet, die Ankunft unserer kleinen Expedition auszunützen, indem er dem Galadima erklärte, dass nun, wo die Verhältnisse sich freundlicher gestaltet hätten, nur zwei Weisse mit wenigen Soldaten aus Bassari zu ihm gestossen wären; andernfalls würden noch einmal soviel Weisse mit einer grossen Anzahl von Soldaten zu seiner Unterstützung herbeigeeilt sein. Aber schon die Anzahl von vier Weissen und die durch unsere Leute verstärkte Besatzung, die zusammen etwa 50 Mann stark war, bildeten ausser den bewaffneten und uniformierten Trägern, die von den Eingeborenen stets als Soldaten mitgezählt werden, für afrikanische Verhältnisse den zwei Franzosen mit ihrer geringeren Besatzung gegenüber eine ganz erheb- 
liche Macht. Unser Marsch war also nicht ganz umsonst gewesen und wir konnten mit Dr. Kersting befriedigt auf die zu gunsten der deutschen Sache sich gestaltenden Ereignisse sehen. Da wurde der Pariser Vertrag geschlossen, nach welchem Sugu an Frankreich fiel. Die Erfolge dus Dr. Kersting konnten an dieser diplomatischen Entscheidung nichts mehr ändern. Da Dr. Kersting wegen der schwierigen Verhältnisse keinen Verkehr mit den Franzosen unterhielt, so unterblieb unsererseits ein Besuch auf der französischen Station. Auch den König konnten wir aus politischen Gründen nicht besuchen. Wir beschränkten uns daher darauf, die Stadt Wangara und die Königsstadt selbst in Augenschein zu nehmen.

Beide Städte sind von einer Dornenhecke und einer Lehmmauer umgeben. Wangara hat einen mohamedanischen Anstrich und macht den Handelsstadt Eindruck einer grossen Handelsstadt. In den engen und schmutzigen Strassen herrscht ein reger Verkehr und in der Mitte der Stadt befinden sich zwei Marktplätze, die nach den auf ihnen gehissten Flaggen als deutscher und als französischer Markt bezeichnet wurden. Alle vier Tage findet in Wangara ein grosser Markt statt. Die Hauptprodukte, welche hier feilgeboten werden, sind Reis, Hirse, Yams, Erdnüsse, Tabak, Käse und saure Milch, Wachs und Honig in Flaschen, einheimische blaue, rote und schwarz-weiss-blau gestreifte Tücher und weisse durchbrochene Tücher, welche für eine hochentwickelte Weberindustrie sprechen. Ausser diesen Produkten kommen zubereitete Speisen, wie die bekannten Hirseklösse, geröstete Erdnüsse, Reiskuchen in Oel oder in Schmalz gebacken und die verschiedensten Kräuter- und Pfeffersaucen zum Verkauf. Die Stadt liegt mitten in schönen Reis- und Hirsefarmen und macht mit ihren runden Hütten und engen, schmutzigen Gassen denselben Eindruck wie unsere mohamedanische Handelsstadt Kete. Ungefähr zehn Minuten südlich von Wangara liegt in einem wunderschönen Hain, zwischen Hirse- und Reisfeldern, die wiederum durch einzelne Baumgruppen unterbrochen werden, die Residenz des Königs Peetoni III., die Stadt Sugu-Kyilina. Man glaubt sich in einen grossen Park versetzt, in Residenzstadt welchem tropische Gewächse mit Ueppigkeit gedeihen. Hohe Wein-, Sugu.Kyilina. Oel- und Dumpalmen, Bananen und schattige Fikusarten wechseln mit einander $a b$. In den Bäumen hausen Kappengeier und wilde Tauben, die sich nach Beendigung des Marktes scharenweise auf demselben niederlassen, um Abfälle zu erhaschen. Die eigentliche Königsstadt besteht aus dem Palast des Königs, einigen Gehöften von vornehmen Kyilinaleuten und mehreren mohamedanischen Bethäusern, die sich durch ihre viereckige Bauart von den runden Hütten unterscheiden. Vor dem Palast des Königs, der aus mehreren Hütten besteht und ron einer hohen Lehmmauer umgeben ist, standen zu

Markt und Umgebung 
damaliger Zeit friedlich neben einander die hohen Flaggenmaste mit der deutschen und französischen Flagge. Damit sie nicht von unbefugter Hand, wie es häufig geschehen war, heruntergenommen werden konnten, waren sie an dem Mast angenagelt und wehten demzufolge Tag und Nacht. Vor jeder Flagge stand ein Posten mit scharf geladenem Gewehr.

Die Sugu- Die Sugukönige sollen aus Gurma stammen; deshalb finden wir Könige und noch heute bei der Königsfamilie überall die Tätowierung der Gurma die Kyilina- wieder, 4 grosse Längsstreifen, welche sich vom Ohr bis zum MundBevölkerung winkel ziehen. Diese Tätowierung scheint nach meiner Beobachtung auch sonst in dem Bereiche von Sugu gebräuchlich zu sein, denn ich sah sie in Djerakam wieder. Eigentümlicherweise trifft man sie vereinzelt überall in unserem Hinterlande, hauptsächlich an den mohamedanischen Fürstenhöfen, wie in Gonya und Sugu, an. Vielleicht ist sie eine äussere Spur von der ehemaligen Herrschaft der Mandingo in diesen Gebieten. Im allgemeinen wird von den Kyilinaleuten die in den Temulandschaften gebräuchliche Tätowierung, ein kleiner Querschnitt oberhalb der Nasenlippenfalte, als Stammeszeichen getragen. Die Kyilinaleute haben ihre eigene Sprache; es sind aber auch viele handeltreibende Haussa und Dendileute in Wangara ansässig, welche sich der Dendi- und Haussasprache bedienen. Ausser diesen finden wir im Sugugebiet viele Fulbeniederlassungen, welche Viehzucht treiben. Die Königsfamilie und ein grosser Teil der Bevölkerung ist mohamedanisch. Durch den steten Handelsverkehr mit den mohamedanischen Staaten im Norden hat der Islam speziell in der Handelsstadt Wangara grössere Ausbreitung gefunden, während die Bewohner der kleineren Städte und Dörfer des Sugugebietes noch zum allergrössten Teil Heiden sind.

Kleidung und Die Mohamedaner gehen alle bekleidet und tragen meistens ein Bewaffnung schwarz-weiss-blau gestreiftes Haussahemd, sowie Turban oder phrygische Mütze. Auch hier liegt die Weberei vollkommen in den Händen der Mohamedaner. Es giebt in Sugu ganze Weberkolonieen, in denen man Io bis 20 Webstühle nebeneinander antrifft. Die heidnische Bevölkerung dagegen trägt meistens nur einen Fellschurz; als Koptbedeckung dienen den Männern häufig kleine Strohkappen. Die Frauen tragen gewöhnlich ein Tuch, die jungen Mädchen nur eine Hüftschnur. Unter den Knaben der Mohamedaner wird vielfach die Beschneidung ausgeübt. Knaben von etwa Io bis I 2 Jahren tragen bis zur Heilung der Wunde ein aus Gras geflochtenes kleines Penisfutteral. Die Bewaffnung der Kyilinaleute besteht hauptsächlich aus Pfeil und Bogen, nur einige Leute des Königs sind mit Gewehren oder Steinschlossflinten ausgerüstet. Die Pfeile sind vergiftet und werden mit dem Bogen in einem Köcher über der Schulter getragen. Beim Nahkampf werden auch Messer in mannigfaltiger Form benutzt. Zum 
Spannen des Bogens tragen die Leute am Zeigefinger und Daumen der rechten Hand Bogenspanner in Form eines Ringes und einer kleinen Glocke, mit welchen sie, ebenso wie die Kabréleute, klappern, um im Busch miteinander Fühlung zu behalten.

Der Ackerbau wird weniger in der Nähe der Hauptstadt, als in den im Lande zerstreuten kleinen Farmorten und Niederlassungen betrieben. Die Einwohner der grösseren Orte bauen innerhalb des Stadtbezirks nur Feldfrüchte für den eigenen Bedarf an. So sahen wir Farmen in dem Stadtbezirk zwischen den Schwesterstädten Wangara und SuguKyilina, innerhalb der Umfassungsmauern von Barai und an anderen kleinen Orten. Die Hauptfrüchte, welche in Sudu gebaut werden, sind Reis, Rispen- und Kolbenhirse, Yams, Erdnuss und in kleinen Anpflanzungen dicht an den Gehöften fast überall Tabak. Der Tabak ist ein begehrter Handelsartikel, da er sowohl zum Schnupfen, als auch zum Kauen und Rauchen verwendet wird. Zum Schnupfen und Kauen wird er gerieben zum Rauchen dagegen ist er in kleine runde Rollen gewickelt. Eigentümlich sind die langen Tabakspfeifen, aus welchen die Kyilinaleute schmauchen. Das Rohr besteht aus Bambus, während der Pfeifenkopf aus Thon hergestellt und manchmal mit Füssen versehen ist, sodass die Pfeife nach dem Gebrauch aufgestellt werden kann.

Da die Mohamedaner meistens Handel treiben, werden ihre Farmen Die Sklaven von Sklaven bearbeitet, denen man auf Schritt und Tritt begegnet. Die Landessklaven, d. h. solche, welche ursprünglich frei waren, aber wegen irgend eines Vergehens in die Sklaverei gekommen sind, zeichnen sich durch eine eigentümliche und auffallende Haartracht aus. Die eine Hälfte des Kopfes ist kurz geschoren, während die ganze andere Hälfte glatt rasiert ist. Ihre Kleidung besteht aus einem kleinen Fellschurz. Kriegsgefangene gehen ganz unbekleidet und tragen, nach Hauptmann Kling, häufig nur eine kleine geflochtene Strohkappe als Kopfbedeckung. Die durch Kauf erworberien Sklaven dagegen tragen eine beliebige Tracht und sind deshalb nur an ihren Stammeszeichen erkennbar. Die Sklaven ziehen, mit Hacke und Axt versehen, meistens am frühen Morgen zur Feldarbeit. Einige ältere Sklaven, welche die Aufsicht führen, sind mit Pfeil und Bogen bewaffnet. Die Feldgeräte und Waffen werden über der Schulter getragen. Einige haben ausser ihren Geräten einen kleinen runden Korb auf dem Rücken, in welchem ihr steter Begleiter, ein Huhn, untergebracht ist. Wie in Bassari und anderen Gegenden, ist das sogenannte Sklavenhuhn das einzige Eigentum des Sklaven. Mit dem Dunkelwerden ziehen die Sklaven in langen Reihen wieder in die Dörfer zurück. Jeder trägt in einem Korbe auf dem Kopf die eingeheimsten Früchte. Nicht selten schreiten diesem kleinen Zug einige Trommler voran. 
Die Viehzucht wird von den Kyilinaleuten nur insoweit betrieben, als sie Kleinvieh, Pferde und Esel aufziehen, wogegen Rinderherden hauptsächlich in den Fulbeniederlassungen anzutreffen sind. Da die vornehmen Mohamedaner alle beritten sind, so sieht man auf den Wiesen vor der Stadt Sugu eine Anzahl Pferde grösseren und kleineren Schlages grasen. Auch Esel sind häufig. Sie haben meistens eine hellgraue Farbe mit schwarzen Längsstreifen und Querlinien; viele sind durch tief eingebrannte Marken, auch durch Abschneiden oder Einkerben eines Ohres gekennzeichnet. In den Städten und Dörfern, deren Bewohner wenig Handel und überwiegend Ackerbau und Viehzucht treiben, werden mehr Schafe und Ziegen gehalten. In einzelnen Dörfern, wie in Djerákam und in Butum, bedienen sich die einheimischen Hirten zum Hüten ihrer kleinen Herden gut abgerichteter Hunde, die an unsere Schäferhunde erinnern. Ausser dem gewöhnlichen Haushuhn werden Perlhühner und, namentlich von den Mohamedanern, türkische Enten gehalten, ebenso Kraniche, und, wie Graf Zech in Baraï bemerkt hat, Pfauen. Interessant ist eine primitive Art der Honiggewinnung, die stellenweise in Sudu geübt wird. Die Leute stellen in den Zweigen der Bäume Töpfe auf, deren Oeffnung nach unten gekehrt ist und häufig, bis auf ein kleines Loch, mit Lehm verschmiert wird. In diese Töpfe halten die wilden Bienen ihren Einzug und werden dann ihres Honigs beraubt. Von den Negern an der Küste werden auch wilde Bienenstöcke ausgenommen. Der gewonnene Honig hat gewöhnlich einen sehr scharfen Geschmack und geht bald in Gährung über.

\section{RÜCKMARSCH VON SUGU ÜBER ALEDJO-KURA UND BAFILO NACH BASSARI.}

Da durch die günstige Wendung der Verhältnisse unsere Anwesenheit in Sugu nicht mehr nötig war, traten wir am 8. August r 897 unseren Rückmarsch nach Bassari an, nachdem wir unsere vollkommen leere Proviantkiste durch die Güte unseres Wirts wieder gefüllt hatten. Wir wählten jetzt die östliche Route über Djerákam, Aledjo-Kura, Sugu, Bafilo und Dako. Der Weg führte in südlicher Richtung an der grossen Stadtmauer von Sugu vorbei, durch das kleine Farmendorf Shasiro, welches von einem schönen Busch und von einer Dornhecke umgeben war. Auftällig schön waren hier die in langen Reihen angelegten grossen Reis- und Hirsefelder und Okrofarmen. Nach kurzem Marsch über kleine 
Terrainwellen erreichten wir das in einem schönen Walde gelegene Dorf Suburuku, welches seit dem Gefecht, das Graf Zech hier geliefert hat, nur noch aus ungefähr 300 Hütten besteht. Suburuku ist im Norden durch einen dichten Wald sowie durch einen kleinen, vier Meter breiten Bach und durch sumpfiges Terrain geschützt, nach Süden zu ist es durch eine Dornhecke und eine künstliche Lehmmauer befestigt. Ohne Aufenthalt marschierten wir weiter über mehrere kleine Bäche, die alle mit schönem Galleriewald umgeben waren. In der lichten Baumsavanne lagen Hirsefarmen, auch eine Fulbeniederlassung und zerstörte Farmengehöfte. In Djokoá beschlossen wir unser Nachtquartier aufzuschlagen. Djokoá, welches aus den Orten Yamafuna, Kor, Safadjue und Bobonia besteht, zählt zusammen etwa 300 Hütten. Der Ort ist nicht befestigt, aber durch natürliche Bäche und sumpfiges, mit Gestrüpp und Busch bestandenes Terrain geschützt. Es hielt schwer, Hütten zur Unterkunft zu erhalten, da die Leute äusserst misstrauisch waren; auch die Verpflegung war sehr mangelhaft; mit vieler Mühe gelang es uns etwas Yams und Reis zu erlangen. Noch weniger waren die Leute dahin zu bringen, uns Führer zu stellen. Sie glaubten, dass wir die Führer zu Sklaven machen wollten und als wir auf unserem Verlangen bestanden, liefen sie, bis auf einige alte Männer und Frauen, einfach davon. Die alten Frauen benehmen sich in solchen Fällen merkwürdigerweise am vernünftigsten, aber, obgleich sie die jungen Burschen verspotteten, schienen sie selbst auch nicht aufgelegt, uns zu begleiten. Infolgedessen verfehlten wir den richtigen Weg und wurden erst durch Feldarbeiter soweit zurechtgewiesen, dass wir ein kleines Farmdorf, Gungunink, erreichten, welches bis auf 20 Hütten zerstört war. Eingeborene behaupteten, dass die Bewohner von Suburuku sie früher mit Krieg überzogen und dabei zum Teil ihre Dörfer verwüstet hätten. Hier bekamen wir endlich den erwünschten Führer und zogen nun in welligem Gelände über kleine Bäche und Wasserlachen bis Djerákam, unserem nächsten Rastplatz. Der Ort, der aus etwa I 50 Hütten besteht, erstreckt sich terrassenförmig zwischen zwei kleinen Bächen auf einer Hügelwelle bis zum Bach Abura hinunter und ist neben seiner natürlichen Befestigung mit einer Mimosenhecke und einer Lehmmauer umgeben.

In Djerákam wurden wir von der Bevölkerung freundlich aufgenommen. Palmwein, Reis und Hirsekuchen wurden herbeigeschafft, und in dem ganzen Ort herrschte grosse Freude. Mitten im Dorfe wehte zum Zeichen der Freundschaft unsere Flagge. Aber die Leute begrüssten in uns nicht nur die deutsche Expedition und die Weissen, sondern es stellte sich auch eine gewisse Sprachgemeinschaft mit unseren Evheleuten heraus, so dass viele von diesen sich mit den Eingeborenen verständigen konnten. Die Leute sprechen nämlich die

\footnotetext{
Das Dorf

Djerákam und die Yorubasprache.
} 
Yorubasprache, welche in Atakpame und an der Küste von Benin zu Hause ist und vielfach auch von den Evheleuten verstanden wird, die sie als Anago bezeichnen. Der Häuptling teilte mir auf meine Frage mit, dass die Sprache hier die Kurasprache genannt werde und dass dieselbe auch in Aledjo-Kura sowie in Butum und Paratau, in der Landschaft Adyé, gebräuchlich sei. Er, sowie die Bevölkerung von Djerákam waren deutsch gesinnt. Er erzählte mir, dass die Franzosen versucht hätten, ihn $z u$ bewegen, die deutsche Flagge herunterzunehmen und an deren Stelle die französische aufzuziehen, dass er aber trotz der drohenden Haltung der Franzosen dieses Ansinnen abgelehnt habe. Da wir von dem deutsch-französischen Vertrage, nach dem Djerákam zu Frankreich gehört, noch keine Kenntnis hatten, erklärten wir dem Häuptling, dass er den Uebergriffen der Franzosen Widerstand leisten und nötigenfalls den Dr. Kersting in Sugu um Hilfe bitten sollte, der die deutsche Regierung vertrete und ihn auf jeden Fall unterstützen und schützen würde.

Die

Bewohner von

Djerákam.

Djerákam gehört noch zu Sugu. Viele Leute trugen daher die Tätowierung der Königsfamilie. Namentlich bei Frauen und Mädchen sah ich die vier Längsstreifen; einige hatten noch auf einer oder auf beiden Seiten kleine Querschnitte. Die Männer trugen dagegen häufig auf beiden Backen nur drei Längsstreifen. Ausserdem hatten einige Männer und Frauen, wie die Kabréleute, drei Längsstriche auf dem Oberund Unterarm. Die letztere Tätowierung soll hier ein Schutzzeichen gegen frühzeitigen Tod sein. Einen ähnlichen Gebrauch finden wir bei den Evheleuten, die, wenn ihnen alle Kinder bis auf eines gestorben sind, dem überlebenden Knaben als Schutzmarke einen Querschnitt oberhalb der Nasenlippenfalte geben. Ferner hatten die Frauen noch folgende Nabeltätowierung $\equiv_{\mid i !}^{\text {!I! }} \equiv$. Die männliche Bevölkerung in Djerákam trug ein Haussahemd oder Fell, während die Frauen sich in Tücher kleideten und die Mädchen, abgesehen von einer Hüftschnur, ganz unbekleidet gingen. Trotzdem entfalteten sie in Haltung und Bewegung eine überraschende Anmut und hatten den vollen Beifall unserer schwarzen Marssöhne, ganz wie es bei uns im Manöver zugeht. Des Abends rauchten die Männer friedlich aus langen Pfeifen, während die Frauen an dem Webestuhl klapperten. Auch hier arbeiteten viele Landessklaven mit zur Hälfte abrasiertem Kopf in den Farmen. Die Farmen waren hauptsächlich mit Hirse, Yams und Baumwolle gut bestellt; auch war Okro und nahe bei den Gehöften Tabak angepflanzt. Auf den Wiesen bei Butum wurden Schafe und Ziegen gehütet und von Schäferhunden bewacht. Djerákam hat eine schöne Lage und ist von einem dichten Wald umgeben, in dem sich viele Affen tummeln. 
Da es am nächsten Tage stark regnete, so beschlossen wir, den Regen in Djerákam abzuwarten, und zogen erst zu Mittag von dort ab. Unser Marsch ging über welliges, mit hohem Gras und vereinzelten Bäumen bedecktes Gelände, das von breiten, zum Teil ausgetrockneten Flussläufen durchschnitten wurde. Die Flussbetten waren von einem schönen Galeriewald umgeben, der zum grössten Teil aus Weinpalmen bestand. Ab und zu fanden wir an den feuchteren Stellen auch Dumpalmen. Auf den Höhen trat häufig Brauneisenstein zu Tage. Die grossen Flussbetten und zerrissenen Ufer zeigten deutliche Spuren von der Gewalt des Wassers bei hoher Regenzeit. Niedrige Hügel und eine buschige Grassavanne begleiteten unsern Pfad; bald erreichten wir das kleine Dorf Butum, wo wir nur kurze Rast hielten, um sodann unsern Marsch nach Aledjo-Kura fortzusetzen. Butum ist ebenfalls rings von Wald umgeben, in welchem vorzugsweise die Raphia und Dumpalme vertreten sind. Zahlreiche Ruinen erinnerten an die früheren Kämpfe mit Semere; der Ort zählt heute nicht mehr als jo Hütten.

Nach dreistündigem, anstrengendem Marsche über welliges Terrain, viele kleine Bäche und Sumpfstellen kamen endlich die Berge von Aledjo-Kura in Sicht. Anfangs wechselten Baum- und Grassavannen mit einander $a b$, während die Niederung vor Aledjo-Kura mit Gestrüpp und Busch bestanden war. Am Wege zogen sich grosse Farmen von Yams und Guineakorn entlang. Es dämmerte bereits, als wir endlich bei strömendem Regen das grosse Dorf Aledjo-Kura vor uns liegen sahen und menschliche Stimmen zu uns herüberdrangen. Die Stadt zieht sich terrassenförmig auf einem kahlen Felsen bis zu dem Königsplatze hin. Die runden Hütten und Gehöfte stehen dicht gedrängt, die engen und schmutzigen Strassen sind durch Lehmmauern begrenzt. Aledjo-Kura ist im Norden durch sumpfiges Terrain und durch einen kleinen Bach, im Süden durch eine Lehmmauer und Dornhecken abgeschlossen. Es besteht aus drei Dörfern, welche zusammen etwa tausend Hütten zählen.

Ohne von den Eingeborenen bemerkt zu werden, zogen wir bis zu Ėrıwungene dem Gehöft des Königs, den unsere plötzliche Ankunft nicht wenig überraschte. Er erklärte kurz, dass er keinen Platz fur uns habe, weil bei ihm schon ein Weisser, ein französischer Offizier, einquartiert sei. Natürlich konnten wir uns bei dem herrschenden Regenwetter auf diese Weise nicht abfertigen lassen. Ich erwiderte dem König, dass er uns aufnehmen müsse und dass, falls er sich weigere, wir uns selbst Unterkunft schaffen würden; übrigens hegte ich überhaupt Zweifel, dass in seinem Gehöft ein französischer Offizier liege. Als der Häuptling auf seiner Weigerung bestand, belegte ich ohne weiteres einen Teil seines Gehöfts und quartierte die Leute in den Hütten ein. Wir beiden Weissen bezogen die Vorhalle, in der auch sämtliche 
Waffen, Patronen und Kisten untergebracht wurden, während unsere Leute trotz Einspruchs des Häuptlings von den anstossenden Hütten Besitz ergriffen. Nur unsere armen Pferde mussten die ganze Nacht hindurch bei strömendem Regen unter freiem Himmel kampieren. Zur Sicherheit wurde ein Posten vor dem Gehöft aufgestellt. Früh am anderen Morgen weckte uns das Signal, der Regen hatte aufgehört und mit dem besseren Wetter zeigte uns auch der Häuptling ein etwas freundlicheres Gesicht. Vor dem Gehöft hatte sich eine grosse MenschenFlaggen- menge angesammelt. Viele sprachen Yoruba, so dass unsere Leute sich palaver. mit ihnen verständigen konnten. Indessen bewahrten sie die feindliche Haltung, welche sie schon zu Klings Zeiten gegen dessen Expedition eingenommen hatten. Mein Dolmetscher machte mich darauf aufmerksam, dass hier thatsächlich die französische Flagge gehisst sei. Es war dies nicht immer ganz leicht zu erkennen, weil unsere deutschen Reisenden in Ermangelung von Flaggen, der Not gehorchend, eigene Flaggen zusammengestellt hatten, die nur annähernd aus den richtigen Farben bestanden. Gelblich-weisser Graybaft diente als weiss, die roten Soldatenschärpen als rot und die zu Tauschzwecken gangbaren blauen Stoffe als schwarz. Aus diesem Grunde waren die Flaggen, namentlich bei Regen oder Windstille, schwer von französischen $\mathrm{zu}$ unterscheiden. Es bestätigte sich in der That, dass die französische Flagge gehisst war, der treulose Häuptling also den von Graf Zech mit ihm geschlossenen Vertrag gebrochen hatte. Da die Menge immer aufdringlicher wurde, liess ich vor dem Gehöft unsere sämtlichen Gewehre in Pyramiden aufstellen und auch unsere deutsche Expeditionsflagge aufrollen. Inzwischen schien sich der Häuptling in Anbetracht unserer Gewehre eines Besseren besonnen zu haben und liess uns einige Geschenke überbringen. Wir wiesen sie jedoch zurück mit der Erklärung, dass wir von einem wortbrüchigen Häuptlinge nichts annehmen wollten. Während ich noch im Begriff war, dem Häuptling Vorwürfe wegen seines Treubruchs zu Begegnung machen, trat zu unserem Erstaunen ein französischer Offizier in tadelmit einem französischen loser weisser Tropenuniform aus der Vorhalle heraus, begrüsste uns als Offizier. Kameraden und fragte, ob wir noch nicht von dem Pariser Vertrage gehört hätten. Wir erwiderten, dass wir leider noch keine Post empfangen hätten, aber im Begriff wären, nach Sugu zu marschieren, wo wir dieselbe erwarteten. Zwar schenkten wir der Mitteilung des französischen Offiziers ohne bestimmte Unterlage noch immer kein volles Vertrauen, entschuldigten uns aber ihm gegenüber, indem wir darauf hinwiesen, dass es Pflicht eines jeden sei, fur seinen Staat das zu thun, was er für das Richtige halte. Im übrigen seien wir als weisse Kavaliere selbstverständlich bereit, freundschaftlich mit ihm zu verkehren. Wir bedauerten, ihm nicht vorher einen Besuch abgestattet zu haben, hätten 
aber nicht geglaubt, dass wirklich ein weisser Offizier im Orte sei, sondern vielmehr angenommen, dass der Häuptling nur versucht habe, sich durch eine Lüge von uns zu befreien, um so mehr, als weder wir noch unsere Leute eine Spur von seiner Anwesenheit bemerkt hätten.

Nachdem wir schliesslich mit vieler Mühe einen Führer erlangt Marschüber hatten, marschierten wir unter Protest gegen den Vertragsbruch und das Gebirge die Hissung der französischen Flagge von Aledjo-Kura ab. Bald erreichten wir ein Hochplateau, von wo aus wir einen schönen Ausblick auf die weite Ebene hatten, während im Norden der Berg von Semere, Post und das die Berge von Sirka und die dunklen Linien der Kabré-Berge erkennbar Ergebnis des waren. Merkwürdig hoch zogen sich an diesem Plateau Yams- und Erdnussfarmen herauf. Im übrigen waren die Hänge mit niedrigem BaumPariser und Graswuchs bestanden. Das Gestein war zum grossen Teil Quarzit, auch Glimmerschiefer, öfters mit eingesprengten, kleinen, schwarzen Kristallen. Nach einem anstrengenden, $2{ }^{x} / 2$ stündigen Marsch über das bergige Terrain des Hochplateaus kam Sudu mit der Station und der deutschen Flagge in Sicht. Hier fanden wir zu unserer Freude nach langer Zeit Briefe aus der geliebten Heimat, sowie einige Tauschartikel aus Bassari vor. Die Zeitungen, die natürlich fast vier Monate alt waren, brachten uns gleichfalls Neuigkeiten. Der ganze Tag wurde selbstverständlich der Lektüre gewidmet. $\mathrm{Zu}$ unserer Betrübnis erfuhren wir, dass thatsächlich der Pariser Vertrag unterzeichnet war und die Gebiete von Sugu, Semere und Aledjo-Kura, welche wir soeben durchreist hatten, den Franzosen zugefallen seien. Ausserdem hatte Frankreich den östlichen Teil von Kabré, das grosse Gebiet von Borgu, Gurma, Pama und alles Land nördlich des $x$ r. Breitengrades erhalten. Uns dagegen waren Bafilo, Dako, Aledjo-Kadara, Kumondé, der bisherige französische Posten Kirikri, der westliche Teil von Kabré sowie Mangu bis zum Ir. Breitengrade verblieben und das bekannte Mono-Dreieck zugefallen. Die näheren Grenzen sollten durch eine deutsch-französische Kommission an Ort und Stelle geregelt werden. Im allgemeinen ist der Vertrag für uns in keiner Weise ungünstig zu nennen, da wir von vornherein geringere Anrechte hatten, als die Franzosen. Nur dadurch, dass wir in den Gebieten von Sugu, Semere, Borgu und Gurma eine verhältnismässig späte und geringe Thätigkeit entwickelt haben, sind uns diese Länder verloren gegangen, doch können wir mit der Erwerbung des Mono-Dreiecks, des grossen Komplexes von Bafilo und der übrigen bisher nur von Franzosen besetzt gewesenen Stationen von Dako und Kirikri zufrieden sein und den Verlust ron Sugu, worauf wir durch Wolf und Kling Anrechte erworben hatten, verschmerzen. 
Im neuen deutschen Gebiet, an den Nord. abhängen des

BafiloGebirges.

Am nächsten Tage brachen wir früh auf, um unseren Marsch nach Bafilo fortzusetzen. Es ging an den Nordabhängen des Gebirgszuges zwischen Sugu und Dako weiter. Zur Linken stieg die etwa r 50 Meter hohe Gebirgskette von unserem Pfade ab gerechnet bis zum Kamm des Gebirges um $50 \mathrm{~m}$ an, wodurch uns nach Süden die Aussicht versperrt war, während im Norden die Berge von Semere und Sirka und hinter diesen allmählich deutlicher die Kabréberge in der grossen Ebene auftauchten. Nach kurzem Marsch erreichten wir das zu Sugu gehörige Dorf Gande, welches am Hange des Gebirges liegt. Im Süden zieht sich die Gebirgskette hin, welche nach Westen hin abnimmt und schroff abfallende Quarzitfelsen aufweist. Gande selbst ist ein ziemlich grosses Dorf von etwa 600 Hütten, in welchem ein reges Treiben herrschte. Vor uns lag das schöne Panorama der Kabréberge, welche ich durch Peilung festlegte. Von Gande aus marschierten wir, nach einem schwierigen Abstieg über Quarzit-Schieferplatten, in der Ebene am Fusse des Gebirges in westlicher Richtung weiter. Ab und zu setzten wir über kleine Bäche und Flüsschen, welche teils in den Pindi, teils auch direkt in den Kara mündeten. Am Wege lagen einzelne Guineakornfarmen, sonst bestand die Ebene aus einer lichten Baumsavanne oder einer baumlosen Grassavanne. An den kleinen Gewässern waren Wein- und Dattelpalmen und in dem sumpfigen Terrain Pandanusarten häufig. Das Gebirge fällt jetzt in kleinen Ketten nach Westen stark ab und hat nur noch eine durchschnittliche Höhe von etwa ıoo Meter. Wir erreichen den kleinen Bach Para und sehen im Süden den Wasserfall dieses Flüsschens wie einen Silberfaden über die Quarzitfelsen des Gebirges in die Ebene hinabstürzen. Der Weg führt aus dem Thal des Para wieder aufwärts und an dem Berghange liegt, sich bis in die Ebene ziehend, die grosse Stadt Bafilo. Wir passieren mehrere kleine Dörfer, die zwischen schönen Yams- und Hirsefarmen eingebettet und von den hohen Stauden des Guineakorns vollkommen eingeschlossen sind. Die Hütten sind hier sämtlich rund. Ueberall liefen der Karawane die Kinder nach und in den Dörfern sammelte sich das Volk, um die ankommenden Fremdlinge zu sehen.

Abzug der Nach ungefähr zwei Stunden erreichten wir endlich in einem der französischen westlichen Dörfer den Königsplatz von Bafilo, wo wir uns einquartierten. Besatzung aus Der Häuptling nahm uns gut auf; auch die Häuptlinge der übrigen OrtBafilo und schaften erschienen, um uns Geschenke zu überbringen. Wir erfuhren, dass die französische Station schon geräumt sei. Ueberhaupt sollen die

Flagge Franzosen nach dem Bekanntwerden des Pariser Vertrages mit einer musterhaften Ordnung und Schnelligkeit aus dem uns zufallenden Gebiete abgezogen sein. Sehr drastisch drückte sich der alte Häuptling über den Abzug der Franzosen aus. Er liess uns durch den Dolmetscher mit- 
teilen, die Franzosen seien weggelaufen (the frenchmen run away). In der Annahme, dass uns in Sugu dasselbe nachgesagt werden würde, versuchte ich, ihn über den eigentlichen Sachverhalt aufzuklären; doch wollte es ihm nicht in den Sinn, dass man aus freien Stücken ein Gebiet aufgeben könne. Da Bafilo nunmehr deutsch war, hissten wir auf die Bitte des Häuptlings die deutsche Flagge. Zu diesem feierlichen Akt versammelten sich eine Menge Volks und die Grossen des Gebiets auf dem Königsplatz. Die letzteren waren mit einheimisch gewebten Haussahemden und phrygischen Mützen bekleidet, während der grösste Teil der heidnischen Bevölkerung, ganz wie in Bassari, ein grosses fiell oder einen aus Leder gegerbten Schurz trug. Einige führten, wie die Bassarileute, einen kleinen Fellsack mit sich, in welchem sie ihre Schnupftabakdose oder sonstige Kleinigkeiten untergebracht hatten. Ferner erschienen eine Menge Haussa in langen schönen Gewändern mit Turban oder Fez aus den westlichen Ortschaften von Bafilo, wo sich grosse Haussakolonieen befinden. Unter einem Hurra auf unseren Kaiser, Präsentieren des Gewehrs und einer dreimaligen Salve ging die schwarz-weiss-rote Flagge hoch, um von nun an für immer über Bafilo zu wehen.

Das Volk hat dieselben Sitten und Gebräuche wie die Bevölkerung der Landschaft Adyé, in Aledyo-Kadara und Kumondé. Auch hier besorgen die Mohamedaner die Handelsgeschäfte und betreiben die Weberei, ausserdem sollen sie in Bafilo Handel mit Kabré-Sklaven betreiben. Die Bevölkerung ist, abgesehen von einigen angesiedelten Haussa und anderen Mohamedanern, bis auf die Häuptlinge fast ausschliesslich heidnisch. Bafilo zählt ungefähr 30 Dörfer, von denen jedes etwa 400 bis 600 Hütten hat. Der ganze Komplex von Bafilo wird demnach etwa i 5000 Hütten, mit einer Einwohnerzahl von 60000 Köpfen umfassen. Die einzelnen Stadtbezirke ziehen sich inmitten schöner Hirse-, Yams- und Erdnussfarmen von Osten nach Westen in der Ebene und an den Hängen des Gebirges hin. Die Hütten und Gehöfte sind ebenso gebaut wie in den Temulandschaften. Von Waffen sah ich fast nur Pfeil und Bogen, Speere und einzelne Griffmesser mit dem bekannten O-Griff.

Da unser Proviant sowie unsere Tauschartikel und Geschenke vollkommen erschöpft waren, mussten wir bald den Weitermarsch antreten. Wir brauchten für unsere inzwischen erkrankten Träger einige Hilfsträger nach Dako. Der König, welcher sie stellen sollte, schien aber fast gar keine Macht zu besitzen, denn erst nach vieler Mühe und Versprechungen gelang es ihm einige seiner eigenen Sklaven zum Mitgehen $z u$ bewegen. Begleitet von einer grossen Volksmenge rückten wir endlich, verhältnismässig spät, von Bafilo ab. Zur Seite des Weges lagen viele kleine Ortschaften und reiche Farmen. Bei den Haussakolonieen der westlichen Ortschaften sah man auf herrlichen Wiesen schöne Pferde 
weiden, welche den Mohamedanern gehörten; die Eingeborenen selbst scheinen keine Pferde zu besitzen. Ganz im Westen der vielen BafiloOrtschaften, am Hange des Gebirges, sahen wir von Weitem die auf der Höhe angelegte ehemalige französische Station liegen. Da schwarze französische Agenten noch mit dem Räumen der Station beschäftigt waren und wir die Leute nicht stören wollten, diese neuen Bezirke auch Dr. Kersting zur Verwaltung zugewiesen waren, so marschierten wir direkt weiter. Ueber das Wir gelangten nun, auf welligem Terrain eine Menge kleiner Bäche Gebirge nach überschreitend, wieder in das Gebirge von Dako. Im Norden befand Dako und die sich die weite Ebene des Kara, aus der die einzelnen Kegel der KabréEbene des Kara. berge deutlich hervorragten, sodass ich eine grosse Anzahl von Peilungen vornehmen konnte. Im Süden zog sich der ungefähr 4 bis 5 oo Meter hohe Gebirgsstock von Sudu bis Dako hin und versperrte mit seinen schroffen Felsen die Fernsicht. Viele kleine Bäche hatten tiefe Furchen in diesen Gebirgszug eingeschnitten und rieselten in die Ebene des Kara. Ihre Ufer waren häufig von Wein- und Oelpalmen bestanden, während weiter in der Ebene auf sumpfigem Terrain die Dumpalme und Pandanusarten gediehen. Dieser Gebirgszug und das Hochplateau ron Kumondé scheinen eine Wasserscheide zwischen dem Kara im Norden und dem Mono im Süden zu bilden. Nun begann wieder der schwierige Aufstieg in den Bergen von Dako. Mühsam wurden die einzelnen Bergpartieen genommen, weil immer wieder tief eingeschnittene Bäche die Hänge der Bergketten durchkreuzten. Unsere Pferde hatten sich bei den anstrengenden Gebirgsmärschen die Hufe durchgelaufen, wir waren daher öfters gezwungen, zu Fuss zu gehen. Quartier ron Soré und marschierten ohne Aufenthalt über den Kamm hinunter nach

Dako Daude in unser altes Quartier. Bei dem König in Soré liessen wir uns durch den Dolmetscher entschuldigen, dass wir ihn wegen grosser Ermüdung nicht selbst besuchen könnten und baten ihn gleichzeitig um Träger. In Daude angekommen, wurden wir von unseren alten Wirtsleuten freundlich aufgenommen, und nach kurzer Zeit lag alles, von den Strapazen des Gebirgsmarsches ermüdet, im tiefen Schlaf. Am nächsten Morgen wurden wir von dem Häuptling aus Soré besucht, der es sich nicht hatte nehmen lassen, selbst zu kommen und uns Träger zu stellen. Die französische Besatzung von der Station in Soré war abgezogen. Am Tage vorher waren wir einem kleinen Trupp französischer Soldaten begegnet, deren schwarzer Führer sich bei uns meldete und seinen Befehl vorzeigte, in dem die Marschordre stand und die Bitte ausgesprochen war, sie ungehindert durch deutsches Gebiet ziehen zu lassen. Wegen des Abzugs der Franzosen bat der Häuptling von Dako um die deutsche Flagge, welche wir ihm mit mehreren anderen Geschenken überreichten, 
jedoch wegen Mangels an Zeit nicht hissen konnten. Die uns in Bafik gestellten Träger waren entlaufen, weil sie füchteten, dass wir sie nach Bassari mitnehmen würden. Wie gefürchtet Bassari bei allen umliegenden Landschaften war, geht daraus hervor, dass der Häuptling von Dako uns bat, die von ihm gestellten Träger in Bassari bei unseren Leuten schlafen und sie auf dem Rückmarsche nach Dako durch das Bassarigebiet von Soldaten begleiten zu lassen, was wir natürlich versprachen und auch ausführten.

Des Abends erreichten wir auf unserer alten Route Bassari und zogen bei strömendem Regen in unsere kleine Station ein, wo wir von dem Expeditionsmeister Hoyer und dem Assistenten des Dr.Gruner, Britsch, herzlich begrüsst wurden. An demselben Tage kamen zu unser nicht geringen Freude fast zu gleicher Zeit mit uns Träger mit Proviant von der Station Kratyi an. So konnte das Wiedersehen trotz des Regenwetters bei einem nach afrikanischen Begriffen solennen Schmause in entsprechend gehobener Stimmung gefeiert werden. Wir erfuhren, dass Dr. Gruner zum Einkauf von Pferden nach Paratau gezogen war. Während der Abwesenheit so vieler Weissen und Soldaten hatte die Streitsucht der Bassari wieder die Oberhand gewonnen. Sie hatten unserem Expeditionsmeister gedroht, seine Hütten und Waren abzubrennen, wenn er Bassari nicht räumte. Das Gerücht von dem Anmarsch der Truppe von der Küste, welches inzwischen nach Bassari gedrungen war, hatte aber ihren Mut rasch abgekühlt. Dieses Gerücht bestätigte sich bald darauf durch Briefe des Herrn v. Massow. Wir beschlossen daher, vorläufig die Ankunft der Truppe in Bassari abzuwarten. Während Assessor Hupfeld seine geologischen Funde ordnete, konstruierte ich meine Routen und stellte die gemachten Notizen zusammen. Ab und zu versuchte ich noch die Ortsbestimmungen in Bassari zu ergänzen, doch machte mir der Harmattan, der im Oktober einsetzte, einen Strich durch die Rechnung.

Mit dem Einsetzen des Harmattan tritt auch ein Wechsel der Temperatur ein. Des Abends, des Nachts und des Morgens früh verspürt man eine empfindliche Kälte; die ganze Landschaft ist wie in Nebel gehüllt, so dass man, namentlich morgens und abends, kaum die nahen Bergketten erkennen kann, die Sonne erscheint des Tages über wie ein roter Feuerball, der von einem gelben Hof umgeben ist und man kann mit unbewaffnetem Auge hineinsehen. Der Mond und die grösseren Sterne geben nur einen schwachen Lichtschimmer, kleine Sterne verschwinden ganz. Der trockene Nordostwind bringt auch bei Tage im allgemeinen eine Abkühlung mit sich, doch scheint die Temperatur durchschnittlich über Mittag höher zu steigen als in harmattanfreien Zeiten. Die Luft ist mit kleinen Staubpartikeln geschwängert, welche ihr eine gelbliche

Wiedereintreffen in Bassari Harmattan. 
Farbe verleihen. Dieser Wüstensand, der selbst bis zu den Kanarischen Inseln hinübergetragen wird, hat nach den Beobachtungen, welche ich im Hinterlande zu machen Gelegenheit hatte, hauptsächlich eine gelbliche Farbe. Der Grundton ändert sich allerdings häufig, namentlich in den unteren Schichten, durch den aufgewirbelten Staub nach der Farbe des Erdbodens. An höher gelegenen Punkten kommt die eigentliche gelbe Farbe des Wústensandes mehr zur Geltung. Der Staub ist so fein, dass er uberall hindurchdringt und alles wie mit feinem Pulver überzieht. Er setzt sich in die Schleimhäute der Nase, in die Augen, in die Atmungsorgane und Luftwege und erzeugt Reizerscheinungen. Die Augen entzünden sich, Hals und Kehle sind wie ausgetrocknet und es besteht ein beständiger Hustenreiz.

\section{RÜCKKEHR ZUR KÜSTE UND HEIMKEHR.}

Inzwischen war Dr. Gruner wieder zurückgekehrt und v. Massow an der Spitze der etwa I 50 Mann starken Truppe in Bassari eingezogen. Gleichzeitig erhielten wir von der Küste die Nachricht, dass das Verhältnis unserer Expedition zur Regierung aufgelöst sei. Infolge dessen schloss sich Assessor Hupfeld mit Hoyer der Truppe des v. Massow an, um seine geologischen Untersuchungen mit mehreren Bergleuten später in dem Agome-Gebirge fortzusetzen. Ich selbst trat, da unsere Pferde sämtlich eingegangen waren, mit Bassarileuten und anderen Trägern zu Fuss auf dem bereits bekannten Wege über die Station Misahöhe den Rückmarsch zur Küste an. Nach mehreren heftigen Fiebern, welche mich noch zu einigem Aufenthalt in dem grossen Busch zwischen Dutukpene und Kratyi zwangen, gelangte ich Ende des Jahres 1897 nach Lome und trat auf dem Südwest-Dampfer "Jeanette Woermann" im Januar I 898 über Marokko die Heimreise an.

Ueber Es war stets mein Wunsch gewesen, die marokkanische Küste Marokko zur mit ihren alten maurischen Städten kennen zu lernen. Wir legten in Heimat Mogador an, das ganz wie eine Festung von hohen weissen Mauern und In Marokko. Zinnen eingeschlossen ist. Die braunen, bärtigen Berber und Araber lassen Afrika von einer ganz anderen Seite erscheinen als seine schwarzen Bewohner. In Mogador herrschen noch ganz patriarchalische Verhältnisse. Abends um 6 Uhr werden die grossen, schweren Thore der Stadt geschlossen und kein Mensch darf mehr heraus noch herein. Auct die einzelnen Stadtteile sind durch grosse, fast 6 Meter hohe Mauern gegen 


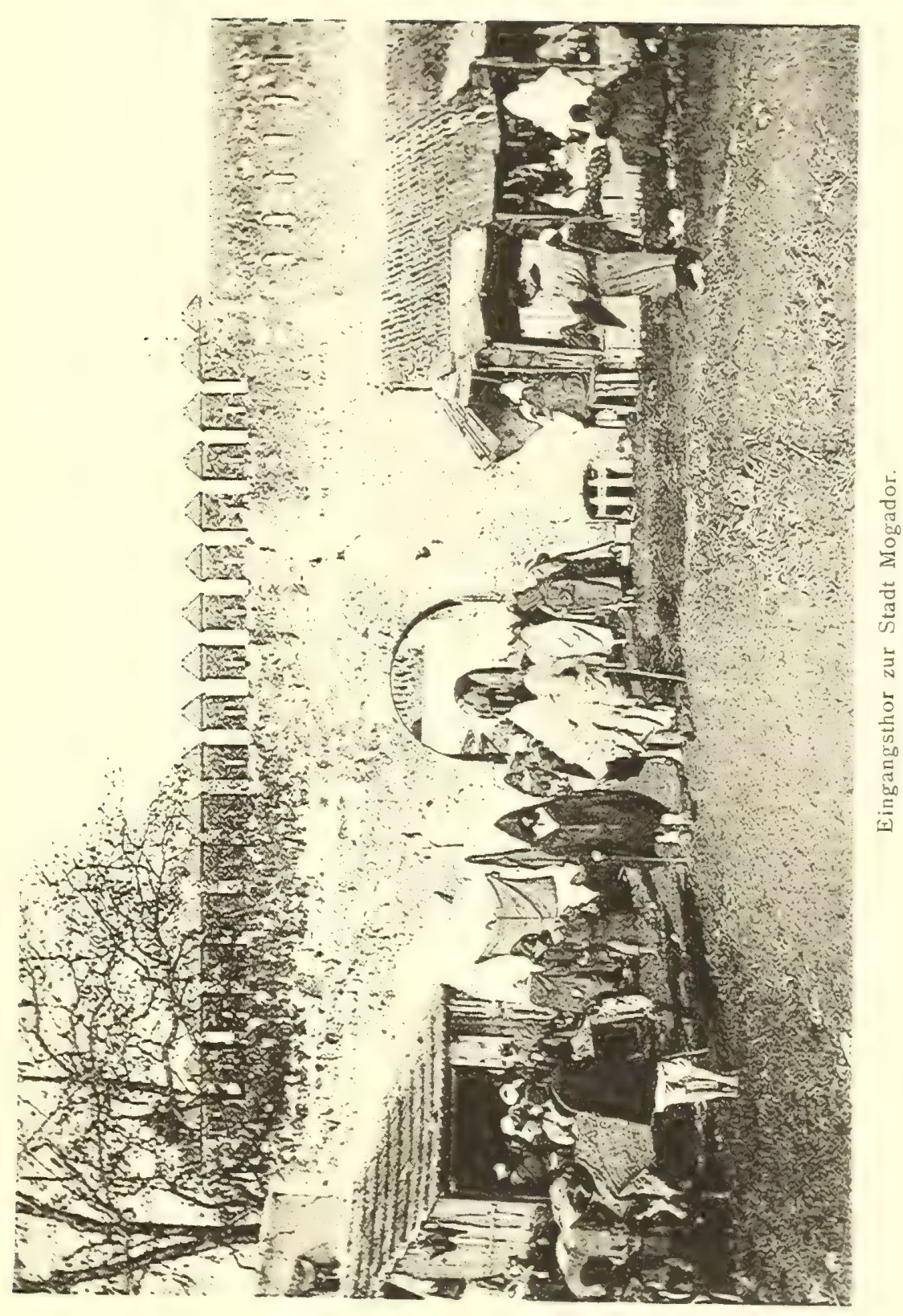



einander abgegrenzt, welche in der Nacht verschlossen werden. In dem nach der See zu gelegenen Stadtviertel wohnen die Europäer und grosse marokkanische Händler, in einem anderen Viertel die Mohamedaner, in einem dritten die Juden. Die europäischen Kaufleute sind zum grössten Teil unsere Landsleute und machten es sich zur Pflicht, uns in liebenswürdigster Weise Mogador zu zeigen. In den engen Strassen herrscht ein reges Treiben; beladene Kameele, Maultiere und kleine Esel vermitteln den Transport, während in den Läden und auf der Strasse Marokkaner und Juden ihre Waren feilhalten. In dem Mohamedaner- und Judenviertel giebt es konfessionelle Schulen, die mit Kindern überfüllt sind, welche im Chor Gebete absingen. Die arbeitenden Klassen, Sackträger, Bootsleute etc. bestehen aus Marokkanern, während das Kleinhandwerk sich in den Händen der Juden befindet. Alles wird in offenen Läden verhandelt, selbst die Konsultationen der marokkanischen, weissbärtigen Aerzte, sowie die Behandlung der Patienten wird öffentlich vorgenommen.

In der bedeutenden Handelsstadt Casablanca hatten wir nochmals Gelegenheit, einen Einblick in das marokkanische Leben zu thun. Ein ungemein reger Verkehr herrschte an dem Bollwerk sowie in der Stadt selbst. Auf dem vor den Thoren gelegenen grossen Marktplatz lagerten in zahllosen Körben oder in Haufen aufgeschüttet Apfelsinen, die Fleischer schlachteten auf dem Markte Schafe, und in dem dichten Menschengewühl bewegten sich Kamele, beladene Esel und Maultiere. Ab und zu ritt ein marokkanischer Grosser in malerischer blauer Tracht, weisser Tobe, buntem Turban und heruntergeschlagenem Litwan durch die engen Strassen, was mich lebhaft an die Haussa in Kete erinnerte.

Als letzte Station in Afrika berührten wir Tanger. Diese Stadt bildet schon den Uebergang zu europäischer Kultur. Die zahlreichen Europäer, welche die Strasse beleben, die grossen Läden mit Schaufenstern, die Restaurationen und Cafés geben ihr schon das Aussehen einer europäischen Stadt, während die marokkanischen Viertel mit dem schönen grossen Hafen noch afrikanisches Gepräge tragen.

Mit Volldampf ging es nun der geliebten Heimat zu. Es ist Ankunft schwer, dem Leser eine Vorstellung davon zu geben, mit welchen in Hamburg. Gefühlen der Reisende nach mehrjährigem Aufenthalt unter unkultivierten Völkern und nach sechswöchentlicher Fahrt, wenn die Mündung der Elbe erreicht ist, die Zinnen von Cuxhaven auftauchen sieht. Der Fluss wimmelt von grossen und kleinen Schiffen, deren Insassen uns durch Schwenken der Tücher und Zurufe in der Heimat begrüssen; denn sie kennen die Wörmann-Dampfer und wissen, dass 
Landsleute auf diesen Schiffen sind, welche draussen in den Kolonieen, sei es als Kaufleute, Beamte oder Soldaten im Dienste der deutschen Sache thätig waren. Immer dichter wird das Gewirr der Masten und Raen und endlich befinden wir uns mitten unter den Strassen und Thürmen der freien deutschen Handelsstadt Hamburg. Mit Abschied und Händedruck vom Kapitän, den übrigen Seeleuten und Passagieren, verliess ich die "Jeanette Wörmann" und begab mich zunächst nach Berlin, dann im März 1898 in meine engere Heimat, wo ich bei Eltern und Bekannten ein herzliches Willkommen fand. 


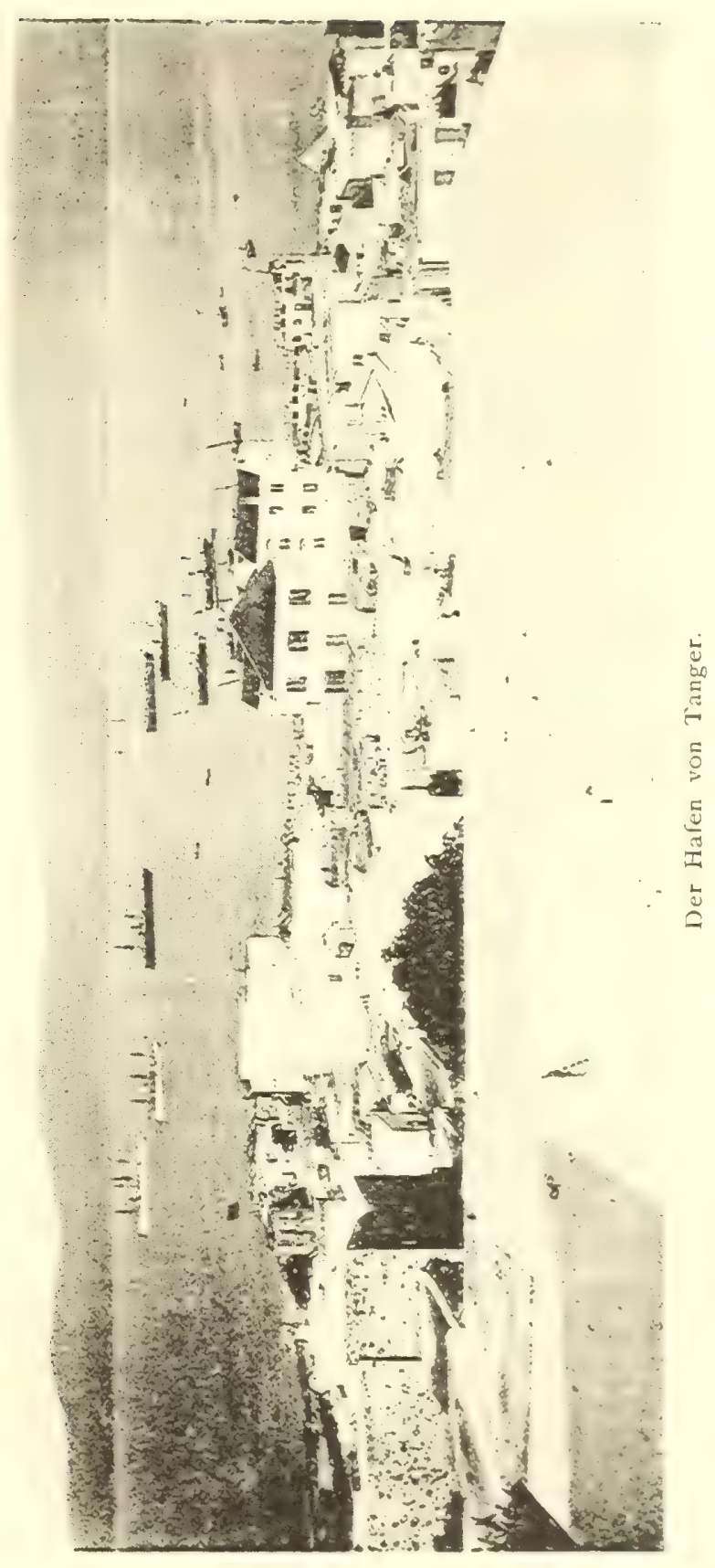





\section{ENTWICKLUNG DER KULTURVERHÄLTNISSE.}

\section{DIE WIRTSCHAFTLICHE BEDEUTUNG DER PRODUKTE UNSERER TOGO-KOLONIE UND DEREN VERWERTUNG.}

Bevor wir die Ausfuhrprodukte unserer Togokolonie näher betrachten, wollen wir nicht unterlassen, das Zollwesen der Kolonie zu erwähnen, welches von so einschneidender Natur für die Handelsverhältnisse ist. Die Einführung der jetzt giltigen Zollsätze, wie das ganze Zollwesen, ist das gemeinschaftliche Werk des damaligen Landeshauptmannes von Puttkamer und des Zolldirektors Boeder, wobei die Einfuhrzölle der benachbarten englischen Goldküstenkolonie als Unterlage dienten. Die deutsch-englische Zollkonvention, welche das linksseitige englische Voltagebiet mit dem deutschen Gebiet als ein einheitliches Zollgebiet ansieht, blieb bestehen. Die Zollsätze, namentlich für Spirituosen und Pulver wurden bei diesem neuen Zolltarif im Jahre I 894 bedeutend erhöht. Danach werden Spirituosen jeglicher Art das Liter mit 22 Pfennigen verzollt, während der Zollsatz für das Pfund Pulver 5o Pfennige beträgt. Auch der Tabak unterliegt einem hohen Zollsatz von 5o Pfennigen für das Kilo. Nach der Brüsseler Konvention dürfen auch in Togo nur Steinschlossflinten eingeführt werden, alle übrigen Waffen zur Jagd und zur Verteidigung für Europäer sind der Genehmigung der Regierung unterworfen und müssen zur Kontrolle abgestempelt werden. Der Zollsatz für Feuerwaffen ist daher ein verhältnismässig hoher und beträgt für das Stück 2 Mark. Alle sonstigen eingeführten Gegenstände unterliegen einem Zollsatz, dessen Höhe 4 Prozent vom Werte der zu verzollenden Gegenstände gleichkommt. Alle wissenschaftlichen Instrumente, Bücher und landwirtschaftliche Geräte und alle Gegenstände, welche zu Kulturzwecken eingeführt werden, gehen mit Genehmigang des Gouverneurs zollfrei in das Gebiet ein. Ferner geniessen auch die Missionen für die nötigen Gebrauchsartikel Zollfreiheit. 
Was die Urprodukte des Landes anbetrifft, so sind bis jetzt in Oelpalme. erster Linie für die Togokolonie die reichen Oelpalmwälder und die Gummidistrikte ron wirtschaftlicher Bedeutung. Leider kommt bisher nur die Ernte der Oelpalmen in den Küstendistrikten bis etwa fünf bis sechs Tagemärsche ins Innere für eine wirtschaftliche Ausbeute in Betracht, die weiter nach dem Innern liegenden reichen Oelpalmenbezirke sind für den Handel ohne Bedeutung, da die Trägerlöhne zu kostspielig sind und die Eingeborenen selbst die Waren wegen des geringen Verdienstes nicht zur Küste bringen. So verfaulen jährlich im Hinterlande viele Produkte; erst mit der Anlegung von Strassen und Eisenbahnen wird diesen Verlusten Einhalt gethan werden können. Aus den näheren Gebieten kommen hauptsächlich die gedörrten Palmkerne an die Küste, die Bewohner der entfernter liegenden Gegenden geben sich mit dem Transport der voluminösen Palmenkerne nicht ab, sondern bringen nur Palmöl zum Verkauf in die Faktoreien der Küstenplätze. Nach den statistischen Angaben von $1897 / 98$ betrugen die Preise für einen Liter Palmöl 22 Pfennige, während ein Kilo Palmkerne nur I3 Pfennige brachte. Die Ausfuhr von Palmkernen belief sich im Jahre I897/98 auf 3064883 Kilo, während die Ausfuhr des Palmöls 473788 Liter betrug. Der Gesamtwert der ausgeführten Palmkerne beziffert sich demnach etwa 398 ooo Mark, der des Palmöls auf 3 Io ooo Mark. Das schmutzige, von den Eingeborenen aus dem Fleische der Oelpalmenfrucht gewonnene Oel wird in Europa in den Oelfabriken gereinigt und als Palmöl!, welches meistens eine gelbliche Farbe besitzt, zur weiteren Verarbeitung in den Handel gebracht. Die Palmkerne werden in Europa zu Palmkernöl, Glycerin und Fettsäuren verarbeitet. Die Rückstände werden zur Herstellung eines beliebten Viehfutters, des Palmkuchens, benutzt. Aus den Fettsäuren und minderwertigen Qualitäten werden Stearinkerzen und Palmkernseifen hergestellt.

Gummi. Mit das wertvollste Produkt ist der Kautschuk. Er wird, wie wir gesehen haben, aus dem Saft der Landolfia-Lianen gewonnen, welche hauptsächlich im Hinterlande, in Adele, Adjuti, Akposso, Tribu und Kebu wachsen. Früher soll die Liane auch in den Küstenbezirken reichlich vorgekommen, aber durch die rohe Methode der Saftgewinnung bis auf einen kleinen Bestand, welcher für die Industrie nicht mehr lohnt, ausgerottet sein. Aus diesem Grunde wäre es dringend notwendig, dass in den noch ergiebigen Kautschukdistrikten durch ein Gesetz und durch die Anstellung von erfahrenen Pflanzern der systematischen Ausrottung dieser so wertvollen Pflanze vorgebeugt würde. Neben den Landolfiaarten soll im Hinterlande die Kickxia africana vorkommen, deren Ausbeutung den Eingeborenen aber noch nicht bekannt zu sein scheint. Leider geht bis jetzt der grösste Teil des Gummis aus 
unserem Hinterlande per Kanoe den Volta abwärts nach Adda an der Guldküste, sowie auch auf dem Landwege nach Kitta. Der Kautschuk wird gewöhnlich von den Eingeborenen in faustgrossen Bällen zur Küste gebracht, in den Faktoreien in Fässern verpackt und kommt dann direkt in die Kautschukfabriken, wo er gemahlen, gewaschen und getrocknet, mit Schwefelblumen gemischt und vulkanisiert wird. Aus den so gereinigten (iummi wird dann Weich- und Hartgummi hergestellt und zu den mannigfaltigsten Gummiartikeln verarbeitet. Die Ausfuhr des Kautschuks belief sich im Jahre r $897 / 98$ auf 88598 Kilogramm, während sie im Vorjahre nur 7 620 Kilogramm betrug. Der Durchschnittspreis für dem Kautschuls war für das Kilogramm 3,50 Mark, so dass der Cxesamtwert der Ausfuhr im Jahre $1897 / 98$ ungefähr 310000 Mark betragen hat. Abgesehen von dem von den Eingeborenen aus wildwachsenden Lianen gewonnenen Kautschuk, lassen erfolgreiche Versuche mit der Anlage von Gummibaumplantagen in absehbarer Zeit eine Erhöhung der Kautschukproduktion erwarten. So haben besonders in den letzten Jahren ausgedehnte Anpflanzungen mit "Manihot Glaziorii“ zu einem guten Ergebnis geführt. Hoffentlich gelingt es auch den wertvollen Kautschukbaum Kickxia, der in Togo und im Hinterlande wild rorkommen soll, in grösseren Plantagen zu kultivieren.

Eine Ausbeutung der verschiedenen Akazienarten, beispielsweise der Akacia senegalensis, welche durch den Botaniker Baumann in unserem Hinterlande vorgefunden worden ist, hat zwar noch nicht stattgefunden, doch dürfte, falls der Baum in genügender Nenge rorkommt, das gewonnene Produkt, das sogenannte Gummi arabicum, in der Zukunft einen nicht zu unterschätzenden Ausfuhrartikel und eine neue Einnahmequelle für Togo bilden.

Was die bisher ausgeführten Plantagenerzeugnisse der Togokolonie Kokosnuss. anbetrifft, so steht in erster Linie die Kokosnuss, welche an der Küste selbst auf ganz minderwertigem Boden vorzüglich gedeiht. Die Ausfuhr betrug im Jahre $1897 / 9 \$ 9900$ Stück, während an Kopra 2900 Kilogramm verschifft wurden. Diese geringe Ausfuhr erklärt sich daraus, dass die Früchte der jungen Bäume vorerst hauptsächlich zur Anpflanzung neuer Plantagen verwendet werden, ausserdem aber die ältesten Plantagen nicht viel über acht Jahre bestehen, mit welcher \%eit die Kokospalme erst Früchte zu tragen beginnt. Wegen der geringeren Transportkosten wird vielfach nur der zerschlagene und getrocknete Kern der Nuss, die Kopra, ausgeführt. Dieselbe wird in Europa hauptsächlich zur Seifenfabrikation verwendet. In neuerer Zeit hat man auch das Oel der Kopra von den unangenehmen Fettsäuren chemisch gereinigt und zur Herstellung der sogenannten Kokosbutter verarbeitet, die ein vorzügliches Speisefett abgiebt und jedenfalls der Margarine vorzuziehen ist. Die 
Pressrückstände der Kopra werden zu Oelkuchen verarbeitet, die ein vorzügliches Viehfutter sind. Auch die äussere Hülle der Nuss ist nicht ohne Wert. Es lohnt sich daher, nicht bloss die Kopra, sondern auch die Schale auszuführen. Aus Kokosfasern werden dauerhafte Seile und Taue, Läufer, Matten, Besen, Handbürsten und Pinsel angefertigt. Die Eingeborenen verwenden die Schale zu Gefässen, aber auch bei uns wird sie wegen ihrer Härte zu den mannigfaltigsten Drechslerarbeiten benutzt.

Der Kaffee, dessen eigentliches Heimatsland das tropische Afrika ist, kommt wildwachsend in Arabien, in Deutsch-Ostafrika und an der Westküste in Liberia vor. Selbst Kamerun hat wilde Kaffeearten in dem Kamerungebirge aufzuweisen. Darnach scheinen sich unsere westafrikanischen Kolonieen für den Anbau von grösseren Kaffeeplantagen besonders zu eignen. Namentlich der liberianische Kaffee scheint in den Küstengegenden den richtigen Nährboden und das ihm zusagende Klima gefunden zu haben. Die in Togo angelegten Plantagen gedeihen bei normalen Witterungsverhältnissen und bei guter Pflege ganz ausgezeichnet. Die Plantagen an der Küste haben heute schon die stattliche Anzahl von 98 ooo Bäumen erreicht. Auch im Innern sind bei der Station Misahöhe und von den Missionaren in Ho Versuchsplantagen angelegt worden, welche deutlich beweisen, dass hier sowohl liberianischer als auch arabischer Kaffee gut gedeiht. Sogar die wilden Kaffeeplantagen in Kuma und Wurupong werfen schon einen verhältnismässig guten Ertrag ab. Die Ausfuhr des meistens nach Hamburg verschickten Kaffees betrug im Jahre $1897 / 98$ schon 3 oro Kilogramm, während er im Jahre 1894 , eigentlich dem ersten Erntejahr des Togokaffees, noch in der winzigen Menge von I 30 Kilogramm nach Hamburg auf den Markt kam und dort einen Preis von 84 Pfennig pro Pfund erzielte. Je nach der Güte des liberianischen Togokaffees schwankte der Preis durchschnittlich zwischen 80 und 96 Pfennig pro Pfund ohne Zoll. Ausser den grossen unbebauten Küstenstrecken, die sich für den liberianischen Kaffee eignen, scheinen auch die humusreichen Hänge des Agomegebirges wegen ihrer höheren Lage besonders für den Anbau von arabischem Kaffee empfehlenswert zu sein. Die grosse Strasse ins Innere, namentlich aber die hoffentlich in nicht allzu ferner Zeit anzulegende Eisenbahn wird den Transport verbilligen und die Anlegung von Plantagen in diesen Gegenden höchst rentabel machen. Da diese grossen fruchtbaren Ländereien zur Zeit noch sehr billig sind, würden sie sich vorzüglich zur Anlegung deutschen Grosskapitals eignen, welches später reiche Zinsen einbringen dürfte.

Kakao. Mit Kakao sind leider bis jetzt in Togo keine grösseren Versuche gemacht worden, da die Probepflanzungen auf dem harten und trockenen Lataritboden an der Küste ein ungünstiges Resultat ergeben haben. Neuerdings sind in dem Versuchsgarten bei Lome die Versuche wieder- 
holt worden, doch müssen die Resultate noch abgewartet werden. Für die Kakao-Pflanze scheinen sich die fruchtbaren Ländereien an dem Fusse und den Hängen des Agomegebirges wegen der grösseren Niederschlagmengen ebenfalls zu eignen.

Auf besserem Boden scheint sich der Anbau von Tabak zu empfehlen, da schon die kleinen Versuche auf der Plantage Kpemme als gelungen betrachtet werden können und die erste Ernte des dort gebauten Tabaks ein gutes Produkt geliefert hat. Auch im Hinterlande wird Tabak von den Eingeborenen gebaut und gedeiht trotz der primitiven Kultur ganz vorzüglich. Aehnliche Versuche sollten im Hinterlande mit Vanille, Ingwer, Kardamom, Paradieskörnern und Mazisbohnen gemacht werden, da speziell Ingwer in Westafrika, namentlich in Sierra-Leone schon einen bedeutenden Handelsartikel bildet und die übrigen Pflanzen in Kamerun gut eingeschlagen sein sollen. Ebenso wären Versuche mit Thee wünschenswert, die bis jetzt fast in unseren sämtlichen westafrikanischen Kolonieen unterblieben sind.

Eine für Togo besonders wichtige Pflanze ist der Kolabaum (Cola acuminata). Wie wir gesehen haben, ist die Frucht dieses Baumes, die Kolanuss, in unserem Hinterlande und in den Haussastaaten ein beliebtes narkotisches Mittel und wird aus dem Inneren nach dem Kolacentrum und den Märkten im englischen Gebiet, beispielsweise Ateobu verhandelt; schon allein die kleinen Kolavorräte in unserem Gebiet, wie in Tappa, bringen einen verhältnismässig bedeutenden Handelsverkehr mit sich. Die Versuche in Misahöhe und Bismarckburg haben gezeigt, dass der Kolabaum in Plantagen gut gedeiht, er dürfte daher künftig bei der Anlage von Plantagen in den Gebirgsgegenden eine ganz bedeutende Rolle spielen. Der Anbau von Kolapflanzungen in Togo ist um so mehr zu empfehlen, als in neuerer Zeit die Kolafrucht auf dem europäischen Markt an Bedeutung gewinnt. Im Jahre 1892 wurden in Kamerun nur ı 9 Kilogramm Kolanüsse exportiert, während sich im Jahre I $897 / 98$ die Ausfuhr auf 50272 Kilogramm gesteigert hat. Das Kolaïn soll die Nerven anregen und bei grossen Strapazen und Ermüdungen belebend auf die Kräfte wirken. Es wird deshalb von den Haussa auf ihren Märschen genossen. In Europa wird die Kolanuss, zu Pulver zerrieben, zu medizinischen Zwecken, sowie als anregendes Genussmittel in Chokoladefabrikaten, zur Herstellung des schmackhaften Kolalikörs und Kolaweins, als Zusatz zu Biskuits und auch direkt als Kolatablette verarbeitet.

Mit dem Plantagenbau von Baumwolle sind grössere Versuche Baumwolle. bisher nur von der Firma Vietor gemacht, aber leider wieder aufgegeben worden. Doch trifft man überall grössere und kleinere Baumwollfarmen von Eingeborenen bis tief in das Hinterland hinein und nicht selten findet man die Pflanze wild wachsend vor, ein Beweis, dass sie 
auch ohne Pflege die Bodenverhältnisse und das Klima im Hinterlande gut verträgt. Die Baumwolle ist daher für den Plantagenbau in den niederschlagsreichen Gebirgsgegenden nicht zu unterschätzen. Die nur mit der Hand gereinigten und entkörnten Baumwollproben erzielten einen Preis ven 43 Pfennig für das Pfund; der Preis würde sich jedenfalls höher stellen, wenn zu der Entkörnung der Baumwolle Maschinen benutzt und dadurch die Qualität verbessert würde. Bei einem Preise von t5 bis 48 Pfennig pro Pfund dürfte sich schon der Anbau und Seetransport lohnen. Mit der Verfeinerung und Auswahl des Saatgutes könnte wahrscheinlich ein höherer Preis erzielt werden. Die festgesponnenen Garne und derben aber haltbaren Tücher der Eingeborenen sprechen dafür, dass sich die Baumwolle wenn auch nicht für feine, so doch für gröbere Stoffe in Europa verwenden liesse.

Der Mais wird von den Eingeborenen in grösseren Mengen angebaut. Die grössten Maisfarmen trifft man im Evhegebiet, wo sie sich von der Küste hinter der Lagune bis weit in das Innere hineinziehen und mit zu dem Lebensunterhalt der Evheleute gehören. In günstigen Jahren wird nicht bloss der Bedarf im Lande selber gedeckt, sondern auch Mais ausgeführt. Die Ausfuhr betrug im Jahre 1897/98: 8 r 835 Kilogramm zu einem Durchschnittspreise von o,o3 M. pro Kilogramm. Auch sind schon früher, im Jahre I890/91, 638000 Kilogramm exportiert worden. Wenn der im allgemeinen sehr träge Neger zur Arbeit angehalten und geeignete Zugtiere sowie einfache Maschinen, wie z. B. der Pflug, eingeführt würden, so könnte bei den grossen, noch unbebauten Flächen ein Aufschwung des Ackerbaues und damit eine intensivere Maiskultur für Togo herbeigeführt werden. Bis jetzt wird der Mais hauptsächlich zu Maisöl, Maizena und Mondamin verarbeitet. Auch wird er in Europa bei einer schlechten Roggenernte als Ersatz für Roggen gebraucht.

Erdnuss. Die Eingeborenen haben ebenfalls grosse Erdnussfarmen angelegt. Leider werden die Erdnüsse im Verhältnis zu dem starken Anbau nur in geringerem Maasse exportiert Jedoch war in dieser Beziehung in dem letzten Berichtsjahre $1897 / 98$ ein kleiner Aufschwung zu bemerken, indem I 7820 Kilogramm zur Verschiffung gelangten. Für ein Kilogramm Erdnüsse wurden I2 Pfennige gezahlt, so dass dieses Produkt bei einer etwas grösseren Rührigkeit einen bedeutenden Ausfuhrartikel repräsentieren könnte. Die Einführung von Maschinen zur Enthülsung der Früchte könnten auch hier segensreich wirken, da bis jetzt die Schwierigkeit, die Nüsse mit der Hand $z u$ enthülsen, viele der Eingeborenen abhält, die Erdnüsse zum Verkauf in die Faktoreien zu bringen; der Bedarf an Erdnüssen, welche namentlich in letzterer Zeit zur Herstellung von Oel u. a. verwendet werden, ist in Deutschland so gross, dass weder Togo noch Deutsch-Ost-Afrika ihn zu 
decken vermochten und die Ware aus fremden Kolonieen eingeführt werden musste. Die Erdnüsse werden in Oelfabriken zu einem vortrefflichen Maschinenöl und Speiseöl verarbeitet; das letztere kommt nicht selten unter der Marke von Olivenöl in den Handel. In neuerer Zeit wird auch Butter aus dem Oel hergestellt. Die Pressrückstände bilden als Erdnusskuchen ein vorzügliches Kraftfutter für das Vieh. Das Erdnussmehl dient ferner zur Fälschung von Kaffee und Kakao. 1)ie Samenschalen geben, zerstampft, ein sehr brauchbares T'erpackungsmaterial ab. Neben der Erdnuss wird im Togogebiet in geringerem Maasse die Erderbse oder schwarze Erdnuss zum eigenen Gebrauch angebaut.

Der Reis kann vorläufig als Ausfuhrprodukt nicht in Frage kommen, Reis, Hirse, da ein grösserer Anbau desselben in der Trockenzeit in den Küsten- Bohnen. gegenden unthunlich ist. D)agegen wäre es mit dem Anbau von Reis in den sumpfigen Thälern am Fusse des Gebirges zu versuchen, da weiter im Hinterlande, namentlich in Sugu, der Reis kultiviert und auch näher der Küste in einzelnen sumpfigen Thälern sogenannter Sumpfreis und in den Gebirgsgegenden Bergreis gebaut wird. Ferner produziert Tog( namentlich weiter von der Küste ab, drei Hirsearten, gelbliche und weisse Kolbenhirse und Rispenhirse; letztere ist allgemein unter dem Namen Guineakorn bekannt. Die Hirse wird nur zum eigenen Bedarf angebaut, ebenso verschiedene Bohnenarten.

Der Schibutterbaum ist in den grossen Baumsavannen des Voltathals überall vorhanden. Die Ausbeutung desselben ist verhältnismässig gering gegen seine massenhafte Verbreitung. Die Eingeborenen in dem weiteren Hinterlancle, namentlich in Dagomba, bereiten aus den Früchten des Baumes ein gelbliches fiett, welches meistens in Zuckerhutform mit Blättern verpackt auf den Markt kommt und ron den Eingeborenen als Speisefett genossen wird. Leider wird bis jetzt wegen des kostspieligen Transports zur Küste die Schibutter nur vereinzelt und in geringen Quantitäten ausgeführt. Im Jahre 1892 wurden 634 Kilogramm im Werte von 253 Mark ausgeführt, von da ab bis 1897 unterblieb die Ausfuhr ganz, und in dem letzten Berichtsjahre $1897 / 98$ wurde nur die kaum nennenswerte Menge von 6i Kilogramm exportiert. Hoffentlich wird sich mit den besseren Verkehrsverhältnissen die Ausfuhr dieses Produktes heben, und da dasselbe im Jahre 1892 mit 39 bis 40 Pfennigen für ein Kilogramm bezahlt wurde, für die Kolonie eine nicht zu unterschätzende Einnahmequelle werden. Bei uns wird die Schibutter gewöhnlich nur zur Herstellung ron Schmierfetten, wie Wagen- oder Hufschmiere etc. verarbeitet. Auch Sesam, welches von den Eingeborenen im Hinterlande unserer Kolonie gebaut wird, ist bis jetzt ausser einigen Proben so gut wie garnicht ausgeführt worden, obwohl das Sesamöl wirtschaftlich keine geringe Bedeutung hat. 
Für Togo kommt hauptsächlich eine weisse Sesamsaat in Betracht. Neuerdings haben die Anbauversuche an der Küste auf Laterit- und auf Sandboden ein günstiges und vielversprechendes Resultat ergeben. Das Sesamöl dient als Speiseöl und soll vielfach zur Fälschung des Olivenöls sowie bei der Bereitung der Margarine benutzt werden. Das minderwertige Oel wird für die Seifenfabrikation, sowie als Schmier- und Brennöl verwendet. Rizinus, das in Togo ebenfalls wächst, kommt nicht zur Ausfuhr, trotzdem es nicht nur als Arzneimittel, sondern auch in der Technik verwendet wird. Dasselbe gilt von dem Kürbissamen, der nur früher in ganz kleinen Mengen ausgeführt worden ist und zur Bereitung von Oelen dient. Auch der Aschantipfeffer (piper guineense), der in grossen Mengen überall in unserem Hinterlande vorkommt, wird nur auf die Negermärkte gebracht, aber bis jetzt noch gar nicht exportiert

Zuckerrohr wird von den Eingeborenen, jedoch nur in geringen Mengen zum eigenen Gebrauch angebaut; die Staude wird roh zerkleinert und kommt als Leckerei auf die einheimischen Märkte. Ein grösserer Anbau würde bei den hohen Transportkosten wohl kaum mit unserer europäischen Rübenzuckerproduktion konkurrieren können.

Bau. und Wenig Beachtung haben bis jetzt die in nicht geringem Umfange Zierbölzer. vorhandenen Bau- und Zierhölzer gefunden, welche in den Wäldern unserer Togokolonie vorkommen. Eine grössere Ausbeutung derselben dürfte wohl erst mit der Besserung der Verkehrsverhältnisse zu erwarten sein. Ein vorzügliches hartes Holz ist das rötliche Odumholz, welches termitenfest ist und infolge dessen als Baumaterial bei europäischen Bauten in der Kolonie mit Vorteil verwendet wird. Die Mangrovenhölzer von den grösseren Flüssen sind noch nicht zur Ausfuhr gelangt, nur die sogenannte Delebpalme ist im vorigen sowie im letzten Berichtsjahre $1897 / 98$ in der geringen Menge von 5700 Kilogramm ausgeführt worden. Ebenholz kommt zwar zur Ausfuhr, doch nur vereinzelt in geringen Mengen; so wurden I 898: 65 Kilogramm exportiert, während Mahagoni leider noch garnicht oder in nicht nennenswerten Proben ausgeführt worden ist. Als Farbstoff spielt das Rotholz eine grössere Rolle, das hauptsächlich im Hinterlande vorkommt und von den Eingeborenen zum Färben ihrer einheimischen Tücher verwendet wird. Die Indigopflanze wird teils von den Leuten für den eigenen Gebrauch angepflanzt, teils gepresst in Form von kleinen Kugeln oder Würfeln auf die einheimischen Märkte gebracht. Namentlich für die Haussa ist das Indigo ein wichtiger Artikel, da sie neben weissen hauptsächlich blaue Stoffe tragen. Bis jetzt ist weder Rotholz noch Indigo exportiert worden.

'aserstoffe und $\mathrm{Zu}$ erwähnen sind noch die verschiedenen Palmenarten, welche zu Flechtstoffe. Flechtzwecken benutzt werden. Es wurden im Jahre $1896 / 9736256$ Kilogramm exportiert, während in dem letzten Berichtsjahre I $897 / 98$ nur die 
geringe Menge von 86 Kilogramm Palmenblättern zur Ausfuhr gelangte. Die häufig, auch an der Küste vorkommende Delebpalme würde sich zur Bereitung von Bassine eignen, woraus sich vorzügliche Besen und Faserbürsten herstellen lassen. Bedauerlicherweise sind in dieser Hinsicht noch keine Versuche gemacht worden. Im weiteren Hinterlande gedeiht die Weinpalme (Raphia vinifera), die von den Eingeborenen zur Anfertigung ron Matten und Stricken für den eigenen Gebrauch verwendet wird. Die grosse Entfernung von der Küste verbietet leider bis jetzt die Ausfuhr dieses immerhin wertvollen Produktes. Ferner könnten mit dem Bast der fast überall in Togo wachsenden Banane und des Affenbrotbaumes, der zur Papierfabrikation verwendet wird, Versuche angestellt werden. Die Dumpalmen können als Ausfuhrprodukt nicht in Betracht kommen, da sie nur vereinzelt im weiten Hinterlande in Sugu anzutreffen sind. Dagegen würden die Blätter der vielen Pandanuspflanzen sowie die allerdings nicht sehr häufige wilde Dattelpalme zu Flechtzwecken heranzuziehen sein. Auch wären Anbauversuche mit Boehmeria-Pflanzen im Hinblick auf die aufblühende Ramiekultur von nicht zu unterschätzendem Wert.

Von Arzneipflanzen kommt in Togo das schon erwähnte Rizinus Arzneistoffe. vor, welches auch als Oel verwendet wird, weiter im Hinterlande eine Strophantusart, aus der die Eingeborenen das Gift für ihre Pfeile und Speere gewinnen. Der Samen dieser Pflanze wird auch bei uns als Mittel gegen Herzleiden angewandt, so dass das Strophantusgift ein Ausfuhrartikel für die Kolonie werden kann.

Ausser den an anderer Stelle erwähnten Früchten könnte eventuell bei sorgfältiger Konservierung die Ananas verwertet werden. Sie findet sich in den schattigen Gebirgsgegenden in grossen Mengen an Wegen und Stegen und man erhält schöne grosse Früchte, namentlich in einiger Entfernung von der Küste, schon für 5 Pfennige. Die Pflanze ist nach einer einmaligen Aussaat kaum auszurotten und wächst wild ohne jegliche Pflege. Leider verträgt die reife Frucht in rohem Zustande nicht den langen Seetransport; mit Zucker eingekocht, der aus dem Zuckerrohr an Ort und Stelle gewonnen werden könnte, und gut verpackt müsste sie jedoch verschiffbar sein und könnte im Grossbetriebe unter Umständen eine schöne Rente abwerfen. Sonst eignen sich vielleicht noch zum. Export eine kleine schöne Limonenart, Tomaten oder sogenannte Paradiesäpfel, sowie eine ziemlich minderwertige Orangenart.

Das wertvollste tierische Produkt, das Elfenbein, gelangt im Verhältnis nur wenig nach Deutschland zur Ausfuhr, da in den Küsten gebieten wie in der Gbinebene die Elephantenherden schon sehr abgenommen haben, ausserdem aber ein grosser Teil des Elfenbeins aus unserem Hinterlande in die englischen Faktoreien an der Goldküste verkauft wird. Es wurden im Jahre $1895 / 965+3$ Kilogramm, im Jahre

Früchte.

Verschiedene Produite. 
1896/97 972 Kilogramm und in dem letzten Berichtjahre $1897 / 98$ nur 7 to Kilogramm Elfenbein ausgeführt. Leider sind die Elephanten bis jetzt noch durch kein Jagdgesetz geschützt und ihre Ausrottung macht stetige Fortschritte. Nach dem Erfolg, welchen die Missionare von Fernan Vaz mit der Zähmung des afrikanischen Elephanten errungen haben, wird man wohl mit der Verwendung der Elephanten zur Arbeit beginnen und sich deshalb zu grösserer Schonung des Bestandes entschliessen.

Weit nützlicher als die Elephantenjagd wäre die Jagd auf Flusspferde, weil sowohl die Zähne als Elfenbein, wie auch die Haut zu Peitschen u. s. w. verwendet werden können, die Tiere sonst aber keinen Vorteil bringen. Das Elfenbein wird hauptsächlich zur Anfertigung von Billardkugeln und Klaviaturen und zu den verschiedensten Drechslerarbeiten benutzt. Die Flusspferdzähne, die bis jetzt aus unserer Kolonie ausgeführt worden sind, werden zu Stockkrücken und anderen kleinen Gegenständen verarbeitet.

Ein anderes wertvolles Material für Drechslerarbeiten ist das Schildpatt, welches leider nur in ganz geringer Menge ausgeführt werden kann, da der Fang der grossen Seeschildkröte bei der geringen Ausdehnung der Küste nicht von Bedeutung ist. So wurden im letzten Berichtsjahre nur 5 Stück exportiert.

Hăute und Anders könnte es mit der Ausfuhr von Häuten und Fellen sein, Felle. da besonders in unserem Hinterlande im Gebirge der schwarzschenklige Seidenaffe (colobus vellerosus) häufig vorkommt und ein wunderschönes Pelzwerk abgiebt. Auch viele Leoparden- und Antilopenfelle, welche einen schönen Zimmerschmuck bilden, sowie Ziegen- und Schaffelle könnten in grösserer Menge ausgeführt werden, als bisher. Im Jahre r 892 wurden 575 Kilogramm Felle im Werte von 592 Mark, I 893 nur 260 Stück mit dem hohen Werte von I 535 Mark und I 894242 Stück mit dem Werte von 726 Mark ausgeführt. Im Berichtsjahre I $895 / 96$ ging die Anzahl der ausgeführten Affenfelle auf I 26 Stück zurück, während in dem Berichtsjahre I896/97 nur 94 Stück und in dem letzten Jahre $1897 / 98$ überhaupt keine Felle zur Ausfuhr gelangten. Die Ausfuhr dieser Felle aus der benachbarten Goldküsten-Kolonie betrug dagegen in den Jahren von $1887 / 92$ jährlich durchschnittlich 175 ooo Stück mit einem Werte von etwa 600 ooo Mark. In Europa werden die schönen, schwarzen, langhaarigen, seidenartigen Felle zu Muffen und Pelzkragen verarbeitet. Leider unterliegt aber dieser Artikel sehr der Mode und ist daher grösseren Preisschwankungen ausgesetzt, was den Export der Felle beeinträchtigt. Die Ausfuhr von Ochsenhäuten, Schaf- und Ziegenfellen, ist bedauerlicherweise ebenfalls zurückgegangen; während im Jahre I 895/96 94 Stück und im Jahre I986/97 32 Stück ausgeführt worden sind, hat dieses Ausfuhrgut im Jahre $1897 / 98$ nur die geringe Menge 
ron 9 Stück erreicht. Wenig in den Handel gebracht sind bisher Krokodilhäute, obwohl dieselben, in bestimmter Weise präpariert, vielleicht einen lohnenden Ertrag bringen könnten. Da in der Lagune und in den Flussläufen Unmengen von Krokodilen vorhanden sind, so wäre es immerhin eine Wohlthat für die Bewohner der Kolonie, sie von diesen gefährlichen Tieren zu befreien. Antilopen- und Büffelhörner werden in kleinen Mengen zum Schmuck und zu Drechslerarbeiten ausgeführt; die Ausfuhranzahl im Jahre $1897 / 98$ betrug nur 33 Stück, während das vorhergehende Jahr noch 54 Stück zur Ausfuhr brachte. Straussenfedern kommen nur selten auf die grossen Märkte von Kete und sind nicht als Ausfuhrartikel zu rechnen. Honig und Wachs findet man auf den einheimischen Märkten häufig, doch nur von wilden Bienen und in verhältnismässig so geringen Mengen, dass er nur zum eigenen Gebrauch der Eingeborenen hinreicht. Erst im Hinterlande wird eine halbwilde Bienenzucht betrieben. Ein Export kann daher bis jetzt nicht stattfinden.

Als Luxusgegenstände kommen in neuerer Zeit Waffen der Eingeborenen, wie Haussaschwerte, Bogen, Köcher, Pfeile, Speere und Aexte, auch Matten, wenn auch in geringer Menge, in den Handel. Bei den durchtriebenen Haussa hat sich dadurch in den Küstenstädten eine neue Industrie entwickelt. Speere und Pfeile werden an der Küste angefertigt und als ächte Salagaprodukte verkauft.

Von Bedeutung für das Schutzgebiet wäre bei besserenVerkehrsmitteln und einer Anlegebrücke für dieSeeschiffe inLome die Ausfuhr von lebendem Vieh aus Atakpame, speziell zur Versorgung der Seeschiffe mit Fleisch.

Das Hinterland ist reich an Eisenerzen, die, wie wir gesehen haben, an Ort und Stelle von den Eingeborenen gewonnen und zu ihren Geräten verarbeitet werden. Als Ausfuhrprodukt kann dasselbe leider jetzt noch nicht in Betracht kommen, immerhin aber spricht es für den Wert und die Zukunft der Kolonie. Auch Graphit ist gefunden worden, jedoch sind über die vorhandene Menge und die Abbauwürdigkeit desselben keine näheren Untersuchungen gemacht worden. Obwohl in der benachbarten Goldküste bei ähnlichen Gebirgsverhältnissen Gold gegraben und in den Quellflüssen des Volta von den Eingeborenen gewaschen wird, so ist es bis jetzt in unserer Kolonie noch nicht gelungen, Gold aufzufinden. Immerhin brauchen wir angesichts der grossen Quarzgebirge die Hoffnung auf das Auffinden von Goldadern nicht ganz aufgeben.

Aus diesen Angaben geht hervor, dass die Togokolonie keineswegs arm ist und dass ihre Produktionstähigkeit durch energische Arbeit noch gesteigert werden kann. Hoffen wir also, dass sie dermaleinst zu einer der wertvollsten Kolonieen unseres deutschen Vaterlandes erblühen wird. 


\section{ZWECKE UND ZIELE \\ UNSERER KOLONIALEN BESTREBUNGEN.}

Häufig werden unsere Kolonieen mit denjenigen anderer Staaten verglichen und es wird dabei hervorgehoben, dass unsere Kolonialarbeit nicht mit derjenigen anderer Völker, wie der Holländer und Engländer, Schritt halte. Wenn Ungunst des Klimas Krankheiten verursacht, Viehseuchen oder schlechte Erntejahre die Ausfuhr der Landesprodukte verringern, Kämpfe mit den Eingeborenen das Leben von Europäern kosten, so wird die Staatsregierung gewissermaassen dafür verantwortlich gemacht und die Anlage von Kolonieen als zwecklos hingestellt. Meistens werden die uralten englischen Kolonieen zum Vergleich herangezogen. Die öffentliche Meinung kolonialfeindlicher Gruppen bricht dann den Stab über jeden Misserfolg und schädigt dadurch nicht nur das Interesse für unsere Kolonieen, sondern auch Deutschlands Ansehen im Auslande. Die Anfänge anderer Kolonialmächte, die lange Jahre zurückliegen und zum Teil der Geschichte angehören, werden nur selten geprüft; vielmehr werden die Verhältnisse unserer neuen Kolonieen, die noch in den Kinderschuhen stecken, mit denjenigen altkultivierter in eine Reihe gestellt. Erwägt man die unglaublichen Schwierigkeiten, mit denen beispielsweise die erste Kolonialmacht Grossbritannien im i6. Jahrhundert bei der Kolonisierung von dem damals neu entdeckten Amerika oder von West-Indien zu kämpfen hatte, wo ganze Kolonieen durch Krankheit oder durch Kriege mit den Eingeborenen vernichtet wurden und viele Segelgeschwader auf der Fahrt nach Westindien untergingen oder verschollen sind, so wäre es geradezu ein Zeichen von Energielosigkeit des deutschen Volkes, wollte es nicht ebenso wie sein Vetter jenseits des Kanals den Hindernissen siegreich entgegentreten.

Unzugängliche Sümpfe sind in blühende Plantagen und Aecker umgewandelt worden, die mit ihrem Mutterlande, ja mit ganz Europa wetteifern. Auf dem Gebiete der Maschinentechnik ist das alte Europa von dem neuen Weltteil sogar fast überflügelt worden. Dass Amerika einst eine Kolonie war, davon spricht heute kein Mensch mehr. Als muster- 
gültige englische Kolonie werden immer die reichen ostindischen Bcsitzungen angeführt. Niemand erwähnt aber dabei die grossen Kosten und Opfer, welche Alt-England dieser Kolonie gebracht hat. In dieser Beziehung können wir von den Engländern, Holländern und Franzosen lernen, die es als nationale Ehre ansehen, Opfer für ihre Kolonieen zu bringen. Auch die älteren Kolonialmächte hatten Kolonieen, deren Bodenbeschaffenheit und Ertragfähigkeit anfangs zu wünschen übrig liess. Diese sind mit den Jahren wirtschaftlich gehoben worden und bringen nun für den Fleiss und die Arbeit, die an sie verwendet worden sind, reichlichen Lohn. Jeder neue Gedanke muss vor der Ausführung eingehend geprüft werden. Der Deutsche aber zeichnet sich durch allzugrosse Genauigkeit und Vorsicht bei allen Unternehmungen aus; nicht immer zu seinem Vorteil. Dem Volke der Denker, welches so grosses auf dem Gebiete der Wissenschaft geleistet hat, fehlt manchmal bei praktischen Unternehmungen der rasche Entschluss. Aus diesem Grunde sind wir bei der Kolonialpolitik den Engländern und Franzosen gegenüber im Nachteil geblieben. Auch die wirtschaftlichen Verhältnisse unserer Kolonieen sind durch die Zurückhaltung der Grosskapitalisten verhältnismässig weniger gefördert worden, wie in anderen Kolonien. Man hat häufig die Ansicht geltend gemacht, dass unsere Kolonien keine Auswandererkolonieen seien, dass sie daher keinen Zweck für uns hätten. Leider muss zugegeben werden, dass, abgesehen von Süd-West-Afrika, einem kleinen Teile von Ostafrika am Kilima-Ndjaro und unseren jüngsten Kolonieen in Ostasien und der Südsee, die übrigen Kolonieen infolge der ungünstigen klimatischen Verhältnisse vorläufig nicht geeignet sind, dem deutschen Ackerbauer oder Arbeiter ein Feld der Thätigkeit zu bieten. Dagegen sind dem Handel neue Absatzgebiete erschlossen und Schutz und Stützpunkte für die freie Weltkonkurrenz unserer deutschen Produkte geschaffen worden. Damit geht das Wachstum der deutschen Handelsflotte und des deutschen Schiffsbaues Hand in Hand. Schon jetzt kann der letztere mit dem englischen konkurrieren. Auch die Kriegsflotte muss zum Schutze unserer neuen überseeischen Interesșen der Macht und Würde des deutsches Reiches entsprechend vergrössert werden. Trotz der durch die Initiative unseres Kaisers herbeigeführten erfreulichen Erwerbung des Kiau-Tschou-Gebietes, sowie der Karolinen, Marianen und Palau-Inseln fehlen uns noch einzelne Stützpunkte sowohl für die Handels- als auch für die Kriegsflotte, namentlich Kohlenstationen an den fernen Meeresküsten, um uns auch in dieser Hinsicht selbständig und von anderen Kolonialmächten unabhängig zu machen.

Inzwischen verwirklicht sich der angedeutete Plan immer mehr, denn noch in letzter Stunde, nach fast vollständiger Drucklegung dieses 
Buches, wird ein neuer deutsch-englischer Vertrag veroffentlicht, den ich wegen seiner einschneidenden Bedeutung für Togo noch einfügen will. Danach hat der vielbesprochene Streitpunkt, die neutrale Zone, zu bestehen aufgehört. Die neue Grenze in dieser Zone bildet von nun ab bis zum Schnittpunkt mit dem 9. Grad der Dakáfluss. Von hier soll die Grenze in nördlicher Richtung noch durch eine Kommission näher festgelegt werden, wobei die Länder Yendi und Yakoshi an Deutschland, Mamprushi und Gambaga an England fallen. Dass zu Gunsten dieser Erwerbungen und der endgültigen Abgrenzung unseres Togo-Hinterlandes auch Salaga den Engländern zufällt, dass wir unsere Rechte auf die Tonga-Inseln und die Savage Island aufgeben, auf die ohnehin 1902 ablaufenden unabänderlichen Exterritorialitätsrechte verzichten und zwei noch unerforschte Salomon-Inseln abtreten, müssen wir verschmerzen bei der freudigen Nachricht, dass der deutsche Traum in Erfüllung geht und wir die beiden grössten Samoa-Inseln Upolu und Savai erhalten, welche von hervorragendem wirtschaftlichem Interesse für Deutschland sind. Dieser erfolgreiche Abschluss des Samoa-Streites ist als ein Sieg unserer Diplomatie zu betrachten und wird nicht verfehlen, unser Ansehen im Auslande zu erhöhen. Auch wird er ein neues Unterpfand für die Einigkeit unserer Parteien sein und dadurch hoffentlich ein einstimmiges Eintreten für die Vermehrung unserer Flotte bewirken.

Wie wir gesehen haben, sind uns schon jetzt selbst ohne grosse wirtschaftliche Anlagen durch unsere Kolonieen neue Absatzgebiete erschlossen worden. Von hervorragender Wichtigkeit und Bedeutung ist aber die wirtschaftliche Hebung der Kolonieen durch Urbarmachung und Anlegung von Plantagen, um Kolonialprodukte zu erzielen, die wir jetzt zum grössten Teile noch aus fremden Kolonieen beziehen müssen. Geben wir deshalb dem deutschen Kapital einen neuen Nährstoff, lassen wir es nicht in andere Kolonialstaaten fliessen, erhalten wir es vielmehr unserem eigenen Volke durch Verwendung in unseren Kolonieen. Muss es doch jedem national gesinnten Deutschen ein Gefühl der Befriedigung gewähren, wenn er sich sagen kann, dass er sich mit eigener Baumwolle bekleidet, eigenen Thee, Kaffee und Zucker geniesst. Soll das Kapital mit Vorteil arbeiten, so muss es natürlich auch etwas wagen. In dieser Beziehung ist ein erfreulicher Aufschwung in Kamerun und Togo, sowie in den übrigen Kolonieen in neuerer Zeit zu bemerken gewesen. Wir sind jetzt nach Eroberung und Erforschung des Landes in das wirtschaftliche Stadium getreten. Hoffentlich werden unsere Kolonieen nach dem Aufbau der wirtschaftlichen Verhältnisse die gewünschten Früchte tragen. Jedenfalls dürfen wir mit Bestimmtheit erwarten, dass durch die Kulturarbeit, die Anlage von Plantagen und die Bebauung grösserer Flächen, die A Ausrodung und Durchforstung der Urwälder, die Trockenlegung 
der Sümpfe, die Regulierung der Flussläufe und den Bau wohnlicher Häuser das Klima und damit die Gesundheitsverhältnisse sich bessern. Wir sind demnach zu der Annahme berechtigt, dass selbst die unter den jetzigen Verhältnissen für die Auswanderung ungeeigneten Kolonieen sich später zu Niederlassungen entwickeln werden, in welchen auch der deutsche Ackerbauer und Arbeiter Arbeit und Befriedigung findet. Freilich können alle diese Bestrebungen nicht mit den von der Regierung und dem Reichstag karg bewilligten Mitteln allein erreicht werden; auch kaufmännische und andere Privat-Unternehmungen müssen das Gedeihen der Kolonieen unterstützen.

Was die Verwaltung unserer Kolonieen anbetrifft, ist es, abgesehen von der Gewährung genügender Mittel, hauptsächlich nötig, dass zwischen den leitenden Kreisen in der Heimat und den Verwaltungsorganen in den Kolonieen gegenseitiges Vertrauen herrsche. Auch in dieser Beziehung können wir uns an Engländern und Franzosen ein Beispiel nehmen, die jedem einzelnen Beamten überlassen, auf exponierten Punkten nach seinem eigenen besten Ermessen zu handeln. Jede unter dem Personal aufkeimende Zwistigkeit oder Intrigue muss unparteiisch geprüft und der Wohlfahrt der Kolonie gemäss aus dem Schutzgebiete beseitigt werden. Unterstützen wir also die Pläne und Ziele der Staatsregierung im Sinne unseres Kaisers und hoffen wir, dass unsere Kolonieen, insbesondere auch Togo als ein Unterpfand für deutschen Fleiss und Arbeit wachsen, blühen und gedeihen mögen! Das walte Gott! 




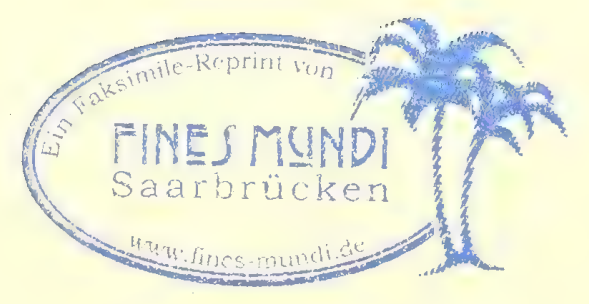






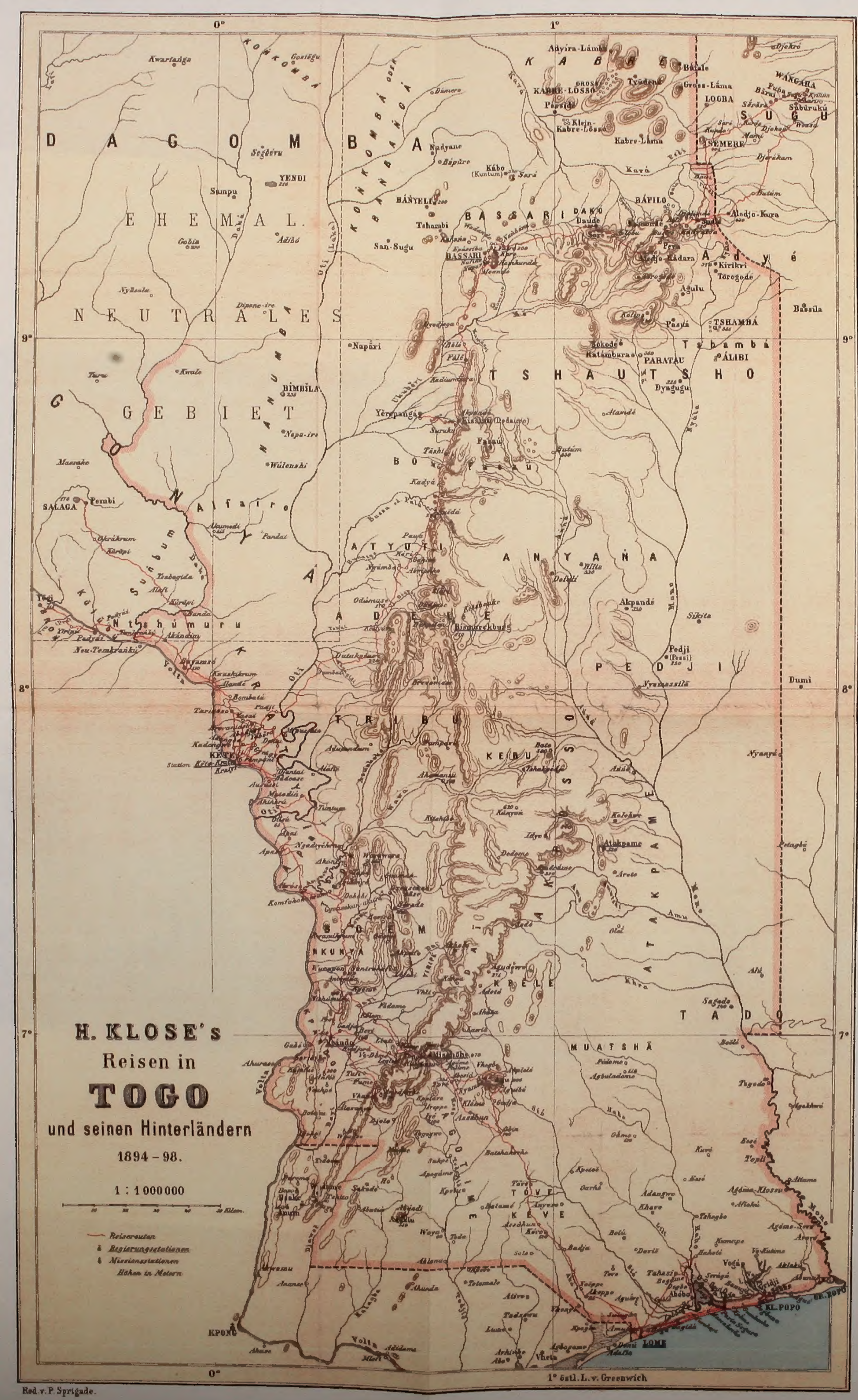



Fhrshirze von Lome. (Fach Den Qufnahmen von 5. Hhlose.)

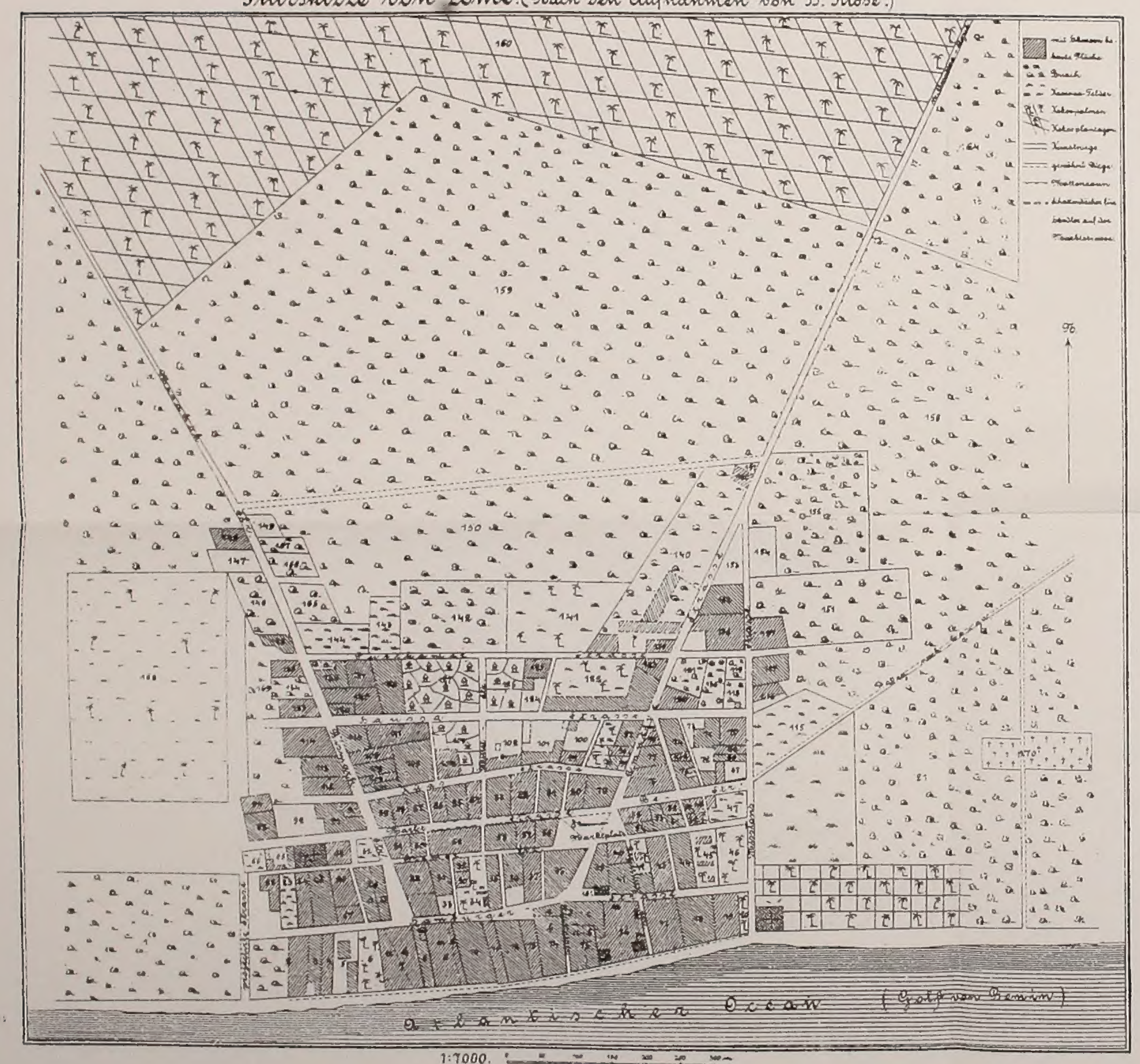

\section{Lome.}

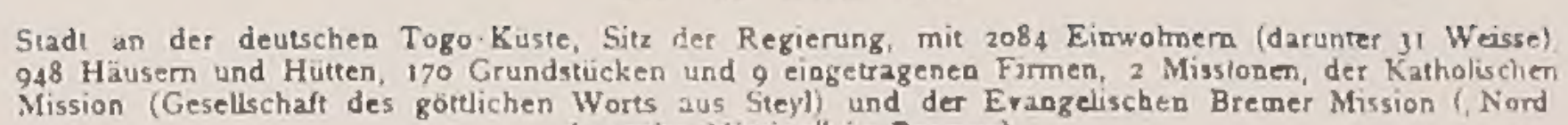
Aufgenommen in Februar 1896 von Heinrich Klose.

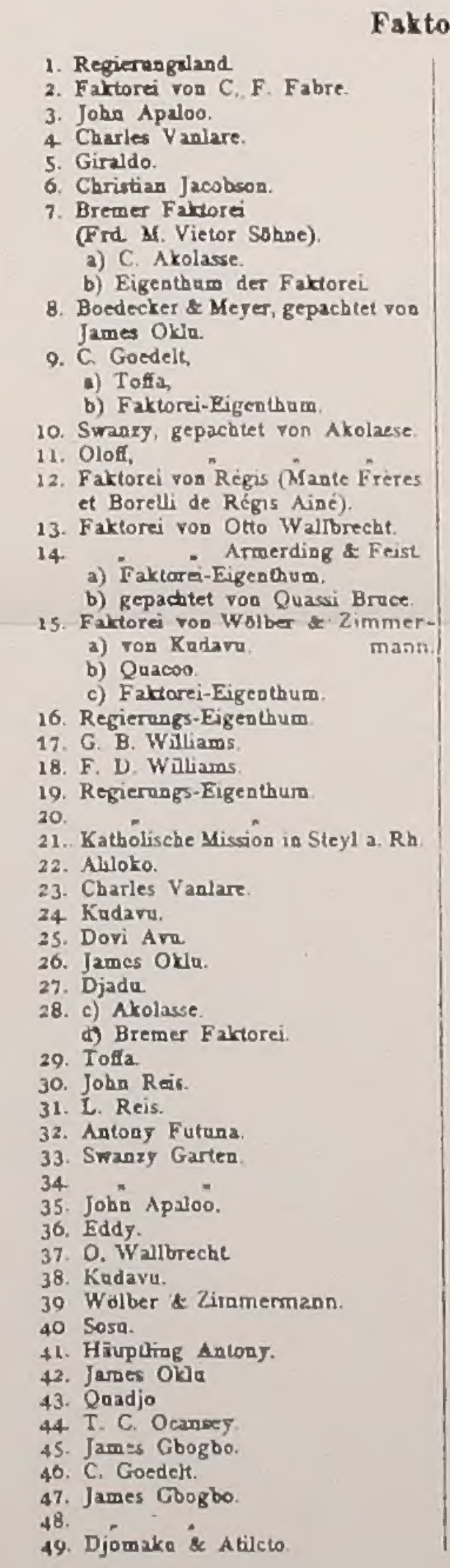

\begin{tabular}{|c|c|}
\hline 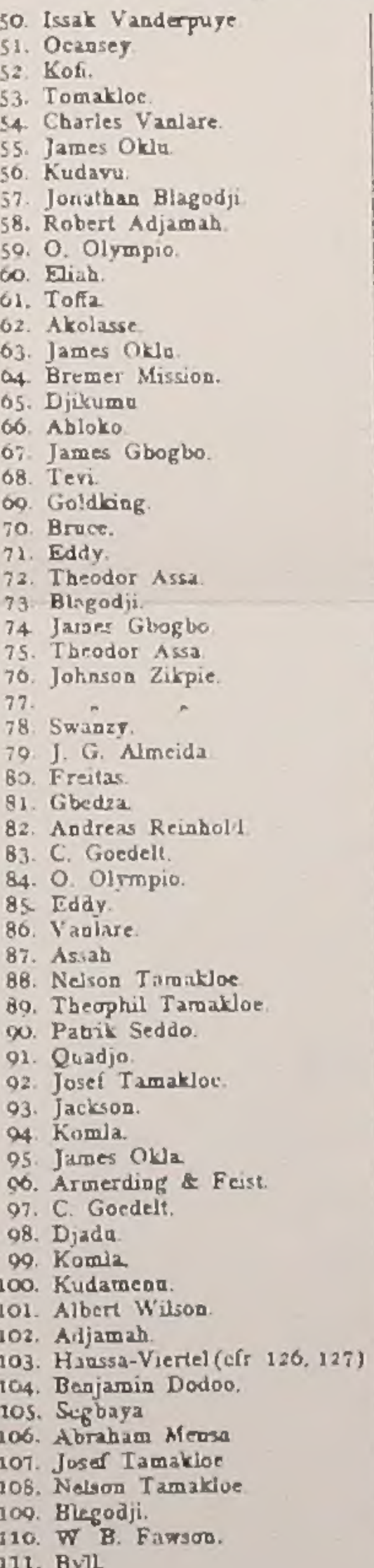 & 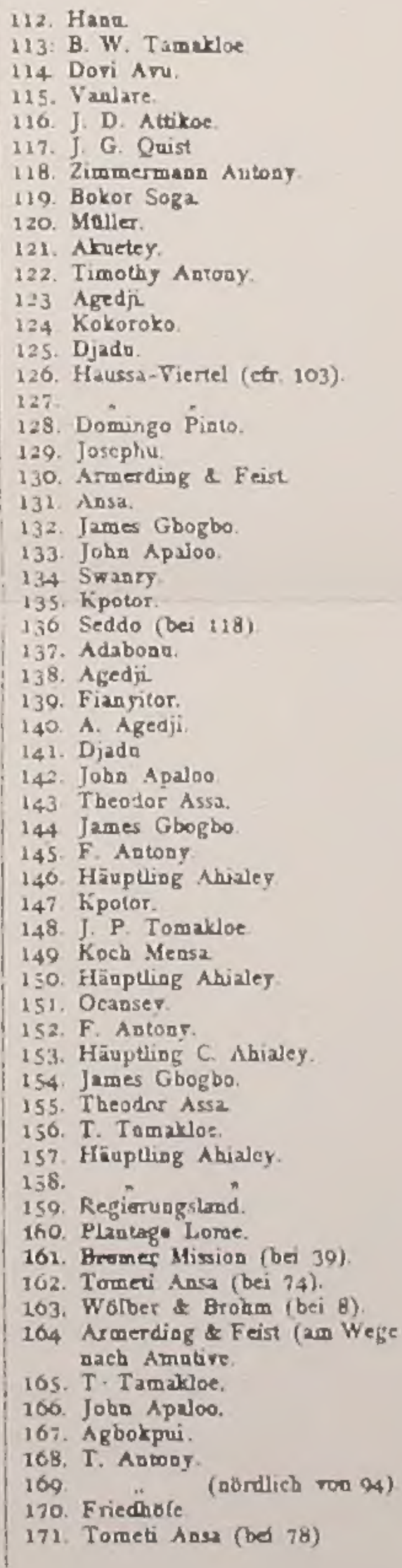 \\
\hline
\end{tabular}


